\title{
Rekultivierung von Tagebaufolgeflächen mit verschiedenen Bodenhilfsstoffen und Baumarten
}

\author{
Dissertation \\ zur Erlangung des Doktorgrades \\ der Fakultät für Forstwissenschaften und Waldökologie \\ der Georg-August-Universität Göttingen
}

vorgelegt von

Meike Kirscht

geboren in Celle 
1. Gutachter: Prof. Dr. Achim Dohrenbusch

2. Gutachter: Prof. Dr. Norbert Lamersdorf

Tag der mündlichen Prüfung: 31. März 2011 
Meinen Eltern

Fokko († 1997) und Irene Strackholder 



\section{Danke an...}

die Mitarbeiterinnen und Mitarbeiter der Wismut-GmbH, Ulrike Westphal, Max Wolf, Torsten Vor, Cemal Visnjic, Michael Unger, Mario Streit, Freia Sippel-Klemp, Heiko Rubbert, Veronika Riedl, Andrea Polle, Alvaro Perez Ruiz, Andreas Parth, Vasyl Myastkivskyy, Manfred Dieter Lechner, Christa Lang, Norbert Lamersdorf, Jürgen Kutscheidt, Anita Kriegel und ihre Kolleginnen, Reinhard Köpp, Martina Knaust, Linnea Kirscht, Andreas Kirscht, August Kapelle, Tomas Johansson, Sam Jenkin, Kalle Heine, Merle Fastenrath, das Evangelische Studienwerk e.V. (Villigst), Gisela Deppe-Wehmeyer, Achim Dohrenbusch, Rebecca Denning, Markus BernhardRömermann, Friedrich Beese, Andrea Bauer, Timo Baldauf und seine Azubis, Wolfgang Arenhövel und die Mitarbeiterinnen und Mitarbeiter der Thüringer Landesanstalt für Wald, Jagd und Fischerei, vormals Thüringer Landesanstalt für Wald und Forstwirtschaft

...für die vielgestaltige, unermesslich wertvolle Unterstützung meiner Arbeit an der Dissertation. 



\section{Inhaltsverzeichnis}

Abkürzungsverzeichnis

I. Einleitung 1

1. Problematik von Tagebaufolgeflächen ............................................................................................1

2. Lösungsansatz planmäßige Rekultivierung; Aufforstung ………………........................................

3. Lösungsansatz natürliche Rekultivierung; Sukzession ................................................................4

4. Lösungsansatz der vorliegenden Dissertation ..................................................................................

II. Ziele \& Arbeitshypothesen .9

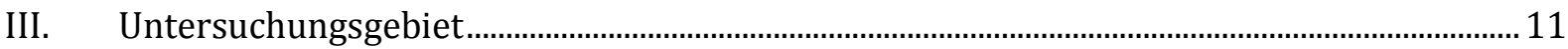

1. Lage und naturräumliche Einordnung ……...................................................................................11

2. Nutzungsgeschichte ........................................................................................................... 11

3. Geologie, Böden und Wasserhaushalt ……...................................................................................... 13

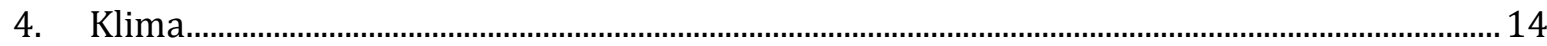

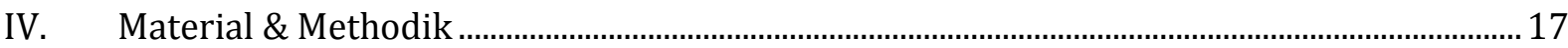

1. Freiland-Versuche - Versuchsanlage ..........................................................................................17

1.1. Versuchsflächen ................................................................................................................ 17

1.2. Baumarten und Pflanzenmaterial........................................................................................... 17

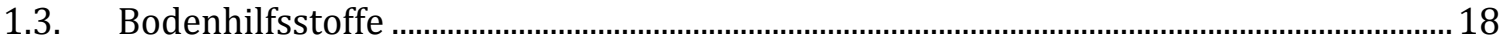

1.3.1. Zur Verbesserung der Bodenphysik: Perlit, Wasserspeichersubstanzen.............. 18

1.3.2. Zur Verbesserung der Bodenchemie: Kalk.................................................................... 19

1.3.3. Zur Verbesserung der Bodenphysik und -chemie: Kompost....................................... 19

1.3.4. Zur Verbesserung der Bodenbiologie: Mykorrhiza-Inokulum.................................... 19

1.3.5. Bodenhilfstoff-Kombinationen..................................................................................... 20

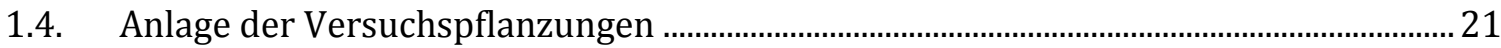

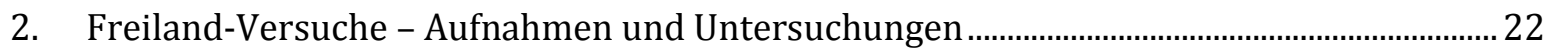

2.1. Klima-Messungen ........................................................................................................... 22

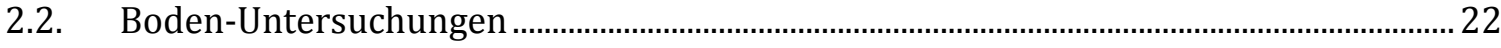

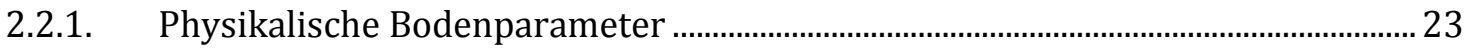

2.2.2. Chemische Bodenparameter ........................................................................................ 25 


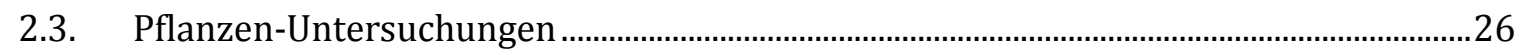

2.3.1. Chemische Analysen der Assimilationsorgane ............................................................26

2.3.2. Visuelle Beurteilung der Pflanzenvitalität ......................................................................27

2.3.3. Messungen von Wuchsparametern ...............................................................................27

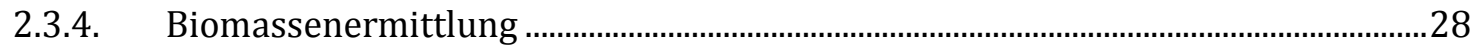

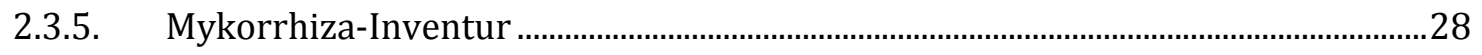

2.3.6. Weitere Aufnahmen an den Versuchspflanzen...............................................................29

3. Topf-Versuche - Versuchsanlage .............................................................................................

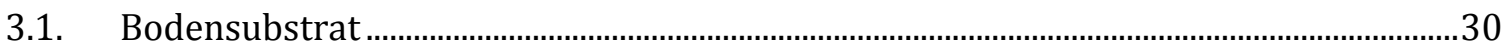

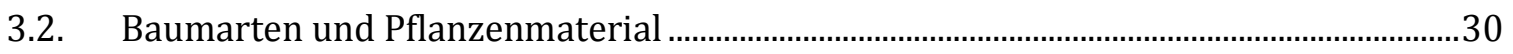

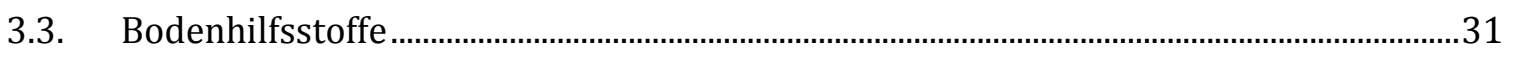

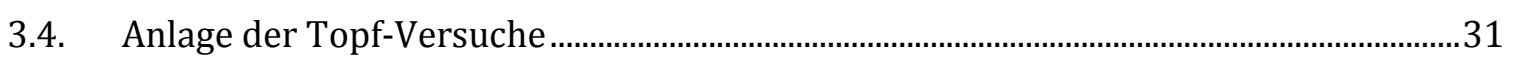

4. Topf-Versuche - Aufnahmen und Untersuchungen .....................................................................32

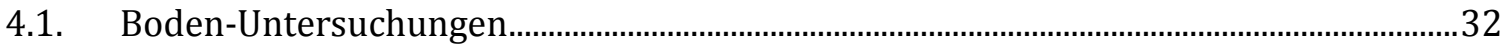

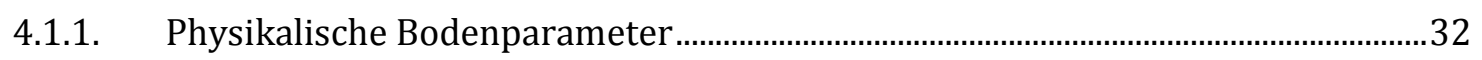

4.1.2. Chemische Bodenparameter...........................................................................................33

4.2. Pflanzen-Untersuchungen ................................................................................................ 33

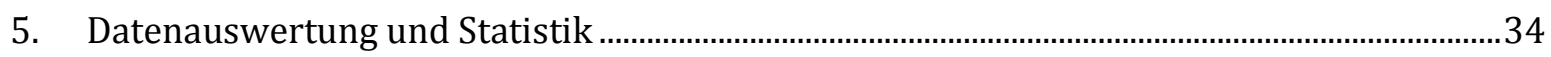

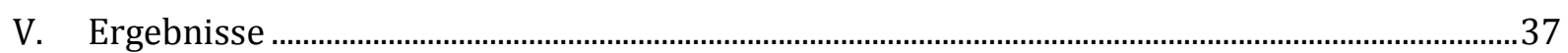

1. Freiland-Versuche - Bodeneigenschaften ....................................................................................

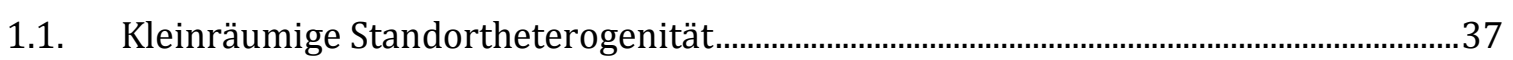

1.2. Physikalische Bodeneigenschaften ...................................................................................

1.2.1. Skelettgehalt ..................................................................................................

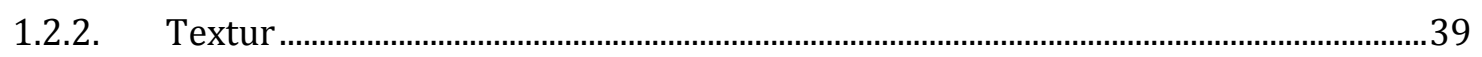

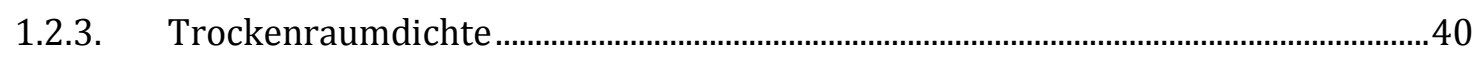

1.2.4. Wassergehalt-Wasserspannungsbeziehungen (pF-Kurven)......................................40

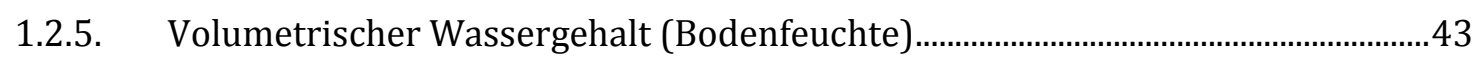

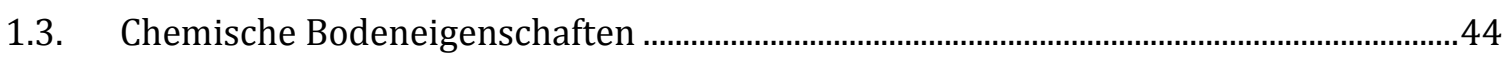

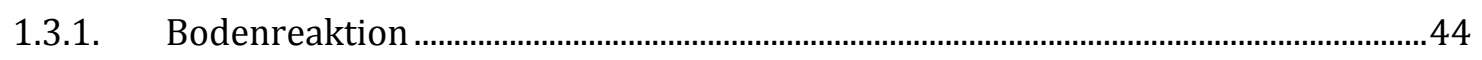

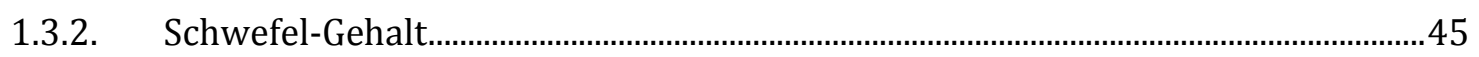

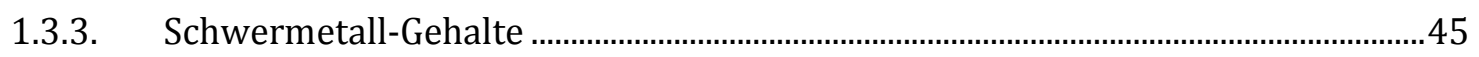

1.3.4. Kohlenstoff-, Stickstoff-Gehalte und C/N-Verhältnis................................................4

1.3.5. Posphor-Gehalt und C/P-Verhältnis..........................................................................4 
1.3.6. Weitere Nährelement-Gehalte.......................................................................................... 48

1.3.7. Effektive Kationen-Austauschkapazität ........................................................................ 49

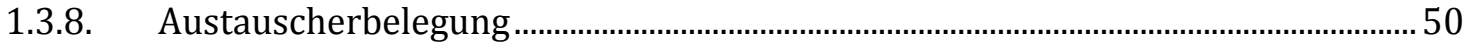

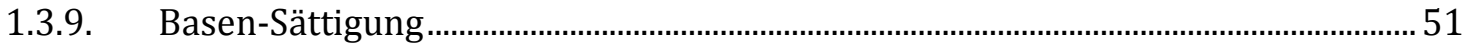

1.3.10. Vergleich Nährelement-Gehalte und Nährelement-Sättigungen ............................. 51

1.3.11. Elastizität gegenüber Säurebelastung .............................................................................. 52

2. Topf-Versuche - Effekte der Bodenhilfsstoffe auf die Bodeneigenschaften ............................. 55

2.1. Effekte der Bodenhilfsstoffe auf die physikalischen Bodeneigenschaften ..................... 55

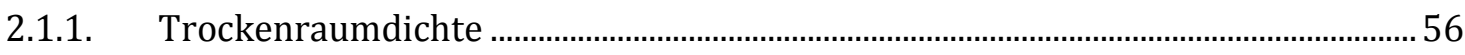

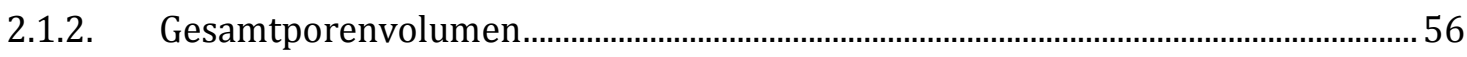

2.1.3. Volumetrischer Wassergehalt (Bodenfeuchte) ........................................................... 57

2.2. Effekte der Bodenhilfsstoffe auf die chemischen Bodeneigenschaften............................ 58

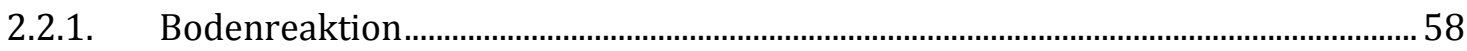

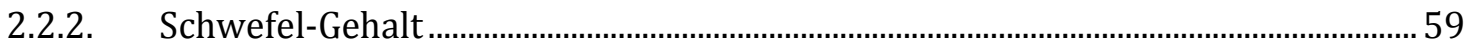

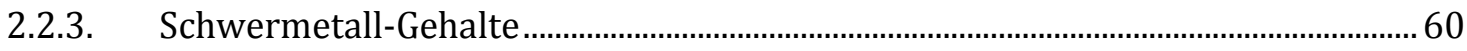

2.2.4. Kohlenstoff-, Stickstoff-Gehalte und C/N-Verhältnis .................................................. 61

2.2.5. Phosphor-Gehalt und C/P-Verhältnis............................................................................. 62

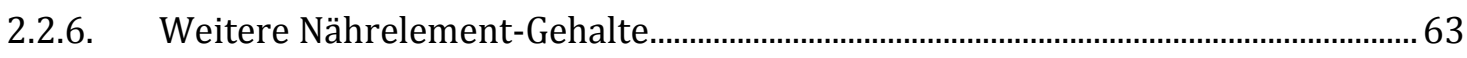

2.2.7. Effektive Kationen-Austauschkapazität ............................................................................. 64

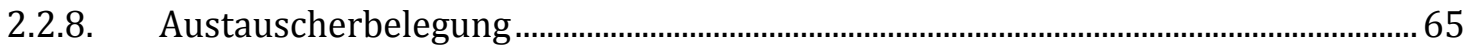

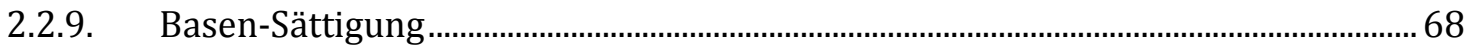

2.2.10. Vergleich Nährelement-Gehalte und Nährelement-Sättigungen ............................... 68

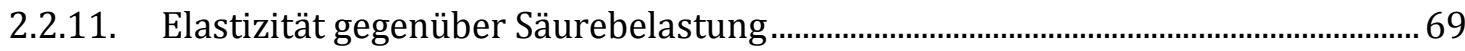

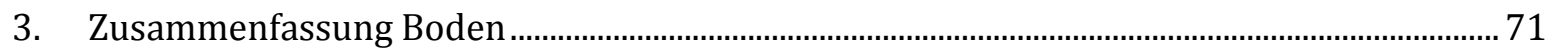

3.1. Physikalische Bodeneigenschaften .................................................................................... 71

3.2. Effekte der Bodenhilfsstoffe auf die physikalischen Bodeneigenschaften .................... 71

3.3. Chemische Bodeneigenschaften ........................................................................................... 72

3.4. Effekte der Bodenhilfsstoffe auf die chemischen Bodeneigenschaften............................ 73

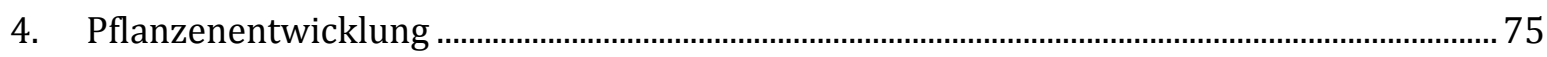

4.1. Ausgangszustand der Versuchspflanzen ...................................................................... 75

4.2. Einfluss der kleinräumigen Standortheterogenität........................................................ 76

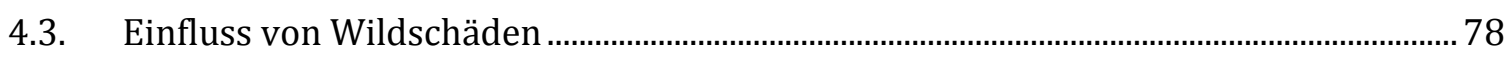

4.4. Ergebnisse der Regressionen zwischen Wachstumsparametern..................................... 79 
4.5. Pflanzenentwicklung ohne Bodenhilfsstoff-Behandlung (Kontrollen) .82

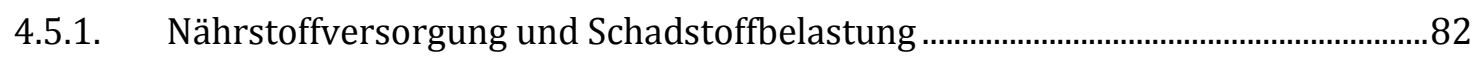

4.5.1.1. Hauptnährelemente, Makronährstoffe (N, P, K, Ca, Mg, S) ...................................82

4.5.1.2. Spurennährelemente, Mikronährstoffe (Fe, Mn, Zn, Cu)......................................87

4.5.1.3. Potentiell nützliche Elemente (Al, Na, Ni, Co)........................................................91

4.5.1.4. Toxisch wirkende Schwermetalle ohne Nährelementfunktion (Pb, Cd, Cr) ....93

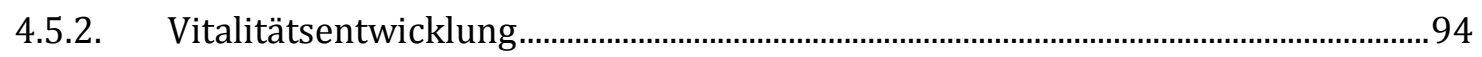

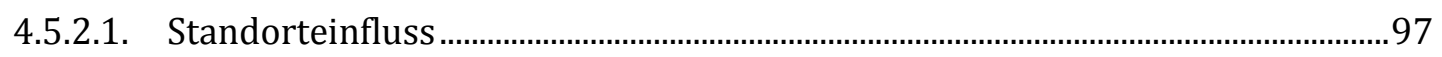

4.5.2.2. Vergleich Nullvariante - Gesamtdurchschnitt ......................................................99

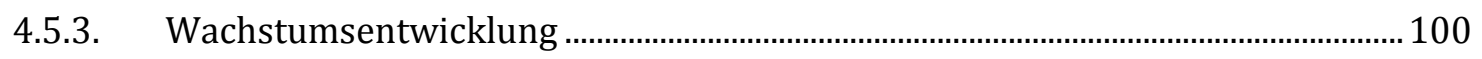

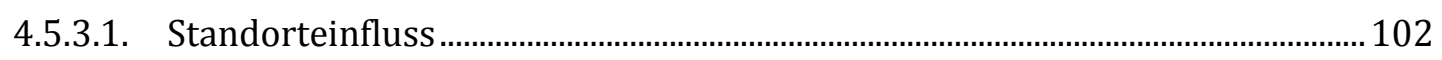

4.5.3.2. Vergleich Nullvariante - Gesamtdurchschnitt ................................................... 104

4.6. Effekte der Behandlungsvarianten auf die Pflanzenentwicklung................................... 105

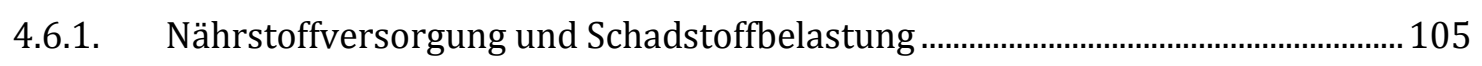

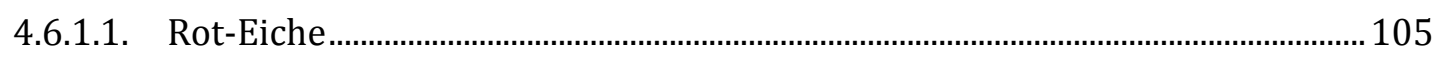

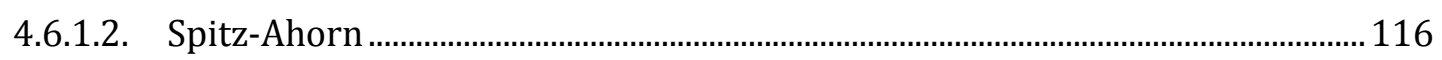

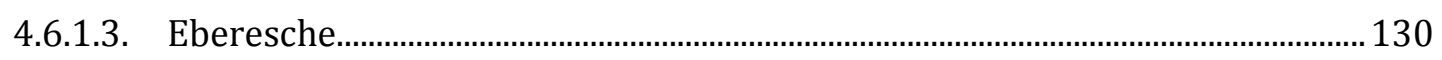

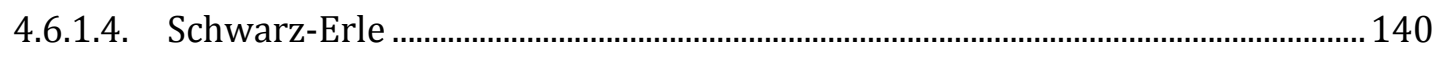

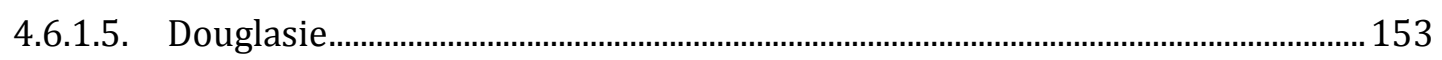

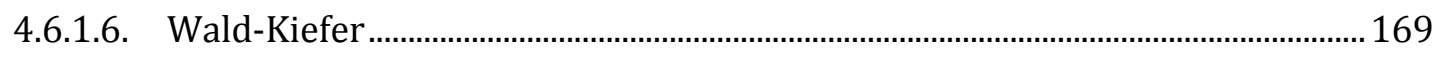

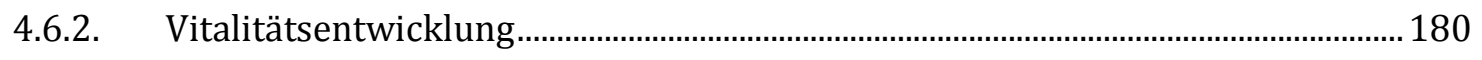

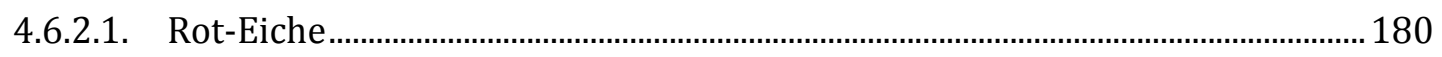

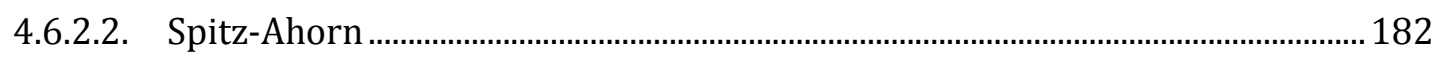

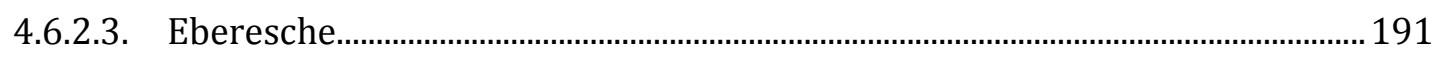

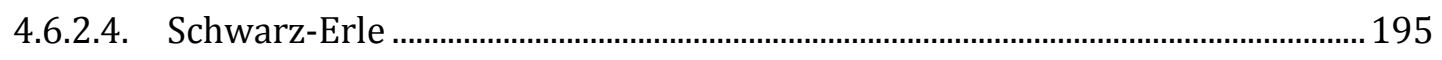

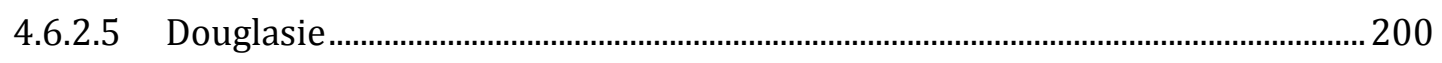

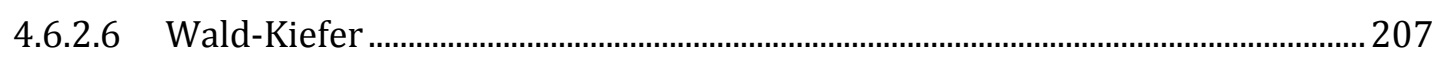

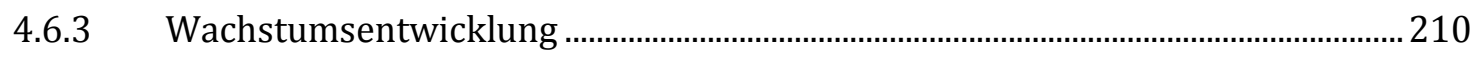

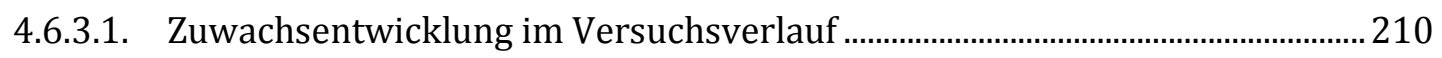

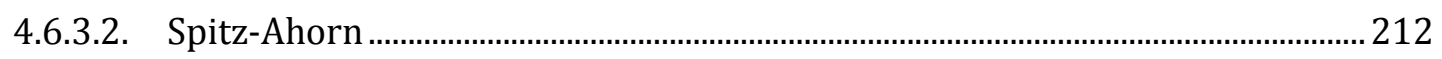

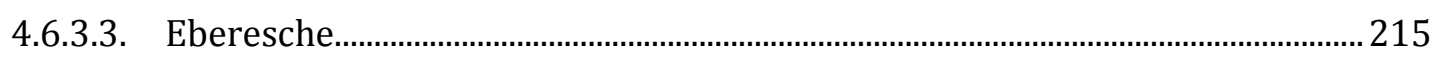

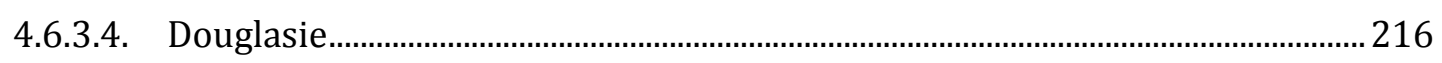

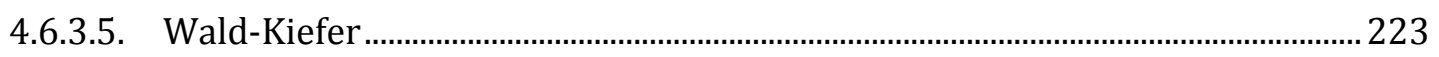


4.7. Einfluss des Standortes auf einer der drei Versuchsflächen

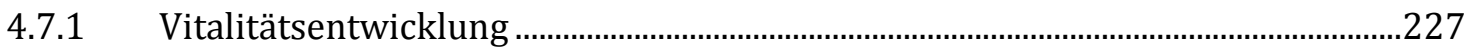

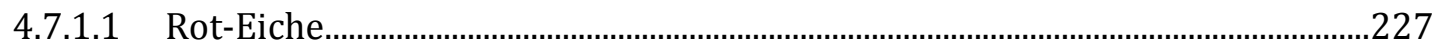

4.7.1.2 Spitz-Ahorn ....................................................................................................230

4.7.1.3 Eberesche ……………...........................................................................................233

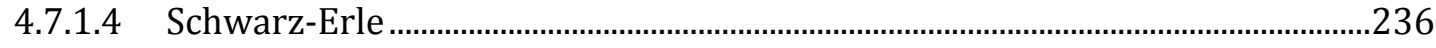

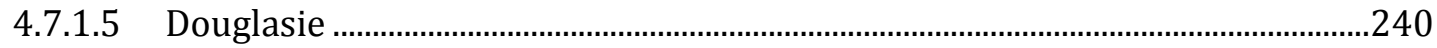

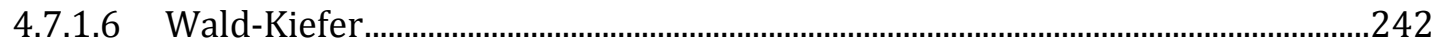

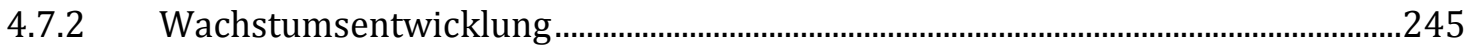

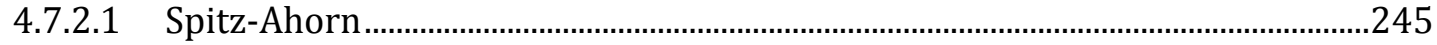

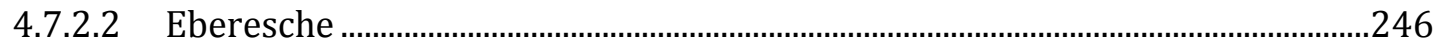

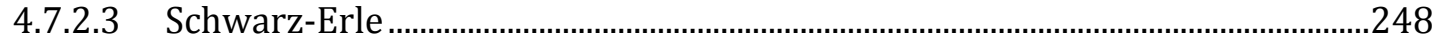

4.7.2.4 Douglasie .................................................................................................................251

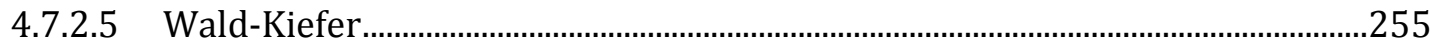

4.8 Einfluss des Standortes in Bereichen mit oder ohne Spontanvegetation ......................257

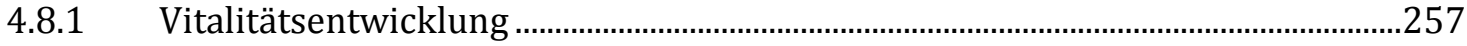

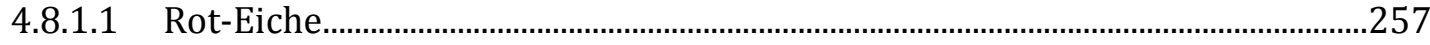

4.8.1.2 Spitz-Ahorn ..............................................................................................................260

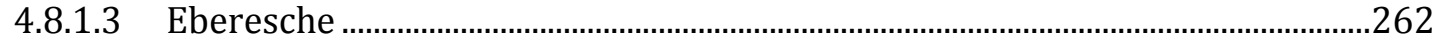

4.8.1.4 Schwarz-Erle ............................................................................................................264

4.8.1.5 Douglasie ...........................................................................................................267

4.8.1.6 Wald-Kiefer........................................................................................................269

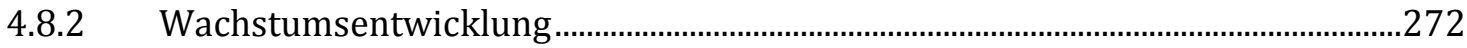

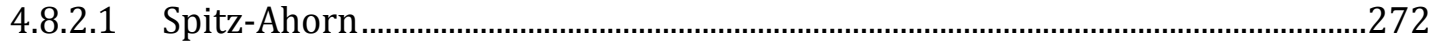

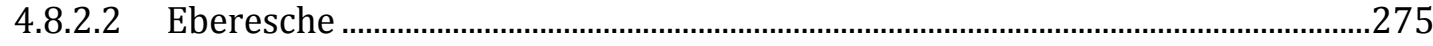

4.8.2.3 Schwarz-Erle .........................................................................................................279

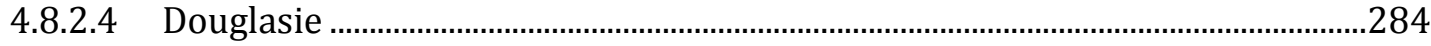

4.8.2.5 Wald-Kiefer..............................................................................................................286

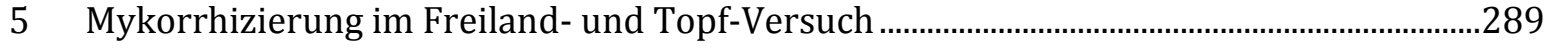

6 Wurzelentwicklung im Topf-Versuch 


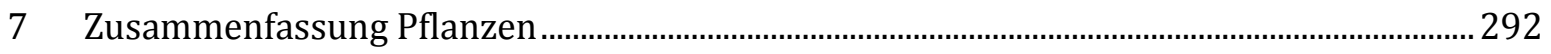

7.1 Einfluss des Standortes auf einer der drei Versuchsflächen .............................................292

7.2 Einfluss des Standortes mit oder ohne Spontanvegetation................................................297

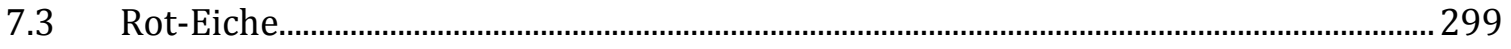

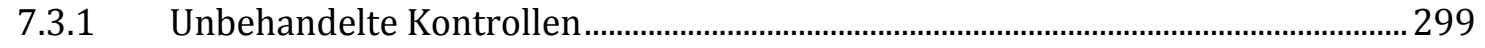

7.3.2 Effekte der Behandlungsvarianten.................................................................................. 301

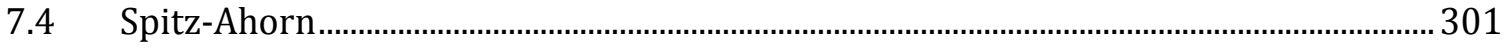

7.4.1 Unbehandelte Kontrollen......................................................................................... 302

7.4.2 Effekte der Behandlungsvarianten.............................................................................. 304

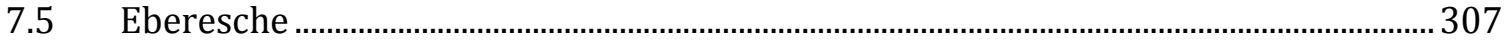

7.5.1 Unbehandelte Kontrollen.......................................................................................... 308

7.5.2 Effekte der Behandlungsvarianten.............................................................................. 310

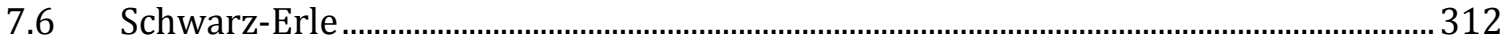

7.6.1 Unbehandelte Kontrollen.............................................................................................. 313

7.6.2 Effekte der Behandlungsvarianten.................................................................................. 315

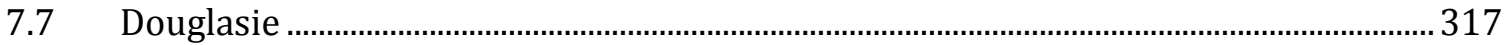

7.7.1 Unbehandelte Kontrollen...................................................................................... 318

7.7.2 Effekte der Behandlungsvarianten..................................................................................... 319

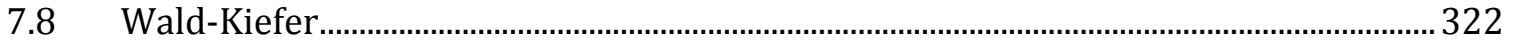

7.8.1 Unbehandelte Kontrollen......................................................................................... 323

7.8.2 Effekte der Behandlungsvarianten..................................................................................... 325

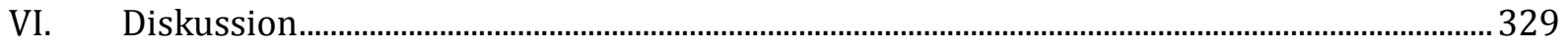

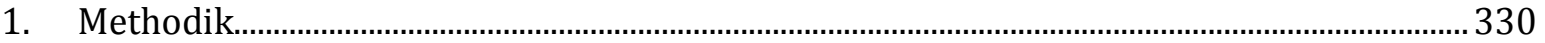

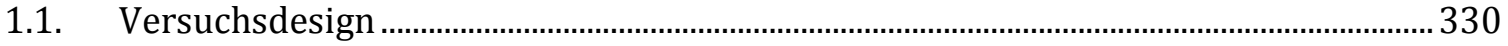

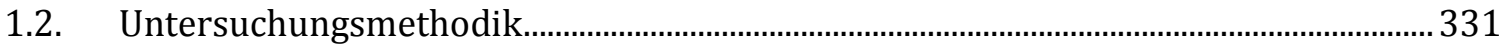

2. Bewertungen von Element-Gehalten in Assimilationsorganen in der Literatur.

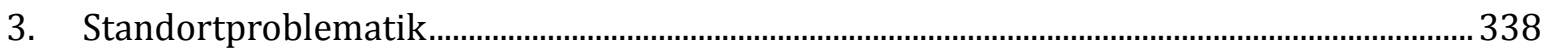

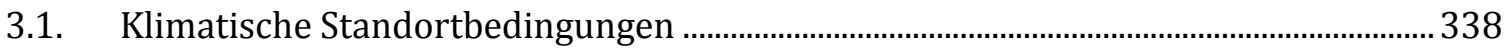

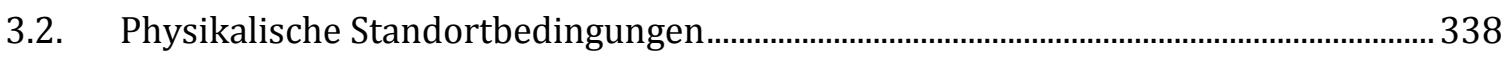

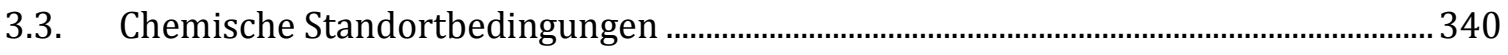

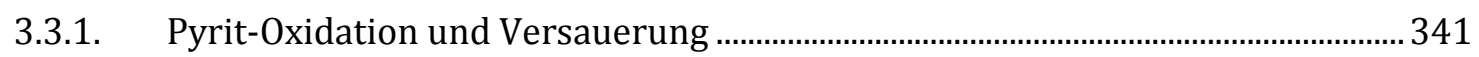

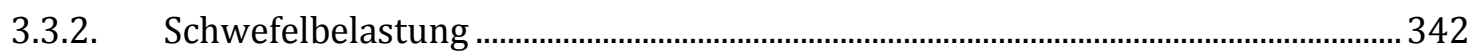

3.3.3. Aluminium- und Mangantoxizität.................................................................................. 342 


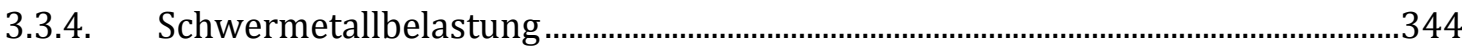

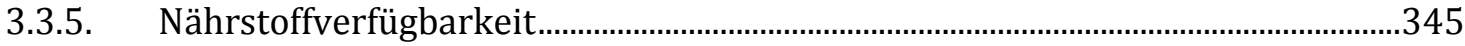

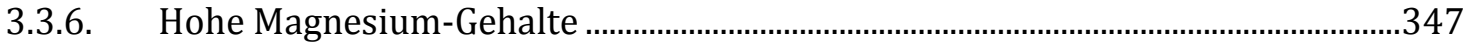

3.4. Kleinräumige Standortheterogenität ……............................................................................348

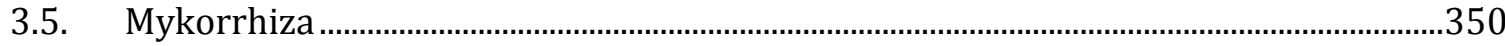

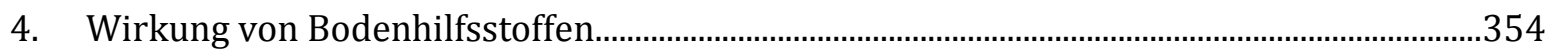

4.1. Zur Verbesserung der Bodenphysik: Perlit, Wasserspeichersubstanzen ......................354

4.2. Zur Verbesserung der Bodenchemie: Kalk ………..............................................................358

4.3. Zur Verbesserung der Bodenphysik und -chemie: Kompost.............................................360

4.4. Zur Verbesserung der Bodenbiologie: Mykorrhiza-Inokulum ............................................361

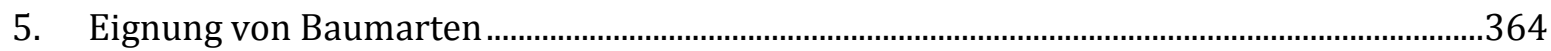

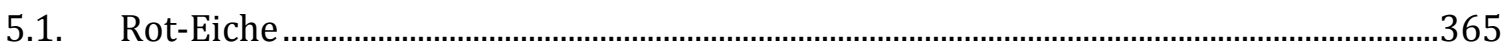

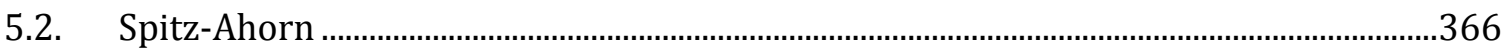

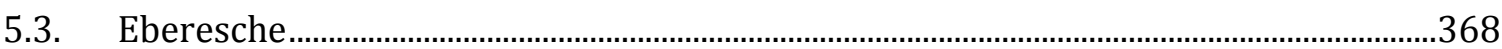

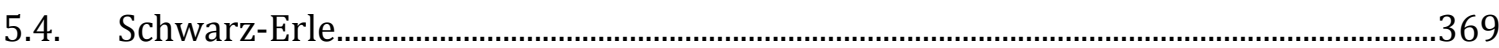

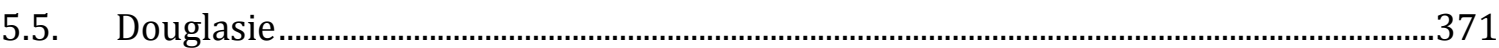

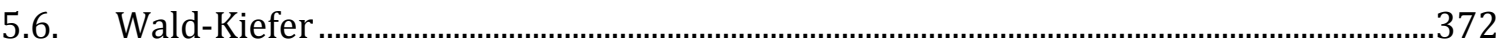

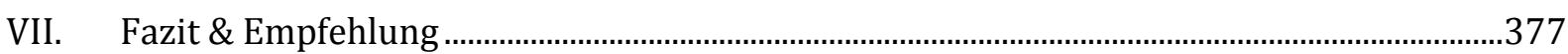

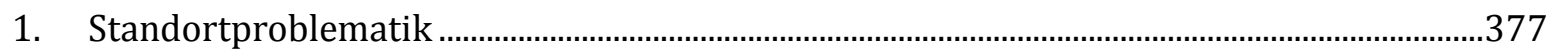

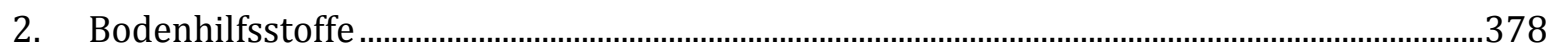

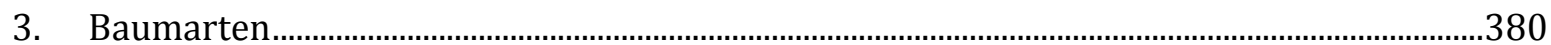

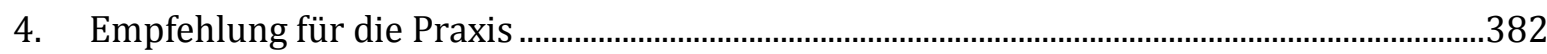

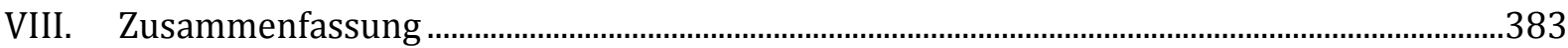

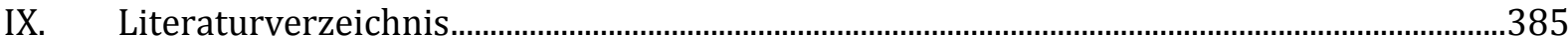

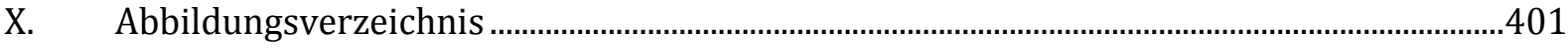

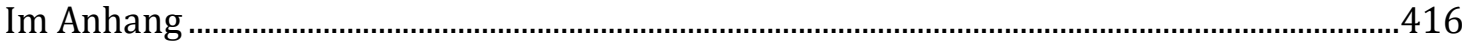

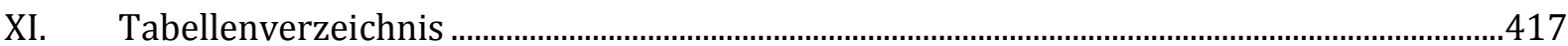

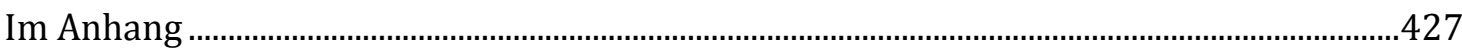




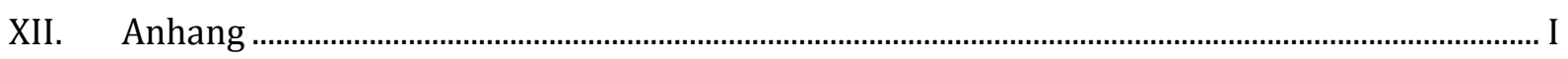

1. Quellen zur Bewertung der Schwermetallgehalte im Boden .................................................... I

2. Quellen zur Bewertung der Elementgehalte in den Assimilationsorganen ............................. II

3. Überlebensraten nach Standort, Vitalität der Kontrollen im Versuchsverlauf nach Standort, Wachstumswerte der Kontrollen und Gesamtmittel, Zuwachsentwicklung der Varianten im Versuchsverlauf..

4. Versorgung und Belastung der Rot-Eiche ....................................................................................XIV

5. Versorgung und Belastung des Spitz-Ahorns............................................................................... XVII

6. Versorgung und Belastung der Eberesche ....................................................................................XXI

7. Versorgung und Belastung der Schwarz-Erle .............................................................................XXIV

8. Versorgung und Belastung der Douglasie ............................................................................... XXVII

9. Versorgung und Belastung der Kiefer .........................................................................................XXX

10. Photos der Vitalitätsstufen „2“ $2^{\prime \prime}, 3^{\prime \prime}$ und „4“ ......................................................................XXXII 


\section{Abkürzungsverzeichnis}

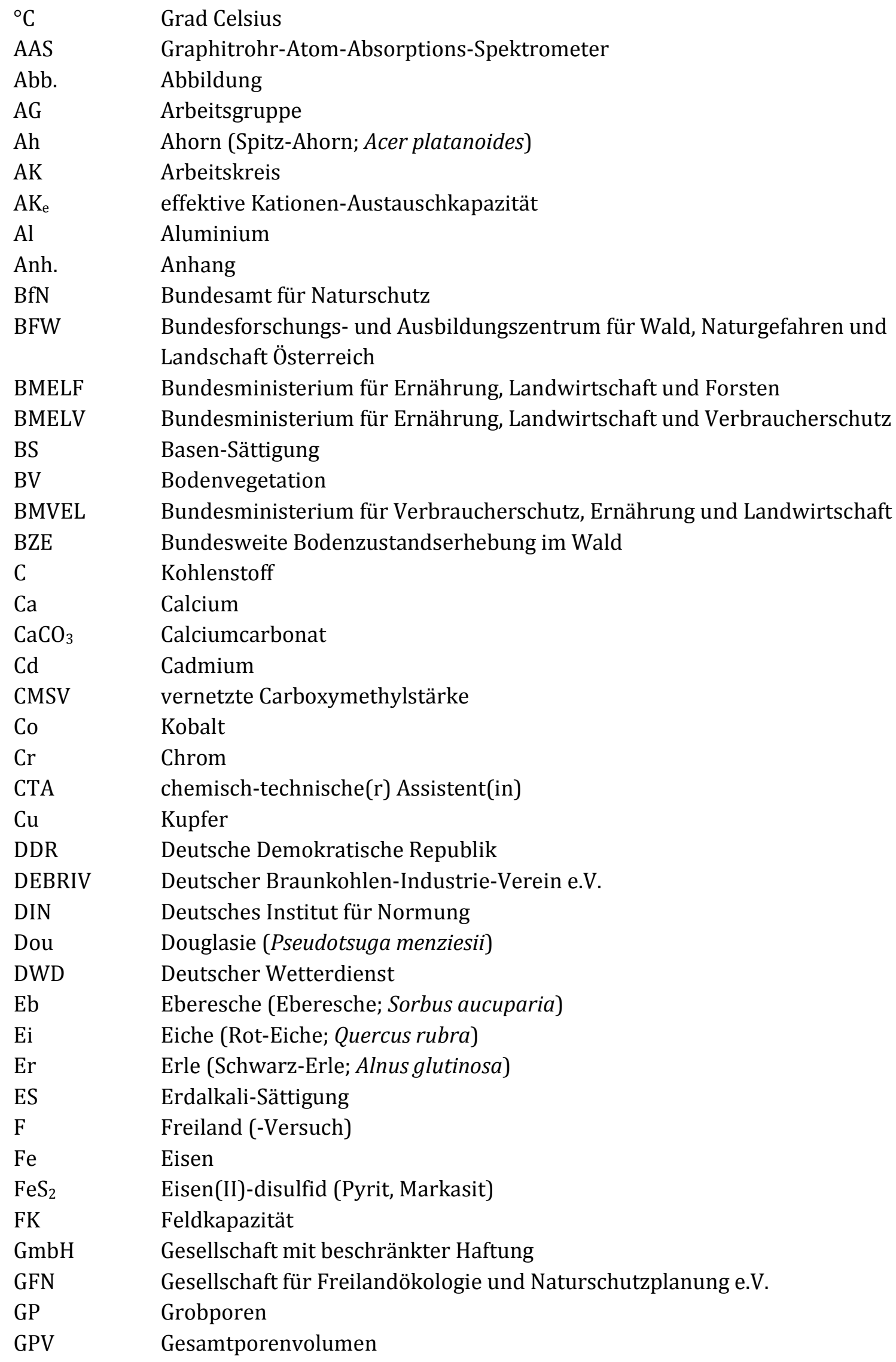

Dou

DWD

$\mathrm{Eb}$

$\mathrm{Ei}$

Er

ES

$\mathrm{F}$

$\mathrm{Fe}$ Bundesweite Bodenzustandserhebung im Wald

Kohlenstoff

Calcium

Calciumcarbonat

Cadmium

vernetzte Carboxymethylstärke

Kobalt

Chrom

chemisch-technische(r) Assistent(in)

Kupfer

Deutsche Demokratische Republik

Deutscher Braunkohlen-Industrie-Verein e.V.

Deutsches Institut für Normung

Douglasie (Pseudotsuga menziesii)

Deutscher Wetterdienst

Eberesche (Eberesche; Sorbus aucuparia)

Eiche (Rot-Eiche; Quercus rubra)

Erle (Schwarz-Erle; Alnus glutinosa)

Erdalkali-Sättigung

Freiland (-Versuch)

$\mathrm{FeS}_{2} \quad$ Eisen(II)-disulfid (Pyrit, Markasit)

FK Feldkapazität

$\mathrm{GmbH} \quad$ Gesellschaft mit beschränkter Haftung

GFN Gesellschaft für Freilandökologie und Naturschutzplanung e.V.

GP Grobporen

GPV Gesamtporenvolumen 


\begin{tabular}{|c|c|}
\hline $\mathrm{H}_{2} \mathrm{O}$ & Wasser \\
\hline $\mathrm{H}_{2} \mathrm{SO}_{4}$ & Schwefelsäure \\
\hline $\mathrm{HNO}_{3}$ & Salpetersäure \\
\hline HT & Haupttrieb \\
\hline Jg. & Jahrgang \\
\hline ICP-OES & Optisches Emissions-Spektrometer mit induktiv gekoppeltem Plasma \\
\hline IFTNC & Intermountain Forest Tree Nutrition Cooperative \\
\hline IVÖR & Institut für Vegetationskunde, Ökologie und Raumplanung \\
\hline K & Kalium \\
\hline Kap. & Kapitel \\
\hline $\mathrm{KCl}$ & Kaliumchlorid \\
\hline $\mathrm{Ki}$ & Kiefer (Wald-Kiefer; Pinus sylvestris subsp. sylvestris) \\
\hline Ko & Kompost \\
\hline LAWuF & Thüringer Landesanstalt für Wald und Forstwirtschaft (jetzt TLWJF) \\
\hline LK & Luftkapazität \\
\hline LMBV & Lausitzer und Mitteldeutsche Bergbau-Verwaltungsgesellschaft mbH \\
\hline Lsg. & Lösung \\
\hline Mrd. & Milliarden \\
\hline $\mathrm{Mg}$ & Magnesium \\
\hline $\mathrm{MgCO}_{3}$ & Magnesiumcarbonat \\
\hline Mio. & Millionen \\
\hline Mn & Mangan \\
\hline MW & Mittelwert \\
\hline $\mathrm{n}$ & Anzahl \\
\hline $\mathrm{N}$ & Stickstoff \\
\hline $\mathrm{Na}$ & Natrium \\
\hline $\mathrm{nFK}$ & nutzbare Feldkapazität \\
\hline $\mathrm{NH}_{4} \mathrm{Cl}$ & Ammoniumchlorid \\
\hline $\mathrm{Ni}$ & Nickel \\
\hline o.A. & ohne Angabe \\
\hline oB & ohne Ballen, wurzelnackt \\
\hline $0 . / \mathrm{m}$. & ohne/mit \\
\hline $\mathrm{P}$ & Phosphor \\
\hline PANV & neutralisierte, vernetzte Polyacrylsäure \\
\hline $\mathrm{Pb}$ & Blei \\
\hline $\mathrm{Pe}$ & Perlit \\
\hline pF-Kurve & Wasserspannungskurve \\
\hline pF-Wert & $\begin{array}{l}\mathrm{p}=\text { Potenz, F = „Freie Energie“ des Wassers; natürlicher Logarithmus }(\log 10) \\
\text { eines Wasserspannungswertes }\end{array}$ \\
\hline pH-Wert & $\begin{array}{l}\text { potentia Hydrogenii (= Kraft des Wasserstoffs); Protonenaktivität in der } \\
\text { Bodenlösung, Säuremesswert }\end{array}$ \\
\hline PIK & Potsdam-Institut für Klimafolgenforschung \\
\hline $\mathrm{S}$ & Schwefel \\
\hline Sab & Superabsorber \\
\hline SAG & Staatliche Aktiengesellschaft \\
\hline SDAG & Sowjetisch-Deutsche Aktiengesellschaft \\
\hline Std.abw. & Standardabweichung \\
\hline ST & Seitentriebe \\
\hline
\end{tabular}




$\begin{array}{ll}\text { Sto } & \text { Stockosorb® } \\ \text { Sup } & \text { Superabsorber } \\ \text { T } & \text { Topf (-Versuch) } \\ \text { Tab. } & \text { Tabelle } \\ \text { TLL } & \text { Thüringer Landesanstalt für Landwirtschaft } \\ \text { TLWJF } & \text { Thüringer Landesanstalt für Wald, Jagd und Fischerei } \\ \text { TM } & \text { Trockenmasse } \\ \text { TMLNU } & \text { Thüringer Ministerium für Landwirtschaft, Naturschutz und Umwelt } \\ \text { TRD } & \text { Trockenraumdichte } \\ \text { u } & \text { Elementgehalt unter der Nachweisgrenze für dieses Element } \\ \text { UBA } & \text { Umweltbundesamt } \\ \text { UdSSR } & \text { Union der Sozialistischen Sowjet Republiken } \\ \text { V } & \text { Variante } \\ \text { VAM } & \text { vesikulär-arbuskuläre Mykorrhiza } \\ \text { VG } & \text { Vermehrungsgut } \\ \text { Vol.WG } & \text { volumetrischer Wassergehalt } \\ \text { WG } & \text { Wassergehalt } \\ \text { WAK } & \text { Wasseraufnahmekapazität } \\ \text { WHD } & \text { Wurzelhalsdurchmesser } \\ \text { WS } & \text { Wassersäule } \\ \text { Zn } & \text { Zink }\end{array}$





\section{Einleitung}

Die Gewinnung von Rohstoffen wie Erz oder Kohle im Tagebauverfahren stellt einen der extremsten Eingriffe in die Landschaft dar. Dabei werden nach Beseitigung der vorhandenen Vegetationsdecke auch die Bodeneigenschaften grundlegend verändert und somit die ursprünglichen Landschaften vollständig zerstört.

\section{Problematik von Tagebaufolgeflächen}

Im Idealfall sollte der durch Abbaumaßnahmen anfallende Bodenabraum nach Schichten und Horizonten getrennt gelagert und bei der anschließenden Flächenrekultivierung wieder verwendet werden. Dies gilt vor allem für den Oberboden (heute bei Tagebauvorhaben in Deutschland in der Regel so weit wie möglich praktiziert). Beim Einbau müssen Bodenverdichtung vermieden und die Bodenstruktur wiederhergestellt werden. Zur Vermeidung einer Verdichtung sollten die Flächen so wenig wie möglich mit schwerem Gerät befahren werden, was gerade beim Einbau vieler unterschiedlicher Schichten und Horizonte schwierig ist (Zwölfer et al. 1994, Häge et al. 1996).

Bei Tagebautätigkeiten in der Vergangenheit erfolgten die Lagerung und der anschließende Einbau des Abraums meist nicht nach Bodenschichten bzw. -horizonten getrennt, was ein wesentlicher Grund für die Standortproblematik von Tagebaufolgeflächen ist:

\section{Versauerung}

Bei der Wiederablagerung des Bodenabraums gelangen häufig aus tieferen Lagen stammende Tertiärsubstrate an die Oberfläche. Diese sind durch einen hohen Gehalt an Eisensulfid (Pyrit) gekennzeichnet, bei dessen Verwitterung Schwefelsäure entsteht (Knabe 1957). Die pH-Werte des Bodens können so weit unter 3,5 sinken (Katzur et al., 1998, Böcker et al. 1999), was die Nährstoffverfügbarkeit stark einschränkt. Oft sind die sehr sauren und basenarmen Bedingungen der Bodenlösungen (Aluminium- und Mangan-Toxizität) von einem hohen Gehalt an Schwermetallen begleitet, die ebenfalls toxische Konzentrationen erreichen können (Häge 1996, Hüttl 2001, Walker 2002).

\section{Verdichtung}

Die Verschüttung der Haldensubstrate erfolgt oft von Fließbändern aus großer Höhe, wobei das Bodenmaterial beim Aufprall verdichtet wird. Die verdichteten Böden (Bussler et al. 1984, Katzur \& Haubold-Rosar 1996, LAWuF Gotha 2002, Hohensee 2005, Simmons et al. 2008) setzen dem Wurzelwachstum zunächst einen mechanischen Widerstand entgegen. Weiterhin sind durch das geringe Grobporenvolumen bzw. die Zerscherung der vorhandenen vertikalen Grobporen der Luftaustausch im Boden und seine Infiltrations- und Wasserleitfähigkeit eingeschränkt (Bussler et al. 1984, Hohensee 2005, Shrestha \& Lal 2008, Simmons et al. 2008). 
Dadurch kann sowohl Wassermangel als auch Staunässe auftreten, was im Wurzelbereich zu Sauerstoffmangel führt (Petrova 1995, Häge 1996). Der erhöhte Oberflächenabfluss auf den verdichteten Böden verursacht Wassererosion bis hin zur Ausbildung von Gräben (Katzur \& Haubold-Rosar 1996).

\section{Trockenheit}

Ebenfalls aufgrund der Bodenverdichtung können Kippenböden oft nur geringe Mengen pflanzenverfügbaren Wassers speichern (Bussler et al. 1984, Walker et al. 2004, Hohensee 2005). In der warmen Jahreszeit trocknen die exponierten Haldenböden bei hoher Sonneneinstrahlung stark aus, wobei sie von Rissen durchzogen werden. Die Verdunstung wird durch hohe Windgeschwindigkeiten verstärkt, da die Oberflächenrauigkeit der ausgeräumten Bergbaufolgelandschaften aufgrund fehlender Vegetation nur gering ist. Die Pflanzen auf diesen Standorten sind somit einem erheblichen Trockenstress ausgesetzt (Katzur et al. 1998, Schulz \& Wiegleb 2000, Walker 2002). Zudem kann es zur mechanischen Destabilisierung der Pflanzen durch Wind kommen. Die Böden sind dabei durch Winderosion gefährdet (Katzur et al. 1998).

\section{Fehlende Mykorrhiza-Partner}

Haldenrohböden sind in der Regel zunächst frei von Mykorrhiza-Pilzen, die meist langsam wieder einwandern und bei über längere Zeit fehlenden Wirtspflanzen wieder zurückgehen können (Miller 1987, Thompson 1987). Mykorrhiza-Pilze stellen laut Sänger (2003) einen wichtigen Faktor bei der Primärsukzession auf Bergbauhalden dar. Die Mehrzahl der Gehölzarten, die zum großen Teil obligat auf die Symbiose mit Pilzen angewiesen sind, können ohne Mykorrhiza den Standort Halde nicht besiedeln. Auch Baumarten, die in der Regel fakultativ mit Mykorrhiza-Pilzen Symbiosen eingehen, zeigen höhere Ausfallraten, wenn diese im Boden fehlen (Grime et al. 1987).

Aufgrund der Heterogenität des Haldenmaterials können die Bodenparameter von Kippenböden auf kleinstem Raum erheblich variieren (LAWuF Gotha 2002, Münzenberger et al. 2004). Katzur et al. (1998) nennen neben den klimatisch, bodenphysikalisch und bodenchemisch schwierigen Bedingungen ausdrücklich auch hohe Wilddichten als einen ungünstigen Standortfaktor auf Tagebaufolgeflächen.

Zwischen den aufgeführten, jeweils für sich schon problematischen Faktoren bestehen zusätzlich Wechselwirkungen mit Negativ-Effekten für das Pflanzenwachstum.

Die Möglichkeiten zum Umgang mit ehemaligen Tagebaugebieten beinhalten technische Rekultivierungsmaßnahmen ebenso wie das Überlassen von Flächen einer natürlichen Sukzession.

Mit der Rekultivierung ehemaliger Tagebaustandorte gibt es unter anderem im ostdeutschen Raum umfangreiche Erfahrungen, die sich vor allem auf das Lausitzer und das Mitteldeutsche Braunkohlerevier beziehen (z.B. Katzur 1995, Katzur et al. 1998, 1999a,b, Katzur \& Böcker 2001, Hüttl 2001, Fettweis et al. 2002, Gerke et al. 2002, Hüttl \& Bens 2003). 


\section{Lösungsansatz planmäßige Rekultivierung; Aufforstung}

Dort erfolgt überwiegend eine Rekultivierung der Halden durch Aufforstungen (DEBRIV 2000). Hiervon wird eine nachhaltige Verbesserung des Bodenzustands, insbesondere der Nährstoffverhältnisse und der Gefügebildung, erwartet (Katzur et al. 1999a, Knoche et al. 2000). In den industriell beeinflussten Agrarlandschaften Mitteldeutschlands bilden Haldenforste zudem eine wichtige ökologische Komponente als Lebensraum und tragen wesentlich zur Diversifizierung des Landschaftraumes bei (Katzur 1997, Thomasius \& Häfker 1998). Angestrebt werden langzeitstabile, multifunktionale und regionaltypische Waldökosysteme, wie sie für Bergbaufolgelandschaften gefordert werden (Hildmann 1998, Preußner 1998, Thomasius et al. 1999, Wünsche \& Selent 2000). Die Holzproduktion ist unter diesen Bedingungen nur von untergeordneter Bedeutung.

Bei den angewandten Rekultivierungsmethoden spielen vor allem zwei Aspekte eine Rolle, das eingesetzte Baumartenspektrum und die Rekultivierungsverfahren einschließlich der Bodenmeliorationsmaßnahmen.

\section{Baumartenspektrum}

Das in der Vergangenheit zur Aufforstung ehemaliger Tagebauflächen eingesetzte Baumartenspektrum entwickelte sich in der Lausitz in verschiedenen Phasen (Häge 1996, Katzur \& Haubold-Rosar 1996). Dies waren vom Beginn der Rekultivierungen in den 1920er Jahren (Heuson 1929) bis etwa 1960 die Birken-Phase (v.a. Birke, Kiefer, auch Rot-Eiche, Pappel, Erle), daraufhin bis etwa 1975 die Rot-Eichen-Phase (v.a. Rot-Eiche, Kiefer, auch Pappel, Birke, Erle, Lärche, Trauben-Eiche, Robinie, Linde) und anschließend bis etwa 1990 die Kiefern-Phase (v.a. Kiefer, auch Rot-Eiche, Pappel, Birke, Trauben-Eiche). Seitdem geht der Trend im Sinne eines naturnahen Waldumbaus (LMBV 2009) vor allem in Richtung einer Reduzierung des Anteils von Kiefern- (und Rot-Eichen) und einer Erhöhung des Anteils von Trauben-Eichen und anderen Laubbäumen sowie anderen Nadelbäumen (Häge 1996).

\section{Rekultivierungsverfahren und Bodenmeliorationsmaßnahmen}

Die Aufforstung von Tagebaufolgeflächen ist aufgrund der geschilderten ungünstigen Standortbedingungen oft mit erheblichen Schwierigkeiten verbunden. Um diese zu umgehen, wurden auf den Kippenböden im Lausitzer und Mitteldeutschen Revier häufig mit großem technischen und finanziellen Aufwand über die mehr oder weniger sterilen Abraumschichten aus tieferen Lagen mächtige Deckschichten (bis $1 \mathrm{~m}$ ) aus Oberboden oder anderem kulturfreundlichen Substrat aufgebracht (Katzur 1995, Katzur et al. 1998). Alternativ wurden umfangreiche Kalkungen und Düngungen der schwefelsauren Haldensubstrate mit Braunkohleasche und NPK-Dünger durchgeführt (Katzur et al. 1999a, b; Katzur \& Böcker 2001). Auf kohlefreien Haldenböden ist dabei jedoch häufig eine Nachkalkung erforderlich, um das Überleben der Bäume auf Dauer zu gewährleisten (Katzur et al. 1999a, b).

Zudem sind die hohen Ausfallraten von Jungpflanzen auf Tagebaufolgeflächen angesichts der Vielzahl ungünstiger Standortfaktoren vermutlich nicht nur den bodenchemischen Bedingungen allein zuzuschreiben. Die Frage nach dem langfristigen Erfolg der genannten Methoden, der Stabilität der entstandenen Kippenforste und der Nachhaltigkeit der Ökosystementwicklung in den durch Tagebau stark veränderten Landschaften ist noch ungeklärt (Hüttl 2001). 


\section{Lösungsansatz natürliche Rekultivierung; Sukzession}

Das Konzept eines bewussten Nichts-Tuns und damit einer Ausnutzung natürlicher Sukzessionsprozesse für die Wiederbegrünung von Tagebaufolgeflächen gewinnt gegenwärtig an Bedeutung.

So sind in der Lausitz $15 \%$ der Abbauflächen als Vorrangflächen für den Naturschutz vorgesehen und damit als unbehandelte Sukzessionsflächen einer natürlichen Entwicklung und Regeneration überlassen (Häge 1996, Katzur 1997, Schulz \& Wiegleb 2000, Hüttl \& Weber 2001). Rohbodenbiotope werden dabei als wichtige Landschaftselemente positiv betrachtet.

Untersuchungen zur Sukzession auf Tagebaufolgeflächen führten erwartungsgemäß zu je nach Standort sehr unterschiedlichen Ergebnissen. So begann auf manchen Flächen bereits kurz nach dem Ende der Verkippung eine Besiedelung mit Spontanvegetation (Sänger 1995, Jochimsen 1996). Nach weiteren Jahrzehnten wurden sowohl geschlossene Vegetationsdecken (Erosionsschutz) mit geringen Gehölzanteilen (Prach et al. 1999, Hodacova \& Prach 2003) als auch Vorwaldstadien (Sänger 2003) und schließlich die Etablierung von Wald (Jochimsen 1996) beschrieben.

Wo es die standörtlichen Gegebenheiten erlauben, siedeln sich im natürlichen Sukzessionsverlauf auf vielen einstigen Abbauflächen einheimische Eichenarten (Quercus robur, Q. petraea) und verschiedene Edellaubhölzer an (Tischew 1996). Oft ist jedoch die Regeneration der potentiell natürlichen Vegetation durch die ungünstigen Standortbedingungen sowie das Fehlen entsprechender Samenträger im Umland der Tagebaue erschwert (Katzur 1997, Lorenz et al. 2009). Um zumindest dem letztgenannten Problem zu begegnen, sprechen sich Benkwitz et al. (2002) dafür aus, Waldreste in und um ehemalige Tagebaugebiete zu erhalten und als Diasporenquellen für eine Wiederbesiedelung zu nutzen.

Allerdings gibt es Flächen, auf denen aufgrund der schwierigen standörtlichen Bedingungen auch lange Zeit nach der Nutzungsaufgabe nur eine sehr langsame oder gar keine Pflanzenansiedlung stattfindet (Sänger 2003). So waren schwermetallreiche Bergbauhalden ohne Bodenbehandlung auch nach 15 Jahren noch vollkommen vegetationsfrei (Rodenkirchen 1996). Schwefelhaltige Kippsubstrate werden ohne Abpufferung der Säureproduktion aus der Pyrit-Verwitterung auch nach vielen Jahrzehnten nicht von Spontanvegetation besiedelt (Katzur \& Haubold-Rosar 1996, Hüttl \& Weber 2001).

Läuft in Gebieten von teils großer Ausdehnung eine natürliche Wiederbesiedlung durch Pflanzen nur innerhalb sehr langfristiger Zeiträume oder gar nicht ab, so ist dies nicht nur unter dem Aspekt der Landschaftsästhetik problematisch. Durch die fortschreitende Versauerung kommt es zu Auswaschungen von Schwermetallen und anderen Stoffen, die Grundwasser und Oberflächengewässer belasten. Der Boden ist ohne jegliche Vegetationsbedeckung auch Windund Wassererosion ausgesetzt, so dass sich die standörtliche Problematik immer weiter verschärft.

Schulz \& Wiegleb (2000) gehen in der Lausitz davon aus, dass auch bei unterbleibenden Meliorationsmaßnahmen und Zulassen einer natürlichen Entwicklung nur ein sehr kleiner Teil der Gesamtfläche tatsächlich vegetationsfrei bleiben würde. Allerdings sollten sich solche frei bleibenden Flächen nicht in unmittelbarer Nähe von Siedlungsräumen befinden. Wo dies der Fall 
ist (sowie generell bei stark erosionsgefährdeten Flächen) unterstreichen auch Hodacova \& Prach (2003) die Bedeutung technischer Rekultivierungsmaßnahmen.

\section{Insel-Strategie}

In Anlehnung an Benkwitz et al. (2002), die für den Erhalt von Restwaldinseln in und um ehemalige Tagebaue als Diasporenquellen plädieren, ist eine erweiterte „Insel-Strategie“ denkbar: So könnten in zu rekultivierenden Gebieten, die weder über adäquate Standorteigenschaften für die Ansiedelung von Spontanvegetation noch über derartige Startpunkte verfügen, mit Hilfe von erfolgreich getesteten Kombinationen aus Baumarten und Bodenhilfsstoffen derartige Inseln aktiv angelegt werden. Gelingt so auf kleiner Fläche die Etablierung von Bäumen, könnten diese Inseln nicht nur als Diasporenquellen, sondern auch z.B. durch Windschutz und Humusbildung (Laubfall) zu Startpunkten einer Sukzession auf angrenzenden Flächen werden.

Eine ähnliche Idee war die Grundlage einer erfolgreichen Renaturierung und Aufforstung in mediterranen Trockengebieten. Hier wurden die entsprechenden Zielpflanzen gemeinsam mit Bodenhilfsstoffen (mykorrhizahaltigem Waldboden, Kompost u.a.) nicht flächendeckend, sondern punktuell eingebracht. Dies führte zu einem „Mosaik bioaktiver Inseln“, so genannten „erosionsgeschützten Fruchtbarkeitsspots" auf einem Teil der Fläche, die durch Erhöhung der Oberflächenrauigkeit und Erosionsschutz die weitere Sukzession unterstützten (Kesel et al. 2005).

\section{Lösungsansatz der vorliegenden Dissertation}

Im Sinne der geschilderten „Insel-Strategie“ muss zunächst ein Verfahren entwickelt werden, um den problematischen Wachstumsbedingungen ehemaliger Tagebaue zumindest auf kleiner Fläche mit so geringem Aufwand wie möglich zu begegnen. Zu diesem Zweck wurden in der vorliegenden Arbeit die Eignung von Baumarten und die Wirkungen verschiedener Bodenhilfsstoffe und Bodenhilfsstoff-Kombinationen auf Versuchsflächen im ehemaligen Uranerz-Tagebaugebiet bei Ronneburg, Thüringen getestet.

Vorversuche auf diesen Flächen mit einer großen Zahl verschiedener Baumarten bildeten die Grundlage für die Auswahl der untersuchten Arten Spitz-Ahorn, Eberesche, Douglasie, Rot-Eiche, Wald-Kiefer und Schwarz-Erle.

Die eingesetzten Bodenhilfsstoffe sollten der Verbesserung der auf Tagebaufolgeflächen ungünstigen physikalischen, chemischen sowie biologischen Bodeneigenschaften dienen.

\section{Bodenhilfsstoffe zur Verbesserung der Bodenphysik: Perlit, Wasserspeichersubstanzen}

Die Einarbeitung von Perlit, einem Material vulkanischen Ursprungs, das unter großer Hitze zur Volumenexpansion gebracht wurde (vgl. Popcorn), ist ein im Garten- und Landschafts- und auch Sportplatzbau sowie in der Landwirtschaft bekanntes Verfahren. Ziel ist die Lockerung und Verbesserung der Bodenstruktur und Luftführung in verdichteten, nassen und/oder bindigen Böden. In leichten, sandigen Böden kann unter Umständen die Wasserkapazität durch die Zugabe von Perlit erhöht werden. 
Versuche zum Einsatz von Perlit bei der Bepflanzung von Haldensubstraten führten teils zu viel versprechenden Ergebnissen (Uresk \& Yamamoto 1986, 1994, Larson \& Patel 1992).

In der vorliegenden Arbeit kamen Wasserspeichersubstanzen, sowohl herkömmliche Hydrogele als auch neuartige so genannte Superabsorber, zum Einsatz. Beides sind stark hygroskopische Granulate, die im Wurzelraum von Pflanzen das Wasserspeichervermögen eines Bodens erhöhen und so die Wasserversorgung verbessern sollen.

Während herkömmliche Hydrogele aus neutralisierter, vernetzter Polyacrylsäure (PANV) auf Erdöl-Basis hergestellt werden, bestehen die neuartigen Superabsorber aus vernetzter Carboxymethylstärke (CMSV) auf pflanzlicher Basis (Lechner 2002). Diese Superabsorber aus nachwachsenden Rohstoffen wurden in der Arbeitsgruppe von Prof. Dr. Lechner am chemischen Institut der Universität Osnabrück entwickelt. Erstmalig wurden sie im Rahmen dieser Arbeit in bereits 2004 angelegten Topf-Versuchen getestet. Bis dahin hatten noch keine Feldversuche stattgefunden; folglich stellte ihr Einsatz bei der Anlage der Freiland-Versuchsflächen in 2005 einen völlig neuen Versuchsansatz dar.

Herkömmliches Hydrogel sollte dabei auch als Referenz dienen, da es bereits Untersuchungen über ihre Anwendung bei Aufforstungen auf problematischen Kippenstandorten gibt, wo sie teils deutlich positive Effekte hatten (Katzur et al. 2002, Brofas et al. 2004), teils eher weniger erfolgreich waren (Hicks 1992, Ashby 1997, Ptach et al. 2009).

\section{Bodenhilfsstoff zur Verbesserung der Bodenchemie: Kalk}

Kalkungen sind in Waldbau und Forstwirtschaft weit verbreitet. Sie dienen dem Ziel, die niedrigen pH-Werte stark versauerter Böden anzuheben und somit gleichzeitig die Menge pflanzenverfügbarer Nährstoffe zu erhöhen und Schwermetalle zu binden (z. B. Häge 1996, Katzur \& Haubold-Rosar 1996, Rodenkirchen 1996).

Bei der Rekultivierung von meist stark versauerten Kippenböden gelten sie als grundlegende Meliorationsmaßnahme (z. B. Bussler et al. 1984, Katzur 1997, Katzur et al. 1999a,b, Böcker et al. 1999).

\section{Bodenhilfsstoff zur Verbesserung der Bodenphysik und -chemie: Kompost}

Die Beimischung von Kompost zur Bodenmelioration findet bislang vor allem im Garten- und Landschaftsbau sowie auch in der Landwirtschaft statt und dient der Verbesserung der Bodenstruktur und des Wasserspeichervermögens, der Bodenreaktion, der Nährstoffsituation und der Schwermetallfestlegung.

Nach Cunha-Queda et al. (2010) werden Komposte inzwischen auch zunehmend bei Rekultivierungsmaßnahmen eingesetzt, um die Bodenqualität zu verbessern und den Bedarf an anorganischen Düngern zu senken. Häge et al. (1996) sehen die Vorteile der Verwendung von Kompost auf Rekultivierungsstandorten in einer schnellen Humusanreicherung und einer Aktivierung des Rohbodens.

\section{Bodenhilfsstoff zur Verbesserung der Bodenbiologie: Mykorrhiza-Inokulum}

Mykorrhiza-Pilze und höhere Pflanzen gehen miteinander Symbiosen (Mykorrhiza) ein, indem sich Pilzhyphen und Wurzeln verbinden. Das Pilzmycel vergrößert dabei nicht nur die 
Oberfläche von Pflanzenwurzeln, es ist auch in der Lage, kleinere Bodenporen zu erschließen als Feinwurzeln (Jongmans et al. 1997), was beides zur Erhöhung der Nährstoff- und Wasseraufnahme der Pflanze führt. Die Pilzpartner liefern Nährstoffe und Mineralien (Stickstoff, Phosphor...) an die Pflanze und erhalten von dieser Kohlenstoff in Form von photosynthetischem Zucker (Höster 1993, Le Quéré et al. 2005).

Mykorrhiza kann zudem eine Filterfunktion bei der Aufnahme von Schwermetallen ausüben, was bei mykorrhizierten Pflanzen zu einer erhöhten Toleranz gegenüber SchwermetallBelastung und damit einer erhöhten Resistenz auf kontaminierten Böden führen kann (Sharples et al. 2000, Baum 2004, Marian et al. 2009). Auch gegenüber durch Boden-Versauerung ausgelöster Aluminium-Toxizität sind mykorrhizierte Bäume unempfindlicher (Hüttl 1991). Darüber hinaus scheint Mykorrhiza in der Lage zu sein, Bäume effizient vor Salzstress zu schützen (Weissenhorn 2002).

Aufgrund der geschilderten Eigenschaften ist Mykorrhiza für Pflanzen auf problematischen Standorten mit ungünstiger Wasser- und Nährstoffversorgung sowie Schadstoff-Belastung von größter Bedeutung.

Durch die Impfung mit Mykorrhiza-Pilzen bei der Pflanzung finden Bäume direkt geeignete Symbiosepartner vor. Damit kann das eventuelle Fehlen entsprechender Pilz-Populationen auf Rohböden ausgeglichen werden, was für obligat auf Mykorrhiza angewiesene Baumarten existentiell ist, aber ebenso für fakultativ Symbiosen eingehende Arten einen Vorteil bedeutet. Zudem kann auch bei bereits im Boden vorhandenen Pilzen durch eine Beimpfung die Besiedelung der Wurzeln gefördert werden (Startvorteil durch Ammenkolonisation; Schmid 2006b).

Beim Zusammenkommen von passenden Partnern beginnt schon zwischen dem 4. und dem 8. Tag der Aufbau einer Symbiose; bis zur funktionierenden Symbiose dauert es insgesamt nur 1520 Tage (Le Quéré et al. 2005). Die unterstützende Wirkung von Mykorrhiza kommt also ziemlich direkt und bereits während der auf problematischen Standorten kritischen Anwuchsphase zum Tragen.

Eine Mykorrhiza-Impfung kann in Form einer Ausbringung von Substrat erfolgen, das Mykorrhiza-Pilze enthält, etwa Waldboden, Plantagenboden oder Substrat aus Baumschulen (Mikola 1969).

Eine wachsende Zahl von Herstellern bietet inzwischen „Impfstoffe“ mit Mykorrhiza-Pilzen, sogenanntes Inokulum, in verschiedenen Formen (frisch, getrocknet...) und für verschiedene Bereiche (Aufforstungen, Landwirtschaft, Ziergarten) an. Dabei werden je nach Pflanzenarten unterschiedliche Pilzarten (-mischungen) empfohlen.

In Nordamerika werden seit Beginn der 1980er Jahre Mykorrhiza-Impfungen erfolgreich bei der Rekultivierung von ehemaligen Tagebaugebieten eingesetzt (Beckjord \& McIntosh 1984, LoBuglio \& Wilcox 1988, Cordell et al. 2002).

Der innovative Charakter des in der vorliegenden Arbeit dargestellten Projektes bestand vor allem auch in der Kombination der beschriebenen Hilfsstoffe aus den Bereichen Bodenphysik, Bodenchemie und Bodenbiologie. Das Spektrum sowohl der getesteten Bodenhilfsstoffe als auch der untersuchten Baumarten umfasste Stoffe bzw. Arten, die teils mit langer Tradition, teils (noch) eher selten bei der Rekultivierung von Tagebauflächen eingesetzt werden. 


\section{Ziele \& Arbeitshypothesen}

Die Ziele des in der vorliegenden Dissertation dargestellten Projektes umfassten

A. die grundlegende Verbesserung der Kenntnisse, welche Standortfaktoren bzw. Faktorenkombinationen das Pflanzenwachstum auf ehemaligen Tagebauflächen limitieren.

B. die Erweiterung der Kenntnisse zur Ökologie der Baumarten, v. a. zu ihren ökologischen Ansprüchen im standörtlichen Grenzbereich. Diese Erkenntnisse bilden die Grundlage für die Ermittlung eines für die Aufforstung von Tagebauhalden geeigneten Baumartenspektrums.

C. die Erforschung der Wirkungsweise bodenverbessernder Maßnahmen hinsichtlich Bodenphysik (Wasserspeichersubstanzen auf pflanzlicher und synthetischer Basis, Perlit, Kompost), Bodenchemie (Kompensationskalkung, Kompost) und Bodenbiologie (Mykorrhizierung). Hierzu zählen auch erwartete Wirkungssynergismen bei Behandlungskombinationen.

D. die Anpassung der fördernden Maßnahmen für unterschiedliche Baumarten. Es ist anzunehmen, dass unterschiedliche Baumarten in unterschiedlicher Weise durch die Hilfsmaßnahmen begünstigt werden. Die optimale Kombination aus geeigneter Baumart und passender Fördermaßnahme kann den Anwuchserfolg erheblich verbessern.

Anhand der am Beispiel des ehemaligen Uranerz-Tagebaus Ronneburg erworbenen Kenntnisse zur Wiederbegrünung von standörtlich hoch problematischen Tagebaufolgeflächen soll ein praktikables und auf ähnliche Standorte übertragbares Konzept entwickelt werden, um mit möglichst geringem technischem und finanziellem Aufwand sowie unter Ausnutzung natürlicher Prozesse wieder eine Vegetationsbedeckung zu erreichen. Dies gewährleistet zum einen die Umsetzbarkeit solcher Maßnahmen, zum anderen wird nicht mehr als nötig in natürliche Entwicklungen eingegriffen.

Mit diesem Ziel hängt die Idee einer „Insel-Strategie“ zusammen (s. S. 5). Dabei soll auf ohne Hilfsmaßnahmen vegetationsfrei bleibenden Flächen durch Initialstandorte, auf denen durch entsprechende Baumarten-Bodenhilfsstoff-Kombinationen erfolgreich Bäume etabliert werden, eine natürliche Wiederbesiedelung initiiert und unterstützt werden.

Neben Zielen des Boden- und Grundwasserschutzes wird damit durch die Schaffung von potenziellen Lebensräumen auch ökologischen Zielen entsprochen. Zudem werden soziale, gesellschaftliche und wirtschaftliche Zielsetzungen verfolgt, indem eine den Bewohnern der Region lange Zeit durch zerstörerische Nutzung entzogene Landschaft wieder neu entsteht. Dies lässt neben der Schaffung von Naherholungsraum positive Auswirkungen auf die touristische Anziehungskraft der Region erwarten. 
Folgende Arbeitshypothesen bildeten die Grundlage des in der vorliegenden Dissertation dargestellten Projektes:

A. Hypothesen zur Komplexität der Standortproblematik

1) Die Begrünung von ehemaligen Tagebaustandorten wird durch eine Reihe von Faktoren erschwert. Eine monokausale Ursachen-Wirkungskette (z.B. Pyrit-Versauerung) ist unwahrscheinlich.

2) Die ungünstigen klimatischen, bodenphysikalischen, bodenchemischen und bodenbiologischen Bedingungen wirken synergistisch schädlich auf das Pflanzenwachstum.

B. Hypothesen zur Eignung von Baumarten

3) Die im mitteleuropäischen Waldbau verwendeten Baumarten zeigen unterschiedliche Anpassungsstrategien an die schwierigen Standortbedingungen. Daraus ergibt sich eine differenzierte artspezifische Eignung für solche Problemstandorte.

4) Die Baumarten reagieren unterschiedlich auf verschiedene Bodenhilfsstoffe.

\section{Hypothesen zur Wirkung von Bodenhilfsstoffen}

\section{Bodenphysik}

5) Wasserspeichernde Stoffe können die Wasserspeicherkapazität eines Substrats erhöhen und damit die Austrocknungsgefahr auf Haldenstandorten senken.

6) Superabsorber auf Stärke-Basis sind im Gegensatz zu Hydrogelen auf Erdöl-Basis ökologisch verträglich bei vergleichbarer Wirkung.

7) Bodenlockernde Stoffe wie z. B. Perlit oder Kompost, die im Garten- und Landschaftsbau sowie in der Landwirtschaft erfolgreich eingesetzt werden, können auch auf Haldenstandorten die ungünstigen physikalischen Eigenschaften der Böden nachhaltig verbessern.

\section{Bodenchemie}

8) Kompensationskalkungen können die oft sehr niedrigen pH-Werte der Böden ehemaliger Tagebauflächen abpuffern und so die Pflanzenernährung, ihre Schadstoffbelastung und damit die Wuchsbedingungen verbessern.

9) Das Einbringen organischer Substanz in Form von Kompost kann die sehr niedrigen Kohlenstoff- und Stickstoff-Gehalte der jungen Haldenböden mit geringer Humusakkumulation sowie den pH-Wert anheben, außerdem die Nährstoffverfügbarkeit und die Wasserspeicherkapazität erhöhen sowie die Bodenstruktur verbessern.

\section{Bodenbiologie}

10) Die Impfung des Substrats mit Mykorrhiza-Pilzen führt $\mathrm{zu}$ einer schnellen Mykorrhizierung der Bäume. Dies verbessert ihre Nährstoff- und Wasserversorgung und reduziert ihre Schadstoffbelastung. Der positive Effekt der Mykorrhiza-Impfung kann in der Kombination mit anderen Bodenhilfsstoffen wie Wasserspeichersubstanzen oder Kalk-Gaben verstärkt werden. 


\section{Untersuchungsgebiet}

\section{Lage und naturräumliche Einordnung}

Die im Rahmen dieser Arbeit bepflanzten und untersuchten Freiland-Versuchsflächen befinden sich in einem ehemaligen Uranerzbergbaurevier bei Ronneburg im Landkreis Greiz in OstThüringen, etwa $10 \mathrm{~km}$ südöstlich von Gera.

Die entsprechende Naturraumuntereinheit wird als „Ronneburger Acker- und Bergbaugebiet“ innerhalb der naturräumlichen Großlandschaft „Mittelgebirge“ bezeichnet. Die umgebenden Naturraumuntereinheiten sind südlich die „Ostthüringisch-Vogtländischen Hochflächen“ (GFN \& IVÖR) bzw. das „Ostthüringer Schiefergebirge-Vogtland“, nördlich das „Altenburger Lössgebiet“ und westlich die „Saale-Sandsteinplatte“ (Hiekel et al. 2004).

Das Gebiet hat eine Ausdehnung von $160 \mathrm{~km}^{2}$ und befindet sich zwischen dem Tal des Fließgewässers Weiße Elster und der Grenze zu Sachsen. Es handelt sich um den nördlichsten und am tiefsten gelegenen Teil des Thüringer Schiefergebirges, der Meereshöhen von im Mittel 300-350 m Meereshöhe erreicht. Die flachwellige, fast ebene Landschaft wird von mäßig tiefen, flach eingesenkten Kerbsohlentälern (Sprotte sowie Zuflüsse zur Weißen Elster und Pleiße) zerschnitten.

Sie ist heute von den Hinterlassenschaften des Bergbaus (Tagebaurestlöcher, Halden) und von Ackerflächen geprägt; selten finden sich kleine Wäldchen (Waldanteil ca. $5 \%$; überwiegend Kiefer) (Hiekel et al. 2004). Als potenziell natürliche Vegetation wären im Ronneburger Ackerund Bergland Hainsimsen-Eichen-Buchenwald (Querceto-Luzuletum nemorosae) und EichenHainbuchenwald (Carpinetum betuli) der kollinen Stufe zu nennen (GFN \& IVÖR).

Die genaue geographische Lage der ehemaligen Absetzerhalde (s. folgendes Kapitel), auf der sich die Versuchsflächen befinden, ist 50 $49^{\prime}$ Nord; $12^{\circ} 09^{\prime}$ Ost; die Meereshöhe beträgt für eine Versuchsfläche (A) 290 m, für die anderen beiden Flächen (B und D) 320 m (Google Earth).

\section{Nutzungsgeschichte}

Die folgenden Informationen sind, soweit nicht anders bezeichnet, aus der Wismut-Chronik (1999) und aus Sänger (2006) entnommen.

Die Staatliche Aktiengesellschaft (SAG) „Wismut" wurde 1947 von der sowjetischen Besatzungsmacht gegründet, um deutsche Uranvorkommen in Sachsen und Thüringen für das Atomprogramm der UdSSR auszubeuten. In den ersten Jahren prägten schlechte Arbeitsbedingungen für die rasch wachsende Zahl an Arbeitern, rigorose Eingriffe in die Natur dicht besiedelter Gebiete und rücksichtsloser Gebrauch der Ressourcen im Erzgebirge und in Ostthüringen den Uranerzbergbau. 
Der Wandel vom Ziel der kurzfristigen Ausbeute zu einem langfristig effektiven Abbau führte dann zu einer Intensivierung der wissenschaftlichen Erkundung von Lagerstätten sowie zu einer Verbesserung der Arbeitsbedingungen unter Tage. Ab 1954 stieg die DDR in die dann Sowjetisch-Deutsche Aktiengesellschaft (SDAG) Wismut ein. Bis 1990 wurden im Tage- und Untertagebau 231.000 Tonnen Uran gewonnen und in die UdSSR geliefert, was die Wismut hinter den USA und Kanada zum drittgrößten Uranproduzenten der Welt macht. Dafür wurden ca. 1,2 Mrd. Tonnen Erz und Gestein abgebaut und gefördert, wovon ca. 1 Mrd. Tonnen als taubes Material auf Halden geschüttet und ca. 200 Mio. Tonnen in den Aufbereitungsbetrieben verarbeitet wurden, um das enthaltene Uran zu gewinnen.

Seit den 1970er Jahren vollzog sich infolge der abnehmenden Uranvorräte bzw. Verschlechterung der Gewinnungsbedingungen eine rückläufige Entwicklung. Der in den 1980er Jahren zunehmende internationale Entspannungsprozess und damit abnehmende Bedarf an Uran für militärische Zwecke verstärkte diesen Trend.

Mit der Wiedervereinigung Deutschlands wurde der Uranerzbergbau am 31. Dezember 1990 eingestellt. Nachdem die UdSSR Mitte 1991 per Staatsvertrag aus dem Unternehmen ausgestiegen war, ging es ganz in den Besitz der Bundesrepublik über. Die Wismut GmbH wurde gegründet, deren zentrale Aufgabe die Stillegung, Verwahrung, Sanierung und Rekultivierung der ehemals bergbaulich genutzten, großflächig radioaktiv kontaminierten Gebiete ist.

Eines der ehemaligen Uranerzabbaugebiete ist Ronneburg, in unmittelbarer Nachbarschaft des gleichnamigen Ortes in der Region Greiz-Gera (Ostthüringen) gelegen. Hier wurde von 1952 bis 1990 im Tage- und Untertagebau gut die Hälfte des insgesamt von der Wismut produzierten Urans gewonnen. Etwa 14.100 Tonnen Uran entstammten dem Tagebau Lichtenberg, wofür dort von 1958 bis 1977 insgesamt 15 Mio. Tonnen Uranerz gefördert werden mussten, was den für die ostthüringischen Lagerstätten typischen, relativ geringen Urananteil des Erzes von weniger als 0,1\% deutlich macht. Die Tiefe des bereits während des Abbaus teilweise wieder verfüllten Tagebaulochs betrug maximal $240 \mathrm{~m}$, sein Volumen maximal 160 Mio. ${ }^{3}$. Bei Aufgabe des Uranerzbergbaus 1990 betrug das Volumen des Lochs 84 Mio. $\mathrm{m}^{3}$, seine Ausdehnung etwa 1,6 x 0,9 km, seine Fläche etwa 150 ha.

Im Ronneburger Abbaugebiet entstanden durch den Bergbau neben anderen Altlasten 13 Halden mit insgesamt rund 180 Mio. $\mathrm{m}^{3}$ abgelagertem Material und einer Haldenaufstandsfläche von insgesamt rund 550 ha. Die mit Abstand größte dieser Halden ist mit einer Aufstandsfläche von 225 ha und einem Volumen von knapp 70 Mio. $\mathrm{m}^{3}$ die sogenannte Absetzerhalde, die zwischen 1959 und 1970 südlich des Tagebaus Lichtenberg aufgeschüttet wurde. Im Zuge der laufenden Verwahrungs- und Sanierungsarbeiten wurden und werden die meisten der Halden in den Tagebau Lichtenberg verbracht, so auch die Absetzerhalde, deren Umlagerung 2005 abgeschlossen war (Wismut 2006). Im südlichen Bereich der Haldenaufstandsfläche befinden sich die im Rahmen der vorliegenden Arbeit angelegten Freiland-Versuchsflächen. 


\section{Geologie, Böden und Wasserhaushalt}

Bei den Standorten der drei Freiland-Versuchsflächen, die in unterschiedlichen Bereichen der ehemaligen Absetzerhalde angelegt wurden, handelt es sich nicht um gewachsene Böden als Produkt einer von unterschiedlichen Faktoren beeinflussten Bodenentwicklung, sondern um geschüttetes Haldenmaterial.

Die wichtigsten Kennwerte zur dem Naturraum Ronneburger Acker- und Bergbaugebiet zugrunde liegenden Geologie, den darüber entstandenen Böden und dem auch nutzungsbedingt problematischen Wasserhaushalt sind in Tab. 1 dargestellt.

Tab. 1: Kennwerte zu Geologie, Böden und Wasserhaushalt im Naturraum Ronneburger Acker- und Bergbaugebiet (Hiekel et al. 2004)

\begin{tabular}{|c|c|c|c|}
\hline Naturraum & Geologie & Böden & Wasserhaushalt \\
\hline $\begin{array}{l}\text { Ronneburger } \\
\text { Acker- und } \\
\text { Bergbaugebiet }\end{array}$ & $\begin{array}{l}\text { Ronneburger Horst } \\
\text { - bruchtektonisch } \\
\text { gegen das Thüringer } \\
\text { Becken abgesetzt } \\
\text { - aus paläozoischen } \\
\text { silikatischen } \\
\text { Sedimentgesteinen } \\
\text { (Quarzite, Tonschiefer) } \\
\text { des Ordoviziums bis } \\
\text { Devons aufgebaut } \\
\text { - meist mit } \\
\text { periglazialer } \\
\text { Schuttdecke bedeckt } \\
\text { - darauf z.T. } \\
\text { Lössdecken, } \\
\text { Lössschleier, } \\
\text { Lössderivate } \\
\text { (Schwemmlöss) }\end{array}$ & $\begin{array}{l}\text { Schuttdecken: } \\
\text { Steinig-grusige Lehme } \\
\text { mit Berglehm-Braunerde, } \\
\text { lehmiger Skelettboden mit } \\
\text { Fels-Ranker } \\
\text { Löss über } \\
\text { Schiefergesteinsschutt: } \\
\text { Steinig-grusiger } \\
\text { Schlufflehm (Staunässe!) } \\
\text { mit Berglehm- } \\
\text { Braunstaugley und Löss- } \\
\text { Braunstaugley; Auelehme } \\
\text { aus Schlufflehm und } \\
\text { sandigem Lehm mit Schluff- } \\
\text { und Lehm-Vega }\end{array}$ & $\begin{array}{l}\text { Sedimentgestein } \\
\text { grundwasserarm bis } \\
\text { grundwasserfrei, in } \\
\text { Talsohlen hoher } \\
\text { Grundwasserstand, } \\
\text { Vernässungen, Staunässe, } \\
\text { hoher Oberflächenabfluß } \\
\text { (Jahresmittel: 150-180 } \\
\text { mm) aufgrund minimaler } \\
\text { Wasseraufnahmefähigkeit } \\
\text { des Untergrundes und } \\
\text { Waldentblößung }\end{array}$ \\
\hline
\end{tabular}

Zur Zusammensetzung des Haldenmaterials findet sich bei Sänger (1993) eine Aufstellung. Demnach bestand die bei Abschluss ihrer Aufschüttung 1970 rund $85 \mathrm{~m}$ hohe Absetzerhalde (Meereshöhen von 290 bis 375 m) aus verstürzten Massen des unmittelbar benachbarten Tagebaus Lichtenberg. Diese setzten sich anteilig aus $40 \%$ Unterdevonschiefer, $30 \%$ Ockerkalkgruppe, $20 \%$ unterer und oberer Graptolithenschiefer, $5 \%$ Lederschiefer und $5 \%$ Diabas zusammen. Hohe Gehalte an Eisensulfiden Pyrit und Markasit (5-7 \%) sowie an organischem Kohlenstoff (10-12 \%) im silurischen Schwarzschiefer führten durch Oxidationsprozesse in den Bruchmassen immer wieder zu endogenen Bränden, die durch Abdeckungen mit inertem Material bekämpft wurden. Dabei wurden im Verlauf der Zeit unterschiedliche Substrate verwendet: Überwiegend lehmiges Material aus dem Sandtagebau Lichtenberg, überwiegend sandiges Material aus einem Kulturbodenaufschluss, Material mit hochwertigem Lösslehm aus den Randbereichen des Lehmtagebaus sowie pleistozänes Material aus der Erztagebauerweiterung. Insgesamt wurden etwa $75 \%$ der Haldenoberfläche mit Abdeckungen versehen, die auf den Plateauflächen im Schnitt $1 \mathrm{~m}$, auf den Böschungen etwa $2 \mathrm{~m}$ mächtig waren. 


\section{Klima}

Das Ronneburger Acker- und Bergbaugebiet befindet sich im Klimabereich „Südostdeutsche Becken und Hügel“ (UBA 2005) bzw. im „Mitteldeutschen Berg- und Hügelland-Klima“ (Klimaatlas 1953) und ist dem Klimabezirk „Thüringisch-Sächsisches Mittelgebirgsvorland“ zuzuordnen (Hiekel et al. 2004). Das Klima ist subkontinental bis kontinental geprägt und bezogen auf gesamt Thüringen verhältnismäßig warm und trocken. Einige wichtige klimacharakteristische Merkmale des Klimabereichs und -bezirks sind in Tab. 2 zusammengefasst.

Tab. 2: Klimacharakteristische Merkmale des Klimabereichs „Südostdeutsche Becken und Hügel“ (UBA 2005), des Klimabezirks „Thüringisch-Sächsisches Mittelgebirgsvorland“ (Hiekel et al. 2004) sowie langfristige Klimawerte der DWD-Messstation Flughafen Gera-Leumitz (1961-1990; Niederschlag: 19611990 u. 1971-2000)

\begin{tabular}{|l|l|l|l|}
\hline Langjährige Mittelwerte & $\begin{array}{l}\text { Klimabereich } \\
\text { „Südostdeutsche } \\
\text { Becken und Hügel“ }\end{array}$ & $\begin{array}{l}\text { Klimabezirk } \\
\text { „Thüringisch- } \\
\text { Sächsisches } \\
\text { Mittelgebirgsvorland“ }\end{array}$ & $\begin{array}{l}\text { DWD-Messstation } \\
\text { Flughafen Gera- } \\
\text { Leumitz }\end{array}$ \\
\hline Jahrestemperatur & 6,7 bis $9,6^{\circ} \mathrm{C}$ & 7,9 bis $8^{\circ} \mathrm{C}$ & $7,8^{\circ} \mathrm{C}$ \\
\hline Januartemperatur & & 0 bis $-1^{\circ} \mathrm{C}$ & $-1,3^{\circ} \mathrm{C}$ \\
\hline Julitemperatur & & 17 bis $17,5^{\circ} \mathrm{C}$ & $16,7^{\circ} \mathrm{C}$ \\
\hline Jahresniederschläge & $450-891 \mathrm{~mm}$ & $<600-650 \mathrm{~mm}$ & $592-625 \mathrm{~mm}$ \\
\hline Geringster Niederschlag & & & Februar $32-35 \mathrm{~mm}$ \\
\hline Höchster Niederschlag & & & $\begin{array}{l}\text { Juni/Juli/Aug. } \\
67-73 \mathrm{~mm}\end{array}$ \\
\hline Nebeltage & & 40 & \\
\hline Schneedecke > $10 \mathrm{~cm}$ & $0-95$ Tage & & \\
\hline Sonnenscheindauer & 1.412 bis $1.608 \mathrm{~h}$ & & \\
\hline $\begin{array}{l}\text { Überwiegend vor- } \\
\text { herrschende Wind- } \\
\text { richtung in freien Lagen }\end{array}$ & $\begin{array}{l}\text { Südsüdwest - } \\
\text { Westsüdwest }\end{array}$ & & \\
\hline
\end{tabular}

In der Untersuchungsregion liegt die mittlere Jahrestemperatur im langjährigen Mittel bei $7,8^{\circ} \mathrm{C}$, die durchschnittliche Temperatur während der forstlichen Vegetationszeit von Mai bis September bei $14,7^{\circ} \mathrm{C}$. Der langjährige mittlere Jahresniederschlag beträgt $592-625 \mathrm{~mm}$, in der forstlichen Vegetationszeit von Mai bis September sind es im Schnitt 282-326 mm (s. Tab. 3).

Das Jahr 2005 lag mit einer Durchschnittstemperatur während der Vegetationszeit von $15,8^{\circ} \mathrm{C}$ um $1,1^{\circ} \mathrm{C}$ über dem langjährigen Mittel. Der insgesamt in der Vegetationszeit gefallene Niederschlag bewegte sich mit 298 mm im Rahmen des langjährigen Mittels.

Tab. 3: Durchschnittstemperatur $\left[{ }^{\circ} \mathrm{C}\right]$ und Niederschlagssumme $[\mathrm{mm}]$ im langjährigen Mittel (DWDWetterstation Gera-Leumitz) u. während des Versuchszeitraumes (Wismut-Wetterstation Ronneburg)

\begin{tabular}{|c|c|c|c|c|c|c|c|c|c|}
\hline \multicolumn{3}{|c|}{ 1961-1990 bzw. 1971-2000 } & \multicolumn{2}{c|}{2005} & \multicolumn{4}{c|}{2006} \\
\hline \multicolumn{2}{|c|}{ Jahr } & \multicolumn{2}{c|}{ Veg.Zeit } & \multicolumn{2}{c|}{ Veg.Zeit } & \multicolumn{2}{c|}{ Jahr } & \multicolumn{2}{c|}{ Veg.Zeit } \\
\hline${ }^{\circ} \mathrm{C}$ & $\mathrm{mm}$ & ${ }^{\circ} \mathrm{C}$ & $\mathrm{mm}$ & ${ }^{\circ} \mathrm{C}$ & $\mathrm{mm}$ & ${ }^{\circ} \mathrm{C}$ & $\mathrm{mm}$ & ${ }^{\circ} \mathrm{C}$ & $\mathrm{mm}$ \\
\hline 7,8 & $592-625$ & 14,7 & $282-326$ & 15,8 & 298 & 10 & 471 & 17,9 & 250 \\
\hline
\end{tabular}




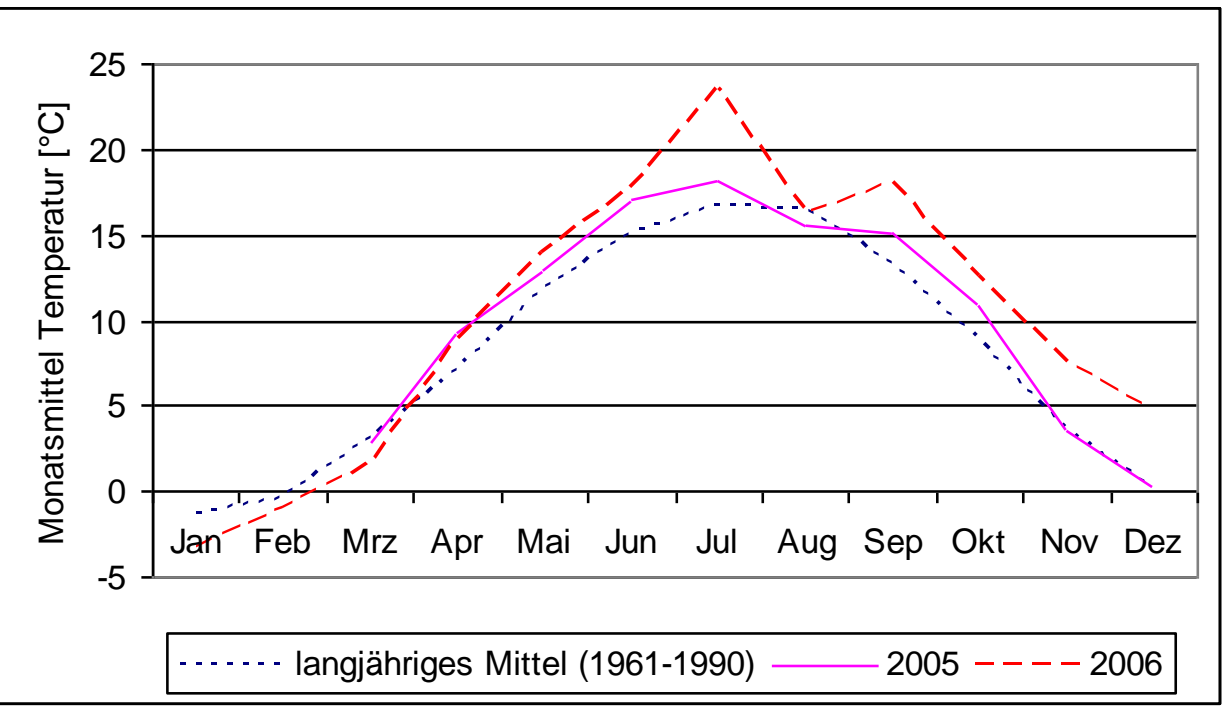

Abb. 1: Temperatur (Monatsmittel); langjähriges Mittel 1961-1990 (DWD-Wetterstation Flughafen GeraLeumitz) sowie 2005 (Wismut-Wetterstation Ronneburg Hochplateau Absetzerhalde; keine Werte für JanFeb) und 2006 (Wismut-Wetterstation Ronneburg Tagebau)

Die Niederschlagsverteilung im Anlagejahr war allerdings problematisch für die Jungpflanzen. Nach einem kalten, niederschlagsreichen Februar und einem langen Spätwinter mit Schnee bis weit in den März folgte ein sehr trockenes, warmes Frühjahr. Vor allem der April 2005 (Monat der Pflanzung) wich mit Temperaturen von durchschnittlich 9,3-10,1 ${ }^{\circ} \mathrm{C}$ und einem Gesamtniederschlag von 7,6-9,5 mm erheblich vom langjährigen Monatsmittel $\left(7^{\circ} \mathrm{C}\right.$ und $48,8-$ $57,1 \mathrm{~mm}$ ) ab (s. Abb. 1, Abb. 2).

Der regenreiche Juli mit zum Teil sehr ergiebigen Niederschlägen konnte das Niederschlagsdefizit der vorangegangenen Monate etwas auffüllen; die klimatische Wasserbilanz (die Differenz aus der Summe des Niederschlages und der Summe der potenziellen Verdunstung) des Jahres 2005 blieb jedoch insgesamt negativ (TMLNU 2005).

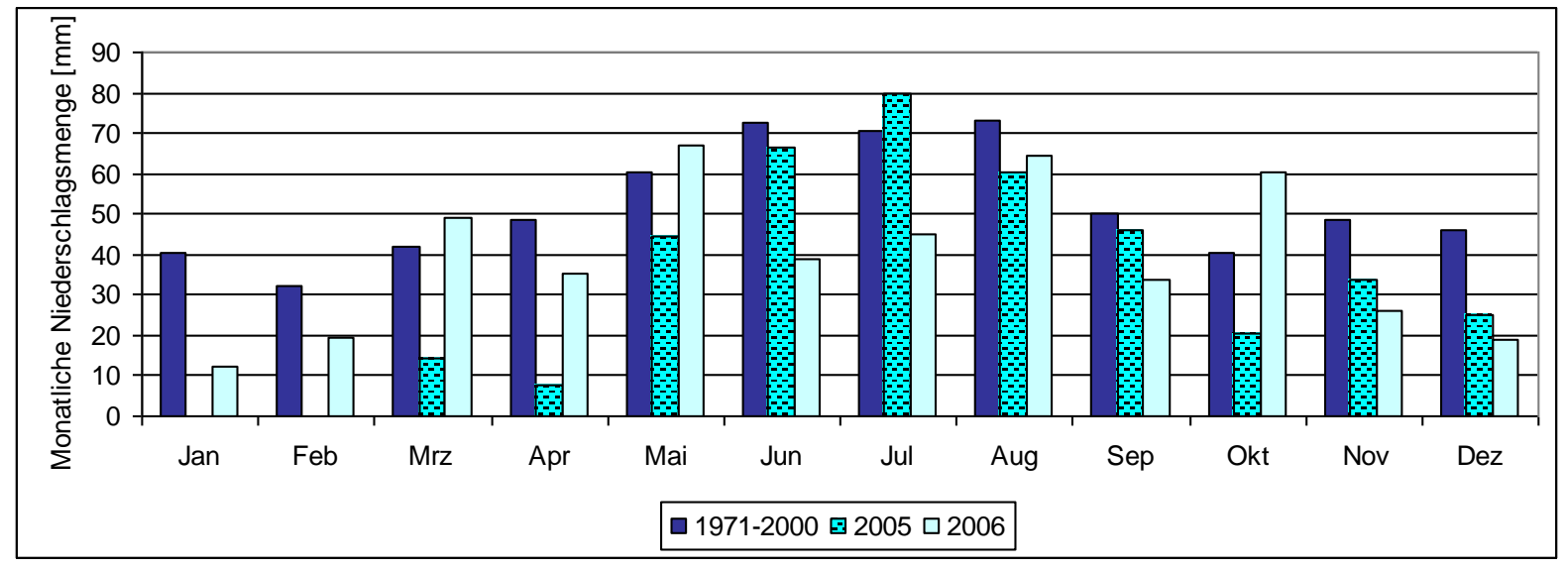

Abb. 2: Monatliche Niederschlagsmenge; langjähriges Mittel 1971-2000 (DWD-Wetterstation Flughafen Gera-Leumitz) sowie 2005 (Wismut-Wetterstation Ronneburg Hochplateau Absetzerhalde; keine Werte für Jan-Feb) und 2006 (Wismut-Wetterstation Ronneburg Tagebau)

In 2006 war die Durchschnittstemperatur sowohl im Jahresmittel als auch während der Vegetationszeit um $2,2^{\circ} \mathrm{C}$ höher als im langfristigen Mittel. Der während des gesamten Jahres und auch der in der Vegetationszeit gefallene Niederschlag lag mit 471 bzw. $250 \mathrm{~mm}$ rund $25 \%$ unter den langfristigen Durchschnittswerten (s. Tab. 3). 
Auf einen langen Winter mit geschlossener Schneedecke bis in den März folgte ein bezüglich der Lufttemperaturen und Niederschläge relativ durchschnittliches Frühjahr.

Nachdem der Juni mit nur wenigen Regentagen bereits deutlich trockener und wärmer als der langfristige Monatsdurchschnitt war, stieg die Juli-Mitteltemperatur auf $23,5^{\circ} \mathrm{C}$ an und lag damit um 6,8 $8^{\circ} \mathrm{C}$ über dem langjährigen Mittel (s. Abb. 1). Damit war der Juli 2006 der bis dahin wärmste Monat seit Beginn der meteorologischen Aufzeichnungen. Die Niederschläge (s. Abb. 2) lagen mit $45 \mathrm{~mm}$ wie im Juni $(39 \mathrm{~mm})$ erheblich unter den Normalwerten $(73 \mathrm{bzw} .71 \mathrm{~mm})$ und fielen im Juli meist in Form von teils unwetterartigen Gewitterschauern. Dabei floss ein Großteil des Wassers oberflächlich ab, ohne die Bodenwasservorräte aufzufüllen. Als Folge des Sommers 2006, der Parallelen mit dem des Jahres 2003 aufwies, traten in Thüringen vielfach Hitze- und Dürreschäden an Kulturen und Altbeständen (Altbuchen) sowie Trockenschäden und Absterbeerscheinungen an Birken auf. Erst ab Ende Juli und vor allem im August verminderte sich das Bodenfeuchtedefizit (TMLNU 2006).

Aufgrund der zunächst geringen Oberflächenrauhigkeit ausgeräumter Haldenlandschaften weht an solchen Standorten meist ein stetiger Wind, der zur Austrocknung der obersten Bodenschicht beiträgt. Die von der WISMUT im Bereich der Versuchsflächen durchgeführten Windmessungen ergaben für 2005 und 2006 typische Tagesmittelwerte von im Monatsdurchschnitt zwischen 2,8 und $6,5 \mathrm{~m} / \mathrm{s}$, was Windstärken von 2 (leichter oder sehr schwacher Wind) bis 4 (mäßiger Wind) entspricht. In Böen wurden Windgeschwindigkeiten von maximal 24,5 m/s erreicht (Sturmböen und schwere Sturmböen der Windstärke 9-10).

In einer 2005 veröffentlichten Studie des Potsdam-Institutes für Klimafolgenforschung (PIK) im Auftrag des Umweltbundesamtes zum Klimawandel in Deutschland (UBA 2005) wird der Klimabereich „Südostdeutsche Becken und Hügel“ zusammen mit dem "Nordostdeutschen Tiefland“ deutschlandweit als zukünftig am stärksten vom Klimawandel betroffen eingeschätzt. Dabei werden vor allem Dürregefahr für Land- und Forstwirtschaft (geringere Wasserverfügbarkeit, ungünstige klimatische Wasserbilanz, Abnahme der Sommerniederschläge, erhöhte Verdunstung) sowie Hochwasser genannt. 


\section{Material \& Methodik}

\section{Freiland-Versuche - Versuchsanlage}

\subsection{Versuchsflächen}

Bereits für den dieser Arbeit vorangegangenen Vorversuch waren insgesamt vier Versuchsflächen auf der ehemaligen Absetzerhalde des Ronneburger Tagebaus Lichtenberg ausgewählt worden. Auswahlkriterien waren das Bodenmaterial (Rohboden ohne Bodenauftrag) sowie die Homogenität der Bodenoberflächen (relativ ebenes Gelände; Vergleichbarkeit der Bedingungen). Jede Fläche maß etwa $2.000 \mathrm{~m}^{2}$ und wurde wilddicht gezäunt. Für die Anlage der in diesem Kapitel beschriebenen Freiland-Versuche wurden drei dieser Versuchsflächen ausgewählt (A, B, D). Fläche $C$ hatte sich als nicht geeignet erwiesen, da aufgrund von starker Bodenverdichtung weite Teile der Fläche bei Niederschlag dauerhaft unter Wasser standen.

Wie erst nach Versuchsanlage bekannt wurde, waren im Jahr 2000 die befahrbaren Bereiche der Halde, darunter auch die Versuchsflächen B-D, mit 2,7 t/ha kohlensaurem Magnesiumkalk (50 \% $\mathrm{CaCO}_{3}, 35 \% \mathrm{MgCO}_{3}$ ) gekalkt worden (LAWuF Gotha 2002, Arenhövel 2002).

Im Gegensatz zur Versuchsfläche A siedelte sich auf Fläche B und D im Verlauf des Versuchs in einigen Bereichen Spontanvegetation (Moos, Gras) an, in anderen Bereichen konnte sich bislang keine Vegetation etablieren (Ursache dafür könnte eine ungleichmäßige Verteilung des im Jahr 2000 ausgebrachten Kalks sein). Als Indiz für die offensichtlich kleinräumig variierenden Standortsbedingungen wurden die bewachsenen Bereiche erfasst und in einen schematischen Plan der Versuchsflächen eingezeichnet, wobei zusätzlich die Positionen der Versuchspflanzen markiert wurden (s. Abb. 3). Die in der Spontanvegetation häufig vorkommenden Arten wurden bestimmt.

\subsection{Baumarten und Pflanzenmaterial}

Im Freiland-Versuch auf den Ronneburger Tagebaufolgeflächen wurden vier Laub- und zwei Nadelbaumarten eingesetzt:

Die einheimischen Arten Spitz-Ahorn (Acer platanoides, im Folgenden: Ahorn), Eberesche (Sorbus aucuparia), Schwarz-Erle (Alnus glutinosa; im Folgenden: Erle) und Wald-Kiefer (Pinus sylvestris, im Folgenden: Kiefer) sowie die beiden aus Nordamerika stammenden Arten RotEiche (Quercus rubra; im Folgenden: Eiche) und Douglasie (Pseudotsuga menziesii) (s. Tab. 4).

Die Auswahl erfolgte aufgrund von Vorversuchen auf dem Ronneburger Kippenstandort, in denen insgesamt 15 verschiedene Baumarten getestet wurden, wobei die sechs ausgewählten Arten die vielversprechendsten Ergebnisse zeigten (Dohrenbusch \& Arenhövel, unveröffentlicht). Vorteile (und Nachteile) der ausgewählten Baumarten sowie ihre Eignung und ihr bisheriger Einsatz bei der Rekultivierung von ehemaligen Tagebauflächen werden ab S. 364 diskutiert (Diskussion Eignung von Baumarten). 
Tab. 4: Im Freiland-Versuch eingesetzte Baumarten, Herkünfte (o.A. = ohne Angabe), Sortimente (Alter / Form (ohne Ballen) / Haupttrieblängen [cm], in Klammern: tatsächlich gemessene Haupttrieblängen), Anzahlen; botanische/deutsche Artnamen: Rothmaler 1994

\begin{tabular}{|l|l|l|l|}
\hline Art & Herkunft & Sortiment & Anzahl \\
\hline $\begin{array}{l}\text { Rot-Eiche } \\
\text { (Quercus rubra l.) }\end{array}$ & $\begin{array}{l}81602 \text { (Bundesgebiet } \\
\text { ohne Norddt. Tiefland) }\end{array}$ & $\begin{array}{l}\text { 2j.v. / oB / 30-50 } \\
(30-100)\end{array}$ & 192 \\
\hline $\begin{array}{l}\text { Spitz-Ahorn } \\
\text { (Acer platanoides l.) }\end{array}$ & o.A. & $\begin{array}{l}\text { 2j.v. / oB / 60-100 } \\
(20-40)\end{array}$ & 192 \\
\hline $\begin{array}{l}\text { Eberesche, Vogelbeere } \\
\text { (Sorbus aucuparia l. em. hedl.) }\end{array}$ & o.A. & $\begin{array}{l}\text { 2j.v. / oB / 50-80 } \\
(40-95)\end{array}$ & 120 \\
\hline $\begin{array}{l}\text { Schwarz-Erle } \\
\text { (Alnus glutinosa l.) }\end{array}$ & o.A. & $\begin{array}{l}\text { 2j.v. / oB / 60-100 } \\
(85-120)\end{array}$ & 120 \\
\hline $\begin{array}{l}\text { Douglasie } \\
\text { (Pseudotsuga menziesii } \\
\text { (mirbel) franco) }\end{array}$ & $\begin{array}{l}\text { 853 06 } \\
\text { (Südostdt. Hügel- und } \\
\text { Bergland; ausgew. VG, } \\
\text { nicht autochthon) }\end{array}$ & $\begin{array}{l}1 / 1 / \text { oB / 20-40 } \\
(10-40)\end{array}$ & 192 \\
\hline $\begin{array}{l}\text { Wald-Kiefer } \\
\text { (Pinus sylvestris subsp. } \\
\text { sylvestris })\end{array}$ & $\begin{array}{l}\text { 851 10 } \\
\text { (Erzgebirge, kolline } \\
\text { Stufe; ausgew. VG, } \\
\text { autochthon) }\end{array}$ & 2j.v. / oB / o.A. (10-50) & 120 \\
\hline Gesamt & \multicolumn{2}{|l}{} & 936 \\
\hline
\end{tabular}

Das in den Freiland-Versuchen verwendete Pflanzenmaterial wurde bei einer Baumschule in der Region Gera-Greiz (Baumschule Zech, Langenwetzendorf) bezogen.

\subsection{Bodenhilfsstoffe}

In den Versuchspflanzungen im Rahmen der vorliegenden Arbeit wurden mit Perlit, je einer synthetischen und Stärke-basierten Wasserspeichersubstanz, Kalk, Kompost und (jeweils an die Baumart angepassten) Mykorrhiza-Pilz-Inokula insgesamt sechs Bodenhilfsstoffe zur Verbesserung der problematischen Standortbedingungen getestet.

\subsubsection{Zur Verbesserung der Bodenphysik: Perlit, Wasserspeichersubstanzen}

Unter den zahlreichen erhältlichen Perlit-Produkten wurde das unbehandelte „Isoself® “ (Knauf Perlite GmbH Dortmund) mit einer Körnung von 0-6 mm und einer Schüttdichte von ca. 90 $\mathrm{kg} / \mathrm{m}^{3}$ ausgewählt. Entsprechend den Anwendungsempfehlungen der Hersteller wurde bei der Versuchsanlage ein Anteil von 30 Vol.-\% Perlit pro Pflanzloch zugegeben.

Als synthetische Wasserspeichersubstanz wurde "Stockosorb® 500 micro" (GEFA Produkte Fabritz $\mathrm{GmbH}$ ) eingesetzt. Im Gegensatz $\mathrm{zu}$ anderen handelsüblichen synthetischen Wasserspeicherprodukten verfügt Stockosorb® über ein Kalium-Zentralatom, was es in salzhaltigen Böden stabiler und langlebiger macht. Andere Acrylate werden durch Salze in der Bodenlösung schneller zersetzt; ihre Wasserspeicherkapazität wird gemindert (Kutscheidt 2006). Die feinkristalline Substanz wurde den Herstellerangaben entsprechend dosiert, trocken zugegeben und mit dem Boden vermischt. 
Bei der verwendeten Wasserspeichersubstanz aus pflanzlicher Stärke handelte es sich um eine Neu-Entwicklung der Arbeitsgruppe von Prof. Dr. Lechner am Institut für Chemie der Universität Osnabrück. Für die Freiland-Versuche wurde die zum Zeitpunkt der Anlage (Frühjahr 2005) aktuellste Entwicklungsstufe dieses so genannten Superabsorbers (,5/8“) verwendet. Die Konzentration von $1 \%$ oder 50 g je Pflanzloch war so berechnet worden, dass die zuvor im Laborversuch ermittelte Wasseraufnahmekapazität derjenigen von Stockosorb ${ }^{\circ}$ angepasst war. Der Superabsorber wurden ebenfalls trocken in den Boden gemischt.

\subsubsection{Zur Verbesserung der Bodenchemie: Kalk}

Da eine Kalkung zur Anhebung des niedrigen pH-Wertes des sauren Ronneburger Haldensubstrats (s. S. 44) existentiell zu sein schien, wurden alle sonstigen BodenhilfsstoffVarianten einmal ohne und einmal mit Kalk-Gabe angelegt (s. Abb. 3).

Damit wurde auch der Thüringer Landesanstalt für Wald und Forstwirtschaft Rechnung getragen, die angesichts des Pyrit-Gehaltes und der niedrigen pH-Werte des Haldensubstrats ausdrücklich Kalkungsvarianten im Versuchsdesign empfiehlt. Die Kalkmenge müsse dabei deutlich über den herkömmlichen, im Wald üblichen Kalk-Gaben liegen (LAWuF Gotha 2002). Während bei einer Flächenkalkung der Halden im Jahr 2000 Kalk in einer Größenordnung von 2,7 t/ha ausgebracht wurde (LAWuF Gotha 2002, Arenhövel 2002), entsprach die im FreilandVersuch verwendete Kalk-Gabe von je 50 g pro Pflanzloch einer Flächenkalkung von 4 t/ha. Unter den im Handel erhältlichen Düngekalkprodukten wurde „Dolomitkalk - Kohlensaurer Magnesiumkalk 90“ (gpi green partners international GmbH \& Co. KG Gladbeck) ausgewählt, der $55 \%$ Calciumcarbonat $\left(\mathrm{CaCO}_{3}\right)$ und $35 \%$ Magnesiumcarbonat $\left(\mathrm{MgCO}_{3}\right)$ enthält.

\subsubsection{Zur Verbesserung der Bodenphysik und -chemie: Kompost}

Im Ronneburger Freiland-Versuch wurde fein gesiebter Kompost des Göttinger Kompostwerks (Produktinformation s. kompostwerk.goettingen.de) in einer Dosierung von 30 Vol.-\% je Pflanzloch zugegeben. Diese Menge entspricht den Anwendungsempfehlungen für Komposte im Landschaftsbau nach DIN 18916 (2002) zur Vegetationstechnik im Landschaftsbau, die im Teil Pflanzen und Pflanzarbeiten eine Kompost-Einbringung in Pflanzlöcher und -gruben von je nach Boden- und Pflanzenart bis zu 30 Vol.-\% der Verfüllmenge vorgibt.

\subsubsection{Zur Verbesserung der Bodenbiologie: Mykorrhiza-Inokulum}

In den Mykorrhiza-Varianten des Freiland-Versuchs (V11-V16, s. Tab. 5) wurden eine Nadelbaum- und zwei Laubbaumarten mit Mykorrhiza-Pilz-Inokula gepflanzt (Douglasie, Eiche, Ahorn).

Douglasie und Eiche bilden mit entsprechenden Pilzpartnern Ekto-Mykorrhiza aus, wobei die Pilzhyphen die Feinwurzelenden des Baumes wie einen Mantel umhüllen und sich in den Zellzwischenräumen der Wurzelrinde netzartig verflechten (Höster 1993). Ahorn bildet im Gegensatz zu den anderen beiden Baumarten eine der insgesamt 6 bekannten (Le Quéré et al. 2005) Endo-Mykorrhiza- bzw. VAM- (vesikulär-arbuskuläre-Mykorrhiza) Formen aus. Dabei werden keine Mycelmäntel ausgebildet, sondern die Pilzhyphen dringen in die Zellen der 
Wurzelrinde ein und schwellen dort zu Vesikeln an oder bilden büschelartige Verzweigungen, die Arbuskeln (Höster 1993).

In den Mykorrhiza-Varianten im Ronneburger Freiland-Versuch wurden die Douglasien mit dem Ekto-Mmykorrhiza-Pilz „Kahler Krempling“ (Paxillus involutus) beimpft, die Eichen mit dem ebenfalls Ekto-Mykorrhiza bildenden „Dickschaligen Kartoffelbovist“ (Scleroderma citrinum). Die Ahorne wurden mit einer Mischung aus VAM bildenden Glomus-Arten (G. geospora, G. mosseae, G. luzidum) inokuliert.

Die Beimpfung erfolgte entsprechend den Herstellerangaben durch Zugabe von insgesamt $50 \mathrm{ml}$ Inokulum (ein mit Pilzhyphen durchzogenes Trägermaterial, in diesem Fall Bodensubstrat) ins Pflanzloch und auf die Wurzeln der Pflanze. Die Inokula für die Freiland-Versuche wurden von GEFA Produkte Fabritz GmbH bezogen (Mischungen „Ekto Nadel“, „Ekto Spezial Eiche“ und „Endo Laub“).

\subsubsection{Bodenhilfstoff-Kombinationen}

Die verschiedenen Bodenhilfsstoffe wurden im Freiland-Versuch teilweise miteinander kombiniert, um die erwarteten positiven Wirkungen $\mathrm{zu}$ summieren oder sogar positive Wirkungssynergismen zu erreichen. Die getesteten Kombinationen sind in Tab. 5 aufgeführt.

Tab. 5: Behandlungsvarianten im Freiland-Versuch

\begin{tabular}{|c|c|c|c|c|c|c|c|}
\hline Variante & $\begin{array}{l}\text { Kalk } \\
50 \mathrm{~g}\end{array}$ & $\begin{array}{l}\text { Stockosorb }{ }^{2} \\
5 \% 0=25 \mathrm{~g}\end{array}$ & $\begin{array}{l}\text { Superabsorber } \\
1 \%=50 \mathrm{~g}\end{array}$ & $\begin{array}{l}\text { Perlit } \\
30 \%\end{array}$ & $\begin{array}{l}\text { Kompost } \\
30 \%\end{array}$ & $\begin{array}{l}\text { Mykorrhiza } \\
\text {-Inokulum }\end{array}$ & Baumarten \\
\hline V1 & & & & & & & \multirow{10}{*}{$\begin{array}{l}\text { Eiche, } \\
\text { Ahorn, } \\
\text { Douglasie, } \\
\text { Eberesche, } \\
\text { Kiefer, Erle }\end{array}$} \\
\hline V2 & - & & & & & & \\
\hline V3 & & - & & & & & \\
\hline V4 & $\bullet$ & $\bullet$ & & & & & \\
\hline V5 & & & • & & & & \\
\hline V6 & $\bullet$ & & $\bullet$ & & & & \\
\hline V7 & & & & • & & & \\
\hline V8 & • & & & • & & & \\
\hline V9 & & & & & $\bullet$ & & \\
\hline V10 & $\bullet$ & & & & • & & \\
\hline V11 & & & & & & $\bullet$ & \multirow{6}{*}{$\begin{array}{l}\text { Eiche, } \\
\text { Ahorn, } \\
\text { Douglasie }\end{array}$} \\
\hline V12 & $\bullet$ & & & & & $\bullet$ & \\
\hline V13 & & • & & & & $\bullet$ & \\
\hline V14 & • & $\bullet$ & & & & • & \\
\hline V15 & & & $\bullet$ & & & • & \\
\hline V16 & $\bullet$ & & $\bullet$ & & & • & \\
\hline
\end{tabular}




\subsection{Anlage der Versuchspflanzungen}

Die Freiland-Versuchspflanzungen wurden im April 2005 (11.-14.) angelegt. Insgesamt wurden 936 Bäume - verteilt auf drei etwa $2.000 \mathrm{~m}^{2}$ große Versuchsflächen - gepflanzt. Die Pflanzlöcher wurden mit einem Pflanzlochbohrer (Pflanzfuchs) hergestellt. Die verschiedenen Bodenhilfsstoffe wurden grundsätzlich nicht flächig, sondern pflanzlochweise eingebracht. Dazu wurde der beim Bohren herausgedrehte Boden (ca. 5 Liter) in einem Eimer je nach Variante mit den entsprechenden Bodenhilfsstoffen (Kalk, Perlit, Kompost, Superabsorber, Stockosorb®) vermischt und anschließend mit der jeweiligen Pflanze wieder ins Pflanzloch gefüllt. Das Mykorrhiza-Inokulum wurde direkt in den Wurzelbereich und auf die Wurzeln der Pflanzen gestreut. Die Stockosorb® und Superabsorber-Gaben waren zuvor im Labor abgewogen worden, während Kalk, Perlit, Kompost und Mykorrhiza-Inokulum vor Ort mit entsprechend großen Messbechern abgemessen wurden. Jede Variante wurde pro Baumart insgesamt 12-fach (auf jeder der drei Versuchsflächen 4-fach) wiederholt. Die Einhaltung einer festgelegten Reihenfolge der Baumarten sorgte dafür, dass Bäume einer Art nicht geklumpt, sondern systematisch verteilt gepflanzt wurden. Die Abstände der Bäume innerhalb der Reihen sowie zwischen den Reihen richteten sich nach den örtlichen Gegebenheiten (z.B. wurden offensichtlich stark verdichtete Bereiche, auf denen Niederschlagswasser in Pfützen stand, ausgespart), betrugen aber mindestens 1,5 bzw. $2 \mathrm{~m}$.

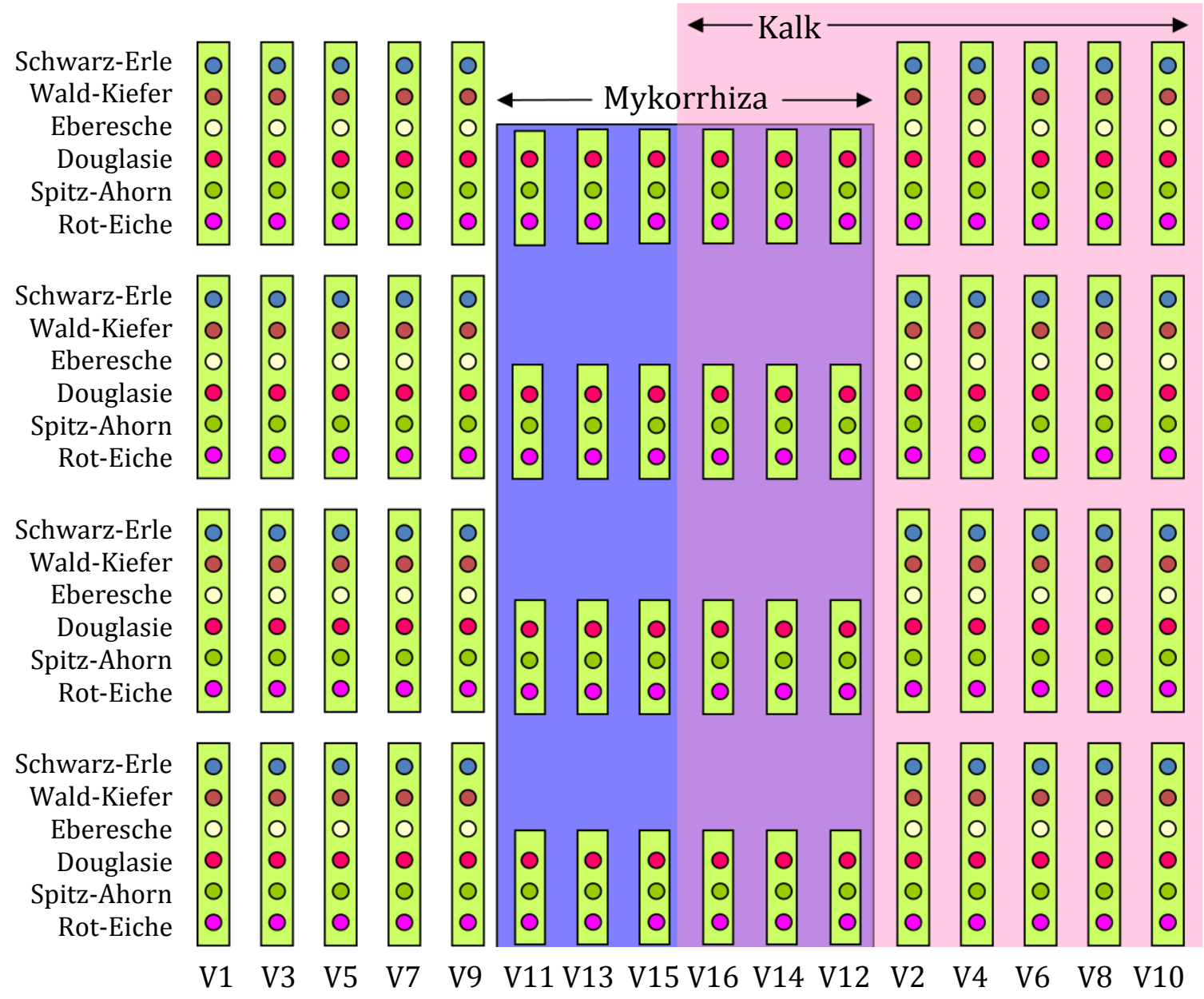

Abb. 3: Versuchsdesign (schematische Darstellung) des Freiland-Versuchs, im April 2005 auf drei Versuchsflächen auf der ehem. Ronneburger Absetzerhalde realisiert; Varianten s. S. 20 


\section{Freiland-Versuche - Aufnahmen und Untersuchungen}

\subsection{Klima-Messungen}

Von der WISMUT-GmbH wird mittels Klimastationen unmittelbar im Gebiet des Tagebaus Lichtenberg und der Absetzerhalde fortlaufend eine Vielzahl an meteorologischen Messwerten erhoben (s. Tab. 6), die der Bearbeiterin für die Dauer ihres Projektes freundlicherweise zur Verfügung gestellt wurden. Damit entfiel das Aufstellen und Ablesen eigener Messstationen.

Tab. 6: Im Untersuchungsgebiet täglich erhobene meteorologische Parameter

\begin{tabular}{|l|l|l|}
\hline Klimaparameter & Messintervall & Einheit \\
\hline \multirow{3}{*}{ Lufttemperatur in 2 m Höhe } & Tagesmittel & \multirow{n}{*}{${ }^{\circ} \mathrm{C}$} \\
\cline { 2 - 2 } & Tagesmaximum & \multirow{3}{*}{$\%$} \\
\cline { 2 - 2 } & Tagesminimum & \\
\hline \multirow{3}{*}{ Relative Luftfeuchte } & Tagesmittel & \\
\cline { 2 - 2 } & Tagesmaximum & \\
\cline { 2 - 2 } & Tagesminimum & \\
\hline Luftdruck & & $\mathrm{hPa}$ \\
\hline Niederschlagshöhe & Tagessumme & $\mathrm{mm}$ \\
\hline Windrichtung & & $\mathrm{Grad}$ \\
\hline \multirow{2}{*}{ Windgeschwindigkeit } & Tagesmittel & $\mathrm{m} / \mathrm{s}$ \\
\cline { 2 - 2 } & Tagesmaximum & \\
\hline $\begin{array}{l}\text { Globalstrahlung } \\
\text { (Bestrahlungsstärke) }\end{array}$ & & $\mathrm{W} / \mathrm{m}^{2}$ \\
\hline
\end{tabular}

\subsection{Boden-Untersuchungen}

Sämtliche im Folgenden beschriebenen Bodenuntersuchungen bezogen sich auf die oberste Bodenschicht $(0-15 \mathrm{~cm})$, da die bei Versuchsanlage zweijährigen Pflanzen zunächst vor allem in diesem Bereich ihren Wurzelraum hatten. Es handelte sich jedoch nicht um einen Oberboden im Sinne der meist humusreichen obersten Bodenschicht, wie sie bei durch Bodenbildung und Streuzersetzung entstandenen Bodenprofilen zu finden ist. Vielmehr bestehen die Kippenböden aus geschüttetem Mineralboden, der teilweise aus großen Tiefen stammt (s. ab S. 11). In weiten, vegetationsfreien Bereichen haben bislang keine Bodenbildungsprozesse wie etwa Humusakkumulation stattgefunden. Kleinflächig entwickelte sich im Versuchsverlauf Spontanvegetation (Moose, Gras; s. S. 37).

Die Entnahme, Behandlung, Vorbereitung und Analyse der im Folgenden genannten Bodenproben entsprach der „Bundesweite Bodenzustandserhebung im Wald (BZE) II Arbeitsanleitung" (BMELV 2006) sowie dem "Handbuch forstliche Analytik“ (Gutachterausschuss Forstliche Analytik 2005).

Erforderte die jeweilige Untersuchungsmethodik eine volumengerechte Probennahme, so wurden die Proben durch das Einschlagen und Herauslösen von Stechzylindern mit $250 \mathrm{ccm}$ Inhalt genommen. 


\subsubsection{Physikalische Bodenparameter}

\section{Skelettgehalt}

Der Skelettgehalt des Haldenbodens wurde durch Sieben $(2 \mathrm{~mm}$ ) und Wägen an insgesamt 12 Proben (je Versuchsfläche in Bereichen mit und ohne Bodenvegetation und in zwei Tiefenstufen, $0-5 \mathrm{~cm}$ und $10-15 \mathrm{~cm}$ ) bestimmt.

\section{Textur}

Um die Bodenartenuntergruppen zu bestimmen, wurden von den drei Versuchsflächen insgesamt acht Bodenproben auf ihre Korngrößenzusammensetzung analysiert. Darunter befanden sich jeweils Proben aus vegetationsfreien und im Verlauf des Versuchs mit Spontanvegetation besiedelten Teilbereichen. Die Proben wurden Anfang Oktober 2006 aus der obersten Bodenschicht $(0-5 \mathrm{~cm})$ entnommen. Die Analyse der Korngrößenzusammensetzung wurde nach der Arbeitsvorschrift für Texturanalysen der Abteilung Ökopedologie der gemäßigten Zonen der Universität Göttingen unter Anleitung von F. Sippel-Klemp (CTA) durchgeführt.

Die Bodenproben wurden luftgetrocknet und auf $2 \mathrm{~mm}$ gesiebt. Als Vorbehandlung erfolgte standardmäßig die Zerstörung des (in diesem Fall kaum enthaltenen) Humus durch Oxidation mit Wasserstoffperoxyd. Bei der Schlämmanalyse wurden zunächst der Tongehalt bestimmt und anschließend die suspendierbaren Feinbestandteile (die Fraktionen 2-20 $\mu \mathrm{g}$; Ton, Fein- und Mittelschluff) abgeschlämmt. Die zurückbleibenden Fraktionen Grobschluff, Feinsand, Mittelsand und Grobsand wurden getrocknet und durch eine Siebanalyse voneinander getrennt. Ihre Gewichte sowie das Gewicht der Tonfraktion wurden summiert und diese Summe vom ursprünglichen Gesamtgewicht der Probe abgezogen. Die Differenz entsprach dem Anteil der noch fehlenden Fraktionen Fein- und Mittelschluff.

\section{Trockenraumdichte, Gesamtporenvolumen und Wassergehalt}

Um die Trockenraumdichte (TRD), das Gesamtporenvolumen (GPV) und den volumetrischen Wassergehalt (WG) des Haldenbodens zu bestimmen, wurden auf jeder Versuchsfläche zufällig (entlang eines Transekts, der diagonal über die Fläche gelegt wurde) je 5-6 volumengerechte Proben $\left(250 \mathrm{~cm}^{3}\right)$ aus der obersten Bodenschicht $(0-5 \mathrm{~cm})$ entnommen. Die Probenahme fand Anfang Oktober 2005 nach 2 - 3 Tagen niederschlagsfreier Zeit nach mehreren Regentagen mit je $4-8 \mathrm{l} / \mathrm{m}^{2}$ statt.

Die Proben wurden unmittelbar vor Ort gewogen, im Labor (Trockenschrank) bei $105^{\circ} \mathrm{C}$ bis zur Gewichtskonstanz getrocknet und erneut gewogen. Das jeweilige Trockengewicht und das bekannte Volumen jeder Probe erlaubten die Errechnung der Trockenraumdichte. Die Differenz zwischen Feucht- und Trockengewicht einer Probe ergab den zum Zeitpunkt der Probennahme im Boden enthaltenen gravimetrischen Wassergehalt (g/g bzw. Gewichts- oder Massenprozent). Die Multiplikation dieses Wertes mit der jeweiligen TRD führte zum volumetrischen Wassergehalt der Probe $\left(\mathrm{cm}^{3} / \mathrm{cm}^{3}\right.$ bzw. Volumenprozent) (Ehlers 1996). Die Ermittlung der Gesamtporenvolumina erfolgte nach der Formel

$G P V=1-\frac{T R D}{\text { Dichte der festen Bodensubstanz (spezifisches Gewicht der Körner) }}[\%]$ 
Für Mineralböden wird die Dichte der festen Bodensubstanz mit 2,65 g/ $\mathrm{cm}^{3}$ angegeben (spezifisches Gewicht von Quarz, dem häufigsten Mineral in Böden) (Scheffer \& Schachtschabel 2010).

Bei der Entnahme der Bodenproben wurde versucht, jeweils auch die aktuelle Bodenfeuchte in den beprobten Tiefenstufen mit einer Theta-Sonde zu messen. Die starke Verhärtung des Haldenbodens bei Austrocknung sowie seine teilweise sehr hohen Skelettanteile (s. S. 39) machten es jedoch unmöglich, aussagefähige Theta-Messungen durchzuführen (diese Probleme bestanden sowohl im Freiland- als auch im Topf-Versuch, s. S. 32). Laut Rupp (o. J.) kann zudem ein skelettreicher Boden die Theta-Probe sehr erschweren, da sich aufgrund punktuell großer Porenvolumina keine ausreichende Verbindung zwischen den Elektroden der Theta-Sonde und dem umgebenden Boden herstellen lässt.

\section{Wassergehalt-Wasserspannungsbeziehungen (pF-Kurven), Gesamtporenvolumen, Porengrößenverteilung, Luftkapazität, (nutzbare) Feldkapazität und Totwasser}

Die Beziehung zwischen Wasserspannung (= Matrixpotential = Energie oder Bindungskraft, die das Wasser entgegen der Schwerkraft in der Bodenmatrix hält) und volumetrischem Wassergehalt eines Bodens ist eine wichtige Größe des Bodenwasserhaushaltes. Sie ist von der Korngrößenverteilung, dem Gefüge und dem Gehalt an organischer Substanz abhängig, da die Wasserspannung eine Funktion der Porenverteilung eines Bodens ist.

Für diese Untersuchung wurden insgesamt 12 volumengerechte Proben genommen, auf jeder Versuchsfläche jeweils in Bereichen mit und ohne Bodenvegetation und in zwei Tiefenstufen (0$5 \mathrm{~cm}$ und 10-15 cm). Im Labor wurden die Proben zunächst vollständig wassergesättigt und dann im Überdruckverfahren schrittweise wieder entwässert. Dazu wurden die Proben auf einer keramischen Platte Luftdrücken [hPa] ausgesetzt, die bestimmten Wasserspannungen in Zentimeter Wassersäule [cm WS] entsprechen. Die jeweils aus dem Boden verdrängte bzw. im Boden verbleibende Wassermenge wurde gemessen.

Thüringer Landesanstalt für Landwirtschaft 2001:

„... Die Methode beruht auf einem Porenmodell, das das Porensystem als Bündel von Kapillaren mit unterschiedlichen Durchmessern ansieht. Die Kapillaren entwickeln Meniskenkräfte, die von ihrem Durchmesser abhängen. Durch Anlegen eines Druckes oder Unterdruckes, der den Meniskenkräften eines gesuchten Porendurchmessers entspricht, werden alle Poren mit größerem als dem gesuchten Durchmesser entwässert. Die Methode wird an ungestörten Bodenproben durchgeführt. Die Proben werden wassergesättigt und anschließend mit dem vom gesuchten Porendurchmesser abhängigen Druck bzw. Unterdruck entwässert. Das ausgepresste Volumen an Wasser (Masse des Wassers multipliziert mit der Dichte des Wassers) entspricht dem Volumen der Poren oberhalb des gesuchten Durchmessers. ..." 
Die Beziehung von Wasserspannung und zugehörigem Wassergehalt wird mit einer Wasserspannungskurve dargestellt. Dazu werden meist die natürlichen Logarithmen (log10) der Wasserspannungswerte verwendet, die sogenannten pF-Werte ( $\mathrm{p}=$ Potenz, $\mathrm{F}=$ „Freie Energie“ des Wassers; Schroeder 1992), weshalb Wasserspannungskurven auch als pF-Kurven bezeichnet werden.

Tab. 7: Einteilung der Porengrößenbereiche nach dem Äquivalentdurchmesser und der Wasserspannung [pF] als Grenzwert zur Entwässerung kreiskapillarer Poren (aus: Scheffer \& Schachtschabel 2010, verändert)

\begin{tabular}{|l|l|l|l|}
\hline \multicolumn{2}{|l|}{ Porengrößenbereiche } & $\begin{array}{l}\text { Porendurchmesser } \\
{[\boldsymbol{\mu m}]}\end{array}$ & $\begin{array}{l}\text { Wasserspannung } \\
{[\mathbf{p F}]}\end{array}$ \\
\hline \multirow{2}{*}{ Grobporen } & weite & $>50$ & $<1,8$ \\
\cline { 2 - 4 } & enge & $50-10$ & $1,8-2,5$ \\
\hline Mittelporen & $10-0,2$ & $2,5-4,2$ \\
\hline Feinporen & $<0,2$ & $>4,2$ \\
\hline
\end{tabular}

Anhand des Verlaufs dieser Kurve können die Porengrößenverteilung (die Anteile der Porengrößenbereiche) eines Bodens (s. Tab. 7) in Volumenprozent und damit u. a. die Menge des pflanzenverfügbaren Wassers (nutzbare Feldkapazität) ermittelt werden. Dabei handelt es sich um den Wasseranteil, der in den Mittelporen gehalten wird, während das in den Feinporen gespeicherte Wasser (Totwasser) für Pflanzen nicht nutzbar ist, da es zu stark gebunden ist ( $\mathrm{pF}$ $>4,2$, sog. Permanenter Welkepunkt). Oft wird das zunächst in den engen Grobporen gehaltene langsam bewegliche Sickerwasser dem pflanzenverfügbaren Wasser hinzugerechnet, da wachsende Pflanzenwurzeln auch dieses teilweise erreichen können, so dass dann der Bereich der nutzbaren Feldkapazität bereits bei $\mathrm{pF}$ 1,8 beginnt (Schroeder 1992). In den weiten Grobporen kann Wasser nicht gegen die Schwerkraft gehalten werden, sie sind bereits kurz nach einer Vollsättigung des Bodens (im Freiland nach 1-2 Tagen, sog. Feldkapazität, $\mathrm{pF}<2,5$ ) wieder luftgefüllt. Der Anteil dieser weiten Grobporen am Gesamtporenvolumen wird deshalb auch als Luftkapazität bezeichnet. Sie sind von besonderer Bedeutung für den Luft- und Wassertransport und bestimmen somit die Infiltrationsfähigkeit und Wasserdurchlässigkeit eines Bodens (Zwölfer et al. 1994, TLL Thüringen 2001, Scheffer \& Schachtschabel 2010, BMVEL 2003).

\subsubsection{Chemische Bodenparameter}

Um chemische Parameter wie pH-Wert, Nährstoffversorgung und Schadstoffbelastung (u.a. durch Schwermetalle) des Bodens zu ermitteln und eventuelle Unterschiede festzustellen, wurden insgesamt 12 Proben entnommen, pro Versuchsfläche jeweils in vegetationsfreien und spontan besiedelten Bereichen und in zwei Tiefenstufen $(0-5 \mathrm{~cm}, 10-15 \mathrm{~cm})$. Die untersuchten bodenchemischen Parameter sowie die Methodik der chemischen Analyse sind in Tab. 8 aufgelistet. Zur Ermittlung von pH-Werten und effektiver Basen-Austauschkapazität $\left(\mathrm{Ak}_{\mathrm{e}}\right)$ wurde lufttrockener Boden verwendet, für die übrigen Analysen wurden die Proben vorbereitend bei $50-60^{\circ} \mathrm{C}$ getrocknet, auf $2 \mathrm{~mm}$ gesiebt und anschließend mit einer Achat-Mühle fein gemahlen. 
Tab. 8: Methoden der chemischen Analyse verschiedener Parameter in den Boden- und Pflanzenproben beider Aufnahmejahre (2005 und 2006)

\begin{tabular}{|c|c|}
\hline Parameter & Methode \\
\hline $\begin{array}{l}\text { pH-Wert d. Bodens } \\
\text { (Protonenaktivität } \\
\text { Bodenlösung) }\end{array}$ & $\begin{array}{l}\text { Messung mit elektronischem pH-Meter (Glaselektrode) in } \\
\mathrm{H}_{2} \mathrm{O} \text { und in } 1 \mathrm{M} \mathrm{KCl-Lösung;} \mathrm{Verhältnis} \mathrm{Boden:Lösung} \mathrm{jeweils} \\
1: 2,5\end{array}$ \\
\hline $\begin{array}{l}\text { Effektive Kationen- } \\
\left.\text { Austauschkapazität ( } \mathrm{Ak}_{\mathrm{e}}\right) \mathrm{d} . \\
\text { Bodens (mit Einzelwerten) }\end{array}$ & $\begin{array}{l}\mathrm{NH}_{4} \mathrm{Cl} \text {-Perkolation }\left(2,5 \mathrm{~g} \text { lufttrockener Boden }+1 \mathrm{M} \mathrm{NH}{ }_{4} \mathrm{Cl}-\right. \\
\text { Lsg.); Messung der Kationen am Graphitrohr-Atom- } \\
\text { Absorptions-Spektrometer (AAS) (Varian) }\end{array}$ \\
\hline $\mathrm{C}^{*}, \mathrm{~N}^{*}$ & $\begin{array}{l}\text { Trockene Verbrennung } \\
\text { C-N-Analysator (Carlo Erba; Elementar "Vario EL") }\end{array}$ \\
\hline $\mathrm{P}^{*}$ & $\begin{array}{l}\text { Druckaufschluss mit } \mathrm{HNO}_{3}\left(0,25 \mathrm{~g} \text { Boden }+1 \mathrm{ml} \mathrm{HNO}_{3}\right) \\
\text { (Salpetersäure-Aufschluß) } \\
\text { Messung am ICP-OES (Optisches Emissions-Spektrometer } \\
\text { mit induktiv gekoppeltem Plasma) (Spectro „ciros } \\
\text { ccd/flame“) }\end{array}$ \\
\hline S & $\begin{array}{l}\text { Druckaufschluss mit } \mathrm{HNO}_{3} \text { (Salpetersäure-Aufschluß) } \\
\text { Messung am ICP }\end{array}$ \\
\hline $\mathrm{Na}, \mathrm{K}^{*}, \mathrm{Ca}^{*}, \mathrm{Mg}^{*}, \mathrm{Mn}, \mathrm{Fe}, \mathrm{Al}$ & $\begin{array}{l}\text { Druckaufschluss mit } \mathrm{HNO}_{3} \text { (Salpetersäure-Aufschluß) } \\
\text { Messung am AAS / ICP }\end{array}$ \\
\hline $\mathrm{Zn}^{*}, \mathrm{Cu}^{*}, \mathrm{Cr}^{*}, \mathrm{Co}^{*}, \mathrm{Ni}^{*}, \mathrm{Cd}^{*}, \mathrm{~Pb}^{*}$ & $\begin{array}{l}\text { Druckaufschluss mit } \mathrm{HNO}_{3} \text { (Salpetersäure-Aufschluß) } \\
\text { Messung am ICP }\end{array}$ \\
\hline
\end{tabular}

* in den Pflanzenproben des Aufnahmejahrs 2005 wurden nur diese Gehalte bestimmt

\subsection{Pflanzen-Untersuchungen}

Die im Folgenden beschriebenen Vitalitätsschätzungen wurden jeweils an jeder einzelnen der insgesamt 936 Versuchspflanzen im Freiland-Versuch, die Messungen an allen zum jeweiligen Zeitpunkt lebenden, nicht (durch Wild) geschädigten Exemplaren vorgenommen. Bei den an Stichproben durchgeführten Untersuchungen (Biomasseermittlung, Mykorrhiza-Inventur) wurde soweit möglich auf eine gleichmäßige Verteilung der entnommenen Bäume zwischen den betreffenden Arten, Varianten und Versuchsflächen (A, B, D) geachtet.

\subsubsection{Chemische Analysen der Assimilationsorgane}

Um zunächst einen Überblick über die Versorgungs- und Belastungssituation der Pflanzen zu gewinnen, wurden im Anlagejahr (2005) pro Baumart und Versuchsfläche Mischproben der jeweiligen Assimilationsorgane gebildet.

Im darauf folgenden Jahr (2006) wurden je Baumart für jede Variante Mischproben der Blätter bzw. Nadeln genommen, um gezielt die Auswirkungen der diversen Bodenhilfsstoffe auf die Nährstoffversorgung und Schadstoffbelastung der Pflanzen zu untersuchen. Um den Probenumfang einzuschränken und dennoch aussagekräftige Ergebnisse zu erhalten, wurde in diese Untersuchung nur eine der drei Versuchsflächen einbezogen. Ausgewählt wurde Fläche D, da auf Fläche A die hohen Pflanzenausfälle (s. S. 76), auf Fläche B der starke Standorteinfluss (ebenda) die Probennahme bzw. die Interpretation der Analysedaten erschwert hätten. 
Aus den Analyseergebnissen für die einzelnen Varianten konnten je Baumart auch Mittelwerte für die gesamte Versuchsfläche D errechnet werden. Dies erlaubte zusätzlich einen Vergleich der Element-Gehalte in den Assimilationsorganen der Baumarten auf Fläche D zwischen dem ersten (2005) und dem zweiten (2006) Untersuchungsjahr und somit die Untersuchung zeitlich bedingter Schwankungen.

Die Entnahme, Behandlung, Vorbereitung und Analyse der Pflanzenproben stand im Einklang mit der BZE II - Arbeitsanleitung (BMELF 2006). Bei den untersuchten Nadelproben handelte es sich generell um Mischproben aller Nadeljahrgänge, da andernfalls zu wenig Probenmaterial zusammengekommen wäre bzw. einzelne Pflanzen durch die Probennahme stark in Mitleidenschaft gezogen worden wären.

Die Methodik der Analyse sowie die untersuchten Elemente sind in Tab. 8 aufgeführt. Aufgrund der Ergebnisse der Bodenanalysen (s. S. 44ff) wurde in 2006 das Untersuchungsprogramm der Pflanzenproben gegenüber 2005 um die Elemente Schwefel (S), Eisen (Fe), Mangan (Mn), Aluminium (Al) und Natrium ( $\mathrm{Na}$ ) erweitert.

\subsubsection{Visuelle Beurteilung der Pflanzenvitalität}

Bei jeder Pflanze wurde in regelmäßigen Abständen der Vitalitätszustand auf folgender Ordinalskala gutachterlich eingeschätzt (in Anhang 10 veranschaulichen Photos für jede der sechs Baumarten die Vitalitätsstufen „2“, „3“ und „4“):

$" 0^{\prime \prime}=$ tot

"1“ = fast völlig abgestorben, aber (noch) lebend, kein Zuwachs, d.h. kein neuer Trieb, Regenerationsfähigkeit kaum mehr gegeben

"2“ = neuer Trieb, aber kümmerliche Entwicklung, teils abgestorbene Pflanzenteile, Regeneration nur eingeschränkt möglich

„3“ = relativ gut entwickelt, aber Einschränkungen (Blattgröße/Nadellänge unterdurchschnittlich, vergleichsweise helle Färbung der Blätter/Nadeln, geringe Wuchsleistung, vereinzelte Schäden), gute Regenerationsfähigkeit

„4“ = normale/gute Entwicklung, voll vital, vitale Triebe, keine erkennbaren Schäden

Die Vitalitätsschätzungen wurden bei Versuchsanlage (Ausgangszustand) im April 2005 und in beiden Vegetationsjahren $(2005,2006)$ jeweils im Juni und im Oktober vorgenommen.

\subsubsection{Messungen von Wuchsparametern}

Um den jeweiligen Jahreszuwachs zu ermitteln, wurden bei allen Pflanzen die Haupttrieblängen bei Versuchsanlage (Ausgangszustand) im April 2005 sowie jeweils im Oktober 2005 und 2006 gemessen. Bei Abschluss des Versuchs nach der 2. Vegetationsperiode wurden außerdem bei allen Pflanzen Spitzen- und Wurzelhalsdurchmesser sowie bei allen Ebereschen, Erlen und Kiefern die Seitentrieblängen erfasst. Mit diesen Messwerten konnten Größen wie das Verhältnis zwischen Haupt- und Seitentrieblängen oder das Volumen des Haupttriebs (nach der Formel zur Errechnung von Kegelstumpf-Volumina: $1 / 3 *$ Länge des Haupttriebs ${ }^{*} \pi *$ (Spitzenradius $^{2}+$

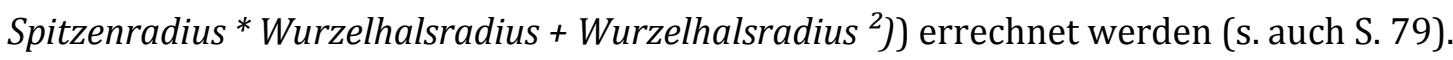




\subsubsection{Biomassenermittlung}

Nach Abschluss des Versuchs wurden stichprobenartig Bäume komplett geerntet, insgesamt 33 Ahorne, 35 Douglasien und je 8 Ebereschen, Kiefern und Erlen. Aufgrund der besonderen Situation der Eichen, deren Haupttriebe bereits zu Versuchsbeginn größtenteils abstarben (teilweise erfolgte im Versuchsverlauf ein Neuaustrieb von unten, s. S. 180), erschien eine Beprobung bei dieser Baumart nicht sinnvoll.

Die betreffenden Bäume wurden ausgegraben, im Labor in die Fraktionen Wurzel, Haupttrieb, Seitentriebe und ggf. Nadeln zerlegt, im Trockenschrank bei $105^{\circ} \mathrm{C}$ bis zur Gewichtskonstanz getrocknet und gewogen. Auf diese Weise wurden die Trockenmasse der einzelnen Fraktionen sowie die gesamte, also die ober- und unterirdische Biomasse (Trockenmasse) nach zwei Jahren Versuchsdauer ermittelt. Anschließend konnten durch Regressionen für jede Baumart die Güte der Zusammenhänge zwischen Messwerten und Trockenmassen, beispielsweise zwischen der Länge und dem Trockengewicht des Haupttriebs, festgestellt werden.

\subsubsection{Mykorrhiza-Inventur}

Douglasien- und Eichenwurzeln bilden mit den passenden Pilz-Partnern Ekto-Mykorrhza, wobei die Pilzhyphen die Wurzeln (Wurzelspitzen) von außen mit einem Mycelmantel umhüllen, so dass mit der unten beschriebenen Methode vorhandene Mykorrhizierungen gut erkannt werden konnten. Im Gegensatz zu diesen beiden Baumarten bildet der ebenfalls in den MykorrhizaVarianten verwendete Ahorn VA-Mykorrhiza. Dabei wird kein Mycelmantel ausgebildet, sondern die Pilzhyphen dringen in die Wurzelzellen ein und schwellen dort zu Vesikeln an oder formen büschelartige Verzweigungen, so genannte Arbuskeln (Höster 1993).

VAM lässt sich erst nach Anfärben der Pilzzellen mit z.B. Methylenblau (Koske \& Gemma 1989) unter dem Mikroskop erkennen. Da für die sehr empfindlichen Ahornwurzeln bislang noch kein Anfärbe- und Untersuchungsverfahren entwickelt werden konnte (Polle 2007), musste auf eine Untersuchung der Mykorrhizierung der Ahornwurzeln verzichtet werden.

Zur Ermittlung des Mykorrhizierungserfolgs und der Mykorrhizierungsgrade der Douglasien und Eichen wurden innerhalb der Mykorrhiza-Varianten V11-V16 (s. S. 20) nach Abschluss der zweiten Vegetationszeit die Wurzeln einer Stichprobe von insgesamt 35 Douglasien und 13 Eichen (aufgrund der geringen Anzahl überlebender, vitaler Exemplare dieser Baumart, s. S. 180) auf Mykorrhizierung untersucht. Dazu wurden die Bäume ausgegraben und von jeder Wurzel Stichproben genommen, die vor Ort in 50 \% Ethanol fixiert wurden. Die Probennahme fand im Oktober statt (laut Sänger 2003 sind die Monate April sowie September/Oktober die günstigsten Zeitpunkte für eine Mykorrhiza-Probennahme, da dann die höchsten MykorrhizaVorkommen erwartet werden können).

Im Labor wurden die Wurzeln vorsichtig mit Wasser abgespült. Je Probe wurden vier etwa $5 \mathrm{~cm}$ lange, etwa 200 mg schwere Teilproben mit Hilfe eines Binokulars auf das Vorhandensein von Mykorrhiza und Pilzhyphen untersucht. Die Proben lagen dabei in mit Wasser gefüllten Petrischalen, wie auch zwischen den einzelnen Arbeitsschritten darauf geachtet wurde, die Wurzeln nicht austrocknen zu lassen (Aufbewahrung über kurze Zeitspannen in feuchten Papiertüchern). 
Jeder Teilprobe wurde ein Mykorrhizierungsgrad nach der Ordinalskala

"0“ = keine Mykorrhiza erkennbar

"1“ = niedriger Mykorrhizierungsgrad; wenige Wurzelspitzen mykorrhiziert

${ } 2^{\prime \prime}=$ mittlerer Mykorrhizierungsgrad; viele mykorrhizierte, aber auch nicht-mykorrhizierte Wurzelspitzen

„3“ = hoher Mykorrhizierungsgrad; (fast) alle Wurzelspitzen mykorrhiziert

zugewiesen. Der Mittelwert der Mykorrhizierungsgrade der vier Teilproben ergab den Mykorrhizierungsgrad der jeweiligen Wurzel.

\subsubsection{Weitere Aufnahmen an den Versuchspflanzen}

Bei den Aufnahmen auf den Freiland-Versuchsflächen wurden für jede Pflanze Beobachtungen wie Absterben des Haupttriebs, Bildung eines neuen Haupttriebs, oberirdisches Absterben und Neuaustrieb von unten, abgeknickte Triebe sowie Wildschäden erfasst. Diese Faktoren spielten eine wichtige Rolle für die Interpretation der erhobenen Daten und flossen in die statistische Auswertung mit ein, indem etwa durch Wild geschädigte Bäume (Abknicken, Verbiss) aus den Zuwachsanalysen ausgeklammert wurden, um Verfälschungen der Mittelwerte durch „negative Zuwächse“ zu vermeiden. 


\section{Topf-Versuche - Versuchsanlage}

Um die Wirkungen der im Freiland-Versuch eingesetzten Bodenhilfsstoffe begleitend und vertiefend zu untersuchen, waren bereits ein Jahr zuvor (2004) Topf-Versuche mit Haldensubstrat im Gewächshaus angelegt worden. Auf diese Weise konnten unter bekannten Bedingungen und auf begrenztem Raum an leicht zu gewinnenden Stichproben der Einfluss der verwendeten Bodenhilfsstoffe auf die physikalischen und chemischen Bodenparameter sowie auf die Pflanzenentwicklung untersucht werden. In die vorliegende Arbeit flossen als Ergänzung der Freiland-Versuchsergebnisse vor allem die Ergebnisse der Boden- und Wurzeluntersuchungen im Topf-Versuch mit ein. Bei der Frage der Übertragbarkeit der Ergebnisse aus Topf-Versuchen auf die Freiland-Situation sind die unterschiedlichen Versuchsbedingungen zu beachten (Bodenlockerung durch Versuchsanlage, Regelmäßigkeit der Bewässerung u. a.). Auch kann beispielsweise in Töpfen mehr pflanzenverfügbares Wasser gehalten werden als im Freiland (Beese 2007). Die Nährstoff- und Schadstoffsituation ist im Topf-Versuch durch fehlende Nachlieferung aus dem umgebenden Boden und Ausgangsmaterial ebenfalls eine andere als im Freiland. Um aus den Topf-Versuchen Rückschlüsse auf die Wirkungsweise der verschiedenen Bodenhilfsstoffe im Freiland zu ziehen, können deshalb ausschließlich die relativen Veränderungen von Bodenparametern (z.B. eine Erhöhung eines Parameters durch die Zugabe eines bestimmten Bodenhilfsstoffes), nicht jedoch die absoluten Messwerte (z.B. eine Erhöhung von einem Betrag X auf einen Betrag Y) herangezogen werden.

\subsection{Bodensubstrat}

Das für alle Topf-Versuche verwendete Bodensubstrat wurde kurz vor Versuchsanlage im April 2004 von der ehemaligen Ronneburger Absetzerhalde geholt. Es stammte aus einem bislang vegetationsfreien Bereich oberhalb der Freiland-Versuchsfläche A. Die Bodeneigenschaften des Haldensubstrats sind ab S. 38 beschrieben.

\subsection{Baumarten und Pflanzenmaterial}

Für die Gewächshaus-Versuche wurden zwei Laub- und zwei Nadelbaumarten ausgewählt, die auch in den späteren Freiland-Versuchen zum Einsatz kamen: Spitz-Ahorn (im Folgenden: Ahorn), Eberesche, Douglasie und Wald-Kiefer (im Folgenden: Kiefer) (s. Tab. 9). Das Pflanzenmaterial wurde (wie auch später die im Freiland-Versuch verwendeten Bäume) bei einer Baumschule in der Region Gera-Greiz (Baumschule Zech, Langenwetzendorf) bezogen und bis zur Pflanzung in einer Klimakammer bei $5^{\circ} \mathrm{C}$ gelagert, wobei die Wurzeln stets feucht gehalten wurden. Insgesamt wurden 480 Topf-Versuche angelegt (je Baumart 120). 
Tab. 9: Im Gewächshaus-Versuch eingesetzte Baumarten, Herkünfte (o.A. = ohne Angabe), Sortimente (Alter / Form (ohne Ballen) / Haupttrieblängen [cm], in Klammern: tatsächlich gemessene Haupttrieblängen), Anzahlen; botanische/deutsche Artnamen: Rothmaler 1994

\begin{tabular}{|l|l|l|l|}
\hline Art & Herkunft & Sortiment & Anzahl \\
\hline $\begin{array}{l}\text { Spitz-Ahorn } \\
\text { (Acer platanoides l.) }\end{array}$ & o.A. & $\begin{array}{l}1 \mathrm{j} . / \mathrm{oB} / 20-40 \\
(20-45)\end{array}$ & 120 \\
\hline $\begin{array}{l}\text { Eberesche, Vogelbeere } \\
\text { (Sorbus aucuparia l. em. hedl.) }\end{array}$ & o.A. & $\begin{array}{l}1 \mathrm{j} . / \mathrm{oB} / 30-50 \\
(20-100)\end{array}$ & 120 \\
\hline $\begin{array}{l}\text { Douglasie } \\
\text { (Pseudotsuga menziesii } \\
\text { (mirbel) franco) }\end{array}$ & $\begin{array}{l}85306 \\
\text { (Südostdt. Hügel- und } \\
\text { Bergland) }\end{array}$ & $\begin{array}{l}1 \mathrm{j} . / \mathrm{oB} / 20-40 \\
(10-30)\end{array}$ & 120 \\
\hline $\begin{array}{l}\text { Wald-Kiefer } \\
\text { (Pinus sylvestris subsp. } \\
\text { sylvestris) }\end{array}$ & $\begin{array}{l}\text { 851 07 } \\
\text { (Vogtland, Thüringer Wald, } \\
\text { Frankenwald; kolline Stufe) }\end{array}$ & $\begin{array}{l}\text { 2j.v. / oB / o.A. } \\
(10-30)\end{array}$ & 120 \\
\hline Gesamt & \multicolumn{2}{|l}{} & 480 \\
\hline
\end{tabular}

\subsection{Bodenhilfsstoffe}

In den Gewächshaus-Versuchen wurden die gleichen Bodenhilfsstoffe wie in den FreilandVersuchen verwendet (Perlit, Wasserspeichersubstanzen, Kalk, Kompost und MykorrhizaInokulum). Die Bodenhilfsstoffe und ihre jeweiligen Bezugsquellen sind auf S. 18 beschrieben. Die jeweils verwendeten Mengen entsprachen im Wesentlichen den im Freiland verwendeten Mengen (heruntergerechnet auf 2-Liter-Töpfe mit einer Bodenoberfläche von ca. $150 \mathrm{~cm}^{2}$ ). Anstatt wie im Freiland-Versuch drei verschiedene Mykorrhiza-Inokula für die drei Baumarten Eiche, Ahorn und Douglasie einzusetzen, wurden im Gewächshaus-Versuch jeweils ein Teil der Kiefern und Douglasien zusammen mit dem Mykorrhiza-Pilz "Kahler Krempling“ (Paxillus involutus) gepflanzt, der zu diesem Zweck im Institut für Forstbotanik der Universität Göttingen herangezogen wurde. Wie auch im Freiland wurden im Gewächshaus die Bodenhilfsstoffe teilweise miteinander kombiniert.

\subsection{Anlage der Topf-Versuche}

Bei der Versuchsanlage wurden je 2 Liter Boden abgemessen und in einem 10 Liter-Eimer je nach Variante mit den entsprechenden Bodenhilfsstoffen vermischt. Die Kalk-, Stockosorb®und Superabsorber-Gaben wurden dabei abgewogen, während Perlit und Kompost mit einem Messbecher abgemessen wurden. Die gezüchteten Mykorrhiza-Pilze (Paxillus involutus) wurden dem Boden ohne weiteres Trägermedium beigemischt. Die Pflanzen wurden zeitnah vor der Pflanzung aus der Kühlkammer geholt und ihre Wurzeln bis zur Pflanzung feucht gehalten. Boden und Pflanze wurden in runde 2-Liter-Töpfe gegeben bzw. gesetzt. Entsprechend zugeschnittene Stücke Vlies sowie Plastiknetz (zur Stabilisierung) am Topfboden verhinderten ein Herausschwemmen des Bodens durch die Topfbodenperforation bei Bewässerung. 


\section{Topf-Versuche - Aufnahmen und Untersuchungen}

\subsection{Boden-Untersuchungen}

Die Entnahme, Behandlung, Vorbereitung und Analyse der im Folgenden genannten Bodenproben entsprach der „Bundesweite Bodenzustandserhebung im Wald (BZE) II Arbeitsanleitung" (BMELV 2006) sowie dem „Handbuch forstliche Analytik“ (Gutachterausschuss Forstliche Analytik 2005).

\subsubsection{Physikalische Bodenparameter}

Der mögliche Einfluss verschiedener Bodenhilfsstoffe auf die bodenphysikalischen Parameter Trockenraumdichte, Gesamtporenvolumen und Wassergehalt wurde an einer Stichprobe von insgesamt 25 Töpfen mit verschiedenen Bodenhilfsstoff-Haldensubstratmischungen sowie unbehandeltem Haldensubstrat (Kontrolle) untersucht. Ausgewählt wurden Varianten mit Bodenhilfsstoffen, von denen eine Wirkung auf einen oder mehrere der genannten Parameter erwartet wurde (Kompost, Perlit, Stockosorb® und Superabsorber; s. „Arbeitshypothesen“ auf S. 10). Die Töpfe wurden erst bei Beendigung des Gewächshaus-Versuchs im Winter 2006 untersucht, um ein Bild der Langzeitwirkung der zugegebenen Hilfsstoffe zu erhalten. Wie in verschiedenen vorangegangenen Laborversuchen (Kirscht, unveröffentlicht) deutlich wurde, kann etwa die Langzeitwirkung der Wasserspeichersubstanzen erheblich von ihrer Wirkung bei Erstbefeuchtung abweichen.

Für die Untersuchung wurden die Töpfe mit Wasser gesättigt, 24 Stunden später gewogen, im Trockenschrank bei $105^{\circ} \mathrm{C}$ bis zur Gewichtskonstanz getrocknet und erneut gewogen, so dass Trockenraumdichten, gravimetrische und volumetrische Wassergehalte sowie Gesamtporenvolumina der Substrate ermittelt werden konnten (s. S. 23). Für die Kontrollen und die Varianten Superabsorber und Stockosorb® wurde für die zur Errechnung des Gesamtporenvolumens benötigte Größe „Dichte der festen Bodensubstanz“ der für Mineralböden allgemein übliche Wert von 2,65 g/ $\mathrm{cm}^{3}$ angenommen (spezifisches Gewicht von Quarz, dem häufigsten Mineral in Böden; Scheffer \& Schachtschabel 2010). Für die Substratmischungen „Haldenboden-Kompost" und „Haldenboden-Perlit" mussten entsprechend den Mischungsverhältnissen aus Haldensubstrat (Dichte: 2,65 g/ $\mathrm{cm}^{3}$ ) und Kompost (Dichte: orientiert an Werten für Humus ca. $1,4 \mathrm{~g} / \mathrm{cm}^{3}$ ) bzw. Perlit (Dichte: laut Herstellerangaben ca. 2,0-2,2 $\left.\mathrm{g} / \mathrm{cm}^{3}\right)$ neue spezifische Bodendichten nach den Formeln: 2,65 - $(0,0125$ * Gewichtsprozent Kompost) bzw. 2,65 - (0,0055* Gewichtsprozent Perlit) errechnet werden (Beese 2007). Die Gewichtsprozent der Kompost- und Kalk-Gaben wurden ermittelt, indem der Anteil des Trockengewichts der jeweils zugegebenen Menge Bodenhilfsstoff (im Fall von Kompost musste diese zunächst im Trockenschrank bei $105^{\circ} \mathrm{C}$ bis zur Gewichtskonstante getrocknet werden; Perlit liegt ohnehin stets in trockener Form vor) am Trockengewicht des gesamten Topfes errechnet wurde.

Eine Untersuchung der Wassergehalt-Wasserspannungsbeziehungen (pF-Kurve) wie im Freiland-Versuch konnte nicht durchgeführt werden, da die dafür nötige volumengerechte Probennahme in den Töpfen nicht möglich war.

Theta-Messungen zur zumindest in der Theorie einfachen und schnellen Ermittlung der Bodenfeuchte hatten sich im Rahmen der vorliegenden Arbeit als nicht geeignet erwiesen. Der 
hohe Skelettanteil des Bodens und seine rasche Verhärtung bei zunehmender Austrocknung erschwerten das Einstecken der Sonde und den Kontakt zwischen Boden und Sonde sowohl im Freiland (s. S. 23) als auch im Topf-Versuch. Zuverlässige Messergebnisse konnten so nicht erzielt werden.

\subsubsection{Chemische Bodenparameter}

Um die mögliche Wirkung von Kalk- und Kompost-Gaben auf die bodenchemischen Eigenschaften des Haldensubstrats (s. S. 10 „Arbeitshypothesen“) zu untersuchen, wurden nach Abschluss der Gewächshaus-Versuche bei allen vier Baumarten die Bodensubstrate der entsprechenden Varianten einer chemischen Analyse unterzogen. Insgesamt wurden 22 Töpfe (4 Töpfe mit unbehandeltem Haldensubstrat als Kontrolle, 12 Töpfe mit Haldensubstrat und Kalk-Gabe sowie 6 Töpfe mit Haldensubstrat und Kompost-Gabe) beprobt. Die Beprobung der Nullvariante nach dreijähriger Versuchsdauer sollte auch zeigen, inwieweit sich die bodenchemischen Eigenschaften durch Auswaschung, Pflanzenaufnahme und fehlende Nachlieferung im Vergleich zum Ausgangssubstrat verändert hatten, um so Aussagen zur Problematik der Übertragbarkeit der Ergebnisse von Gewächshaus-Versuchen auf FreilandBedingungen machen zu können. Die untersuchten bodenchemischen Parameter sowie die chemischen Analysemethoden sind in Tab. 8, S. 25 aufgelistet.

\subsection{Pflanzen-Untersuchungen}

Mykorrhizierung, Wurzel-Entwicklung und Varianz der Blattspiegelwerte

Um festzustellen, ob die Nadelbäume mit geeigneten Pilzarten Mykorrhizen gebildet hatten, wurden zunächst alle Töpfe regelmäßig auf Pilzfruchtkörper abgesucht. Nach Abschluss der dritten Vegetationszeit wurden alle Pflanzen aus ihren Töpfen genommen und von Boden befreit, wobei das Wurzelwerk vorsichtig mit Wasser abgespült wurde. Die Wurzeln wurden optisch auf Mykorrhizza untersucht. Auffallende Besonderheiten bei der Ausbildung und Verteilung der Wurzeln im Topf sowie der Ausformung des Wurzelballens wurden bei allen vier Baumarten festgehalten. Stichprobenartig wurden von jeweils 10 Douglasien und Kiefern, die zusammen mit Mykorrhiza-Pilzen gepflanzt worden waren, Wurzelproben genommen und in 50 $\%$ Ethanol fixiert. Anschließend erfolgte eine genauere Untersuchung der Wurzeln auf Pilzhyphen unter dem Mikroskop (s. S. 28).

Eine einzelbaumweise Analyse der Blattspiegelwerte (s. S. 26) in verschiedenen AhornVarianten sollte Aufschluss über die Varianz der Blattspiegelwerte innerhalb von Versuchsvarianten geben, da diese im Freiland-Versuch lediglich in Form von Mischproben untersucht wurden. 


\section{Datenauswertung und Statistik}

Zur Datenverwaltung diente Microsoft $₫$ Excel 2002. Die statistische Datenanalyse wurde mit WinSTAT® 1999.3 vorgenommen. Grafiken wurden mit beiden Programmen erstellt. Die zu analysierenden Daten wurden zunächst mit dem Kolmogorov-Smirnov-Test (kontinuierliche Variablen) oder dem Chi-Quadrat-Test (diskrete Variablen) auf Normalverteilung getestet.

\section{Vergleich der Mittelwerte von zwei Gruppen:}

Bei Normalverteilung sowie mindestens intervallskalierten Daten wurde ein t-Test durchgeführt; im Fall von Wiederholungsaufnahmen (z.B. Zuwachsmessungen aus zwei Aufnahmejahren) ein verbundener t-Test.

War keine Normalverteilung gegeben oder waren die Daten ordinalskaliert, wurde der parameterfreie U-Test (Mann-Whitney) vorgenommen; bei verbundenen Daten (s.o.) der ebenfalls nicht parametrische Wilcoxon-Test.

\section{Vergleich der Mittelwerte mehrerer Gruppen:}

Bei Normalverteilung und Varianzenhomogenität (Prüfung mit dem Bartlett-Test) sowie mindestens intervallskalierten Daten wurde eine Varianzanalyse (ANOVA) durchgeführt; bei verbundenen Daten (s.o.) eine Varianzanalyse mit wiederholten Messungen.

Bei signifikanten Unterschieden zwischen den getesteten Gruppen bietet WinSTAT® als nachgeschaltete A-posteriori- oder Post-hoc-Tests insgesamt acht verschiedenen multiple Mittelwertvergleiche oder Spannweiten-Tests zur Bildung homogener Untergruppen an.

Bei Vorliegen der Voraussetzungen wurde davon der als übliches und robustes Verfahren empfohlene Tukey-Test ausgewählt. Dieses Verfahren verwendet für alle Vergleichsgruppenpaare unabhängig von der Anzahl der verglichenen Mittelwerte den gleichen Range-Wert. Eine Einschränkung ist, dass sich bei ungleich großen Gruppen nur ein Näherungswert ergibt (Janssen \& Laatz 2005). Der Tukey-Test berechnet beim paarweisen Vergleich der Mittelwerte nur eine einzige kritische Differenz $D_{k}$ mit der vorgegebenen, versuchsbezogenen Irrtumswahrscheinlichkeit und verwendet damit nur eine Wahrscheinlichkeit für die gesamte Auswertung. Eine zweite Einschränkung ist deshalb, dass sich der Tukey-Test eher für den Vergleich einer kleinen Anzahl von Stichproben eignet (Lozán \& Kausch 2007).

Bei einer großen Anzahl von Stichproben und/oder ungleich großen Gruppen wurde deshalb anstelle des Tukey-Tests der Scheffé-Test gewählt, der sich laut Sachs (2002) für ungleich große und gleich große Stichprobengruppen und beliebige Paare von Mittelwerten eignet. Der SchefféTest verwendet für alle Vergleichspaare einen einzigen Range-Wert, ist strenger als andere Tests und sehr konservativ. Die gelieferten Werte sind auch für ungleich große Gruppen exakt. Er wird bei komplexen Vergleichen von Linearkombinationen empfohlen (Janssen \& Laatz 2005).

Wenn keine Normalverteilung und/oder Varianzenhomogenität gegeben war, wurde als parameterfreies Prüfverfahren für ordinalskalierte, stetige Daten der H-Test (Kruskal-Wallis) angewandt; im Fall von verbundenen Daten (s.o.) der Friedmann-Test (Voraussetzung für den Friedmann-Test ist laut Sachs (2002) die gleich große Besetzung aller Variablen).

Da es nach diesen parameterfreien Methoden zum Vergleich der Mittelwerte mehrerer Gruppen kein Äquivalent zu den A-posteriori- oder Post-hoc-Tests nach der ANOVA gibt, wurden zur 
Bestimmung homogener Gruppen im Anschluss an einen signifikanten H- bzw. Friedmann-Test paarweise U-Tests (Mann-Whitney) (u. a. bei Dytham 2003 empfohlen) bzw. Wilcoxon-Tests durchgeführt (Köhler et al. 2002, Sachs 2002).

In Tabellen und Abbildungen sind homogene Gruppen mit Buchstaben gekennzeichnet $(\mathrm{a}=$ niedrigste Mittelwerte).

Beim statistischen Vergleich zweier oder mehrerer Gruppen wurden grundsätzlich nur Gruppen einbezogen, die aus mindestens drei Werten bestanden. Beispielsweise beschränkte sich die Analyse des Einflusses der Behandlungsvariante auf den Gesamtzuwachs der nach 2 Standjahren noch lebenden Bäume nur auf die Varianten, die nach 2 Standjahren noch mindestens drei lebende Wiederholungen aufwiesen. Dabei war nicht zu vermeiden, dass bei einigen Analysen die meist von einer hohen Sterblichkeitsrate geprägte Nullvariante V1 aus der Auswertung heraus fiel, womit diesen Analysen die Kontrolle als Referenz leider fehlt.

Bei der Darstellung von Mittelwerten wurden stets die jeweiligen Standardabweichungen (der Übersichtlichkeit halber meist nur die positiven) mit abgebildet.

\section{Untersuchungen von Zusammenhängen zwischen Variablen}

Für die Untersuchung einfacher Zusammenhänge zwischen zwei Variablen, etwa die Frage nach der Abhängigkeit der Sterblichkeitsrate der Versuchspflanzen von ihrem Standort, wurden Kreuztabellen verwendet.

Lineare Zusammenhänge zwischen zwei Variablen, etwa zwischen errechnetem Volumen und gemessener Trockenmasse des Haupttriebs der geernteten Bäume, wurden mittels Korrelationen (normal verteilte Stichproben: Pearson-Korrelation; nicht normal verteilte Stichproben: Spearman Rangkorrelation) und einfachen Regressionsanalysen untersucht. Das $r^{2}$ einer einfachen Regressionsanalyse entspricht dem Quadrat des Pearson'schen Korrelationskoeffizienten.

Die von den jeweiligen Regressionsgleichungen beschriebenen Ausgleichsgeraden wurden grundsätzlich durch den Nullpunkt geführt, da etwa einem Haupttriebsvolumen von $0 \mathrm{~cm}^{3}$ logischerweise nur eine Haupttriebs-Trockenmasse von $0 \mathrm{~g}$ gegenüberstehen kann. Bei als ausreichend hoch erachtetem $r^{2}(>0,5)$ wurden die Regressionsgleichungen verwendet, um für alle Bäume der entsprechenden Baumart beispielsweise die Trockenmassen der Haupttriebe anhand ihrer Volumina zu berechnen.

Um einen ersten Eindruck vom Einfluss der verwendeten Bodenhilfsstoffe auf die Vitalität der Versuchsbäume zu gewinnen, wurden zudem für jede der sechs Baumarten schrittweise multiple Regressionen für die Analyse mehrerer Einflussfaktoren auf eine abhängige Variable durchgeführt.

Das Signifikanzniveau lag bei allen hier aufgeführten Analysen einheitlich bei 5 \%.

Die Güte der Signifikanz wurde wie folgt dargestellt:

\begin{tabular}{|c|c|c|c|c|c|c|}
\hline$* * *$ & $=$ & höchst signifikant & $=$ & $\mathrm{p}$ & unter & 0,001 \\
\hline$* *$ & $=$ & hoch signifikant & $=$ & $\mathrm{p}$ & zwischen & 0,001 und 0,01 \\
\hline * & $=$ & signifikant & $=$ & $\mathrm{p}$ & zwischen & 0,01 und 0,05 \\
\hline
\end{tabular}




\section{Ergebnisse}

\section{Freiland-Versuche - Bodeneigenschaften}

Im Folgenden werden die Ergebnisse der physikalischen und chemischen Bodenuntersuchungen dargestellt und die Eigenschaften des Haldensubstrats mit seinen problematischen Standortbedingungen beschrieben. Teil der Standortproblematik ist, dass die Bodenbedingungen kleinräumig erheblich variieren können.

\subsection{Kleinräumige Standortheterogenität}

Eine große Rolle bei der Auswertung der im Rahmen der Freiland-Versuche gewonnenen Daten spielten die kleinräumig variierenden standörtlichen Bedingungen. So bestanden bei vielen chemischen Bodenparametern signifikante Unterschiede zwischen den drei Versuchsflächen. Darüber hinaus konnte sich auf den Versuchsflächen B und D im Verlauf des Projektes in manchen Bereichen Spontanvegetation (Gras, Moose) ansiedeln, während direkt angrenzende Bereiche bis zum Versuchsabschluss frei von Bodenvegetation blieben.

Wie erst nach Versuchsanlage bekannt wurde, wurde in den befahrbaren Bereichen der Halden im Jahr 2000 eine Flächenkalkung vorgenommen (Fläche B und D waren darin eingeschlossen, Fläche A nicht). Zu den Standortunterschieden innerhalb der Flächen B und D könnte somit auch eine ungleichmäßige Verteilung des Düngekalks beigetragen haben.
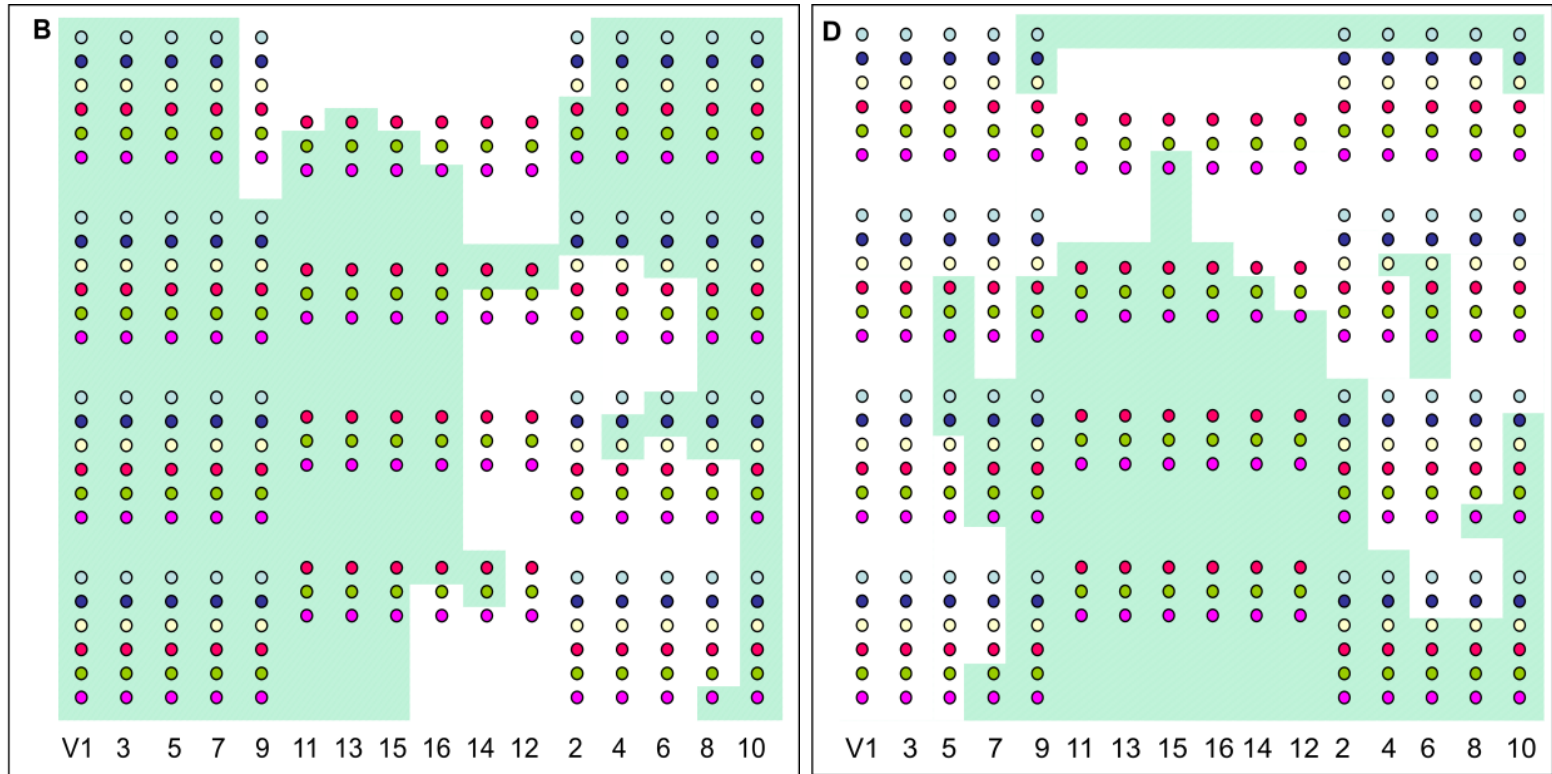

Abb. 4: Bereiche, in denen sich im Versuchsverlauf Spontanvegetation entwickelte (schraffiert) und bis Versuchsende vegetationsfreie Bereiche auf den Versuchsflächen B (links) und D (rechts); schematische Darstellung; Kreise = Standorte der Versuchspflanzen; Varianten s. S. 20 
Die bis zum Ende des zweijährigen Untersuchungszeitraums (un)bewachsenen Bereiche sind in Abb. 4 dargestellt, wobei zusätzlich die Positionen der Versuchspflanzen markiert sind. Das spontan aufgelaufene Gras war vorwiegend Land-Reitgras (Calamagrostis epigejos). Bei den Moosen wurden vor allem drei Arten unterschieden: Brachythecium rutabulum, B. velutinum und Ceratodon purpureus. Laut Sänger (2006) kommen diese drei Arten auf den verschiedenen Halden des Tagebaus Lichtenberg häufig vor. Auf die Pilzarten, deren Fruchtkörper vor allem auf Fläche B, aber auch auf Fläche D in Bereichen mit Spontanvegetation gefunden wurden, wird auf Seite 289 eingegangen.

Um diese offensichtlichen standörtlichen Unterschiede $\mathrm{zu}$ quantifizieren, wurden bei der Entnahme von Bodenproben zur Untersuchung bodenphysikalischer und bodenchemischer Parameter auf allen Versuchsflächen stets Proben aus Bereichen mit und ohne Bodenvegetation entnommen und miteinander verglichen. Auf Fläche A spielte dieser Aspekt keine Rolle, da sich lediglich in einem eng begrenzten Randbereich außerhalb der Versuchspflanzung Spontanvegetation ansiedeln konnte. Der Vergleichbarkeit halber wurden jedoch auch auf Fläche A aus diesem Bereich Proben entnommen und analysiert.

Die Ergebnisse der Bodenuntersuchungen sind in den folgenden Kapiteln ausführlich dargestellt. Demnach unterschieden sich die Bereiche mit und ohne Spontanvegetation hinsichtlich physikalischer Bodenparameter insgesamt nicht signifikant. Denkbar sind allerdings zukünftig positive Effekte ausgehend von der sich etablierenden Bodenvegetation (Verdunstungsschutz, Verbesserung der Bodenstruktur durch Durchwurzelung u.ä.).

Hinsichtlich chemischer Bodenparameter bestanden dagegen signifikante Unterschiede zwischen Bereichen, in denen sich spontane Bodenvegetation ansiedeln konnte, und vegetationsfreien Bereichen (s. ab S. 44). So lag der pH-Wert in bewachsenen Bereichen leicht höher als in unbewachsenen, was zu Unterschieden bei der Austauscherbelegung (höhere Kalium- und Calcium-Sättigung, geringere Eisen-, Mangan- und Aluminium-Sättigung in Bereichen mit Spontanvegetation) und damit zu einer günstigeren Nährstoffsituation in bewachsenen Bereichen führte.

\subsection{Physikalische Bodeneigenschaften}

Zur Beschreibung der bodenphysikalischen Eigenschaften des Haldensubstrats werden im Folgenden die Ergebnisse der Untersuchungen des Skelettgehaltes, der Korngrößenverteilung (Textur) mit Bestimmung der Bodenartenuntergruppen, der Trockenraumdichte, der Beziehung zwischen Wasserspannung und Wassergehalt (pF-Kurve), des Gesamtporenvolumens, der Porengrößenverteilung, der nutzbaren Feldkapazität (pflanzenverfügbares Wasser) sowie des aktuellen Wassergehaltes bei Probennahme zum Ende der Vegetationszeit dargestellt. Die Proben für die entsprechenden Analysen waren aus der obersten Bodenschicht (2 Tiefenstufen, 0-5 cm und 10-15 cm) aller drei Versuchsflächen aus Bereichen mit und ohne Spontanvegetation entnommen worden.

Anders als bei den bodenchemischen Untersuchungen (s. ab S. 44) konnten zwischen den drei Versuchsflächen sowie zwischen Teilbereichen mit und ohne Bodenbewuchs trotz teilweise unterschiedlicher Korngrößenverteilungen keine signifikanten Unterschiede hinsichtlich der untersuchten bodenphysikalischen Parameter ermittelt werden. Vorstellbar sind jedoch positive Effekte der sich in manchen Bereichen der Versuchsflächen etablierenden Bodenvegetation (Verdunstungsschutz, Verbesserung der Bodenstruktur durch Durchwurzelung u.ä.). Oft war 
bereits innerhalb der Versuchsflächen eine große Varianz der bodenphysikalischen Verhältnisse festzustellen, die auf ihre Entstehungsgeschichte (kein gewachsener Boden, sondern gestörtes Substrat durch Schüttung von heterogenem Abraummaterial, s. ab S. 11) zurückzuführen ist. Aus diesem Grund werden im Folgenden Untersuchungsergebnisse meist als Gesamtmittelwerte mit Standardabweichungen angegeben, ohne zwischen den einzelnen Versuchsflächen und/oder Bereichen mit und ohne Spontanvegetation zu differenzieren.

\subsubsection{Skelettgehalt}

Der Skelettgehalt des Haldenbodens war durch Sieben $(2 \mathrm{~mm})$ und Wägen an insgesamt 12 Proben bestimmt worden.

Aufgrund der sehr heterogenen Bedingungen des geschütteten Haldensubstrats reichte der Massenanteil an Steinen von $7 \%$ bis $55 \%$ und lag im Mittel bei $23 \%$. Von den 12 Proben wies eine einen schwachen Skelettanteil auf (1-10\%), sechs lagen im mittleren Bereich (10-30 \%), und fünf waren als stark steinig (Skelettanteil 30-75 \%) einzustufen (Schroeder 1992).

\subsubsection{Textur}

Zur Bestimmung der Bodenartenuntergruppen wurden insgesamt acht Bodenproben aus der obersten Bodenschicht (0-5 cm) auf ihre Korngrößenzusammensetzung analysiert.

Im Gesamtmittel ist das untersuchte Haldensubstrat als „schluffiger Lehm“ einzuordnen. Vier der insgesamt acht Proben wiesen die für diese Bodenartenuntergruppe charakteristische Verteilung der einzelnen Korngrößenfraktionen auf, wobei eine dieser Proben sich im Grenzbereich zum „schwach sandigen Lehm“ befand. Die übrigen vier Proben ließen sich als „schwach“ bzw. „mittel sandiger Lehm“, „schwach toniger Lehm“ sowie „mittel toniger Schluff” ansprechen (Scheffer \& Schachtschabel 2010).

Tab. 10: Anteile [\%] der Fraktionen Ton, Fein- u. Mittelschluff ( $f+m U$ ), Grobschluff (gU), Fein-, Mittel- u. Grobsand (fS, mS, gS) sowie Bodenartenuntergruppen im Freiland-Versuch, gesamt sowie getrennt nach Versuchsflächen und Bereichen o./m. Spontanvegetation; MW u. Std.abw.

\begin{tabular}{|c|c|c|c|c|c|c|c|c|}
\hline Fläche & $\begin{array}{l}\text { Spontan- } \\
\text { vegetation }\end{array}$ & Ton & $\begin{array}{c}\mathbf{f}+\mathbf{m} \\
\mathbf{U}\end{array}$ & gU & fS & $\mathbf{m S}$ & gS & Bodenartenuntergruppe \\
\hline \multirow{4}{*}{ A } & ja & 19,2 & 31,7 & 18,7 & 11,8 & 11,0 & 7,5 & Lu(-Ls2) schluffiger Lehm \\
\hline & \multirow{3}{*}{ nein } & 19,6 & 34,9 & 22,8 & 10,0 & 7,2 & 5,5 & Lu schluffiger Lehm \\
\hline & & 22,8 & 29,2 & 18,6 & 8,9 & 9,0 & 11,4 & Ls2 schwach sandiger L. \\
\hline & & 15,2 & 38,7 & 31,8 & 6,6 & 4,5 & 3,1 & Ut3 mittel toniger Schluff \\
\hline \multirow{2}{*}{ B } & ja & 24,8 & 32,0 & 26,8 & 6,7 & 5,1 & 4,7 & Lu schluffiger Lehm \\
\hline & nein & 23,6 & 28,1 & 25,4 & 9,9 & 7,2 & 5,8 & Lu schluffiger Lehm \\
\hline \multirow{2}{*}{$\mathrm{D}$} & ja & 26 & 28,2 & 18,2 & 10,3 & 8,0 & 9,3 & Lt2 schwach toniger L. \\
\hline & nein & 19,6 & 20,3 & 15,7 & 13,1 & 15,4 & 15,9 & Ls3 mittel sandiger L. \\
\hline \multicolumn{2}{|c|}{ Gesamtmittel } & $\begin{array}{l}21,4 \\
\pm 3,6\end{array}$ & $\begin{array}{l}30,4 \\
\pm 5,4\end{array}$ & $\begin{array}{l}22,2 \\
\pm 5,4\end{array}$ & $\begin{array}{l}9,7 \\
\pm 2,3\end{array}$ & $\begin{array}{l}8,4 \\
\pm 3,5\end{array}$ & $\begin{array}{l}7,9 \\
\pm 4,2\end{array}$ & Lu schluffiger Lehm \\
\hline
\end{tabular}


Die einzelnen Ergebnisse der auf S. 23 beschriebenen Korngrößenanalyse sind in Tab. 10 dargestellt. Sie decken sich mit den Ergebnissen der 2002 auf den Versuchsflächen durch die Thüringer Landesanstalt für Wald und Forstwirtschaft vorgenommenen Korngrößenanalyse (LAWuF Gotha 2002).

\subsubsection{Trockenraumdichte}

Die Bodendichte oder Trockenraumdichte (TRD) auf den Freiland-Versuchsflächen wurde an insgesamt 16 Proben aus der obersten Bodenschicht $(0-5 \mathrm{~cm})$ bestimmt. Dabei wurden Werte $1,8 \mathrm{~g} / \mathrm{cm}^{3}$ zwischen 1,3 und ermittelt, die im Schnitt bei $1,5 \mathrm{~g} / \mathrm{cm}^{3}$ lagen.

Der Bewertungsschlüssel des AK Standortskartierung (2003) und der Ad-hoc-AG Boden (2005) stuft die durchschnittliche TRD als mittel ein. In ihren Untersuchungen zum Bodenzustand der Versuchsflächen vom März 2002 ermittelte die Thüringer Landesanstalt für Wald- und Forstwirtschaft vergleichbare Werte. Die Bodendichte wurde dabei als im Vergleich zu Dichten mineralischer Oberböden von Waldstandorten sehr hoch bewertet (LAWuF Gotha 2002).

\subsubsection{Wassergehalt-Wasserspannungsbeziehungen (pF-Kurven)}

Die Beziehung von Wasserspannung und zugehörigem Wassergehalt wurde in zwei Tiefenstufen (0-5 cm und 10-15 cm) an jeweils 6 volumengerecht entnommenen Proben untersucht. Die Ergebnisse wurden in Form von Wasserspannungskurven (pF-Kurven) dargestellt (s. Abb. 5).
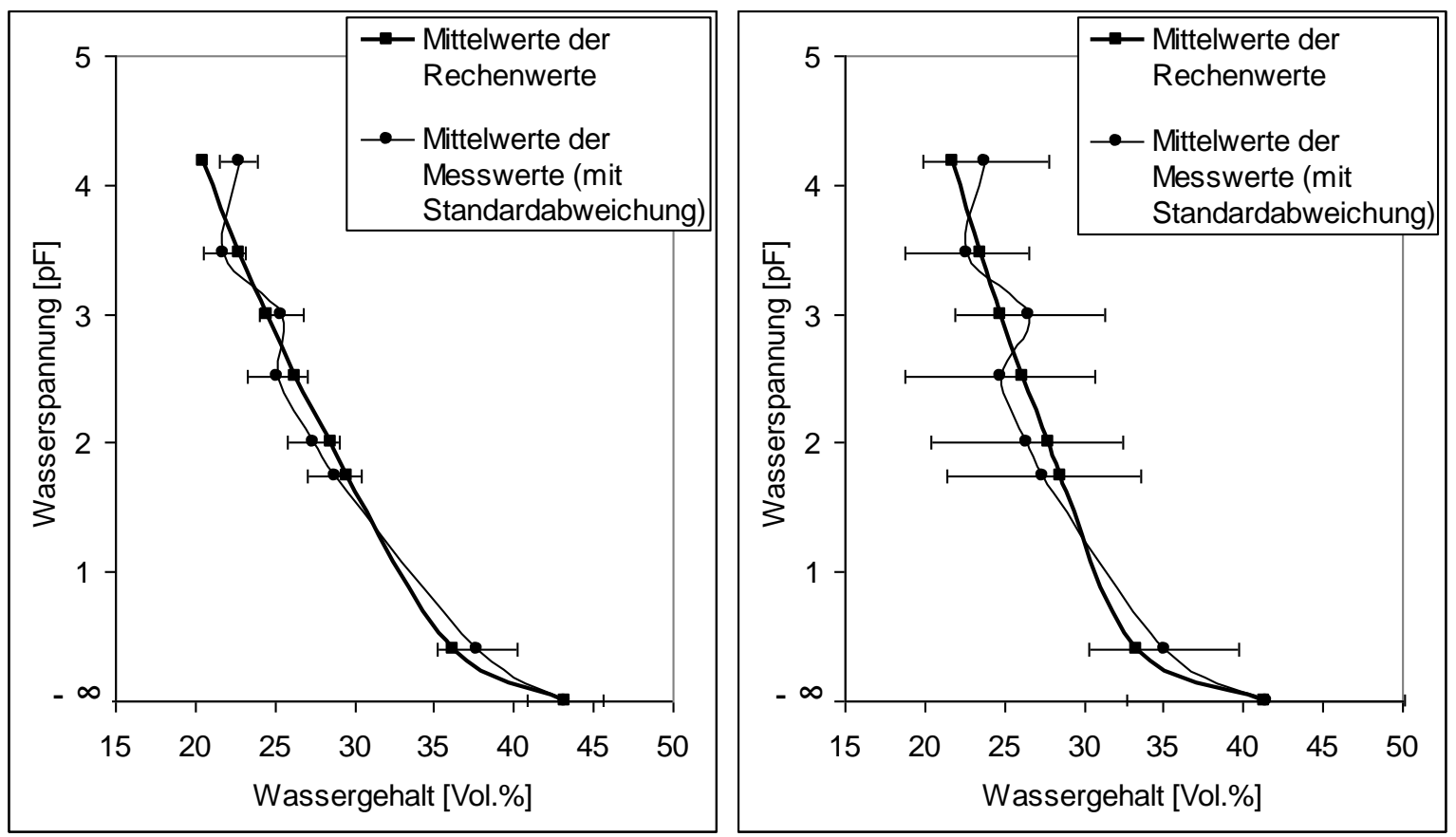

Abb. 5: Beziehung zwischen Wasserspannung [pF] und Wassergehalt [Vol.-\%] des Haldenbodens (links: Tiefenstufe 0-5 cm; rechts: Tiefenstufe 10-15 cm) (pF-Kurve); Kurve durch Mittelwerte der gemessenen Werte mit Standardabweichungen sowie Kurve durch Mittelwerte der mit Hilfe der van-GenuchtenGleichung errechneten Werte (interpolierte pF-Kurve) (links: alpha $=5,614, \mathrm{n}=1,066$, Theta_r $=0$, Theta_s $=0,4333$; rechts: alpha $=34,54, n=1,049$, Theta_r $=0$, Theta_s $=0,4142$ ) 
Am Verlauf der Kurven konnten die Gesamtporenvolumina sowie die Porengrößenverteilungen in Volumenprozent abgelesen werden (s. Tab. 11).

Tab. 11: Gesamtporenvolumina (GPV) und Porengrößenverteilung [Vol.-\%] im Haldenboden in zwei Tiefenstufen; MW u. Std.abw.; Ergebnisse von U-Tests (Z) auf signifikante Unterschiede (n=12)

\begin{tabular}{|c|c|c|c|c|c|}
\hline \multirow{2}{*}{$\begin{array}{l}\text { Tiefen- } \\
\text { stufe } \\
\text { [cm] }\end{array}$} & \multirow{2}{*}{$\begin{array}{l}\text { GPV } \\
\text { [Vol.-\%] }\end{array}$} & \multicolumn{2}{|c|}{ Grobporen [Vol.-\%] } & \multirow{2}{*}{$\begin{array}{l}\text { Mittelporen } \\
\text { [Vol.-\%] }\end{array}$} & \multirow{2}{*}{$\begin{array}{l}\text { Feinporen } \\
\text { [Vol.-\%] }\end{array}$} \\
\hline & & $\begin{array}{l}\text { weite GP } \\
\text { [Vol.-\%] }\end{array}$ & $\begin{array}{l}\text { enge GP } \\
\text { [Vol.-\%] }\end{array}$ & & \\
\hline \multirow{2}{*}{$0-5$} & \multirow{2}{*}{$43,3 \pm 2,4$} & $16,9 \pm 0,9$ & & \multirow{2}{*}{$5,9 \pm 0,3$} & \multirow{2}{*}{$20,5 \pm 1,1$} \\
\hline & & $13,7 \pm 0,8$ & $3,3 \pm 0,2$ & & \\
\hline \multirow{2}{*}{$10-15$} & \multirow{2}{*}{$41,4 \pm 8,8$} & $15,2 \pm 3,2$ & & \multirow{2}{*}{$4,5 \pm 0,9$} & \multirow{2}{*}{$21,7 \pm 4,6$} \\
\hline & & $12,8 \pm 2,7$ & $2,4 \pm 0,5$ & & \\
\hline \multirow{2}{*}{$\mathrm{Z}$} & \multirow{2}{*}{$-0,64$} & $-1,12$ & & \multirow{2}{*}{$-2,56^{* *}$} & \multirow{2}{*}{$-1,28$} \\
\hline & & $-0,64$ & $-2,88^{* *}$ & & \\
\hline
\end{tabular}

Das Volumen der weiten Grobporen entspricht der Luftkapazität des Haldenbodens, das des daneben verbleibenden Porenvolumens der Feldkapazität (Differenz von Gesamtporenvolumen und Luftkapazität, entsprechend also die Summe der Volumina der Fein-, Mittel- und engen Grobporen). Dabei bezeichnet nur die Summe der Volumina der engen Grobporen und Mittelporen die tatsächlich nutzbare Feldkapazität. Dem Anteil der Feinporen entspricht dagegen der nicht pflanzenverfügbare Totwasser-Gehalt (s. Tab. 12).

\section{Gesamtporenvolumen}

Die ermittelten Gesamtporenvolumina (GPV) lagen in der ersten Tiefenstufe $(0-5 \mathrm{~cm}$ ) bei 43,3 Vol.-\%, in der zweiten Tiefenstufe $(10-15 \mathrm{~cm})$ bei 41,4 Vol.-\% und insgesamt bei 42,3 Vol.-\%. Das für die oberste Tiefenstufe zusätzlich rechnerisch aus der Trockenraumdichte ermittelte Gesamtporenvolumen (s. S. 23) betrug 43,0 Vol.-\% und stimmte somit mit dem an der pF-Kurve abgelesenen überein.

Tab. 12: Gesamtporenvolumina (GPV), Luftkapazität (LK = weite Grobporen), Feldkapazität (FK = GPV $\mathrm{LK})$, nutzbare Feldkapazität $(\mathrm{nFK}=$ enge Grobporen + Mittelporen) sowie Totwasser $(=\mathrm{FK}-\mathrm{nFK}=$ Feinporen) [Vol.-\%] im Haldenboden in zwei Tiefenstufen; MW u. Std.abw.; Ergebnisse von U-Tests (Z) auf signifikante Unterschiede $(\mathrm{n}=12)$

\begin{tabular}{|l|l|l|l|l|l|}
\hline $\begin{array}{l}\text { Tiefen- } \\
\text { stufe [cm] }\end{array}$ & $\begin{array}{l}\text { GPV } \\
\text { [Vol.-\%] }\end{array}$ & $\begin{array}{l}\text { LK } \\
\text { [Vol.-\%] }\end{array}$ & $\begin{array}{l}\text { FK } \\
\text { [Vol.-\%] }\end{array}$ & $\begin{array}{l}\text { nFK } \\
\text { [Vol.-\%] }\end{array}$ & $\begin{array}{l}\text { Totwasser } \\
\text { [Vol.-\%] }\end{array}$ \\
\hline $0-5$ & $43,3 \pm 2,4$ & $13,7 \pm 0,8$ & $29,6 \pm 1,6$ & $9,1 \pm 0,5$ & $20,5 \pm 1,1$ \\
\hline $10-15$ & $41,4 \pm 8,8$ & $12,8 \pm 2,7$ & $28,6 \pm 6,0$ & $6,9 \pm 1,4$ & $21,7 \pm 4,6$ \\
\hline $\mathrm{Z}$ & $-0,64$ & $-0,64$ & $-0,48$ & $-2,88^{* *}$ & $-1,28$ \\
\hline
\end{tabular}

\section{Luftkapazität}

Der Anteil der weiten Grobporen und somit die Luftkapazität betrug 13,7 Vol.-\% bzw. 12,8 Vol.\%, im Mittel 13,2 Vol.-\%. Nach dem Bewertungsschlüssel der Bodenkundlichen Kartieranleitung (2005) ist die Luftkapazität des Haldenbodens damit bereits als hoch einzustufen (s. Tab. 13). 
Tab. 13: Kennwerte des Wasser- und Lufthaushaltes des Haldenbodens und Bewertung nach Bodenkundlicher Kartieranleitung (2005)

\begin{tabular}{|l|l|l|}
\hline $\begin{array}{l}\text { Kennwerte des } \\
\text { Wasser- und } \\
\text { Lufthaushaltes } \\
\text { eines Bodens }\end{array}$ & $\begin{array}{l}\text { Durchschnittlicher } \\
\text { Anteil im Halden- } \\
\text { boden [Vol.-\%] }\end{array}$ & $\begin{array}{l}\text { Bewertung nach } \\
\text { Bodenkundlicher } \\
\text { Kartieranleitung }\end{array}$ \\
\hline Gesamtporenvolumen & $42,3 \pm 6,2$ & \\
\hline Luftkapazität & $13,2 \pm 1,9$ & hoch $(12-20)$ \\
\hline Feldkapazität & $29,1 \pm 4,3$ & mittel $(26-39)$ \\
\hline Nutzbare Feldkapazität & $8,0 \pm 1,6$ & gering $(6-14)$ \\
\hline
\end{tabular}

\section{(Nutzbare) Feldkapazität}

Die Feldkapazität (FK) lag mit 29,6 \pm 1,6 Vol.-\% in der ersten und 28,6 \pm 6,0 Vol.-\% in der zweiten Tiefenstufe sowie 29,1 \pm 4,3 Vol.-\% im Gesamtdurchschnitt knapp im mittleren Bewertungsbereich (Bodenkundliche Kartieranleitung 2005). Dagegen kann die nutzbare Feldkapazität (nFK), also der Anteil des tatsächlich pflanzenverfügbaren Wassers, nur als gering eingestuft werden. Wie in Abb. 6 veranschaulicht, war die nFK in 10-15 cm Tiefe mit 6,9 Vol.-\% signifikant geringer als in der obersten Bodenschicht mit 9,1 Vol.-\%. Die Volumenanteile der engen Grobporen und Mittelporen, die zusammen die nFK bilden, waren ebenfalls in der zweiten Bodenschicht mit 2,4 Vol.-\%. bzw. 4,5 Vol.-\% jeweils signifikant niedriger als in der ersten mit 3,3 Vol.-\% bzw. 5,9 Vol.-\% (s. Tab. 11).

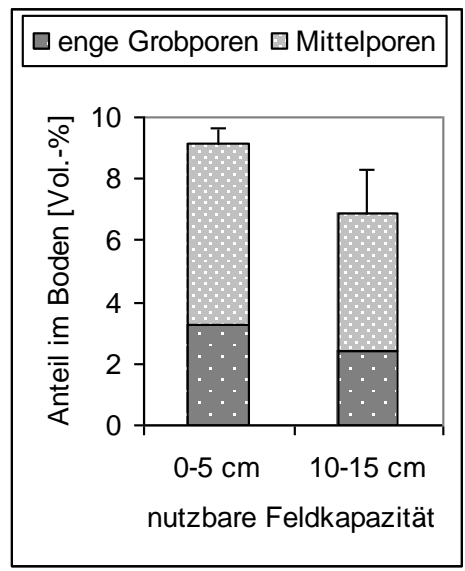

Abb. 6: Nutzbare Feldkapazität (= Anteile enge Grobporen + Mittelporen im Boden) [Vol.-\%] des Haldenbodens in zwei Tiefenstufen; MW u. Std.abw.; jeweils signifikante Unterschiede zwischen den Tiefenstufen nach U-Tests (n= je 6)

Grund für die geringe nutzbare Feldkapazität ist die starke Verdichtung des Haldenbodens (Scheffer \& Schachtschabel 2010), die aus seiner Nutzungs- und Entstehungsgeschichte resultiert (s. ab S. 11).

\section{Totwasser}

Der Anteil der Feinporen und damit der Totwasser-Anteil lag insgesamt bei 21,1 Vol.-\% (0-5 cm Bodentiefe: 20,5 Vol.-\%; 10-15 cm Bodentiefe: 21,7 Vol.-\%) und machte damit die Hälfte des GPV aus. Ebenso wie beim diesem und der LK (weite Grobporen) bestanden keine signifikanten Unterschiede je nach Tiefenstufe. 
Die Problematik des Wasserhaushalts des Haldenbodens besteht nicht nur in seiner aufgrund der starken Bodenverdichtung vergleichsweise geringen nutzbaren Feldkapazität (= wenig pflanzenverfügbares Wasser), sondern auch und vor allem in seiner geringen Wasserleitfähigkeit und damit seinem geringen Infiltrationsvermögen.

Dies wurde durch Beobachtungen im Gewächshaus-Versuch und auf den Ronneburger FreilandVersuchsflächen deutlich. Dort floss das Niederschlagswasser je nach Geländeneigung entweder oberflächlich ab, was zur Ausprägung von Rinnen und bis über $1 \mathrm{~m}$ tiefen Gräben führte, oder bildete dauerhafte Pfützen, während das Gießwasser im Topf-Versuch sehr lange auf den Topfoberflächen stand und nur sehr langsam versickerte.

\subsubsection{Volumetrischer Wassergehalt (Bodenfeuchte)}

Im Zuge der Ermittlung der Trockenraumdichte des Haldensubstrats wurde auch der zu diesem Zeitpunkt im Boden enthaltene volumetrische Wassergehalt errechnet (s. S. 23). Die Probenahme fand Anfang Oktober 2005 nach 2-3 Tagen niederschlagsfreier Zeit nach mehreren Regentagen mit je 4-8 l/ $\mathrm{m}^{2}$ statt.

Der volumetrische Wassergehalt der insgesamt 16 Proben bewegte sich zwischen 12 und 26 Vol.-\% und betrug im Mittel 17 Vol.-\%. Damit lag der mittlere volumetrische Wassergehalt trotz einer Regenperiode fast unmittelbar vor der Probennahme bereits unterhalb der nutzbaren Feldkapazität des Haldensubstrats (für die Tiefenstufe 0-5 cm ist dies der Bereich zwischen 20 und 30 Vol.-\%; s. Tab. 11) und damit im Bereich des für die Nutzung durch Pflanzen zu stark gebundenen Wassers. Lediglich 4 der 16 Proben wiesen einen ausreichend hohen Wassergehalt auf, um tatsächlich geringe Mengen pflanzenverfügbares Wasser zu enthalten. Der Zeitpunkt der Probennahme (s.o.) hätte jedoch einen höheren Wassergehalt (Feldkapazität) erwarten lassen. Das Ergebnis weist deshalb auf eine verminderte Infiltrations- und Wasserleitfähigkeit des Bodens hin. 


\subsection{Chemische Bodeneigenschaften}

Zur Bestimmung der Bodenreaktion, des Nährstoffangebotes und der Schadstoffbelastung (durch Schwermetalle u. a.) waren pro Versuchsfläche jeweils in vegetationsfreien und spontan besiedelten Bereichen in zwei Tiefenstufen (0-5 cm, 10-15 cm) Bodenproben entnommen worden. Der Vollständigkeit und Vergleichbarkeit halber wurde dabei auch auf der beinahe komplett vegetationsfreien Fläche A ein sehr kleiner bewachsener Teilbereich am Rand der Versuchsfläche beprobt. Für die gesamte Versuchspflanzung auf Fläche A sind jedoch die im vegetationsfreien Bereich entnommenen Proben repräsentativ. Die erfolgte Entnahme, Behandlung, Vorbereitung und Analyse der im Folgenden genannten Bodenproben stand im Einklang mit der „BZE II - Arbeitsanleitung“ (BMELF 2006) sowie dem „Handbuch forstliche Analytik" (Gutachterausschuss Forstliche Analytik 2005).

\subsubsection{Bodenreaktion}

Die pH-Werte wurden in wässriger sowie in KCl-Lösung gemessen. Alle auf diese Weise bestimmten $\mathrm{pH}$-Werte lagen unter 5 und damit deutlich im sauren Bereich. Bei pH-Werten unter 5 wird davon ausgegangen, dass durch die Zugabe eines Salzes (in diesem Fall Kaliumchlorid = $\mathrm{KCl}$ ) der gemessene pH-Wert dem der natürlichen Bodenlösung nahe kommt (Meiwes et al. 1984). Laut Schlichting et al. (1995) bringen die Kalium-Ionen einen Teil leichter austauschbarer Protonen (bzw. Aluminium-Ionen) in Lösung, so dass eine höhere Protonenaktivität als in wässriger Lösung entsteht, die dem pH-Wert der unverdünnten Bodenlösung eher entspricht. Bei den im Rahmen der vorliegenden Arbeit genannten und interpretierten $\mathrm{pH}$-Werten handelt es sich deshalb nicht um die in wässriger Lösung gemessenen Werte, sondern um die Werte, die in KCl-Lösung gemessen wurden.

Tab. 14: Bodenreaktion (pH-Wert in KCl-Lsg.) in der oberen Schicht des Haldenbodens in zwei Tiefenstufen, gesamt sowie getrennt nach Bereichen o./m. Spontanvegetation; MW u. Std.abw.; Ergebnisse von t-Tests ( $\mathrm{T})$ auf signifikante Unterschiede $(\mathrm{n}=12)$

\begin{tabular}{|c|c|c|c|c|c|c|c|}
\hline & \multirow[t]{2}{*}{ gesamt } & \multicolumn{2}{|c|}{$\begin{array}{c}\text { Ohne } \\
\text { Spontanvegetation }\end{array}$} & \multicolumn{2}{|c|}{$\begin{array}{c}\text { Mit } \\
\text { Spontanvegetation }\end{array}$} & \multicolumn{2}{|c|}{$\mathbf{T}$} \\
\hline & & $0-5 \mathrm{~cm}$ & $10-15 \mathrm{~cm}$ & $0-5 \mathrm{~cm}$ & $10-15 \mathrm{~cm}$ & $0-5 \mathrm{~cm}$ & $10-15 \mathrm{~cm}$ \\
\hline \multirow{2}{*}{$\begin{array}{l}\mathrm{pH} \\
(\mathrm{KCl})\end{array}$} & \multirow{2}{*}{$3,6 \pm 0,3$} & $3,6 \pm 0,1$ & $3,3 \pm 0,4$ & $4,0 \pm 0,1$ & $3,6 \pm 0,2$ & $-4,4^{*}$ & $-1,1$ \\
\hline & & & $4 \pm 0,3$ & \multicolumn{2}{|c|}{$3,8 \pm 0,3$} & \multicolumn{2}{|c|}{$-2,3^{*}$} \\
\hline
\end{tabular}

Der durchschnittliche pH-Wert lag bei 3,6 (s. Tab. 14). Die leicht unterschiedlich hohen pHWerte des Bodens in Bereichen mit Spontanvegetation $(3,8)$ und vegetationsfreien Bereichen $(3,4)$ waren signifikant verschieden, jedoch nur in der obersten Bodenschicht $(0-5 \mathrm{~cm})$. Darunter (10-15 cm) waren die gemessenen Unterschiede der $\mathrm{pH}$-Werte nicht mehr signifikant. Zwischen den drei Freiland-Versuchsflächen war der pH-Wert nicht signifikant unterschiedlich.

Die Bodenreaktion ist generell als sehr stark sauer einzustufen. Die Böden liegen damit im Eisen/Aluminium-Pufferbereich (vegetationsfreie Teilflächen) bzw. im AluminiumPufferbereich (Teilflächen mit Spontanvegetation) (AK Standortskartierung 2003, Scheffer \& Schachtschabel 2010). Die Ergebnisse stimmen mit den 2002 auf den Versuchsflächen vorgenommenen Messungen der Landesanstalt für Wald und Forstwirtschaft Thüringen überein (LAWuF Gotha 2002). Die Versauerung des Haldensubstrats kann auf seinen Pyrit-Gehalt zurückgeführt werden (s. S. 13), da bei der Verwitterung dieses Eisensulfids Schwefelsäure entsteht. 


\subsubsection{Schwefel-Gehalt}

Die gemessenen Schwefelkonzentrationen, die sowohl auf Pyrit-Verwitterung als auch auf Depositionen aus anthropogenen Emissionen zurückgehen werden, reichten von $0,4 \mathrm{mg} / \mathrm{g}$ bis $3,2 \mathrm{mg} / \mathrm{g}$ trockenem Boden $(\mathrm{n}=12)$ und waren damit vergleichsweise hoch. Der Mittelwert lag bei $1,4 \mathrm{mg} / \mathrm{g}$. Zwischen Bereichen mit $(1,1 \mathrm{mg} / \mathrm{g})$ und ohne Spontanvegetation $(1,7 \mathrm{mg} / \mathrm{g})$ konnten keine signifikanten Unterschiede festgestellt werden. Unterschiedliche Werte für die drei Versuchsflächen (A: 2,0 mg/g; B: 1,4 mg/g; D: 0,8 mg/g) waren ebenfalls nicht signifikant.

Die nach Scheffer \& Schachtschabel (2010) in Böden des humiden Klimabereichs meist üblichen Schwefel-Gehalte von $0,1-0,5 \mathrm{mg} / \mathrm{g}$ sind damit deutlich überschritten. Überwiegend gilt dies auch für die weitere Spanne für Mineralböden nach Schwerdtfeger et al. (1994), die GesamtSchwefel-Gehalte in der Trockensubstanz von 0,1-1 mg/g umfasst. Laut Thüringer Landesanstalt für Wald und Forstwirtschaft (LAWuF Gotha 2002), die im Jahr 2002 auf den Versuchsflächen noch höhere Schwefel-Gehalte ermittelte $(1,2-5 \mathrm{mg} / \mathrm{g}$, im Mittel 2,6 mg/g), liegen die GesamtSchwefel-Gehalte mineralischer Oberböden meist deutlich unter $0,5 \mathrm{mg} / \mathrm{g}$ (Grund für die unterschiedlichen Messergebnisse könnte die starke Abhängigkeit der $\mathrm{SO}_{4}$-Gehalte von Faktoren wie Witterung, Entnahmetiefe und Zeitpunkt der Probenahme sein).

\subsubsection{Schwermetall-Gehalte}

Die im Haldenboden gemessenen Gehalte der Schwermetalle Zink, Kupfer, Blei, Cadmium, Chrom, Nickel und Kobalt sind in Tab. 15 dargestellt. Mit Ausnahme von Cadmium, Chrom und Nickel bestanden signifikante Unterschiede zwischen den drei Flächen. Dagegen waren die Gehalte in Bereichen mit und ohne Bodenbewuchs nicht signifikant verschieden. Die zur Bewertung der Schwermetall-Gehalte herangezogenen Quellen finden sich in Anhang 1.

Tab. 15: Schwermetall-Gehalte [mg/kg] in der oberen Schicht des Haldenbodens, gesamt sowie getrennt nach Versuchsflächen; MW u. Std.abw.; Ergebnisse von H-Tests [H] auf signifikante Unterschiede; Buchstaben kennzeichnen je Zeile homogene Gruppen nach U-Tests $(n=12)$

\begin{tabular}{|l|l|l|l|l|l|}
\hline $\mathrm{mg} / \mathrm{kg}$ & gesamt & Fläche A & Fläche B & Fläche D & $\mathrm{H}$ \\
\hline $\mathrm{Zn}$ & $70,9 \pm 18,9$ & $76,3 \pm 12,6 \mathrm{a}, \mathrm{b}$ & $84,2 \pm 15,3 \mathrm{~b}$ & $52,1 \pm 13,2 \mathrm{a}$ & $7,5^{*}$ \\
\hline $\mathrm{Cu}$ & $103,8 \pm 60,2$ & $168,1 \pm 41,1 \mathrm{~b}$ & $96,5 \pm 39,6 \mathrm{a}$ & $46,8 \pm 11,4 \mathrm{a}$ & $8,8^{*}$ \\
\hline $\mathrm{Ni}$ & $60,4 \pm 20,4$ & $66,5 \pm 20,1$ & $67,9 \pm 25,8$ & $46,8 \pm 9,0$ & 1,0 \\
\hline $\mathrm{Co}$ & $13,2 \pm 9,5$ & $20,2 \pm 10,5 \mathrm{~b}$ & $15,4 \pm 5,1 \mathrm{a}, \mathrm{b}$ & $3,8 \pm 1,1 \mathrm{a}$ & $7,5^{*}$ \\
\hline $\mathrm{Cr}$ & $85,7 \pm 15,8$ & $74,7 \pm 3,4$ & $81,8 \pm 3,3$ & $100,7 \pm 20,2$ & 5,3 \\
\hline $\mathrm{Pb}$ & $22,7 \pm 11,7$ & $13,2 \pm 0,7 \mathrm{a}$ & $16,6 \pm 1,3 \mathrm{a}$ & $36,7 \pm 6,2 \mathrm{~b}$ & $8,9^{*}$ \\
\hline $\mathrm{Cd}$ & $5,9 \pm 2,0$ & $6,5 \pm 0,2$ & $7,1 \pm 1,0$ & $4,1 \pm 2,5$ & 3,5 \\
\hline
\end{tabular}

\subsubsection{Zink}

Der durchschnittliche Zink-Gehalt des Bodens auf den Versuchsflächen lag bei $71 \mathrm{mg} / \mathrm{kg}$, wobei der mittlere Wert für Fläche B (84 mg/kg) signifikant höher war als für Fläche D (52 mg/kg). Die Werte befinden sich im oberen Normalbereich (Forstliche Bundesversuchsanstalt 1992) und bleiben noch unter dem tolerierbaren Gesamtgehalt nach Kloke (1989) mit Ausnahme einer Probe auf Fläche B, die einen Zink-Gehalt von $105 \mathrm{mg} / \mathrm{kg}$ aufwies. Der Vorsorgewert nach Prüeß (1992, 1994) und der kritische Wert nach Tyler (1992) für Humusauflagen werden ebenfalls nicht überschritten. Die Zink-Gehalte der Waldböden in Thüringen (Mineralböden) liegen zwischen 3 und $100 \mathrm{mg} / \mathrm{kg}$ (LAWuF Gotha 2002). 


\subsubsection{Kupfer}

Der mittlere Kupfer-Gehalt des Bodens auf den Versuchsflächen betrug $104 \mathrm{mg} / \mathrm{kg}$. Der Wert auf Fläche A (168 mg/kg) hob sich dabei signifikant gegen die Werte auf Fläche B ( $97 \mathrm{mg} / \mathrm{kg}$ ) und D (47 mg/kg) ab. Abgesehen von Fläche D lagen erhöhte bis stark belastende Kupfer-Gehalte vor (Forstliche Bundesversuchsanstalt 1992), die auf Fläche A teilweise über $200 \mathrm{mg} / \mathrm{kg}$ erreichten. Die Kupfer-Gehalte aller Proben auf Fläche A sowie einer Probe auf Fläche B liegen über dem bei Alloway (1999) genannten Bereich, oberhalb dessen toxische Wirkungen möglich sind. Die von Prüeß $(1992,1994)$ und Tyler (1992) genannten Werte für Humusauflagen sind damit ebenfalls weit überschritten; eine schädigende Wirkung auf Ökosystemkomponenten dürfte nach Tyler (1992) gegeben sein.

\subsubsection{Nickel}

Durchschnittlich enthielt der Boden auf den Versuchsflächen 60 mg Nickel / kg (Fläche A: 61 $\mathrm{mg} / \mathrm{kg}$, Fläche B: $68 \mathrm{mg} / \mathrm{kg}$, Fläche D: $47 \mathrm{mg} / \mathrm{kg}$ ); maximal wurden $94 \mathrm{mg} / \mathrm{kg}$ gemessen (eine Probe auf Fläche B). Nach Alloway (1999) sind erst bei Werten oberhalb von $100 \mathrm{mg} / \mathrm{kg}$ toxische Wirkungen wahrscheinlich.

\subsubsection{Kobalt}

Die mittlere Kobaltkonzentration auf den Versuchsflächen lag bei 13,2 mg/kg, das Maximum (eine Probe auf Fläche A) bei $33 \mathrm{mg} / \mathrm{kg}$. Der Mittelwert auf Fläche D war mit 3,8 mg/kg signifikant geringer als der auf Fläche A mit $20,2 \mathrm{mg} / \mathrm{kg}$. Toxische Wirkungen sind laut Alloway (1999) erst bei Gehalten über 25-50 mg/kg wahrscheinlich.

\subsubsection{Blei}

Das Haldensubstrat enthielt durchschnittlich $23 \mathrm{mg}$ Blei / kg Boden, wobei der mittlere Gehalt auf Fläche D (37 mg/kg) signifikant höher war als auf Fläche A $(13 \mathrm{mg} / \mathrm{kg})$ und Fläche B (17 $\mathrm{mg} / \mathrm{kg}$ ). Maximal wurden auf Fläche D $46 \mathrm{mg} / \mathrm{kg}$ erreicht. Die Werte auf Fläche A und B lagen damit im Normalbereich, der Wert auf Fläche D im oberen Normalbereich (Forstliche Bundesversuchsanstalt 1992).

\subsubsection{Cadmium}

Der mittlere Cadmium-Gehalt der auf den Versuchsflächen entnommenen Proben betrug 5,9 mg/kg (Fläche A: 6,5 mg/kg, Fläche B: 7,1 mg/kg, Fläche D: 4,1 mg/kg), das Maximum lag bei 8,6 $\mathrm{mg} / \mathrm{kg}$ (eine Probe auf Fläche B). Bei solch hohen Werten liegt eine starke Cadmium-Belastung vor (Forstliche Bundesversuchsanstalt 1992); schädigende Wirkungen auf Pflanzen und andere Ökosystemkomponenten sind $\mathrm{zu}$ erwarten. In den Ergebnissen der bundesweiten Bodenzustandserhebung im Wald von 1987-1993 (BZE), die im Deutschen Waldbodenbericht 1996 (Stand 2007) veröffentlicht sind, werden Cadmium-Gehalte von äußerst stark belasteten BZE-Punkten im Harz mit 6,6 mg/kg , 10,1 mg/kg und 17,2 mg/kg angegeben. Als mögliche Ursachen für diese Kontaminationen werden Lagerstätten und lokale Emittenten (Erzabbau, metallverarbeitende Industrie) genannt (BMELF 1997a).

\subsubsection{Chrom}

Das Bodensubstrat auf den Versuchsflächen enthielt im Mittel 86 mg Chrom / kg. Mit 101 mg/kg war der Mittelwert auf Fläche D signifikant höher als der auf Fläche A (75 mg/kg). Damit liegen die Chrom-Gehalte des Haldensubstrats im bei Alloway (1999) genannten (sehr allgemeinen und weit gefassten) Bereich kritischer Gesamtkonzentrationen (75-100 mg/kg), in einer Probe von Fläche D mit $123 \mathrm{mg} / \mathrm{kg}$ auch deutlich darüber. 
Die Analysen der Schwermetall-Gehalte des Versuchsflächensubstrats durch die Thüringer Landesanstalt für Wald und Forstwirtschaft im Jahr 2002 (LAWuF Gotha 2002) lieferten bezogen auf die Kupfer-, Nickel- und Zink-Gehalte ähnliche Ergebnisse wie die im Rahmen der vorliegenden Arbeit im Jahr 2005 durchgeführten Messungen. Der mittlere Blei-Gehalt 2002 ähnelte ebenfalls dem 2005 gemessenen, der Maximalwert war 2002 mit $24 \mathrm{mg} / \mathrm{kg}$ jedoch deutlich geringer als 2005 mit $46 \mathrm{mg} / \mathrm{kg}$. Auch die Chrom-Gehalte lagen 2002 mit maximal 49 $\mathrm{mg} / \mathrm{kg}$ erheblich unter den jüngeren Messwerten mit maximal $123 \mathrm{mg} / \mathrm{kg}$. Die Analyse des Cadmium-Gehaltes führte 2002 mit einem Durchschnittswert von 0,19 mg/kg und einem Maximalwert von 0,48 mg/kg zu um ein Vielfaches niedrigeren Werten als 2005 (Mittelwert 5,9 $\mathrm{mg} / \mathrm{kg}$, Maximum 8,6 mg/kg).

Der sehr geringe Stichprobenumfang der 2002 in Gotha durchgeführten Schwermetallanalyse von den damals noch vier Versuchsflächen (s. S. 17) wurden jeweils nur 1-2 Proben analysiert kann angesichts der heterogenen bodenchemischen Bedingungen teilweise Abweichungen gegenüber der ebenfalls nicht umfangreichen Analyse von 2005 (vier Proben pro Versuchsfläche) erklären. Schwierig scheint eine Begründung für den sehr großen Unterschied der Cadmiumkonzentration, die 2005 im Mittel das 31-fache der 2002 gemessenen betrug und ein 18-mal höheres Maximum aufwies. Messfehler sowie Fehlinterpretationen (durch fehlerhafte Umrechnung der Messwerte) erschienen durch den Vergleich mit den Bodenanalysen der Topf-Versuche im Folgejahr (s. S. 60) zunächst unwahrscheinlich.

\subsubsection{Kohlenstoff-, Stickstoff-Gehalte und C/N-Verhältnis}

Da in den Haldenböden bislang nur wenig Humusakkumulation stattgefunden hat, waren die Kohlenstoff- und Stickstoff-Vorräte im Boden äußerst gering (LAWuF Gotha 2002).

Vor allem die mittleren Kohlenstoff-Gehalte lagen mit ca. $3 \mathrm{mg} / \mathrm{g}$ (Fläche B, D) bis $7 \mathrm{mg} / \mathrm{g}$ (Fläche A; signifikant höherer Wert) weit unter entsprechenden Werten für Thüringer Waldböden (durchschnittlich $42 \mathrm{mg} / \mathrm{g}$ in der oberen Bodenschicht; Wirth et al. 2004). Mit einem $\mathrm{C}_{\mathrm{t}}$-Gehalt von durchschnittlich unter $5 \mathrm{mg} / \mathrm{g}$ sind die Ronneburger Kippenböden als kohlefrei zu bezeichnen (Katzur et al. 1999b).

Die Stickstoff-Gehalte des Haldensubstrats lagen mit Werten von 0,6-0,8 mg/g nur etwa bei der Hälfte der in Waldböden üblichen mittleren Gehalte (LAWuF Gotha 2002).

Die Thüringer Landesanstalt für Wald und Forstwirtschaft kam im Jahr 2002 auf ähnlich niedrige Kohlenstoff- und Stickstoff-Gehalte in den Haldenböden (LAWuF Gotha 2002).

Das sich aus den genannten, jeweils sehr niedrigen Werten ergebende durchschnittliche $\mathrm{C} / \mathrm{N}$ Verhältnis (s. Tab. 16) liegt auf Fläche A bei 10,2, was einem engen (günstigen) C/N-Verhältnis entspricht (BMELF 1997a). Es unterscheidet sich signifikant von den durchschnittlichen C/NVerhältnissen der Flächen B und D, die bei 4,9 bzw. 3,1 liegen und damit als sehr eng einzustufen sind (AK Standortskartierung 2003, Scheffer \& Schachtschabel 2010). Zwischen Bereichen mit und ohne Spontanvegetation konnten keine signifikanten Unterschiede der Kohlenstoff- und Stickstoff-Gehalte sowie der C/N-Verhältnisse festgestellt werden. 
Tab. 16: Kohlenstoff-, Stickstoff- und Phosphor-Gehalte [mg/g], C/N- und C/P-Verhältnisse in der oberen Schicht des Haldenbodens, gesamt sowie getrennt nach Versuchsflächen; MW u. Std.abw.; Ergebnisse von Varianzanalysen auf signifikante Unterschiede (F); Buchstaben kennzeichnen je Zeile homogene Gruppen nach Tukey-Tests $(n=12)$

\begin{tabular}{|l|l|l|l|l|l|}
\hline & gesamt & Fläche A & Fläche B & Fläche D & $\mathrm{F}$ \\
\hline C [mg/g] & $4,2 \pm 2,4$ & $7,1 \pm 0,9 \mathrm{~b}$ & $3,1 \pm 1,1 \mathrm{a}$ & $2,6 \pm 1,1 \mathrm{a}$ & $22,1^{* * *}$ \\
\hline $\mathrm{N}[\mathrm{mg} / \mathrm{g}]$ & $0,7 \pm 0,09$ & $0,7 \pm 0,03$ & $0,6 \pm 0,07$ & $0,8 \pm 0,1$ & 4,2 \\
\hline P [mg/g] & $0,7 \pm 0,19$ & $0,6 \pm 0,03 \mathrm{~b}$ & $0,9 \pm 0,04 \mathrm{c}$ & $0,5 \pm 0,08 \mathrm{a}$ & $63,3^{* * *}$ \\
\hline C/N-Verhältnis & $6,1 \pm 3,4$ & $10,2 \pm 0,8 \mathrm{~b}$ & $4,9 \pm 1,8 \mathrm{a}$ & $3,1 \pm 1,2 \mathrm{a}$ & $31,0^{* * *}$ \\
\hline C/P-Verhältnis & $6,7 \pm 3,8$ & $11,2 \pm 1,0 \mathrm{~b}$ & $3,5 \pm 1,4 \mathrm{a}$ & $5,3 \pm 2,3 \mathrm{a}$ & $23,0^{* * *}$ \\
\hline
\end{tabular}

\subsubsection{Posphor-Gehalt und C/P-Verhältnis}

Der Phosphor-Gehalt des Haldenbodens lag im Mittel bei 0,7 mg/g. Bezüglich dieses Makronährstoffes unterschieden sich alle drei Versuchsflächen signifikant voneinander, wobei der Gehalt auf Fläche D mit 0,5 mg/g am niedrigsten, auf Fläche B mit 0,9 mg/g am höchsten war. Der Gehalt auf Fläche A nahm mit 0,6 mg/g eine Mittelstellung ein.

Laut Scheffer \& Schachtschabel (2010) liegt der Phosphor-Gehalt in ungedüngten Böden der gemäßigten Breiten meist zwischen 0,2 und 0,8 mg/g.

Das C/P-Verhältnis gibt wie das $\mathrm{C} / \mathrm{N}-$ Verhältnis Hinweise auf die biologische Aktivität von Böden. Aufgrund der sehr geringen Kohlenstoff-Gehalte sind die C/P-Verhältnisse der Böden aller drei Versuchsflächen (s. Tab. 16) ebenfalls als sehr eng $(<50)$ und damit als günstig einzustufen (BMELF 1997a). Wiederum unterschied sich das C/P-Verhältnis auf Fläche A $(11,2)$ signifikant von den C/P-Verhältnissen der Flächen B $(3,5)$ und D $(5,3)$. Weder bei den PhosphorGehalten noch bei den C/P-Verhältnissen bestanden signifikante Unterschiede zwischen Bereichen mit und ohne Spontanvegetation.

\subsubsection{Weitere Nährelement-Gehalte}

Neben den Einzelsättigungswerten der Nährelemente an der gesamten Austauschkapazität (s. S. 50) waren auch die absoluten Nährelement-Gehalte in der oberen Bodenschicht ermittelt worden (s. Tab. 17). Dabei konnten zwischen vegetationsfreien und bewachsenen Teilbereichen der Versuchsflächen keine signifikanten Unterschiede festgestellt werden.

Dagegen waren die Gehalte fast aller Nährelemente je nach Versuchsfläche signifikant verschieden. Allein die Eisen-Gehalte (Gesamtmittel: 34,3 $\pm 10,7$ ) in der oberen Bodenschicht der drei Versuchsflächen unterschieden sich nicht signifikant. Bei den übrigen Nährelementen Natrium, Kalium, Calcium, Magnesium, Mangan und Aluminium wies Fläche D stets signifikant geringere Gehalte auf als die Flächen A und B. Die Natrium-, Kalium- und Aluminium-Gehalte lagen auf Fläche B signifikant höher als auf Fläche A. Umgekehrt waren die Calcium- und Mangan-Gehalte auf Fläche A signifikant höher als auf Fläche B. Keinen signifikanten Unterschied zwischen diesen beiden Flächen gab es bei den Magnesium-Gehalten, die jeweils 6,5 mg/g betrugen (im Gegensatz zu 2,9 mg/g auf Fläche D). 
Tab. 17: Nährelement-Gehalte in der oberen Schicht des Haldenbodens, gesamt sowie getrennt nach Versuchsflächen; MW u. Std.abw.; Ergebnisse von H-Tests [H] auf signifikante Unterschiede; Buchstaben kennzeichnen je Zeile homogene Gruppen nach U-Tests $(n=12)$

\begin{tabular}{|l|l|l|l|l|l|}
\hline$[\mathrm{mg} / \mathrm{g}]$ & gesamt & Fläche A & Fläche B & Fläche D & $\mathrm{H}$ \\
\hline $\mathrm{Na}$ & $0,6 \pm 0,2$ & $0,7 \pm 0,03 \mathrm{~b}$ & $0,8 \pm 0,17 \mathrm{c}$ & $0,3 \pm 0,09 \mathrm{a}$ & $8,77^{*}$ \\
\hline $\mathrm{K}$ & $18,1 \pm 4,4$ & $18,3 \pm 0,6 \mathrm{~b}$ & $21,5 \pm 4,8 \mathrm{c}$ & $14,3 \pm 3,5 \mathrm{a}$ & $8,65^{*}$ \\
\hline $\mathrm{Ca}$ & $1,2 \pm 1,0$ & $2,1 \pm 1,2 \mathrm{c}$ & $1,0 \pm 0,6 \mathrm{~b}$ & $0,4 \pm 0,2 \mathrm{a}$ & $8,12^{*}$ \\
\hline $\mathrm{Mg}$ & $5,3 \pm 1,9$ & $6,5 \pm 0,1 \mathrm{~b}$ & $6,5 \pm 1,1 \mathrm{~b}$ & $2,9 \pm 0,6 \mathrm{a}$ & $8,00^{*}$ \\
\hline $\mathrm{Fe}$ & $34,3 \pm 10,7$ & $36,7 \pm 0,5$ & $40,6 \pm 5,3$ & $25,6 \pm 15,2$ & 4,5 \\
\hline $\mathrm{Mn}$ & $0,2 \pm 0,1$ & $0,3 \pm 0,07 \mathrm{c}$ & $0,2 \pm 0,02 \mathrm{~b}$ & $0,1 \pm 0,03 \mathrm{a}$ & $9,27^{* *}$ \\
\hline $\mathrm{Al}$ & $59,6 \pm 12,9$ & $59,7 \pm 1,8 \mathrm{~b}$ & $70,8 \pm 13,3 \mathrm{c}$ & $48,2 \pm 9,5 \mathrm{a}$ & $9,85^{* *}$ \\
\hline
\end{tabular}

Die Natrium-Gehalte lagen mit $<1 \mathrm{mg} / \mathrm{g}$ niedriger als die nach Scheffer \& Schachtschabel (2010) meist üblichen Bodengehalte zwischen 1 und $10 \mathrm{mg} / \mathrm{g}$. Demnach betragen die Calcium-Gehalte häufig zwischen 1 und $12 \mathrm{mg} / \mathrm{g}$, liegen jedoch in Sandböden und extrem versauerten Waldböden meist tiefer, so dass die hier relativ geringen Gehalte von durchschnittlich 1,2 mg/g nicht überraschen. Die Kalium- (18,1 mg/g), Eisen- (34,3 mg/g) und Mangan-Gehalte $(0,2 \mathrm{mg} / \mathrm{g})$ liegen innerhalb der bei Scheffer \& Schachtschabel (2010) recht weit gesteckten Rahmen üblicher Gehalte (K: meist zwischen 2 und $33 \mathrm{mg} / \mathrm{g}$; Fe: 2-50 mg/g, Mn: 0,04-1 mg/g). Der im Haldenboden gemessene Magnesium-Gehalt ist mit 5,3 mg/g demnach vergleichsweise hoch, da (salz- u. carbonatarme) mitteleuropäische Böden meist Werte zwischen 0,5 und $5 \mathrm{mg} / \mathrm{g}$ aufweisen. Der Aluminium-Gehalt bewegt sich mit im Schnitt $60 \mathrm{mg} / \mathrm{g}$ im Rahmen der bei Rehfuess (1990) angegebenen Gesamtgehalte in Mineralböden von 41-110 mg/g Alt.

\subsubsection{Effektive Kationen-Austauschkapazität}

An Austauschern (negativ geladenen Bodenteilchen) adsorbierte Ionen stellen für Pflanzen die wichtigste Quelle relativ leicht verfügbarer Nährstoffkationen dar (AK Standortskartierung 2003). Mit der effektiven Kationen-Austauschkapazität $\left(\mathrm{AK}_{\mathrm{e}}\right)$, der Austauscherbelegung und der Basen-Sättigung lassen sich die basischen Nährstoffvorräte in Böden, die Pflanzen nur in Form von austauschbaren Kationen als Nährstoffe zur Verfügung stehen, quantifizieren.

Die $\mathrm{AK}_{\mathrm{e}}$ des Haldenbodens betrug durchschnittlich rund $90 \mathrm{mmol}(+) / \mathrm{kg}$ und ist damit als mittel einzustufen (AK Standortskartierung 2003; Werte für B/C-Horizonte). Zwischen den einzelnen Versuchsflächen bestanden teilweise signifikante Unterschiede (s. Tab. 18).

Tab. 18: Effektive Kationen-Austauschkapazität $[\mathrm{mmol}(+) / \mathrm{kg}]$ in der oberen Schicht des Haldenbodens, gesamt sowie getrennt nach Versuchsflächen; MW u. Std.abw.; Ergebnis der Varianzanalyse auf signifikante Unterschiede (F); Buchstaben kennzeichnen homogene Gruppen nach Tukey-Test ( $\mathrm{n}=12$ )

\begin{tabular}{|l|l|l|l|l|l|}
\hline & gesamt & Fläche A & Fläche B & Fläche D & $\mathrm{F}$ \\
\hline $\begin{array}{l}\mathrm{AK} \\
{[\mathrm{mmol}(+) / \mathrm{kg}]}\end{array}$ & $87,9 \pm 44,5$ & $\begin{array}{l}99,2 \pm 37,0 \\
\mathrm{~b}\end{array}$ & $\begin{array}{l}118,6 \pm 45,0 \\
\mathrm{~b}\end{array}$ & $\begin{array}{l}45,9 \pm 8,5 \\
\mathrm{a}\end{array}$ & $4,9 *$ \\
\hline
\end{tabular}

Die $\mathrm{AK}_{\mathrm{e}}$ der Proben von Fläche A und B lagen mit durchschnittlich 99,2 bzw. 118,6 mmol(+)/kg Boden ebenfalls im mittleren Bewertungsbereich. Dagegen wiesen die Proben von Fläche D im Durchschnitt eine $\mathrm{AK}_{\mathrm{e}}$ von 45,9 mmol( + )/kg Boden auf, was als niedrig bis mittel bewertet wird. Zwischen Bereichen mit und ohne Spontanvegetation konnten hinsichtlich der $\mathrm{AK}_{\mathrm{e}}$ keine signifikanten Unterschiede festgestellt werden. Die 2002 durchgeführte Bodenanalyse der 
Thüringer Landesanstalt für Wald und Forstwirtschaft (LAWuF Gotha 2002) ergab etwas höhere $\mathrm{AK}_{\mathrm{e}}$ im mittleren und mittleren bis hohen Bewertungsbereich.

\subsubsection{Austauscherbelegung}

Bei Betrachtung der relativen Austauscherbelegung (s. Tab. 19) fällt auf, dass die Einzelsättigungswerte für Kalium und Calcium in bewachsenen Bereichen (ca. 2,8 \% und 44,1 \%) signifikant höher lagen als in unbewachsenen Bereichen (ca. 0,6 \% und 14,6 \%). Für Eisen, Mangan und Aluminium waren sie dagegen in spontan besiedelten Bereichen signifikant niedriger $(0,14 \%, 0,8 \%$ und 28,3 \%) als in vegetationsfreien Bereichen $(1,4 \%, 1,2 \%$ und 53,9 $\%)$. Die bewachsenen Bereiche wiesen damit eine günstigere Nährstoffverfügbarkeit auf.

Tab. 19: Austauscherbelegung, Basen-Sättigung (BS), Erdalkali-Sättigung (ES) sowie Summe der Protonen- u. Eisen-Sättigungen [\% der $\mathrm{AK}_{\mathrm{e}}$ ] in der oberen Schicht des Haldenbodens, gesamt sowie getrennt nach Bereichen o./m. Spontanvegetation; MW u. Std.abw.; Ergebnisse von U-Tests (Z) auf signifikante Unterschiede $(\mathrm{n}=12)$

\begin{tabular}{|l|l|l|l|l|}
\hline$\%$ der $\mathrm{AK}_{\mathrm{e}}$ & gesamt & Ohne Spontanvegetation & Mit Spontanvegetation & $\mathrm{Z}$ \\
\hline $\mathrm{H}$ & $5,4 \pm 5,0$ & $6,6 \pm 3,2$ & $4,2 \pm 6,3$ & $-1,6$ \\
\hline $\mathrm{Na}$ & $0,35 \pm 0,35$ & $0,37 \pm 0,45$ & $0,33 \pm 0,27$ & $-0,5$ \\
\hline $\mathrm{K}$ & $1,7 \pm 1,6$ & $0,6 \pm 0,18$ & $2,8 \pm 1,6$ & $-2,7^{* *}$ \\
\hline $\mathrm{Ca}$ & $29,4 \pm 25,9$ & $14,6 \pm 12,8$ & $44,1 \pm 28,1$ & $-1,8^{*}$ \\
\hline $\mathrm{Mg}$ & $20,4 \pm 13,0$ & $21,3 \pm 15,0$ & $19,4 \pm 12,1$ & $-0,3$ \\
\hline $\mathrm{Fe}$ & $0,8 \pm 1,0$ & $1,4 \pm 1,1$ & $0,14 \pm 0,16$ & $-2,4^{* *}$ \\
\hline $\mathrm{Mn}$ & $1,0 \pm 0,4$ & $1,2 \pm 0,4$ & $0,8 \pm 0,2$ & $-1,8^{*}$ \\
\hline $\mathrm{Al}$ & $41,1 \pm 24,0$ & $53,9 \pm 13,2$ & $28,2 \pm 26,3$ & $-1,9^{*}$ \\
\hline $\mathrm{BS}$ & $51,8 \pm 25,9$ & $36,9 \pm 11,8$ & $66,7 \pm 28,3$ & $-1,9^{*}$ \\
\hline $\mathrm{ES}$ & $49,7 \pm 25,0$ & $35,9 \pm 11,3$ & $63,6 \pm 28,1$ & $-1,8^{*}$ \\
\hline $\mathrm{H}+\mathrm{Fe}$ & $6,2 \pm 5,5$ & $8,0 \pm 4,3$ & $4,3 \pm 6,4$ & $-1,6$ \\
\hline
\end{tabular}

Während in den unbewachsenen Böden die Al-Ionen den größten Anteil an der Austauscherbelegung hatten, waren es in bewachsenen Böden die Ca-Ionen. Hier besteht ein Zusammenhang mit den im Freiland gemessenen pH-Werten, die auf vegetationsfreien Teilflächen signifikant niedriger lagen als auf besiedelten Teilflächen (s. S. 44).

Trennt man die Daten zur relativen Austauscherbelegung nach den drei Versuchsflächen, so ergeben sich bei den Einzelsättigungswerten für Natrium und Magnesium signifikante Unterschiede (s. Tab. 20). Auf Fläche A (0,12 \%) und B (0,16 \%) lag der Anteil der Na-Ionen signifikant um ein Vielfaches unter dem Wert auf Fläche D (0,77 \%). Der Anteil der Mg-Ionen war auf Fläche A (8 \%) signifikant um das 4-fache geringer als auf Fläche D $(33,7 \%)$.

Insgesamt sind die Magnesium-Sättigungen im Vergleich zu den meisten Waldböden recht hoch, vor allem im Hinblick auf die niedrigen pH-Werte und die entsprechende Ionenkonkurrenz. Auch war der Magnesium-Anteil an der Austauscherbelegung teilweise höher als der CalciumAnteil. 
Tab. 20: Austauscherbelegung, Basen-Sättigung (BS), Erdalkali-Sättigung (ES) sowie Summe der Protonen- $u$. Eisen-Sättigungen [\% der $\left.\mathrm{AK}_{\mathrm{e}}\right]$ in der oberen Schicht des Haldenbodens, gesamt sowie getrennt nach Versuchsflächen; MW u. Std.abw.; Ergebnisse von H-Tests [H] auf signifikante Unterschiede; Buchstaben kennzeichnen je Zeile homogene Gruppen nach U-Tests $(n=12)$

\begin{tabular}{|l|l|l|l|l|l|}
\hline \% der $\mathrm{AK}_{\mathrm{e}}$ & gesamt & Fläche A & Fläche B & Fläche D & $\mathrm{H}$ \\
\hline $\mathrm{H}$ & $5,4 \pm 5,0$ & $3,7 \pm 3,5$ & $3,9 \pm 4,7$ & $8,6 \pm 5,9$ & 1,3 \\
\hline $\mathrm{Na}$ & $0,35 \pm 0,35$ & $0,12 \pm 0,09 \mathrm{a}$ & $0,16 \pm 0,12 \mathrm{a}$ & $0,77 \pm 0,29 \mathrm{~b}$ & $14,4^{* *}$ \\
\hline $\mathrm{K}$ & $1,7 \pm 1,6$ & $1,0 \pm 0,7$ & $2,2 \pm 2,4$ & $2,0 \pm 1,4$ & 0,6 \\
\hline $\mathrm{Ca}$ & $29,4 \pm 25,9$ & $51,7 \pm 27,8$ & $16,7 \pm 21,6$ & $19,7 \pm 14,8$ & 3,1 \\
\hline $\mathrm{Mg}$ & $20,4 \pm 13,0$ & $8,0 \pm 5,4 \mathrm{a}$ & $19,4 \pm 10,5 \mathrm{a}, \mathrm{b}$ & $33,7 \pm 6,4 \mathrm{~b}$ & $11,0^{* *}$ \\
\hline $\mathrm{Fe}$ & $0,8 \pm 1,0$ & $0,6 \pm 0,8$ & $0,9 \pm 1,5$ & $0,7 \pm 0,8$ & 0,1 \\
\hline $\mathrm{Mn}$ & $1,0 \pm 0,4$ & $0,8 \pm 0,2$ & $1,1 \pm 0,6$ & $1,0 \pm 0,2$ & 0,6 \\
\hline $\mathrm{Al}$ & $41,1 \pm 24,0$ & $34,0 \pm 25,5$ & $55,7 \pm 30,6$ & $33,5 \pm 9,5$ & 1,2 \\
\hline $\mathrm{BS}$ & $51,8 \pm 25,9$ & $60,9 \pm 29,3$ & $38,4 \pm 33,0$ & $56,2 \pm 11,8$ & 0,8 \\
\hline $\mathrm{ES}$ & $49,7 \pm 25,0$ & $59,7 \pm 28,8$ & $36,1 \pm 30,8$ & $53,4 \pm 11,0$ & 2,9 \\
\hline $\mathrm{H}+\mathrm{Fe}$ & $6,2 \pm 5,5$ & $4,3 \pm 4,3$ & $4,8 \pm 6,3$ & $9,3 \pm 5,6$ & 2,3 \\
\hline
\end{tabular}

In der 2002 durchgeführten Bodenanalyse der Thüringer Landesanstalt für Wald und Forstwirtschaft wurden für Aluminium-, Calcium- und Magnesium-Kationen durchschnittliche Einzelsättigungswerte (in \% von der $\mathrm{AK}_{\mathrm{e}}$ ) ermittelt, die mit den in der vorliegenden Arbeit gemessenen Durchschnittswerten etwa übereinstimmen (LAWuF Gotha 2002).

\subsubsection{Basen-Sättigung}

Die Basen-Sättigung (Summe der Anteile von Na, K, Ca, Mg an der Austauscherbelegung) lag insgesamt im Mittel bei 51,8 \% (s. Tab. 19), was im Deutschen Waldbodenbericht (BMELF 1997b) als mäßig hoch einzustufen ist und laut Ak Standortskartierung (2003) als basenreich bezeichnet wird. Hinsichtlich der drei Versuchsflächen unterschied sich die Basen-Sättigung (BS) nicht signifikant, wohl aber hinsichtlich der Aufteilung in Bereiche ohne und mit Spontanvegetation. Auf vegetationsfreien Teilflächen war die BS mit 36,9\% als mittel zu bewerten, während sie auf mit Pflanzen besiedelten Teilflächen mit 66,7 \% deutlich höher im mäßig hohen bzw. basenreichen Bewertungsbereich lag. Die von der Thüringer Landesanstalt für Wald und Forstwirtschaft im Jahr 2002 ermittelte durchschnittliche BS entsprach ziemlich genau dem oben genannten Mittelwert (LAWuF Gotha 2002).

\subsubsection{Vergleich Nährelement-Gehalte und Nährelement-Sättigungen}

Der relative Anteil der verschiedenen Nährelement-Kationen an der Austauscherbelegung hing kaum vom jeweiligen Nährelement-Gehalt ab; hier spielten andere Bodenfaktoren eine Rolle. So bestanden trotz deutlich unterschiedlicher Element-Gehalte im Boden (s. Tab. 17) bei der relativen Austauscher-Belegung mit Kalium- und Calcium-Kationen sowie mit Mangan- und Aluminium-Kationen keine signifikanten Unterschiede zwischen den drei Versuchsflächen (s. Tab. 20). Im Fall von Natrium und Magnesium wurden auf Fläche D mit den signifikant geringsten Element-Gehalten sogar die signifikant höchsten Anteile an der Austauscherbelegung ermittelt (Na: 0,77 \%, Mg: 33,7\%). 
Andererseits unterschieden sich bei keinem Element die Gehalte im Boden nach Bereichen mit und ohne Spontanvegetation - die Anteile ihrer Kationen an der relativen Austauscherbelegung waren dagegen je nach Bereich signifikant unterschiedlich hoch (s. Tab. 19). Dies ist auf die ebenfalls signifikant unterschiedlichen pH-Werte zurückzuführen (s. S. 44), da die Verfügbarkeit der verschiedenen Elemente im Boden stark von der jeweiligen Bodenreaktion abhängig ist (Scheffer \& Schachtschabel 2010).

\subsubsection{Elastizität gegenüber Säurebelastung}

Neben der Basen-Sättigung (BS) geben auch die Summe der Calcium- und MagnesiumSättigungen (Erdalkali-Sättigung), jeweils die Magnesium- und Kalium-Sättigung sowie die Summe der Protonen- und Eisen-Sättigungen Aufschluss über die Elastizität eines Bodens gegenüber Säurebelastung (AK Standortskartierung 2003).

Tab. 21: Bewertung (= Elastizität gegenüber Säurebelastung) der relativen Austauscherbelegung bezogen auf die $\mathrm{AK}_{\mathrm{e}}$ im Haldenboden nach $\mathrm{AK}$ Standortskartierung (2003), gesamt sowie getrennt nach Bereichen o./m. Spontanvegetation; Fettdruck markiert signifikante Unterschiede $(\mathrm{n}=12)$

\begin{tabular}{|l|l|l|l|}
\hline Anteil an AK $\mathbf{e}[\%]$ & Gesamt & $\begin{array}{l}\text { Ohne } \\
\text { Spontanvegetation }\end{array}$ & $\begin{array}{l}\text { Mit } \\
\text { Spontanvegetation } \\
\text { mäßig hoch }\end{array}$ \\
\hline (BS) Basen-Sättigung & mäßig hoch & mittel & mäßig hoch \\
\hline (ES) Erdalkali-Sättigung & mittel & mittel & sehr hoch \\
\hline Mg-Sättigung & sehr hoch & sehr hoch & mittel \\
\hline K-Sättigung & gering & sehr gering & gering \\
\hline $\mathrm{H}^{+}+$Fe-Sättigung & gering & gering & \\
\hline
\end{tabular}

Tab. 22: Bewertung (= Elastizität gegenüber Säurebelastung) der relativen Austauscherbelegung bezogen auf die $\mathrm{AK}_{\mathrm{e}}$ im Haldenboden nach $\mathrm{AK}$ Standortskartierung (2003), gesamt sowie getrennt nach Versuchsflächen; Fettdruck markiert signifikante Unterschiede $(\mathrm{n}=12)$

\begin{tabular}{|l|l|l|l|l|}
\hline Anteil an AK $\mathbf{e}[\%]$ & Gesamt & Fläche A & Fläche B & Fläche D \\
\hline (BS) Basen-Sättigung & mäßig hoch & mäßig hoch & mittel & mäßig hoch \\
\hline (ES) Erdalkali-Sättigung & mittel & mäßig hoch & mittel & mäßig hoch \\
\hline Mg-Sättigung & sehr hoch & hoch - sehr hoch & sehr hoch & sehr hoch \\
\hline K-Sättigung & gering & sehr gering - gering & mittel & gering - mittel \\
\hline $\mathrm{H}^{+}+$Fe-Sättigung & gering & gering & gering & gering \\
\hline
\end{tabular}

\section{Basen-Sättigung}

Ausgehend von der beschriebenen Basen-Sättigung (BS) ist die Elastizität des Haldenbodens gegenüber weiterer Versauerung als mittel bis mäßig hoch einzustufen. Die je nach Bodenbewuchs signifikant unterschiedlich hohen BS führen zu einer mittleren Bewertung in Bereichen ohne und einer mäßig hohen Bewertung in Bereichen mit Spontanvegetation (s. Tab. 21). 
Deutscher Waldbodenbericht (BMELF 1997a):

„...Die Basen-Sättigung eignet sich als Indikator für die Säureneutralisationskapazität der Böden und kann bei Berücksichtigung des Ausgangssubstrates zur Beurteilung der Versauerung und Elastizität gegenüber weiteren Säureeinträgen dienen. Bei konstantem pH können im Boden sehr unterschiedliche Basen-Sättigungsgrade vorliegen. Der pHWert allein stellt mithin nur einen unzureichenden Indikator für das Ausmaß der tatsächlichen Bodenversauerung dar...."

\section{Erdalkali-Sättigung}

Die Erdalkali-Sättigung (ES) weist sowohl insgesamt (49,8 \%) als auch bei einzelner Betrachtung der Bereiche ohne und mit Bodenbewuchs sowie der drei Versuchsflächen auf eine mittlere bis mäßig hohe Säureelastizität hin. In Bereichen ohne Bodenvegetation war die ES mit 35,9\% (mittlere Elastizität) signifikant geringer als in Bereichen mit Bodenvegetation mit 63,5\% (mäßig hohe Elastizität). Zwischen den einzelnen Versuchsflächen gab es keine signifikanten Unterschiede.

\section{Magnesium- sowie Kalium-Sättigung}

Die sowohl gesamt als auch in Bereichen ohne und mit Spontanbewuchs sowie auf jeder der drei Versuchsflächen vergleichsweise hohen Anteile an Magnesium-Ionen an der Austauscherbelegung führen $\mathrm{zu}$ einer sehr hohen diesbezüglichen Bewertung der Säureelastizität. Zwischen den auf Fläche A (8,0 \%: hoch - sehr hoch) und Fläche D (33,7 \%: sehr hoch) ermittelten Anteilen bestand ein signifikanter Unterschied (s. Tab. 22).

Bei Betrachtung des Faktors Anteil der Kalium-Ionen an der Austauscherbelegung ergaben sich signifikante Unterschiede zwischen Bereichen ohne und mit Spontanvegetationsbesiedelung, während die Unterschiede zwischen den drei Versuchsflächen nicht signifikant waren. Ohne Bewuchs (niedrigerer pH-Wert; höhere Al-Sättigung) ist die Bodenelastizität gegenüber Säurebelastung bei einem Kalium-Ionenanteil von 0,6 \% als sehr gering zu bewerten. In bewachsenen Bereichen (höherer pH-Wert; niedrigere Al-Sättigung) lag der Kalium-Ionenanteil dagegen bei 2,8 \%, was als mittel einzustufen ist (Gesamtdurchschnitt: 1,7 \% = gering).

\section{Summe der Protonen- und Eisen-Sättigungen}

Die Summe der Anteile austauschbarer Eisen-Ionen und Protonen an der $\mathrm{AK}_{\mathrm{e}}$ gilt als der Kennwert für die Elastizität des Bodens gegenüber Säurebelastung. Diese Summe betrug für den Haldenboden insgesamt 6,2 \%. Zwischen Bereichen ohne und mit Spontanvegetation und zwischen den drei Versuchsflächen gab es keine signifikanten Unterschiede. Alle gemessenen Summen lagen in einem Wertebereich zwischen 2,0 \% und 10,0\%, somit ist die Elastizität des Bodens gegenüber weiterer Säurebelastung in allen Bereichen der Versuchsflächen als gering zu bewerten (BMELF 1997b).

Zum Abschluss dieses Kapitels ist der vielfach deutlich gewordene Einfluss der heterogenen Bodenbedingungen auf den Ronneburger Tagebaufolgeflächen in Tab. 23 nochmals zusammengefasst. 
Tab. 23: Kleinräumiger Standorteinfluss auf die bodenchemischen Eigenschaften des Ronneburger Haldensubstrats

\begin{tabular}{|c|c|c|}
\hline \multirow{2}{*}{ Boden-Parameter } & \multicolumn{2}{|c|}{ Signifikante Unterschiede je nach } \\
\hline & Versuchsfläche & Bodenvegetation \\
\hline pH-Wert & nein & mit $>$ ohne \\
\hline S-Gehalt & nein & nein \\
\hline Zn-Gehalt & $\mathrm{B}>\mathrm{D}$ & nein \\
\hline Cu-Gehalt & $\mathrm{A}>\mathrm{B}, \mathrm{D}$ & nein \\
\hline Pb-Gehalt & $\mathrm{D}>\mathrm{A}, \mathrm{B}$ & nein \\
\hline Cd-Gehalt & nein & nein \\
\hline Cr-Gehalt & nein & nein \\
\hline Ni-Gehalt & nein & nein \\
\hline Co-Gehalt & $A>D$ & nein \\
\hline C-Gehalt & $A>B, D$ & nein \\
\hline N-Gehalt & $\mathrm{D}>\mathrm{B}$ & nein \\
\hline C/N-Verhältnis & $\mathrm{A}>\mathrm{B}, \mathrm{D}$ & nein \\
\hline P-Gehalt & $\mathrm{B}>\mathrm{A}>\mathrm{D}$ & nein \\
\hline C/P-Verhältnis & $\mathrm{A}>\mathrm{B}, \mathrm{D}$ & nein \\
\hline Na-Gehalt & $\mathrm{B}>\mathrm{A}>\mathrm{D}$ & nein \\
\hline K-Gehalt & $\mathrm{B}>\mathrm{A}>\mathrm{D}$ & nein \\
\hline Ca-Gehalt & $\mathrm{A}>\mathrm{B}>\mathrm{D}$ & nein \\
\hline Mg-Gehalt & $A, B>D$ & nein \\
\hline Fe-Gehalt & nein & nein \\
\hline Mn-Gehalt & $A>B>D$ & nein \\
\hline Al-Gehalt & $\mathrm{B}>\mathrm{A}>\mathrm{D}$ & nein \\
\hline $\mathrm{AK}_{\mathrm{e}}$ & $\mathrm{A}, \mathrm{B}>\mathrm{D}$ & nein \\
\hline H-Sättigung & nein & nein \\
\hline Na-Sättigung & $\mathrm{D}>\mathrm{A}, \mathrm{B}$ & nein \\
\hline K-Sättigung & nein & mit > ohne \\
\hline Ca-Sättigung & nein & mit > ohne \\
\hline Mg-Sättigung & $\mathrm{D}>\mathrm{A}$ & nein \\
\hline Fe-Sättigung & nein & ohne $>$ mit \\
\hline Mn-Sättigung & nein & ohne $>$ mit \\
\hline Al-Sättigung & nein & ohne $>$ mit \\
\hline Basen-Sättigung & nein & mit > ohne \\
\hline Erdalkali-Sättigung & nein & mit > ohne \\
\hline H- + Fe-Sättigung & nein & nein \\
\hline
\end{tabular}




\section{Topf-Versuche - Effekte der Bodenhilfsstoffe auf die Bodeneigenschaften}

Zum Ende des dreijährigen Topf-Versuchs (s. ab S. 30) wurde gemäß den Arbeitshypothesen (s. S. 10) untersucht, inwieweit die eingesetzten Bodenhilfsstoffe Einfluss auf bodenphysikalische und bodenchemische Parameter des Haldensubstrats hatten.

Zusätzlich wurden die Analyseergebnisse der Nullvariante im Gewächshaus und des unbehandelten Substrats der Freiland-Versuchsflächen (s. S. 17) miteinander verglichen, um so Auskunft über die Übertragbarkeit der Ergebnisse des Topf-Versuchs auf Freiland-Bedingungen zu erhalten.

So konnte durch die Lockerung bei Gewinnung und Transport des Substrats sowie der Versuchsanlage eine veränderte Bodenstruktur (Dichte und Porenvolumen) gegenüber dem vor Jahren auf den Freiland-Versuchsfläche verschütteten, durch Transportmaschinen verdichteten Bodens erwartet werden.

Vor allem war auch wahrscheinlich, dass sich verschiedene Element-Gehalte des Bodens nach drei Vegetationszeiten im Topf durch Verbrauch, Auswaschung und fehlende Nachlieferung gegenüber dem „Ausgangszustand“ im Freiland verändert hatten.

Generell ließ sich durch die Topf-Versuche jedoch ermitteln, welche Bodenhilfsstoffe einen positiven (oder negativen) Einfluss auf welche Bodenparameter hatten.

\subsection{Effekte der Bodenhilfsstoffe auf die physikalischen Bodeneigenschaften} Skelettgehalt und Textur (Korngrößenzusammensetzung, Bodenartenuntergruppe) des für die Topf-Versuche verwendeten Haldensubstrats sind auf Seite 39 beschrieben. Die bodenphysikalischen Kennwerte Trockenraumdichte und Gesamtporenvolumen veränderten sich durch den Einsatz von Kompost oder Perlit deutlich. Auf den volumetrischen Wassergehalt des Haldensubstrats hatte die Verwendung von Perlit und teilweise von Wasserspeichersubstanzen Einfluss (s. Tab. 24). Keinen Effekt auf die bodenphysikalischen Parameter hatten dagegen erwartungsgemäß die Zugaben von Kalk oder Mykorrhiza, so dass auf die Darstellung der diesbezüglichen Untersuchungsergebnisse verzichtet wurde.

Tab. 24: Trockenraumdichten (TRD) $\left[\mathrm{g} / \mathrm{cm}^{3}\right]$, Gesamtporenvolumina (GPV) [Vol.-\%] u. volumetrischer Wassergehalt (Vol. WG) [\%] im Freiland-Versuch $u$. in verschiedenen Varianten im Topf-Versuch nach 3 Jahren; MW u. Std.abw.; Ergebnisse von H-Tests [H] auf signifikante Unterschiede; Buchstaben kennzeichnen je Spalte homogene Gruppen nach U-Tests

\begin{tabular}{|l|l|l|l|l|}
\hline Versuch & Variante (n) & TRD [g/cm ${ }^{\mathbf{3}}$ ] & GPV [Vol.-\%] & Vol. WG [Vol.-\%] \\
\hline Freiland & unbehandelt (16) & $1,5 \pm 0,16 \mathrm{~d}$ & $43 \pm 6 \mathrm{a}$ & $17 \pm 4 \mathrm{a}$ \\
\hline \multirow{4}{*}{ Topf } & Kontrolle (6) & $1,3 \pm 0,01 \mathrm{c}$ & $51 \pm 1 \mathrm{~b}$ & $28 \pm 1 \mathrm{c}$ \\
\cline { 2 - 5 } & Stockosorb® (4) & $1,3 \pm 0,04 \mathrm{c}$ & $51 \pm 2 \mathrm{~b}$ & $29 \pm 2 \mathrm{c}$ \\
\cline { 2 - 5 } & Superabsorber (5) & $1,3 \pm 0,03 \mathrm{c}$ & $51 \pm 1 \mathrm{~b}$ & $25 \pm 2 \mathrm{~b}$ \\
\cline { 2 - 5 } & Kompost (4) & $1,1 \pm 0,02 \mathrm{~b}$ & $56 \pm 1 \mathrm{c}$ & $29 \pm 1 \mathrm{c}$ \\
\cline { 2 - 5 } & Perlit (6) & $0,9 \pm 0,05 \mathrm{a}$ & $66 \pm 2 \mathrm{~d}$ & $26 \pm 1 \mathrm{~b}$ \\
\hline $\mathrm{H}$ & & $31,42^{* * *}$ & $31,42^{* * *}$ & $33,15^{* * *}$ \\
\hline
\end{tabular}




\subsubsection{Trockenraumdichte}

Die Trockenraumdichte (TRD) des Haldensubstrats im Topf-Versuch (Kontrolle) lag mit 1,3 $\mathrm{g} / \mathrm{cm}^{3}$ signifikant unterhalb der TRD des Haldensubstrats auf den Freiland-Versuchsflächen, das bei seiner Anschüttung durch den Aufprall aus großer Höhe (Absetzanlage) und das Befahren mit schwerem Gerät verdichtet wurde und eine durchschnittliche TRD von 1,5 g/ $\mathrm{cm}^{3}$ (maximal $1,8 \mathrm{~g} / \mathrm{cm}^{3}$ ) aufwies (s. Abb. 7). Bodendichten von $1,3 \mathrm{~g} / \mathrm{cm}^{3}$ werden laut AK Standortskartierung (2003) und Ad-hoc-AG Boden (2005) als gering, von 1,5 g/ $\mathrm{cm}^{3}$ als mittel eingestuft.

Die Zugabe von Stockosorb® oder Superabsorber führte im Topf-Versuch gegenüber der Kontrolle zu keiner Veränderung der Trockenraumdichte (s. Tab. 24). Die Substratmischungen mit Perlit und Kompost zeigten dagegen signifikant niedrigere Bodendichten, die bei der Kompostvariante bei $1,1 \mathrm{~g} / \mathrm{cm}^{3}$ lag und bei der Perlit-Variante mit $0,9 \mathrm{~g} / \mathrm{cm}^{3}$ am niedrigsten war. Laut AK Standortskartierung (2003) und Ad-hoc-AG Boden (2005) sind diese Bodendichten als sehr gering zu bewerten.

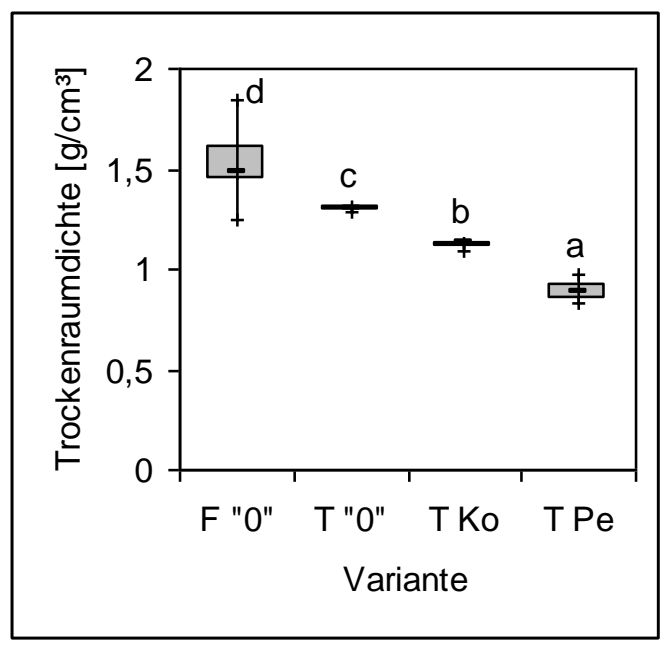

Abb. 7: Trockenraumdichten [g/ $\left.\mathrm{cm}^{3}\right]$ im Freiland-Versuch (F "0“; n=16) u. im Topf-Versuch in der Null- (T „0“; n=6), Kompost- (T Ko; n=4) u. Perlit-Variante (T Pe; n=6) nach 3 Jahren; Mediane, 25. u. 75. Perzentil (die Box repräsentiert $50 \%$ der Werte), Spannweite (5. und 95. Perzentil), Minimum und Maximum; Buchstaben kennzeichnen homogene Gruppen nach U-Tests

\subsubsection{Gesamtporenvolumen}

Ebenso wie bei der Trockenraumdichte bestanden auch beim Gesamtporenvolumen signifikante Unterschiede zwischen dem durch die Versuchsanlage gelockerten Haldensubstrat im TopfVersuch und dem verdichteten Boden der Freiland-Versuchsflächen. Die unbehandelte Kontrolle im Gewächshaus wies mit 51 Vol.-\% ein signifikant höheres Gesamtporenvolumen auf als die Freiland-Proben mit 43 Vol.-\% (s. Abb. 8). Die Gesamtporenvolumina in den mit Kompost bzw. Perlit gemischten Substraten waren mit 56 Vol.-\% bzw. 66 Vol.-\% jeweils signifikant höher als die der anderen Varianten.

Aufgrund der relativ groben Struktur der beiden Bodenhilfsstoffe ist dabei von einem Anstieg vor allem des Grobporenanteils auszugehen. Beobachtungen bestätigten ein im Vergleich zur Kontrolle wesentlich schnelleres Versickern des Gießwassers in mit Kompost bzw. Perlit gemischtem Substrat (mit Perlit schneller als mit Kompost), was auf eine verbesserte Infiltrations- und Wasserleitfähigkeit schließen lässt. 


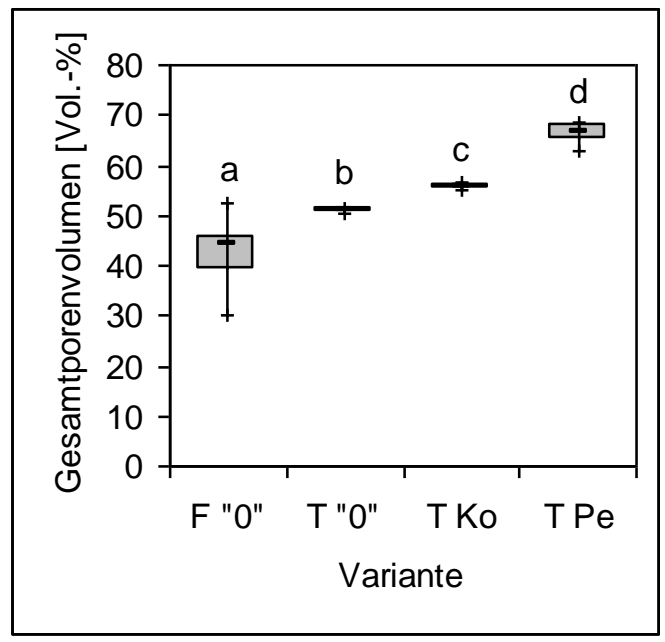

Abb. 8: Gesamtporenvolumina [Vol.-\%] im Freiland-Versuch (F “0“; n=16) u. im Topf-Versuch in der Null(T „0“; n=6), Kompost- (T Ko; n=4) u. Perlit-Variante (T Pe; n=6) nach 3 Jahren; Mediane, 25. u. 75. Perzentil (die Box repräsentiert 50 \% der Werte), Spannweite (5. und 95. Perzentil), Minimum und Maximum; Buchstaben kennzeichnen homogene Gruppen nach U-Tests

\subsubsection{Volumetrischer Wassergehalt (Bodenfeuchte)}

Die Gegenüberstellung der volumetrischen Wassergehalte der Freiland- und Gewächshausproben verdeutlichte die Unmöglichkeit eines solchen Vergleichs aufgrund der völlig unterschiedlichen Bedingungen. So fand die Probenahme im Freiland 2 - 3 Tage nach einer Regenperiode statt. Für die Untersuchung der Topf-Versuche wurden die Töpfe dagegen mit Wasser gesättigt und 24 Stunden später gewogen.

Die Wasseraufnahme war dabei höchst unterschiedlich: Im Freiland floss der Niederschlag großenteils oberflächlich ab, was auf eine geringe Infiltrations- und Wasserleitfähigkeit hinweist. Auf den Topfoberflächen stand das Gießwasser je nach Variante teilweise sehr lange, bis schließlich alles versickert war (oberflächiges Abfließen war hier nicht möglich).

Entsprechend wiesen alle untersuchten Varianten im Topf-Versuch signifikant höhere volumetrische Wassergehalte auf als die unbehandelten Freiland-Proben mit durchschnittlich 17 Vol.-\%. Innerhalb der Topf-Versuche bewirkte die Beimischung von Kompost (29 Vol.-\%) oder Stockosorb® (29 Vol.-\%) keine signifikante Veränderung des volumetrischen Wassergehaltes gegenüber der Nullvariante (28 Vol.-\%). Dagegen wies das mit Perlit oder Superabsorber versetzte Haldensubstrat mit 26 Vol.-\% bzw. 25 Vol.-\% signifikant geringere volumetrische Wassergehalte auf (s. Abb. 9).

Legt man den anhand von Freiland-Proben ermittelten Bereich pflanzenverfügbaren Wassers (nutzbare Feldkapazität = nFK; s. S. 42) des Haldensubstrats zugrunde, der etwa von 21 bis 30 Vol.-\% reichte, so enthielten alle Töpfe zum Zeitpunkt der Probennahme pflanzenverfügbares Wasser. Demnach wurde im Fall der Kontrollen, der Kompost- und der Stockosorb®-Varianten die maximale nFK des Haldenbodens im Freiland-Versuch erreicht, im Fall der Perlit- und Superabsorber-Varianten etwa zwei Drittel des Freiland-Maximums. Es muss jedoch beachtet werden, dass generell in Töpfen mehr pflanzenverfügbares Wasser gehalten werden kann als im Freiland (Beese 2007). 


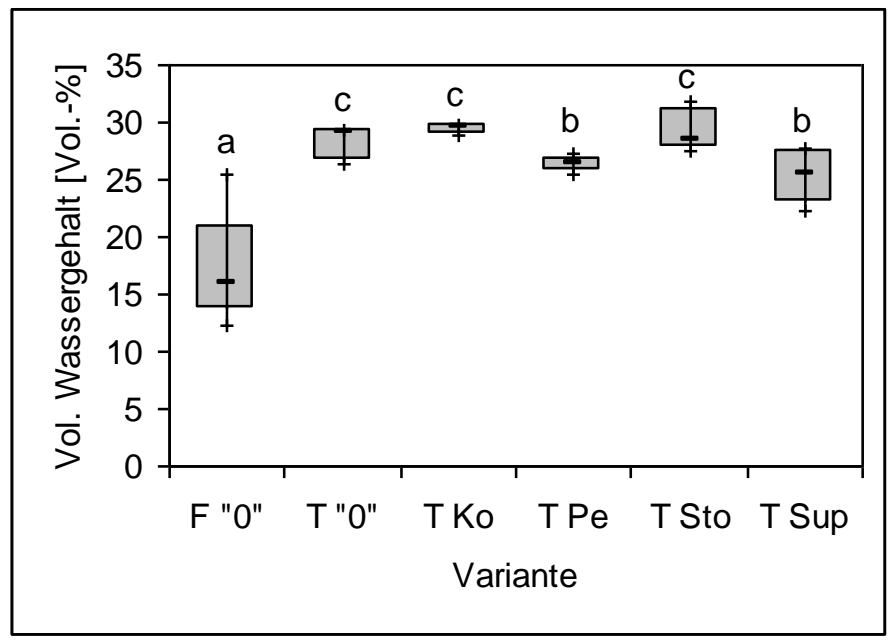

Abb. 9: Volumetrischer Wassergehalt [\%] im Freiland-Versuch (F “0“; n=16) u. im Topf-Versuch in der Null- (T „0“; n=6), Kompost- (T Ko; n=4), Perlit- (T Pe; n=6), Stockosorb®- (T Sto; n=4) u. SuperabsorberVariante (T Sup; $n=5$ ) nach 3 Jahren; Mediane, 25. u. 75. Perzentil (die Box repräsentiert 50 \% der Werte), Spannweite (5. und 95. Perzentil), Minimum und Maximum; Buchstaben kennzeichnen homogene Gruppen nach U-Tests

\subsection{Effekte der Bodenhilfsstoffe auf die chemischen Bodeneigenschaften}

Die bodenchemischen Bedingungen wurden durch die Zugabe von Kalk oder Kompost zum Haldensubstrat teilweise erheblich beeinflusst, während Stockosorb®, Superabsorber, Perlit oder Mykorrhiza diesbezüglich keine Veränderungen bewirkten. In den folgenden Darstellungen der Analyseergebnisse sind deshalb neben den Kontrollen nur die Kalk- und Kompost-Varianten enthalten.

\subsubsection{Bodenreaktion}

Ein Vergleich des mittleren pH-Wertes der Freiland-Versuchsflächen $(3,6)$ und der Kontrollen im Topf-Versuch nach drei Vegetationszeiten $(3,6)$ ergab keine signifikanten Unterschiede.

Kalk- und Kompost-Gaben konnten den pH-Wert des Haldensubstrats gleichermaßen deutlich auf 5,6 bzw. 5,7 anheben (s. Tab. 25 u. Abb. 10).

Tab. 25: Bodenreaktion (pH-Wert in KCl-Lsg.) im Freiland-Versuch u. in verschiedenen Varianten im TopfVersuch nach 3 Jahren; MW u. Std.abw.; Ergebnis des H-Tests auf signifikante Unterschiede; Buchstaben kennzeichnen homogene Gruppen nach U-Tests

\begin{tabular}{|l|l|l|}
\hline Versuch & Variante (n) & pH (KCl) \\
\hline Freiland & unbehandelt (12) & $3,6 \pm 0,3 \mathrm{a}$ \\
\hline \multirow{3}{*}{ Topf } & Kontrolle (4) & $3,6 \pm 0,1 \mathrm{a}$ \\
\cline { 2 - 3 } & Kalk (12) & $5,6 \pm 0,9 \mathrm{~b}$ \\
\cline { 2 - 3 } & Kompost (6) & $5,7 \pm 0,7 \mathrm{~b}$ \\
\hline H & & $24,71^{* * *}$ \\
\hline
\end{tabular}

Die Bodenreaktion ist damit nur noch als mäßig sauer einzustufen; die Substrate in beiden Behandlungsvarianten lagen im Silikat-Pufferbereich (AK Standortskartierung 2003; Scheffer \& Schachtschabel 2010). In diesem Bereich ist Aluminium im Boden in Form von Aluminium- 
Phosphaten festgelegt. $\mathrm{Al}^{3+}$-Überschuss (und damit Aluminium-Toxizität) lässt sich folglich durch eine Anhebung des pH-Wertes auf über 5/5,5 vermeiden (Bergmann 1993). In Ulrich (1980/81) wird der Silikat-Pufferbereich als ökologisches Optimum bezeichnet.

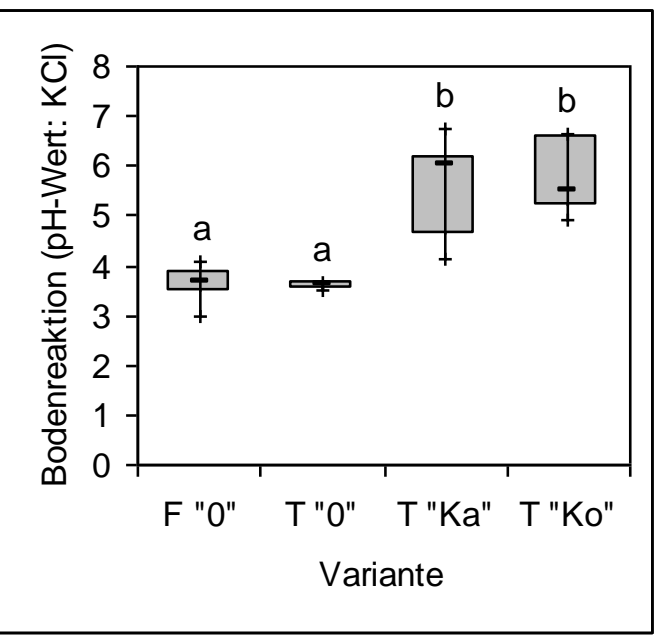

Abb. 10: Bodenreaktion (pH-Wert in KCl-Lsg.) im Freiland-Versuch (F " 0 “; $n=12$ ) u. im Topf-Versuch in der Null- ( $\mathrm{T}$ „0“; $\mathrm{n}=4$ ), Kalk- ( $\mathrm{T}$ „Ka“; $\mathrm{n}=12$ ) u. Kompost-Variante ( $\mathrm{T}$ „Ko“; $\mathrm{n}=6$ ) nach 3 Jahren; Mediane, 25. u. 75. Perzentil (die Box repräsentiert 50 \% der Werte), Spannweite (5. und 95. Perzentil), Minimum und Maximum; Buchstaben kennzeichnen homogene Gruppen nach U-Tests

\subsubsection{Schwefel-Gehalt}

Der mittlere Schwefel-Gehalt in der Nullvariante des Topf-Versuchs zum Ende der Versuchsdauer unterschied sich mit $0,9 \mathrm{mg} / \mathrm{g}$ nicht signifikant von dem im Boden der FreilandVersuchsflächen gemessenen Mittelwert, der bei 1,4 mg/g lag (s. Tab. 26).

Tab. 26: Schwefel-Bodengehalt [mg/g] im Freiland-Versuch u. im Topf-Versuch in der Null-, Kalk- u. Kompost-Variante nach 3 Jahren; MW u. Std.abw.; Ergebnis des H-Tests auf signifikante Unterschiede; Buchstaben kennzeichnen homogene Gruppen nach U-Tests

\begin{tabular}{|l|l|l|}
\hline Versuch & Variante (n) & S [mg/g] \\
\hline Freiland & unbehandelt (12) & $1,4 \pm 0,8 \mathrm{~b}$ \\
\hline \multirow{3}{*}{ Topf } & Kontrolle (4) & $0,9 \pm 0,03 \mathrm{~b}$ \\
\cline { 2 - 3 } & Kalk (12) & $0,7 \pm 0,1 \mathrm{a}$ \\
\cline { 2 - 3 } & Kompost (6) & $0,9 \pm 0,06 \mathrm{~b}$ \\
\hline H & & $12,27^{* *}$ \\
\hline
\end{tabular}

Die Beimischung von Kompost hatte keinen Effekt auf den Schwefel-Gehalt. Die Kalk-Variante wies dagegen signifikant geringere Schwefel-Gehalte von $0,7 \mathrm{mg} / \mathrm{g}$ auf (s. Abb. 11), was jedoch immer noch erheblich über den Gesamt-Schwefel-Gehalten mineralischer Oberböden nach LAWuF Gotha (2002) (meist deutlich unter 0,5 mg/g) bzw. den nach Scheffer \& Schachtschabel (2010) in Böden des humiden Klimabereichs üblichen Schwefel-Gehalten (0,1 - 0,5 mg/g) lag. 


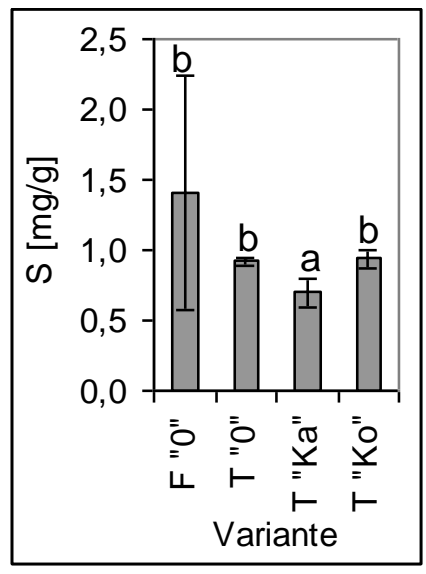

Abb. 11: Schwefel-Bodengehalt [mg/g] im Freiland-Versuch (F “0“; n=12) u. im Topf-Versuch in der Null( $\mathrm{T}$ „0“; $\mathrm{n=4}$ ), Kalk- ( $\mathrm{T}$ „Ka“; $\mathrm{n=12}$ ) u. Kompost-Variante (T Ko; n=6) nach 3 Jahren; MW u. Std.abw.; Buchstaben kennzeichnen homogene Gruppen nach U-Tests

\subsubsection{Schwermetall-Gehalte}

Die Schwermetall-Gehalte im Haldenboden (s. Tab. 27) lagen bzgl. Zink, Cadmium, Chrom und Nickel in der Nullvariante der Topf-Versuche signifikant niedriger als im Freiland-Versuch und entsprachen etwa 77 \% (Zn), 32 \% (Cd), $63 \%$ (Cr) und $49 \%$ (Ni) der im Freiland gemessenen Mittelwerte.

Neben aufgrund der Heterogenität des Haldensubstrats unterschiedlichen Ausgangsbedingungen könnten hierbei Auswaschung und Pflanzenaufnahme bei fehlender Nachlieferung im Verlauf des dreijährigen Topf-Versuchs eine Rolle spielen (vgl. Gehalte austauschbarer Nährelemente). So gelten Zink und Cadmium in sauren Böden als besonders mobil, da sie bereits bei $\mathrm{pH}<6$ stark löslich und entsprechend verlagerbar sind (BMELF 1997a).

Die Kupfer- und Blei-Gehalte unterschieden sich im Freiland- und im Topf-Versuch (unbehandelte Kontrolle) nicht signifikant. Der Kobalt-Gehalt lag dagegen im Topf-Versuch beinahe doppelt so hoch wie der Freiland-Durchschnittswert.

Die zur Bewertung der Schwermetall-Gehalte herangezogenen Quellen finden sich in Anhang 1.

Tab. 27: Schwermetall-Bodengehalte $[\mathrm{mg} / \mathrm{kg}]$ im Freiland-Versuch u. im Topf-Versuch in der Null-, Kalku. Kompost-Variante nach 3 Jahren; MW u. Std.abw.; Ergebnisse von H-Tests [H] auf signifikante Unterschiede; Buchstaben kennzeichnen je Zeile homogene Gruppen nach U-Tests; Fettdruck markiert signifikante Unterschiede gegenüber der Kontrolle im Topf-Versuch

\begin{tabular}{|l|l|l|l|l|l|}
\hline \multirow{2}{*}[\mathrm{mg}/\mathrm{kg}]{} & Freiland (n) & \multicolumn{3}{|l|}{ Topf (n) } & \\
\cline { 2 - 6 } & unbehandelt (12) & Kontrolle (4) & Kalk (12) & Kompost (6) & $\mathrm{H}$ \\
\hline $\mathrm{Zn}$ & $70,9 \pm 18,9 \mathrm{c}$ & $54,8 \pm 2,6 \mathrm{a}$ & $\mathbf{6 2 , 3} \pm \mathbf{7 , 9} \mathbf{~ b}$ & $\mathbf{7 7 , 8} \pm \mathbf{1 4 , 7} \mathbf{~ c}$ & $12,78^{* *}$ \\
\hline $\mathrm{Cu}$ & $103,8 \pm 60,2 \mathrm{a}-\mathrm{c}$ & $106,0 \pm 5,8 \mathrm{a}$ & $\mathbf{1 1 9 , 8} \pm \mathbf{6 , 4} \mathbf{~ b}$ & $\mathbf{1 2 9 , 7} \pm \mathbf{9 , 6} \mathbf{~ c}$ & $7,52^{*}$ \\
\hline $\mathrm{Pb}$ & $22,7 \pm 11,7$ & $27,7 \pm 0,8$ & $27,6 \pm 1,5$ & $29,1 \pm 1,3$ & 3,84 \\
\hline $\mathrm{Cd}$ & $5,9 \pm 2,0 \mathrm{c}$ & $1,9 \pm 0,2 \mathrm{a}, \mathrm{b}$ & $2,0 \pm 0,2 \mathrm{~b}$ & $\mathbf{1 , 7} \pm \mathbf{0 , 3} \mathbf{~ a}$ & $17,22^{* * *}$ \\
\hline $\mathrm{Cr}$ & $85,7 \pm 15,8 \mathrm{c}$ & $54,0 \pm 0,6 \mathrm{~b}$ & $53,2 \pm 1,3 \mathrm{~b}$ & $\mathbf{5 0 , 8} \pm \mathbf{1 , 1} \mathbf{a}$ & $27,01^{* * *}$ \\
\hline $\mathrm{Ni}$ & $60,4 \pm 20,4 \mathrm{~d}$ & $29,9 \pm 1,0 \mathrm{a}$ & $\mathbf{3 4 , 4} \pm \mathbf{2 , 0} \mathbf{~ b}$ & $\mathbf{3 6 , 7} \pm \mathbf{1 , 0} \mathbf{c}$ & $24,68^{* * *}$ \\
\hline $\mathrm{Co}$ & $13,2 \pm 9,5 \mathrm{a}$ & $24,7 \pm 5,1 \mathrm{~b}$ & $25,8 \pm 4,0 \mathrm{~b}$ & $27,6 \pm 3,2 \mathrm{~b}$ & $13,28^{* *}$ \\
\hline
\end{tabular}


Bei Zugabe von Kalk oder Kompost im Topf-Versuch wurden gegenüber der Kontrolle signifikant höhere Zink-, Kupfer- und Nickel-Bodengehalte gemessen, wobei die Gehalte bei Kompostbeimischung signifikant höher waren als bei Kalk-Gaben. Der Grund könnte auch hier eine stärkere Auswaschung und Pflanzenaufnahme in der unbehandelten Kontrolle sein, in der durch den gegenüber den Behandlungsvarianten erheblich geringeren $\mathrm{pH}$-Wert wesentlich mehr Zink, Kupfer und Nickel in Lösung und somit mobil war. Zudem enthält auch Kompost in der Regel Schwermetalle, so dass über eine Kompost-Düngung Schwermetalle eingetragen werden können.

Dagegen war der Chrom-Gehalt in der Kompostvariante leicht, aber signifikant geringer als in der Nullvariante. Bei Blei, Cadmium und Kobalt wurden in den Behandlungsvarianten und der unbehandelten Kontrolle keine signifikant unterschiedlichen Bodengehalte festgestellt (abgesehen von einem gegenüber der Kalkvariante leicht geringeren Cadmium-Gehalt in der Kompostvariante).

Nach dem Bewertungsschlüssel der Österreichischen Waldbodenzustandsinventur (Forstliche Bundesversuchsanstalt 1992) lagen die Zink- und Blei-Gehalte der Varianten des Topf-Versuchs im oberen Normalbereich, die Kupfer-Gehalte entsprachen bereits einer starken Belastung, die Cadmium-Konzentrationen einer Belastung des Bodens. Die Chrom-, Nickel- und KobaltGehalte lagen unterhalb der bei Alloway (1999) genannten Bereiche kritischer Gesamtkonzentrationen.

\subsubsection{Kohlenstoff-, Stickstoff-Gehalte und C/N-Verhältnis}

Die mittleren Kohlenstoff- und Stickstoff-Gehalte (s. Tab. 28) der Kontrollen im Topf-Versuch nach drei Vegetationszeiten lagen mit $8,4 \mathrm{mg} / \mathrm{g}$ und $0,8 \mathrm{mg} / \mathrm{g}$ signifikant höher als die entsprechenden im Freiland gemessenen Durchschnittswerte, waren aber wie diese äußerst gering. Auch das C/N-Verhältnis war mit 10,2 signifikant höher, lag aber ebenfalls im engen und damit günstigen Bewertungsbereich (AK Standortskartierung 2003, Scheffer \& Schachtschabel 2010).

Tab. 28: Kohlenstoff-, Stickstoff-Bodengehalte [mg/g] u. C/N-Verhältnisse im Freiland-Versuch u. im TopfVersuch in der Null-, Kalk- u. Kompost-Variante nach 3 Jahren; MW u. Std.abw.; Ergebnisse von H-Tests [H] auf signifikante Unterschiede; Buchstaben kennzeichnen je Spalte homogene Gruppen nach U-Tests; Fettdruck markiert signifikante Unterschiede gegenüber der Kontrolle im Topf-Versuch

\begin{tabular}{|l|l|l|l|l|}
\hline Versuch & Variante (n) & $\mathbf{C}[\mathbf{m g} / \mathbf{g}]$ & $\mathbf{N}[\mathbf{m g} / \mathbf{g}]$ & $\mathbf{C} / \mathbf{N}-$ Verhältnis \\
\hline Freiland & unbehandelt (12) & $4,2 \pm 2,4 \mathrm{a}$ & $0,7 \pm 0,09 \mathrm{a}$ & $6,1 \pm 3,4 \mathrm{a}$ \\
\hline \multirow{3}{*}{ Topf } & Kontrolle (4) & $8,4 \pm 0,5 \mathrm{~b}$ & $0,8 \pm 0,05 \mathrm{~b}$ & $10,2 \pm 0,4 \mathrm{~b}$ \\
\cline { 2 - 5 } & Kalk (12) & $\mathbf{9 , 3} \pm \mathbf{0 , 9} \mathbf{~ c}$ & $0,8 \pm 0,04 \mathrm{~b}$ & $\mathbf{1 1 , 6} \pm \mathbf{0 , 9} \mathbf{~ c}$ \\
\cline { 2 - 5 } & Kompost (6) & $\mathbf{3 4 , 1} \pm \mathbf{1 3 , 6} \mathbf{~ d}$ & $\mathbf{3 , 1} \pm \mathbf{1 , 4} \mathbf{~ c}$ & $\mathbf{1 1 , 2} \pm \mathbf{0 , 8} \mathbf{~ c}$ \\
\hline H & & $28,45^{* * *}$ & $22,57^{* * *}$ & $22,24^{* * *}$ \\
\hline
\end{tabular}

Von den verwendeten Bodenhilfsstoffen hatte vor allem Kompost Auswirkungen auf die Kohlenstoff- und Stickstoff-Gehalte des Haldensubstrats, die sich jeweils etwa vervierfachten (s. Abb. 12). Der Kohlenstoff-Gehalt näherte sich mit $34,1 \mathrm{mg} / \mathrm{g}$ den mittleren Gehalten in Thüringer Waldböden (durchschnittlich $42 \mathrm{mg} / \mathrm{g}$ C in der oberen Bodenschicht; Wirth et al. 2004), während der Stickstoff-Gehalt mit 3,1 mg/g höher lag als manche in Waldböden üblichen mittleren Gehalte (LAWuF Gotha 2002). Das C/N-Verhältnis des mit Kompost vermischten 
Haldenbodens blieb mit 11,2 unverändert eng und damit günstig (BMELF 1997a). Das C/NVerhältnis des Bodens in den mit Kalk gedüngten Töpfen lag mit 11,6 bei einem ähnlichen Wert. Der Kohlenstoff-Gehalt war in dieser Variante leicht höher als in der Nullvariante und betrug 9,3 $\mathrm{mg} / \mathrm{g}$, während sich der Stickstoff-Gehalt mit $0,8 \mathrm{mg} / \mathrm{g}$ von dem der Kontrolle nicht unterschied.
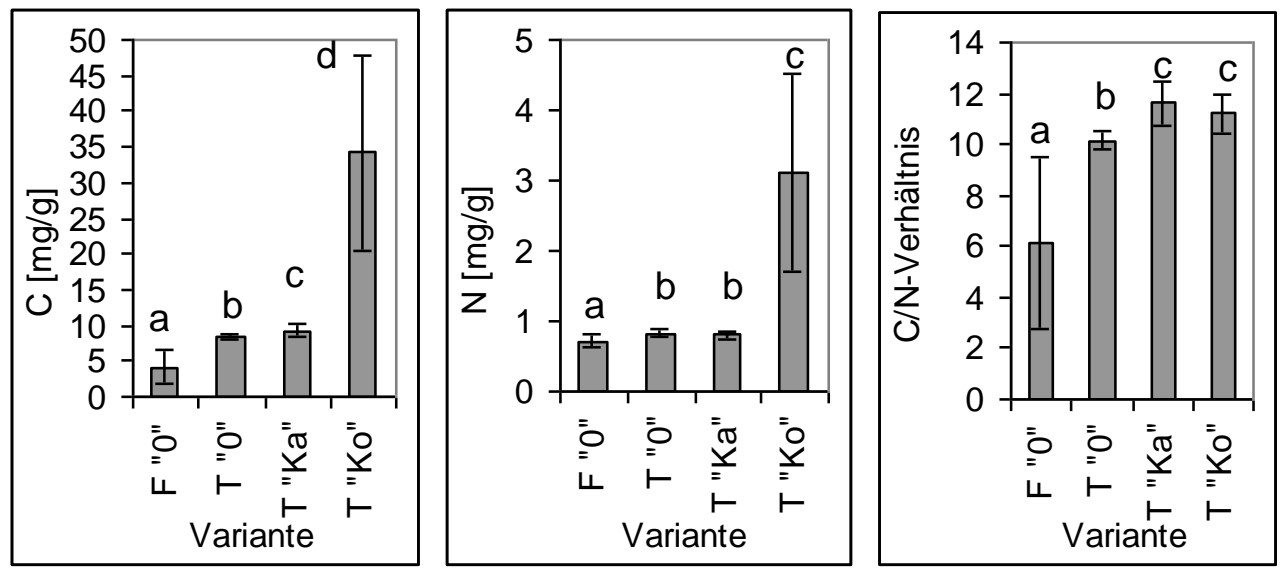

Abb. 12: Kohlenstoff- (links), Stickstoff-Bodengehalte [mg/g] (Mitte) u. C/N-Verhältnisse (rechts) im Freiland-Versuch (F “0“; n=12) u. im Topf-Versuch in der Null- (T „0“; n=4), Kalk- (T „Ka“; n=12) u. Kompost-Variante ( $\mathrm{T}$ „Ko“; $\mathrm{n}=6$ ) nach 3 Jahren; MW u. Std.abw.; Buchstaben kennzeichnen jeweils homogene Gruppen nach U-Tests

\subsubsection{Phosphor-Gehalt und C/P-Verhältnis}

Der Phosphor-Gehalt (s. Tab. 29) des unbehandelten Bodens im Topf-Versuch $(0,6 \mathrm{mg} / \mathrm{g})$ unterschied sich nicht signifikant von dem im Freiland gemessenen Wert $(0,7 \mathrm{mg} / \mathrm{g})$. KalkGaben führten im Topf-Versuch zu keiner Veränderung $(0,6 \mathrm{mg} / \mathrm{g})$, während Kompost-Gaben den Phosphor-Gehalt signifikant auf 0,9 mg/g erhöhten (s. Abb. 13 links).

Tab. 29: Phosphor-Bodengehalte [mg/g] u. C/P-Verhältnisse im Freiland-Versuch u. im Topf-Versuch in der Null-, Kalk- u. Kompost-Variante nach 3 Jahren; MW u. Std.abw.; Ergebnisse von H-Tests [H] auf signifikante Unterschiede; Buchstaben kennzeichnen je Spalte homogene Gruppen nach U-Tests; Fettdruck markiert signifikante Unterschiede gegenüber der Kontrolle im Topf-Versuch

\begin{tabular}{|l|l|l|l|}
\hline Versuch & Variante (n) & P [mg/g] & C/P-Verhältnis \\
\hline Freiland & unbehandelt (12) & $0,7 \pm 0,19$ a & $6,5 \pm 3,8$ a \\
\hline \multirow{3}{*}{ Topf } & Kontrolle (4) & $0,6 \pm 0,03$ a & $13,2 \pm 1,3 \mathrm{~b}$ \\
\cline { 2 - 4 } & Kalk (12) & $0,6 \pm 0,01$ a & $\mathbf{1 5 , 3} \pm \mathbf{1 , 3} \mathbf{~ c}$ \\
\cline { 2 - 4 } & Kompost (6) & $\mathbf{0 , 9} \pm \mathbf{0 , 1 5}$ b & $\mathbf{3 7 , 1} \pm \mathbf{9 , 1} \mathbf{~ d}$ \\
\hline H & & $11,59^{* *}$ & $28,85^{* * *}$ \\
\hline
\end{tabular}

Das Verhältnis aus Kohlenstoff- und Phosphor-Bodengehalten betrug in der GewächshausNullvariante mit 13,2 etwa das Doppelte des Freiland-Wertes (6,5). In der Kalk-Variante lag das Verhältnis mit 15,3 etwas höher als in der Kontrolle. In der Kompost-Variante betrug es knapp das 3-fache des Kontrollwertes. Alle C/P-Verhältnisse unterschieden sich signifikant voneinander (s. Abb. 13 rechts). Zurückzuführen sind diese Ergebnisse auf die sehr unterschiedlichen Kohlenstoff-Gehalte der getesteten Varianten. Ungeachtet dieser großen Unterschiede sind die ermittelten C/P-Verhältnisse alle als sehr eng $(<50)$ und damit günstig einzustufen (BMELF 1997a). 

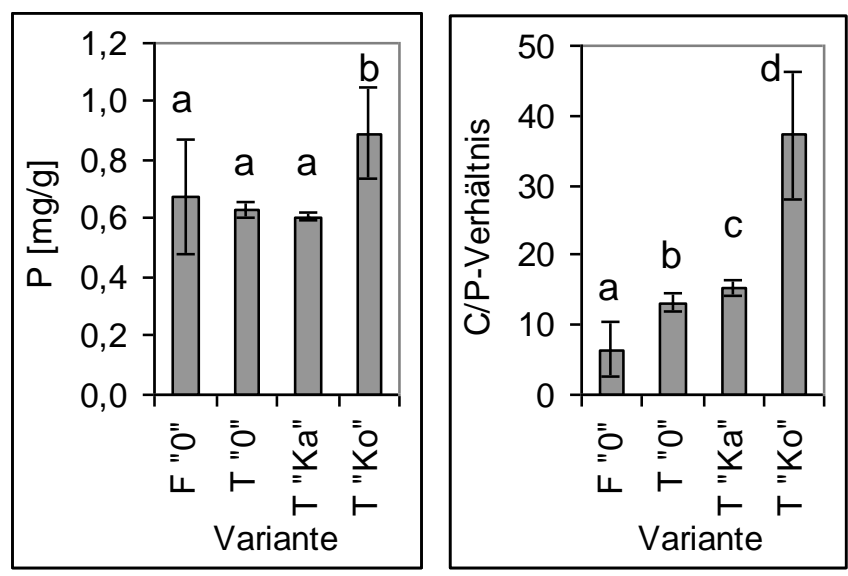

Abb. 13: Phosphor-Bodengehalte $[\mathrm{mg} / \mathrm{g}]$ (links) u. C/P-Verhältnisse (rechts) im Freiland-Versuch (F "0"; $\mathrm{n}=12$ ) u. im Topf-Versuch in der Null- ( $\mathrm{T}$ „0“; $\mathrm{n}=4$ ), Kalk- ( $\mathrm{T}$ „Ka“; $\mathrm{n}=12$ ) u. Kompost-Variante ( $\mathrm{T}$ „Ko“; $\mathrm{n}=6$ ) nach 3 Jahren; MW u. Std.abw.; Buchstaben kennzeichnen jeweils homogene Gruppen nach U-Tests

\subsubsection{Weitere Nährelement-Gehalte}

Die Bodengehalte (s. Tab. 30) der Nährelemente Kalium, Magnesium, Eisen und Aluminium waren im Topf-Versuch (unbehandelte Kontrolle) signifikant geringer als im Freiland-Versuch. Sie lagen etwa bei $49 \%(\mathrm{~K}), 55 \%(\mathrm{Mg}), 69 \%$ (Fe) und $56 \%$ (Al) der FreilandDurchschnittswerte. Grund dafür könnte - neben unterschiedlichen Ausgangsbedingungen durch die Heterogenität des Haldensubstrats - die Auswaschung und Pflanzenaufnahme bei fehlender Nachlieferung im Verlauf des dreijährigen Topf-Versuchs sein (vgl. SchwermetallGehalte).

Zwischen den im Freiland- und im Topf-Versuch (unbehandelte Nullvariante) gemessenen Natrium-, Calcium- und Mangan-Gehalten bestanden keine signifikanten Unterschiede.

In den Töpfen mit Kalk- oder Kompost-Beimischung wurden gegenüber der Nullvariante sowohl signifikant höhere Calcium- und Magnesium- als auch signifikant höhere Mangan-Gehalte ermittelt.

Tab. 30: Nährelement-Bodengehalte [mg/g] im Freiland-Versuch u. im Topf-Versuch in der Null-, Kalk- u. Kompost-Variante nach 3 Jahren; MW u. Std.abw.; Ergebnisse von H-Tests [H] auf signifikante Unterschiede; Buchstaben kennzeichnen je Zeile homogene Gruppen nach U-Tests; Fettdruck markiert signifikante Unterschiede gegenüber der Kontrolle im Topf-Versuch

\begin{tabular}{|c|c|c|c|c|c|}
\hline \multirow{2}{*}[\mathrm{mg}/\mathrm{g}]{} & \multirow{2}{*}{$\begin{array}{l}\text { Freiland (n) } \\
\text { unbehandelt (12) }\end{array}$} & \multicolumn{3}{|l|}{ Topf (n) } & \multirow[b]{2}{*}{$\mathrm{H}$} \\
\hline & & Kontrolle (4) & Kalk (12) & Kompost (6) & \\
\hline $\mathrm{Na}$ & $0,6 \pm 0,2$ & $0,4 \pm 0,02$ & $0,4 \pm 0,02$ & $0,4 \pm 0,02$ & 6,65 \\
\hline $\mathrm{K}$ & $18,1 \pm 4,4 \mathrm{~b}$ & $8,9 \pm 0,4 \mathrm{a}$ & $8,7 \pm 0,3 \mathrm{a}$ & $8,7 \pm 0,2 \mathrm{a}$ & $23,30^{* * *}$ \\
\hline $\mathrm{Ca}$ & $1,2 \pm 1,0 \mathrm{a}$ & $1,2 \pm 0,1 \mathrm{a}$ & $2,4 \pm 0,6 \mathrm{~b}$ & $4,1 \pm 1,6 \mathrm{c}$ & $19,74^{* * *}$ \\
\hline $\mathrm{Mg}$ & $5,3 \pm 1,9 c$ & $2,9 \pm 0,1 \mathrm{a}$ & $3,5 \pm 0,3 \mathrm{~b}$ & $3,3 \pm 0,2 \mathrm{~b}$ & $12,61^{* *}$ \\
\hline $\mathrm{Fe}$ & $34,3 \pm 10,7 \mathrm{c}$ & $23,6 \pm 0,8 \mathrm{~b}$ & $23,6 \pm 0,7 \mathrm{~b}$ & $22,1 \pm 0,9 a$ & $14,49^{* *}$ \\
\hline $\mathrm{Mn}$ & $0,2 \pm 0,1 \mathrm{a}, \mathrm{b}$ & $0,1 \pm 0,01 \mathrm{a}$ & $0,2 \pm 0,03 \mathrm{~b}$ & $0,3 \pm 0,05 c$ & $14,26^{* *}$ \\
\hline $\mathrm{Al}$ & $59,6 \pm 12,9 c$ & $33,6 \pm 0,9 a, b$ & $33,5 \pm 0,7 \mathrm{~b}$ & $32,3 \pm 1,2 \mathrm{a}$ & $22,81^{* * *}$ \\
\hline
\end{tabular}

In der Kalk-Variante betrug der Calcium-Gehalt mit 2,4 mg/g das Doppelte, in der KompostVariante mit 4,1 mg/g mehr als das 3-fache des Kontrollwertes (1,2 mg/g). Der Magnesium- 
Gehalt stieg von 2,9 mg/g (unbehandelte Kontrolle) auf 3,5 mg/g mit Kalk- bzw. 3,3 mg/g mit Kompost-Düngung. Der Mangan-Gehalt lag bei Kalk-Gabe mit 0,2 mg/g doppelt, bei KompostGabe mit 0,3 mg/g 3-mal so hoch wie der Kontrollwert (0,1 mg/g).

Während der Anstieg der Calcium- und Magnesium-Gehalte durch die Kalk-Düngung aufgrund der Zusammensetzung des verwendeten Kalkprodukts („Dolomitkalk - Kohlensaurer Magnesiumkalk 90" mit $55 \%$ Calciumcarbonat $\left(\mathrm{CaCO}_{3}\right)$ und $35 \%$ Magnesiumcarbonat $\left(\mathrm{MgCO}_{3}\right)$; s. S. 19) erwartet worden war, ist der gegenüber der Kontrolle höhere Mangan-Wert in dieser Variante zunächst überraschend.

Hier kommt vermutlich eine Besonderheit des Topf-Versuchs zum Tragen, die so nicht auf Freiland-Bedingungen übertragbar ist. Im Verlauf des dreijährigen Untersuchungszeitraums wurde aller Wahrscheinlichkeit nach durch Auswaschung (Mangan wird stark verlagert und ausgewaschen; Scheffer \& Schachtschabel 2010) und Pflanzenaufnahme ein Teil des Mangans „verbraucht" (und anders als im Freiland nicht nachgeliefert). Dieser Vorgang betraf vor allem die unbehandelten Kontrollen im Topf-Versuch, da hier ein sehr niedriger pH-Wert vorherrschte und folglich viel Mangan in Lösung war. In den Behandlungsvarianten mit erheblich höherem pH-Wert verblieb durch Festlegung und geringere Pflanzenaufnahme dagegen ein größerer Teil des Mangans bis Versuchsende im Boden.

Der Eisen-Gehalt war in der Kompost-Variante gegenüber der Kontrolle leicht, aber signifikant geringer, während die Kalk-Düngung hier keine Rolle spielte. Ebenfalls keinen Einfluss gemessen an der Nullvariante hatten die Kalk- und Kompost-Gaben auf die Natrium-, Kaliumund Aluminium-Gehalte des Bodens (wobei der Aluminium-Gehalt in den mit Kompost versetzten Töpfen leicht, aber signifikant geringer war als in der Kalk-Variante).

\subsubsection{Effektive Kationen-Austauschkapazität}

Die mittlere effektive Kationen-Austauschkapazität $\left(\mathrm{AK}_{\mathrm{e}}\right)$ der Kontrollen im Topf-Versuch betrug mit $45 \mathrm{mmol}(+) / \mathrm{kg}$ etwa die Hälfte des im Freiland gemessenen Mittelwertes (88 $\mathrm{mmol}(+) / \mathrm{kg})$, der jedoch kleinräumig stark schwankte, wie die hohe Standardabweichung erkennen lässt (s. Tab. 31).

Tab. 31: Effektive Kationen-Austauschkapazität $[\mathrm{mmol}(+) / \mathrm{kg}]$ im Freiland-Versuch u. im Topf-Versuch in der Null-, Kalk- u. Kompost-Variante nach 3 Jahren; MW u. Std.abw.; Ergebnisse von H-Tests [H] auf signifikante Unterschiede; Buchstaben kennzeichnen homogene Gruppen nach U-Tests; Bewertung nach AK Standortskartierung 2003 (Werte für B/C-Horizonte)

\begin{tabular}{|l|l|l|l|}
\hline Versuch & Variante (n) & $\mathbf{A K}_{\mathrm{e}}[\mathbf{m m o l}(+) / \mathbf{k g}]$ & Bewertungsbereich \\
\hline Freiland & unbehandelt (12) & $88 \pm 44 \mathrm{~b}$ & mittel $(\mathrm{ab} 60 \mathrm{mmol}(+) / \mathrm{kg})$ \\
\hline \multirow{3}{*}{ Topf } & Kontrolle (4) & $45 \pm 3 \mathrm{a}$ & niedrig-mittel \\
\cline { 2 - 4 } & Kalk (12) & $65 \pm 15 \mathrm{~b}$ & mittel \\
\cline { 2 - 4 } & Kompost (6) & $146 \pm 66 \mathrm{c}$ & mittel-hoch $(\mathrm{ab} 120 \mathrm{mmol}(+) / \mathrm{kg})$ \\
\hline $\mathrm{H}$ & & $14,21^{* *}$ & \\
\hline
\end{tabular}

Kalk-Gaben erhöhten im Topf-Versuch die $A K_{e}$ gegenüber der Kontrolle signifikant auf durchschnittlich $65 \mathrm{mmol}(+) / \mathrm{kg}$ (Grund: $\mathrm{pH}$-Anhebung). Kompost-Gaben konnten die $\mathrm{AK}_{\mathrm{e}}$ noch deutlich stärker auf im Mittel $146 \mathrm{mmol}(+) / \mathrm{kg}$ erhöhen (Gründe: $\mathrm{pH}$-Anhebung und Einbringung organischer Substanz, die als Austauscher fungiert). Die Messwerte waren dabei trotz starker Schwankungen und damit großer Standardabweichungen (s. Tab. 31) sowohl gegenüber den 
Werten der Kontrolle als auch gegenüber den Werten der gekalkten Variante signifikant höher (s. Abb. 14).

Die niedrige-mittlere $\mathrm{AK}_{\mathrm{e}}$ des unbehandelten Haldensubstrats erhöhte sich somit durch KalkGaben auf einen Wert im mittleren Bewertungsbereich, durch Kompost-Gaben sogar auf einen Wert im mittleren-hohen Bewertungsbereich (AK Standortskartierung 2003; s. Tab. 31).

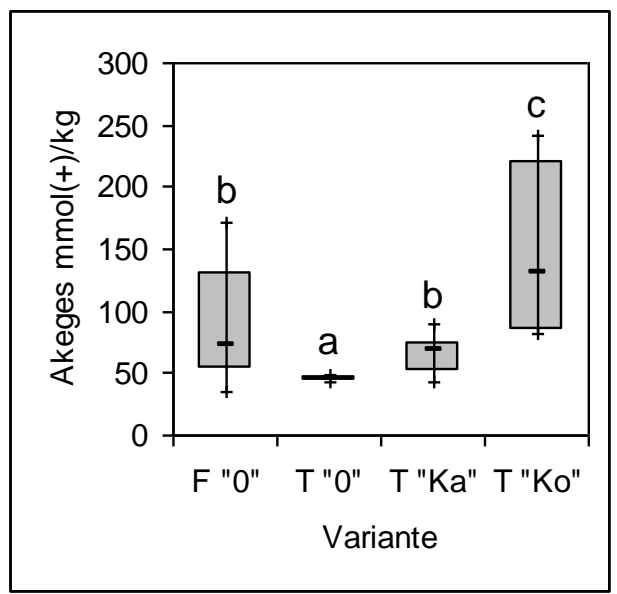

Abb. 14: Effektive Kationen- Austauschkapazität $\left(\mathrm{AK}_{\mathrm{e}}\right)[\mathrm{mmol}(+) / \mathrm{kg}]$ im Freiland-Versuch (F "0"; n=16) u. im Topf-Versuch in der Null- ( $\mathrm{T}$ „0“; $\mathrm{n=6}$ ), Kalk- ( $\mathrm{T}$ „Ka“; $\mathrm{n=12}$ ) u. Kompost-Variante ( $\mathrm{T}$ „Ko“; $\mathrm{n}=4$ ); Mediane, 25. u. 75. Perzentil (die Box repräsentiert 50 \% der Werte), Spannweite (5. und 95. Perzentil), Minimum und Maximum; Buchstaben kennzeichnen homogene Gruppen nach U-Tests

\subsubsection{Austauscherbelegung}

Tab. 32: Austauscherbelegung, Basen-Sättigung (BS), Erdalkali-Sättigung (ES) sowie Summe der Protonen- und Eisen-Sättigungen [\% der $\mathrm{AK}_{\mathrm{e}}$ ] im Freiland-Versuch u. im Topf-Versuch in der Null-, Kalku. Kompost-Variante nach 3 Jahren; MW u. Std.abw.; Ergebnisse von H-Tests $[\mathrm{H}]$ auf signifikante Unterschiede; Buchstaben kennzeichnen je Zeile homogene Gruppen nach U-Tests; Fettdruck markiert signifikante Unterschiede gegenüber der Kontrolle im Topf-Versuch

\begin{tabular}{|c|c|c|c|c|c|}
\hline \multirow{2}{*}{$\begin{array}{l}\% \\
\text { der } A K_{e}\end{array}$} & \multirow{2}{*}{$\begin{array}{l}\text { Freiland (n) } \\
\text { unbehandelt (12) }\end{array}$} & \multicolumn{3}{|l|}{ Topf (n) } & \multirow[b]{2}{*}{$\mathrm{H}$} \\
\hline & & Kontrolle (4) & Kalk (12) & Kompost (6) & \\
\hline $\mathrm{H}$ & $5,4 \pm 5,0 \mathrm{~b}$ & $13,2 \pm 4,1 \mathrm{c}$ & $0,4 \pm 1,1 \mathrm{a}$ & $0 \pm 0 \mathrm{a}$ & $25,83^{* * *}$ \\
\hline $\mathrm{Na}$ & $0,35 \pm 0,35 \mathrm{a}$ & $1,5 \pm 0,5 b$ & $1,7 \pm 0,4 \mathrm{~b}$ & $1,4 \pm 0,7 \mathrm{~b}$ & $20,95^{* * *}$ \\
\hline $\mathrm{K}$ & $1,7 \pm 1,6 \mathrm{a}$ & $2,4 \pm 0,5 \mathrm{a}$ & $2,0 \pm 0,7 \mathrm{a}$ & $4,6 \pm 2,6 b$ & $11,67^{* *}$ \\
\hline $\mathrm{Ca}$ & $29,4 \pm 25,9 \mathrm{a}$ & $22,0 \pm 5,5 \mathrm{a}$ & $62,3 \pm 7,7 \mathrm{~b}$ & $80,6 \pm 5,1 \mathrm{c}$ & 20,50 *** \\
\hline $\mathrm{Mg}$ & $20,4 \pm 13,0 \mathrm{~b}$ & $7,2 \pm 1,5 \mathrm{a}$ & $29,2 \pm 6,2 \mathrm{c}$ & $11,2 \pm 3,8 \mathrm{a}, \mathrm{b}$ & $14,73^{* *}$ \\
\hline $\mathrm{Fe}$ & $0,8 \pm 1,0 \mathrm{~b}$ & $1,7 \pm 0,9 \mathrm{c}$ & $0,16 \pm 0,24 a$ & $0,22 \pm 0,45 a$ & $11,79^{* *}$ \\
\hline $\mathrm{Mn}$ & $0,98 \pm 0,38 c$ & $0,35 \pm 0,10 \mathrm{a}$ & $0,66 \pm 0,26 b$ & $0,79 \pm 0,87$ a-c & $11,01^{*}$ \\
\hline $\mathrm{Al}$ & $41,1 \pm 24,0 \mathrm{~b}$ & $51,7 \pm 7,3 \mathrm{~b}$ & $3,5 \pm 5,2 a$ & $1,3 \pm 1,8 a$ & $24,00^{* * *}$ \\
\hline BS & $52 \pm 26 \mathrm{a}$ & $33 \pm 7 a$ & $95 \pm 7 b$ & $98 \pm 3 b$ & $24,34^{* * *}$ \\
\hline ES & $50 \pm 25 a$ & $29 \pm 7 a$ & $92 \pm 7 b$ & $92 \pm 4 b$ & $23,86^{* * *}$ \\
\hline $\mathrm{H}+\mathrm{Fe}$ & $6,2 \pm 5,5 b$ & $14,9 \pm 5,0 \mathrm{c}$ & $0,6 \pm 1,3 a$ & $0,2 \pm 0,4 a$ & $21,75^{* * *}$ \\
\hline
\end{tabular}



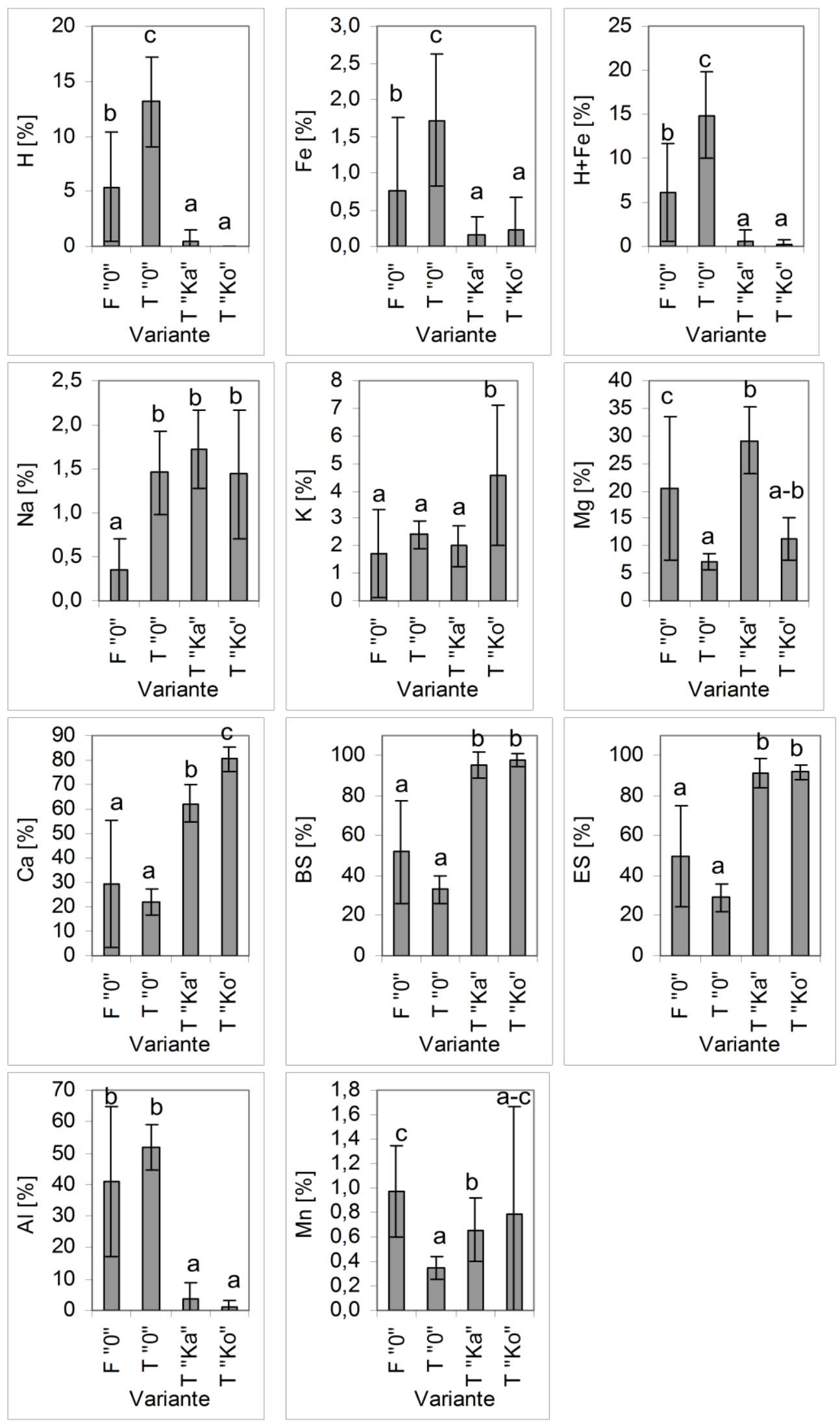

Abb. 15 a-k: Austauscherbelegung, Basen-Sättigung (BS), Erdalkali-Sättigung (ES) sowie Summe der Protonen- u. Eisen-Sättigungen [\% der $\mathrm{AK}_{\mathrm{e}}$ ] im Freiland-Versuch (F " 0 "; n=12) u. im Topf-Versuch in der Null- ( ${ }_{\text {„0“; }}$ n=4), Kalk- (T „Ka“; n=12) u. Kompost-Variante (T „Ko“; n=6) nach 3 Jahren; MW u. Std.abw.; Buchstaben kennzeichnen jeweils homogene Gruppen nach U-Tests 
Die Austauscherbelegung der Nullvariante im Topf-Versuch unterschied sich nach dreijähriger Versuchsdauer teilweise deutlich von der im Freiland-Substrat ermittelten (s. Tab. 32).

So waren die Anteile der Magnesium- und Mangan-Ionen signifikant niedriger als im FreilandVersuch und betrugen jeweils etwa ein Drittel des Freilandwertes. Hier mögen Auswaschung und Pflanzenaufnahme bei fehlender Nachlieferung im Versuchsverlauf eine Rolle spielen.

Die Anteile der Protonen, der Eisen- und der Natrium-Ionen an der $\mathrm{AK}_{\mathrm{e}}$ im eingetopften Substrat lagen dafür signifikant höher (H: doppelt, Fe: 2,5-mal, Na: 4-mal so hoch wie im Freiland). Da die Natrium-Sättigung in allen drei untersuchten Topf-Versuch-Varianten etwa gleich hoch ist, kann dies eher auf unterschiedliche Ausgangsbedingungen durch die Heterogenität des Haldensubstrats zurückgeführt werden.

Bei der Calcium- und Kalium-Sättigung bestanden keine signifikanten Unterschiede zwischen Freiland- und Topf-Versuchen (unbehandelte Kontrolle).

Mit Kalk- bzw. Kompost-Düngung lag im Topf-Versuch der Anteil der Calcium-Ionen an der Austauscherbelegung signifikant deutlich höher als in der unbehandelten Kontrolle (s. Abb. 15g). Dabei stieg die Calcium-Sättigung je nach Variante signifikant unterschiedlich stark an, mit Kalk-Gabe auf 62 \%, mit Kompost-Gabe auf 81 \% (Nullvariante: $22 \%$ ).

Da Magnesiumkalk verwendet wurde (s. S. 19), erhöhte sich in der Kalk-Variante zudem der Anteil der Magnesium-Ionen an der Austauscherbelegung deutlich von $7 \%$ auf $29 \%$ (s. Abb. 15f), was einen vergleichsweise sehr hohen Sättigungsgrad darstellt.

In beiden Düngevarianten machen die Ca- und Mg-Sättigungen zusammengenommen über $90 \%$ des Ionenbelages aus, was mit Werten in den meisten schwach sauren bis neutralen landwirtschaftlich genutzten Böden vergleichbar ist (Scheffer \& Schachtschabel 2010).

In der Kompost-Variante war außerdem ein signifikanter Anstieg des Kalium-Anteils zu messen, der sich von 2,4 \% auf 4,6 \% verdoppelte (s. Abb. 15e). Die Natrium-Sättigung blieb von den verwendeten Bodenhilfsstoffen unbeeinflusst (s. Abb. 15d).

Dagegen bewirkten die Kalk- und Kompost-Gaben durch Anhebung des pH-Wertes bei den Protonen-, Eisen- und Aluminium-Sättigungen einen signifikanten Rückgang gegenüber der Kontrolle (s. Abb. 15a, b, j). Somit wurde die Ionenkonkurrenz verringert, was sich positiv auf die den Pflanzen zur Verfügung stehenden Nährstoffe auswirkt (Scheffer \& Schachtschabel 2010). Der Protonen-Anteil an der $\mathrm{AK}_{\mathrm{e}}$ ging von $13 \%$ auf knapp über Null (Kalk-Variante) bzw. Null (Kompost-Variante) zurück. Der Eisen-Ionen-Anteil sank von 1,7 \% auf 0,22 \% (KompostVariante) bzw. 0,16 \% (Kalk-Variante). Die Aluminium-Sättigung nahm deutlich von $52 \%$ in der unbehandelten Kontrolle auf 3,5 \% mit Kalk- und 1,3 \% mit Kompost-Düngung ab.

Der Mangan-Anteil an der Austauscherbelegung war in der gekalkten Variante signifikant höher (s. Abb. 15k) und lag mit 0,66 \% etwa doppelt so hoch wie in der Nullvariante (0,35 \%), während in der Kompost-Variante stark schwankende Werte (relativ hoher Mittelwert mit hoher Standardabweichung) gemessen wurden. Die Ursache dafür ist in einer Reduzierung des Mangans durch Auswaschung und Aufnahme bei fehlender Nachlieferung in der unbehandelten Kontrolle zu vermuten (siehe auch unter: Nährelement-Gehalte im Boden). 


\subsubsection{Basen-Sättigung}

Die Basen-Sättigung (Summe der Anteile von Na-, K-, Ca-, Mg-Ionen an der Austauscherbelegung) des unbehandelten Haldensubstrats nach dreijährigem Topf-Versuch lag mit 33 \% im mittleren Bewertungsbereich (BMELF 1997b, AK Standortskartierung 2003). Zwischen der in der Nullvariante des Topf-Versuchs und der im Freiland ermittelten BS (52 \%; mäßig hoch bzw. basenreich) bestand aufgrund der hohen Standardabweichung des FreilandMittelwertes (s. Tab. 32) kein signifikanter Unterschied. Sowohl Kalk als auch Kompost erhöhten die BS gegenüber der Kontrolle signifikant (s. Abb. 15h) auf sehr hohe Werte (95 \% bzw. 98 \%).

\subsubsection{Vergleich Nährelement-Gehalte und Nährelement-Sättigungen}

Zwischen den Nährelement-Gehalten im Boden und den relativen Anteilen der jeweiligen Nährelement-Kationen an der Austauscherbelegung gab es kaum Zusammenhänge. Die Austauscherbelegung wurde von anderen Bodenfaktoren, vor allem den in den Topf-VersuchVarianten sehr unterschiedlichen $\mathrm{pH}$-Werten, bedingt.

So unterschieden sich weder die Kalium- noch die Aluminium-Bodengehalte der mit Kalk bzw. Kompost gedüngten Varianten signifikant von der unbehandelten Kontrolle. Auch die EisenGehalte in den drei Varianten stimmten mehr oder weniger überein.

Dagegen waren die Anteile der Aluminium- und der Eisen-Ionen an der Austauscherbelegung im gedüngten Boden um ein Vielfaches geringer als in der Nullvariante, während sich die Kalium-Sättigung in der Kompost-Variante gegenüber dem Kontrollwert verdoppelte.

Dies ist auf die veränderte Mobilität der Nährelemente bei den durch Kalk- bzw. KompostGaben gegenüber der Kontrolle deutlich unterschiedlichen Bodenreaktionen (erheblich höhere pH-Werte; s. S. 58) zurückzuführen (Scheffer \& Schachtschabel 2010). Allgemein hängt die sorbierte Kalium-Menge auch von Art und Konzentration der konkurrierenden Kationen (in diesem Fall v. a. Aluminium; in Abwesenheit von Aluminium wird das Austauschverhalten von Calcium und Magnesium bestimmt) ab (Scheffer \& Schachtschabel 2010).

In den mit Kalk und Kompost gedüngten Töpfen waren die Calcium-, Magnesium- und Mangan-Gehalte gegenüber der Kontrolle signifikant höher (die Calcium- und Mangan-Gehalte lagen mit Kompost höher als mit Kalk, die Magnesium-Gehalte waren gleichermaßen hoch). Dies und die genannte, durch die Calcium-Zufuhr bedingte $\mathrm{pH}$-Wert-Anhebung führten zu erheblich höheren Calcium- und Magnesium-Sättigungen. Dabei stieg in der Kompost-Variante die Calcium-Sättigung auf über $80 \%$, während sich die Magnesium-Sättigung nicht veränderte. In der Kalk-Variante nahmen dagegen sowohl die Calcium-Sättigung als auch die MagnesiumSättigung auf $62 \%$ bzw. $29 \%$ zu.

Grund für den höheren Calcium-Anteil an der Austauscherbelegung in der Kompost-Variante ist neben dem höheren pH-Wert und der dadurch geringeren Ionenkonkurrenz der ebenfalls höhere Calcium-Gehalt in dieser Variante. Da calciumhaltige Mineralien leicht verwitterbar und leicht löslich sind und zudem Calcium-Kationen von den Austauschern der Böden stark gebunden werden, liegt ein wesentlicher Teil des Gesamt-Calciums in austauschbarer Form vor (Scheffer \& Schachtschabel 2010).

Der höhere Bodengehalt an Mangan führte bei höheren pH-Werten in der Kalk-Variante auch zu signifikant höheren Mangan-Anteilen an der Austauscherbelegung. 


\subsubsection{Elastizität gegenüber Säurebelastung}

Neben der Basen-Sättigung (BS) geben auch die Summe der Calcium- und MagnesiumSättigungen (Erdalkali-Sättigung), jeweils die Magnesium- und Kalium-Sättigungen sowie die Summe der Protonen- und Eisen-Sättigungen Aufschluss über die Elastizität eines Bodens gegenüber Säurebelastung (AK Standortskartierung 2003). Die diesbezüglichen Bewertungen dieser fünf Faktoren im Freiland-Versuch sowie in den drei relevanten Topf-Versuch-Varianten sind in Tab. 33 zusammengefasst. Die im unbehandelten Substrat sehr unterschiedlichen, teilweise geringen Bewertungen verschoben sich durch Kalk- bzw. Kompost-Düngung zu einer überwiegend sehr hohen Einstufung der Säureelastizität.

Tab. 33: Bewertung (= Elastizität gegenüber Säurebelastung) der relativen Austauscherbelegung bezogen auf die $\mathrm{AK}_{\mathrm{e}}$ im Freiland-Versuch u. im Topf-Versuch in der Null-, Kalk- u. Kompost-Variante nach AK Standortskartierung (2003) und *BMELF 1997b; Fettdruck markiert signifikante Unterschiede gegenüber der Kontrolle im Topf-Versuch

\begin{tabular}{|l|l|l|l|l|}
\hline \multirow{2}{*}{ Anteil an AKe [\%] } & Freiland (n) & Topf (n) \\
\cline { 2 - 5 } & unbehand. (12) & Kontrolle (4) & Kalk (12) & Kompost (6) \\
\hline (BS) Basen-Sättigung & mäßig hoch & mittel & sehr hoch & sehr hoch \\
\hline $\begin{array}{l}\text { (ES) Erdalkali- } \\
\text { Sättigung }\end{array}$ & mittel & mäßig - mittel & sehr hoch & sehr hoch \\
\hline Mg-Sättigung & sehr hoch & hoch & sehr hoch & sehr hoch \\
\hline K-Sättigung & gering & mittel & gering - mittel & hoch \\
\hline $\mathrm{H}^{+}+$Fe-Sättigung & gering & sehr gering & $\begin{array}{l}\text { mäßig - sehr } \\
\text { hoch* }\end{array}$ & $\begin{array}{l}\text { mäßig - sehr } \\
\text { hoch* }\end{array}$ \\
\hline
\end{tabular}

\section{Basen-Sättigung}

Ausgehend von der beschriebenen Basen-Sättigung (BS) ist die Elastizität des unbehandelten Haldenbodens gegenüber weiterer Versauerung im Freiland als mäßig hoch, im Topf-Versuch als mittel einzustufen. Zwischen den Messwerten (52 \% bzw. $33 \%$ ) bestehen aufgrund der hohen Standardabweichungen im Freiland keine signifikanten Unterschiede (s. Tab. 32). Die durch Kalk- bzw. Kompost-Düngung signifikant höheren, bei 95 \% bzw. 98 \% liegenden BS (s. Abb. 15h) weisen auf eine sehr hohe Säureelastizität des Bodens in diesen Behandlungsvarianten hin.

\section{Erdalkali-Sättigung}

Die ermittelten Erdalkali-Sättigungen (ES) waren hinsichtlich der Elastizität des Bodens gegenüber weiterer Säurebelastung ähnlich der Basen-Sättigung zu bewerten. Zwischen dem Freiland-Durchschnittswert (50\%; mittel) und dem Kontrollwert im Topf-Versuch (29\%; mäßig bis mittel) bestanden aufgrund hoher Standardabweichungen im Freiland ebenfalls keine signifikanten Unterschiede (s. Abb. 15i). Kalk- und Kompost-Gaben ließen die ES auf $92 \%$ ansteigen, was wiederum einer sehr hohen Säureelastizität entspricht.

\section{Magnesium- sowie Kalium-Sättigung}

Sowohl im Freiland-Versuch als auch in den untersuchten Topf-Versuch-Varianten wurde die Bodenelastizität gegenüber Säurebelastung aufgrund des Anteils der Magnesium-Ionen an der Austauscherbelegung als mindestens hoch bis sehr hoch eingestuft. 
Dagegen wiesen die Anteile der Kalium-Ionen im Freiland und in der unbehandelten Nullvariante sowie der Kalkvariante im Topf-Versuch auf eine geringe oder geringe bis mittlere Säureelastizität hin. Der mit Kompost-Düngung signifikant höhere Anteil an Kalium-Ionen führte dagegen zu einer hohen Bewertung der diesbezüglichen Säureelastizität.

\section{Summe der Protonen- und Eisen-Sättigungen}

Die Summe der Anteile austauschbarer Eisen-Ionen und Protonen an der $\mathrm{AK}_{\mathrm{e}}$ (Kennwert für die Elastizität des Bodens gegenüber Säurebelastung) lag im unbehandelten Topf-Versuch mit 14,9 \% (sehr geringe Elastizität gegenüber weiterer Säurebelastung) mehr als doppelt so hoch wie der Freiland-Mittelwert (6,2 \%; geringe Elastizität gegenüber weiterer Säurebelastung). Sie sank jedoch in beiden Behandlungsvarianten gleichermaßen stark auf unter $1 \%$ (s. Abb. 15c). Die sehr geringe Säureelastizität des unbehandelten Bodens (Werte $\geq 10 \%$ ) wandelte sich somit durch Kalk- oder Kompost-Gaben hin zu einer mäßigen bis sehr hohen Elastizität (Werte < $2 \%$; BMELF 1997b). 


\section{Zusammenfassung Boden}

\subsection{Physikalische Bodeneigenschaften}

Der Skelettgehalt der untersuchten Proben schwankte sehr stark zwischen 7 \% („schwacher Skelettanteil“) und 55 \% („stark steinig“) (Schroeder 1992).

An Bodenartenuntergruppen waren "mittel sandiger Lehm“, „schwach sandiger Lehm“, „schluffiger Lehm“, „schwach toniger Lehm“ und "mittel toniger Schluff" vertreten. Der Durchschnitt aller ermittelten Anteile je Korngrößenfraktion entsprach der Bodenartenuntergruppe „schluffiger Lehm“ (Scheffer \& Schachtschabel 2010).

Die Trockenraumdichte mit durchschnittlich 1,5 g/ $\mathrm{cm}^{3}$ (1,3-1,8 g/ $\mathrm{cm}^{3}$ ) wurde als „mittel“ (AK Standortskartierung 2003, Ad-hoc-AG Boden 2005) bzw. im Vergleich zu Dichten mineralischer Oberböden unter Wald als „sehr hoch“ eingestuft (LAWuF Gotha 2002).

Das Gesamtporenvolumen betrug 42 Vol.-\%. Die Luftkapazität (Anteil weiter Grobporen; wichtig für Gas- und Wassertransport) lag mit 13 Vol.-\% „hoch“ (AK Standortskartierung 2003; Ad-hoc-AG Boden 2005). Dennoch waren Infiltrationsvermögen und Wasserleitfähigkeit des Haldenbodens sehr gering, da Länge und Durchgängigkeit der vertikalen Grobporen durch Zerscherung aufgrund von mechanischer Bodenbelastung und -verdichtung vermindert wurden. Die Feldkapazität lag mit 29 Vol.-\% im „mittleren“ Bewertungsbereich, die nutzbare Feldkapazität dagegen war mit 9 Vol.-\% in der obersten und 7 Vol.-\% in der darunter liegenden Bodenschicht „gering“. Die Hälfte des GPV entfiel auf den Totwasser-Anteil (21 Vol.-\%).

Der volumetrische Wassergehalt der Bodenproben lag 2-3 Tage nach einer Regenperiode bei 17 Vol.-\% und damit bereits unterhalb der nFk (Bereich zwischen 21 und 30 Vol.-\%).

Unterschiedliche physikalische Bodenbedingungen zwischen den drei Versuchsflächen oder zwischen Bereichen ohne und mit Spontanvegetation wurden trotz teils unterschiedlicher Korngrößenzusammensetzungen nicht nachgewiesen. Denkbar sind jedoch positive Effekte auf die Standortbedingungen durch die Bodenbesiedelung (Verdunstungsschutz, Verbesserung der Bodenstruktur durch Durchwurzelung u. ä.).

\subsection{Effekte der Bodenhilfsstoffe auf die physikalischen Bodeneigenschaften}

Die Trockenraumdichte im Topf-Versuch war durch die Bodenlockerung bei Versuchsanlage mit $1,3 \mathrm{~g} / \mathrm{cm}^{3}$ signifikant geringer als im Freiland $\left(1,5 \mathrm{~g} / \mathrm{cm}^{3}\right)$. Entsprechend lag im TopfVersuch das Gesamtporenvolumen mit 51 Vol.-\% höher als im Freiland (42 Vol.-\%). Kompostund Perlit-Beimischungen senkten die TRD gegenüber der unbehandelten Kontrolle signifikant auf $1,1 \mathrm{~g} / \mathrm{cm}^{3}$ und $0,9 \mathrm{~g} / \mathrm{cm}^{3}$. Das GPV nahm signifikant auf 56 Vol.-\% und $66 \mathrm{Vol.} \% \mathrm{zu}$. Wahrscheinlich stieg dabei vor allem der Grobporenanteil (verbesserte Infiltrations- und Wasserleitfähigkeit). Der volumetrische Wassergehalt der Proben lag im Topf-Versuch aufgrund der unterschiedlichen Versuchsbedingungen deutlich höher als im Freiland. Innerhalb des Topf-Versuchs gab es keine signifikanten Unterschiede zwischen der unbehandelten Kontrolle, der Kompost- und der Stockosorb ${ }^{\circledR}$-Variante, in denen mit WG von 28 Vol.-\% bzw. 29 Vol.-\% jeweils die maximale nFk (Spanne zwischen 21-30 Vol.-\%) des Freiland-Substrats erreicht wurde. Mit Superabsorber oder Perlit wurden dagegen zum gleichen Zeitpunkt mit 25 Vol.-\% bzw. 26 Vol.-\% signifikant geringere WG gemessen. 


\subsection{Chemische Bodeneigenschaften}

Die Bodenreaktion war mit durchschnittlich pH 3,6 „sehr stark sauer“, was auf die Entstehung von Schwefelsäure bei der Pyrit-Verwitterung zurückzuführen ist. Zwischen Bereichen ohne (pH 3,6 in den obersten $5 \mathrm{~cm}, \mathrm{pH}$ 3,4 in den obersten $15 \mathrm{~cm}$; Eisen-/Aluminium-Pufferbereich) und mit Spontanvegetation (pH 4 in den obersten $5 \mathrm{~cm}, \mathrm{pH} \mathrm{3,8}$ in den obersten $15 \mathrm{~cm}$; AluminiumPufferbereich) bestanden signifikante Unterschiede (AK Standortskartierung 2003, Scheffer \& Schachtschabel 2010). Die Kohlenstoff- $(4,2 \mathrm{mg} / \mathrm{g})$ und Stickstoff-Gehalte $(0,7 \mathrm{mg} / \mathrm{g})$ (kaum Humusakkumulation bislang) waren äußerst gering. Der Phosphor-Gehalt $(0,7 \mathrm{mg} / \mathrm{g})$ lag innerhalb der üblichen Spanne in ungedüngten Böden der gemäßigten Breiten (Scheffer \& Schachtschabel 2010). C/N- und C/P-Verhältnisse waren „eng bis sehr eng“ bzw. „sehr eng“ (günstig) (BMELF 1997a, AK Standortskartierung 2003, Scheffer \& Schachtschabel 2010).

Das Haldensubstrat wies sehr hohe Schwefel-Gehalte (Mittel 1,4 mg/g; Maximum 3,2 mg/g) auf, die sowohl auf Pyrit-Verwitterung als auch auf Depositionen aus anthropogenen Emissionen zurückgehen werden. Schwefel als Schwefelwasserstoff (starkes Pflanzengift) kann das Pflanzenwachstum vollständig unterbinden (Scheffer \& Schachtschabel 2010).

Die effektive Austauschkapazität $\left(\mathrm{AK}_{\mathrm{e}}\right)$ wurde mit $88 \mathrm{mmol}(+) / \mathrm{kg}$ als "mittel“ eingestuft (AK Standortskartierung 2003; Werte für B/C-Horizonte). Auf Fläche D war sie mit $46 \mathrm{mmol}(+) / \mathrm{kg}$ signifikant geringer und lag im „niedrigen bis mittleren“ Bewertungsbereich.

Die Austauscherbelegung wies folgende Einzelsättigungswerte auf: H 5,4 \%, Na 0,4 \%, K 1,7 \%, Ca 29 \%, Mg 20 \%, Fe 0,8 \%, Mn 1 \%, Al 41 \%. In Bereichen ohne Bodenvegetation (signifikant geringere $\mathrm{pH}$-Werte) waren die Anteile der $\mathrm{K}-(0,6 \%)$ und Ca-Ionen $(15 \%)$ deutlich niedriger, die der Fe- (1,4\%), Mn- (1,2\%) und Al-Ionen (54\%) deutlich höher. In Bereichen mit Spontanbewuchs lag das Gegenteil vor (K 2,8 \%, Ca 44 \%, Fe 0,14 \%, Mn 0,8 \%, Al 28 \%). Das Verhältnis von Ca- und Al-Ionen war dort beinahe umgekehrt. Auffällig war eine insgesamt vergleichsweise sehr hohe Magnesium-Sättigung (sehr unterschiedlich zwischen den drei Versuchsflächen: A 8 \%, B $19 \%$, D $34 \%$ ).

Im Durchschnitt wurde eine „mäßig hohe“ (BMELF 1997b) Basen-Sättigung (BS) von 52 \% ermittelt (Ak Standortskartierung 2003: „basenreich“). Ebenso bewertet wurde die BS in Bereichen mit Spontanvegetation (67\%). In Bereichen ohne Bodenbewuchs wurde eine signifikant geringere BS (37 \%; „mittel“) gemessen.

Die Bewertung der relativen Austauscherbelegung (bezogen auf die $\mathrm{AK}_{\mathrm{e}}$ im Haldenboden) hinsichtlich der Elastizität gegenüber Säurebelastung (Ak Standortskartierung 2003) ergab unterschiedliche Einschätzungen (Basen-Sättigung: „mäßig hoch“, Erdalkali-Sättigung (Anteil Ca- + Mg-Ionen): „mittel“, Anteil Mg-Ionen: „sehr hoch“, Anteil K-Ionen: „gering“, Anteil Protonen + Fe-Ionen: „gering“). Je nach Versuchsfläche oder dem Vorhandensein von Bodenvegetation unterschied sich vor allem die entsprechende Einstufung des Kalium-Ionen-Anteils (Bereiche ohne Bodenbewuchs: „sehr gering“, Fläche A: „sehr gering bis gering“, Fläche D „gering bis mittel“, Fläche B sowie Bereiche mit Bodenbewuchs: „mittel“).

Bei den mittleren Nährelement-Gehalten im Haldensubstrat (Na 0,6 mg/g, K $18 \mathrm{mg} / \mathrm{g}$, Ca 1,2 $\mathrm{mg} / \mathrm{g}$, Mg 5,3 mg/g, Fe $34 \mathrm{mg} / \mathrm{g}$, Mn 0,2 mg/g, Al 60 mg/g) bestanden außer beim Eisen-Gehalt signifikante Unterschiede je nach Versuchsfläche, wobei Fläche D stets die geringsten Gehalte aufwies. Nach Scheffer \& Schachtschabel (2010) lagen die Na- und Ca-Gehalte vergleichsweise niedrig, die Mg-Gehalte hoch und die K-, Fe-, Mn- und Al-Gehalte im (recht weit gefassten) Rahmen üblicher Bodengehalte. 
Zwischen den Nährelement-Gehalten im Boden und der Austauscherbelegung bestand kaum ein Zusammenhang.

Die Bodengehalte der Schwermetalle Zink, Blei, Nickel und Kobalt waren nach den verschiedenen zur Einschätzung verwendeten Quellen (s. Anhang 1) unbedenklich. Dagegen lagen erhöhte bis stark belastende Kupfer-Gehalte mit möglichen toxischen Wirkungen vor. Auch die ermittelten Cadmium-Gehalte stellten eine starke Belastung mit zu erwartender schädigender Wirkung auf Pflanzen dar. Die Chrom-Gehalte lagen im sehr allgemeinen, weit gefassten Bereich kritischer Gesamtkonzentrationen.

Aufgrund der Heterogenität des Haldensubstrats unterschieden sich die drei Versuchsflächen des Freiland-Versuchs signifikant hinsichtlich ihrer Bodengehalte an Nährelementen und Schwermetallen sowie ihrer effektiven Kationen-Austauschkapazität.

Die im Verlauf des Versuchs innerhalb der Versuchsflächen B und D entstandenen Bereiche ohne und mit Bodenvegetationsansiedlung wiesen vor allem eine signifikant unterschiedliche Bodenreaktion auf (nur die Bereiche mit leicht höherem pH-Wert wurden von Spontanvegetation besiedelt). Auch die stark von der Bodenreaktion abhängige Austauscherbelegung war zwischen den Bereichen mit und ohne Bodenbewuchs signifikant unterschiedlich. Es ist zu vermuten, dass diese standörtlichen Unterschiede auch auf eine bereits im Jahr 2000 durchgeführte Flächenkalkung zurückzuführen sind, bei der der Düngekalk ungleichmäßig verteilt wurde (durch Wind, oberflächlich abfließende Niederschläge, Ausbringungstechnik). Dafür spricht auch die Tatsache, dass sich auf Fläche A im Gegensatz zu den Flächen B und D so gut wie keine Spontanvegetation entwickelte (Fläche A war im Gegensatz zu den Flächen B und D nicht in die Kalkungsmaßnahme eingeschlossen).

\subsection{Effekte der Bodenhilfsstoffe auf die chemischen Bodeneigenschaften}

Der Vergleich der unbehandelten Kontrolle im Topf-Versuch mit den Freiland-Proben zeigte signifikante Unterschiede auf, die auf die Heterogenität des Haldensubstrats sowie auf Auswaschung und Verbrauch durch Pflanzen bei fehlender Nachlieferung im Verlauf des dreijährigen Topf-Versuchs zurückzuführen sind.

Im Topf-Versuch (unbehandelte Kontrolle) war die effektive Kationen-Austauschkapazität $\left(\mathrm{AK}_{\mathrm{e}}\right)$ mit $45 \mathrm{mmol}(+) / \mathrm{kg}$ („niedrig bis mittel“) signifikant niedriger als der Freiland-Mittelwert.

Die Bodengehalte der Nährelemente Kalium, Magnesium, Eisen und Aluminium waren im Topf ebenso deutlich geringer wie die der Schwermetalle Zink, Cadmium, Chrom und Nickel. Zudem waren die Anteile von Mg- und Mn-Ionen an der Austauscherbelegung deutlich kleiner, die der Protonen und Fe-Ionen dafür größer.

Die Kalk- und die Kompost-Düngungen hatten im Topf-Versuch vielfältige Auswirkungen auf die bodenchemischen Eigenschaften des Haldensubstrats.

Der pH-Wert wurde auf 5,6 bzw. 5,7 („mäßig sauer“; Silikat-Pufferbereich; „ökologisches Optimum“ laut Ulrich 1980/81) angehoben, wobei durch Festlegung von $\mathrm{Al}^{3+}$ AluminiumToxizität verhindert wird. 
In der Kalk-Variante lag ein signifikant geringerer Schwefel-Gehalt $(0,7 \mathrm{mg} / \mathrm{g})$ vor, der jedoch immer noch deutlich höher war als die in Böden des humiden Klimabereichs üblichen Gehalte (Scheffer \& Schachtschabel 2010).

Die Gehalte der Schwermetalle Zink, Kupfer und Nickel lagen in der Kalk-Variante aufgrund von stärkere Auswaschung und Pflanzenaufnahme in der unbehandelten Kontrolle (niedrigerer pHWert), in der Kompost-Variante vermutlich auch aufgrund von dessen Schwermetall-Gehalt höher als in der Kontrolle. In allen Varianten waren die gemessenen Zink-, Blei-, Chrom-, Nickel-, und Kobalt-Gehalte unbedenklich, während die Kupfer- und Cadmium-Gehalte eine (starke) Belastung darstellten.

Mit Kompost-Gaben wurden deutlich höhere Kohlenstoff- $(34 \mathrm{mg} / \mathrm{g}$ bei durchschnittlich 42 $\mathrm{mg} / \mathrm{g} \mathrm{C}$ in der oberen Bodenschicht in Thüringer Waldböden laut Wirth et al. 2004) und Stickstoff-Gehalte $(3 \mathrm{mg} / \mathrm{g}$ und damit höher als manche in Waldböden üblichen mittleren Gehalte laut LAWuF Gotha 2002) sowie leicht höhere Phosphor-Gehalte $(0,9 \mathrm{mg} / \mathrm{g})$ gemessen. Die C/N- und C/P-Verhältnisse blieben unverändert „eng“ bzw. „sehr eng“ und damit günstig.

In den Behandlungsvarianten wurden gegenüber der Kontrolle bei Magnesium, Calcium (Verdoppelung mit Kalk, mehr als Verdreifachung mit Kompost) und Mangan höhere ElementGehalte im Haldenboden gemessen. Die höheren Mangan-Gehalte können vermutlich auf die stärkere Auswaschung und Pflanzenaufnahme in der unbehandelten Kontrolle (niedrigerer pHWert) zurückgeführt werden.

Die effektive Austauschkapazität $\left(\mathrm{AK}_{\mathrm{e}}\right)$ wurde durch Kalk auf einen „mittleren“ Wert (65 mmol $(+) / \mathrm{kg})$, durch Kompost deutlich stärker auf einen „mittel bis hohen“ Wert (146 $\mathrm{mmol}(+) / \mathrm{kg})$ angehoben.

Die Austauscherbelegung wies durch Kalk-Düngung erheblich höhere Ca- (62 \%) und Mg- (29 \%) Sättigungen, durch Kompost-Gabe erheblich höhere Ca- (81 \%) und K- (4,6 \%) Sättigungen auf. Die Protonen- $(0,4 \%$ / 0 \%), Fe- $(0,16 \%$ / 0,22 \%) und Al- (3,5 \% / 1,3 \%) Sättigungen waren gegenüber der unbehandelten Kontrolle deutlich geringer. In beiden Düngevarianten machten die Ca- + Mg-Sättigungen über $90 \%$ des Ionenbelages aus. Die Basen-Sättigung insgesamt wurde auf „sehr hohe“ Werte (95\% bzw. $98 \%$ ) angehoben.

Mit Kompost- bzw. Kalk-Gabe waren die Bewertungen der relativen Austauscherbelegung (bezogen auf die $\mathrm{AK}_{\mathrm{e}}$ im Haldenboden) hinsichtlich der Elastizität gegenüber Säurebelastung insgesamt deutlich besser. Basen-Sättigung, Erdalkali-Sättigung und Mg-Sättigung wurden diesbezüglich als „sehr hoch“, die Summe aus Protonen und Eisen-Ionen als „mäßig bis sehr hoch“ (BMELF 1997b) eingestuft. Mit Kalk wurde die Säureelastizität aufgrund der K-Sättigung als „gering bis mittel“, mit Kompost als „hoch“ bewertet. 


\section{Pflanzenentwicklung}

In den folgenden Kapiteln werden nach einer kurzen Beschreibung des Ausgangszustands der Versuchspflanzen die Ergebnisse der im Verlauf des zweijährigen Untersuchungszeitraums vorgenommenen Vitalitätsschätzungen, Wachstumsuntersuchungen sowie Blatt- und Nadelanalysen zur Nährstoff-Versorgung und Schadstoff-Belastung dargestellt. Zum besseren Verständnis der analysierten Wachstumsparameter erfolgt eine kurze Hinführung. Zunächst wird die Entwicklung der Versuchspflanzen ohne Einsatz von Bodenhilfsstoffen beschrieben, dann die Wirkung der Behandlungsvarianten auf die Pflanzenentwicklung analysiert. Auch der Einfluss standörtlicher Faktoren wird umfassend dargestellt. Die Punkte „Wildschäden“, „Mykorrhizierung" und „Wurzelentwicklung“ bilden jeweils eigene Kapitel.

\subsection{Ausgangszustand der Versuchspflanzen}

Als Bezugsgröße und Bewertungsmaßstab aller Vitalitäts- und Wachstumsuntersuchungen ist in Tab. 34 baumartenspezifisch die Ausgangssituation bezüglich Vitalitätszustand $(4=$ uneingeschränkt vital bis 0 = abgestorben; s. S. 27) und Haupttrieblänge als Ergebnis der ersten Untersuchung bei Anlage der Versuchspflanzung dargestellt.

Tab. 34: Haupttrieblänge [cm] u. Vitalität [codiert: 4 = vital - 0 = tot; s. S. 27] der Bäume im FreilandVersuch; MW u. Std.abw.; Ausgangszustand bei Versuchsanlage im April 2005 (n=936)

\begin{tabular}{|l|c|c|}
\hline Baumart & Haupttrieblänge bei Pflanzung [cm] & Vitalität bei Pflanzung [codiert] \\
\hline Eiche $(\mathrm{n}=192)$ & $63 \pm 13$ & $2,3 \pm 0,5$ \\
\hline Ahorn $(\mathrm{n}=192)$ & $26 \pm 6$ & $2,5 \pm 0,6$ \\
\hline Eberesche $(\mathrm{n}=120)$ & $73 \pm 12$ & $3,0 \pm 0,4$ \\
\hline Erle $(\mathrm{n}=120)$ & $101 \pm 9$ & $3,6 \pm 0,5$ \\
\hline Douglasie $(\mathrm{n}=192)$ & $26 \pm 7$ & $3,1 \pm 0,5$ \\
\hline Kiefer $(\mathrm{n}=120)$ & $27 \pm 8$ & $3,0 \pm 0,5$ \\
\hline
\end{tabular}

Die Douglasien, Ebereschen und Kiefern waren bei der Pflanzung mit einem Vitalitätswert von im Schnitt etwa „3“ in einem zufrieden stellenden Zustand. Die Haupttrieblänge betrug bei den Nadelbäumen im Mittel 26 bzw. $27 \mathrm{~cm}$, bei den Ebereschen $73 \mathrm{~cm}$. Die Erlen wiesen überwiegend sehr gute Vitalitätswerte auf (durchschnittlich 3,6) und waren mit durchschnittlich $101 \mathrm{~cm}$ Haupttrieblänge angesichts des bestellten Sortimentes (s. S. 17) bereits relativ groß. Im Gegensatz dazu waren die Ahorne mit im Mittel $26 \mathrm{~cm}$ Haupttrieblänge für das bestellte Sortiment deutlich zu klein (es ist vermutlich davon auszugehen, dass anstatt der bestellten zweijährigen Pflanzen lediglich einjährige geliefert wurden). Auch der Vitalitätszustand war mit einem Durchschnitt von 2,5 etwas schlechter als bei den anderen Baumarten. Eine Ausnahme stellten die Eichen dar, deren durchschnittlicher Vitalitätswert mit 2,3 noch darunter lag. 


\section{2. $\quad$ Einfluss der kleinräumigen Standortheterogenität}

Die Verteilung der Versuchspflanzen der insgesamt 10 (Eberesche, Erle, Kiefer) bzw. 16 (Eiche, Ahorn, Douglasie) Versuchsvarianten (s. S. 20) auf den drei Versuchsflächen A, B und D (s. S. 17) erfolgte nach dem auf Seite $21 \mathrm{f}$ vorgestellten Schema (Abb. 3). Dabei wurden zufällig ein Teil der Versuchspflanzen in Bereiche mit späterer spontaner Entwicklung von Bodenvegetation, der andere Teil in bis zum Versuchsende vegetationsfreie Bereiche gesetzt.

Dies galt für die beiden Versuchsflächen B und D, auf denen sich schließlich die gesamte Fläche als Mosaik aus bewachsenen und unbewachsenen Teilflächen darstellte (s. S. 37, Abb. 4), während auf Versuchsfläche A nur in eng begrenzten Bereichen außerhalb der Versuchspflanzung Vegetationsansiedelung stattfand.

Insgesamt wurden bei der Anlage der Versuche im April 2005 etwa ein Drittel (38\%) der 936 Bäume in Bereiche mit (späterer) spontaner Vegetationsansiedlung und entsprechend etwa zwei Drittel (62\%) in bis zum Abschluss der Untersuchungen vegetationsfreie Bereiche gepflanzt. Diese Verteilung galt ebenso für jede einzelne der sechs Baumarten.

Tab. 35: Anzahl und Anteil [\%] der Versuchsbäume in Bereichen o./m. Spontanvegetation sowie Sterblichkeitsraten im Versuchsverlauf ( $\mathrm{n}=936)$

\begin{tabular}{|l|l|l|}
\hline & $\begin{array}{l}\text { Bereiche ohne } \\
\text { Spontanvegetation }\end{array}$ & $\begin{array}{l}\text { Bereiche mit } \\
\text { Spontanvegetation }\end{array}$ \\
\hline $\begin{array}{l}\text { Anzahl (Anteil) } \\
\text { Versuchsbäume (gesamt) }\end{array}$ & $577(62 \%)$ & $359(38 \%)$ \\
\hline $\begin{array}{l}\text { Davon bis Okt. 2006 } \\
\text { abgestorben (gesamt) }\end{array}$ & $343(59 \%)$ & $104(29 \%)$ \\
\hline $\begin{array}{l}\text { Anzahl (Anteil) } \\
\text { Versuchsbäume (Fläche A) }\end{array}$ & $312(100 \%)$ & - \\
\hline $\begin{array}{l}\text { Davon bis Okt. 2006 } \\
\text { abgestorben (Fläche A) }\end{array}$ & $194(62 \%)$ & - \\
\hline $\begin{array}{l}\text { Anzahl (Anteil) } \\
\text { Versuchsbäume (Fläche B) }\end{array}$ & $86(28 \%)$ & $226(72 \%)$ \\
\hline $\begin{array}{l}\text { Davon bis Okt. 2006 } \\
\text { abgestorben (Fläche B) }\end{array}$ & $50(58 \%)$ & $133(43 \%)$ \\
\hline $\begin{array}{l}\text { Anzahl (Anteil) } \\
\text { Versuchsbäume (Fläche D) }\end{array}$ & $179(57 \%)$ & $45(34 \%)$ \\
\hline $\begin{array}{l}\text { Davon bis Okt. 2006 } \\
\text { abgestorben (Fläche D) }\end{array}$ & $99(55 \%)$ & \\
\hline
\end{tabular}

Die Verteilung innerhalb der Flächen war dabei höchst unterschiedlich (s. Tab. 35): Während alle Versuchspflanzen auf Fläche A einen Standort im unbesiedelten Bereich hatten, standen auf Fläche B rund drei Viertel aller Pflanzen in Bereichen mit späterer spontaner Bodenvegetation. Auf Fläche D wurde dagegen knapp die Hälfte der Bäume in später erwiesenermaßen "günstigere“ und etwas über die Hälfte in „ungünstigere“ Bereiche gepflanzt. Die vor allem hinsichtlich der bodenchemischen Bedingungen unterschiedlichen Standortbedingungen (s. ab S. 44 u. Tab. 23), auf die das Vorhandensein bzw. Nicht-Vorhandensein von Spontanvegetation erst zu einem späteren Zeitpunkt des Freiland-Versuchs deutlich hinwies, spielten auch für Vitalität und Wachstum der Versuchspflanzen eine große Rolle. Denkbar sind auch verbesserte 
Standortbedingungen durch die Besiedlung mit Bodenvegetation (Verdunstungsschutz, bessere Bodenstruktur durch Durchwurzelung u.ä.). Zudem deuteten die Untersuchungsergebnisse auf eine höhere Präsenz Mykorrhiza-bildender Pilze in den günstigeren Bereichen hin (s. S. 289). Die Unterschiede zwischen bewachsenen und unbewachsenen Bereichen werden bereits bei der Betrachtung der Sterblichkeitsrate (bzw. Überlebensrate) der Versuchsbäume insgesamt deutlich (s. Tab. 35; genauer nach Baumarten und Standorten aufgeschlüsselt in Tab. A 12).

Kreuztabellen weisen bei vier der sechs Baumarten einen signifikanten Einfluss des Standortes sowohl auf einer der drei Versuchsflächen als auch in Bereichen mit oder ohne Bodenvegetation auf die Sterblichkeitsrate nach (s. Tab. 36). Die Sterblichkeit der Ebereschen und Erlen hing dagegen nicht mit ihrem Standort auf einer der drei Versuchsflächen zusammen; jedoch bestand auch bei diesen beiden Baumarten eine Abhängigkeit vom Standort in bewachsenen oder unbewachsenen Bereichen.

Tab. 36: Standortabhängigkeit der Sterblichkeitsrate der Baumarten; Ergebnisse von Kreuztabellen $(\mathrm{n}=936)$

\begin{tabular}{|c|c|c|}
\hline Baumart & $\begin{array}{l}\text { Sterblichkeitsrate abhängig von } \\
\text { der Versuchsfläche (A, B, D) }\end{array}$ & $\begin{array}{l}\text { Sterblichkeitsrate abhängig vom } \\
\text { Standort ohne/mit Spontanvegetation }\end{array}$ \\
\hline $\begin{array}{l}\text { Eiche } \\
(n=192)\end{array}$ & $\begin{array}{l}\text { Ja } \\
\text { Chi-Quadrat }=12,53 \\
\text { Freiheitsgrade }=2 \\
\mathrm{p}<0,01\end{array}$ & $\begin{array}{l}\text { Ja } \\
\text { Chi-Quadrat }=18,97 \\
\text { Freiheitsgrade }=1 \\
\mathrm{p}<0,001\end{array}$ \\
\hline $\begin{array}{l}\text { Ahorn } \\
(n=192)\end{array}$ & $\begin{array}{l}\text { Ja } \\
\text { Chi-Quadrat }=24,64 \\
\text { Freiheitsgrade }=2 \\
\text { p }<0,001\end{array}$ & $\begin{array}{l}\text { Ja } \\
\text { Chi-Quadrat }=22,23 \\
\text { Freiheitsgrade }=1 \\
\text { p }<0,001\end{array}$ \\
\hline $\begin{array}{l}\text { Eberesche } \\
(n=120)\end{array}$ & Nein & $\begin{array}{l}\text { Ja } \\
\text { Chi-Quadrat }=13,55 \\
\text { Freiheitsgrade }=1 \\
p<0,001\end{array}$ \\
\hline $\begin{array}{l}\text { Erle } \\
(n=120)\end{array}$ & Nein & $\begin{array}{l}\text { Ja } \\
\text { Chi-Quadrat }=10,08 \\
\text { Freiheitsgrade }=1 \\
\text { p }<0,01\end{array}$ \\
\hline $\begin{array}{l}\text { Douglasie } \\
(n=192)\end{array}$ & $\begin{array}{l}\text { Ja } \\
\text { Chi-Quadrat }=17,35 \\
\text { Freiheitsgrade }=2 \\
\mathrm{p}<0,001\end{array}$ & $\begin{array}{l}\text { Ja } \\
\text { Chi-Quadrat }=24,37 \\
\text { Freiheitsgrade }=1 \\
\mathrm{p}<0,001\end{array}$ \\
\hline $\begin{array}{l}\text { Kiefer } \\
(n=120)\end{array}$ & $\begin{array}{l}\text { Ja } \\
\text { Chi-Quadrat }=23,75 \\
\text { Freiheitsgrade }=2 \\
\text { p }<0,001\end{array}$ & $\begin{array}{l}\text { Ja } \\
\text { Chi-Quadrat }=23,33 \\
\text { Freiheitsgrade }=1 \\
\text { p }<0,001\end{array}$ \\
\hline
\end{tabular}

Auf allen Flächen waren bis Oktober 2006 von den Bäumen in vegetationsfreien Bereichen zwischen $55 \%$ und $62 \%$ (insgesamt $59 \%$ ) abgestorben, von den in spontan besiedelten Bereichen dagegen nur 26 \% bzw. 34 \% (insgesamt $29 \%$ ). Dies spricht ebenso für bessere Standortverhältnisse in Bereichen mit Spontanvegetation wie die durchschnittlichen Vitalitätswerte aller lebenden Bäume bei Abschluss des Versuchs (s. Tab. 37). 
Tab. 37: Vitalität der lebenden Bäume bei Versuchsabschluss [codiert: 4 = vital - 0 = tot; s. S. 27]; insgesamt sowie getrennt nach Standorten in Bereichen o./m. Spontanvegetation; MW u. Std.abw.; Ergebnisse der H- bzw. U-Tests auf signifikante Unterschiede (H bzw. Z); Buchstaben kennzeichnen je Spalte homogene Gruppen nach U-Tests

\begin{tabular}{|l|l|l|l|l|}
\hline $\begin{array}{l}\text { Vitalität aller } \\
\text { lebenden Bäume } \\
\text { nach dem 2. Jahr }\end{array}$ & $\begin{array}{l}\text { Versuchs- } \\
\text { fläche }\end{array}$ & $\begin{array}{l}\text { Bereiche ohne } \\
\text { Spontanvegetation }\end{array}$ & $\begin{array}{l}\text { Bereiche mit } \\
\text { Spontanvegetation }\end{array}$ & $\begin{array}{l}\text { Ergebnis } \\
\text { U-Test }(\mathrm{Z})\end{array}$ \\
\hline \multirow{2}{*}{$2,6 \pm 0,9(\mathrm{n}=489)$} & $\mathrm{A}$ & $2,1 \pm 0,8 \mathrm{a}(\mathrm{n}=118)$ & - & \\
\cline { 2 - 5 } & $\mathrm{B}$ & $2,3 \pm 0,9 \mathrm{a}, \mathrm{b}(\mathrm{n}=36)$ & $2,8 \pm 0,8(\mathrm{n}=167)$ & $-3,17^{* * *}$ \\
\cline { 2 - 5 } & $\mathrm{D}$ & $2,6 \pm 0,8 \mathrm{~b}(\mathrm{n}=80)$ & $3,0 \pm 0,9(\mathrm{n}=88)$ & $-3,26^{* * *}$ \\
\hline \multicolumn{2}{|l}{ Ergebnis U-Test (Z) / H-Test $(\mathrm{H})$} & $\mathrm{H}=12,27^{* *}$ & $\mathrm{Z}=1,38$ & \\
\hline
\end{tabular}

Im unbesiedelten Bereich waren diese Vitalitätswerte über alle Baumarten und Varianten hinweg mit im Mittel „2,3“ (Fläche B) bzw. „2,6“ (Fläche D) signifikant niedriger als im bewachsenen Bereich mit „2,8“ (B) bzw. „3,0“ (D). Der Vitalitätszustand der lebenden Bäume auf der unbewachsenen Fläche A wurde bei Abschluss des Versuchs mit durchschnittlich „2,1“ bewertet. Er ist damit signifikant geringer als die durchschnittlichen Vitalitätswerte der lebenden Pflanzen in ebenfalls vegetationsfreien Bereichen auf Fläche D (s. Tab. 37).

Mit Blick auf diese Ergebnisse ist es wichtig, bei der Analyse der Wirkung der verschiedenen Behandlungsvarianten auf Vitalität und Wachstum der Bäume den davon unabhängigen Einfluss der kleinräumigen Standortbedingungen nicht zu vernachlässigen.

Bei der Auswertung der im Verlauf des zweijährigen Untersuchungszeitraums an den Pflanzen erhobenen Daten wurde der Einfluss des Standort-Faktors („Standort auf Versuchsfläche A, B oder D“ sowie „Standort im vegetationsfreien/spontan besiedelten Bereich“) deshalb stets mit untersucht.

Da der Standorteinfluss die Effekte der eingesetzten Bodenhilfsstoffe teilweise überlagerte, wurden grundsätzlich die Wirkungen der Behandlungsvarianten auf die Vitalitäts- und Wachstumsentwicklung der Versuchspflanzen auch unter Ausschluss dieses Faktors untersucht, indem die Gruppen der Bäume mit Standorten auf Teilflächen ohne/mit Bodenvegetation oder auf einer bestimmten Versuchsfläche auch getrennt betrachtet wurden.

\subsection{Einfluss von Wildschäden}

Wie Tab. 38 zeigt, waren die verschiedenen Baumarten unterschiedlich stark von Wildschäden (Verbiss und Abknicken durch Hasen, Rehe, Wildschweine) betroffen. Am stärksten vor allem durch Wildverbiss geschädigt wurden die Ahorne (zu insgesamt $41 \%$ ), gefolgt von den Eichen, Ebereschen und Kiefern (Schäden ausschließlich durch Abknicken) mit insgesamt je $26 \%, 25 \%$ und $22 \%$ geschädigten Bäumen. Von den bereits bei der Pflanzung sehr großen Erlen sowie den Douglasien waren mit insgesamt $11 \%$ bzw. 5 \% deutlich weniger Bäume von Wildschäden betroffen.

In 2005 waren die Versuchspflanzen insgesamt stärker verbissen bzw. geknickt als im Folgejahr. Grund dafür war ein zeitweise umgestürzter Wildzaun auf Fläche A, was auf dieser Fläche auch zu mehr Schäden als auf den anderen Versuchsflächen führte. Die Schäden durch Abknicken und durch Verbeißen in 2006 wurden auf allen drei Versuchsflächen in ähnlichem Maß beobachtet. 
Tab. 38: Anteil [\%] der durch Wild geschädigten Versuchsbäume

\begin{tabular}{|l|r|c|c|c|c|c|c|}
\hline Zeitraum & Wildschäden & Eiche & Ahorn & Douglasie & Eberesche & Kiefer & Erle \\
\hline \multirow{3}{*}{2005} & Verbiss [\%] & 17 & 34 & 1 & 13 & - & 2 \\
\cline { 2 - 9 } & Abknicken [\%] & 6 & 2 & 3 & 2 & 22 & 2 \\
\cline { 2 - 9 } & Gesamt [\%] & 23 & 36 & 4 & 14 & 22 & 3 \\
\hline \multirow{3}{*}{2006} & Verbiss [\%] & 1 & 4 & 1 & 9 & - & 3 \\
\cline { 2 - 9 } & Abknicken [\%] & 3 & 4 & 2 & 8 & - & 8 \\
\cline { 2 - 9 } & Gesamt [\%] & 3 & 8 & 2 & 13 & - & 8 \\
\hline \multirow{3}{*}{ gesamt } & Verbiss [\%] & 18 & 39 & 1 & 23 & - & 4 \\
\cline { 2 - 8 } & Abknicken [\%] & 9 & 6 & 5 & 10 & 22 & 10 \\
\cline { 2 - 8 } & Gesamt [\%] & 26 & 41 & 5 & 25 & 22 & 11 \\
\hline
\end{tabular}

Um das Einrechnen negativer Werte und damit verfälschte Durchschnittswerte zu vermeiden, wurden Messergebnisse von Bäumen, die in dem betreffenden Aufnahmejahr durch Wild verbissen oder abgeknickt worden waren, nicht in die Zuwachsanalysen mit einbezogen.

\subsection{Ergebnisse der Regressionen zwischen Wachstumsparametern}

An den zum jeweiligen Aufnahmezeitpunkt lebenden, nicht (durch Wild) geschädigten Versuchsbäumen wurden nach dem 1. Untersuchungsjahr (2005) die Haupttrieblängen, nach dem 2. Untersuchungsjahr

- die Haupttrieblängen,

- die Wurzelhalsdurchmesser,

- die Durchmesser der Haupttriebspitzen sowie

- bei Ebereschen, Erlen und Kiefern die Seitentrieblängen erfasst.

Diese Daten erlaubten die Berechnung vom

- Zuwachs des Haupttriebs im 1. Untersuchungsjahr,

- Zuwachs des Haupttriebs im 2. Untersuchungsjahr,

- Zuwachs des Haupttriebs insgesamt,

- Volumen des Haupttriebs (s. S. 27) sowie

- Verhältnis aus Haupt- und Seitentrieblängen (bei Ebereschen, Erlen und Kiefern).

Da ein Teil der Versuchsbäume jeder Baumart zur Biomassebestimmung geerntet wurde (s. S. 28), konnten statistische Zusammenhänge untersucht werden zwischen

- Länge und Trockenmasse des Haupttriebs,

- Volumen und Trockenmasse des Haupttriebs,

- Durchmesser des Wurzelhalses und Trockenmasse der Wurzel sowie

- Länge und Trockenmasse der Seitentriebe (bei Ebereschen, Erlen und Kiefern).

Dabei wurde in einem zweiten Schritt die durch die jeweilige Regressionsgleichung beschriebene Trendlinie durch den Nullpunkt geführt, was teilweise eine Abnahme der Güte des Zusammenhangs (des Bestimmtheitsmaßes $\mathrm{R}^{2}$ ) zur Folge hatte. 
Bei dann noch ausreichend hoch erachteten Zusammenhängen (Bestimmtheitsmaß $\mathrm{R}^{2}$ deutlich über 0,5; in Tab. 40, Tab. 41 und Tab. 42 durch Fettdruck hervorgehoben) wurden die mit Hilfe der entsprechenden Regressionsgleichungen für alle Probebäume errechneten Werte

- Trockenmasse des Haupttriebs (bei allen Baumarten),

- Trockenmasse der Wurzel (nur bei Nadelbäumen) sowie

- Trockenmasse der Seitentriebe (bei Ebereschen, Erlen und Kiefern) in die statistischen Analysen einbezogen.

Gleiches galt für die aus diesen errechneten Werten gebildeten Summen und Quotienten

- oberirdische Biomasse (Summe der Trockenmassen von Haupt- und Seitentrieben; nur bei Ebereschen, Erlen und Kiefern),

- Verhältnis aus den Trockenmassen von Haupt- und Seitentrieben (nur bei Ebereschen, Erlen und Kiefern),

- Summe der Trockenmassen von Haupttrieben und Wurzeln (nur bei Nadelbäumen),

- Verhältnis aus den Trockenmassen von Haupttrieben und Wurzeln (nur bei Nadelbäumen),

- Gesamt-Biomasse (Summe der Trockenmassen von Haupt- und Seitentrieben sowie Wurzeln; nur bei Kiefern) sowie

- Verhältnis aus ober- und unterirdischer Biomasse (nur bei Kiefern).

Bei den verwendeten Regressionsgleichungen handelte es sich stets um lineare Gleichungen. Mit nicht-proportionalen Gleichungen wurden bei diesen sehr jungen Versuchspflanzen keine Verbesserung der Kurvenanpassung und somit keine bessere Prognose der Biomassen über die Messwerte (Längen, Durchmesser) erreicht.

Tab. 39: Beziehungen zwischen Länge des Haupttriebs (x) in $\mathrm{cm}$ und Trockenmasse des Haupttriebs (y) in g (Regressionsgleichungen und Bestimmtheitsmaße) für die beprobten Baumarten bei unbeeinflusster sowie durch den Nullpunkt gezwungener Trendlinie

\begin{tabular}{|c|c|c|c|c|}
\hline \multirow[b]{2}{*}{ Baumart (n) } & \multicolumn{2}{|c|}{ Trendlinie unbeeinflusst } & \multicolumn{2}{|c|}{ Trendlinie durch Nullpunkt } \\
\hline & $\begin{array}{l}\text { Regressions- } \\
\text { gleichung }\end{array}$ & $\begin{array}{l}\text { Bestimmt- } \\
\text { heitsmaß }\left(R^{2}\right)\end{array}$ & $\begin{array}{l}\text { Regressions- } \\
\text { gleichung }\end{array}$ & $\begin{array}{l}\text { Bestimmt- } \\
\text { heitsmaß }\left(R^{2}\right)\end{array}$ \\
\hline Ahorn (33) & $y=0,3488 x-3,7413$ & 0,42 & $y=0,2347 x$ & 0,37 \\
\hline Eberesche (6) & $y=0,4883 x-22,992$ & 0,30 & $y=0,2501 x$ & 0,23 \\
\hline Erle (6) & $y=1,5449 x-134,54$ & 0,76 & $y=0,5151 x$ & 0,42 \\
\hline Douglasie (35) & $y=0,2522 x-3,8458$ & 0,40 & $y=0,1549 x$ & 0,33 \\
\hline Kiefer (6) & $y=0,8321 x-22,669$ & 0,48 & $y=0,4096 x$ & 0,35 \\
\hline
\end{tabular}

Der Zusammenhang zwischen Länge und Trockenmasse der Haupttriebe der geernteten Probebäume wurde bei keiner Baumart als ausreichend hoch erachtet $\left(R^{2}\right.$ zwischen 0,23 und 0,42; s. Tab. 39), um mit Hilfe der jeweiligen Regressionsgleichung die Trockenmassen der Haupttriebe aller Versuchspflanzen zu berechnen. Dagegen lagen die Bestimmtheitsmaße $\mathrm{R}^{2}$ als Maße für die Güte des Zusammenhangs zwischen Volumen und Trockenmasse der Haupttriebe der geernteten Probebäume mit Werten zwischen 0,68 und 0,96 (s. Tab. 40) deutlich höher. Damit konnte ein Zusammenhang zwischen dem aus den Messwerten Haupttrieblänge, Wurzelhalsdurchmesser und Spitzendurchmesser errechneten Volumen der Haupttriebe (s. S. 27) und ihrer tatsächlich ermittelten Trockenmasse hergestellt werden. 
Tab. 40: Beziehungen zwischen Volumen des Haupttriebs (y) in $\mathrm{cm}^{3}$ und Trockenmasse des Haupttriebs $(\mathrm{x})$ in $\mathrm{g}$ (Regressionsgleichungen und Bestimmtheitsmaße) für die beprobten Baumarten bei unbeeinflusster sowie durch den Nullpunkt gezwungener Trendlinie

\begin{tabular}{|l|l|l|l|l|}
\hline \multirow{2}{*}{ Baumart (n) } & \multicolumn{2}{|l|}{ Trendlinie unbeeinflusst } & \multicolumn{2}{l|}{ Trendlinie durch Nullpunkt } \\
\cline { 2 - 5 } & $\begin{array}{l}\text { Regressions- } \\
\text { gleichung }\end{array}$ & $\begin{array}{l}\text { Bestimmt- } \\
\text { heitsmaß } \mathbf{( R}^{\mathbf{2}} \text { ) }\end{array}$ & $\begin{array}{l}\text { Regressions- } \\
\text { gleichung }\end{array}$ & $\begin{array}{l}\text { Bestimmt- } \\
\text { heitsmaß }\left(\mathbf{R}^{\mathbf{2}}\right)\end{array}$ \\
\hline Ahorn (33) & $\mathrm{y}=0,8571 \mathrm{x}-0,331$ & 0,68 & $\mathrm{y}=0,8223 \mathrm{x}$ & $\mathbf{0 , 6 8}$ \\
\hline Eberesche (6) & $\mathrm{y}=1,6057 \mathrm{x}-1,2346$ & 0,93 & $\mathrm{y}=1,5612 \mathrm{x}$ & $\mathbf{0 , 9 3}$ \\
\hline Erle (6) & $\mathrm{y}=1,647 \mathrm{x}+38,149$ & 0,94 & $\mathrm{y}=2,1667 \mathrm{x}$ & $\mathbf{0 , 8 4}$ \\
\hline Douglasie (35) & $\mathrm{y}=1,402 \mathrm{x}+0,2172$ & 0,74 & $\mathrm{y}=1,4291 \mathrm{x}$ & $\mathbf{0 , 7 4}$ \\
\hline Kiefer (6) & $\mathrm{y}=2,1304 \mathrm{x}-6,985$ & 0,97 & $\mathrm{y}=1,9065 \mathrm{x}$ & $\mathbf{0 , 9 6}$ \\
\hline
\end{tabular}

Zusätzlich erlaubte der bei den geernteten Bäumen bestätigte Zusammenhang die Anwendung der Regressionsgleichungen zur Berechnung der Trockenmassen der Haupttriebe aller Probebäume und somit eine non-destruktive Biomasse-Ermittlung. Gleiches galt für die Zusammenhänge zwischen den Längen und Trockenmassen der Seitentriebe (s. Tab. 41). Hier betrugen die Bestimmtheitsmaße $\left(R^{2}\right)$ 0,76 bei den Erlen, 0,84 bei den Ebereschen und 0,88 bei den Kiefern.

Tab. 41: Beziehungen zwischen Länge der Seitentriebe (x) in $\mathrm{cm}^{3}$ und Trockenmasse der Seitentriebe (y) in $g$ (Regressionsgleichungen und Bestimmtheitsmaße) für die beprobten Baumarten bei unbeeinflusster sowie durch den Nullpunkt gezwungener Trendlinie

\begin{tabular}{|l|l|l|l|l|}
\hline \multirow{2}{*}{ Baumart (n) } & \multicolumn{2}{|l|}{ Trendlinie unbeeinflusst } & Trendlinie durch Nullpunkt \\
\cline { 2 - 5 } & $\begin{array}{l}\text { Regressions- } \\
\text { gleichung }\end{array}$ & $\begin{array}{l}\text { Bestimmt- } \\
\text { heitsmaß } \mathbf{( R}^{\mathbf{2}} \text { ) }\end{array}$ & $\begin{array}{l}\text { Regressions- } \\
\text { gleichung }\end{array}$ & $\begin{array}{l}\text { Bestimmt- } \\
\text { heitsmaß } \mathbf{( R}^{\mathbf{2}} \text { ) }\end{array}$ \\
\hline Eberesche (6) & $\mathrm{y}=0,0767 \mathrm{x}-1,9849$ & 0,88 & $\mathrm{y}=0,0614 \mathrm{x}$ & $\mathbf{0 , 8 4}$ \\
\hline Erle (6) & $\mathrm{y}=0,1086 \mathrm{x}-20,447$ & 0,92 & $\mathrm{y}=0,0652 \mathrm{x}$ & $\mathbf{0 , 7 6}$ \\
\hline Kiefer (6) & $\mathrm{y}=0,0553 \mathrm{x}-0,5077$ & 0,88 & $\mathrm{y}=0,0533 \mathrm{x}$ & $\mathbf{0 , 8 8}$ \\
\hline
\end{tabular}

Der Zusammenhang zwischen den Wurzelhalsdurchmessern und den Trockenmassen der Wurzeln der geernteten Bäume (s. Tab. 42) wurde nur bei den Nadelbäumen als ausreichend hoch erachtet, um die Berechnung der unterirdischen Biomasse (Trockenmasse der Wurzel) aller Versuchspflanzen anhand der entsprechenden Regressionsgleichungen vorzunehmen.

Tab. 42: Beziehungen zwischen Durchmesser des Wurzelhalses (x) in $\mathrm{cm}^{3}$ und Trockenmasse der Wurzel (y) in $\mathrm{g}$ (Regressionsgleichungen und Bestimmtheitsmaße) für die beprobten Baumarten bei unbeeinflusster sowie durch den Nullpunkt gezwungener Trendlinie

\begin{tabular}{|c|c|c|c|c|}
\hline \multirow[b]{2}{*}{ Baumart (n) } & \multicolumn{2}{|c|}{ Trendlinie unbeeinflusst } & \multicolumn{2}{|c|}{ Trendlinie durch Nullpunkt } \\
\hline & $\begin{array}{l}\text { Regressions- } \\
\text { gleichung }\end{array}$ & $\begin{array}{l}\text { Bestimmt- } \\
\text { heitsmaß }\left(R^{2}\right)\end{array}$ & $\begin{array}{l}\text { Regressions- } \\
\text { gleichung }\end{array}$ & $\begin{array}{l}\text { Bestimmt- } \\
\text { heitsmaß }\left(R^{2}\right)\end{array}$ \\
\hline Ahorn (33) & $y=2,3335 x-5,5557$ & 0,32 & $y=1,5199 x$ & 0,28 \\
\hline Eberesche (6) & $y=5,1756 x-28,671$ & 0,63 & $y=2,4798 x$ & 0,45 \\
\hline Erle (6) & $y=12,982 x-168,15$ & 0,94 & $y=4,3455 x$ & 0,52 \\
\hline Douglasie (35) & $y=2,2312 x-7,1887$ & 0,78 & $y=1,3186 x$ & 0,64 \\
\hline Kiefer (6) & $y=1,8325 x-7,3828$ & 0,91 & $y=1,2986 x$ & 0,82 \\
\hline
\end{tabular}




\subsection{Pflanzenentwicklung ohne Bodenhilfsstoff-Behandlung (Kontrollen)}

Im Folgenden werden Versorgungs- und Belastungssituation sowie Vitalität und Wachstum der unbehandelten Kontrollbäume (jeweils mit Beschreibung des Standorteinflusses und Vergleich zum Gesamtdurchschnitt) im Freiland-Versuch auf den Ronneburger Tagebaufolgeflächen dargestellt. Die Ergebnisse zeigen die Entwicklung der verschiedenen Baumarten an diesem Standort und dienen als Referenz für die Effekte der eigesetzten Bodenhilfsstoff-Behandlungen.

\subsubsection{Nährstoffversorgung und Schadstoffbelastung}

Um gezielt die Auswirkungen der diversen Bodenhilfsstoffe auf die Nährstoffversorgung und Schadstoffbelastung der Pflanzen zu untersuchen, wurden im 2. Vegetationsjahr auf Fläche D für jede Baumart und Versuchsvariante Mischproben der Blätter bzw. Nadeln analysiert (s. S. 26). Als Bezugspunkt für die in den Behandlungsvarianten gemessenen Werte erfolgt zunächst eine Darstellung und Bewertung der Nadel- und Blattspiegelwerte der Bäume der Nullvariante. Grundlage der Bewertung sind die in Anhang 2 aufgeführten Quellen. Bei auffallend hohen Gehalten werden als Vergleich die im Rahmen des Deutschen Waldbodenberichtes an Buchen, Fichten und Kiefern gemessenen Maximalwerte genannt (BMELF 1997b).

\subsubsection{Hauptnährelemente, Makronährstoffe (N, P, K, Ca, Mg, S)}

Stickstoff, Phosphor, Kalium, Calcium, Magnesium und Schwefel werden als Hauptnährelemente oder Makronährstoffe bezeichnet (z.B. Bergmann 1993, Scheffer \& Schachtschabel 2010). Die in den Assimilationsorganen der Kontrollen gemessenen Makronährstoff-Gehalte zeigt Abb. 16.

\section{Rot-Eiche}

Die Analyseergebnisse des Eichen-Laubs der Nullvariante auf Fläche D (s. Tab. 43) zeigten laut den verwendeten Quellen Stickstoff- und Phosphormangel bzw. eine nicht oder nur knapp ausreichende Versorgung mit diesen beiden Nährstoffen. Der gemessene Calcium-Gehalt war demnach im Grenzbereich zwischen Unter- und Optimalversorgung (Heinsdorf 1996) bzw. (knapp) ausreichend (BFW 2005/7, Bergmann 1993). Der Kalium-Gehalt lag im ausreichenden/Optimalbereich, nach Bergmann (1993) war er jedoch nicht ausreichend. Der wie bei anderen Baumarten (Ausnahmen: Erle, Douglasie) auffallend hohe Magnesium-Gehalt lag im Extrembereich. Der wie bei allen Baumarten hohe Schwefel-Gehalt überschritt mit 4,2 $\mathrm{mg} / \mathrm{g}$ trockener Blattmasse deutlich die obere Grenze der Extremversorgung (2,3-2,8 mg/g) nach Heinsdorf $(1996,1999)$ sowie den Gehalt, ab dem bei Ahornen Toxizitätssymptome oder Wachstumsrückgang festgestellt wurden (3,3 mg/g; van den Burg 1985, 1990).

Tab. 43: Makronährstoff-Gehalte im Laub unbehandelter Eichen im Freiland-Versuch (Fläche D) im 2. Untersuchungsjahr (Mischproben), Einstufung durch verschiedene Autoren

\begin{tabular}{|l|l|l|l|l|}
\hline Element & mg/g & BFW (2005/7) & Heinsdorf (1996, 1999) & Bergmann (1993) \\
\hline Stickstoff & 15,3 & $\begin{array}{l}\text { Mangel bis } \\
\text { knapp ausreichend }\end{array}$ & Mangel, gering & nicht ausreichend \\
\hline Phosphor & 1,2 & knapp ausreichend & unterversorgt & nicht ausreichend \\
\hline Kalium & 6,1 & ausreichend & optimal & nicht ausreichend \\
\hline Calcium & 4,7 & knapp ausreichend & unterversorgt bis optimal & ausreichend \\
\hline Magnesium & 3,9 & über optimal & extrem & über ausreichend \\
\hline Schwefel & 4,2 & & mehr als extrem & \\
\hline
\end{tabular}



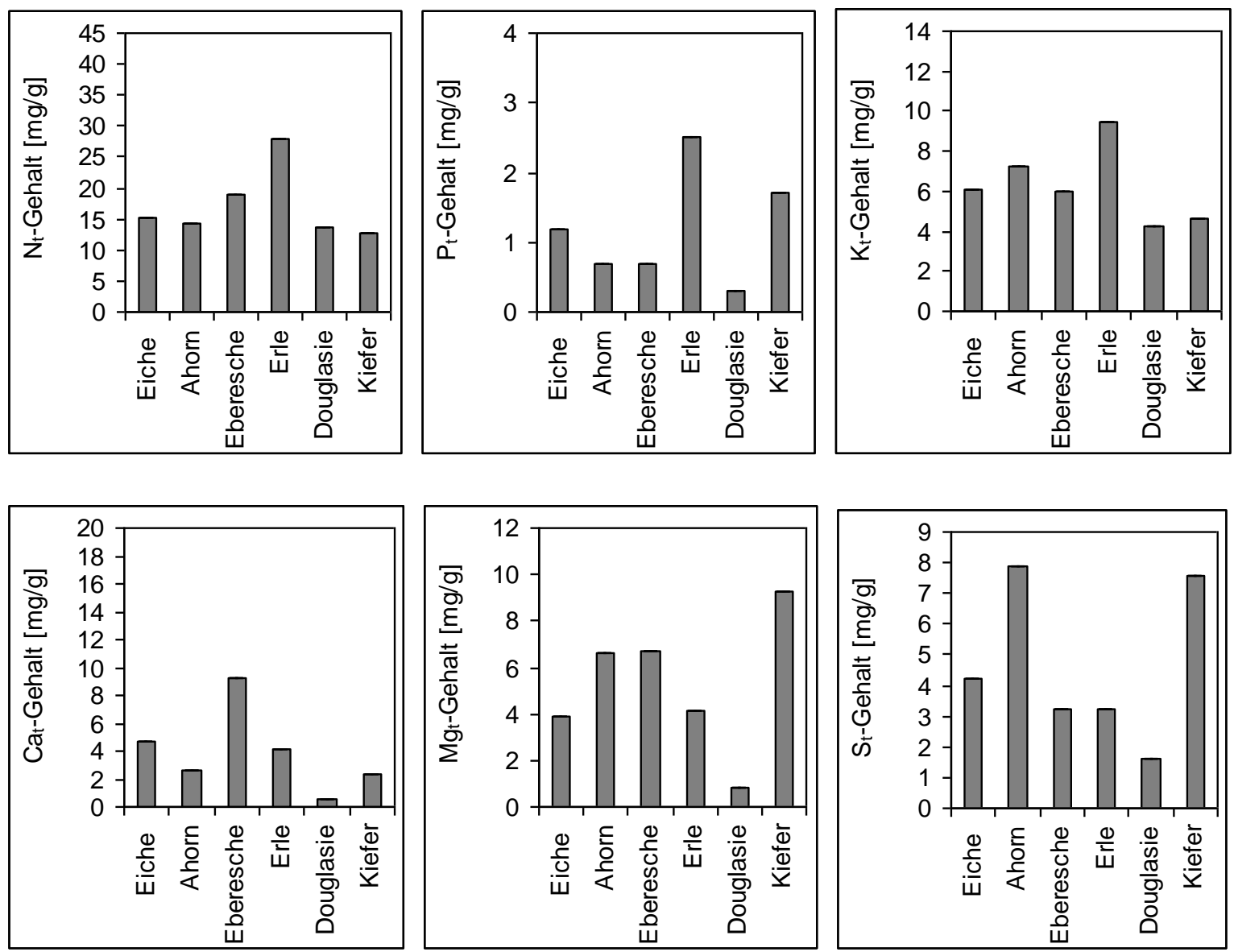

Abb. 16: Makronährstoff-Gehalte (N, P, K, Ca, Mg, S) [mg/g] in den Assimilationsorganen der Nullvariante der sechs Baumarten im Freiland-Versuch (Fläche D) im 2. Untersuchungsjahr (Mischproben)

\section{Spitz-Ahorn}

Nach van den Burg $(1985,1990)$, Bergmann (1993) und BFW (2005/07) wies das Ahorn-Laub der Nullvariante auf Fläche D Stickstoff-, Phosphor-, Calcium- und Kalium-Gehalte im Mangelbereich auf (s. Tab. 44), wobei der Kalium-Gehalt knapp unter der Grenze ausreichender Normalgehalte $(7,8-16,0 \mathrm{mg} / \mathrm{kg})$ nach van den Burg $(1985,1990)$ lag. Der wiederum auffallend hohe Magnesium-Gehalt überschritt mit 6,6 mg/kg die ausreichenden Normalgehalte (1,9-4,6 $\mathrm{mg} / \mathrm{kg}$ ) dagegen deutlich. Die wie bei allen Baumarten hohe Schwefelkonzentration von 7,9 $\mathrm{mg} / \mathrm{kg}$ lag weit über dem Schwellenwert (> 3,3 mg/kg), ab dem nach van den Burg $(1985,1990)$ Toxizitätssymptome und Wachstumsrückgang festgestellt wurden oder möglich sind.

Tab. 44: Makronährstoff-Gehalte im Laub unbehandelter Ahorne im Freiland-Versuch (Fläche D) im 2. Untersuchungsjahr (Mischproben), Einstufung durch verschiedene Autoren

\begin{tabular}{|l|l|l|l|l|}
\hline Element & $\mathbf{m g} / \mathbf{g}$ & BFW (2005/7) & van den Burg (1985, 1990) & Bergmann (1993) \\
\hline Stickstoff & 14,2 & Mangel & Mangel & nicht ausreichend \\
\hline Phosphor & 0,7 & Mangel & Mangel & nicht ausreichend \\
\hline Kalium & 7,2 & Mangel & $\begin{array}{l}\text { Mangel bis knapp } \\
\text { ausreichend }\end{array}$ & nicht ausreichend \\
\hline Calcium & 2,6 & Mangel & nicht ausreichend & nicht ausreichend \\
\hline Magnesium & 6,6 & über optimal & über normal & über ausreichend \\
\hline Schwefel & 7,9 & & toxisch & \\
\hline
\end{tabular}




\section{Eberesche}

Der gemessene Stickstoff-Gehalt der Ebereschen-Blätter der Nullvariante (Fläche D) lag im Vergleich mit Werten für andere Laubbaumarten (Bergmann 1993) im gerade ausreichenden Bereich. Demnach war der Calcium-Gehalt ebenfalls ausreichend, die Kalium- und PhosphorGehalte waren es jedoch nicht (s. Tab. 45). Der wie bei anderen Baumarten (Ausnahmen: Erle, Douglasie) auffallend hohe Magnesium-Gehalt lag mit 6,7 $\mathrm{mg} / \mathrm{g}$ deutlich über der oberen Grenze des bei Laubbäumen als ausreichend bezeichneten Wertebereichs (3 bzw. $4 \mathrm{mg} / \mathrm{g}$ trockener Blattmasse). Die wie bei allen Baumarten hohe Schwefelkonzentration überstieg mit 3,2 mg/g die von Heinsdorf (1996) genannte obere Grenze einer Extremversorgung bei Eichen $(2,3-2,8 \mathrm{mg} / \mathrm{g})$ und kam dem Wert nahe, ab dem laut van den Burg $(1985,1990)$ bei Ahornen Toxizitätssymptome und Wachstumsrückgang festgestellt wurden oder möglich sind (3,3 mg/g).

Tab. 45: Makronährstoff-Gehalte im Laub unbehandelter Ebereschen im Freiland-Versuch (Fläche D) im 2. Untersuchungsjahr (Mischproben), Einstufung durch verschiedene Autoren

\begin{tabular}{|l|l|l|}
\hline Element & $\mathbf{m g} / \mathbf{g}$ & Bergmann (1993)* $^{*}$ \\
\hline Stickstoff & 18,8 & knapp ausreichend \\
\hline Phosphor & 0,7 & nicht ausreichend \\
\hline Kalium & 6,0 & nicht ausreichend \\
\hline Calcium & 9,2 & ausreichend \\
\hline Magnesium & 6,7 & über ausreichend \\
\hline Schwefel & 3,2 & über extrem**; knapp toxisch*** \\
\hline
\end{tabular}

* Bewertung der Mineralstoff-Gehalte in der Trockenmasse von Blättern verschiedener Laubbaumarten (Ahorn, Birke, Buche, Eiche, Esche, Linde, Pappel)

** bei Eichen nach Heinsdorf (1996)

*** bei Ahornen nach van den Burg $(1985,1990)$

\section{Schwarz-Erle}

Durch die Symbiose von Erlenwurzeln mit Actinomyceten, die im Gegensatz zu Pflanzen in der Lage sind, Stickstoff aus der Luft zu binden und ihrem Symbionten zur Verfügung zu stellen, lag der Stickstoff-Gehalt in den Erlen-Blättern der Nullvariante (Fläche D) deutlich höher als in den Assimilationsorganen der übrigen untersuchten Baumarten (s. Tab. 46). Von einer ausreichenden Versorgung ist auszugehen.

Tab. 46: Makronährstoff-Gehalte im Laub unbehandelter Erlen im Freiland-Versuch (Fläche D) im 2. Untersuchungsjahr (Mischproben), Einstufung durch verschiedene Autoren

\begin{tabular}{|l|l|l|}
\hline Element & $\mathbf{m g} / \mathbf{g}$ & Bergmann (1993)* \\
\hline Stickstoff & 27,8 & \\
\hline Phosphor & 2,5 & ausreichend \\
\hline Kalium & 9,5 & knapp nicht ausreichend \\
\hline Calcium & 4,2 & ausreichend \\
\hline Magnesium & 4,1 & knapp über ausreichend \\
\hline Schwefel & 3,2 & über extrem**; knapp toxisch*** \\
\hline
\end{tabular}

* Bewertung der Mineralstoff-Gehalte in der Trockenmasse von Blättern verschiedener Laubbaumarten (Ahorn, Birke, Buche, Eiche, Esche, Linde, Pappel)

** bei Eichen nach Heinsdorf (1996)

*** bei Ahornen nach van den Burg $(1985,1990)$ 
Gemessen an bei Bergmann (1993) aufgeführten Werten für verschiedene Laubbaumarten waren die Gehalte der anderen Makronährstoffe überwiegend ebenfalls ausreichend, wobei der gemessene Kaliumwert knapp unter diesem Bereich (ab $10 \mathrm{mg} / \mathrm{g}$ ), der Magnesiumwert dagegen etwas darüber (bis 3 bzw. $4 \mathrm{mg} / \mathrm{g}$ ) lag. Der wie bei allen Baumarten hohe SchwefelGehalt betrug ebenso wie bei den Ebereschen 3,2 g/mg und lag damit oberhalb einer Extremversorgung (Werte für Eichen, Heinsdorf 1996) und möglicherweise bereits im toxischen Bereich (Werte für Ahorn, van den Burg 1985, 1990).

Zur Veranschaulichung der außergewöhnlichen Höhe der hier beschriebenen Magnesium- und Schwefel-Blattgehalte seien die im Rahmen des deutschen Waldbodenberichtes in Buchenlaub ermittelten Maximalwerte (BMELF 1997b) genannt. Für die Magnesium-Blattgehalte lag das Maximum bei $\mathbf{4 , 8} \mathrm{mg} / \mathrm{g}$ (hier: $6,6 \mathrm{mg} / \mathrm{g}$ bzw. $6,7 \mathrm{mg} / \mathrm{g}$ bei den unbehandelten Ahornen und Ebereschen), für die Schwefel-Blattgehalte bei $\mathbf{2 , 4} \mathrm{mg} / \mathrm{g}$ (hier: $4,2 \mathrm{mg} / \mathrm{g}$ bei Eichen, 7,9 $\mathrm{mg} / \mathrm{g}$ bei Ahornen sowie 3,2 mg/g bei Ebereschen und Erlen ohne Bodenhilfsstoffbehandlung).

\section{Douglasie}

Der Stickstoff-Gehalt der Douglasien-Nadeln der Nullvariante (Fläche D) war mit 13,8 mg/g nach IFTNC (1987) als knapp unzureichend (< $14 \mathrm{mg} / \mathrm{g}$ ), nach Heinsdorf (1999) als gering (< $14,9 \mathrm{mg} / \mathrm{g}$ ), nach Bergmann (1993) jedoch als ausreichend (11-17 mg/g) einzustufen. Die Kalium-, Calcium-, Magnesium- und Phosphor-Gehalte (s. Tab. 47) waren nicht ausreichend (IFTNC 1987, Bergmann 1993), der Phosphor-Gehalt dabei auffallend gering. Zur Bewertung des wie bei allen Baumarten hohen Schwefel-Gehaltes konnte keine Klassifikation für DouglasienNadeln gefunden werden. Gemessen an der Bewertungsskala des Deutschen Waldbodenberichtes für Schwefel-Gehalte in Fichten- und Kiefern-Nadeln ist die gemessene Konzentration von $1,6 \mathrm{mg} / \mathrm{kg}$ als sehr hoch $(\geq 1,4 \mathrm{mg} / \mathrm{kg}$ ) einzustufen (BMELF 1997b). Sie überstieg die österreichischen Schadstoffgrenzwerte für die Nadeljahrgänge $1(1,1 \mathrm{mg} / \mathrm{g})$ und 2 (1,4 mg/g) von Fichten und Kiefern (BFW 2005/7).

Tab. 47: Makronährstoff-Gehalte in den Nadeln unbehandelter Douglasien im Freiland-Versuch (Fläche D) im 2. Untersuchungsjahr (Mischproben), Einstufung durch verschiedene Autoren

\begin{tabular}{|l|l|l|l|l|l|}
\hline Element & $\mathbf{m g} / \mathbf{g}$ & $\begin{array}{l}\text { Heinsdorf } \\
\text { (1999) }\end{array}$ & $\begin{array}{l}\text { BMELF } \\
\text { (1997b) }\end{array}$ & $\begin{array}{l}\text { IFTNC } \\
\text { (1987) }\end{array}$ & $\begin{array}{l}\text { Bergmann } \\
\text { (1993) }\end{array}$ \\
\hline Stickstoff & 13,8 & gering & & knapp unzureichend & ausreichend \\
\hline Phosphor & 0,3 & & & & nicht ausreichend \\
\hline Kalium & 4,2 & & & unzureichend & nicht ausreichend \\
\hline Calcium & 0,6 & & & & nicht ausreichend \\
\hline Magnesium & 0,8 & & & & nicht ausreichend \\
\hline Schwefel & 1,6 & & sehr hoch* & & \\
\hline
\end{tabular}

* Bewertungsskala des Deutschen Waldbodenberichtes für Fichten- und Kiefern-Nadeln

\section{Wald-Kiefer}

Nach dem Bewertungsschlüssel des Deutschen Waldbodenberichtes (BMELF 1997b), des österreichischen BFW (2005/7) und den bei Hofmann \& Krauss (1988) sowie Bergmann (1993) angegebenen Werten war der Stickstoff-Gehalt der Kiefern-Nadeln der Nullvariante auf Fläche D (s. Tab. 48) als sehr gering, weniger als ausreichend bzw. im Bereich des Mangels oder der Unterversorgung einzustufen; nach Heinsdorf (1999) war er ebenfalls gering. Der Phosphor- 
Gehalt lag dagegen im mittleren, ausreichenden Bereich, nach Hofmann \& Krauss (1988) sogar im Bereich der Überversorgung. Der Kalium-Gehalt wurde nach der Bewertung des BFW (2005/7) als nicht ausreichend, nach den drei anderen Quellen jedoch als mittel bzw. ausreichend oder optimal eingestuft. Der Calcium-Gehalt wurde nach drei Quellen als gering und nicht ausreichend, nach Hofmann \& Krauss (1988) dagegen als optimal bewertet. Der wie bei den Laubbäumen (Ausnahme: Erle) auffällige Magnesium-Gehalt (9,3 mg/g) und der wie bei allen Baumarten hohe Schwefel-Gehalt (7,6 mg/g) waren sehr hoch (BMELF 1997b) und lagen um ein Vielfaches oberhalb des jeweiligen Extremversorgungsbereichs nach Hofmann \& Krauss (1988). Sie betrugen etwa das 4,5-fache bzw. das Doppelte der im Rahmen der Nadelanalysen im Deutschen Waldbodenbericht gemessenen Maximalwerte. Die Schwefelkonzentration lag um ein Vielfaches über den österreichischen Schadstoffgrenzwerten für die Nadeljahrgänge $1(1,1$ mg/g), 2 (1,4 mg/g) und 3 (1,7 mg/g) von Fichten und Kiefern (BFW 2005/7).

Tab. 48: Makronährstoff-Gehalte in den Nadeln unbehandelter Kiefern im Freiland-Versuch (Fläche D) im 2. Untersuchungsjahr (Mischproben), Einstufung durch verschiedene Autoren

\begin{tabular}{|l|l|l|l|l|l|}
\hline Element & $\mathbf{m g} / \mathbf{g}$ & $\begin{array}{l}\text { BMELF } \\
\mathbf{( 1 9 9 7 b )}\end{array}$ & $\begin{array}{l}\text { BFW } \\
\mathbf{( 2 0 0 5 / 7 )}\end{array}$ & $\begin{array}{l}\text { Hofmann \& } \\
\text { Krauss (1988) }\end{array}$ & $\begin{array}{l}\text { Bergmann } \\
\mathbf{( 1 9 9 3 )}\end{array}$ \\
\hline Stickstoff & 12,7 & sehr gering & Mangel & unterversorgt & $\begin{array}{l}\text { nicht } \\
\text { ausreichend }\end{array}$ \\
\hline Phosphor & 1,7 & mittel & ausreichend/optimal & überversorgt & ausreichend \\
\hline Kalium & 4,6 & mittel & nicht ausreichend & optimal & ausreichend \\
\hline Calcium & 2,3 & gering & nicht ausreichend & optimal & $\begin{array}{l}\text { nicht } \\
\text { ausreichend }\end{array}$ \\
\hline Magnesium & 9,3 & sehr hoch & über optimal & über extrem & $\begin{array}{l}\text { über } \\
\text { ausreichend }\end{array}$ \\
\hline Schwefel & 7,6 & sehr hoch & & über extrem & \\
\hline
\end{tabular}

Zur Veranschaulichung der außergewöhnlichen Höhe der hier beschriebenen Magnesium- und Schwefel-Nadelgehalte seien die im Rahmen des deutschen Waldbodenberichtes in Kiefern- und Fichtennadeln ermittelten Maxima (BMELF 1997b) genannt. Für die Magnesium-Nadelgehalte lag dieses bei den Fichten bei 3,0 mg/g im ersten und 2,6 mg/g im dritten Nadeljahrgang, bei den Kiefern bei 2,0 mg/g (zum Vergleich: $9,3 \mathbf{~ m g} / \mathbf{g}$ bei den unbehandelten Kiefern in Ronneburg). Für die Schwefel-Nadelgehalte wurden Maxima von bei den Fichten 2,9 mg/g im ersten und 5,4 mg/g im dritten Nadeljahrgang, bei den Kiefern 4,1 mg/g im ersten und 2,6 mg/g im zweiten Nadeljahrgang gemessen (zum Vergleich: 7,6 mg/g bei den unbehandelten Kiefern in Ronneburg). 


\subsubsection{Spurennährelemente, Mikronährstoffe (Fe, $\mathrm{Mn}, \mathrm{Zn}, \mathrm{Cu}$ )}

Mit Spurennährelementen oder Mikronährstoffen sind die Elemente Eisen, Mangan, Zink und Kupfer gemeint (z.B. Bergmann 1993, Scheffer \& Schachtschabel 2010). In Abb. 17 sind die Mikronährstoff-Gehalte in den Assimilationsorganen der unbehandelten Kontrollbäume zusammengestellt.
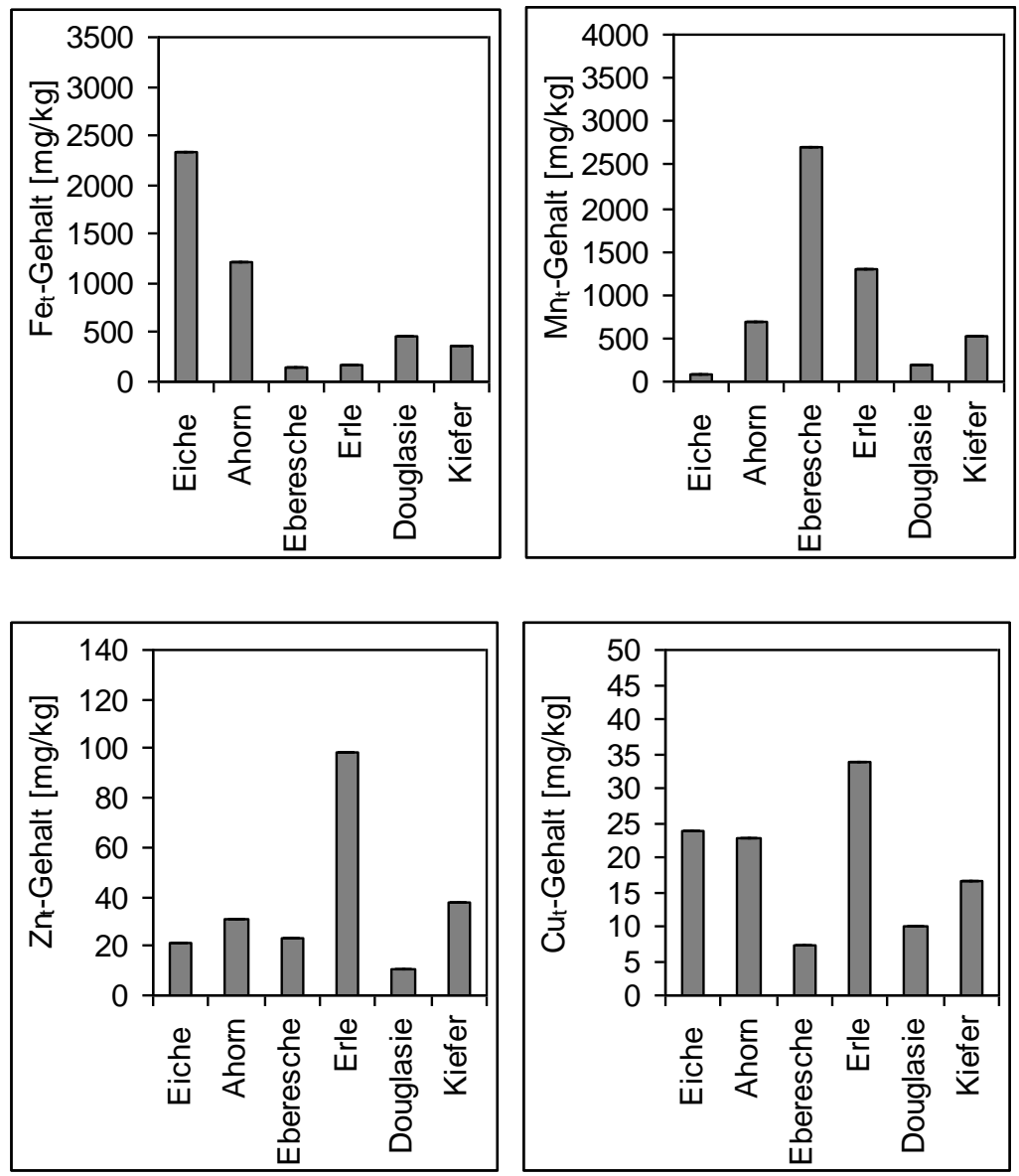

Abb. 17: Mikronährstoff-Gehalte (Fe, $\mathrm{Mn}, \mathrm{Zn}, \mathrm{Cu})$ [mg/kg Trockenmasse] in den Assimilationsorganen der Nullvariante der sechs Baumarten im Freiland-Versuch (Fläche D) im 2. Untersuchungsjahr (Mischproben)

\section{Rot-Eiche}

Der Eisen-Gehalt der Eichen-Blätter (Kontrolle, Fläche D) lag mit 2324 mg/kg weit höher als bei den übrigen untersuchten Baumarten und betrug etwa das 8-fache der Obergrenze des bei Heinsdorf (1996) als Extremversorgung bezeichneten Bereichs (205-300 mg/kg). Die Vermutung eines Messfehlers kann mit Blick auf die ebenfalls sehr hohen Eisen-Gehalte, die in der trockenen Blattmasse der Behandlungsvarianten gemessen wurden (s. ab S. 110), wohl ausgeschlossen werden. Die gemessene Mangankonzentration deutete mit $87 \mathrm{mg} / \mathrm{kg}$ nach Heinsdorf (1996) auf einen starken Mangel hin (Bereich der Mangelversorgung nach Heinsdorf 1996: 200-396 mg/kg), während der Wert beim BFW (2005/7) und bei Bergmann (1993) als ausreichend eingestuft wurde. Der Zink-Gehalt war ausreichend und lag auf der Grenze zwischen Optimal- und Überversorgung (s. Tab. 49). Der Kupfer-Gehalt war laut BFW (2005/7) über optimal. Er lag mit 23,7 mg/kg doppelt so hoch wie der bei Bergmann (1993) als ausreichend bezeichnete Wert $(6-12 \mathrm{mg} / \mathrm{kg})$ und überstieg auch die Normalgehalte in Pflanzen 
nach Smidt (1999) (10-20 mg/kg). Nach den sehr allgemeinen Einteilungen in Alloway (1999) kann es bei Kupfer-Gehalten von über 20-100 mg/kg zu Schadwirkungen kommen.

Tab. 49: Mikronährstoff-Gehalte im Laub unbehandelter Eichen im Freiland-Versuch (Fläche D) im 2. Untersuchungsjahr (Mischproben), Einstufung durch verschiedene Autoren

\begin{tabular}{|l|l|l|l|l|}
\hline Element & $\mathbf{m g} / \mathbf{k g}$ & BFW (2005/7) & Heinsdorf (1996) & Bergmann (1993) \\
\hline Eisen & 2324 & & über extrem & \\
\hline Mangan & 87 & ausreichend & Mangel & ausreichend \\
\hline Zink & 21,2 & ausreichend & optimal bis überversorgt & ausreichend \\
\hline Kupfer & 23,7 & über optimal & & über ausreichend \\
\hline
\end{tabular}

\section{Spitz-Ahorn}

Nach van den Burg $(1985,1990)$ lag der in den Ahorn-Blättern (Kontrolle, Fläche D) gemessene Eisen-Gehalt mit $1216 \mathrm{mg} / \mathrm{kg}$ 6-mal so hoch wie die obere Grenze ausreichender Normalgehalte. Zink war nach den verwendeten Quellen in (knapp) ausreichender Konzentration vorhanden (s. Tab. 50). Der Mangan-Gehalt lag mit 703 mg/kg deutlich über den ausreichenden/optimalen Normalgehalten. Eine genauere Einschätzung (auch einer möglichen Toxizität) ist aufgrund stark abweichender Literaturwerte schwierig (s. ab S. 333). Die Kupferkonzentration war über optimal und mit $22,8 \mathrm{mg} / \mathrm{kg}$ fast doppelt so hoch wie der maximale ausreichende Normalgehalt nach van den Burg $(1985,1990)(12,8 \mathrm{mg} / \mathrm{kg})$ und damit auch höher als die bei Smidt (1999) angegebene Spanne von Normalgehalten (10-20 mg/kg). Nach den sehr allgemeinen Einteilungen in Alloway (1999) kann es bei Kupfer-Gehalten von über 20-100 mg/kg zu Schadwirkungen kommen.

Tab. 50: Mikronährstoff-Gehalte im Laub unbehandelter Ahorne im Freiland-Versuch (Fläche D) im 2. Untersuchungsjahr (Mischproben), Einstufung durch verschiedene Autoren

\begin{tabular}{|l|l|l|l|l|}
\hline Element & $\mathbf{m g} / \mathbf{k g}$ & BFW (2005/7) & van den Burg (1985, 1990) & Bergmann (1993) \\
\hline Eisen & 1216 & & über ausreichend/normal & \\
\hline Mangan & 703 & über optimal & über ausreichend/normal & über ausreichend \\
\hline Zink & 30,9 & ausreichend & knapp ausreichend & ausreichend \\
\hline Kupfer & 22,8 & über optimal & über ausreichend/normal & über ausreichend \\
\hline
\end{tabular}

\section{Eberesche}

Die Ebereschen-Blätter (Kontrolle, Fläche D) wiesen mit $2714 \mathrm{mg} / \mathrm{kg}$ den mit Abstand höchsten Mangan-Gehalt aller sechs untersuchten Baumarten auf. Der Wert lag weit über den ausreichenden, normalen bzw. optimalen Gehalten bei anderen Laubbäumen nach Bergmann (1993), van den Burg (1985, 1990) sowie Heinsdorf (1996). Eine genauere Einschätzung (auch einer möglichen Toxizität) ist aufgrund stark abweichender Literaturwerte schwierig (s. ab S. 333). Die gemessenen Zink- und Kupfer-Gehalte (s. Tab. 51) sind nach Bergmann (1993) als ausreichend einzustufen. Die Eisen-Gehalte lagen gemessen an den Einstufungen der Eisenkonzentrationen in Ahorn-Blättern (van den Burg 1985, 1990) im Bereich ausreichender Normalgehalte $(63-212 \mathrm{mg} / \mathrm{kg})$. 
Tab. 51: Mikronährstoff-Gehalte im Laub unbehandelter Ebereschen im Freiland-Versuch (Fläche D) im 2. Untersuchungsjahr (Mischproben), Einstufung durch verschiedene Autoren

\begin{tabular}{|l|l|l|}
\hline Element & $\mathbf{m g} / \mathbf{k g}$ & Bergmann (1993)* $^{*}$ \\
\hline Eisen & 140 & ausreichend, normal** \\
\hline Mangan & 2714 & über ausreichend; über optimal \\
\hline Zink & 22,7 & ausreichend \\
\hline Kupfer & 7,3 & ausreichend \\
\hline
\end{tabular}

* Bewertung der Mineralstoff-Gehalte in der Trockenmasse von Blättern verschiedener Laubbaumarten (Ahorn, Birke, Buche, Eiche, Esche, Linde, Pappel)

** bei Ahornen nach van den Burg $(1985,1990)$

*** bei Eichen nach Heinsdorf (1996)

\section{Schwarz-Erle}

Die vergleichsweise hohe Mangankonzentration in den Erlen-Blättern (Kontrolle, Fläche D) wies auf eine mehr als ausreichende Versorgung hin (s. Tab. 52). Eine genauere Einschätzung (auch einer möglichen Toxizität) ist aufgrund stark abweichender Literaturwerte schwierig (s. ab S. 333). Die gemessenen Zink- (98,6 mg/kg) und Kupfer-Gehalte $(33,9 \mathrm{mg} / \mathrm{kg})$ waren höher als bei den übrigen untersuchten Baumarten und lagen nach Bergmann (1993) oberhalb des ausreichenden Bereichs, der Kupfer-Gehalt zudem deutlich oberhalb des Normalgehalts in Pflanzen nach Smidt (1999). Nach den sehr allgemeinen Einteilungen in Alloway (1999) kann es bei Kupfer-Gehalten von über 20-100 mg/kg zu Schadwirkungen kommen. Die Eisen-Gehalte lagen gemessen an den Einstufungen der Eisenkonzentrationen in Ahorn-Blättern (van den Burg $1985,1990)$ im Bereich ausreichender Normalgehalte $(63-212$ mg/kg).

Tab. 52: Mikronährstoff-Gehalte im Laub unbehandelter Erlen im Freiland-Versuch (Fläche D) im 2. Untersuchungsjahr (Mischproben), Einstufung durch verschiedene Autoren

\begin{tabular}{|l|l|l|}
\hline Element & $\mathbf{m g} / \mathbf{k g}$ & Bergmann (1993)* $^{*}$ \\
\hline Eisen & 171 & ausreichend, normal $^{* *}$ \\
\hline Mangan & 1303 & über ausreichend \\
\hline Zink & 98,6 & über ausreichend \\
\hline Kupfer & 33,9 & über ausreichend \\
\hline
\end{tabular}

* Bewertung der Mineralstoff-Gehalte in der Trockenmasse von Blättern verschiedener Laubbaumarten (Ahorn, Birke, Buche, Eiche, Esche, Linde, Pappel)

** bei Ahornen nach van den Burg $(1985,1990)$

Die exorbitante Höhe der im Laub der unbehandelten Eichen und Ahorne gemessenen EisenGehalte (2324 mg/kg bzw. 1216 mg/kg) wird bei einem Vergleich mit dem im Rahmen des Deutschen Waldbodenberichtes in Buchenblättern maximal ermittelten Eisen-Gehalt anschaulich, der bei $350 \mathrm{mg} / \mathrm{kg}$ lag.

Verglichen mit den Mangan-Blattgehalten der im Rahmen des Deutschen Waldbodenberichts untersuchten Buchen (Minimum: $90 \mathrm{mg} / \mathrm{kg}, 10 \mathrm{er}-$ Perzentil $210 \mathrm{mg} / \mathrm{kg}, 25 \mathrm{er}-$ Perzentil 570 mg/kg, Median 1270 mg/kg, 75er-Perzentil 1910 mg/kg, 90er-Perzentil 3470 mg/kg, Maximum $5460 \mathrm{mg} / \mathrm{kg}$, in: BMELF 1997b) scheinen die bei den unbehandelten Ebereschen $(2714 \mathrm{mg} / \mathrm{kg})$ und Erlen $(1303 \mathrm{mg} / \mathrm{kg}$ ) ermittelten Werte zumindest nicht ungewöhnlich zu sein (zur Diskussion der Einschätzung von Mangan-Gehalten s. ab S. 333). 


\section{Douglasie}

Zur Einstufung des in den Douglasien-Nadeln (Kontrolle, Fläche D) gemessenen Eisen-Gehaltes (s. Tab. 53) konnte keine artspezifische Klassifikation gefunden werden. Die im Deutschen Waldbodenbericht verwendete Bewertungsskala für Eisen-Gehalte in Fichten- und KiefernNadeln stuft Eisen-Gehalte von 100-500 mg/kg als hoch ein (BMELF 1997b). Der in den Douglasien-Nadeln gemessene Eisen-Gehalt lag mit $473 \mathrm{mg} / \mathrm{kg}$ demnach knapp unterhalb des sehr hohen Wertebereichs. Der Kupfer-Gehalt ist mit 10,1 mg/kg nach Bergmann (1993) an der oberen Grenze ausreichender Gehalte anzusiedeln und liegt gleichzeitig an der unteren Grenze der sehr allgemeinen, weit gefassten Normalgehalte in Pflanzen $(10-20 \mathrm{mg} / \mathrm{kg})$ nach Smidt (1999). Im Deutschen Waldbodenbericht (BMELF 1997b) werden bereits Kupfer-Gehalte von über $7 \mathrm{mg} / \mathrm{kg}$ trockener Nadelmasse von Fichten und Kiefern als sehr hoch eingestuft, wobei dieser Wert von weniger als $2 \%$ aller untersuchten Fichten überschritten wurde. Der ZinkGehalt war mit 10,8 mg/kg sehr gering (Fichte/Kiefer: < $15 \mathrm{mg} / \mathrm{kg}$; BMELF 1997b) und auch nach der Klassifikation von Bergmann (1993) nicht ausreichend. Die gemessene Mangankonzentration von $180 \mathrm{mg} / \mathrm{kg}$ ist nach Bergmann (1993) als ausreichend (50-500), nach Vergleichsdaten für Fichte und Kiefer aus dem Deutschen Waldbodenbericht (BMELF $1997 \mathrm{~b})$ dagegen als gering (50-1000 mg/kg) einzustufen. Ebensolche Vergleichsdaten finden sich beim österreichischen BFW (2005/7), demnach liegt der Mangan-Gehalt im dort sehr weit gefassten Bereich ausreichender bzw. optimaler Versorgung (50-6000 mg/kg). Dies verdeutlicht einmal mehr die Problematik sehr unterschiedlicher Literaturangaben zu diesem Mikronährstoff (s. ab S. 333).

Tab. 53: Mikronährstoff-Gehalte in den Nadeln unbehandelter Douglasien im Freiland-Versuch (Fläche D) im 2. Untersuchungsjahr (Mischproben), Einstufung durch verschiedene Autoren

\begin{tabular}{|l|l|l|}
\hline Element & $\mathbf{m g} / \mathbf{k g}$ & Bergmann (1993) \\
\hline Eisen & 473 & hoch* \\
\hline Mangan & 180 & ausreichend; gering* \\
\hline Zink & 10,8 & nicht ausreichend; sehr gering* \\
\hline Kupfer & 10,1 & knapp über ausreichend; sehr hoch* \\
\hline
\end{tabular}

* Bewertung für Fichten und Kiefern im Deutschen Waldbodenbericht (BMELF 1997b)

\section{Wald-Kiefer}

Der Eisen-Gehalt der Kiefern-Nadeln (Kontrolle, Fläche D) entspricht nach Hofmann \& Kraus (1988) einer Überversorgung (202-550 mg/kg) und ist auch nach den im Deutschen Waldbodenbericht (BMELF 1997b) und vom österreichischen BFW (2005/7) verwendeten Klassifikationen hoch oder über ausreichend bzw. über optimal (s. Tab. 54). Der gemessene Zink-Gehalt lag nach den Quellen im mittleren/ausreichenden/optimalen Bereich. Der KupferGehalt war mit 16,4 mg/kg sehr hoch (BMELF 1997b: $>7 \mathrm{mg} / \mathrm{kg}$ ) und lag erheblich über ausreichenden bzw. optimalen Werten, laut Hofmann \& Krauss (1988) sogar deutlich oberhalb einer Extremversorgung. Laut BMELF (1997b) wäre die ermittelte Mangankonzentration als gering (50-1000 mg/kg) einzustufen, während etwa Fiedler \& Höhne (1985, zit. in Bergmann 1993) Mangan-Gehalte in Kiefern-Nadeln von $100-1000 \mathrm{mg} / \mathrm{kg}$ als ausreichend ansehen. Auch das BFW (2005/7) sowie Hofmann \& Krauss (1988) bezeichnen den gemessenen Manganwert als ausreichend bzw. optimal. Die Problematik der unterschiedlichen Einschätzung von ManganGehalten in der Literatur wird ab Seite 333 diskutiert. 
Tab. 54: Mikronährstoff-Gehalte in den Nadeln unbehandelter Kiefern im Freiland-Versuch (Fläche D) im 2. Untersuchungsjahr (Mischproben), Einstufung durch verschiedene Autoren

\begin{tabular}{|l|l|l|l|l|l|}
\hline Element & $\mathbf{m g} / \mathbf{k g}$ & $\begin{array}{l}\text { BFW } \\
\mathbf{( 2 0 0 5 / 7 )}\end{array}$ & $\begin{array}{l}\text { BMELF } \\
\mathbf{( 1 9 9 7 b )}\end{array}$ & $\begin{array}{l}\text { Hofmann \& } \\
\text { Krauss (1988) }\end{array}$ & $\begin{array}{l}\text { Bergmann } \\
\mathbf{( 1 9 9 3 )}\end{array}$ \\
\hline Eisen & 357 & $\begin{array}{l}\text { über } \\
\text { ausreichend/optimal }\end{array}$ & hoch & überversorgt & \\
\hline Mangan & 516 & ausreichend/optimal & gering & optimal & ausreichend \\
\hline Zink & 37,3 & ausreichend/optimal & mittel & knapp optimal & ausreichend \\
\hline Kupfer & 16,4 & $\begin{array}{l}\text { über } \\
\text { ausreichend/optimal }\end{array}$ & sehr hoch & über extrem & $\begin{array}{l}\text { über } \\
\text { ausreichend }\end{array}$ \\
\hline
\end{tabular}

\subsubsection{Potentiell nützliche Elemente ( $\mathrm{Al}, \mathrm{Na}, \mathrm{Ni}, \mathrm{Co})$}

Aluminium, Natrium, Nickel und Kobalt sind potentiell nützliche, teilweise ebenfalls als Mikronährstoffe eingeordnete Elemente (z.B. Bergmann 1993, Scheffer \& Schachtschabel 2010). In Abb. 18 sind für jedes dieser Elemente die entsprechenden Gehalte in den Assimilationsorganen der unbehandelten Kontrollbäume zusammengestellt.
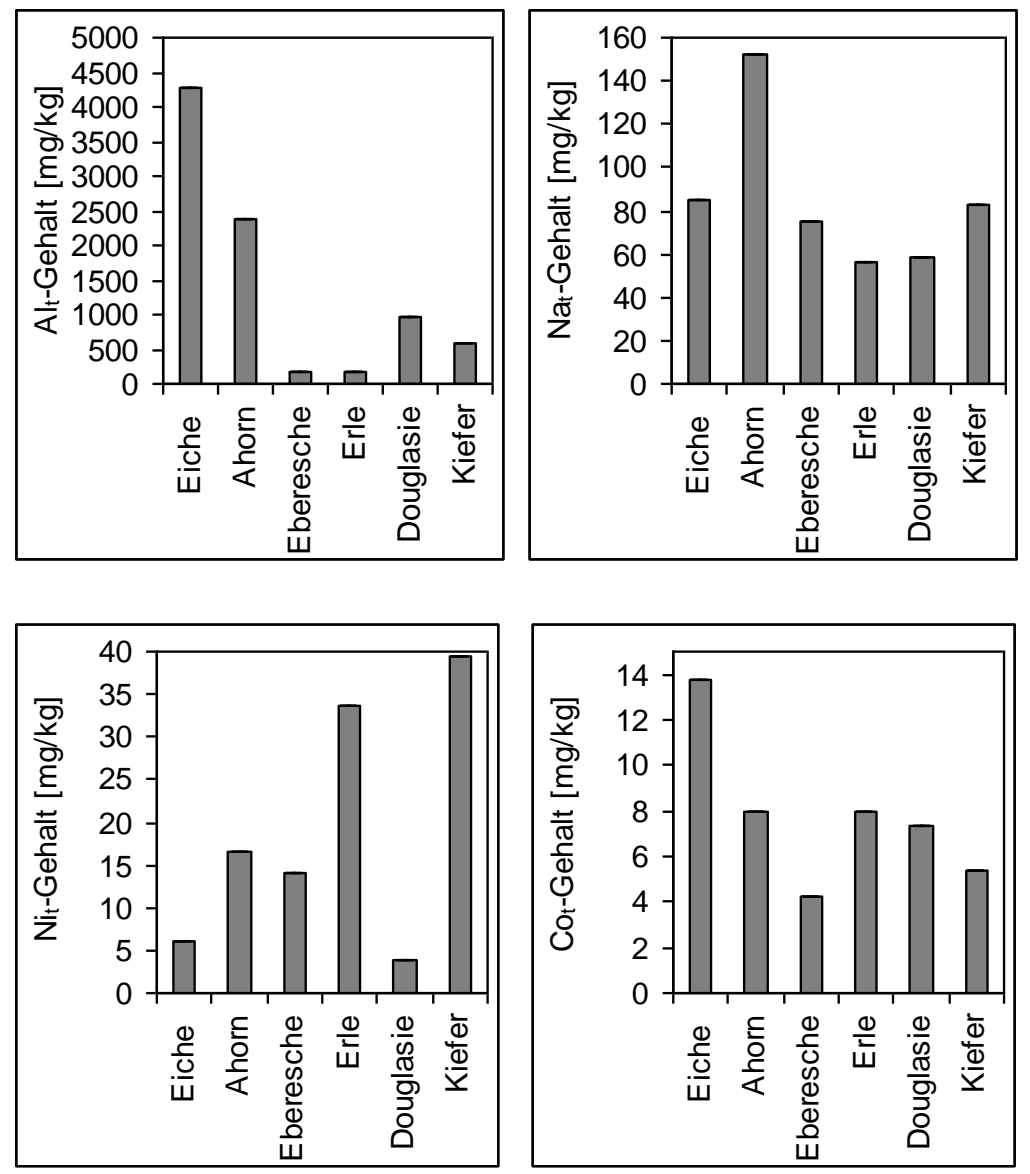

Abb. 18: Gehalte potentiell nützlicher Elemente ( $\mathrm{Al}, \mathrm{Na}, \mathrm{Ni}, \mathrm{Co})[\mathrm{mg} / \mathrm{kg}$ Trockenmasse] in den Assimilationsorganen der Nullvariante der sechs Baumarten im Freiland-Versuch (Fläche D) im 2. Untersuchungsjahr (Mischproben) 
Bei Betrachtung der in den Assimilationsorganen der unbehandelten Kontrollpflanzen im Freiland-Versuch (Fläche D) gemessenen Aluminium-Gehalte fielen zunächst sehr große Unterschiede zwischen den sechs untersuchten Baumarten auf. In der Reihenfolge Erle/Eberesche - Kiefer - Douglasie - Ahorn - Eiche stiegen die Konzentrationen von 165/175 $\mathrm{mg} / \mathrm{kg}$ auf $4263 \mathrm{mg} / \mathrm{kg}$ an, wobei sie sich von Baumart zu Baumart jeweils mindestens verdoppelten. Nach Heinsdorf (1996) liegt bei Eichen die obere Grenze einer Überversorgung mit Aluminium bei 119 mg/kg trockener Blattmasse. Hofmann \& Krauss (1988) legen den Bereich einer Extremversorgung von Kiefern mit Aluminium bei 391-550 mg/kg trockener Nadelmasse fest, so dass der hier ermittelte Wert noch über diesem Extrembereich lag. Für die übrigen untersuchten Baumarten konnten keine artspezifischen Klassifikationen gefunden werden. Mindestens bei den untersuchten Eichen, Ahornen und Douglasien könnte durch die exorbitant hohen Aluminium-Gehalte mit schädigenden Auswirkungen zu rechnen sein.

Laut Bergmann (1993) wird jedoch durch Aluminium-Toxizität neben der Phosphor- auch die Aluminium-Verlagerung selbst gehemmt, so dass keine Proportionalität zwischen AluminiumToxizität und dem Aluminium-Gehalt in Assimilationsorganen bestehe. Dagegen seien Aluminium-Toxizität und Phosphor-Mangel nicht voneinander zu trennen, so dass niedrige Phosphor-Gehalte stets auf $\mathrm{Al}^{3+}$ Überschuss schließen ließen, falls kein Phosphor-Mangel im Boden vorliege, was im Ronneburger Haldensubstrat nicht der Fall ist (s. S. 48). Demnach würde der beschriebene Phosphor-Mangel bei den Nullvarianten der Eichen, Ahorne, Ebereschen und Douglasien auf Aluminium-Toxizität hinweisen, während die Kontroll-Erlen und -Kiefern hiervon nicht betroffen wären.

Einen Bezugsrahmen für die teilweise exorbitant hohen Aluminium-Gehalte in den Assimilationsorganen der unbehandelten Kontrollbäume geben die für den Deutschen Waldbodenbericht gemessenen Maximalwerte (BMELF 1997b). Diese lagen für Buchen bei 149 $\mathrm{mg} / \mathrm{kg}$ (zum Vergleich: $4263 \mathrm{mg} / \mathrm{kg}$ bei den Eichen, $2380 \mathrm{mg} / \mathrm{kg}$ bei den Ahornen ohne Bodenhilfsstoffe), für Fichten bei $223 \mathrm{mg} / \mathrm{kg}$ im ersten und $396 \mathrm{mg} / \mathrm{kg}$ im dritten Nadeljahrgang sowie für Kiefern bei $599 \mathrm{mg} / \mathrm{kg}$ im ersten und $430 \mathrm{mg} / \mathrm{kg}$ im zweiten Nadeljahrgang (zum Vergleich: $963 \mathrm{mg} / \mathrm{kg}$ bei den unbehandelten Douglasien, $574 \mathrm{mg} / \mathrm{kg}$ bei den unbehandelten Kiefern in Ronneburg).

Tab. 55: Gehalte potentiell nützlicher Elemente ( $\mathrm{Al}, \mathrm{Ni}, \mathrm{Na}, \mathrm{Co}$ ) [mg/kg Trockenmasse] in den Assimilationsorganen der Nullvariante der sechs Baumarten im Freiland-Versuch (Fläche D) im 2. Untersuchungsjahr (Mischproben)

\begin{tabular}{|l|l|l|l|l|l|l|}
\hline Element [mg/kg] & Eiche & Ahorn & Eberesche & Erle & Douglasie & Kiefer \\
\hline Aluminium & 4263 & 2380 & 175 & 165 & 963 & 574 \\
\hline Natrium & 85,3 & 152,7 & 75,1 & 56,2 & 58,8 & 82,9 \\
\hline Nickel & 6,1 & 16,5 & 14,1 & 33,6 & 3,9 & 39,5 \\
\hline Kobalt & 13,8 & 8,0 & 4,2 & 8,0 & 7,3 & 5,4 \\
\hline
\end{tabular}

Für das Spurenelement Natrium konnten außer für die Baumart Eiche keine Klassifizierungen von Blatt- und Nadelgehalten gefunden werden. Nach Heinsdorf (1996) lag der Natrium-Gehalt der untersuchten Eichen-Blätter mit 85,3 mg/kg im Bereich der Überversorgung (58-120,5 $\mathrm{mg} / \mathrm{kg}$ ). Die Natrium-Gehalte der Ebereschen und Erlen lagen leicht bzw. deutlich unterhalb des Wertes der Eichen (s. Tab. 55). Die Natriumkonzentration in den Ahorn-Blättern war dagegen mit 153,7 mg/kg fast doppelt so hoch und überstieg den Bereich extremer Gehalte bei Eichen. Die in den Nadeln der Kiefern und Douglasien ermittelten Natriumkonzentrationen lagen im 
Bereich der im Deutschen Waldbodenbericht (BMELF 1997b) gemessenen und nicht weiter klassifizierten Natrium-Gehalte von Kiefern und Fichten.

Die gemessenen Nickelkonzentrationen der Eichen-, Ahorn- und Ebereschen-Blätter sowie der Douglasien-Nadeln waren geringer als die bei Smidt (1999) angegebenen Normalgehalte in Pflanzen (20-30 mg/kg). Die Nickel-Gehalte der Erlen-Blätter $(33,6 \mathrm{mg} / \mathrm{kg}$ ) und der KiefernNadeln (39,5 mg/kg) lagen oberhalb des genannten Normalbereichs. Der bei Alloway (1999) als kritisch bezeichnete Bereich von Nickel-Gehalten in Pflanzen, oberhalb dessen toxische Auswirkungen wahrscheinlich sind, ist mit einer Spanne von 10 bis $100 \mathrm{mg} / \mathrm{kg}$ sehr groß, so dass auf dieser Grundlage allein keine Aussage darüber gemacht werden kann, ob die gemessenen Gehalte bereits toxisch wirken könnten.

Die Kobalt-Gehalte der Assimilationsorgane von fünf der sechs untersuchten Baumarten lagen unterhalb, der Kobalt-Gehalt der Eichen-Blätter im Bereich der Normalgehalte $(10-20 \mathrm{mg} / \mathrm{kg})$ nach Smidt (1999). Sie erreichten nicht die in Alloway (1999) als kritisch angegebene Spanne $(15-50 \mathrm{mg} / \mathrm{kg})$, oberhalb der toxische Auswirkungen wahrscheinlich sind.

\subsubsection{Toxisch wirkende Schwermetalle ohne Nährelementfunktion $(\mathrm{Pb}, \mathrm{Cd}, \mathrm{Cr})$}

Den Elementen Blei, Cadmium und Chrom kommt keine Nährelementfunktion zu. Zu hohe Gehalte in den Assimilationsorganen von Pflanzen haben toxische Wirkung (z.B. Bergmann 1993, Scheffer \& Schachtschabel 2010).

In den Assimilationsorganen aller sechs Baumarten der Nullvariante auf Versuchsfläche D konnten keine nachweisbaren Blei- oder Cadmium-Gehalte gemessen werden (s. Tab. 56).

Tab. 56: Gehalte an Schwermetallen ohne Nährelementfunktion ( $\mathrm{Pb}, \mathrm{Cd}, \mathrm{Cr})$ [mg/kg Trockenmasse] in den Assimilationsorganen der Nullvariante der sechs Baumarten im Freiland-Versuch (Fläche D) im 2. Untersuchungsjahr (Mischproben)

\begin{tabular}{|l|l|l|l|l|l|l|}
\hline Element [mg/kg] & Eiche & Ahorn & Eberesche & Erle & Douglasie & Kiefer \\
\hline Blei & $\mathrm{u}$ & $\mathrm{u}$ & $\mathrm{u}$ & $\mathrm{u}$ & $\mathrm{u}$ & $\mathrm{u}$ \\
\hline Cadmium & $\mathrm{u}$ & $\mathrm{u}$ & $\mathrm{u}$ & $\mathrm{u}$ & $\mathrm{u}$ & $\mathrm{u}$ \\
\hline Chrom & 6,9 & 3,8 & 0,7 & 3,3 & 3,1 & 1,3 \\
\hline
\end{tabular}

u Gehalt unterhalb der Nachweisgrenze

Das Ebereschen-Laub wies die geringsten Chrom-Gehalte auf, gefolgt von den Kiefern-Nadeln (s. Abb. 19). Das Ahorn- und Erlen-Laub sowie die Douglasien-Nadeln enthielten Chrom in ähnlichen Konzentrationen. Allenfalls der im Eichen-Laub gemessene Chrom-Gehalt befand sich bereits in dem in Alloway (1999) genannten, mit 5-30 mg/kg wiederum sehr weit gefassten Bereich kritischer Chromkonzentrationen in Pflanzen, oberhalb dessen toxische Auswirkungen wahrscheinlich sind. 


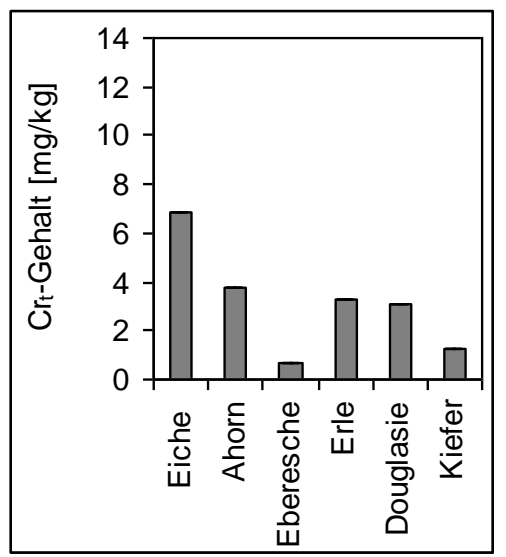

Abb. 19: Chrom-Gehalte [mg/kg Trockenmasse] in den Assimilationsorganen der Nullvariante der sechs Baumarten im Freiland-Versuch (Fläche D) im 2. Untersuchungsjahr (Mischproben)

\subsubsection{Vitalitätsentwicklung}

Bei Versuchsanlage im April 2005 und jeweils im Juni und Oktober der beiden Versuchsjahre wurde die Vitalität jeder einzelnen der 936 Pflanzen auf einer Ordinalskala von „0“ (tot) bis „4“ (vital) gutachterlich eingeschätzt (s. S. 27).

Im Folgenden wird die Vitalitätsentwicklung der insgesamt 72 unbehandelten Kontroll-Bäume (Nullvariante V1) im Verlauf dieses Untersuchungszeitraums nach Baumarten getrennt vergleichend dargestellt (s. Abb. 20). Die Ergebnisse dienen als Referenz zur Bewertung der Effekte der in den Behandlungsvarianten eingesetzten Bodenhilfsstoffe.

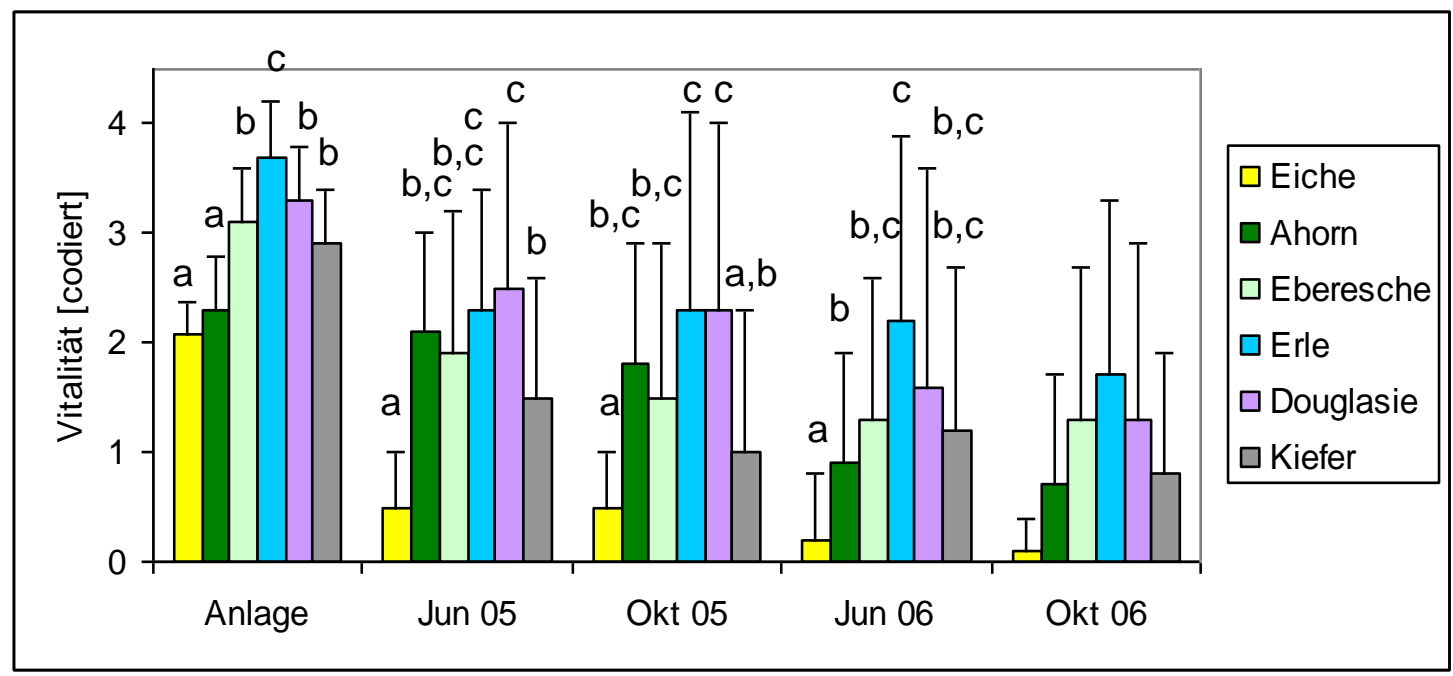

Abb. 20: Vitalität der Kontrollen [codiert: 4 = vital - 0 = tot; s. S. 27] im Versuchsverlauf; MW u. Std.abw.; Buchstaben kennzeichnen je Aufnahmezeitpunkt homogene Gruppen nach U-Tests (je Baumart n=12)

Aufgrund unterschiedlich guter Qualität der gelieferten Pflanzen bestanden bereits bei Versuchsbeginn signifikante Unterschiede hinsichtlich der Ausgangsvitalität.

Die mit 2,1 $\pm 0,3$ und 2,3 $\pm 0,5$ geringsten Mittelwerte wiesen die unbehandelten Eichen und Ahorne auf. Signifikant höher lag die Durchschnittsvitalität der Kiefern, Ebereschen und Douglasien mit Werten um „3“. Die Kontroll-Erlen unterschieden sich mit einer hohen Ausgangsvitalität von 3,7 $\pm 0,5$ signifikant von allen anderen Baumarten. 
Im Versuchsverlauf bestanden zu keinem Aufnahmezeitpunkt signifikante Vitalitätsunterschiede zwischen den Kontrollen der Baumarten Eberesche, Erle und Douglasie. Gleiches galt für die Kiefern, Ahorne und Ebereschen (s. Tab. 57).

Die sehr geringen Vitalitätsmittelwerte der unbehandelten Eichen unterschieden sich bis einschließlich Juni 2006 signifikant von denen der übrigen Baumarten (Ausnahme: Vitalität der Kontroll-Kiefern im Oktober 2005).

Im 1. Jahr bildeten die Ebereschen, Erlen, Douglasien und Ahorne eine homogene Gruppe, während im Juni 2006 die Durchschnittsvitalität der Ahorne mit „0,9“ signifikant geringer war als die der Erlen mit „2,2“. Zum selben Aufnahmezeitpunkt bestand eine homogene Gruppe aus Ahornen, Ebereschen, Douglasien und Kiefern, nachdem im Vorjahr die durchschnittliche Vitalität der Douglasien noch signifikant höher war als die der Kiefern.

Nach zwei Vegetationszeiten bestanden keine signifikanten Vitalitätsunterschiede zwischen den unbehandelten Kontrollen der sechs verwendeten Baumarten mehr.

Tab. 57: Vitalität der Kontrollen [codiert: $4=$ vital $-0=$ tot; s. S. 27] im Versuchsverlauf; MW u. Std.abw.; Ergebnisse von H-Tests $(\mathrm{H})$ auf signifikante Unterschiede zwischen den Baumarten (Buchstaben kennzeichnen je Spalte homogene Gruppen nach U-Tests); Ergebnisse der Friedmann-Tests $\left(\mathrm{Chi}^{2}\right)$ auf signifikante Unterschiede zwischen den Aufnahmezeitpunkten; kursiver Fettdruck markiert signifikant geringere Mittelwerte als im Gesamtdurchschnitt der jeweiligen Baumart

\begin{tabular}{|c|c|c|c|c|c|c|c|c|c|c|}
\hline & $\begin{array}{l}\text { April } \\
2005 \\
\end{array}$ & & $\begin{array}{l}\text { Juni } \\
2005 \\
\end{array}$ & & $\begin{array}{l}\text { Oktober } \\
2005\end{array}$ & & $\begin{array}{l}\text { Juni } \\
2006 \\
\end{array}$ & & $\begin{array}{l}\text { Oktober } \\
2006\end{array}$ & $\mathrm{Chi}^{2}$ \\
\hline alle & $2,9 \pm 0,7$ & $>$ & $1,8 \pm 1,3$ & $>$ & $1,5 \pm 1,5$ & $>$ & $1,2 \pm 1,5$ & $>$ & $1,0 \pm 1,3$ & 88,89 *** \\
\hline $\mathrm{Ei}$ & $\begin{array}{l}2,1 \pm 0,3 \\
\mathrm{a}\end{array}$ & $>$ & $\begin{array}{l}0,5 \pm 0,5 \\
\mathrm{a}\end{array}$ & & $\begin{array}{l}0,5 \pm 0,5 \\
\mathrm{a}\end{array}$ & & $\begin{array}{l}0,2 \pm 0,6 \\
\mathrm{a}\end{array}$ & & $0,1 \pm 0,3$ & $25,67 * * *$ \\
\hline $\mathrm{Ah}$ & $\begin{array}{l}2,3 \pm 0,5 \\
\mathrm{a}\end{array}$ & & $\begin{array}{l}2,1 \pm 0,9 \\
\mathrm{~b}, \mathrm{c}\end{array}$ & $>$ & $\begin{array}{l}1,8 \pm 1,1 \\
\mathrm{~b}, \mathrm{c}\end{array}$ & $>$ & $\begin{array}{l}0,9 \pm 1,0 \\
\mathrm{~b}\end{array}$ & & $0,7 \pm 1,0$ & $22,88 * * *$ \\
\hline $\mathrm{Eb}$ & $\begin{array}{l}3,1 \pm 0,5 \\
\mathrm{~b}\end{array}$ & $>$ & $\begin{array}{l}1,9 \pm 1,3 \\
\text { b,c }\end{array}$ & $>$ & $\begin{array}{l}1,5 \pm 1,4 \\
\mathrm{~b}, \mathrm{c}\end{array}$ & & $\begin{array}{l}1,3 \pm 1,3 \\
b, c\end{array}$ & & $1,3 \pm 1,4$ & $16,03 * *$ \\
\hline Er & $\begin{array}{l}3,7 \pm 0,5 \\
\mathrm{c}\end{array}$ & $>$ & $\begin{array}{l}2,3 \pm 1,1 \\
\mathrm{c}\end{array}$ & & $\begin{array}{l}2,3 \pm 1,8 \\
\mathrm{c}\end{array}$ & & $\begin{array}{l}2,2 \pm 1,7 \\
\mathrm{c}\end{array}$ & $>$ & $1,7 \pm 1,6$ & $13,22 *$ \\
\hline Dou & $\begin{array}{l}3,3 \pm 0,5 \\
\mathrm{~b}\end{array}$ & & $\begin{array}{l}2,5 \pm 1,5 \\
\mathrm{c}\end{array}$ & & $\begin{array}{l}2,3 \pm 1,7 \\
\mathrm{c}\end{array}$ & $>$ & $\begin{array}{l}1,6 \pm 2,0 \\
b, c\end{array}$ & $>$ & $1,3 \pm 1,6$ & $11,75^{*}$ \\
\hline $\mathrm{Ki}$ & $\begin{array}{l}2,9 \pm 0,5 \\
\mathrm{~b}\end{array}$ & $>$ & $\begin{array}{l}1,5 \pm 1,1 \\
\text { b }\end{array}$ & $>$ & $\begin{array}{l}1,0 \pm 1,3 \\
\mathrm{a}, \mathrm{b}\end{array}$ & & $\begin{array}{l}1,2 \pm 1,5 \\
b, c\end{array}$ & & $0,8 \pm 1,1$ & $15,27 * *$ \\
\hline $\mathrm{H}$ & $44,50 * * *$ & & $20,05 * *$ & & $12,44 *$ & & $11,50 *$ & & 9,28 & \\
\hline
\end{tabular}

$>$ kennzeichnet signifikanten Vitalitätsrückgang, < signifikanten Vitalitätsanstieg nach Wilcoxon-Test

Die durchschnittliche Vitalität der unbehandelten Ebereschen und Kiefern nahm bereits im 1. Jahr deutlich von rund „3“ auf Werte zwischen „2“ und „1“ ab, um dann bis zum Abschluss der Untersuchungen konstant zu bleiben. Dagegen sank der mittlere Vitalitätswert der Douglasien erst zum und im 2. Jahr signifikant von Werten zwischen „3“ und „2“ in 2005 auf Werte deutlich unter "2“ in 2006. Auch die Ahorne verzeichneten zum 2. Jahr den deutlichsten Vitalitätsrückgang von Werten um „2“ auf unter „1“. Die mittlere Vitalität der Erlen nahm bald nach der Pflanzung signifikant ab, blieb dann im weiteren Versuchsverlauf jedoch auf einem vergleichsweise hohen Niveau von über „2“, um zwischen Juni und Oktober 2006 nochmals auf knapp unter „2“ zurückzugehen. Bei den Eichen sank die mittlere Vitalität direkt nach Versuchsanlage auf einen Wert, der nur knapp über „0“ lag. 

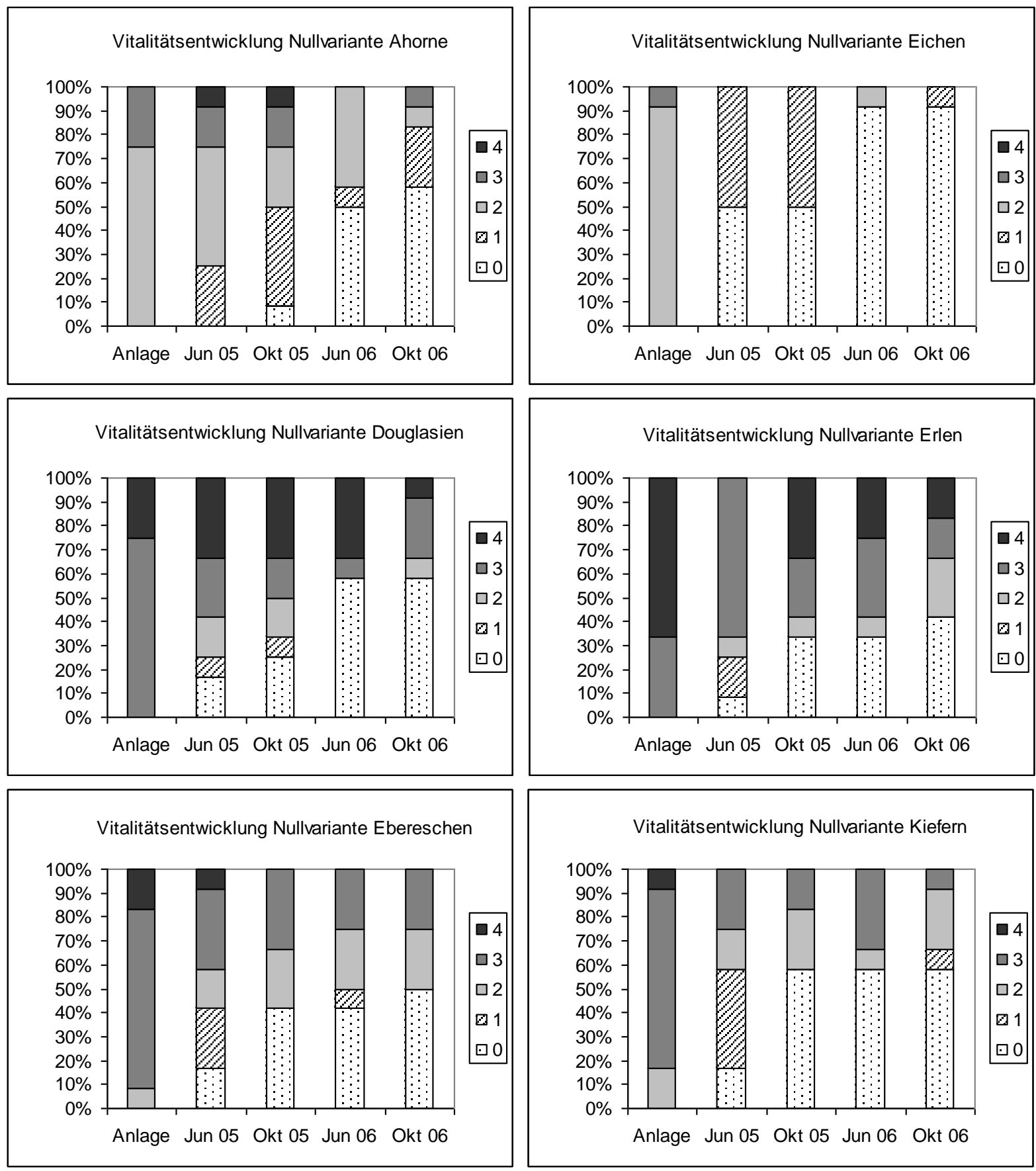

Abb. 21: Häufigkeit der an die Kontrollen vergebenen Vitalitätswerte [codiert: $4=$ vital $-0=$ tot; s. S. 27] im Versuchsverlauf (je $n=12$ )

Generell wurde das Absinken der durchschnittlichen Vitalitätswerte durch zwei Faktoren bedingt: Durch die Abnahme von Pflanzen mit Vitalitätswerten im oberen Bewertungsbereich, vor allem aber durch den Anstieg der Pflanzenausfälle von Aufnahme zu Aufnahme (s. Abb. 21), die mit dem Vitalitätswert „0“ in die errechneten Mittelwerte einfließen.

Bei den Ebereschen und Kiefern wurde die geschilderte Vitalitätsentwicklung vor allem durch die überwiegend bereits kurz nach der Pflanzung stattfindenden Pflanzenausfälle bedingt. So wiesen im Juni 2005 über $40 \%$ der unbehandelten Ebereschen (Oktober 2006: 50 \%) und knapp 60 \% der unbehandelten Kiefern (Oktober 2006: 67 \%) nur noch Vitalitätswerte von „0“ oder „1“ auf. 
Die Kontroll-Douglasien verzeichneten dagegen in beiden Jahren etwa den gleichen Anteil an Ausfällen (je ca. 30 \%). Hier spielte für die Vitalitätsentwicklung auch der deutliche Rückgang sehr guter Vitalitätsbewertungen ("4") im Oktober 2006 eine Rolle.

Bei den unbehandelten Ahornen nahm der Anteil der toten („0“) und absterbenden ("1“) Pflanzen zwischen Juni und Oktober 2005 deutlich zu. Bis Juni 2006 waren die meisten der absterbenden Pflanzen tot; zusätzlich ging der Anteil gut („3“) und sehr gut („4") bewerteter Pflanzen komplett zurück.

Die Durchschnittswerte der Vitalitätsentwicklung der Kontroll-Erlen spiegeln im Juni 2005 zunächst die Herabstufung sämtlicher bei der Pflanzung sehr gut bewerteter Bäume von "4" auf „3“ sowie die nach der Pflanzung erfolgten Ausfälle wieder. Die Vitalitätsentwicklung zwischen Juni und Oktober 2006 wurde durch den Vitalitätsrückgang bei den noch lebenden Erlen bestimmt.

Bis zum Ende der zweiten Vegetationsperiode (Oktober 2006) waren schließlich rund $60 \%$ der unbehandelten Bäume abgestorben, wobei die Eichen nahezu komplett ausfielen, während bei den Ahornen, Douglasien und Kiefern je 58 \%, bei den Ebereschen $50 \%$ und bei den Erlen 42 $\%$ der ohne Bodenhilfsstoffe gepflanzten Bäume abstarben.

\subsubsection{Standorteinfluss}

Die Verteilung der Bäume bei der Versuchsanlage hatte zufällig dazu geführt, dass für die Kontrollen die Gruppen „Standort auf Versuchsfläche B“ und „Standort mit Spontanvegetation“ ebenso überein stimmten wie die Gruppen „Standort auf Fläche A oder D“ und „Standort ohne Spontanvegetation“. In Tab. A 13 sind für die Nullvarianten der 6 Baumarten die Ergebnisse der insgesamt 5 Vitalitätsschätzungen differenziert nach Standorten tabellarisch zusammengestellt.

Wie im Folgenden ausgeführt wird, entwickelte sich die Vitalität der unbehandelten Kontrollbäume bei 5 der 6 Baumarten in Abhängigkeit vom individuellen Pflanzenstandort (auf einer der drei Versuchsflächen; in Bereichen mit oder ohne Bodenvegetation) unterschiedlich (s. Abb. 22). Nur bei den unbehandelten Eichen nahm die mittlere Vitalität gleich nach Versuchsbeginn auf allen Versuchsflächen und damit sowohl in Bereichen mit als auch ohne Spontanvegetation gleichermaßen stark ab. Signifikante Vitalitätsunterschiede je nach Standort konnten für diese Baumart nicht festgestellt werden.

Bei den übrigen verwendeten Baumarten bestanden einige Gemeinsamkeiten in ihrer Reaktion auf die unterschiedlichen Standortbedingungen:

Die mittlere Vitalität der Kontrollpflanzen mit Standorten auf Fläche B (bewachsener Bereich) war mit Ausnahme der Erle bei allen fünf Arten signifikant höher als auf der unbewachsenen Fläche A. Hier fiel die Nullvariante im Verlauf des Versuchszeitraums mit Ausnahme von zwei Erlen komplett aus. Dagegen gab es unter den unbehandelten Douglasien, Kiefern und Ebereschen auf Fläche B überhaupt keine Ausfälle.

Mit Ausnahme der Kontroll-Ahorne, deren mittlere Vitalität im 2. Versuchsjahr auch auf Fläche B auf den niedrigen Wert „1“ fiel, und der Kontroll-Kiefern, die dort immerhin Werte zwischen „2“ und „3“ erreichten, blieb die Vitalität der Nullvarianten auf Fläche B während des gesamten Versuchsverlaufs recht hoch, am höchsten bei den Kontroll-Douglasien, die bei drei Aufnahmen alle den Spitzenwert "4“ erhielten. 

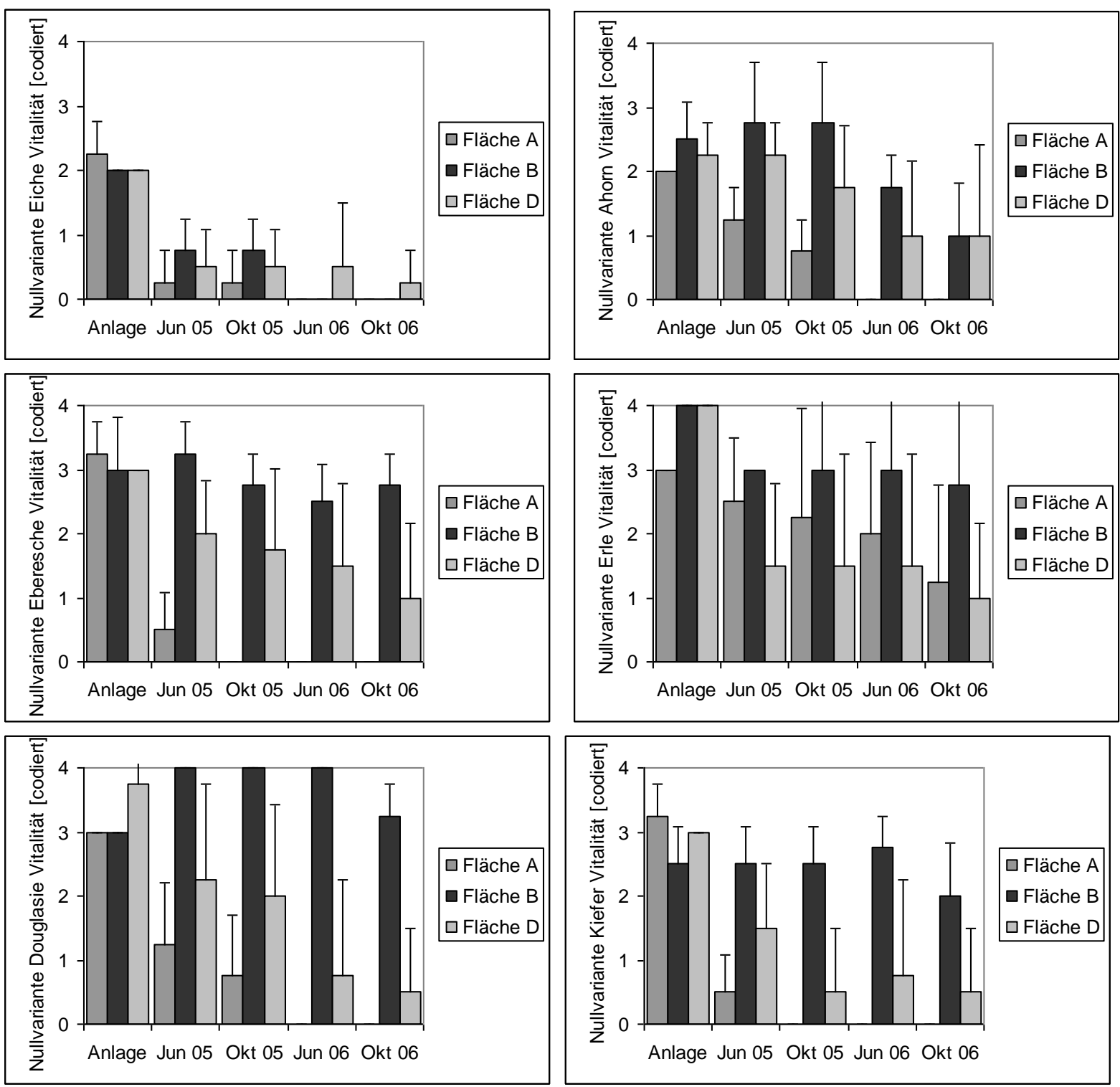

Abb. 22: Vitalität der Kontrollen [codiert: $4=$ vital $-0=$ tot; s. S. 27] im Versuchsverlauf, getrennt nach Standorten; MW u. Std.abw. (je n=12)

Die mittlere Vitalität der Nullvarianten auf Fläche A und D (vegetationsfreie Standorte) sank dagegen bei allen Arten im Versuchsverlauf mehr oder weniger schnell, wobei die Werte auf Fläche A stets geringer waren als auf Fläche D. Eine Ausnahme bildeten die Kontroll-Erlen, bei denen es sich umgekehrt verhielt.

Bei allen Aufnahmen der Nadelbäume (Ausnahme: Kiefern im Juni 05) sowie der letzten Aufnahme (Okt. 06) der Ebereschen waren dabei die mittleren Vitalitätswerte der Nullvariante auf Fläche B signifikant höher als auf den Flächen $\mathbf{A}$ und $\mathbf{D}$, zwischen denen keine signifikanten Unterschiede bestanden. Dieses Ergebnis entspricht einem statistisch signifikanten Unterschied zwischen Bereichen mit und ohne Bodenvegetation.

In den übrigen Fällen, also vor allem bei den Laubbäumen Ahorn und Eberesche, war die durchschnittliche Vitalität der Nullvarianten auf den Flächen B und D mindestens im 1. Versuchsjahr signifikant höher als auf Fläche A (in einem Fall unterschieden sich alle drei Flächen signifikant voneinander). Dies zeigt, dass für diese Baumarten zumindest im 1. 
Vegetationsjahr die Standortbedingungen im vegetationsfreien Bereich der Fläche D besser waren als auf der vegetationsfreien Fläche A.

Ein Vergleich der mittleren Vitalitätswerte der überlebenden Kontrollen bei Versuchsende zwischen Standorten in Bereichen mit Spontanvegetation bzw. auf Fläche B oder ohne Bodenbewuchs bzw. auf Fläche D (und A) ergab insgesamt keine signifikanten Unterschiede. Eine diesbezügliche Betrachtung der einzelnen Baumarten war aufgrund zu geringer Pflanzenzahlen nur bei der Erle möglich. Hier war die im Oktober 2006 erfasste mittlere Vitalität der überlebenden Kontrollen auf bewachsenen Standorten $(3,7 \pm 0,6 ; n=3)$ signifikant $\left(Z-2,06^{*}\right)$ höher als auf vegetationsfreien $(2,3 \pm 0,5 ; n=4)$ Standorten.

\subsubsection{Vergleich Nullvariante - Gesamtdurchschnitt}

Für jede Baumart wurden die an den unbehandelten Kontrollen gemessenen Mittelwerte den an der Gesamtheit aller Versuchspflanzen gemessenen Mittelwerten (s. ab S. 180) gegenübergestellt. In Tab. A 14 sind im Vergleich zum Gesamtdurchschnitt signifikant geringere Mittelwerte der Kontrollen kursiv, signifikant höhere Mittelwerte unterstrichen hervorgehoben.

Vergleicht man zunächst baumartübergreifend die Vitalität sämtlicher Kontrollen $(n=72)$ mit der Vitalität aller Versuchsbäume $(\mathrm{n}=936)$, so lag der Mittelwert der unbehandelten Nullvarianten nur bei der letzten Aufnahme im Oktober 2006 signifikant niedriger als der Gesamtdurchschnitt. Bei allen anderen Aufnahmen im Verlauf des Untersuchungszeitraums bestanden dagegen keine signifikanten Unterschiede, was mit den nicht nur in der Kontrolle, sondern auch in den Behandlungsvarianten teilweise hohen Pflanzenausfällen zusammenhing, die mit dem Vitalitätswert „0“ in die Berechnung eingingen (hohe Standardabweichungen).

Bei den Eichen (insgesamt sehr geringe Vitalität) und den Erlen (insgesamt recht hohe Vitalität) sowie den Douglasien bestanden zu keinem Zeitpunkt signifikante Vitalitätsunterschiede zwischen den unbehandelten Bäumen und dem Gesamtmittelwert aller Varianten.

Dagegen wiesen die unbehandelten Ahorne und Ebereschen im 2. Untersuchungsjahr, die unbehandelten Kiefern direkt nach der Pflanzung signifikant geringere Vitalitätswerte auf als die Gesamtheit aller Ahorne, Ebereschen bzw. Kiefern zum gleichen Aufnahmezeitpunkt.

Auf der vegetationsfreien Fläche A war die sehr geringe mittlere Vitalität der unbehandelten Ahorne, Ebereschen und Douglasien (zwischen "1,25“ und "0“ = Totalausfall) in beiden Vegetationsjahren signifikant geringer als der jeweilige Mittelwert aller Ahorne, Ebereschen bzw. Douglasien auf Fläche A. Dies lässt bereits auf positive Effekte von mindestens einem der eingesetzten Bodenhilfsstoffe bei diesen drei Baumarten auf dieser Fläche schließen, die ihnen ohne Bodenbehandlung offensichtlich sehr schwierige Standortbedingungen bot. Augrund der hohen Ausfallrate der Kiefern auf Fläche A (95 \%) bestanden dort bei dieser Baumart keine signifikanten Vitalitätsunterschiede zwischen der Nullvariante und dem Gesamtdurchschnitt.

Auf Fläche D, auf der die Kontrollen ebenfalls zufällig im vegetationsfreien Bereich standen, gab es bei den Nadelbaumarten kaum signifikante Unterschiede zwischen der Vitalität der unbehandelten Bäume und dem Mittelwert aller Varianten. Lediglich zu Versuchsbeginn lag die Vitalität der unbehandelten Kiefern im Mittel kurzzeitig signifikant höher als der Gesamtdurchschnitt. Insgesamt fielen auf Fläche D 90 \% der gepflanzten Kiefern aus. Bei den 
Laubbäumen Ahorn und Eberesche wurden dagegen im 2. Vegetationsjahr in der Nullvariante signifikant niedrigere Vitalitätswerte ermittelt als im jeweiligen Gesamtdurchschnitt. Dies deutet auf eine - durch den Pflanzschock zeitlich verzögerte - bessere Vitalität der Behandlungsvarianten hin, was einerseits eine positive Wirkung von mindestens einem der verwendeten Bodenhilfsstoffe vermuten lässt, andererseits aber auch mit besseren Vitalitätsmittelwerten der Bäume zusammenhängen kann, die (im Gegensatz zur Kontrolle) zufällig in mit späterer Spontanvegetation bewachsenen Bereichen standen.

Auf Fläche B, auf der die Kontrollen in später mit Spontanvegetation besiedelte Bereiche gepflanzt wurden, war die Vitalität der unbehandelten Douglasien während des gesamten Untersuchungszeitraums sowie die der unbehandelten Ebereschen zumindest zu Beginn der Untersuchung derart hoch, dass sie sich signifikant von dem jeweiligen Gesamtdurchschnitt der Douglasien und Ebereschen auf dieser Fläche abhob. Im weiteren Versuchsverlauf unterschieden sich auf dieser Fläche die Vitalitätswerte der unbehandelten Ebereschen, die der Kontroll-Kiefern und überwiegend auch die der Kontroll-Ahorne nicht von den entsprechenden Gesamt-Mittelwerten. Lediglich die geringe Vitalität der Ahorn-Nullvariante zum Abschluss des Versuchs lag signifikant unter der mittleren Vitalität aller Ahorne auf Fläche B.

\subsubsection{Wachstumsentwicklung}

Im Folgenden wird die Wachstumsentwicklung der unbehandelten Kontroll-Bäume (Nullvariante V1) im Verlauf des Untersuchungszeitraums (April 2005 - Oktober 2006) für 5 der 6 getesteten Baumarten (Ahorn, Eberesche, Erle, Douglasie, Kiefer) beschrieben. Bei den Eichen starben die Haupttriebe überwiegend bereits zu Versuchsbeginn ab (teilweise erfolgte im Versuchsverlauf ein Neuaustrieb von unten, s. ab S. 180), so dass diese Baumart nicht in die Wachstumsanalysen einbezogen werden konnte.

Sämtliche Ergebnisse der an den Kontrollen durchgeführten Wachstumsuntersuchungen (gemessene und errechnete Parameter, s. ab S. 27 u. ab S. 79) sind in Tab. A 14 tabellarisch zusammengestellt und werden im Folgenden beschrieben. Sie dienen als Referenz zur Bewertung der Effekte der in den Behandlungsvarianten eingesetzten Bodenhilfsstoffe.

Je nach Baumart wurden bei den unbehandelten Nullvarianten im Anlagejahr (2005) Haupttriebs-Zuwächse zwischen $2 \mathrm{~cm}$ und $8 \mathrm{~cm}$ ermittelt. Betrachtet man (zwecks Vergleichbarkeit mit dem Zuwachs in 2006) nur diejenigen Kontrollen, die auch im Folgejahr noch vorhanden waren („Zuwachs Haupttrieb 2005 red.“ = reduziert), so lagen die HaupttriebsZuwächse zwischen $2 \mathrm{~cm}$ und $10 \mathrm{~cm}$. In beiden Fällen bestanden aufgrund der hohen Standardabweichungen bei einer jeweils nur geringen Anzahl an Wiederholungen keine signifikanten Zuwachsunterschiede zwischen den Baumarten.

Dies änderte sich im 2. Untersuchungsjahr (2006): Die Kontroll-Ebereschen wiesen nur noch einen sehr geringen Zuwachs von $3 \mathrm{~cm}$ auf. Die Zuwächse der unbehandelten Erlen $(16 \mathrm{~cm})$, Douglasien $(10 \mathrm{~cm})$ und Kiefern $(8 \mathrm{~cm})$ waren dagegen deutlich höher und unterschieden sich von dem der Ebereschen signifikant. Bei den unbehandelten Ahornen konnte kein Zuwachs mehr verzeichnet werden.

Hinsichtlich des gesamten Zuwachses der Haupttriebe während der zweijährigen Versuchsdauer bestanden nur zwischen dem sehr geringen Mittelwert der Kontroll-Ahorne (2 $\mathrm{cm})$ und den anderen Baumarten signifikante Unterschiede. Der Gesamtzuwachs dieser übrigen 
vier Baumarten lag zwischen $9 \mathrm{~cm}$ und $26 \mathrm{~cm}$. Die Unterschiede zwischen diesen Mittelwerten waren wiederum aufgrund teils hoher Standardabweichungen bei einer nur kleinen Zahl an Wiederholungen nicht signifikant.

Sowohl die gesamte Länge $(369 \mathrm{~cm})$ als auch die Trockenmasse $(24 \mathrm{~g})$ der Seitentriebe (errechnet aus der Länge, s. ab S. 79) lagen bei den unbehandelten Erlen mehr als 6-mal so hoch wie bei den Kontroll-Ebereschen und -Kiefern mit rund $60 \mathrm{~cm}$ bzw. rund 3,5 g. Aufgrund dieser vergleichsweise sehr hohen Seitentrieblänge war der Quotient aus Haupt- und Seitentrieblängen bei den Erlen folgerichtig deutlich kleiner. Die Unterschiede zwischen den Erlen und den anderen beiden Baumarten waren jeweils signifikant, zwischen den Ebereschen und Kiefern gab es dagegen keine signifikanten Unterschiede.

Auch bei den Wachstumsparametern Wurzelhalsdurchmesser, Volumen des Haupttriebs (errechnet aus den Durchmessern von Wurzelhals und Spitze sowie der Haupttrieblänge, s. S. 27), Trockenmasse des Haupttriebs (errechnet aus dem Volumen, s. ab S. 79) sowie oberirdische Trockenmasse (Summe aus den Trockenmassen des Haupttriebs und der Seitentriebe) wiesen die unbehandelten Erlen stets den signifikant höchsten Wert auf, der um ein Vielfaches über den Mittelwerten der übrigen Kontrollen lag.

So war der durchschnittliche Wurzelhalsdurchmesser der unbehandelten Erlen mit $16 \mathrm{~mm}$ 2bis 3-mal so hoch wie bei den andern Baumarten. Bei den Ahornen betrug er $5 \mathrm{~mm}$, die übrigen drei Baumarten wiesen Werte zwischen 7 und $8 \mathrm{~mm}$ auf. Der hier wie auch bei allen anderen Wachstumsparametern geringste Mittelwert bei den Ahornen unterschied sich signifikant von den an den Ebereschen und Douglasien ermittelten Wurzelhalsdurchmessern.

Das mittlere Volumen des Haupttriebs der Kontroll-Erlen betrug mit $103 \mathrm{~cm}^{3}$ das 6- bis 26fache der für die anderen Baumarten errechneten Werte. Mit weitem Abstand folgte das ebenfalls signifikant von den Volumina der übrigen Baumarten (mit Ausnahme der Douglasie) verschiedene Haupttriebsvolumen der unbehandelten Ebereschen mit $17 \mathrm{~cm}^{3}$. Zwischen Douglasien $\left(7 \mathrm{~cm}^{3}\right)$ und Kiefern $\left(10 \mathrm{~cm}^{3}\right)$ sowie zwischen Kiefern und Ahornen $\left(4 \mathrm{~cm}^{3}\right)$ gab es keine signifikanten Unterschiede, wohl aber zwischen Douglasien und Ahornen.

Der mit 47 g verglichen mit den anderen Baumarten 4- bis 9-mal so hohen Trockenmasse des Haupttriebs der Kontroll-Erlen folgte wiederum der Mittelwert der Ebereschen, der sich mit 11 g signifikant von den übrigen Baumarten (mit Ausnahme der Kiefern) unterschied. Die errechneten Trockenmassen der unbehandelten Ahorne, Douglasien und Kiefern lagen bei rund $5 \mathrm{~g}$.

Die oberirdischen Biomassen (Trockenmassen), die nur an den drei Baumarten bestimmt werden konnten, an denen auch Daten zu Seitentrieben erhoben worden waren, unterschieden sich zwischen allen diesen drei Baumarten signifikant. Den mit $9 \mathrm{~g}$ geringsten Mittelwert wiesen die unbehandelten Kiefern, mit 16 g knapp das Doppelte die Ebereschen auf. Die Erlen übertrafen diese Werte mit $71 \mathrm{~g}$ um ein Vielfaches. Aufgrund der in ähnlichem Maße unterschiedlichen Trockenmassen der Haupt- und Seitentriebe sowie teils sehr hoher Standardabweichungen unterschieden sich die Trockenmasse-Quotienten zwischen den betreffenden Baumarten nicht signifikant.

Hinsichtlich der nur an den Nadelbaumarten bestimmten Trockenmassen der Wurzeln (je rund $9 \mathrm{~g}$ ) und den Summen aus diesen und den Trockenmassen der Haupttriebe (je rund 14 
g) bestanden keine signifikanten Unterschiede zwischen den beiden Baumarten. Gleiches gilt für die Quotienten aus diesen beiden Trockenmassen.

Generell konnten zwischen den unbehandelten Douglasien und Kiefern keine signifikanten Unterschiede ihrer Wachstumsentwicklung festgestellt werden.

Die nur bei den Kiefern summierbare Gesamttrockenmasse (Trockenmassen des Haupttriebs, der Seitentriebe und der Wurzel) betrug in der unbehandelten Kontrolle $18 \mathrm{~g}$. Der Quotient aus ober- und unterirdischer Trockenmasse lag aufgrund der etwas höheren unterirdischen Trockenmasse bei $0,9 \pm 0,3$.

\subsubsection{Standorteinfluss}

Bei der Analyse der Wachstumsentwicklung der Versuchspflanzen ohne BodenhilfsstoffBehandlung wurde stets auch der Einfluss standörtlicher Faktoren (individueller Standort der Pflanze auf einer der drei Versuchsflächen bzw. in Bereichen mit oder ohne Spontanvegetation) untersucht. Voraussetzung war eine jeweils genügende Anzahl $(n>2)$ überlebender, nicht (durch Wild) geschädigter Wiederholungen.

Der Standorteinfluss auf die Vitalität der unbehandelten Ahorne, Ebereschen, Douglasien und Kiefern konnte deshalb nur für den Zuwachs des Haupttriebs im 1. Jahr (2005) untersucht werden, da im Folgejahr nicht mehr genügend Pflanzenmaterial und somit keine ausreichenden Messdaten zur Verfügung standen. Durch die hohen Ausfälle auf Fläche A war zudem nur bei den Erlen und Douglasien ein Vergleich aller drei Versuchsflächen möglich. Im 2. Jahr (2006) konnten nur noch die Kontroll-Erlen in ausreichender Zahl beprobt und hinsichtlich ihres Wachstums (gemessene und errechnete Parameter, s. ab S. 27 u. ab S. 79) analysiert werden.

Zufällig waren alle Kontrollbäume auf Fläche $B$ in einen Bereich mit späterer Bodenvegetationsentwicklung gepflanzt worden. Auf Fläche A und D standen dagegen alle Pflanzen der Nullvariante in Bereichen ohne Spontanvegetation, wobei auf Fläche A im Versuchsverlauf mit Ausnahme von zwei Erlen sämtliche Kontrollbäume ausfielen. Für die Pflanzen in der Nullvariante sind also die Gruppen "Standort im bewachsenen Bereich" und „Standort auf Fläche B“ ebenso wie die Gruppen „Standort im unbewachsenen Bereich“ und „Standort auf Fläche D (und A)“ identisch.

Wie Abb. 23 zeigt, wiesen die Ahorn-Kontrollen unabhängig vom Standort kaum Wachstum auf $(Z=-0,39)$. Bei den Nullvarianten der Ebereschen lag der Zuwachs in bewachsenen Bereichen bzw. auf Fläche $B(n=4)$ mit $7 \pm 4 \mathrm{~cm}$ vielfach höher als in unbewachsenen Bereichen bzw. auf Fläche D (n=6) mit $2 \pm 2 \mathrm{~cm}\left(\mathrm{Z}=-2,28^{*}\right)$. Bei den Kontroll-Erlen wurde auf Standorten mit Bodenbewuchs mit $13 \pm 5 \mathrm{~cm}(\mathrm{n}=4)$ ein doppelt so hoher Zuwachs ermittelt wie auf vegetationsfreien Standorten mit $6 \pm 5 \mathrm{~cm}(\mathrm{n}=7)\left(\mathrm{Z}=-1,18^{*}\right)$.

Der Zuwachs der Kontroll-Douglasien betrug bei vorhandener Spontanvegetation (bzw. auf Fläche B) mit $10 \pm 2 \mathrm{~cm}(\mathrm{n}=4)$ das 3-fache gegenüber ihrem Zuwachs ohne Bodenbewuchs (bzw. auf den Flächen $A$ und $D)$ mit $3 \pm 3 \mathrm{~cm}(\mathrm{n}=6)\left(\mathrm{Z}=-2,38^{* *}\right)$. Interessant ist der in Abb. 24 graphisch veranschaulichte, signifikante Unterschied ( $\left.\mathrm{Z}-1,99^{*}\right)$ zwischen dem Zuwachs auf Fläche D ( $6 \pm 2 \mathrm{~cm} ; n=3)$ und dem sehr geringen Zuwachs auf Fläche A $(0,7 \pm 1,2 \mathrm{~cm} ; n=3)$. Die vegetationsfreie Fläche A scheint demnach zumindest den Douglasien noch schlechtere Wuchsbedingungen zu bieten als die vegetationsfreien Bereiche auf Fläche D. 
Die Haupttriebe der unbehandelten Kiefern wuchsen auf vegetationsfreien Standorten bzw. auf Fläche $D(n=4)$ überhaupt nicht, auf bewachsenen Standorten bzw. auf Fläche $B(n=4)$ dagegen um $9 \pm 3 \mathrm{~cm}\left(\mathrm{Z}=-2,46^{* *}\right)$.

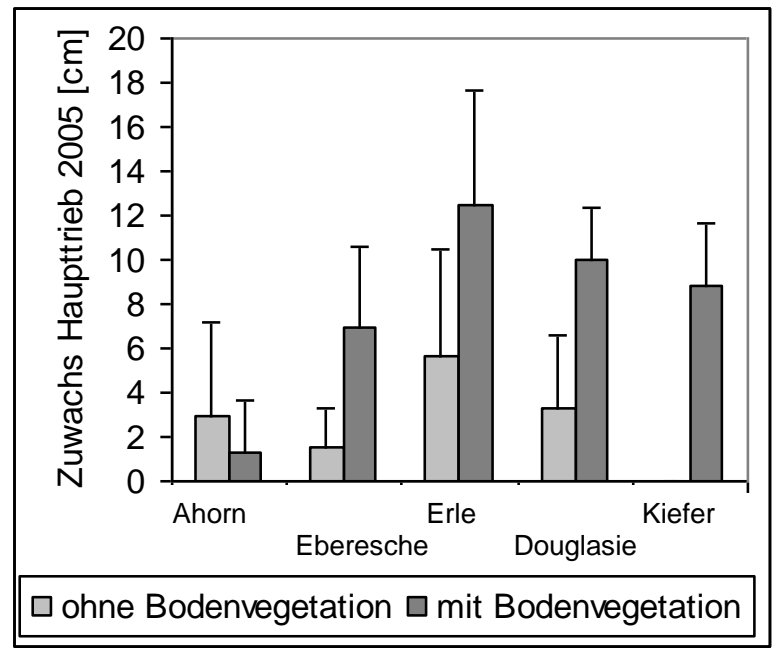

Abb. 23: Zuwachs des Haupttriebs der Kontrollen im Anlagejahr (2005) auf Standorten o./m. Spontanvegetation; MW u. Std.abw.; außer bei Ahorn jeweils signifikante Unterschiede nach U-Tests

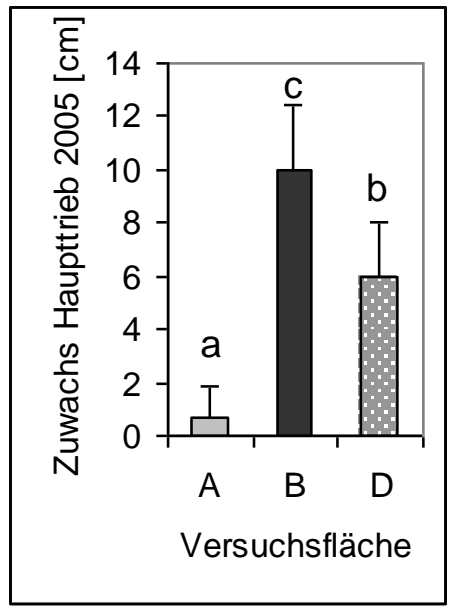

Abb. 24: Zuwachs des Haupttriebs der Kontroll-Douglasien im Anlagejahr (2005) getrennt nach Versuchsflächen (A: n=3; B: n=4; D: n=3); MW u. Std.abw.; Buchstaben kennzeichnen homogene Gruppen nach U-Tests

Bei den unbehandelten Erlen konnten auch im 2. Untersuchungsjahr signifikante Wachstumsunterschiede $\left(\mathrm{Z}-2,12^{*}\right)$ je nach Pflanzenstandort in Bereichen mit $(n=4)$ oder ohne Bodenvegetation ( $\mathrm{n}=7$ ) festgestellt werden.

Das Volumen des Haupttriebs (61 $\pm 8 \mathrm{~cm}^{3}$ ohne, $158 \pm 19 \mathrm{~cm}^{3}$ mit Bewuchs), seine Trockenmasse (28 $\pm 4 \mathrm{~g}$ ohne, $73 \pm 9 \mathrm{~g}$ mit Bewuchs) und sein zweijähriger Gesamtzuwachs (15 $\pm 9 \mathrm{~cm}$ ohne, $40 \pm 17 \mathrm{~cm}$ mit Bewuchs), die gesamte Seitentrieblänge pro Pflanze $(211 \pm 31 \mathrm{~cm}$ ohne, $580 \pm 178 \mathrm{~cm}$ mit Bewuchs), die Trockenmasse der Seitentriebe (14 $\pm 2 \mathrm{~g}$ ohne, $38 \pm 12 \mathrm{~g}$ mit Bewuchs) sowie die gesamte oberirdische Biomasse ( $42 \pm 5 \mathrm{~g}$ ohne, $111 \pm 20 \mathrm{~g}$ mit Bewuchs) lagen im Mittel bei den Kontrollerlen in Bereichen mit Spontanvegetation mehr als 2,5-mal so hoch wie in unbewachsenen Bereichen. Bei dem Quotienten aus Haupt- und Seitentrieblängen $(0,5 \pm 0,08$ ohne, $0,2 \pm 0,04$ mit Bewuchs $)$ galt dies entsprechend umgekehrt. Der ebenfalls signifikant unterschiedliche ( $\left.\mathrm{Z}-2,20^{*}\right)$ mittlere Wurzelhalsdurchmesser betrug auf bewachsenen 
Standorten $(13 \pm 1 \mathrm{~mm})$ das 1,5-fache des auf vegetationsfreien Standorten gemessenen $(20 \pm 0$ $\mathrm{mm})$.

Dass der offensichtliche positive Effekt der höheren pH-Werte in Bereichen mit Spontanvegetationsentwicklung (s. ab S. 44) im 2. Jahr noch zunahm, zeigte der durchschnittliche Zuwachs des Haupttriebs der Erlen (s. Abb. 25), der sich in bewachsenen Bereichen in 2006 gegenüber 2005 verdoppelte $(13 \pm 6 \mathrm{~cm}$ in 2005, $27 \pm 13 \mathrm{~cm}$ in 2006; Z = $1,18^{*}$ ). Er betrug damit das 3,5-fache des Zuwachses in vegetationsfreien Bereichen, der sich gegenüber dem Vorjahr nicht veränderte ( $8 \pm 4 \mathrm{~cm}$ in $2005,8 \pm 6 \mathrm{~cm}$ in $2006 ; Z=-2,12$ ).

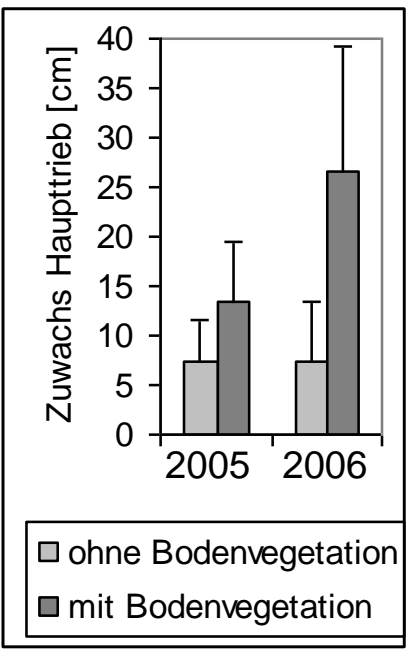

Abb. 25: Zuwachs des Haupttriebs der Kontroll-Erlen in beiden Untersuchungsjahren auf Standorten ohne $(n=4)$ und mit $(n=3)$ Spontanvegetation; MW u. Std.abw.; jeweils signifikante Unterschiede nach U-Tests

\subsubsection{Vergleich Nullvariante - Gesamtdurchschnitt}

Bei jeder Baumart wurden die an den unbehandelten Kontrollen gemessenen WachstumsMittelwerte (s. Tab. A 14) den an der Gesamtheit aller Versuchspflanzen gemessenen Mittelwerten gegenübergestellt (s. Tab. A 15). Die Vergleiche führten je nach Baumart zu sehr unterschiedlichen Ergebnissen.

Zwischen den Kontroll-Erlen und der Gesamtheit aller im Feldversuch eingesetzten Erlen gab es keine signifikanten Wachstums-Unterschiede. Die Douglasien wiesen in der unbehandelten Kontrolle sowohl im 1. Untersuchungsjahr als auch insgesamt einen signifikant höheren Haupttriebs-Zuwachs auf als alle in den verschiedenen Varianten gepflanzten Douglasien im Durchschnitt. Dieses Ergebnis spiegelt vor allem die bei den Douglasien sehr gute Kontrolle auf Fläche B wider. Bei den Ahornen waren der (nicht vorhandene) Zuwachs des Haupttriebs im 2. Untersuchungsjahr und der aufgrund dessen sehr geringe Gesamtzuwachs der Kontrollen signifikant geringer als der jeweilige Gesamtdurchschnitt. Bei den Kontroll-Ebereschen waren zusätzlich zu diesen beiden Wachstumsparametern auch der Wurzelhalsdurchmesser, Volumen und Trockenmasse des Haupttriebs sowie die oberirdische Trockenmasse signifikant geringer als das Gesamtmittel. Die unbehandelten Kiefern wiesen bei annähernd allen Wachstumsparametern signifikant geringere Mittelwerte auf als alle Kiefern im Gesamtdurchschnitt. 


\subsection{Effekte der Behandlungsvarianten auf die Pflanzenentwicklung}

Neben den jeweiligen Kontrollen (Nullvarianten) waren bei den Ebereschen, Erlen und Kiefern 9, bei den Eichen, Ahornen und Douglasien 15 Behandlungsvarianten (Zugabe verschiedener, teilweise miteinander kombinierter Bodenhilfsstoffe bei der Pflanzung; s. S. 20) angelegt worden. Die Ergebnisse der Analysen der Assimilationsorgane, der Vitalitätsschätzungen sowie der Wuchsuntersuchungen verdeutlichen den Einfluss der Behandlungen auf die Pflanzenentwicklung.

\subsubsection{Nährstoffversorgung und Schadstoffbelastung}

In beiden Untersuchungsjahren wurden chemische Analysen der Assimilationsorgane der 6 Baumarten durchgeführt (s. S. 26). So konnten die Versorgungs- und Belastungssituation der Baumarten auf den drei Versuchsflächen und zeitlich bedingte Schwankungen der ElementGehalte in den Nadeln und Blättern erfasst sowie mögliche Wirkungen der eingesetzten Bodenhilfsstoffe untersucht werden.

Zur Beschränkung der Probenanzahl handelte es sich bei sämtlichen im Freiland-Versuch analysierten Pflanzen-Proben um Mischproben.

Um einen Eindruck der Varianz innerhalb einer Variante zu gewinnen, wurden im Topf-Versuch bei verschiedenen Ahorn-Varianten sämtliche Wiederholungen beprobt. Aus den Ergebnissen der Blattanalysen wurden anschließend je Variante Mittelwerte gebildet, die überwiegend recht hohe Standardabweichungen zeigten. Aufgrund dieser Resultate ist zu beachten, dass sich die im Freiland-Versuch an Mischproben gemessenen Element-Gehalte überwiegend wahrscheinlich nicht signifikant voneinander unterschieden, wenn sie weniger als 20-25\% voneinander abwichen.

Zudem handelt es sich bei den Analyseergebnissen stets um Momentaufnahmen, da die ElementGehalte in den Assimilationsorganen je nach Witterungseinflüssen, Aufnahmezeitpunkt etc. schwanken können. Dies zeigte der Vergleich der auf Fläche D sowohl im 1. (2005) als auch im 2. (2006) Untersuchungsjahr gewonnenen Daten.

Im Anhang (Tab. A 17 - A 41) sind für jede Baumart die in den Assimilationsorganen gemessenen Elementgehalte und ihre Bewertung auf Grundlage der in Anhang 2 aufgeführten Quellen tabellarisch zusammengestellt. Zudem wurden die $\mathrm{Zu}$ - und Abnahmen von Nährstoffund Schadstoff-Gehalten in den Behandlungsvarianten (Nullvariante als Bezugspunkt) tabellarisch dargestellt und graphisch aufbereitet (Abb. A 1 - A 6).

\subsubsection{Rot-Eiche}

Im Folgenden werden die Ergebnisse der Blattanalysen (Mischproben, s. S. 26) zur Versorgung und Belastung der Eichen auf den Versuchsflächen B und D insgesamt sowie innerhalb der Versuchs-Varianten auf Versuchsfläche D dargestellt.

Aufgrund hoher Pflanzenausfälle bei dieser Baumart konnten Versuchsfläche A sowie die Behandlungs-Varianten V2, V3, V5, V6, V8, V9 (s. S. 20) auf Fläche D nicht mit in die Untersuchungen einbezogen werden. 
Hauptnährelemente, Makronährstoffe (N, P, K, Ca, Mg, S)

Die durchschnittliche Stickstoff-Versorgung der Eichen (s. Abb. 26) war in beiden Untersuchungsjahren auf den jeweils beprobten Flächen mit Werten zwischen 19,6 und 21,9 mg/g mittel (Heinsdorf 1999) bzw. ausreichend (BFW 2005/7, Bergmann 1993). Zwischen den Mittelwerten der Versuchsflächen bestand kaum ein Unterschied; im 2. Jahr (2006) war der Gehalt auf Fläche D etwas geringer als in 2005.
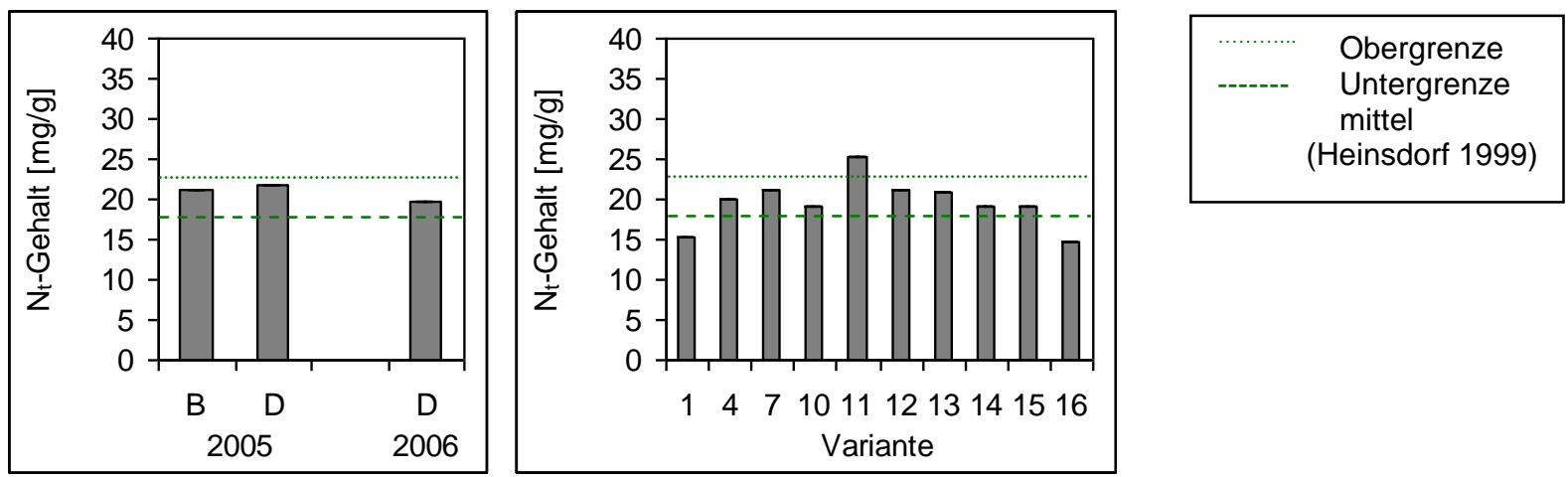

Abb. 26 links: $\mathrm{N}_{\mathrm{t}}$-Gehalte [mg/g] im Laub der Eichen auf den Versuchsflächen B und D im 1. (2005) und auf Fläche D im 2. (2006) Vegetationsjahr (Mischproben); rechts: differenziert nach Varianten (s. S. 20) auf Fläche D im 2. Jahr (2006) (Mischproben)

Die dort in 2006 in den einzelnen Behandlungsvarianten erhobenen Stickstoff-Gehalte lagen zwischen 14,7 mg/g (V16) und 25,4 mg/g (V11). Die Versorgung der unbehandelten Kontrolle (V1) sowie der Mykorrhiza-Superabsorber-Kalk-Variante (V16) war mit 15,3 mg/g bzw. 14,7 mg/g gering (Heinsdorf 1999) bzw. mangelhaft (BFW 2005/7). Alle übrigen Behandlungen führten zu höheren Stickstoff-Gehalten, die als mittel (Heinsdorf 1999) bzw. ausreichend (BFW 2005/7) eingestuft wurden. Die mit 25,4 mg/g deutlich beste Stickstoff-Versorgung (hoch laut Heinsdorf 1999, optimal laut BFW 2005/7) wurde durch die alleinige Zugabe von MykorrhizaInokulum bei der Pflanzung (V11) erzielt.
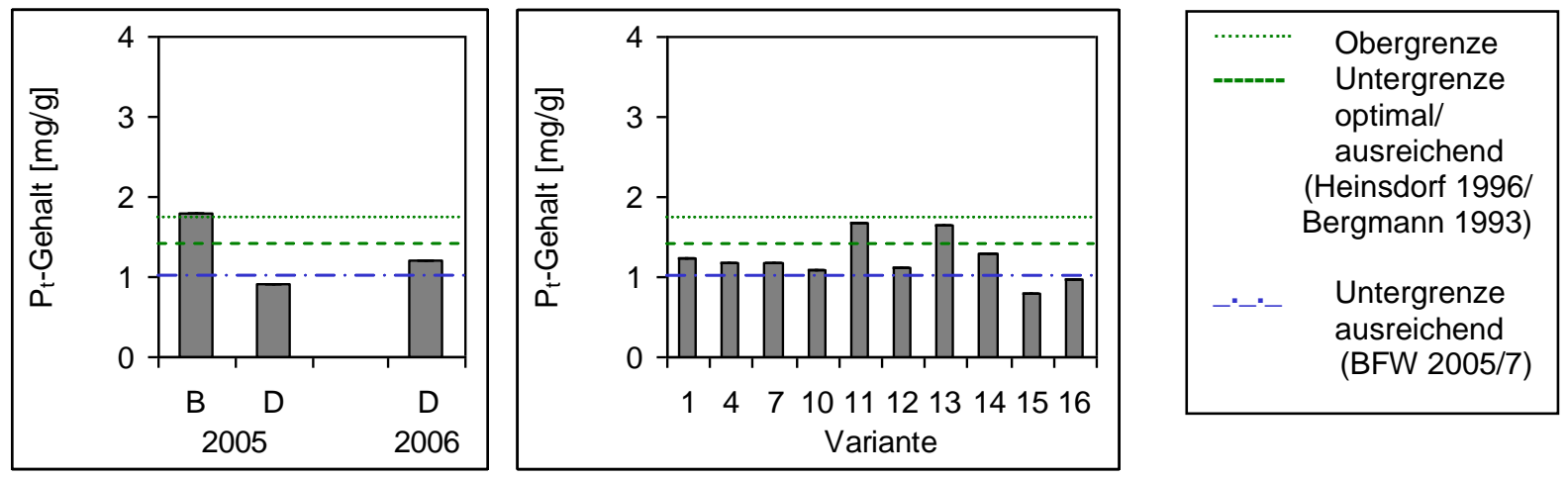

Abb. 27 links: $\mathrm{P}_{\mathrm{t}}$-Gehalte [mg/g] im Laub der Eichen auf den Versuchsflächen B und D im 1. (2005) und auf Fläche D im 2. (2006) Vegetationsjahr (Mischproben); rechts: differenziert nach Varianten (s. S. 20) auf Fläche D im 2. Jahr (2006) (Mischproben)

Der Phosphor-Gehalt (s. Abb. 27) lag 2005 auf Fläche B mit 1,8 mg/g knapp über der Obergrenze einer ausreichenden bzw. Optimalversorgung bei Rot-Eichen laut Heinsdorf (1996) und Bergmann (1993) und war dem BFW zufolge ausreichend (BFW 2005/7). Auf Fläche D dagegen lag 2005 Phosphormangel vor (0,9 mg/g); 2006 war der Wert nur wenig höher $(1,2$ mg/g) und nur nach BFW (2005/7) ausreichend (laut Heinsdorf 1996 Unterversorgung; laut Bergmann 1993 nicht ausreichend). 
Variantenweise betrachtet ergaben sich in 2006 auf Fläche D Phosphor-Gehalte im Eichen-Laub zwischen 0,8 mg/g (V15) und 1,7 mg/g (V11). Den verwendeten Quellen zufolge waren die Eichen in der unbehandelten Kontrolle (V1) sowie in den meisten Behandlungsvarianten nicht (Bergmann 1993) oder nur knapp ausreichend (BFW 2005/7) mit Phosphor versorgt bzw. unterversorgt (Heinsdorf 1996). In den Mykorrhiza-Varianten V11 (Mykorrhiza) und V13 (Mykorrhiza-Stockosorb ${ }^{\circledR}$ ) wurden deutlich höhere Phosphor-Gehalte gemessen, die sich mit $1,7 \mathrm{mg} / \mathrm{g}$ bzw. 1,6 mg/g an der oberen Grenze der Optimalversorgung bei Rot-Eichen laut Heinsdorf (1999) befanden. In Kombination mit Superabsorber (V15, MykorrhizaSuperabsorber) wurde dagegen mit nur 0,8 mg Phosphor pro Gramm trockener Blattmasse der stärkste Phosphormangel ermittelt.
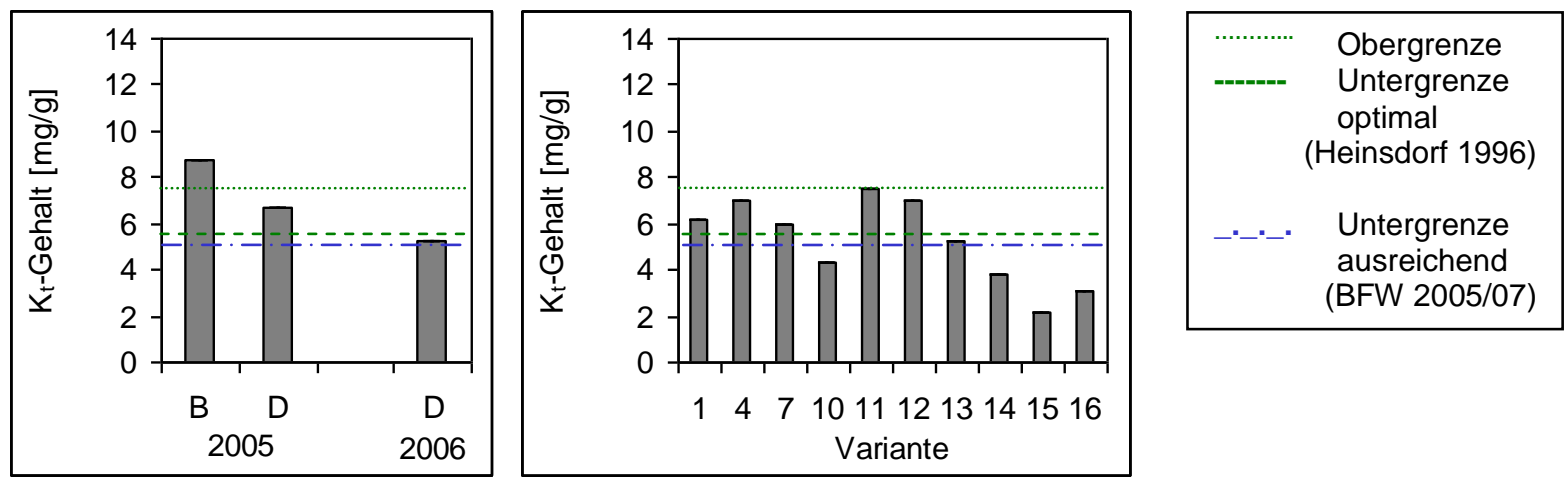

Abb. 28 links: $\mathrm{K}_{\mathrm{t}}$-Gehalte [mg/g] im Laub der Eichen auf den Versuchsflächen B und D im 1. (2005) und auf Fläche D im 2. (2006) Vegetationsjahr (Mischproben); rechts: differenziert nach Varianten (s. S. 20) auf Fläche D im 2. Jahr (2006) (Mischproben)

Ebenso wie der Phosphorwert lag auch der ermittelte Kalium-Gehalt (s. Abb. 28) auf Fläche B mit $8,8 \mathrm{mg} / \mathrm{g}$ höher als auf Fläche D, wo er im 2. Untersuchungsjahr (2006) mit 5,2 mg/g leicht geringer war als in $2005 \mathrm{mit} 6,7 \mathrm{mg} / \mathrm{g}$. In der Literatur gibt es sehr unterschiedliche Bewertungen von Kalium-Gehalten in Eichen-Blättern (s. auch ab S. 334). So waren nach BFW (2005/7) alle drei Werte (knapp) ausreichend. Laut Heinsdorf (1996) bestand in 2005 auf Fläche B eine Überversorgung, auf Fläche D eine Optimalversorgung und in 2006 auf Fläche D knapp eine Unterversorgung mit Kalium. Nach Bergmann (1993), der die Untergrenze einer ausreichenden Versorgung erst bei $10 \mathrm{mg} / \mathrm{g}$ ansetzt, war keiner der im Versuchsverlauf in den Eichen-Blättern ermittelten Kalium-Gehalte ausreichend.

In den einzelnen Eichen-Varianten auf Fläche D wurden in 2006 Kalium-Blattgehalte zwischen 2,1 mg/g (V15) und 7,5 mg/g (V11) gemessen.

Mit 6,1 mg/g war der Wert in der unbehandelten Kontrolle (V1) nach BFW (2005/7) ausreichend, nach Heinsdorf (1996) optimal. In der Perlit-Variante (V7) wurde ein vergleichbarer Kalium-Gehalt ermittelt. Die Pflanzbeigabe von Stockosorb® und Kalk (V4) sowie von Mykorrhiza-Inokulum und Kalk (V12), vor allem aber von Mykorrhiza-Inokulum allein (V11) sorgte für höhere Kalium-Blattgehalte, die in Variante V11 laut Heinsdorf (1996) bereits an der Grenze zur Überversorgung lagen. In der Kompost-Kalk-Variante (V10) und in den Varianten mit Behandlungskombinationen aus Mykorrhiza und Wasserspeichersubstanzen (V13-V16) wurden deutlich niedrigere Kalium-Gehalte als in den Blättern der Kontroll-Eichen gemessen, die (ausgenommen V13 mit 5,2 mg/g) bereits im Bereich eines Kalium-Mangels (BFW 2005/7) bzw. einer Kalium-Unterversorgung (Heinsdorf 1996) lagen. 

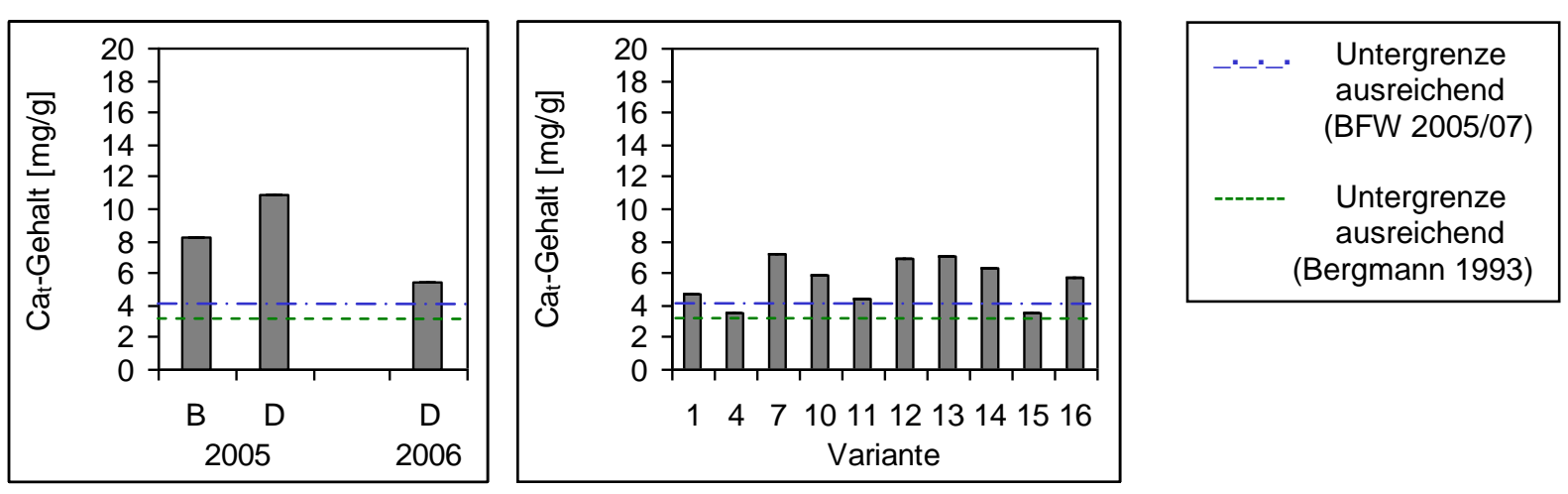

Abb. 29 links: Cat-Gehalte [mg/g] im Laub der Eichen auf den Versuchsflächen B und D im 1. (2005) und auf Fläche D im 2. (2006) Vegetationsjahr (Mischproben); rechts: differenziert nach Varianten (s. S. 20) auf Fläche D im 2. Jahr (2006) (Mischproben)

Die gemessenen Calcium-Gehalte (s. Abb. 29) gelten bei BFW (2005/7) und Bergmann (1993) als ausreichend. Heinsdorf (1996) bewertet die Eichen auf Fläche B als mit Calcium überversorgt (8,2 mg/g); der höhere Wert auf Fläche D (2005) lag mit 10,9 mg/g demnach bereits knapp oberhalb einer Überversorgung. In 2006 war der Calcium-Gehalt auf Fläche D mit 5,5 mg/g nur halb so hoch wie im Vorjahr und laut Heinsdorf (1996) optimal.

In den verschiedenen Behandlungsvarianten auf Fläche D lagen die Calcium-Gehalte in 2006 zwischen 3,5 mg/g (V4, V15) und 7,3 mg/g (V7). In den Blättern der Kontroll-Eichen (V1) wurde mit 4,7 mg/g ein ausreichender (BFW 2005/7, Bergmann 1993) bzw. zwischen Unter- und Optimalversorgung liegender (Heinsdorf 1996) Calcium-Gehalt gemessen. Ein mit 4,4 mg/g vergleichbarer Wert wurde in der Mykorrhiza-Variante (V11) ermittelt. Durch den erwarteten positiven Einfluss der Kalk-Gaben lagen die Calcium-Gehalte in den Varianten V10, V12, V14 und V16 deutlich höher. Jedoch wurden in den kalkfreien Varianten V7 (Perlit) und V13 (Mykorrhiza-Stockosorb®) mindestens ebenso hohe Werte gemessen. Ebenfalls unerwartet war der geringe Calcium-Gehalt in der Stockosorb ${ }^{\circledR}$-Kalk-Variante (V4), der ebenso wie der CalciumGehalt in der Mykorrhiza-Superabsorber-Variante (V15) als Unterversorgung bzw. Mangel gilt.
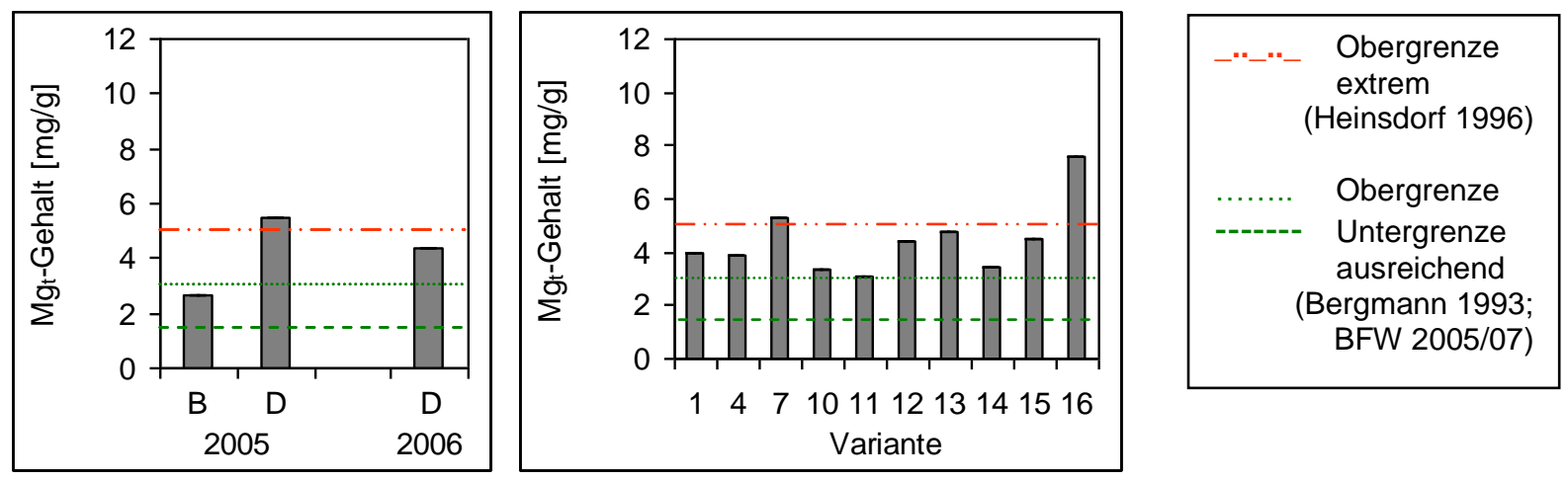

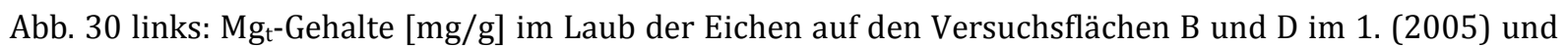
auf Fläche D im 2. (2006) Vegetationsjahr (Mischproben); rechts: differenziert nach Varianten (s. S. 20) auf Fläche D im 2. Jahr (2006) (Mischproben)

Die Magnesiumversorgung der Eichen (s. Abb. 30) auf Fläche B wurde mit 2,7 mg/g als optimal (BFW 2005/7) bzw. ausreichend (Bergmann 1993) eingestuft. Nach Heinsdorf (1996) lag dieser Wert bereits im Bereich einer Überversorgung. Der mehr als doppelt so hohe Magnesium-Gehalt der Eichen-Blätter auf Fläche D (2005) war mit 5,5 mg/g demnach noch oberhalb einer 
Extremversorgung anzusiedeln. Im 2. Untersuchungsjahr (2006) war der Wert auf Fläche D etwas geringer $(4,4 \mathrm{mg} / \mathrm{g})$ und lag damit im Bereich einer Extremversorgung.

Einzeln betrachtet waren die Magnesium-Gehalte in den Blättern der Eichen-Varianten auf Fläche D in 2006 mit Werten zwischen 3,1 mg/g (V11) und 7,6 mg/g (V16) sämtlich über den ausreichenden Gehalten nach Bergmann (1993) und dem BFW (2005/7) anzusiedeln. In der unbehandelten Kontrolle (V1) lag der Magnesium-Gehalt bei 3,9 mg/g, was bei Heinsdorf (1996) als extrem bewertet wird. In der Stockosorb®-Kalk-Variante (V4) wurde ein vergleichbarer Wert, in der Kompost-Kalk-Variante (V10) und der Mykorrhiza-Stockosorb®-Kalk-Variante (V14) wurden leicht geringere Werte gemessen. Nur in der reinen Mykorrhiza-Variante (V11) wurde mit 3,1 mg/g ein Magnesium-Gehalt ermittelt, der nach Heinsdorf (1996) nicht als extrem, sondern lediglich als überversorgt eingestuft wird. In den übrigen Behandlungsvarianten wurden Magnesium-Gehalte deutlich oberhalb des Kontrollwertes gemessen, wobei der Gehalt in der Perlit-Variante (V7) mit 5,3 mg/g die obere Grenze des Extrembereichs nach Heinsdorf (1996) bereits leicht überschritt. In der Behandlungskombination Mykorrhiza-Superabsorber-Kalk (V16) wurde mit 7,6 mg/g ein Magnesium-Gehalt festgestellt, der doppelt so hoch wie der Kontrollwert und damit weit jenseits des Extrembereichs nach Heinsdorf (1996) lag.
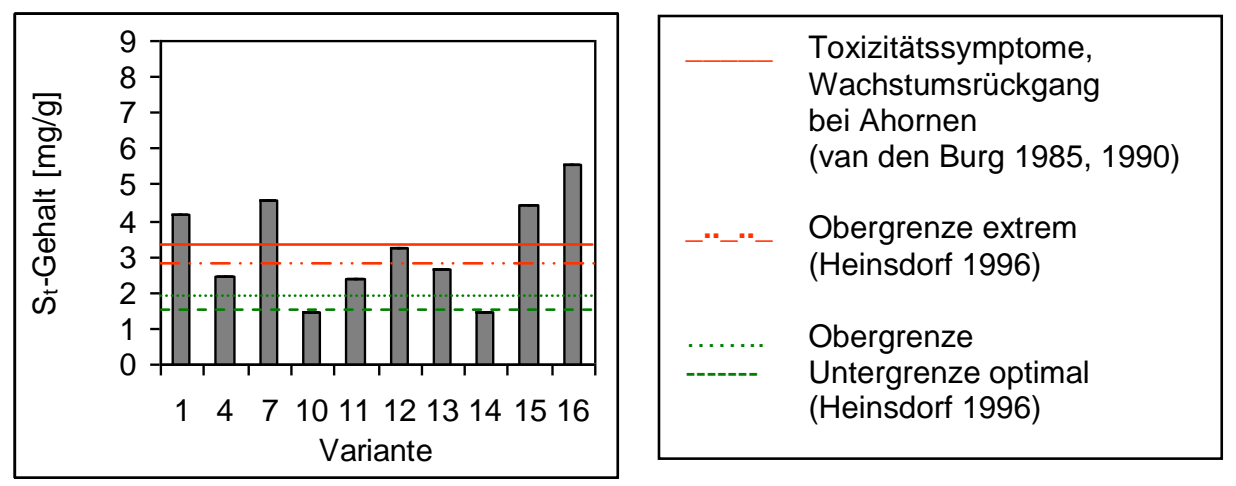

Abb. 31: St-Gehalte [mg/g] im Laub der Eichen-Varianten (s. S. 20) auf Versuchsfläche D im 2. (2006) Vegetationsjahr (Mischproben)

Der mittlere Schwefel-Gehalt der Eichen-Blätter auf Fläche D (s. Abb. 31) lag im 2. Untersuchungsjahr (2006) insgesamt bei $3,2 \mathrm{mg} / \mathrm{g}$ trockener Blattmasse. Je nach Variante betrug er zwischen 1,4 mg/g (V14) und 5,6 mg/g (V16). In der unbehandelten Kontrolle wurde mit 4,2 mg/g ein Schwefel-Gehalt gemessen, der sowohl die Obergrenze einer Extremversorgung (2,8 mg/g) laut Heinsdorf (1996) als auch den Gehalt, ab dem bei Ahornen Toxizitätssymptome oder Wachstumsrückgang festgestellt wurden (3,3 mg/g; van den Burg 1985, 1990), deutlich überschreitet. Vergleichbar hohe Werte wurden in der Perlit-Variante (V7) und in der Kombination aus Mykorrhiza und Superabsorber (V15) ermittelt, wobei in dieser Kombination mit Kalk-Gabe (V16: Mykorrhiza-Superabsorber-Kalk) mit 5,6 mg/g der höchste Schwefel-Gehalt aller Varianten gemessen wurde. Einen geringeren Schwefel-Gehalt (aber immer noch oberhalb des Extrembereichs) wiesen die Eichen-Blätter in der Mykorrhiza-Kalk-Variante (V12) auf. In den Varianten Stockosorb®-Kalk (V4), Mykorrhiza (V11) und Mykorrhiza-Stockosorb® (V13) lagen die Schwefel-Gehalte noch deutlich darunter und damit innerhalb des Extrembereichs. Optimale bzw. bereits knapp im Bereich einer Unterversorgung liegende Schwefel-Gehalte nach der Bewertung von Heinsdorf (1996) wurden mit 1,5 mg/g in der Kompost-Kalk-Variante (V10) und mit 1,4 mg/g in der Mykorrhiza-Stockosorb®-Kalk-Variante (V14) erreicht. 


\section{Spurennährelemente, Mikronährstoffe (Fe, Mn, Zn, Cu)}

Im Laub der Eichen auf Fläche D wurde im 2. Untersuchungsjahr (2006) ein durchschnittlicher

Eisen-Gehalt von insgesamt $1163 \mathrm{mg} / \mathrm{kg}$ ermittelt, der im Einzelnen je nach Behandlungsvariante zwischen $167 \mathrm{mg} / \mathrm{kg}$ (V14) und $3291 \mathrm{mg} / \mathrm{kg}$ (V7) schwankte (s. Abb. 32). Es fällt eine deutliche Parallele zur Verteilung der Aluminium-Gehalte auf die einzelnen Varianten auf.
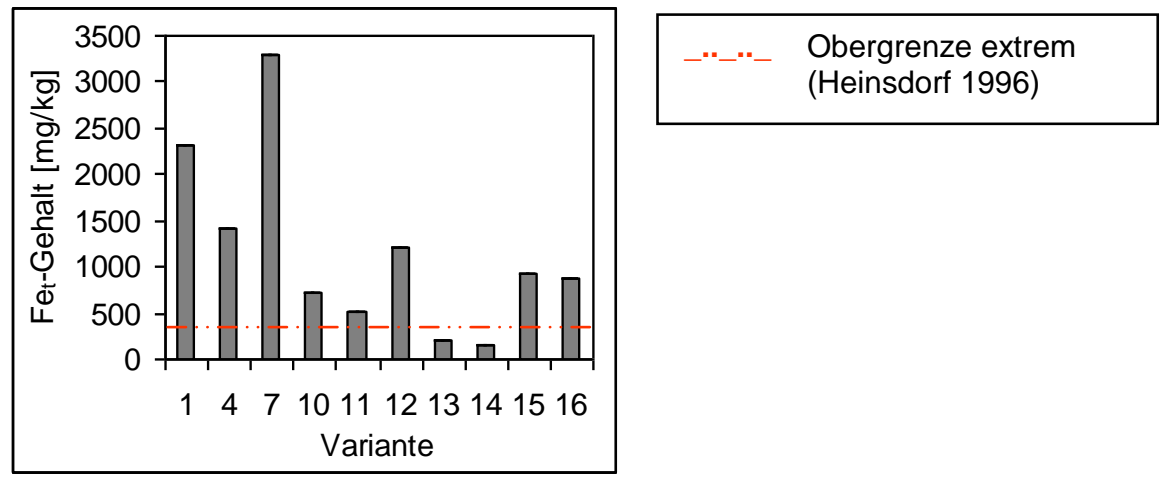

Abb. 32: $\mathrm{Fe}_{\mathrm{t}}-\mathrm{Gehalte}[\mathrm{mg} / \mathrm{kg}]$ im Laub der Eichen-Varianten (s. S. 20) auf Versuchsfläche D im 2. (2006) Vegetationsjahr (Mischproben)

In der Nullvariante (V1) lag der Wert mit $2324 \mathrm{mg} / \mathrm{kg}$ etwa 8-mal so hoch wie die Obergrenze des Extrembereichs (300 mg/kg) laut Heinsdorf (1996). Mit $3291 \mathrm{mg} / \mathrm{kg}$ noch deutlich darüber (und 11-mal so hoch wie die Obergrenze des Extrembereichs) lag nur der Eisen-Gehalt in der Perlit-Variante (V7). Bei den übrigen Varianten waren die Eisen-Gehalte deutlich niedriger, die meisten Werte lagen aber immer noch oberhalb einer Extremversorgung. Lediglich die Eichen mit kombinierten Mykorrhiza-Stockosorb®-Behandlungen (ohne Kalk-Gabe: V13; mit KalkGabe: V14) wiesen mit 195 mg/kg bzw. 167 mg/kg Eisen-Gehalte in ihren Blättern auf, die nur noch im Bereich einer Überversorgung nach Heinsdorf (1996) lagen.
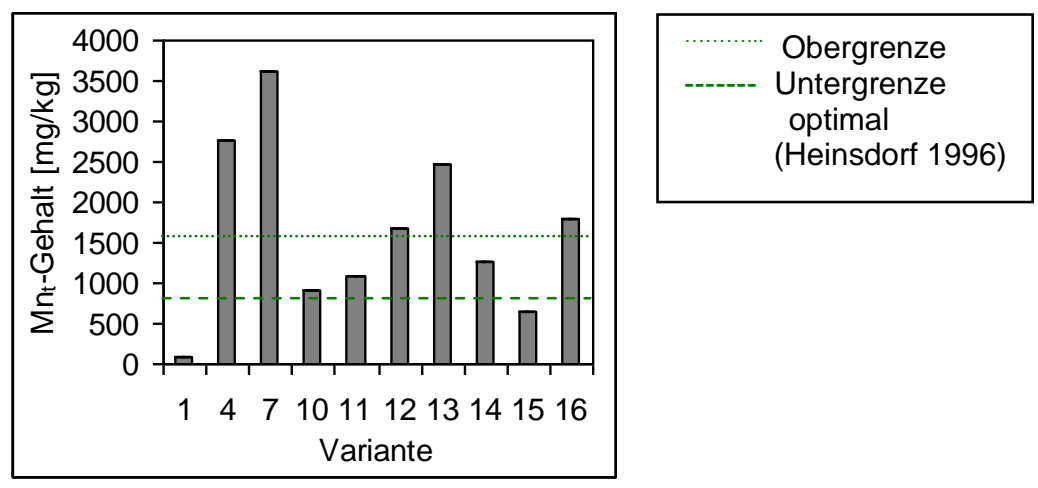

Abb. 33: $\mathrm{Mn}_{\mathrm{t}}-$ Gehalte $[\mathrm{mg} / \mathrm{kg}]$ im Laub der Eichen-Varianten (s. S. 20) auf Versuchsfläche D im 2. (2006) Vegetationsjahr (Mischproben)

Die in den Blättern der Eichen auf Fläche D in 2006 gemessenen Mangan-Gehalte (s. Abb. 33) schwankten sehr stark zwischen $87 \mathrm{mg} / \mathrm{kg}$ (V1) und $3604 \mathrm{mg} / \mathrm{kg}$ (V7); der Mittelwert lag bei $1631 \mathrm{mg} / \mathrm{kg}$ trockener Blattmasse. In der unbehandelten Kontrolle wurde mit nur $87 \mathrm{mg} / \mathrm{kg}$ ein deutlicher Mangel nach Heinsdorf (1996) festgestellt, während Bergmann (1993) und das BFW (2005/7) diesen Wert bereits als ausreichend (35-100/150 mg/kg) einstufen. Die Ergebnisse anderer Untersuchungen (z.B. Stähr 2003) weisen jedoch darauf hin, dass diese in Bergmann (1993) und BFW (2005/7) genannten Spannen teilweise deutlich nach oben korrigiert werden 
können. An dieser Stelle soll auf die Problematik der überaus unterschiedlichen Bewertungsskalen von Mangan-Blattgehalten in der Literatur verwiesen werden (s. ab S. 333).

Alle Manganwerte in den Behandlungsvarianten lagen um ein Vielfaches über dem Kontrollwert. In der Mykorrhiza-Superabsorber-Variante (V15) bestand mit $638 \mathrm{mg} / \mathrm{kg}$ nach Einstufung durch Heinsdorf (1996) eine Unterversorgung mit Mangan, während bei den Eichen mit Kompost- und Kalk-Gabe (V10), mit Mykorrhiza-Inokulum allein (V11) sowie mit Mykorrhiza, Stockosorb® und Kalk (V14) Mangan-Gehalte im Optimalbereich gemessen wurden. Mit Behandlungskombinationen aus Mykorrhiza und Kalk (V12) oder Mykorrhiza, Superabsorber und Kalk (V16) lagen die Mangan-Werte knapp über diesem Optimum. Mit Mykorrhiza und Stockosorb® (V13), Stockosorb® und Kalk (V4) sowie Perlit (V7) wurden im Eichen-Laub Mangan-Gehalte von $2483 \mathrm{mg} / \mathrm{kg}, 2774 \mathrm{mg} / \mathrm{kg}$ bzw. $3604 \mathrm{mg} / \mathrm{kg}$ ermittelt, die weit über der Obergrenze des Optimalbereichs nach Heinsdorf (1996) lagen und vermutlich toxisch sind.
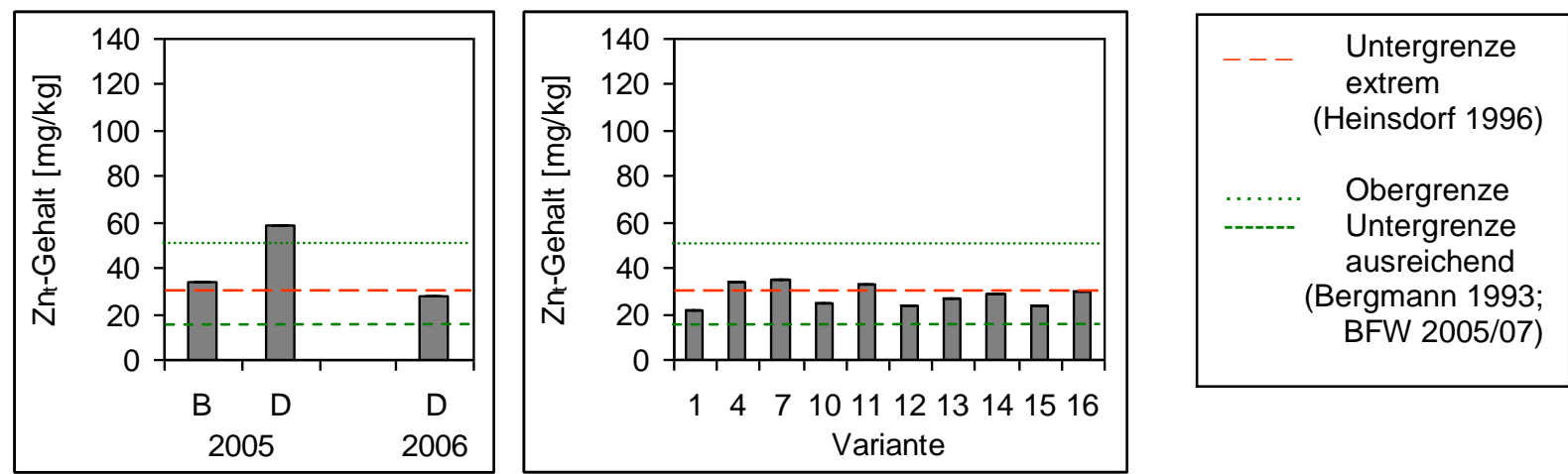

Abb. 34 links: $\mathrm{Zn}_{\mathrm{t}}$-Gehalte [mg/kg] im Laub der Eichen auf den Versuchsflächen B und D im 1. (2005) und auf Fläche D im 2. (2006) Vegetationsjahr (Mischproben); rechts: differenziert nach Varianten (s. S. 20) auf Fläche D im 2. Jahr (2006) (Mischproben)

Der Zink-Gehalt im Eichen-Laub (s. Abb. 34) auf Fläche B (2005) betrug 33,9 mg/kg und war damit als ausreichend (BFW 2005/7, Bergmann 1993), nach Heinsdorf (1996) jedoch bereits als extrem einzustufen. Auf Fläche D lag der Wert in 2005 mit 58,8 mg/kg deutlich höher (laut BFW 2005/7 optimal, laut Bergmann 1993 über ausreichend, laut Heinsdorf 1996 über extrem). Im Folgejahr war der Zink-Gehalt in den Blättern der Eichen auf dieser Fläche mit 28,0 mg/kg nur noch halb so hoch und damit ausreichend (BFW 2005/7, Bergmann 1993) bzw. im Bereich einer Überversorgung (Heinsdorf 1996).

Die im 2. Untersuchungsjahr (2006) auf Fläche D auch innerhalb der einzelnen Varianten erhobenen Zink-Werte lagen zwischen $21,2 \mathrm{mg} / \mathrm{kg}$ (V1) und $35 \mathrm{mg} / \mathrm{kg}$ und waren damit nach Bergmann (1993) und dem BFW (2005/7) sämtlich ausreichend. Dagegen stuft Heinsdorf (1996) die Zink-Gehalte in der Kontrolle (V1), der Mykorrhiza-Kalk-Variante (V12), der Mykorrhiza-Superabsorber-Variante (V15) und der Kompost-Kalk-Variante (V10) sowie die etwas höheren Werte in der Mykorrhiza-Stockosorb®- und der Mykorrhiza-Stockosorb®-KalkVariante (V13, V14) als überversorgt ein. Die Eichen in der Mykorrhiza-Superabsorber-KalkVariante (V16), der Mykorrhiza-Variante (V11), der Stockosorb®-Kalk-Variante (V4) und der Perlit-Variante (V7) waren bei Gehalten zwischen $30 \mathrm{mg} / \mathrm{kg}$ und $35 \mathrm{mg} / \mathrm{kg}$ trockener Blattmasse demnach bereits extrem mit Zink versorgt. 

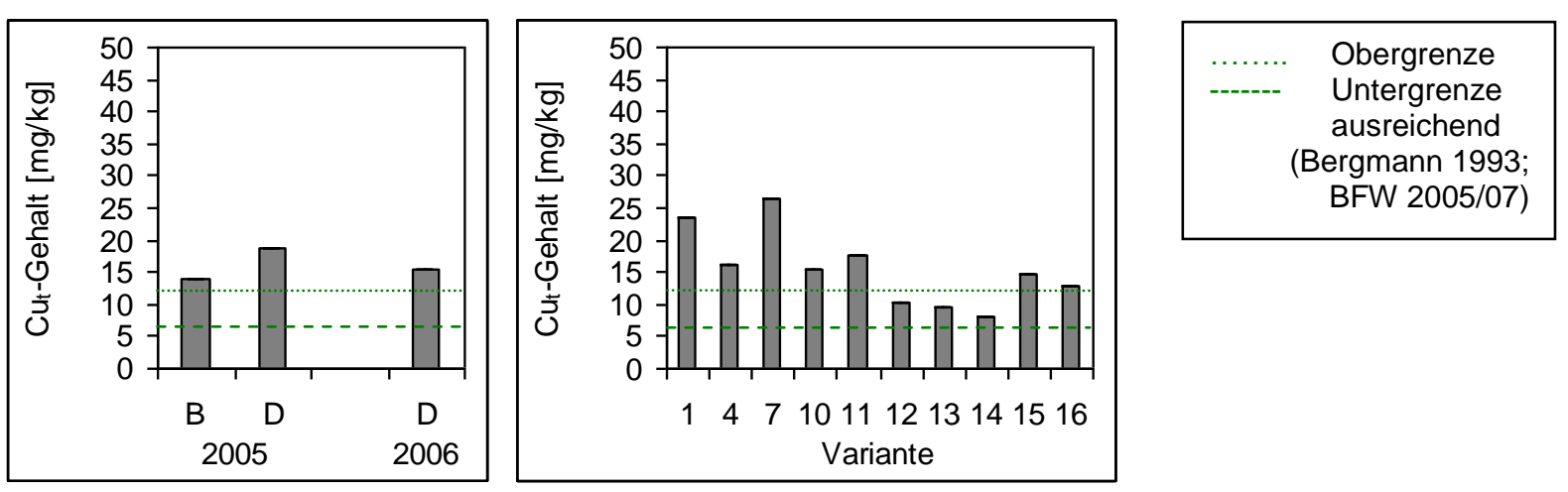

Abb. 35 links: $\mathrm{Cu}_{\mathrm{t}}-\mathrm{Gehalte}[\mathrm{mg} / \mathrm{kg}]$ im Laub der Eichen auf den Versuchsflächen B und D im 1. (2005) und auf Fläche D im 2. (2006) Vegetationsjahr (Mischproben); rechts: differenziert nach Varianten (s. S. 20) auf Fläche D im 2. Jahr (2006) (Mischproben)

Die im Laub der Eichen ermittelten Kupfer-Gehalte (s. Abb. 35) lagen auf Fläche B und D über den ausreichenden Gehalten laut BFW (2005/7) und Bergmann (1993), jedoch im Bereich der Normalgehalte in Pflanzen nach Smidt (1999; $15-20 \mathrm{mg} / \mathrm{kg}$ ) und unterhalb der kritischen Konzentrationen in Alloway (1999; 20-100 mg/kg). Auf Fläche D war der Wert mit 18,6 mg/kg höher als auf Fläche B mit 14,1 mg/kg. Im 2. Aufnahmejahr (2006) war er auf Fläche D mit 15,5 $\mathrm{mg} / \mathrm{kg}$ geringer als in 2005.

Die in 2006 in jeder Eichen-Variante auf Fläche D gemessenen Kupfer-Gehalte bewegten sich zwischen 8,0 mg/kg (V14) und 26,4 mg/kg (V7). In der unbehandelten Kontrolle (V1) und der Perlit-Variante (V7) überstiegen die Kupfer-Gehalte mit $23,7 \mathrm{mg} / \mathrm{kg}$ und $26,4 \mathrm{mg} / \mathrm{kg}$ den ausreichenden Bereich nach BFW (2005/7) und Bergmann (1993) sowie die Normalgehalte nach Smidt (1999) und lagen bereits innerhalb der kritischen Konzentrationen (Alloway 1999), oberhalb deren toxische Auswirkungen wahrscheinlich sind. Die Kupfer-Gehalte der übrigen Varianten, in denen die Eichen bei der Pflanzung mit Bodenhilfsstoffen zur Anhebung des Boden-pH-Wertes (Kalk, Kompost) und/oder Mykorrhiza-Inokulum behandelt wurden, waren deutlich niedriger. Mit Stockosorb ${ }^{\circledR}$ und Kalk (V4), mit Kompost und Kalk (V10) sowie mit Mykorrhiza (V11) wurden Kupfer-Gehalte im Normalbereich nach Smidt (1999) gemessen, die aber wie auch die Gehalte in der Mykorrhiza-Superabsorber-Variante (V15) und der Mykorrhiza-Superabsorber-Kalk-Variante (V16) oberhalb des ausreichenden Bereichs nach BFW (2005/7) und Bergmann (1993) lagen. In diesem ausreichenden Bereich und damit auch deutlich unterhalb des Wertes in der reinen Mykorrhiza-Variante (V11) lagen die KupferGehalte in den Varianten Mykorrhiza und Kalk (V12) mit 10,1 mg/kg sowie Mykorrhiza und Stockosorb® (V13) mit 9,7 mg/kg. Der mit 8,0 mg/kg niedrigste (aber immer noch ausreichende) Kupfer-Gehalt wurde bei einer Kombination der drei Bodenhilfsstoffe Mykorrhiza, Stockosorb® und Kalk (V14) ermittelt.

\section{Potentiell nützliche Elemente ( $\mathrm{Al}, \mathrm{Na}, \mathrm{Ni}, \mathrm{Co}$ )}

Der durchschnittliche Aluminium-Gehalt in den Blättern der Eichen auf Fläche D (s. Abb. 36) lag im auf die Pflanzung folgenden Jahr (2006) bei $2058 \mathrm{mg} / \mathrm{kg}$. Je nach Behandlungsvariante schwankten die Werte sehr stark zwischen $345 \mathrm{mg} / \mathrm{kg}$ (V14) und $4850 \mathrm{mg} / \mathrm{kg}$ (V7). Es fällt eine deutliche Parallele zur Verteilung der Eisen-Gehalte auf die einzelnen Varianten auf. 

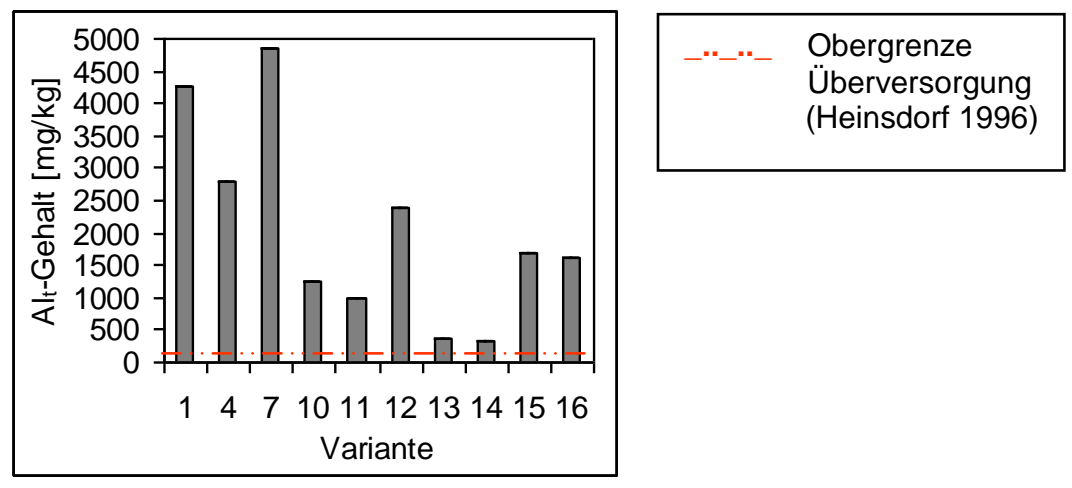

Abb. 36: $\mathrm{Al}_{\mathrm{t}}$-Gehalte $[\mathrm{mg} / \mathrm{kg}]$ im Laub der Eichen-Varianten (s. S. 20) auf Versuchsfläche D im 2. (2006) Vegetationsjahr (Mischproben)

In allen Varianten wurde die obere Grenze einer Überversorgung von Eichen mit Aluminium (119 mg/kg) nach Heinsdorf (1996) um ein Mehrfaches überschritten. Vor allem in der unbehandelten Kontrolle (V1) und der Perlit-Variante (V7) wurden exorbitant hohe AluminiumGehalte gemessen, die mit $4263 \mathrm{mg} / \mathrm{kg}$ bzw. $4850 \mathrm{mg} / \mathrm{kg}$ das 36- bzw. 41-fache der Überversorgungsgrenze erreichten. Deutlich darunter lagen zunächst die Werte in der Stockosorb®-Kalk-Variante (V4) und der Mykorrhiza-Kalk-Variante (V12) mit $2811 \mathrm{mg} / \mathrm{kg}$ bzw. $2375 \mathrm{mg} / \mathrm{kg}$, dann die Gehalte in den Mykorrhiza-Superabsorber-Varianten (V15 sowie mit Kalk-Gabe V16) mit 1709 mg/kg bzw. 1609 mg/kg. Mit Kompost und Kalk (V10) betrug der Aluminium-Gehalt der Eichen-Blätter noch $1237 \mathrm{mg} / \mathrm{kg}$, mit Mykorrhiza-Inokulum (V11) war er noch etwas geringer $(1005 \mathrm{mg} / \mathrm{kg})$. Bei einer Kombination von Mykorrhiza und Stockosorb® (V13 sowie mit Kalk-Gabe V14) wurden mit 377 mg/kg (ca. $9 \%$ des Kontrollwertes) bzw. 345 mg/kg (ca. $8 \%$ des Kontrollwertes) die mit Abstand geringsten Aluminium-Gehalte im EichenLaub auf Fläche D gemessen.

Eine Phytotoxizität der übrigen, sehr hohen Gehalte ist möglich, wenngleich laut Bergmann (1993) keine Proportionalität zwischen Aluminium-Toxizität und dem Aluminium-Gehalt in Assimilationsorganen besteht; hier sei Phosphor-Mangel bei ausreichend mit Phosphor versorgten Böden (wie in diesem Fall, s. S. 48) das bessere Indiz. Demnach könnte mit Ausnahme von V11 und V13 in allen Varianten $\mathrm{Al}^{3+-U ̈ b e r s c h u s s ~ u n d ~ A l u m i n i u m-T o x i z i t a ̈ t ~}$ bestehen.
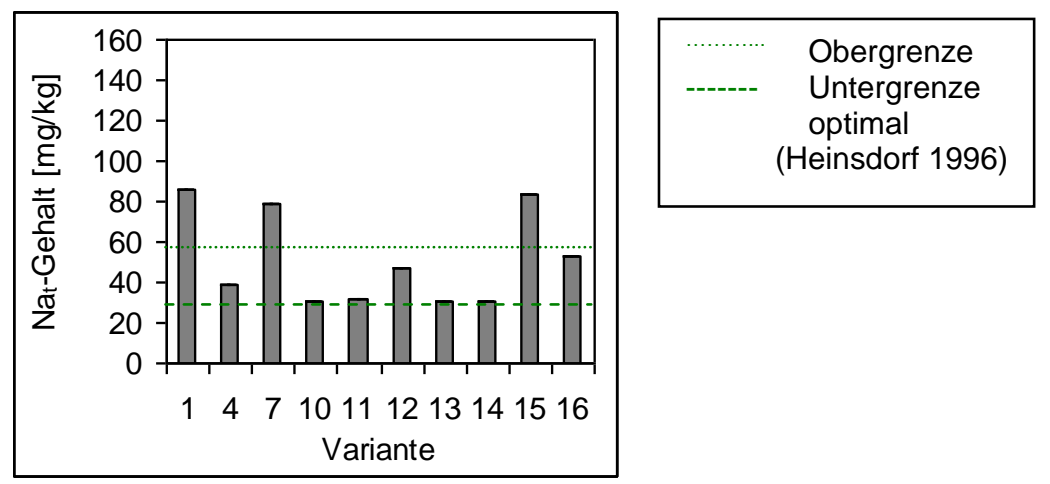

Abb. 37: Nat-Gehalte [mg/kg] im Laub der Eichen-Varianten (s. S. 20) auf Versuchsfläche D im 2. (2006) Vegetationsjahr (Mischproben)

Insgesamt wiesen in 2006 die Eichen auf Fläche D in ihrem Laub einen durchschnittlichen Natrium-Gehalt (s. Abb. 37) von 51,1 mg/kg auf. Je nach Variante lag dieser Gehalt zwischen 
30,1 mg/kg (V10, V13) und 85,3 mg/kg (V1). In der unbehandelten Kontrolle (V1), der PerlitVariante (V7) und der Mykorrhiza-Superabsorber-Variante (V15) wurden mit 85,3 mg/kg, 79,0 $\mathrm{mg} / \mathrm{kg}$ sowie 83,6 mg/kg Werte erreicht, die nach Heinsdorf (1996) einer Überversorgung entsprechen. Weit darunter und demnach im Optimalbereich lagen die Natrium-Gehalte der Eichen in der Stockosorb®-Kalk-Variante (V4) mit 38,6 mg/kg, der Mykorrhiza-Kalk-Variante (V12) mit 47,6 mg/kg und der Mykorrhiza-Superabsorber-Kalk-Variante (V16) mit 53,5 mg/kg. Mit Kompost und Kalk (V10), Mykorrhiza-Inokulum (V11) sowie in den MykorrhizaStockosorb®-Varianten (V13 ohne, V14 mit zusätzlicher Kalk-Gabe) lagen die Natrium-Gehalte um $30 \mathrm{mg} / \mathrm{kg}$ und damit an der unteren Grenze des Optimalbereichs laut Heinsdorf (1996).
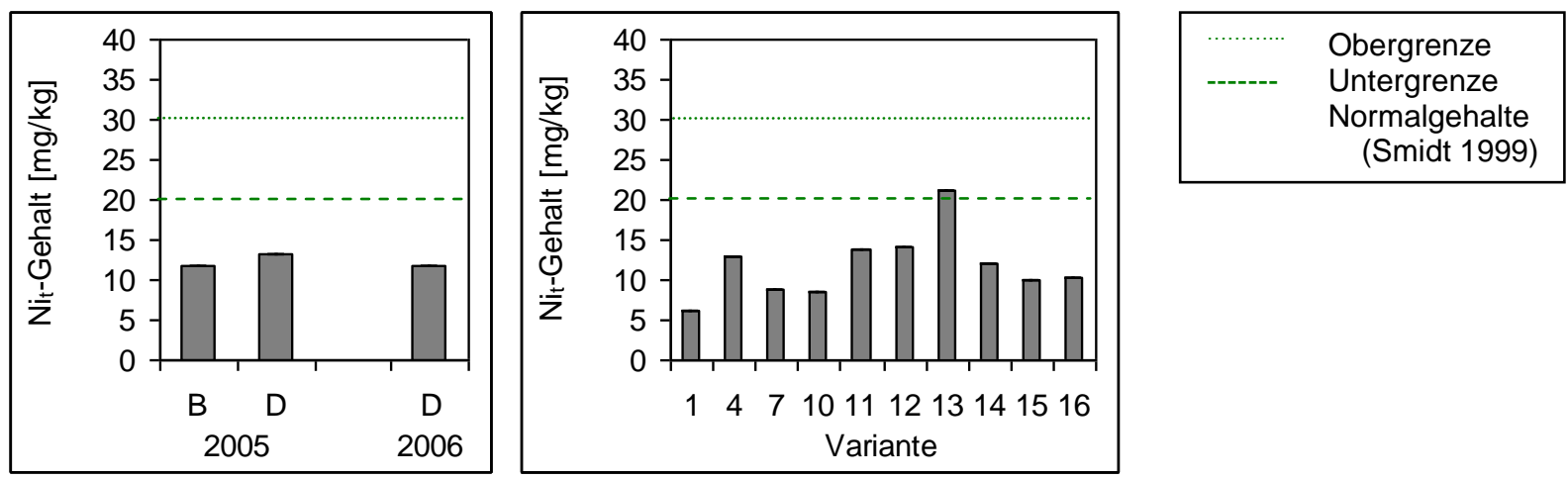

Abb. 38 links: $\mathrm{Ni}_{\mathrm{t}}-$ Gehalte $[\mathrm{mg} / \mathrm{kg}]$ im Laub der Eichen auf den Versuchsflächen B und D im 1. (2005) und auf Fläche D im 2. (2006) Vegetationsjahr (Mischproben); rechts: differenziert nach Varianten (s. S. 20) auf Fläche D im 2. Jahr (2006) (Mischproben)

Die in den Blättern der Eichen ermittelten Nickel-Gehalte (s. Abb. 38) lagen auf beiden Flächen sowohl in 2005 als auch in 2006 im Durchschnitt unterhalb der Normalgehalte in Pflanzen (20$30 \mathrm{mg} / \mathrm{kg}$ ) bei Smidt (1999). Auf Fläche B $(11,7 \mathrm{mg} / \mathrm{kg})$ war der Wert leicht niedriger als auf Fläche D (13,1 mg/kg) und hier in 2005 leicht höher als in $2006(11,8 \mathrm{mg} / \mathrm{kg})$. Nach Varianten getrennt ergaben sich in 2006 im Laub der Eichen auf Fläche D Nickel-Gehalte zwischen 6,1 $\mathrm{mg} / \mathrm{kg}$ (V1) und 21,1 mg/kg (V13). In allen Behandlungsvarianten waren die Werte höher als der Kontrollwert $(6,1 \mathrm{mg} / \mathrm{kg})$. Nur der mit Abstand höchste Nickel-Gehalt der Eichen mit Mykorrhiza-Stockosorb®-Behandlung (V13) lag mit 21,1 mg/kg bereits knapp innerhalb der bei Smidt (1999) angegebenen Normalgehalte.
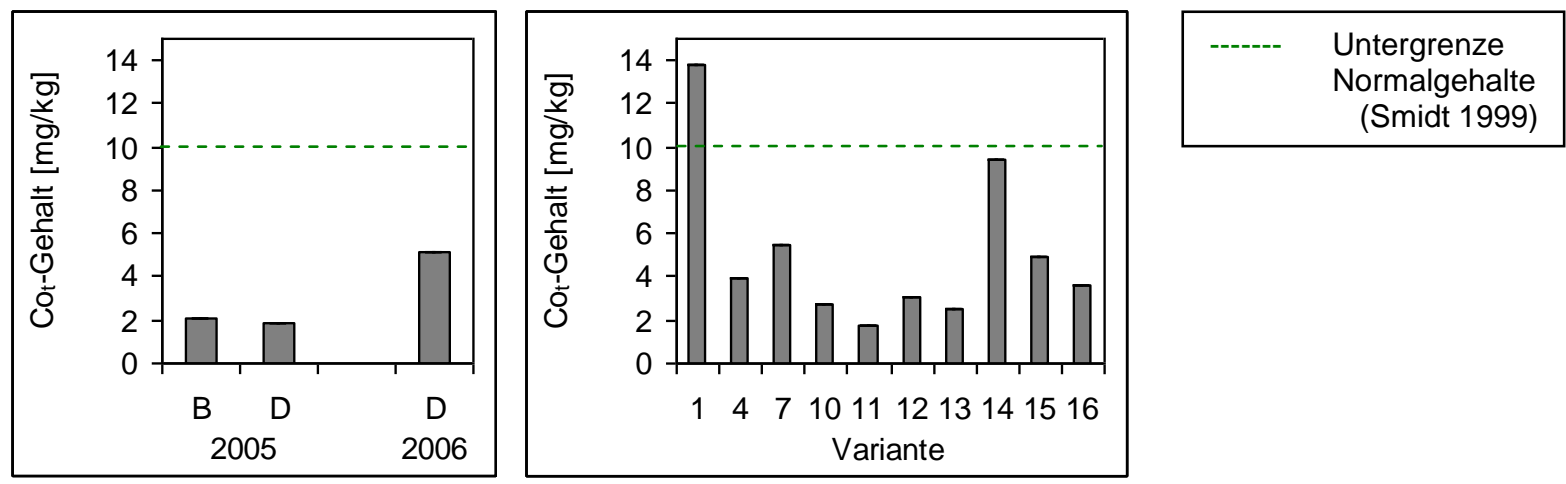

Abb. 39 links: $\mathrm{Co}_{\mathrm{t}}$-Gehalte $[\mathrm{mg} / \mathrm{kg}]$ im Laub der Eichen auf den Versuchsflächen B und D im 1. (2005) und auf Fläche D im 2. (2006) Vegetationsjahr (Mischproben); rechts: differenziert nach Varianten (s. S. 20) auf Fläche D im 2. Jahr (2006) (Mischproben)

Die Kobalt-Gehalte des Eichen-Laubs (s. Abb. 39) lagen auf beiden Flächen und in beiden Untersuchungsjahren im Mittel unterhalb der Normalgehalte in Pflanzen $(10-20 \mathrm{mg} / \mathrm{kg})$ bei 
Smidt (1999). Die Werte waren in 2005 auf Fläche B und D nahezu gleich (2,1 bzw. 1,9 mg/kg), in 2006 auf Fläche D deutlich höher $(5,1 \mathrm{mg} / \mathrm{kg})$.

Im Einzelnen lagen die Kobalt-Gehalte dort zu diesem Zeitpunkt je nach Variante zwischen 1,8 $\mathrm{mg} / \mathrm{kg}$ (V11) und 13,8 mg/kg (V1). Die Werte aller Behandlungsvarianten waren deutlich geringer als der Kontrollwert, der sich mit 13,8 mg/kg als einziger im Bereich der Normalgehalte nach Smidt (1999) befand. Der Gehalt in den Eichen mit MykorrhizaStockosorb®-Kalk-Behandlung (V14) nahm mit 9,4 mg/kg eine Mittelstellung knapp unterhalb dieser Normalgehalte ein. Alle übrigen Varianten wiesen Werte unterhalb von $5,5 \mathrm{mg} / \mathrm{kg}$ auf, wobei der mit 1,8 mg/kg geringste Gehalt in der Mykorrhiza-Variante (V11) gemessen wurde, gefolgt von der Mykorrhiza-Stockosorb®-Variante (V13) mit 2,5 mg/kg, der Kompost-KalkVariante (V10) mit 2,7 mg/kg und der Mykorrhiza-Kalk-Variante (V12) mit 3,1 mg/kg.

\section{Toxisch wirkende Schwermetalle ohne Nährelementfunktion ( $\mathrm{Pb}, \mathrm{Cd}, \mathrm{Cr}$ )}

Nur auf Fläche D im 1. Untersuchungsjahr (2005) wurde ein messbarer Blei-Gehalt von 3,9 $\mathrm{mg} / \mathrm{kg}$ ermittelt. Nach den sehr allgemeinen Normalgehalten von Schwermetallen in Pflanzen (Smidt 1999) sowie den ebenso allgemeinen kritischen Konzentrationen von Schwermetallen in Pflanzen (Alloway 1999) wären damit weder normale $(10-20 \mathrm{mg} / \mathrm{kg}$ ) noch kritische (30-300 $\mathrm{mg} / \mathrm{kg}$ ) Blei-Gehalte erreicht. Der Wert überstieg jedoch deutlich das $90 \mathrm{er}-$ Perzentil $(3,0 \mathrm{mg} / \mathrm{kg})$ der im Rahmen des Deutschen Waldbodenberichtes in Buchenblättern gemessenen Blei-Gehalte (BMELF 1997b).

Die Cadmium-Gehalte im Eichen-Laub lagen unterhalb der Nachweisgrenze für dieses Element.
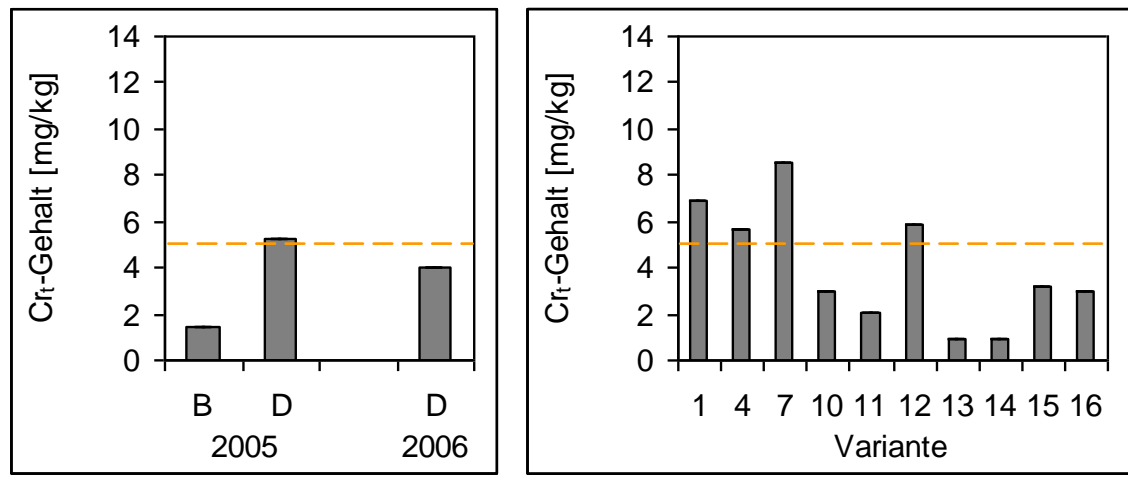

Untergrenze kritischer Bereich in Pflanzen (Alloway 1999)

Abb. 40 links: $\mathrm{Cr}_{\mathrm{t}}$-Gehalte [mg/kg] im Laub der Eichen auf den Versuchsflächen B und D im 1. (2005) und auf Fläche D im 2. (2006) Vegetationsjahr (Mischproben); rechts: differenziert nach Varianten (s. S. 20) auf Fläche D im 2. Jahr (2006) (Mischproben)

Die in den Eichen-Blättern gemessenen Chrom-Anteile (s. Abb. 40) waren mit 1,4 mg/kg auf Fläche B, deutlich höheren 5,2 mg/kg auf Fläche D in 2005 und etwas darunter liegenden 4,0 mg/kg auf Fläche D in 2006 unkritisch nach Alloway (1999), der einen mit 5-30 mg/kg sehr weit gefassten Bereich kritischer Chrom-Konzentrationen in Pflanzen nennt, oberhalb dessen toxische Auswirkungen wahrscheinlich sind.

Unterschieden nach Behandlungsvarianten (in 2006 auf Fläche D) bewegten sich die ChromGehalte in den Eichen-Blättern zwischen $0,9 \mathrm{mg} / \mathrm{kg}$ (V14) und $8,5 \mathrm{mg} / \mathrm{kg}$ (V7). In der 
Nullvariante (V1), der Stockosorb®-Kalk-Variante (V4), der Mykorrhiza-Kalk-Variante (V12) sowie der Perlit-Variante (V7) lagen die Chrom-Gehalte um $6 \mathrm{mg} / \mathrm{kg}$ bzw. bei 8,5 mg/kg (V7) und damit innerhalb des kritischen Bereichs bei Alloway (1999). Die übrigen MykorrhizaVarianten und die Kompost-Kalk-Variante (V10) wiesen deutlich geringere Chrom-Gehalte auf. Dabei war der Wert im Laub der Eichen mit Mykorrhiza-SuperabsorberBehandlungskombinationen (V15, V16) höher als in der reinen Mykorrhiza-Variante (V11), am geringsten jedoch in den Mykorrhiza-Stockosorb®-Varianten (V13, V14).

\subsubsection{Spitz-Ahorn}

Im Folgenden werden die Ergebnisse der Blattanalysen (Mischproben, s. S. 26) zur Versorgung und Belastung der Ahorne auf den drei Versuchsflächen insgesamt sowie innerhalb der Versuchs-Varianten auf Versuchsfläche D dargestellt.

Aufgrund von Pflanzenausfällen konnte bei dieser Baumart die Superabsorber-Variante V5 (s. S. 20) nicht in die Untersuchungen mit einbezogen werden.

\section{Hauptnährelemente, Makronährstoffe ( N, P, K, Ca, Mg, S)}

Der mittlere Stickstoff-Gehalt im Laub der Ahorne (s. Abb. 41) zeigte auf Fläche A eine mit 2,7 mg/g laut Bergmann (1993) und dem BFW (2005/7) mehr als ausreichende, laut van den Burg $(1985,1990)$ voll ausreichende Versorgung an. Auf Fläche B war dieser Wert dagegen mit 13,3 $\mathrm{mg} / \mathrm{g}$ erheblich geringer und lag damit deutlich unterhalb der Untergrenzen ausreichender Gehalte (17 bzw. $18 \mathrm{mg} / \mathrm{g}$ ). Auf Fläche D war der Stickstoff-Blattgehalt der Ahorne im 1. Untersuchungsjahr (2005) mit 19,3 mg/g ausreichend, im 2. Untersuchungsjahr (2006) mit 15,7 mg/g jedoch nicht. Diese auf Fläche A und D (2005) ausreichende, auf Fläche B und D (2006) nicht ausreichende Versorgung fand sich auch bei den Elementen Phosphor und Kalium wieder.
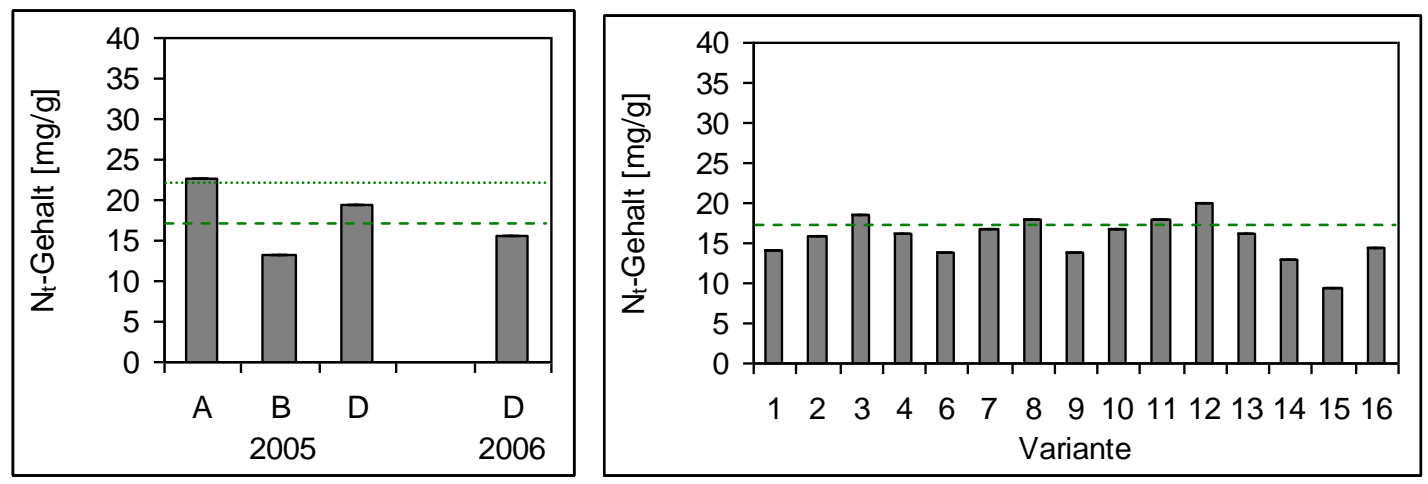

\section{Obergrenze \\ Untergrenze ausreichend (Bergmann 1993, BFW 2005/7)}

Abb. 41 links: $\mathrm{N}_{\mathrm{t}}-$ Gehalte $[\mathrm{mg} / \mathrm{g}]$ im Laub der Ahorne auf den Versuchsflächen A, B und D im 1. (2005) und auf Fläche D im 2. (2006) Vegetationsjahr (Mischproben); rechts: differenziert nach Varianten (s. S. 20) auf Fläche D im 2. Jahr (2006) (Mischproben)

In den einzelnen Ahorn-Varianten auf Fläche D wurden in 2006 Stickstoff-Blattgehalte zwischen 9,4 mg/g (V15) und 20,1 mg/g (V12) festgestellt. Dabei bestand in der unbehandelten Kontrolle (V1) mit 14,2 mg/g Stickstoff-Blattgehalt ein deutlicher Stickstoffmangel. Ähnlich niedrige Werte wurden in der Kompost-Variante (V9), sämtlichen beprobten Superabsorber-Varianten 
(V6: Superabsorber-Kalk, V15: Mykorrhiza-Superabsorber, V16: Mykorrhiza-SuperabsorberKalk) sowie der Mykorrhiza-Stockosorb®-Kalk-Variante (V14) gemessen, wobei die Gehalte in Variante V14, vor allem aber in Variante V15 mit nur 9,4 mg/g noch erheblich geringer als der Kontrollwert waren.

In den gekalkten Varianten V2 (Kalk), V4 (Stockosorb®-Kalk) und V10 (Kompost-Kalk), in der Mykorrhiza-Stockosorb®-Variante (V13) sowie in der Perlit-Variante (V7) wurden mit Werten zwischen $16 \mathrm{mg} / \mathrm{g}$ und $17 \mathrm{mg} / \mathrm{g}$ Stickstoff-Blattgehalte knapp unterhalb ausreichender Gehalte laut Bergmann (1993) und dem BFW (2005/7) gemessen. Bei Behandlung mit Perlit und Kalk (V8), bei reiner Mykorrhiza-Impfung (V11) und bei Zugabe von Stockosorb® allein (V3) wurden mit Werten um $18 \mathrm{mg} / g$ Stickstoff-Blattgehalte im Bereich der Untergrenze ausreichender Gehalte nach van den Burg $(1985,1990)$ ermittelt. Der höchste, mit 20,1 mg/g voll ausreichende Stickstoff-Gehalt wurde im Laub der Ahorne gemessen, die mit einer Kombination aus Mykorrhiza-Impfung und Kalk-Gabe (V12) gepflanzt worden waren.
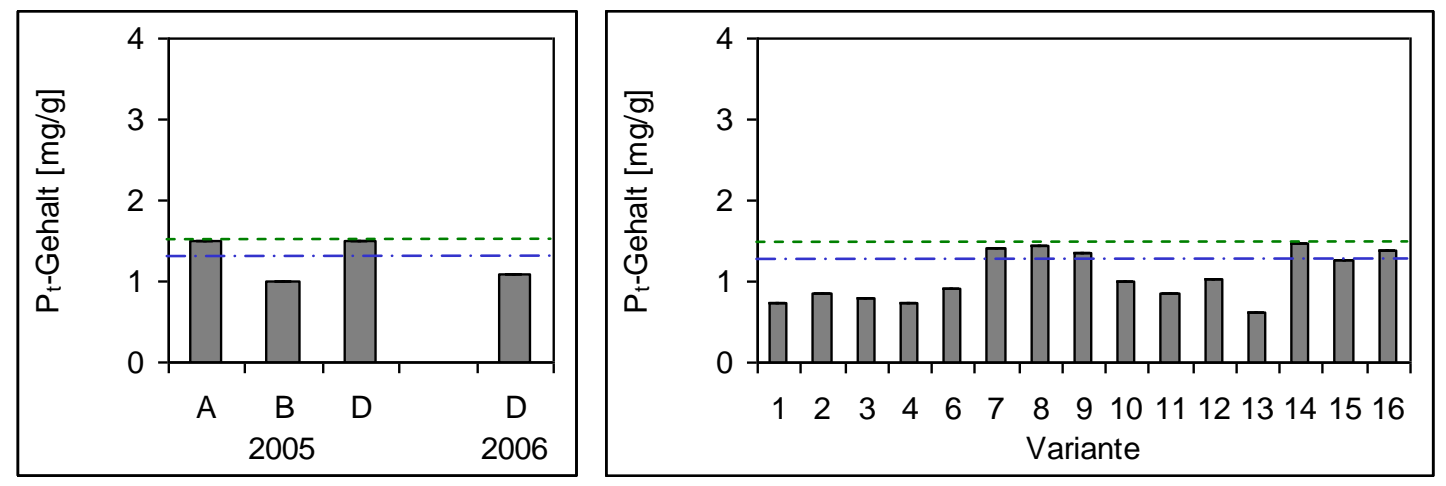

\footnotetext{
------ Untergrenze ausreichend (Bergmann 1993, BFW 2005/7)

Untergrenze ausreichend (van den Burg 1985, 1990)
}

Abb. 42 links: $\mathrm{P}_{\mathrm{t}}-\mathrm{Gehalte}[\mathrm{mg} / \mathrm{g}]$ im Laub der Ahorne auf den Versuchsflächen A, B und D im 1. (2005) und auf Fläche D im 2. (2006) Vegetationsjahr (Mischproben); rechts: differenziert nach Varianten (s. S. 20) auf Fläche D im 2. Jahr (2006) (Mischproben)

Die mittleren Phosphor-Gehalte in den Blättern der Ahorne (s. Abb. 42) waren im 1. Untersuchungsjahr (2005) auf den Flächen A und D mit 1,5 mg/g ausreichend (van den Burg 1985, 1990: ab 1,3 mg/g) bzw. knapp ausreichend (Bergmann 1993, BFW 2005/7: ab 1,5 mg/g). Auf Fläche B und im 2. Untersuchungsjahr (2006) auch auf Fläche D lagen die Werte mit 1,0 mg/g bzw. 1,1 mg/g dagegen deutlich unterhalb ausreichender Phosphor-Blattgehalte. Diese auf Fläche A und D (2005) ausreichende, auf Fläche B und D (2006) nicht ausreichende Versorgung fand sich auch bei den Elementen Stickstoff und Kalium wieder.

Getrennt nach Varianten wurden im Laub der Ahorne auf Fläche D in 2006 Phosphor-Gehalte zwischen 0,6 mg/g (V13) und 1,5 mg/g (V14) gemessen. In der unbehandelten Kontrolle (V1) sowie in 8 der 14 beprobten Behandlungsvarianten lag mit Werten zwischen 0,6 mg/g und 1,0 $\mathrm{mg} / \mathrm{g}$ Phosphormangel vor. Deutlich höhere Phosphor-Blattgehalte wurden bei Pflanzung der Ahorne mit Perlit (V7 ohne, V8 mit zusätzlicher Kalk-Gabe) oder Kompost (V9) und bei den Kombinationen aus Mykorrhiza, Wasserspeichersubstanz und Kalk (V14 mit Stockosorb®, V16 mit Superabsorber als Wasserspeicher) sowie aus Mykorrhiza und Superabsorber (V15) 
gemessen. Mit Werten zwischen 1,3 mg/g und 1,5 mg/g sind sie zumindest nach van den Burg $(1985,1990)$ als ausreichend einzustufen.

Interessant war der mit $1,3 \mathrm{mg} / \mathrm{g}$ mehr als doppelt so hohe Phosphor-Blattgehalt bei der kombinierten Behandlung aus Mykorrhiza-Impfung und Superabsorber (V15) gegenüber dem mit 0,6 mg/g geringsten gemessenen Wert in der Mykorrhiza-Stockosorb®-Variante (V13).
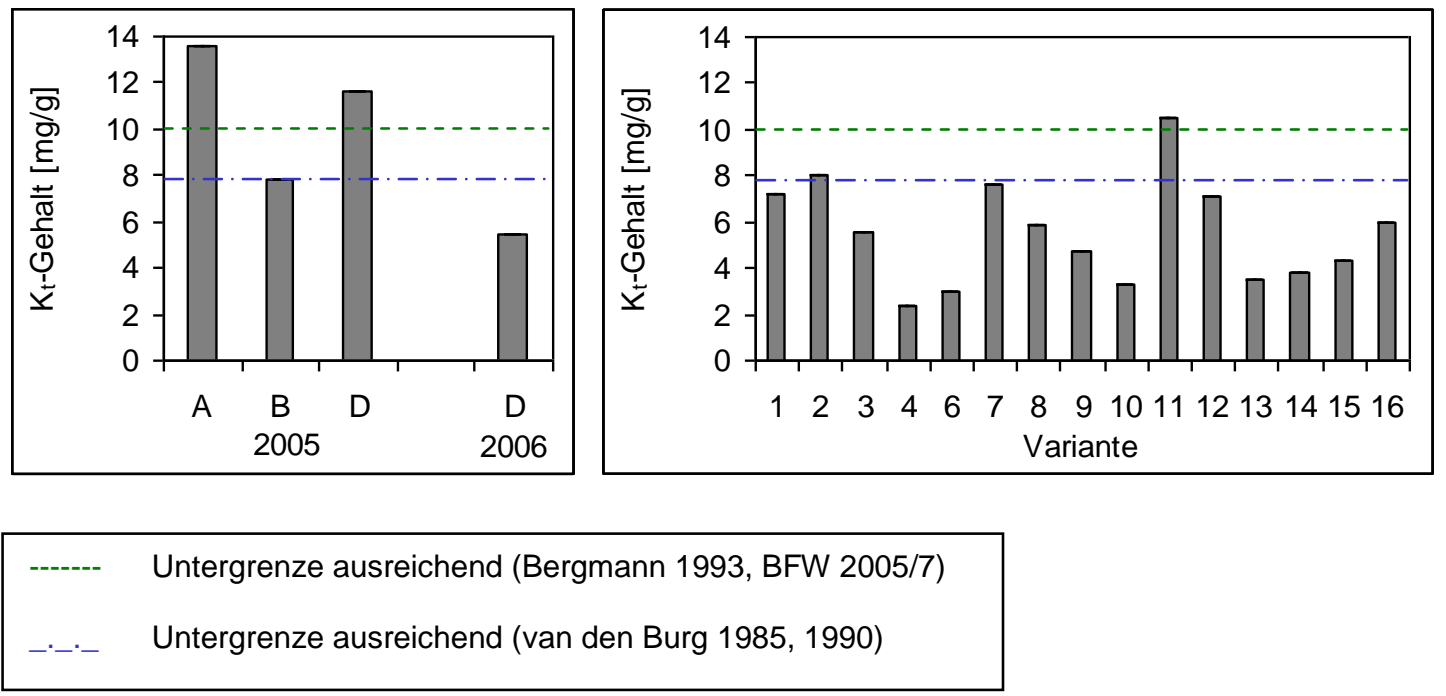

Abb. 43 links: $\mathrm{K}_{\mathrm{t}}-\mathrm{Gehalte}[\mathrm{mg} / \mathrm{g}$ ] im Laub der Ahorne auf den Versuchsflächen A, B und D im 1. (2005) und auf Fläche D im 2. (2006) Vegetationsjahr (Mischproben); rechts: differenziert nach Varianten (s. S. 20) auf Fläche D im 2. Jahr (2006) (Mischproben)

Die durchschnittlichen Kalium-Blattgehalte der Ahorne (s. Abb. 43) auf den Flächen A und D (2005) waren mit 13,6 mg/g bzw. 11,6 mg/g nach den verwendeten Quellen voll ausreichend. Der entsprechende Wert auf Fläche B dagegen markierte mit 7,8 mg/g die Untergrenze ausreichender Kalium-Gehalte nach van den Burg $(1985,1990)$ und war nach Bergmann (1993) und dem BFW (2005/7) nicht mehr ausreichend ( $<10 \mathrm{mg} / \mathrm{g}$ ). Der in 2006 auf Fläche D erneut gemessene mittlere Kalium-Blattgehalt lag noch deutlich darunter bei 5,5 mg/g, was allen zitierten Quellen zufolge nicht ausreichend ist. Diese auf Fläche A und D (2005) ausreichende, auf Fläche B und D (2006) nicht ausreichende Versorgung fand sich auch bei den Elementen Stickstoff und Phosphor wieder.

Die in den einzelnen Ahorn-Varianten auf Fläche D (2006) ermittelten Kalium-Blattgehalte schwankten zwischen $2,4 \mathrm{mg} / \mathrm{g}$ (V4) und 10,5 mg/g (V11).

In der unbehandelten Kontrolle (V1) war die Kalium-Versorgung mit 7,2 mg/g (je nach Autor knapp) nicht ausreichend. Mit Mykorrhiza und Kalk (V12) wurde ein vergleichbarer, mit Kalk (V2) oder Perlit (V7) wurden nur leicht darüber liegende Kalium-Blattgehalte gemessen.

Einzig bei den allein mit Mykorrhiza beimpften Ahornen (V11) wurde ein mit 10,5 mg/g gegenüber der Kontrolle deutlich höherer, nach allen verwendeten Quellen (knapp) ausreichender Kalium-Blattgehalt festgestellt. Die übrigen Behandlungsvarianten wiesen teils erheblich geringere Kalium-Gehalte als die Nullvariante auf. 

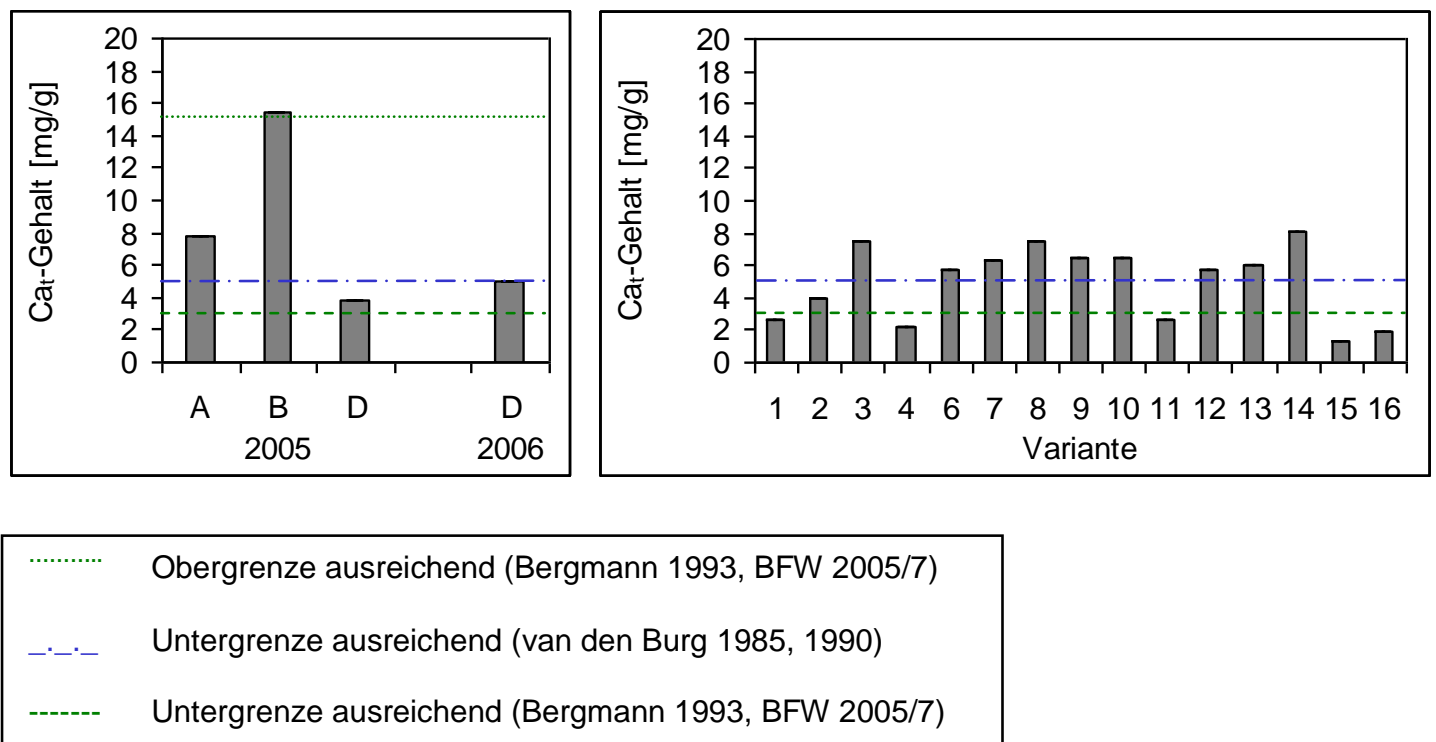

Abb. 44 links: Cat-Gehalte [mg/g] im Laub der Ahorne auf den Versuchsflächen A, B und D im 1. (2005) und auf Fläche D im 2. (2006) Vegetationsjahr (Mischproben); rechts: differenziert nach Varianten (s. S. 20) auf Fläche D im 2. Jahr (2006) (Mischproben)

Bei Betrachtung der mittleren Calcium-Gehalte im Laub der Ahorne (s. Abb. 44) auf den verschiedenen Versuchsflächen fiel zunächst der vergleichsweise hohe Durchschnittsgehalt auf Fläche B auf. Mit 15,4 mg/g befand er sich knapp über der Obergrenze ausreichender Gehalte (315 mg/g) nach Bergmann (1993) und dem BFW (2005/7) und betrug damit das Doppelte bzw. 3- bis 4-fache der Werte auf den Flächen A (7,8 mg/g) und D (2005: 3,8 mg/g; 2006: 5,0 mg/g). Nach den genannten Quellen waren auch diese Calcium-Gehalte ausreichend. Nach van den Burg $(1985,1990)$ waren die auf Fläche D gemessenen Werte dagegen nicht bzw. nur knapp ausreichend (ab $5 \mathrm{mg} / \mathrm{g}$ ).

Die Erfassung der Calcium-Blattgehalte in den einzelnen Ahorn-Varianten auf Fläche D (2006) ergab Werte zwischen 1,3 mg/g (V15) und 8,1 mg/g (V14).

Die unbehandelte Kontrolle (V1) lag mit 2,6 mg/g im Mangelbereich, ebenso wie die vergleichbare Mykorrhiza-Variante (V11) mit 2,7 mg/g. Noch darunter lagen die Werte in der Stockosorb®-Kalk-Variante (V4) mit 2,2 mg/g und den Mykorrhiza-Superabsorber-Varianten (V15 ohne, V16 mit zusätzlicher Kalk-Gabe) mit 1,3 mg/g bzw. 2,0 mg/g. In der reinen KalkVariante wurde ein Calcium-Blattgehalt gemessen, der mit 3,9 mg/g zumindest nach einem Teil der verwendeten Quellen als ausreichend einzustufen ist. In allen übrigen Varianten wurden mit Werten zwischen $5,8 \mathrm{mg} / \mathrm{g}$ und $8,1 \mathrm{mg} / \mathrm{g}$ deutlich höhere, ausreichende Calcium-Gehalte ermittelt. Bei der Anwendung der Bodenhilfsstoffe Perlit (V7 ohne, V8 mit zusätzlicher KalkGabe), Kompost (V9 ohne, V10 mit zusätzlicher Kalk-Gabe) und Mykorrhiza in Kombination mit Kalk (V12) oder/und Stockosorb® (V13, V14) konnte somit ein positiver Effekt auf die ansonsten nicht ausreichende Calcium-Aufnahme festgestellt werden. Gleiches gilt für die Anwendung von Stocksorb ${ }^{\circledR}$ allein (V3) oder Superabsorber kombiniert mit Kalk-Gabe (V6), interessanterweise jedoch nicht für die Kombination aus Stockosorb® und Kalk (V4). Die höchsten Calcium-Gehalte, die etwas das 3-fache des Kontrollwertes betrugen, wurden mit Stockosorb® (V3: 7,5 mg/g), Perlit und Kalk (V8: 7,5 mg/g) sowie Mykorrhiza, Stockosorb® und Kalk (V14: 8,1 mg/g) ermittelt. Die Kalk-Gabe selbst, die bei der Pflanzung der Ahorne in den Varianten V2, V4, V6, V8, V10, V12, V14 und V16 erfolgte, schien bei diesen im Folgejahr aufgenommenen Calcium-Blattgehalten keine zentrale Rolle zu spielen. 


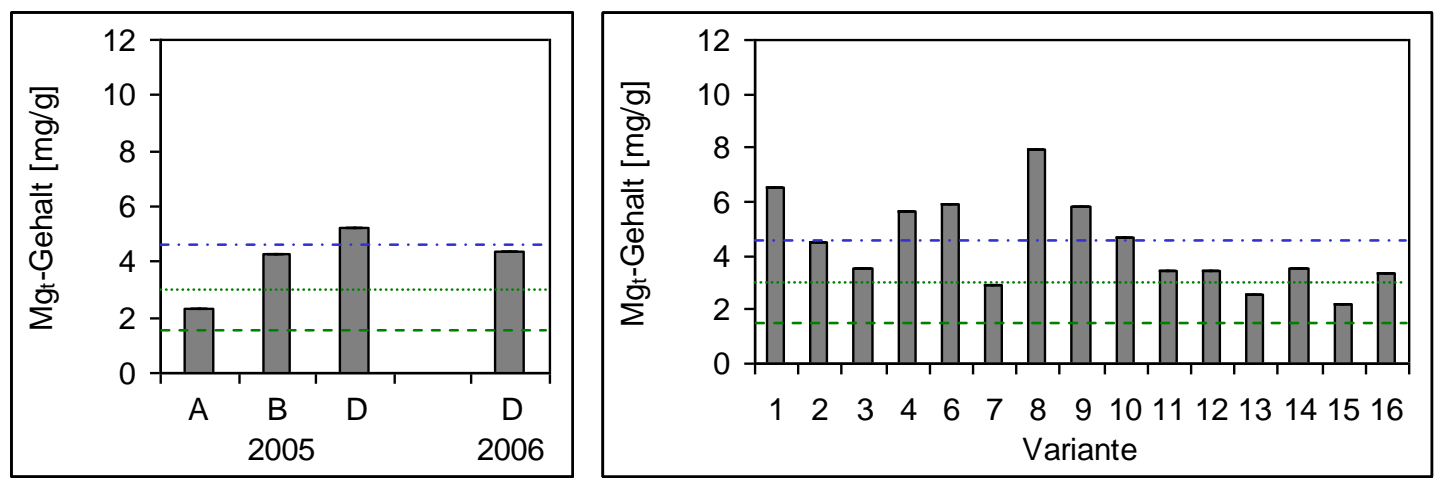

Obergrenze ausreichend (van den Burg 1985, 1990)
Obergrenze ausreichend (Bergmann 1993, BFW 2005/7)
Untergrenze ausreichend (Bergmann 1993, BFW 2005/7)

Abb. 45 links: $\mathrm{Mg}_{\mathrm{t}}-\mathrm{Gehalte}$ [mg/g] im Laub der Ahorne auf den Versuchsflächen A, B und D im 1. (2005) und auf Fläche D im 2. (2006) Vegetationsjahr (Mischproben); rechts: differenziert nach Varianten (s. S. 20) auf Fläche D im 2. Jahr (2006) (Mischproben)

Alle im Laub der Ahorne gemessenen Magnesium-Gehalte (s. Abb. 45) waren nach Einstufung durch verschiedene Quellen mindestens ausreichend (Bergmann 1993, BFW 2005/7: ab 1,5 mg/g; van den Burg 1985, 1990: ab 1,9 mg/g).

Auf Versuchsfläche A lag der durchschnittliche Gehalt mit 2,3 mg/g voll im ausreichenden Bereich. Die entsprechenden Werte auf Fläche B und D waren dagegen mit 4,3 mg/g (B), 5,2 mg/g (D: 2005) und 4,4 mg/g (D: 2006) deutlich höher als die obere Grenze ausreichender Gehalte (3 mg/g) laut Bergmann (1993) und BFW (2005/7). Der im 1. Untersuchungsjahr (2005) auf Fläche D gemessene Gehalt überstieg zudem die deutlich höhere Obergrenze ausreichender Gehalte $(4,5 \mathrm{mg} / \mathrm{g})$ nach van den Burg $(1985,1990)$.

Im 2. Untersuchungsjahr (2006) wurden auf Fläche D je nach Variante Magnesium-Blattgehalte der Ahorne zwischen 2,2 mg/g (V15) und 7,9 mg/g (V8) ermittelt. In der unbehandelten Kontrolle (V1) lag der Wert mit 6,6 mg/g deutlich oberhalb aller in den verschiedenen Quellen als ausreichend bezeichneten Gehalte. Fast vergleichbar hohe, nur leicht unter $6 \mathrm{mg} / \mathrm{g}$ liegende Werte wurden in den Wasserspeichersubstanz-Kalk-Varianten (V4: Stockosorb®-Kalk, V6: Superabsorber-Kalk) sowie in der Kompost-Variante (V9) gemessen. Die Perlit-Kalk-Variante (V8) wies als Einzige einen mit 7,9 mg/g noch erheblich höheren Magnesium-Blattgehalt als die Kontrolle auf. Die Werte in den Varianten Kalk (V2) und Kompost-Kalk (V10) markierten etwa die obere Grenze ausreichender Gehalte $(4,5 \mathrm{mg} / \mathrm{g})$ laut van den Burg $(1985,1990)$ und waren damit deutlich geringer als der Kontrollwert. Noch niedriger lagen die Magnesium-Blattgehalte in der Stockosorb®-Variante (V3), der Perlit-Variante (V7) sowie in sämtlichen MykorrhizaVarianten (V11-V16). In der Stockosorb®-Variante (V3), der reinen Mykorrhiza-Variante (V11) und allen Mykorrhiza-Varianten mit zusätzlicher Kalk-Gabe (V12, V14, V16) wurden Werte zwischen 3,3 mg/g und 3,6 mg/g ermittelt. Der Gehalt in der Perlit-Variante (V7) markiert mit $2,9 \mathrm{mg} / \mathrm{g}$ etwa die obere Grenze ausreichender Gehalte laut Bergmann (1993) und dem BFW (2005/7). Die niedrigsten Magnesium-Blattgehalte, mit 2,5 mg/g und 2,2 mg/g nach diesen Quellen voll ausreichend, wiesen die Varianten mit einer kombinierten Behandlung aus Mykorrhiza und Wasserspeichersubstanz (V13: Mykorrhiza-Stockosorb®, V15: MykorrhizaSuperabsorber) auf. In diesen Kombinationen konnte somit der sehr hohe Magnesium-Gehalt der unbehandelten Kontrolle auf etwa ein Drittel reduziert werden. 

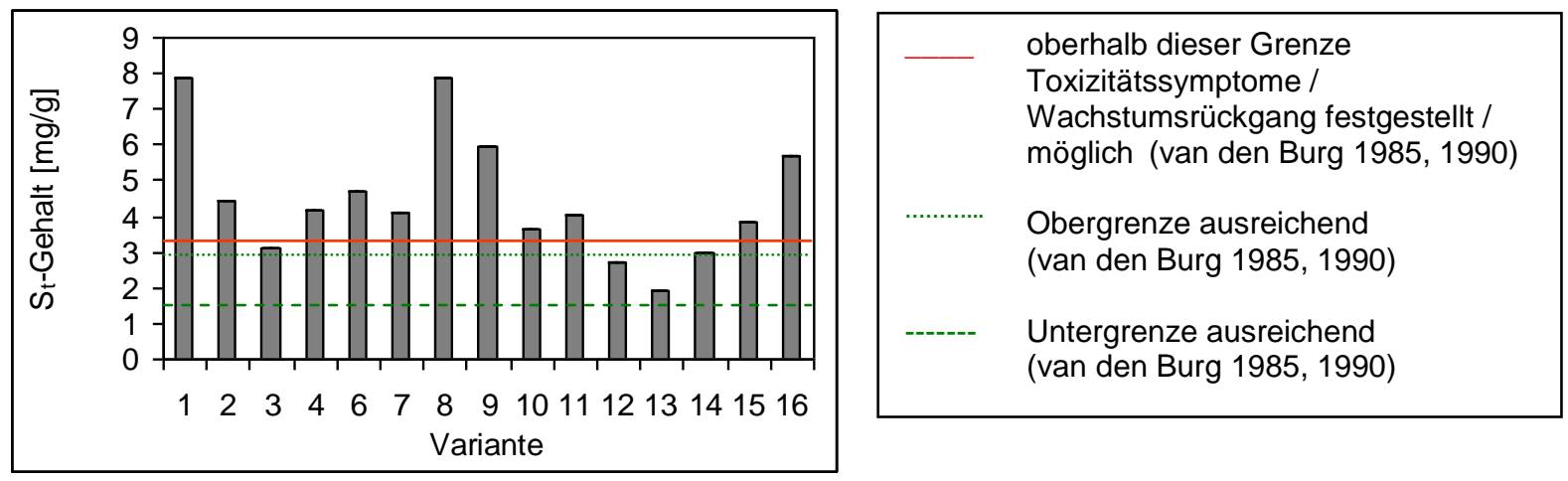

Abb. 46: $\mathrm{S}_{\mathrm{t}}$-Gehalte $[\mathrm{mg} / \mathrm{g}]$ im Laub der Ahorn-Varianten (s. S. 20) auf Versuchsfläche D im 2. (2006) Vegetationsjahr (Mischproben)

Der durchschnittliche Schwefel-Gehalt im Laub der Ahorne (s. Abb. 46) auf Fläche D betrug im 2. Untersuchungsjahr 4,5 mg/g. Je nach Variante wurden Werte zwischen 1,9 mg/g (V13) und 7,9 mg/g (V1, V8) gemessen. Die Grenze für Schwefel-Blattgehalte, oberhalb der nach van den Burg (1985, 1990) bei Ahornen Toxizitätssymptome oder Wachstumsrückgang festgestellt wurden oder möglich sind, liegt bei $3,3 \mathrm{mg} / \mathrm{g}$. Diese Grenze wurde in der unbehandelten Kontrolle (V1) sowie der Perlit-Kalk-Variante (V8) mit 7,9 mg/g um mehr als das Doppelte überschritten. In der Kompost-Variante (V9) und der Mykorrhiza-Superabsorber-Kalk-Variante (V16) lagen die Werte mit 5,9 mg/g und 5,7 mg/g etwas niedriger; alle übrigen Varianten wiesen noch deutlich geringere Schwefel-Blattgehalte auf. Die genannte Grenze toxischer Gehalte wurde jedoch lediglich in vier Varianten, der Stockosorb®-Variante (V3) sowie den drei Mykorrhiza-Varianten V12 (M.-Kalk), V13 (M.-Stockosorb®) und V14 (M.-Stockosorb®-Kalk) unterschritten. Dabei wurde der mit 1,9 mg/g mit Abstand niedrigste Schwefel-Blattgehalt in der Kombination Mykorrhiza-Stockosorb ${ }^{\circledR}$ (V13) gemessen, was nach van den Burg $(1985,1990)$ im ausreichenden Bereich (1,5-3 mg/g) liegt. Die Ahorne in den anderen drei genannten Varianten wiesen Schwefel-Blattgehalte leicht über (V3, V14) bzw. leicht unter (V12) der Obergrenze dieses ausreichenden Bereichs auf.

\section{Spurennährelemente, Mikronährstoffe ( $\mathrm{Fe}, \mathrm{Mn}, \mathrm{Zn}, \mathrm{Cu})$}

Die Eisen-Gehalte im Laub der Ahorne auf Fläche D (2006) lagen im Mittel bei $819 \mathrm{mg} / \mathrm{kg}$. Je nach Variante wurden Werte zwischen $253 \mathrm{mg} / \mathrm{kg}$ (V13) und $1466 \mathrm{mg} / \mathrm{kg}$ (V11) erreicht (s. Abb. 47).

Die relative Höhe der Eisen-Gehalte in den einzelnen Varianten (z.B. vergleichsweise geringe Eisen-Gehalte in den Mykorrhiza-Varianten V12-V16; höchster Gehalt in V11; in V7 und V9 jeweils geringere Gehalte als in V8 und V10 etc.) fand sich ziemlich genau so auch bei den Aluminium- und Kupfer-Gehalten wieder (Abb. A 2).

Alle Messwerte lagen (teilweise um ein Vielfaches) über der oberen Grenze ausreichender Gehalte $(63-212 \mathrm{mg} / \mathrm{kg})$ nach van den Burg $(1985,1990)$. Ausgenommen in Variante V13 (Mykorrhiza-Stockosorb $®$ ) wurde in allen Varianten zudem die obere Grenze extremer EisenGehalte in Eichen-Blättern (300 mg/kg nach Heinsdorf 1996) mehr oder weniger deutlich überschritten. 


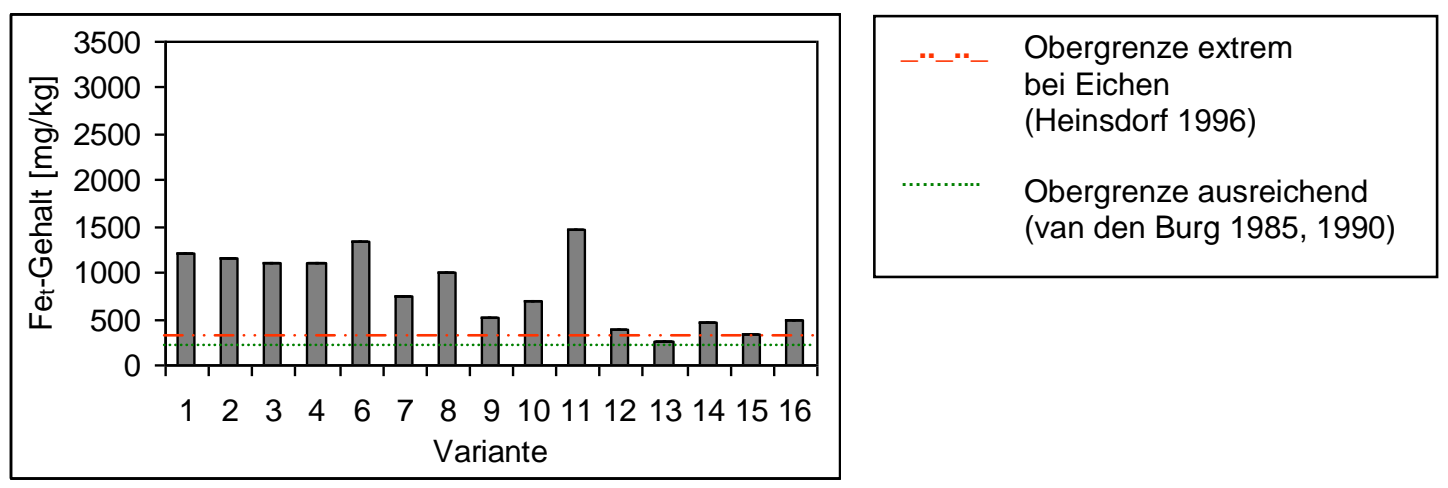

Abb. 47: $\mathrm{Fe}_{\mathrm{t}}-\mathrm{Gehalte}[\mathrm{mg} / \mathrm{kg}]$ im Laub der Ahorn-Varianten (s. S. 20) auf Versuchsfläche D im 2. (2006) Vegetationsjahr (Mischproben)

Mit 1216 mg/kg betrug der mittlere Eisen-Blattgehalt der unbehandelten Kontrolle (V1) das 4fache dieser Obergrenze. In den Varianten Kalk (V2), Stockosorb® (V3), Stockosorb®-Kalk (V4) und Perlit-Kalk (V8) wurden mit Werten zwischen $1004 \mathrm{mg} / \mathrm{kg}$ und $1170 \mathrm{mg} / \mathrm{kg}$ vergleichbare oder nur leicht geringere Eisen-Blattgehalte gemessen.

Bei Einsatz von Superabsorber und Kalk (V6) sowie Mykorrhiza-Inokulation ohne weitere Bodenhilfsstoffe (V11) lagen die Eisen-Gehalte mit 1336 mg/kg und 1466 mg/kg noch oberhalb des bereits sehr hohen Kontrollwertes.

In den übrigen Varianten, in denen Perlit, Kompost und Mykorrhiza (in Kombination mit anderen Bodenhilfsstoffen) eingesetzt wurden, waren die Eisen-Blattgehalte erheblich geringer als in der Nullvariante. Mit Perlit (V7) sowie mit Kompost und Kalk (V10) lagen sie bei 745 $\mathrm{mg} / \mathrm{kg}$ bzw. $702 \mathrm{mg} / \mathrm{kg}$ und damit etwa beim 3-fachen der Obergrenze ausreichender Gehalte nach van den Burg $(1985,1990)$ sowie beim 2,5-fachen der Obergrenze extremer Gehalte nach Heinsdorf (1996). Beim Einsatz von Kompost allein (V9) wurden deutlich geringere 514 mg/kg gemessen. Knapp darunter lagen die Eisen-Gehalte in den kombinierten Varianten aus Mykorrhiza, Wasserspeichersubstanz und Kalk mit 457 mg/kg (V14 mit Stockosorb®) bzw. 501 mg/kg (V16 mit Superabsorber). Mit Mykorrhiza und Kalk, aber ohne Wasserspeichersubstanz (V12) war der Wert wiederum deutlich geringer (385 mg/kg). Die niedrigsten EisenBlattgehalte wurden in den kalkfreien Varianten mit Mykorrhiza und Wasserspeichersubstanzen ermittelt. Dabei unterschritt der Gehalt bei Einsatz von Stocksorb® (V13) mit $253 \mathrm{mg} / \mathrm{kg}$ noch deutlich den Gehalt bei Einsatz von Superabsorber (V15) mit $345 \mathrm{mg} / \mathrm{kg}$ und lag nur noch wenig oberhalb der Obergrenze ausreichender Gehalte $(212 \mathrm{mg} / \mathrm{kg})$. 


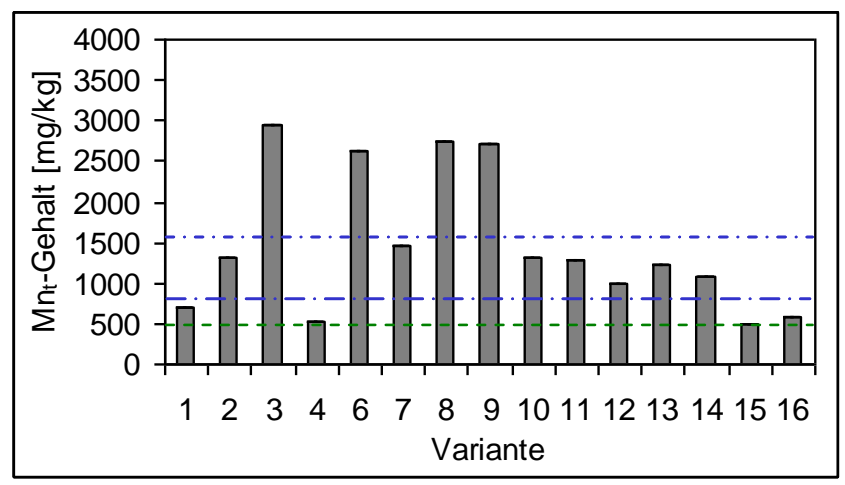

Obergrenze

Untergrenze optimal bei Eichen

(Heinsdorf 1996)

Obergrenze ausreichende

Normalgehalte (van den Burg 1985, 1990)

Abb. 48: $\mathrm{Mn}_{\mathrm{t}}$-Gehalte $[\mathrm{mg} / \mathrm{kg}]$ im Laub der Ahorn-Varianten (s. S. 20) auf Versuchsfläche D im 2. (2006) Vegetationsjahr (Mischproben)

Der durchschnittliche Mangan-Gehalt des Ahorn-Laubs (s. Abb. 48) auf Fläche D im 2. Untersuchungsjahr (2006) betrug $1464 \mathrm{mg} / \mathrm{kg}$. Je nach Variante wurden mittlere Gehalte zwischen $482 \mathrm{mg} / \mathrm{kg}$ (V15) und $2943 \mathrm{mg} / \mathrm{kg}$ (V3) gemessen.

Dabei waren nur die Messwerte in der Stockosorb®-Kalk-Variante (V4) mit $512 \mathrm{mg} / \mathrm{kg}$ sowie in den Mykorrhiza-Superabsorber-Varianten (V15 ohne, V16 mit Kalk) mit 482 mg/kg bzw. 579 $\mathrm{mg} / \mathrm{kg}$ geringer als in der unbehandelten Kontrolle (V1) mit $703 \mathrm{mg} / \mathrm{kg}$. Nach der Bewertungsskala für Mangan-Gehalte in Eichen-Laub bei Heinsdorf (1996) sind die ManganGehalte dieser vier Varianten als suboptimal einzustufen.

In allen übrigen Varianten lagen die Mangan-Blattgehalte deutlich höher. Die mit Abstand höchsten Gehalte wurden in den Varianten Stockosorb® (V3), Superabsorber-Kalk (V6), PerlitKalk (V8) und Kompost (V9) ermittelt. Mit Werten zwischen 2616 mg/g und 2943 mg/g betrugen sie rund das 4-fache des Kontrollwertes und überschritten damit deutlich den Optimalbereich für Eichen (Heinsdorf 1996).

In den verbleibenden Varianten wurden mit maximal $1456 \mathrm{mg} / \mathrm{kg}$ höchstens halb so hohe Mangan-Blattgehalte gemessen, die folglich maximal das Doppelte des Kontrollwertes darstellten. Nach Heinsdorf (1996) befanden sich diese mit Kalk (V2), Perlit (V7), Kompost und Kalk (V10) sowie in allen sechs Mykorrhiza-Varianten gemessenen Mangan-Gehalte im genannten Optimalbereich für Eichen. Gleichzeitig lagen sämtliche Messwerte jedoch teilweise weit oberhalb von in verschiedenen Quellen als ausreichend bezeichneten Spannen (van den Burg 1985, 1990: max. 473 mg/kg; Bergmann 1993: 30-100 mg/kg; BWF 2005/7: 30-150 $\mathrm{mg} / \mathrm{kg}$ ausreichend, ab $150 \mathrm{mg} / \mathrm{kg}$ optimal).

Konkrete Angaben einer Toxizitätsgrenze fehlen, so dass eine diesbezügliche Einschätzung der zum Teil sehr hohen Mangan-Gehalte schwierig ist. Zur Problematik der sehr unterschiedlichen Literaturangaben $\mathrm{zu}$ Mangan-Gehalten in Assimilationsorganen sei auch auf Seite 333ff verwiesen. 

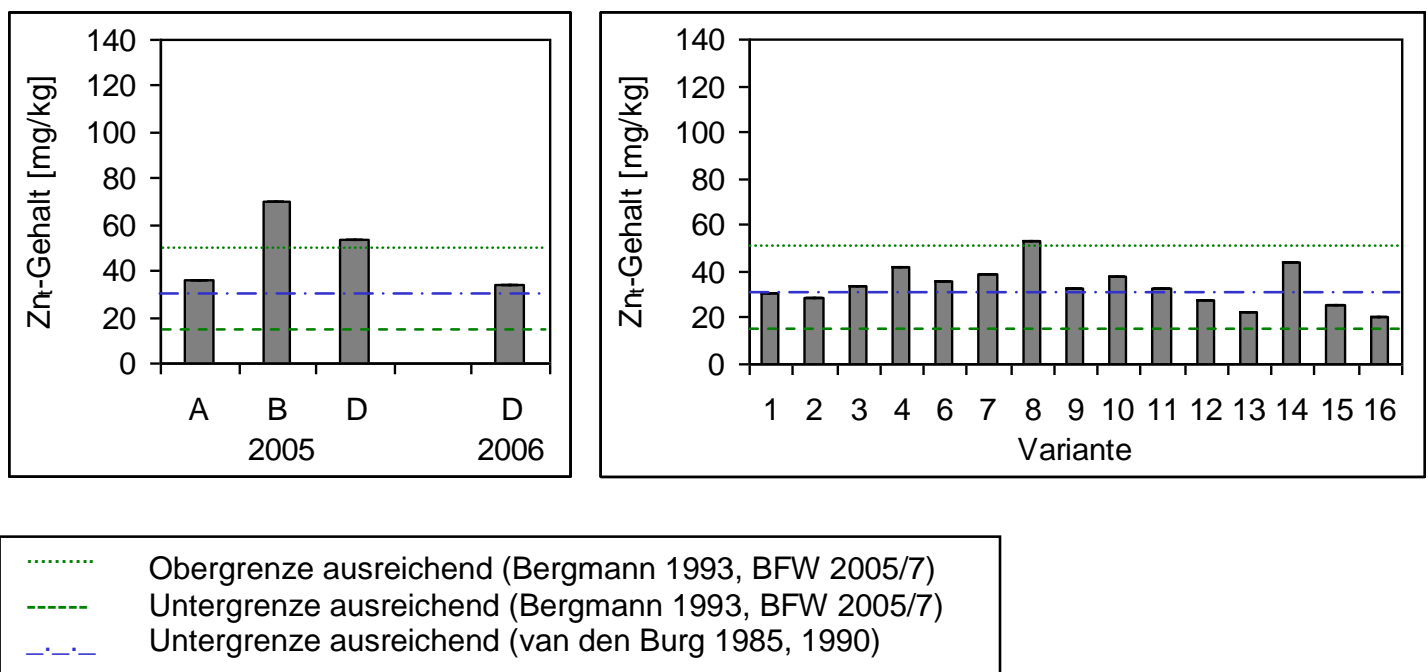

Abb. 49 links: $\mathrm{Zn}_{\mathrm{t}}$-Gehalte [mg/kg] im Laub der Ahorne auf den Versuchsflächen A, B und D im 1. (2005) und auf Fläche D im 2. (2006) Vegetationsjahr (Mischproben); rechts: differenziert nach Varianten (s. S. 20) auf Fläche D im 2. Jahr (2006) (Mischproben)

Die durchschnittlichen Zink-Gehalte in den Blättern der Ahorne (s. Abb. 49) lagen im 1. Untersuchungsjahr (2005) auf Fläche A mit 35,7 mg/kg halb so hoch wie auf Fläche B mit 70,3 $\mathrm{mg} / \mathrm{kg}$. Der Mittelwert auf Fläche D lag zu dem Zeitpunkt mit 53,1 mg/kg ziemlich genau dazwischen. Im 2. Untersuchungsjahr (2006) war er dagegen mit 33,8 mg/kg auf das Niveau des Vorjahreswertes auf Fläche A abgesunken. Damit war der durchschnittliche Zink-Gehalt im Ahorn-Laub in allen Fällen ausreichend, auf Fläche B und D (2005) auch über ausreichend (Bergmann 1993) bzw. optimal (BFW 2005/7).

In den einzelnen Varianten auf Fläche D wurden in 2006 Zink-Blattgehalte der Ahorne zwischen $20,4 \mathrm{mg} / \mathrm{kg}$ (V16) und 53,2 mg/kg (V8) ermittelt. In der unbehandelten Kontrolle markierte der Messwert mit 30,9 mg/kg in etwa die untere Grenze ausreichender Gehalte (30 mg/kg) nach van den Burg $(1985,1990)$. Leicht bis deutlich darunter liegende Zink-Gehalte wies das Ahorn-Laub in der reinen Kalk-Variante (V2) mit $28,7 \mathrm{mg} / \mathrm{kg}$ sowie in den Mykorrhiza-Varianten V12 (Mykorrhiza-Kalk) mit 27,8 mg/kg, V15 (Mykorrhiza-Superabsorber) mit 25,7 mg/kg, V13 (Mykorrhiza-Stockosorb®) mit 22,6 mg/kg und V16 (Mykorrhiza-Superabsorber-Kalk) mit 20,4 $\mathrm{mg} / \mathrm{kg}$ auf. Nach Bergmann (1993) und dem österreichischen BFW (2005/7) waren auch diese Werte noch ausreichend $(15-50 \mathrm{mg} / \mathrm{kg})$.

Leicht bis deutlich höhere Zink-Gehalte als in der Nullvariante (V1) wurden in den Varianten reine Mykorrhiza (V11) mit 32,8 mg/kg, Kompost (V9) mit 33,0 mg/kg, Stockosorb® (V3) mit $33,4 \mathrm{mg} / \mathrm{kg}$ und Superabsorber-Kalk (V6) mit 35,8 mg/kg ermittelt. Bei der Zugabe von Kompost und Kalk (V10) sowie von Perlit (V7) betrug der Zink-Gehalt bereits etwas mehr als 38 mg/kg. Mit zusätzlicher Kalk-Gabe (V8: Perlit-Kalk) wurde mit 53,2 mg/kg der mit Abstand höchste Zink-Blattgehalt gemessen, der als über ausreichend (Bergmann 1993) bzw. optimal (BFW 2005/7) eingestuft wird. Die mit etwas über $42 \mathrm{mg} / \mathrm{kg}$ zweithöchsten Zink-Gehalte wurden im Ahorn-Laub in den Varianten mit Kombinationen aus Stockosorb® und Kalk (V4 ohne, V14 mit Mykorrhiza) ermittelt. 

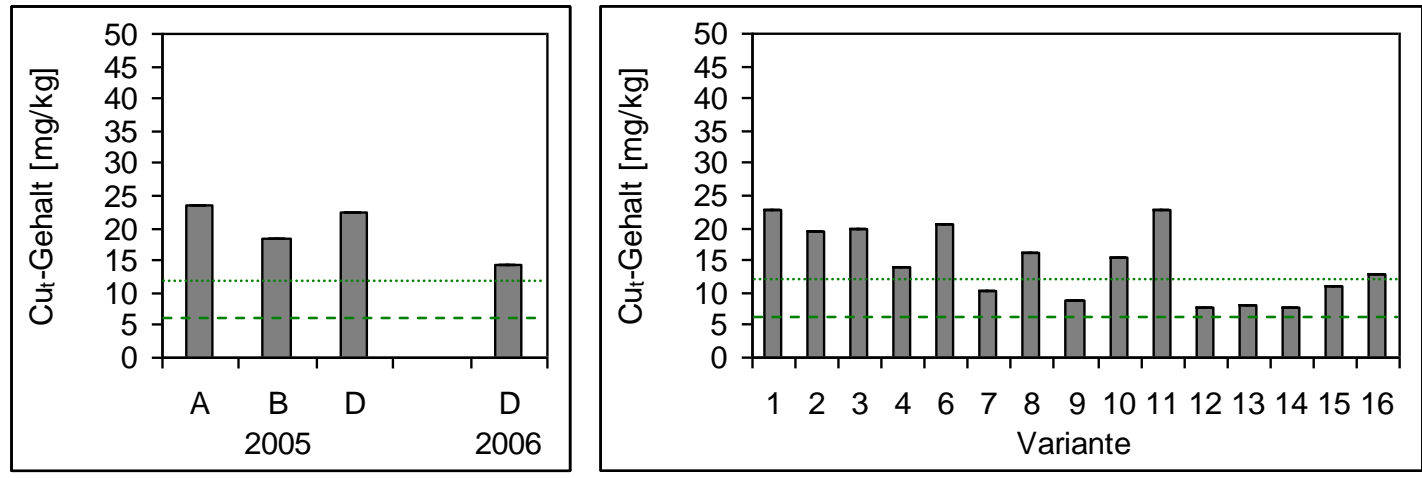

Obergrenze ausreichend

Untergrenze ausreichend (Bergmann 1993, BFW 2005/7)

Abb. 50 links: $\mathrm{Cu}_{\mathrm{t}}-\mathrm{Gehalte}[\mathrm{mg} / \mathrm{kg}]$ im Laub der Ahorne auf den Versuchsflächen A, B und D im 1. (2005) und auf Fläche D im 2. (2006) Vegetationsjahr (Mischproben); rechts: differenziert nach Varianten (s. S. 20) auf Fläche D im 2. Jahr (2006) (Mischproben)

Die Kupfer-Gehalte im Laub der Ahorne (s. Abb. 50) auf allen drei Versuchsfläche lagen mit 23,5 $\mathrm{mg} / \mathrm{kg}$ (A), 22,4 mg/kg (D 2005) sowie etwas geringeren $18,4 \mathrm{mg} / \mathrm{kg}$ (B) und 14,5 mg/kg (D 2006) mehr oder weniger deutlich oberhalb der Spanne ausreichender Normalgehalte (6-12 $\mathrm{mg} / \mathrm{kg}$ ) nach Bergmann (1993) und dem BFW (2005/7).

Auf Fläche D (2006) wurden je nach Variante Werte zwischen 7,7 mg/kg (V12, V14) und 22,8 mg/kg (V1, V11) ermittelt. Die relative Höhe der Kupfer-Gehalte in den einzelnen Varianten (z.B. vergleichsweise geringe Eisen-Gehalte in den Mykorrhiza-Varianten V12-V16; höchster Gehalt in V11; in V7 und V9 jeweils geringere Gehalte als in V8 und V10 etc.) fand sich ziemlich genau so auch bei den Eisen- und Aluminium-Gehalten wieder (Abb. A 2).

In der unbehandelten Kontrolle (V1) sowie der reinen Mykorrhiza-Variante (V11) betrugen die Kupfer-Blattgehalte mit je 22,8 mg/kg fast das Doppelte der Obergrenze ausreichender Normalgehalte. In den Varianten Kalk (V2), Stockosorb® (V3) und Superabsorber-Kalk (V6) lagen die Werte mit um $20 \mathrm{mg} / \mathrm{kg}$ nur wenig darunter. In weiteren BodenhilfsstoffKombinationen mit Kalk wurden niedrigere Kupfer-Blattgehalte gemessen, die in den Varianten V8 (Perlit-Kalk) und V10 (Kompost-Kalk) 16,1 mg/kg und 15,6 mg/kg, in den Varianten V4 (Stockosorb®-Kalk) und V16 (Mykorrhiza-Superabsorber-Kalk) 13,9 mg/kg und 13,0 mg/kg betrugen. In den entsprechenden kalkfreien Varianten wurden zum Teil Kupfer-Gehalte ermittelt, die noch deutlich unter diesen Messwerten lagen und sich mit Werten von $10,9 \mathrm{mg} / \mathrm{kg}$ (V15: Mykorhiza-Superabsorber), 10,3 mg/kg (V7: Perlit) und 9,0 mg/kg (V9: Kompost) innerhalb der Spanne ausreichender Normalgehalte befanden. Die mit 7,7 mg/kg bzw. 8,0 mg/kg geringsten, ebenfalls ausreichenden Kupfer-Blattgehalte, die nur noch ein Drittel des Kontrollwertes betrugen, wurden in den Ahornen mit kombinierter Behandlung aus Mykorrhiza-Impfung und Kalk- oder/und Stockosorb®-Gaben ermittelt (V12-V14).

\section{Potentiell nützliche Elemente (Al, Na, Ni, Co)}

Der im Laub der Ahorne auf Fläche D (2006) gemessene Aluminium-Gehalt (s. Abb. 51) lag im Mittel bei $1562 \mathrm{mg} / \mathrm{kg}$. Je nach Variante wurden durchschnittliche Gehalte zwischen $444 \mathrm{mg} / \mathrm{kg}$ (V13) und $2903 \mathrm{mg} / \mathrm{kg}$ (V11) ermittelt. Die relative Höhe der Aluminium-Gehalte in den einzelnen Varianten (z.B. vergleichsweise geringe Eisen-Gehalte in den Mykorrhiza-Varianten 
V12-V16; höchster Gehalt in V11; in V7 und V9 jeweils geringere Gehalte als in V8 und V10 etc.) fand sich ziemlich genau so auch bei den Eisen- und Kupfer-Gehalten wieder (Abb. A 2).
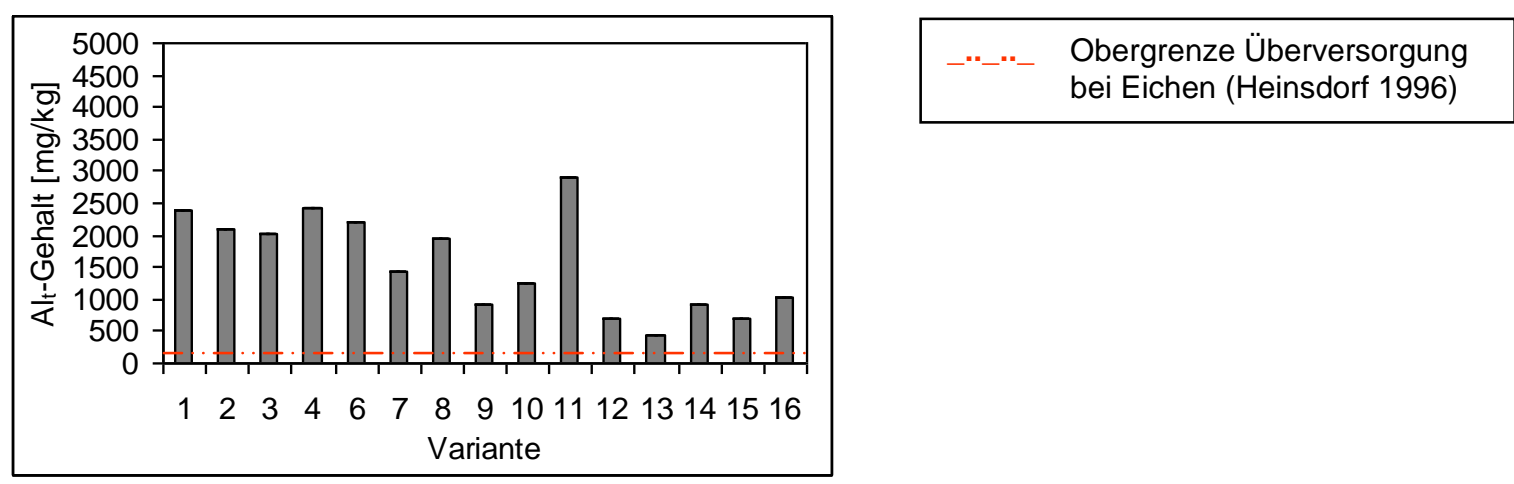

Abb. 51: Alt-Gehalte [mg/kg] im Laub der Ahorn-Varianten (s. S. 20) auf Versuchsfläche D im 2. (2006) Vegetationsjahr (Mischproben)

Alle Messwerte überstiegen die obere Grenze einer Überversorgung bei Eichen $(119 \mathrm{mg} / \mathrm{kg}$ nach Heinsdorf 1996) um das knapp 4- bis gut 24-fache.

Nur in der reinen Mykorrhiza-Variante (V11) wurde ein mit $2903 \mathrm{mg} / \mathrm{kg}$ noch deutlich höherer Aluminium-Gehalt gemessen als in der unbehandelten Kontrolle (V1) mit $2380 \mathrm{mg} / \mathrm{kg}$. In der Stocksorb®-Kalk-Variante (V4) lag der Aluminium-Blattgehalt mit $2438 \mathrm{mg} / \mathrm{kg}$ im Bereich des Kontrollwertes. In den Varianten Kalk (V2), Stockosorb® (V3), Superabsorber-Kalk (V6) und Perlit-Kalk (V8) wurden mit Werten zwischen knapp 2000 mg/kg und knapp 2200 mg/kg Aluminium-Gehalte nur leicht unterhalb des Kontrollwertes festgestellt.

Erheblich geringer war der Wert in der reinen Perlit-Variante (V7) mit $1447 \mathrm{mg} / \mathrm{kg}$, gefolgt von der Kompost-Kalk-Variante (V10) mit 1263 mg/kg. In der ungekalkten Kompost-Variante (V9) sowie den beiden Kombinationen aus Mykorrhiza, Wasserspeichersubstanz und Kalk (V14 mit Stockosorb®, V16 mit Superabsorber) waren die Aluminium-Gehalte mit 929 mg/kg, 923 mg $/ \mathrm{kg}$ und $1012 \mathrm{mg} / \mathrm{kg}$ wiederum niedriger. Mit Werten um $700 \mathrm{mg} / \mathrm{kg}$ lagen die Gehalte in den Mykorrhiza-Varianten V12 (Mykorrhiza-Kalk) und V15 (Mykorrhiza-Superabsorber) noch darunter. Der mit Abstand geringste Aluminium-Gehalt, der mit $444 \mathrm{mg} / \mathrm{kg}$ nur noch etwa $19 \%$ des Kontrollwertes entsprach, wurde in der Mykorrhiza-Stockosorb®-Variante gemessen. Insgesamt waren jedoch auch diese auf einen Bruchteil des Kontrollwertes reduzierten Aluminium-Blattgehalte immer noch vergleichsweise sehr hoch. Sie überstiegen die Obergrenze einer Überversorgung bei Eichen (Heinsdorf 1996) von 119 mg/kg bei weitem.

Laut Bergmann (1993) ist Aluminium-Toxizität weniger durch hohe Aluminium-Gehalte als durch Phosphor-Mangel auf ausreichend mit Phosphor versorgten Böden (wie in diesem Fall, s. S. 48) nachweisbar. Nach den dargestellten Phosphor-Blattgehalten in den verschiedenen Ahorn-Varianten wäre demnach mit Ausnahme der Varianten V7, 8, 9 und V14, 15, 16 in allen Varianten von $\mathrm{Al}^{3+-}$ Überschuss und Aluminium-Toxizität auszugehen. 

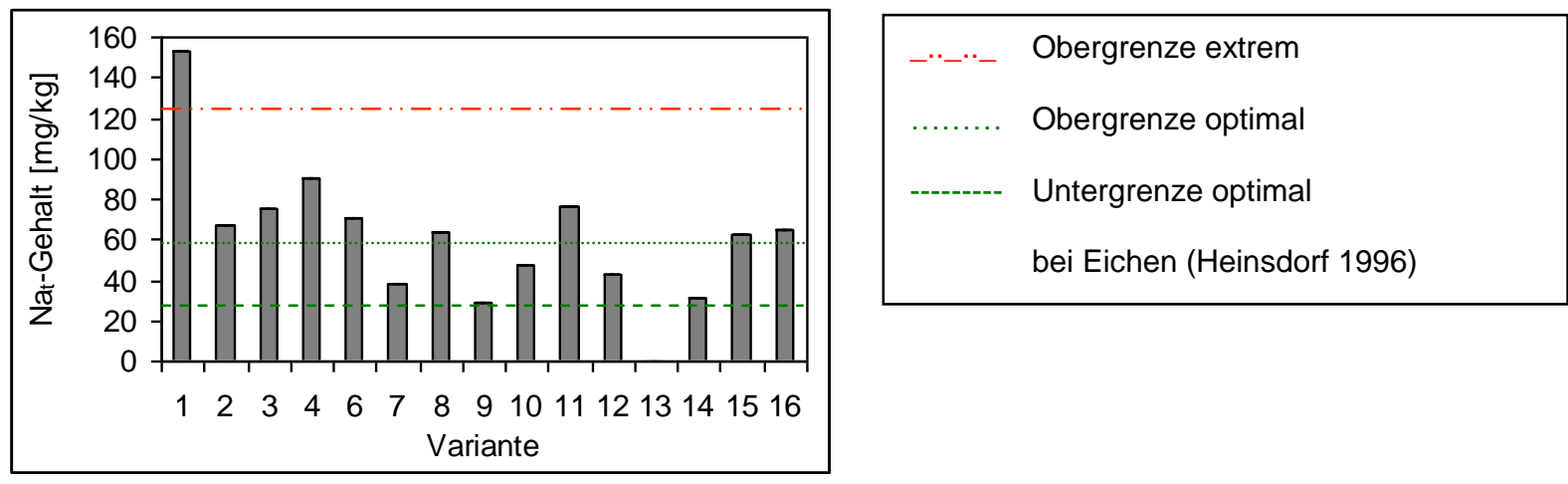

Abb. 52: Nat-Gehalte [mg/kg] im Laub der Ahorn-Varianten (s. S. 20) auf Versuchsfläche D im 2. (2006) Vegetationsjahr (Mischproben)

Der Natrium-Gehalt in den Blättern der Ahorne (s. Abb. 52) auf Fläche D lag im 2. Untersuchungsjahr (2006) im Mittel bei 65,3 mg/kg. Je nach Variante wurden Durchschnittswerte zwischen 29,5 mg/kg (V9) und 152,7 mg/kg (V1) gemessen. In der unbehandelten Kontrolle (V1) wiesen die Ahorne mit 152,7 mg/kg die mit Abstand höchsten Natrium-Blattgehalte auf. Gemessen an den Einstufungen von Natrium-Gehalten in EichenBlättern durch Heinsdorf (1996) lag dieser Kontrollwert bereits deutlich oberhalb einer Extremversorgung. Die Natrium-Gehalte in allen Behandlungsvarianten lagen erheblich niedriger. In der Perlit-Variante (V7) mit 38,3 mg/kg, den beiden Kompost-Varianten (V9 ohne, V10 mit Kalk) mit 29,5 mg/kg und 47,8 mg/kg sowie in zwei Mykorrhiza-Varianten (V12: Mykorrhiza-Kalk und V14: Mykorrhiza-Stockosorb®-Kalk) mit 42,2 mg/kg bzw. 31,9 mg/kg wurden Natrium-Gehalte im Optimalbereich (für Eichen nach Heinsdorf 1996) gemessen. Die Ahorne in den übrigen Varianten wiesen mit Werten zwischen $62,4 \mathrm{mg} / \mathrm{kg}$ und 76,9 mg/kg Natrium-Blattgehalte auf, die höchstens die Hälfte des Kontrollwertes betrugen. Nach den Vergleichswerten für Eichen in Heinsdorf (1996) lagen sie damit im Bereich einer Überversorgung. Der nach dem Kontrollwert höchste Natrium-Gehalt von 90,1 mg/kg in der Stockosorb®-Kalk-Variante (V4) ist demnach ebenso einzustufen.
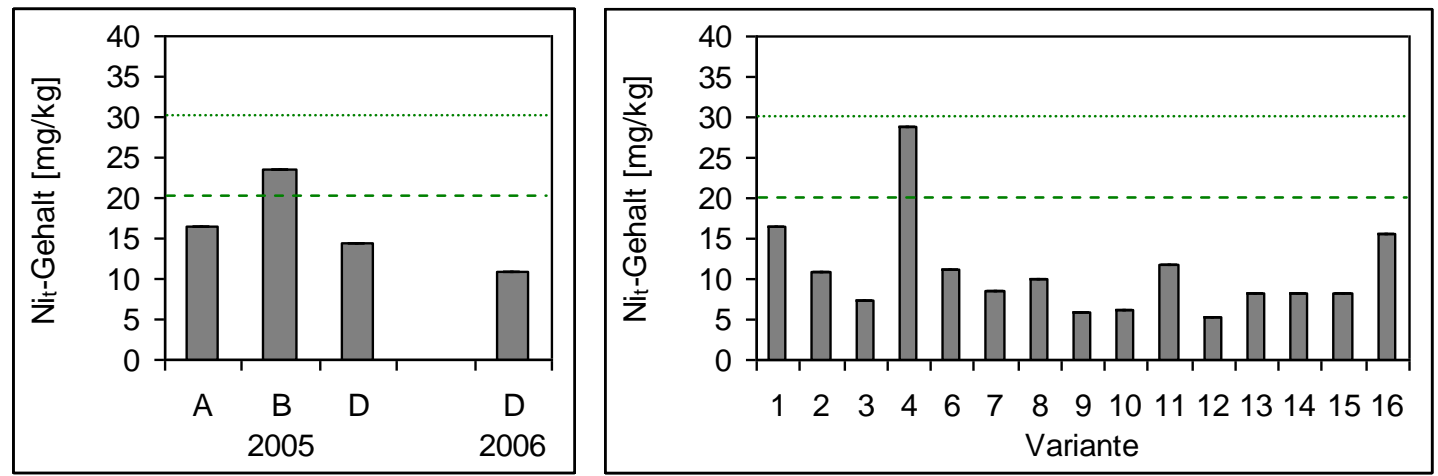

$\begin{array}{ll}\ldots \ldots . . & \text { Obergrenze } \\ ----- & \text { Untergrenze Normalgehalte in Pflanzen (Smidt 1999) }\end{array}$

Abb. 53 links: $\mathrm{Ni}_{\mathrm{t}}-\mathrm{Gehalte}[\mathrm{mg} / \mathrm{kg}]$ im Laub der Ahorne auf den Versuchsflächen A, B und D im 1. (2005) und auf Fläche D im 2. (2006) Vegetationsjahr (Mischproben); rechts: differenziert nach Varianten (s. S. 20) auf Fläche D im 2. Jahr (2006) (Mischproben)

Der durchschnittliche Nickel-Gehalt im Laub der Ahorne (s. Abb. 53) auf Fläche B lag mit 23,5 $\mathrm{mg} / \mathrm{kg}$ im Bereich der sehr allgemein gehaltenen Normalgehalte in Pflanzen (20-30 mg/kg) nach 
Smidt (1999), während die mittleren Nickel-Gehalte auf Fläche A mit 16,5 mg/kg sowie auf Fläche D mit 14,4 mg/kg im 1. und geringeren $10,8 \mathrm{mg} / \mathrm{kg}$ im 2. Untersuchungsjahr deutlich darunter lagen.

Getrennt nach Varianten wurden auf Fläche D in 2006 Werte zwischen 5,4 mg/kg (V12) und $28,7 \mathrm{mg} / \mathrm{kg}$ (V4) erreicht. Die Nickel-Gehalte in der unbehandelten Kontrolle (V1) sowie in der Mykorrhiza-Superabsorber-Kalk-Variante (V16) waren mit $16,5 \mathrm{mg} / \mathrm{kg}$ und 15,5 mg/kg etwa gleich hoch. Darüber lag nur der mit Abstand höchste gemessene Nickel-Gehalt in der Stockosorb®-Kalk-Variante (V4), der mit $28,7 \mathrm{mg} / \mathrm{kg}$ fast doppelt so hoch war und als einziger Wert innerhalb der Normalgehalte nach Smidt (1999) lag. In allen übrigen Varianten waren die Nickel-Blattgehalte der Ahorne teilweise erheblich geringer. Die niedrigsten Gehalte wurden in der Mykorrhiza-Kalk-Variante (V12) mit 5,4 mg/kg sowie in den Kompost-Varianten (V9 ohne Kalk, V10 mit Kalk) mit Werten um 6 mg/kg ermittelt. In den Varianten mit Stockosorb® (V3), Perlit (V7) oder Kombinationen aus Mykorrhiza und Stockosorb® (V13), Stockosorb® sowie Kalk (V14) bzw. Superabsorber (V15) wurden die Nickel-Gehalte in den Ahorn-Blättern mit Werten um $8 \mathrm{mg} / \mathrm{kg}$ gegenüber der unbehandelten Kontrolle halbiert. Die Werte in den verbleibenden Varianten, den Kalk-Varianten V2 (reiner Kalk), V6 (Stockosorb®-Kalk) und V8 (Perlit-Kalk) sowie in der reinen Mykorrhiza-Variante (V11) lagen mit 10,0 mg/kg bis 11,7 $\mathrm{mg} / \mathrm{kg}$ etwas höher, aber dennoch deutlich unterhalb des Kontrollwertes.
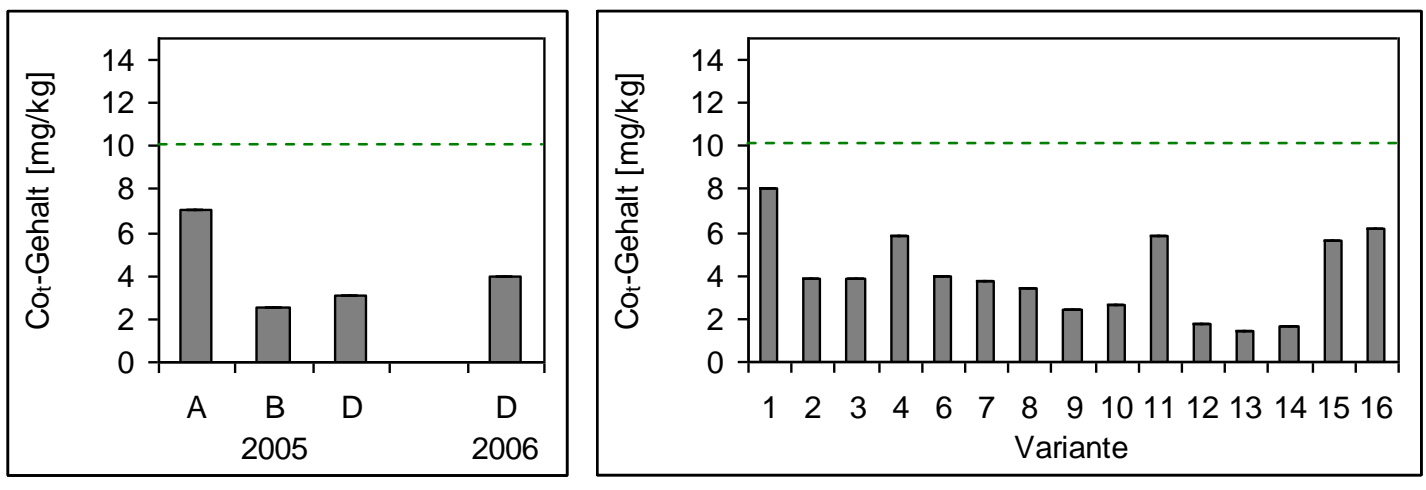

Untergrenze Normalgehalte in Pflanzen (Smidt 1999)

Abb. 54 links: $\mathrm{Co}_{\mathrm{t}}$-Gehalte [mg/kg] im Laub der Ahorne auf den Versuchsflächen A, B und D im 1. (2005) und auf Fläche D im 2. (2006) Vegetationsjahr (Mischproben); rechts: differenziert nach Varianten (s. S. 20) auf Fläche D im 2. Jahr (2006) (Mischproben)

Der mittlere Kobalt-Gehalt im Ahorn-Laub (s. Abb. 54) auf Versuchsfläche A lag mit 7,1 mg/kg deutlich höher als auf den Versuchsflächen B mit 2,5 mg/kg und D mit 3,1 mg/kg (2005) sowie $4,0 \mathrm{mg} / \mathrm{kg}$ (2006). Je nach Variante bewegten sich die Gehalte auf Fläche D in 2006 zwischen 1,4 $\mathrm{mg} / \mathrm{kg}$ (V13) und 8,0 mg/kg (V1). Damit lagen sämtliche Messwerte unterhalb der sehr allgemeinen Untergrenze für Normalgehalte in Pflanzen $(10 \mathrm{mg} / \mathrm{kg}$ ) nach Smidt (1999).

Auf den mit Abstand höchsten Wert in der unbehandelten Kontrolle (V1: 8,0 mg/kg) folgten die Kobalt-Gehalte in den Varianten Stockosorb®-Kalk (V4), Mykorrhiza (V11), MykorrhizaSuperabsorber (V15) und Mykorrhiza-Superabsorber-Kalk (V16) mit Werten um 6 mg/kg. Die Gehalte in der kalkfreien Stockosorb®-Variante (V3), der reinen Kalk- (V2) und der Superabsorber-Kalk-Variante (V6) sowie den Perlit-Varianten (V7 ohne, V8 mit Kalk) lagen zwischen $3,5 \mathrm{mg} / \mathrm{kg}$ und $4,0 \mathrm{mg} / \mathrm{kg}$, was der Hälfte des Kontrollwertes entsprach. In den Kompost-Varianten (V9 ohne, V10 mit Kalk) mit 2,5 mg/kg bzw. 2,6 mg/kg, vor allem aber in 
den drei Mykorrhiza-Varianten V12 (Mykorrhiza-Kalk: 1,7 mg/kg), V13 (MykorrhizaStockosorb®: $1,4 \mathrm{mg} / \mathrm{kg}$ ) und V14 (Mykorrhiza-Stockosorb ${ }^{\circledR}-K a l k: 1,7 \mathrm{mg} / \mathrm{kg}$ ) waren die ermittelten Kobalt-Blattgehalte noch einmal deutlich geringer.

\section{Toxisch wirkende Schwermetalle ohne Nährelementfunktion ( $\mathrm{Pb}, \mathrm{Cd}, \mathrm{Cr})$}

Im Laub der Ahorne auf Versuchsfläche A konnte im 1. Untersuchungsjahr (2005) kein messbarer Blei-Gehalt festgestellt werden. Die Blätter der Ahorne auf den Flächen B und D enthielten dagegen im Durchschnitt 3,7 mg/kg und 4,7 mg/kg Blei (s. Abb. 55). Nach den sehr allgemeinen Normalgehalten von Schwermetallen in Pflanzen (Smidt 1999) sowie den ebenso allgemeinen kritischen Konzentrationen von Schwermetallen in Pflanzen (Alloway 1999) wären damit weder normale $(10-20 \mathrm{mg} / \mathrm{kg})$ noch kritische $(30-300 \mathrm{mg} / \mathrm{kg})$ Blei-Gehalte erreicht. Die Werte lagen jedoch deutlich oberhalb des 90er-Perzentils $(3,0 \mathrm{mg} / \mathrm{kg})$ der im Rahmen des Deutschen Waldbodenberichtes in Buchenblättern gemessenen Blei-Gehalte (BMELF 1997b), so dass von einem vergleichsweise hohen Gehalt ausgegangen werden kann. Im 2 . Untersuchungsjahr (2006) lagen die Blei-Gehalte im Ahorn-Laub auf Fläche D dagegen sowohl insgesamt als auch innerhalb der einzelnen Varianten unterhalb der Nachweisgrenze für dieses Schwermetall.

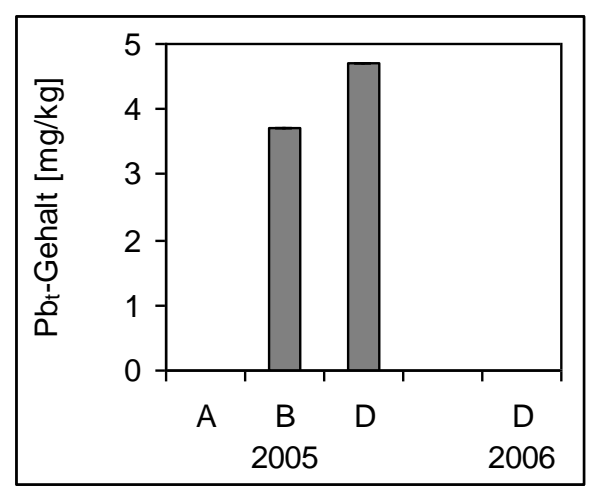

Abb. 55: $\mathrm{Pb}_{\mathrm{t}}-\mathrm{Gehalte}[\mathrm{mg} / \mathrm{kg}]$ im Laub der Ahorne auf den Versuchsflächen A, B und D im 1. (2005) und auf Fläche D im 2. (2006) Vegetationsjahr (Mischproben)

Ein messbarer Cadmium-Gehalt wurde nur im 1. Untersuchungsjahr in den Blättern der Ahorne auf Fläche B ermittelt. Mit 0,36 mg/kg lag dieser oberhalb des 75er-Perzentils $(0,13 \mathrm{mg} / \mathrm{kg})$ der entsprechenden Werte bei den für den Deutschen Waldbodenbericht untersuchten Buchen (BMELF 1997b). Wie bei den Blei-Gehalten wären die sehr allgemeinen normalen (in Smidt 1999) sowie kritischen (Alloway 1999) Konzentrationen in Pflanzen (5-10 mg/kg bzw. 5-30 $\mathrm{mg} / \mathrm{kg}$ ) damit noch lange nicht erreicht.

Auf Fläche D wurde im 2. Untersuchungsjahr im Ahorn-Laub ein sehr geringer mittlerer Cadmium-Gehalt von 0,0074 mg/kg gemessen. Die nach Varianten getrennte Betrachtung ergab, dass dieser Mittelwert lediglich auf den Cadmium-Blattgehalt in einer Variante, der Stockosorb®-Variante (V3), zurückzuführen ist, der mit $0,11 \mathrm{mg} / \mathrm{kg}$ wiederum in etwa dem genannten 75er-Perzentil entsprach. In allen übrigen Varianten konnten keine CadmiumBlattgehalte oberhalb der Nachweisgrenze festgestellt werden. 

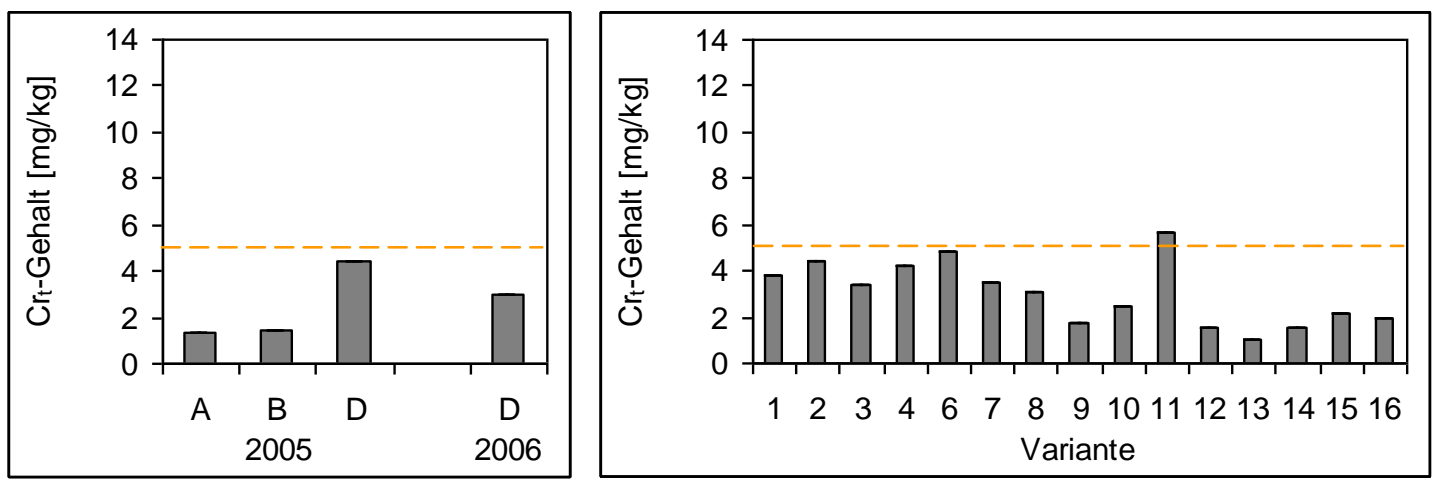

Untergrenze kritischer Bereich in Pflanzen (Alloway 1999)

Abb. 56 links: $\mathrm{Cr}_{\mathrm{t}}-\mathrm{Gehalte}$ [mg/kg] im Laub der Ahorne auf den Versuchsflächen A, B und D im 1. (2005) und auf Fläche D im 2. (2006) Vegetationsjahr (Mischproben); rechts: differenziert nach Varianten (s. S. 20) auf Fläche D im 2. Jahr (2006) (Mischproben)

Der Chrom-Gehalt in den Blättern der Ahorne (s. Abb. 56) auf den Versuchsflächen A und B lag im Schnitt bei 1,3 mg/kg bzw. 1,4 mg/kg. Auf Fläche D betrug er im 1. Versuchsjahr (2005) mit $4,4 \mathrm{mg} / \mathrm{kg}$ das 3-fache, im 2. Versuchsjahr (2006) mit etwas geringeren 3,0 mg/kg das Doppelte dieser Werte. Nach der in Alloway (1999) dargestellten, sehr allgemeinen Einteilung beginnt der Bereich kritischer Chrom-Konzentrationen erst bei $5 \mathrm{mg} / \mathrm{kg}$. In den einzelnen Varianten auf Fläche D wurden im Ahorn-Laub Chrom-Gehalte zwischen 1,0 mg/kg (V13) und 5,6 mg/kg (V11) gemessen. Im Bereich der unbehandelten Kontrolle (V1) mit 3,8 mg/kg lagen die Chrom-Gehalte in der Kalk-Variante (V2), den Stockosorb®-Varianten (V3 ohne, V4 mit Kalk) sowie den PerlitVarianten (V7 ohne, V8 mit Kalk) mit Werten zwischen 3,1 mg/kg und 4,4 mg/kg. In der Kombination Superabsorber-Kalk (V6) reichte der Chrom-Gehalt der Ahorn-Blätter mit 4,8 $\mathrm{mg} / \mathrm{kg}$ knapp an die Untergrenze des genannten kritischen Bereichs heran. In der reinen Mykorrhiza-Variante (V11) wurde diese Untergrenze mit 5,6 mg/kg leicht überschritten. Die Kompost-Varianten (V9 ohne, V10 mit Kalk) sowie sämtliche Mykorrhiza-Varianten mit zusätzlichen Bodenhilfsstoffen (V12-V16) wiesen mit $1,0 \mathrm{mg} / \mathrm{kg}$ bis $2,5 \mathrm{mg} / \mathrm{kg}$ gegenüber der Nullvariante (V1) deutlich geringere Chrom-Blattgehalte auf. Die geringsten Werte wurden in den Kombinationen aus Mykorrhiza mit Stockosorb® (und/oder Kalk) gemessen. In der Kombination von Mykorrhiza und Superabsorber (V15 ohne Kalk, V16 mit Kalk) wurden mit 2,2 $\mathrm{mg} / \mathrm{kg}$ bzw. 2,0 mg/kg doppelt so hohe, wenngleich auch immer noch erheblich geringere Gehalte als in der Kontrolle (V1: 3,8 mg/kg) ermittelt.

\subsubsection{Eberesche}

Im Folgenden werden die Ergebnisse der Blattanalysen (Mischproben, s. S. 26) zur Versorgung und Belastung der Ebereschen auf den drei Versuchsflächen insgesamt sowie innerhalb der Versuchs-Varianten auf Versuchsfläche D dargestellt.

\section{Hauptnährelemente, Makronährstoffe (N, P, K, Ca, Mg, S)}

Die Stickstoff-Gehalte im Laub der Ebereschen (s. Abb. 57) lagen im 1. Untersuchungsjahr (2005) auf Fläche A bei 19,3 mg/g, auf Fläche B bei $15,7 \mathrm{mg} / \mathrm{g}$ und auf Fläche D bei $18,5 \mathrm{mg} / \mathrm{g}$. Damit waren die Werte auf Fläche A und D im Vergleich mit Werten für andere Laubbaumarten (Bergmann 1993) ausreichend, auf Fläche B dagegen nicht. Im 2. Untersuchungsjahr (2006) war 
der Stickstoff-Gehalt in den Ebereschen-Blättern auf Fläche D auf 14,7 mg/g abgesunken und damit ebenfalls nicht mehr ausreichend.
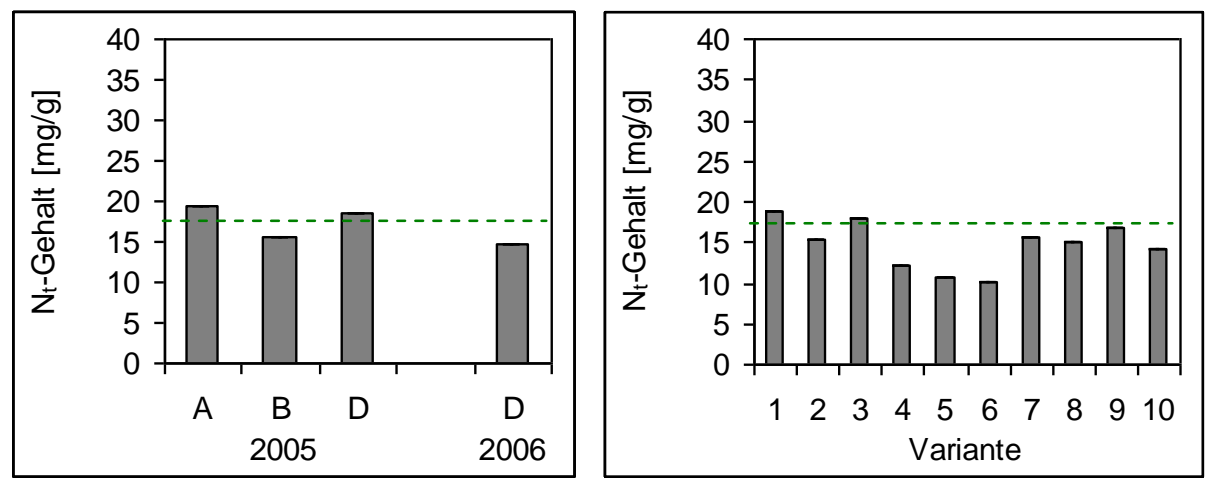

Untergrenze ausreichend (Bergmann 1993)

Abb. 57 links: $\mathrm{N}_{\mathrm{t}}-$ Gehalte [mg/g] im Laub der Ebereschen auf den Versuchsflächen A, B und D im 1. (2005) und auf Fläche D im 2. (2006) Vegetationsjahr (Mischproben); rechts: differenziert nach Varianten (s. S. 20) auf Fläche D im 2. Jahr (2006) (Mischproben)

In den Ebereschen-Varianten auf Fläche D (2006) wurden Stickstoff-Blattgehalte zwischen 10,2 mg/g (V6) und 18,8 mg/g (V1) gemessen. In der Kontrolle (V1), der Stockosorb®-Variante (V3) und der Kompost-Variante (V9) waren die Werte im Vergleich mit Werten für andere Laubbaumarten (Bergmann 1993) knapp ausreichend. In allen übrigen Varianten waren die Stickstoff-Gehalte geringer, am deutlichsten in der Stockosorb®-Kalk- (V4), der Superabsorber(V5) und der Superabsorber-Kalk-Variante (V6).
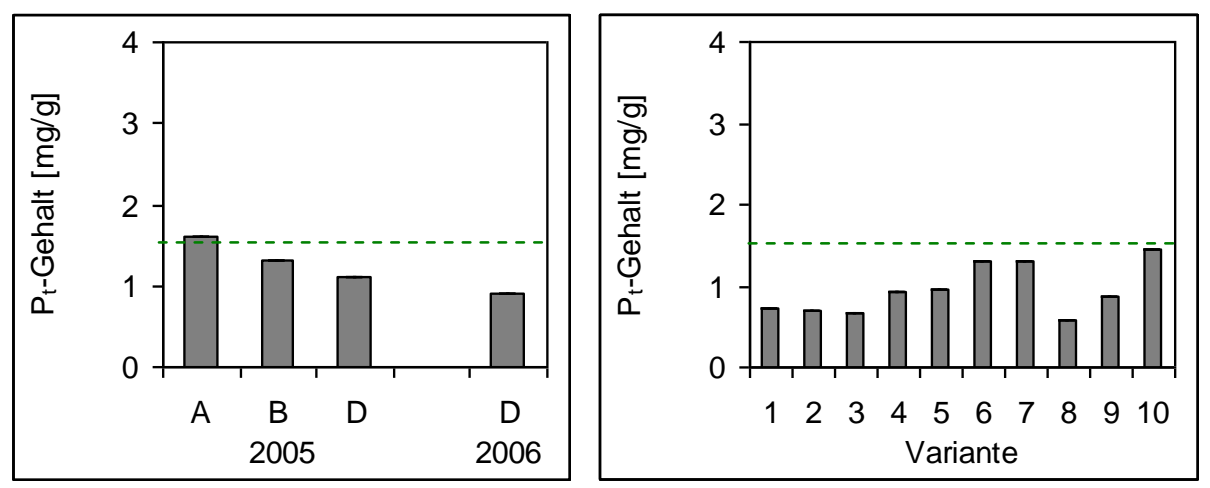

Untergrenze ausreichend (Bergmann 1993)

Abb. 58 links: $\mathrm{P}_{\mathrm{t}}$-Gehalte [mg/g] im Laub der Ebereschen auf den Versuchsflächen A, B und D im 1. (2005) und auf Fläche D im 2. (2006) Vegetationsjahr (Mischproben); rechts: differenziert nach Varianten (s. S. 20) auf Fläche D im 2. Jahr (2006) (Mischproben)

Die im Laub der Ebereschen auf den drei Versuchsflächen ermittelten Phosphor-Gehalte (s. Abb. 58) lagen mit 1,6 mg/g nur auf Fläche A im ausreichenden Bereich. Auf Fläche B (1,3 mg/g) sowie auf Fläche D reichten die Werte sowohl in $2005(1,1 \mathrm{mg} / \mathrm{g})$ als auch noch deutlicher in 2006 (0,9 mg/g) nicht mehr aus. In den Blättern der Ebereschen-Varianten auf Fläche D (2006) wurden Phosphor-Gehalte zwischen 0,6 mg/g (V8) und 1,4 mg/g (V10) ermittelt. Gemessen an Werten für andere Laubbaumarten (Bergmann 1993) war die Phosphorversorgung aller Varianten nicht ausreichend. Mit Superabsorber und Kalk (V6), Perlit (V7) sowie mit Kompost 
und Kalk (V10) waren die Gehalte etwa doppelt so hoch wie in der unbehandelten Kontrolle (V1). Der Phosphor-Gehalt reichte mit Kompost und Kalk (V10) knapp an den ausreichenden Bereich heran.
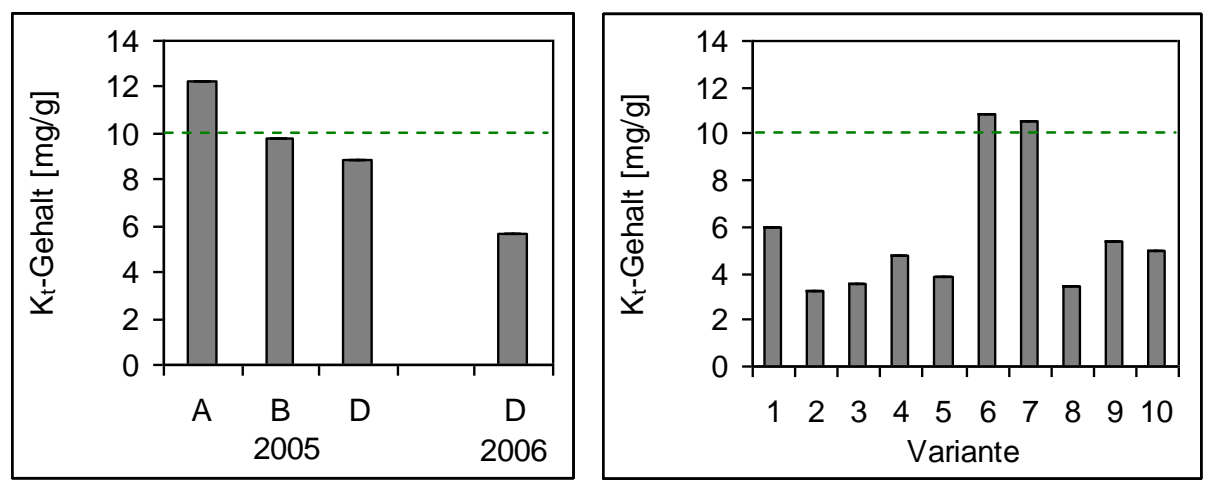

\section{------ Untergrenze ausreichend (Bergmann 1993)}

Abb. 59 links: $\mathrm{K}_{\mathrm{t}}-\mathrm{Gehalte}[\mathrm{mg} / \mathrm{g}]$ im Laub der Ebereschen auf den Versuchsflächen A, B und D im 1. (2005) und auf Fläche D im 2. (2006) Vegetationsjahr (Mischproben); rechts: differenziert nach Varianten (s. S. 20) auf Fläche D im 2. Jahr (2006) (Mischproben)

Die mittlere Kalium-Versorgung der Ebereschen (s. Abb. 59) war mit 12,2 mg/g nur auf Fläche A ausreichend (Bergmann 1993). Der Mittelwert auf Fläche B markierte mit $9,8 \mathrm{mg} / \mathrm{g}$ die Untergrenze ausreichender Gehalte. Auf Fläche D reichten die Werte sowohl in 2005 (8,9 mg/g) als auch noch deutlicher in 2006 (5,7 mg/g) nicht aus. Die in den Ebereschen-Varianten auf Fläche D (2006) gemessenen Kalium-Gehalte lagen zwischen 3,2 mg/g (V2) und 10,9 mg/g (V6). Mit Superabsorber und Kalk (V6) sowie mit Perlit (V7) enthielt das Ebereschen-Laub fast doppelt so viel Kalium wie in der unbehandelten Kontrolle (V1), was verglichen mit Werten für andere Laubbaumarten (Bergmann 1993) einer knapp ausreichenden Versorgung entsprach. Die Kalium-Blattgehalte aller übrigen Varianten waren demnach nicht ausreichend.
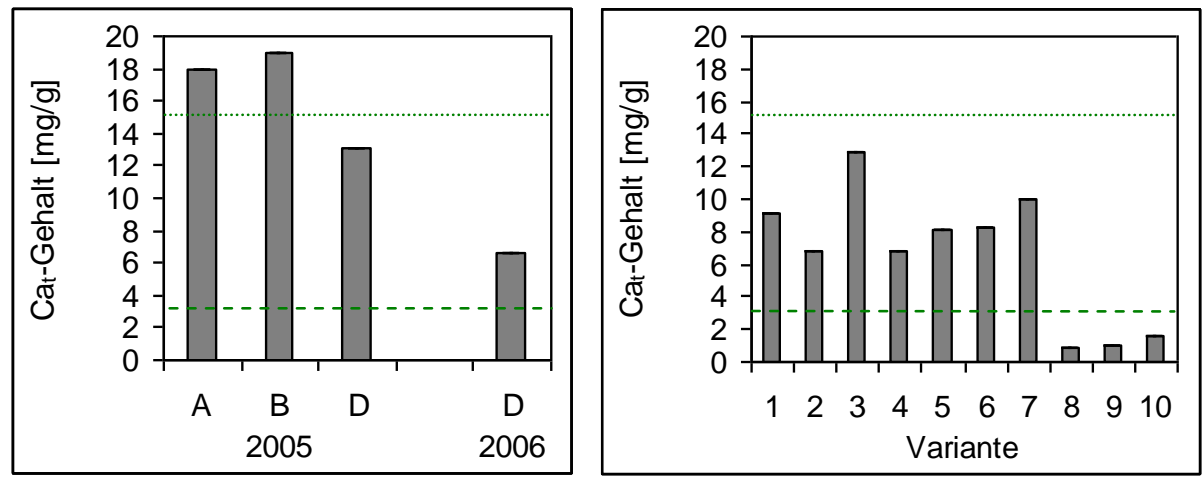

Obergrenze ausreichend

Untergrenze ausreichend (Bergmann 1993)

Abb. 60 links: Cat-Gehalte [mg/g] im Laub der Ebereschen auf den Versuchsflächen A, B und D im 1. (2005) und auf Fläche D im 2. (2006) Vegetationsjahr (Mischproben); rechts: differenziert nach Varianten (s. S. 20) auf Fläche D im 2. Jahr (2006) (Mischproben)

Die Calcium-Gehalte in den Ebereschen-Blättern (s. Abb. 60) auf Fläche A (18,0 mg/g) und B $(18,9 \mathrm{mg} / \mathrm{g})$ lagen oberhalb des ausreichenden Bereichs nach Bergmann (1993). Auf Fläche D 
befanden sie sich dagegen in diesem ausreichenden Bereich, wobei der Wert im 1. Untersuchungsjahr mit $13,1 \mathrm{mg} / \mathrm{g}$ doppelt so hoch war wie im 2 . mit 6,6 mg/g.

Das Laub der Ebereschen-Varianten auf Fläche D (2006) enthielt zwischen 0,9 mg/g (V8) und 12,6 mg/g (V3) Calcium. Mit Ausnahme der Varianten 8-10 (Perlit-Kalk, Kompost, KompostKalk), in denen nur sehr geringe Calcium-Gehalte gemessen wurden, waren im Vergleich mit Werten für andere Laubbaumarten (Bergmann 1993) alle Varianten ausreichend mit Calcium versorgt. Diese in den Varianten V8, V9, und V10 vergleichsweise niedrigen Gehalte waren ebenso bei den Elementen Magnesium, Schwefel, Mangan und Natrium zu beobachten.

Mit Stockosorb® (V3) lag der Calcium-Gehalt deutlich über dem der Nullvariante (V1). Interessanterweise enthielten die Blätter der mit Kalk versorgten Varianten (V2, V4, V6, V8, V10) meist deutlich weniger oder höchstens ebensoviel Calcium wie die jeweils entsprechende Variante ohne Kalkung (V1, V3, V5, V7, V9).
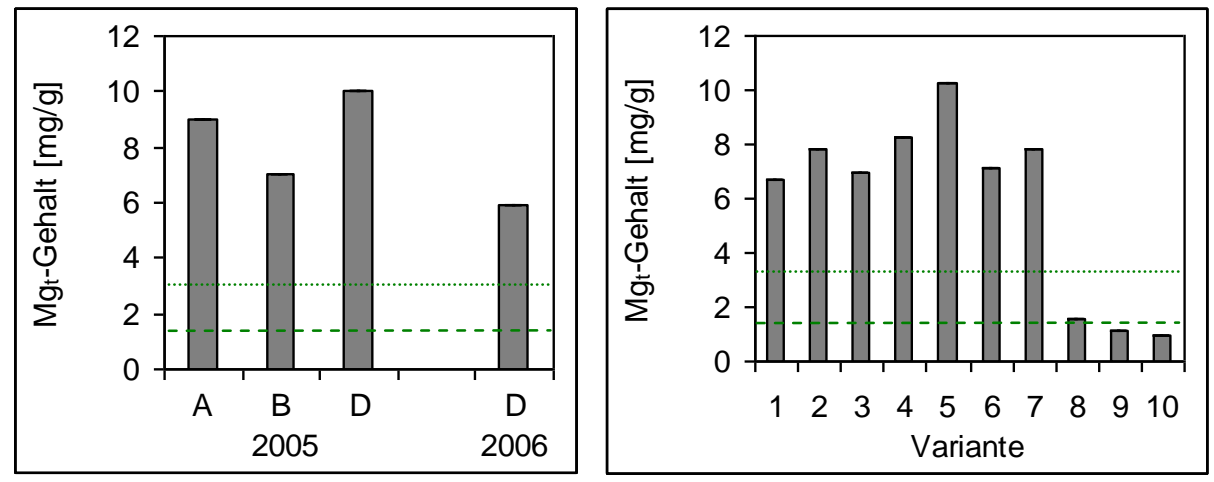

Obergrenze ausreichend

Untergrenze ausreichend (Bergmann 1993)

Abb. 61 links: Mgt-Gehalte [mg/g] im Laub der Ebereschen auf den Versuchsflächen A, B und D im 1. (2005) und auf Fläche D im 2. (2006) Vegetationsjahr (Mischproben); rechts: differenziert nach Varianten (s. S. 20) auf Fläche D im 2. Jahr (2006) (Mischproben)

Die gemessenen Magnesium-Anteile im Laub der Ebereschen (s. Abb. 61) auf Fläche A und D (2005) betrugen rund das 3-fache der Obergrenze ausreichender Gehalte laut Bergmann (1993). Die Gehalte auf Fläche B und D (2006) lagen etwas niedriger und etwa doppelt so hoch wie diese Obergrenze (3 mg/g).

In den Blättern der Ebereschen-Varianten auf Fläche D (2006) betrugen die Magnesium-Gehalte zwischen $1,0 \mathrm{mg} / \mathrm{g}$ (V10) und 10,2 mg/g (V5). In Variante V8 (Perlit-Kalk) mit 1,6 mg/g Magnesium lag der Gehalt innerhalb des bei anderen Laubbäumen ausreichenden Wertebereichs (Bergmann 1993). In der Kompost-Variante (V9) und der Kompost-Kalk-Variante (V10) waren die Magnesium-Gehalte demnach (knapp) nicht ausreichend, in allen übrigen Varianten dagegen deutlich höher als die obere Grenze des ausreichenden Bereichs. Diese in den Varianten V8, V9, und V10 vergleichsweise niedrigen Gehalte waren ebenso bei den Elementen Calcium, Schwefel, Mangan und Natrium zu beobachten.

Die mit Magnesiumkalk gedüngten Varianten V2 (Kalk) und V4 (Stockosorb®-Kalk) wiesen erwartungsgemäß höhere Magnesium-Gehalte auf als die nicht gekalkten Varianten V1 (Kontrolle) und V3 (Stockosorb®). Bei den übrigen „Varianten-Paaren“ war dies jedoch nicht zu beobachten. Der höchste Magnesium-Gehalt wurde zudem in der ohne Kalk-Gabe gepflanzten Variante V5 (Superabsorber) ermittelt. 


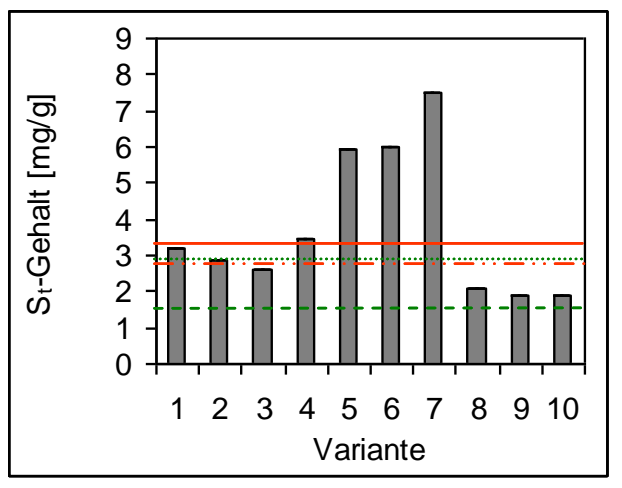

Toxizitätssymptome, Wachstumsrückgang bei Ahornen (van den Burg 1985, 1990) Obergrenze extrem bei Eichen (Heinsdorf 1996)

Obergrenze ausreichend/normal

Untergrenze ausreichend/normal bei Ahornen (van den Burg 1985, 1990)

Abb. 62: St-Gehalte [mg/g] im Laub der Ebereschen-Varianten (s. S. 20) auf Versuchsfläche D im 2. (2006) Vegetationsjahr (Mischproben)

Das Laub der Ebereschen auf Fläche D (2006) wies einen mittleren Schwefel-Gehalt von 3,7 $\mathrm{mg} / \mathrm{g}$ auf. Je nach Variante enthielt es zwischen 1,9 mg/g (V9, V10) und 7,5 mg/g (V7) Schwefel (s. Abb. 62). Der Schwefel-Gehalt in den Blättern der unbehandelten Kontrolle überstieg mit 3,2 mg/g die von Heinsdorf (1996) genannte obere Grenze einer Extremversorgung bei Eichen und kam dem Wert nahe, ab dem laut van den Burg $(1985,1990)$ bei Ahornen Toxizitätssymptome und Wachstumsrückgang festgestellt wurden oder möglich sind. Etwas darüber lag der Schwefel-Gehalt in der Stockosorb®-Kalk-Variante (V4) mit 3,5 mg/g, etwas darunter dagegen in der reinen Kalk-Variante (V2) mit 2,9 mg/g. Dieser Wert und der in der reinen Stocksorb®Variante (V3) ermittelte, noch etwas geringere Schwefel-Gehalt von 2,6 mg/g lagen bereits im Bereich ausreichender Normalgehalte für Ahorne laut van den Burg $(1985,1990)$, gleichzeitig aber etwas über (V2) oder im (V3) Extrembereich für Eichen laut Heinsdorf (1996). Deutlich geringer als in der Nullvariante (V1) waren die Schwefel-Gehalte in der Perlit-Kalk- (V8; 2,1 mg/kg), der Kompost- (V9; 1,9 mg/kg) und der Kompost-Kalk-Variante (V10; 1,9 mg/kg). Sie lagen ebenfalls im Bereich ausreichender Normalgehalte für Ahorne (van den Burg 1985, 1990) und gleichzeitig nur noch im Bereich einer Überversorgung bei Eichen (Heinsdorf 1996). Diese in den Varianten V8, V9, und V10 vergleichsweise niedrigen Gehalte waren ebenso bei den Elementen Calcium, Magnesium, Mangan und Natrium zu beobachten. Doppelt so hoch wie in der unbehandelten Kontrolle waren dagegen die Schwefel-Blattgehalte der beiden Superabsorber-Varianten V5 (Superabsorber) mit 5,9 mg/g und V6 (Superabsorber-Kalk) mit 6,0 mg/g. Die Werte lagen ebenso wie der mit 7,0 mg/g noch einmal deutlich höhere SchwefelGehalt in der reinen Perlit-Variante jenseits aller Klassifizierungen und sind wahrscheinlich als phytotoxisch einzustufen.

\section{Spurennährelemente, Mikronährstoffe ( $\mathrm{Fe}, \mathrm{Mn}, \mathrm{Zn}, \mathrm{Cu})$}

Der durchschnittliche Eisen-Gehalt im Laub der Ebereschen auf Fläche D (2006) lag bei 197 $\mathrm{mg} / \mathrm{kg}$. Je nach Variante wurden Werte zwischen $100 \mathrm{mg} / \mathrm{kg}$ (V9) und $403 \mathrm{mg} / \mathrm{kg}$ (V5) ermittelt (s. Abb. 63).

Gemessen an den Einstufungen der Eisenkonzentrationen in Ahorn-Blättern (van den Burg 1985, 1990) lagen die Eisen-Gehalte der meisten Varianten im Bereich ausreichender Normalgehalte $(63-212 \mathrm{mg} / \mathrm{kg})$. 

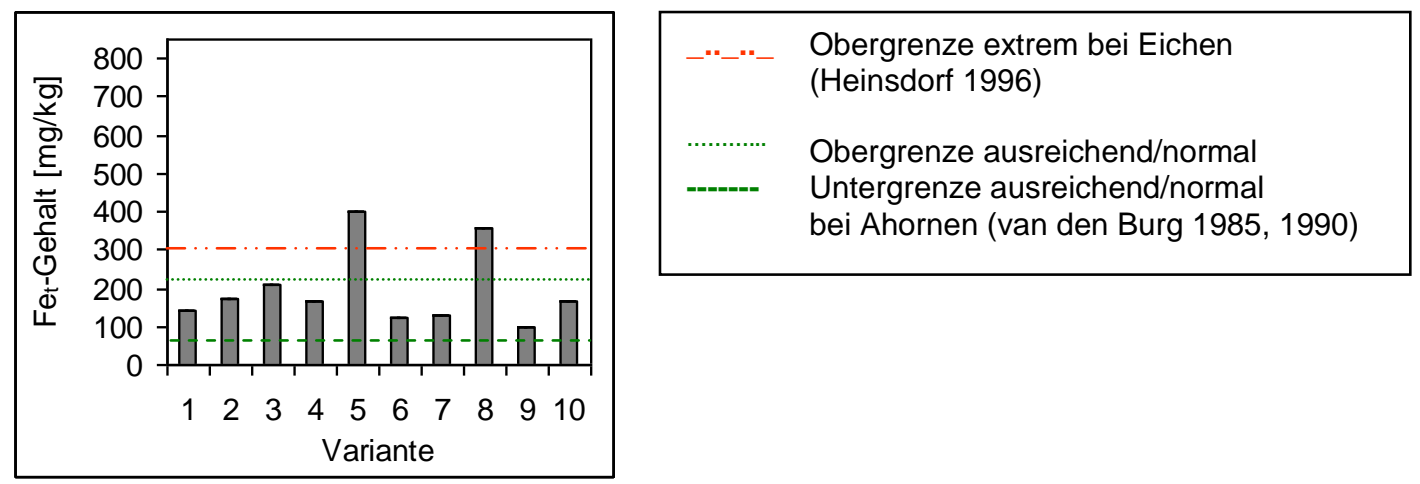

Abb. 63: $\mathrm{Fe}_{\mathrm{t}}-\mathrm{Gehalte}[\mathrm{mg} / \mathrm{kg}]$ im Laub der Ebereschen-Varianten (s. S. 20) auf Versuchsfläche D im 2. (2006) Vegetationsjahr (Mischproben)

Ausnahmen bildeten die Superabsorber-Variante (V5) mit $403 \mathrm{mg} / \mathrm{kg}$ und die Perlit-KalkVariante (V8) mit $356 \mathrm{mg} / \mathrm{kg}$; hier enthielten die Ebereschen-Blätter 2- bis 3-mal so viel Eisen wie in der unbehandelten Kontrolle. Die Werte lagen damit weit über dem bei Ahornen ausreichenden Bereich und überstiegen die Obergrenze extremer Gehalte bei Eichen. In den genannten Varianten waren auch relativ hohe Aluminium- und Chrom-Gehalte aufgefallen.
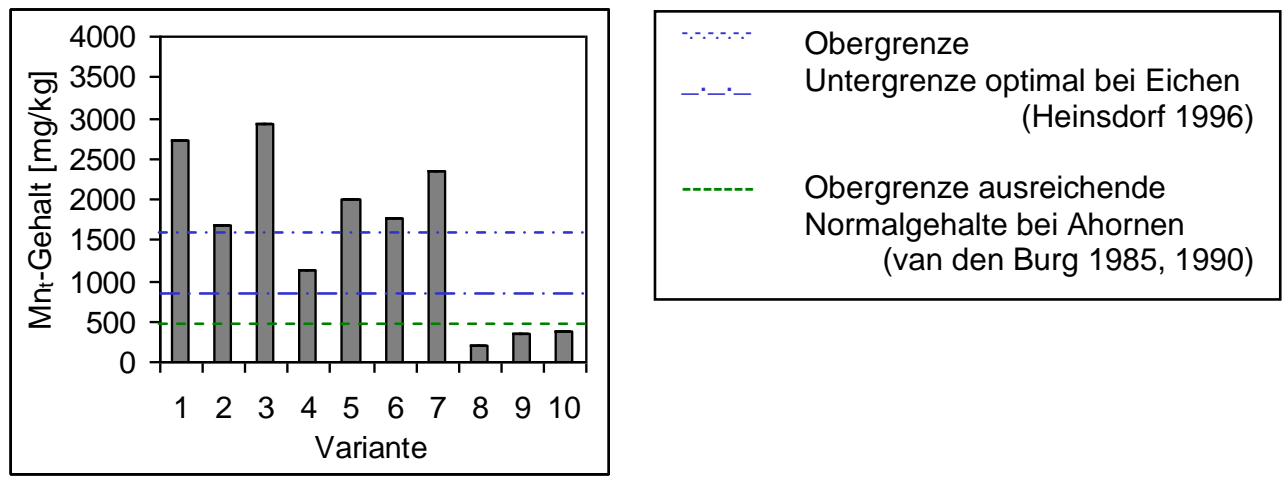

Abb. 64: $\mathrm{Mn}_{\mathrm{t}}$-Gehalte [mg/kg] im Laub der Ebereschen-Varianten (s. S. 20) auf Versuchsfläche D im 2. (2006) Vegetationsjahr (Mischproben)

Die im Laub der Ebereschen-Varianten auf Fläche D (2006) gemessenen Mangan-Gehalte (s. Abb. 64) schwankten sehr stark zwischen $195 \mathrm{mg} / \mathrm{kg}$ (V8) und $2931 \mathrm{mg} / \mathrm{kg}$ (V3). Im Mittel betrug der Mangan-Anteil in den Blättern $1551 \mathrm{mg} / \mathrm{kg}$. Damit lagen die Messwerte größtenteils weit über den beispielsweise in Bergmann (1993) (35-100 mg/kg) oder van den Burg (1985, 1990) (11-473 mg/kg) genannten ausreichenden Gehalten für andere Laubbäume. Der bei Heinsdorf (1996) für Eichen angegebene Optimalbereich wurde dagegen von drei Varianten unter-, von zweien knapp und von vier der Varianten deutlich überschritten. Eine Phytotoxizität dieser sehr hohen Gehalte ist zumindest wahrscheinlich. In Variante V2 (Kalk) und V4 (Stockosorb®-Kalk) lagen die Werte gegenüber der Nullvariante (V1) und der reinen Stockosorb®-Variante (V3) niedriger. V4 lag damit im, V2 knapp über dem Optimalbereich bei Eichen. In beiden Superabsorber-Varianten (V5, V6) lag der Mangan-Gehalt etwas niedriger als in der unbehandelten Kontrolle, überschritt aber auch den Optimalbereich bei Eichen. Die PerlitGabe (V7) senkte den Mangan-Gehalt gegenüber der Nullvariante ebenfalls etwas. Die Einmischung von Perlit und Kalk (V8) sowie die Kompost-Gaben (V9 ohne, V10 mit zusätzlicher Kalk-Gabe) führten zu Mangan-Gehalten, die nur einen Bruchteil des Gehaltes in der unbehandelten Kontrolle betrugen (V8: $195 \mathrm{mg} / \mathrm{kg}$, V9: 346 mg/kg, V10: 388 mg/kg gegenüber V1: $2714 \mathrm{mg} / \mathrm{kg})$. Die Werte lagen innerhalb der nach van den Burg $(1985,1990)$ bei Ahornen 
ausreichenden Mangan-Gehalte (11-473 mg/kg) sowie unterhalb des Optimalbereichs für Eichen laut Heinsdorf (1996). Diese in den Varianten V8, V9, und V10 vergleichsweise niedrigen Gehalte waren ebenso bei den Elementen Calcium, Magnesium, Schwefel und Natrium zu beobachten.
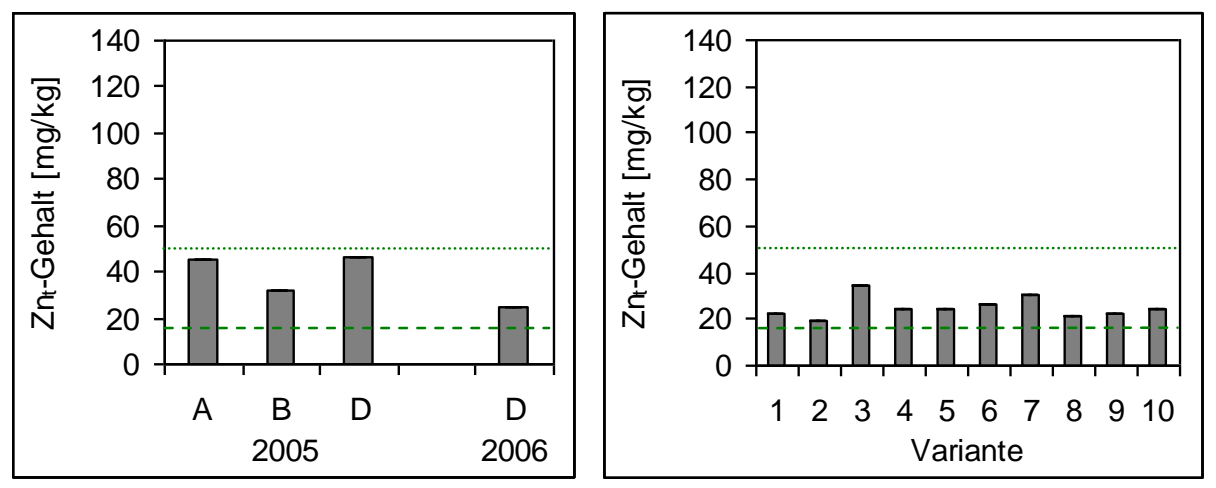

Obergrenze ausreichend

Untergrenze ausreichend (Bergmann 1993)

Abb. 65 links: $\mathrm{Zn}_{\mathrm{t}}-\mathrm{Gehalte}[\mathrm{mg} / \mathrm{kg}]$ im Laub der Ebereschen auf den Versuchsflächen A, B und D im 1. (2005) und auf Fläche D im 2. (2006) Vegetationsjahr (Mischproben); rechts: differenziert nach Varianten (s. S. 20) auf Fläche D im 2. Jahr (2006) (Mischproben)

Die Zink-Gehalte in den Blättern der Ebereschen (s. Abb. 65) lagen sämtlich in dem bei Bergmann (1993) für verschiedene Laubbaumarten als ausreichend angegebenen Bereich. Wie auch schon bei den Stickstoff- und den Magnesium-Gehalten waren dabei die Zink-Gehalte auf Fläche A und D (2005) höher als auf Fläche B und D (2006).

Im Laub der Ebereschen-Varianten auf Fläche D (2006) wurden Zink-Blattgehalte zwischen 19,8 $\mathrm{mg} / \mathrm{kg}$ (V2) und $34,6 \mathrm{mg} / \mathrm{kg}$ (V3) gemessen. Alle Werte lagen innerhalb des bei Bergmann (1993) für verschiedene Laubbaumarten als ausreichend angegebenen Bereichs.

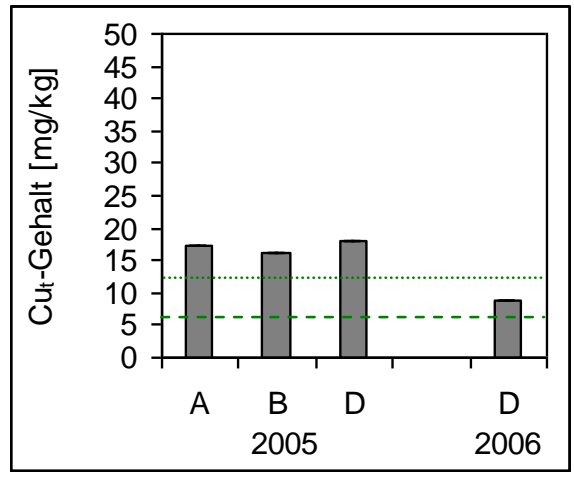

Obergrenze ausreichend

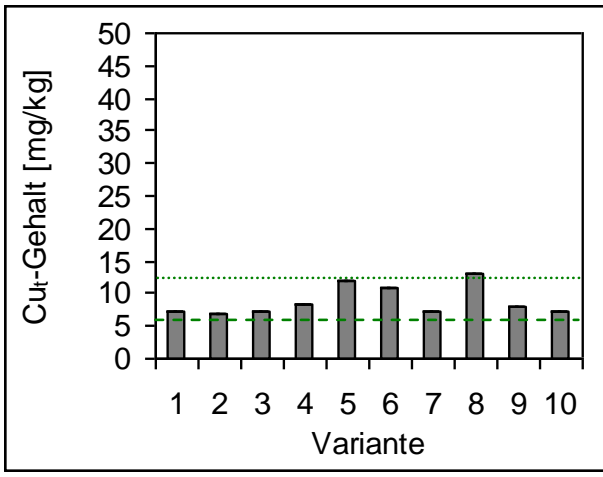

Untergrenze ausreichend (Bergmann 1993)

Abb. 66 links: $\mathrm{Cu}_{\mathrm{t}}-\mathrm{Gehalte}[\mathrm{mg} / \mathrm{kg}$ ] im Laub der Ebereschen auf den Versuchsflächen A, B und D im 1. (2005) und auf Fläche D im 2. (2006) Vegetationsjahr (Mischproben); rechts: differenziert nach Varianten (s. S. 20) auf Fläche D im 2. Jahr (2006) (Mischproben)

Die Kupfer-Gehalte des Ebereschen-Laubs (s. Abb. 66) lagen im 1. Untersuchungsjahr (2005) auf allen drei Versuchsflächen mit 17,2 mg/kg (A), 16,0 mg/kg (B) und 18,0 mg/kg (D) deutlich oberhalb des ausreichenden Bereichs für andere Laubbaumarten (Bergmann 1993: 6-12 
mg/kg). Nach Smidt (1999) lagen sie jedoch noch innerhalb der Normalgehalte in Pflanzen (15$20 \mathrm{mg} / \mathrm{kg}$ ). Auch blieben die Werte unterhalb des in Alloway (1999) genannten Bereichs kritischer Konzentrationen (20-100 mg/kg). Im 2. Untersuchungsjahr (2006) betrug der durchschnittliche Kupfer-Gehalt der Ebereschen auf Fläche D erheblich geringere 8,8 mg/kg und lag damit im ausreichenden Bereich nach Bergmann (1993).

Im Laub der Ebereschen-Varianten auf Fläche D (2006) wurden Kupfer-Gehalte zwischen 7,1 $\mathrm{mg} / \mathrm{kg}$ (V10) und 12,9 mg/kg (V8) gemessen. In den Superabsorber-Varianten (V5: Superabsorber, V6: Superabsorber-Kalk) sowie in der Perlit-Kalk-Variante (V8) lagen die Werte deutlich höher als in der unbehandelten Kontrolle und bereits an der oberen Grenze des in Laubbäumen ausreichenden Kupfer-Gehaltes laut Bergmann (1993) (V5) bzw. leicht darüber (V8). Alle übrigen Kupfer-Werte lagen innerhalb dieses ausreichenden Bereichs.

\section{Potentiell nützliche Elemente (Al, Na, Ni, Co)}

Die Aluminium-Gehalte im Laub der Ebereschen-Varianten (s. Abb. 67) auf Fläche D (2006) reichten von $173 \mathrm{mg} / \mathrm{kg}$ (V6) bis $813 \mathrm{mg} / \mathrm{kg}$ (V8); der Durchschnittswert betrug $351 \mathrm{mg} / \mathrm{kg}$. Nach Heinsdorf (1996) liegt bei Eichen die obere Grenze einer Überversorgung mit Aluminium bei $119 \mathrm{mg} / \mathrm{kg}$ trockener Blattmasse. Die Aluminium-Gehalte sämtlicher Varianten überschritten diese Grenze mehr oder weniger deutlich, wobei kein Bodenhilfsstoff den Wert gegenüber der unbehandelten Kontrolle $(175 \mathrm{mg} / \mathrm{kg})$ senken konnte, im Gegenteil: Vor allem bei den mit Superabsorber (V5) sowie den mit Perlit und Kalk (V8) gepflanzten Ebereschen wurden sehr hohe Aluminium-Gehalte von $717 \mathrm{mg} / \mathrm{kg}$ bzw. $813 \mathrm{mg} / \mathrm{kg}$ ermittelt, was dem mehr als 4fachen des Kontrollwertes entspricht. In diesen Varianten waren auch vergleichsweise hohe Eisen- und Chrom-Gehalte aufgefallen. Mit Stockosorb® (V3), Kompost (V9) und Kompost-Kalk (V10) wurden gegenüber der Nullvariante ebenfalls erhöhte Aluminium-Gehalte gemessen.
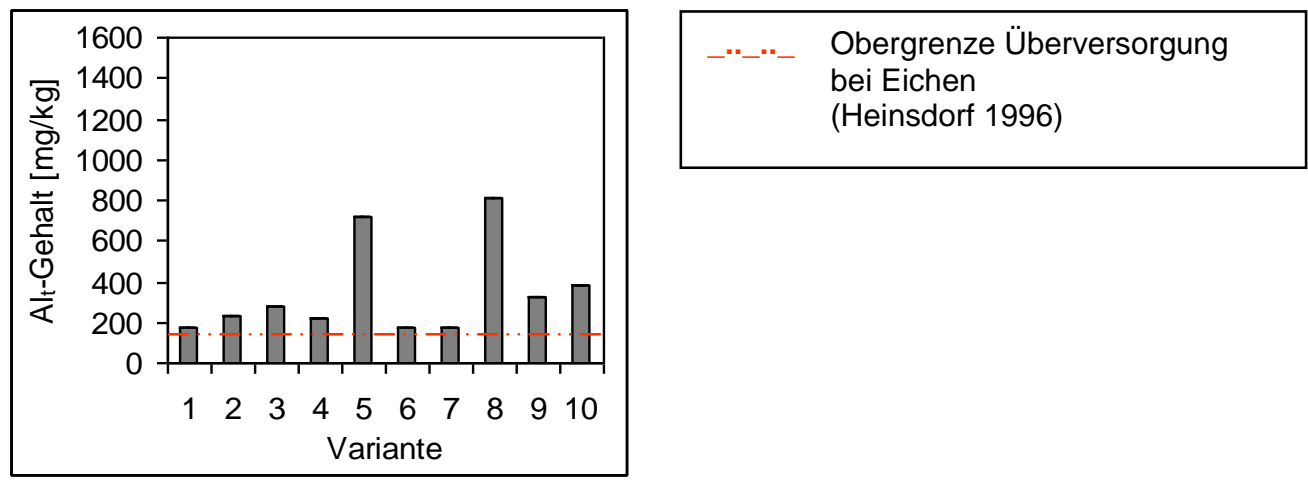

Abb. 67: Alt-Gehalte [mg/kg] im Laub der Ebereschen-Varianten (s. S. 20) auf Versuchsfläche D im 2. (2006) Vegetationsjahr (Mischproben)

Bei der Frage nach einer möglichen Aluminium-Toxizität weist Bergmann (1993) darauf hin, dass Phosphor-Mangel bei - wie in diesem Fall, s. S. 48 - ausreichend versorgten Böden ein sichereres Zeichen für Aluminium-Toxizität darstellt als der tatsächliche Aluminium-Gehalt in Assimilationsorganen. Demnach wäre bei allen Varianten außer der Kompost-Kalk-Kombination (V10) von $\mathrm{Al}^{3+-U ̈ b e r s c h u s s ~ u n d ~ A l u m i n i u m-T o x i z i t a ̈ t ~ a u s z u g e h e n . ~}$ 

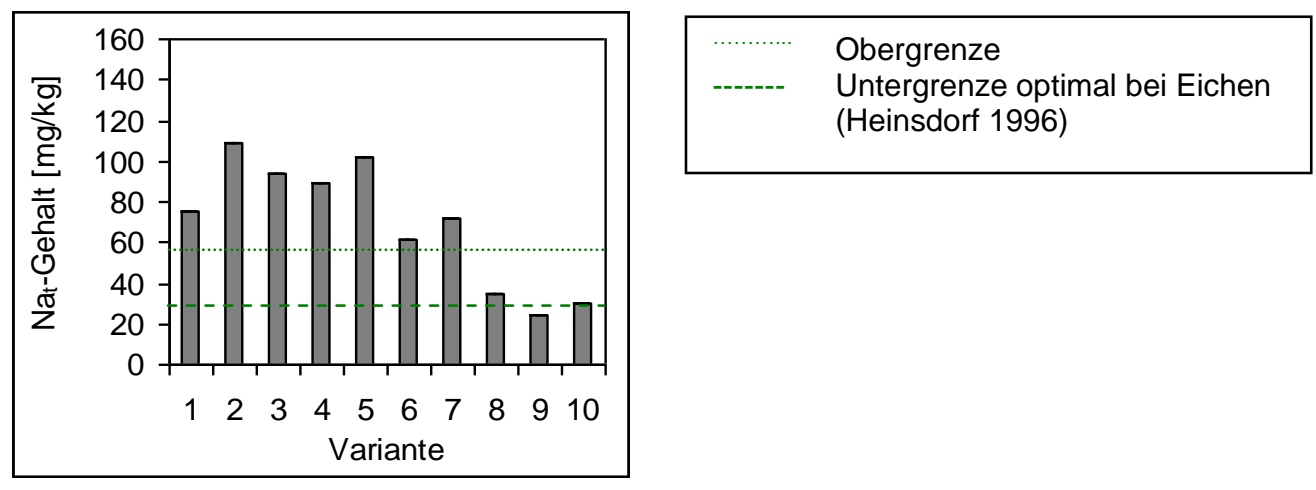

Abb. 68: $\mathrm{Na}_{\mathrm{t}}$-Gehalte $[\mathrm{mg} / \mathrm{kg}]$ im Laub der Ebereschen-Varianten (s. S. 20) auf Versuchsfläche D im 2. (2006) Vegetationsjahr (Mischproben)

Die in den Blättern der Ebereschen ermittelten Natrium-Anteile (s. Abb. 68) bewegten sich zwischen 24,4 mg/kg (V9) und 108,7 mg/kg (V2) und betrugen im Durchschnitt 69,1 mg/kg. Mit Perlit und Kalk (V8), mit Kompost (V9) sowie mit Kompost und Kalk (V10) lagen die Werte bei $34,8 \mathrm{mg} / \mathrm{kg}, 24,4 \mathrm{mg} / \mathrm{kg}$ bzw. 29,8 mg/kg und damit deutlich niedriger als in der Nullvariante (V1) mit 75,1 mg/kg. Diese in den Varianten V8, V9, und V10 vergleichsweise niedrigen Gehalte waren ebenso bei den Elementen Calcium, Magnesium, Schwefel und Mangan zu beobachten. Die Natrium-Gehalte in Variante V8 und V10 lagen damit im Optimalbereich für Eichen (28-58 mg/kg) nach Heinsdorf (1996), der Wert in Variante V9 im Bereich einer Unterversorgung, während alle übrigen Varianten Natrium-Gehalte im Bereich einer Überversorgung aufwiesen. Deutlich höhere Gehalte als die unbehandelte Kontrolle (V1) wurden in der Kalk-Variante (V2: $108,7 \mathrm{mg} / \mathrm{kg}$ ), der Superabsorber-Variante (V5: 101,6 mg/kg) und den Stockosorb®-Varianten (V3: $94,0 \mathrm{mg} / \mathrm{kg}, \mathrm{V} 4: 88,8 \mathrm{mg} / \mathrm{kg}$ ) ermittelt.
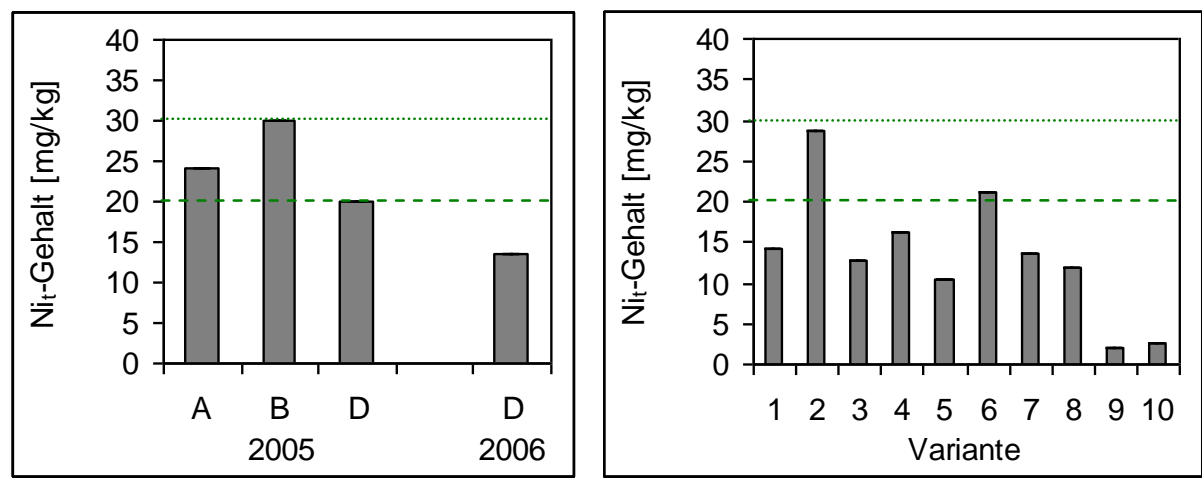

Obergrenze Normalgehalte

Untergrenze Normalgehalte (Smidt 1999)

Abb. 69 links: $\mathrm{Ni}_{\mathrm{t}}$-Gehalte [mg/kg] im Laub der Ebereschen auf den Versuchsflächen A, B und D im 1. (2005) und auf Fläche D im 2. (2006) Vegetationsjahr (Mischproben); rechts: differenziert nach Varianten (s. S. 20) auf Fläche D im 2. Jahr (2006) (Mischproben)

Die Nickel-Gehalte des Ebereschen-Laubs (s. Abb. 69) lagen im 1. Untersuchungsjahr (2005) auf allen drei Flächen mit 24,1 mg/kg (A), 29,9 mg/kg (B) und 20,2 mg/kg (D) im Bereich der Normalgehalte in Pflanzen nach Smidt (1999), wobei der Wert auf Fläche B dessen Obergrenze, der auf Fläche D dessen Untergrenze entsprach. Im 2. Untersuchungsjahr war der mittlere Nickel-Gehalt auf Fläche D niedriger und lag bei $13,4 \mathrm{mg} / \mathrm{kg}$. 
In den einzelnen Ebereschen-Varianten auf Fläche D (2006) wurden Nickel-Blattgehalte zwischen 1,9 mg/kg (V9) und 28,6 mg/kg (V2) gemessen. Mit Kalk-Düngung (V2) enthielt das Laub mit 28,6 mg/kg etwa doppelt so viel Nickel wie die unbehandelte Kontrolle (V1) mit 14,1 $\mathrm{mg} / \mathrm{kg}$. Die kombinierte Pflanzbeigabe von Superabsorber und Kalk (V6) führte mit 21,2 mg/kg zu etwa 50 \% höheren Nickel-Gehalten gegenüber der Nullvariante. Mit Ausnahme dieser beiden Varianten V2 und V6 lagen die Nickel-Gehalte aller Varianten deutlich unterhalb der Normalgehalte in Pflanzen nach Smidt (1999). In den Kompost-Varianten (V9, V10) betrug der Nickel-Gehalt mit 1,9 mg/kg bzw. 2,6 mg/kg nur einen Bruchteil des Gehaltes in der Kontrolle.
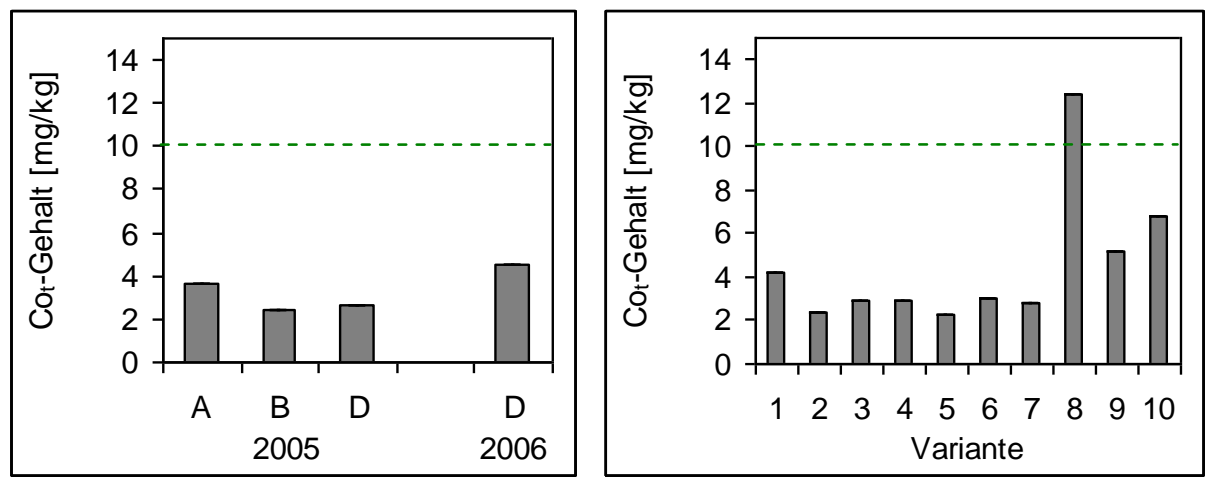

Untergrenze Normalgehalte (Smidt 1999)

Abb. 70 links: $\mathrm{Co}_{\mathrm{t}}$-Gehalte $[\mathrm{mg} / \mathrm{kg}]$ im Laub der Ebereschen auf den Versuchsflächen A, B und D im 1. (2005) und auf Fläche D im 2. (2006) Vegetationsjahr (Mischproben); rechts: differenziert nach Varianten (s. S. 20) auf Fläche D im 2. Jahr (2006) (Mischproben)

Die in den Blättern der Ebereschen gemessenen Kobalt-Gehalte (s. Abb. 70) lagen auf allen drei Versuchsflächen und in beiden Untersuchungsjahren mit 3,6 mg/kg (A), 2,4 mg/kg (B) und 2,7 $\mathrm{mg} / \mathrm{kg}$ (D: 2005) bzw. 4,5 mg/kg (D: 2006) weit unterhalb der Normalgehalte (10-20 mg/kg) nach Smidt (1999). Der Kobalt-Gehalt war damit der einzige Element-Gehalt im Laub der Ebereschen auf Fläche D, der im 2. Jahr (2006) höher war als im ersten (2005). Je nach Variante wurden in den Blättern der Ebereschen auf Fläche D (2006) Kobalt-Gehalte zwischen 2,2 mg/kg (V5) und 12,4 mg/kg (V8) ermittelt. Mit Ausnahme der Perlit-Kalk-Variante (V8), in der mit 12,4 $\mathrm{mg} / \mathrm{kg}$ ein Kobalt-Gehalt gemessen wurde, der deutlich höher als in den übrigen Varianten lag und das 3-fache des Kontrollwertes $(4,2 \mathrm{mg} / \mathrm{kg})$ betrug, lagen die Werte aller Varianten weit unterhalb der Normalgehalte (10-20 mg/kg) nach Smidt (1999). Ebenfalls gegenüber der Kontrolle erhöhte Kobalt-Gehalte wiesen die Kompost-Varianten (V9, V10) mit 5,1 bzw. 6,8 $\mathrm{mg} / \mathrm{kg}$ auf. In den Varianten V2-V7 waren die ermittelten Werte dagegen geringer als in der Nullvariante.

\section{Toxisch wirkende Schwermetalle ohne Nährelementfunktion ( $\mathrm{Pb}, \mathrm{Cd}, \mathrm{Cr})$}

Nur bei der ersten Untersuchung (2005) auf Fläche D ließ sich im Laub der Ebereschen ein messbarer Blei-Gehalt von $2,7 \mathrm{mg} / \mathrm{kg}$ feststellen. Nach den sehr allgemeinen Normalgehalten von Schwermetallen in Pflanzen (in Smidt 1999) sowie den ebenso allgemeinen kritischen Konzentrationen von Schwermetallen in Pflanzen (Alloway 1999) wären damit weder normale (10-20 mg/kg) noch kritische (30-300 mg/kg) Blei-Gehalte erreicht. Zieht man die im Rahmen des Deutschen Waldbodenberichtes in Buchenblättern gemessenen Blei-Gehalte als Vergleich heran, so lag dieser Wert zwischen dem 75er und dem 90er-Perzentil (BMELF 1997b). 
Die Cadmium-Gehalte in den Blättern sämtlicher beprobter Ebereschen lagen unterhalb der Nachweisgrenze für dieses Element.
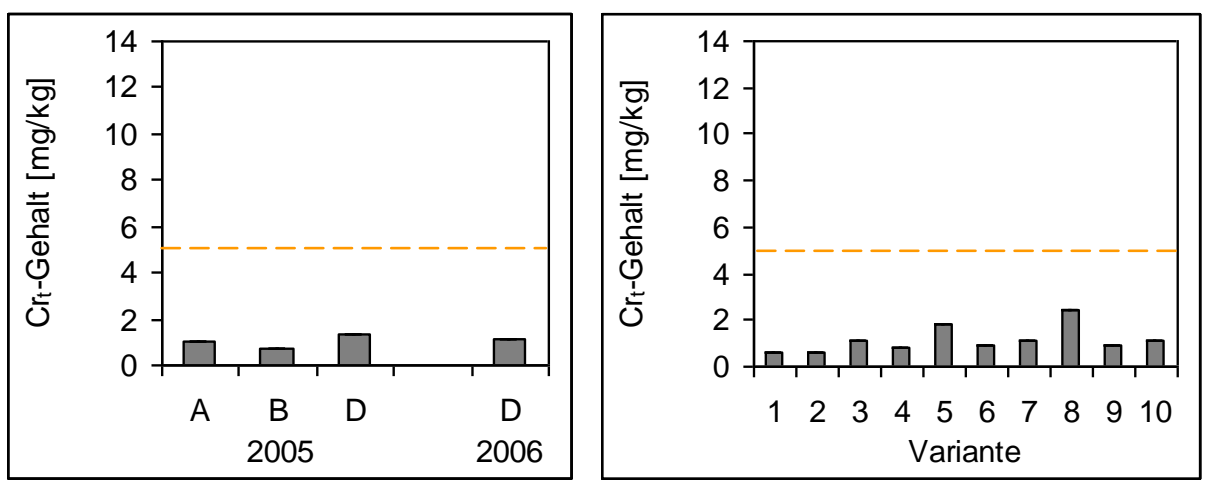

Untergrenze kritischer Bereich in Pflanzen (Alloway 1999)

Abb. 71 links: $\mathrm{Cr}_{\mathrm{t}}-$ Gehalte [mg/kg] im Laub der Ebereschen auf den Versuchsflächen A, B und D im 1. (2005) und auf Fläche D im 2. (2006) Vegetationsjahr (Mischproben); rechts: differenziert nach Varianten (s. S. 20) auf Fläche D im 2. Jahr (2006) (Mischproben)

Die in den Blättern der Ebereschen gemessenen Chrom-Gehalte (s. Abb. 71) lagen auf allen drei Versuchsflächen und in beiden Untersuchungsjahren mit $1,0 \mathrm{mg} / \mathrm{kg}(\mathrm{A}), 0,7 \mathrm{mg} / \mathrm{kg}$ (B) und 1,3 $\mathrm{mg} / \mathrm{kg}$ (D: 2005) bzw. 1,1 mg/kg (D: 2006) deutlich niedriger als die Untergrenze des Bereichs kritischer Konzentrationen in Pflanzen (5-30 mg/kg) in Alloway (1999).

Auch die Chrom-Gehalte im Laub der Ebereschen-Varianten auf Fläche D (2006) lagen mit Werten zwischen $0,6 \mathrm{mg} / \mathrm{kg}$ (V2) und 2,5 mg/kg (V8) deutlich unterhalb dieses Bereichs. Mit Superabsorber (V5) sowie mit Perlit und Kalk (V8) betrug der Chrom-Anteil in der BlattTrockenmasse mit 1,8 mg/kg bzw. 2,5 mg/kg das 3- bis 4-fache des Wertes in der unbehandelten Kontrolle (V1) mit 0,7 mg/kg. In diesen Varianten waren auch die vergleichsweise hohen Eisen- und Aluminium-Gehalte aufgefallen.

\subsubsection{Schwarz-Erle}

Im Folgenden werden die Ergebnisse der Blattanalysen (Mischproben, s. S. 26) zur Versorgung und Belastung der Erlen auf den drei Versuchsflächen insgesamt sowie innerhalb der VersuchsVarianten auf Versuchsfläche D dargestellt.

\section{Hauptnährelemente, Makronährstoffe (N, P, K, Ca, Mg, S)}

Die im Laub der Erlen auf allen drei Versuchsflächen gemessenen mittleren Stickstoff-Gehalte (s. Abb. 72) lagen dicht beieinander zwischen 30,5 mg/g (Fläche B) und 31,3 mg/g (Fläche A) trockener Blattmasse. Im Vergleich mit den Bewertungen von Stickstoff-Gehalten verschiedener anderer Laubbaumarten in Bergmann (1993) ist von einer ausreichenden Versorgung auszugehen. Grund für die vergleichsweise hohen Werte ist die Fähigkeit der Erlen, Symbiosen mit Luftstickstoff-bindenden Bakterien (Actinomyceten) einzugehen, was diese Baumart unabhängig vom Stickstoffangebot des Standortes macht. 

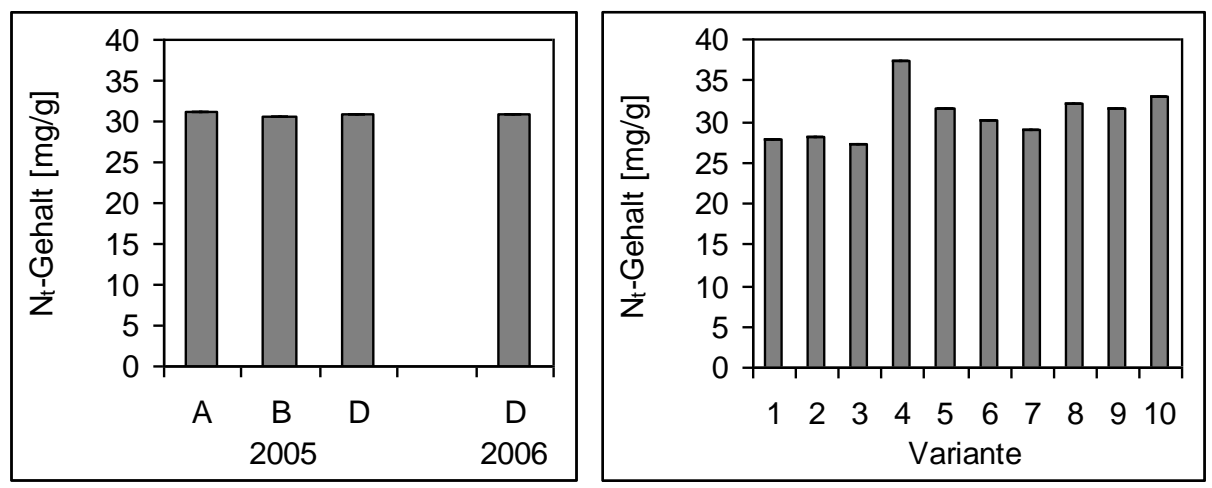

Abb. 72 links: $\mathrm{N}_{\mathrm{t}}-\mathrm{Gehalte}[\mathrm{mg} / \mathrm{g}]$ im Laub der Erlen auf den Versuchsflächen A, B und D im 1. (2005) und auf Fläche D im 2. (2006) Vegetationsjahr (Mischproben); rechts: differenziert nach Varianten (s. S. 20) auf Fläche D im 2. Jahr (2006) (Mischproben)

Die meisten der im 2. Versuchsjahr (2006) in den einzelnen Varianten auf Versuchsfläche D ermittelten Stickstoff-Gehalte reichten von $27,3 \mathrm{mg} / \mathrm{g}$ bis $32,9 \mathrm{mg} / \mathrm{g}$ (in aufsteigender Reihenfolge: V3, V1, V2, V7, V6, V5, V9, V8, V10, V4); nur in der Stockosorb®-Kalk-Variante (V4) wurde mit 37,5 mg/g ein noch deutlich höherer Wert gemessen. Von einer ausreichenden Versorgung sowohl der unbehandelten Kontrolle als auch aller Behandlungsvarianten ist aus dem genannten Grund auszugehen.
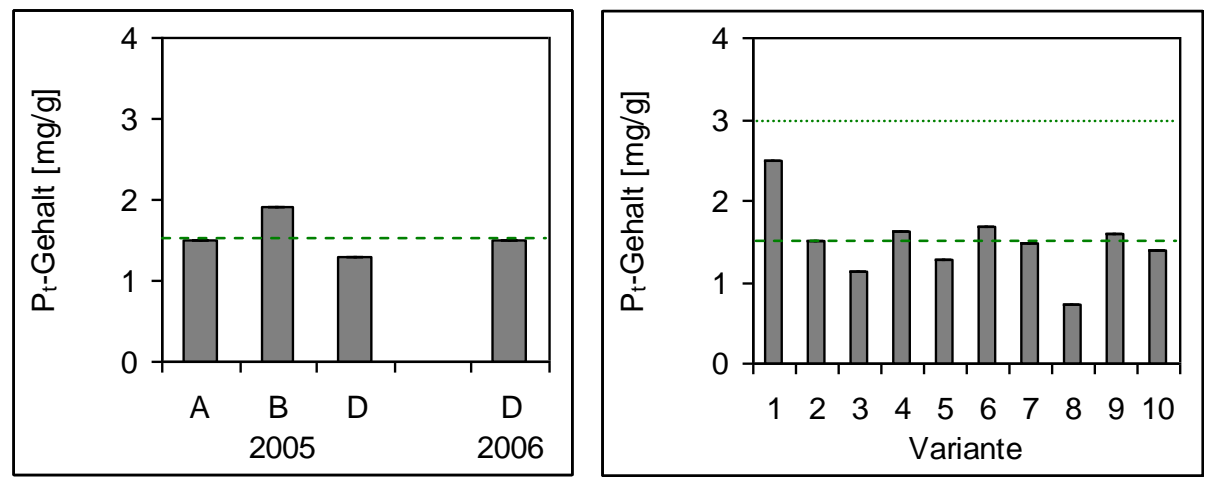

\footnotetext{
....... Obergrenze

------ $\quad$ Untergrenze ausreichend (Bergmann 1993)
}

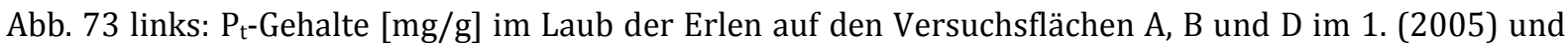
auf Fläche D im 2. (2006) Vegetationsjahr (Mischproben); rechts: differenziert nach Varianten (s. S. 20) auf Fläche D im 2. Jahr (2006) (Mischproben)

Der mittlere Phosphor-Gehalt in den Erlen-Blättern (s. Abb. 73) war nur auf Fläche B (1,9 mg/g) eindeutig ausreichend laut Bergmann (1993). Die auf Fläche A und D (2006) ermittelten Werte markierten mit 1,5 mg/g die untere Grenze dieses ausreichenden Bereichs. In 2005 war der durchschnittliche Phosphor-Gehalt auf Fläche D mit 1,3 mg/g dagegen nicht ausreichend.

Bei Beprobung der einzelnen Varianten auf Fläche D in 2006 wurde der mit 2,5 mg/g höchste, nach Bergmann (1993) voll ausreichende Phosphor-Gehalt interessanterweise in der unbehandelten Kontrolle gemessen. Alle Behandlungsvarianten wiesen deutlich niedrigere Werte auf, die bis hinunter zu nicht mehr ausreichenden $0,7 \mathrm{mg} / \mathrm{g}$ in der Perlit-Kalk-Variante (V8) reichten. Ebenfalls nicht ausreichend waren die Phosphor-Gehalte in den reinen Wasserspeichersubstanz-Varianten (V3: Stockosorb®, V5: Superabsorber) mit 1,1 mg/g bzw. 
$1,3 \mathrm{mg} / \mathrm{g}$. Auch der Gehalt in den mit Kompost und Kalk (V10) behandelten Erlen lag mit 1,4 $\mathrm{mg} / \mathrm{g}$ noch knapp unterhalb des ausreichenden Bereichs.

Bei den Wasserspeichersubstanz-Varianten wurden in der jeweiligen Variante mit Kalk-Gabe (V4: Stockosorb®-Kalk, V6: Superabsorber-Kalk) mit 1,6 mg/g bzw. 1,7 mg/g höhere (und nach Bergmann (1993) knapp ausreichende) Phosphor-Gehalte gemessen als in den kalkfreien Varianten. Bei den Perlit- und Kompost-Behandlungen verhielt es sich genau umgekehrt: In den Varianten ohne Kalk-Gabe (V7: Perlit, V9: Kompost) waren die ermittelten Phosphor-Gehalte mit $1,5 \mathrm{mg} / \mathrm{g}$ bzw. $1,6 \mathrm{mg} / \mathrm{g}$ höher als in den gekalkten Varianten und knapp ausreichend nach Bergmann (1993).
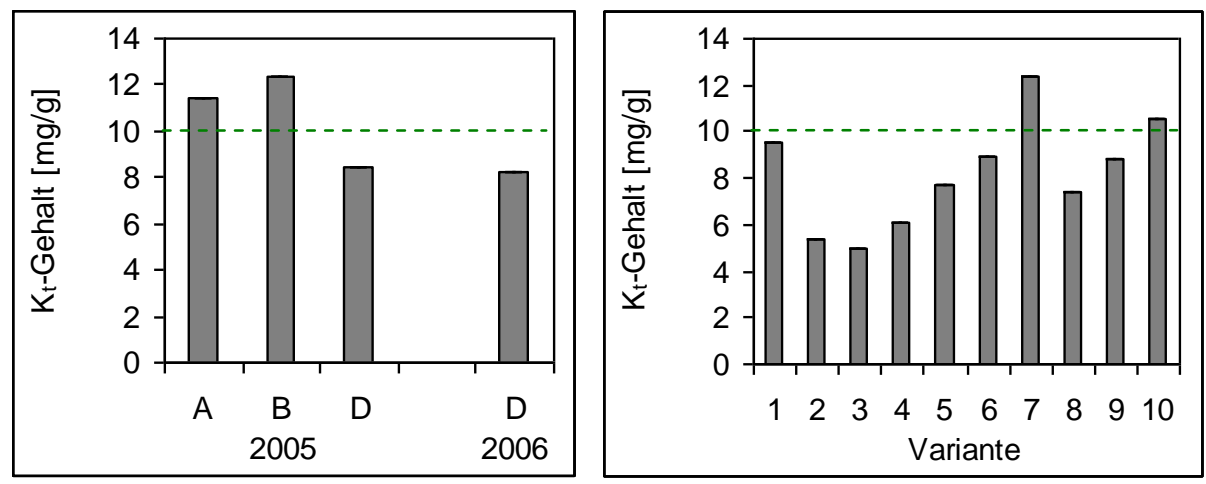

Untergrenze ausreichend (Bergmann 1993)

Abb. 74 links: $\mathrm{K}_{\mathrm{t}}-\mathrm{Gehalte}[\mathrm{mg} / \mathrm{g}]$ im Laub der Erlen auf den Versuchsflächen A, B und D im 1. (2005) und auf Fläche D im 2. (2006) Vegetationsjahr (Mischproben); rechts: differenziert nach Varianten (s. S. 20) auf Fläche D im 2. Jahr (2006) (Mischproben)

Auf den Versuchsflächen A und B wurden in den Erlen-Blättern ausreichende (Bergmann 1993) mittlere Kalium-Gehalte (s. Abb. 74) von 11,4 mg/g bzw. 12,4 mg/g gemessen. Auf Fläche D war die Versorgung in beiden Aufnahmejahren mit durchschnittlich 8,4 mg/g bzw. 8,2 mg/g dagegen nicht ausreichend.

In den einzelnen Varianten auf Fläche D (2006) lagen die Kalium-Gehalte der Erlen-Blätter zwischen 5,0 mg/g (V3) und 12,4 mg/g (V7). Nur in der Kompost-Kalk-Variante (V10) und in der Perlit-Variante (V7) wurden mit 10,6 mg/g bzw. 12,4 mg/g ausreichende Werte erreicht. Die übrigen Behandlungsvarianten wiesen teilweise deutlich geringere Kalium-Blattgehalte auf; die niedrigsten Werte lagen zwischen $5 \mathrm{mg} / \mathrm{g}$ und $6 \mathrm{mg} / \mathrm{g}$ und wurden in der Kalk-Variante (V2) sowie den Stockosorb®-Varianten (V3: Stockosorb®, V4: Stockosorb®-Kalk) ermittelt. 

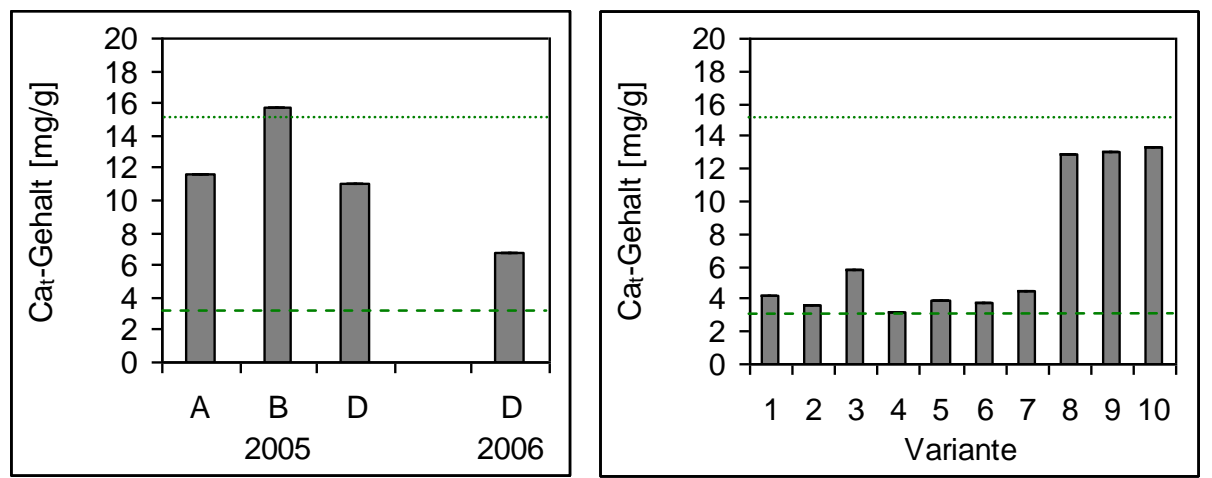

....... Obergrenze

------ Untergrenze ausreichend (Bergmann 1993)

Abb. 75 links: Cat-Gehalte [mg/g] im Laub der Erlen auf den Versuchsflächen A, B und D im 1. (2005) und auf Fläche D im 2. (2006) Vegetationsjahr (Mischproben); rechts: differenziert nach Varianten (s. S. 20) auf Fläche D im 2. Jahr (2006) (Mischproben)

Mit im Durchschnitt 15,7 mg Calcium pro Gramm trockener Blattmasse (s. Abb. 75) waren die Erlen auf Fläche B mehr als ausreichend (Bergmann 1993) versorgt. Auf den Flächen A und D lagen die Werte mit 11,6 mg/g (A), 11,1 mg/g (D 2005) und deutlich geringeren 6,8 mg/g auf Fläche D im 2. Untersuchungsjahr (2006) sämtlich im ausreichenden Bereich.

Die in 2006 auf Fläche D für jede Variante erfassten Calcium-Gehalte der Erlen-Blätter betrugen zwischen 3,1 mg/g (V4) und 13,4 mg/g (V10). Die unbehandelte Kontrolle (V1) sowie ein großer Teil der Behandlungsvarianten wiesen mit 3,1 mg/g bis 4,5 mg/g Werte knapp innerhalb des ausreichenden Bereichs auf. Ein mit $5,9 \mathrm{mg} / \mathrm{g}$ etwas höherer Calcium-Gehalt wurde in der Stockosorb®-Variante (V3) gemessen. Mit Werten um $13 \mathrm{mg} / \mathrm{g}$ mehr als 3-mal so hoch wie in der Kontrolle lagen die Calcium-Blattgehalte in den Varianten (V8: Perlit-Kalk, V9: Kompost, V10: Kompost-Kalk), die mit Bodenhilfsstoffen zur Bodenlockerung sowie zur Erhöhung des Boden-pH-Wertes angelegt wurden (im Gegenzug wurden in diesen Varianten die Mg-, S-, Cu-, $\mathrm{Al}-, \mathrm{Ni}-$, Co- und Cr-Aufnahmen stark gesenkt). Die Kalk-Gabe an sich (V2 sowie zusätzlich in V4, V6, V8, V10) sorgte im Jahr nach der Anlage nicht (mehr) für eine erkennbare Erhöhung der Calcium-Gehalte. 

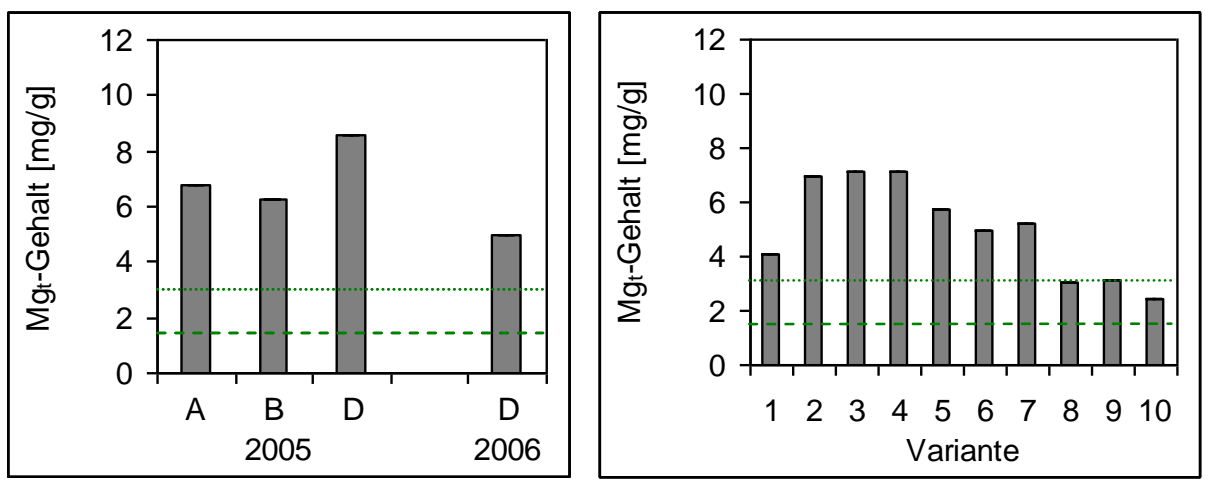

Obergrenze

Untergrenze ausreichend (Bergmann 1993)

Abb. 76 links: $\mathrm{Mg}_{\mathrm{t}}$-Gehalte [mg/g] im Laub der Erlen auf den Versuchsflächen A, B und D im 1. (2005) und auf Fläche D im 2. (2006) Vegetationsjahr (Mischproben); rechts: differenziert nach Varianten (s. S. 20) auf Fläche D im 2. Jahr (2006) (Mischproben)

Die durchschnittlichen Magnesium-Gehalte im Laub der Erlen (s. Abb. 76) auf Fläche A (6,8 $\mathrm{mg} / \mathrm{g})$, Fläche B $(6,3 \mathrm{mg} / \mathrm{g})$ und Fläche D $(8,6 \mathrm{mg} / \mathrm{g})$ im 1. Versuchsjahr (2005) sowie auf Fläche D (5,0 mg/g) im 2. Versuchsjahr (2006) lagen sämtlich weit oberhalb der ausreichenden Gehalte (1,5-3 mg/g) laut Bergmann (1993), auch wenn der Wert auf Fläche D sich vom ersten zum 2. Jahr beinahe halbierte.

Dort wurden in 2006 in den einzelnen Erlen-Varianten Magnesium-Blattgehalte zwischen 2,4 $\mathrm{mg} / \mathrm{g}(\mathrm{V} 10)$ und 7,1 mg/g (V3, V4) gemessen.

In der unbehandelten Kontrolle (V1) lag der Wert mit 4,1 mg/g bereits über den ausreichenden Gehalten. Die meisten der Behandlungsvarianten wiesen noch deutlich höhere MagnesiumGehalte auf, vor allem die Kalk-Variante (V2) und die Stockosorb®-Varianten (V3: Stockosorb®, V4: Stockosorb®-Kalk) mit Werten von gut $7 \mathrm{mg} / \mathrm{g}$. Magnesium-Blattgehalte innerhalb bzw. an der oberen Grenze der ausreichenden Spanne nach Bergmann (1993) wurden nur in den Varianten ermittelt, die mit einer Kombination von Bodenhilfsstoffen zur Bodenlockerung sowie zur Erhöhung des Boden-pH-Wertes angelegt wurden (V8: Perlit-Kalk: 3,0 mg/g, V9: Kompost: 3,1 mg/g, V10: Kompost-Kalk: 2,4 mg/g). Wie auch bei anderen Element-Gehalten (Schwefel, Kupfer, Aluminium, Nickel, Kobalt, Chrom) senkten diese Behandlungskombinationen die Aufnahme von Magnesium in die Pflanzen (ein umgekehrter Effekt trat bei Calcium ein).

Die Gabe von Magnesiumkalk (V2 sowie zusätzlich in V4, V6, V8, V10) sorgte nicht in allen Fällen für eine erkennbare Erhöhung der Magnesium-Gehalte. 


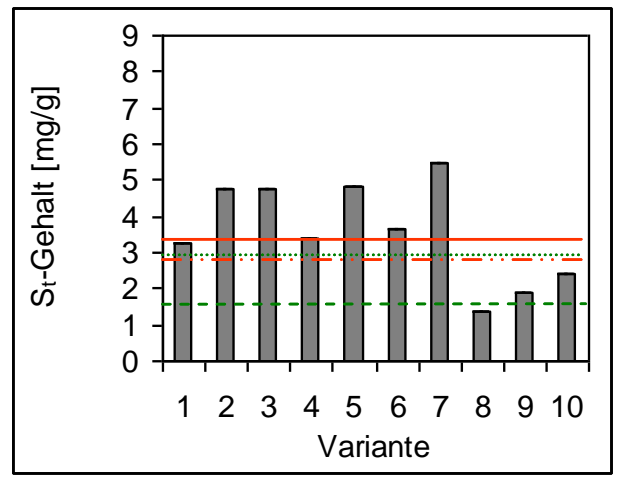

Toxizitätssymptome, Wachstumsrückgang bei Ahornen (van den Burg 1985, 1990) Obergrenze extrem bei Eichen (Heinsdorf 1996)

Obergrenze ausreichend/normal Untergrenze ausreichend/normal bei Ahornen (van den Burg 1985, 1990)

Abb. 77: $\mathrm{S}_{\mathrm{t}}$-Gehalte [mg/g] im Laub der Erlen-Varianten (s. S. 20) auf Versuchsfläche D im 2. (2006) Vegetationsjahr (Mischproben)

Insgesamt betrug der durchschnittliche Schwefel-Gehalt des Erlen-Laubs (s. Abb. 77) auf Fläche D im 2. Untersuchungsjahr 3,6 mg/g, was über einer Extremversorgung bei Eichen nach Heinsdorf (1996) sowie oberhalb der Grenze von 3,3 mg/g liegt, ab der bei Ahornen Toxizitätssymptome oder Wachstumsrückgang festgestellt wurden oder möglich sind (van den Burg 1985, 1990). Je nach Variante lag er in 2006 auf Fläche D zwischen 1,3 mg/g (V8) und 5,5 $\mathrm{mg} / \mathrm{g}(\mathrm{V} 7)$.

In der unbehandelten Kontrolle (V1) und den beiden Wasserspeichersubstanz-Kalk-Varianten (V4: Stockosorb®-Kalk, V6: Superabsorber-Kalk) wurden Schwefel-Gehalte im Bereich der genannten Toxizitäts-Grenze ermittelt. In der reinen Kalk-Variante (V2) und den beiden kalkfreien Wasserspeichersubstanz-Varianten (V3: Stockosorb®, V5: Superabsorber) lagen sie deutlich höher bei knapp $5 \mathrm{mg} / \mathrm{g}$. Der mit 5,5 mg/g höchste Schwefel-Blattgehalt wurde in der Perlit-Variante (V7) gemessen. Sehr viel weniger Schwefel enthielt das Erlen-Laub in den Kompost-Varianten: Mit Kompost und Kalk (V10) waren es 2,4 mg/g (ausreichend bzw. normal für Ahorne laut van den Burg 1985, 1990; extrem für Eichen laut Heinsdorf 1996), mit Kompost allein (V9) 1,9 mg/g (ausreichend bzw. normal für Ahorne laut van den Burg 1985, 1990; optimal bis überversorgt für Eichen laut Heinsdorf 1996). Den mit 1,3 mg/g geringsten Schwefel-Blattgehalt, der bereits unterhalb der ausreichenden Normalgehalte in Ahorn-Blättern (van den Burg 1985, 1990) und im Bereich einer Unterversorgung bei Eichen (Heinsdorf 1996) liegt, wiesen die Erlen in der Perlit-Kalk-Variante auf.

Wie auch bei den Calcium-, Magnesium-, Aluminium-, Kupfer- Nickel-, Kobalt- und ChromGehalten hatten also diejenigen Bodenhilfsstoffe bzw. Bodenhilfsstoff-Kombinationen, die sowohl der Verdichtung als auch der Versauerung des Bodens entgegenwirken sollen (V8: Perlit-Kalk, V9: Kompost, V10: Kompost-Kalk), positiven Einfluss auf die Schwefel-Gehalte der Erlen-Blätter. In diesem Fall wurden die im Übrigen extrem hohen (toxischen) Schwefel-Gehalte deutlich gesenkt.

\section{Spurennährelemente, Mikronährstoffe ( $\mathrm{Fe}, \mathrm{Mn}, \mathrm{Zn}, \mathrm{Cu})$}

Der Eisen-Gehalt im Erlen-Laub (s. Abb. 78) auf Fläche D betrug in 2006 im Mittel 308 mg/kg, was oberhalb der ausreichenden Normalgehalte für Ahorne $663-212 \mathrm{mg} / \mathrm{kg}$ nach van den Burg 1985, 1990) sowie an der Obergrenze des Extrembereichs für Eichen $(300 \mathrm{mg} / \mathrm{kg}$ nach Heinsdorf 1996) liegt. In den einzelnen Varianten wurden sehr unterschiedliche Werte zwischen $152 \mathrm{mg} / \mathrm{kg}$ (V8) und $798 \mathrm{mg} / \mathrm{kg}$ (V3) gemessen. Die Verteilung der Eisen-Gehalte auf die einzelnen Varianten folgte beinahe exakt dem gleichen Muster wie die der Aluminium-Gehalte. 

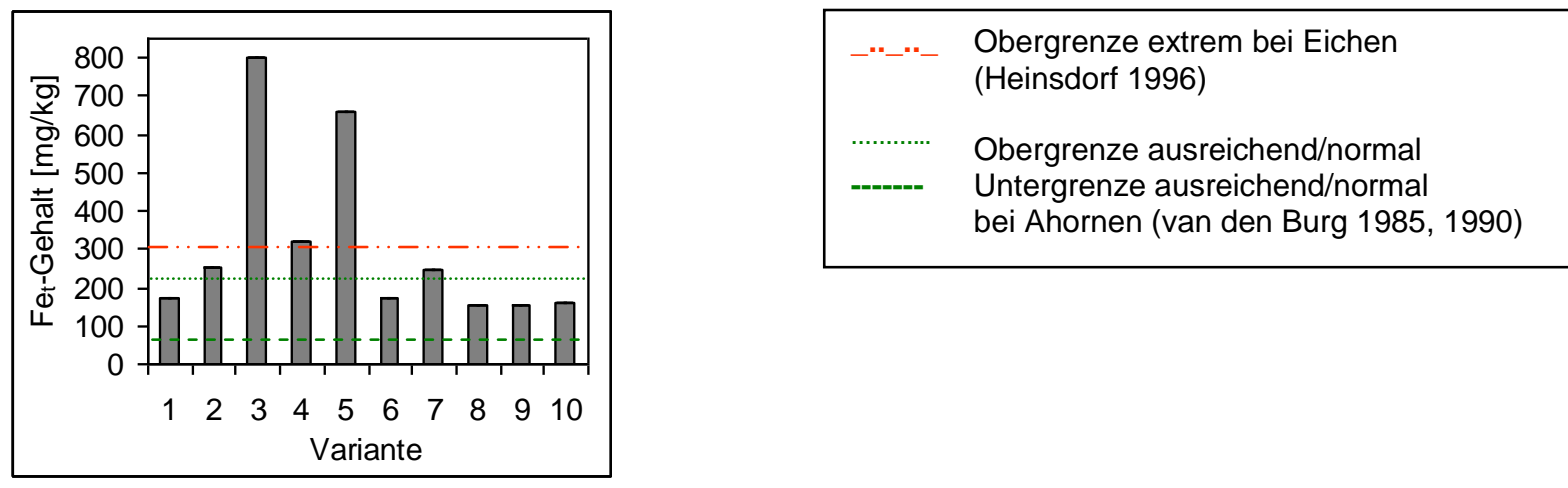

Abb. 78: $\mathrm{Fe}_{\mathrm{t}}-\mathrm{Gehalte}[\mathrm{mg} / \mathrm{kg}]$ im Laub der Erlen-Varianten (s. S. 20) auf Versuchsfläche D im 2. (2006) Vegetationsjahr (Mischproben)

In der Nullvariante (V1), der Superabsorber-Kalk-Variante (V6), der Perlit-Kalk-Variante (V8) und den beiden Kompost-Varianten (V9, V10) lagen die Eisen-Blattgehalte der Erlen mit Werten um $160 \mathrm{mg} / \mathrm{kg}$ im genannten Bereich ausreichender Normalgehalte. In keiner Variante wurden gegenüber der Kontrolle erheblich geringere Eisen-Gehalte gemessen. Mit rund $250 \mathrm{mg} / \mathrm{kg}$ etwas oberhalb der Obergrenze des ausreichenden Bereichs lagen die Eisen-Gehalte in der reinen Kalk- (V2) und der reinen Perlit-Variante (V7). Mit Abstand die höchsten, deutlich oberhalb des Extrembereichs liegenden Eisen-Blattgehalte hatten die Erlen in den reinen Wasserspeichersubstanz-Varianten, wobei der Gehalt in der Stockosorb®-Variante (V3) mit 798 $\mathrm{mg} / \mathrm{kg}$ noch einmal deutlich über dem in der Superabsorber-Variante (V5) mit $658 \mathrm{mg} / \mathrm{kg}$ lag. Die Kombination mit Kalk (V4: Stockosorb®-Kalk, V6: Superabsorber-Kalk) führte jeweils zu einem erheblich geringeren Eisen-Gehalt, der im Fall von V4 mit 318 mg/kg jedoch auch noch klar über den ausreichenden Bereich und knapp über den Extrembereich hinausging.
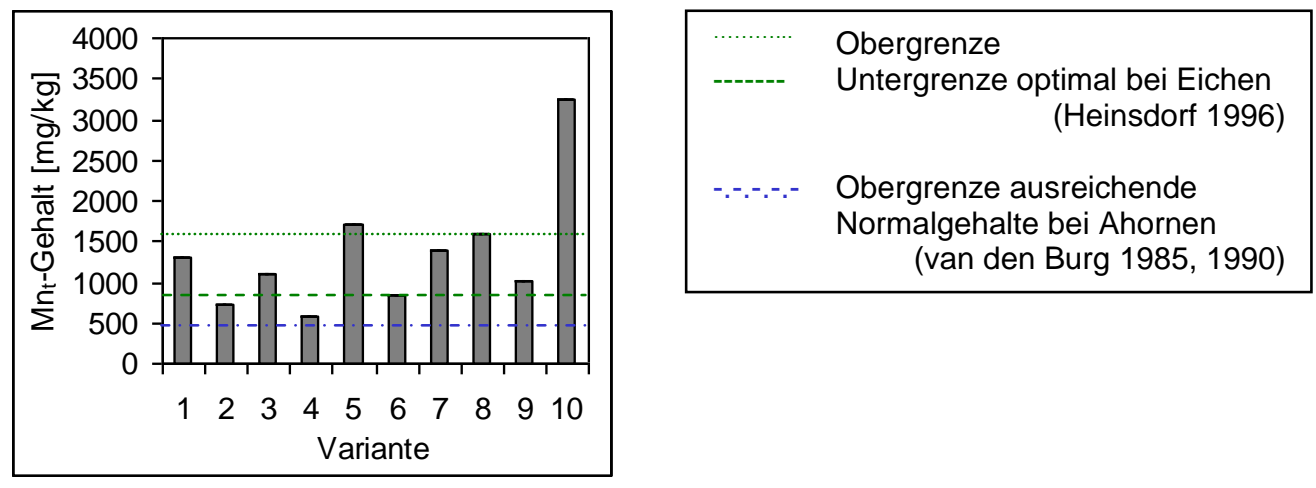

Abb. 79: $\mathrm{Mn}_{\mathrm{t}}-\mathrm{Gehalte}[\mathrm{mg} / \mathrm{kg}]$ im Laub der Erlen-Varianten (s. S. 20) auf Versuchsfläche D im 2. (2006) Vegetationsjahr (Mischproben)

Im Laub der Erlen auf Fläche D wurden in 2006 Mangan-Gehalte von durchschnittlich 1353 $\mathrm{mg} / \mathrm{kg}$ gemessen, die je nach Variante zwischen $577 \mathrm{mg} / \mathrm{kg}$ (V4) und $3240 \mathrm{mg} / \mathrm{kg}$ (V10) schwankten (s. Abb. 79). Alle Werte lagen weit über den in Bergmann (1993) (35-100 mg/kg) oder van den Burg $(1985,1990)$ (11-473 mg/kg) genannten ausreichenden Gehalten für andere Laubbäume. Nach der Einstufung der Mangan-Gehalte bei Eichen durch Heinsdorf (1996) dagegen lagen die Gehalte in den Varianten V1 (Kontrolle), V3 (Stockosorb®), V7 (Perlit) und V9 (Kompost) im optimalen Bereich. In V2 (Kalk) und V4 (Stockosorb®-Kalk) unterschritten die Werte diesen Bereich, während V6 (Superabsorber-Kalk) knapp darin lag. Lediglich in den Varianten V5 (Superabsorber) und V8 (Perlit-Kalk) wurde demnach der Optimalbereich knapp, in V10 (Kompost-Kalk) dagegen deutlich überschritten. Eine Toxizität der sehr hohen Gehalte ist 
wahrscheinlich; die Literaturangaben zur Bewertung von Mangan-Gehalten in Assimilationsorganen sind teilweise widersprüchlich (s. auch ab S. 333).

Bei Betrachtung der Messwerte fällt auf, dass zumindest bei einigen Varianten mit Kalk-Gabe die Mangan-Gehalte deutlich niedriger waren als ohne Kalk-Gabe: Während in der Kontrolle (V1), der Stockosorb®- (V3) und der Superabsorber-Variante (V5) Werte zwischen $1103 \mathrm{mg} / \mathrm{kg}$ und 1714 mg/kg gemessen wurden, lagen die Gehalte in der Kalk- (V2), der Stockosorb®-Kalk- (V4) und der Superabsorber-Kalk-Variante (V6) zwischen $577 \mathrm{mg} / \mathrm{kg}$ und $839 \mathrm{mg} / \mathrm{kg}$. Bei den PerlitVarianten (V7: Perlit, V8: Perlit-Kalk) war dagegen kein Einfluss der zusätzlichen Kalk-Gabe in Variante V8 erkennbar. Bei den Kompost-Varianten (V9: Kompost, V10: Kompost-Kalk) wurde sogar im Gegensatz zu den meisten übrigen Varianten in der Kombination mit Kalk (V10) der sehr viel höhere Mangan-Gehalt gemessen - mit 3240 mg/kg der mit Abstand höchste Wert aller Varianten.

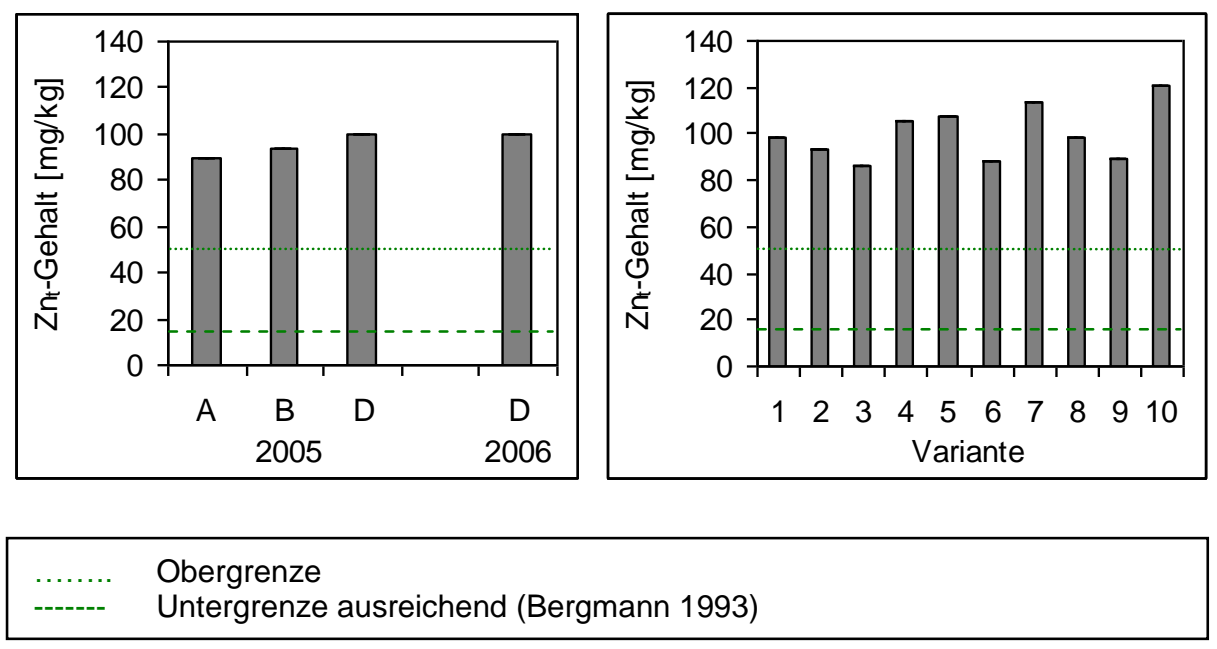

Abb. 80 links: $\mathrm{Zn}_{\mathrm{t}}$-Gehalte [mg/kg] im Laub der Erlen auf den Versuchsflächen A, B und D im 1. (2005) und auf Fläche D im 2. (2006) Vegetationsjahr (Mischproben); rechts: differenziert nach Varianten (s. S. 20) auf Fläche D im 2. Jahr (2006) (Mischproben)

Der durchschnittliche Zink-Gehalt des Erlen-Laubs (s. Abb. 80) lag auf Fläche A bei $90 \mathrm{mg} / \mathrm{kg}$, auf Fläche B bei $94,1 \mathrm{mg} / \mathrm{kg}$ und auf Fläche D in beiden Untersuchungsjahren gleich bleibend bei $100,2 \mathrm{mg} / \mathrm{kg}$. Je nach Variante wurden im 2. Untersuchungsjahr (2006) auf Fläche D ZinkBlattgehalte zwischen $86,4 \mathrm{mg} / \mathrm{kg}$ (V3) und 120,9 mg/kg (V10) ermittelt.

Damit waren sowohl in der Kontrolle als auch in sämtlichen Behandlungsvarianten die ZinkGehalte nach den Bewertungen für andere Laubbäume in Bergmann (1993) deutlich über ausreichend. Gleichzeitig lagen sie unterhalb der Normalgehalte in Pflanzen (150-200 mg/kg) nach Smidt (1999). In der Stockosorb®-Kalk- (V4), der Superabsorber- (V5), der Perlit- (V7) und der Kompost-Kalk-Variante (V10) lagen die Zink-Gehalte bei über $100 \mathrm{mg} / \mathrm{kg}$ und damit innerhalb der in Alloway (1999) genannten (recht weiten) Spanne kritischer ZinkKonzentrationen, oberhalb der toxische Auswirkungen wahrscheinlich sind (100-400 mg/kg). 

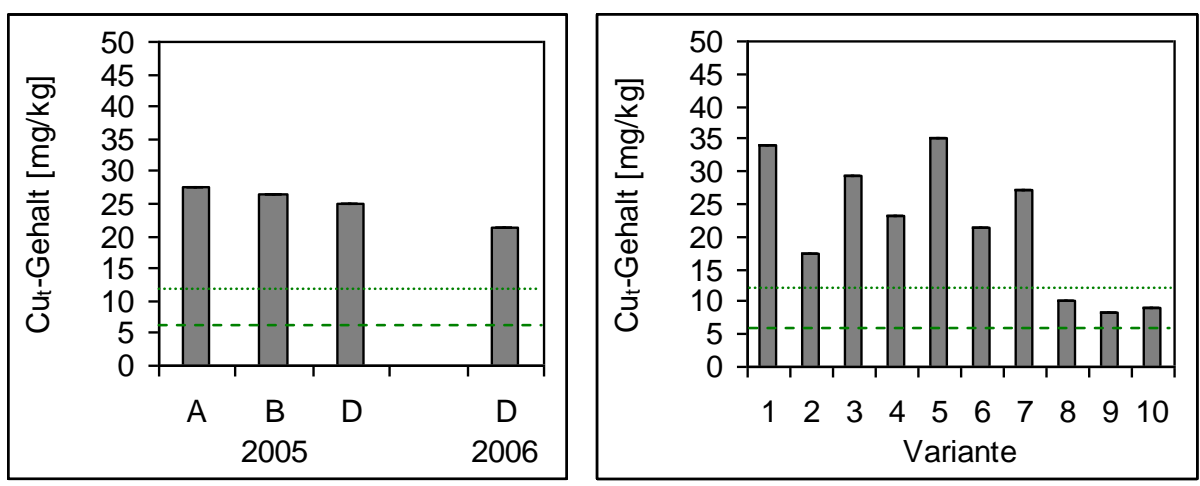

Obergrenze

Untergrenze ausreichend (Bergmann 1993)

Abb. 81 links: $\mathrm{Cu}_{\mathrm{t}}-\mathrm{Gehalte}$ [mg/kg] im Laub der Erlen auf den Versuchsflächen A, B und D im 1. (2005) und auf Fläche D im 2. (2006) Vegetationsjahr (Mischproben); rechts: differenziert nach Varianten (s. S. 20) auf Fläche D im 2. Jahr (2006) (Mischproben)

Die Kupfer-Gehalte in den Erlen-Blättern (s. Abb. 81) auf den drei Versuchsflächen lagen mit durchschnittlich 27,6 mg/kg (A), 26,4 mg/kg (B) und 25,0 mg/kg (D: 2005) bzw. 21, $4 \mathrm{mg} / \mathrm{kg}$ (D: 2006) etwa doppelt so hoch wie die obere Grenze ausreichender Gehalte nach Bergmann (1993). Die Normalgehalte (15-20 mg/kg) nach Smidt (1999) waren damit ebenfalls überschritten. Die Werte lagen zudem innerhalb der in Alloway (1999) genannten (recht weiten) Spanne kritischer Kupfer-Konzentrationen, oberhalb der toxische Auswirkungen wahrscheinlich sind (20-100 mg/kg).

Nach Varianten getrennt wurden auf Fläche D in 2006 Kupfer-Blattgehalte zwischen 8,3 mg/kg (V9) und 35,0 mg/kg (V5) gemessen. Die höchsten Gehalte wiesen die kalkfreien Varianten V1 (unbehandelte Kontrolle: 33,9 mg/kg) und V5 (Superabsorber: 35,0 mg/kg) auf, gefolgt von den ebenfalls kalkfreien Varianten V3 (Stockosorb®: 29,4 mg/kg) und V7 (Perlit: 27,0 mg/kg). Die zusätzliche Kalk-Gabe in den Varianten V2, V4, V6 und V8 führte zu niedrigeren KupferGehalten, im Fall von V2 (Kalk) mit 17,4 mg/kg zu einem Wert innerhalb der Normalgehalte nach Smidt (1999) und unterhalb des kritischen Bereichs nach Alloway (1999). Die geringsten Kupfer-Blattgehalte wurden in den Varianten ermittelt, die mit Bodenhilfsstoffen zur Bodenlockerung sowie zur Erhöhung des Boden-pH-Wertes angelegt wurden (V8: Perlit-Kalk: 10,1 mg/kg, V9: Kompost: 8,3 mg/kg, V10: Kompost-Kalk: 9,0 mg/g). Dort befanden sich die Werte innerhalb des ausreichenden Bereichs nach Bergmann (1993) und unterhalb der Normalgehalte nach Smidt (1999). Wie auch bei den Calcium-, Magnesium-, Schwefel-, Aluminium-, Nickel-, Kobalt- und Chrom-Gehalten hatten diese drei Behandlungsvarianten einen positiven Einfluss auf die Kupfer-Gehalte des Erlen-Laubs, wobei in diesem Fall die ansonsten sehr hohen Gehalte gesenkt wurden.

\section{Potentiell nützliche Elemente (Al, $\mathrm{Na}, \mathrm{Ni}, \mathrm{Co}$ )}

Der Aluminium-Gehalt des in 2006 auf Fläche D beprobten Erlen-Laubs (s. Abb. 82) lag im Durchschnitt bei $477 \mathrm{mg} / \mathrm{kg}$, reichte aber je nach Variante von $83 \mathrm{mg} / \mathrm{kg}$ (V10) bis $1568 \mathrm{mg} / \mathrm{kg}$ (V3). Die Verteilung der Aluminium-Gehalte auf die einzelnen Varianten folgte beinahe exakt dem gleichen Muster wie die der Eisen-Gehalte. 

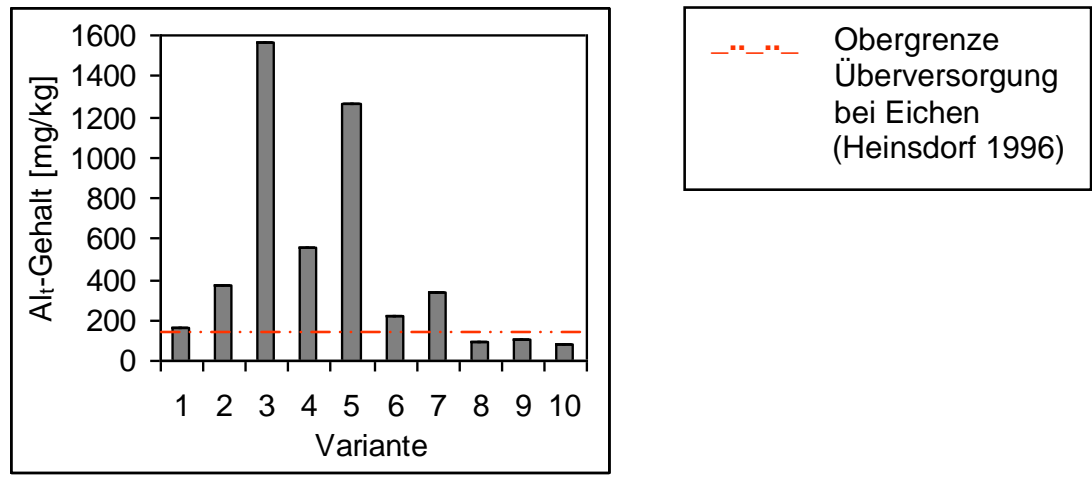

Abb. 82: $\mathrm{Al}_{\mathrm{t}}-\mathrm{Gehalte}[\mathrm{mg} / \mathrm{kg}]$ im Laub der Erlen-Varianten (s. S. 20) auf Versuchsfläche D im 2. (2006) Vegetationsjahr (Mischproben)

In der unbehandelten Kontrolle (V1) lag der Aluminium-Blattgehalt der Erlen mit $165 \mathrm{mg} / \mathrm{kg}$ bereits deutlich über der oberen Grenze einer Überversorgung bei Eichen $(119 \mathrm{mg} / \mathrm{kg})$ nach Heinsdorf (1996).

Mit Abstand die höchsten Aluminium-Blattgehalte hatten die Erlen in den reinen Wasserspeichersubstanz-Varianten, wobei der Gehalt in der Stockosorb®-Variante (V3) mit $1568 \mathrm{mg} / \mathrm{kg}$ (das 9,5-fache des Kontrollwertes) noch einmal deutlich über dem in der Superabsorber-Variante (V5) mit $1267 \mathrm{mg} / \mathrm{kg}$ (das 8-fache des Kontrollwertes) lag. Die Kombination mit Kalk (V4: Stockosorb®-Kalk, V6: Superabsorber-Kalk) führte jeweils zu erheblich geringeren Aluminium-Gehalten, wobei die stärkere Reduktion gegenüber der kalkfreien Behandlung im Fall von V6 erfolgte (mit einem Aluminium-Gehalt von $226 \mathrm{mg} / \mathrm{kg}$, was nur noch $17 \%$ des Wertes in V5 entspricht, gegenüber einem Gehalt von $554 \mathrm{mg} / \mathrm{kg}$ in V4, was $35 \%$ des Wertes in V3 entspricht). Trotz dieser erheblich geringeren Werte lagen die Aluminium-Gehalte in V6 und V4 noch deutlich bzw. erheblich oberhalb der oberen Grenze einer Überversorgung (bei Eichen nach Heinsdorf 1996). In der reinen Kalk-Variante (V2) und der reinen Perlit-Variante (V7) wurden mit $374 \mathrm{mg} / \mathrm{kg}$ bzw. $337 \mathrm{mg} / \mathrm{kg}$ ebenfalls AluminiumGehalte ermittelt, die höher als der Kontrollwert und als die Überversorgungsgrenze lagen.

Erst mit der Kombination von pH-Wert erhöhenden (Kalk, Kompost) und Boden lockernden (Perlit, Kompost) Hilfsstoffen schien ein positiver Effekt in Form einer geringeren AluminiumAufnahme einzutreten: Die Aluminium-Gehalte in der Perlit-Kalk-Variante (V8) und den beiden Kompost-Varianten (V9, V10) mit 93, 99 und 83 mg/kg lagen nur noch im Bereich einer Überversorgung bei Eichen laut Heinsdorf (1996).

Dies bestätigt zunächst den auch bei anderen Element-Gehalten (Calcium, Magnesium, Schwefel, Kupfer, Nickel, Kobalt, Chrom) positiven Einfluss dieser Behandlungskombinationen aus Bodenstruktur und Bodenchemismus verbessernden Bodenhilfsstoffen.

Jedoch ist laut Bergmann (1993) Phosphormangel bei ausreichend mit Phosphor versorgten Böden (wie in diesem Fall, s. S. 48) ein deutlich sichereres Zeichen für Aluminium-Toxizität als ein hoher Aluminium-Gehalt in den Assimilationsorganen. Bei den untersuchten Erlen könnte demnach mindestens in den Varianten V3 und V5 sowie - trotz des vergleichsweise geringen Aluminium-Gehaltes in den Blättern dieser Variante - V8 von $\mathrm{Al}^{3+-U ̈ b e r s c h u s s ~ u n d ~ A l u m i n i u m-~}$ Toxizität ausgegangen werden. 

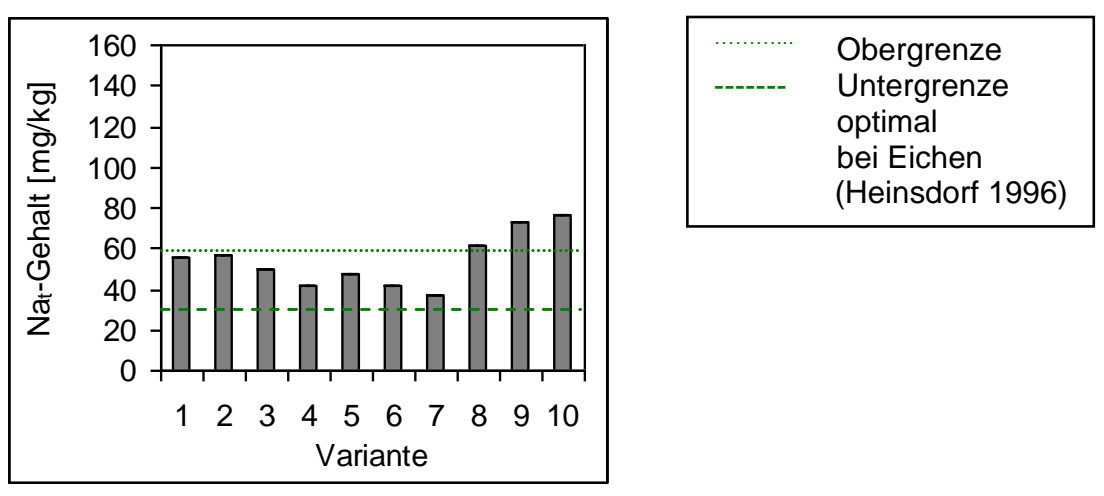

Abb. 83: $\mathrm{Na}_{\mathrm{t}}$-Gehalte $[\mathrm{mg} / \mathrm{kg}]$ im Laub der Erlen-Varianten (s. S. 20) auf Versuchsfläche D im 2. (2006) Vegetationsjahr (Mischproben)

Die im 2. Untersuchungsjahr (2006) im Laub der Erlen auf Versuchsfläche D gemessenen Natrium-Gehalte (s. Abb. 83) lagen bei einem Durchschnittswert von $54,1 \mathrm{mg} / \mathrm{kg}$ je nach Variante zwischen 37,6 mg/kg (V7) und 76,5 mg/kg (V10).

In der unbehandelten Kontrolle (V1) und der Kalk-Variante (V2) wurden Natrium-Gehalte von rund $56 \mathrm{mg} / \mathrm{kg}$ ermittelt, die annähernd der oberen Grenze der Optimalversorgung bei Eichen (28-58 mg/kg) laut Heinsdorf (1996) entsprachen. Niedriger lagen die Werte in den Wasserspeichersubstanz-Varianten (V3-V6); ohne Kalk-Gabe bei 49,7 mg/kg (V3) bzw. 47,8 $\mathrm{mg} / \mathrm{kg}$ (V5), mit Kalk-Gabe noch etwas darunter bei je 41,4 mg/kg (V4, V6). Diese Werte wie auch der in der Perlit-Variante (V7) ermittelte Natrium-Gehalt von 37,6 mg/kg lagen sämtlich innerhalb des genannten optimalen Bereichs. Dagegen war der Natrium-Gehalt der Perlit-KalkVariante (V8) mit 61,5 mg/kg bereits knapp als Überversorgung (bei Eichen; Heinsdorf 1996) einzustufen. Noch deutlicher im Bereich einer Überversorgung lagen demnach die Werte in den Kompost-Varianten mit 73,2 mg/kg (V9) bzw. 76,5 mg/kg (V10).
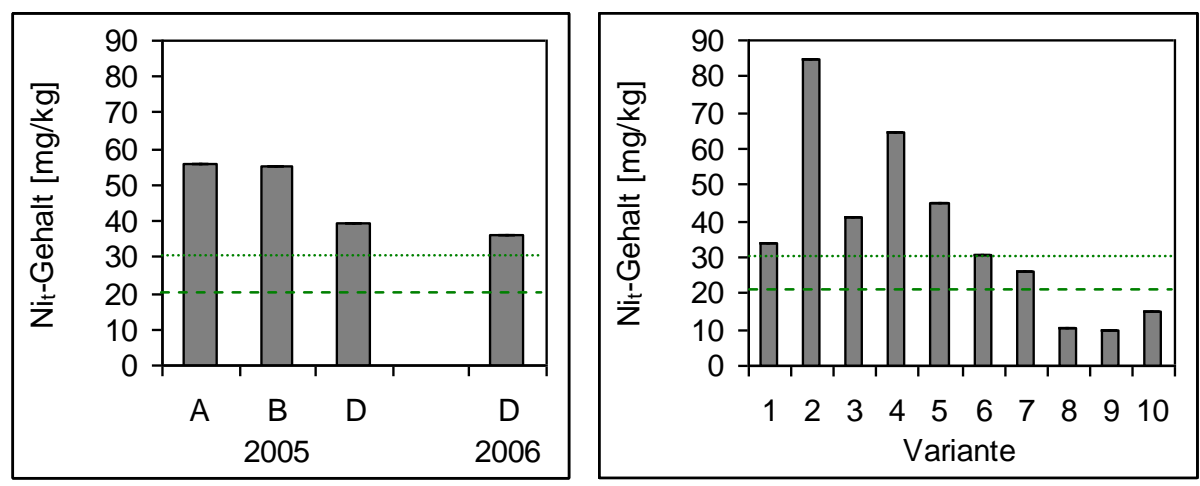

Obergrenze

Untergrenze Normalgehalte in Pflanzen (Smidt 1999)

Abb. 84 links: $\mathrm{Ni}_{\mathrm{t}}$-Gehalte [mg/kg] im Laub der Erlen auf den Versuchsflächen A, B und D im 1. (2005) und auf Fläche D im 2. (2006) Vegetationsjahr (Mischproben); rechts: differenziert nach Varianten (s. S. 20) auf Fläche D im 2. Jahr (2006) (Mischproben)

Die durchschnittlichen Nickel-Gehalte des Erlen-Laubs (s. Abb. 84) auf den Versuchsflächen A und B lagen mit rund $56 \mathrm{mg} / \mathrm{kg}$ deutlich oberhalb der bei Smidt (1999) angegebenen Normalgehalte in Pflanzen $(20-30 \mathrm{mg} / \mathrm{kg})$. Auf Fläche D wurden in beiden Aufnahmejahren mit 39,6 (2005) mg/kg bzw. 36,1 mg/kg (2006) sehr viel geringere, aber immer noch oberhalb dieser Spanne liegende Werte ermittelt. Nach Varianten getrennt ergaben sich recht 
unterschiedliche Gehalte zwischen $10,0 \mathrm{mg} / \mathrm{kg}$ (V9) und $84,9 \mathrm{mg} / \mathrm{kg}$ (V2). Alle gemessenen Werte lagen innerhalb des bei Alloway (1999) als kritisch bezeichneten Bereichs, oberhalb dessen toxische Auswirkungen wahrscheinlich sind (10-100 mg/kg).

In der unbehandelten Kontrolle lag der Nickel-Blattgehalt mit 33,6 mg/kg leicht oberhalb der genannten Normalgehalte. Jeweils noch darüber lagen die Werte in den beiden Wasserspeichersubstanz-Varianten mit 40,8 mg/kg (V3: Stockosorb®) und 45,0 mg/kg (V5: Superabsorber). Im letzteren Fall ergab sich mit zusätzlicher Kalk-Gabe (V6: SuperabsorberKalk) ein deutlich niedrigerer Nickel-Gehalt, der mit 30,8 mg/kg die obere Grenze der Normalgehalte markierte. Im Gegensatz dazu wurde in der Stockosorb®-Kalk-Variante (V4) mit $64,4 \mathrm{mg} / \mathrm{kg}$ ein erheblich höherer Nickel-Gehalt gemessen. Der mit Abstand höchste NickelGehalt von $84,9 \mathrm{mg} / \mathrm{kg}$ wurde in der ebenfalls mit Kalk-Gabe gepflanzten Variante V2 ermittelt.

In Variante V7, in der zur Lockerung des verdichteten Bodens Perlit eingebracht wurde, lag der Nickel-Gehalt der Erlen-Blätter mit 26,1 mg/kg unterhalb des Kontrollwertes und innerhalb der Normalgehalte nach Smidt (1999). Noch deutlich niedrigere, unterhalb dieser Normalgehalte liegende Werte wiesen die Perlit-Kalk-Variante (V8) mit 10,2 mg/kg, die Kompost-Variante (V9) mit 10,0 mg/kg und die Kompost-Kalk-Variante (V10) mit etwas höheren 15,0 mg/kg auf.

Wie auch bei anderen Element-Gehalten (Magnesium, Schwefel, Kupfer, Aluminium, Kobalt, Chrom; bei Calcium trat ein umgekehrter Effekt ein) senkten diese Behandlungskombinationen aus Bodenstruktur und Bodenchemismus verbessernden Bodenhilfsstoffen die Aufnahme des Elements Nickel in die Pflanzen am stärksten.
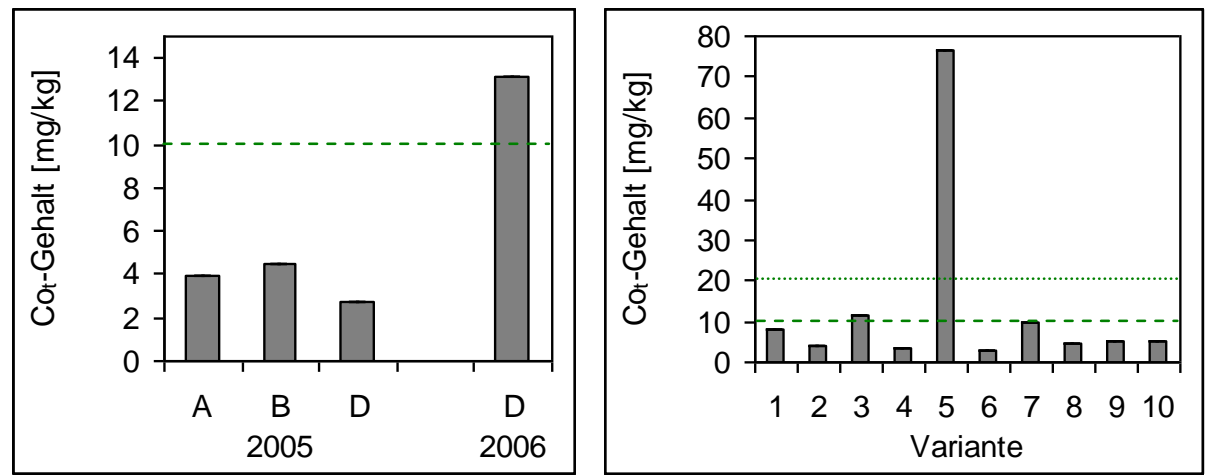

Obergrenze

Untergrenze Normalgehalte in Pflanzen (Smidt 1999)

Abb. 85 links: $\mathrm{Co}_{\mathrm{t}}$-Gehalte [mg/kg] im Laub der Erlen auf den Versuchsflächen A, B und D im 1. (2005) und auf Fläche D im 2. (2006) Vegetationsjahr (Mischproben); rechts: differenziert nach Varianten (s. S. 20) auf Fläche D im 2. Jahr (2006) (Mischproben)

Im 1. Untersuchungsjahr (2005) wurden in den Erlen-Blättern auf allen drei Versuchsflächen Kobalt-Gehalte (s. Abb. 85) gemessen, die mit durchschnittlich 3,9 mg/kg (A), 4,5 mg/kg (B) und $2,7 \mathrm{mg} / \mathrm{kg}$ (D) deutlich unterhalb der Normalgehalte in Pflanzen $(10-20 \mathrm{mg} / \mathrm{kg})$ nach Smidt (1999) lagen. Bei der Wiederholungsuntersuchung auf Fläche D im Folgejahr (2006) lag der Durchschnittswert aufgrund des mit 76,3 mg/kg vergleichsweise sehr hohen Wertes in der Superabsorber-Variante (V5) bei erheblich höheren 13,1 mg/kg (und damit im Bereich der Normalgehalte nach Smidt 1999). Die Möglichkeit eines Messfehlers konnte durch wiederholte Messung an einem zweiten ICP-Gerät, die zu gleichen Ergebnissen führte, ausgeschlossen werden. Dieser gegenüber dem Kontrollwert beinahe 10-mal so hohe Kobalt-Gehalt in der 
Superabsorber-Variante (V5) kann als toxisch angesehen werden, da er um einiges oberhalb der in Alloway (1999) als kritisch angegebenen Spanne (15-50 mg/kg) liegt, oberhalb der toxische Auswirkungen wahrscheinlich sind.

In den übrigen Varianten waren die Kobalt-Gehalte mit Werten zwischen 3,1 mg/kg (V6) und $11,8 \mathrm{mg} / \mathrm{kg}$ (V3) wesentlich geringer. Das Erlen-Laub der unbehandelten Kontrolle (V1) wies mit 8,0 mg/kg einen Kobalt-Gehalt etwas unterhalb der Normalgehalte nach Smidt (1999) auf, während der Wert in der Perlit-Variante (V7) mit 9,7 mg/kg ziemlich genau deren untere Grenze markierte und der Gehalt in der Stockosorb®-Variante mit $11,8 \mathrm{mg} / \mathrm{kg}$ bereits innerhalb dieses Bereichs lag. In allen übrigen Varianten, in denen durch Kalk- und/oder Kompost-Gabe Einfluss auf die bodenchemischen Bedingungen genommen wurde, wurden in den Erlen-Blättern deutlich geringere Kobalt-Gehalte von maximal 5,4 mg/kg gemessen.

\section{Toxisch wirkende Schwermetalle ohne Nährelementfunktion ( $\mathrm{Pb}, \mathrm{Cd}, \mathrm{Cr}$ )}

Nur im 1. Untersuchungsjahr (2005) ließen sich messbare Blei-Gehalte im Laub der Erlen (s. Abb. 86) feststellen, die 3,2 mg/kg (Fläche A), 4,4 mg/kg (Fläche B) bzw. 4,6 mg/kg (Fläche D) betrugen. Nach den sehr allgemeinen Normalgehalten von Schwermetallen in Pflanzen (in Smidt 1999) sowie den ebenso allgemeinen kritischen Konzentrationen (Alloway 1999) wären damit weder normale (10-20 mg/kg) noch kritische $(30-300 \mathrm{mg} / \mathrm{kg})$ Blei-Gehalte erreicht. Die Werte überstiegen jedoch deutlich das 90er-Perzentil (3,0 mg/kg) der im Rahmen des Deutschen Waldbodenberichtes in Buchenblättern gemessenen Blei-Gehalte (BMELF 1997b).

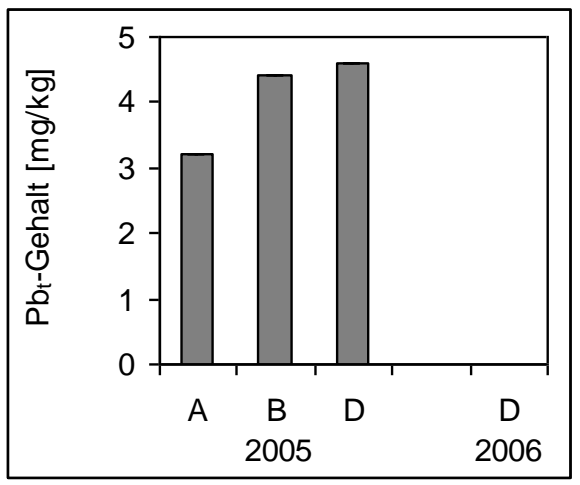

Abb. 86: $\mathrm{Pb}_{\mathrm{t}}$-Gehalte $[\mathrm{mg} / \mathrm{kg}]$ im Laub der Erlen auf den Versuchsflächen A, B und D im 1. (2005) und auf Fläche D im 2. (2006) Vegetationsjahr (Mischproben)

Ein nachweisbarer Cadmium-Gehalt konnte nur im Laub der Erlen auf Fläche B (ebenfalls in 2005) ermittelt werden. Dieser lag mit $0,12 \mathrm{mg} / \mathrm{kg}$ ebenso wie die Blei-Gehalte weit unter den Normalgehalten (5-10 mg/kg) nach Smidt (1999) und den kritischen Konzentrationen (5-30 $\mathrm{mg} / \mathrm{kg}$ ) in Alloway (1999). Er entspricht knapp dem 75er-Perzentil $(0,13 \mathrm{mg} / \mathrm{kg})$ der im Rahmen des Deutschen Waldbodenberichtes in Buchenblättern gemessenen Cadmium-Gehalte (BMELF 1997b).

Die Blei- und Cadmium-Gehalte in den Blättern sämtlicher in 2006 auf Fläche D beprobter ErlenVarianten lagen unterhalb der Nachweisgrenze für diese Elemente. 

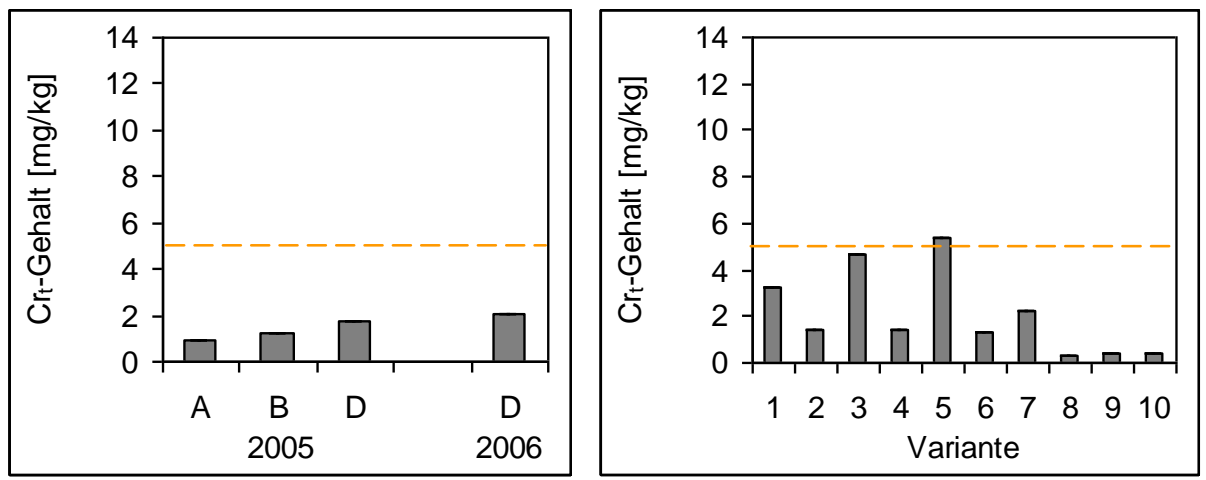

Untergrenze kritischer Bereich in Pflanzen (Alloway 1999)

Abb. 87 links: $\mathrm{Cr}_{\mathrm{t}}-\mathrm{Gehalte}[\mathrm{mg} / \mathrm{kg}]$ im Laub der Erlen auf den Versuchsflächen A, B und D im 1. (2005) und auf Fläche D im 2. (2006) Vegetationsjahr (Mischproben); rechts: differenziert nach Varianten (s. S. 20) auf Fläche D im 2. Jahr (2006) (Mischproben)

Die durchschnittlichen Chrom-Gehalte im Laub der Erlen (s. Abb. 87) von 0,9 mg/kg (Fläche A), $1,2 \mathrm{mg} / \mathrm{kg}$ (Fläche B) und 1,8 mg/kg bzw. 2,1 mg/kg (Fläche D 2005 bzw. 2006) lagen deutlich unterhalb des in Alloway (1999) aufgeführten Bereichs kritischer Chromkonzentrationen in Pflanzen, oberhalb dessen toxische Auswirkungen wahrscheinlich sind (5-30 mg/kg).

Nach Varianten getrennt ergaben sich auf Fläche D in 2006 Chrom-Gehalte zwischen 0,3 mg/kg (V8) und 5,4 mg/kg (V5). Die kalkfreien Varianten wiesen dabei stets höhere Chrom-Gehalte auf als die Varianten mit Kalk-Gabe (Ausnahme: Kompost-Varianten V9 und V10), die bei maximal 1,3 bzw. 1,4 mg/kg (V2, V4, V6) lagen. In der Perlit-Variante (V7) wurde mit 2,2 mg/kg ein geringerer, in den Wasserspeichersubstanz-Varianten (V3: Stockosorb®, V5: Superabsorber) wurden höhere Chrom-Gehalte als in der unbehandelten Kontrolle $(3,3 \mathrm{mg} / \mathrm{kg})$ gemessen, wobei der höchste Wert (V5: 5,4 mg/kg) bereits knapp innerhalb des genannten Bereichs kritischer Konzentrationen lag. In den Varianten, die mit Bodenhilfsstoffen zur Verbesserung der Bodenstruktur sowie des Bodenchemismus angelegt wurden (V8: Perlit-Kalk, V9: Kompost, V10: Kompost-Kalk), wurden mit 0,4 mg/kg bzw. 0,3 mg/kg die mit Abstand geringsten ChromBlattgehalte gemessen.

\subsubsection{Douglasie}

Im Folgenden werden die Ergebnisse der Nadelanalysen (Mischproben, s. S. 26) zur Versorgung und Belastung der Douglasien auf den drei Versuchsflächen insgesamt sowie innerhalb von einzelnen Bodenhilfsstoff-Varianten auf Versuchsfläche D dargestellt.

Aufgrund von Pflanzenausfällen konnte bei dieser Baumart die Versuchsvariante V3 (s. S. 20) nicht in die Untersuchungen mit einbezogen werden.

\section{Hauptnährelemente, Makronährstoffe (N, P, K, Ca, Mg, S)}

Die Stickstoff-Gehalte in den Nadeln der Douglasien (s. Abb. 88) auf den Versuchsflächen A und D (2005) waren mit durchschnittlich $16,9 \mathrm{mg} / \mathrm{g}$ und 17,5 mg/g ausreichend (IFTNC 1987; Bergmann 1993) bzw. mittel (Heinsdorf 1996). Auf Fläche B sowie bei der Wiederholungsuntersuchung auf Fläche D in 2006 war der jeweilige Durchschnittswert mit 12,4 
$\mathrm{mg} / \mathrm{g}$ und 13,1 mg/g geringer und nur nach Bergmann (1993) noch ausreichend, sonst unzureichend (IFTNC 1987) bzw. gering (Heinsdorf 1996).
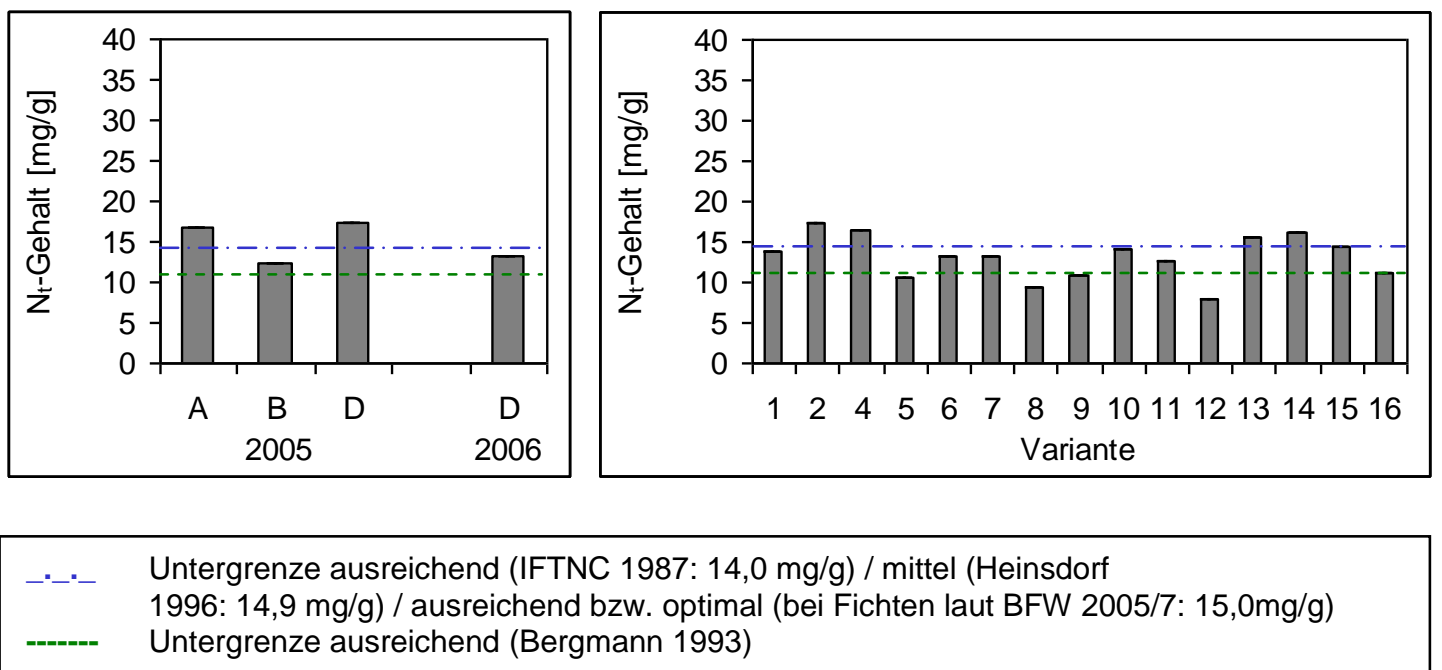

Abb. 88 links: $\mathrm{N}_{\mathrm{t}}$-Gehalte [mg/g] in den Nadeln der Douglasien auf den Versuchsflächen A, B und D im 1. (2005) und auf Fläche D im 2. (2006) Vegetationsjahr (Mischproben); rechts: differenziert nach Varianten (s. S. 20) auf Fläche D im 2. Jahr (2006) (Mischproben)

Je nach Variante wurden auf Fläche D in 2006 Stickstoff-Nadelgehalte zwischen 7,8 mg/g (V12) und 17,3 mg/g (V2) gemessen. Der Kontrollwert entsprach mit 13,8 mg/g mehr oder weniger dem Durchschnittswert für die gesamte Fläche und war dementsprechend nur nach Bergmann (1993) noch als ausreichend, sonst als knapp unzureichend (IFTNC 1987) bzw. als gering (Heinsdorf 1996) einzustufen. In den Varianten Superabsorber-Kalk (V6), Perlit (V7), KompostKalk (V10), Mykorrhiza (V11) und Mykorrhiza-Superabsorber (V15) wurden vergleichbare Stickstoff-Gehalte ermittelt, wobei die Werte in den Varianten V10 und V15 laut IFTNC (1987) knapp ausreichend waren.

In insgesamt fünf Behandlungsvarianten wurden teils deutlich geringere Stickstoff-Nadelgehalte gemessen als in der Nullvariante: Mit 10,5 mg/g, 10,8 mg/g bzw. 11,2 mg/g bewegten sich die Werte in den Varianten Superabsorber (V5), Kompost (V9) und Mykorrhiza-Superabsorber-Kalk (V16) um die untere Grenze ausreichender Gehalte laut Bergmann (1993), während sie nach den anderen Quellen nicht mehr ausreichend waren. In den Varianten Perlit-Kalk (V8) mit 9,4 mg/g und vor allem Mykorrhiza-Kalk (V12) mit noch deutlich geringeren 7,8 mg/g war die StickstoffVersorgung auch nach Bergmann (1993) nicht mehr ausreichend.

In vier Behandlungsvarianten, der Kalk-Variante (V2), der Stockosorb®-Kalk-Variante (V4) und den beiden Mykorrhiza-Stockosorb®-Varianten (V13 ohne, V14 mit Kalk) wurden deutlich höhere Stickstoff-Gehalte ermittelt als in der unbehandelten Kontrolle. Mit Werten zwischen $15,5 \mathrm{mg} / \mathrm{g}$ und 17,3 mg/g waren die Gehalte als mittel (Heinsdorf 1999) bzw. (knapp) gut (IFTNC 1987) einzustufen. Laut Bergmann (1993) war der Wert in Variante V2 bereits mehr als ausreichend. 

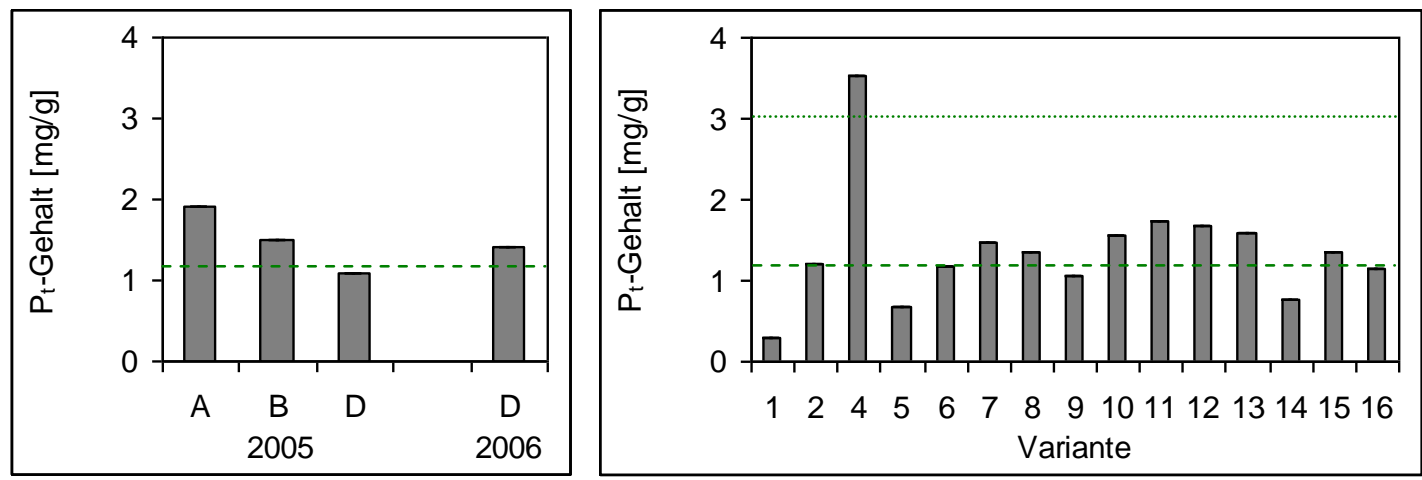

....... Obergrenze ausreichend (Bergmann 1993) / Grenzwert bei Fichten (BFW 2005/7)

------ Untergrenze ausreichend (Bergmann 1993)

Abb. 89 links: $\mathrm{P}_{\mathrm{t}}$-Gehalte $[\mathrm{mg} / \mathrm{g}]$ in den Nadeln der Douglasien auf den Versuchsflächen A, B und D im 1. (2005) und auf Fläche D im 2. (2006) Vegetationsjahr (Mischproben); rechts: differenziert nach Varianten (s. S. 20) auf Fläche D im 2. Jahr (2006) (Mischproben)

Auf Fläche A und B wurden in den Douglasien-Nadeln durchschnittliche Phosphor-Gehalte (s. Abb. 89) von 1,9 mg/g und 1,5 mg/g ermittelt, was nach Bergmann (1993) im ausreichenden Bereich (1,2-3 mg/g) lag. Auf Fläche D war der Wert im 1. Untersuchungsjahr (2005) mit 1,1 $\mathrm{mg} / \mathrm{g}$ demnach knapp nicht ausreichend, im 2. Untersuchungsjahr (2006) mit 1,4 mg/g dagegen schon.

Je nach Variante wurden dort Phosphor-Nadelgehalte zwischen sehr geringen, deutlich nicht ausreichenden 0,3 mg/g in der unbehandelten Kontrolle (V1) und bereits über ausreichenden $3,5 \mathrm{mg} / \mathrm{g}$ in der Stockosorb®-Kalk-Variante (V4) ermittelt. Letzterer Wert lag mit Abstand am höchsten und betrug mindestens das Doppelte der Werte in allen übrigen Behandlungsvarianten. Ein im Vergleich zu den (meisten) anderen Varianten höherer Gehalt in dieser Variante (V4) wurde auch bei den Elementen Calcium, Magnesium und Kobalt beobachtet.

Alle Behandlungsvarianten wiesen erheblich höhere Phosphor-Gehalte als die Nullvariante auf. Dabei waren die Werte in den Varianten Superabsorber (V5), Kompost (V9) und MykorrhizaStockosorb® (V14) mit 0,7 mg/g, 1,0 mg/g und 0,8 mg/g immer noch nicht ausreichend laut Bergmann (1993). Die Gehalte in den Varianten Kalk (V2), Superabsorber-Kalk (V6) und Mykorrhiza-Superabsorber-Kalk (V16) markierten demnach die untere Grenze ausreichender Gehalte. Beide Perlit-Varianten (V7 ohne, V8 mit Kalk), die Kompost-Kalk-Variante (V10) sowie sämtliche verbleibenden Mykorrhiza-Varianten (V11, V12, V13, V15) wiesen mit Werten zwischen 1,4 mg/g und 1,7 mg/g Phosphor-Nadelgehalte auf, die laut Bergmann (1993) für Douglasien ausreichend sind. 

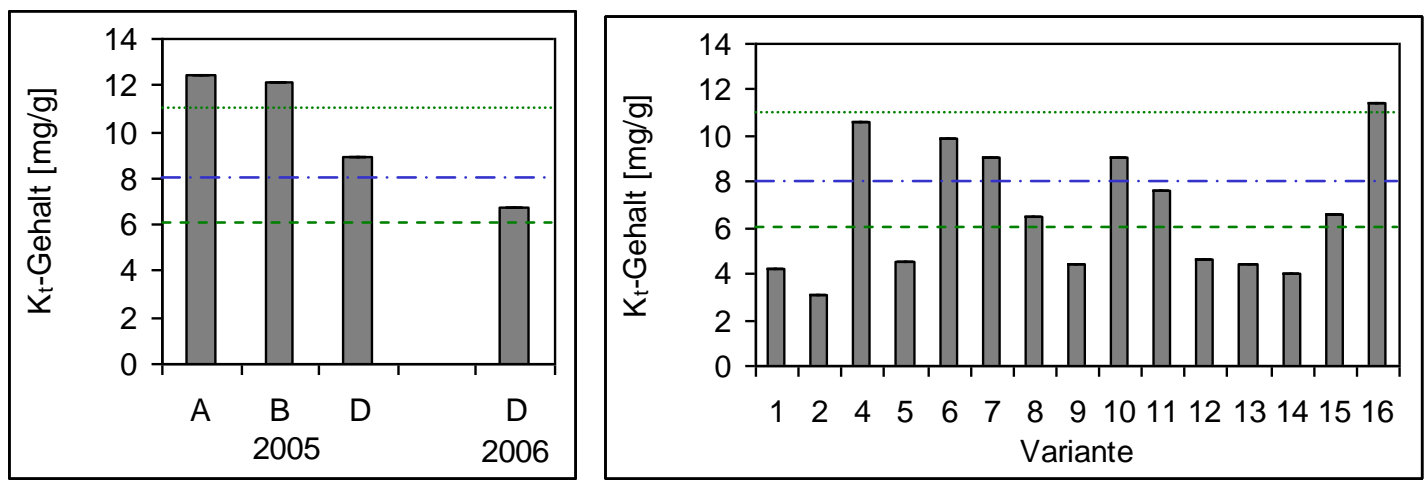

\begin{tabular}{|ll|}
\hline$\ldots . . .$. & Obergrenze ausreichend (Bergmann 1993) \\
----- & Untergrenze gut (IFTNC 1987) \\
\hline---- & Untergrenze ausreichend (Bergmann 1993; IFTNC 1987) \\
\hline
\end{tabular}

Abb. 90 links: $\mathrm{K}_{\mathrm{t}}$-Gehalte [mg/g] in den Nadeln der Douglasien auf den Versuchsflächen A, B und D im 1. (2005) und auf Fläche D im 2. (2006) Vegetationsjahr (Mischproben); rechts: differenziert nach Varianten (s. S. 20) auf Fläche D im 2. Jahr (2006) (Mischproben)

Auf den Versuchsflächen A und B überstiegen die mittleren Kalium-Gehalte in den DouglasienNadeln (s. Abb. 90) mit 12,4 mg/g und 12,1 mg/g die nach Bergmann (1993) ausreichenden Gehalte (6-11 mg/kg). Nach IFTNC (1987) lagen sie in einem guten Wertebereich (ab $8 \mathrm{mg} / \mathrm{g})$. Auf Fläche D befanden sich die Werte mit $8,9 \mathrm{mg} / \mathrm{g}$ im ersten und geringeren $6,7 \mathrm{mg} / \mathrm{g}$ im 2 . Untersuchungsjahr (noch) innerhalb der ausreichenden Spanne nach Bergmann (1993) und im guten bzw. ausreichenden Bereich (6-8 mg/g) nach IFTNC (1987).

Dabei schwankten die Kalium-Nadelgehalte je nach Variante stark zwischen 3,1 mg/g (V2) und $11,5 \mathrm{mg} / \mathrm{g}(\mathrm{V} 16)$.

In den Nadeln der Douglasien in der unbehandelten Kontrolle wurden mit 4,2 mg/g nicht ausreichende Kalium-Gehalte gemessen (Bergmann 1993, IFTNC 1987). Mit zwischen 4,0 mg/g und 4,7 mg/g waren die Werte in den Varianten Superabsorber (V5), Kompost (V9), Mykorrhiza-Kalk (V12), Mykorrhiza-Stockosorb® (V13) und Mykorrhiza-Stockosorb®-Kalk (V14) mit dem Kontrollwert vergleichbar und ebenfalls nicht ausreichend. Ein mit 3,1 mg/g noch deutlich geringerer Kalium-Gehalt wurde in der Kalk-Variante (V2) ermittelt. Die Werte in den übrigen Varianten waren teils erheblich höher und lagen sämtlich im ausreichenden, ausgenommen V8, V11 und V16 auch im guten Wertebereich nach Bergmann (1993) und IFTNC (1987).

Bei der Kombination von Kalk mit einer Wasserspeichersubstanz (Stockosorb® bzw. Superabsorber) oder Kompost (V4, V6, V10) wurden mit 10,6 mg/g, 9,9 mg/g und 9,0 mg/g gut doppelt so hohe Kalium-Nadelgehalte gemessen wie ohne Kalk-Gabe. In beiden Perlit-Varianten waren die Werte ausreichend bzw. gut, jedoch lag hier der Gehalt mit Kalk-Gabe (V8: 6,5 mg/g) deutlich niedriger als ohne Kalk-Gabe (V7: 9,0 mg/g). In der kombinierten Behandlung Mykorrhiza/Superabsorber (V15) wurde mit 6,6 mg/g ebenfalls ein ausreichender, bei zusätzlicher Kalk-Gabe (V16) sogar ein mit 11,5 mg/g fast doppelt so hoher, über ausreichender (Bergmann 1993) bzw. guter (IFTNC 1987) Gehalt ermittelt. Die Douglasien mit alleiniger Mykorrhiza-Impfung (V11) wiesen mit 7,7 mg/g ebenfalls einen ausreichenden KaliumNadelgehalt auf. 

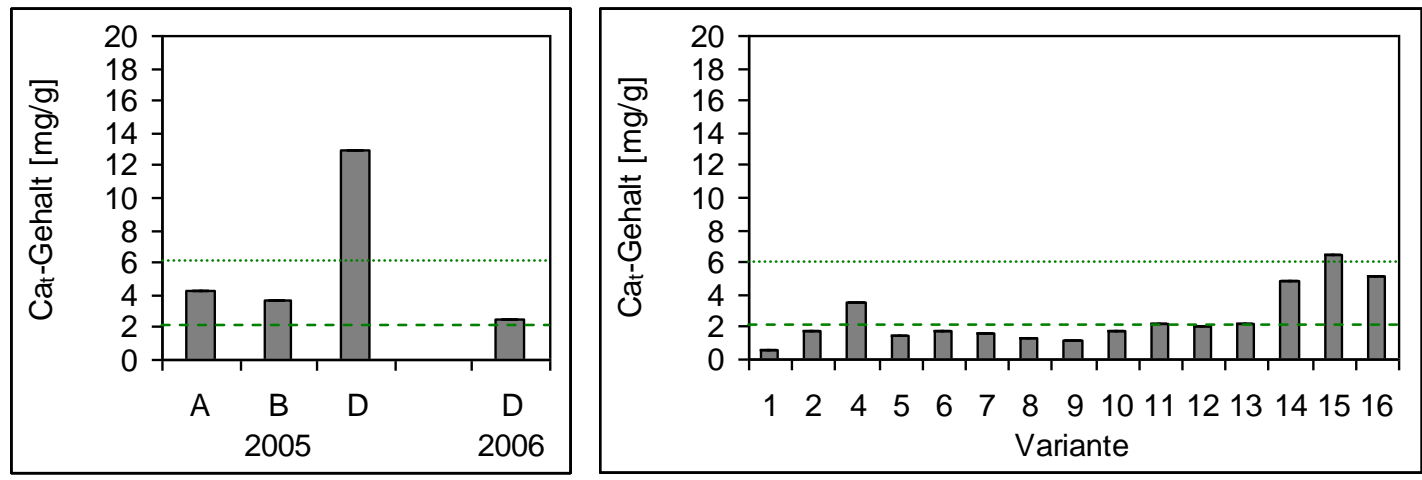

........ Obergrenze

------ Untergrenze ausreichend (Bergmann 1993)

Abb. 91 links: Cat-Gehalte [mg/g] in den Nadeln der Douglasien auf den Versuchsflächen A, B und D im 1. (2005) und auf Fläche D im 2. (2006) Vegetationsjahr (Mischproben); rechts: differenziert nach Varianten (s. S. 20) auf Fläche D im 2. Jahr (2006) (Mischproben)

Die durchschnittlichen Calcium-Gehalte in den Nadeln der Douglasien (s. Abb. 91) auf den Versuchsflächen A und B lagen mit 4,3 mg/g und 3,7 mg/g im ausreichenden Bereich $(2-6 \mathrm{mg} / \mathrm{g}$ ) nach Bergmann (1993). Auf Fläche D lag der Wert im 1. Untersuchungsjahr etwa 3-mal so hoch bei $13,0 \mathrm{mg} / \mathrm{g}$, womit er diesen ausreichenden Bereich um mehr als das Doppelte überstieg. Im 2. Untersuchungsjahr wurde dagegen ein erheblich geringerer mittlerer Calcium-Gehalt gemessen, der mit 2,5 mg/g im unteren Bereich der ausreichenden Spanne lag.

Je nach Variante wurden dabei zwischen $0,6 \mathrm{mg} / \mathrm{g}$ (V1) und 6,4 mg/g (V15) ermittelt. Der mit $0,6 \mathrm{mg} / \mathrm{g}$ geringste Wert, laut Bergmann (1993) nicht ausreichend, wurde in der unbehandelten Kontrolle (V1) gemessen. Alle Behandlungsvarianten wiesen höhere Calcium-Gehalte auf. In den Varianten Kalk (V2), Superabsorber (V5 ohne, V6 mit Kalk), Perlit (V7 ohne, V8 mit Kalk) und Kompost (V9 ohne, V10 mit Kalk) blieben diese mit Werten zwischen 1,2 mg/g und 1,8 mg/g ebenfalls unterhalb des ausreichenden Bereichs.

In den Mykorrhiza-Varianten V11 (Mykorrhiza), V12 Mykorhiza-Kalk) und V13 (MykorrhizaStockosorb $®$ ) wurden mit Werten von 2,0 mg/g bzw. 2,2 mg/g demnach knapp ausreichende Calcium-Gehalte gemessen. Die mit Abstand höchsten Gehalte wurden in den drei übrigen Mykorrhiza-Varianten V14 (Mykorrhiza-Stockosorb®-Kalk), V15 (Mykorrhiza-Superabsorber) und V16 (Mykorrhiza-Superabsorber-Kalk) gemessen, wobei die Werte in V14 und V16 mit 4,8 $\mathrm{mg} / \mathrm{g}$ und 5,1 mg/g innerhalb, in V15 mit 6,4 mg/g knapp oberhalb des ausreichenden Bereichs nach Bergmann (1993) lagen. Ebenso wie die Magnesium- und Mangan-Gehalte waren also auch die Calcium-Gehalte in diesen drei Varianten (V14, V15 und V16) deutlich höher als in den übrigen. Einen mit 3,5 mg/g geringeren, aber laut Bergmann (1993) voll ausreichenden CalciumGehalt wiesen die Douglasien in der Stockosorb®-Kalk-Variante (V4) auf. Ein im Vergleich zu den (meisten) anderen Varianten höherer Gehalt in dieser Variante (V4) wurde auch bei den Elementen Phosphor, Magnesium und Kobalt beobachtet.

Ein eindeutiger Einfluss der Düngung mit Magnesiumkalk (in den Varianten mit geraden Ziffern) auf die Calcium-Nadelgehalte war nicht feststellbar. 

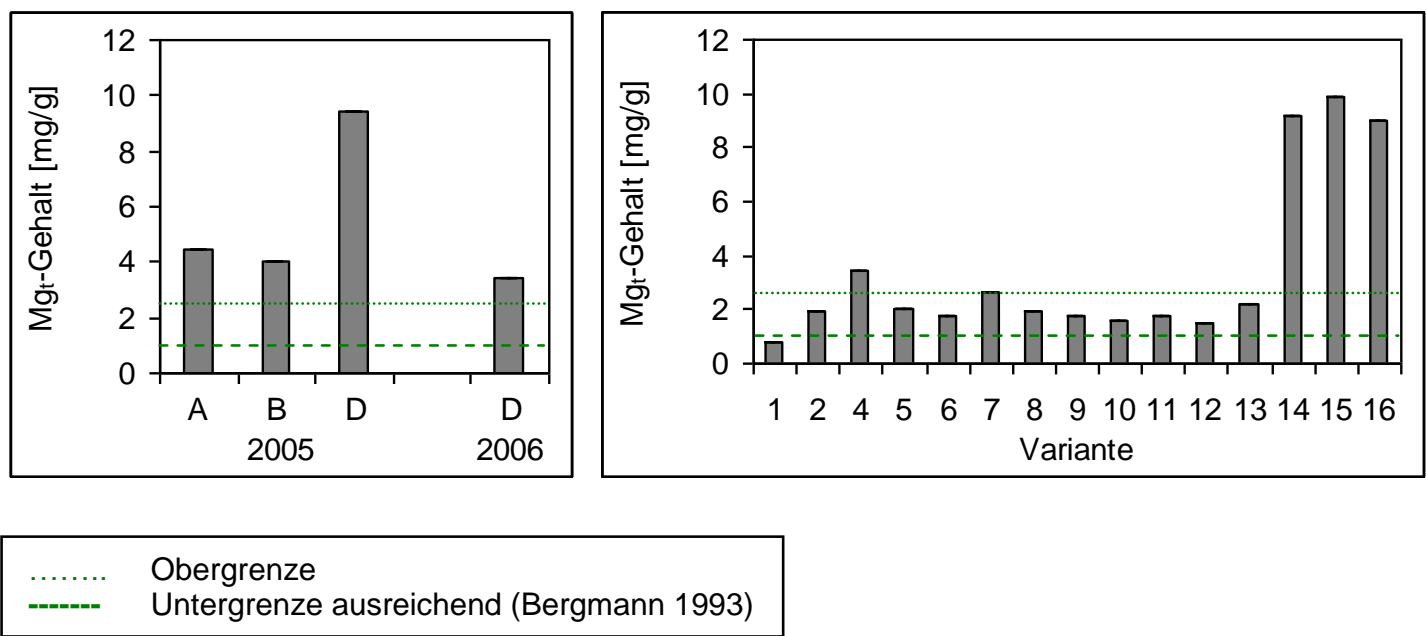

Abb. 92 links: $\mathrm{Mg}_{\mathrm{t}}-\mathrm{Gehalte}[\mathrm{mg} / \mathrm{g}]$ in den Nadeln der Douglasien auf den Versuchsflächen A, B und D im 1. (2005) und auf Fläche D im 2. (2006) Vegetationsjahr (Mischproben); rechts: differenziert nach Varianten (s. S. 20) auf Fläche D im 2. Jahr (2006) (Mischproben)

Die durchschnittlichen Magnesium-Gehalte in den Nadeln der Douglasien (s. Abb. 92) auf allen in den beiden Untersuchungsjahren beprobten Versuchsflächen lagen mit 4,5 mg/g auf Fläche A (2005), 4,0 mg/g auf Fläche B (2005), rund doppelt so hohen 9,4 mg/g auf Fläche D (2005) und deutlich geringeren 3,4 mg/g auf Fläche D (2006) oberhalb des Bereichs ausreichender Gehalte (1-2,5 mg/g) nach Bergmann (1993). Die im Rahmen des Deutschen Waldbodenberichtes an Fichten gemessenen Maximalwerte (1. Nadeljahrgang: $3 \mathrm{mg} / \mathrm{g}$; 3 . Nadeljahrgang: 2,6 mg/g; BMELF 1997b) wurden ebenfalls von allen Durchschnittswerten deutlich überschritten, wobei der im Anlagejahr auf Fläche D gemessene Wert mehr als das 3-fache betrug.

Je nach Variante wurden Magnesium-Gehalte zwischen 0,8 mg/g (V1) und 9,9 mg/g (V15) ermittelt. Der Kontrollwert war demnach nicht ausreichend. Alle Behandlungsvarianten wiesen höhere Magnesium-Nadelgehalte auf, davon befanden sich die Werte in den Varianten Kalk (V2), Superabsorber (V5) und Superabsorber-Kalk (V6), Perlit-Kalk (V8), Kompost (V9) und KompostKalk (V10), Mykorrhiza (V11), Mykorrhiza-Kalk (V12) und Mykorrhiza-Stockosorb® (V13) mit $1,5 \mathrm{mg} / \mathrm{g}$ bis $2,2 \mathrm{mg} / \mathrm{g}$ im ausreichenden Bereich. In der kalkfreien Perlit-Variante (V7) wurde mit 2,6 mg/g ein knapp über ausreichender Wert gemessen. Auch der Magnesium-Gehalt in der Stockosorb®-Kalk-Variante (V4) lag mit 3,5 mg/g oberhalb des ausreichenden Bereichs. Ein im Vergleich zu den (meisten) anderen Varianten höherer Gehalt in dieser Variante (V4) wurde auch bei den Elementen Phosphor, Calcium und Kobalt beobachtet. Mit Werten zwischen 9,0 $\mathrm{mg} / \mathrm{g}$ und 9,9 $\mathrm{mg} / \mathrm{g}$ vielfach über ausreichend mit Magnesium versorgt waren die übrigen Mykorrhiza-Varianten Mykorrhiza-Stockosorb®-Kalk (V14), Mykorrhiza-Superabsorber (V15) und Mykorrhiza-Superabsorber-Kalk (V16). Ebenso wie die Calcium- und Mangan-Gehalte lagen also auch die Magnesium-Gehalte in diesen drei Varianten (V14, V15 und V16) deutlich höher als in den anderen. Die Werte lagen mehr als 3-mal so hoch wie die im Rahmen des Deutschen Waldbodenberichtes an Fichten gemessenen Maximalwerte (1. Nadeljahrgang: 3 mg/g; 3. Nadeljahrgang: 2,6 mg/g; BMELF 1997b).

Ein eindeutiger Einfluss der Düngung mit Magnesium-Kalk (in den Varianten mit geraden Ziffern) auf die Magnesium-Nadelgehalte war nicht feststellbar. 


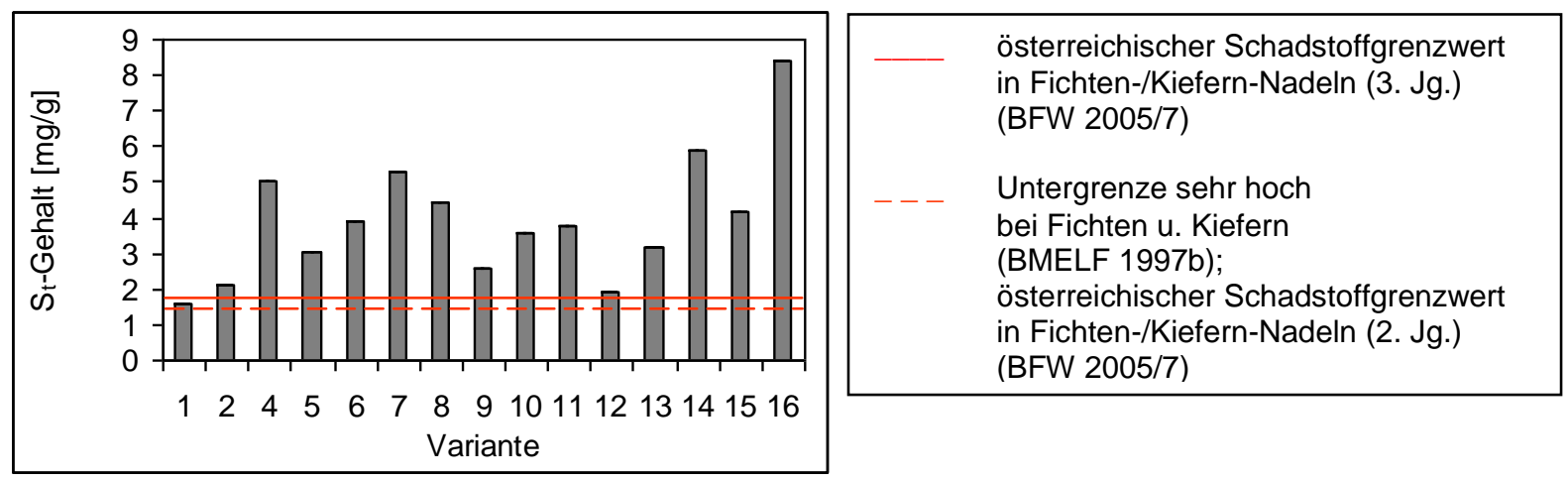

Abb. 93: St-Gehalte [mg/g] in den Nadeln der Douglasien-Varianten (s. S. 20) auf Versuchsfläche D im 2. (2006) Vegetationsjahr (Mischproben)

Der mittlere Schwefel-Gehalt (s. Abb. 93) der Douglasien-Nadeln (Fläche D, 2006) betrug 3,9 $\mathrm{mg} / \mathrm{g}$ bei einem Minimum von 1,6 mg/g (V1) und einem Maximum von 8,4 mg/g (V16). Damit waren sämtliche Werte sehr hoch laut der Bewertungsskala des Deutschen Waldbodenberichtes für Schwefelgehalte in Fichten- und Kiefern-Nadeln (BMELF 1997b) und lagen gleichzeitig oberhalb der entsprechenden österreichischen Schadstoffgrenzwerte (BFW 2005/7). In allen Behandlungsvarianten wurden Schwefel-Gehalte ermittelt, die - teilweise um ein Vielfaches höher lagen als in der unbehandelten Nullvariante (V1). Die im Rahmen des Deutschen Waldbodenberichtes an Fichten gemessenen Maximalwerte (1. Nadeljahrgang: 2,9 mg/g; 3 . Nadeljahrgang 5,4 mg/g; BMELF 1997b) wurden dabei teilweise deutlich überschritten. Der mit einigem Abstand höchste Schwefel-Gehalt, der mit 8,4 mg/kg mehr als 5-mal so hoch wie der Kontrollwert lag, wurde in den Nadeln der Douglasien gemessen, die mit Mykorrhiza, Superabsorber und Kalk (V16) gepflanzt wurden. In den Varianten Stockosorb®-Kalk (V4), Perlit (V7) und Mykorrhiza-Stockosorb®-Kalk (V14) waren die Schwefel-Gehalte mit 5,0 mg/g, $5,3 \mathrm{mg} / \mathrm{g}$ und 5,9 mg/g 3- bis 4-mal so hoch wie ohne Behandlung. In den übrigen Varianten betrugen sie mit Werten zwischen 3,0 und 4,4 mg/g das Doppelte bis 3-fache des Kontrollwertes. Ausnahmen bildeten die Varianten Mykorrhiza-Kalk (V12), Kalk (V2) und Kompost (V9), die mit 1,9 mg/g, 2,1 mg/g und 2,6 mg/g Schwefel-Gehalte etwas oberhalb der Kontrolle aufwiesen.

Spurennährelemente, Mikronährstoffe ( $\mathrm{Fe}, \mathrm{Mn}, \mathrm{Zn}, \mathrm{Cu}$ )

Die Eisen-Gehalte (s. Abb. 94) der Douglasien-Nadeln (Fläche D, 2006) schwankten zwischen 73 mg/kg (V12) und 519 mg/kg (V7). Der Durchschnittswert lag bei 297 mg/kg. Die relative Höhe der Eisen-Gehalte in den einzelnen Varianten lässt deutliche Parallelen zur Verteilung der Aluminium-Gehalte erkennen.

Die Douglasien der unbehandelten Kontrolle (V1) wiesen mit $473 \mathrm{mg} / \mathrm{kg}$ einen Wert an der Obergrenze des Bereichs hoher Eisen-Gehalte in Fichten- und Kiefern-Nadeln (100-500 mg/kg) laut Deutschem Waldbodenbericht (BMELF 1997b) auf. In der Perlit-Kalk-Variante wurde mit $437 \mathrm{mg} / \mathrm{kg}$ ein ähnlicher Wert gemessen, in der kalkfreien Perlit-Variante ein mit $519 \mathrm{mg} / \mathrm{kg}$ noch etwas höherer Wert, der bereits knapp im sehr hohen Bewertungsbereich (ab $500 \mathrm{mg} / \mathrm{kg}$ ) lag (BMELF 1997b). 

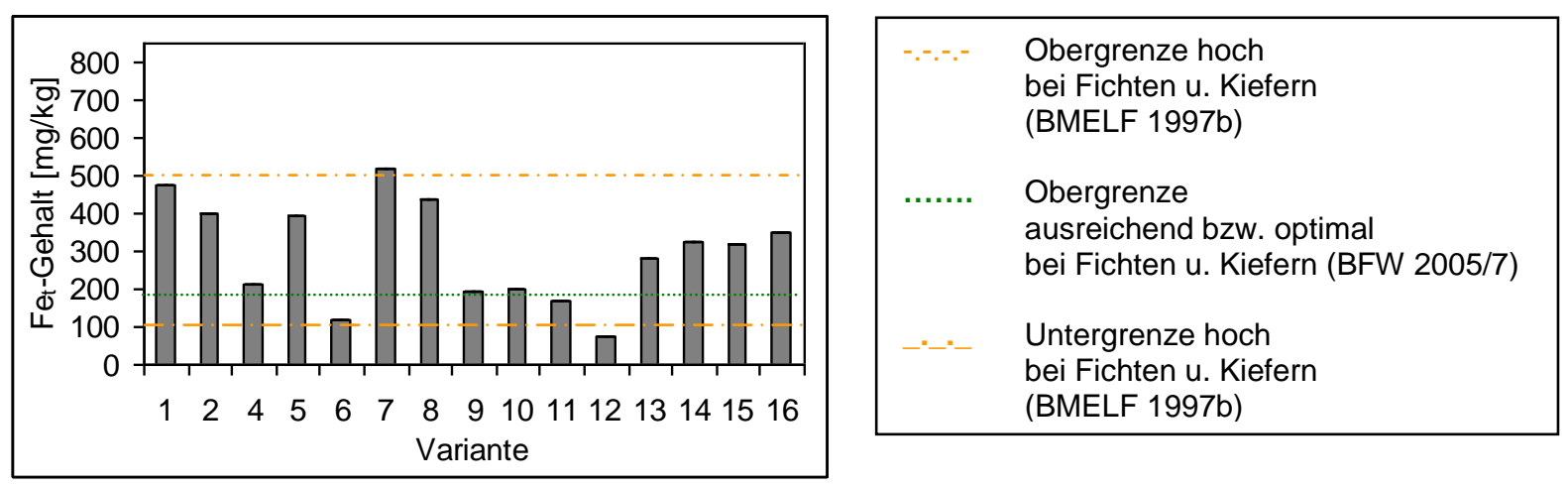

Abb. 94: $\mathrm{Fe}_{\mathrm{t}}-\mathrm{Gehalte}[\mathrm{mg} / \mathrm{kg}]$ in den Nadeln der Douglasien-Varianten (s. S. 20) auf Versuchsfläche D im 2. (2006) Vegetationsjahr (Mischproben)

Die Eisen-Nadelgehalte der Douglasien in allen übrigen Varianten lagen teilweise erheblich unterhalb des Kontrollwertes. In den Varianten mit Kalk- (V2) bzw. Superabsorber-Gabe (V5) betrugen sie rund $400 \mathrm{mg} / \mathrm{kg}$. In den kombinierten Behandlungen aus Mykorrhiza und Wasserspeichersubstanzen (V13, V15), teilweise mit zusätzlicher Kalk-Gabe (V14, V16), wurden Eisen-Nadelgehalte zwischen rund $280 \mathrm{mg} / \mathrm{kg}$ und rund $350 \mathrm{mg} / \mathrm{kg}$ ermittelt. Weniger als die Hälfte des Eisen-Gehaltes der Nullvariante (V1) wurde in den Varianten Stockosorb®-Kalk (V4), Kompost (V9), Kompost-Kalk (V10) und Mykorrhiza (V11) gemessen. Die Werte in diesen Varianten lagen teilweise etwas oberhalb (V4 mit $214 \mathrm{mg} / \mathrm{kg}$, V9 mit $193 \mathrm{mg} / \mathrm{kg}$ und V10 mit $199 \mathrm{mg} / \mathrm{kg}$ ), teilweise knapp innerhalb (V11 mit $166 \mathrm{mg} / \mathrm{kg}$ ) des ausreichenden bzw. optimalen Bereichs für Fichten und Kiefern (30-180 mg/kg) nach BFW (2005/7). In der MykorrhizaVariante mit zusätzlicher Kalk-Gabe (V12) wurde der Eisen-Nadelgehalt gegenüber dem Kontrollwert am deutlichsten auf $73 \mathrm{mg} / \mathrm{kg}$ gesenkt, was laut BMELF (1997b) im mittleren, laut BFW (2005/7) im ausreichenden/optimalen Bereich einzuordnen ist. Mit $116 \mathrm{mg} / \mathrm{kg}$ lag der Eisen-Gehalt in den Douglasien-Nadeln auch bei einer Behandlung mit Superabsorber und Kalk (V6) um ein Vielfaches unter dem Kontrollwert, laut BMELF (1997b) dennoch bereits im hohen, laut BFW (2005/7) ebenfalls im ausreichenden/optimalen Bereich. Mit Ausnahme von diesen beiden geringsten Werten (V6; V12) lagen alle ermittelten Eisen-Gehalte deutlich oberhalb des 90er-Perzentils der im Rahmen des Deutschen Waldbodenberichtes an Fichten gemessenen Werte (1. Nadeljahrgang: 120 mg/kg; 3. Nadeljahrgang: 135 mg/kg; BMELF 1997b).

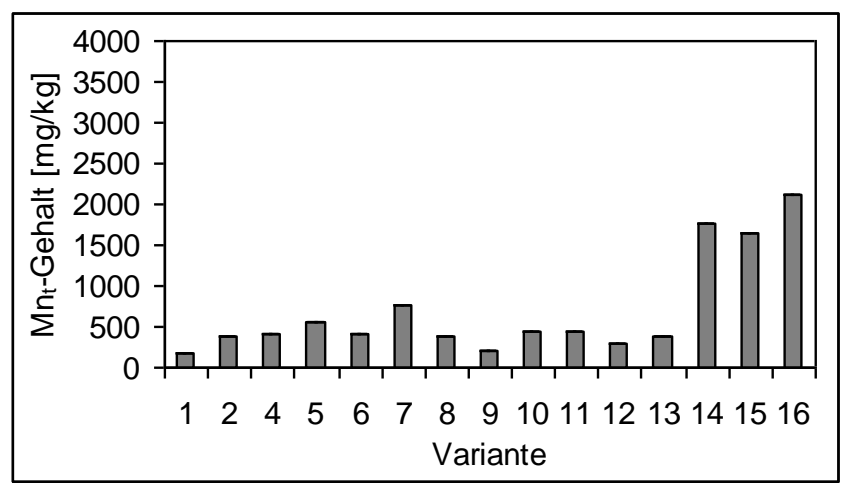

Abb. 95: $\mathrm{Mn}_{\mathrm{t}}$-Gehalte [mg/kg] in den Nadeln der Douglasien-Varianten (s. S. 20) auf Versuchsfläche D im 2. (2006) Vegetationsjahr (Mischproben)

Im Mittel wurde in den Douglasien-Nadeln auf Fläche D im 2. Untersuchungsjahr (2006) ein Mangan-Gehalt von $692 \mathrm{mg} / \mathrm{kg}$ gemessen. Die Werte in den einzelnen Varianten (s. Abb. 95) waren sehr unterschiedlich und schwankten zwischen $180 \mathrm{mg} / \mathrm{kg}$ in der unbehandelten 
Kontrolle (V1) und $2104 \mathrm{mg} / \mathrm{kg}$ in der Mykorrhiza-Superabsorber-Kalk-Variante (V16). Mit $1766 \mathrm{mg} / \mathrm{kg}$ immer noch beim 10-fachen des Kontrollwertes lag der Mangan-Gehalt in der Mykorrhiza-Stockosorb®-Kalk-Variante (V14), die sich von V16 nur durch die Verwendung einer anderen Wasserspeichersubstanz unterschied. In der kalkfreien MykorrhizaSuperabsorber-Variante (V15) wurde mit $1655 \mathrm{mg} / \mathrm{kg}$ ein mehr oder weniger ebenso hoher Wert ermittelt. Ebenso wie die Calcium- und Magnesium-Gehalte lagen also auch die ManganGehalte in diesen drei Varianten (V14, V15 und V16) deutlich höher als in den anderen.

Dagegen betrug der Mangan-Gehalt in der kalkfreien Mykorrhiza-Stockosorb®-Variante (V13) $384 \mathrm{mg} / \mathrm{kg}$ und lag damit in einem Bereich zwischen $306 \mathrm{mg} / \mathrm{kg}$ und $448 \mathrm{mg} / \mathrm{kg}$, in dem auch die mittleren Mangan-Gehalte der meisten übrigen Varianten lagen. Ausnahmen waren die Kompost-Variante (V9), deren Mangan-Nadelgehalt mit $213 \mathrm{mg} / \mathrm{kg}$ im Bereich der Nullvariante (V1) lag, sowie die Superabsorber- (V5) und die Perlit-Variante (V7), die mit $562 \mathrm{mg} / \mathrm{kg}$ bzw. $758 \mathrm{mg} / \mathrm{kg}$ höhere Mangan-Gehalte aufwiesen.

Die Bewertung der unterschiedlichen Mangan-Gehalte durch verschiedene Autoren weicht erheblich voneinander ab (s. ab S. 333). Das österreichische BFW (2005/7) sieht sämtliche Messwerte innerhalb des mit 50-6000 mg/kg sehr weit gefassten Bereichs ausreichender bzw. optimaler Mangan-Gehalte in Fichten- und Kiefern-Nadeln. Nach Bergmann (1993) lag bereits der in der Superabsorber-Variante (V5) gemessene Mangan-Gehalt von $562 \mathrm{mg} / \mathrm{kg}$ oberhalb des für Douglasien ausreichenden Bereichs (50-500 mg/kg). Nach der Bewertung von ManganGehalten in Fichten- und Kiefern-Nadeln im Deutschen Waldbodenbericht (BMELF 1997b) gelten nur die Werte in den Varianten V14 $(1766 \mathrm{mg} / \mathrm{kg})$ und V15 $(1655 \mathrm{mg} / \mathrm{kg})$ als mittel $(1000-2000 \mathrm{mg} / \mathrm{kg})$ sowie in Variante V16 $(2104 \mathrm{mg} / \mathrm{kg})$ als hoch $(2000-4000 \mathrm{mg} / \mathrm{kg})$, alle übrigen Messwerte werden als gering eingestuft.
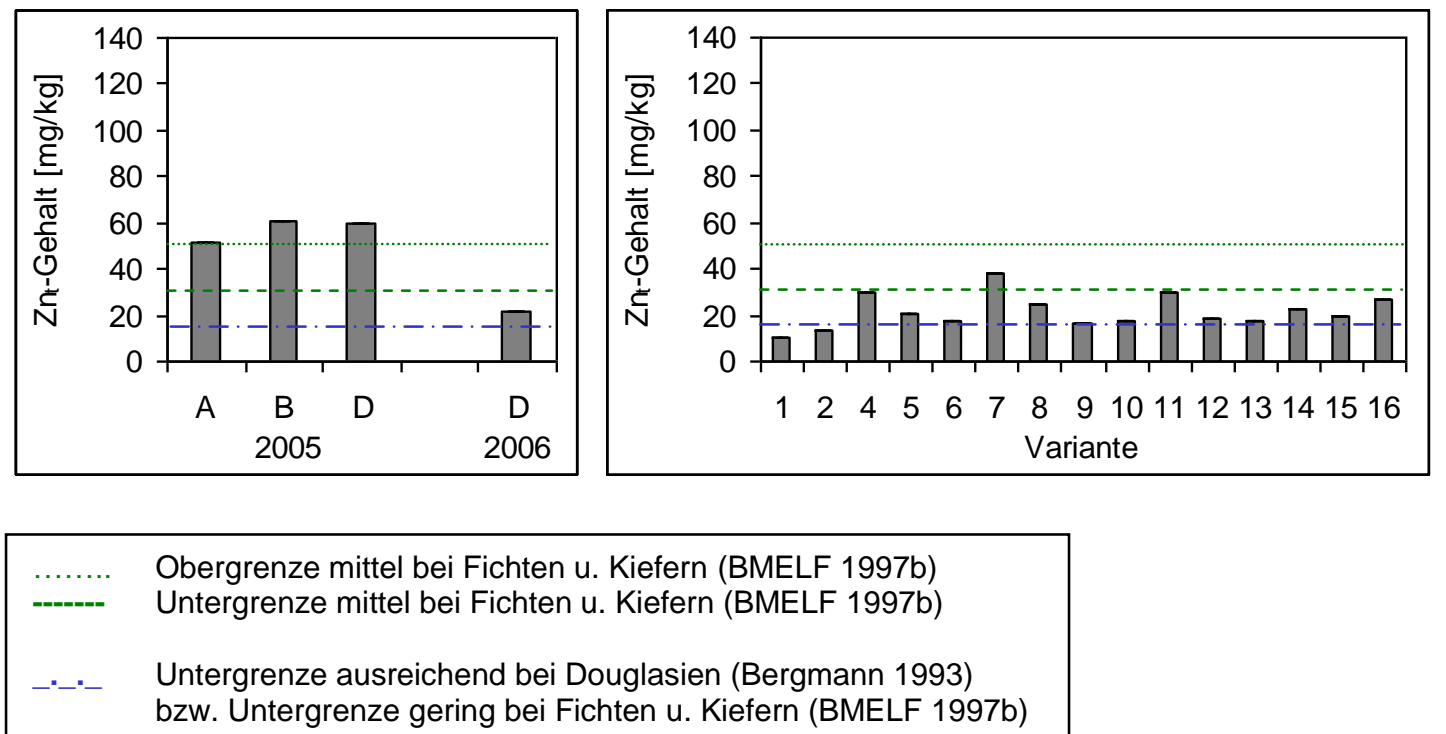

Abb. 96 links: $\mathrm{Zn}_{\mathrm{t}}-\mathrm{Gehalte}[\mathrm{mg} / \mathrm{kg}]$ in den Nadeln der Douglasien auf den Versuchsflächen A, B und D im 1. (2005) und auf Fläche D im 2. (2006) Vegetationsjahr (Mischproben); rechts: differenziert nach Varianten (s. S. 20) auf Fläche D im 2. Jahr (2006) (Mischproben)

Die mittleren Zink-Gehalte in den Nadeln der Douglasien (s. Abb. 96) lagen im 1. Untersuchungsjahr (2005) auf Fläche A bei $51,1 \mathrm{mg} / \mathrm{kg}$, auf Fläche B bei $60,8 \mathrm{mg} / \mathrm{kg}$ und auf Fläche D bei 59,8 mg/kg. Nach Bergmann (1993) sind diese Werte ausreichend (15-80 mg/kg), nach den Einstufungen von Zink-Gehalten in Fichten- und Kiefern-Nadeln im Deutschen 
Waldbodenbericht (BMELF 1997b) hoch (50-70 mg/kg). Im 2. Untersuchungsjahr (2006) lag der Durchschnittswert auf Fläche D mit 21,7 mg/kg bei weniger als der Hälfte des Vorjahreswertes auf dieser Fläche, was von Bergmann (1993) ebenfalls als ausreichend, vom BMELF (1997b) dagegen als gering eingestuft wird.

Je nach Variante wurden im 2. Jahr in den Douglasien-Nadeln auf Fläche D Zink-Gehalte zwischen 10,8 (V1) und 38,5 (V7) ermittelt. Der Kontrollwert war damit nicht ausreichend (Bergmann 1993) oder sehr gering (BMELF 1997b). Ebenso bewertet wird der mit 13,5 mg/kg nur wenig höhere Zink-Gehalt in der Kalk-Variante (V2).

In den übrigen Varianten lagen die Zink-Gehalte deutlich, in einzelnen Fällen um ein Vielfaches über dem Kontrollwert. Die Kompost-Varianten (V9, V10), die Superabsorber-Varianten (V5, V6) und ein Teil der Mykorrhiza-Varianten (V12, V13, V15) wiesen mit Werten zwischen 17,7 mg/kg und 20,6 mg/kg Zink-Gehalte im ausreichenden (Bergmann 1993) beziehungsweise geringen (BMELF 1997b) Wertebereich auf. Die gleiche Einstufung galt für die etwas höheren Gehalte in den Varianten Mykorrhiza-Stockosorb®-Kalk (V14: 22,2 mg/kg), Perlit-Kalk (V8: 25,2 mg/kg) und Mykorrhiza-Superabsorber-Kalk (V16: 26,5 mg/kg). Die Zink-Gehalte in den Nadeln der Douglasien in der Stockosorb®-Kalk-Variante (V4) und der reinen Mykorrhiza-Variante (V11) markierten mit knapp $30 \mathrm{mg} / \mathrm{kg}$ den Übergang zwischen geringen und mittleren Zink-Gehalten laut BMELF (1997b). Der mit 38,5 mg/kg mit Abstand höchste, laut BMELF (1997b) einzige als mittel eingestufte Zink-Gehalt wurde in den Nadeln der Douglasien gemessen, die allein mit Perlit (V7) gepflanzt worden waren.
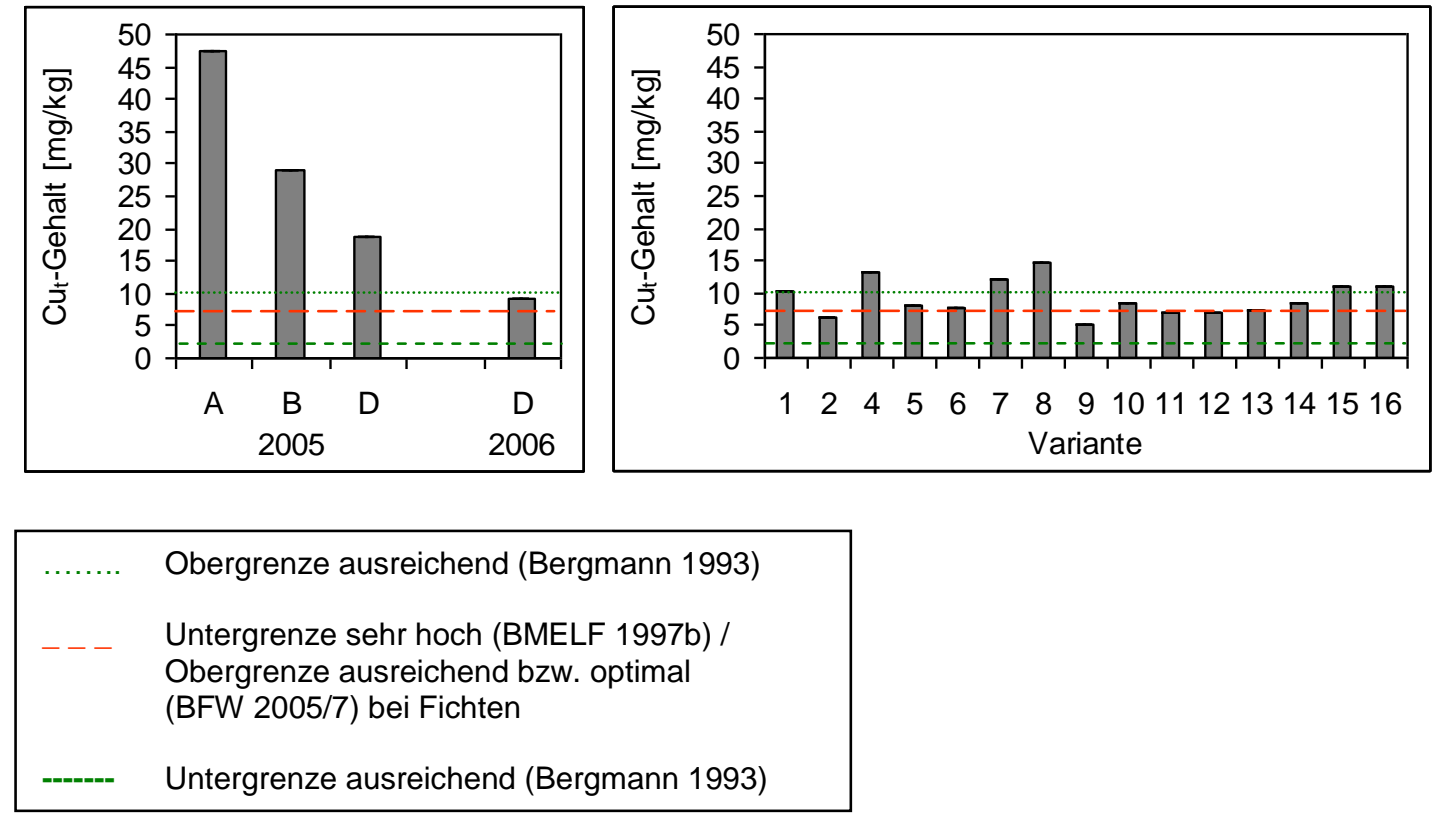

Abb. 97 links: $\mathrm{Cu}_{\mathrm{t}}-\mathrm{Gehalte}[\mathrm{mg} / \mathrm{kg}]$ in den Nadeln der Douglasien auf den Versuchsflächen A, B und D im 1. (2005) und auf Fläche D im 2. (2006) Vegetationsjahr (Mischproben); rechts: differenziert nach Varianten (s. S. 20) auf Fläche D im 2. Jahr (2006) (Mischproben)

Im 1. Untersuchungsjahr (2005) lagen die mittleren Kupfer-Gehalte der Douglasien-Nadeln (s. Abb. 97) auf Fläche A bei 47,3 mg/kg, auf Fläche B bei $29,0 \mathrm{mg} / \mathrm{kg}$ und auf Fläche D bei 18,6 $\mathrm{mg} / \mathrm{kg}$, was jeweils den Bereich ausreichender Kupfer-Gehalte in Douglasien-Nadeln (2-10 $\mathrm{mg} / \mathrm{kg}$ ) laut Bergmann (1993) unterschiedlich deutlich überstieg. Die im Rahmen des Deutschen Waldbodenberichts an Fichten gemessenen Maxima (1. Nadeljahrgang: $35 \mathrm{mg} / \mathrm{kg} ; 2$. 
Nadeljahrgang 28 mg/kg; BMELF 1997b) wurden von dem Durchschnittswert auf Fläche A erheblich überschritten.

Bei der Wiederholungsuntersuchung in 2006 wurde auf Fläche D ein rund halb so hoher Gehalt von 9,2 mg/kg ermittelt, der im oberen Bereich dieser ausreichenden Spanne lag. Im Deutschen Waldbodenbericht (BMELF 1997b) werden bereits Kupfer-Gehalte von über $7 \mathrm{mg} / \mathrm{kg}$ trockener Nadelmasse von Fichten und Kiefern als sehr hoch eingestuft. Nach Einschätzung des österreichischen BFW (2005/7) markiert dieser Wert die obere Grenze ausreichender bzw. optimaler Gehalte (3-7 mg/kg). Auf Fläche A betrug der Kupfer-Nadelgehalt das 6,5-fache, auf Fläche B das 4-fache und auf Fläche D (2005) das 2,5-fache dieses Wertes, der von weniger als 2 $\%$ aller im Rahmen des Deutschen Waldbodenberichts untersuchten Fichten überschritten wurde (BMELF 1997b).

In den Varianten auf Fläche D (2006) lagen die Kupfer-Gehalte der Douglasien-Nadeln zwischen $5,0 \mathrm{mg} / \mathrm{kg}$ (V9) und 14,9 mg/kg (V8).

Mit 10,1 mg/kg entsprach der Wert in der unbehandelten Kontrolle (V1) der oberen Grenze ausreichender Gehalte nach Bergmann (1993). Laut den Vergleichswerten des BMELF (1997b) für Fichten und Kiefern überstieg dieser Kontrollwert ebenso wie die Kupfer-Gehalte der meisten anderen Varianten die Untergrenze sehr hoher Gehalte deutlich. Höhere Kupfer-Gehalte als in der Nullvariante wurden in den Mykorrhiza-Superabsorber-Varianten (V15 ohne, V16 mit Kalk) mit jeweils $11,0 \mathrm{mg} / \mathrm{kg}$, in den Perlit-Varianten (V7 ohne, V8 mit Kalk) mit 12,1 mg/kg bzw. 14,9 mg/kg sowie in der Stockosorb®-Kalk-Variante (V4) mit 13,3 mg/kg gemessen.

In den Superabsorber-Varianten (V5 ohne, V6 mit Kalk), den Mykorrhiza-Stockosorb®Varianten (V13 ohne, V14 mit Kalk) und der Kompost-Kalk-Variante (V10) waren die KupferGehalte mit Werten zwischen 7,5 mg/kg und 8,6 mg/kg deutlich geringer als der Kontrollwert. Sie lagen innerhalb des ausreichenden Bereichs nach Bergmann (1993), jedoch immer noch im sehr hohen Wertebereich nach BMELF (1997b). Dessen unterer Grenze (7,0 mg/kg) entsprachen die wiederum etwas geringeren Werte in den übrigen Mykorrhiza-Varianten (V11 ohne, V12 mit Kalk). In der Kalk-Variante (V2) wurde mit 6,4 mg/kg ein Kupfer-Gehalt ermittelt, der nach BMELF (1997b) nur noch als hoch, nach BFW (2005/7) als ausreichend bzw. optimal einzustufen ist. Der mit Abstand geringste Kupfer-Gehalt, der mit 5,0 mg/kg nur halb so hoch wie der Kontrollwert lag, wurde in der Kompost-Variante (V9) gemessen. Nach der Bewertungsskala des BMELF (1997b) entspricht dieser Wert der Grenze zwischen mittleren und hohen Gehalten, nach BFW (2005/7) wäre er wiederum ausreichend bzw. optimal.

Alle in den Douglasien-Nadeln ermittelten Kupfer-Gehalte lagen deutlich oberhalb des 90erPerzentils der im Rahmen des Deutschen Waldbodenberichtes in Fichtennadeln gemessenen Gehalte (3,6 mg/kg im ersten, 3,1 mg/kg im dritten Nadeljahrgang; BMELF 1997b).

\section{Potentiell nützliche Elemente (Al, Na, Ni, Co)}

Der durchschnittliche Aluminium-Gehalt in den Nadeln der Douglasien (s. Abb. 98) auf Fläche D (2006) lag bei $598 \mathrm{mg} / \mathrm{kg}$ und damit oberhalb einer Extremversorgung bei Kiefern (391-550 $\mathrm{mg} / \mathrm{kg}$ ) nach Hofmann \& Krauss (1988). In den verschiedenen Behandlungsvarianten wurden mit Werten zwischen 189 mg/kg (V12) und 1087 mg/kg (V7) sehr unterschiedliche AluminiumGehalte gemessen. Deren relative Höhe in den einzelnen Varianten ließ deutliche Parallelen zur Verteilung der Eisen-Gehalte erkennen. 

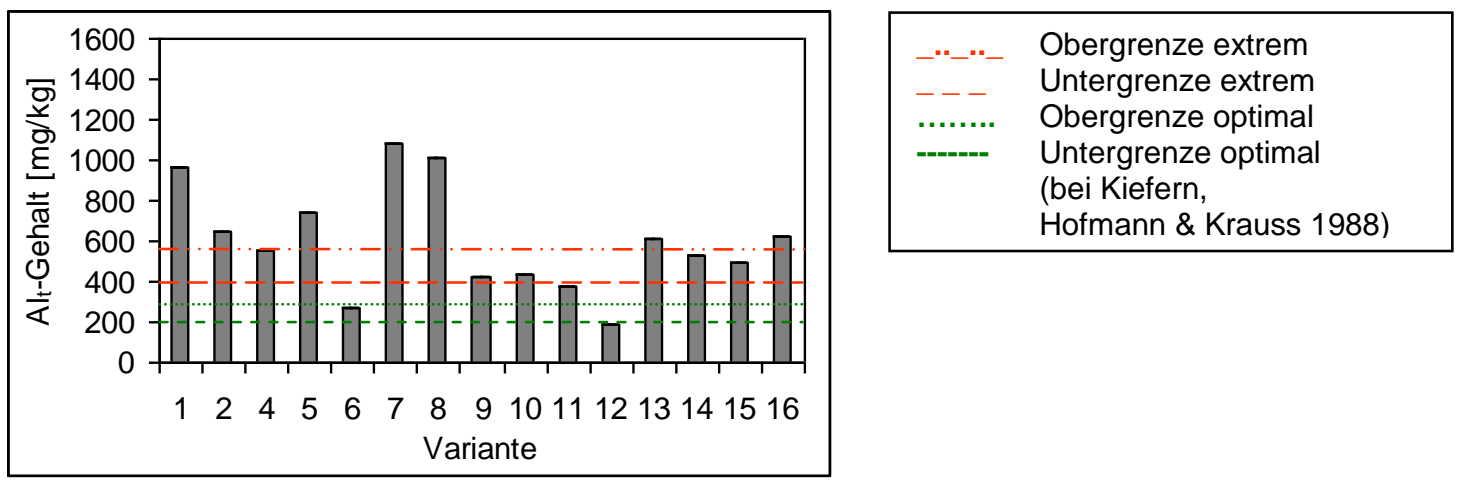

Abb. 98: $\mathrm{Al}_{\mathrm{t}}-\mathrm{Gehalte}[\mathrm{mg} / \mathrm{kg}]$ in den Nadeln der Douglasien-Varianten (s. S. 20) auf Versuchsfläche D im 2. (2006) Vegetationsjahr (Mischproben)

Höher als der Wert in der unbehandelten Kontrolle (V1) mit $963 \mathrm{mg} / \mathrm{kg}$ und wie dieser weit oberhalb des genannten extremen Bereichs lagen nur die Aluminium-Gehalte in den PerlitVarianten V7 (reines Perlit) mit 1087 mg/kg und V8 (Perlit-Kalk) mit 1013 mg/kg.

Deutlich geringer, aber immer noch oberhalb des Extrembereichs lagen die Gehalte in der Superabsorber-Variante (V5) mit $738 \mathrm{mg} / \mathrm{kg}$ sowie in den Varianten Kalk (V2), MykorrhizaStockosorb® (V13) und Mykorrhiza-Superabsorber-Kalk (V16) mit Werten zwischen 616 und $653 \mathrm{mg} / \mathrm{kg}$. In den Varianten Stockosorb®-Kalk (V4), Mykorrhiza-Stockosorb®-Kalk (V14) und Mykorrhiza-Superabsorber (V15) wurden mit Werten zwischen $495 \mathrm{mg} / \mathrm{kg}$ und $549 \mathrm{mg} / \mathrm{kg}$ Aluminium-Gehalte im oberen Bereich einer Extremversorgung ermittelt, während die Gehalte in den Kompost-Varianten mit 422 mg/kg (V9) bzw. 435 mg/kg (V10) im unteren Bereich einer Extremversorgung lagen. Die Douglasien mit reiner Mykorrhiza-Impfung (V11) wiesen einen Aluminium-Nadelgehalt auf, der mit 373 mg/kg nur noch knapp $39 \%$ des Kontrollwertes betrug und laut Vergleichswerten von Hofmann \& Krauss (1988) für Kiefern dem Bereich einer Überversorgung zuzuordnen ist. In der Superabsorber-Kalk-Variante (V6) lag der Gehalt mit 274 $\mathrm{mg} / \mathrm{kg}$ (28\% des Kontrollwertes) demnach im Optimalbereich, während in der Kombination von Mykorrhiza und Kalk (V12) mit 189 mg/kg (20\% des Kontrollwertes) sogar ein Wert im Bereich einer Unterversorgung gemessen wurde.

Um die teilweise exorbitant hohen Aluminium-Gehalte in den Douglasien-Nadeln vergleichend einordnen zu können, sei auf die im Rahmen des Deutschen Waldbodenberichts 1996 erhobenen Daten verwiesen: Der im 1. Nadeljahrgang von Fichten gemessenen Maximalwert lag dort bei 223 mg/kg. Im 3. Nadeljahrgang wurde ein Maximum von 396 mg/kg ermittelt (BMELF 1997b). Wie oben dargestellt, wurde der Höchstwert des 1. Nadeljahrgangs von den AluminiumGehalten in 14 der 15 beprobten Varianten, der Höchstwert des 3. Nadeljahrgangs von den Gehalten in 12 der 15 beprobten Varianten deutlich überschritten. Der auf Versuchsfläche D gemessene Höchstwert stellte das knapp 5-fache bzw. knapp 3-fache der Maxima im Deutschen Waldbodenbericht dar.

Aluminium-Toxizität ist laut Bergmann (1993) besser anhand einer mangelhaften PhosphorVersorgung (bei ausreichenden Phosphor-Gehalten im Boden, wie in diesem Fall, s. S. 48) als anhand des tatsächlichen Aluminium-Gehaltes in den Assimilationsorganen zu diagnostizieren. Die dargestellten Phosphor-Gehalte deuten demnach auf $\mathrm{Al}^{3+-}$ Überschuss und AluminiumToxizität zumindest in den Varianten V1, V5 und V14 hin. 


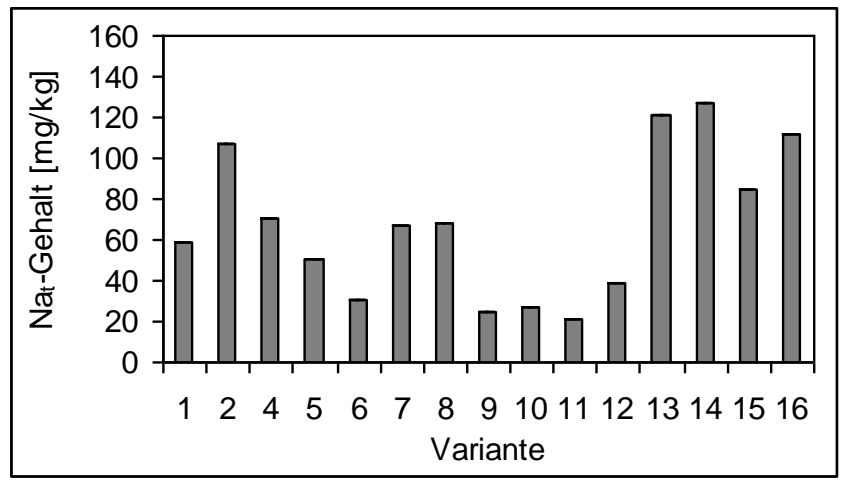

Abb. 99: $\mathrm{Na}_{\mathrm{t}}$-Gehalte [mg/kg] in den Nadeln der Douglasien-Varianten (s. S. 20) auf Versuchsfläche D im 2. (2006) Vegetationsjahr (Mischproben)

Der Natrium-Gehalt in den Nadeln der Douglasien (s. Abb. 99) auf Fläche D lag im 2. Untersuchungsjahr (2006) bei durchschnittlich 67,4 mg/kg. Je nach Variante wurden Werte zwischen 21,6 mg/kg (V11) und 126,9 mg/kg (V14) ermittelt. Alle Messwerte lagen im Bereich der im Deutschen Waldbodenbericht (BMELF 1997b) gemessenen und nicht weiter klassifizierten Natrium-Gehalte von Fichten und Kiefern.

Die Natrium-Gehalte in der Superabsorber-Variante (V5) mit 51,1 mg/kg sowie in der Stockosorb®-Kalk-Variante (V4) und den beiden Perlit-Varianten (V7, V8) mit leicht höheren rund $70 \mathrm{mg} / \mathrm{kg}$ lagen im Bereich des Kontrollwertes $(58,8 \mathrm{mg} / \mathrm{kg}$ ). In der MykorrhizaSuperabsorber-Variante (V15) mit 84,7 mg/kg, vor allem aber in den Mykorrhiza-Stockosorb®(V13, V14), der Mykorrhiza-Superabsorber-Kalk- (V16) und der reinen Kalk-Variante (V2) lagen die Natrium-Gehalte mit Werten zwischen $107,4 \mathrm{mg} / \mathrm{kg}$ und 126,9 mg/kg deutlich darüber. Erheblich geringere Gehalte als in der unbehandelten Kontrolle (V1) wurden dagegen in der Mykorrhiza-Kalk-Variante (V12) mit 39,0 mg/kg, vor allem jedoch in der reinen MykorrhizaVariante (V11), den Kompost-Varianten (V9, V10) und der Superabsorber-Kalk-Variante (V6) mit Werten zwischen $21,6 \mathrm{mg} / \mathrm{kg}$ und $30,6 \mathrm{mg} / \mathrm{kg}$ gemessen.
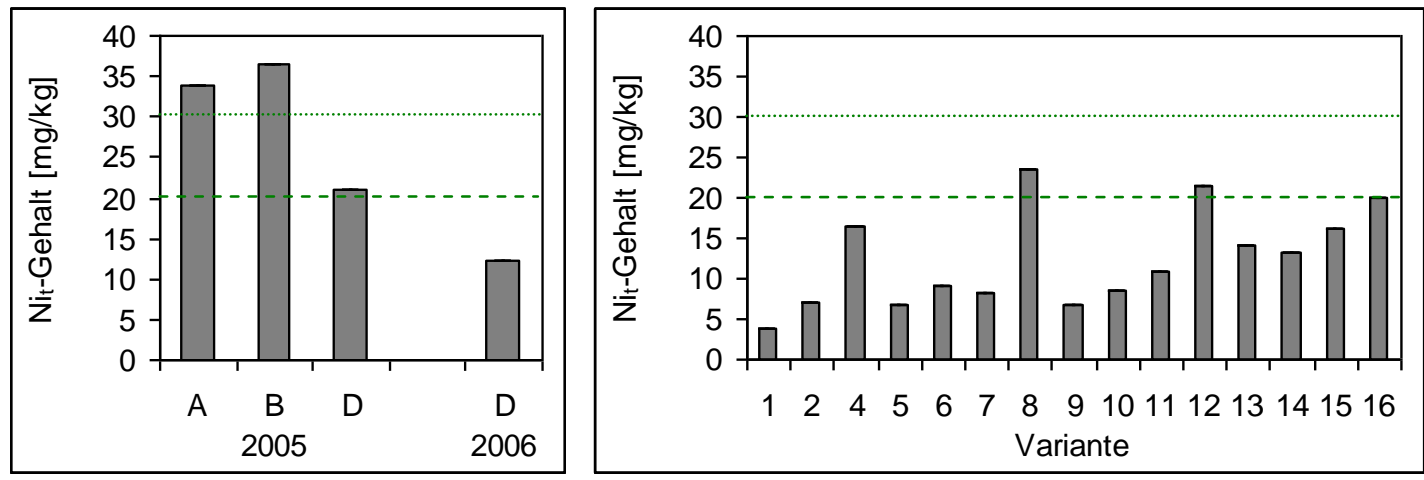

Obergrenze

Untergrenze Normalgehalte in Pflanzen (Smidt 1999)

Abb. 100 links: $\mathrm{Ni}_{\mathrm{t}}$-Gehalte $[\mathrm{mg} / \mathrm{kg}]$ in den Nadeln der Douglasien auf den Versuchsflächen A, B und D im 1. (2005) und auf Fläche D im 2. (2006) Vegetationsjahr (Mischproben); rechts: differenziert nach Varianten (s. S. 20) auf Fläche D im 2. Jahr (2006) (Mischproben)

Die durchschnittlichen Nickel-Gehalte in den Nadeln der Douglasien (s. Abb. 100) auf den Flächen A und B überstiegen mit 33,9 mg/kg bzw. 36,5 mg/kg die Normalgehalte in Pflanzen 
(20-30 mg/kg) nach Smidt (1999). Auf Fläche D lag der Nickel-Gehalt in 2005 mit 21,1 mg/g noch innerhalb dieser Normalgehalte, in 2006 mit 12,4 mg/kg dagegen deutlich darunter.

Dort bestanden in den einzelnen Varianten sehr unterschiedliche Nickel-Gehalte zwischen 3,9 $\mathrm{mg} / \mathrm{kg}$ in der unbehandelten Kontrolle (V1) und 23,4 mg/kg in der Perlit-Kalk-Variante (V8). Nur in dieser und in der Mykorrhiza-Kalk-Variante (V12) mit 21,5 mg/kg wurden NickelNadelgehalte innerhalb der genannten Normalgehalte gemessen. Der Wert in der MykorrhizaSuperabsorber-Kalk-Variante (V16) mit 19,9 mg/kg markierte die untere Grenze dieser Normalgehalte. Die Stockosorb-Kalk-Variante (V4) sowie die Mykorrhiza-Varianten V13 (Mykorrhiza-Stockosorb®), V14 (Mykorrhiza-Stockosorb®-Kalk) und V15 (MykorrhizaSuperabsorber) wiesen Nickel-Gehalte von $13,2 \mathrm{mg} / \mathrm{kg}$ bis $16,6 \mathrm{mg} / \mathrm{kg}$ auf. In der reinen Mykorrhiza-Variante (V11) wurden $10,9 \mathrm{mg} / \mathrm{kg}$ ermittelt. Die übrigen Varianten hatten geringere Nickel-Gehalte zwischen $6,7 \mathrm{mg} / \mathrm{kg}$ und 9,2 mg/kg.
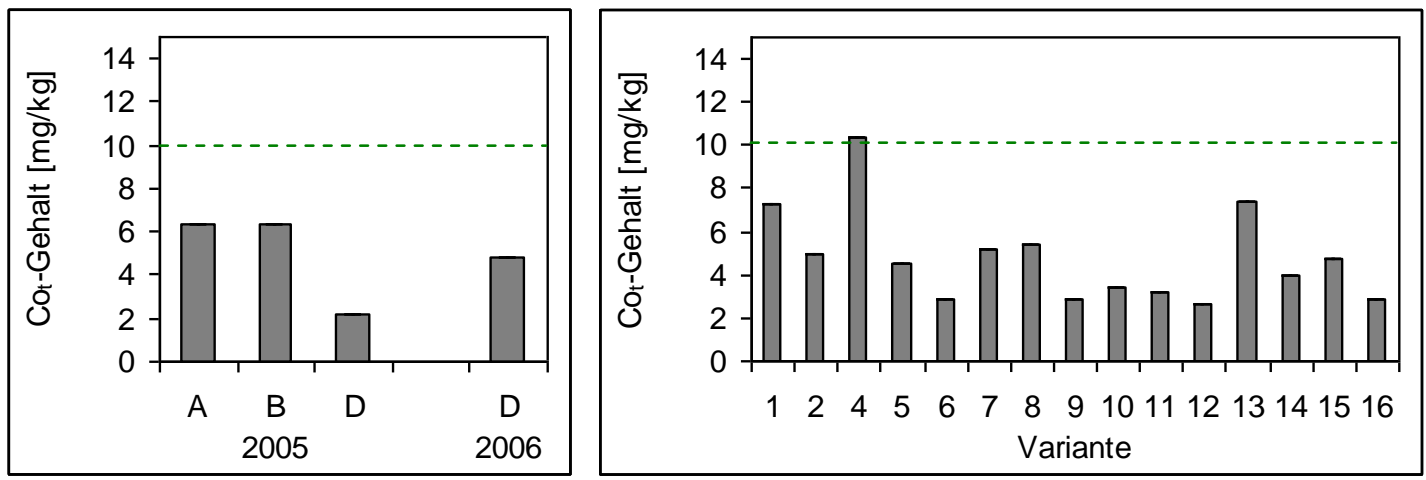

Untergrenze Normalgehalte in Pflanzen (Smidt 1999)

Abb. 101 links: $\mathrm{Co}_{\mathrm{t}}$-Gehalte [mg/kg] in den Nadeln der Douglasien auf den Versuchsflächen A, B und D im 1. (2005) und auf Fläche D im 2. (2006) Vegetationsjahr (Mischproben); rechts: differenziert nach Varianten (s. S. 20) auf Fläche D im 2. Jahr (2006) (Mischproben)

Die mittleren Kobalt-Gehalte in den Nadeln der Douglasien (s. Abb. 101) betrugen auf Fläche A und B $6,3 \mathrm{mg} / \mathrm{kg}$, auf Fläche D deutlich geringere $2,2 \mathrm{mg} / \mathrm{kg}$, die im 2. Untersuchungsjahr auf 4,8 $\mathrm{mg} / \mathrm{kg}$ anstiegen. Die einzelnen Varianten auf Fläche D (2006) wiesen Kobalt-Nadelgehalte zwischen 2,6 mg/kg (V12) und 10,4 mg/kg (V4) auf. Damit lagen alle Messwerte (ausgenommen der in der Stockosorb®-Kalk-Variante (V4) ermittelte) unterhalb der Normalgehalte (10-20 $\mathrm{mg} / \mathrm{kg}$ ) nach Smidt (1999). Ein im Vergleich zu den (meisten) anderen Varianten höherer Gehalt in Variante V4 wurde auch bei den Elementen Phosphor, Calcium und Magnesium beobachtet.

In der Mykorrhiza-Stockosorb®-Variante (V13) wurde ein Kobalt-Gehalt von 7,3 mg/kg gemessen, was dem Kontrollwert (V1) entsprach. Die mit Werten zwischen 2,6 mg/kg und 3,4 $\mathrm{mg} / \mathrm{kg}$ geringsten Kobalt-Gehalte hatten die Douglasien in der Superabsorber-Kalk-Variante (V6), den beiden Kompost-Varianten sowie den Mykorrhiza-Varianten V11 (reine Mykorrhiza), V12 (Mykorrhiza-Kalk) und V16 (Mykorrhiza-Superabsorber-Kalk). Die übrigen Varianten wiesen Kobalt-Gehalt zwischen 4,0 mg/kg und 5,4 mg/kg auf. 
Toxisch wirkende Schwermetalle ohne Nährelementfunktion ( $\mathrm{Pb}, \mathrm{Cd}, \mathrm{Cr})$

Auf Fläche A und Fläche D wurden im 1. Untersuchungsjahr (2005) in den Douglasien-Nadeln Blei-Gehalte (s. Abb. 102) von im Durchschnitt 2,4 mg/kg bzw. 3,9 mg/kg gemessen. Auf Fläche B und im Folgejahr (2006) auch auf Fläche D gab es dagegen keine Blei-Gehalte oberhalb der Nachweisgrenze.

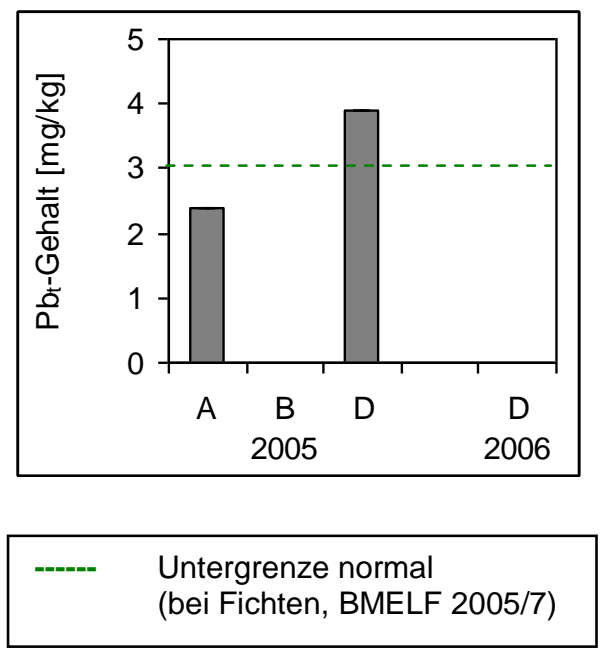

Abb. 102: $\mathrm{Pb}_{\mathrm{t}}$-Gehalte $[\mathrm{mg} / \mathrm{kg}]$ in den Nadeln der Douglasien auf den Versuchsflächen A, B und D im 1. (2005) und auf Fläche D im 2. (2006) Vegetationsjahr (Mischproben)

Wie auch bei den anderen beprobten Baumarten lagen die Messwerte deutlich unterhalb der sehr allgemeinen Normalgehalte in Pflanzen (10-20 mg/kg) nach Smidt (1999) und der ebenso allgemeinen kritischen Konzentrationen (30-300 mg/kg) in Alloway (1999).

Nach der Bewertungstabelle des österreichischen BFW (2005/7) für Element-Gehalte in Fichtennadeln war der Blei-Gehalt in den Douglasien-Nadeln auf Fläche A als minimal $(<3$ $\mathrm{mg} / \mathrm{kg})$, auf Fläche D als normal (3,0 - 5,9 mg/kg) einzustufen.

Zieht man die im Rahmen des Deutschen Waldbodenberichts 1996 (BMELF 1997b) im 1. Nadeljahrgang von Fichten gemessenen Blei-Gehalte vergleichend heran, so lagen die auf Fläche A und D ermittelten Durchschnittswerte oberhalb deren 90er-Perzentils $(1,4 \mathrm{mg} / \mathrm{kg})$. Bei einem Vergleich mit den Werten für den 3. Nadeljahrgang lag der Blei-Gehalt auf Fläche A zwischen dem Median (1,9 mg/kg) und dem 75er Perzentil (2,7 mg/kg), der Gehalt auf Fläche D entsprach dem 90er-Perzentil (3,9 mg/kg). 

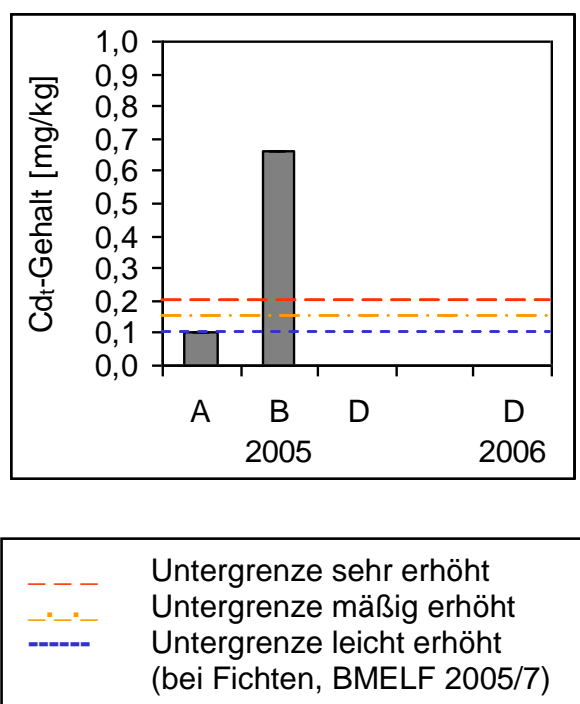

Abb. 103: $\mathrm{Cd}_{\mathrm{t}}-\mathrm{Gehalte}[\mathrm{mg} / \mathrm{kg}]$ in den Nadeln der Douglasien auf den Versuchsflächen A, B und D im 1. (2005) und auf Fläche D im 2. (2006) Vegetationsjahr (Mischproben)

Während auf Fläche D in beiden Untersuchungsjahren kein Cadmium nachweisbar war, enthielten die Douglasien-Nadeln auf Fläche A und B in 2005 durchschnittlich 0,1 mg/kg bzw. $0,66 \mathrm{mg} / \mathrm{kg}$ (s. Abb. 103). Wie auch bei den anderen beprobten Baumarten lagen die Messwerte deutlich unterhalb der sehr allgemeinen Normalgehalte in Pflanzen $(10-20 \mathrm{mg} / \mathrm{kg})$ nach Smidt (1999) und der ebenso allgemeinen kritischen Konzentrationen $(30-300 \mathrm{mg} / \mathrm{kg}$ ) in Alloway (1999).

Die Bewertungstabelle des österreichischen BFW (2005/7) für Element-Gehalte in Fichtennadeln stuft den Cadmium-Gehalt in den Douglasien-Nadeln auf Fläche A als leicht erhöht $(0,10-0,14 \mathrm{mg} / \mathrm{kg})$, auf Fläche B als sehr erhöht $(>0,20 \mathrm{mg} / \mathrm{kg})$ ein.

Der Wert auf Fläche A entsprach dem Median der im Deutschen Waldbodenbericht an Fichten vorgenommenen Messungen für den 1 . Nadeljahrgang $(0,11 \mathrm{mg} / \mathrm{kg})$ bzw. lag zwischen dem Median (0,08 mg/kg) und dem 75er Perzentil $(0,14 \mathrm{mg} / \mathrm{kg})$ für den 3. Nadeljahrgang. Der Wert auf Fläche B lag dagegen deutlich oberhalb des entsprechenden $90 \mathrm{er}-$ Perzentils $(0,3 \mathrm{mg} / \mathrm{kg} \mathrm{im}$ 1., $0,22 \mathrm{mg} / \mathrm{kg}$ im 3. Nadeljahrgang).

Die Blei- und Cadmium-Gehalte in den Nadeln sämtlicher Douglasien-Varianten auf Fläche D (2006) lagen unterhalb der Nachweisgrenzen für diese Elemente. 

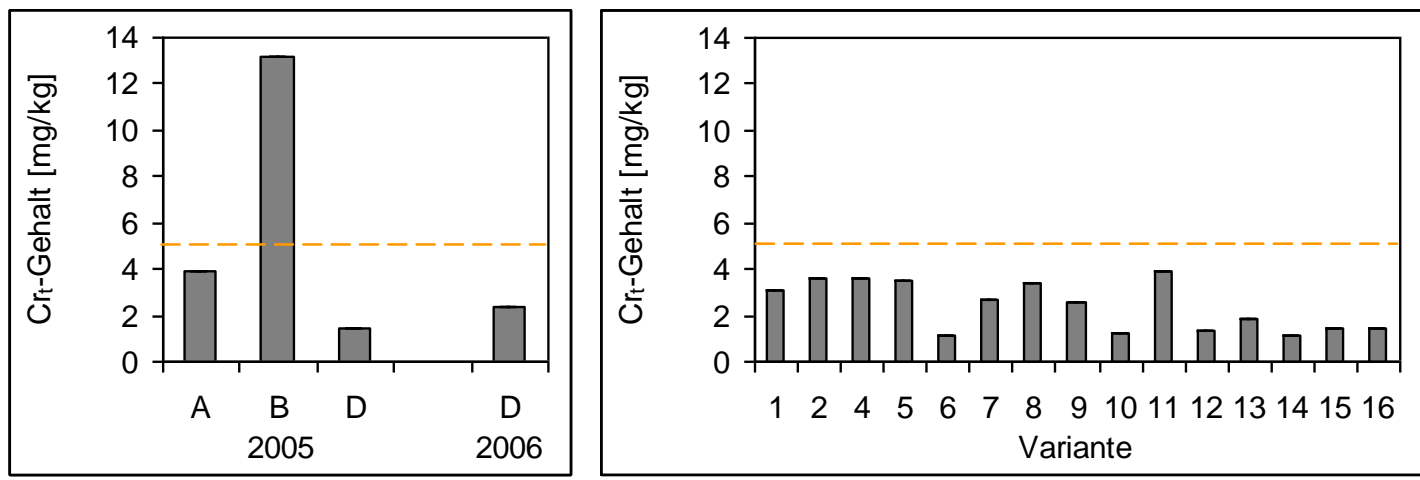

Untergrenze kritischer Bereich in Pflanzen (Alloway 1999)

Abb. 104 links: $\mathrm{Cr}_{\mathrm{t}}-\mathrm{Gehalte}[\mathrm{mg} / \mathrm{kg}]$ in den Nadeln der Douglasien auf den Versuchsflächen A, B und D im 1. (2005) und auf Fläche D im 2. (2006) Vegetationsjahr (Mischproben); rechts: differenziert nach Varianten (s. S. 20) auf Fläche D im 2. Jahr (2006) (Mischproben)

Die in den Nadeln der Douglasien gemessenen durchschnittlichen Chrom-Gehalte (s. Abb. 104) lagen mit 3,9 mg/kg auf Versuchsfläche A und 1,4 mg/kg (2005) bzw. 2,4 mg/kg (2006) auf Fläche D deutlich unterhalb des kritischen Bereichs bei Alloway (1999), oberhalb dessen toxische Auswirkungen wahrscheinlich sind (5-30 mg/kg). Der wesentlich höhere Mittelwert auf Fläche B (13,2 mg/kg) lag dagegen bereits innerhalb dieses Bereichs.

Die in 2006 in den einzelnen Varianten auf Fläche D ermittelten Chrom-Gehalte der DouglasienNadeln bewegten sich zwischen 1,1 mg/kg (V6, V14) und 3,9 mg/kg (V11) und lagen damit sämtlich unterhalb des genannten kritischen Bereichs. In den Varianten mit Superabsorber und Kalk (V6), Kompost und Kalk (V10) sowie in allen Mykorrhiza-Kombinationsbehandlungen (V12-V16) mit Ausnahme der reinen Mykorrhiza-Variante (V11) waren die Chrom-Gehalte mit Werten zwischen 1,1 und 1,8 mg/kg deutlich geringer als in der unbehandelten Kontrolle mit 3,1 $\mathrm{mg} / \mathrm{kg}$. Die übrigen Varianten wiesen Chrom-Gehalte im Bereich des Kontrollwertes auf.

\subsubsection{Wald-Kiefer}

Im Folgenden werden die Ergebnisse der Nadelanalysen (Mischproben, s. S. 26) zur Versorgung und Belastung der Kiefern auf den drei Versuchsflächen insgesamt sowie innerhalb von einzelnen Bodenhilfsstoff-Varianten auf Versuchsfläche D dargestellt.

Aufgrund hoher Pflanzenausfälle bei dieser Baumart konnten die Versuchsvarianten V2, V3, V4, V5, V6, V7, V8 (s. S. 20) nicht in die Untersuchungen mit einbezogen werden.

\section{Hauptnährelemente, Makronährstoffe (N, P, K, Ca, Mg, S)}

Laut den Einstufungen in BFW (2005/7), Heinsdorf (1999) sowie Hofmann \& Krauss (1988) lagen die in den Kiefern-Nadeln im Freiland-Versuch gemessenen Stickstoff-Gehalte (s. Abb. 105) im nicht ausreichenden, geringen bzw. unterversorgten Wertebereich. 

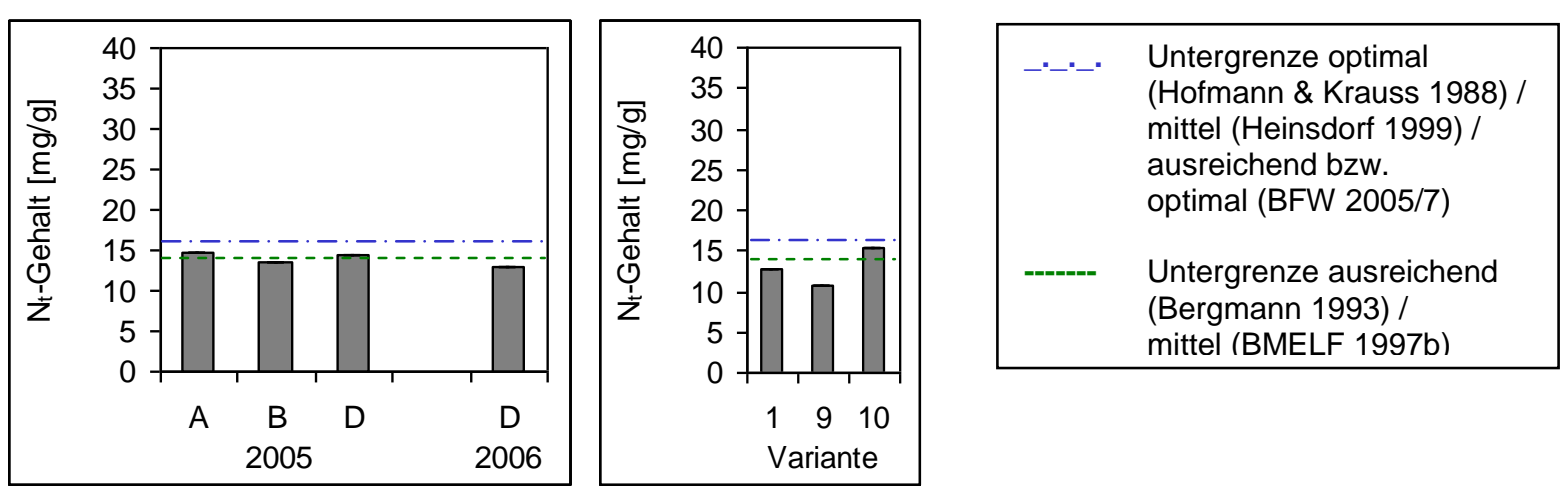

Abb. 105 links: $\mathrm{N}_{\mathrm{t}}-\mathrm{Gehalte}[\mathrm{mg} / \mathrm{g}]$ in den Nadeln der Kiefern auf den Versuchsflächen A, B und D im 1. (2005) und auf Fläche D im 2. (2006) Vegetationsjahr (Mischproben); rechts: differenziert nach Varianten (s. S. 20) auf Fläche D im 2. Jahr (2006) (Mischproben)

Nach Bergmann (1993) und dem BMELF (1997b) waren die Stickstoff-Gehalte in den KiefernNadeln auf Fläche A und D (2005) mit 14,3 mg/g bzw. 14,7 mg/g knapp ausreichend bzw. mittel, die Werte auf Fläche B $(13,6 \mathrm{mg} / \mathrm{g})$ und im 2. Versuchsjahr auch auf Fläche D $(13,0 \mathrm{mg} / \mathrm{g})$ dagegen ebenfalls nicht ausreichend bzw. gering.

Der Stickstoff-Gehalt in den Kiefern-Nadeln der dortigen Nullvariante war nach den herangezogenen Quellen mit 12,7 mg/g sehr gering, mangelhaft, unterversorgt, weniger als ausreichend (BMELF 1997b, BFW 2005/7, Hofmann \& Krauss 1988, Bergmann 1993) bzw. gering (Heinsdorf 1999). Ebenso ist der mit $10,8 \mathrm{mg} / \mathrm{g}$ noch etwas niedrigere Stickstoff-Gehalt in der Kompostvariante (V9) einzuschätzen, der nach Hofmann \& Krauss (1988) bereits im Mangelbereich lag. Die Düngung der Kiefern mit Kompost und Kalk (V10) führte mit 15,4 mg/g zu einem Stickstoff-Gehalt leicht über dem Kontrollwert, der uneinheitlich einerseits als ausreichend (Bergmann 1993) oder sogar mittel-hoch (BMELF 1997b), andererseits als nicht ausreichend (BFW 2005/7), gering (Heinsdorf 1999) und im Bereich einer Unterversorgung (Hofmann \& Krauss 1988) bewertet wird.
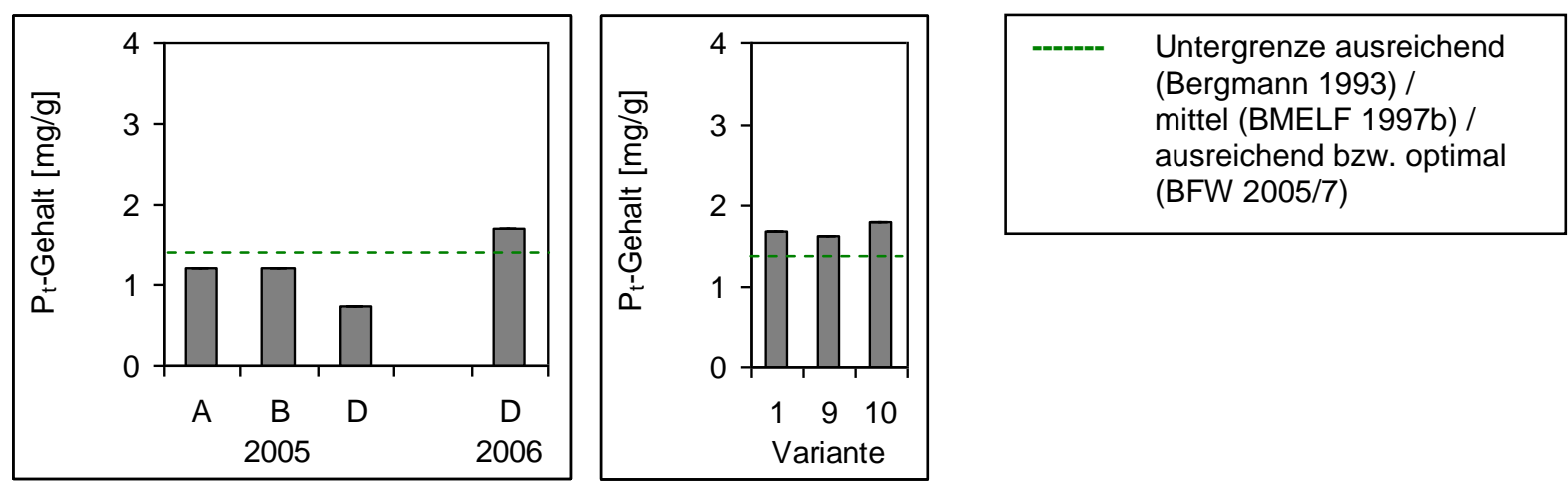

Abb. 106 links: $\mathrm{P}_{\mathrm{t}}$-Gehalte [mg/g] in den Nadeln der Kiefern auf den Versuchsflächen A, B und D im 1. (2005) und auf Fläche D im 2. (2006) Vegetationsjahr (Mischproben); rechts: differenziert nach Varianten (s. S. 20) auf Fläche D im 2. Jahr (2006) (Mischproben)

Im 1. Untersuchungsjahr (2005) lagen die Phosphor-Gehalte in den Kiefern-Nadeln (s. Abb. 106) auf allen drei Versuchsflächen mit Werten von $1,2 \mathrm{mg} / \mathrm{g}(\mathrm{A}, \mathrm{B})$ und sehr niedrigen 0,75 $\mathrm{mg} / \mathrm{g}$ (D) unterhalb mittlerer/ausreichender/optimaler Gehalte laut Bergmann (1993), BMELF (1997b) sowie BFW (2005/7). Ganz anders im 2. Untersuchungsjahr (2006), als die KiefernNadeln auf Fläche D mit 1,7 mg/g mehr als doppelt so hohe Phosphor-Gehalte aufwiesen, was 
von drei Quellen als mittel oder optimal bzw. ausreichend, von Hofmann \& Krauss (1988) bereits als überversorgt eingestuft wird.

Der Phosphor-Gehalt in den Kiefern-Nadeln aller drei Varianten auf Fläche D (2006) lag zwischen1,6 und 1,8 mg/g und wird von drei Quellen als mittel oder optimal bzw. ausreichend, nach Hofmann \& Krauss (1988) als überversorgt bewertet.
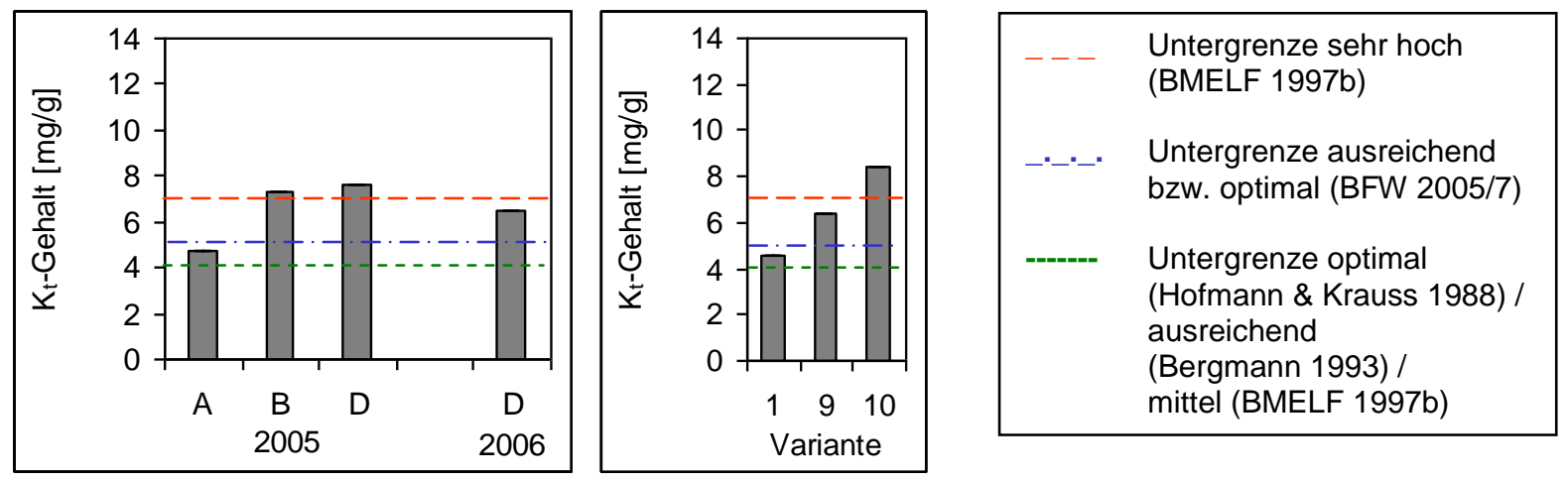

Abb. 107 links: $\mathrm{K}_{\mathrm{t}}-$ Gehalte $[\mathrm{mg} / \mathrm{g}]$ in den Nadeln der Kiefern auf den Versuchsflächen A, B und D im 1. (2005) und auf Fläche D im 2. (2006) Vegetationsjahr (Mischproben); rechts: differenziert nach Varianten (s. S. 20) auf Fläche D im 2. Jahr (2006) (Mischproben)

Im 1. Untersuchungsjahr (2005) wurde in den Kiefern-Nadeln auf Versuchsfläche A ein mittlerer (BMELF 1997b), ausreichender (Bergmann 1993), optimaler (Hofmann \& Krauss 1988), laut BFW (2005/7) allerdings nicht ausreichender Kalium-Gehalt (s. Abb. 107) von $4,7 \mathrm{mg} / \mathrm{g}$ gemessen. Auf Fläche B und D lagen die Kalium-Gehalte mit 7,3 bzw. 7,6 mg/g deutlich höher, was nach BMELF (1997b) sehr hoch (>7,0 mg/g), nach Hofmann \& Krauss (1988) extrem (6,0$7,7 \mathrm{mg} / \mathrm{g}$ ) ist. Mit 6,5 mg/g etwas darunter lag der Kalium-Gehalt in den Kiefern-Nadeln auf Fläche D im Folgejahr 2006 (laut BMELF 1997b im hohen Wertebereich).

In den Kiefern-Nadeln der dortigen Nullvariante (V1) wurde ein mittlerer (BMELF 1997b), ausreichender (Bergmann 1993), optimaler (Hofmann \& Krauss 1988), laut BFW (2005/7) allerdings nicht ausreichender Kalium-Gehalt von 4,6 mg/g gemessen. Mit Kompost-Düngung (V9) lag der Gehalt deutlich höher bei 6,4 mg/g, was als ausreichend bzw. optimal (BFW 2005/7, Bergmann 1993) oder hoch (BMELF 1997b), von Hofmann \& Krauss (1988) auch bereits als extrem eingestuft wird. Mit Kompost- und Kalk-Düngung (V10) wurde ein noch deutlich darüber liegender Gehalt von 8,4 mg/g erreicht, der als sehr hoch (BMELF 1997b), deutlich über ausreichend bzw. optimal (BFW 2005/7 Bergmann 1993) und als extrem (Hofmann \& Krauss 1988) bewertet wird. 

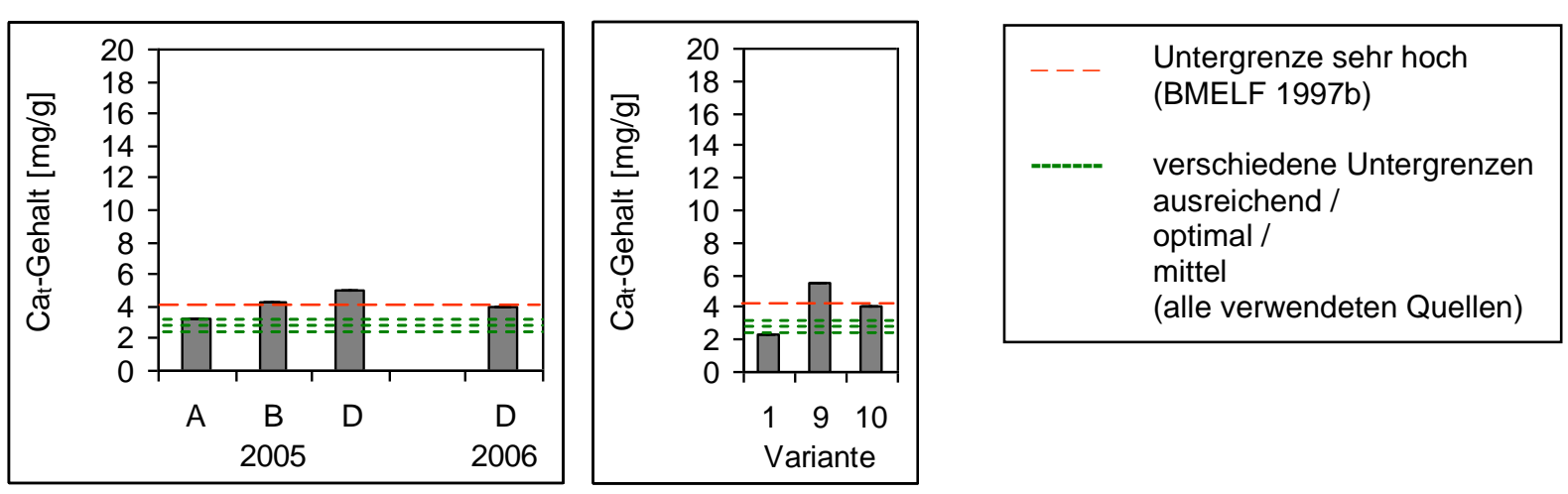

Abb. 108 links: Cat-Gehalte [mg/g] in den Nadeln der Kiefern auf den Versuchsflächen A, B und D im 1. (2005) und auf Fläche D im 2. (2006) Vegetationsjahr (Mischproben); rechts: differenziert nach Varianten (s. S. 20) auf Fläche D im 2. Jahr (2006) (Mischproben)

Die in den Kiefern-Nadeln auf allen drei Versuchsflächen gemessenen Calcium-Gehalte (s. Abb. 108) waren nach Bergmann (1993) und dem BFW (2005/7) als ausreichend bzw. optimal einzustufen. Nach der Skala im Deutschen Waldbodenbericht (BMELF 1997b) waren die Calcium-Gehalte auf Fläche A (3,3 mg/g) und D (2006: 3,9 mg/g) hoch, auf Fläche B (4,2 mg/g) und D (2005: 5,0 mg/g) sehr hoch. Hofmann \& Krauss (1988) sprechen bei letzterem Wert von Extremversorgung, bei den drei zuvor genannten dagegen von Überversorgung.

Der in den Nadeln der Kontroll-Kiefern (V1) auf Fläche D (2006) gemessene Calcium-Gehalt war mit $2,3 \mathrm{mg} / \mathrm{g}$ nach den meisten verwendeten Quellen gering (BMELF 1997b) oder nicht ausreichend (BFW 2005/7, Bergmann 1993), nach Hofmann \& Krauss (1988) dagegen bereits optimal. Mit Kompost-Düngung (V9) lag er mehr als doppelt so hoch bei 5,4 mg/g und wurde als optimal bzw. ausreichend (BFW 2005/7, Bergmann 1993), aber auch als sehr hoch (BMELF 1997b) sowie bereits als extrem (Hofmann \& Krauss 1988) eingestuft. Mit Kompost- und KalkGabe (V10) war der Gehalt etwas geringer und lag mit 4,0 mg/g knapp doppelt so hoch wie der Kontrollwert. Seine Bewertung reicht von optimal bzw. ausreichend (BFW 2005/7, Bergmann 1993) bis hoch-sehr hoch (BMELF 1997b) und Überversorgung (Hofmann \& Krauss 1988).
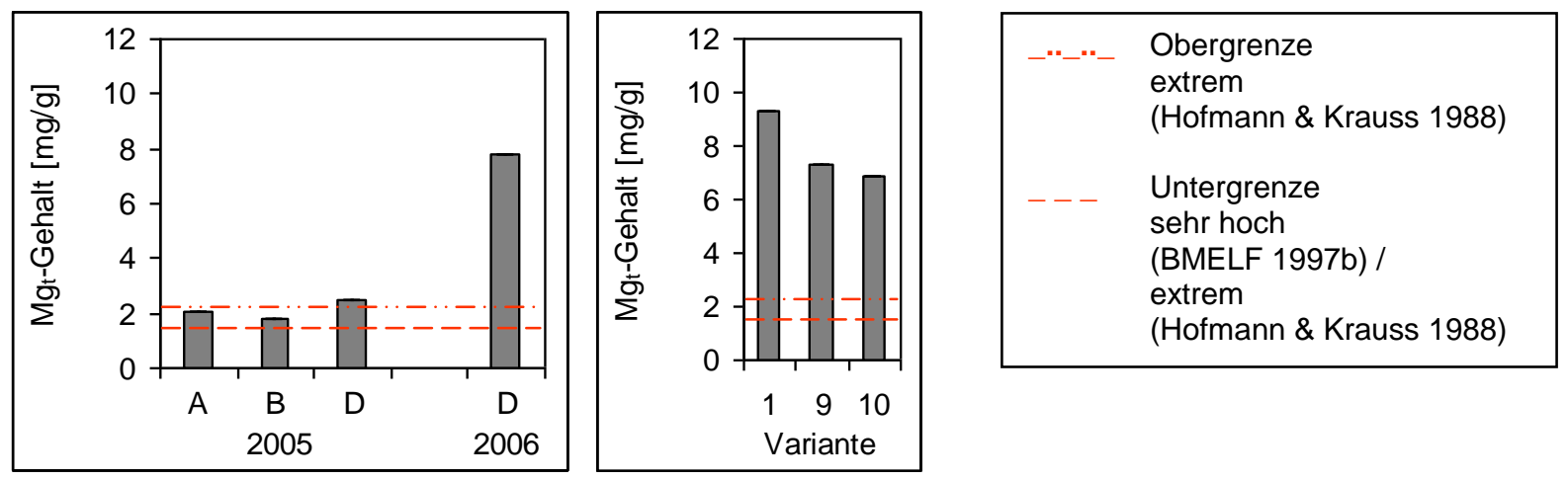

Abb. 109 links: $\mathrm{Mg}_{\mathrm{t}}$-Gehalte [mg/g] in den Nadeln der Kiefern auf den Versuchsflächen A, B und D im 1. (2005) und auf Fläche D im 2. (2006) Vegetationsjahr (Mischproben); rechts: differenziert nach Varianten (s. S. 20) auf Fläche D im 2. Jahr (2006) (Mischproben)

In den Nadeln der Kiefern im Freiland-Versuch wurden durchweg sehr hohe MagnesiumGehalte (s. Abb. 109) gemessen (> 1,5 mg/g; BMELF 1997b). In 2005 lagen die Werte auf Fläche A und B mit 2,1 mg/g bzw. 1,8 mg/g innerhalb des bei Hofmann \& Krauss (1988) als extrem angegebenen Bereichs (1,5-2,25 mg/g). Auf Fläche D lag er mit 2,5 mg/g bereits knapp darüber und überstieg auch die im Rahmen der Nadelanalysen im Deutschen Waldbodenbericht 
gemessenen Maximalwerte ( $2 \mathrm{mg} / \mathrm{g}$ ). Im Folgejahr (2006) betrug der Magnesium-Gehalt in den Kiefern-Nadeln auf Fläche D mit 7,8 mg/g das 3-fache des Vorjahreswertes und lag damit um ein Vielfaches über der oberen Grenze einer Extremversorgung nach Hofmann \& Krauss (1988).

Der Magnesium-Gehalt in den Kiefern-Nadeln der dortigen Kontrolle (V1) war mit 9,3 mg/g sehr hoch (BMELF 1997b) und lag um ein Vielfaches über den ausreichenden Gehalten laut Bergmann (1993) sowie mehrfach oberhalb einer Extremversorgung laut Hofmann \& Krauss (1988). Er betrug etwa das 4,5-fache der im Rahmen der Nadelanalysen im Deutschen Waldbodenbericht gemessenen Maximalwerte (2 mg/g). In den mit Kompost (V9) und KompostKalk (V10) gedüngten Varianten war der Gehalt mit 7,3 bzw. 6,8 mg/g etwas geringer, jedoch ebenso einzustufen wie in der Kontrolle.

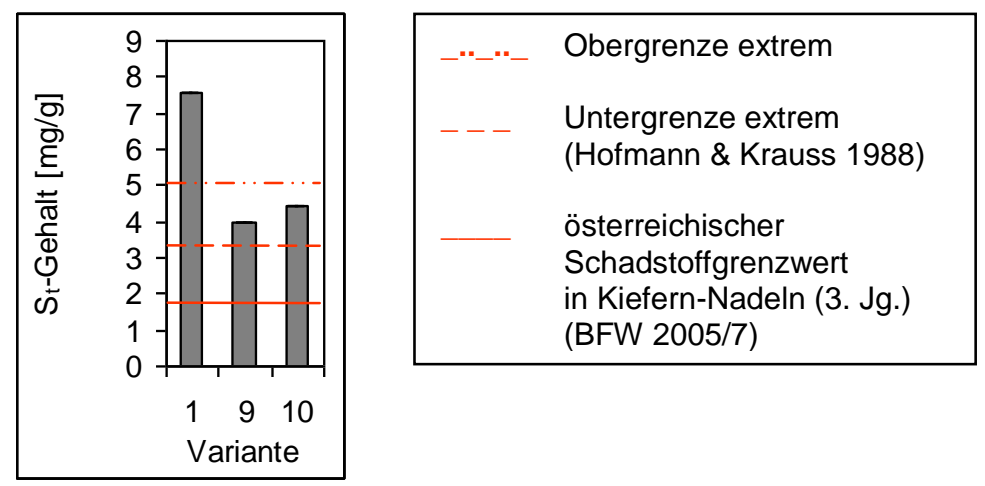

Abb. 110: St-Gehalte [mg/g] in den Nadeln der Kiefern-Varianten (s. S. 20) auf Versuchsfläche D im 2. (2006) Vegetationsjahr (Mischproben)

Die Nadeln der Kiefern auf Fläche D (2006) wiesen einen mittleren Schwefel-Gehalt (s. Abb. 110) von $5,3 \mathrm{mg} / \mathrm{g}$ auf. Der in der unbehandelten Kontrolle gemessene Wert war mit 7,6 mg/g sehr hoch (BMELF 1997b) und lag deutlich jenseits einer Extremversorgung (Hofmann \& Krauss 1988).

Mit Kompost- (V9) und Kompost-Kalk (V10)-Düngung waren die Schwefel-Nadelgehalte deutlich geringer $(4,0$ bzw. $4,4 \mathrm{mg} / \mathrm{g})$, jedoch immer noch so hoch, dass ihre Einstufung durch die verwendeten Quellen der der Kontrollwerte gleicht (auch wenn die Werte laut Hofmann \& Krauss (1988) nicht mehr jenseits von, sondern nun im Bereich einer Extremversorgung liegen). Die gemessenen Schwefel-Gehalte waren höher als die im Rahmen der Nadelanalysen im Deutschen Waldbodenbericht gemessenen Maximalwerte (1. Nadeljahrgang: 4,1 mg/g; 2 . Nadeljahrgang: 2,6 $\mathrm{mg} / \mathrm{g}$ ) und betrugen ein Vielfaches der österreichischen Schadstoffgrenzwerte in Kiefern-Nadeln (BFW 2005/7).

\section{Spurennährelemente, Mikronährstoffe ( $\mathrm{Fe}, \mathrm{Mn}, \mathrm{Zn}, \mathrm{Cu})$}

Der mittlere Eisen-Gehalt der Kiefern-Nadeln (s. Abb. 111) auf Fläche D (2006) betrug 280 mg/kg. Mit Kompost- bzw. Kompost- und Kalk-Düngung (V9 bzw. V10) lagen die gemessenen Gehalte mit 210 bzw. $274 \mathrm{mg} / \mathrm{kg}$ deutlich unter dem Wert der Kontrollpflanzen (V1: 357 $\mathrm{mg} / \mathrm{kg}$ ). 


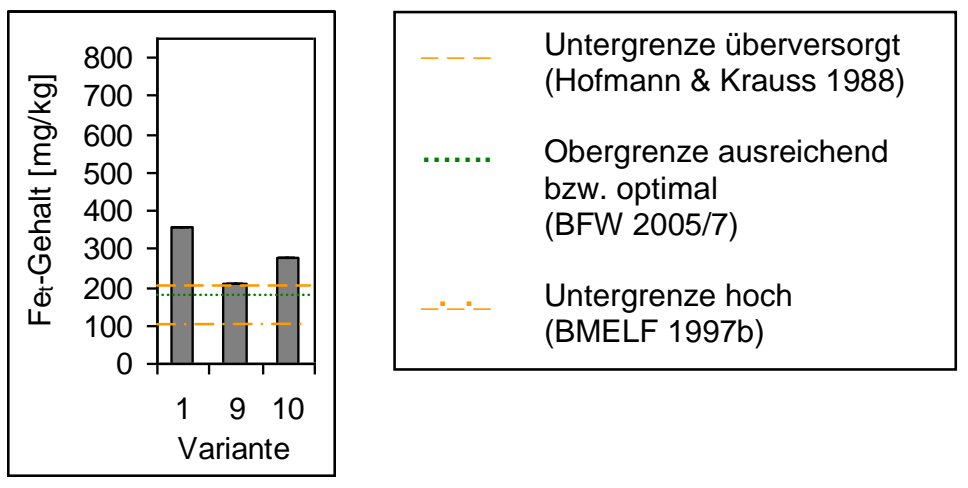

Abb. 111: $\mathrm{Fe}_{\mathrm{t}}$-Gehalte [mg/kg] in den Nadeln der Kiefern-Varianten (s. S. 20) auf Versuchsfläche D im 2. (2006) Vegetationsjahr (Mischproben)

Dennoch waren die Eisen-Nadelgehalte aller drei Varianten gleichermaßen einem hohen (BMELF 1997b) oder überversorgten (Hofmann \& Krauss 1988) Wertebereich zuzurechnen und überstiegen auch die vom BFW (2005/7) genannte Spanne ausreichender bzw. optimaler EisenGehalte (30-180 mg/kg).

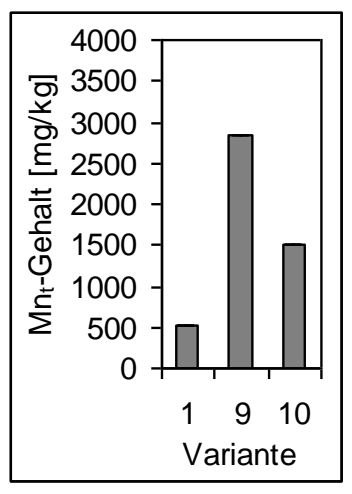

Abb. 112: $\mathrm{Mn}_{\mathrm{t}}$-Gehalte [mg/kg] in den Nadeln der Kiefern-Varianten (s. S. 20) auf Versuchsfläche D im 2. (2006) Vegetationsjahr (Mischproben)

Der in den Nadeln der Kiefern auf Fläche D (2006) gemessene Mangan-Gehalt (s. Abb. 112) lag im Mittel bei $1615 \mathrm{mg} / \mathrm{kg}$. In der unbehandelten Kontrolle (V1) war der Wert mit $516 \mathrm{mg} / \mathrm{kg}$ nach den Bewertungskriterien des BMELF (1997b) gering, nach Einstufung der übrigen drei Quellen dagegen ausreichend bzw. optimal (BFW 2005/7, Fiedler \& Höhne 1985 zit. in Bergmann 1993, Hofmann \& Krauss 1988).

Mit Kompost-Düngung (V9) enthielten die Kiefern-Nadeln fast 6-mal so viel Mangan (2829 $\mathrm{mg} / \mathrm{kg}$ ), was als hoch (BMELF 1997b), über ausreichend (Bergmann 1993) sowie als jenseits einer Extremversorgung (Hofmann \& Krauss 1988), von einer Quelle aber auch als ausreichend bzw. optimal (BFW 2005/7) bewertet wird. Der Wert lag höher als bzw. etwa so hoch wie die im Rahmen des Deutschen Waldbodenberichts in Kiefern-Nadeln gemessene Maxima $(2210 \mathrm{mg} / \mathrm{kg}$ im 1. Nadeljahrgang; 2980 mg/kg im 2. Nadeljahrgang; BMELF 1997b).

Der Nadelgehalt der Kiefern mit Kompost- und Kalk-Düngung lag mit 1500 mg/kg) etwa 3-mal so hoch wie der Kontrollwert. Auch hier gehen die Bewertungen auseinander (s. auch ab S. 333); laut BMELF (1997b) und BFW (2005/7) ist dieser Gehalt mittel oder ausreichend bzw. optimal, nach Bergmann (1993) über ausreichend und nach Hofmann \& Krauss (1988) extrem. In dieser Variante wurde das 90er-Perzentil der im Deutschen Waldbodenbericht ermittelten ManganGehalte (1270 bzw. $1330 \mathrm{mg} / \mathrm{kg}$ ) überschritten (BMELF 1997b). 

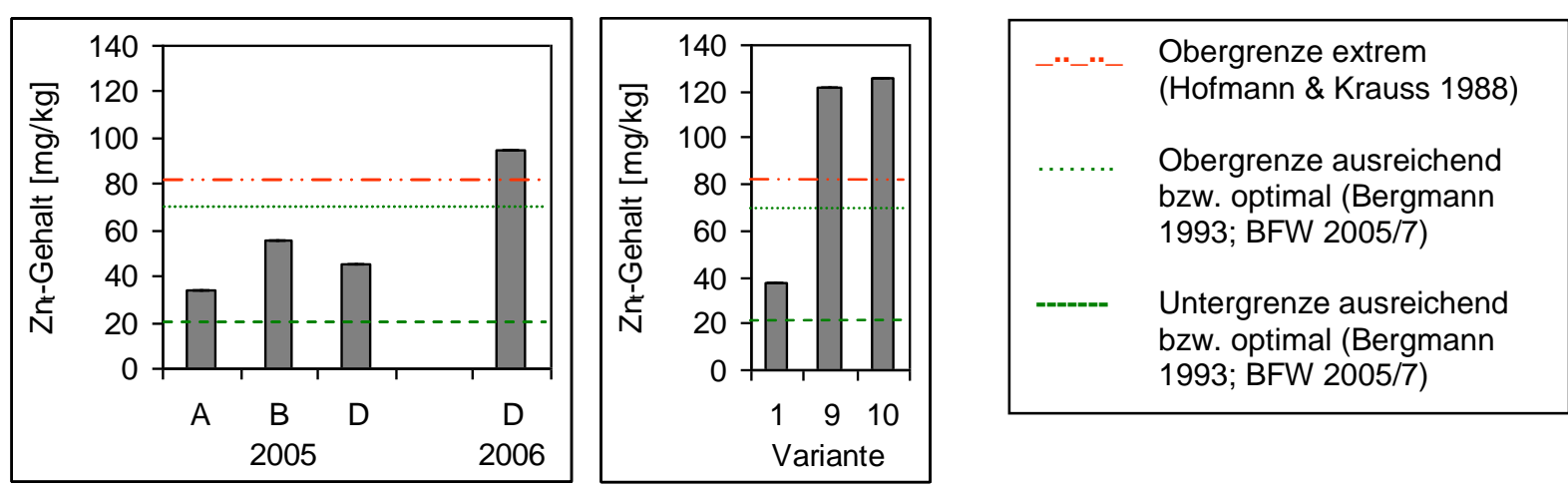

Abb. 113 links: $\mathrm{Zn}_{\mathrm{t}}$-Gehalte [mg/kg] in den Nadeln der Kiefern auf den Versuchsflächen A, B und D im 1. (2005) und auf Fläche D im 2. (2006) Vegetationsjahr (Mischproben); rechts: differenziert nach Varianten (s. S. 20) auf Fläche D im 2. Jahr (2006) (Mischproben)

Die im 1. Untersuchungsjahr (2005) in den Nadeln der Kiefern ermittelten Zink-Gehalte (s. Abb. 113) lagen mit 33,8 mg/kg (Fläche A), 45,8 mg/kg (Fläche D) und 55,9 mg/kg (Fläche B) nach Bergmann (1993) und dem BFW (2005/7) in einem ausreichenden bzw. optimalen Bereich (20$70 \mathrm{mg} / \mathrm{kg}$ ). Im 2. Untersuchungsjahr (2006) war der Zink-Nadelgehalt auf Fläche D dagegen doppelt so hoch $(94,9 \mathrm{mg} / \mathrm{kg})$ und lag damit jenseits einer Extremversorgung $(64-83 \mathrm{mg} / \mathrm{kg})$ nach Hofmann \& Krauss (1988) bzw. im sehr hohen Bereich (> 70 mg/kg) nach BMELF (1997b).

Der in den Kiefern-Nadeln der dortigen Nullvariante (V1) gemessene Zink-Gehalt (37,3 mg/kg) lag nach den verwendeten Quellen in einem mittleren / ausreichenden / optimalen Bereich. Die Zink-Gehalte mit Düngung (V9: Kompost; V10: Kompost-Kalk) waren mit 121,3 bzw. 126,0 mg/kg 3- bis 4-mal so hoch wie der Kontrollwert und als sehr hoch (BMELF 1997b), deutlich über ausreichend bzw. optimal (BFW 2005/7, Bergmann 1993) oder deutlich jenseits einer Extremversorgung (Hofmann \& Krauss 1988) einzustufen. Sie überstiegen die im Rahmen des Deutschen Waldbodenberichts in Kiefern-Nadeln gemessenen Maximalwerte (96 bzw. 92 mg/kg; BMELF 1997b). Nach Zimmermann (1990) treten bei Zink-Nadelgehalten von über 100 $\mathrm{mg} / \mathrm{kg}$ toxische Effekte auf.
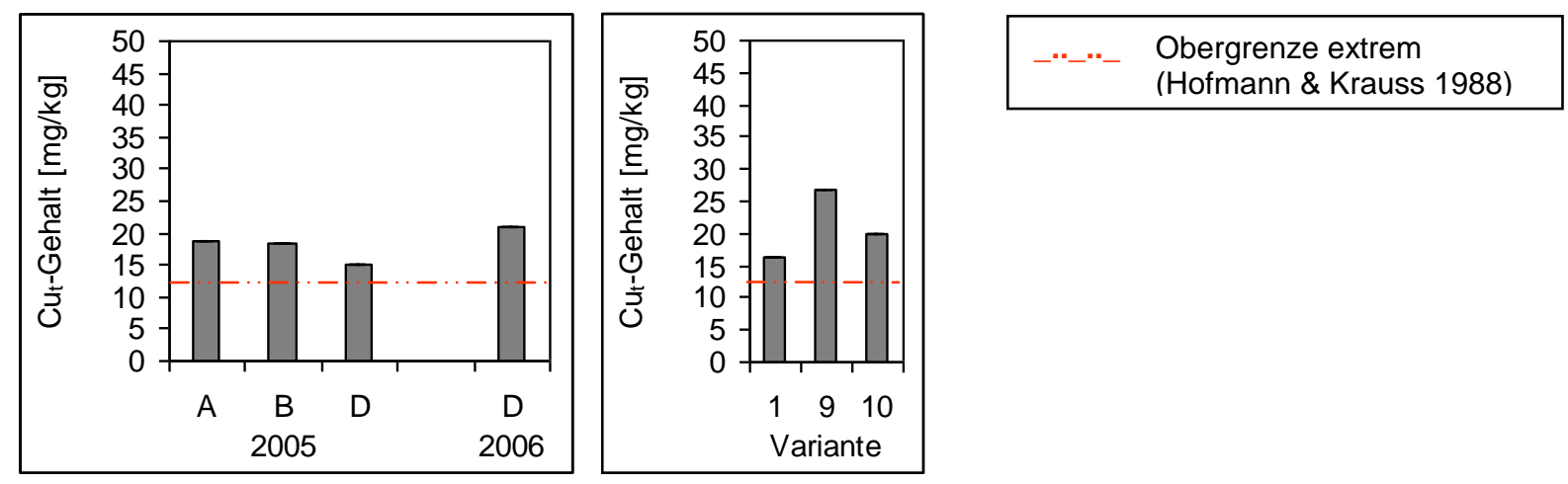

Abb. 114 links: $\mathrm{Cu}_{\mathrm{t}}-$ Gehalte $[\mathrm{mg} / \mathrm{kg}]$ in den Nadeln der Kiefern auf den Versuchsflächen A, B und D im 1. (2005) und auf Fläche D im 2. (2006) Vegetationsjahr (Mischproben); rechts: differenziert nach Varianten (s. S. 20) auf Fläche D im 2. Jahr (2006) (Mischproben)

Alle in den Kiefern-Nadeln gemessenen Kupfer-Gehalte (s. Abb. 114) lagen erheblich über der oberen Grenze einer Extremversorgung (7,6-12 mg/kg) laut Hofmann \& Krauss (1988). Der mit $15,1 \mathrm{mg} / \mathrm{kg}$ geringste Wert wurde dabei in 2005 auf Fläche D, der höchste Wert $(21,0 \mathrm{mg} / \mathrm{kg})$ ebenfalls auf Fläche D im darauf folgenden Jahr 2006 ermittelt. 
Mit Kompost- und Kalk-Düngung (V10) lag der dortige Kupfer-Gehalt der Kiefern-Nadeln bei $19,8 \mathrm{mg} / \mathrm{kg}$ und damit noch etwas über dem Kontrollwert $(16,4 \mathrm{mg} / \mathrm{kg})$, der von den verwendeten Quellen bereits als sehr hoch (BMELF 1997b), deutlich über ausreichend bzw. optimal (BFW 2005/7, Bergmann 1993) sowie deutlich oberhalb einer Extremversorgung (Hofmann \& Krauss 1988) eingestuft wird. Der Kupfer-Gehalt in den Nadeln der mit Kompost gedüngten Kiefern (V9) war mit 26,8 mg/kg noch erheblich höher als die anderen beiden Werte. Alle Messwerte lagen deutlich oberhalb des 90er-Perzentils der im Rahmen des Deutschen Waldbodenberichts in Kiefern-Nadeln ermittelten Kupfer-Gehalte (4,8 bzw. 6,7 mg/kg; BMELF 1997b).

\section{Potentiell nützliche Elemente (Al, Na, Ni, Co)}

Der Aluminium-Gehalt in den Kiefern-Nadeln (s. Abb. 115) auf Fläche D (2006) betrug im Mittel $430 \mathrm{mg} / \mathrm{kg}$, was nach Hofmann \& Krauss (1988) einer Extremversorgung (391-551 mg/kg) entspricht.

In der unbehandelten Nullvariante (V1) lag der Wert mit $574 \mathrm{mg} / \mathrm{kg}$ knapp oberhalb dieses extremen Bereichs. Mit Kompost-Düngung (V9) war er deutlich geringer (258 mg/kg) und dem Bereich der Optimalversorgung zuzurechnen. Der Aluminium-Gehalt der mit Kompost und Kalk gedüngten Kiefern war mit 457 mg/kg etwas geringer als der Kontrollwert, lag aber immer noch im Extrembereich. Beide Gehalte (V1, V10) lagen über dem 90er-Perzentil (1. Nadeljahrgang: $407 \mathrm{mg} / \mathrm{kg}$ ) bzw. über dem Maximum (2. Nadeljahrgang: $430 \mathrm{mg} / \mathrm{kg}$ ) der im Rahmen des Deutschen Waldbodenberichts an Kiefern ermittelten Werte.

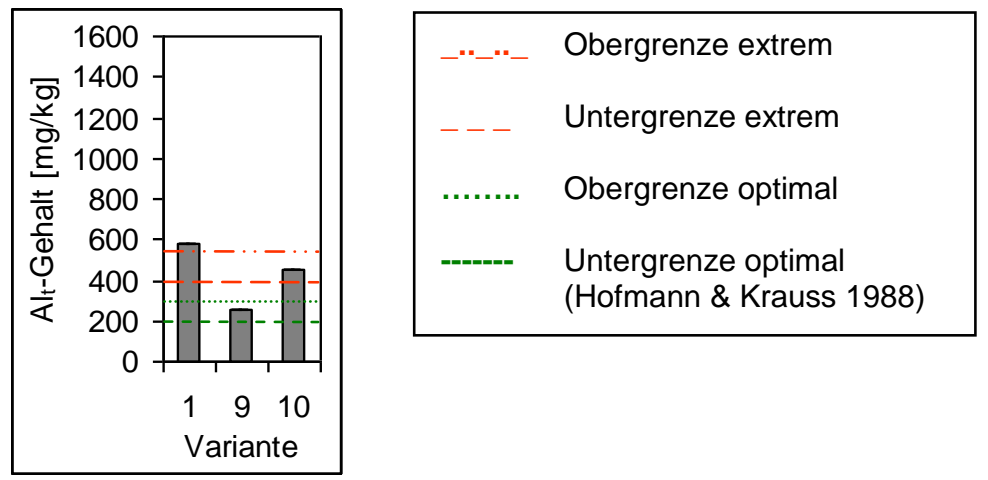

Abb. 115: $\mathrm{Al}_{\mathrm{t}}$-Gehalte [mg/kg] in den Nadeln der Kiefern-Varianten (s. S. 20) auf Versuchsfläche D im 2. (2006) Vegetationsjahr (Mischproben)

Laut Bergmann (1993) ist Phosphormangel bei ausreichend mit Phosphor versorgten Böden (wie in diesem Fall, s. S. 48) ein sichereres Zeichen für Aluminium-Toxizität als ein hoher Aluminium-Gehalt in den Assimilationsorganen. Da bei den drei untersuchten Kiefern-Varianten ausreichende Phosphor-Gehalte ermittelt wurden, scheinen $\mathrm{Al}^{3+}$-Überschuss und AluminiumToxizität bei dieser Baumart keine Rolle zu spielen. 


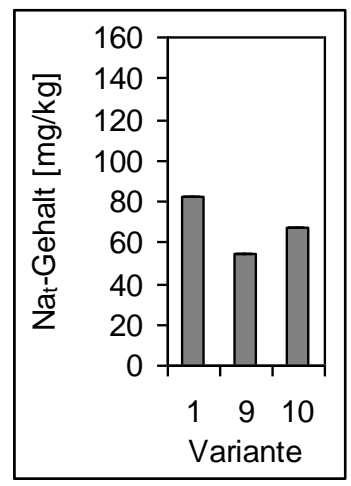

Abb. 116: $\mathrm{Na}_{\mathrm{t}}$-Gehalte [mg/kg] in den Nadeln der Kiefern-Varianten (s. S. 20) auf Versuchsfläche D im 2. (2006) Vegetationsjahr (Mischproben)

Der mittlere Natrium-Gehalt der Kiefern-Nadeln (s. Abb. 116) auf Fläche D (2006) betrug 68,2 mg/kg. Mit Kompost- bzw. Kompost- und Kalk-Düngung (V9 bzw. V10) waren die Werte mit 54,9 bzw. 66,8 mg/kg deutlich geringer als in den Kontrollpflanzen (V1; 82,9 mg/kg). Alle ermittelten Natrium-Nadelgehalte lagen im Bereich der im Deutschen Waldbodenbericht (BMELF 1997b) gemessenen und nicht weiter klassifizierten Natrium-Gehalte von KiefernNadeln.
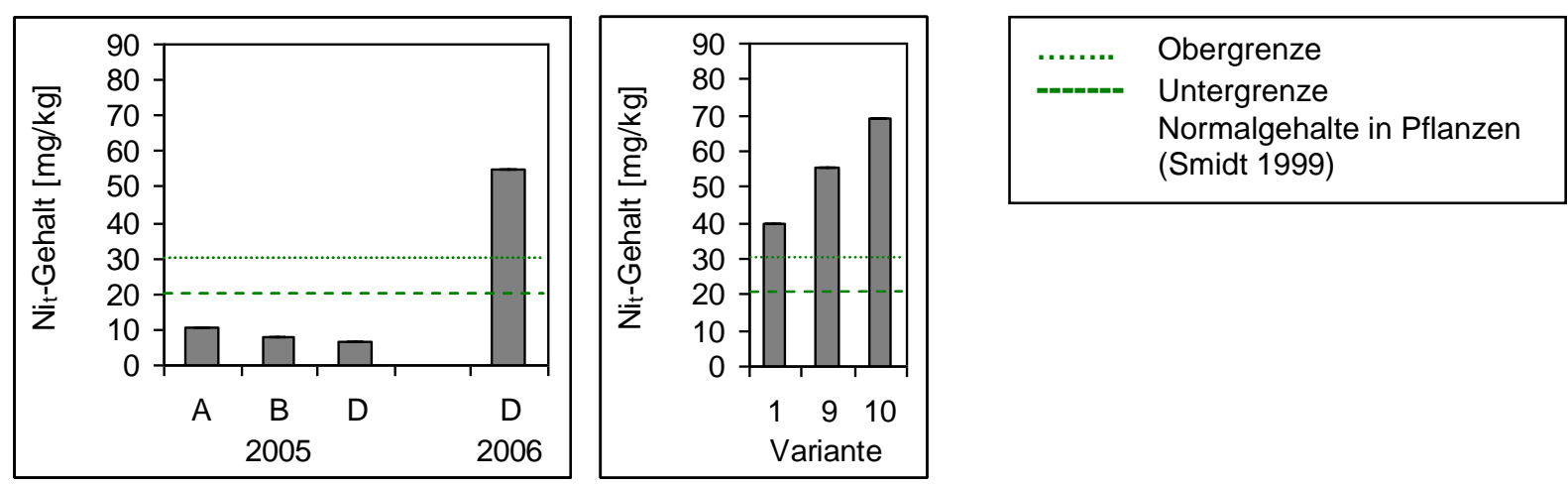

Abb. 117 links: $\mathrm{Ni}_{\mathrm{t}}$-Gehalte [mg/kg] in den Nadeln der Kiefern auf den Versuchsflächen A, B und D im 1. (2005) und auf Fläche D im 2. (2006) Vegetationsjahr (Mischproben); rechts: differenziert nach Varianten (s. S. 20) auf Fläche D im 2. Jahr (2006) (Mischproben)

Die Nickel-Gehalte in den Nadeln der Kiefern (s. Abb. 117) auf den drei Versuchsflächen betrugen in 2005 zwischen $6,3 \mathrm{mg} / \mathrm{kg}$ und $10,5 \mathrm{mg} / \mathrm{kg}$, was deutlich unterhalb der bei Smidt (1999) angegebenen Normalgehalte in Pflanzen (20-30 mg/kg) bleibt. Der in 2006 auf Fläche D erneut ermittelte Nickel-Gehalt lag mit $54,6 \mathrm{mg} / \mathrm{kg}$ dagegen erheblich über dieser Spanne und fast 9-mal so hoch wie im Vorjahr.

Der Nickel-Gehalt in den Nadeln der dortigen Kontroll-Kiefern (V1) lag mit 39,5 mg/kg oberhalb der bei Smidt (1999) angegebenen Normalgehalte in Pflanzen $(20-30 \mathrm{mg} / \mathrm{kg}$ ). Die Werte der gedüngten Kiefern (V9: Kompost; V10: Kompost-Kalk) waren mit 55,3 bzw. 68,9 mg/kg noch deutlich höher und betrugen etwa des Doppelte dieser Normalgehalte. 

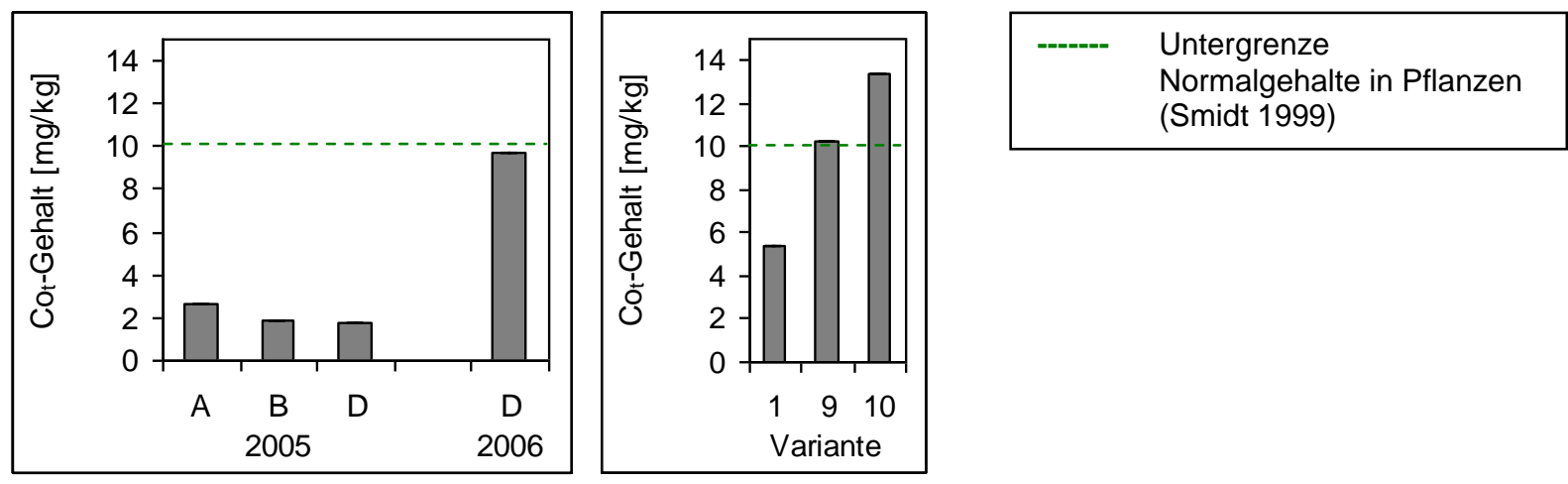

Abb. 118 links: $\mathrm{Co}_{\mathrm{t}}-\mathrm{Gehalte}[\mathrm{mg} / \mathrm{kg}]$ in den Nadeln der Kiefern auf den Versuchsflächen A, B und D im 1. (2005) und auf Fläche D im 2. (2006) Vegetationsjahr (Mischproben); rechts: differenziert nach Varianten (s. S. 20) auf Fläche D im 2. Jahr (2006) (Mischproben)

Die Kobalt-Gehalte in den Kiefern-Nadeln (s. Abb. 118) auf den drei Versuchsflächen lagen in 2005 mit Werten zwischen 1,8 und 2,6 mg/kg deutlich unterhalb der Normalgehalte (10-20 mg/kg) nach Smidt (1999). In 2006 betrug der Kobalt-Gehalt in den Kiefern-Nadeln auf Fläche D mit 9,7 mg/kg dagegen das mehr als 5-fache des Vorjahreswertes und lag damit nur noch knapp unterhalb dieser Normalgehalte.

Während dort der Kobalt-Gehalt in den Nadeln unbehandelter Kiefern (V1) bei 5,4 mg/kg und damit unterhalb der Normalgehalte (10-20 mg/kg) nach Smidt (1999) lag, waren die Werte in den mit Kompost (V9) und Kompost und Kalk (V10) gedüngten Varianten mit 10,3 bzw. 13,4 $\mathrm{mg} / \mathrm{kg}$ mindestens doppelt so hoch und befanden sich damit im Bereich dieser Normalgehalte.

\section{Toxisch wirkende Schwermetalle ohne Nährelementfunktion ( $\mathrm{Pb}, \mathrm{Cd}, \mathrm{Cr})$}

Nur auf Fläche A ließ sich in den Kiefern-Nadeln ein messbarer Blei-Gehalt in Höhe von 2,4 $\mathrm{mg} / \mathrm{kg}$ feststellen. Nach den sehr allgemeinen Normalgehalten von Schwermetallen in Pflanzen (in Smidt 1999) sowie den ebenso allgemeinen kritischen Konzentrationen (Alloway 1999) wären damit weder normale $(10-20 \mathrm{mg} / \mathrm{kg})$ noch kritische $(30-300 \mathrm{mg} / \mathrm{kg})$ Blei-Gehalte erreicht. Nach der Bewertungstabelle des österreichischen BFW (2005/7) für Element-Gehalte in Fichtennadeln ist der Blei-Gehalt in den Kiefern-Nadeln auf Fläche A als minimal $(<3 \mathrm{mg} / \mathrm{kg})$ einzustufen.

Die Cadmium-Gehalte in den Nadeln sämtlicher beprobter Kiefern lagen unterhalb der Nachweisgrenze für dieses Element.

Die in den Kiefern-Nadeln auf den drei Versuchsflächen gemessenen durchschnittlichen ChromGehalte (s. Abb. 119) lagen zwischen 1,2 mg/kg und 1,7 mg/kg und damit deutlich unterhalb des in Alloway (1999) genannten Bereichs kritischer Chromkonzentrationen in Pflanzen, oberhalb dessen toxische Auswirkungen wahrscheinlich sind (5-30 mg/kg).

Gleiches galt für die in den Kiefern-Varianten auf Fläche D (2006) gemessenen ChromNadelgehalte. Dabei war der Wert in der Kompost-Variante (V9) mit 0,7 mg/kg halb so hoch wie der Kontrollwert (1,3 mg/kg), in der Kompost-Kalk-Variante (V10) dagegen mit 1,6 mg/kg leicht höher als dieser. 

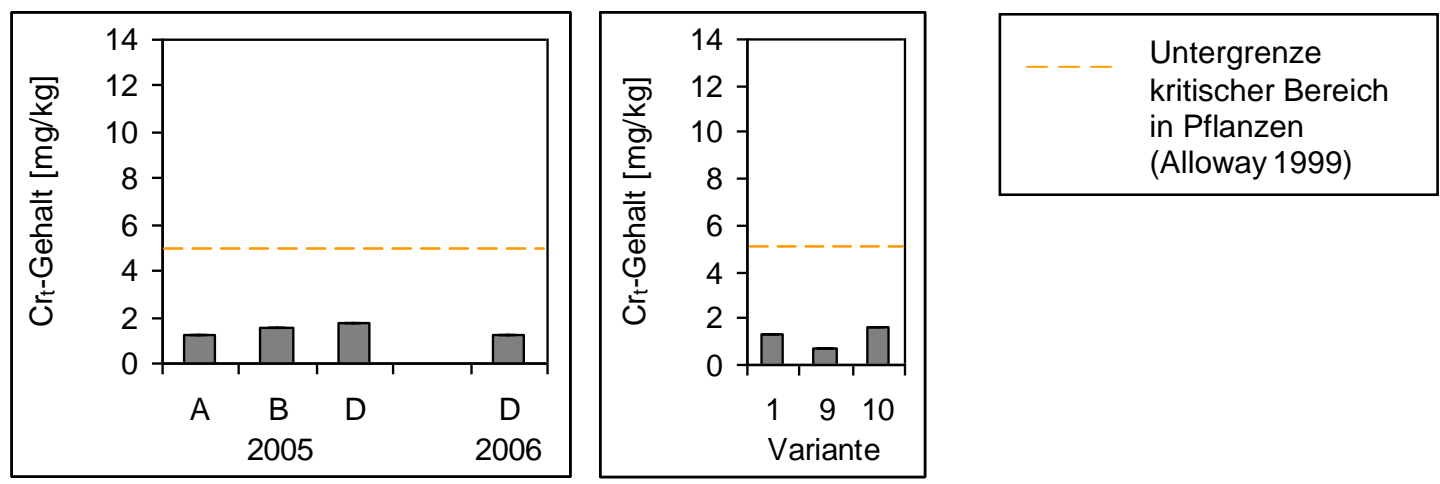

Abb. 119 links: $\mathrm{Cr}_{\mathrm{t}}$-Gehalte [mg/kg] in den Nadeln der Kiefern auf den Versuchsflächen A, B und D im 1. (2005) und auf Fläche D im 2. (2006) Vegetationsjahr (Mischproben); rechts: differenziert nach Varianten (s. S. 20) auf Fläche D im 2. Jahr (2006) (Mischproben) 


\subsubsection{Vitalitätsentwicklung}

Die Vitalität aller 936 Bäume des Freiland-Versuchs wurde im Verlauf des zweijährigen Untersuchungszeitraums wiederholt auf einer Skala von „4“ (vital) bis „0“ (tot) eingeschätzt (s. S. 27).

Im Folgenden wird die Vitalitätsentwicklung der Versuchsbäume anhand der Ergebnisse statistischer Analysen der Vitalitätswerte auf Effekte der in den Behandlungsvarianten eingesetzten Bodenhilfsstoffe und -kombinationen (s. S. 20) untersucht.

Da die Einflussfaktoren „Pflanzenstandort auf einer der drei Versuchsflächen“ (s. ab S. 227) sowie "Pflanzenstandort in Bereichen ohne oder mit Spontanvegetationsentwicklung" (s. ab S. 257) teilweise eine wichtige Rolle spielten, wurden die Wirkungen der Behandlungsvarianten auf die Vitalitätsentwicklung der Versuchspflanzen auch unter Ausschluss dieser Faktoren untersucht. Dies geschah, indem ausschließlich die Bäume mit Standorten auf Teilflächen ohne Spontanvegetation (vergleichsweise ungünstigere Bedingungen), auf Standorten mit Spontanvegetation (vergleichsweise günstigere Bedingungen) oder auf einer bestimmten Versuchsfläche betrachtet wurden (zu den unterschiedlichen Standortbedingungen s. ab S. 44).

\subsubsection{Rot-Eiche}

Nach aufgrund des schlechten Pflanzenmaterials bereits eher mäßigen Ausgangswerten (s. ab S. 75) war die durchschnittliche Vitalität der Eichen im gesamten Versuchsverlauf sehr gering. Dabei nahm der mittlere Vitalitätswert von anfänglich 2,3 $\pm 0,5$ signifikant auf nur noch sehr geringe 0,7 $\pm 0,5$ im Juni 2005 ab. Zum und im 2. Versuchsjahr sank er weiter signifikant auf schließlich $0,4 \pm 1,0$ (s. Tab. 58).

Tab. 58: Vitalität [codiert: $4=$ vital bis $0=$ tot, s. S. 27] der Eichen im Versuchsverlauf; MW u. Std.abw.; Ergebnis des Friedmann-Tests $\left(\mathrm{Chi}^{2}\right)$ auf signifikante Unterschiede zwischen den Aufnahmezeitpunkten $(n=192)$

\begin{tabular}{|l|l|l|l|l|l|l|l|l|}
\hline $\begin{array}{l}\text { April } \\
2005\end{array}$ & & $\begin{array}{l}\text { Juni } \\
2005\end{array}$ & $\begin{array}{l}\text { Oktober } \\
2005\end{array}$ & & $\begin{array}{l}\text { Juni } \\
2006\end{array}$ & & $\begin{array}{l}\text { Oktober } \\
2006\end{array}$ & Chi $^{2}$ \\
\hline $2,3 \pm 0,5$ & $>$ & $0,7 \pm 0,5$ & $0,7 \pm 0,8$ & $>$ & $0,5 \pm 0,9$ & $>$ & $0,4 \pm 1,0$ & $328,10^{* * *}$ \\
\hline
\end{tabular}

$>$ kennzeichnet signifikanten Vitalitätsrückgang laut Wilcoxon-Test

Grund für die niedrigen Durchschnittswerte (s. Abb. 120) war die große Zahl abgestorbener Pflanzen, die mit dem Vitalitätswert „ 0 “ in die Auswertung eingehen, aber auch die sehr geringe Zahl vitaler Pflanzen mit einem Vitalitätswert von „3“ oder „4“ (s. Abb. 121). 


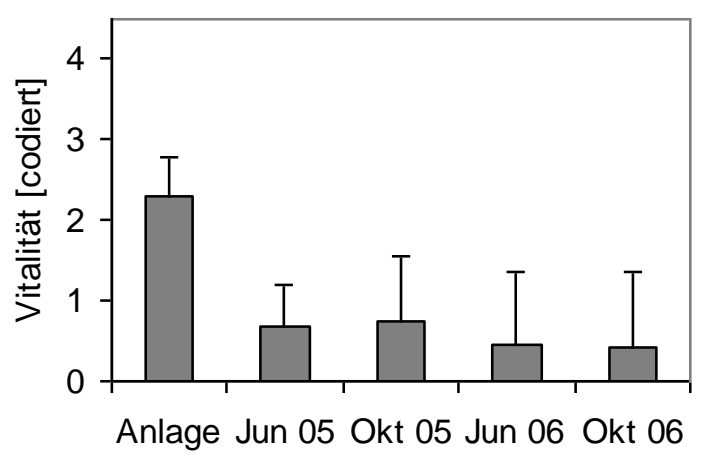

Abb. 120: Vitalität [codiert: $4=$ vital bis $0=$ tot, s. S. 27] der Eichen im Versuchsverlauf; MW u. Std.abw. $(\mathrm{n}=192)$

Die Ausfallrate war von Beginn an relativ hoch und stieg vom 1. zum 2. Untersuchungsjahr noch einmal deutlich an, von $35 \%$ und $46 \%$ in 2005 auf $75 \%$ und $82 \%$ in 2006. Die mittleren Vitalitätswerte der lebenden Eichen lagen jeweils bei $1,0 \pm 0,2 ; 1,4 \pm 0,7 ; 1,8 \pm 0,9$ und 2,3 $\pm 0,9$.

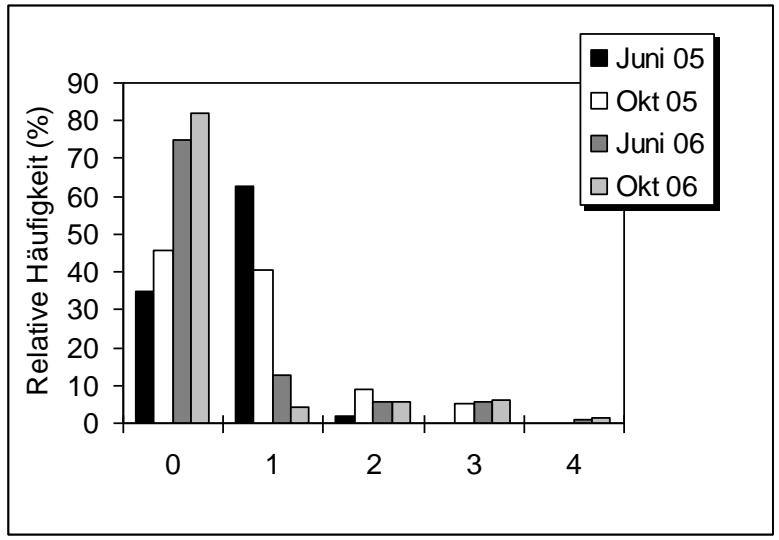

Abb. 121: Relative Häufigkeit der Vitalitätswerte [codiert: $4=$ vital bis $0=$ tot, s. S. 27] der Eichen im Versuchsverlauf $(\mathrm{n}=192)$

Von der Pflanzung im April 2005 bis zur nächsten Aufnahme im Juni 2005 sank die durchschnittliche Vitalität der Eichen in allen Varianten signifikant auf nur noch sehr geringe Werte (überwiegend unter "1“ = fast völlig abgestorben). In einigen Varianten erfolgte zum 2. Versuchsjahr noch eine weitere signifikante Abnahme. Die Unterschiede der mittleren Vitalitätswerte der Eichen in den einzelnen Varianten waren für keinen Aufnahmezeitpunkt signifikant (s. Tab. 59).

Zwecks eines ersten Eindrucks waren zu Beginn der Datenanalyse multiple schrittweise Regressionen zum Einfluss der eingesetzten Bodenhilfsstoffe auf die Vitalitätsentwicklung der Eichen durchgeführt worden. Einziges Ergebnis dabei war ein bei allen Aufnahmen positiver Einfluss der Mykorrhizierung.

Wie Tab. 59 zeigt, erreichten ausschließlich einige Mykorrhiza-Varianten durchschnittliche Vitalitätswerte von über „1“. Ein positiver Effekt der Beigabe von Mykorrhiza-Inokulum bei der Pflanzung auf die hier verwendeten Rot-Eichen, die zur obligat auf Mykorrhiza angewiesenen Baumgattung Quercus (Höster 1993) gehören und wie die heimischen Arten als stark mykotroph gelten (Sammler 2004), lässt sich durch weitere Beobachtungen belegen: So hatten zwei Monate 
nach Versuchsanlage nur $7 \%$ der Eichen ausgetrieben, davon $62 \%$ in den MykorrhizaVarianten. Nur die Hälfte der ausgetriebenen Bäume überlebte bis Ende des zweijährigen Untersuchungszeitraums, dabei handelte es sich ausschließlich um Pflanzen mit MykorrhizaImpfung.

Ein Großteil der Eichen war dagegen bereits nach kurzer Zeit oberirdisch abgestorben, was in diesem Fall wohl auch auf die schlechte gelieferte Pflanzenqualität zurückgeführt werden muss. Bei 9 \% dieser Bäume erfolgte im Versuchsverlauf ein Neuaustrieb von unten, $71 \%$ davon innerhalb der Mykorrhiza-Varianten. Auch die wenigen Eichen (13-14 \%), die zu den verschiedenen Aufnahmezeitpunkten Vitalitätswerte von „2“, „3“ oder „4“ aufwiesen (s. Abb. 121), waren überwiegend in den Mykorrhiza-Varianten zu finden (2005: 56 \%, 2006: 63-65 \%).

Tab. 59: Vitalität [codiert: 4 = vital bis $0=$ tot, s. S. 27] der Eichen-Varianten (s. S. 20) im Versuchsverlauf; MW u. Std.abw.; je Aufnahmezeitpunkt Ergebnisse von H-Tests (H) auf signifikante Unterschiede zwischen den Varianten; je Variante Ergebnisse von Friedmann-Tests $\left(\mathrm{Chi}^{2}\right)$ auf signifikante Unterschiede zwischen den Aufnahmezeitpunkten (je Variante $\mathrm{n}=12$ )

\begin{tabular}{|l|l|l|l|l|l|l|l|l|l|}
\hline & $\begin{array}{l}\text { April } \\
2005\end{array}$ & & $\begin{array}{l}\text { Juni } \\
2005\end{array}$ & $\begin{array}{l}\text { Oktober } \\
2005\end{array}$ & & $\begin{array}{l}\text { Juni } \\
2006\end{array}$ & $\begin{array}{l}\text { Oktober } \\
2006\end{array}$ & Chi $^{2}$ \\
\hline V1 & $2,1 \pm 0,3$ & $>$ & $0,5 \pm 0,5$ & $0,5 \pm 0,5$ & & $0,2 \pm 0,6$ & $0,1 \pm 0,3$ & $25,67^{* * *}$ \\
\hline V2 & $2,5 \pm 0,5$ & $>$ & $0,4 \pm 0,5$ & $0,4 \pm 0,7$ & & $0,2 \pm 0,6$ & $0,2 \pm 0,6$ & $25,2^{* * *}$ \\
\hline V3 & $2,3 \pm 0,5$ & $>$ & $0,6 \pm 0,5$ & $0,5 \pm 0,5$ & $>$ & $0,2 \pm 0,4$ & 0 & $28,37^{* * *}$ \\
\hline V4 & $2,3 \pm 0,5$ & $>$ & $0,7 \pm 0,5$ & $0,7 \pm 0,8$ & & $0,4 \pm 1,0$ & & $0,4 \pm 1,0$ & $17,87^{* *}$ \\
\hline V5 & $2,2 \pm 0,4$ & $>$ & $0,5 \pm 0,5$ & $0,8 \pm 1,1$ & & $0,6 \pm 1,2$ & & $0,5 \pm 1,2$ & $17,02^{* *}$ \\
\hline V6 & $1,8 \pm 0,4$ & $>$ & $0,5 \pm 0,5$ & $0,7 \pm 0,8$ & $>$ & $0,3 \pm 0,5$ & 0 & $26,08^{* * *}$ \\
\hline V7 & $2,3 \pm 0,5$ & $>$ & $0,8 \pm 0,5$ & $0,8 \pm 0,9$ & & $0,6 \pm 1,0$ & $0,7 \pm 1,1$ & $15,72^{* *}$ \\
\hline V8 & $2,4 \pm 0,7$ & $>$ & $0,4 \pm 0,5$ & $0,3 \pm 0,5$ & & $0,2 \pm 0,4$ & & $0,1 \pm 0,3$ & $25,33^{* * *}$ \\
\hline V9 & $2,1 \pm 0,3$ & $>$ & $0,7 \pm 0,5$ & $0,5 \pm 0,5$ & $>$ & $0,2 \pm 0,4$ & & 0 & $29,33^{* * *}$ \\
\hline V10 & $2,3 \pm 0,5$ & $>$ & $0,7 \pm 0,5$ & $0,8 \pm 0,8$ & $>$ & $0,3 \pm 0,7$ & & $0,3 \pm 0,6$ & $26,78^{* * *}$ \\
\hline V11 & $2,4 \pm 0,5$ & $>$ & $0,8 \pm 0,4$ & $0,9 \pm 0,9$ & $>$ & $0,5 \pm 1,0$ & & $0,5 \pm 1,2$ & $20,68^{* * *}$ \\
\hline V12 & $2,5 \pm 0,5$ & $>$ & $0,7 \pm 0,7$ & $0,4 \pm 0,5$ & & $0,3 \pm 0,6$ & & $0,3 \pm 0,9$ & $24,02^{* * *}$ \\
\hline V13 & $2,5 \pm 0,5$ & $>$ & $0,9 \pm 0,3$ & $1,2 \pm 0,9$ & & $1,0 \pm 1,3$ & & $1,0 \pm 1,3$ & $14,47^{* *}$ \\
\hline V14 & $2,4 \pm 0,5$ & $>$ & $0,8 \pm 0,4$ & $1,0 \pm 0,9$ & & $0,7 \pm 1,2$ & & $0,6 \pm 1,2$ & $18,93^{* * *}$ \\
\hline V15 & $2,3 \pm 0,5$ & $>$ & $0,8 \pm 0,5$ & $1,2 \pm 1,1$ & & $0,9 \pm 1,4$ & & $1,0 \pm 1,4$ & $13,48^{* *}$ \\
\hline V16 & $2,4 \pm 0,5$ & $>$ & $1,1 \pm 0,7$ & $1,1 \pm 1,2$ & & $1,0 \pm 1,3$ & & $1,1 \pm 1,5$ & $12,91^{*}$ \\
\hline H & 23,24 & & 21,78 & 17,26 & & 16,43 & & 16,04 & \\
\hline & $\mathrm{N}=192$ & & $\mathrm{~N}=192$ & $\mathrm{~N}=192$ & & $\mathrm{~N}=192$ & $\mathrm{~N}=192$ & \\
\hline
\end{tabular}

Oktober 2006: H-Test ohne V3, 6, 9

> kennzeichnet signifikanten Vitalitätsrückgang laut Wilcoxon-Test

\subsubsection{Spitz-Ahorn}

Die mittlere Vitalität aller 192 auf den Freiland-Versuchsflächen gepflanzten Ahorne nahm während des zweijährigen Untersuchungszeitraums von Aufnahme zu Aufnahme in kleinen Schritten signifikant ab (s. Abb. 122). Der Ausgangswert lag bei vergleichsweise mäßigen 2,5 \pm 0,6, zum Versuchsende wurden im Schnitt recht geringe 1,6 \pm 1,4 erreicht (s. Tab. 60). 
Tab. 60: Vitalität [codiert: $4=$ vital bis $0=$ tot, s. S. 27] der Ahorne im Versuchsverlauf; MW u. Std.abw.; Ergebnis des Friedmann-Tests $\left(\mathrm{Chi}^{2}\right)$ auf signifikante Unterschiede zwischen den Aufnahmezeitpunkten $(n=192)$

\begin{tabular}{|l|l|l|l|l|l|l|l|l|l|}
\hline $\begin{array}{l}\text { April } \\
2005\end{array}$ & & $\begin{array}{l}\text { Juni } \\
2005\end{array}$ & & $\begin{array}{l}\text { Oktober } \\
2005\end{array}$ & & $\begin{array}{l}\text { Juni } \\
2006\end{array}$ & $\begin{array}{l}\text { Oktober } \\
2006\end{array}$ & Chi $^{2}$ \\
\hline $2,5 \pm 0,6$ & $>$ & $2,3 \pm 0,9$ & $>$ & $1,9 \pm 1,1$ & $>$ & $1,7 \pm 1,3$ & $>$ & $1,6 \pm 1,4$ & $89,40^{* * *}$ \\
\hline
\end{tabular}

$>$ kennzeichnet signifikanten Vitalitätsrückgang laut Wilcoxon-Test

Die Ausfallrate stieg vom 1. zum 2. Untersuchungsjahr deutlich von $2 \%$ und $8 \%$ in 2005 auf 30 $\%$ und $35 \%$ in 2006 an (in den Topf-Versuchen im Gewächshaus war die Ausfallrate der Ahorne mit insgesamt $37 \%$ vergleichbar). Die mittleren Vitalitätswerte der lebenden Ahorne lagen jeweils bei $2,4 \pm 0,9 ; 2,1 \pm 1,0 ; 2,5 \pm 0,8$ und $2,5 \pm 0,9$.

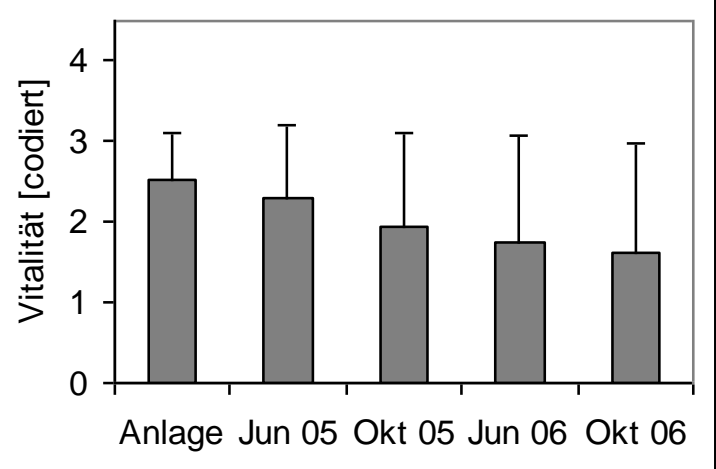

Abb. 122: Vitalität [codiert: $4=$ vital bis $0=$ tot, s. S. 27] der Ahorne im Versuchsverlauf; MW u. Std.abw. $(\mathrm{n}=192)$

\section{Ahorne insgesamt}

Betrachtet man zunächst die Vitalitätsentwicklung der Ahorn-Varianten über die Zeit (s. Tab. 61), so fällt auf, dass sich nur bei einigen wenigen Varianten der durchschnittliche Vitalitätswert der Ahorne im Verlauf des zweijährigen Untersuchungszeitraums signifikant veränderte. In der Kontrolle (V1), der Stockosorb®-Variante (V3) und der Perlit-Variante (V7) ging die mittlere Vitalität der Ahorne im ersten Sommer und nochmals zum 2. Versuchsjahr signifikant auf letztlich nur noch sehr geringe Werte zurück. Einzig in der Superabsorber-Variante (V5) nahm die mittlere Vitalität bereits zu Beginn des Versuchs signifikant auf geringe 1,3 $\pm 0,7 \mathrm{ab}$, um dann zum Juni 2006 erneut auf nur noch sehr geringe 0,4 $\pm 1,0 \mathrm{zu}$ sinken. Die fünfte und letzte Variante, in der sich im Laufe der Zeit überhaupt Unterschiede der mittleren Vitalität der Ahorne feststellen ließen, ist die Mykorrhiza-Variante V11: Hier lagen die Werte jedoch bis zum Schluss über „2“ (vergleichsweise hoch) mit einer signifikanten Abnahme von 2,9 \pm 0,8 auf 2,3 $\pm 1,2$ im ersten Sommer.

Insgesamt lag 2005 der geringste Vitalitätsmittelwert bei 1,3 $\pm 0,7$ (V5, Superabsorber), der höchste bei 2,9 $\pm 0,8$ (V11, Mykorrhiza). In 2006 betrug der niedrigste Wert nur noch 0,4 $\pm 1,0$ (V5, Superabsorber), der höchste 2,6 \pm 1,2 (V14, Mykorrhiza + Stockosorb® + Kalk). 
Tab. 61: Vitalität [codiert: $4=$ vital bis $0=$ tot, s. S. 27] der Ahorn-Varianten (s. S. 20) im Versuchsverlauf; MW u. Std.abw.; je Aufnahmezeitpunkt Ergebnisse von H-Tests (H) auf signifikante Unterschiede zwischen den Varianten; je Variante Ergebnisse von Friedmann-Tests $\left(\mathrm{Chi}^{2}\right)$ auf signifikante Unterschiede zwischen den Aufnahmezeitpunkten (je Variante $\mathrm{n}=12$ )

\begin{tabular}{|c|c|c|c|c|c|c|c|c|c|}
\hline & $\begin{array}{l}\text { April } \\
2005\end{array}$ & & $\begin{array}{l}\text { Juni } \\
2005\end{array}$ & & $\begin{array}{l}\text { Oktober } \\
2005\end{array}$ & & $\begin{array}{l}\text { Juni } \\
2006\end{array}$ & $\begin{array}{l}\text { Oktober } \\
2006\end{array}$ & $\mathrm{Chi}^{2}$ \\
\hline V1 & $2,3 \pm 0,5$ & & $2,1 \pm 0,9$ & $>$ & $1,8 \pm 1,1$ & $>$ & $0,9 \pm 1,0$ & $0,7 \pm 1,0$ & $22,88^{* * *}$ \\
\hline V2 & $2,7 \pm 0,5$ & & $2,3 \pm 0,9$ & & $1,5 \pm 1,1$ & & $1,7 \pm 1,3$ & $1,7 \pm 1,3$ & 7,65 \\
\hline V3 & $2,8 \pm 0,8$ & & $2,3 \pm 0,8$ & $>$ & $1,9 \pm 1,0$ & $>$ & $1,0 \pm 1,0$ & $1,0 \pm 1,0$ & $27,63^{* * *}$ \\
\hline V4 & $2,4 \pm 0,5$ & & $2,7 \pm 0,7$ & & $2,0 \pm 1,1$ & & $2,3 \pm 1,0$ & $1,8 \pm 1,3$ & 3,52 \\
\hline V5 & $2,2 \pm 0,4$ & $>$ & $1,3 \pm 0,7$ & & $1,1 \pm 1,0$ & $>$ & $0,4 \pm 1,0$ & $0,4 \pm 1,0$ & $24,9 * * *$ \\
\hline V6 & $2,5 \pm 0,7$ & & $1,9 \pm 0,8$ & & $1,9 \pm 0,9$ & & $1,4 \pm 1,2$ & $1,3 \pm 1,3$ & 6,95 \\
\hline V7 & $2,5 \pm 0,5$ & & $2,3 \pm 1,1$ & $>$ & $1,7 \pm 1,4$ & $>$ & $1,2 \pm 1,1$ & $1,2 \pm 1,3$ & $16,73^{* *}$ \\
\hline V8 & $2,5 \pm 0,7$ & & $1,6 \pm 1,1$ & & $1,8 \pm 1,2$ & & $1,5 \pm 1,4$ & $1,4 \pm 1,5$ & 8,7 \\
\hline V9 & $2,5 \pm 0,5$ & & $2,3 \pm 1,0$ & & $1,8 \pm 1,1$ & & $1,9 \pm 1,5$ & $1,8 \pm 1,6$ & 3,32 \\
\hline V10 & $2,4 \pm 0,7$ & & $2,3 \pm 1,1$ & & $2,3 \pm 1,3$ & & $2,3 \pm 1,4$ & $2,3 \pm 1,4$ & 0,33 \\
\hline V11 & $2,7 \pm 0,7$ & & $2,9 \pm 0,8$ & $>$ & $2,3 \pm 1,2$ & & $2,0 \pm 1,1$ & $2,1 \pm 1,2$ & $10,85^{*}$ \\
\hline V12 & $2,8 \pm 0,4$ & & $2,8 \pm 0,6$ & & $2,2 \pm 0,9$ & & $2,3 \pm 1,2$ & $2,0 \pm 1,4$ & 5,12 \\
\hline V13 & $2,5 \pm 0,5$ & & $2,2 \pm 0,9$ & & $2,0 \pm 1,0$ & & $1,8 \pm 1,2$ & $1,6 \pm 1,4$ & 6,12 \\
\hline V14 & $2,5 \pm 0,5$ & & $2,8 \pm 0,4$ & & $2,3 \pm 1,1$ & & $2,6 \pm 1,2$ & $2,3 \pm 1,3$ & 3,13 \\
\hline V15 & $2,8 \pm 0,4$ & & $2,8 \pm 0,9$ & & $2,6 \pm 1,2$ & & $2,3 \pm 1,5$ & $2,2 \pm 1,4$ & 3,38 \\
\hline V16 & $2,6 \pm 0,5$ & & $2,5 \pm 0,7$ & & $2,2 \pm 1,3$ & & $2,2 \pm 1,4$ & $1,9 \pm 1,5$ & 2,12 \\
\hline $\mathrm{H}$ & 20,45 & & $42,47^{* * *}$ & & 17,75 & & $41,61^{* * *}$ & $29,95^{*}$ & \\
\hline & $\mathrm{N}=192$ & & $\mathrm{~N}=192$ & & $\mathrm{~N}=192$ & & $\mathrm{~N}=192$ & $\mathrm{~N}=192$ & \\
\hline
\end{tabular}

$>$ signifikanter Vitalitätsrückgang laut Wilcoxon-Test

Bei den mittleren Vitalitätswerten der Ahorne bestanden mit Ausnahme der Aufnahme im Oktober 2005 zu jedem Aufnahmezeitpunkt signifikante Unterschiede zwischen verschiedenen Behandlungsvarianten.

Zwecks eines ersten Eindrucks waren zu Beginn der Datenanalyse multiple schrittweise Regressionen zum Einfluss der eingesetzten Bodenhilfsstoffe auf die Vitalitätsentwicklung der Ahorne durchgeführt worden. Demnach bestand zu Versuchsbeginn ein negativer Einfluss der Superabsorber-Gabe. Mykorrhiza hatte während des gesamten Versuchs, Kompost und Kalk hatten im 2. Untersuchungsjahr (2006) einen positiven Einfluss. Die Stockosorb®- und PerlitGaben hatten keinerlei Effekt.

Bei den folgenden tiefer gehenden Analysen des Einflusses der Behandlungsvarianten wurden deren Wirkungen quantifiziert und genauer beschrieben; dabei konnten diese Ergebnisse im Wesentlichen bekräftigt werden.

Signifikant bessere Vitalitätswerte als die Nullvariante V1 hatten im Juni 2005 die Stockosorb®Kalk-Variante V4 sowie vier der sechs Mykorrhiza-Varianten (V11, 12, 14, 15), wie Abb. 123 zeigt. In 2006 wiesen neben V4 auch V2, die reine Kalk-Variante, die beiden Kompost-Varianten V9 und V10 sowie inzwischen sämtliche sechs Mykorrhiza-Varianten (V11-16) signifikant höhere Mittelwerte als die Kontrolle auf.

In der Superabsorber-Variante V5 wurde im Juni 2005 der einzige gegenüber der Kontrolle signifikant geringere Vitalitätsmittelwert erfasst. 


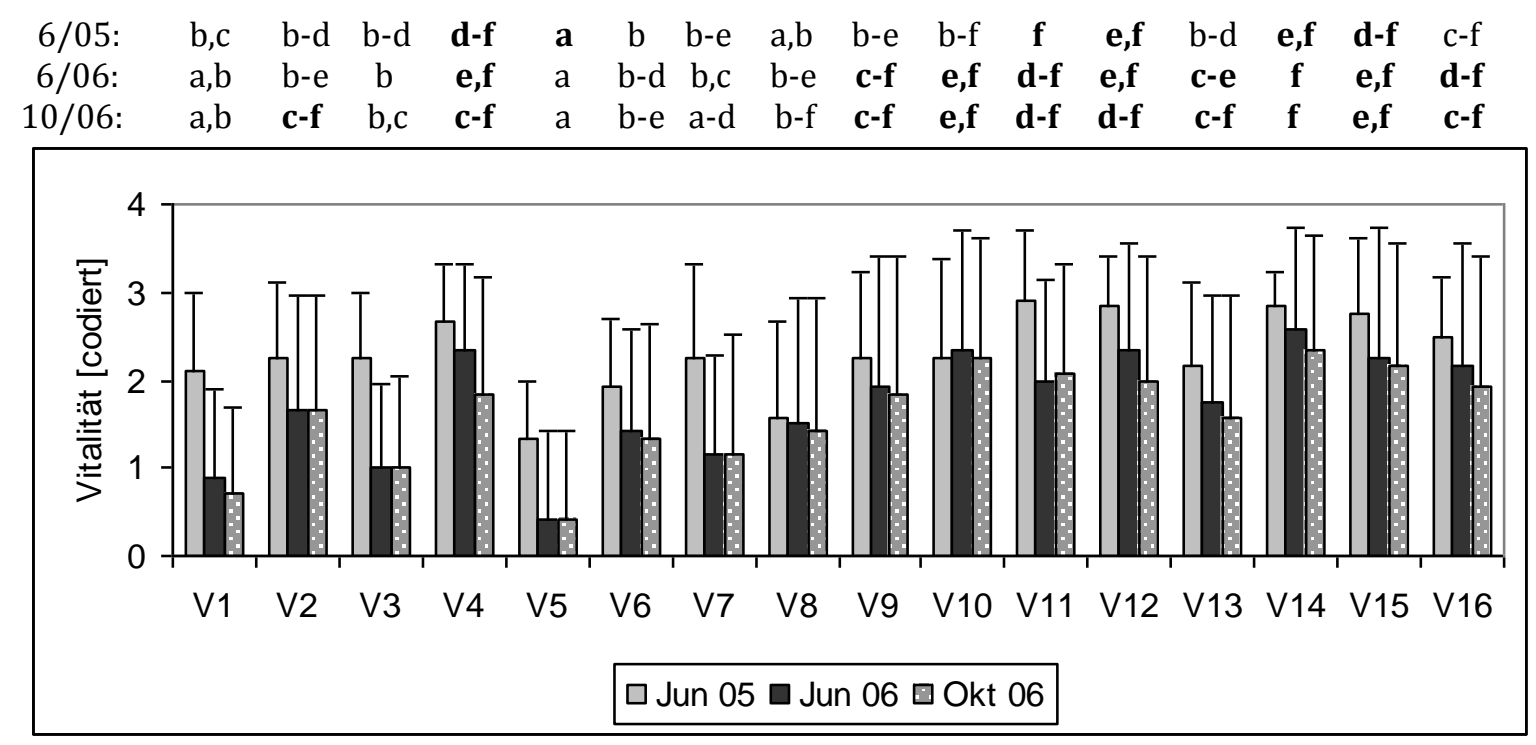

Abb. 123: Vitalität [codiert: 4 = vital bis $0=$ tot, s. S. 27] der Ahorn-Varianten (s. S. 20) im Juni 2005, Juni 2006 und Oktober 2006; MW u. Std.abw.; Buchstaben kennzeichnen je Aufnahmezeitpunkt homogene Gruppen nach U-Tests, Fettdruck markiert signifikanten Unterschied zur Nullvariante (V1) (je Variante $\mathrm{n}=12$ )

Gleichzeitig waren die Mittelwerte der reinen Superabsorber-Variante V5 stets signifikant niedriger als die der Superabsorber-Kalk-Variante V6, aber auch als die der Stockosorb®Variante V3. Letztere beide Varianten unterschieden sich allerdings nicht signifikant von der Nullvariante; dies war erst bei der Kombination von Stockosorb® und Kalk (V4) der Fall.

Auch wenn die Werte in Variante V4 zunächst etwas höher waren als in der reinen Kalk-Variante V2, waren diese Unterschiede nicht signifikant, so dass hier eher von einem positiven Einfluss der Kalk-Gabe ausgegangen werden muss. In Kombination mit Superabsorber (V6) oder Perlit (V8) war dieser positive Kalk-Einfluss dagegen nicht ablesbar. Die Perlitgabe selbst (V7, V8) schien ebenfalls ohne Wirkung zu bleiben. Die Kompost-Gabe (V9, V10) dagegen hielt die mittlere Vitalität der damit versorgten Ahorne über die zwei Versuchsjahre hinweg auf einem sehr konstanten Niveau von um „2“, was im 2. Jahr signifikant höher war als die Werte der Nullvariante. Da V9 und V10 fast identische Werte haben, scheint hier der in beiden Varianten eingesetzte Kompost, nicht der nur in V10 zusätzlich verwendete Kalk die Ursache für diese vergleichsweise positive Vitalitätsentwicklung zu sein. Innerhalb der sechs MykorrhizaVarianten gab es kaum Vitalitätsunterschiede, so dass von einer Wirkung der Mykorrhizierung selbst ausgegangen werden kann. Lediglich V13 (Mykorrhiza-Stockosorb®) wies im Juni 2005 eine signifikant geringere Vitalität auf als V11 (Mykorrhiza), V12 (Mykorrhiza-Kalk) und V14 (Mykorrhiza-Stockosorb®-Kalk), im Juni 2006 als V14. Im Oktober 2005 waren dann zwischen allen sechs Mykorrhiza-Varianten keine signifikanten Unterschiede mehr feststellbar.

\section{Ahorne auf Versuchsfläche A}

Auch bei Betrachtung jeder Versuchsfläche einzeln konnten bei den Ahornen auf allen drei Flächen signifikante Vitalitätsunterschiede zwischen verschiedenen Behandlungsvarianten festgestellt werden. Auf Versuchsfläche A galt dies allerdings nur für die Aufnahme im Juni 2005, also zwei Monate nach Versuchsanlage (s. Abb. 124). Zu diesem Aufnahmezeitpunkt lag dort die durchschnittliche Vitalität der Ahorne bei 2,0 \pm ,9. Bei den weiteren Aufnahmen war ihr Vitalitätsmittelwert so weit abgesunken (Okt. 2005: 1,0 \pm 0,4; Juni 2006: 0,9 $\pm 1,1$; Okt. 2006: 0,6 $\pm 0,9$ ), dass keine statistisch gesicherten Unterschiede zwischen einzelnen Varianten mehr bestanden. 


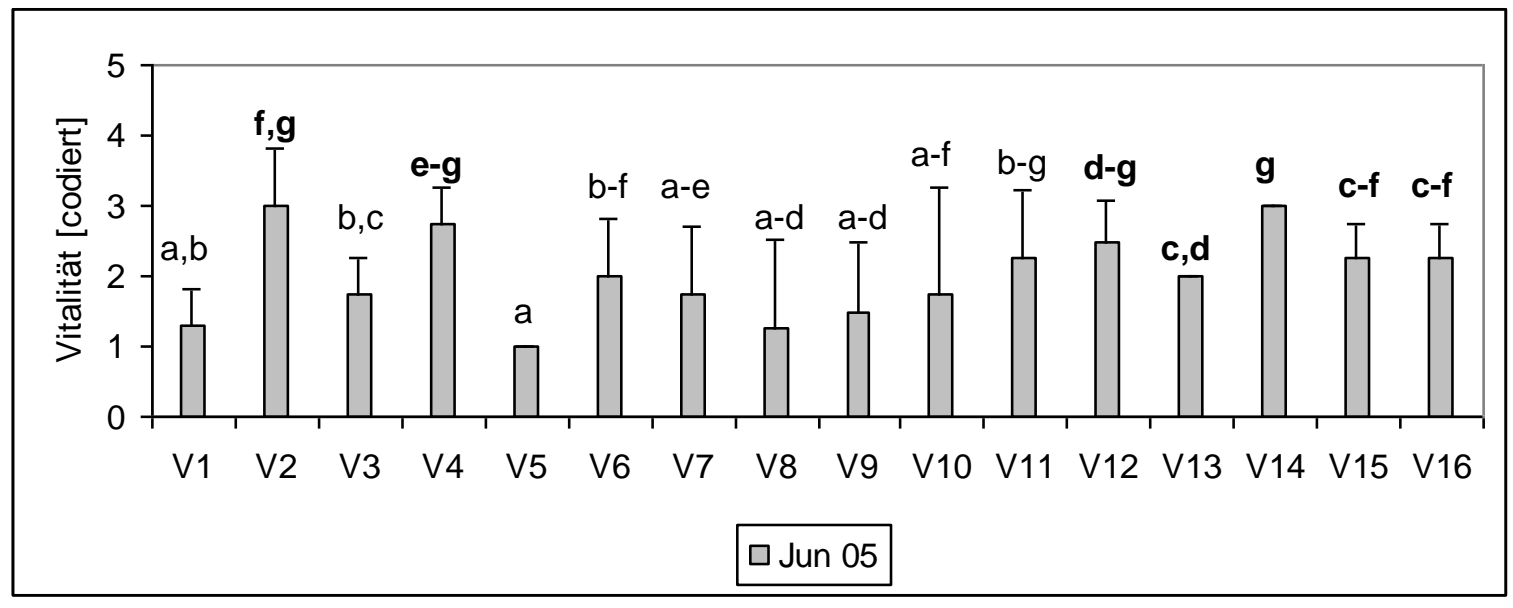

Abb. 124: Vitalität [codiert: 4 = vital bis $0=$ tot, s. S. 27] der Ahorn-Varianten (s. S. 20) auf Versuchsfläche A im Juni 2005; MW u. Std.abw.; Buchstaben kennzeichnen homogene Gruppen nach U-Tests, Fettdruck markiert signifikanten Unterschied zur Nullvariante (V1) (je Variante $n=4$ )

Relativ zu Beginn des Versuchs spielte die Kalk-Gabe auf Fläche A (vergleichsweise sehr ungünstige Standortbedingungen, s. ab S. 44) eine große Rolle. Ihr positiver Einfluss bestand in Kombination mit Superabsorber (V6), Perlit (V8) und interessanterweise auch Kompost (V10) jedoch nicht. Die höchsten Vitalitätsmittelwerte hatten die Pflanzen in der reinen Kalk-Variante V2 $(3,0 \pm 0,8)$ und der Mykorrhiza-Stockosorb $®$-Kalk-Variante V14 (3,0 \pm 0$)$, den niedrigsten Wert wies die Superabsorber-Variante V5 $(1,0 \pm 0)$ auf. Signifikant höhere mittlere Vitalitätswerte als die Nullvariante V1 $(1,3 \pm 0,5)$ hatten V2, die Stockosorb®-Kalk-Variante V4 $(2,8 \pm 0,5)$ sowie die Varianten V12 (2,5 $\pm 0,6), \mathrm{V} 13$ (2,0 \pm 0$), \mathrm{V} 14$ (3,0 \pm 0$), \mathrm{V} 15$ und V16 (je 2,3 \pm 0,5 ) und somit alle Mykorrhiza-Varianten mit Ausnahme von V11 (reine Mykorrhiza). Dabei wurde in der Kombination Mykorrhiza, Stockosorb® und Kalk (V14) ein signifikant höherer Vitalitätswert ermittelt als in der gleichen, jedoch kalkfreien Kombination (V13) sowie in den Kombinationen mit Superabsorber (V15 ohne, V16 mit Kalk).

Da die Vitalität in der reinen Stockosorb®-Variante V3 $(1,8 \pm 0,5)$ sich nicht signifikant von der Kontrolle unterschied, aber signifikant geringer war als in der Kombination mit Kalk (V4), ging hier der positive Einfluss vermutlich von der Kalk-Gabe aus.

Die Anwendung von Stockosorb ${ }^{\circledR}$, Superabsorber, Perlit oder Kompost allein hatte gemessen an der Kontrolle keinen statistisch nachweisbaren Effekt auf die Vitalität der Ahorne auf Fläche A.

\section{Ahorne auf Versuchsfläche B}

Auf Versuchsfläche B bestanden mit Ausnahme von Oktober 2005 zu jedem Aufnahmezeitpunkt signifikante Unterschiede der mittleren Vitalitätswerte der Ahorne zwischen einzelnen Behandlungsvarianten (s. Abb. 125). Insgesamt betrug die durchschnittliche Vitalität hier im Juni 2005, zwei Monate nach der Pflanzung, 2,6 $\pm 0,8$. Im 2. Versuchsjahr sank dieser Wert leicht auf 2,2 $\pm 1,1$ (Juni) bzw. 2,1 \pm 1,3 (Oktober). Im Oktober 2005 (nicht dargestellt, da keine signifikanten Unterschiede zwischen den Behandlungsvarianten) lag er im Mittel bei 2,5 $\pm 1,1$.

Im Juni 2005 erreichte die Mykorrhiza-Superabsorber-Variante V15 den höchsten Vitalitätsmittelwert, in 2006 war es die Kompost-Kalk-Variante V10 (je 3,5 \pm 0,6). Die niedrigsten Vitalitätsmittelwerte hatten im Juni 2005 die Kalk-Variante V2 sowie die Superabsorber-Kalk-Variante V6 (je 1,5 \pm 0,6), in 2006 die Kalk-Variante V2 (0,5 \pm 1,0). 


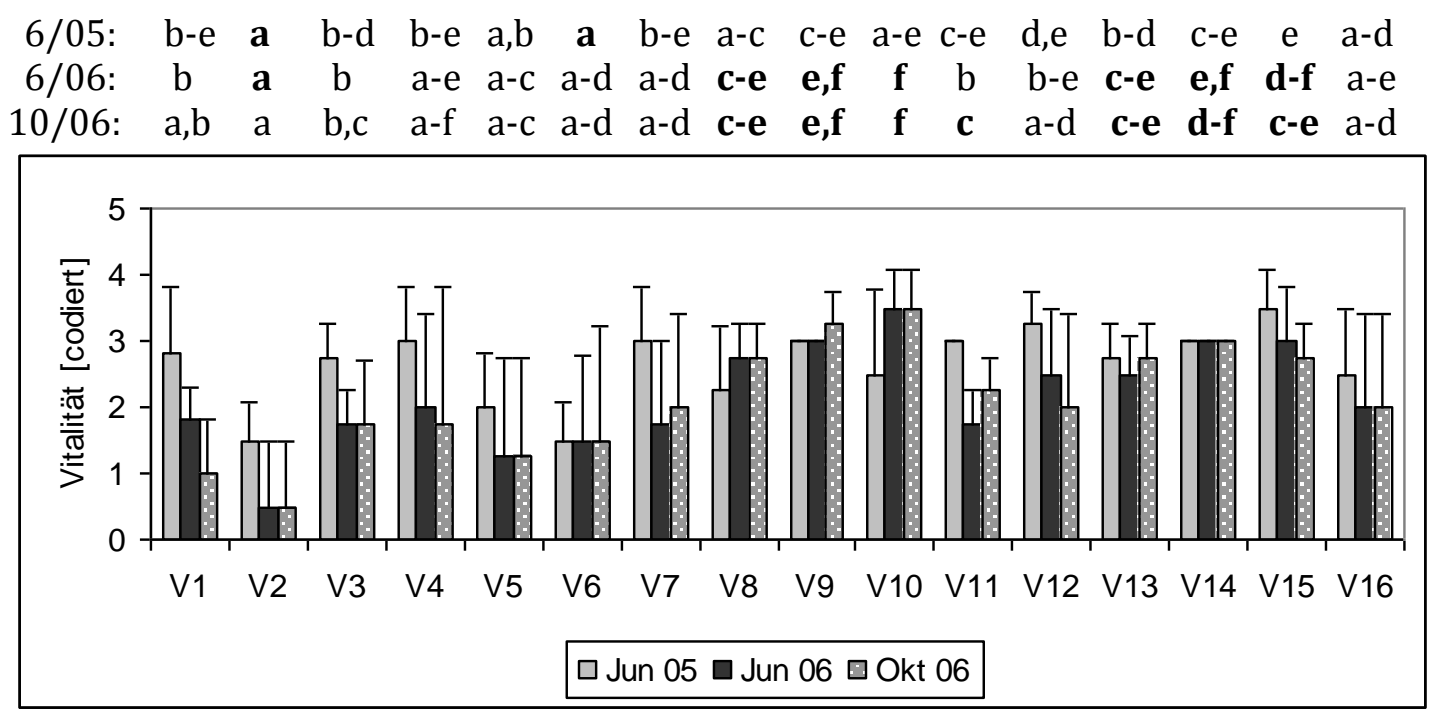

Abb. 125: Vitalität [codiert: 4 = vital bis 0 = tot, s. S. 27] der Ahorn-Varianten (s. S. 20) auf Versuchsfläche B im Juni 2005, Juni 2006 und Oktober 2006; MW u. Std.abw.; Buchstaben kennzeichnen je Aufnahmezeitpunkt homogene Gruppen nach U-Tests, Fettdruck markiert signifikanten Unterschied zur Nullvariante (V1) (je Variante $n=4$ )

Im Juni 2005, zwei Monate nach Versuchsanlage, gab es in keiner Variante signifikant höhere Vitalitätsmittelwerte als in der Nullvariante V1, in der die Ahorne zu diesem Zeitpunkt noch einen relativ hohen mittleren Vitalitätswert von 2,8 \pm 1,0 hatten. In der Kalk-Variante V2 und der Superabsorber-Kalk-Variante V6 war die durchschnittliche Vitalität mit jeweils 1,5 \pm 0,6 sogar signifikant geringer als in der Kontrolle. Grund für das gute Abschneiden der Nullvariante war, dass sämtliche Kontrollen auf Fläche B zufällig in einen Bereich gepflanzt worden waren, in dem sich im Versuchsverlauf auch spontan Bodenvegetation ansiedeln konnte, in dem die Wuchsbedingungen also vergleichsweise besser waren (s. ab S. 44 u. S. 297), während z. B. V2 und V6 in bis Versuchsende vegetationsfreien Bereichen platziert waren (ebenda). Insgesamt schien jedoch der Einfluss der unterschiedlichen Standortbedingungen auf dieser Fläche auf die Vitalität der Ahorne nicht so stark zu sein wie z.B. auf die Vitalität der Douglasien (s. ab S. 267).

In 2006 sank die Durchschnittsvitalität der Kontroll-Ahorne auf Fläche B auf 1,8 \pm 0,5 im Juni und schließlich auf 1,0 \pm ,8 im Oktober, während in einigen anderen Varianten die Werte gleich blieben oder sogar anstiegen. Signifikant bessere Vitalitätsmittelwerte wurden in der PerlitKalk-Variante V8 (jeweils 2,8 $\pm 0,5)$, in der Kompost-Variante V9 $(3,0 \pm 0 ; 3,3 \pm 0,5)$ und der Kompost-Kalk-Variante V10 (jeweils 3,5 \pm 0,6) sowie in den Mykorrhiza-Varianten V13 (M. + Stockosorb®: 2,5 \pm 0,6; 2,8 \pm 0,5), V14 (M. + Stockosorb® + Kalk: jeweils 3,0 \pm 0) und V15 (M. + Superabsorber: 3,0 $\pm 0,8,2,8 \pm 0,5$ ) ermittelt; im Oktober auch in der reinen MykorrhizaVariante V11 $(2,3 \pm 0,5)$. Die in 2006 nur noch sehr geringe mittlere Vitalität der Ahorne in der Kalk-Variante V2 $(0,5 \pm 1,0)$ lag im Juni signifikant unter dem Wert in der Kontrolle.

Auf Grund des starken Einflusses standörtlicher Unterschiede (v.a. hinsichtlich des pH-Wertes; s. ab S. 44) ist die Wirkungsweise der angewendeten Behandlungsvarianten auf Versuchsfläche B recht schwierig zu deuten. Der Einsatz von Kompost und Mykorrhiza hat ab dem 2. Versuchsjahr einen gegenüber der Nullvariante deutlich positiven Effekt, wobei die Mykorrhiza-Impfung offenbar in Kombination mit Stockosorb® und Kalk (V14), im (wie ab S. 14 dargestellt sehr trockenen) Sommer auch in Kombination mit den beiden Wasserspeichersubstanzen (V13, V15) signifikant bessere Wirkung entfaltet als allein (V11). Betrachtet man die schematische Darstellung der Spontanvegetation und der Versuchspflanzenstandorte auf Fläche B (s. S. 37, 
Abb. 4), so würde man nur aufgrund dessen ein schlechteres Abschneiden der Varianten V12, V14 und V16 gegenüber den anderen Mykorrhiza-Varianten, deren Standorte sich im mit Bodenvegetation besiedelten Bereich befinden, erwarten. Dennoch wurden in der MykorhizaStockosorb®-Kalk-Varianten V14 konstant gute durchschnittliche Vitalitätswerte ermittelt, die im 2. Versuchsjahr auch signifikant besser waren als die der Kontrolle.

Der auf allen anderen Flächen positive Effekt der Kalk-Gaben war auf dieser Fläche nicht eindeutig erkennbar. Die Ursache liegt vermutlich darin, dass sich die Kalk-Varianten (= Varianten mit geraden Zahlen) überwiegend in Teilbereichen ohne Spontanvegetation und somit mit schlechteren Standortbedingungen sowie teilweise Staunässe befanden, während die Varianten ohne Kalk-Gabe von den besseren Bodenbedingungen in später bewachsenen Bereichen profitierten. In Variante V8, der Kombination aus Perlit (Bodenstrukturverbesserung) und Kalk (pH-Anhebung), erreichten die Ahorne dennoch stabil relativ gute Vitalitätswerte $(2,8$ $\pm 0,5 \mathrm{im}$ 2. Jahr), die auch signifikant höher lagen als in der Nullvariante.

\section{Ahorne auf Versuchsfläche D}

Auf Versuchsfläche D bestanden im Oktober 2005 und im Juni 2006 signifikante Unterschiede zwischen den mittleren Vitalitätswerten der Ahorne in verschiedenen Behandlungsvarianten (s. Abb. 126). Insgesamt betrug die Durchschnittsvitalität der Ahorne auf Fläche D im Oktober 2005 $2,3 \pm 1,2$, im Juni 2006 mehr oder weniger unverändert 2,1 \pm 1 ,4. In den hier nicht dargestellten Aufnahmen (keine signifikanten Unterschiede zwischen den Behandlungsvarianten) wurden ähnliche mittlere Vitalitätswerte von 2,3 \pm 0,9 (Juni 2005) und 2,1 $\pm 1,4$ (Oktober 2006) erreicht.

$\begin{array}{lllllllllllllllll}\text { 10/05: } & \text { b } & \text { b,c } & \text { a,b } & \text { b,c } & \text { a } & \text { b,c } & \text { a-c } & \text { a,b } & \text { b } & \text { b,c } & \mathbf{d} & \mathbf{c , d} & \text { a-c } & \text { b-d } & \mathbf{d} & \mathbf{c , d} \\ \text { 6/06: } & \text { a,b } & \text { c,d } & \text { a,b } & \mathbf{c , d} & \text { a } & \text { c } & \text { a,b } & \text { a-c } & \text { a-d } & \mathbf{c} & \mathbf{d} & \mathbf{d} & \text { b,c } & \text { b-d } & \mathbf{d} & \text { b-d }\end{array}$

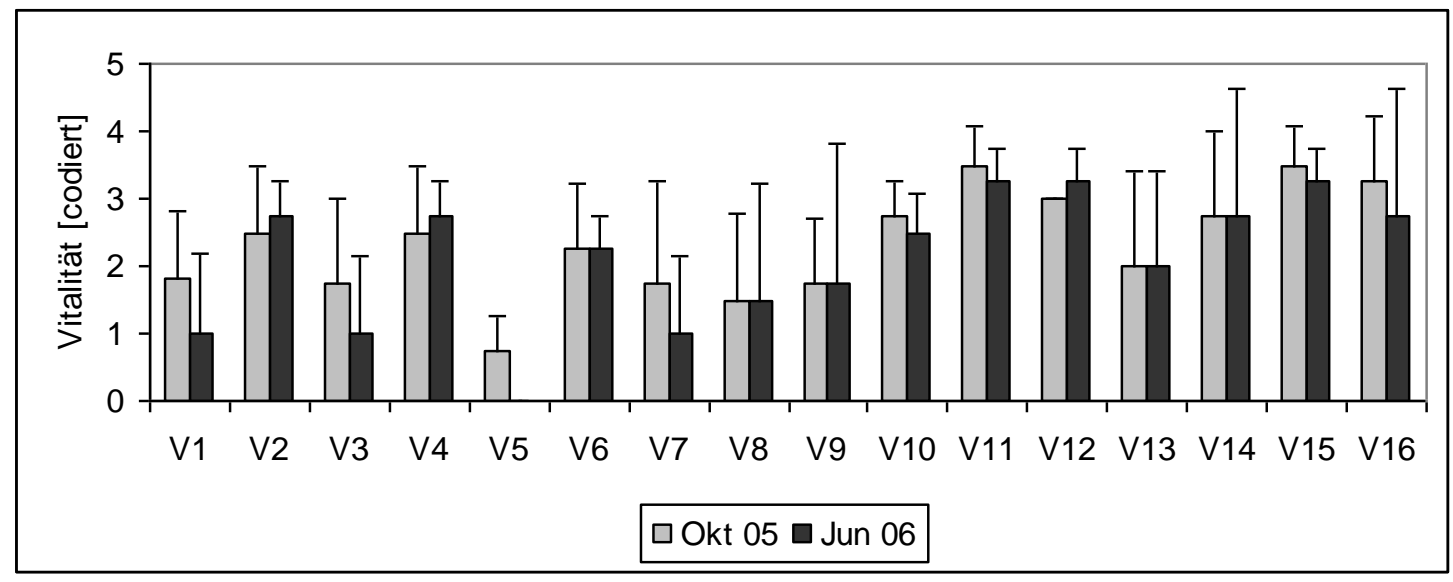

Abb. 126: Vitalität [codiert: 4 = vital bis $0=$ tot, s. S. 27] der Ahorn-Varianten (s. S. 20) auf Versuchsfläche D im Oktober 2005 und Juni 2006; MW u. Std.abw.; Buchstaben kennzeichnen je Aufnahmezeitpunkt homogene Gruppen nach U-Tests; Fettdruck markiert signifikanten Unterschied zur Nullvariante (V1) (je Variante $n=4$ )

Auch auf Fläche D war ein positiver Einfluss der Kalk-Gabe zu erkennen. Die höchsten Vitalitätsmittelwerte lagen im Oktober 2005 bei 3,5 \pm 0,6 (Mykorrhiza-Variante V11 u. Mykorrhiza-Superabsorber-Variante V15), im Juni 2006 bei 3,3 \pm 0,5 (V11, V15 u. MykorrhizaKalk-Variante V12). Die niedrigsten durchschnittlichen Vitalitätswerte hatten jeweils die Ahorne in der Superabsorber-Variante V5 (0,8 \pm 0,5 im Oktober 2005 und damit signifikant schlechter als in der Kontrolle, Totalausfall im Juni 2006). 
Signifikant bessere Vitalitätsmittelwerte als in der Nullvariante V1 $(1,8 \pm 1,0)$ wurden im Oktober 2005 in den vier Stockosorb®-freien Mykorrhiza-Varianten, nämlich V11 (reine Mykorrhiza; 3,5 \pm 0,6), V12 (Mykorrhiza + Kalk; 3,0 \pm 0), V15 (Mykorrhiza + Superabsorber; 3,5 $\pm 0,6$ ) und V16 (Mykorrhiza + Superabsorber + Kalk; 3,3 $\pm 1,0$ ) erreicht.

Im Juni 2006 war die mittlere Vitalität der Kontroll-Ahorne auf $1 \pm 1,2$ gesunken. Signifikant höhere Werte hatten die reine Kalk-Variante V2 und die Stockosorb®-Kalk-Variante V4 (beide 2,8 \pm 0,5), die Superabsorber-Kalk-Variante V6 $(2,3 \pm 0,5)$, die Kompost-Kalk-Variante V10 (2,5 \pm $0,6)$ sowie diesmal die drei Mykorrhiza-Varianten V11, V12 und V $15(3,3 \pm 0,5)$.

Zwischen den gegenüber der Kontrolle signifikant besseren Mykorrhiza-Varianten und den verbleibenden Mykorrhiza-Varianten bestanden mit einer Ausnahme keine statistisch nachweisbaren Vitalitätsunterschiede: Variante V13, die Kombination von Mykorrhiza und Stockosorb®, wies bei beiden Aufnahmen interessanterweise signifikant geringere Vitalitätsmittelwerte auf als die reine Mykorrhiza-Variante V11 und auch als die MykorrhizaSuperabsorber-Variante V15.

Das gegenüber der Kontrolle bessere Abschneiden der Varianten V4, 6 und 10 lag offensichtlich an der Kalk-Gabe, da die in diesen Varianten mit Kalk kombinierten Bodenhilfsstoffe (Stockosorb ${ }^{\circledR}$, Superabsorber, Kompost) bei alleiniger Anwendung (V3, V5, V9) keine signifikante Verbesserung herbeiführten. Die Perlit-Kalk-Variante V8 wies (ebenso wie die reine Perlit-Variante V7) trotz Kalk-Gabe auch im Juni 2006 gegenüber der Kontrolle keine signifikant unterschiedlichen Vitalitätsmittelwerte auf.

\section{Ahorne in Bereichen ohne Spontanvegetation}

Bei der Gruppe der Ahorne mit Standorten auf Teilflächen ohne Bodenvegetation ließen sich jeweils im Sommer (in beiden Juni-Aufnahmen 2005 und 2006) signifikante Unterschiede der durchschnittlichen Pflanzenvitalität zwischen einzelnen der insgesamt 16 Behandlungsvarianten feststellen (s. Abb. 127).

6/05: b,c b-e b-d d-f a b,c b-d a-c b-d b-f b-f e,f $\quad$ b $\quad$ f $\quad$ c-e $\quad$ b-e 6/06: a,b b-f $\quad$ b,c $\quad$ g $\quad$ a $\quad$ b-d b-d b-g b-f $\quad$ c-g b-g f,g b-d e-g b-e $\quad$ d-g

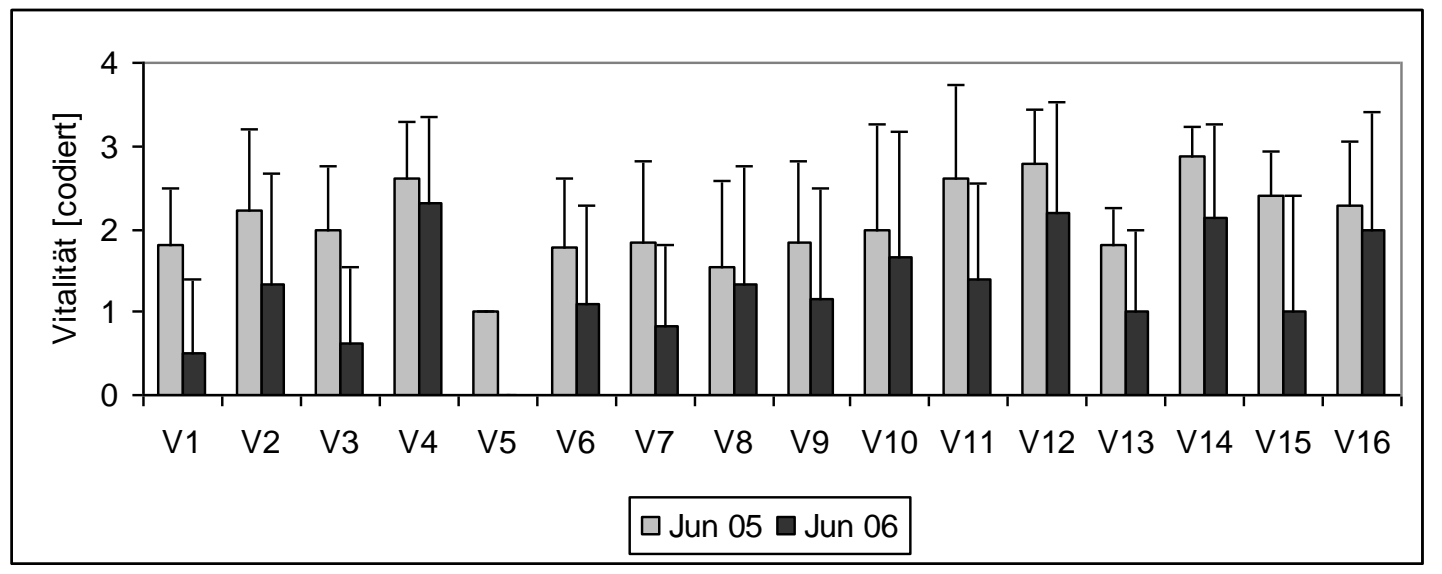

Abb. 127: Vitalität [codiert: $4=$ vital bis $0=$ tot, s. S. 27] der Ahorn-Varianten (s. S. 20) in vegetationsfreien Bereichen im Juni 2005 und Juni 2006; MW u. Std.abw.; Buchstaben kennzeichnen je Aufnahmezeitpunkt homogene Gruppen nach U-Tests, Fettdruck markiert signifikanten Unterschied zur Nullvariante (V1) $(\mathrm{n}=118)$ 
Die Durchschnittsvitalität aller Ahorne auf diesen Standorten lag im Juni 2005 bei 2,1 \pm 0,9, der höchste Mittelwert war 2,9 \pm 0,4 (V14, Mykorrhiza + Stockosorb $®+$ Kalk), der niedrigste 1,0 \pm 0 (V5, Superabsorber). Im Juni 2006 war der Gesamt-Mittelwert auf niedrige 1,3 \pm 1,3 gesunken mit 2,3 $\pm 1,1$ (V4, Stockosorb ${ }^{\circledR}+$ Kalk) als höchstem und 0 (V5, Superabsorber) als niedrigstem Einzel-Mittelwert. Zum Zeitpunkt der hier nicht dargestellten Aufnahmen (keine signifikanten Unterschiede zwischen Varianten) lag die Vitalität der Ahorne im Mittel bei niedrigen 1,5 $\pm 1,0$ (Oktober 2005) bzw. 1,2 $\pm 1,3$ (Oktober 2006).

Die Kalk-Gabe war auf diesen vergleichsweise stärker versauerten Standorten (pH 3,6) erkennbar von Bedeutung. Jedoch konnte die Vitalität der Ahorne weder mit Kalk allein (V2) noch in Kombination mit Superabsorber (V6) oder Perlit (V8) gegenüber der Kontrolle (V1: 2005: 1,8 \pm 0,7; 2006: 0,5 \pm 0,9) signifikant verbessert werden. In Kombination mit Stockosorb ${ }^{\circledR}$ (V4: 2005: 2,6 \pm 0,7; 2006: 2,3 $\pm 1,1$ ), Mykorrhiza (V12: 2005: 2,8 \pm 0,6; 2006: 2,2 $\pm 1,3$ ) oder beidem (V14: 2005: 2,9 \pm 0,4; 2006: 2,1 $\pm 1,1$ ) war dies dagegen der Fall, im 2. Vegetationsjahr dann auch in Kombination mit Kompost (V10: 1,7 $\pm 1,5$ ) oder Mykorrhiza und Superabsorber (V16: 2,0 \pm 1,4). Dabei lag im 2. Sommer (Juni 2006) die Vitalität der Ahorne mit Stockosorb® und Kalk (V4) signifikant höher als bei einzelner Anwendung dieser beiden Hilfsstoffe (Kalk: V2 bzw. Stockosorb®: V3). Die Mykorrhiza-Stockosorb®-Kombination mit Kalk (V14) lieferte in beiden Sommern bessere Vitalitätswerte als ohne Kalk (V13).

Sämtliche Varianten ohne Kalk-Gabe spielten auf den ungünstigeren, unbewachsenen Standorten keine Rolle. Die Superabsorber-Variante V5 zeigte bereits im Juni 2005, 2 Monate nach Versuchsanlage, einen signifikant schlechteren Vitalitätsmittelwert als die Kontrolle und fiel im folgenden Jahr komplett aus.

\section{Ahorne in Bereichen mit Spontanvegetation}

Unter den Ahornen mit Standorten auf Teilflächen mit Bodenbesiedelung gab es nur im Juni 2006 signifikante Unterschiede der durchschnittlichen Pflanzenvitalität je nach Behandlungsvariante (s. Abb. 128).

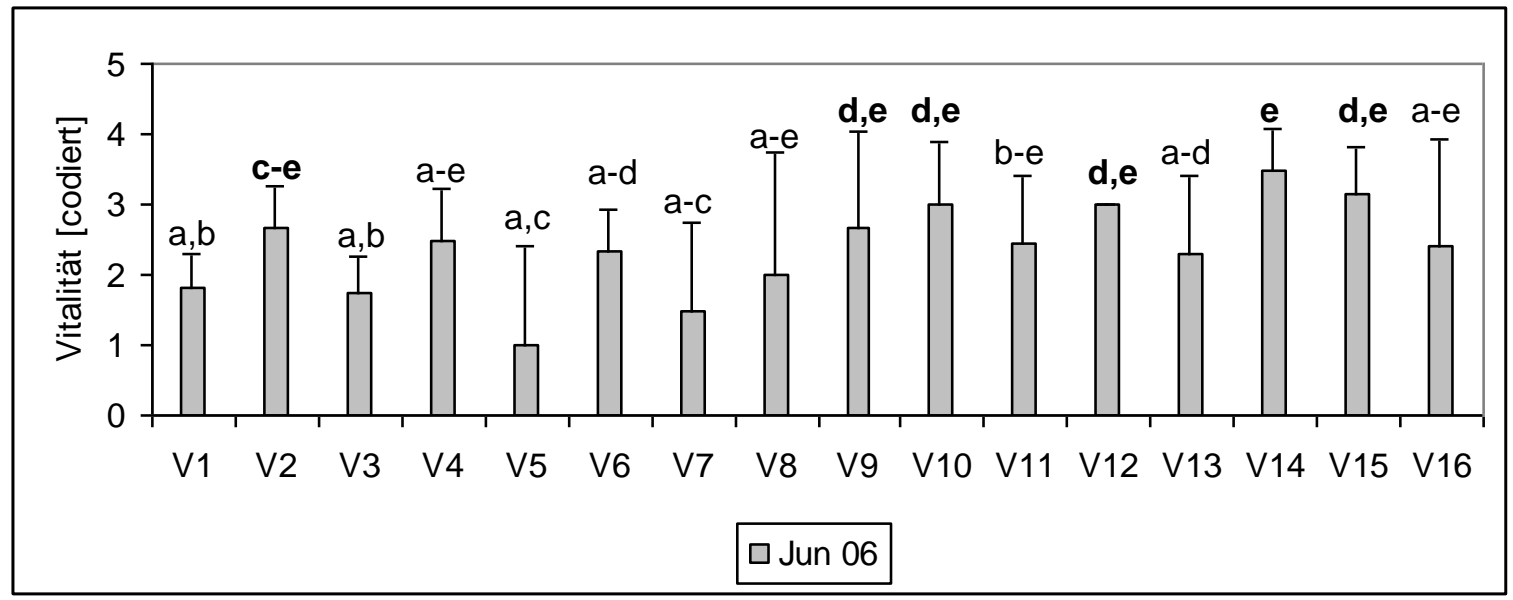

Abb. 128: Vitalität [codiert: $4=$ vital bis $0=$ tot, s. S. 27] der Ahorn-Varianten (s. S. 20) in bewachsenen Bereichen im Juni 2006; MW u. Std.abw.; Buchstaben kennzeichnen homogene Gruppen nach U-Tests, Fettdruck markiert signifikanten Unterschied zur Nullvariante (V1) (n=74)

Die mittlere Vitalität aller Ahorne auf diesen Standorten lag zu dem Zeitpunkt bei 2,4 \pm 1,1, der höchste Mittelwert war 3,5 \pm 0,6 (V14, Mykorrhiza + Stockosorb ${ }^{\circledR}+$ Kalk), der niedrigste 1,0 \pm 
1,4 (V5, Superabsorber). In den hier nicht dargestellten Aufnahmen (keine signifikanten Unterschiede zwischen den Behandlungsvarianten) wurden auf diesen Standorten durchschnittliche Vitalitätswerte der Ahorne von 2,6 \pm 0,9 (Juni 2005), 2,7 $\pm 1,0$ (Oktober 2005) und 2,3 \pm 1,2 (Oktober 2006) ermittelt. Die mittlere Vitalität der Ahorne auf Standorten mit Bodenvegetation blieb also im Laufe des Versuchs recht konstant.

Überwiegend war auch hier trotz leicht höherer pH-Werte des Bodens $(4,0)$ der positive Einfluss der Bodenhilfsstoffe mit Wirkung auf die Bodenchemie (Kalk, Kompost) zu erkennen. Die reine Kalk-Variante V2 $(2,7 \pm 0,6)$, die Kompost-Variante V9 $(2,7 \pm 1,4)$ und die Kompost-KalkVariante V10 $(3,0 \pm 0,9)$ wiesen signifikant höhere Vitalitätsmittelwerte auf als die Nullvariante V1 $(1,8 \pm 0,5)$. Gleiches galt wiederum für die Mykorrhiza-Varianten V12 (Mykorrhiza-Kalk; 3,0 \pm 0 ) und V14 (Mykorrhiza-Stockosorb $®$-Kalk; 3,5 \pm 0,6) sowie für V15 mit einer Kombination aus Mykorrhiza und Superabsorber, jedoch ohne Kalk (3,1 $\pm 0,7)$. In Kombination mit Perlit (V8), Stockosorb® (V4) oder Superabsorber (V6 sowie V16) führte die Kalk-Gabe nicht zu gegenüber der Kontrolle signifikant besseren Werten.

\subsubsection{Eberesche}

Die Vitalität aller 120 im Freiland-Versuch eingesetzten Ebereschen lag bei Versuchsanlage im April 2005 im Mittel bei recht guten 3,0 \pm 0,4. Bis Juni 2005 sank dieser Durchschnittswert signifikant auf 2,2 $\pm 0,9$ und blieb im weiteren Versuchsverlauf (s. Tab. 62) etwa auf diesem mäßigen Niveau $(2,1 \pm 1,3$ im Oktober 2005, 2,0 \pm 1,3 im Juni 2006 und schließlich eine leichte, signifikante Abnahme auf 1,9 $\pm 1,3$ im Oktober 2006, s. Abb. 129).

Tab. 62: Vitalität [codiert: 4 = vital bis $0=$ tot, s. S. 27] der Ebereschen im Versuchsverlauf; MW u. Std.abw.; Ergebnis des Friedmann-Tests $\left(\mathrm{Chi}^{2}\right)$ auf signifikante Unterschiede zwischen den Aufnahmezeitpunkten $(n=120)$

\begin{tabular}{|l|l|l|l|l|l|l|l|l|l|}
\hline $\begin{array}{l}\text { April } \\
2005\end{array}$ & & $\begin{array}{l}\text { Juni } \\
2005\end{array}$ & & $\begin{array}{l}\text { Oktober } \\
2005\end{array}$ & & $\begin{array}{l}\text { Juni } \\
2006\end{array}$ & & $\begin{array}{l}\text { Oktober } \\
2006\end{array}$ & $\mathrm{Chi}^{2}$ \\
\hline $3,0 \pm 0,4$ & $>$ & $2,2 \pm 0,9$ & & $2,1 \pm 1,3$ & & $2,0 \pm 1,3$ & $>$ & $1,9 \pm 1,3$ & $47,91^{* * *}$ \\
\hline
\end{tabular}

$>$ signifikanter Vitalitätsrückgang laut Wilcoxon-Test

Die Ausfallrate stieg im Versuchsverlauf von 2,5 \% im Juni 2005 über $17 \%$ und $25 \%$ auf $29 \%$ im Oktober 2006 an. Die mittlere Vitalität der lebenden Ebereschen lag jeweils bei 2,2 $\pm 0,8 ; 2,5$ $\pm 0,9 ; 2,6 \pm 0,6$ und $2,6 \pm 0,7$.

In den Topf-Versuchen im Gewächshaus war die Ausfallrate der Ebereschen mit insgesamt nur 2,5 \% deutlich geringer. Ursachen dafür könnten der Ausschluss von Wildschäden (im Freiland wurde ein Viertel aller Ebereschen durch Wild geschädigt) und die regelmäßige Bewässerung im Gewächshaus sein. 


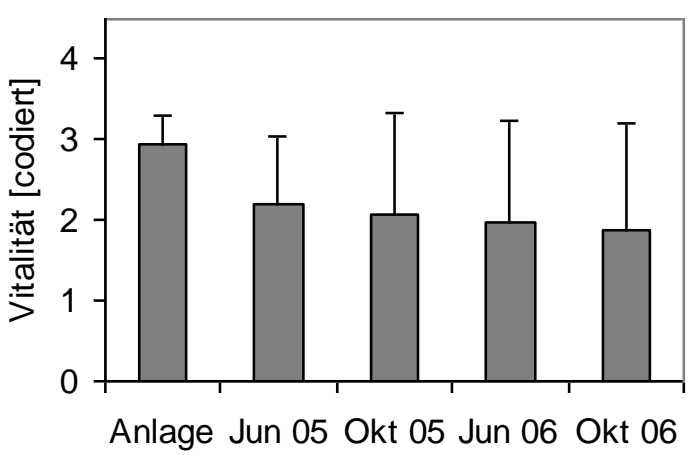

Abb. 129: Vitalität [codiert: $4=$ vital bis $0=$ tot, s. S. 27] der Ebereschen im Versuchsverlauf; MW u. Std.abw. $(\mathrm{n}=120)$

\section{Ebereschen insgesamt}

Bei den Ebereschen insgesamt bestanden bei beiden Aufnahmen im 2. Untersuchungsjahr (Juni und Oktober 2006) signifikante Unterschiede zwischen den Vitalitätswerten in einzelnen Varianten, im Jahr der Pflanzung (2005) dagegen noch nicht (s. Tab. 63).

Tab. 63: Vitalität [codiert: $4=$ vital bis $0=$ tot, s. S. 27] der Ebereschen-Varianten (s. S. 20) im Versuchsverlauf; MW u. Std.abw.; je Aufnahmezeitpunkt Ergebnisse von H-Tests (H) auf signifikante Unterschiede zwischen den Varianten; je Variante Ergebnisse von Friedmann-Tests ( $\mathrm{Chi}^{2}{ }^{2}$ ) auf signifikante Unterschiede zwischen den Aufnahmezeitpunkten (je Variante n=12)

\begin{tabular}{|l|l|l|l|l|l|l|l|l|l|l|}
\hline & $\begin{array}{l}\text { April } \\
2005\end{array}$ & & $\begin{array}{l}\text { Juni } \\
2005\end{array}$ & & $\begin{array}{l}\text { Oktober } \\
2005\end{array}$ & $\begin{array}{l}\text { Juni } \\
2006\end{array}$ & $\begin{array}{l}\text { Oktober } \\
2006\end{array}$ & Chi $^{2}$ \\
\hline V1 & $3,1 \pm 0,5$ & $>$ & $1,9 \pm 1,3$ & $>$ & $1,5 \pm 1,4$ & & $1,3 \pm 1,3$ & & $1,3 \pm 1,4$ & $16,03^{* *}$ \\
\hline V2 & $2,8 \pm 0,5$ & & $2,4 \pm 0,7$ & & $2,8 \pm 0,8$ & & $2,5 \pm 0,5$ & $2,3 \pm 0,9$ & 2,58 \\
\hline V3 & $3,1 \pm 0,3$ & $>$ & $1,9 \pm 0,8$ & & $1,6 \pm 1,2$ & & $1,3 \pm 1,4$ & $1,1 \pm 1,4$ & $16,78^{* *}$ \\
\hline V4 & $2,8 \pm 0,4$ & & $2,3 \pm 1,1$ & & $2,0 \pm 1,3$ & & $2,0 \pm 1,5$ & $2,0 \pm 1,5$ & 2,47 \\
\hline V5 & $3,0 \pm 0,4$ & $>$ & $1,8 \pm 0,7$ & & $1,4 \pm 1,5$ & & $1,3 \pm 1,5$ & $1,2 \pm 1,5$ & $10,02^{*}$ \\
\hline V6 & $3,0 \pm 0$ & & $2,0 \pm 0,7$ & & $2,3 \pm 1,2$ & & $2,3 \pm 1,1$ & $1,8 \pm 1,3$ & 7,97 \\
\hline V7 & $2,9 \pm 0,3$ & $>$ & $2,3 \pm 0,8$ & $>$ & $1,8 \pm 1,1$ & $>$ & $1,5 \pm 1,2$ & $1,8 \pm 1,4$ & $12,43^{*}$ \\
\hline V8 & $3,0 \pm 0$ & & $2,1 \pm 0,7$ & & $2,4 \pm 1,1$ & & $2,3 \pm 0,9$ & $2,2 \pm 0,9$ & 8,58 \\
\hline V9 & $3,0 \pm 0$ & & $2,6 \pm 0,8$ & & $2,4 \pm 1,4$ & & $2,7 \pm 1,0$ & $2,6 \pm 1,2$ & 1,13 \\
\hline V10 & $2,8 \pm 0,6$ & & $2,6 \pm 0,7$ & & $2,5 \pm 1,2$ & & $2,8 \pm 1,0$ & $2,6 \pm 1,1$ & 0,6 \\
\hline H & 10,46 & & 12,59 & & 14,08 & & $22,6 * *$ & & $18,96^{*}$ & \\
\hline & $\mathrm{N}=120$ & & $\mathrm{~N}=120$ & & $\mathrm{~N}=120$ & & $\mathrm{~N}=120$ & $\mathrm{~N}=120$ & \\
\hline
\end{tabular}

> signifikanter Vitalitätsrückgang laut Wilcoxon-Test

Zwecks eines ersten Eindrucks wurden zu Beginn der Datenanalyse multiple schrittweise Regressionen zum Effekt der eingesetzten Bodenhilfsstoffe auf die Vitalitätsentwicklung der Ebereschen durchgeführt. Demnach hatten die Kompost-Gaben zu Versuchsbeginn sowie im 2. Versuchsjahr, die Kalk-Gaben ab Oktober 2005 eine positive Wirkung, während die Wasserspeichersubstanzen und Perlit keinen Einfluss hatten.

Genauere Analysen zeigten, dass sich die mittlere Vitalität der Ebereschen mit Kalk- oder Kompost-Gabe (V2, 4, 6, 8, 9, 10) von Versuchsanlage bis -ende nicht signifikant veränderte. Die 
durchschnittlichen Vitalitätswerte der Pflanzen ohne Bodenhilfsstoffe mit Einfluss auf den Bodenchemismus nahmen dagegen im Versuchsverlauf signifikant ab. In der Nullvariante V1 sank die Pflanzenvitalität im Mittel von 3,1 $\pm 0,5$ auf 1,3 $\pm 1,4$, in der Stockosorb®-Variante V3 von 3,1 $\pm 0,3$ auf 1,1 $\pm 1,4$, in der Superabsorber-Variante V5 von 3,0 $\pm 0,4$ auf 1,2 $\pm 1,5$ und in der Perlit-Variante V7 von 2,9 $\pm 0,3$ auf im Vergleich nicht ganz so niedrige 1,8 $\pm 1,4$. Bei allen vier genannten Varianten war vor allem innerhalb der ersten Wochen nach der Pflanzung (Aufnahme im Juni 2005) ein deutliches Absinken der Vitalitätsmittelwerte zu verzeichnen.

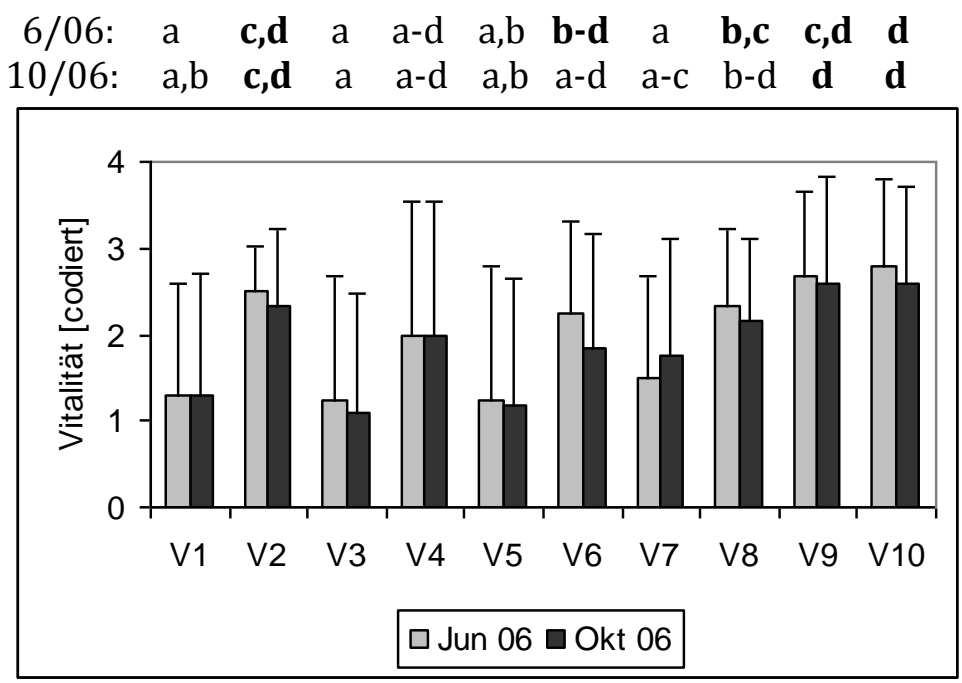

Abb. 130: Vitalität [codiert: $4=$ vital bis $0=$ tot, s. S. 27] der Ebereschen-Varianten (s. S. 20) im Juni und Oktober 2006; MW u. Std.abw.; Buchstaben kennzeichnen je Aufnahmezeitpunkt homogene Gruppen nach U-Tests, Fettdruck markiert signifikanten Unterschied zur Nullvariante (V1) (je Variante n=12)

Bei Betrachtung der mittleren Vitalitätswerte der Ebereschen im 2. Untersuchungsjahr wurde der positive Einfluss der Kalk-Gabe offensichtlich (s. Abb. 130). Mit Ausnahme der KompostVarianten V9 und V10 - hier hatte die Kompost-Gabe an sich unabhängig von einer zusätzlichen Kalk-Gabe bereits positive Wirkungen auf den Bodenchemismus (s. ab S. 58) - war die mittlere Vitalität in den Varianten mit Kalk-Gabe (V2, 4, 6, 8) höher als in den ungekalkten Pendants (V1, $3,5,7)$. Diese Vitalitätsunterschiede waren bei der Nullvariante V1 und der reinen Kalk-Variante V2 bei beiden Aufnahmen, bei den Superabsorber- und den Perlit-Varianten (V5, V6 bzw. V7, V8) zumindest bei der Juni-Aufnahme signifikant.

Ohne Kalk-Gabe ließ sich keine Wirkung der Stockosorb® (V3)-, Superabsorber (V5)- oder Perlit-Zugaben (V7) gegenüber der Nullvariante (V1) feststellen. Die Vitalitätsmittelwerte lagen in diesen Varianten überwiegend bei schwachen $1,1 \pm 1,4$ bis 1,3 $\pm 1,5$, in V7 bei 1,5 $\pm 1,2$ bzw. $1,8 \pm 1$,4. Signifikant besser als in diesen Varianten war die durchschnittliche Vitalität im Juni 2006 in der Kalk-Variante V2 (2,5 \pm 0,5), der Superabsorber-Kalk-Variante V6 $(2,3 \pm 1,1)$, der Perlit-Kalk-Variante V8 $(2,3 \pm 0,9)$ sowie in den beiden Kompost-Varianten V9 (ohne Kalk-Gabe; $2,7 \pm 1,0$ ) und V10 (mit Kalk-Gabe; $2,8 \pm 1,0$ ), die den höchsten Durchschnittswert erhielt. Bei der letzten Aufnahme im Oktober 2006 waren nur noch die Vitalitätsmittelwerte von V2 (2,3 \pm 0,9), V9 $(2,6 \pm 1,2)$ und V10 $(2,6 \pm 1,1)$ signifikant höher als in der Kontrolle. Der positive Effekt der Kalkung gegenüber der Nullvariante war in Kombination mit Stockosorb® nicht signifikant, in Kombination mit Superabsorber (V6) oder Perlit (V8) hielt er nicht lange an.

\section{Ebereschen auf Versuchsfläche A}

Die mittlere Vitalität der Ebereschen auf Fläche A betrug zunächst 2,1 $\pm 0,9$ (Juni 2005) und nahm dann auf geringe 1,3 \pm 1,0 (Oktober 2005), 1,5 \pm 1,3 (Juni 2006) und 1,3 \pm 1,3 (Oktober 
2006) ab. Nur bei der Aufnahme im Juni 2005, zwei Monate nach der Pflanzung, bestanden signifikante Vitalitätsunterschiede zwischen einzelnen Varianten (s. Abb. 131).

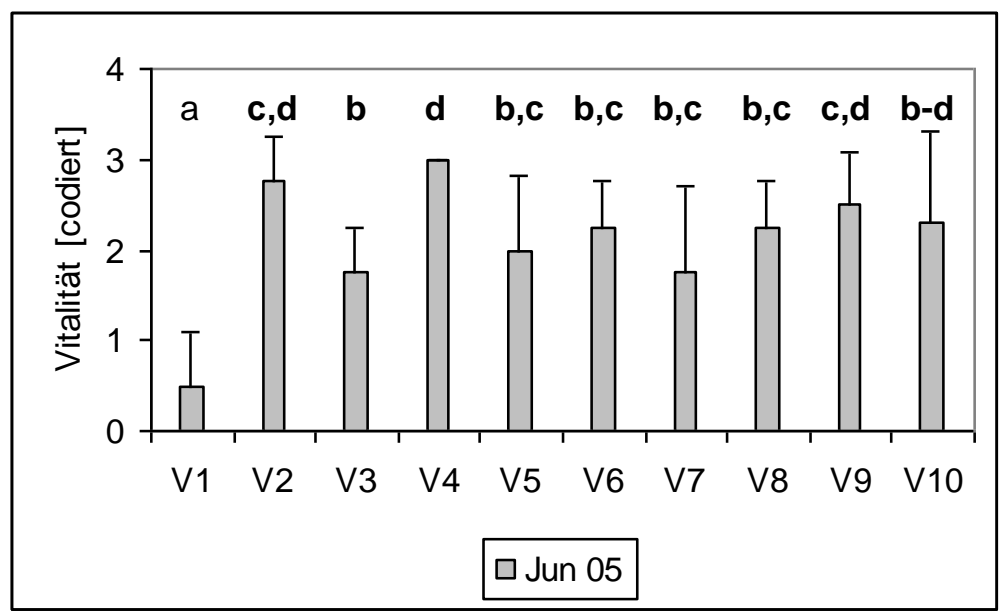

Abb. 131: Vitalität [codiert: $4=$ vital bis $0=$ tot, s. S. 27] der Ebereschen-Varianten (s. S. 20) auf Versuchsfläche A $(\mathrm{n}=40)$ im Juni 2005; MW u. Std.abw.; Buchstaben kennzeichnen homogene Gruppen nach U-Tests, Fettdruck markiert signifikanten Unterschied zur Nullvariante (V1) (je Variante $n=4$ )

In der dortigen Nullvariante war die mittlere Vitalität der Ebereschen mit 0,5 $\pm 0,6$ bereits zu diesem Zeitpunkt derart gering, dass sämtliche Behandlungsvarianten signifikant bessere Werte aufwiesen. Spitzenreiter war dabei die Stockosorb®-Kalk-Variante V4, deren Mittelwert mit 3,0 \pm 0 auch signifikant höher lag als die Werte der meisten übrigen Varianten (Ausnahmen: KalkVariante V2 mit 2,8 \pm 0,5, Kompost-Variante V9 mit 2,5 $\pm 0,6$ und Kompost-Kalk-Variante V10 mit 2,3 $\pm 1,0$ ). Die reine Stockosorb $®$-Variante V3 wies dagegen mit 1,8 $\pm 0,5$ eine signifikant niedrigere mittlere Vitalität auf als V2, V4 und V9.

Ebereschen auf den Versuchsflächen B und D sowie in Bereichen ohne Spontanvegetation

Die durchschnittliche Vitalität der Ebereschen auf den Versuchsflächen B und D lag relativ konstant bei $2,4 \pm 0,8$ bzw. $2,1 \pm 0,9$ im Juni 2005, 2,6 $\pm 1,1$ bzw. 2,4 $\pm 1,2$ im Oktober 2005 und jeweils bei $2,2 \pm 1,2 / 1,3 \mathrm{im} 2$. Untersuchungsjahr.

In Bereichen ohne Spontanvegetation nahm die Vitalität der Ebereschen dagegen ab auf 2,0 $\pm 0,9$ im Juni 2005, 1,6 \$1,2/1,3 im Oktober 2005 bzw. im Juni 2006 und 1,4 \pm 1,3 im Oktober 2006.

Weder auf Fläche B oder auf Fläche D noch in den standörtlich ungünstigeren Bereichen ohne Bodenbewuchs konnten signifikante Unterschiede in der Vitalität der Ebereschen je nach Behandlungsvariante festgestellt werden.

\section{Ebereschen in Bereichen mit Spontanvegetation}

Ein vergleichsweise ungewöhnliches Bild ergab sich bei Analyse der bald nach Versuchsbeginn im Juni 2005 erhobenen durchschnittlichen Vitalität der Ebereschen, die zufällig auf Teilflächen mit späterer Bodenvegetationsentwicklung gepflanzt worden waren. Insgesamt lag die mittlere Vitalität aller Ebereschen auf diesen Standorten relativ gleich bleibend (mäßig) hoch bei 2,6 \pm 0,7 (Juni 2005), 3,0 \pm 0,8 (Oktober 2005), 2,6 \pm 0,9 (Juni 2006) und 2,7 $\pm 1,0$ (Oktober 2006). Signifikante Vitalitätsunterschiede je nach Variante bestanden nur im Juni 2005 (s. Abb. 132). 
Die Kalk-Gaben spielten in diesen Bereichen, in denen der pH-Wert etwas höher war als in vegetationsfreien Bereichen, keine Rolle für die Vitalität der Ebereschen. Die Nullvariante V1 wies mit 3,3 \pm 0,5 den Spitzenwert auf, gefolgt von der Perlit-Variante V7 $(3,0 \pm 0)$ und der Kompost-Kalk-Variante V10 $(2,9 \pm 0,4)$. Beide Superabsorber-Varianten (V5 ohne, V6 mit KalkGabe) bildeten mit Vitalitätsmittelwerten von $1,8 \pm 0,5 / 1,0$ die Schlusslichter der 10 Behandlungsvarianten und waren signifikant schlechter als die Kontrolle. Dies galt auch für die Perlit-Kalk-Variante V8 mit 2,3 \pm 0,5; hier war zudem die reine Perlit-Variante V7 signifikant besser.

Die Ergebnisse spiegeln zum Teil auch die vergleichsweise guten Standortverhältnisse in bewachsenen Bereichen auf Fläche B wider, wo etwa V1 und V7 gute Werte erhielten.

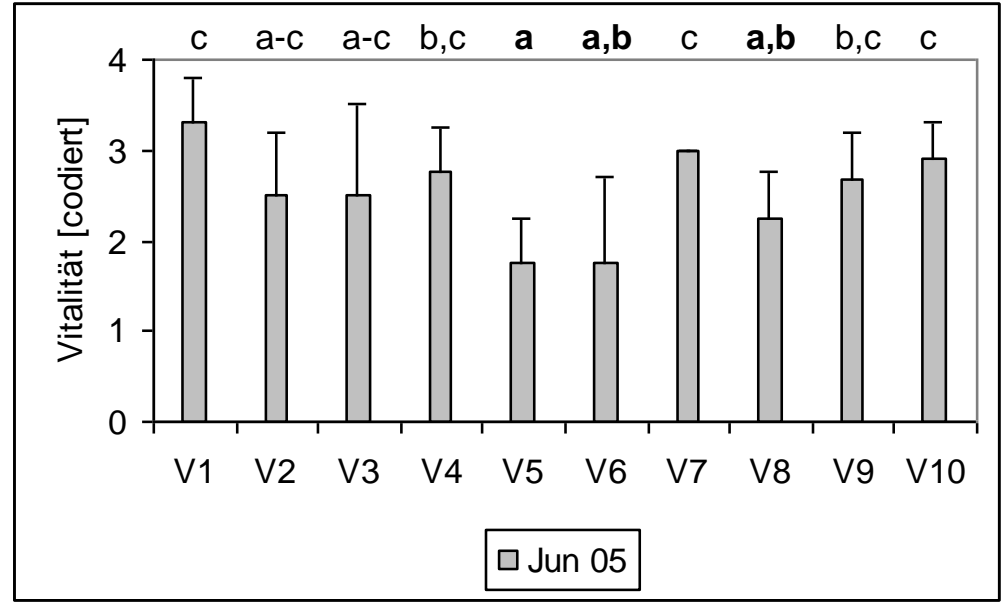

Abb. 132: Vitalität [codiert: $4=$ vital bis $0=$ tot, s. S. 27] der Ebereschen-Varianten (s. S. 20) in bewachsenen Bereichen im Juni 2005; MW u. Std.abw.; Buchstaben kennzeichnen homogene Gruppen nach U-Tests, Fettdruck markiert signifikanten Unterschied zur Nullvariante (V1) (n=44)

\subsubsection{Schwarz-Erle}

Die durchschnittliche Vitalität aller 120 Erlen des Freiland-Versuchs betrug bei Versuchsanlage im April 2005 sehr gute 3,6 $\pm 0,5$. Zwei Monate später war dieser Mittelwert signifikant auf immer noch mäßig bis gute 2,5 \pm 1,0 abgesunken. Dieser „Pflanzschock“ wurde vergleichsweise schnell überwunden (s. Abb. 133), und bis Oktober 2005 fand wieder ein leichter, signifikanter Anstieg der mittleren Vitalität auf 2,7 \pm 1,3 statt. Im 2. Jahr blieb die Vitalität der Erlen zunächst konstant (s. Tab. 64); zum Ende des Untersuchungszeitraums erfolgte eine leichte, signifikante Abnahme auf nun eher mäßige 2,3 \pm 1,5 im Oktober 2006 .

Tab. 64: Vitalität [codiert: 4 = vital bis $0=$ tot, s. S. 27] der Erlen im Versuchsverlauf; MW u. Std.abw.; Ergebnis des Friedmann-Tests $\left(\mathrm{Chi}^{2}\right)$ auf signifikante Unterschiede zwischen den Aufnahmezeitpunkten $(n=120)$

\begin{tabular}{|l|l|l|l|l|l|l|l|l|l|}
\hline $\begin{array}{l}\text { April } \\
2005\end{array}$ & & $\begin{array}{l}\text { Juni } \\
2005\end{array}$ & & $\begin{array}{l}\text { Oktober } \\
2005\end{array}$ & & $\begin{array}{l}\text { Juni } \\
2006\end{array}$ & & $\begin{array}{l}\text { Oktober } \\
2006\end{array}$ & Chi $^{2}$ \\
\hline $3,6 \pm 0,5$ & $>$ & $2,5 \pm 1,0$ & $<$ & $2,7 \pm 1,3$ & & $2,6 \pm 1,4$ & $>$ & $2,3 \pm 1,5$ & $87,60^{* * *}$ \\
\hline
\end{tabular}

$>$ signifikanter Rückgang, < signifikanter Anstieg der Vitalität laut Wilcoxon-Test 
Die Ausfallrate stieg im Versuchsverlauf von 2,5 \% im Juni 2005 über $10 \%$ und $17 \%$ auf $22 \%$ im Oktober 2006 an. Die mittlere Vitalität der lebenden Erlen lag jeweils bei 2,5 $\pm 0,9 ; 3,0 \pm 0,9$; 3,2 $\pm 0,9$ und 2,9 $\pm 0,9$. Damit wies die Erle im Vergleich zu den anderen getesteten Baumarten sowohl insgesamt als auch bezogen auch die jeweils lebenden Pflanzen recht gute Vitalitätswerte auf.

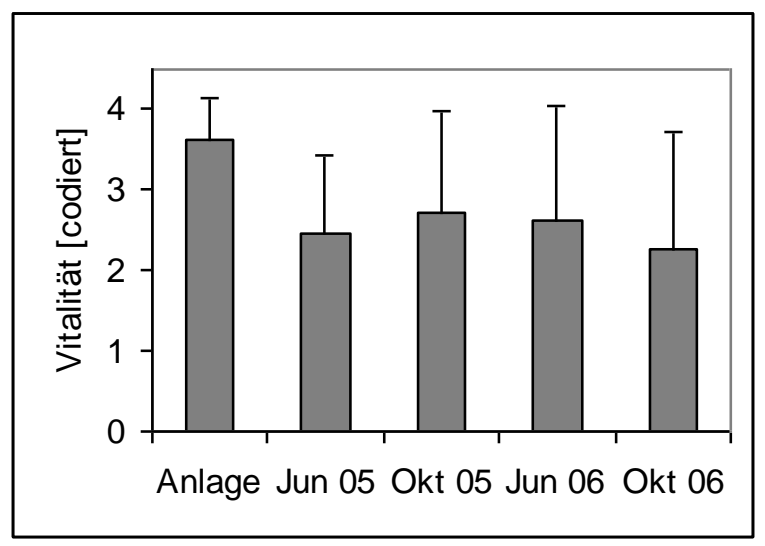

Abb. 133: Vitalität [codiert: $4=$ vital bis $0=$ tot, s. S. 27] der Erlen im Versuchsverlauf; MW u. Std.abw. $(n=120)$

\section{Erlen insgesamt}

Untersucht man den Einfluss der 10 verschiedenen Behandlungsvarianten auf die Vitalitätsentwicklung der Erlen insgesamt, so ergeben sich zu keinem Aufnahmezeitpunkt signifikante Vitalitätsunterschiede zwischen den einzelnen Varianten (s. Tab. 65). Zu stark überwogen die Einflüsse der heterogenen Standortbedingungen mögliche Wirkungen der eingesetzten Bodenhilfsstoffe.

Tab. 65: Vitalität [codiert: $4=$ vital bis $0=$ tot, s. S. 27] der Erlen-Varianten (s. S. 20) im Versuchsverlauf; MW u. Std.abw.; je Aufnahmezeitpunkt Ergebnisse von H-Tests (H) auf signifikante Unterschiede zwischen den Varianten; je Variante Ergebnisse von Friedmann-Tests $\left(\mathrm{Chi}^{2}\right)$ auf signifikante Unterschiede zwischen den Aufnahmezeitpunkten (je Variante n=12)

\begin{tabular}{|l|l|l|l|l|l|l|l|l|l|l|}
\hline & $\begin{array}{l}\text { April } \\
2005\end{array}$ & & $\begin{array}{l}\text { Juni } \\
2005\end{array}$ & & $\begin{array}{l}\text { Oktober } \\
2005\end{array}$ & $\begin{array}{l}\text { Juni } \\
2006\end{array}$ & $\begin{array}{l}\text { Oktober } \\
2006\end{array}$ & Chi $^{2}$ \\
\hline V1 & $3,7 \pm 0,5$ & $>$ & $2,3 \pm 1,1$ & & $2,3 \pm 1,8$ & & $2,2 \pm 1,7$ & $>$ & $1,7 \pm 1,6$ & $13,22^{*}$ \\
\hline V2 & $3,7 \pm 0,5$ & $>$ & $2,6 \pm 0,8$ & & $2,8 \pm 1,2$ & & $2,6 \pm 1,4$ & $>$ & $2,1 \pm 1,3$ & $14,83^{* *}$ \\
\hline V3 & $3,6 \pm 0,5$ & $>$ & $2,6 \pm 0,8$ & & $2,6 \pm 1,4$ & & $2,2 \pm 1,7$ & & $2,0 \pm 1,7$ & $14,22^{* *}$ \\
\hline V4 & $3,7 \pm 0,5$ & & $2,8 \pm 1,1$ & & $3,1 \pm 1,0$ & & $2,8 \pm 1,3$ & & $2,5 \pm 1,3$ & 6,52 \\
\hline V5 & $3,5 \pm 0,7$ & $>$ & $1,8 \pm 1,2$ & & $1,9 \pm 1,6$ & & $1,4 \pm 1,7$ & & $1,8 \pm 1,9$ & $9,58^{*}$ \\
\hline V6 & $3,6 \pm 0,5$ & $>$ & $2,5 \pm 0,7$ & $<$ & $3,0 \pm 1,0$ & & $2,9 \pm 0,9$ & $>$ & $2,3 \pm 1,4$ & $9,92^{*}$ \\
\hline V7 & $3,4 \pm 0,5$ & & $2,3 \pm 1,2$ & & $2,7 \pm 1,4$ & & $2,7 \pm 1,6$ & & $2,2 \pm 1,6$ & 8,2 \\
\hline V8 & $3,8 \pm 0,4$ & $>$ & $2,2 \pm 0,9$ & $<$ & $3,1 \pm 0,9$ & & $2,9 \pm 1,1$ & $>$ & $2,3 \pm 1,4$ & $20,4^{* * *}$ \\
\hline V9 & $3,6 \pm 0,5$ & & $2,8 \pm 0,7$ & & $3,0 \pm 1,1$ & & $3,3 \pm 1,2$ & & $3,0 \pm 1,1$ & 5,87 \\
\hline V10 & $3,8 \pm 0,5$ & & $2,9 \pm 0,7$ & & $2,8 \pm 0,7$ & & $3,3 \pm 0,8$ & & $3,0 \pm 0,9$ & 7,98 \\
\hline H & 5,91 & & 11,12 & & 6,12 & & 13,3 & & 8,87 & \\
\hline & $\mathrm{N}=120$ & & $\mathrm{~N}=120$ & & $\mathrm{~N}=120$ & & $\mathrm{~N}=120$ & & $\mathrm{~N}=120$ & \\
\hline
\end{tabular}

$>$ signifikanter Rückgang, < signifikanter Anstieg der Vitalität laut Wilcoxon-Test 
Es fällt jedoch auf, dass sich die mittleren Vitalitätswerte der Varianten V4 (Stockosorb®-Kalk), V7 (Perlit; hier jedoch insgesamt leicht geringere Werte), V9 (Kompost) und V10 (KompostKalk) im Versuchsverlauf nicht signifikant veränderten. Sie lagen bei V4 zwischen 3,7 $\pm 0,5$ und $2,5 \pm 1,3$, bei V7 zwischen 3,4 $\pm 0,5$ und 2,2 $\pm 1,6$, bei V9 zwischen $3,6 \pm 0,5$ und 2,8 $\pm 0,7$ sowie bei V10 zwischen 3,8 $\pm 0,5$ und 2,8 $\pm 0,7$. Dagegen nahm bei allen übrigen Varianten die durchschnittliche Vitalität von der Versuchsanlage bis Juni 2005 signifikant ab. In den Varianten V6 (Superabsorber-Kalk) und V8 (Perlit-Kalk) folgte bis Oktober 2005 wieder ein deutlicher, signifikanter Anstieg der Vitalität. Zum Ende des Untersuchungszeitraums kam es in diesen Varianten sowie bei der Kontrolle (V1) und der Kalk-Variante (V2) jedoch zu einer erneuten signifikanten Abnahme.

Wie ab Seite 236 und ab Seite 264 beschrieben, war der individuelle Pflanzenstandort auf einer der drei Versuchsflächen sowie in besiedelten oder vegetationsfreien Teilbereichen für die Vitalitätsentwicklung der Erlen von großer Bedeutung. Erst unter Ausschluss dieser Faktoren, also bei Betrachtung ausschließlich der Erlen mit Standorten auf Teilflächen ohne/mit Bodenvegetation oder auf einer bestimmten Versuchsfläche wurden teilweise Auswirkungen der Behandlungsvarianten erkennbar. Dabei handelte es sich um die Vitalitätsmittelwerte der Erlen auf Teilflächen ohne Spontanvegetation im Juni 2006 sowie auf den Versuchsflächen A und B zu Beginn des Versuchs im Juni 2005.

Zwecks eines ersten Eindrucks wurden zu Beginn der Datenanalyse multiple schrittweise Regressionen zum Einfluss der eingesetzten Bodenhilfsstoffe auf die Vitalitätsentwicklung der Erlen durchgeführt. Demnach hatten die Kompost-Gaben zu Versuchsbeginn sowie im 2. Versuchsjahr, die Kalk-Gaben im Oktober 2005 und Juni 2006 eine positive Wirkung, während die Wasserspeichersubstanzen und Perlit keinen Einfluss hatten. Diese Ergebnisse konnten bei der Analyse der Vitalitätsentwicklung ausschließlich der Erlen auf ungünstigeren Standorten (in Bereichen ohne Spontanvegetation sowie auf Versuchsfläche A) bestätigt werden.

\section{Erlen auf Versuchsfläche A}

Nur im Juni 2005, zwei Monate nach Versuchsanlage, bestanden je nach Behandlungsvariante signifikante Unterschiede zwischen den durchschnittlichen Vitalitätswerten der Erlen auf Versuchsfläche A (s. Abb. 134). Insgesamt betrug dort ihre (im Vergleich zu andern Baumarten auf dieser Fläche recht hohe) Vitalität im Mittel 2,7 \pm 1,1 (Juni 2005), 2,5 \pm 1,3 (Oktober 2005) und 2,5 \pm 1,5 (Juni 2006); im Oktober 2006 dann nur noch 1,9 $\pm 1,3$.

Im Juni 2005 lagen die hohen Vitalitätsmittelwerte der Erlen mit Kalk-Gabe (V2; 3,5 \pm 0,6), mit Stockosorb ${ }^{\circledR}$ und Kalk-Gabe (V4; 4,0 \pm ) ) sowie mit Kompost und Kalk-Gabe (V10; 3,5 \pm 0,6) signifikant über dem Durchschnittswert der Nullvariante $(2,5 \pm 1,0)$. Da die reine Stockosorb®und die reine Kompost-Variante (V3: 2,3 \pm 1,0 bzw. V9: 3,0 \pm 0,8) keine signifikant besseren Werte als die Kontrolle aufwiesen, ist die positive Wirkung der Varianten V4 und V10 zu diesem Zeitpunkt der Kalk-Gabe zuzuschreiben. In Kombination mit Superabsorber (V6: 2,8 \pm 0,5) oder Perlit (V8: 2,3 $\pm 1,0$ ) reichte es trotz Kalk-Gabe dagegen nicht für einen gegenüber der Kontrolle signifikant höheren Vitalitätsmittelwert.

Im Fall der Nullvariante (V1) und der Varianten mit Wasserspeichersubstanzen (V3, V5) war die Pflanzenvitalität in den jeweiligen Kombinationen mit Kalk-Gaben (V2, V4, V6) signifikant besser als ohne Kalk. Bei den Perlit-Varianten (V7, V8) war dies dagegen nicht zu beobachten. 


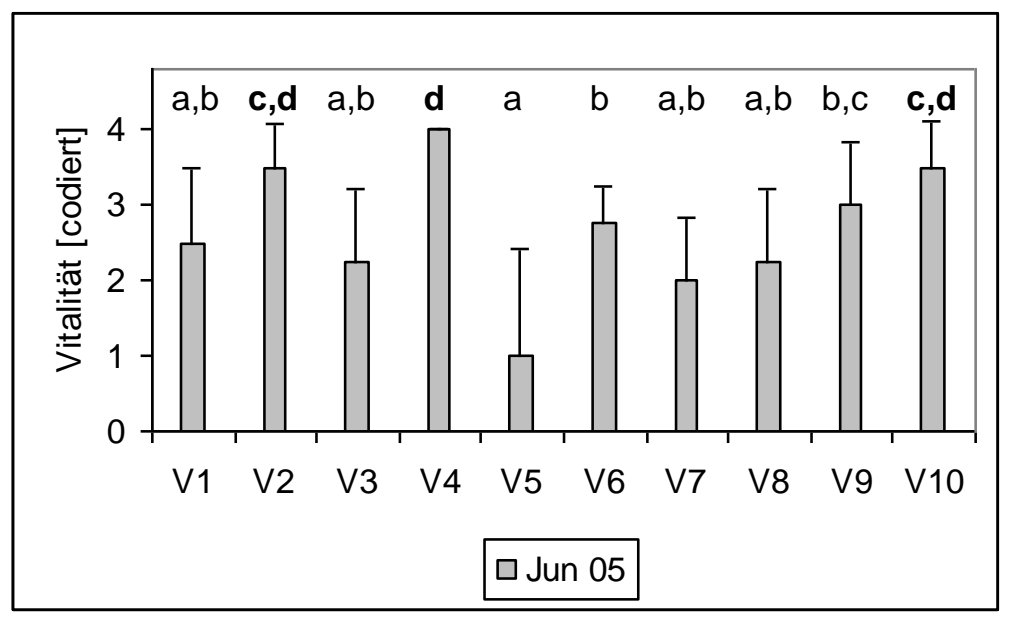

Abb. 134: Vitalität [codiert: 4 = vital bis 0 = tot, s. S. 27] der Erlen-Varianten (s. S. 20) auf Versuchsfläche A (n=40) im Juni 2005; MW u. Std.abw.; Buchstaben kennzeichnen homogene Gruppen nach U-Tests, Fettdruck markiert signifikanten Unterschied zur Nullvariante (V1) (je Variante n=4)

Wiederum hatte die reine Superabsorber-Variante V5 mit 1,0 $\pm 1,4$ den niedrigsten Vitalitätsmittelwert von allen 10 Varianten. Mit Ausnahme der Nullvariante, der Stockosorb®Variante (V3) und den Perlit-Varianten (V7, V8) bestanden zu allen Varianten signifikante Unterschiede.

\section{Erlen auf Versuchsfläche B}

Ganz anders als auf der komplett vegetationsfreien Fläche A präsentierte sich im Juni 2005 die Vitalitätsentwicklung der Erlen in den verschiedenen Behandlungsvarianten auf Fläche B, wo ein erheblicher Einfluss der unterschiedlichen Standortbedingungen (mit/ohne Bodenvegetation) bestand. Im gesamten Durchschnitt wurden bei den Erlen auf Fläche B stets relativ gute Vitalitätsmittelwerte von 2,8 $\pm 0,7$ (Juni 2005), 3,2 $\pm 1,1$ (Oktober 2005), 3,0 $\pm 1,3$ (Juni 2006) und 2,7 $\pm 1,4$ (Oktober 2006) ermittelt. Signifikante Unterschiede zwischen einzelnen Varianten gab es dabei nur im Juni 2005 (s. Abb. 135).

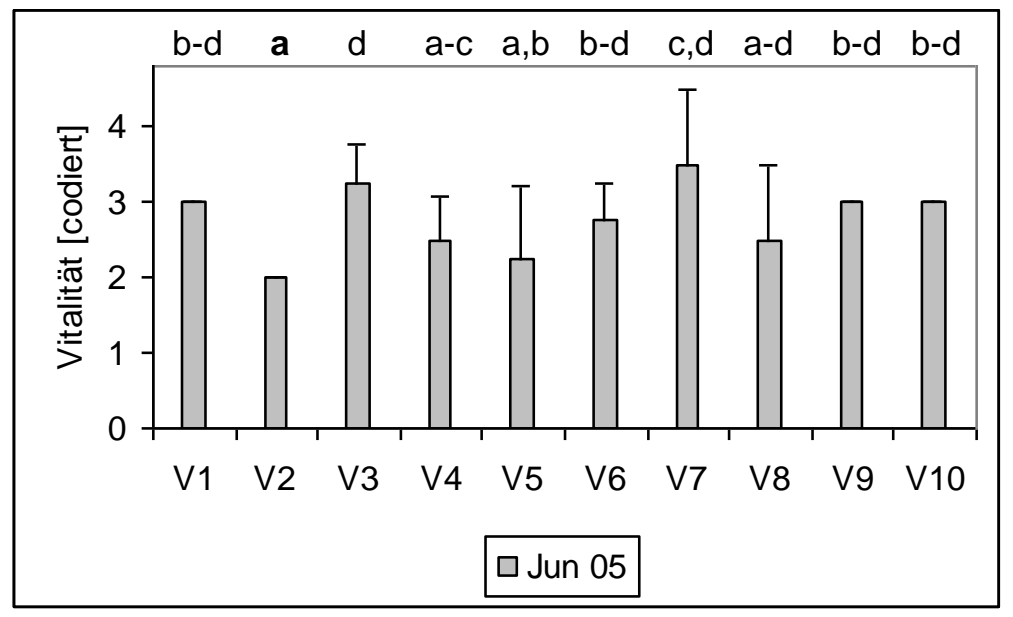

Abb. 135: Vitalität [codiert: 4 = vital bis $0=$ tot, s. S. 27] der Erlen-Varianten (s. S. 20) auf Versuchsfläche B (n=40) im Juni 2005; MW u. Std.abw.; Buchstaben kennzeichnen homogene Gruppen nach U-Tests, Fettdruck markiert signifikanten Unterschied zur Nullvariante (V1) (je Variante $n=4$ ) 
Die einzige Variante, in der sich im Juni 2005 die mittlere Vitalität der Erlen signifikant von der in der Nullvariante $(3,0 \pm 0)$ unterschied, war die reine Kalk-Variante V2, die einen signifikant geringeren durchschnittlichen Vitalitätswert von 2,0 \pm 0 und damit den niedrigsten Wert aller 10 Varianten aufwies. Mit Ausnahme der Varianten Stockosorb®-Kalk (V4), Superabsorber (V5) und Perlit-Kalk (V8) bestanden in allen Varianten signifikant höhere Vitalitätswerte. Die Vitalität der Erlen in der Superabsorber-Variante V5 nahm mit im Mittel 2,3 \pm 0,5 den vorletzten Platz ein und war signifikant geringer als in der Variante mit der anderen verwendeten Wasserspeichersubstanz Stockosorb ${ }^{\circledR}(V 3 ; 3,3 \pm 0,5)$ sowie in der Perlit-Variante V7 $(3,5 \pm 1,0)$. Da Variante V5 im Versuchsdesign (s. S. 21f, Abb. 3) zwischen V3 und V7 platziert wurde, ist nicht davon auszugehen, dass diese Vitalitätsunterschiede auf erheblich unterschiedliche Standortbedingungen zurückzuführen waren. Dagegen ist dies vermutlich der Fall bei dem gegenüber der reinen Stockosorb®-Variante V3 signifikant geringeren durchschnittlichen Vitalitätswert der Erlen in der Stockosorb ${ }^{\circledR}$-Kalk-Variante V4 $(2,5 \pm 0,6)$. Ein Blick auf die Verteilung der Spontanvegetation auf Fläche B (s. S. 37, Abb. 4) zeigt, dass sich V3 komplett im bewachsenen Bereich und damit im Bereich mit besseren Wuchsbedingungen befand, während V4 teilweise im vegetationsfreien Bereich lag. Dies galt ebenso für die Kalk-Variante V2 (Vitalitätsmittelwert auf dieser Versuchsfläche vergleichsweise gering), der einzigen Variante auf Fläche B, in der mehr als die Hälfte der Wiederholungen (75\%) in unbewachsenen Bereichen standen.

\section{Erlen auf Versuchsfläche D}

Auf Versuchsfläche D sank die Vitalität der Erlen zunächst auf 2,0 \pm 0,8 (Juni 2005), um dann relativ stabil bei 2,4 \pm 1,3/1,5 (Oktober 2005 bzw. Juni 2006) bzw. 2,3 \pm 1,5 (Oktober 2006) zu liegen. Signifikante Vitalitätsunterschiede zwischen den verschiedenen Varianten konnten nicht festgestellt werden.

\section{Erlen in Bereichen ohne Spontanvegetationsentwicklung}

Relativ zu Beginn des 2. Vegetationsjahres (Juni 2006) bestanden zwischen den durchschnittlichen Vitalitätswerten der Erlen, die zufällig in Teilbereiche ohne spätere Spontanvegetation gepflanzt worden waren, signifikante Unterschiede je nach Behandlungsvariante (s. Abb. 136).

Mit Kompost-Gabe (V9) war die durchschnittliche Vitalität der Erlen mit 3,5 \pm 0,5 gegenüber der Kontrolle mit 1,8 $\pm 1,5$ signifikant besser.

Bei den Kombinationen verschiedener Bodenhilfsstoffe wiesen stets die Varianten mit KalkGabe $(V 4,6,8)$ höhere Vitalitätsmittelwerte auf als die entsprechenden Varianten ohne Kalkung $(V 3,5,7)$. Dies gilt auch für die Nullvariante V1 und die reine Kalkvariante V2, nicht jedoch für die Kompost-Varianten (V9 ohne Kalk-Gabe, V10 mit Kalk-Gabe). Hier lagen beide Mittelwerte ähnlich hoch, da die Kompost-Gabe selbst bereits für eine positive Veränderung des Bodenchemismus sorgte (s. ab S. 58). 


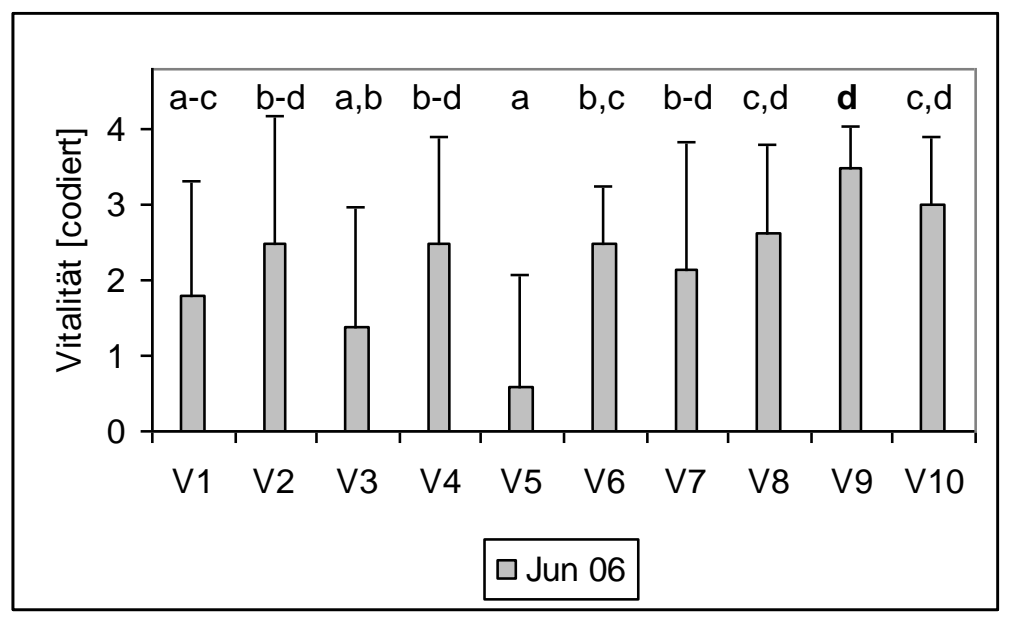

Abb. 136: Vitalität [codiert: 4 = vital bis $0=$ tot, s. S. 27] der Erlen-Varianten (s. S. 20) in vegetationsfreien Bereichen im Juni 2006; MW u. Std.abw.; Buchstaben kennzeichnen homogene Gruppen nach U-Tests, Fettdruck markiert signifikanten Unterschied zur Nullvariante (V1) (n=74)

Die Vitalitätsunterschiede zwischen gekalkten und kalkfreien Kombinationen waren jedoch nur bei den Superabsorber-Varianten (V5 ohne, V6 mit Kalk) signifikant. Die reine SuperabsorberVariante V5 hatte mit 0,6 \pm 1,5 von allen 10 Varianten den niedrigsten Vitalitätsmittelwert. Mit Ausnahme der Nullvariante und der Stockosorb®-Variante (V3) bestanden zu allen Varianten signifikante Unterschiede. Der ebenfalls recht niedrige Vitalitätswert der Stockosorb®-Variante war signifikant geringer als der der Perlit-Kalk-Variante (V8) und der Kompost-Varianten.

$\mathrm{Zu}$ den anderen Aufnahmezeitpunkten konnten bei den Erlen in vegetationsfreien Bereichen keine signifikanten Vitalitätsunterschiede je nach Behandlungsvariante festgestellt werden. Insgesamt lag die mittlere Vitalität der Erlen auf diesen Standorten zunächst bei 2,3 \pm 1,0 (Juni 2005), 2,3 $\pm 1,2$ (Oktober 2005) und 2,2 $\pm 1,5$ (Juni 2006), um dann auf 1,7 $\pm 1,4$ (Oktober 2006) abzusinken.

\section{Erlen in Bereichen mit Spontanvegetationsentwicklung}

Auf vergleichsweise günstigeren Standorten, auf denen auch die Entwicklung von Spontanvegetation möglich war, wiesen die Erlen nach einem leichten Pflanzschock $(2,7 \pm 0,7 \mathrm{im}$ Juni 2005) konstant gute Vitalitätswerte von 3,4 $\pm 1,0$ (Oktober 2005), 3,3 $\pm 1,1$ (Juni 2006) und $3,2 \pm 1,1$ (Oktober 2006) auf. Die verschiedenen Versuchsvarianten hatten hier keinen nachweisbaren Einfluss auf die Pflanzenvitalität.

\subsubsection{Douglasie}

Die durchschnittliche Vitalität aller 192 Douglasien (s. Tab. 66) sank in den ersten zwei Monaten des Freiland-Versuchs signifikant von zunächst guten 3,1 \pm 0,5 auf eher mäßige 2,1 $\pm 1,0$. Im weiteren Verlauf der ersten Vegetationsperiode blieb dieser Wert konstant (s. Abb. 137), dann folgten zwei weitere signifikante Abnahmen auf schließlich recht geringe 1,6 $\pm 1,4$ im Oktober 2006. 
Tab. 66: Vitalität [codiert: $4=$ vital bis $0=$ tot, s. S. 27] der Douglasien im Versuchsverlauf; MW u. Std.abw.; Ergebnis des Friedmann-Tests $\left(\mathrm{Chi}^{2}\right)$ auf signifikante Unterschiede zwischen den Aufnahmezeitpunkten $(n=192)$

\begin{tabular}{|l|l|l|l|l|l|l|l|l|l|}
\hline $\begin{array}{l}\text { April } \\
2005\end{array}$ & & $\begin{array}{l}\text { Juni } \\
2005\end{array}$ & & $\begin{array}{l}\text { Oktober } \\
2005\end{array}$ & & $\begin{array}{l}\text { Juni } \\
2006\end{array}$ & $\begin{array}{l}\text { Oktober } \\
2006\end{array}$ & $\mathrm{Chi}^{2}$ \\
\hline $3,1 \pm 0,5$ & $>$ & $2,1 \pm 1,0$ & & $2,1 \pm 1,2$ & $>$ & $1,7 \pm 1,4$ & $>$ & $1,6 \pm 1,4$ & $153,36^{* * *}$ \\
\hline
\end{tabular}

$>$ signifikanter Vitalitätsrückgang laut Wilcoxon-Test

Die Ausfallrate stieg vom 1. zum 2. Untersuchungsjahr deutlich von $10 \%$ und $17 \%$ in 2005 auf $30 \%$ und $34 \%$ in 2006 an (in den Topf-Versuchen im Gewächshaus war die Ausfallrate der Douglasien mit insgesamt $33 \%$ vergleichbar). Die mittleren Vitalitätswerte der lebenden Douglasien lagen jeweils bei $2,4 \pm 0,8 ; 2,6 \pm 0,7 ; 2,5 \pm 0,9$ und $2,4 \pm 0,9$.

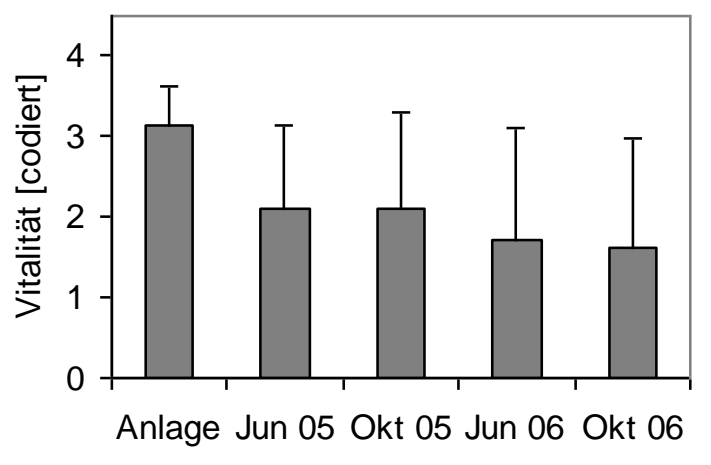

Abb. 137: Vitalität [codiert: $4=$ vital bis $0=$ tot, s. S. 27] der Douglasien im Versuchsverlauf; MW u. Std.abw. $(\mathrm{n}=192)$

\section{Douglasien insgesamt}

Betrachtet man die Gesamtheit aller Douglasien, so bestanden zwischen den Vitalitätsmittelwerten in den 16 verschiedenen Behandlungsvarianten $\mathrm{zu}$ keinem Aufnahmezeitpunkt signifikante Unterschiede.

Es fällt jedoch auf, dass sich die mittleren Vitalitätswerte der Varianten Perlit (V7; hier aber insgesamt recht geringe Werte), Kompost (V9), Kompost-Kalk (V10), Mykorrhiza-Stockosorb® (V13), Mykorrhiza-Stockosorb®-Kalk (V14), Mykorrhiza-Superabsorber (V15) und MykorrhizaSuperabsorber-Kalk (V16) im gesamten Versuchsverlauf laut Friedmann-Tests nicht signifikant veränderten (s. Tab. 67).

Bei allen anderen Varianten sank der durchschnittliche Vitalitätswert der Douglasien überwiegend bereits zu Beginn des Versuchs signifikant ab, bei einigen Varianten auch nochmals zum bzw. im 2. Vegetationsjahr. Die Kontrolle V1 bildete eine Ausnahme; hier nahm die mittlere Vitalität der Douglasien erst zum und im 2. Untersuchungsjahr ab. Bei der Superabsorber-KalkVariante (V6) fand nach einem ersten Absinken des Vitalitätsmittelwertes zwischen Juni und Oktober 2005 wieder ein signifikanter Anstieg von 1,7 $\pm 0,5$ auf 2,1 $\pm 0,3$ statt. 
Tab. 67: Vitalität [codiert: $4=$ vital bis $0=$ tot, s. S. 27] der Douglasien-Varianten (s. S. 20) im Versuchsverlauf; MW u. Std.abw.; je Aufnahmezeitpunkt Ergebnisse von H-Tests (H) auf signifikante Unterschiede zwischen den Varianten; je Variante Ergebnisse von Friedmann-Tests $\left(\mathrm{Chi}^{2}{ }^{2}\right)$ auf signifikante Unterschiede zwischen den Aufnahmezeitpunkten (je Variante n=12)

\begin{tabular}{|l|l|l|l|l|l|l|l|l|l|l|}
\hline & $\begin{array}{l}\text { April } \\
2005\end{array}$ & & $\begin{array}{l}\text { Juni } \\
2005\end{array}$ & & $\begin{array}{l}\text { Oktober } \\
2005\end{array}$ & & $\begin{array}{l}\text { Juni } \\
2006\end{array}$ & $\begin{array}{l}\text { Oktober } \\
2006\end{array}$ & Chi $^{2}$ \\
\hline V1 & $3,3 \pm 0,5$ & & $2,5 \pm 1,5$ & & $2,3 \pm 1,7$ & $>$ & $1,6 \pm 2,0$ & $>$ & $1,3 \pm 1,6$ & $11,75^{*}$ \\
\hline V2 & $3,3 \pm 0,5$ & $>$ & $2,5 \pm 0,7$ & & $2,4 \pm 1,0$ & $>$ & $1,8 \pm 1,3$ & & $1,7 \pm 1,2$ & $18,25^{* *}$ \\
\hline V3 & $3,1 \pm 0,3$ & $>$ & $2,0 \pm 1,2$ & & $2,0 \pm 1,5$ & $>$ & $1,3 \pm 1,7$ & $>$ & $1,0 \pm 1,6$ & $13,42^{* *}$ \\
\hline V4 & $3,2 \pm 0,6$ & $>$ & $1,9 \pm 0,9$ & & $1,9 \pm 1,2$ & $>$ & $1,5 \pm 1,0$ & & $1,5 \pm 1,1$ & $16,0^{* *}$ \\
\hline V5 & $3,4 \pm 0,5$ & $>$ & $1,8 \pm 1,1$ & & $1,7 \pm 1,4$ & & $1,6 \pm 1,4$ & & $1,5 \pm 1,4$ & $10,85^{*}$ \\
\hline V6 & $3,2 \pm 0,4$ & $>$ & $1,7 \pm 0,5$ & $<$ & $2,1 \pm 0,3$ & & $1,8 \pm 1,1$ & & $1,8 \pm 1,1$ & $16,95^{* *}$ \\
\hline V7 & $2,9 \pm 0,3$ & & $1,8 \pm 1,1$ & & $1,7 \pm 1,6$ & & $1,3 \pm 1,7$ & & $1,2 \pm 1,6$ & 8,92 \\
\hline V8 & $3,0 \pm 0,4$ & $>$ & $1,6 \pm 0,8$ & & $1,8 \pm 0,9$ & & $1,8 \pm 1,3$ & & $1,6 \pm 1,2$ & $16,32^{* *}$ \\
\hline V9 & $3,1 \pm 0,5$ & & $2,0 \pm 1,2$ & & $1,8 \pm 1,4$ & & $1,8 \pm 1,7$ & & $1,8 \pm 1,7$ & 7,53 \\
\hline V10 & $3,2 \pm 0,4$ & & $2,6 \pm 0,5$ & & $2,5 \pm 0,5$ & & $2,0 \pm 1,3$ & & $1,9 \pm 1,4$ & 7,23 \\
\hline V11 & $3,0 \pm 0,6$ & $>$ & $2,0 \pm 1,3$ & & $1,9 \pm 1,2$ & $>$ & $1,3 \pm 1,2$ & & $1,3 \pm 1,2$ & $14,18^{* *}$ \\
\hline V12 & $3,2 \pm 0,6$ & $>$ & $2,1 \pm 1,2$ & & $2,0 \pm 1,1$ & $>$ & $1,4 \pm 1,2$ & & $1,3 \pm 1,4$ & $12,55^{*}$ \\
\hline V13 & $3,1 \pm 0,5$ & & $2,6 \pm 0,7$ & & $2,7 \pm 1,0$ & & $2,4 \pm 1,4$ & & $2,3 \pm 1,3$ & 3,73 \\
\hline V14 & $3,3 \pm 0,5$ & & $2,6 \pm 0,9$ & & $2,8 \pm 1,0$ & & $2,3 \pm 1,5$ & & $2,1 \pm 1,4$ & 6,12 \\
\hline V15 & $3,2 \pm 0,6$ & & $2,1 \pm 1,0$ & & $2,3 \pm 1,1$ & & $1,9 \pm 1,2$ & & $1,9 \pm 1,2$ & 8,78 \\
\hline V16 & $2,9 \pm 0,5$ & & $2,2 \pm 1,0$ & & $2,3 \pm 1,1$ & & $2,0 \pm 1,2$ & & $1,8 \pm 1,3$ & 5,6 \\
\hline H & 23,24 & & 24,8 & & 16,31 & & 10,16 & & 13,0 & \\
\hline & $\mathrm{N}=192$ & & $\mathrm{~N}=192$ & & $\mathrm{~N}=192$ & & $\mathrm{~N}=192$ & & $\mathrm{~N}=192$ & \\
\hline
\end{tabular}

> signifikanter Rückgang, < signifikanter Anstieg der Vitalität laut Wilcoxon-Test

Der Bodenhilfsstoff Kompost und die Bodenhilfsstoff-Kombinationen aus Mykorrhiza und unterstützenden Wasserspeicher- und Kalk-Gaben schienen also das signifikante Absinken der mittleren Vitalität der Douglasien zu verhindern. Dies galt zwar auch für die Perlit-Gabe; hier jedoch nur auf einem recht geringen Vitalitätsniveau. Die Kombination aus Superabsorber und Kalk hatte offenbar auch einen positiven Effekt.

In multiplen schrittweisen Regressionen zum Einfluss der eingesetzten Bodenhilfsstoffe auf die Vitalitätsentwicklung der Douglasien, die zwecks eines ersten Eindrucks zu Beginn der Datenanalyse durchgeführt worden waren, wurden im Juni 2005 (also lediglich bei dieser einen Aufnahme zwei Monate nach Versuchsanlage) negative Wirkungen der Superabsorber- und Perlit-Gaben festgestellt. Tiefer gehende Analysen zeigen, dass die durchschnittlichen Vitalitätswerte der Douglasien insgesamt, der Douglasien in Bereichen ohne Bodenvegetation und der Douglasien auf Versuchsfläche A in den betreffenden Varianten zu diesem Zeitpunkt vergleichsweise gering, zum Teil sogar am geringsten von allen Varianten waren. Signifikante Unterschiede zur Kontrolle gab es aufgrund großer Streuungen der Werte und entsprechend großer Standardabweichungen aber nicht.

\section{Douglasien auf Versuchsfläche A}

Auf der komplett bodenvegetationsfreien Fläche A bestanden im 1. Versuchsjahr signifikante Vitalitätsunterschiede zwischen den Douglasien in verschiedenen Behandlungsvarianten (s. Abb. 138). 
Insgesamt betrug die durchschnittliche Vitalität der Douglasien auf dieser Fläche in $20051,9 \pm$ 1,0/1,1. In 2006, als keine signifikanten Vitalitätsunterschiede mehr festgestellt werden konnten, war dieser Wert auf 1,2 $\pm 1,1 / 1,2$ gesunken.

$\begin{array}{rllllllllllllllll}\text { 6/05: } & \text { a,b } & \text { d,e } & \text { a,b } & \mathbf{c , d} & \text { a,b } & \text { a-c } & \text { a } & \text { a } & \text { a,b } & \text { d,e } & \text { a-e } & \text { d,e } & \text { a-d } & \text { e } & \text { a-d } & \text { b-e } \\ \text { 10/05: } & \text { a,b } & \mathbf{f , g} & \text { a,b } & \mathbf{f , g} & \text { a-c } & \text { c-e } & \text { a } & \text { a-d } & \text { a,b } & \text { e-g } & \text { a-f } & \text { g } & \text { b-g } & \text { g } & \text { d-f } & \mathbf{d - g}\end{array}$

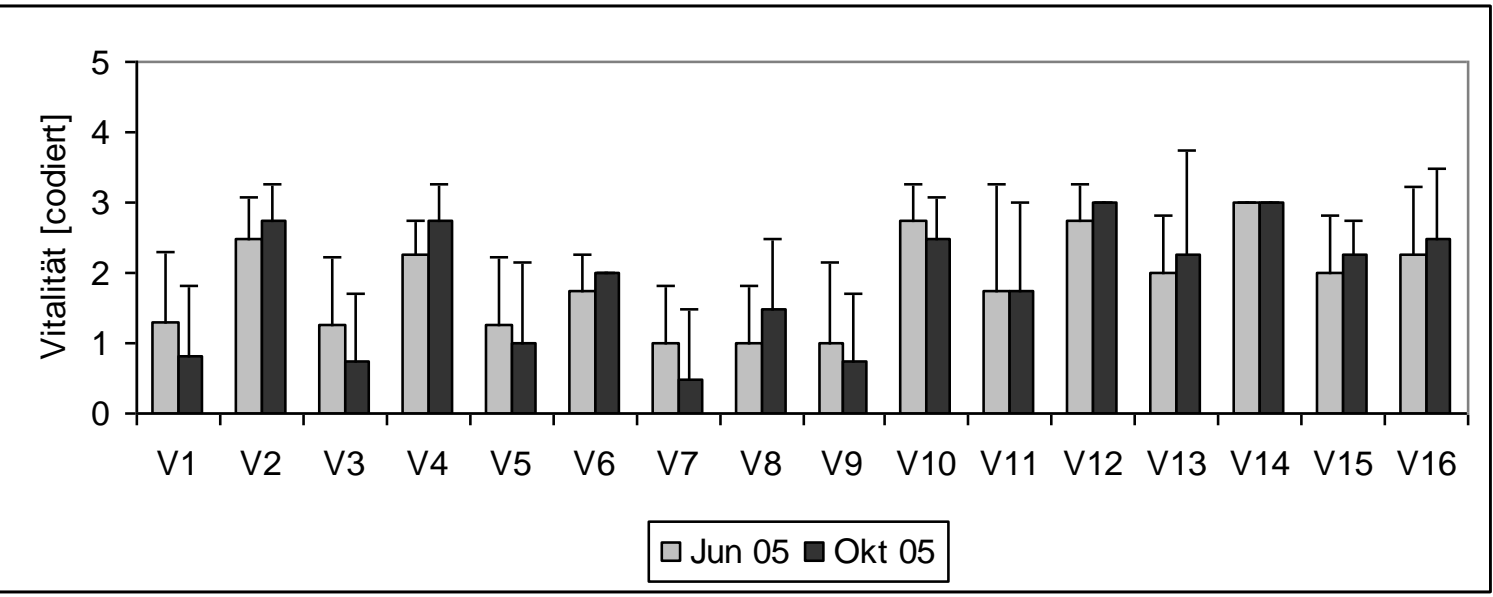

Abb. 138: Vitalität [codiert: $4=$ vital bis $0=$ tot, s. S. 27] der Douglasien-Varianten (s. S. 20) auf Versuchsfläche A im Juni und Oktober 2005; MW u. Std.abw.; Buchstaben kennzeichnen je Aufnahmezeitpunkt homogene Gruppen nach U-Tests, Fettdruck markiert signifikanten Unterschied zur Nullvariante (V1) (je Variante $n=4$ )

Bei beiden Aufnahmen in 2005 lag der höchste Vitalitätsmittelwert bei 3,0 00 (Juni: MykorrhizaStockosorb®-Kalk-Variante V14; Oktober: V14 und Mykorrhiza-Kalk-Variante V12). Die geringste Durchschnittsvitalität betrug im Juni 1,0 \pm 0,8 (Perlit-Variante V7, Perlit-Kalk-Variante V8) bzw. 1,0 $\pm 1,2$ (Kompost-Variante V9), im Oktober 0,5 \pm 0,8 (Perlit-Variante V7).

Zwei Monate nach der Pflanzung, im Juni 2005, war auf Fläche A die Vitalität der Douglasien in den Kalk-Varianten V2 (reiner Kalk; 2,5 \pm 0,6), V4 (Stockosorb®-Kalk; 2,3 \pm 0,5), V10 (KompostKalk; 2,8 \pm 0,5), V12 (Mykorrhiza-Kalk; 2,8 \pm 0,5) und V14 (Mykorrhiza-Stockosorb®-Kalk; 3,0 \pm 0 ) signifikant besser als in der Nullvariante V1 $(1,3 \pm 1,0)$. Dabei lag der Wert mit der zusätzlich zur Stockosorb®- und Kalk-Gabe eingesetzten Mykorrhiza-Impfung in Variante V14 signifikant höher als in Variante V4, der gleichen Kombination ohne Mykorrhiza.

Im Oktober wiesen zusätzlich zu den fünf genannten (V2, V4: 2,8 \pm 0,5; V10: 2,5 $\pm 0,6 ; \mathrm{V} 12, \mathrm{~V} 14$ : $3,0 \pm 0$ ) weitere drei Varianten signifikant höhere durchschnittliche Vitalitätswerte auf als die Kontrolle (0,8 \pm 1,0): Die Superabsorber-Kalk-Variante V6 $(2,0 \pm 0)$, die MykorrhizaSuperabsorber-Kalk-Variante V16 $(2,5 \pm 1,0)$ und - als einzige Variante ohne Kalk-Gabe - die Mykorrhiza-Superabsorber-Variante V15 $(2,3 \pm 0,5)$. Dabei blieb die Kombination aus der Wasserspeichersubstanz Superabsorber und Kalk (V6) jedoch signifikant unter der reinen KalkVariante (V2) und der weiteren Wasserspeichersubstanz-Kalk-Kombination (V4) sowie - ebenso wie V15 - unter den Spitzenwerten der Varianten V12 und V14.

Die entscheidende Rolle für eine signifikante Verbesserung der Vitalität im Vergleich zur Nullvariante spielte auf Fläche A offensichtlich die Kalk-Gabe. Interessanterweise erzielte auch die kalkfreie Kombination aus Mykorrhiza und Superabsorber einen positiven Effekt, während beide Bodenhilfsstoffe allein jeweils keine signifikante Wirkung zeigten. 


\section{Douglasien auf Versuchsfläche B}

Bei den mittleren Vitalitätswerten der Douglasien auf Fläche B bestanden zwar bei allen Aufnahmen mit Ausnahme der letzten im Oktober 2006 signifikante Unterschiede zwischen einzelnen Varianten (s. Abb. 139), die Effekte der Bodenhilfsstoffe wurden jedoch stark durch den Einfluss der standörtlichen Unterschiede innerhalb der Fläche überlagert (s. S. 37).

$\begin{array}{ccccccccccccccccc}\text { 6/05: } & \mathrm{e} & \mathbf{b}-\mathbf{d} & \mathbf{d} & \mathbf{a}-\mathbf{c} & \mathbf{c , d} & \mathbf{a} & \mathbf{c , d} & \mathbf{a}, \mathbf{b} & \mathbf{c , d} & \mathbf{c} & \mathbf{a}-\mathbf{d} & \mathbf{c , d} & \mathbf{c , d} & \mathbf{c , d} & \mathbf{c , d} & \mathbf{c , d} \\ 10 / 05: & \mathrm{d} & \mathbf{a}, \mathbf{b} & \mathrm{d} & \mathbf{a}-\mathbf{c} & \mathbf{c} & \mathbf{a} & \mathbf{b}, \mathbf{c} & \mathbf{a}, \mathbf{b} & \mathbf{c} & \mathbf{b}, \mathbf{c} & \mathbf{a}-\mathbf{c} & \mathbf{a}, \mathbf{b} & \mathbf{a}-\mathbf{c} & \mathbf{c} & \mathbf{a}-\mathbf{c} & \mathbf{c} \\ \text { 6/06: } & \mathrm{e} & \mathbf{a} & \mathrm{d}, \mathrm{e} & \mathbf{a} & \mathbf{a}-\mathbf{c} & \mathbf{a}-\mathbf{c} & \mathbf{c , d} & \mathbf{a , b} & \mathbf{b}, \mathbf{c} & \mathbf{c , d} & \mathbf{a}-\mathbf{c} & \mathbf{a , b} & \mathbf{b}-\mathbf{d} & \mathbf{a}-\mathbf{c} & \mathbf{a}-\mathbf{c} & \mathbf{b}-\mathbf{d}\end{array}$

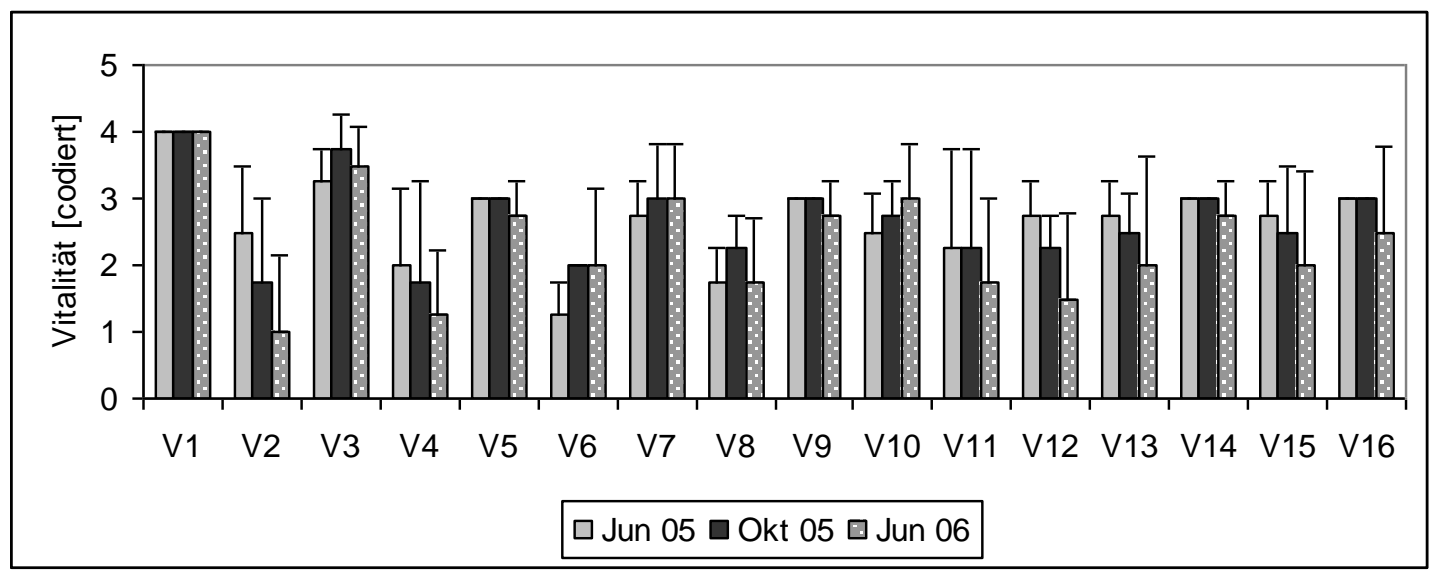

Abb. 139: Vitalität [codiert: $4=$ vital bis $0=$ tot, s. S. 27] der Douglasien-Varianten (s. S. 20) auf Versuchsfläche B im Juni 2005, Oktober 2005 und Juni 2006; MW u. Std.abw.; Buchstaben kennzeichnen je Aufnahmezeitpunkt homogene Gruppen nach U-Tests, Fettdruck markiert signifikanten Unterschied zur Nullvariante (V1) (je Variante $n=4$ )

Die zufällige Platzierung einiger (kalkfreier) Varianten in Bereiche mit späterem Bodenbewuchs und somit besseren Wuchsbedingungen führte zu vergleichsweise sehr guten durchschnittlichen Vitalitätswerten in diesen Varianten, während einige (Kalk-) Varianten mit bis Versuchsende bodenvegetationsfreien, schlechter versorgten Standorten entsprechend geringere Vitalitätswerte hatten.

Insgesamt betrug die mittlere Vitalität der Douglasien auf Fläche B im 1. Versuchsjahr (2005) 2,7 $\pm 0,8$ (Juni) bzw. 2,1 $\pm 0,9$ (Oktober), im 2. Versuchsjahr (2006) 2,3 $\pm 1,2$ (Juni) bzw. 2,2 $\pm 1,2$ (Oktober). Den höchsten Mittelwert hatte stets die Kontrolle mit 4,0 \pm 0 , den niedrigsten im Juni 2005 die Superabsorber-Kalk-Variante V6 (1,3 \pm 0,5), im Oktober 2005 die Kalk- und die Stockosorb®-Kalk-Varianten (V2: 1,8 \pm 1,3; V4: 1,8 \pm 1,5) und im Juni 2006 die Kalk-Variante V2 $(1,0 \pm 1,2)$.

Gegenüber der sehr guten Kontrolle schnitten alle anderen Varianten signifikant schlechter ab; ausgenommen war ab Oktober 2005 die direkt benachbarte Variante V3 (Stockosorb®).

\section{Douglasien auf Versuchsfläche D}

Die mittlere Vitalität der auf Versuchsfläche D gepflanzten Douglasien sank im 1. Untersuchungsjahr auf 1,8 $\pm 1,1 / 1,3$ (Juni bzw. Oktober 2005), um im 2. Jahr von 1,7 $\pm 1,6$ (Juni 2006) auf 1,5 $\pm 1,5$ (Oktober 2006) zu fallen. Signifikante Unterschiede zwischen den Versuchsvarianten wurden hier nicht festgestellt. 


\section{Douglasien in Bereichen ohne Spontanvegetation}

Bei den Douglasien mit Standorten in Teilbereichen ohne Bodenvegetation bestanden nur im 1. Versuchsjahr signifikante Unterschiede der Vitalität der Pflanzen zwischen den verschiedenen Behandlungsvarianten (s. Abb. 140). Insgesamt betrug die mittlere Vitalität der Douglasien auf diesen Standorten sowohl im Juni 2005, nur zwei Monate nach der Pflanzung, als auch im Oktober 2005 lediglich 1,8 $\pm 1,0 / 1,2$. Im 2. Versuchsjahr waren keine signifikanten Unterschiede zwischen einzelnen Varianten mehr zu ermitteln. Die mittlere Vitalität der Douglasien auf vegetationsfreien Standorten war zum Zeitpunkt der deshalb hier nicht dargestellten Aufnahmen auf 1,2 \pm 1,2 (Juni 2006) bzw. 1,1 $\pm 1,2$ (Oktober 2006) abgesunken.

Die niedrigsten durchschnittlichen Vitalitätswerte wurden im 1. Versuchsjahr jeweils in der Perlit-Variante V7 ermittelt (1,0 \pm 0,8 im Juni; 0,6 \pm 1,0 im Oktober), die höchsten im Juni in der Kompost-Kalk-Variante V10 $(2,7 \pm 0,5)$, im Oktober in V10 $(2,5 \pm 0,5)$, V14 (MykorrhizaStockosorb®-Kalk; 2,5 \pm 1,1) und V16 (Mykorrhiza-Superabsorber-Kalk; $2,5 \pm 0,8$ ). Im Juni unterschied sich in keiner Variante die Pflanzenvitalität signifikant von der in der Nullvariante V1 (1,8 $\pm 1,3)$. Im Oktober dagegen lag die mittlere Vitalität in den MykorrhizaWasserspeichersubstanz-Kalk-Varianten V14 und V16 signifikant höher als in der Kontrolle V1 $(1,4 \pm 1,3)$.

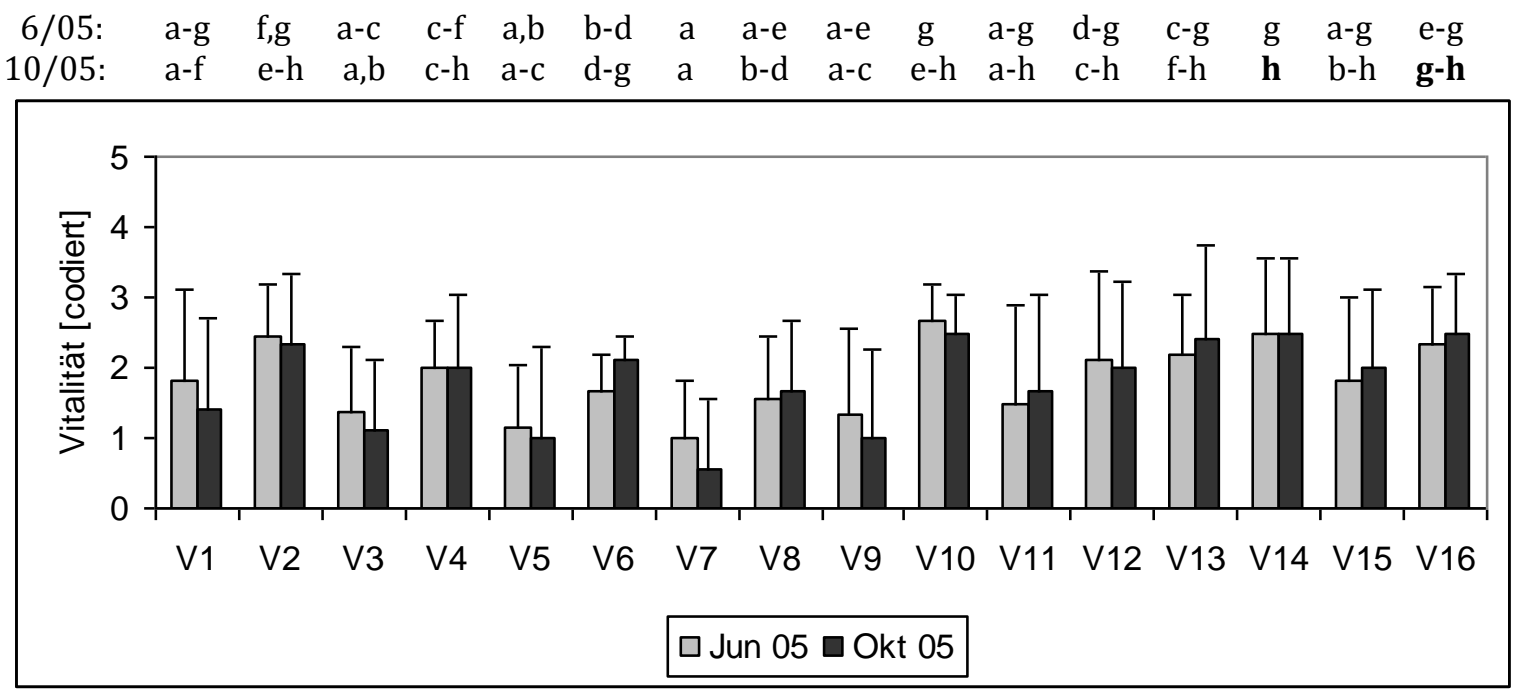

Abb. 140: Vitalität [codiert: $4=$ vital bis 0 = tot, s. S. 27] der Douglasien-Varianten (s. S. 20) in vegetationsfreien Bereichen im Juni und Oktober 2005; MW u. Std.abw.; Buchstaben kennzeichnen je Aufnahmezeitpunkt homogene Gruppen nach U-Tests, Fettdruck markiert signifikanten Unterschied zur Nullvariante (V1) (n=119)

Für die Vitalität der Douglasien auf diesen vegetationsfreien Standorten, die sich von den besiedelten u. a. durch niedrigere pH-Werte des Bodens unterschieden, spielten die Kalk-Gaben offenbar eine große Rolle. Dies lässt sich daran ablesen, dass bei den Varianten V3 und V4 (Stockosorb® mit und ohne Kalk), V5 und V6 (Superabsorber mit und ohne Kalk), V7 und V8 (Perlit mit und ohne Kalk) sowie V9 und V10 (Kompost mit und ohne Kalk) jeweils die Kombination mit Kalk zumindest im Oktober 2005 zu signifikant besseren durchschnittlichen Vitalitätswerten führte (bei V9 und V10 auch schon im Juni 2005).

Innerhalb der Mykorrhiza-Varianten bestanden dagegen zu keinem Zeitpunkt signifikante Vitalitäts-Unterschiede, auch nicht zwischen gekalkten und kalkfreien Varianten. Einen signifikanten Unterschied gegenüber der Nullvariante V1 machte auf diesen schwierigen Standorten zum Ende der ersten Vegetationszeit nur die Gabe von Mykorrhiza unterstützt von 
einer Kombination aus Wasserspeichersubstanz (V14: Stockosorb®; V16: Superabsorber) und Kalk-Gabe. Im 2. Untersuchungsjahr (2006) war dieser Einfluss nicht mehr signifikant.

\section{Douglasien in Bereichen mit Spontanvegetation}

Insgesamt betrug die Durchschnittsvitalität der Douglasien auf bewachsenen Standorten im Juni 2005 2,5 \pm 0,9, im Oktober 2005 2,6 \pm 1,0. Der niedrigste Wert wurde jeweils in Variante V4 ermittelt $(1,5 \pm 2,1$; im Oktober 2005 war dies der einzige Mittelwert unter „2“). Im 2 . Versuchsjahr lag die Vitalität der Douglasien auf diesen Standort unverändert bei 2,6 \pm 1,3 im Juni bzw. 2,4 $\pm 1,2$ im Oktober.

Der Vergleich der Vitalitätsmittelwerte in den Douglasien-Varianten, die in Bereiche mit späterer Bodenvegetation (auf Fläche B und D) gepflanzt wurden, ist schwierig, da eventuelle Wirkungen der Bodenhilfsstoffe von Standorteinflüssen überlagert wurden. So bestanden wie ab Seite 241 gezeigt bereits signifikante Vitalitätsunterschiede zwischen den Douglasien in bewachsenen Bereichen auf Fläche B und jenen in bewachsenen Bereichen auf Fläche D.

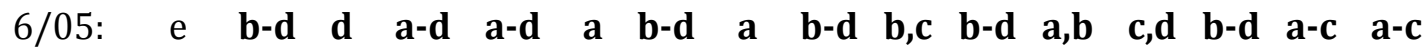 10/05: e a-d e,d a-c a-c a}

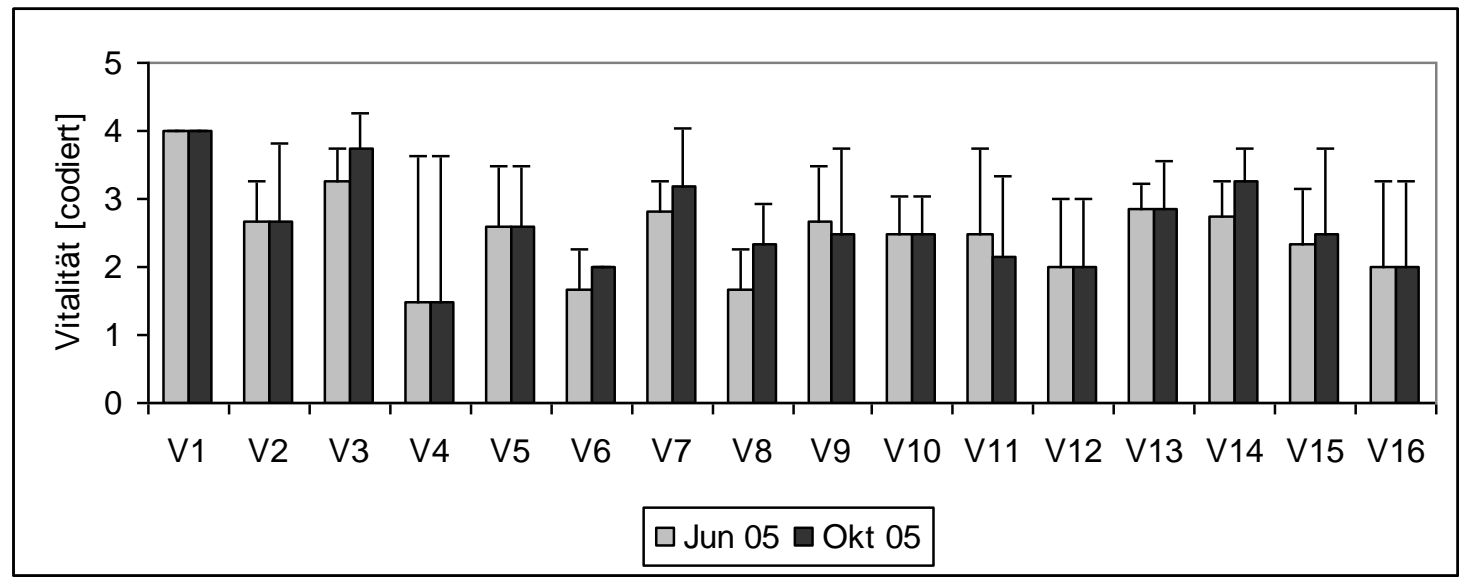

Abb. 141: Vitalität [codiert: $4=$ vital bis $0=$ tot, s. S. 27] der Douglasien-Varianten (s. S. 20) in bewachsenen Bereichen im Juni und Oktober 2005; MW u. Std.abw.; Buchstaben kennzeichnen je Aufnahmezeitpunkt homogene Gruppen nach U-Tests, Fettdruck markiert signifikanten Unterschied zur Nullvariante (V1) $(n=73)$

Zumindest im 1. Versuchsjahr gab es zwar signifikante Unterschiede zwischen den Vitalitätswerten einiger Varianten (s. Abb. 141). Als Nullvariante konnte jedoch nur die Variante V1 auf Fläche B berücksichtigt werden (auf Fläche D stand die Kontrolle in einem vegetationsfreien Bereich), die komplett in einem im Versuchsverlauf bewachsenen Bereich mit relativ guten Standortbedingungen gepflanzt worden war. Hier erhielten im 1. Versuchsjahr sämtliche Douglasien den Spitzenwert „4“ (voll vital). Da dies in keiner anderen Variante so erreicht wurde, waren die durchschnittlichen Vitalitätswerte der anderen Varianten signifikant schlechter als in der Kontrolle. Einzige Ausnahme bildete im Oktober 2005 Variante V3, die jedoch in direkter Nachbarschaft zur Nullvariante stand, so dass dies ebenso auf die Standorteinflüsse auf Fläche B zurückzuführen ist. 


\subsubsection{Wald-Kiefer}

Der durchschnittliche Vitalitätszustand aller 120 im Freiland-Versuch gepflanzten Kiefern hatte sich bereits zwei Monate nach der Pflanzung signifikant erheblich von recht guten 3,0 $\pm 0,5$ auf nur noch $0,9 \pm 1,2$ verschlechtert (s. Abb. 142). Im weiteren Versuchsverlauf nahm die mittlere Vitalität weiter auf $0,6 \pm 1,3 \mathrm{ab}$, um zum 2 . Untersuchungsjahr ganz leicht auf $0,7 \pm 1,4$ anzusteigen, worauf wieder eine Abnahme auf schließlich sehr geringe 0,6 $\pm 1,3$ folgte (s. Tab. 68).

Tab. 68: Vitalität [codiert: $4=$ vital bis $0=$ tot, s. S. 27] der Kiefern im Versuchsverlauf; MW u. Std.abw.; Ergebnis des Friedmann-Tests $\left(\mathrm{Chi}^{2}\right)$ auf signifikante Unterschiede zwischen den Aufnahmezeitpunkten $(\mathrm{n}=120)$

\begin{tabular}{|l|l|l|l|l|l|l|l|l|l|}
\hline $\begin{array}{l}\text { April } \\
2005\end{array}$ & & $\begin{array}{l}\text { Juni } \\
2005\end{array}$ & & $\begin{array}{l}\text { Oktober } \\
2005\end{array}$ & & $\begin{array}{l}\text { Juni } \\
2006\end{array}$ & & $\begin{array}{l}\text { Oktober } \\
2006\end{array}$ & $\mathrm{Chi}^{2}$ \\
\hline $3,0 \pm 0,5$ & $>$ & $0,9 \pm 1,2$ & $>$ & $0,6 \pm 1,3$ & $<$ & $0,7 \pm 1,4$ & $>$ & $0,6 \pm 1,3$ & $149,08^{* * *}$ \\
\hline
\end{tabular}

$>$ signifikanter Rückgang, < signifikanter Anstieg der Vitalität laut Wilcoxon-Test

Grund für diese sehr geringen Mittelwerte war eine hohe Sterblichkeit (s. Abb. 143), da für jeden abgestorbenen Baum der Wert " $0^{\prime \prime}=$ tot in die Berechnung des durchschnittlichen Vitalitätswertes eingeht.

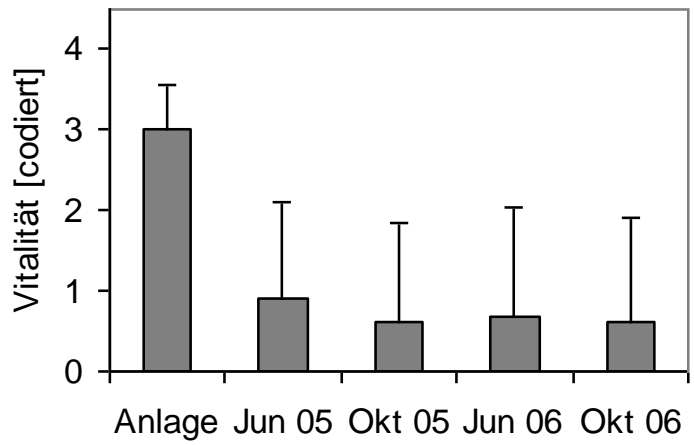

Abb. 142: Vitalität [codiert: $4=$ vital bis $0=$ tot, s. S. 27] der Kiefern im Versuchsverlauf; MW u. Std.abw. $(\mathrm{n}=120)$

Die Ausfallrate war von Beginn an relativ hoch und stieg im 1. Untersuchungsjahr deutlich von $56 \%$ im Juni auf $80 \%$ im Oktober an. Im 2. Jahr kamen keine weiteren Ausfälle hinzu. Die mittleren Vitalitätswerte der lebenden Kiefern lagen jeweils bei $2,1 \pm 0,9 ; 3,0 \pm 0,8 ; 3,3 \pm 0,7$ und $3,0 \pm 1,0$. Damit wiesen die wenigen lebenden Kiefern recht gute Vitalitätswerte auf. 


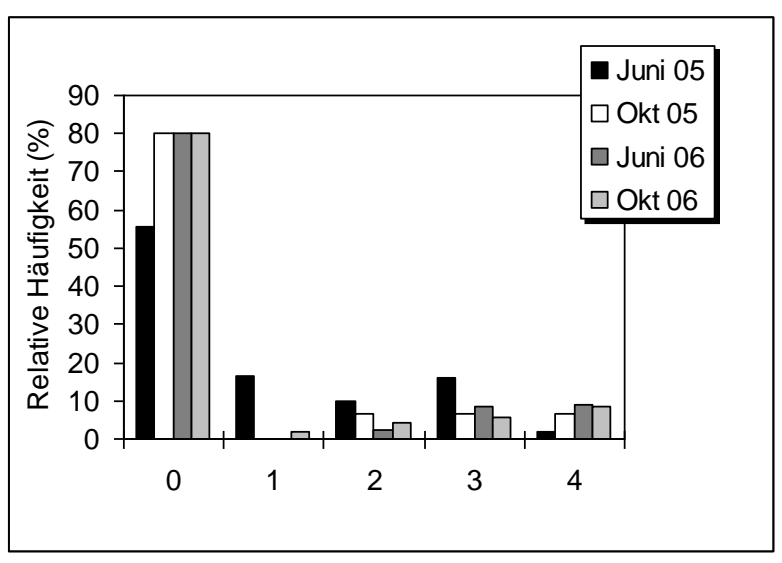

Abb. 143: Relative Häufigkeit der Vitalitätswerte [codiert: $4=$ vital bis $0=$ tot, s. S. 27] der Kiefern im Versuchsverlauf $(n=120)$

\section{Kiefern insgesamt}

Betrachtet man die Entwicklung der mittleren Vitalitätswerte innerhalb jeder Variante über die Zeit und bezieht dabei die vergleichsweise hohen Ausgangswerte mit ein, so lassen sich erwartungsgemäß signifikante Vitalitätsunterschiede zwischen den ersten beiden Aufnahmen (Anlage im April 2005 und Juni 2005) nachweisen, allerdings nicht für die Kompost-Varianten (V9 und V10). Diese wiesen im Gegensatz zu allen übrigen Varianten bis zum Ende des Untersuchungszeitraums durchschnittliche Vitalitätswerte zwischen "1“ und „2“ auf, während die Vitalität der Bäume aller übrigen Varianten im Mittel schließlich unterhalb der Stufe „1“ lag (s. Tab.69) .

Tab. 69: Vitalität [codiert: $4=$ vital bis $0=$ tot, s. S. 27] der Kiefern-Varianten (s. S. 20) im Versuchsverlauf; MW u. Std.abw.; je Aufnahmezeitpunkt Ergebnisse von H-Tests (H) auf signifikante Unterschiede zwischen den Varianten; je Variante Ergebnisse von Friedmann-Tests $\left(\mathrm{Chi}^{2}\right)$ auf signifikante Unterschiede zwischen den Aufnahmezeitpunkten (je Variante $\mathrm{n}=12$ )

\begin{tabular}{|l|l|l|l|l|l|l|l|l|l|l|}
\hline & $\begin{array}{l}\text { April } \\
2005\end{array}$ & & $\begin{array}{l}\text { Juni } \\
2005\end{array}$ & & $\begin{array}{l}\text { Oktober } \\
2005\end{array}$ & $\begin{array}{l}\text { Juni } \\
2006\end{array}$ & $\begin{array}{l}\text { Oktober } \\
2006\end{array}$ & Chi $^{2}$ \\
\hline V1 & $2,9 \pm 0,5$ & $>$ & $1,5 \pm 1,1$ & $>$ & $1,0 \pm 1,3$ & & $1,2 \pm 1,5$ & & $0,8 \pm 1,1$ & $15,27^{* *}$ \\
\hline V2 & $2,8 \pm 0,4$ & $>$ & $0,8 \pm 1,4$ & & $0,5 \pm 1,2$ & & $0,5 \pm 1,2$ & & $0,6 \pm 1,4$ & $15,57^{* *}$ \\
\hline V3 & $3,2 \pm 0,6$ & $>$ & $0,8 \pm 1,1$ & $>$ & $0,3 \pm 0,9$ & & $0,3 \pm 1,2$ & & $0,3 \pm 0,9$ & $20,68^{* * *}$ \\
\hline V4 & $2,8 \pm 0,5$ & $>$ & $0,6 \pm 1,2$ & & $0,3 \pm 1,2$ & & $0,3 \pm 1,2$ & & $0,3 \pm 1,2$ & $16,0^{* *}$ \\
\hline V5 & $3,1 \pm 0,7$ & $>$ & $0,6 \pm 1,1$ & & $0,6 \pm 1,1$ & & $0,8 \pm 1,4$ & & $0,6 \pm 1,1$ & $15,67^{* *}$ \\
\hline V6 & $2,9 \pm 0,5$ & $>$ & $0,3 \pm 0,7$ & & 0 & & 0 & & 0 & $24,9^{* * *}$ \\
\hline V7 & $2,9 \pm 0,7$ & $>$ & $0,7 \pm 1,2$ & & $0,3 \pm 0,9$ & & $0,3 \pm 1,2$ & & $0,3 \pm 1,2$ & $16,6^{* *}$ \\
\hline V8 & $3,4 \pm 0,5$ & $>$ & $0,8 \pm 1,1$ & & $0,5 \pm 1,2$ & & $0,5 \pm 1,2$ & & $0,4 \pm 1,2$ & $18,32^{* *}$ \\
\hline V9 & $3,1 \pm 0,5$ & & $1,8 \pm 1,6$ & & $1,3 \pm 1,9$ & & $1,3 \pm 2,0$ & & $1,3 \pm 2,0$ & 7,18 \\
\hline V10 & $3,1 \pm 0,3$ & & $1,4 \pm 1,1$ & & $1,3 \pm 1,7$ & & $1,4 \pm 1,8$ & & $1,4 \pm 1,8$ & 8,85 \\
\hline H & 13,95 & & $19,49^{*}$ & & $14,26 / 10,14$ & & $13,82 / 9,69$ & & $13,97 / 9,86$ & \\
\hline & $\mathrm{N}=120$ & & $\mathrm{~N}=120$ & & $\mathrm{~N}=120$ & & $\mathrm{~N}=120$ & & $\mathrm{~N}=120$ & \\
\hline
\end{tabular}

Oktober 2005, Juni 2006 und Oktober 2006: H-Test-Ergebnis mit V6/ohne V6

> signifikanter Rückgang, < signifikanter Anstieg der Vitalität laut Wilcoxon-Test 
Obwohl die durchschnittlichen Vitalitätswerte bei den Kompostvarianten im Versuchsverlauf auch deutlich niedriger lagen als die guten Ausgangswerte, sind diese Unterschiede nicht signifikant. Grund dafür ist die hohe Streuung der Vitalitätswerte, da innerhalb dieser Varianten zwar auch einige Pflanzen abstarben (Vitalitätswert: „0“), die überlebenden Pflanzen aber oft sehr gute Werte erhielten (Vitalitätswert „3“ oder "4“).

Die vergleichsweise guten Ergebnisse in den Kompost-Varianten bestätigen das Resultat von multiplen schrittweisen Regressionen zum Einfluss der eingesetzten Bodenhilfsstoffe auf die Vitalitätsentwicklung der Kiefern, die zwecks eines ersten Eindrucks zu Beginn der Datenanalyse durchgeführt wurden und im gesamten Versuchsverlauf einen positiven Einfluss der Kompost-Gaben feststellten, während alle anderen Bodenhilfsstoffe ohne Wirkung blieben.

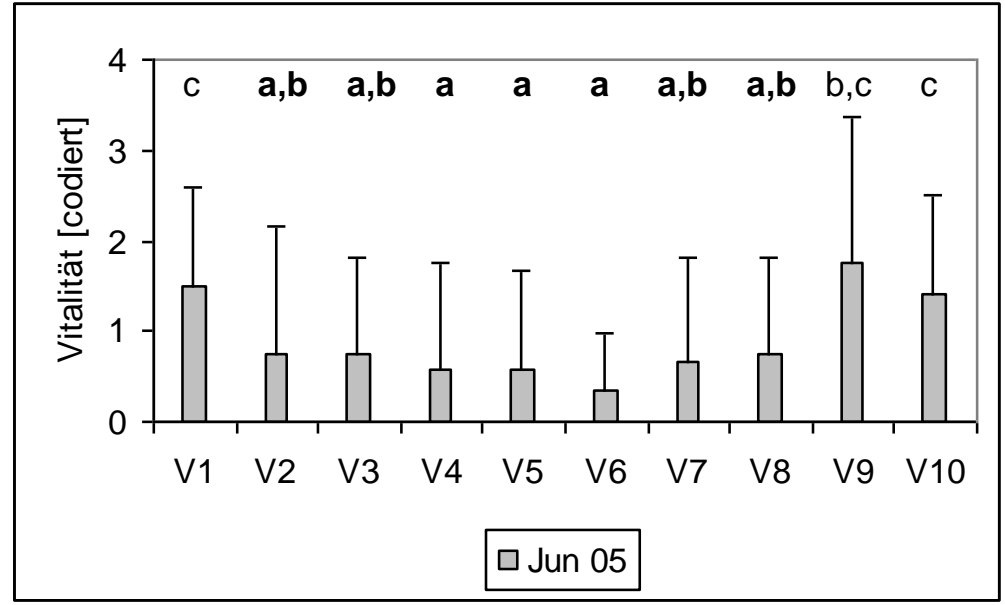

Abb. 144: Vitalität [codiert: 4 = vital bis $0=$ tot, s. S. 27] der Kiefern-Varianten (s. S. 20) im Juni 2005; MW u. Std.abw.; Buchstaben kennzeichnen homogene Gruppen nach U-Tests; Fettdruck markiert signifikanten Unterschied zur Nullvariante (V1) (je Variante n=12)

Die Vitalitätsunterschiede zwischen den Varianten waren bei der Aufnahme im Juni 2005 (zwei Monate nach der Pflanzung) noch statistisch signifikant (s. Abb. 144), zu den weiteren drei Aufnahmezeitpunkten dagegen nicht mehr. Im Juni 2005 war der mittlere Vitalitätswert der Pflanzen in den Varianten V1 (Kontrolle) und V10 (Kompost-Kalk) signifikant höher als in den übrigen Varianten mit Ausnahme von V9 (Kompost). Der Vitalitätswert von V9 hob sich signifikant von den Varianten mit den niedrigsten Vitalitätswerten, V6 (Superabsorber-Kalk), V5 (Superabsorber) und V4 (Stockosorb-Kalk) ab. Die Varianten V1 (Kontrolle) und V10 (KompostKalk) zeigten mit je $58 \%$ die geringsten Ausfälle, gefolgt von V9 (Kompost) mit $67 \%$ und V5 (Superabsorber) mit 75 \%. Variante V6 (Superabsorber-Kalk) fiel komplett aus. Innerhalb der Kompost-Variante (V9), der Kompost-Kalk-Variante (V10) und der Kontrolle (V1) erreichten zu jedem Aufnahmezeitpunkt 4 bzw. 5 der jeweils 12 Wiederholungen (s. S. 21f) einen Vitalitätswert von „2“ und darüber, während dies bei den übrigen Varianten nur noch bei einzelnen Pflanzen der Fall war. Das vergleichsweise gute Abschneiden der unbehandelten Kontrolle ist vermutlich auch auf die ebenfalls vergleichsweise günstigen Standortbedingungen der Nullvariante auf Fläche B zurückzuführen, die zufällig komplett in einem später auch mit Spontanvegetation bewachsenen Bereich angelegt wurde. 
Kiefern auf den Versuchsflächen A, B oder D sowie in Bereichen mit oder ohne Spontanvegetation

Betrachtet man ausschließlich die Kiefern auf Versuchsfläche A, D oder in vegetationsfrei bleibenden Bereichen, so führte ihr früher annähernder Totalausfall auf diesen Standorten zu Vitalitätsmittelwerten deutlich unter „1“. Auf Fläche B sowie in Bereichen mit Spontanvegetation lag die mittlere Vitalität der Kiefern aufgrund auch hier starker Ausfälle im Versuchsverlauf bei Werten zwischen "1,3“ und „1,6“. Bei den derart nach Standort gruppierten Kiefern konnte in keinem Fall ein Einfluss der Behandlungsvarianten auf ihre Vitalität nachgewiesen werden.

\subsubsection{Wachstumsentwicklung}

Im Folgenden wird die Wuchsentwicklung der Versuchsbäume anhand der Ergebnisse statistischer Analysen verschiedener Wuchsparameter (s. S. 79) auf Effekte der in den Behandlungsvarianten eingesetzten Bodenhilfsstoffe und -kombinationen (s. S. 20) untersucht.

Da die Einflussfaktoren „Pflanzenstandort auf einer der drei Versuchsflächen“ (s. ab S. 245) sowie "Pflanzenstandort in Bereichen ohne oder mit Spontanvegetationsentwicklung" (s. ab S. 272) teilweise eine wichtige Rolle spielten, wurden die Wirkungen der Behandlungsvarianten auf die Wachstumsentwicklung der Versuchspflanzen auch unter Ausschluss dieser Faktoren untersucht. Dies geschah, indem ausschließlich die Bäume mit Standorten auf Teilflächen ohne Spontanvegetation (vergleichsweise ungünstigere Bedingungen), auf Standorten mit Spontanvegetation (vergleichsweise günstigere Bedingungen) oder auf einer bestimmten Versuchsfläche betrachtet wurden (zu den unterschiedlichen Standortbedingungen s. ab S. 44).

Beinahe alle Eichen starben bereits früh oberirdisch ab, so dass diese Baumart nicht in die Wachstumsanalysen einbezogen werden konnte. Die Baumart Erle fehlt an dieser Stelle ebenfalls, da in den einzelnen Behandlungsvarianten keine signifikant unterschiedlichen Wachstumsentwicklungen festgestellt werden konnten. Die Mittelwerte der im Einzelnen erhobenen Wachstumsparameter können für jede Baumart (mit Ausnahme der Eiche) in Tab. A 15 eingesehen werden.

Bevor auf die Effekte der Bodenhilfsstoffe auf verschiedene, meist bei Versuchsabschluss erhobene oder berechnete Wachstumsparameter (s. S. 79) eingegangen wird, soll zunächst die Wirkung einzelner Varianten auf die Zuwachsentwicklung der Baumarten im Versuchsverlauf beschrieben werden.

\subsubsection{Zuwachsentwicklung im Versuchsverlauf}

Die Messungen der Haupttrieblängen aller Versuchsbäume bei Versuchsanlage (April 2005), nach dem 1. Vegetationsjahr (Oktober 2005) und nach dem 2. Jahr (Oktober 2006) ermöglichten den statistischen Vergleich der Haupttriebs-Zuwächse über die Zeit. Eine Trennung der untersuchten Baumarten (die Eichen konnten in diese wie auch in andere Wachstumsanalysen nicht einbezogen werden, da ihre Haupttriebe überwiegend bereits im 1. Jahr abstarben) nach Behandlungsvarianten führte je nach Baumart in einigen der Varianten zu signifikant höheren Zuwächsen im 2. gegenüber dem 1. Jahr. Die Messergebnisse und die Ergebnisse der 
durchgeführten Wilcoxon-Tests sind für jede Baumart und Variante in Tab. A 16 tabellarisch zusammengestellt und werden im Folgenden beschrieben.

Im Fall der unbehandelten Ebereschen (Nullvariante V1) war eine negative Zuwachsentwicklung im Versuchsverlauf nachweisbar, indem im 2. Jahr mit $3 \pm 2 \mathrm{~cm}$ ein signifikant geringerer durchschnittlicher Zuwachs gemessen wurde als im 1. Jahr mit $6 \pm 4 \mathrm{~cm}$. Bei den mit Kompost und Kalk (V10) gedüngten Ebereschen verdoppelte sich der Zuwachs dagegen von $9 \pm 4 \mathrm{~cm}$ auf $19 \pm 9 \mathrm{~cm}$. In allen übrigen Behandlungsvarianten unterschied sich der Zuwachs der Ebereschen in beiden Untersuchungsjahren nicht signifikant.

Von den untersuchten Kiefern-Varianten (durch hohe Pflanzenausfälle konnten sechs der zehn Varianten nicht einbezogen werden) wiesen nur die mit Kompost gedüngten Bäume (V9 ohne, V10 mit zusätzlicher Kalk-Gabe) im 2. Untersuchungsjahr signifikant höhere HaupttriebsZuwächse auf, die mit $24 \pm 4 \mathrm{~cm}$ und $25 \pm 11 \mathrm{~cm}$ jeweils ein Vielfaches des Vorjahreszuwachses $(5 \pm 5 \mathrm{~cm} ; 10 \pm 7 \mathrm{~cm})$ betrugen.

Bei der Baumart Erle konnten in fünf der insgesamt 9 Behandlungsvarianten (+ Kontrolle) signifikant höhere Zuwächse im 2. Versuchsjahr festgestellt werden. Dabei handelte es sich um die beiden Behandlungskombinationen aus Wasserspeichersubstanzen und Kalk (V4: Stockosorb®-Kalk, V6: Superabsorber-Kalk), die reine Perlit-Variante (V7) sowie die beiden Kompost-Varianten (V9 ohne, V10 mit zusätzlicher Kalk-Gabe).

Die Ahorne wiesen mit Kompost-Düngung (V9 ohne, V10 mit zusätzlicher Kalk-Gabe) sowie bei Kombination von Mykorrhiza-Impfung und Stockosorb®-Gabe (V13 ohne, V14 mit zusätzlicher Kalk-Düngung) im 2. Jahr signifikant höhere Zuwächse auf als im ersten.

Gleiches galt für die Douglasien in den Perlit-Varianten (V7 ohne, V8 mit zusätzlicher KalkGabe), mit reiner Kompost-Düngung (V9) sowie in sämtlichen Kombinationen aus MykorrhizaImpfung und Wasserspeichersubstanz-Gabe (V13, V15 ohne; V14, V16 mit zusätzlicher KalkGabe).

Bei der vorliegenden Analyse muss stets beachtet werden, dass hier keine absoluten Zuwachszahlen, sondern relative Zuwachsänderungen vom ersten zum 2. Untersuchungsjahr beschrieben werden. Ein zur korrekten Interpretation deshalb notwendiger Blick auf die absoluten Zuwachs-Zahlen (s. Tab. A 16) zeigt, dass die festgestellten signifikanten Zuwachsunterschiede zwischen dem ersten und 2. Untersuchungsjahr in den meisten Fällen tatsächlich auf einen vergleichsweise starken Zuwachs im 2. Jahr zurückzuführen sind. Im Fall der Ahorne in der kalkfreien Mykorrhiza-Stockosorb®-Variante (V13), bei den mit Superabsorber- und Kalk-Gabe versehenen Erlen (V6) sowie bei den mit Kalk-Gaben gepflanzten Douglasien (V8, V14, V16) kamen die signifikanten Zuwachsunterschiede dagegen aufgrund eines unterdurchschnittlich geringen Zuwachses im 1. Versuchsjahr („schlechter Start") zustande.

Weiterhin können nicht signifikant unterschiedliche Zuwächse sowohl gleichermaßen geringe als auch gleichermaßen hohe Zuwächse (z.B. bei den Ahornen in Variante V4 oder den Erlen in Variante V13) in beiden Untersuchungsjahren bedeuten.

Diese dann insgesamt geringen bzw. hohen Zuwächse werden in den folgenden Kapiteln nach Baumarten getrennt dargestellt. 


\subsubsection{Spitz-Ahorn}

Im Falle der Ahorne konnten zwischen verschiedenen der insgesamt 16 Behandlungsvarianten signifikante Unterschiede des Wurzelhalsdurchmessers festgestellt werden. Dies galt nicht nur für die Gesamtheit aller gepflanzten Ahorne, sondern auch bei Betrachtung nur der Ahorne mit Standorten auf Versuchsfläche B sowie in Bereichen mit Spontanvegetation (s. Tab. 70).

Tab. 70: Wurzelhalsdurchmesser [mm] der Ahorn-Varianten (s. S. 20) insgesamt, auf Fläche B sowie in Bereichen mit Spontanvegetation; MW u. Std.abw.; Ergebnisse von H-Tests [H] auf signifikante Unterschiede; Buchstaben kennzeichnen je Spalte homogene Gruppen nach U-Tests

\begin{tabular}{|c|c|c|c|}
\hline & \multicolumn{3}{|c|}{ Wurzelhalsdurchmesser [mm] der Ahorne } \\
\hline & insgesamt & auf Fläche B & $\begin{array}{c}\text { in Bereichen mit } \\
\text { Spontanvegetation }\end{array}$ \\
\hline V1 & $\begin{array}{l}5,1 \pm 1,1 \\
(n=5) a, b\end{array}$ & $\begin{array}{l}5,0 \pm 1,0 \\
(n=3) a-c\end{array}$ & $\begin{array}{l}5,0 \pm 1,0 \\
(n=3) a, b\end{array}$ \\
\hline V2 & $\begin{array}{l}5,5 \pm 1,1 \\
(n=8) a-f\end{array}$ & - & $\begin{array}{l}5,2 \pm 0,8 \\
(n=3) b, c\end{array}$ \\
\hline V3 & $\begin{array}{l}4,9 \pm 1,1 \\
(n=7) a\end{array}$ & $\begin{array}{l}4,4 \pm 0,3 \\
(n=4) a\end{array}$ & $\begin{array}{l}4,4 \pm 0,3 \\
(n=4) a, b\end{array}$ \\
\hline V4 & $\begin{array}{c}6,7 \pm 1,3 \\
(n=10) e-g\end{array}$ & - & - \\
\hline V5 & - & - & - \\
\hline V6 & $\begin{array}{l}5,7 \pm 1,0 \\
(n=7) a-f\end{array}$ & - & $\begin{array}{l}5,6 \pm 0,8 \\
(n=3) b-d\end{array}$ \\
\hline V7 & $\begin{array}{l}5,5 \pm 0,5 \\
(n=6) a-d\end{array}$ & $\begin{array}{l}5,3 \pm 0,6 \\
(n=3) b, c\end{array}$ & $\begin{array}{l}5,3 \pm 0,5 \\
(n=4) b, c\end{array}$ \\
\hline V8 & $\begin{array}{l}6,3 \pm 1,0 \\
(n=6) f, g\end{array}$ & $\begin{array}{l}6,6 \pm 0,9 \\
(n=4) d, e\end{array}$ & - \\
\hline V9 & $\begin{array}{l}5,8 \pm 1,1 \\
(n=8) a-f\end{array}$ & $\begin{array}{l}6,4 \pm 1,0 \\
(n=4) c-e\end{array}$ & $\begin{array}{l}5,9 \pm 0,7 \\
(n=5) b, c\end{array}$ \\
\hline V10 & $\begin{array}{c}6,7 \pm 1,7 \\
(n=10) d-g\end{array}$ & $\begin{array}{c}8,5 \pm 1,2 \\
(n=4) f\end{array}$ & $\begin{array}{l}7,4 \pm 2,0 \\
(n=6) c, d\end{array}$ \\
\hline V11 & $\begin{array}{c}6,6 \pm 2,6 \\
(n=11) b-g\end{array}$ & $\begin{array}{l}4,8 \pm 0,5 \\
(n=4) a, b\end{array}$ & $\begin{array}{c}6,1 \pm 2,7 \\
(n=7) b-d\end{array}$ \\
\hline $\mathrm{V} 12$ & $\begin{array}{l}6,5 \pm 1,0 \\
(n=9) f, g\end{array}$ & $\begin{array}{l}6,8 \pm 0,3 \\
(n=3) e\end{array}$ & - \\
\hline V13 & $\begin{array}{l}5,6 \pm 0,9 \\
(n=8) a-e\end{array}$ & $\begin{array}{l}5,6 \pm 1,0 \\
(n=4) b, c\end{array}$ & $\begin{array}{l}5,6 \pm 0,9 \\
(n=6) b, c\end{array}$ \\
\hline V14 & $\begin{array}{c}6,5 \pm 1,4 \\
(n=10) c-g\end{array}$ & $\begin{array}{l}5,6 \pm 1,1 \\
(n=4) b-e\end{array}$ & $\begin{array}{l}6,6 \pm 2,0 \\
(n=4) b-d\end{array}$ \\
\hline V15 & $\begin{array}{l}7,1 \pm 1,4 \\
(n=9) g\end{array}$ & $\begin{array}{l}7,0 \pm 1,4 \\
(n=4) c-f\end{array}$ & $\begin{array}{l}7,3 \pm 1,6 \\
(n=7) d\end{array}$ \\
\hline V16 & $\begin{array}{l}6,1 \pm 2,0 \\
(n=9) b-f\end{array}$ & $\begin{array}{l}5,5 \pm 0,5 \\
(n=3) c, d\end{array}$ & $\begin{array}{l}5,8 \pm 1,0 \\
(n=4) b, c\end{array}$ \\
\hline $\mathrm{H}$ & $26,03^{*}$ & $28,91^{*}$ & $20,95^{*}$ \\
\hline & $\mathrm{n}=123$ & $\mathrm{n}=44$ & $n=56$ \\
\hline
\end{tabular}

- zu geringe Zahl (<3) überlebender, nicht (durch Wild) geschädigter Versuchspflanzen 
Interessanterweise hatten die Behandlungsvarianten auf den vergleichsweise ungünstigeren Standorten (Bereiche ohne Spontanvegetation, Fläche A) und auf Fläche D (höherer Anteil vegetationsfreier Bereiche als auf Fläche B) keine Wirkung auf das Wachstum der Ahorne (insgesamt sowie auf Versuchsfläche B wurden in unbewachsenen Bereichen sogar höhere Wurzelhalsdurchmesser ermittelt als auf günstigeren Standorten).

Variante V5 konnte in keiner Gruppe mit in die Untersuchungen einbezogen werden, da zum Zeitpunkt der Aufnahme von den mit Superabsorber-Gabe gepflanzten Ahornen für statistische Analysen nicht mehr genügend (mind. 3) lebende, ungeschädigte Wiederholungen zur Verfügung standen. Gleiches galt auf Fläche B für die Varianten V2 (Kalk), V4 (Stockosorb®Kalk) und V6 (Superabsorber-Kalk) sowie auf Standorten mit Bodenvegetation für V4 (Stockosorb®-Kalk), V8 (Perlit-Kalk) und V12 (Mykorrhiza-Kalk).

\section{Ahorne insgesamt}

Bei Betrachtung der Ahorne insgesamt wiesen sechs der Behandlungsvarianten signifikant höhere Wurzelhalsdurchmesser als die unbehandelte Kontrolle (V1: 5,1 $\pm 1,1 \mathrm{~mm}$ ) auf (s. Abb. 145). Dabei handelte es sich um fünf Behandlungskombinationen mit Kalk-Düngung (V4: Stockosorb®-Kalk, V8: Perlit-Kalk, V10: Kompost-Kalk, V12: Mykorrhiza-Kalk, V14: MykorrhizaStockosorb®-Kalk) mit Mittelwerten zwischen 6,3 \pm 1,0 $\mathrm{mm}$ und 6,7 \pm 1,3/1,7 mm. In der sechsten, einzigen kalkfreien Variante dieser Gruppe, einer Kombination aus MykorrhizaImpfung und Superabsorber-Gabe (V15), wurde mit 7,1 $\pm 1,4 \mathrm{~mm}$ der höchste Wurzelhalsdurchmesser aller untersuchten Varianten ermittelt.

Von allen Varianten mit Kalk-Düngung waren die Wurzelhalsdurchmesser nur in der reinen Kalk-Variante (V2) sowie den beiden Behandlungskombinationen mit Superabsorber und Kalk (V6 ohne, V16 mit Mykorrhiza-Impfung) gegenüber der Kontrolle (V1) nicht signifikant höher.

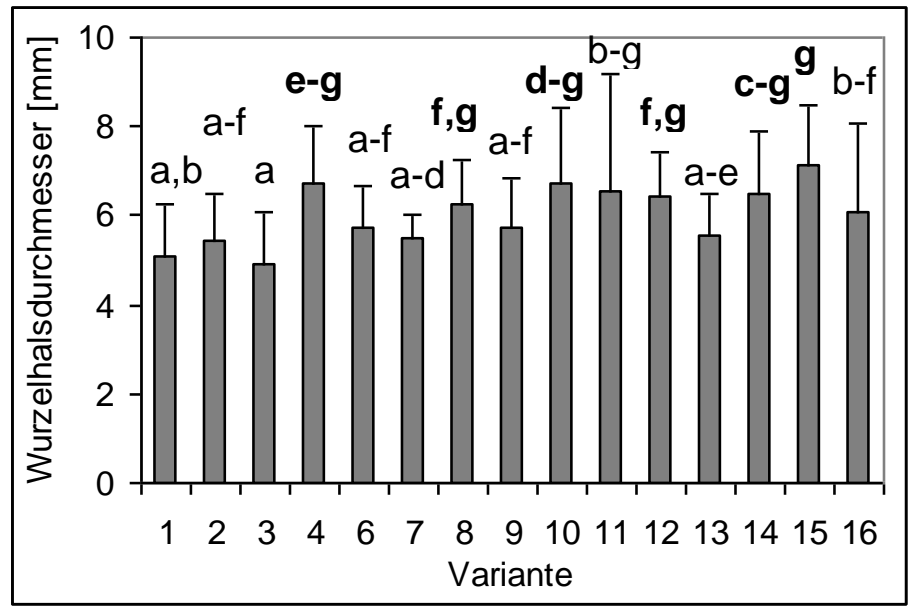

Abb. 145: Wurzelhalsdurchmesser [mm] der Ahorn-Varianten (s. S. 20) insgesamt; MW u. Std.abw.; Buchstaben kennzeichnen homogene Gruppen nach U-Tests; Fettdruck markiert signifikanten Unterschied zur Nullvariante (V1) $(n=123)$

Innerhalb der Mykorrhiza-Varianten wurde der geringste Wurzelhalsdurchmesser in Kombination mit Stockosorb® gemessen (V13: 5,6 ${ }^{\circ}$ 0,9 mm). Er unterschied sich signifikant von den Messwerten in der Mykorrhiza-Kalk-Variante (V12) sowie der zweiten MykorrhizaWasserspeichersubstanz-Kombination, V15 (Mykorrhiza-Superabsorber).

Im Gegensatz zu den meisten anderen Varianten (die mehrheitlich mit Kalk-Düngung bessere Ergebnisse aufwiesen) wurde in der kalkfreien Variante V15 nicht nur der Spitzenwert 
gemessen, in derselben Kombination mit Kalk-Düngung (V16: 6,1 \pm 2,0 $\mathrm{mm}$ ) lag der Wurzelhalsdurchmesser zudem signifikant unter dem Ergebnis ohne Kalk-Düngung (V15: 7,1 \pm $1,4 \mathrm{~mm})$.

\section{Ahorne auf Versuchsfläche B}

Anders als etwa beim Längenwachstum der Douglasien (s. ab S. 284) spielte bei den Ahornen auf Versuchsfläche B der individuelle Pflanzenstandort in besser versorgten (mit Spontanvegetation besiedelten) und schlechter versorgten (vegetationsfreien) Bereichen keine derart große Rolle für die Entwicklung der Wurzelhalsdurchmesser, dass sämtliche eventuell vorhandenen Einflüsse der Behandlungsvarianten überlagert wurden.

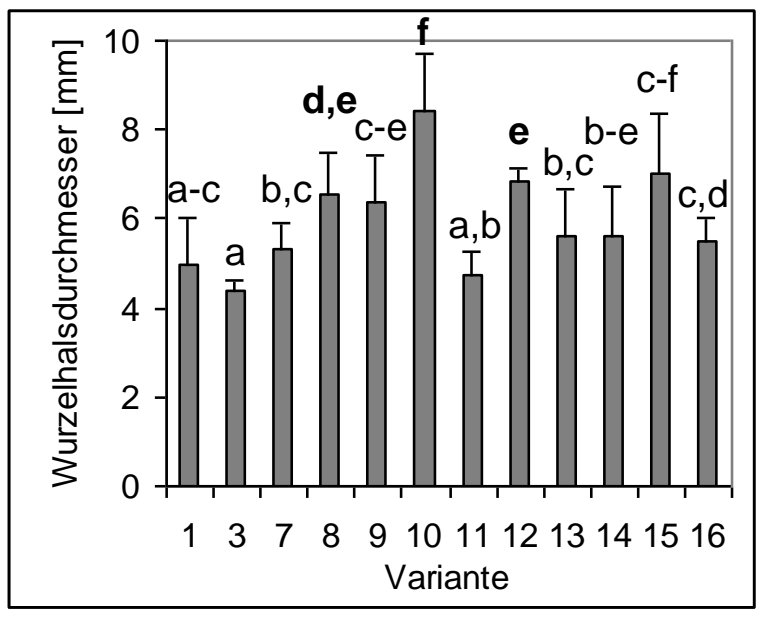

Abb. 146: Wurzelhalsdurchmesser [mm] der Ahorn-Varianten (s. S. 20) auf Fläche B; MW u. Std.abw.; Buchstaben kennzeichnen homogene Gruppen nach U-Tests; Fettdruck markiert signifikanten Unterschied zur Nullvariante (V1) (n=44)

Signifikant höhere Wurzelhalsdurchmesser gegenüber der unbehandelten Kontrolle (V1: 5,0 \pm 1,0 mm) wurden in den Varianten Perlit-Kalk (V8: 6,6 \pm 0,9 mm), Kompost-Kalk (V10: 8,5 $\pm 1,2$ $\mathrm{mm}$ ) und Mykorrhiza-Kalk (V12: 6,8 \pm 0,3 mm) ermittelt (s. Abb. 146). Dabei lag der Mittelwert bei den mit Kompost und Kalk gedüngten Ahornen (V10) signifikant um 29 \% bzw. 25 \% höher als in den anderen beiden Varianten (V8 u. V12).

Gegenüber der jeweils kalkfreien Perlit- (V7), Kompost- (V9) und Mykorrhiza-Variante (V11) wiesen die mit Kalk gedüngten Pendants V8, V10 und V12 signifikant höhere Wurzelhalsdurchmesser auf. Bei den Mykorrhiza-Wasserspeichersubstanz-Varianten (V13-V16) gab es dagegen keine signifikanten Unterschiede zwischen kalkfreien und gekalkten Behandlungskombinationen.

Innerhalb der Mykorrhiza-Varianten war der Wurzelhalsdurchmesser der zusätzlich mit Kalk gedüngten Ahorne (V12) signifikant höher als in der reinen Mykorrhiza-Variante (V11) oder in den Kombinationen aus Mykorrhiza und Stockosorb® (V13) sowie Mykorrhiza, Superabsorber und Kalk (V16). In der reinen Mykorrhiza-Variante (V11: 4,8 $\pm 0,5 \mathrm{~mm}$ ), in der gemeinsam mit der Kontrolle (V1: 5,0 \pm 1,0 mm) und der reinen Stockosorb®-Variante (V3: 4,4 \pm 0,3 mm) die insgesamt geringsten Mittelwerte gemessen wurden, lag der Wurzelhalsdurchmesser zudem signifikant unter denen in den Mykorrhiza-Superabsorber-Varianten (V15 u. V16). Auffällig war auch der signifikante Unterschied zwischen den mittleren Wurzelhalsdurchmessern der Ahorne in der reinen Stockosorb®-Variante (V3: 4,4 \pm 0,3 mm) und in der Mykorrhiza-Stockosorb®Variante (V13: 5,6 $\pm 1,0 \mathrm{~mm}$ ). 


\section{Ahorne in Bereichen mit Spontanvegetation}

In der Gruppe der Ahorne mit Standorten in bewachsenen Bereichen wurden die größten, als einzige gegenüber der unbehandelten Kontrolle (V1: 5,0 $\pm 1,0 \mathrm{~mm}$ ) signifikant unterschiedlichen Wurzelhalsdurchmesser in der Kompost-Kalk-Variante (V10: 7,4 \pm 2,0 mm) und in der Mykorrhiza-Superabsorber-Variante (V15: 7,3 \pm 1,6 $\mathrm{mm}$ ) gemessen. Zwischen den übrigen Varianten bestanden kaum signifikante Unterschiede (s. Abb. 147).

Innerhalb der mit Mykorrhiza beimpften Varianten fällt der signifikant unterschiedliche Zuwachs zwischen den kalkfreien Mykorrhiza-Wasserspeichersubstanz-Kombinationen auf: Mit Superabsorber (V15: 7,3 \pm 1,6 mm) wurden durchschnittlich signifikant höhere Wurzelhalsdurchmesser ermittelt als mit Stockosorb® (V13: 5,6 \pm 0,9 mm). Zudem war der Wurzelhalsdurchmesser in der kalkfreien Mykorrhiza-Superabsorber-Kombination (V15) signifikant höher als in der gekalkten Version dieser Behandlung (V16).

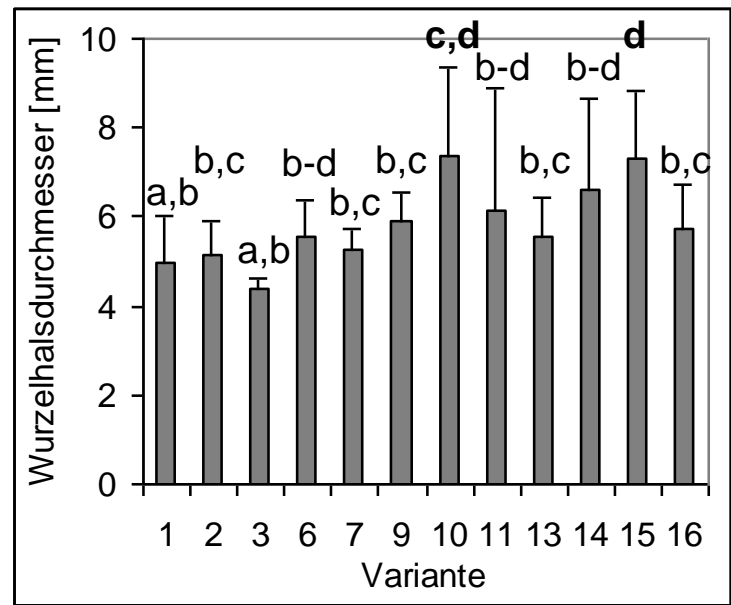

Abb. 147: Wurzelhalsdurchmesser [mm] der Ahorn-Varianten (s. S. 20) in Bereichen mit Spontanvegetation; MW u. Std.abw.; Buchstaben kennzeichnen homogene Gruppen nach U-Tests; Fettdruck markiert signifikanten Unterschied zur Nullvariante (V1) $(n=56)$

\subsubsection{Eberesche}

Im Falle der Ebereschen wurden lediglich im 2. Untersuchungsjahr (2006) zwischen den auf Versuchsfläche D untersuchten Behandlungsvarianten signifikant unterschiedliche HaupttriebsZuwächse festgestellt.

\section{Ebereschen auf Versuchsfläche D}

Bei den Ebereschen auf Versuchsfläche D ließ sich im 2. Untersuchungsjahr ein positiver Einfluss der Kompost-Kalk-Düngung (V10) auf ihren Zuwachs nachweisen (s. Tab. 71). Dabei konnten aufgrund von Pflanzenausfällen und -schädigungen durch Wild die Hälfte der ursprünglich zehn Behandlungsvarianten nicht beprobt werden, darunter auch die unbehandelte Kontrolle (V1). 
Tab. 71: Zuwachs [cm] des Haupttriebs (HT) der Ebereschen-Varianten (s. S. 20) im 2. Vegetationsjahr auf Fläche D; MW u. Std.abw.; Ergebnis des H-Tests auf signifikante Unterschiede; Buchstaben kennzeichnen homogene Gruppen nach U-Tests

\begin{tabular}{|l|l|}
\hline & Zuwachs HT 2006 [cm] \\
\hline V1 & - \\
\hline V2 & $6,3 \pm 6,5(\mathrm{n}=3) \mathrm{a}$ \\
\hline V3 & - \\
\hline V4 & - \\
\hline V5 & - \\
\hline V6 & $6,3 \pm 8,5(\mathrm{n}=3) \mathrm{a}$ \\
\hline V7 & $10,3 \pm 5,9(\mathrm{n}=4) \mathrm{a}$ \\
\hline V8 & - \\
\hline V9 & $12,5 \pm 9,7(\mathrm{n}=4) \mathrm{a}$ \\
\hline V10 & $25,3 \pm 3,4(\mathrm{n}=4) \mathrm{b}$ \\
\hline H & $9,70^{*}$ \\
\hline & $\mathrm{N}=18$ \\
\hline
\end{tabular}

- zu geringe Zahl (<3) überlebender, nicht (durch Wild) geschädigter Versuchspflanzen

In der Kompost-Kalk-Variante (V10) lag der Zuwachs bei 25,3 $\pm 3,4 \mathrm{~cm}$ und damit deutlich höher als in den übrigen untersuchten Varianten, die höchstens halb so große Zuwächse (zwischen 6,3 \pm 8,5 cm und 12,5 \pm 9,7 cm) aufwiesen. Auch der Zuwachs in der kalkfreien Kompost-Variante (V9) war signifikant geringer (s. Abb. 148).

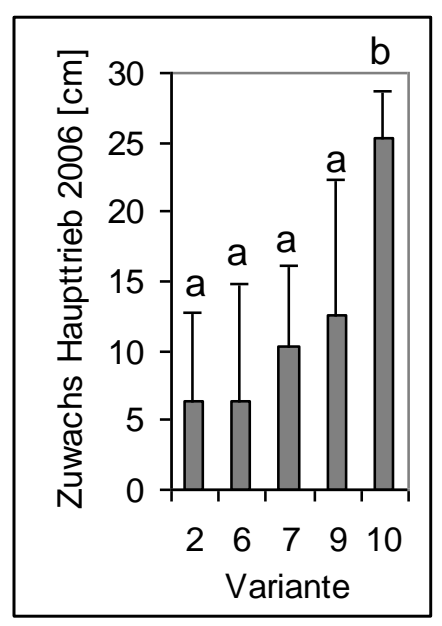

Abb. 148: Zuwachs [cm] des Haupttriebs von Ebereschen-Varianten (s. S. 20) im 2. Vegetationsjahr auf Fläche D; MW u. Std.abw.; Buchstaben kennzeichnen homogene Gruppen nach U-Tests ( $n=18)$

\subsubsection{Douglasie}

Im Falle der Douglasien konnten im 1. Versuchsjahr (2005) zwischen verschiedenen der 16 Behandlungsvarianten signifikante Unterschiede beim Zuwachs des Haupttriebs festgestellt werden (im 2. Jahr nicht mehr). Dies galt nicht nur für die Gesamtheit aller Douglasien, sondern auch bei Betrachtung nur der Douglasien mit Standorten auf Versuchsfläche A oder B sowie in Bereichen ohne oder mit Spontanvegetation (s. Tab. 72). Je nach Standort war der Effekt der 
Behandlungsvarianten teilweise recht unterschiedlich, was einmal mehr auf den Einfluss der jeweiligen Standortbedingungen hinweist.

Tab. 72: Zuwachs [cm] des Haupttriebs der Douglasien-Varianten (s. S. 20) im 1. Vegetationsjahr, insgesamt sowie nach Standorten getrennt; MW u. Std.abw.; Ergebnisse von H-Tests $[\mathrm{H}]$ auf signifikante Unterschiede; Buchstaben kennzeichnen je Spalte homogene Gruppen nach U-Tests

\begin{tabular}{|c|c|c|c|c|c|}
\hline & \multicolumn{5}{|c|}{ Zuwachs des Haupttriebs 2005 [cm] der Douglasien } \\
\hline & insgesamt & auf Fläche A & auf Fläche B & $\begin{array}{l}\text { auf Standorten ohne } \\
\text { Spontanvegetation }\end{array}$ & $\begin{array}{l}\text { auf Standorten mit } \\
\text { Spontanvegetation }\end{array}$ \\
\hline V1 & $\begin{array}{l}9,2 \pm 2,8 \\
(n=5) g\end{array}$ & $\begin{array}{l}0,7 \pm 1,2 \\
(\mathrm{n}=3) \mathrm{a}, \mathrm{b}\end{array}$ & $\begin{array}{l}10,0 \pm 2,4 \\
(\mathrm{n}=4) \mathrm{g}\end{array}$ & $\begin{array}{l}3,3 \pm 3,3 \\
(\mathrm{n}=6) \mathrm{a}-\mathrm{g}\end{array}$ & $\begin{array}{l}10,0 \pm 2,4 \\
(n=4) f\end{array}$ \\
\hline V2 & $\begin{array}{l}5,3 \pm 2,3 \\
(n=8) \text { e-f }\end{array}$ & $\begin{array}{l}5,7 \pm 1,2 \\
(n=3) g\end{array}$ & $\begin{array}{l}4,0 \pm 3,2 \\
(n=4) \text { a-f }\end{array}$ & $\begin{array}{l}3,9 \pm 2,6 \\
(n=8) f, g\end{array}$ & $\begin{array}{l}6,3 \pm 1,2 \\
(n=3) c-e\end{array}$ \\
\hline V3 & $\begin{array}{l}7,0 \pm 1,2 \\
(n=4) f, g\end{array}$ & |- & $\begin{array}{l}7,0 \pm 1,2 \\
(n=4) f\end{array}$ & $\begin{array}{l}1,3 \pm 1,3 \\
(n=4) a\end{array}$ & $\begin{array}{l}7,0 \pm 1,2 \\
(n=4) d\end{array}$ \\
\hline V4 & $\begin{array}{l}3,3 \pm 1,8 \\
(\mathrm{n}=8) \mathrm{a}-\mathrm{d}\end{array}$ & $\begin{array}{l}3,3 \pm 2,1 \\
(\mathrm{n}=3) \text { b-g }\end{array}$ & $\begin{array}{l}2,0 \pm 2,2 \\
(n=4) a-d\end{array}$ & $\begin{array}{l}2,6 \pm 1,8 \\
(n=9) b-f\end{array}$ & - \\
\hline V5 & $\begin{array}{l}3,1 \pm 1,9 \\
(n=7) a-d\end{array}$ & $\begin{array}{l}1,3 \pm 2,3 \\
(n=3) \text { a-d }\end{array}$ & $\begin{array}{l}4,0 \pm 1,4 \\
(n=4) b-e\end{array}$ & $\begin{array}{l}1,6 \pm 1,7 \\
(n=5) a, b\end{array}$ & $\begin{array}{l}3,2 \pm 2,2 \\
(n=5) a, b\end{array}$ \\
\hline V6 & $\begin{array}{l}, 0 \pm 1,2 \\
(\mathrm{n}=8) \mathrm{a}-\mathrm{c}\end{array}$ & $\begin{array}{l}2,3 \pm 0,5 \\
(\mathrm{n}=4) \mathrm{c}\end{array}$ & $\begin{array}{l}3,0 \pm 1,0 \\
(n=3) a-c\end{array}$ & $\begin{array}{l}2,6 \pm 0,9 \\
(n=8) c-f\end{array}$ & $\begin{array}{l}4,0 \pm 1,0 \\
(n=3) a, b\end{array}$ \\
\hline V7 & $\begin{array}{l}6,6 \pm 4,0 \\
(\mathrm{n}=5) \mathrm{c}-\mathrm{g}\end{array}$ & $\begin{array}{l}0,7 \pm 1,2 \\
(\mathrm{n}=3) \mathrm{a}, \mathrm{b}\end{array}$ & $\begin{array}{l}7,5 \pm 4,0 \\
(\mathrm{n}=4) \mathrm{c}-\mathrm{g}\end{array}$ & $\begin{array}{l}1,0 \pm 1,0 \\
(n=5) a\end{array}$ & $\begin{array}{l}6,6 \pm 4,0 \\
(n=5) \text { a-f }\end{array}$ \\
\hline V8 & $\begin{array}{l}3,1 \pm 1,1 \\
(\mathrm{n}=7) \mathrm{a}-\mathrm{c}\end{array}$ & $\begin{array}{l}1,7 \pm 1,5 \\
(\mathrm{n}=3) \mathrm{a}-\mathrm{c}\end{array}$ & $\begin{array}{l}2,0 \pm 0,8 \\
(n=4) a\end{array}$ & $\begin{array}{l}2,1 \pm 1,8 \\
(n=8) a-e\end{array}$ & $\begin{array}{l}2,7 \pm 0,6 \\
(n=3) a\end{array}$ \\
\hline V9 & $\begin{array}{l}6,1 \pm 2,6 \\
(n=7) \text { e,f }\end{array}$ & |- & $\begin{array}{l}6,5 \pm 3,4 \\
(n=4) c-g\end{array}$ & $\begin{array}{l}2,3 \pm 1,7 \\
(n=4) \text { a-e }\end{array}$ & $\begin{array}{l}7,2 \pm 2,3 \\
(n=5) e\end{array}$ \\
\hline V10 & $\begin{array}{l}5,3 \pm 2,1 \\
(n=9) \text { e,f }\end{array}$ & $\begin{array}{l}5,3 \pm 1,9 \\
(n=4) f, g\end{array}$ & $\begin{array}{l}6,0 \pm 2,2 \\
(n=4) c-f\end{array}$ & $\begin{array}{l}4,7 \pm 2,0 \\
(n=6) g\end{array}$ & $\begin{array}{l}6,0 \pm 2,2 \\
(n=4) b-e\end{array}$ \\
\hline V11 & $\begin{array}{l}3,7 \pm 2,9 \\
(\mathrm{n}=7) \mathrm{a}-\mathrm{f}\end{array}$ & $\begin{array}{l}0,3 \pm 0,6 \\
(n=3) a\end{array}$ & $\begin{array}{l}6,3 \pm 2,1 \\
(n=3) e, f\end{array}$ & $\begin{array}{l}1,0 \pm 1,4 \\
(n=4) a\end{array}$ & $\begin{array}{l}5,5 \pm 2,4 \\
(n=4) b-e\end{array}$ \\
\hline V12 & $\begin{array}{l}4,3 \pm 1,2 \\
(n=6) d, e\end{array}$ & $\begin{array}{l}4,0 \pm 1,4 \\
(n=4) \text { e-g }\end{array}$ & $\begin{array}{l}4,8 \pm 1,0 \\
(n=4) d, e\end{array}$ & $\begin{array}{l}4,1 \pm 1,1 \\
(n=7) d-g\end{array}$ & $\begin{array}{l}4,7 \pm 1,5 \\
(n=3) \text { a-c }\end{array}$ \\
\hline V13 & $\begin{array}{l}5,9 \pm 5,6 \\
(n=9) b-f\end{array}$ & $\begin{array}{l}2,7 \pm 0,6 \\
(\mathrm{n}=3) \mathrm{c}-\mathrm{e}\end{array}$ & $\begin{array}{l}3,3 \pm 3,5 \\
(n=3) \text { a-f }\end{array}$ & $\begin{array}{l}3,5 \pm 1,7 \\
(n=4) \text { e-g }\end{array}$ & $\begin{array}{l}7,8 \pm 7,0 \\
(n=5) b-f\end{array}$ \\
\hline V14 & $\begin{array}{l}4,4 \pm 2,6 \\
(n=9) \text { b-e }\end{array}$ & $\begin{array}{l}3,5 \pm 0,6 \\
(n=4) d, e\end{array}$ & $\begin{array}{l}4,8 \pm 2,4 \\
(n=4) b-f\end{array}$ & $\begin{array}{l}3,6 \pm 2,4 \\
(n=7) c-g\end{array}$ & $\begin{array}{l}5,5 \pm 2,1 \\
(n=4) b-e\end{array}$ \\
\hline V15 & $\begin{array}{l}2,6 \pm 3,3 \\
(\mathrm{n}=10) \mathrm{a}\end{array}$ & $\begin{array}{l}1,3 \pm 1,5 \\
(n=4) a-c\end{array}$ & $\begin{array}{l}5,5 \pm 3,8 \\
(n=4) b-g\end{array}$ & $\begin{array}{l}1,6 \pm 1,5 \\
(n=5) a-c\end{array}$ & $\begin{array}{l}3,6 \pm 4,5 \\
(n=5) \text { a-d }\end{array}$ \\
\hline V16 & $\begin{array}{l}2,8 \pm 2,2 \\
(\mathrm{n}=8) \mathrm{a}-\mathrm{d}\end{array}$ & $\begin{array}{l}1,8 \pm 2,4 \\
(\mathrm{n}=4) \mathrm{a}-\mathrm{f}\end{array}$ & $\begin{array}{l}3,0 \pm 1,0 \\
(n=3) a-c\end{array}$ & $\begin{array}{l}1,8 \pm 1,8 \\
(n=6) \text { a-f }\end{array}$ & $\begin{array}{l}3,3 \pm 2,5 \\
(n=4) a, b\end{array}$ \\
\hline $\mathrm{H}$ & $38,85^{* * *}$ & $29,83^{* *}$ & $29,71^{*}$ & $28,05^{*}$ & $24,38^{*}$ \\
\hline & $\mathrm{N}=117$ & $\mathrm{~N}=48$ & $\mathrm{~N}=60$ & $\mathrm{~N}=96$ & $\mathrm{~N}=61$ \\
\hline
\end{tabular}

- zu geringe Zahl $(<3)$ überlebender, nicht (durch Wild) geschädigter Versuchspflanzen

\section{Douglasien insgesamt}

Die mittleren Zuwächse der Haupttriebe der Douglasien im 1. Untersuchungsjahr (s. Abb. 149) wiesen größtenteils hohe Standardabweichungen auf, was eine Einteilung in homogene Gruppen erschwerte. Der mit 9,2 $\pm 2,8 \mathrm{~cm}$ höchste mittlere Zuwachs wurde bei den unbehandelten Kontrollbäumen (V1) gemessen, was auf die sehr gute Kontrolle (Vitalitätsmittelwert „4“) auf 
Fläche B zurückzuführen ist, die dort zufällig komplett im mit Spontanvegetation besiedelten, besser versorgten Bereich stand. Mit Ausnahme der Stockosorb®- (V3) und der Perlit-Variante (V7), die jedoch in direkter Nachbarschaft zur Nullvariante standen und ebenso von den vergleichsweise guten Standortbedingungen profitierten, wiesen alle Behandlungsvarianten signifikant geringere Zuwächse als die Nullvariante (V1) auf. Dabei waren die Zuwächse bei den mit Kalk (V2) und/oder Kompost (V9, V10) gedüngten Bäumen mit im Mittel 5-6 cm signifikant höher als in den gekalkten Stockosorb®- (V4), Perlit- (V8) und Superabsorber-Behandlungen (V6) sowie - trotz der räumlichen Nähe zur Kontrolle - in der reinen Superabsorber-Variante (V5) mit rund $3 \mathrm{~cm}$. Innerhalb der Mykorrhiza-Varianten war der Zuwachs in Kombination mit Superabsorber (V15) signifikant geringer als in Kombination mit Kalk und/oder Stockosorb® (V12 - V14).

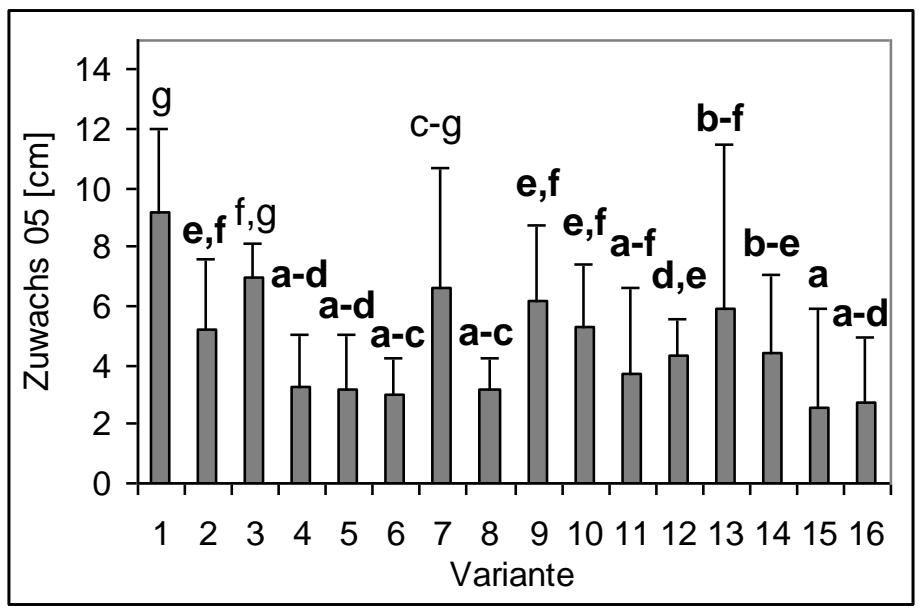

Abb. 149: Zuwachs [cm] des Haupttriebs der Douglasien-Varianten (s. S. 20) im 1. Vegetationsjahr insgesamt; MW u. Std.abw.; Buchstaben kennzeichnen homogene Gruppen nach U-Tests, Fettdruck markiert signifikanten Unterschied zur Nullvariante (V1) (n=117)

\section{Douglasien auf Versuchsfläche $A$}

Bei den Douglasien auf Versuchsfläche A wurden im Jahr der Pflanzung (2005) die höchsten Zuwächse in der Kalk- (V2: 5,7 $\pm 1,2 \mathrm{~cm}$ ) und der Kompost-Kalk-Variante (V10: 5,3 $\pm 1,9 \mathrm{~cm}$ ) gemessen (s. Abb. 150).

Neben diesen beiden wiesen auch die Superabsorber-Kalk-Variante (V6: 2,3 \pm 0,5 cm) sowie die drei Mykorrhiza-Varianten V12 (Mykorrhiza-Kalk: 4,0 \pm 1,4 cm), V13 (Mykorrhiza-Stockosorb®: 2,7 $\pm 0,6 \mathrm{~cm}$ ) und V14 (Mykorrhiza-Stockosorb®-Kalk: 3,5 $\pm 0,6 \mathrm{~cm}$ ) signifikant höhere Zuwächse als die unbehandelte Kontrolle (V1) mit lediglich 0,7 $\pm 1,2 \mathrm{~cm}$ auf. Dabei unterschied sich nur der Zuwachs in der Mykorrhiza-Kalk-Variante (V12) nicht signifikant von den beiden Spitzenwerten.

Der Zuwachs der Douglasien in der reinen Mykorrhiza-Variante (V11) lag mit nur 0,3 $\pm 0,6 \mathrm{~cm}$ signifikant unter den Messwerten in drei der fünf übrigen, in Kombination mit verschiedenen Bodenhilfsstoffen gepflanzten Mykorrhiza-Varianten. 


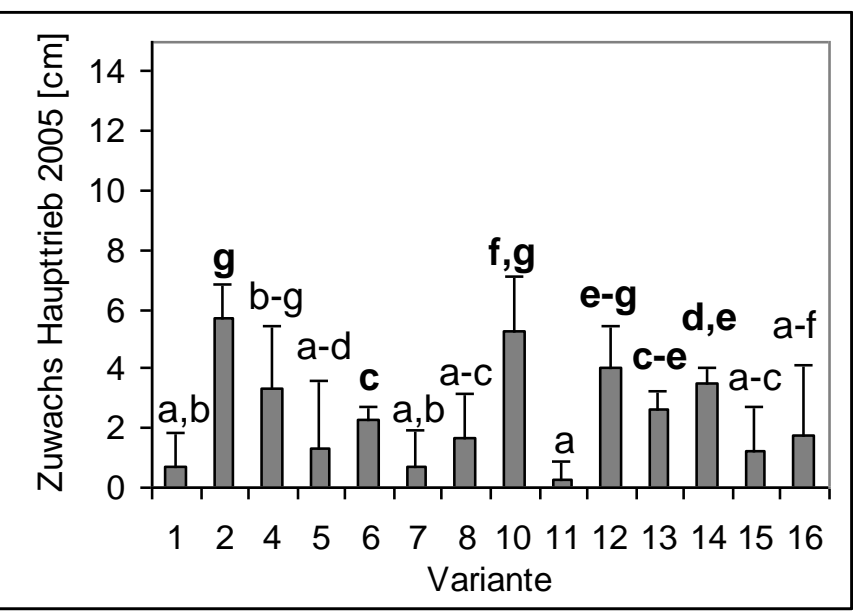

Abb. 150: Zuwachs [cm] des Haupttriebs der Douglasien-Varianten (s. S. 20) im 1. Vegetationsjahr auf Fläche A; MW u. Std.abw.; Buchstaben kennzeichnen homogene Gruppen nach U-Tests, Fettdruck markiert signifikanten Unterschied zur Nullvariante (V1) (n=48)

Die Kombination aus Mykorrhiza und der Wasserspeichersubstanz Superabsorber (V15) wies einen signifikant geringeren Zuwachs als V12 (Mykorrhiza-Kalk) und V14 (MykorrhizaStockosorb®-Kalk) auf. Dagegen unterschied sich der Zuwachs in V15 nicht signifikant von dem in der Kombination aus Mykorrhiza und der Wasserspeichersubstanz Stockosorb® (V13) gemessenen Zuwachs. Auch zur gekalkten Variante V16 (Mykorrhiza-Superabsorber-Kalk) bestand kein signifikanter Zuwachs-Unterschied.

Die einzige kalkfreie Variante, in der ein gegenüber der Kontrolle signifikant höherer Zuwachs ermittelt wurde, war die Kombination aus Mykorrhiza und Stockosorb® (V13).

\section{Douglasien auf Versuchsfläche B}

Auf Versuchsfläche B spielte der individuelle Pflanzenstandort in besser versorgten (mit Spontanvegetation besiedelten) und schlechter versorgten, zeitweise vernässten (vegetationsfreien) Bereichen eine große Rolle für die Vitalitäts- und Wachstumsentwicklung der Versuchspflanzen. Vor dem Hintergrund, dass auf dieser Fläche zufällig ein überwiegender Teil der kalkfreien Varianten in Bereiche mit, ein großer Teil der gekalkten Varianten dagegen in Bereiche ohne späteren Bodenbewuchs gepflanzt wurde (s. Abb. 4, S. 37), sind die im 1. Vegetationsjahr noch signifikanten Zuwachsunterschiede zwischen einzelnen Varianten (s. Abb. 151) schlecht interpretierbar.

So wurde der mit 10,0 $\pm 2,4 \mathrm{~cm}$ höchste Zuwachs im ersten Standjahr (2005) in der unbehandelten Kontrolle (V1) gemessen. Mit Ausnahme der Perlit- (V7), der Kompost- (V9) und der Mykorrhiza-Superabsorber-Variante (V15) war der Zuwachs in allen übrigen Varianten signifikant geringer. Innerhalb der Mykorrhiza-Varianten fiel der signifikant geringere Zuwachs in der Kombination Mykorrhiza-Superabsorber-Kalk (V16: 3,0 \pm 1,0 cm) gegenüber den ohne Zugabe von Wasserspeichersubstanzen angelegten Varianten Mykorrhiza (V11: 6,3 $\pm 2,1 \mathrm{~cm}$ ) und Mykorrhiza-Kalk (V12: 4,8 $\pm 1,0 \mathrm{~cm})$ auf. 


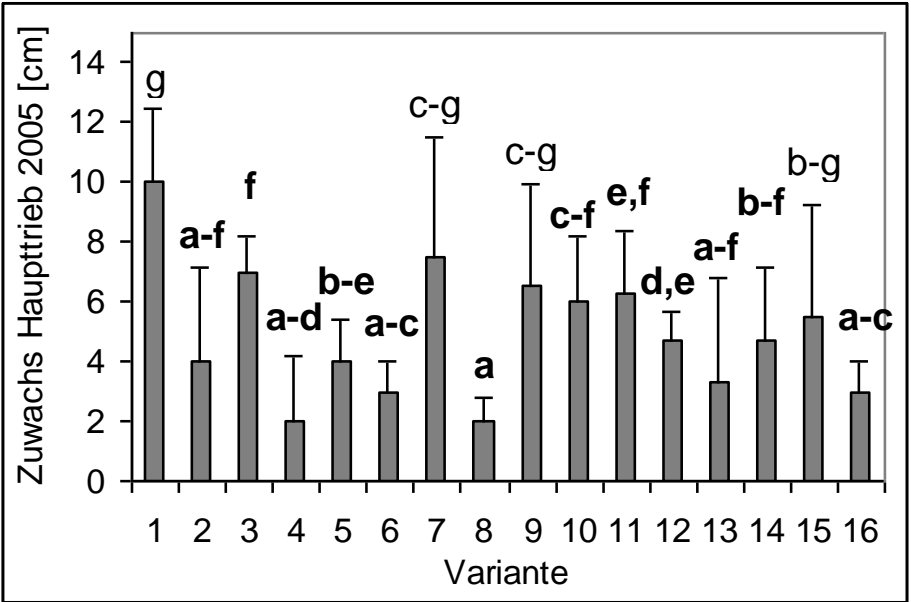

Abb. 151: Zuwachs [cm] des Haupttriebs der Douglasien-Varianten (s. S. 20) im 1. Vegetationsjahr auf Fläche B; MW u. Std.abw.; Buchstaben kennzeichnen homogene Gruppen nach U-Tests; Fettdruck markiert signifikanten Unterschied zur Nullvariante (V1) (n=60)

\section{Douglasien auf Versuchsfläche D}

Der in der ersten Vegetationszeit nach der Pflanzung erreichte Haupttriebs-Zuwachs der Douglasien auf Versuchsfläche D lag mit durchschnittlich 4,2 $\pm 3,4 \mathrm{~cm}$ zwischen dem niedrigeren Mittelwert auf Fläche A $(3,0 \pm 2,0 \mathrm{~cm})$ und dem höheren $(5,7 \pm 2,9 \mathrm{~cm})$ auf Fläche B. Im Gegensatz zu diesen beiden Flächen bestanden auf Fläche D keine nachweisbaren Zuwachsunterschiede zwischen den verschiedenen Varianten.

\section{Douglasien in Bereichen ohne Spontanvegetation}

Die Betrachtung aller Douglasien auf Standorten mit schlechteren Wuchsbedingungen (ohne Bodenvegetation) ergab keine gegenüber der unbehandelten Kontrolle (V1: 3,3 $\pm 3,3 \mathrm{~cm}$ ) signifikant höheren oder geringeren Zuwächse im 1. Untersuchungsjahr (2005).

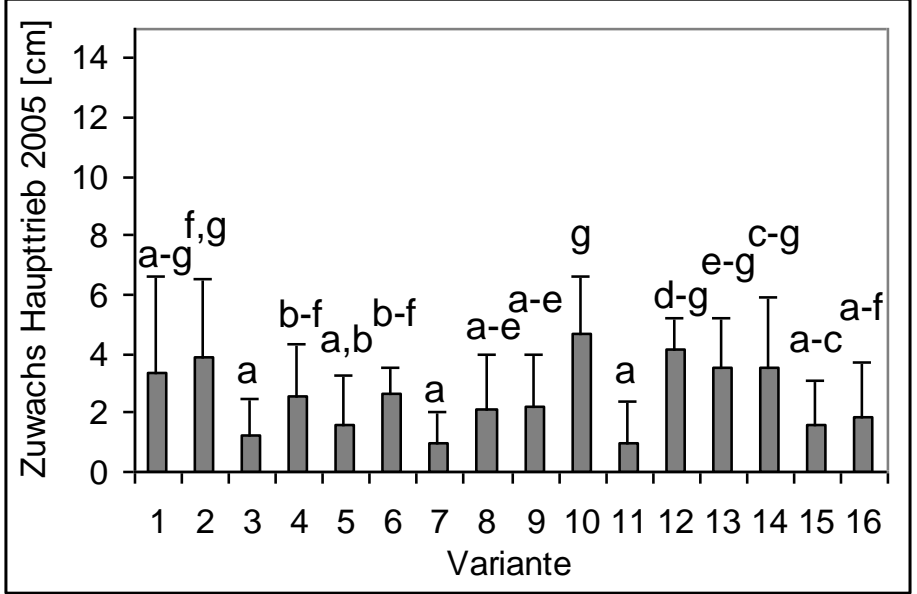

Abb. 152: Zuwachs [cm] des Haupttriebs der Douglasien-Varianten (s. S. 20) im 1. Vegetationsjahr in Bereichen ohne Spontanvegetation; MW u. Std.abw.; Buchstaben kennzeichnen homogene Gruppen nach U-Tests (n=96) 
Bei den meisten Bodenhilfsstoff-Kombinationen auf diesen Standorten, die einen geringeren pHWert in der Bodenlösung als die mit Spontanvegetation besiedelten aufwiesen, fielen jedoch (signifikant) geringere Zuwächse in den jeweils kalkfreien Varianten auf (s. Abb. 152).

Für den Zuwachs des Haupttriebs der Douglasien auf unbewachsenen Standorten spielte somit zum einen die Kalk-Gabe eine große Rolle, wobei in Kombination mit Kompost (V10: 4,7 \pm 2,0 $\mathrm{cm}$ ) bessere Ergebnisse ermittelt wurden als in Kombination mit Perlit (V8: 2,1 $\pm 1,8 \mathrm{~cm}$ ) oder Wasserspeichersubstanzen (V4: 2,6 \pm 1,8 cm, V6: 2,6 \pm 0,9 cm). Auch lag der Zuwachs in der reinen Kalk-Variante (V2: 3,9 $\pm 2,6 \mathrm{~cm}$ ) signifikant höher als in der Kombination mit Perlit (V8).

Zum anderen wurden in den Varianten mit einer durch Kalk und/oder Stockosorb ${ }^{\circledR}$ unterstützen Mykorrhiza-Impfung (V12-V14) vergleichsweise höhere Zuwächse ermittelt.

In der reinen Mykorrhiza-Variante (V11) war der Zuwachs signifikant geringer als in diesen drei Varianten. Der Zuwachs in der kalkfreien Kombination aus Mykorrhiza und Superabsorber (V15) lag signifikant unter den mehr als doppelt so hohen Zuwächsen in der kalkfreien Mykorrhiza-Stockosorb®- (V13) sowie der gekalkten Mykorrhiza-Variante (V12).

\section{Douglasien in Bereichen mit Spontanvegetation}

Werden die Ergebnisse der Zuwachsmessungen aller Douglasien mit Standorten in Bereichen mit besseren Wuchsbedingungen (Bereiche mit Bodenvegetation) zusammengefasst, so entfällt auch in dieser Gruppe der höchste Zuwachs im Anlagejahr (2005) auf die unbehandelte Kontrolle (V1: 10,0 $\pm 2,4 \mathrm{~cm}$ ), die der Kontrolle auf Fläche B entspricht (auf Fläche D befand sich die Kontrolle in einem vegetationsfreien Bereich, auf Fläche A konnte sich überhaupt keine Spontanvegetation ansiedeln).

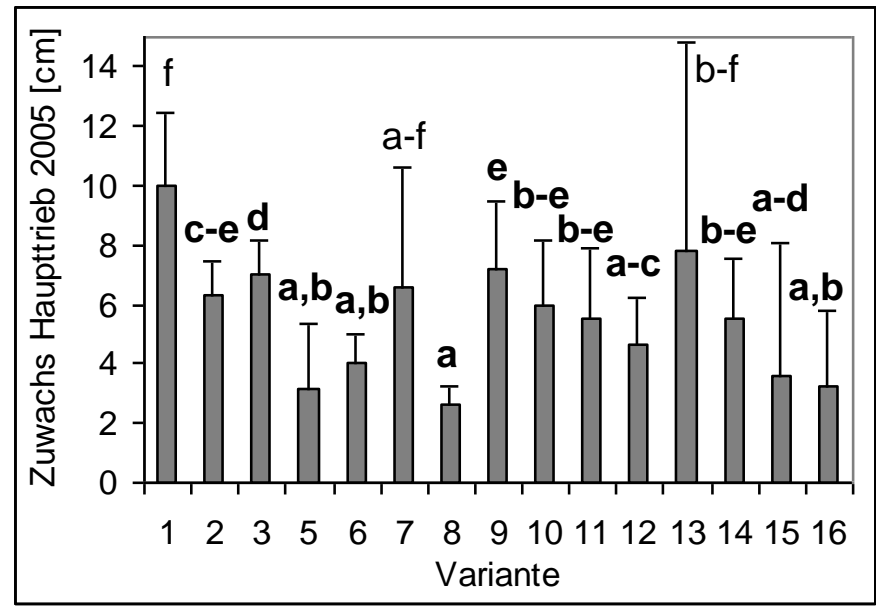

Abb. 153: Zuwachs [cm] des Haupttriebs der Douglasien-Varianten (s. S. 20) im 1. Vegetationsjahr in Bereichen mit Spontanvegetation; MW u. Std.abw.; Buchstaben kennzeichnen homogene Gruppen nach UTests; Fettdruck markiert signifikanten Unterschied zur Nullvariante (V1) (n=61)

Mit Ausnahme der Perlit- (V7) und der Mykorrhiza-Stockosorb®-Variante (V13) war der Zuwachs in allen übrigen Varianten signifikant geringer (s. Abb. 153). Im Gegensatz zu den Ergebnissen auf Standorten mit schlechteren Wuchsbedingungen (Bereiche ohne Bodenvegetation) spielte hier die Kalk-Gabe keine offensichtliche Rolle bei der Höhe des Zuwachses in den verschiedenen Varianten.

In der Kompost-Variante (V9: 7,2 $\pm 2,3 \mathrm{~cm}$ ) lag der Zuwachs signifikant höher als bei der Hälfte der übrigen Varianten (V3, 5, 6, 8, 12, 15, 16). Den niedrigsten Mittelwert wiesen die Douglasien 
in der Kombination Perlit-Kalk (V8: 2,7 \pm 0,6 cm) auf, gefolgt von den Superabsorber-Varianten mit durchschnittlichen Zuwächsen zwischen 3 und $4 \mathrm{~cm}$.

Innerhalb der Mykorrhiza-Varianten bestanden keine signifikanten Zuwachsunterschiede.

\section{Bei Versuchsabschluss geerntete Douglasien}

Bei Versuchsabschluss waren 35 der insgesamt 192 Douglasien geerntet, getrocknet und - in die Fraktionen Haupttrieb, Seitentriebe, Nadeln sowie Wurzel zerlegt - gewogen worden. Da diese Proben vordringlich zur Mykorrhiza-Untersuchung (s. S. 28) genommen wurden, handelte es sich dabei ausschließlich um Douglasien der Mykorrhiza-Varianten (V11-V16). Die Beprobung erlaubte auch die Untersuchung zusätzlicher Wachstumsparameter hinsichtlich eines Einflusses der verschiedenen Behandlungskombinationen mit Mykorrhiza auf die Wuchsentwicklung. Dabei wurden signifikante Unterschiede der Trockenmasse der Seitentriebe sowie der Wurzelhalsdurchmesser zwischen den insgesamt sechs Behandlungsvarianten festgestellt (s. Tab. 73).

Tab. 73: Trockenmasse der Seitentriebe [g] und Wurzelhalsdurchmesser [mm] der geernteten DouglasienVarianten (s. S. 20); MW u. Std.abw.; Ergebnisse von H-Tests [H] auf signifikante Unterschiede; Buchstaben kennzeichnen je Spalte homogene Gruppen nach U-Tests

\begin{tabular}{|l|l|l|}
\hline Variante & $\begin{array}{l}\text { Trockenmasse } \\
\text { Seitentriebe }[\mathrm{g}]\end{array}$ & $\begin{array}{l}\text { Wurzelhals- } \\
\text { durchmesser [mm] }\end{array}$ \\
\hline V11 & $1,8 \pm 0,9$ & $6,1 \pm 0,9$ \\
$\mathrm{n}=6$ & $\mathrm{a}$ & $\mathrm{a}, \mathrm{b}$ \\
\hline V12 & $3,7 \pm 2,0$ & $8,1 \pm 2,5$ \\
$\mathrm{n}=6$ & $\mathrm{~b}$ & $\mathrm{~b}, \mathrm{c}$ \\
\hline V13 & $4,9 \pm 3,2$ & $8,6 \pm 3,0$ \\
$\mathrm{n}=6$ & $\mathrm{~b}$ & $\mathrm{c}$ \\
\hline V14 & $5,3 \pm 5,4$ & $8,3 \pm 2,0$ \\
$\mathrm{n}=6$ & $\mathrm{~b}$ & $\mathrm{c}$ \\
\hline V15 & $2,1 \pm 1,1$ & $5,7 \pm 0,9$ \\
$\mathrm{n}=5$ & $\mathrm{a}, \mathrm{b}$ & $\mathrm{a}$ \\
\hline V16 & $1,3 \pm 0,5$ & $5,9 \pm 1,1$ \\
$\mathrm{n}=5$ & $\mathrm{a}$ & $\mathrm{a}$ \\
\hline H-Tests & $12,78^{*}$ & $11,31^{*}$ \\
\hline
\end{tabular}

Die Trockenmassen der Seitentriebe sowie die Wurzelhalsdurchmesser der Douglasien (s. Abb. 154), die bei der Pflanzung neben der Mykorrhiza-Impfung Superabsorber- (V15) bzw. Superabsorber- und Kalk-Gaben (V16) erhielten, unterschieden sich nicht signifikant von den Werten in Variante V11 (Mykorrhiza-Impfung ohne weitere Bodenhilfsstoffgaben). Dies galt auch für den mittleren Wurzelhalsdurchmesser in Variante V12 (Mykorrhiza-Impfung mit KalkGabe), nicht jedoch für die mittlere Trockenmasse der Seitentriebe in dieser Variante, die mit 3,7 $\pm 2,0$ g signifikant über der in Variante V11 mit 1,8 $\pm 0,9 \mathrm{~g}$ lag und somit etwa das Doppelte betrug. Ebenfalls signifikant höher als bei alleiniger Mykorrhiza-Impfung (V11) lagen sowohl die Trockenmassen der Seitentriebe als auch die Wurzelhalsdurchmesser der zusätzlich mit Stockosorb® (V13) bzw. mit Stockosorb® und Kalk (V14) gepflanzten Douglasien. 

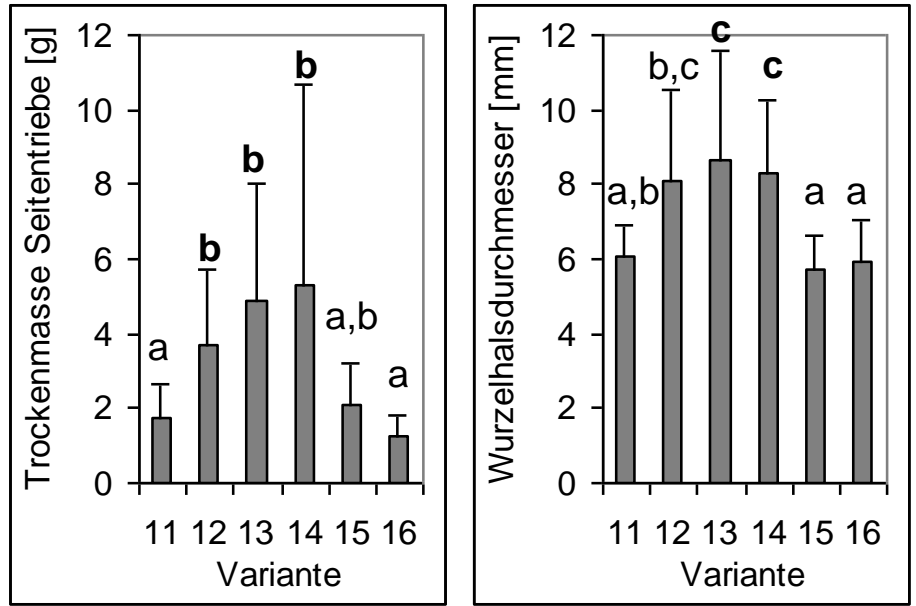

Abb. 154: Trockenmasse der Seitentriebe [g] (links) und Wurzelhalsdurchmesser [mm] (rechts) der geernteten Douglasien-Varianten (s. S. 20); MW u. Std.abw.; Buchstaben kennzeichnen jeweils homogene Gruppen nach U-Tests; Fettdruck markiert signifikanten Unterschied zur reinen Mykorrhiza-Variante V11 $(n=34)$

\subsubsection{Wald-Kiefer}

Im Falle der Kiefern konnten lediglich 4 Varianten (insgesamt 17 Versuchspflanzen) in die Analyse des Einflusses der eingesetzten Bodenhilfsstoffe auf die Wachstumsentwicklung einbezogen werden. In den übrigen der ursprünglich 10 Behandlungsvarianten gab es durch die hohen Pflanzenausfälle bei dieser Baumart nicht genügend $(<3)$ lebende, ungeschädigte Exemplare für statistische Analysen.

Zwischen den 4 untersuchten Varianten wurden bei verschiedenen Wachstumsparametern signifikante Unterschiede je nach eingesetzten Bodenhilfsstoffen festgestellt (s. Tab. 74):

- Zuwachs des Haupttriebs 2006 sowie Gesamtzuwachs

- Volumen des Haupttriebs sowie die daraus errechnete

- Trockenmasse des Haupttriebs

- Summe oberirdische Trockenmasse (Haupttrieb und Seitentriebe)

- Verhältnis oberirdische Trockenmasse/unterirdische Trockenmasse (Wurzel)

- Gesamttrockenmasse (Haupttrieb, Seitentriebe, Wurzel)

- Summe Trockenmasse Haupttrieb und Wurzel

- Verhältnis Trockenmasse Haupttrieb und Wurzel (Spross-Wurzel-Verhältnis)

Da der größte Teil der insgesamt 17 Kiefern Standorte in Bereichen mit Bodenvegetation auf Versuchsfläche B hatte, stimmten die Ergebnisse der Wachstumsuntersuchungen für die Gruppen „Kiefern insgesamt“, „Kiefern auf Fläche B“ und „Kiefern auf Standorten mit Bewuchs“ mehr oder weniger überein. Entsprechend waren auch die für alle Kiefern insgesamt statistisch ermittelten homogenen Gruppen mit den an den Kiefern mit Standorten in bewachsenen Bereichen ermittelten identisch (s. Tab. 74). Hier bestanden aufgrund hoher Standardabweichungen im 2. Untersuchungsjahr (2006) keine signifikanten ZuwachsUnterschiede zwischen den mit Kompost und Kalk (V10) und den mit Superabsorber (V5) 
behandelten Pflanzen, während der Zuwachs mit Kompost (V9) signifikant höher lag als in der Superabsorber-Variante (V5). Bei Betrachtung nur der Kiefern auf Versuchsfläche B war diese Gruppeneinteilung bezogen auf den Gesamt-Zuwachs dagegen umgekehrt (keine signifikanten Unterschiede zwischen V5 und V9, jedoch zwischen V5 und V10).

Tab. 74: Signifikant unterschiedliche Wachstumsparameter der Kiefern-Varianten (s. S. 20) insgesamt, auf Fläche B sowie in Bereichen mit Spontanvegetation; MW u. Std.abw.; Ergebnisse von H-Tests (H) auf signifikante Unterschiede; Buchstaben kennzeichnen je Zeile homogene Gruppen nach U-Tests

\begin{tabular}{|c|c|c|c|c|c|c|}
\hline Kiefern & $\begin{array}{l}\text { Wachstums- } \\
\text { parameter }\end{array}$ & $\begin{array}{l}\mathrm{V} 1 \\
\mathrm{n}=5\end{array}$ & $\begin{array}{l}\text { V5 } \\
n=3\end{array}$ & $\begin{array}{l}\text { V9 } \\
n=4\end{array}$ & $\begin{array}{l}\mathrm{V} 10 \\
\mathrm{n}=5\end{array}$ & $\mathrm{H}$ \\
\hline \multirow{9}{*}{$\begin{array}{l}\text { insgesamt } \\
\mathrm{n}=17\end{array}$} & $\begin{array}{l}\text { Zuwachs } 2006 \\
\text { Haupttrieb [cm] }\end{array}$ & $\begin{array}{l}8 \pm 2 \\
a\end{array}$ & $\begin{array}{l}15 \pm 6 \\
b\end{array}$ & $\begin{array}{l}24 \pm 4 \\
\mathrm{c}\end{array}$ & $\begin{array}{l}25 \pm 11 \\
b, c\end{array}$ & $11,62^{* *}$ \\
\hline & $\begin{array}{l}\text { Gesamtzuwachs } \\
\text { Haupttrieb [cm] }\end{array}$ & $\begin{array}{l}15 \pm 4 \\
\mathrm{a}\end{array}$ & $\begin{array}{l}25 \pm 4 \\
b\end{array}$ & $\begin{array}{l}29 \pm 8 \\
b\end{array}$ & $\begin{array}{l}35 \pm 17 \\
b\end{array}$ & $10,57^{*}$ \\
\hline & $\begin{array}{l}\text { Volumen } \\
\text { Haupttrieb }\left[\mathrm{cm}^{3}\right]\end{array}$ & $\begin{array}{l}10 \pm 8 \\
a\end{array}$ & $\begin{array}{l}16 \pm 10 \\
b\end{array}$ & $\begin{array}{l}47 \pm 25 \\
c\end{array}$ & $\begin{array}{l}51 \pm 43 \\
b, c\end{array}$ & $7,88^{*}$ \\
\hline & $\begin{array}{l}\text { Trockenmasse } \\
\text { Haupttrieb [g] }\end{array}$ & $\begin{array}{l}5 \pm 4 \\
\mathrm{a}\end{array}$ & $\begin{array}{l}8 \pm 5 \\
b\end{array}$ & $\begin{array}{l}25 \pm 13 \\
c\end{array}$ & $\begin{array}{l}27 \pm 23 \\
b, c\end{array}$ & $7,88^{*}$ \\
\hline & $\begin{array}{l}\text { Oberirdische } \\
\text { Trockenmasse [g] }\end{array}$ & $\begin{array}{l}9 \pm 5 \\
a\end{array}$ & $\begin{array}{l}13 \pm 58 \\
a, b\end{array}$ & $\begin{array}{l}36 \pm 13 \\
c\end{array}$ & $\begin{array}{l}36 \pm 28 \\
b, c\end{array}$ & $8,68^{*}$ \\
\hline & $\begin{array}{l}\text { Oberird. TM/ } \\
\text { Unterird. TM }\end{array}$ & $\begin{array}{l}0,9 \pm 0,3 \\
\mathrm{a}\end{array}$ & $\begin{array}{l}1,1 \pm 0,3 \\
a, b\end{array}$ & $\begin{array}{l}2,0 \pm 0,2 \\
c\end{array}$ & $\begin{array}{l}1,9 \pm 0,9 \\
b, c\end{array}$ & $8,06^{*}$ \\
\hline & $\begin{array}{l}\text { Trockenmasse } \\
\text { gesamt [g] }\end{array}$ & $\begin{array}{l}18 \pm 8 \\
\mathrm{a}\end{array}$ & $\begin{array}{l}24 \pm 6 \\
a, b\end{array}$ & $\begin{array}{l}54 \pm 17 \\
\text { c }\end{array}$ & $\begin{array}{l}52 \pm 35 \\
b, c\end{array}$ & $8,37^{*}$ \\
\hline & $\begin{array}{l}\text { TM Haupttrieb } \\
+ \text { TM Wurzel [g] }\end{array}$ & $\begin{array}{l}14 \pm 6 \\
\mathrm{a}\end{array}$ & $\begin{array}{l}19 \pm 7 \\
\mathrm{a}, \mathrm{b}\end{array}$ & $\begin{array}{l}43 \pm 18 \\
\mathrm{c}\end{array}$ & $\begin{array}{l}43 \pm 30 \\
b, c\end{array}$ & $7,88^{*}$ \\
\hline & $\begin{array}{l}\text { Trockenmasse } \\
\text { Spross/Wurzel }\end{array}$ & $\begin{array}{l}0,6 \pm 0,2 \\
a\end{array}$ & $\begin{array}{l}0,7 \pm 0,3 \\
a, b\end{array}$ & $\begin{array}{l}1,3 \pm 0,4 \\
\mathrm{c}\end{array}$ & $\begin{array}{l}1,4 \pm 0,8 \\
b, c\end{array}$ & $8,12^{*}$ \\
\hline \multirow{2}{*}{$\begin{array}{l}\text { Standort } \\
\text { Fläche B } \\
n=13\end{array}$} & $\begin{array}{l}\text { Zuwachs } 2006 \\
\text { Haupttrieb [cm] }\end{array}$ & $\begin{array}{l}8 \pm 3 \\
a(n=4)\end{array}$ & $\begin{array}{l}15 \pm 6 \\
b(n=3)\end{array}$ & $\begin{array}{l}23 \pm 4 \\
b(n=3)\end{array}$ & $\begin{array}{l}29 \pm 13 \\
b(n=3)\end{array}$ & $8,85^{*}$ \\
\hline & $\begin{array}{l}\text { Gesamtzuwachs } \\
\text { Haupttrieb [cm] }\end{array}$ & $\begin{array}{l}17 \pm 2 \\
a(n=4)\end{array}$ & $\begin{array}{l}25 \pm 4 \\
b(n=3)\end{array}$ & $\begin{array}{l}27 \pm 8 \\
b, c(n=3)\end{array}$ & $\begin{array}{l}43 \pm 19 \\
c(n=3)\end{array}$ & $9,45^{*}$ \\
\hline \multirow{2}{*}{$\begin{array}{l}\text { Standort } \\
\text { mit } \\
\text { Bewuchs } \\
\mathrm{n}=15\end{array}$} & $\begin{array}{l}\text { Zuwachs } 2006 \\
\text { Haupttrieb [cm] }\end{array}$ & $\begin{array}{l}8 \pm 3 \\
a(n=4)\end{array}$ & $\begin{array}{l}15 \pm 6 \\
b(n=3)\end{array}$ & $\begin{array}{l}24 \pm 4 \\
\mathrm{c}(\mathrm{n}=4)\end{array}$ & $\begin{array}{l}26 \pm 13 \\
b, c(n=4)\end{array}$ & $9,88^{*}$ \\
\hline & $\begin{array}{l}\text { Gesamtzuwachs } \\
\text { Haupttrieb }[\mathrm{cm}]\end{array}$ & $\begin{array}{l}17 \pm 2 \\
a(n=4)\end{array}$ & $\begin{array}{l}25 \pm 4 \\
b(n=3)\end{array}$ & $\begin{array}{l}29 \pm 8 \\
b(n=4)\end{array}$ & $\begin{array}{l}38 \pm 18 \\
b(n=4)\end{array}$ & $9,38^{*}$ \\
\hline
\end{tabular}

Bei allen drei Bodenhilfsstoffvarianten waren der Zuwachs im 2. Untersuchungsjahr (s. Abb. 155), der Gesamtzuwachs (s. Abb. 156) sowie das Volumen und die Trockenmasse des Haupttriebs (s. Abb. 157) signifikant deutlich höher als in der Nullvariante (V1). Mit Superabsorber lagen die Zuwachswerte 50-90 \% über den Kontrollwerten, mit Kompost 2- bis 3-mal so hoch wie diese. Volumen bzw. Trockenmasse des Haupttriebs waren mit Superabsorber 60 \% höher als ohne Behandlung, wohingegen mit Kompost 3-mal höhere Werte und damit das 5-fache der Kontrollwerte erreicht wurden. 

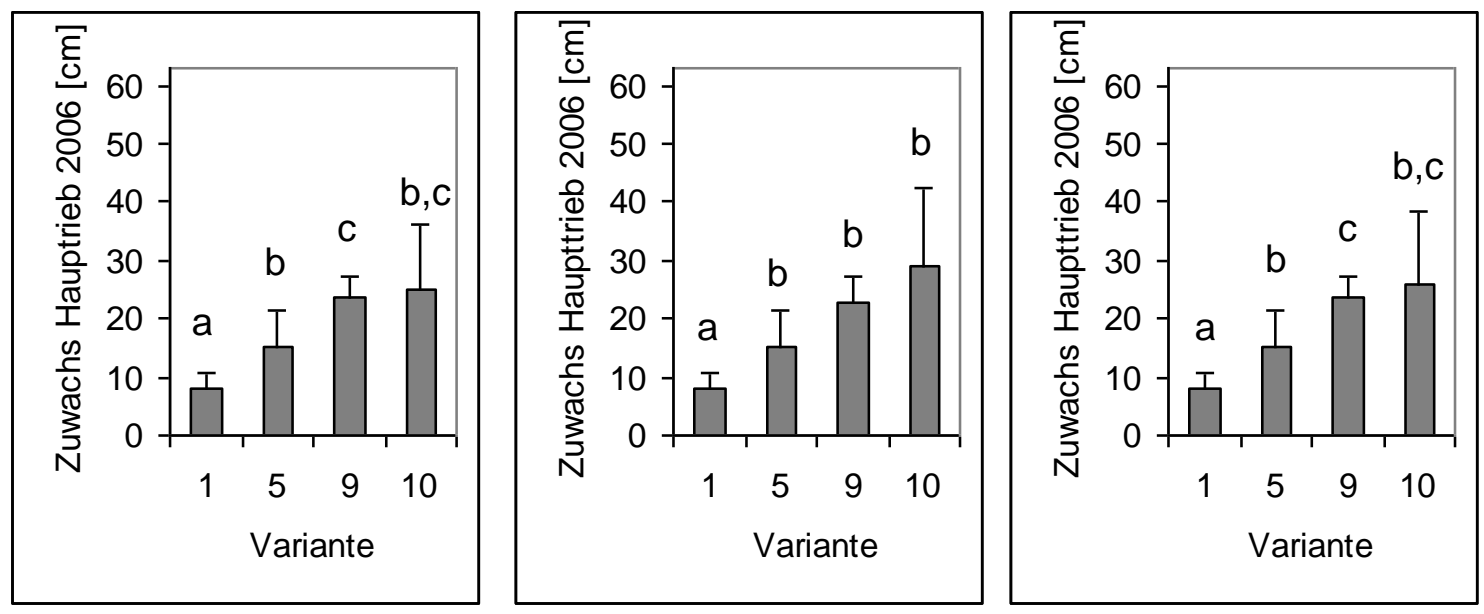

Abb. 155: Zuwachs [cm] des Haupttriebs der Kiefern-Varianten (s. S. 20) im 2. Vegetationsjahr insgesamt (links), auf Versuchsfläche B (Mitte), in Bereichen mit Spontanvegetation (rechts); MW u. Std.abw.; Buchstaben kennzeichnen jeweils homogene Gruppen nach U-Tests ( $n=17)$
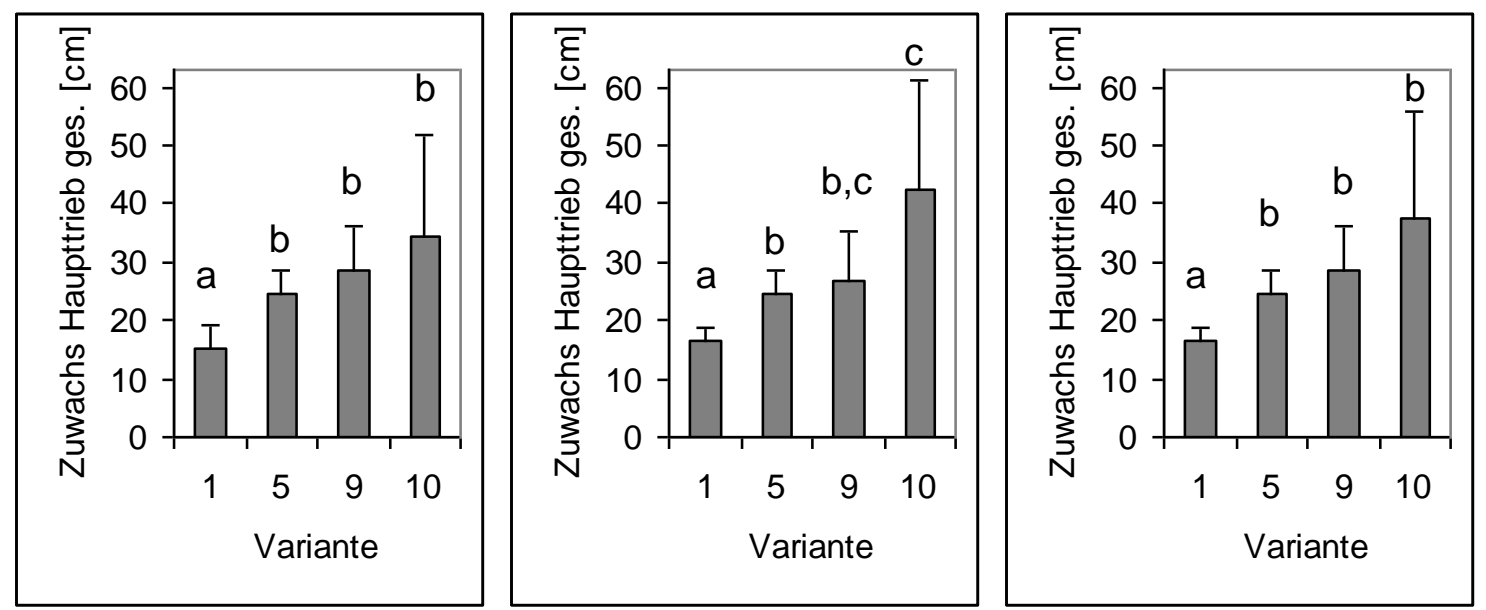

Abb. 156: Gesamtzuwachs [cm] des Haupttriebs der Kiefern-Varianten (s. S. 20) insgesamt (links), auf Versuchsfläche B (Mitte), in Bereichen mit Spontanvegetation (rechts); MW u. Std.abw.; Buchstaben kennzeichnen jeweils homogene Gruppen nach U-Tests ( $n=17$ )
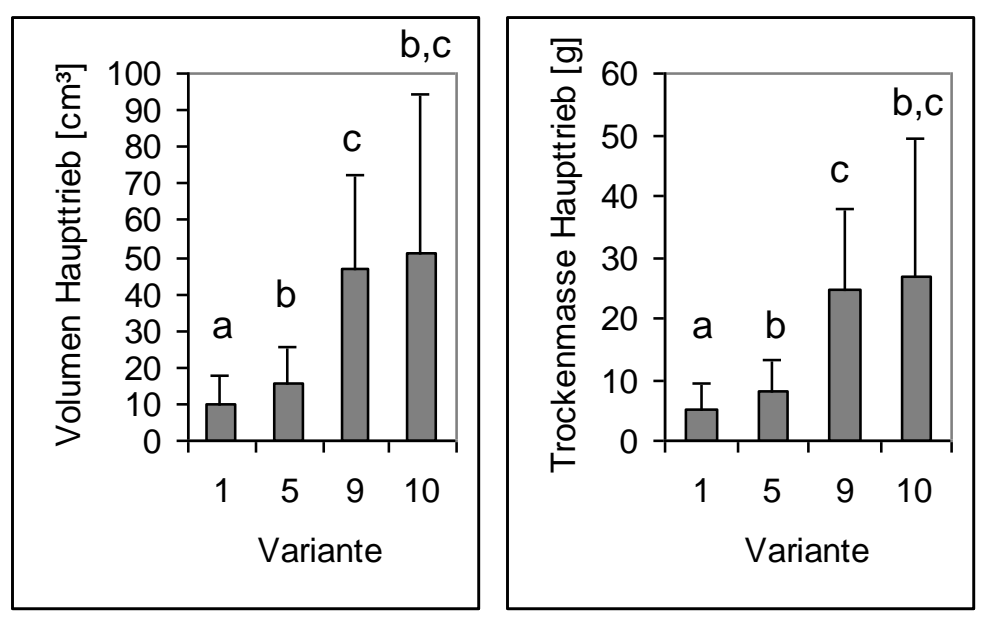

Abb. 157: Volumen $\left[\mathrm{cm}^{3}\right]$ (links) und Trockenmasse [g] (rechts) des Haupttriebs der Kiefern-Varianten (s. S. 20) insgesamt; MW u. Std.abw.; Buchstaben kennzeichnen jeweils homogene Gruppen nach U-Tests $(\mathrm{n}=17)$ 

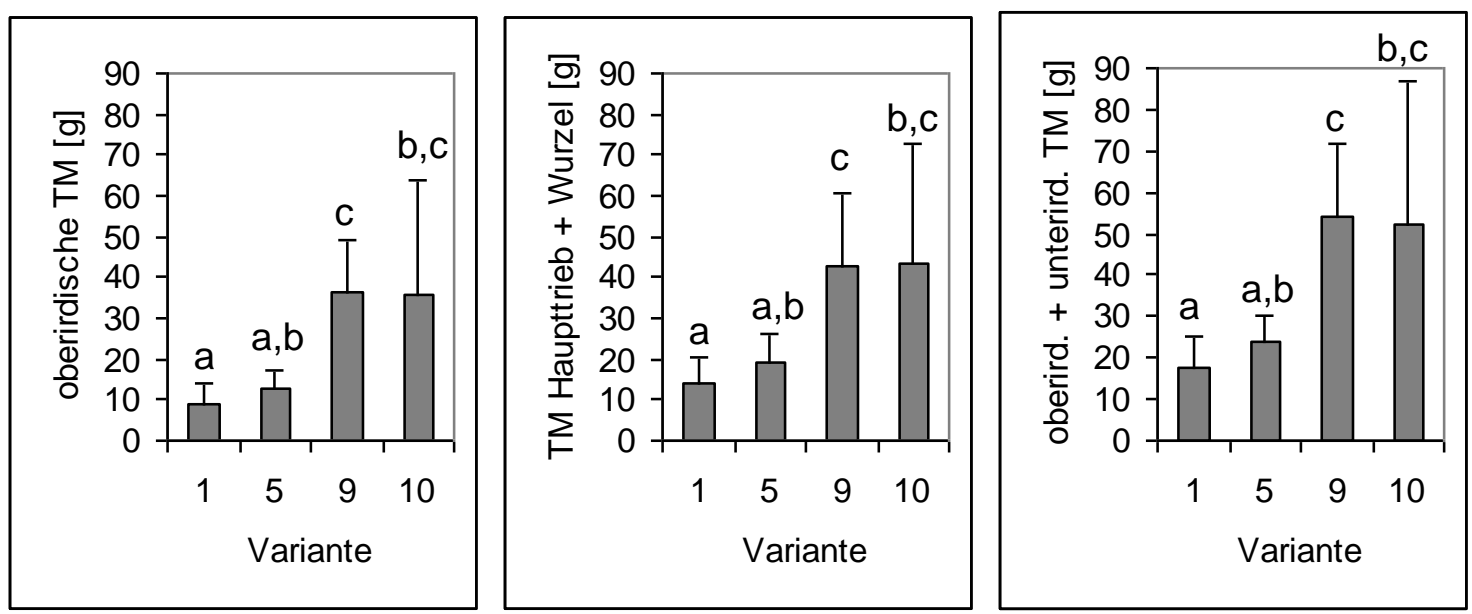

Abb. 158: Oberirdische Trockenmasse [g] (links), Summe der Trockenmassen der Haupttriebe und Wurzeln (Mitte), Gesamt-Trockenmasse (rechts) der Kiefern-Varianten (s. S. 20) insgesamt; MW u. Std.abw.; Buchstaben kennzeichnen jeweils homogene Gruppen nach U-Tests $(n=17)$
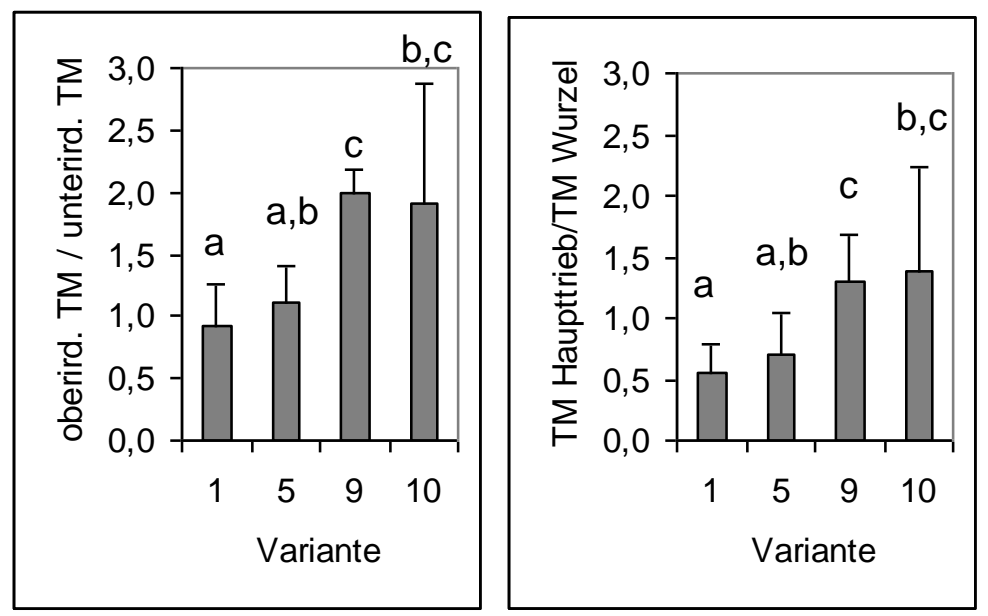

Abb. 159: Verhältnis ober-/unterirdische Trockenmasse (links) sowie Verhältnis der Spross-/WurzelTrockenmassen (rechts) der Kiefern-Varianten (s. S. 20) insgesamt; MW u. Std.abw.; Buchstaben kennzeichnen jeweils homogene Gruppen nach U-Tests $(n=17)$

Die übrigen Vergleiche von gebildeten Biomassen (Trockenmassen) sowie von Verhältnissen zwischen diesen Biomassen ergaben für die mit Superabsorber gepflanzten Kiefern (V5) keine signifikanten Unterschiede gegenüber der unbehandelten Kontrolle (V1). Dagegen lagen die im Vergleich zu den Kontrollwerten 3- bis 4-mal so hohen Trockenmassen (s. Abb. 158) und doppelt so hohen Trockenmasse-Verhältnisse (s. Abb. 159) in den beiden Kompost-Varianten (V9 u. V10) signifikant über den Werten in der Nullvariante (V1).

Grund war eine durch Kompost-Düngung stärkere Zunahme der oberirdischen Biomasse bzw. der Haupttrieb-Biomasse gegenüber der Wurzelmasse. So betrug die Trockenmasse der Haupttriebe in den Kompostvarianten (V9, 10) wie oben genannt etwa das 5-fache des Kontrollwertes, während die Trockenmasse der Wurzeln in V9 und V10 etwa doppelt so hoch wie in der unbehandelten Nullvariante war. Das Spross-Wurzel-Verhältnis wurde damit jedoch größer und ungünstiger, da nach Lavender (1984) ein kleines Spross-Wurzel-Verhältnis (d.h. ein im Verhältnis zum Spross besonders gut entwickeltes Wurzelwerk) gerade bei schwierigen Standortverhältnissen von großer Bedeutung ist und auf die Stresstoleranz einer Pflanze hinweist (Hendry \& Grime 1993). 


\section{7. $\quad$ Einfluss des Standortes auf einer der drei Versuchsflächen}

\subsubsection{Vitalitätsentwicklung}

Die Vitalität aller 936 Bäume des Freiland-Versuchs wurde im Verlauf des zweijährigen Untersuchungszeitraums wiederholt auf einer Skala von "4“ (vital) bis „0“ (tot) eingeschätzt (s. S. 27).

Im Folgenden wird die Vitalitätsentwicklung der Versuchsbäume anhand der Ergebnisse statistischer Analysen der Vitalitätswerte auf Einflüsse durch den Pflanzenstandort auf Versuchsfläche A, B oder D (s. S. 17; zu den unterschiedlichen Standortbedingungen s. ab S. 44) untersucht.

Da der Einflussfaktor „Pflanzenstandort in Bereichen ohne oder mit Spontanvegetationsentwicklung“ (s. ab S. 257) teilweise eine wichtige Rolle spielte, wurde der Einfluss des „Standortes Versuchsfläche“ auf die Vitalitätsentwicklung der Versuchspflanzen auch unter Ausschluss dieses Faktors untersucht. Dies geschah, indem ausschließlich die Bäume mit Standorten auf Teilflächen ohne Entwicklung von Spontanvegetation (vergleichsweise ungünstigere Bedingungen, s. ab S. 44) bzw. mit Entwicklung von Spontanvegetation (vergleichsweise günstigere Bedingungen, s. ab S. 44) betrachtet wurden.

\subsubsection{Rot-Eiche}

Der Standort auf einer der drei Versuchsflächen beeinflusste die Vitalitätsentwicklung der Eichen insgesamt sowie der Eichen in Bereichen ohne und mit Spontanvegetation.

\section{Eichen insgesamt}

Die mittleren Vitalitätswerte der Eichen auf den drei Versuchsflächen waren bereits zwei Monate nach Versuchsanlage durch massive Pflanzenausfälle signifikant auf unter „1“ (fast völlig abgestorben) gesunken. Auf Versuchsfläche A verschlechterte sich der Mittelwert signifikant weiter, so dass zu allen Aufnahmezeitpunkten ab Oktober 2005 signifikante Unterschiede zu den Werten auf den anderen beiden Flächen bestanden. Auf Fläche B sank die mittlere Vitalität ebenfalls bis Juni 2006 signifikant weiter und blieb dann im Verlauf der zweiten Vegetationszeit konstant. Auf Fläche D erfolgte lediglich im 2. Jahr eine weitere signifikante Abnahme der Durchschnittsvitalität der Eichen (s. Tab. 75). 
Tab. 75: Vitalität der Eichen [codiert: $4=$ vital bis $0=$ tot, s. S. 27] auf den drei Versuchsflächen A, B und D im Versuchsverlauf; MW u. Std.abw.; je Aufnahmezeitpunkt Ergebnisse von H-Tests (H) auf signifikante Unterschiede zwischen den Flächen (Buchstaben kennzeichnen homogene Gruppen nach U-Tests); je Fläche Ergebnisse von Friedmann-Tests $\left(\mathrm{Chi}^{2}\right)$ auf signifikante Unterschiede zwischen den Aufnahmezeitpunkten (je Fläche $n=64$ )

\begin{tabular}{|c|c|c|c|c|c|c|c|c|c|c|}
\hline & $\begin{array}{l}\text { April } \\
2005\end{array}$ & & $\begin{array}{l}\text { Juni } \\
2005\end{array}$ & & $\begin{array}{l}\text { Oktober } \\
2005\end{array}$ & & $\begin{array}{l}\text { Juni } \\
2006\end{array}$ & & $\begin{array}{l}\text { Oktober } \\
2006\end{array}$ & $\mathrm{Chi}^{2}$ \\
\hline A & $2,2 \pm 0,5$ & $>$ & $0,6 \pm 0,6$ & $>$ & $\begin{array}{l}0,4 \pm 0,5 \\
a\end{array}$ & $>$ & $\begin{array}{l}0,1 \pm 0,3 \\
\mathrm{a}\end{array}$ & $>$ & $\begin{array}{l}0,1 \pm 0,2 \\
\mathrm{a}\end{array}$ & $145,03^{* * *}$ \\
\hline B & $2,5 \pm 0,5$ & $>$ & $0,7 \pm 0,5$ & $>$ & $\begin{array}{l}0,9 \pm 0,9 \\
b\end{array}$ & $>$ & $\begin{array}{l}0,4 \pm 0,9 \\
b\end{array}$ & & $\begin{array}{l}0,5 \pm 0,9 \\
b\end{array}$ & $115,26^{* * *}$ \\
\hline D & $2,2 \pm 0,4$ & $>$ & $0,8 \pm 0,5$ & & $\begin{array}{l}0,9 \pm 1,0 \\
b\end{array}$ & & $\begin{array}{l}0,8 \pm 1,2 \\
\mathrm{c}\end{array}$ & $>$ & $\begin{array}{l}0,7 \pm 1,3 \\
b\end{array}$ & $79,48^{* * *}$ \\
\hline $\mathrm{H}$ & & & 5,68 & & $9,95^{* *}$ & & $14,47^{* * *}$ & & $13,75^{* *}$ & \\
\hline
\end{tabular}

$>$ signifikanter Rückgang der Vitalität laut Wilcoxon-Test

Im Juni 2006 bestanden zwischen allen drei Flächen signifikante Unterschiede der mittleren Vitalitätswerte der Eichen, wobei auf Fläche D der höchste $(0,8 \pm 1,2)$, auf Fläche A der niedrigste $(0,1 \pm 0,3)$ und auf Fläche B ein dazwischen liegender Mittelwert $(0,4 \pm 0,9)$ ermittelt wurde (s. Abb. 160). Derart niedrige Mittelwerte entstehen durch eine hohe Ausfallrate (Vitalitätswert „0“). Die Aussagekraft dieser statistisch signifikanten Unterschiede zwischen mittleren Vitalitätswerten, die deutlich unter „1“ liegen, ist relativ gering. Es kann jedoch von einem Einfluss des Standortes auf einer der drei Versuchsflächen auf die Vitalität der Eichen gesprochen werden, zumal auch die entsprechende Kreuztabelle eine signifikante Korrelation der Sterblichkeitsrate der Eichen mit der Versuchsfläche feststellt $\left(\mathrm{Chi}^{2}{ }^{2} 12,53^{* *}\right)$.

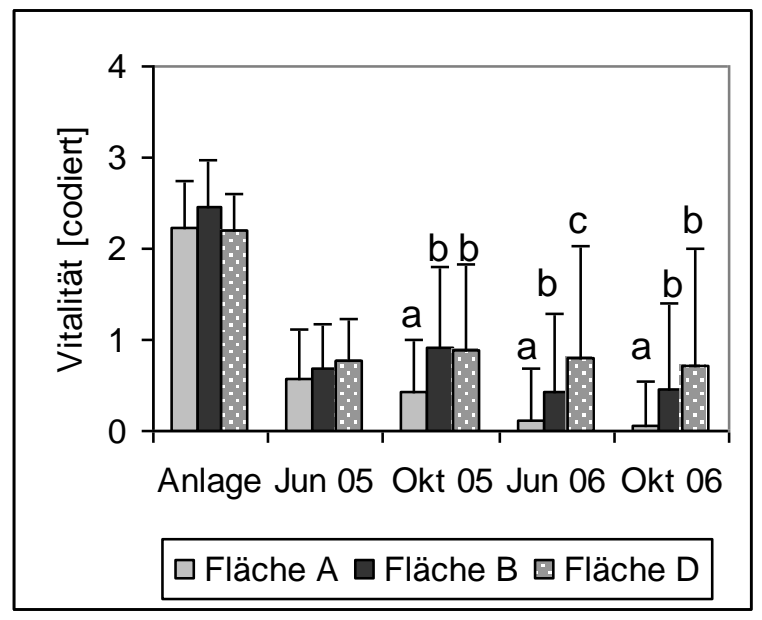

Abb. 160: Vitalität der Eichen [codiert: $4=$ vital bis $0=$ tot, s. S. 27] auf den drei Versuchsflächen A, B und D im Versuchsverlauf; MW u. Std.abw.; Buchstaben kennzeichnen ggf. je Aufnahmezeitpunkt homogene Gruppen nach U-Tests (je Fläche $\mathrm{n}=64$ )

\section{Eichen in Bereichen ohne Spontanvegetation}

Die Durchschnittsvitalität der Eichen mit Standorten in Bereichen ohne Bodenbewuchs (und damit mit schlechteren Standortbedingungen) sank auf allen drei Versuchsflächen bereits wenige Wochen nach Versuchsbeginn signifikant auf nur noch sehr geringe Werte deutlich unter „1“ (s. Tab. 76). 
Auf Fläche A setzte sich die Abnahme im Versuchsverlauf weiter fort, auf Fläche B sank der Wert zum 2. Vegetationsjahr noch einmal signifikant. Auf Fläche D erfolgte keine weitere signifikante Abnahme; die Werte blieben auf sehr geringem Niveau konstant. Hier überlebten bis zum Abschluss der Untersuchungen sechs Eichen mit Standorten im vegetationsfreien Bereich. Auf den Flächen A und B waren dagegen im 2. Untersuchungsjahr sämtliche Eichen mit Standort in unbewachsenen Bereichen abgestorben. Die mittleren Vitalitätswerte sind daher im 2. Versuchsjahr signifikant unterschiedlich, im 1. Versuchsjahr jedoch nicht.

Tab. 76: Vitalität der Eichen [codiert: $4=$ vital bis $0=$ tot, s. S. 27] in vegetationsfreien Bereichen auf den drei Versuchsflächen A $(n=64), B(n=20)$ und D $(n=30)$ im Versuchsverlauf; MW u. Std.abw.; je Aufnahmezeitpunkt Ergebnisse von $\mathrm{H}$-Tests $(\mathrm{H})$ auf signifikante Unterschiede zwischen den Flächen; je Fläche Ergebnisse von Friedmann-Tests $\left(\mathrm{Chi}^{2}\right)$ auf signifikante Unterschiede zwischen den Aufnahmezeitpunkten

\begin{tabular}{|l|l|l|l|l|l|l|l|l|l|l|}
\hline o.BV & $\begin{array}{l}\text { April } \\
2005\end{array}$ & & $\begin{array}{l}\text { Juni } \\
2005\end{array}$ & & $\begin{array}{l}\text { Oktober } \\
2005\end{array}$ & & $\begin{array}{l}\text { Juni } \\
2006\end{array}$ & $\begin{array}{l}\text { Oktober } \\
2006\end{array}$ & $\mathrm{Chi}^{2}$ \\
\hline A & $2,2 \pm 0,5$ & $>$ & $0,6 \pm 0,6$ & $>$ & $0,4 \pm 0,5$ & $>$ & 0 & $>$ & 0 & $145,03^{* * *}$ \\
\hline B & $2,7 \pm 0,5$ & $>$ & $0,5 \pm 0,5$ & & $0,5 \pm 0,6$ & $>$ & 0 & & 0 & $44,96^{* * *}$ \\
\hline D & $2,2 \pm 0,4$ & $>$ & $0,7 \pm 0,5$ & & $0,6 \pm 0,7$ & & $0,5 \pm 0,9$ & & $\begin{array}{l}0,4 \pm \\
0,9\end{array}$ & $52,18^{* * *}$ \\
\hline H & & & 3,13 & & 0,29 & & $6,40^{*}$ & & $9,02^{*}$ & \\
\hline
\end{tabular}

Juni u. Okt 2006: Versuchspflanzen überwiegend abgestorben

> signifikanter Rückgang der Vitalität laut Wilcoxon-Test

\section{Eichen in Bereichen mit Spontanvegetation}

Auch bei den Eichen, die zufällig in Teilbereiche mit späterer Bodenbesiedelung (als Indiz für bessere Standortbedingungen) gepflanzt wurden, ließen sich auf den betreffenden Versuchsflächen (B, D) nur sehr geringe mittlere Vitalitätswerte (wenn auch nicht ganz so gering wie auf vegetationsfreien Standorten) feststellen.

Tab. 77: Vitalität der Eichen [codiert: $4=$ vital bis $0=$ tot, s. S. 27] in bewachsenen Bereichen auf den Versuchsflächen B ( $n=43)$ und D $(n=34)$ im Versuchsverlauf; MW u. Std.abw.; je Aufnahmezeitpunkt Ergebnisse von U-Tests (Z) auf signifikante Unterschiede zwischen den Flächen; je Fläche Ergebnisse von Friedmann-Tests $\left(\mathrm{Chi}^{2}\right)$ auf signifikante Unterschiede zwischen den Aufnahmezeitpunkten

\begin{tabular}{|l|l|l|l|l|l|l|l|l|l|l|}
\hline m.BV & $\begin{array}{l}\text { April } \\
2005\end{array}$ & & $\begin{array}{l}\text { Juni } \\
2005\end{array}$ & & $\begin{array}{l}\text { Oktober } \\
2005\end{array}$ & & $\begin{array}{l}\text { Juni } \\
2006\end{array}$ & $\begin{array}{l}\text { Oktober } \\
2006\end{array}$ & $\mathrm{Chi}^{2}$ \\
\hline $\mathrm{B}$ & $2,4 \pm 0,5$ & $>$ & $0,8 \pm 0,5$ & $<$ & $1,1 \pm 0,9$ & $>$ & $0,6 \pm 1,0$ & & $0,7 \pm 1,1$ & $72,13^{* * *}$ \\
\hline $\mathrm{D}$ & $2,2 \pm 0,4$ & $>$ & $0,8 \pm 0,5$ & $<$ & $1,1 \pm 1,0$ & & $1,1 \pm 1,3$ & & $1,0 \pm 1,5$ & $31,75^{* *}$ \\
\hline $\mathrm{Z}$ & & & 0,31 & & 0,00 & & $1,72^{*}$ & & 0,87 & \\
\hline
\end{tabular}

$>$ signifikanter Rückgang, < signifikanter Anstieg der Vitalität laut Wilcoxon-Test

Auf beiden Flächen nahm die Vitalität der Eichen auf bewachsenen Standorten (s. Tab. 77) von der Anlage im April 2005 bis Juni 2005 signifikant von 2,4 \pm 0,5 bzw. 2,2 $\pm 0,4$ auf nur noch 0,8 \pm 0,5 ab. Darauf folgte auf diesen Standorten eine leichte Erholung mit jeweils leichten, signifikanten Zunahmen der Vitalitätsmittelwerte auf 1,1 $\pm 0,9 / 1,0$ im Oktober 2005. Auf Fläche B sank der Wert zum 2. Versuchsjahr wieder signifikant auf $0,6 \pm 1,0$ ab, während er auf Fläche D bis Versuchsende konstant bei Werten knapp über „1“ blieb. Grund für die insgesamt niedrigen Werte war auch hier der jeweils hohe Anteil toter („0“) und fast völlig abgestorbener ("1“) Pflanzen. Nur bei der Aufnahme im Juni 2006 waren die Mittelwerte auf Fläche D signifikant 
höher als auf Fläche B (s. Abb. 161). In Bereichen mit Bodenbewuchs schien der Standort auf einer der beiden Flächen keine große Rolle für die Vitalitätsentwicklung der Eichen zu spielen.

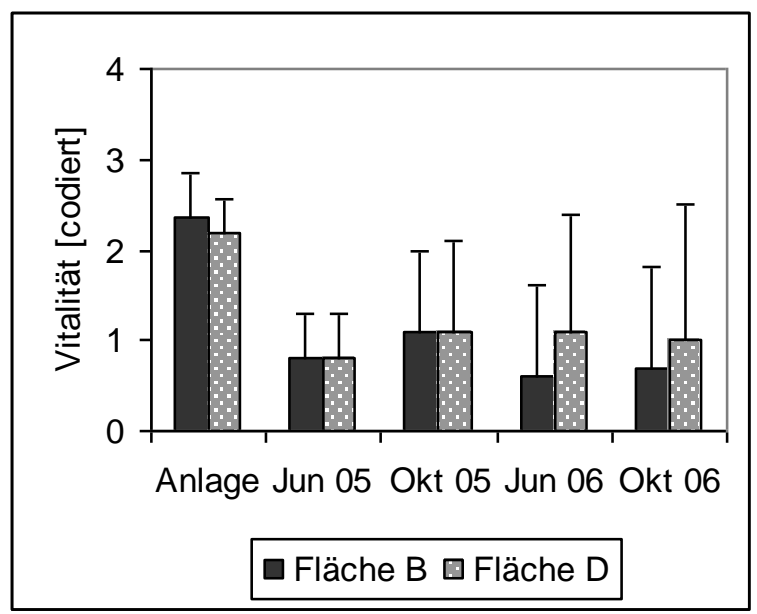

Abb. 161: Vitalität der Eichen [codiert: $4=$ vital bis $0=$ tot, s. S. 27] in bewachsenen Bereichen auf den Versuchsflächen B $(n=43)$ und D $(n=34)$ im Versuchsverlauf; MW u. Std.abw.; im Juni 2006 signifikante Unterschiede nach U-Tests

\subsubsection{Spitz-Ahorn}

Der Standort auf einer der drei Versuchsflächen beeinflusste die Vitalitätsentwicklung der Ahorne insgesamt sowie der Ahorne in Bereichen ohne und mit Spontanvegetation.

\section{Ahorne insgesamt}

Die mittlere Vitalität der Ahorne auf den drei Versuchsflächen entwickelte sich im Versuchsverlauf unterschiedlich (s. Tab. 78). Auch die Sterblichkeitsrate der Ahorne ist signifikant mit ihrem Standort auf einer der drei Versuchsflächen korreliert (Kreuztabelle, $\mathrm{Chi}^{2}$ $24,64^{* * *}$ ).

Auf Fläche A sank der Durchschnittswert bereits im 1. Versuchsjahr deutlich von anfänglich 2,4 $\pm 0,6$ über 2,0 $\pm 0,9$ im Juni auf 1,0 $\pm 0,4$ im Oktober, um dann bis Oktober 2006 auf 0,6 $\pm 0,9$ abzunehmen. Hintergrund dieser starken Vitalitätsabnahme ist, dass im Oktober 2005 nur noch $11 \%$ aller Ahorne auf Fläche A einen besseren Vitalitätswert als „1“ (fast völlig abgestorben) erhielten, während es im Juni 2005 noch 69 \% waren. Zwar erhöhte sich dieser Anteil bei den folgenden zwei Aufnahmen wieder auf 31 \% (Juni 2006) bzw. 19 \% (Oktober 2006), gleichzeitig nahm aber der Anteil abgestorbener Pflanzen von $3 \%$ (Juni 2005) über $8 \%$ (Oktober 2005) auf $48 \%$ (Juni 2006) und schließlich auf 59 \% (Oktober 2006) zu, was die niedrigen Mittelwerte begründet. 
Tab. 78: Vitalität der Ahorne [codiert: $4=$ vital bis $0=$ tot, s. S. 27] auf den drei Versuchsflächen A, B und D im Versuchsverlauf; MW u. Std.abw.; je Aufnahmezeitpunkt Ergebnisse von H-Tests (H) auf signifikante Unterschiede zwischen den Flächen (Buchstaben kennzeichnen homogene Gruppen nach U-Tests); je Fläche Ergebnisse von Friedmann-Tests $\left(\mathrm{Chi}^{2}\right)$ auf signifikante Unterschiede zwischen den Aufnahmezeitpunkten (je Fläche n=64)

\begin{tabular}{|l|l|l|l|l|l|l|l|l|l|l|}
\hline & $\begin{array}{l}\text { April } \\
2005\end{array}$ & & $\begin{array}{l}\text { Juni } \\
2005\end{array}$ & & $\begin{array}{l}\text { Oktober } \\
2005\end{array}$ & & $\begin{array}{l}\text { Juni } \\
2006\end{array}$ & $\begin{array}{l}\text { Oktober } \\
2006\end{array}$ & $\mathrm{Chi}^{2}$ \\
\hline A & $2,4 \pm 0,6$ & $>$ & $\begin{array}{l}2,0 \pm 0,9 \\
\mathrm{a}\end{array}$ & $>$ & $\begin{array}{l}1,0 \pm 0,4 \\
\mathrm{a}\end{array}$ & $\begin{array}{l}0,9 \pm 1,1 \\
\mathrm{a}\end{array}$ & $>$ & $\begin{array}{l}0,6 \pm 0,9 \\
\mathrm{a}\end{array}$ & $129,93^{* * *}$ \\
\hline $\mathrm{B}$ & $2,5 \pm 0,5$ & $\begin{array}{l}2,6 \pm 0,8 \\
\mathrm{~b}\end{array}$ & $\begin{array}{l}2,5 \pm 1,0 \\
\mathrm{~b}\end{array}$ & $>$ & $\begin{array}{l}2,2 \pm 1,1 \\
\mathrm{~b}\end{array}$ & $\begin{array}{l}2,1 \pm 1,3 \\
\mathrm{~b}\end{array}$ & $15,99^{* *}$ \\
\hline $\mathrm{D}$ & $2,7 \pm 0,5$ & $\begin{array}{l}2,3 \pm 0,9 \\
\mathrm{a}\end{array}$ & $\begin{array}{l}2,3 \pm 1,2 \\
\mathrm{~b}\end{array}$ & $\begin{array}{l}2,1 \pm 1,4 \\
\mathrm{~b}\end{array}$ & $\begin{array}{l}2,1 \pm 1,4 \\
\mathrm{~b}\end{array}$ & 9,03 \\
\hline $\mathrm{H}$ & & & $15,24^{* * *}$ & & $64,0^{* * *}$ & & $34,73^{* * *}$ & & $47,31^{* * *}$ & \\
\hline
\end{tabular}

$>$ signifikanter Rückgang der Vitalität laut Wilcoxon-Test

Die Werte auf Fläche A waren zu allen Aufnahmezeitpunkten signifikant schlechter als auf Fläche B, wo die Mittelwerte in 2005 bei mindestens „2,5“, in 2006 leicht (aber signifikant) darunter lagen. Auf Fläche D blieb der mittlere Vitalitätswert mit Werten zwischen 2,7 $\pm 0,5$ und $2,1 \pm 1,4$ recht konstant. Damit lagen die Werte auf Fläche D ab Oktober 2005 ebenfalls signifikant höher als auf Fläche A. Zu dem etwas besseren Wert auf Fläche B bestand lediglich im Juni 2005 ein signifikanter Unterschied (s. Abb. 162).

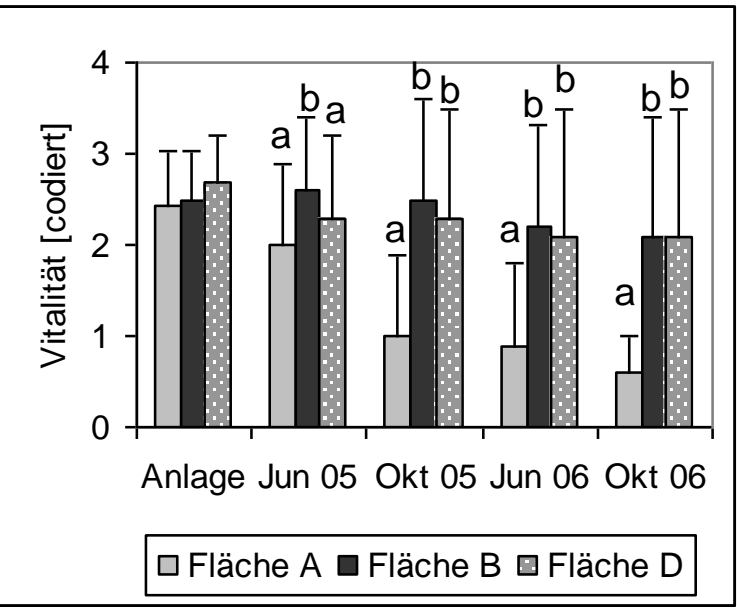

Abb. 162: Vitalität der Ahorne [codiert: $4=$ vital bis $0=$ tot, s. S. 27] auf den drei Versuchsflächen A, B und D im Versuchsverlauf; MW u. Std.abw.; Buchstaben kennzeichnen ggf. je Aufnahmezeitpunkt homogene Gruppen nach U-Tests (je Fläche $n=64$ )

\section{Ahorne in Bereichen ohne Spontanvegetation}

Betrachtet man ausschließlich die Ahorne, die zufällig in Teilbereiche ohne spätere Bodenbesiedelung gepflanzt wurden, fällt zunächst auf, dass die durchschnittlichen Vitalitätswerte (abgesehen von den Ausgangswerten) kaum über „2“ (kümmerliche Entwicklung) hinausgingen und damit in einem eher schwachen Wertebereich lagen. 
Tab. 79: Vitalität der Ahorne [codiert: $4=$ vital bis $0=$ tot, s. S. 27] in vegetationsfreien Bereichen auf den drei Versuchsflächen A $(n=64), B(n=21)$ und D $(n=33)$ im Versuchsverlauf; MW u. Std.abw.; je Aufnahmezeitpunkt Ergebnisse von H-Tests $(\mathrm{H})$ auf signifikante Unterschiede zwischen den Flächen (Buchstaben kennzeichnen homogene Gruppen nach U-Tests); je Fläche Ergebnisse von Friedmann-Tests $\left(\mathrm{Chi}^{2}\right)$ auf signifikante Unterschiede zwischen den Aufnahmezeitpunkten

\begin{tabular}{|l|l|l|l|l|l|l|l|l|l|l|}
\hline o.BV & $\begin{array}{l}\text { April } \\
2005\end{array}$ & & $\begin{array}{l}\text { Juni } \\
2005\end{array}$ & & $\begin{array}{l}\text { Oktober } \\
2005\end{array}$ & $\begin{array}{l}\text { Juni } \\
2006\end{array}$ & $\begin{array}{l}\text { Oktober } \\
2006\end{array}$ & $\mathrm{Chi}^{2}$ \\
\hline A & $2,4 \pm 0,6$ & $>$ & $2,0 \pm 0,9$ & $>$ & $\begin{array}{l}1,0 \pm 0,4 \\
\mathrm{a}\end{array}$ & $\begin{array}{l}0,9 \pm 1,1 \\
\mathrm{a}\end{array}$ & $>\begin{array}{l}0,6 \pm 0,9 \\
\mathrm{a}\end{array}$ & $129,93^{* * *}$ \\
\hline B & $2,6 \pm 0,5$ & $2,4 \pm 1,0$ & $\begin{array}{l}2,1 \pm 1,2 \\
\mathrm{~b}\end{array}$ & $\begin{array}{l}1,9 \pm 1,4 \\
\mathrm{~b}\end{array}$ & $\begin{array}{l}1,8 \pm 1,5 \\
\mathrm{~b}\end{array}$ & 6,48 \\
\hline D & $2,7 \pm 0,6$ & $>$ & $2,1 \pm 0,8$ & $\begin{array}{l}2,0 \pm 1,1 \\
\mathrm{~b}\end{array}$ & $\begin{array}{l}1,8 \pm 1,4 \\
\mathrm{~b}\end{array}$ & $\begin{array}{l}1,8 \pm 1,5 \\
\mathrm{~b}\end{array}$ & $10,98^{*}$ \\
\hline H & & & 2,32 & & $28,97^{* * *}$ & & $12,88^{* *}$ & & $19,18^{* * *}$ & \\
\hline
\end{tabular}

$>$ signifikanter Rückgang der Vitalität laut Wilcoxon-Test

Auf Fläche B veränderte sich die mittlere Vitalität der Ahorne in vegetationsfreien Bereichen im Versuchsverlauf nicht signifikant (s. Tab. 79). Sie lag zwischen $2,6 \pm 0,5$ auf $1,8 \pm 1,5$. Auf Fläche D nahmen die Mittelwerte zu Versuchsbeginn zunächst signifikant von 2,7 $\pm 0,6$ auf 2,1 $\pm 0,8 \mathrm{ab}$, blieben dann aber bis Ende des zweijährigen Untersuchungszeitraums konstant bei um „2“. Ganz anders stellte sich die Vitalitätsentwicklung auf Fläche A dar: Hier folgte auf eine anfängliche signifikante Abnahme des Durchschnittswertes von 2,4 $\pm 0,6$ auf 2,0 $\pm 0,9$ gleich ein weiteres signifikantes Absinken im 1. Versuchsjahr auf nur noch 1,0 $\pm 0,4$. Bis Versuchsende fiel der Wert schließlich auf sehr geringe $0,6 \pm 0,9$.

$\mathrm{Ab}$ Oktober 2005 waren die durchschnittlichen Vitalitätswerte der Ahorne auf der vegetationsfreien Fläche A signifikant niedriger als in den ebenfalls unbewachsenen Bereichen auf den Flächen B und D (s. Abb. 163).

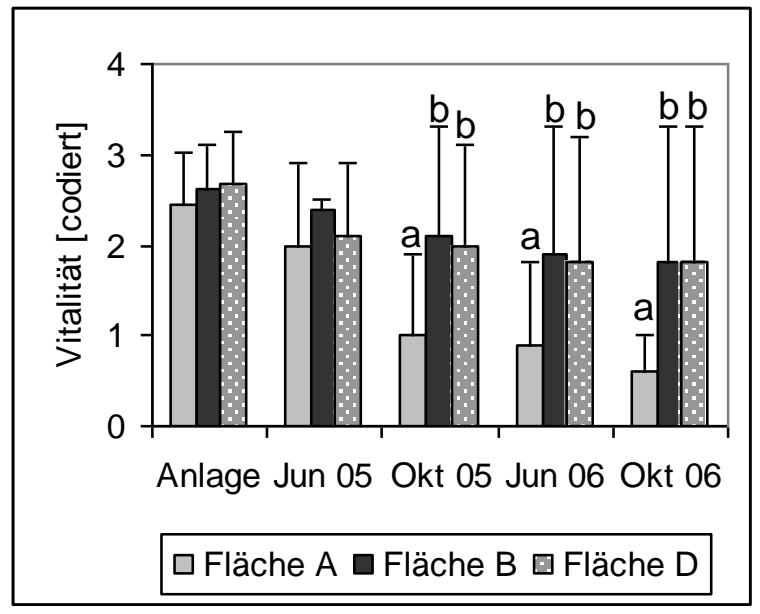

Abb. 163: Vitalität der Ahorne [codiert: $4=$ vital bis $0=$ tot, s. S. 27] in vegetationsfreien Bereichen auf den drei Versuchsflächen A ( $n=64)$, B $(n=21)$ und D ( $n=33)$ im Versuchsverlauf; MW u. Std.abw.; Buchstaben kennzeichnen ggf. je Aufnahmezeitpunkt homogene Gruppen nach U-Tests 


\section{Ahorne in Bereichen mit Spontanvegetation}

Zwischen den im gesamten Versuchsverlauf mäßigen bis guten Vitalitätsmittelwerten der Ahorne in Bereichen mit Bodenvegetation auf den Versuchsflächen B und D bestanden zu keinem Aufnahmezeitpunkt signifikante Unterschiede (s. Tab. 80).

Tab. 80: Vitalität der Ahorne [codiert: $4=$ vital bis $0=$ tot, s. S. 27] in bewachsenen Bereichen auf den Versuchsflächen B (n=33) und D ( $n=11)$ im Versuchsverlauf; MW u. Std.abw.; je Aufnahmezeitpunkt Ergebnisse von U-Tests (Z) auf signifikante Unterschiede zwischen den Flächen; je Fläche Ergebnisse von Friedmann-Tests $\left(\mathrm{Chi}^{2}\right)$ auf signifikante Unterschiede zwischen den Aufnahmezeitpunkten

\begin{tabular}{|l|l|l|l|l|l|l|l|l|l|l|}
\hline m.BV & $\begin{array}{l}\text { April } \\
2005\end{array}$ & & $\begin{array}{l}\text { Juni } \\
2005\end{array}$ & & $\begin{array}{l}\text { Oktober } \\
2005\end{array}$ & & $\begin{array}{l}\text { Juni } \\
2006\end{array}$ & $\begin{array}{l}\text { Oktober } \\
2006\end{array}$ & $\mathrm{Chi}^{2}$ \\
\hline $\mathrm{B}$ & $2,4 \pm 0,5$ & $<$ & $2,8 \pm 0,7$ & & $2,7 \pm 1,0$ & $>$ & $2,3 \pm 1,0$ & $2,3 \pm 1,1$ & $12,71^{*}$ \\
\hline $\mathrm{D}$ & $2,7 \pm 0,5$ & & $2,4 \pm 1,0$ & & $2,7 \pm 1,1$ & & $2,5 \pm 1,4$ & $2,4 \pm 1,3$ & 3,34 \\
\hline $\mathrm{Z}$ & & & $-1,24$ & & 0,57 & & 1,63 & & 0,55 & \\
\hline
\end{tabular}

$>$ signifikanter Rückgang, < signifikanter Anstieg der Vitalität laut Wilcoxon-Test

Auf Fläche D lag die Vitalität der Ahorne in bewachsenen Bereichen im Mittel konstant bei Werten zwischen 2,7 $\pm 0,5$ und 2,4 $\pm 1,3$. Auf Fläche B stieg der Mittelwert von der Anlage im April 2005 bis Juni 2005 entgegen dem allgemeinen Trend (Absinken durch „Pflanzschock“) sogar signifikant von 2,4 $\pm 0,5$ auf recht gute 2,8 $\pm 0,7$ an. Zum 2. Versuchsjahr erfolgte eine leichte, signifikante Abnahme auf 2,3 \pm 1,0, die sich auch in der leichten Abnahme des durchschnittlichen Mittelwertes aller Ahorne in bewachsenen Bereichen insgesamt widerspiegelt (s. ab S. 260).

\subsubsection{Eberesche}

Der Standort auf einer der drei Versuchsflächen beeinflusste die Vitalitätsentwicklung der Ebereschen insgesamt sowie der Ebereschen in Bereichen ohne und mit Spontanvegetation.

\section{Ebereschen insgesamt}

Die mittlere Vitalität der Ebereschen auf Versuchsfläche B blieb im gesamten Versuchsverlauf konstant, auf Fläche A und D dagegen nicht (s. Tab. 81).

Hier fiel der Wert von der Anlage bis zur Aufnahme im Juni 2005 von um „3“ auf jeweils 2,1 \pm 0,9. Auf Fläche A setzte sich das signifikante Absinken des Vitalitätsmittelwertes zum Oktober 2005 fort $(1,3 \pm 1,0)$ und blieb dann relativ konstant, während auf Fläche D im gleichen Zeitraum wieder ein leichter, signifikanter Anstieg auf 2,4 \pm 1,2 zu verzeichnen war; danach blieben die Werte ebenfalls relativ konstant.

Gründe für das deutliche Absinken der Werte auf Fläche A im 1. Versuchsjahr waren zum einen der Anstieg der Sterblichkeitsrate von 5 \% im Juni 2005 auf 28 \% im Oktober 2005 und die Zunahme an Pflanzen mit dem niedrigen Vitalitätswert „1“ (fast völlig abgestorben) von $18 \%$ auf $33 \%$. Eine signifikante Korrelation der Sterblichkeitsrate der Ebereschen mit der Versuchsfläche existierte laut entsprechender Kreuztabelle jedoch nicht ( $\mathrm{Chi}^{2}$ 5,16). Zum anderen nahmen hier im gleichen Zeitraum die Anteile an Ebereschen mit Vitalitätswerten von „2“ und „3“ von $40 \%$ auf $28 \%$ bzw. von $38 \%$ auf $13 \%$ ab. 
Tab. 81: Vitalität der Ebereschen [codiert: $4=$ vital bis $0=$ tot, s. S. 27] auf den drei Versuchsflächen A, B und D im Versuchsverlauf; MW u. Std.abw.; je Aufnahmezeitpunkt Ergebnisse von H-Tests (H) auf signifikante Unterschiede zwischen den Flächen (Buchstaben kennzeichnen homogene Gruppen nach UTests); je Fläche Ergebnisse von Friedmann-Tests $\left(\mathrm{Chi}^{2}\right)$ auf signifikante Unterschiede zwischen den Aufnahmezeitpunkten (je Fläche n=40)

\begin{tabular}{|l|l|l|l|l|l|l|l|l|l|l|}
\hline & $\begin{array}{l}\text { April } \\
2005\end{array}$ & & $\begin{array}{l}\text { Juni } \\
2005\end{array}$ & & $\begin{array}{l}\text { Oktober } \\
2005\end{array}$ & & $\begin{array}{l}\text { Juni } \\
2006\end{array}$ & $\begin{array}{l}\text { Oktober } \\
2006\end{array}$ & $\mathrm{Chi}^{2}$ \\
\hline A & $3,1 \pm 0,2$ & $>$ & $2,1 \pm 0,9$ & $>$ & $\begin{array}{l}1,3 \pm 1,0 \\
\text { a }\end{array}$ & $<$ & $\begin{array}{l}1,5 \pm 1,3 \\
\text { a }\end{array}$ & $>$ & $\begin{array}{l}1,3 \pm 1,3 \\
\text { a }\end{array}$ & $65,88^{* * *}$ \\
\hline B & $2,9 \pm 0,5$ & & $2,4 \pm 0,8$ & & $\begin{array}{l}2,6 \pm 1,1 \\
\text { b }\end{array}$ & & $\begin{array}{l}2,2 \pm 1,2 \\
\text { b }\end{array}$ & $\begin{array}{l}2,2 \pm 1,3 \\
\text { b }\end{array}$ & 6,71 \\
\hline D & $2,9 \pm 0,3$ & $>$ & $2,1 \pm 0,9$ & $<$ & $\begin{array}{l}2,4 \pm 1,2 \\
\text { b }\end{array}$ & $>$ & $\begin{array}{l}2,2 \pm 1,2 \\
\text { b }\end{array}$ & $\begin{array}{l}2,2 \pm 1,3 \\
\text { b }\end{array}$ & $14,14^{* *}$ \\
\hline H & & & 2,71 & & $28,29^{* * *}$ & & $9,03^{*}$ & & $12,86^{* *}$ & \\
\hline
\end{tabular}

$>$ signifikanter Rückgang, < signifikanter Anstieg der Vitalität laut Wilcoxon-Test

Zwei Monate nach der Pflanzung (Aufnahme Juni 2005) unterschieden sich die mittleren Vitalitätswerte der Ebereschen je nach Versuchsfläche noch nicht signifikant. Bei allen drei Aufnahmen ab Oktober 2005 war die mittlere Vitalität der Ebereschen auf Fläche A dann jedoch signifikant schlechter als auf Fläche B und D, die sich nicht unterschieden (s. Abb. 164).

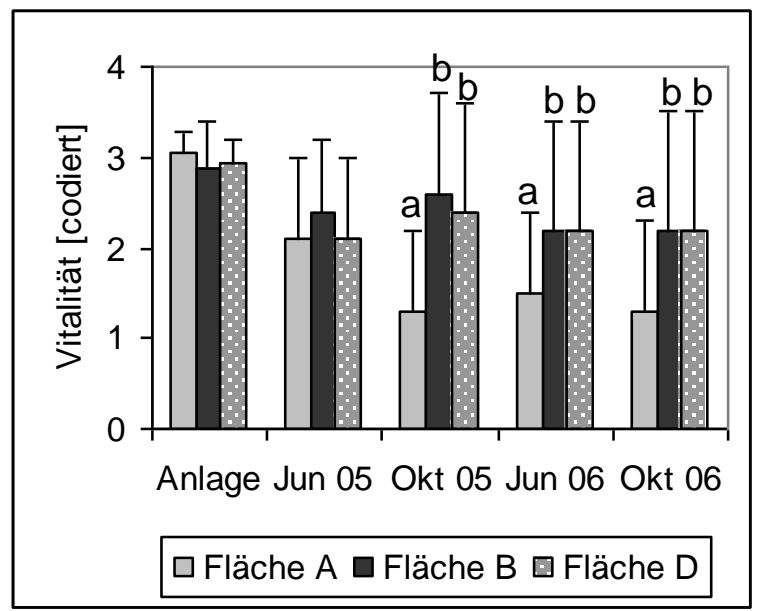

Abb. 164: Vitalität der Ebereschen [codiert: $4=$ vital bis $0=$ tot, s. S. 27] auf den drei Versuchsflächen A, B und D im Versuchsverlauf; MW u. Std.abw.; Buchstaben kennzeichnen ggf. je Aufnahmezeitpunkt homogene Gruppen nach U-Tests (je Fläche $n=40$ )

\section{Ebereschen in Bereichen ohne Spontanvegetation}

Betrachtet man ausschließlich die Ebereschen, die zufällig in Teilbereiche ohne spätere Bodenbesiedelung gepflanzt wurden, fällt zunächst auf, dass die durchschnittlichen Vitalitätswerte außer zum Anlagezeitpunkt in einem eher schwachen Wertebereich zwischen „1“ (fast völlig abgestorben) und „2“ (kümmerliche Entwicklung) lagen.

Auf Fläche A sank der Mittelwert im Versuchsverlauf signifikant von 3,1 $\pm 0,2$ auf 1,3 $\pm 1,3 \mathrm{im}$ Oktober 2006. Auf Fläche B war die Abnahme der mittleren Vitalität im Verlauf des Untersuchungszeitraums von 2,8 $\pm 0,4$ auf schließlich 1,2 $\pm 1,4$ aufgrund der großen Standardabweichungen nicht signifikant. Die durchschnittliche Vitalität der Ebereschen auf 
Fläche D nahm auf diesen Standorten nach anfänglichen 2,9 $\pm 0,3$ signifikant auf Werte zwischen $2,0 \pm 1,3$ und $1,7 \pm 1,3$ ab.

Tab. 82: Vitalität der Ebereschen [codiert: $4=$ vital bis $0=$ tot, s. S. 27] in vegetationsfreien Bereichen auf den drei Versuchsflächen A $(n=40), B(n=10)$ und D $(n=26)$ im Versuchsverlauf; MW u. Std.abw.; je Aufnahmezeitpunkt Ergebnisse von H-Tests $(\mathrm{H})$ auf signifikante Unterschiede zwischen den Flächen; je Fläche Ergebnisse von Friedmann-Tests $\left(\mathrm{Chi}^{2}\right)$ auf signifikante Unterschiede zwischen den Aufnahmezeitpunkten

\begin{tabular}{|l|l|l|l|l|l|l|l|l|l|l|}
\hline o.BV & $\begin{array}{l}\text { April } \\
2005\end{array}$ & & $\begin{array}{l}\text { Juni } \\
2005\end{array}$ & & $\begin{array}{l}\text { Oktober } \\
2005\end{array}$ & & $\begin{array}{l}\text { Juni } \\
2006\end{array}$ & & $\begin{array}{l}\text { Oktober } \\
2006\end{array}$ & Chi $^{2}$ \\
\hline A & $3,1 \pm 0,2$ & $>$ & $2,1 \pm 0,9$ & & $1,3 \pm 1,0$ & $<$ & $1,5 \pm 1,3$ & $>$ & $1,3 \pm 1,3$ & $65,88^{* * *}$ \\
\hline B & $2,8 \pm 0,4$ & & $1,9 \pm 0,9$ & & $1,8 \pm 1,4$ & & $1,7 \pm 1,5$ & & $1,2 \pm 1,4$ & 5,64 \\
\hline D & $2,9 \pm 0,3$ & $>$ & $1,8 \pm 0,8$ & & $2,0 \pm 1,3$ & & $1,8 \pm 1,3$ & $>$ & $1,7 \pm 1,3$ & $19,03^{* * *}$ \\
\hline H & & & 2,70 & & $6,00^{*}$ & & 0,68 & & 1,54 & \\
\hline
\end{tabular}

> signifikanter Rückgang, < signifikanter Anstieg der Vitalität laut Wilcoxon-Test

Auf allen drei Flächen (vegetationsfreie Bereiche) erfolgte die deutlichste Vitalitätsabnahme der Ebereschen um jeweils eine ganze Bewertungsstufe bereits kurz nach der Pflanzung (s. Tab. 82).

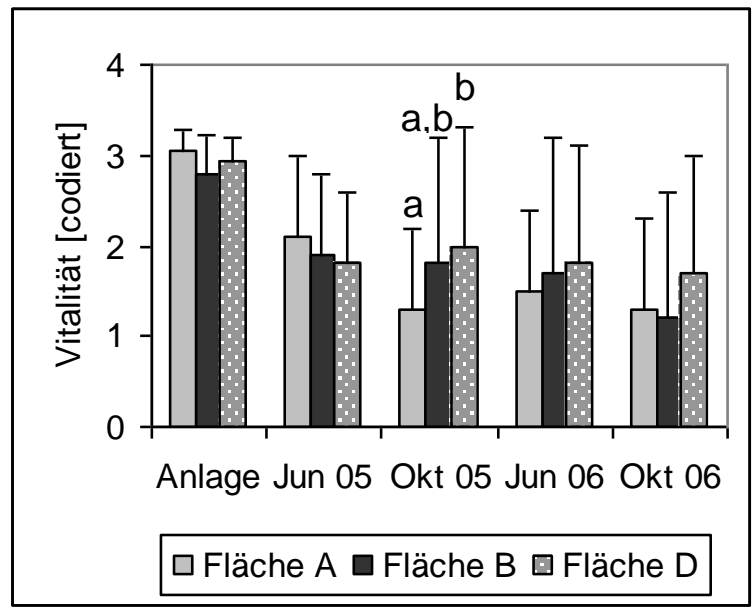

Abb. 165: Vitalität der Ebereschen [codiert: $4=$ vital bis $0=$ tot, s. S. 27] in vegetationsfreien Bereichen auf den drei Versuchsflächen A $(n=40), B(n=10)$ und $D(n=26)$ im Versuchsverlauf; MW u. Std.abw.; Buchstaben kennzeichnen ggf. je Aufnahmezeitpunkt homogene Gruppen nach U-Tests

Der einzige statistisch signifikante Unterschied zwischen den mittleren Vitalitätswerten der Ebereschen in vegetationsfreien Bereichen bestand bei der Aufnahme im Oktober 2005 (s. Abb. 165). Dabei lag der Mittelwert auf Fläche D mit 2,0 \pm 1,3 signifikant höher als auf Fläche A mit $1,3 \pm 1,0$. Im weiteren Versuchsverlauf spielte in diesen Bereichen der Standort auf einer der drei Versuchsflächen keine Rolle mehr für die Vitalitätsentwicklung der Ebereschen.

\section{Ebereschen in Bereichen mit Spontanvegetation}

Die Analyse der Vitalitätsbewertungen ausschließlich der Ebereschen, die zufällig in Bereiche mit späterer Entwicklung von Spontanvegetation gepflanzt wurden, ergab zum einen bessere Durchschnittswerte als in unbesiedelten Bereichen, zum anderen war im gesamten Untersuchungszeitraum keine signifikante Veränderung der Mittelwerte feststellbar (s. Tab. 83). 
Tab. 83: Vitalität der Ebereschen [codiert: $4=$ vital bis $0=$ tot, s. S. 27] in bewachsenen Bereichen auf den Versuchsflächen B $(n=30)$ und D $(n=14)$ im Versuchsverlauf; MW u. Std.abw.; je Aufnahmezeitpunkt Ergebnisse von U-Tests (Z) auf signifikante Unterschiede zwischen den Flächen; je Fläche Ergebnisse von Friedmann-Tests $\left(\mathrm{Chi}^{2}\right)$ auf signifikante Unterschiede zwischen den Aufnahmezeitpunkten

\begin{tabular}{|l|l|l|l|l|l|l|l|l|l|l|}
\hline m.BV & $\begin{array}{l}\text { April } \\
2005\end{array}$ & $\begin{array}{l}\text { Juni } \\
2005\end{array}$ & $\begin{array}{l}\text { Oktober } \\
2005\end{array}$ & $\begin{array}{l}\text { Juni } \\
2006\end{array}$ & $\begin{array}{l}\text { Oktober } \\
2006\end{array}$ & Chi $^{2}$ \\
\hline B & $2,9 \pm 0,5$ & & $2,5 \pm 0,7$ & & $2,8 \pm 0,9$ & & $2,4 \pm 1,1$ & $2,5 \pm 1,1$ & 5,35 \\
\hline D & $2,9 \pm 0,3$ & $2,6 \pm 0,6$ & & $3,3 \pm 0,5$ & & $3,0 \pm 0,4$ & $3,0 \pm 0,6$ & 4,77 \\
\hline Z & & 0,55 & & $1,77^{*}$ & & $2,05^{*}$ & & 1,29 & \\
\hline
\end{tabular}

Die Vitalität der Ebereschen auf diesen besser versorgten Standorten blieb somit konstant bei mäßig zufrieden stellenden bzw. guten Werten. Sie lagen auf Fläche B $(2,9 \pm 0,5$ bei Pflanzung) zwischen $2,4 \pm 1,1$ und 2,8 $\pm 0,9$, auf Fläche D (2,9 $\pm 0,3$ bei Pflanzung) zunächst bei 2,6 $\pm 0,6$, dann zwischen $3,0 \pm 0,4 / 0,5$ und 3,3 $\pm 0,5$.

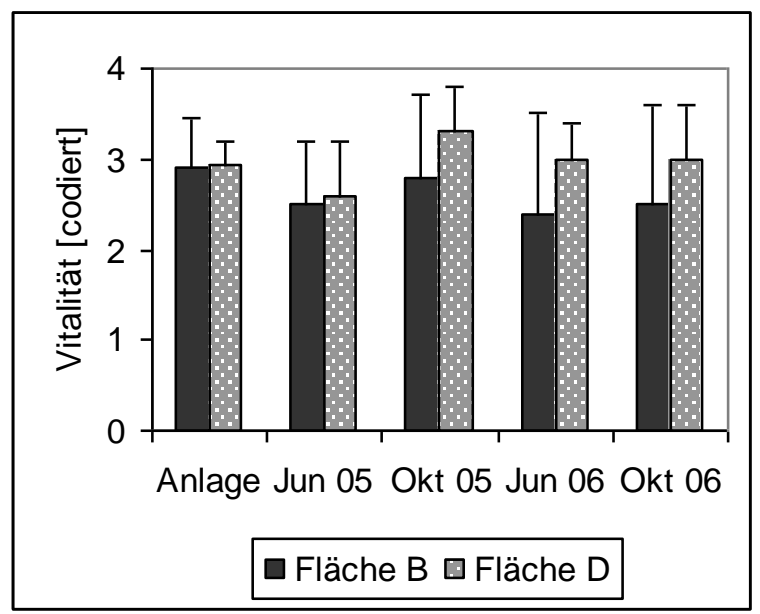

Abb. 166: Vitalität der Ebereschen [codiert: $4=$ vital bis $0=$ tot, s. S. 27] in bewachsenen Bereichen auf den Versuchsflächen B ( $\mathrm{n}=30)$ und D ( $\mathrm{n}=14)$ im Versuchsverlauf; MW u. Std.abw.; im Oktober 2005 und im Juni 2006 signifikante Unterschiede nach U-Tests

Im Oktober 2005 sowie im Juni 2006 waren die Unterschiede zwischen den Vitalitätswerten der Ebereschen in den bewachsenen Bereichen auf Fläche B und Fläche D signifikant (s. Abb. 166). Folglich fand zwar auf beiden Flächen gleichermaßen in Teilbereichen eine Besiedelung mit Bodenvegetation statt, die Standortbedingungen in diesen Teilbereichen waren dennoch so unterschiedlich, dass an der Baumart Eberesche unterschiedliche Vitalitätsentwicklungen (auf Fläche D besser als auf Fläche B) abgelesen werden konnten.

\subsubsection{Schwarz-Erle}

Der Standort auf einer der drei Versuchsflächen beeinflusste die Vitalitätsentwicklung der Erlen insgesamt sowie der Erlen in Bereichen ohne und mit Spontanvegetation. 


\section{Erlen insgesamt}

Der mittlere Vitalitätswert der Erlen auf den drei Versuchsflächen entwickelte sich im Verlauf des Untersuchungszeitraums unterschiedlich (s. Tab. 84). Auf allen drei Flächen sank er von der Anlage im April 2005 bis zur Aufnahme im Juni 2005 signifikant. Auf Fläche A nahm er von anfänglich 3,3 $\pm 0,5$ auf 2,7 $\pm 1,1$ im Juni $2005 \mathrm{ab}$, blieb dann konstant und sank schließlich nochmals signifikant auf $1,9 \pm 1,3$ im Oktober 2006. Auf Fläche B lag er nach anfänglich $3,7 \pm 0,5$ bei 2,8 $\pm 0,7$ im Juni 2005, nahm dann wieder signifikant auf 3,2 $\pm 1,1$ im Oktober 2005 zu und sank schließlich zweimal leicht, aber signifikant auf zuletzt immer noch recht gute $2,7 \pm 1,4$. Auf Fläche D betrug der Durchschnittswert zu Beginn 3,9 \pm 0,4, im Juni 2005 dann nur noch 2,0 \pm 0,8 . Nach einem signifikanten Anstieg zum Oktober 2005 lag er bei 2,4 $\pm 1,3$ und blieb bis zum Ende recht konstant.

Tab. 84: Vitalität der Erlen [codiert: $4=$ vital bis $0=$ tot, s. S. 27] auf den drei Versuchsflächen A, B und D im Versuchsverlauf; MW u. Std.abw.; je Aufnahmezeitpunkt Ergebnisse von H-Tests (H) auf signifikante Unterschiede zwischen den Flächen (Buchstaben kennzeichnen homogene Gruppen nach U-Tests); je Fläche Ergebnisse von Friedmann-Tests $\left(\mathrm{Chi}^{2}\right)$ auf signifikante Unterschiede zwischen den Aufnahmezeitpunkten (je Fläche $n=40$ )

\begin{tabular}{|l|l|l|l|l|l|l|l|l|l|l|}
\hline & $\begin{array}{l}\text { April } \\
2005\end{array}$ & & $\begin{array}{l}\text { Juni } \\
2005\end{array}$ & & $\begin{array}{l}\text { Oktober } \\
2005\end{array}$ & & $\begin{array}{l}\text { Juni } \\
2006\end{array}$ & $\begin{array}{l}\text { Oktober } \\
2006\end{array}$ & Chi $^{2}$ \\
\hline A & $3,3 \pm 0,5$ & $>$ & $\begin{array}{l}2,7 \pm 1,1 \\
\mathrm{~b}\end{array}$ & $\begin{array}{l}2,5 \pm 1,3 \\
\mathrm{a}\end{array}$ & & $2,5 \pm 1,5$ & $>$ & $\begin{array}{l}1,9 \pm 1,3 \\
\mathrm{a}\end{array}$ & $35,20^{* * *}$ \\
\hline $\mathrm{B}$ & $3,7 \pm 0,5$ & $>$ & $\begin{array}{l}2,8 \pm 0,7 \\
\mathrm{~b}\end{array}$ & $<$ & $\begin{array}{l}3,2 \pm 1,1 \\
\mathrm{~b}\end{array}$ & $>$ & $3,0 \pm 1,3$ & $>$ & $\begin{array}{l}2,7 \pm 1,4 \\
\mathrm{~b}\end{array}$ & $28,73^{* * *}$ \\
\hline $\mathrm{D}$ & $3,9 \pm 0,4$ & $>$ & $\begin{array}{l}2,0 \pm 0,8 \\
\mathrm{a}\end{array}$ & $<$ & $\begin{array}{l}2,4 \pm 1,3 \\
\mathrm{a}\end{array}$ & & $2,4 \pm 1,5$ & $\begin{array}{l}2,3 \pm 1,5 \\
\mathrm{a}, \mathrm{b}\end{array}$ & $47,19^{* * *}$ \\
\hline H & & & $19,59^{* * *}$ & & $12,95^{* *}$ & & 5,11 & & $8,09^{*}$ & \\
\hline
\end{tabular}

> signifikanter Rückgang, < signifikanter Anstieg der Vitalität laut Wilcoxon-Test

$\mathrm{Zu}$ allen Aufnahmezeitpunkten ausgenommen im Juni 2006 ließen sich je nach Versuchsfläche signifikante Unterschiede zwischen den durchschnittlichen Vitalitätswerten der Erlen feststellen, auch wenn laut der entsprechenden Kreuztabelle keine signifikante Korrelation der Sterblichkeitsrate der Erlen mit der Versuchsfläche existiert $\left(\mathrm{Chi}^{2}{ }^{1,57}\right)$.

Im Juni 2005, zwei Monate nach Versuchsanlage, war die mittlere Vitalität der Erlen auf Fläche D mit 2,0 $\pm 0,8$ signifikant schlechter als auf den anderen beiden Flächen (A: 2,7 $\pm 1,1 ; B: 2,8 \pm 0,7)$. Im Oktober 2005 war der Durchschnittswert auf Fläche B mit 3,2 \pm 1,1 signifikant besser als auf Fläche A $(2,5 \pm 1,3)$ und $D(2,4 \pm 1,3)$. Bei Versuchsabschluss ein Jahr später bestanden signifikante Unterschiede zwischen der durchschnittlichen Vitalität der Erlen auf Fläche A $(1,9 \pm$ $1,3)$ und B $(2,7 \pm 1,4)$, während der Wert auf Fläche D $(2,3 \pm 1,5)$ sich nicht signifikant von den anderen beiden Flächen unterschied (s. Abb. 167). 


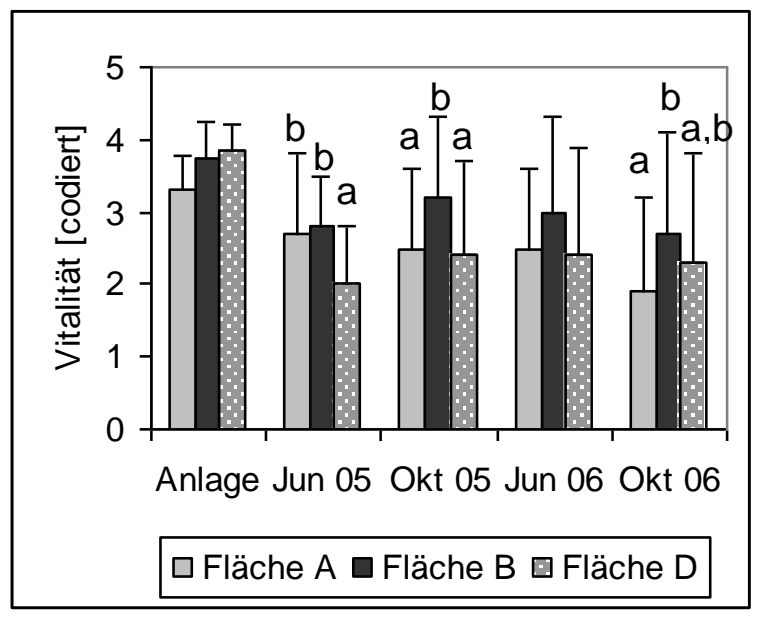

Abb. 167: Vitalität der Erlen [codiert: 4 = vital bis $0=$ tot, s. S. 27] auf den drei Versuchsflächen A, B und D im Versuchsverlauf; MW u. Std.abw.; Buchstaben kennzeichnen ggf. je Aufnahmezeitpunkt homogene Gruppen nach U-Tests (je Fläche $n=40$ )

\section{Erlen in Bereichen ohne Spontanvegetation}

Bei den Erlen, die zufällig in Teilbereiche ohne spätere Bodenbesiedelung gepflanzt wurden, nahm der mittlere Vitalitätswert auf allen drei Versuchsflächen zu Beginn und noch einmal zum Ende des Untersuchungszeitraums signifikant ab (s. Tab. 85).

Auf Fläche A sank der Wert von 3,3 \pm 0,5 bei Anlage auf 2,7 \pm 1,1 im Juni 2005 und schließlich auf 1,9 $\pm 1,3$ im Oktober 2006. Auf Fläche B nahm er von anfänglich 3,9 $\pm 0,4$ auf 2,1 $\pm 0,6 \mathrm{im} \mathrm{Juni}$ 2005 und zuletzt auf sehr geringe 0,9 $\pm 1,1$ im Oktober 2006 ab. Auf Fläche D sank er von zunächst 3,8 $\pm 0,4$ auf 1,8 $\pm 0,8$ im Juni 2005 bzw. 1,8 $\pm 1,5$ im Oktober 2006.

Tab. 85: Vitalität der Erlen [codiert: $4=$ vital bis $0=$ tot, s. S. 27] in vegetationsfreien Bereichen auf den drei Versuchsflächen A $(n=40), B(n=8)$ und D $(n=26)$ im Versuchsverlauf; MW u. Std.abw.; je Aufnahmezeitpunkt Ergebnisse von H-Tests $(\mathrm{H})$ auf signifikante Unterschiede zwischen den Flächen; je Fläche Ergebnisse von Friedmann-Tests $\left(\mathrm{Chi}^{2}\right)$ auf signifikante Unterschiede zwischen den Aufnahmezeitpunkten

\begin{tabular}{|l|l|l|l|l|l|l|l|l|l|l|}
\hline o.BV & $\begin{array}{l}\text { April } \\
2005\end{array}$ & & $\begin{array}{l}\text { Juni } \\
2005\end{array}$ & $\begin{array}{l}\text { Oktober } \\
2005\end{array}$ & $\begin{array}{l}\text { Juni } \\
2006\end{array}$ & $\begin{array}{l}\text { Oktober } \\
2006\end{array}$ & Chi $^{2}$ \\
\hline A & $3,3 \pm 0,5$ & $>$ & $2,7 \pm 1,1$ & & $2,5 \pm 1,3$ & & $2,5 \pm 1,5$ & $>$ & $1,9 \pm 1,3$ & $35,20^{* * *}$ \\
\hline B & $3,9 \pm 0,4$ & $>$ & $2,1 \pm 0,6$ & & $2,1 \pm 1,1$ & & $1,6 \pm 1,3$ & $>$ & $0,9 \pm 1,1$ & $20,75^{* * *}$ \\
\hline D & $3,8 \pm 0,4$ & $>$ & $1,8 \pm 0,8$ & $2,1 \pm 1,2$ & $2,0 \pm 1,5$ & $>$ & $1,8 \pm 1,5$ & $36,76^{* * *}$ \\
\hline H & & & $13,09^{* *}$ & & 2,82 & & 4,01 & & 3,47 & \\
\hline
\end{tabular}

> signifikanter Rückgang, < signifikanter Anstieg der Vitalität laut Wilcoxon-Test

Nur im Juni 2005, zwei Monate nach der Pflanzung, unterschied sich die durchschnittliche Vitalität der Erlen mit Standorten in unbewachsenen Bereichen je nach Versuchsfläche statistisch signifikant. Dabei lag der Wert auf Fläche A signifikant höher als auf B und D (s. Abb. 168). 


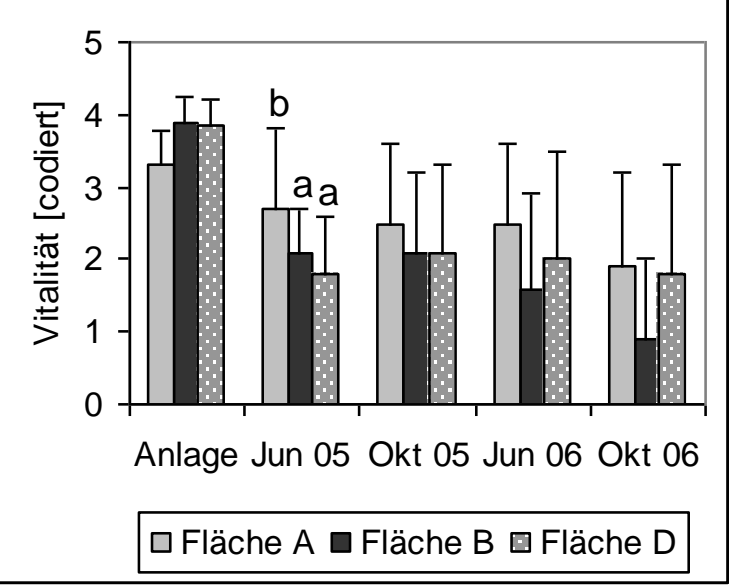

Abb. 168: Vitalität der Erlen [codiert: $4=$ vital bis $0=$ tot, s. S. 27] in vegetationsfreien Bereichen auf den drei Versuchsflächen A $(n=40)$, B ( $n=8)$ und D ( $n=26)$ im Versuchsverlauf; MW u. Std.abw.; Buchstaben kennzeichnen ggf. je Aufnahmezeitpunkt homogene Gruppen nach U-Tests

\section{Erlen in Bereichen mit Spontanvegetation}

Die Vitalität der Erlen, die auf Fläche B und D zufällig in Bereiche mit späterer Entwicklung von Spontanvegetation (bessere Standortbedingungen) gepflanzt worden waren, blieb unabhängig von der Versuchsfläche bis zum Ende des zweijährigen Untersuchungszeitraums relativ konstant gut (s. Tab. 86).

Tab. 86: Vitalität der Erlen [codiert: $4=$ vital bis $0=$ tot, s. S. 27] in bewachsenen Bereichen auf den Versuchsflächen B (n=32) und D (n=14) im Versuchsverlauf; MW u. Std.abw.; je Aufnahmezeitpunkt Ergebnisse von U-Tests (Z) auf signifikante Unterschiede zwischen den Flächen; je Fläche Ergebnisse von Friedmann-Tests $\left(\mathrm{Chi}^{2}\right)$ auf signifikante Unterschiede zwischen den Aufnahmezeitpunkten

\begin{tabular}{|l|l|l|l|l|l|l|l|l|l|l|}
\hline m.BV & $\begin{array}{l}\text { April } \\
2005\end{array}$ & & $\begin{array}{l}\text { Juni } \\
2005\end{array}$ & & $\begin{array}{l}\text { Oktober } \\
2005\end{array}$ & & $\begin{array}{l}\text { Juni } \\
2006\end{array}$ & $\begin{array}{l}\text { Oktober } \\
2006\end{array}$ & Chi $^{2}$ \\
\hline B & $3,7 \pm 0,5$ & $>$ & $2,9 \pm 0,6$ & $<$ & $3,5 \pm 0,9$ & & $3,4 \pm 1,0$ & $>$ & $3,2 \pm 1,1$ & $20,63^{* * *}$ \\
\hline D & $3,9 \pm 0,4$ & $>$ & $2,3 \pm 0,7$ & $<$ & $3,1 \pm 1,1$ & & $3,1 \pm 1,3$ & & $3,1 \pm 1,2$ & $16,29^{* *}$ \\
\hline Z & & & $-2,94^{* *}$ & & $-1,58$ & & $-0,74$ & & 0,18 & \\
\hline
\end{tabular}

$>$ signifikanter Rückgang, < signifikanter Anstieg der Vitalität laut Wilcoxon-Test

Der Pflanzschock ließ auf beiden Flächen die durchschnittliche Vitalität zwar zunächst signifikant absinken (auf Fläche B von 3,7 $\pm 0,5$ auf 2,9 $\pm 0,6$; auf Fläche D von 3,9 $\pm 0,4$ auf 2,3 \pm $0,7)$. Bereits während der ersten Vegetationszeit wurde dieser jedoch überwunden, so dass die Vitalitätsmittelwerte bis Oktober 2005 wieder signifikant auf 3,5 \pm 0,9 bzw. 3,1 \pm 1,1 anstiegen. Die leichte signifikante Abnahme des Wertes auf Fläche B zum Ende des Versuchs von 3,4 $\pm 1,0$ auf 3,2 $\pm 1,1$ minderte das gute Gesamtergebnis auf diesen Standorten nicht.

Lediglich im Juni 2005, zwei Monate nach der Pflanzung, bestand ein signifikanter Unterschied zwischen dem Vitalitätswert auf Fläche B $(2,9 \pm 0,6)$ und dem niedrigeren Wert $(2,3 \pm 0,7)$ auf Fläche D (s. Abb. 169). Obwohl sich auf beiden Standorten im Versuchsverlauf Spontanvegetation etablieren konnte, boten sie den Erlen offensichtlich zumindest unterschiedlich gute "Startbedingungen“. 


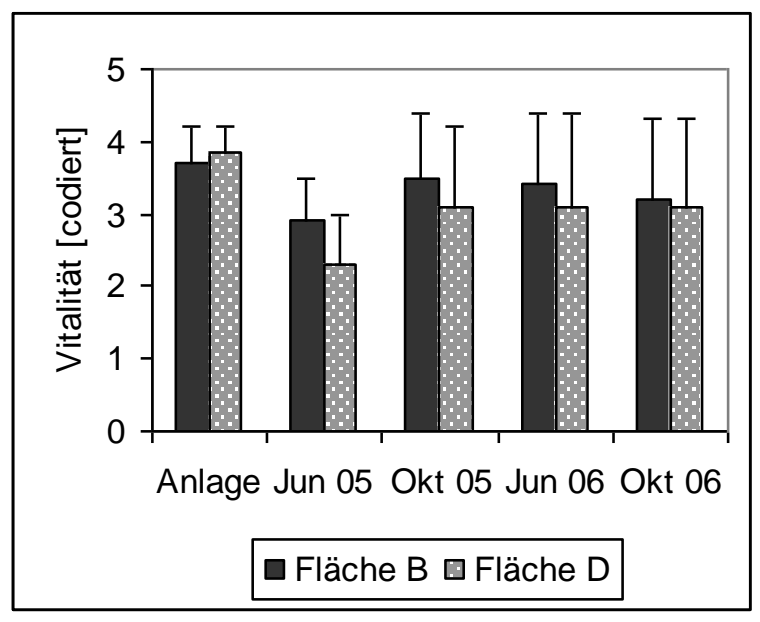

Abb. 169: Vitalität der Erlen [codiert: $4=$ vital bis $0=$ tot, s. S. 27] in bewachsenen Bereichen auf den Versuchsflächen B (n=32) und D (n=14) im Versuchsverlauf; MW u. Std.abw.; im Juni 2005 signifikante Unterschiede nach U-Tests

\subsubsection{Douglasie}

Der Standort auf einer der drei Versuchsflächen beeinflusste die Vitalitätsentwicklung der Douglasien insgesamt sowie der Douglasien in Bereichen mit Spontanvegetation.

\section{Douglasien insgesamt}

Die mittleren Vitalitätswerte der Douglasien auf allen drei Versuchsflächen nahmen von der Anlage im April 2005 bis Juni 2005 signifikant ab (s. Tab. 87); auf den Fläche A und D deutlich von 3,2 $\pm 0,4$ bzw. $3,4 \pm 0,5$ auf nur noch $1,9 \pm 1,0$ bzw. 1,8 $\pm 1,1$, auf Fläche B dagegen nur leicht von 2,9 $\pm 0,4$ auf immer noch mäßig gute $2,7 \pm 0,8$. Im weiteren Verlauf der 1 . Vegetationszeit blieb die Durchschnittsvitalität der Douglasien auf allen drei Flächen konstant.

Tab. 87: Vitalität der Douglasien [codiert: $4=$ vital bis $0=$ tot, s. S. 27] auf den drei Versuchsflächen A, B und D im Versuchsverlauf; MW u. Std.abw.; je Aufnahmezeitpunkt Ergebnisse von H-Tests (H) auf signifikante Unterschiede zwischen den Flächen (Buchstaben kennzeichnen homogene Gruppen nach UTests); je Fläche Ergebnisse von Friedmann-Tests $\left(\mathrm{Chi}^{2}\right)$ auf signifikante Unterschiede zwischen den Aufnahmezeitpunkten (je Fläche n=64)

\begin{tabular}{|l|l|l|l|l|l|l|l|l|l|l|}
\hline & $\begin{array}{l}\text { April } \\
2005\end{array}$ & & $\begin{array}{l}\text { Juni } \\
2005\end{array}$ & $\begin{array}{l}\text { Oktober } \\
2005\end{array}$ & $\begin{array}{l}\text { Juni } \\
2006\end{array}$ & $\begin{array}{l}\text { Oktober } \\
2006\end{array}$ & $\mathrm{Chi}^{2}$ \\
\hline A & $3,2 \pm 0,4$ & $>$ & $\begin{array}{l}1,9 \pm 1,0 \\
\mathrm{a}\end{array}$ & $\begin{array}{l}1,9 \pm 1,1 \\
\mathrm{a}\end{array}$ & $>\begin{array}{l}1,2 \pm 1,1 \\
\mathrm{a}\end{array}$ & $\begin{array}{l}1,2 \pm 1,2 \\
\mathrm{a}\end{array}$ & $104,4^{* * *}$ \\
\hline $\mathrm{B}$ & $2,9 \pm 0,4$ & $>$ & $\begin{array}{l}2,7 \pm 0,8 \\
\mathrm{~b}\end{array}$ & $\begin{array}{l}2,7 \pm 0,8 \\
\mathrm{~b}\end{array}$ & $>$ & $\begin{array}{l}2,3 \pm 1,2 \\
\mathrm{c}\end{array}$ & $>\begin{array}{l}2,2 \pm 1,2 \\
\mathrm{~b}\end{array}$ & $17,09^{* *}$ \\
\hline $\mathrm{D}$ & $3,4 \pm 0,5$ & $>$ & $\begin{array}{l}1,8 \pm 1,1 \\
\mathrm{a}\end{array}$ & $\begin{array}{l}1,8 \pm 1,3 \\
\mathrm{a}\end{array}$ & $\begin{array}{l}1,7 \pm 1,6 \\
\mathrm{~b}\end{array}$ & $>\begin{array}{l}1,5 \pm 1,5 \\
\mathrm{a}\end{array}$ & $73,16^{* * *}$ \\
\hline $\mathrm{H}$ & & & $29,94^{* * *}$ & & $22,36^{* * *}$ & & $22,93^{* * *}$ & & $18,59^{* * *}$ & \\
\hline
\end{tabular}

$>$ signifikanter Rückgang der Vitalität laut Wilcoxon-Test 
Zum 2. Untersuchungsjahr sank der Vitalitätsmittelwert auf Fläche A signifikant auf geringe 1,2 $\pm 1,1$, auf Fläche B auf mäßige 2,3 $\pm 1,2$ im Juni 2005 und 2,2 $\pm 1,2$ im Oktober 2005. Auf Fläche D nahm die Vitalität zum Versuchsende signifikant auf geringe 1,5 $\pm 1,5 \mathrm{ab}$.

$\mathrm{Zu}$ allen vier Aufnahmezeitpunkten ab Juni 2005 wies Fläche B einen signifikant höheren Mittelwert auf als die übrigen beiden Flächen (s. Abb. 170). Die mittlere Vitalität der Douglasien auf Fläche D lag zumindest im Juni 2006 signifikant höher als auf Fläche A. Zusätzlich weist eine entsprechende Kreuztabelle auf eine signifikante Korrelation der Sterblichkeitsrate der Douglasien mit der Versuchsfläche hin ( $\left.\mathrm{Chi}^{2} 17,35^{* * *}\right)$.

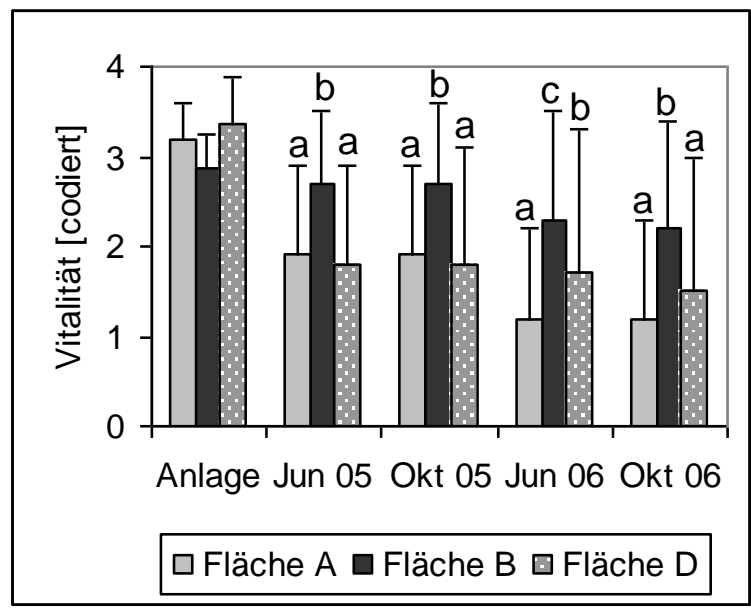

Abb. 170: Vitalität der Douglasien [codiert: $4=$ vital bis $0=$ tot, s. S. 27] auf den drei Versuchsflächen A, B und D im Versuchsverlauf; MW u. Std.abw.; Buchstaben kennzeichnen ggf. je Aufnahmezeitpunkt homogene Gruppen nach U-Tests (je Fläche $n=64$ )

\section{Douglasien in Bereichen ohne Spontanvegetation}

Die vegetationsfreien Bereiche auf allen drei Versuchsflächen A, B und D boten den Douglasien gleichermaßen relativ ungünstige Standortbedingungen. Die mittlere Vitalität der Douglasien sank hier im 1. Jahr auf 1,8, im 2. Jahr auf 1,2 bzw. 1,1. Zwischen den drei Versuchsflächen bestanden keine signifikanten Unterschiede.

\section{Douglasien in Bereichen mit Spontanvegetation}

Bei Analyse der Vitalitätsbewertungen ausschließlich der Douglasien, die zufällig in Bereiche mit späterer Entwicklung von Spontanvegetation gepflanzt wurden, fiel zunächst auf, dass in diesen Bereichen auf Fläche B die Mittelwerte bis zum Ende des Untersuchungszeitraums nicht signifikant zurückgingen (s. Tab. 88). Die Vitalität der Douglasien auf diesen besser versorgten Standorten lag also auf Fläche B zumindest über die ersten zwei Jahre hinweg konstant bei recht guten Werten von knapp unter „3“. Auf Fläche D sank dagegen auch in mit Spontanvegetation besiedelten Bereichen die Vitalität der Douglasien zu Beginn signifikant von 3,4 \pm 0,5 auf 2,0 \pm 1,0 , um während des restlichen Versuchsverlaufs bei sehr mäßigen Werten von knapp über „2“ zu verbleiben. 
Tab. 88: Vitalität der Douglasien [codiert: $4=$ vital bis $0=$ tot, s. S. 27] in bewachsenen Bereichen auf den Versuchsflächen B $(n=44)$ und D $(n=29)$ im Versuchsverlauf; MW u. Std.abw.; je Aufnahmezeitpunkt Ergebnisse von U-Tests (Z) auf signifikante Unterschiede zwischen den Flächen; je Fläche Ergebnisse von Friedmann-Tests $\left(\mathrm{Chi}^{2}\right)$ auf signifikante Unterschiede zwischen den Aufnahmezeitpunkten

\begin{tabular}{|l|l|l|l|l|l|l|l|l|l|l|}
\hline m.BV & $\begin{array}{l}\text { April } \\
2005\end{array}$ & $\begin{array}{l}\text { Juni } \\
2005\end{array}$ & $\begin{array}{l}\text { Oktober } \\
2005\end{array}$ & $\begin{array}{l}\text { Juni } \\
2006\end{array}$ & $\begin{array}{l}\text { Oktober } \\
2006\end{array}$ & Chi $^{2}$ \\
\hline B & $2,8 \pm 0,4$ & & $2,9 \pm 0,7$ & & $3,0 \pm 0,7$ & & $2,8 \pm 0,9$ & & $2,6 \pm 0,9$ & 4,59 \\
\hline D & $3,4 \pm 0,5$ & $>$ & $2,0 \pm 1,0$ & & $2,1 \pm 1,3$ & & $2,2 \pm 1,6$ & $>$ & $2,1 \pm 1,6$ & $25,23^{* *}$ \\
\hline Z & & & $-3,89 * * *$ & & $-3,11^{* * *}$ & & $-1,45$ & & $-1,28$ & \\
\hline
\end{tabular}

$>$ signifikanter Rückgang der Vitalität laut Wilcoxon-Test

Im 1. Versuchsjahr 2005 waren in den im Versuchsverlauf bewachsenen Bereichen die durchschnittlichen Vitalitätswerte der Douglasien auf Fläche B signifikant höher als auf Fläche D (s. Abb. 171). Zwar fand auf beiden Flächen in manchen Bereichen diese Besiedelung mit Bodenvegetation statt, die Standortbedingungen waren dennoch so unterschiedlich, dass sich die Baumart Douglasie zumindest im ersten Pflanzjahr in diesen Bereichen auf Fläche B signifikant besser entwickelte als auf Fläche D.

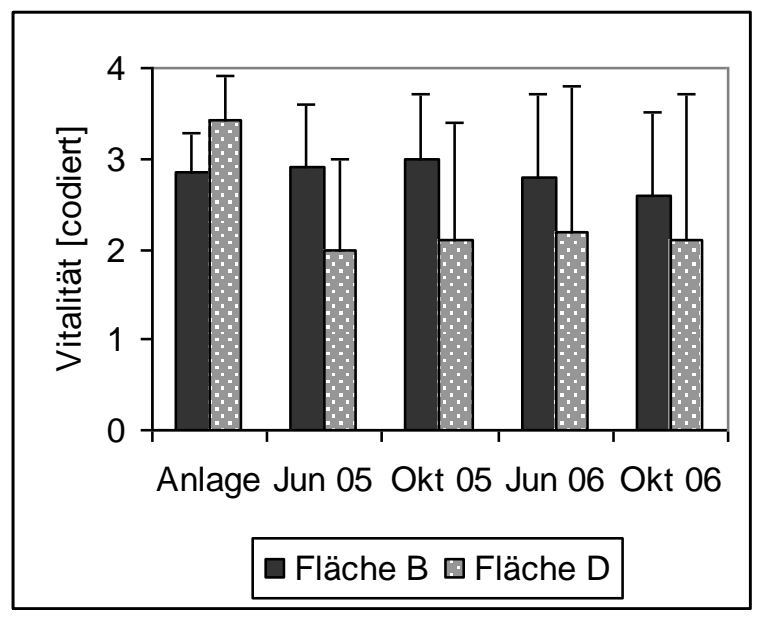

Abb. 171: Vitalität der Douglasien [codiert: $4=$ vital bis $0=$ tot, s. S. 27] in bewachsenen Bereichen auf den Versuchsflächen B $(n=44)$ und D ( $n=29)$ im Versuchsverlauf; MW u. Std.abw.; im Juni und Oktober 2005 signifikante Unterschiede nach U-Tests

\subsubsection{Wald-Kiefer}

Der Standort auf einer der drei Versuchsflächen beeinflusste die Vitalitätsentwicklung der Kiefern insgesamt sowie der Kiefern in Bereichen mit Spontanvegetation.

\section{Kiefern insgesamt}

Bei Betrachtung der durchschnittlichen Vitalität der Kiefern auf den drei Versuchsflächen zeigte sich außer bei der Anlage bei allen vier Aufnahmen ein ähnliches Bild (s. Tab. 89). Stets war der Wert auf Fläche B, der nach einer anfänglichen signifikanten Abnahme von 3,0 $\pm 1,6$ auf 1,6 $\pm 1,3$ auf niedrigem Niveau relativ konstant bleibt, trotz großer Standardabweichungen bei allen Mittelwerten signifikant besser als auf den Flächen A und D (s. Abb. 172). Dort sanken die 
Durchschnittswerte von 3,1 $\pm 0,5$ bei Anlage signifikant auf $0,5 \pm 1,0$ im Juni und weiter auf $0,2 \pm$ 0,7 im Oktober 2005 (A) bzw. von 3,0 $\pm 0,5 \mathrm{zu}$ Versuchsbeginn auf 0,6 \pm 1,1 im Juni und anschließend auf $0,3 \pm 1,0$ im Oktober 2005 (D).

Tab. 89: Vitalität der Kiefern [codiert: $4=$ vital bis $0=$ tot, s. S. 27] auf den drei Versuchsflächen A, B und D im Versuchsverlauf; MW u. Std.abw.; je Aufnahmezeitpunkt Ergebnisse von H-Tests (H) auf signifikante Unterschiede zwischen den Flächen (Buchstaben kennzeichnen homogene Gruppen nach U-Tests); je Fläche Ergebnisse von Friedmann-Tests $\left(\mathrm{Chi}^{2}\right)$ auf signifikante Unterschiede zwischen den Aufnahmezeitpunkten (je Fläche $n=40$ )

\begin{tabular}{|l|l|l|l|l|l|l|l|l|l|l|}
\hline & $\begin{array}{l}\text { April } \\
2005\end{array}$ & & $\begin{array}{l}\text { Juni } \\
2005\end{array}$ & & $\begin{array}{l}\text { Oktober } \\
2005\end{array}$ & & $\begin{array}{l}\text { Juni } \\
2006\end{array}$ & $\begin{array}{l}\text { Oktober } \\
2006\end{array}$ & $\mathrm{Chi}^{2}$ \\
\hline A & $3,1 \pm 0,5$ & $>$ & $\begin{array}{l}0,5 \pm 1,0 \\
\mathrm{a}\end{array}$ & $>$ & $\begin{array}{l}0,2 \pm 0,7 \\
\mathrm{a}\end{array}$ & $\begin{array}{l}0,1 \pm 0,6 \\
\mathrm{a}\end{array}$ & $\begin{array}{l}0,1 \pm 0,6 \\
\mathrm{a}\end{array}$ & $75,55^{* * *}$ \\
\hline $\mathrm{B}$ & $3,0 \pm 0,6$ & $>$ & $\begin{array}{l}1,6 \pm 1,3 \\
\mathrm{~b}\end{array}$ & $\begin{array}{l}1,3 \pm 1,6 \\
\mathrm{~b}\end{array}$ & $<$ & $\begin{array}{l}1,5 \pm 1,8 \\
\mathrm{~b}\end{array}$ & $>\begin{array}{l}1,4 \pm 1,7 \\
\mathrm{~b}\end{array}$ & $20,92^{* * *}$ \\
\hline $\mathrm{D}$ & $3,0 \pm 0,5$ & $>$ & $\begin{array}{l}0,6 \pm 1,1 \\
\mathrm{a}\end{array}$ & $>$ & $\begin{array}{l}0,3 \pm 1,0 \\
\mathrm{a}\end{array}$ & & $\begin{array}{l}0,4 \pm 1,1 \\
\mathrm{a}\end{array}$ & $\begin{array}{l}0,3 \pm 1,0 \\
\mathrm{a}\end{array}$ & $65,67^{* * *}$ \\
\hline H & & & $19,04^{* * *}$ & & $22,64^{* * *}$ & & $24,07^{* * *}$ & & $23,18^{* * *}$ & \\
\hline
\end{tabular}

> signifikanter Rückgang, < signifikanter Anstieg der Vitalität laut Wilcoxon-Test

Die Mittelwerte zeigen, dass bereits im Juni 2005, 2 Monate nach Versuchsanlage, kaum noch lebende Kiefern auf diesen beiden Flächen standen. Auf Fläche A starben $95 \%$ der gepflanzten Kiefern ab, auf Fläche D $90 \%$, auf Fläche B dagegen nur $55 \%$. Auch die entsprechende Kreuztabelle weist signifikante Korrelationen der Sterblichkeitsrate der Kiefern mit dem Standort auf einer der drei Versuchsflächen nach $\left(\mathrm{Chi}^{2} 23,75^{* * *}\right)$.

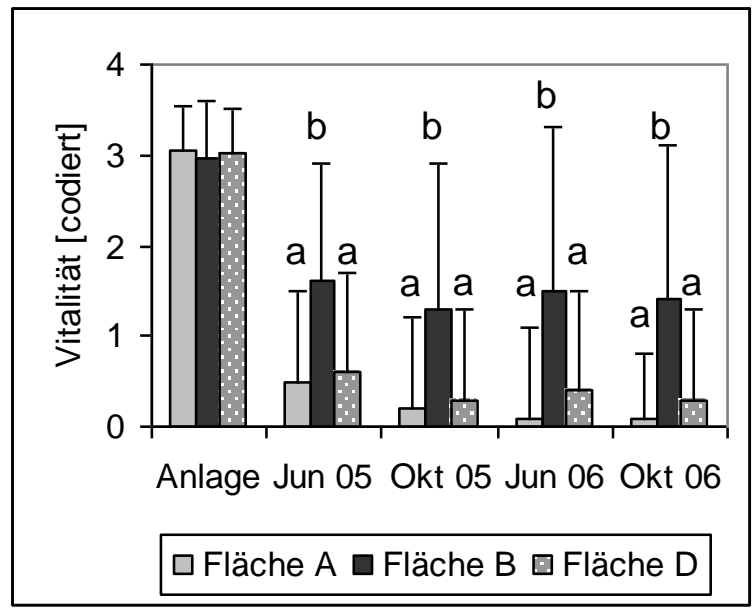

Abb. 172: Vitalität der Kiefern [codiert: $4=$ vital bis $0=$ tot, s. S. 27] auf den drei Versuchsflächen A, B und D im Versuchsverlauf; MW u. Std.abw.; Buchstaben kennzeichnen ggf. je Aufnahmezeitpunkt homogene Gruppen nach U-Tests (je Fläche $\mathrm{n}=40$ )

\section{Kiefern in Bereichen ohne Spontanvegetation}

In Bereichen ohne Entwicklung von Spontanvegetation erfolgte bereits im 1. Jahr ein Vitalitätsrückgang auf 0,2 und damit ein annähernder Totalausfall der Kiefern. Zwischen den drei Versuchsflächen bestanden keine signifikanten Unterschiede. 


\section{Kiefern in Bereichen mit Spontanvegetation}

Die mittlere Vitalität der Kiefern, die zufällig in Bereiche gepflanzt wurden, in denen im Versuchsverlauf Spontanvegetation entstand, ging zu Beginn des Versuchs auf beiden in Frage kommenden Flächen (B und D; A blieb vegetationsfrei) signifikant zurück (s. Tab. 90).

Tab. 90: Vitalität der Kiefern [codiert: $4=$ vital bis $0=$ tot, s. S. 27] in bewachsenen Bereichen auf den Versuchsflächen B ( $n=33)$ und D ( $n=11)$ im Versuchsverlauf; MW u. Std.abw.; je Aufnahmezeitpunkt Ergebnisse von U-Tests (Z) auf signifikante Unterschiede zwischen den Flächen; je Fläche Ergebnisse von Friedmann-Tests $\left(\mathrm{Chi}^{2}\right)$ auf signifikante Unterschiede zwischen den Aufnahmezeitpunkten

\begin{tabular}{|l|l|l|l|l|l|l|l|l|l|}
\hline m.BV & $\begin{array}{l}\text { April } \\
2005\end{array}$ & & $\begin{array}{l}\text { Juni } \\
2005\end{array}$ & $\begin{array}{l}\text { Oktober } \\
2005\end{array}$ & & $\begin{array}{l}\text { Juni } \\
2006\end{array}$ & & $\begin{array}{l}\text { Oktober } \\
2006\end{array}$ & $\mathrm{Chi}^{2}$ \\
\hline $\mathrm{B}$ & $3,0 \pm 0,7$ & $>$ & $1,7 \pm 1,2$ & $1,5 \pm 1,6$ & $<$ & $1,8 \pm 1,8$ & $>$ & $1,6 \pm 1,7$ & $12,97^{*}$ \\
\hline $\mathrm{D}$ & $3,1 \pm 0,3$ & $>$ & $1,1 \pm 1,3$ & $0,7 \pm 1,6$ & & $0,7 \pm 1,6$ & & $0,6 \pm 1,4$ & $10,89^{*}$ \\
\hline $\mathrm{Z}$ & & & $-1,33$ & $-1,46$ & & $-1,59$ & & $-1,70^{*}$ & \\
\hline
\end{tabular}

> signifikanter Rückgang, < signifikanter Anstieg der Vitalität laut Wilcoxon-Test

Auf Fläche B sank sie von anfänglich 3,0 $\pm 0,7$ auf 1,7 $\pm 1,2$ im Juni 2005, auf Fläche D im gleichen Zeitraum von 3,1 $\pm 0,3$ auf $1,1 \pm 1,2$. Auf Fläche B war zum 2. Untersuchungsjahr eine leichte, signifikante Zunahme auf 1,8 \pm 1,8 im Juni $2006 \mathrm{zu}$ verzeichnen, gefolgt von einer ebenso leichten, signifikanten Abnahme auf 1,6 \pm 1,7 im Oktober 2006. Auf Fläche D betrug die mittlere Vitalität der Kiefern in bewachsenen Bereichen zum Ende des Versuchs nur noch 0,6 $\pm 1,4$. Nur bei dieser letzten Aufnahme im Oktober 2006 bestanden signifikante Unterschiede zwischen beiden Flächen (s. Abb. 173). Grund für die niedrigen, aber konstanten Mittelwerte auf Fläche B und die zuletzt sehr niedrigen Mittelwerte auf Fläche D sowie die hohen Standardabweichungen war der jeweils ab 2005 gleich bleibend hohe Anteil an abgestorbenen Pflanzen (Fläche B: $49 \%$, Fläche D: 82 \%).

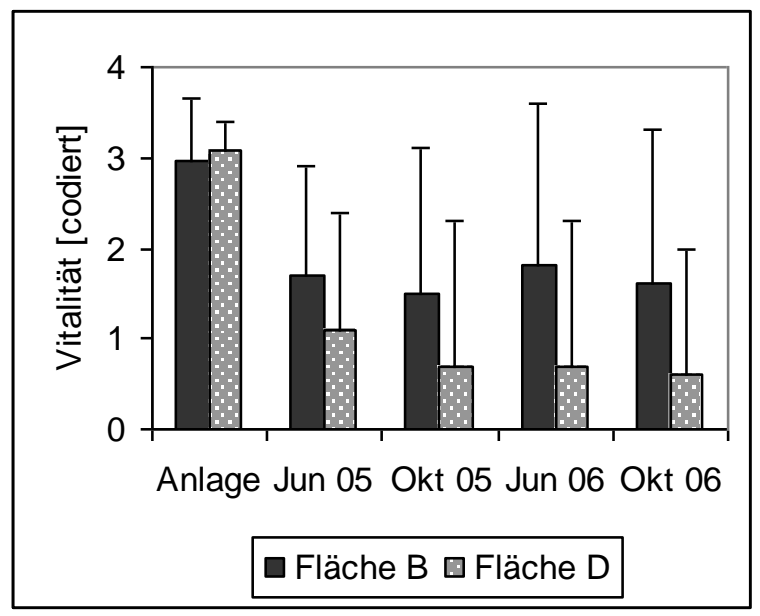

Abb. 173: Vitalität der Kiefern [codiert: $4=$ vital bis $0=$ tot, s. S. 27] in bewachsenen Bereichen auf den Versuchsflächen B $(n=33)$ und D $(n=11)$ im Versuchsverlauf; MW u. Std.abw.; im Oktober 2006 signifikante Unterschiede nach U-Tests 


\subsubsection{Wachstumsentwicklung}

Im Folgenden wird die Wuchsentwicklung der Versuchsbäume anhand der Ergebnisse statistischer Analysen verschiedene Wuchsparameter (s. S. 79) auf Einflüsse durch den Pflanzenstandort auf Versuchsfläche A, B oder D (s. S. 17; zu den unterschiedlichen Standortbedingungen s. ab S. 44) untersucht.

Da der Einflussfaktor „Pflanzenstandort in Bereichen ohne oder mit Spontanvegetationsentwicklung" (s. ab S. 272) teilweise eine wichtige Rolle spielte, wurde der Einfluss des „Standortes Versuchsfläche“ auf die Wachstumsentwicklung der Versuchspflanzen auch unter Ausschluss dieses Faktors untersucht. Dies geschah, indem ausschließlich die Bäume mit Standorten auf Teilflächen ohne Entwicklung von Spontanvegetation (vergleichsweise ungünstigere Bedingungen, s. ab S. 44) bzw. mit Entwicklung von Spontanvegetation (vergleichsweise günstigere Bedingungen, s. ab S. 44) betrachtet wurden.

Die bereits zu einem frühen Zeitpunkt überwiegend oberirdisch abgestorbenen Eichen konnten nicht in die Wachstumsanalysen einbezogen werden.

\subsubsection{Spitz-Ahorn}

Sowohl insgesamt als auch bei den Ahornen, die zufällig in besser (mit Spontanvegetation besiedelt) bzw. schlechter (frei von Bodenvegetation) versorgte Bereiche gepflanzt worden waren, wurde ein Einfluss der Versuchsfläche auf den Zuwachs des Haupttriebs im 1. Untersuchungsjahr (2005) festgestellt (s. Tab. 91).

Tab. 91: Zuwachs [cm] des Haupttriebs der Ahorne im 1. Vegetationsjahr insgesamt sowie mit Standorten in Bereichen ohne und mit Spontanvegetation getrennt nach Versuchsflächen; MW u. Std.abw.; Ergebnisse von $\mathrm{H}$-Tests $[\mathrm{H}]$ auf signifikante Unterschiede; Buchstaben kennzeichnen je Zeile homogene Gruppen nach U-Tests

\begin{tabular}{|c|c|c|c|c|}
\hline \multirow[b]{2}{*}{ Ahorne } & \multicolumn{3}{|c|}{ Zuwachs des Haupttriebs 2005 [cm] } & \multirow{2}{*}{$\begin{array}{l}\text { Ergebnisse } \\
\text { H-Tests }(\mathrm{H})\end{array}$} \\
\hline & $\begin{array}{l}\text { Fläche } \\
\text { A }\end{array}$ & $\begin{array}{l}\text { Fläche } \\
\text { B }\end{array}$ & $\begin{array}{l}\text { Fläche } \\
\text { D }\end{array}$ & \\
\hline $\begin{array}{l}\text { insgesamt } \\
n=13 / 58 / 54\end{array}$ & $\begin{array}{l}0,5 \pm 0,8 \\
\mathrm{a}\end{array}$ & $\begin{array}{l}2,0 \pm 2,9 \\
b\end{array}$ & $\begin{array}{l}2,2 \pm 2,1 \\
b\end{array}$ & $10,76^{* *}$ \\
\hline $\begin{array}{l}\text { in Bereichen ohne } \\
\text { Bewuchs } n=13 / 18 / 26\end{array}$ & $\begin{array}{l}0,5 \pm 0,8 \\
\mathrm{a}\end{array}$ & $\begin{array}{l}2,9 \pm 4,6 \\
b\end{array}$ & $\begin{array}{l}2,1 \pm 2,4 \\
b\end{array}$ & $7,41^{*}$ \\
\hline $\begin{array}{l}\text { in Bereichen mit } \\
\text { Bewuchs } n=-/ 40 / 28\end{array}$ & - & $1,6 \pm 1,7$ & $2,4 \pm 1,9$ & $1,78^{*}$ \\
\hline
\end{tabular}

Im Jahr der Pflanzung (2005) betrug der mittlere Zuwachs der Haupttriebe aller Ahorne auf Fläche A lediglich $0,5 \pm 0,8 \mathrm{~cm}$. Sowohl insgesamt als auch in der Gruppe der Ahorne auf vegetationsfreien Standorten lagen die Zuwächse auf Fläche B und D mit Werten zwischen 2 und $3 \mathrm{~cm}$ trotz großer Standardabweichungen signifikant höher (s. Abb. 174). Bei Betrachtung ausschließlich der Ahorne mit Standorten in Bereichen mit Spontanvegetation war der mittlere Zuwachs der Haupttriebe im 1. Versuchsjahr (2005) auf Fläche D mit 2,4 $\pm 1,9 \mathrm{~cm}$ signifikant höher als auf Fläche B mit 1,6 \pm 1,7 cm. Im weiteren Versuchsverlauf bestanden auch hier keine signifikanten Zuwachsunterschiede zwischen diesen beiden Versuchsflächen. 


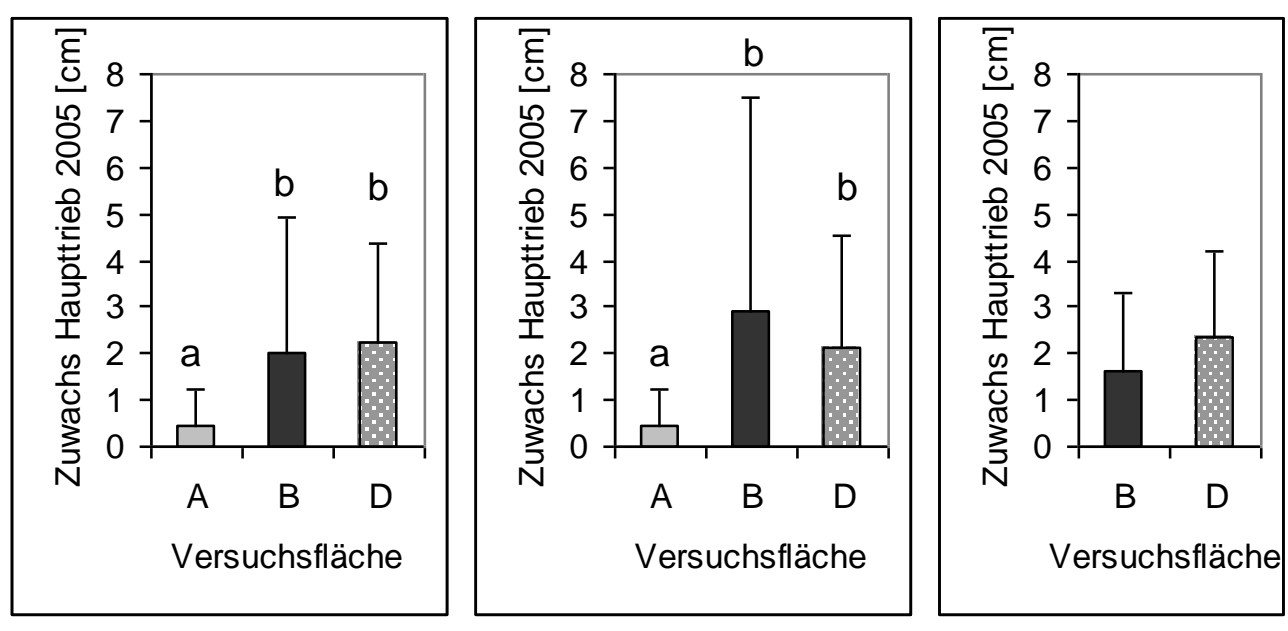

Abb. 174: Zuwachs [cm] des Haupttriebs der Ahorne im 1. Vegetationsjahr insgesamt (links; $n=125 ; A: 13$, B: 58, D: 54), in Bereichen ohne (Mitte; $n=57$; A: 13, B: 18, D: 26) sowie mit (rechts; $n=68 ;$ B: 40 D: 28) Spontanvegetation getrennt nach Versuchsflächen; MW u. Std.abw.; Buchstaben kennzeichnen jeweils homogene Gruppen nach U-Tests

\subsubsection{Eberesche}

Im Falle der Ebereschen wurde nur bei den Pflanzen ein Einfluss der Versuchsfläche auf die Wuchsentwicklung festgestellt, die zufällig in besser versorgte, im Versuchsverlauf mit Spontanvegetation besiedelte Bereiche gepflanzt worden waren, wie sie auf den Flächen B und D, nicht aber auf Fläche A zu finden sind.

\section{Ebereschen insgesamt sowie in Bereichen ohne Spontanvegetation}

In unbewachsenen Bereichen lagen die Ergebnisse der Wachstumsmessungen $30 \%$ - 50 \% unter den Ergebnissen in bewachsenen Bereichen. Insgesamt wiesen die Wachstumsmessungen deshalb relativ hohe Standardabweichungen auf. Signifikante Unterschiede zwischen den drei Versuchsflächen konnten weder insgesamt noch in unbewachsenen Bereichen festgestellt werden.

\section{Ebereschen in Bereichen mit Spontanvegetation}

Bei folgenden Wachstumsparametern wurden signifikante Unterschiede je nach Standort der Ebereschen auf Fläche B oder D (jeweils in Bereichen mit Bodenvegetation) festgestellt:

- Durchmesser des Wurzelhalses

- gesamte Länge der Seitentriebe sowie die daraus errechnete

- Trockenmasse der Seitentriebe

- Oberirdische Trockenmasse (Summe der errechneten Trockenmassen von Haupt- und Seitentrieben)

- Quotient aus Haupt- und Seitentrieblänge 
Tab. 92: Wachstumsparameter der Ebereschen mit Standorten in Bereichen mit Spontanvegetation mit signifikant unterschiedlichen Ergebnissen je nach Versuchsfläche; MW u. Std.abw.; Ergebnisse von U-Tests

\begin{tabular}{|l|l|l|l|}
\hline & \multicolumn{2}{|l|}{$\begin{array}{l}\text { Ebereschen mit Standort in } \\
\text { Bereichen mit Bodenvegetation auf }\end{array}$} & $\begin{array}{l}\text { Ergebnis } \\
\text { U-Tests }\end{array}$ \\
\hline Wachstumsparameter & Versuchsfläche B & Versuchsfläche D & Z \\
\hline Durchmesser Wurzelhals [mm] $\mathrm{n}=25 / 13$ & $10,0 \pm 2,2$ & $11,2 \pm 1,5$ & $1,77^{*}$ \\
\hline Länge Seitentriebe [cm] $\mathrm{n}=23 / 11$ & $90 \pm 66$ & $124 \pm 40$ & $2,17^{*}$ \\
\hline Trockenmasse Seitentriebe [g] $\mathrm{n}=23 / 11$ & $5,5 \pm 4,1$ & $7,6 \pm 2,5$ & $2,17^{*}$ \\
\hline Oberirdische Trockenmasse [g] $\mathrm{n}=23 / 11$ & $27,3 \pm 14,9$ & $32,9 \pm 10,2$ & $1,97^{*}$ \\
\hline Haupt-/Seitentrieblänge $\mathrm{n}=23 / 11$ & $1,6 \pm 1,3$ & $0,8 \pm 0,2$ & $-2,41^{* *}$ \\
\hline
\end{tabular}

Die Wurzelhalsdurchmesser, Längen und Trockenmassen der Seitentriebe sowie die oberirdische Biomasse (Trockenmasse) waren bei den Ebereschen in bewachsenen Bereichen auf Fläche D signifikant höher als in bewachsenen Bereichen auf Fläche B (s. Abb. 175).
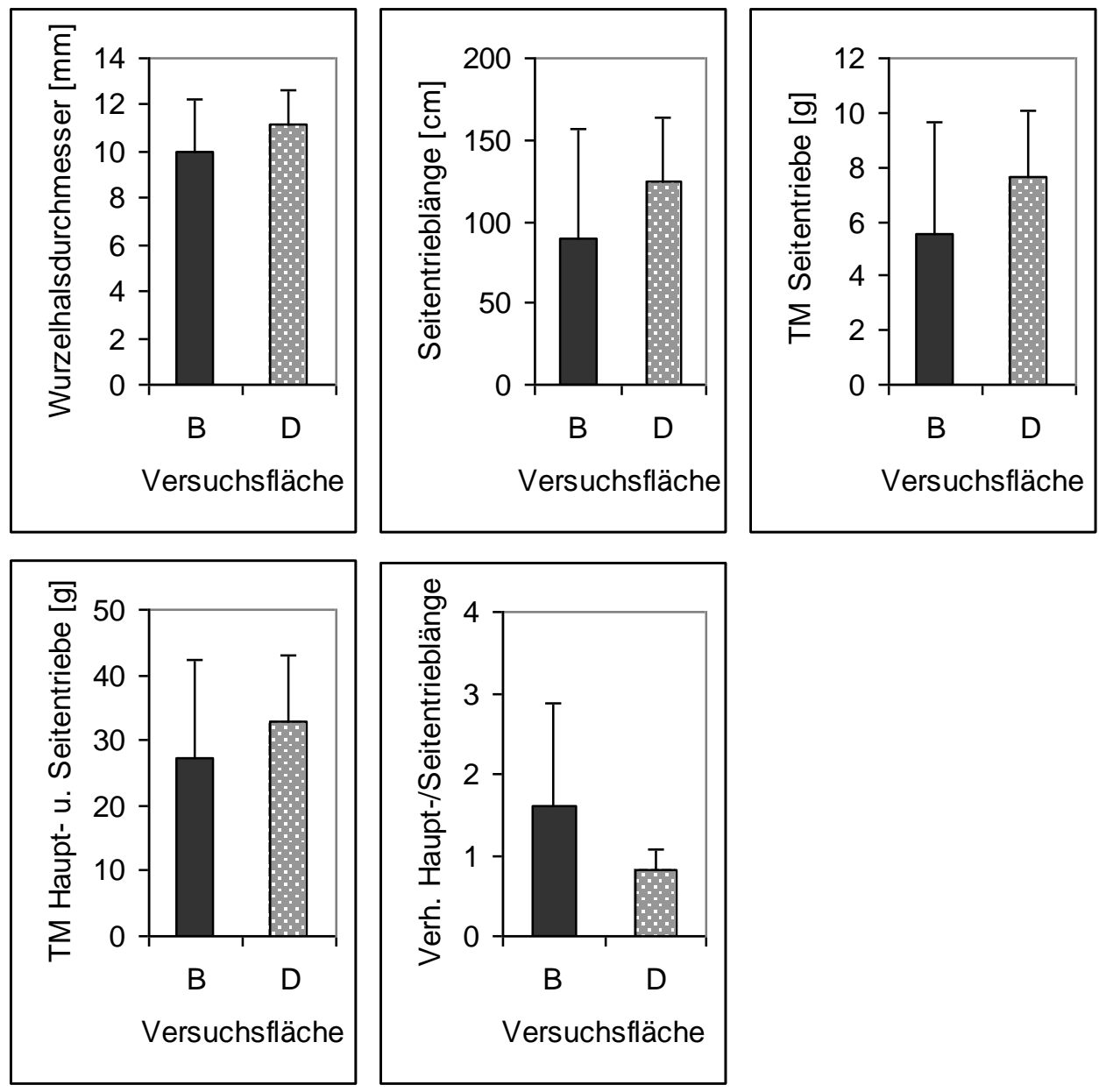

Abb. 175: Wurzelhalsdurchmesser [mm] (n=38; B: 25, D: 13), Länge [cm] und Trockenmasse [g] der Seitentriebe, oberirdische Trockenmasse [g] und Verhältnis aus Haupt- und Seitentrieblängen $(\mathrm{n}=34$; B: 23, D: 11) der Ebereschen in Bereichen mit Spontanvegetation getrennt nach Versuchsflächen; MW u. Std.abw.; jeweils signifikante Unterschiede nach U-Tests

Der Wurzelhalsdurchmesser lag auf Fläche D (11,2 \pm 1,5 mm) um $12 \%$ höher als auf Fläche B $(10,0 \pm 2,2 \mathrm{~mm})$. Die oberirdische Biomasse (Trockenmasse) betrug auf Fläche D $(32,9 \pm 10,2 \mathrm{~g})$ $21 \%$ mehr als auf Fläche B $(27,3 \pm 14,9$ g). Die aufsummierte Länge aller Seitentriebe lag im 
Durchschnitt auf Fläche D $(124 \pm 40 \mathrm{~cm}) 38 \%$ über dem Wert auf Fläche B $(90 \pm 66 \mathrm{~cm})$. Gleiches galt für die aus den Seitentrieblängen errechneten mittleren Trockenmassen der Seitentriebe, die auf Fläche D 7,6 $\pm 2,5 \mathrm{~g}$, auf Fläche B 5,5 $\pm 4,1 \mathrm{~g}$ betrugen (s. Tab. 92 ).

Das Verhältnis aus Haupt- und Seitentrieblängen war auf Fläche D $(0,8 \pm 0,2)$ signifikant niedriger als auf Fläche B $(1,6 \pm 1,3)$. Bei vergleichbaren mittleren Haupttrieblängen (B: $93 \pm 18$ $\mathrm{cm}$; D: $95 \pm 17 \mathrm{~cm}$ ) war der Grund dafür die im Mittel größere Seitentrieblänge auf Fläche D (s. Tab. 92).

\subsubsection{Schwarz-Erle}

Im Falle der Erlen wurde bei nahezu allen aufgenommenen Wachstumsparametern ein Einfluss des Pflanzenstandortes auf einer der drei Versuchsflächen festgestellt (s. Tab. 93). Dies galt vor allem für die Erlen insgesamt, in einem Fall aber auch für die Erlen, die zufällig in schlechter versorgte, im Versuchsverlauf frei von Bodenvegetation gebliebene Bereiche gepflanzt worden waren.

Tab. 93: Wachstumsparameter der Erlen insgesamt sowie in Bereichen ohne Spontanvegetation mit signifikant unterschiedlichen Ergebnissen je nach Versuchsfläche; MW u. Std.abw.; Ergebnisse von H- und U-Tests; Buchstaben kennzeichnen je Zeile homogene Gruppen nach U-Tests

\begin{tabular}{|c|c|c|c|c|c|}
\hline Erlen & Wachstumsparameter & $\begin{array}{l}\text { Fläche } \\
\text { A }\end{array}$ & $\begin{array}{l}\text { Fläche } \\
\text { B }\end{array}$ & $\begin{array}{l}\text { Fläche } \\
\text { D }\end{array}$ & $\begin{array}{l}\text { Ergebnis } \\
\text { H-Tests/ } \\
\text { U-Tests } \\
(\mathrm{H} / \mathrm{Z})\end{array}$ \\
\hline \multirow{10}{*}{$\begin{array}{l}\text { insgesamt } \\
n=20 / 32 / 26 \\
\text { bzw. } \\
n=20 / 30 / 26\end{array}$} & $\begin{array}{l}\text { Zuwachs Haupttrieb } \\
2005[\mathrm{~cm}]\end{array}$ & $\begin{array}{l}8,7 \pm 7,4 \\
a\end{array}$ & $\begin{array}{l}11,8 \pm 5,1 \\
b\end{array}$ & $\begin{array}{l}9,2 \pm 5,2 \\
a, b\end{array}$ & $7,07^{*}$ \\
\hline & $\begin{array}{l}\text { Zuwachs Haupttrieb } \\
2006[\mathrm{~cm}]\end{array}$ & $\begin{array}{l}11,4 \pm 5,3 \\
a\end{array}$ & $\begin{array}{l}20,2 \pm 12,2 \\
b\end{array}$ & $\begin{array}{l}14,7 \pm 12,4 \\
\mathrm{a}\end{array}$ & $6,23^{*}$ \\
\hline & $\begin{array}{l}\text { Zuwachs Haupttrieb } \\
\text { gesamt }[\mathrm{cm}]\end{array}$ & $\begin{array}{l}20,1 \pm 11,5 \\
a\end{array}$ & $\begin{array}{l}31,9 \pm 15,7 \\
b\end{array}$ & $\begin{array}{l}24,0 \pm 16,7 \\
a\end{array}$ & $8,23^{*}$ \\
\hline & $\begin{array}{l}\text { Durchmesser } \\
\text { Wurzelhals [mm] }\end{array}$ & $\begin{array}{l}14,9 \pm 2,6 \\
a\end{array}$ & $\begin{array}{l}17,7 \pm 3,2 \\
b\end{array}$ & $\begin{array}{l}16,4 \pm 4,6 \\
a, b\end{array}$ & $8,99 *$ \\
\hline & $\begin{array}{l}\text { Volumen } \\
\text { Haupttrieb }\left[\mathrm{cm}^{3}\right]\end{array}$ & $\begin{array}{l}88 \pm 44 \\
a\end{array}$ & $\begin{array}{l}130 \pm 52 \\
b\end{array}$ & $\begin{array}{l}116 \pm 79 \\
a, b\end{array}$ & $8,12^{*}$ \\
\hline & $\begin{array}{l}\text { Trockenmasse } \\
\text { Haupttrieb [g] }\end{array}$ & $\begin{array}{l}40,4 \pm 20,3 \\
\mathrm{a}\end{array}$ & $\begin{array}{l}59,9 \pm 23,9 \\
b\end{array}$ & $\begin{array}{l}53,6 \pm 36,3 \\
a, b\end{array}$ & $8,12^{*}$ \\
\hline & $\begin{array}{l}\text { Länge } \\
\text { Seitentriebe }[\mathrm{cm}]\end{array}$ & $\begin{array}{l}296 \pm 147 \\
a\end{array}$ & $\begin{array}{l}447 \pm 19 \\
b\end{array}$ & $\begin{array}{l}368 \pm 243 \\
a\end{array}$ & $9,35^{* *}$ \\
\hline & $\begin{array}{l}\text { Trockenmasse } \\
\text { Seitentriebe [g] }\end{array}$ & $\begin{array}{l}19,3 \pm 9,6 \\
a\end{array}$ & $\begin{array}{l}29,2 \pm 12,5 \\
b\end{array}$ & $\begin{array}{l}24,0 \pm 15,8 \\
\mathrm{a}\end{array}$ & $9,35^{* *}$ \\
\hline & $\begin{array}{l}\text { Oberirdische } \\
\text { Trockenmasse [g] }\end{array}$ & $\begin{array}{l}60 \pm 30 \\
a\end{array}$ & $\begin{array}{l}90 \pm 36 \\
b\end{array}$ & $\begin{array}{l}78 \pm 51 \\
a\end{array}$ & $8,76^{*}$ \\
\hline & $\begin{array}{l}\text { Länge Haupt-/ } \\
\text { Länge Seitentriebe }\end{array}$ & $\begin{array}{l}0,5 \pm 0,2 \\
b\end{array}$ & $\begin{array}{l}0,4 \pm 0,3 \\
\mathrm{a}\end{array}$ & $\begin{array}{l}0,5 \pm 0,2 \\
b\end{array}$ & $8,97^{*}$ \\
\hline $\begin{array}{l}\text { o. Bewuchs } \\
n=20 / 14\end{array}$ & $\begin{array}{l}\text { TM Haupt-/ } \\
\text { TM Seitentriebe }\end{array}$ & $2,1 \pm 0,3$ & - & $2,4 \pm 0,4$ & $-2,03^{*}$ \\
\hline
\end{tabular}




\section{Erlen insgesamt}

Der mittlere Zuwachs der Haupttriebe aller untersuchten Erlen war im gesamten Versuchsverlauf auf Fläche B signifikant höher als auf Fläche A (s. Abb. 176). Er lag im 2. Untersuchungsjahr auf Fläche B mit 20,2 \pm 12,2 cm fast doppelt so hoch wie auf Fläche A mit $11,4 \pm 5,3 \mathrm{~cm}$. Mit Ausnahme des Zuwachses im 1. Untersuchungsjahr (2005) wiesen die Erlen auf Fläche B auch gegenüber den Erlen auf Fläche D signifikant mehr Zuwachs auf. Zwischen den Werten auf Fläche A und D bestanden dagegen keine signifikanten Zuwachsunterschiede.
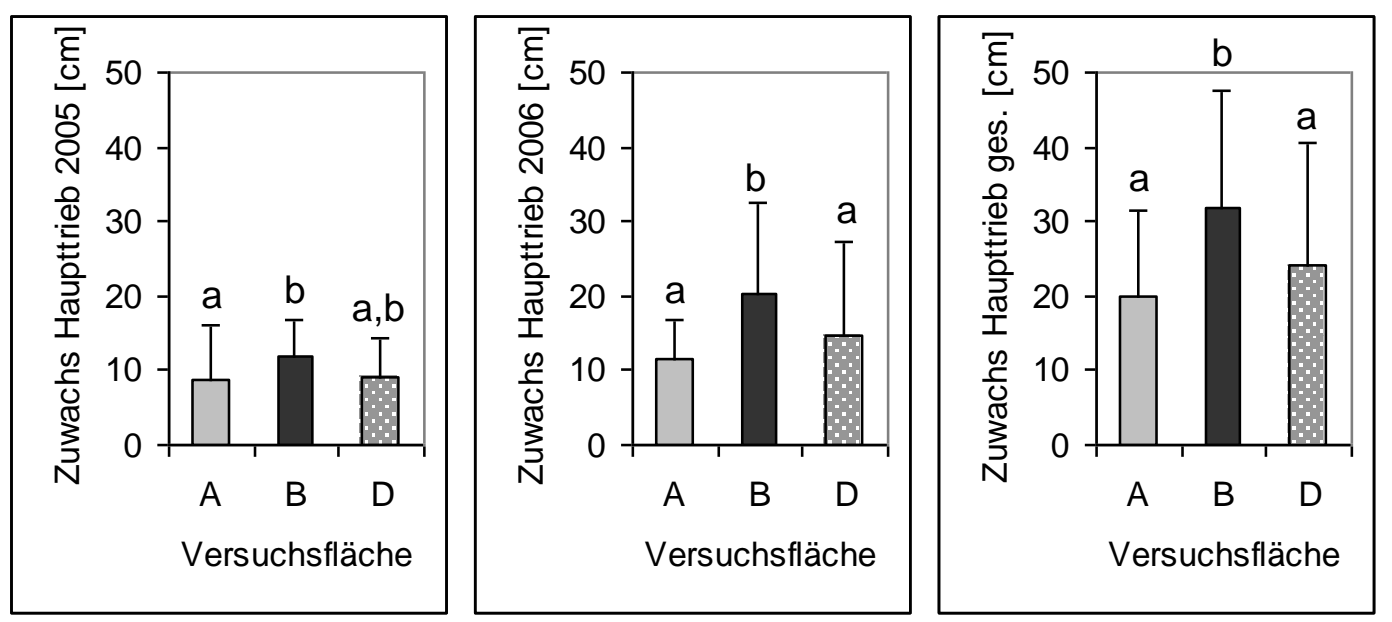

Abb. 176: Zuwachs [cm] des Haupttriebs im 1. (links) und 2. Vegetationsjahr (Mitte) sowie Gesamtzuwachs (rechts) der Erlen getrennt nach Versuchsflächen (n=78; A: 20, B: 32, D: 26); MW u. Std.abw.; Buchstaben kennzeichnen jeweils homogene Gruppen nach U-Tests

Auch der Wurzelhalsdurchmesser, das Volumen sowie die daraus errechnete Trockenmasse der Haupttriebe der Erlen lagen auf Fläche B $\left(17,7 \pm 3,2 \mathrm{~mm} ; 130 \pm 52 \mathrm{~cm}^{3} ; 60 \pm 24 \mathrm{~g}\right) \mathrm{im}$ Durchschnitt signifikant höher als auf Fläche A $\left(14,9 \pm 2,6 \mathrm{~mm} ; 88 \pm 44 \mathrm{~cm}^{3} ; 40 \pm 20 \mathrm{~g}\right)$. Auf Fläche D nahmen die Werte jeweils eine Mittelstellung ein, ohne sich signifikant von den anderen beiden Flächen zu unterscheiden (s. Abb. 177).
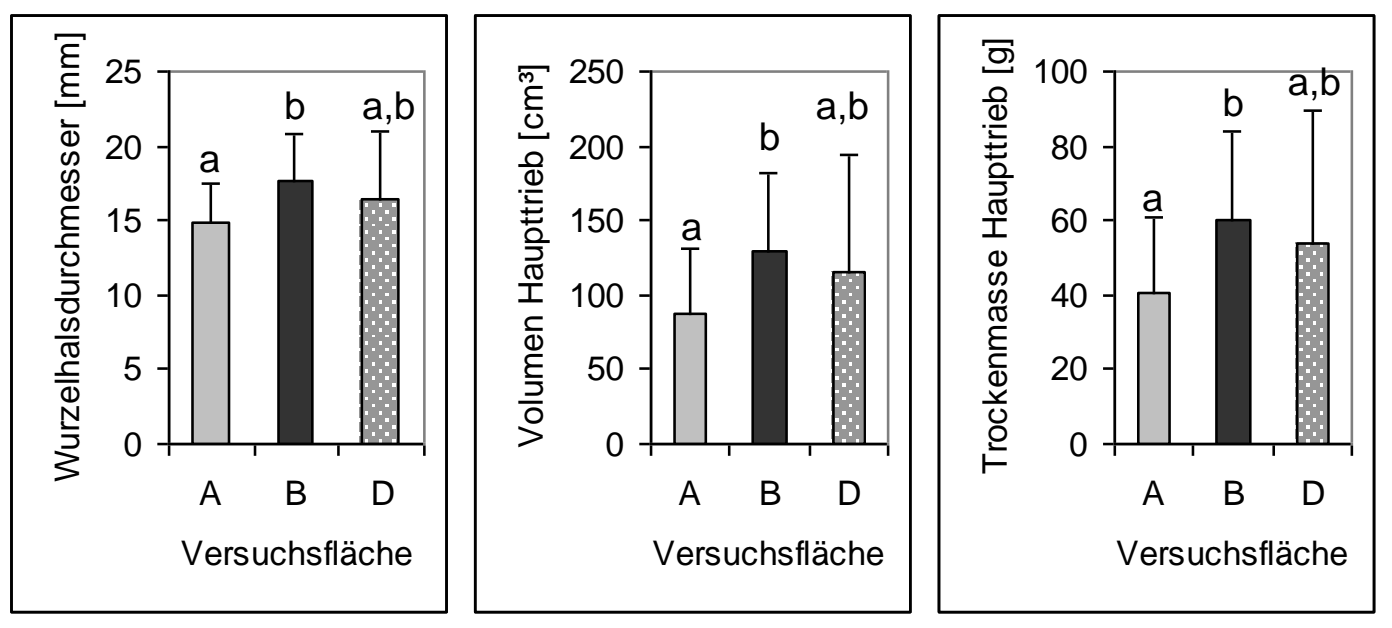

Abb. 177: Wurzelhalsdurchmesser [mm] (links), Volumen $\left[\mathrm{cm}^{3}\right]$ (Mitte) und Trockenmasse [g] (rechts) des Haupttriebs der Erlen getrennt nach Versuchsflächen (n=78; A: 20, B: 32, D: 26); MW u. Std.abw.; Buchstaben kennzeichnen jeweils homogene Gruppen nach U-Tests 
Die Längen und die daraus errechneten Trockenmassen der Seitentriebe der Erlen waren auf Fläche B (447 $\pm 19 \mathrm{~cm} ; 29 \pm 12 \mathrm{~g})$ signifikant höher als auf den Flächen A (296 $\pm 147 \mathrm{~cm} ; 19 \pm 10$ g) und D (368 $\pm 243 \mathrm{~cm} ; 24 \pm 16 \mathrm{~g}$ ), die sich hinsichtlich dieser Parameter nicht signifikant unterschieden (s. Abb. 178).
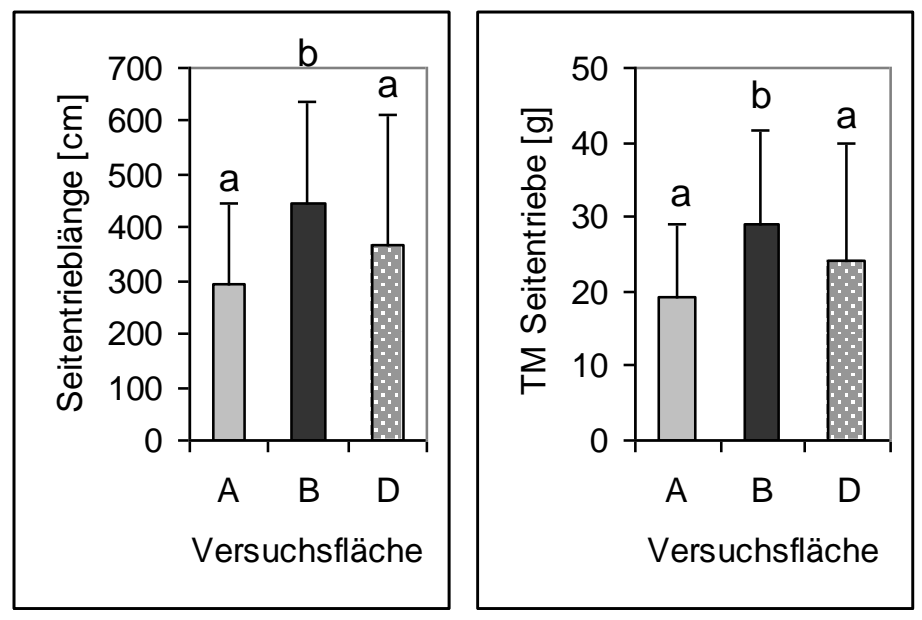

Abb. 178: Länge [cm] (links) und Trockenmasse [g] (rechts) der Seitentriebe der Erlen getrennt nach Versuchsflächen (n=76; A: 20, B: 30, D: 26); MW u. Std.abw.; Buchstaben kennzeichnen jeweils homogene Gruppen nach U-Tests

Die gesamte oberirdische Biomasse (Trockenmasse) war bei den Erlen auf Fläche B mit durchschnittlich $90 \pm 36$ g pro Baum signifikant höher als auf den Flächen A mit $60 \pm 30 \mathrm{~g}$ und D mit $78 \pm 51 \mathrm{~g}$, zwischen denen in dieser Hinsicht kein signifikanter Unterschied bestand (s. Abb. 179). Da von den Erlen auf Fläche B deutlich mehr Seitentriebe als auf den anderen beiden Flächen gebildet wurden (s. Tab. 93 u. Abb. 178), war entsprechend das Verhältnis aus Hauptund Seitentrieblängen auf Fläche B mit 0,4 $\pm 0,3$ signifikant niedriger als auf den Flächen A und D mit jeweils $0,5 \pm 0,2$.
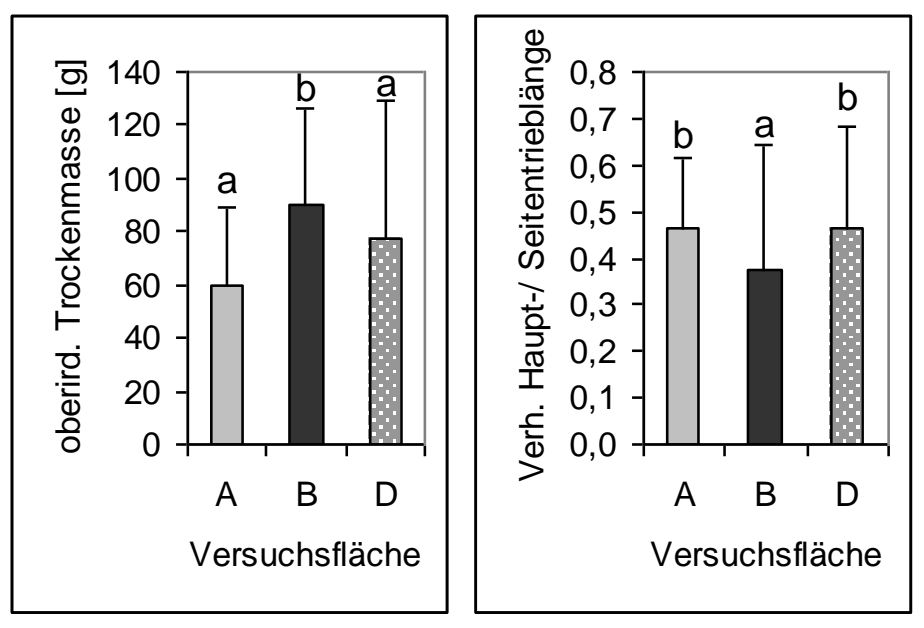

Abb. 179: Oberirdische Trockenmasse [g] (links) und Verhältnis aus Haupt- und Seitentrieblängen (rechts) der Erlen getrennt nach Versuchsflächen (n=76; A: 20, B: 30, D: 26); MW u. Std.abw.; Buchstaben kennzeichnen jeweils homogene Gruppen nach U-Tests 


\section{Erlen in Bereichen ohne sowie mit Spontanvegetation}

Bei ausschließlicher Betrachtung der Erlen auf bis Versuchsende vegetationsfreien bzw. bewachsenen Standorten konnten kaum signifikante Wachstumsunterschiede zwischen den verschiedenen Versuchsflächen festgestellt werden. Lediglich bei den Erlen mit Standorten in vegetationsfreien Bereichen war das Verhältnis der Trockenmassen der Haupt- und Seitentriebe auf Fläche D mit 2,1 $\pm 0,3$ leicht, aber signifikant höher als auf Fläche A mit 2,4 $\pm 0,4$ (s. Abb. 180). Gründe dafür waren sowohl die etwas höheren Trockenmassen der Haupttriebe als auch die gleichzeitig etwas geringeren Trockenmassen der Seitentriebe der Erlen in diesen Bereichen auf Fläche D. Da in vegetationsfreien Bereichen auf Fläche B die entsprechenden Daten an weniger als drei Erlen erhoben werden konnten, war eine Einbeziehung von Fläche B in diese Analyse nicht möglich.

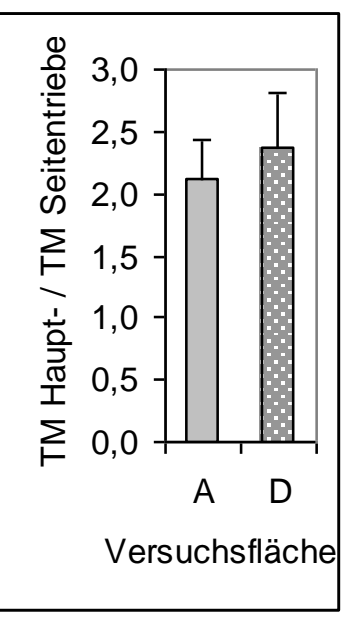

Abb. 180: Verhältnis der Trockenmassen der Haupt- und Seitentriebe der Erlen in unbewachsenen Bereichen getrennt nach Versuchsflächen (n=34; A: 20, D: 14); MW u. Std.abw.; signifikante Unterschiede nach U-Test

\subsubsection{Douglasie}

Im Falle der Douglasien wurde ein deutlicher Einfluss des Standortes auf einer der drei Versuchsflächen auf ihre Wuchsentwicklung festgestellt. Die galt sowohl insgesamt als auch nur für die Pflanzen, die zufällig in besser versorgte, im Versuchsverlauf (auf Fläche B und D, nicht auf A) mit Spontanvegetation besiedelte Bereiche gepflanzt worden waren (s. Tab. 94). Ein anhand geernteter Douglasien vorgenommener Trockenmassen-Vergleich bestätigte die Ergebnisse des Versuchsflächen-Einflusses auf ihre Wuchsentwicklung.

Wachstumsparameter mit signifikanten Unterschieden je nach Standort der Douglasien auf einer der Versuchsflächen:

- Zuwachs des Haupttriebs 2005, 2006 und gesamt

- Durchmesser des Wurzelhalses sowie die daraus errechnete

- Trockenmasse der Wurzel

- Verhältnis aus ober- und unterirdischer Trockenmasse 
Tab. 94: Wachstumsparameter der Douglasien insgesamt, in Bereichen mit Spontanvegetation sowie bei Versuchsabschluss geerntete Stichprobe mit signifikant unterschiedlichen Ergebnissen je nach Versuchsfläche; MW u. Std.abw.; Ergebnisse von H- und U-Tests; Buchstaben kennzeichnen je Zeile homogene Gruppen nach U-Tests

\begin{tabular}{|c|c|c|c|c|c|}
\hline Douglasien & Wachstumsparameter & $\begin{array}{l}\text { Fläche } \\
\text { A }\end{array}$ & $\begin{array}{l}\text { Fläche } \\
\text { B }\end{array}$ & $\begin{array}{l}\text { Fläche } \\
\text { D }\end{array}$ & $\begin{array}{l}\text { Ergebnis } \\
\text { H-Tests/ } \\
\text { U-Tests } \\
(\mathrm{H} / \mathrm{Z})\end{array}$ \\
\hline \multirow{3}{*}{$\begin{array}{l}\text { insgesamt } \\
n=30 / 49 / 38\end{array}$} & $\begin{array}{l}\text { Zuwachs Haupttrieb } \\
2005[\mathrm{~cm}]\end{array}$ & $\begin{array}{l}3,0 \pm 2,0 \\
\mathrm{a}\end{array}$ & $\begin{array}{l}5,7 \pm 2,9 \\
\text { c }\end{array}$ & $\begin{array}{l}4,2 \pm 3,4 \\
b\end{array}$ & $16,61^{* * *}$ \\
\hline & $\begin{array}{l}\text { Zuwachs Haupttrieb } \\
2006[\mathrm{~cm}]\end{array}$ & $\begin{array}{l}5,5 \pm 3,2 \\
a\end{array}$ & $\begin{array}{l}8,8 \pm 6,0 \\
b\end{array}$ & $\begin{array}{l}10,6 \pm 9,5 \\
b\end{array}$ & $6,10^{*}$ \\
\hline & $\begin{array}{l}\text { Zuwachs Haupttrieb } \\
\text { gesamt }[\mathrm{cm}]\end{array}$ & $\begin{array}{l}8,5 \pm 3,6 \\
a\end{array}$ & $\begin{array}{l}14,4 \pm 7,4 \\
b\end{array}$ & $\begin{array}{l}14,7 \pm \\
11,2 \\
b\end{array}$ & $12,99 * *$ \\
\hline \multirow{3}{*}{$\begin{array}{l}\text { mit Standort } \\
\text { in Bereichen mit } \\
\text { Bewuchs }\end{array}$} & $\begin{array}{l}\text { Zuwachs Haupttrieb } \\
2005[\mathrm{~cm}] \mathrm{n}=42 / 26\end{array}$ & - & $6,0 \pm 3,0$ & $4,4 \pm 4,1$ & $-2,19 *$ \\
\hline & $\begin{array}{l}\text { Durchmesser } \\
\text { Wurzelhals } \\
{[\mathrm{mm}] \mathrm{n}=42 / 22}\end{array}$ & - & $7,1 \pm 2,1$ & $9,5 \pm 4,8$ & $1,66^{*}$ \\
\hline & $\begin{array}{l}\text { Trockenmasse } \\
\text { Wurzel } \\
{[\mathrm{g}] \mathrm{n}=42 / 22} \\
\end{array}$ & - & $9,4 \pm 2,8$ & $12,6 \pm 6,4$ & $1,66^{*}$ \\
\hline $\begin{array}{l}\text { geerntet bei } \\
\text { Versuchsabschluss } \\
n=12 / 11 / 11\end{array}$ & $\begin{array}{l}\text { Trockenmasse } \\
\text { Spross (HT, ST, } \\
\text { Nadeln)/Wurzel }\end{array}$ & $\begin{array}{l}1,3 \pm 0,3 \\
\mathrm{a}\end{array}$ & $\begin{array}{l}1,7 \pm 0,5 \\
b\end{array}$ & $\begin{array}{l}1,7 \pm 0,6 \\
b\end{array}$ & $7,11^{*}$ \\
\hline
\end{tabular}

\section{Douglasien insgesamt}

In 2005 unterschieden sich die durchschnittlichen Zuwächse der Haupttriebe der Douglasien auf allen drei Versuchsflächen signifikant voneinander (s. Abb. 181 links). Der höchste Mittelwert $(5,7 \pm 2,9 \mathrm{~cm})$ in diesem 1 . Untersuchungsjahr wurde auf Fläche B gemessen, der geringste $(3,0 \pm$ $2,0 \mathrm{~cm})$ auf Fläche A, während auf Fläche D ein zwischen diesen beiden liegender Wert $(4,2 \pm 3,4$ $\mathrm{cm}$ ) ermittelt wurde. Zwischen Fläche B und D bestanden im 2. Untersuchungsjahr 2006 (B: 8,8 $\pm 6,0 \mathrm{~cm}$; D: $10,6 \pm 9,5 \mathrm{~cm}$ ) sowie insgesamt (B: $14,4 \pm 7,4 \mathrm{~cm}$; $: 14,7 \pm 11,2 \mathrm{~cm}$ ) keine signifikanten Zuwachsunterschiede mehr (s. Abb. 181 Mitte u. rechts), während der Zuwachs auf Fläche A auch im Versuchsverlauf signifikant geringer blieb (2006: 5,5 $\pm 3,2 \mathrm{~cm}$; insgesamt: 8,5 \pm $3,6)$. 

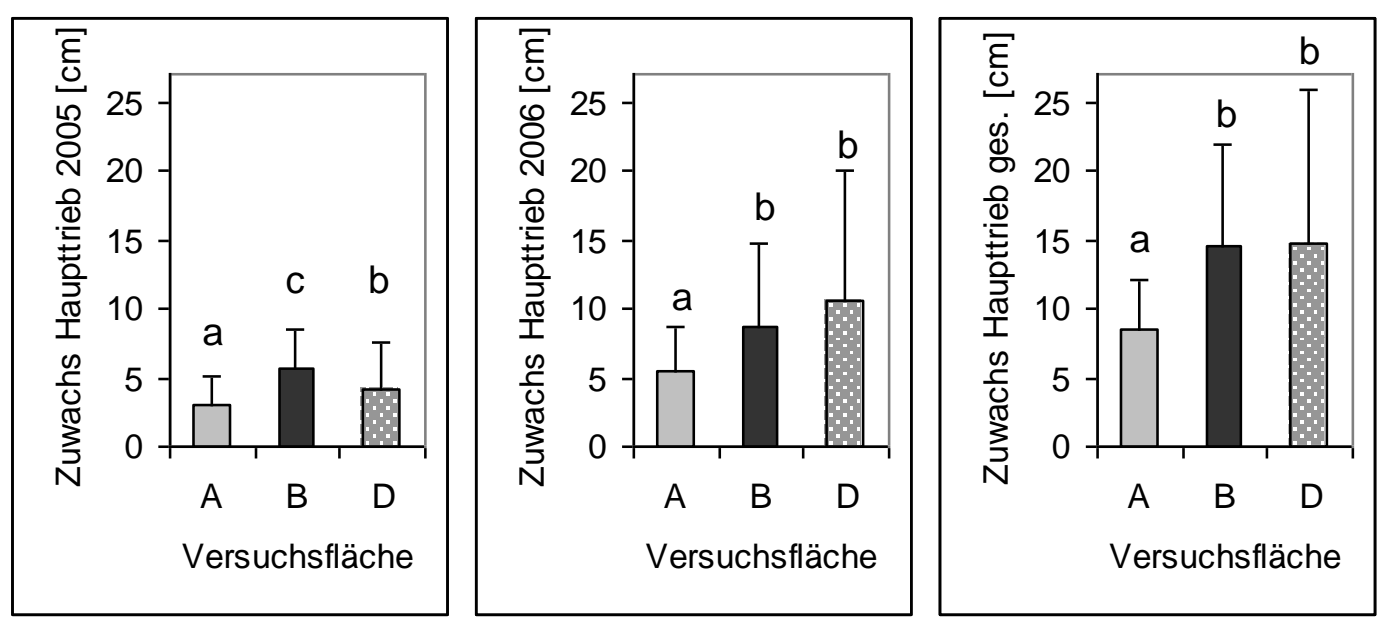

Abb. 181: Zuwachs [cm] des Haupttriebs der Douglasien im 1. (links) und 2. Vegetationsjahr (Mitte) sowie Gesamtzuwachs (rechts) getrennt nach Versuchsflächen (n=117; A: 30, B: 49, D: 38); MW u. Std.abw.; Buchstaben kennzeichnen jeweils homogene Gruppen nach U-Tests

\section{Douglasien in Bereichen ohne Spontanvegetation}

Der Zuwachs der in vegetationsfreien Bereichen gepflanzten Douglasien war etwa $40 \%$ - $50 \%$ geringer als in bewachsenen Bereichen (s. ab S. 284). Anders als in bewachsenen Bereichen konnten keine signifikanten Unterschiede zwischen den drei Versuchsflächen festgestellt werden.

\section{Douglasien in Bereichen mit Spontanvegetation}

Bei Betrachtung ausschließlich der Douglasien mit Standorten in Bereichen mit Spontanvegetation war der mittlere Zuwachs der Haupttriebe im 1. Versuchsjahr (2005) auf Fläche B mit 6,0 $\pm 3,0 \mathrm{~cm}$ signifikant höher als auf Fläche D mit 4,4 $\pm 4,1 \mathrm{~cm}$ (s. Abb. 182 links). Im weiteren Versuchsverlauf bestanden keine signifikanten Zuwachsunterschiede zwischen den beiden betreffenden Versuchsflächen.
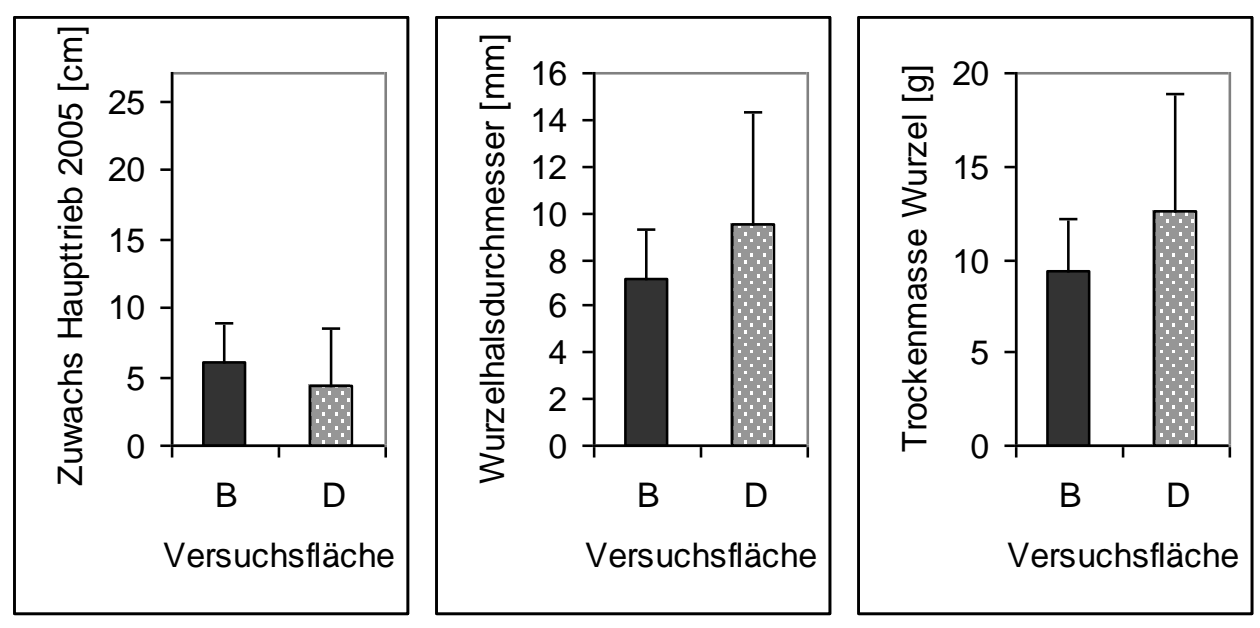

Abb. 182: Zuwachs [cm] des Haupttriebs im 1. Vegetationsjahr (links; $n=68 ;$ B: 42, D: 26) und Wurzelhalsdurchmesser [mm] (Mitte) sowie Trockenmasse der Wurzel (rechts; n=64; B: 42, D: 22) der Douglasien in Bereichen mit Spontanvegetation getrennt nach Versuchsflächen; MW u. Std.abw.; jeweils signifikante Unterschiede nach U-Tests 
Dagegen wiesen die zum Ende des Versuchs (2006) ermittelten, gegenüber Fläche B $(7,1 \pm 2,1$ mm) signifikant höheren Wurzelhalsdurchmesser (s. Abb. 182 Mitte) auf Fläche D $(9,5 \pm 4,8$ $\mathrm{mm}$ ) darauf hin, dass in Bereichen mit Spontanvegetation auf Fläche D trotz schlechterer Startbedingungen die Voraussetzungen für (Dicken-, Wurzel-)Wachstum im Versuchsverlauf sogar besser waren als in diesen Bereichen auf Fläche B. Die mit Hilfe der Wurzelhalsdurchmesser errechneten Trockenmassen der Wurzeln (s. Abb. 182 rechts) betrugen auf Fläche B 9,4 $\pm 2,8 \mathrm{~g}$, auf Fläche D signifikant höhere 12,6 $\pm 6,4 \mathrm{~g}$.

\section{Bei Versuchsabschluss geerntete Douglasien}

Bei Versuchsabschluss waren 35 der insgesamt 192 Douglasien geerntet, getrocknet und - in die Fraktionen Haupttrieb, Seitentriebe, Nadeln sowie Wurzel zerlegt - gewogen worden. Dies erlaubte auch die Untersuchung weiterer Wachstumsparameter hinsichtlich eines standörtlichen Einflusses der Versuchsflächen auf die Wuchsentwicklung. Dabei wurden signifikante Unterschiede des Verhältnisses von oberirdischer (Haupttrieb, Seitentriebe und Nadeln) zu unterirdischer (Wurzel) Biomasse (Trockenmasse) zwischen den drei Versuchsflächen festgestellt.

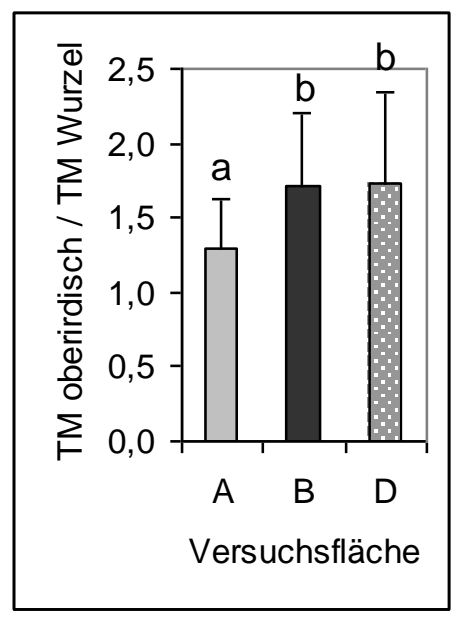

Abb. 183: Verhältnis aus ober- und unterirdischer Trockenmasse der geernteten Douglasien getrennt nach Versuchsflächen (n=34; A: 12, B: 11, D: 11); MW u. Std.abw.; Buchstaben kennzeichnen homogene Gruppen nach U-Tests

Das Verhältnis aus ober- und unterirdischer Trockenmasse der Douglasien war auf Versuchsfläche A mit 1,3 $\pm 0,3$ signifikant geringer als auf den Flächen B und D mit jeweils 1,7 \pm 0,5 bzw. 0,6 (s. Abb. 183). Die mittleren Trockenmassen der geernteten Douglasienwurzeln lagen auf allen drei Flächen bei ähnlichen Werten zwischen 8,3 g und 9,3 g. Der Grund für die so unterschiedlichen Quotienten waren die sehr unterschiedlich großen oberirdischen Trockenmassen, die auf den Flächen B und D mit 15,9 \pm 10,1 g bzw. 15,6 $\pm 14,7$ g um rund $50 \%$ höher lagen als auf Fläche A mit 10,9 \pm 7,2 g. Das Spross-Wurzel-Verhältnis wurde damit jedoch größer und ungünstiger, da nach Lavender (1984) ein kleines Spross-Wurzel-Verhältnis (d.h. ein im Verhältnis zum Spross besonders gut entwickeltes Wurzelwerk) gerade bei schwierigen Standortverhältnissen von großer Bedeutung ist und auf die Stresstoleranz einer Pflanze hinweist (Hendry \& Grime 1993). 


\subsubsection{Wald-Kiefer}

Aufgrund der hohen Ausfallrate bei den Kiefern (95 \% auf Fläche A, 55 \% auf Fläche B, 90 \% auf Fläche D) standen für alle Wachstumsuntersuchungen, die über das 1. Versuchsjahr hinausgingen, von ursprünglich 120 lediglich noch 24 lebende, ungeschädigte Bäume zur Verfügung. Davon konnten wiederum nur 22 in die Analysen einbezogen werden, da die Gruppe „Kiefern auf Fläche A“ (n=2) zu klein war.

Sowohl insgesamt als auch bei den Kiefern, die zufällig in besser versorgte, im Versuchsverlauf mit Spontanvegetation besiedelte Bereiche gepflanzt worden waren, wurde ein signifikanter Einfluss des Pflanzenstandortes auf einer der drei Versuchsflächen auf den Zuwachs des Haupttriebs 2005 und auf das Verhältnis der Trockenmassen der Haupt- und Seitentriebe festgestellt (s. Tab. 95).

Tab. 95: Wachstumsparameter der Kiefern insgesamt sowie in Bereichen mit Spontanvegetation mit signifikant unterschiedlichen Ergebnissen je nach Versuchsfläche; MW u. Std.abw.; Ergebnisse von H- und U-Tests; Buchstaben kennzeichnen je Zeile homogene Gruppen nach U-Tests

\begin{tabular}{|l|l|l|l|l|l|}
\hline Kiefern & $\begin{array}{l}\text { Wachstums- } \\
\text { parameter }\end{array}$ & $\begin{array}{l}\text { Fläche } \\
\text { A }\end{array}$ & $\begin{array}{l}\text { Fläche } \\
\text { B }\end{array}$ & $\begin{array}{l}\text { Fläche } \\
\text { D }\end{array}$ & $\begin{array}{l}\text { Ergebnis H- } \\
\text { Tests/ U-Tests } \\
\text { (H/Z) }\end{array}$ \\
\hline \multirow{3}{*}{ insgesamt } & $\begin{array}{l}\text { Zuwachs Haupttrieb } \\
2005[\mathrm{~cm}] \\
\mathrm{n}=7 / 25 / 12\end{array}$ & $\begin{array}{l}2,3 \pm 3,3 \\
\mathrm{a}\end{array}$ & $\begin{array}{l}6,9 \pm 5,4 \\
\mathrm{~b}\end{array}$ & $\begin{array}{l}1,5 \pm 3,1 \\
\mathrm{a}\end{array}$ & $10,32^{* *}$ \\
\cline { 2 - 6 } & $\begin{array}{l}\text { TM Haupttrieb/TM } \\
\text { Seitentriebe } \\
\mathrm{n}=-/ 18 / 4\end{array}$ & - & $1,9 \pm 1,1$ & $4,1 \pm 1,2$ & $2,64^{* *}$ \\
\hline $\begin{array}{l}\text { mit Standort } \\
\text { in Bereichen mit } \\
\text { Bewuchs }\end{array}$ & $\begin{array}{l}\text { Zuwachs Haupttrieb } \\
\text { 2005 [cm] } \\
\mathrm{n}=22 / 6\end{array}$ & - & $7,6 \pm 5,4$ & $3,0 \pm 3,9$ & $-1,86^{*}$ \\
\hline
\end{tabular}

\section{Kiefern insgesamt sowie in Bereichen mit Spontanvegetation}

Im Jahr der Pflanzung betrug der mittlere Zuwachs der Haupttriebe der auf Versuchsfläche B gepflanzten Kiefern 6,9 5,4 cm. Trotz der hohen Standardabweichung (s. Abb. 184 links) lag er signifikant über den deutlich geringeren Werten auf Fläche A $(2,3 \pm 3,3 \mathrm{~cm})$ und Fläche D $(1,5 \pm$ 3,1 cm). Im Folgejahr (2006) sowie beim Gesamt-Zuwachs bestanden allerdings keine signifikanten Zuwachsunterschiede je nach Versuchsfläche mehr.

Auch bei Betrachtung ausschließlich der Kiefern mit Standorten in Bereichen mit Spontanvegetation war der mittlere Zuwachs der Haupttriebe im 1. Versuchsjahr (2005) auf Fläche B mit 7,6 $\pm 5,4 \mathrm{~cm}$ signifikant höher als auf Fläche D mit 3,0 $\pm 3,9 \mathrm{~cm}$ (s. Abb. 184 Mitte). Im weiteren Versuchsverlauf bestanden auch hier keine signifikanten Zuwachsunterschiede mehr zwischen den beiden betreffenden Versuchsflächen. 


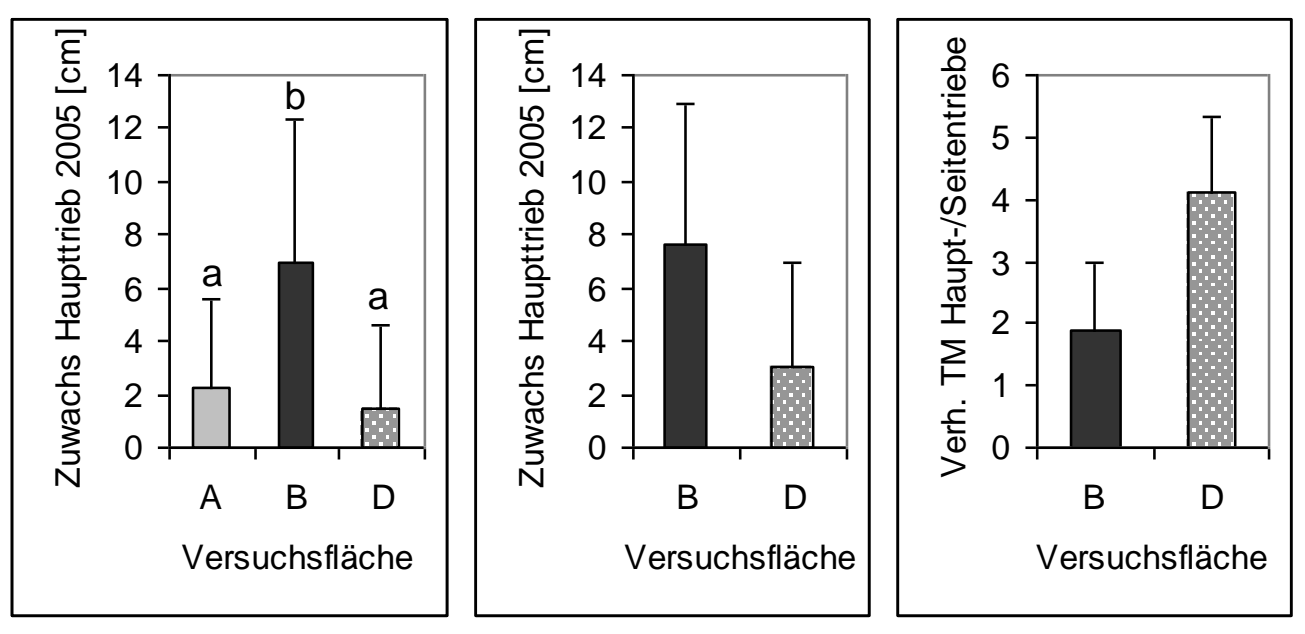

Abb. 184: Zuwachs [cm] des Haupttriebs im 1. Vegetationsjahr getrennt nach Versuchsflächen, Kiefern insgesamt (links; n=44; A: 7, B: 25, D: 12) sowie in Bereichen mit Spontanvegetation (Mitte; n=28; B: 22, D: 6); MW u. Std.abw.; Buchstaben kennzeichnen homogene Gruppen nach U-Tests; Verhältnis der Trockenmassen der Haupt- und Seitentriebe getrennt nach Versuchsflächen, Kiefern insgesamt (rechts; n=22; B: 18, D: 4); MW u. Std.abw.; signifikante Unterschiede nach U-Tests

Der Quotient aus den mittleren Trockenmassen der Haupt- und Seitentriebe lag bei den Kiefern auf Fläche B mit 1,9 $\pm 1,1$ knapp halb so hoch wie auf Fläche D mit 4,1 $\pm 1,2$ (s. Abb. 184 rechts). In diesem Fall stimmten die Trockenmassen der Seitentriebe, die mit Hilfe der an jeder Kiefer gemessenen Seitentrieblänge und den an einer Stichprobe bestimmten Trockenmassen errechnet wurden, beinahe überein (B: 7,4 $\pm 4,8 \mathrm{~g}$; D: 7,3 $\pm 5,2 \mathrm{~g}$ ).

Grund für die stark unterschiedlichen Trockenmassen-Verhältnisse waren somit die bei den 22 zu dieser Analyse herangezogenen Kiefern deutlich voneinander abweichenden Trockenmassen der Haupttriebe (mit Hilfe der an jeder Kiefer gemessenen Haupttrieblängen, Wurzelhalsdurchmesser sowie Spitzendurchmesser und den an einer Stichprobe bestimmten Trockenmassen errechnet), die auf Fläche B 13,5 \pm 11,4 g, auf Fläche D 30,1 $\pm 21,6$ g betrugen.

Die Aussagekraft dieses Vergleichs ist aufgrund der sehr unterschiedlich großen, im Fall von „D“ nur aus 4 Versuchspflanzen bestehenden Gruppen jedoch eher gering.

\section{Kiefern in Bereichen ohne Spontanvegetation}

In unbewachsenen Bereichen, in denen die wenigen überlebenden Kiefern deutlich geringere Wachstumswerte aufwiesen als in bewachsenen Bereichen, konnten keine signifikanten Unterschiede zwischen den Versuchsflächen festgestellt werden. 


\subsection{Einfluss des Standortes in Bereichen mit oder ohne Spontanvegetation}

\subsubsection{Vitalitätsentwicklung}

Die Vitalität aller 936 Bäume des Freiland-Versuchs wurde im Verlauf des zweijährigen Untersuchungszeitraums wiederholt auf einer Skala von "4“ (vital) bis „0“ (tot) eingeschätzt (s. S. 27).

Im Folgenden wird die Vitalitätsentwicklung der Versuchsbäume anhand der Ergebnisse statistischer Analysen der Vitalitätswerte auf Einflüsse durch den Pflanzenstandort in im Versuchsverlauf mit Spontanvegetation bewachsenen (vergleichsweise günstigere Bedingungen) oder bis Versuchsende vegetationsfreien Bereichen (vergleichsweise ungünstigere Bedingungen) untersucht (zu den unterschiedlichen Standortbedingungen s. ab S. 44).

Da der Einflussfaktor „Pflanzenstandort auf einer der drei Versuchsflächen“ (s. ab S. 227) teilweise eine wichtige Rolle spielte, wurden die Wirkungen des „Standortes ohne/mit Spontanvegetation" auf die Vitalitätsentwicklung der Versuchspflanzen auch unter Ausschluss dieses Faktors untersucht. Dies geschah, indem ausschließlich die Bäume mit Standorten auf einer bestimmten Versuchsfläche (zu den unterschiedlichen Standortbedingungen s. ab S. 44) betrachtet wurden.

\subsubsection{Rot-Eiche}

Der Pflanzenstandort in vegetationsfreien oder spontan besiedelten Bereichen (bzw. die zugrunde liegenden Bodenbedingungen) hatte sowohl insgesamt als auch auf den in Frage kommenden Versuchsflächen (B und D; A blieb vegetationsfrei) Einfluss auf die Vitalität der Eichen.

\section{Eichen insgesamt}

Die durchschnittliche Vitalität aller Eichen, die zufällig in Teilbereichen gepflanzt wurden, in denen sich später spontan Bodenvegetation entwickelte, nahm zunächst signifikant von anfänglich 2,3 $\pm 0,5$ auf 0,8 $\pm 0,5$ im Juni 2005 ab, um jedoch zum Oktober 2005 wieder signifikant auf $1,1 \pm 1,0$ anzusteigen. Nach einer weiteren signifikanten Abnahme auf 0,8 $\pm 1,2 \mathrm{im}$ Juni 2006 blieb der Mittelwert dann konstant auf diesem insgesamt sehr geringen Niveau (s. Tab. 96). Auf Standorten in bis zum Abschluss der Versuche vegetationsfreien Bereichen lag der mittlere Vitalitätswert der Eichen noch darunter. Er nahm von Aufnahme zu Aufnahme signifikant von zu Beginn 2,3 \pm 0,5 auf schließlich 0,1 \pm 0,5 im Oktober 2006 ab.

$\mathrm{Zu}$ jedem Aufnahmezeitpunkt waren die Unterschiede zwischen den Durchschnittsvitalitätswerten der Eichen auf bewachsenen und unbewachsenen Standorten signifikant (s. Abb. 185). Die entsprechende Kreuztabelle weist zudem auf eine signifikante Korrelation der Sterblichkeitsrate der Eichen mit ihrem Standort im vegetationsfreien oder besiedelten Bereich hin $\left(\mathrm{Chi}^{2}\right.$ 18,97***). 
Tab. 96: Vitalität der Eichen [codiert: $4=$ vital bis $0=$ tot, s. S. 27] in Bereichen ohne $(n=114)$ und mit ( $\mathrm{n}=77$ ) Spontanvegetation im Versuchsverlauf; MW u. Std.abw.; je Aufnahmezeitpunkt Ergebnisse von UTests (Z) auf signifikante Unterschiede zwischen den Standorten; je Standort Ergebnisse von FriedmannTests $\left(\mathrm{Chi}^{2}\right)$ auf signifikante Unterschiede zwischen den Aufnahmezeitpunkten

\begin{tabular}{|l|l|l|l|l|l|l|l|l|l|l|}
\hline & $\begin{array}{l}\text { April } \\
2005\end{array}$ & & $\begin{array}{l}\text { Juni } \\
2005\end{array}$ & & $\begin{array}{l}\text { Oktober } \\
2005\end{array}$ & & $\begin{array}{l}\text { Juni } \\
2006\end{array}$ & $\begin{array}{l}\text { Oktober } \\
2006\end{array}$ & Chi $^{2}$ \\
\hline o.BV & $2,3 \pm 0,5$ & $>$ & $0,6 \pm 0,5$ & $>$ & $0,5 \pm 0,6$ & $>$ & $0,2 \pm 0,6$ & $>$ & $0,1 \pm 0,5$ & $240,0^{* * *}$ \\
\hline m.BV & $2,3 \pm 0,5$ & $>$ & $0,8 \pm 0,5$ & $<$ & $1,1 \pm 1,0$ & $>$ & $0,8 \pm 1,2$ & & $0,8 \pm 1,3$ & $98,91^{* * *}$ \\
\hline Z & & & $3,04^{* *}$ & & $4,88^{* * *}$ & & $4,82^{* * *}$ & & $4,54^{* * *}$ & \\
\hline
\end{tabular}

$>$ signifikanter Rückgang, < signifikanter Anstieg der Vitalität laut Wilcoxon-Test

Die niedrigen Mittelwerte entstanden durch eine hohe Ausfallrate (Vitalitätswert „0“). Die Aussagekraft dieser statistisch signifikanten Unterschiede zwischen mittleren Vitalitätswerten, die deutlich unter "1“ liegen, ist relativ gering. Dennoch scheint auch bei den Eichen der individuelle Pflanzenstandort in Bereichen mit späterer Bodenvegetation oder in bis Versuchsabschluss vegetationsfreien Bereichen für die Vitalitätsentwicklung - in diesem Fall vor allem für die Sterblichkeits- bzw. Überlebensrate - von Bedeutung zu sein.

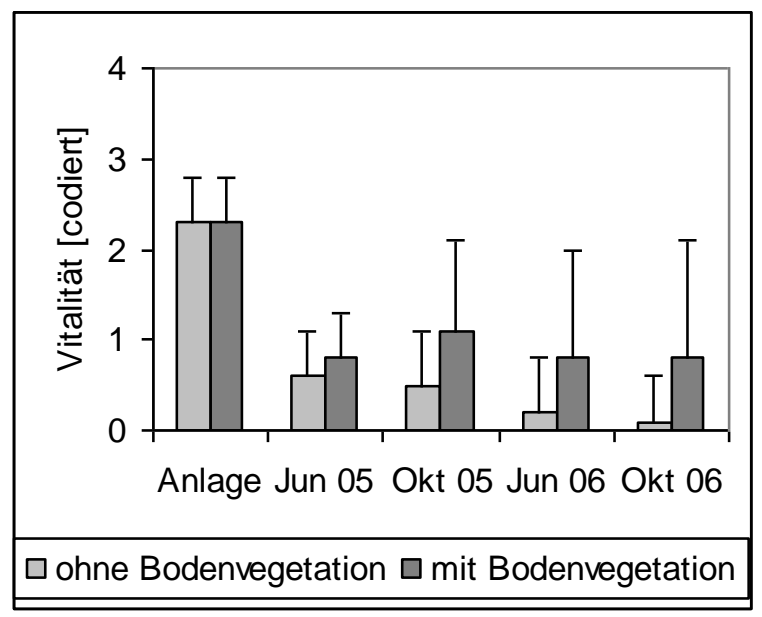

Abb. 185: Vitalität der Eichen [codiert: $4=$ vital bis $0=$ tot, s. S. 27] in Bereichen ohne (n=114) und mit ( $n=77)$ Spontanvegetation im Versuchsverlauf; MW u. Std.abw.; zu jedem Aufnahmezeitpunkt signifikante Unterschiede nach U-Tests

\section{Eichen auf den Versuchsflächen B und D}

Auf beiden Versuchsflächen (B, D) bewegten sich die mittleren Vitalitätswerte der Eichen in Bereichen ohne und mit Bodenbewuchs ausgenommen bei Anlage auf insgesamt sehr niedrigem Niveau (unter oder um „1“). Dabei sank die durchschnittliche Vitalität von der Anlage im April 2005 bis Juni 2005 signifikant und sehr deutlich ab. In Bereichen mit Bodenbewuchs stieg sie auf beiden Flächen bis Oktober 2005 jedoch wieder signifikant an.

Auf Fläche B (s. Tab. 97) nahmen die Werte zum 2. Versuchsjahr daraufhin wieder signifikant ab, wobei in unbewachsenen Bereichen sämtliche Eichen abstarben. Auf dieser Fläche bestanden zu jedem Aufnahmezeitpunkt signifikante Unterschiede zwischen den Werten in Bereichen mit und ohne Bodenbewuchs (s. Abb. 186 links). 
Tab. 97: Vitalität der Eichen [codiert: $4=$ vital bis $0=$ tot, s. S. 27] auf Fläche B in Bereichen ohne $(n=20)$ und mit $(n=43)$ Spontanvegetation im Versuchsverlauf; MW u. Std.abw.; je Aufnahmezeitpunkt Ergebnisse von U-Tests (Z) auf signifikante Unterschiede zwischen den Flächen; je Fläche Ergebnisse von FriedmannTests $\left(\mathrm{Chi}^{2}\right)$ auf signifikante Unterschiede zwischen den Aufnahmezeitpunkten

\begin{tabular}{|l|l|l|l|l|l|l|l|l|l|l|}
\hline B & $\begin{array}{l}\text { April } \\
2005\end{array}$ & & $\begin{array}{l}\text { Juni } \\
2005\end{array}$ & & $\begin{array}{l}\text { Oktober } \\
2005\end{array}$ & & $\begin{array}{l}\text { Juni } \\
2006\end{array}$ & $\begin{array}{l}\text { Oktober } \\
2006\end{array}$ & $\mathrm{Chi}^{2}$ \\
\hline o.BV & $2,7 \pm 0,5$ & $>$ & $0,5 \pm 0,5$ & & $0,5 \pm 0,6$ & $>$ & 0 & & 0 & $44,96^{* * *}$ \\
\hline m.BV & $2,4 \pm 0,5$ & $>$ & $0,8 \pm 0,5$ & $<$ & $1,1 \pm 0,9$ & $>$ & $0,6 \pm 1,0$ & & $0,7 \pm 1,1$ & $72,13^{* * *}$ \\
\hline Z & & & $-2,51^{* *}$ & & $-2,84^{* *}$ & & $-2,97^{* *}$ & & $-2,72^{* *}$ & \\
\hline
\end{tabular}

$>$ signifikanter Rückgang, < signifikanter Anstieg der Vitalität laut Wilcoxon-Test

Auf Fläche D (s. Tab. 98) blieben die Werte in Bereichen ohne Spontanvegetation ab Juni 2005, in Bereichen mit Spontanvegetation ab Oktober 2005 relativ konstant. Hier gab es im Oktober 2005 und im Juni 2006 signifikante Unterschiede zwischen den mittleren Vitalitätswerten der Eichen in besiedelten und unbesiedelten Bereichen (s. Abb. 186 rechts).

Tab. 98: Vitalität der Eichen [codiert: $4=$ vital bis $0=$ tot, s. S. 27] auf Fläche $D$ in Bereichen ohne $(n=30)$ und mit $(n=34)$ Spontanvegetation im Versuchsverlauf; MW u. Std.abw.; je Aufnahmezeitpunkt Ergebnisse von U-Tests (Z) auf signifikante Unterschiede zwischen den Flächen; je Fläche Ergebnisse von FriedmannTests $\left(\mathrm{Chi}^{2}\right)$ auf signifikante Unterschiede zwischen den Aufnahmezeitpunkten

\begin{tabular}{|l|l|l|l|l|l|l|l|l|l|l|}
\hline D & $\begin{array}{l}\text { April } \\
2005\end{array}$ & & $\begin{array}{l}\text { Juni } \\
2005\end{array}$ & & $\begin{array}{l}\text { Oktober } \\
2005\end{array}$ & & $\begin{array}{l}\text { Juni } \\
2006\end{array}$ & $\begin{array}{l}\text { Oktober } \\
2006\end{array}$ & Chi $^{2}$ \\
\hline o.BV & $2,2 \pm 0,4$ & $>$ & $0,7 \pm 0,5$ & & $0,6 \pm 0,7$ & & $0,5 \pm 0,9$ & $0,4 \pm 0,9$ & $52,18^{* * *}$ \\
\hline m.BV & $2,2 \pm 0,4$ & $>$ & $0,8 \pm 0,5$ & $<$ & $1,1 \pm 1,0$ & & $1,1 \pm 1,3$ & & $1,0 \pm 1,5$ & $31,75^{* *}$ \\
\hline Z & & & $-1,03$ & & $-2,29^{*}$ & & $-2,35^{* *}$ & & $-1,61$ & \\
\hline
\end{tabular}

$>$ signifikanter Rückgang, < signifikanter Anstieg der Vitalität laut Wilcoxon-Test

Ohne Frage ist in diesem niedrigen Wertebereich die Aussagekraft statistisch signifikanter Unterschiede zwischen Vitalitätsmittelwerten gering. Dennoch lässt sich auch für die Eichen auf den beiden betroffenen Versuchsflächen ein positiver Einfluss des Standortes in Bereichen mit spontaner Vegetationsentwicklung (und damit besseren Wuchsbedingungen) feststellen.
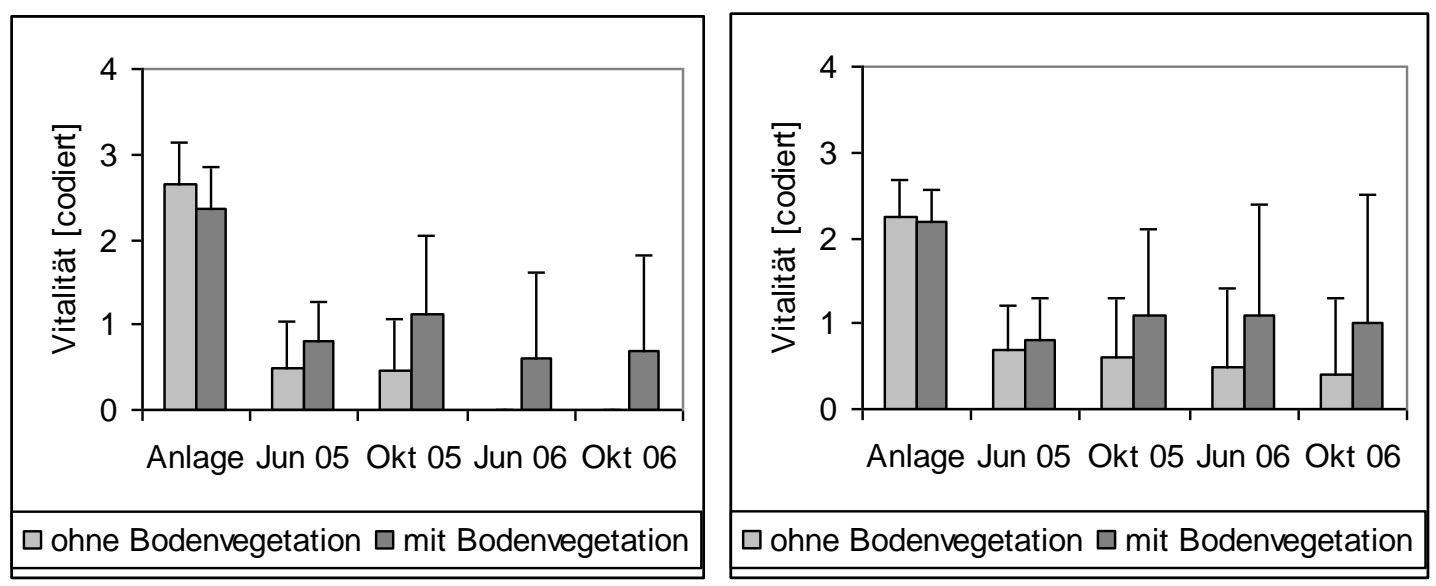

Abb. 186: Vitalität der Eichen [codiert: $4=$ vital bis $0=$ tot, s. S. 27] auf Fläche B (links; $n=20 / 43$ ) sowie Fläche D (rechts; $n=30 / 34$ ) in Bereichen ohne und mit Spontanvegetation im Versuchsverlauf; MW u. Std.abw.; auf Fläche B zu jedem Aufnahmezeitpunkt, auf Fläche D im Oktober 2005 und Juni 2006 signifikante Unterschiede nach U-Tests 


\subsubsection{Spitz-Ahorn}

Der Pflanzenstandort in vegetationsfreien oder spontan besiedelten Bereichen (bzw. die zugrunde liegenden Bodenbedingungen) hatte sowohl insgesamt als auch auf den in Frage kommenden Versuchsflächen (B und D; A blieb vegetationsfrei) Einfluss auf die Vitalität der Ahorne.

\section{Ahorne insgesamt}

Die durchschnittliche Vitalität aller Ahorne, die zufällig in Teilbereichen gepflanzt wurden, in denen sich später spontan Bodenvegetation entwickelte, lag im 1. Versuchsjahr konstant zwischen 2,5 $\pm 0,5$ und 2,7 $\pm 1,0$ und sank im 2. Versuchsjahr leicht, aber dennoch signifikant auf $2,4 \pm 1,1$ bzw. 2,3 $\pm 1,2$ ab (s. Tab. 99). Der mittlere Vitalitätszustand der Ahorne mit Standorten in bis zum Abschluss der Versuche vegetationsfreien Teilbereichen verschlechterte sich von Aufnahme zu Aufnahme signifikant. Insgesamt nahm der Mittelwert dort von 2,5 \pm 0,6 im April 2005 auf geringe 1,2 $\pm 1,3$ im Oktober $2006 \mathrm{ab}$.

Tab. 99: Vitalität der Ahorne [codiert: $4=$ vital bis $0=$ tot, s. S. 27] in Bereichen ohne (n=118) und mit $(n=74)$ Spontanvegetation im Versuchsverlauf; MW u. Std.abw.; je Aufnahmezeitpunkt Ergebnisse von UTests (Z) auf signifikante Unterschiede zwischen den Standorten; je Standort Ergebnisse von FriedmannTests $\left(\mathrm{Chi}^{2}\right)$ auf signifikante Unterschiede zwischen den Aufnahmezeitpunkten

\begin{tabular}{|l|l|l|l|l|l|l|l|l|l|l|}
\hline & $\begin{array}{l}\text { April } \\
2005\end{array}$ & & $\begin{array}{l}\text { Juni } \\
2005\end{array}$ & & $\begin{array}{l}\text { Oktober } \\
2005\end{array}$ & & $\begin{array}{l}\text { Juni } \\
2006\end{array}$ & $\begin{array}{l}\text { Oktober } \\
2006\end{array}$ & $\mathrm{Chi}^{2}$ \\
\hline o.BV & $2,5 \pm 0,6$ & $>$ & $2,1 \pm 0,9$ & $>$ & $1,5 \pm 1,0$ & $>$ & $1,3 \pm 1,3$ & $>$ & $1,2 \pm 1,3$ & $119,0^{* * *}$ \\
\hline m.BV & $2,5 \pm 0,5$ & & $2,6 \pm 0,9$ & & $2,7 \pm 1,0$ & $>$ & $2,4 \pm 1,1$ & & $2,3 \pm 1,2$ & $10,59^{* *}$ \\
\hline Z & & & $4,09^{* * *}$ & & $-6,90^{* * *}$ & & $5,09^{* * *}$ & & $5,54^{* * *}$ & \\
\hline
\end{tabular}

$>$ signifikanter Rückgang der Vitalität laut Wilcoxon-Test

Zu jedem Aufnahmezeitpunkt waren die Unterschiede zwischen den mittleren Vitalitätswerten der Ahorne auf bewachsenen und unbewachsenen Standorten signifikant (s. Abb. 187).

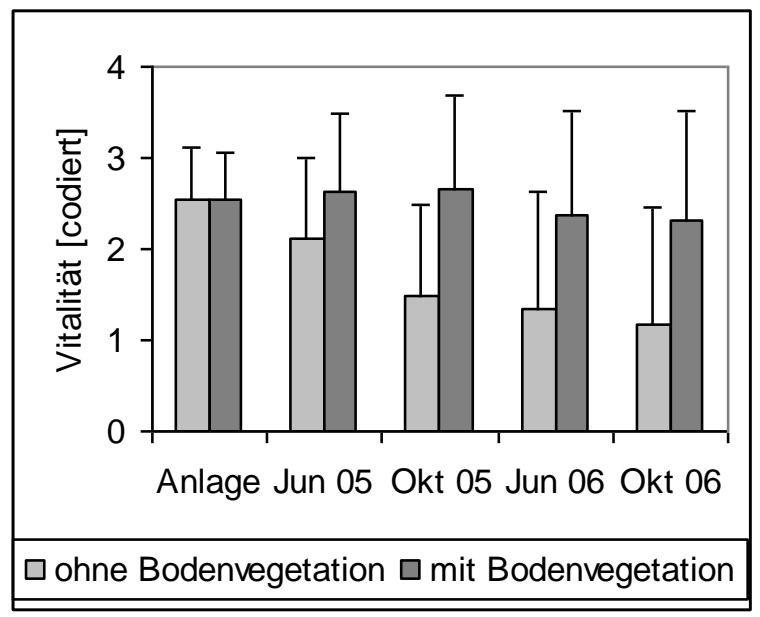

Abb. 187: Vitalität der Ahorne [codiert: $4=$ vital bis $0=$ tot, s. S. 27] in Bereichen ohne ( $\mathrm{n}=118)$ und mit $(n=74)$ Spontanvegetation im Versuchsverlauf; MW u. Std.abw.; zu jedem Aufnahmezeitpunkt signifikante Unterschiede nach U-Tests 
Auch die entsprechende Kreuztabelle weist auf eine signifikante Korrelation der Sterblichkeitsrate der Ahorne mit ihrem Standort im vegetationsfreien oder besiedelten Bereich hin ( $\mathrm{Chi}^{2}$ 22,23***). Der individuelle Pflanzenstandort in Bereichen mit späterer Bodenvegetation oder in bis Versuchsabschluss vegetationsfreien Bereichen war folglich für die Vitalitätsentwicklung der Ahorne von großer Bedeutung.

\section{Ahorne auf Versuchsfläche B}

Auf Fläche B veränderte sich die mittlere Vitalität der Ahorne in vegetationsfreien Bereichen im Versuchsverlauf nicht signifikant. Sie lag zwischen 2,6 $\pm 0,5$ auf 1,8 $\pm 1,5$ und damit in einem geringen bis mäßig guten Bereich (s. Tab. 100). In Bereichen mit späterem Bodenbewuchs waren die Mittelwerte mäßig gut mit einem signifikanten Anstieg auf 2,8 $\pm 0,7 \mathrm{zu}$ Beginn des Versuchs und einer leichten, signifikanten Abnahme auf 2,3 $\pm 1,0$ zum 2. Versuchsjahr.

Signifikante Vitalitätsunterschiede zwischen den Ahornen mit Standorten in Bereichen mit und ohne Entwicklung von Spontanvegetation bestanden auf Fläche B nicht.

Tab. 100: Vitalität der Ahorne [codiert: $4=$ vital bis $0=$ tot, s. S. 27] auf Fläche B in Bereichen ohne $(n=21)$ und mit ( $\mathrm{n}=43$ ) Spontanvegetation im Versuchsverlauf; MW u. Std.abw.; je Aufnahmezeitpunkt Ergebnisse von U-Tests (Z) auf signifikante Unterschiede zwischen den Flächen; je Fläche Ergebnisse von FriedmannTests $\left(\mathrm{Chi}^{2}\right)$ auf signifikante Unterschiede zwischen den Aufnahmezeitpunkten

\begin{tabular}{|l|l|l|l|l|l|l|l|l|l|l|}
\hline B & $\begin{array}{l}\text { April } \\
2005\end{array}$ & & $\begin{array}{l}\text { Juni } \\
2005\end{array}$ & $\begin{array}{l}\text { Oktober } \\
2005\end{array}$ & $\begin{array}{l}\text { Juni } \\
2006\end{array}$ & $\begin{array}{l}\text { Oktober } \\
2006\end{array}$ & $\mathrm{Chi}^{2}$ \\
\hline o.BV & $2,6 \pm 0,5$ & & $2,4 \pm 1,0$ & & $2,1 \pm 1,2$ & & $1,9 \pm 1,4$ & & $1,8 \pm 1,5$ & 6,48 \\
\hline m.BV & $2,4 \pm 0,5$ & $<$ & $2,8 \pm 0,7$ & & $2,7 \pm 1,0$ & $>$ & $2,3 \pm 1,0$ & & $2,3 \pm 1,1$ & $12,71^{*}$ \\
\hline Z & & & $-1,37$ & & $-1,48$ & & $-0,42$ & & $-0,93$ & \\
\hline
\end{tabular}

$>$ signifikanter Rückgang, < signifikanter Anstieg der Vitalität laut Wilcoxon-Test

\section{Ahorne auf Versuchsfläche D}

Auf Fläche D war dagegen bei den Aufnahmen im Juni 2005, Oktober 2005 und Juni 2006 die mittlere Vitalität der Ahorne in bewachsenen Bereichen signifikant höher als in unbewachsenen Bereichen (s. Abb. 188). Zum Ende des Versuchs im Oktober 2006 war dieser Unterschied dann jedoch nicht mehr signifikant.

Tab. 101: Vitalität der Ahorne [codiert: $4=$ vital bis $0=$ tot, s. S. 27] auf Fläche D in Bereichen ohne $(n=33)$ und mit $(\mathrm{n}=31)$ Spontanvegetation im Versuchsverlauf; MW u. Std.abw.; je Aufnahmezeitpunkt Ergebnisse von U-Tests (Z) auf signifikante Unterschiede zwischen den Flächen; je Fläche Ergebnisse von FriedmannTests $\left(\mathrm{Chi}^{2}\right)$ auf signifikante Unterschiede zwischen den Aufnahmezeitpunkten

\begin{tabular}{|l|l|l|l|l|l|l|l|l|l|l|}
\hline D & $\begin{array}{l}\text { April } \\
2005\end{array}$ & & $\begin{array}{l}\text { Juni } \\
2005\end{array}$ & & $\begin{array}{l}\text { Oktober } \\
2005\end{array}$ & & $\begin{array}{l}\text { Juni } \\
2006\end{array}$ & $\begin{array}{l}\text { Oktober } \\
2006\end{array}$ & Chi $^{2}$ \\
\hline o.BV & $2,7 \pm 0,6$ & $>$ & $2,1 \pm 0,8$ & & $2,0 \pm 1,1$ & & $1,8 \pm 1,4$ & $1,8 \pm 1,5$ & $10,98^{*}$ \\
\hline m.BV & $2,7 \pm 0,5$ & & $2,4 \pm 1,0$ & & $2,7 \pm 1,1$ & & $2,5 \pm 1,4$ & $2,4 \pm 1,3$ & 3,34 \\
\hline Z & & & $-1,96^{*}$ & & $-2,63^{* *}$ & & $-2,36^{* *}$ & $-1,53$ & \\
\hline
\end{tabular}

$>$ signifikanter Rückgang der Vitalität laut Wilcoxon-Test

Hier sank die Durchschnittsvitalität der Ahorne in unbewachsenen Bereichen zu Versuchsbeginn signifikant von 2,7 $\pm 0,6$ auf 2,1 $\pm 0,8$ und bewegte sich im weiteren 
Versuchsverlauf in diesem gering bis mäßigen Bereich (s. Tab. 101). In bewachsenen Bereichen lag die Vitalität im Mittel konstant im mäßig guten Bereich zwischen 2,7 $\pm 0,5$ und 2,4 $\pm 1,3$.

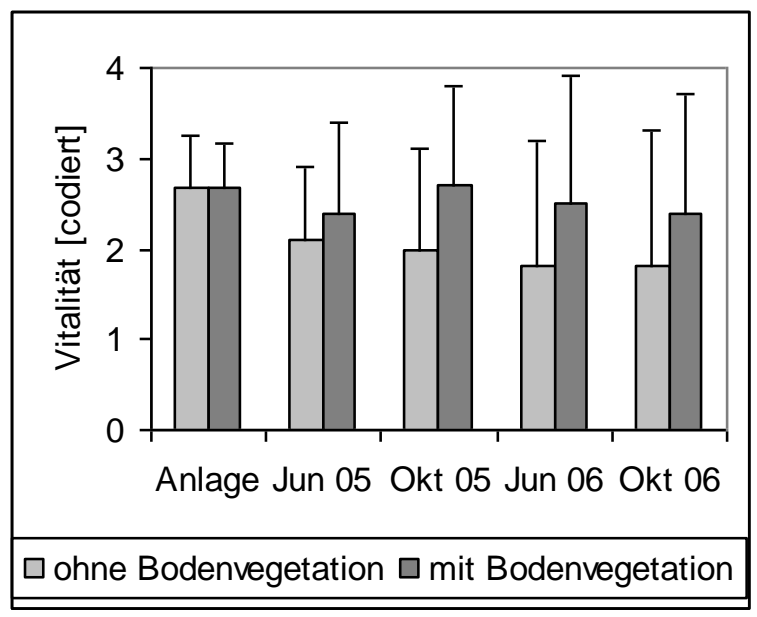

Abb. 188: Vitalität der Ahorne [codiert: $4=$ vital bis $0=$ tot, s. S. 27] auf Fläche D in Bereichen ohne (n=33) und mit ( $\mathrm{n}=31)$ Spontanvegetation im Versuchsverlauf; MW u. Std.abw.; außer im Oktober 2006 zu jedem Aufnahmezeitpunkt signifikante Unterschiede nach U-Tests

\subsubsection{Eberesche}

Der Pflanzenstandort in vegetationsfreien oder spontan besiedelten Bereichen (bzw. die zugrunde liegenden Bodenbedingungen) hatte sowohl insgesamt als auch auf den in Frage kommenden Versuchsflächen (B und D; A blieb vegetationsfrei) Einfluss auf die Vitalität der Ebereschen.

\section{Ebereschen insgesamt}

Die durchschnittliche Vitalität aller Ebereschen, die zufällig in Teilbereichen gepflanzt wurden, in denen sich später spontan Bodenvegetation entwickelte (bessere Standortbedingungen), veränderte sich im Versuchsverlauf nicht signifikant und lag bei recht hohen Werten zwischen 2,6 $\pm 0,9$ und 3,0 $\pm 0,8$ (s. Tab. 102). Dagegen sank der mittlere Vitalitätswert der Ebereschen mit Standorten in bis zum Abschluss der Versuche vegetationsfreien Teilbereichen von 3,0 $\pm 0,3$ bei Anlage auf bereits nur noch 2,0 \pm 0,9 im Juni 2005 und schließlich auf 1,4 $\pm 1,3$ im Oktober 2006 . Dabei fand nur zwischen Oktober 2005 und Juni 2006 keine signifikante Verschlechterung statt.

Tab. 102: Vitalität der Ebereschen [codiert: $4=$ vital bis $0=$ tot, s. S. 27] in Bereichen ohne (n=76) und mit $(n=44)$ Spontanvegetation im Versuchsverlauf; MW u. Std.abw.; je Aufnahmezeitpunkt Ergebnisse von UTests (Z) auf signifikante Unterschiede zwischen den Standorten; je Standort Ergebnisse von FriedmannTests $\left(\mathrm{Chi}^{2}\right)$ auf signifikante Unterschiede zwischen den Aufnahmezeitpunkten

\begin{tabular}{|l|l|l|l|l|l|l|l|l|l|l|}
\hline & $\begin{array}{l}\text { April } \\
2005\end{array}$ & & $\begin{array}{l}\text { Juni } \\
2005\end{array}$ & & $\begin{array}{l}\text { Oktober } \\
2005\end{array}$ & $\begin{array}{l}\text { Juni } \\
2006\end{array}$ & $\begin{array}{l}\text { Oktober } \\
2006\end{array}$ & Chi $^{2}$ \\
\hline o.BV & $3,0 \pm 0,3$ & $>$ & $2,0 \pm 0,9$ & $>$ & $1,6 \pm 1,2$ & & $1,6 \pm 1,3$ & $>$ & $1,4 \pm 1,3$ & $76,23^{* * *}$ \\
\hline m.BV & $2,9 \pm 0,5$ & & $2,6 \pm 0,7$ & & $3,0 \pm 0,8$ & $2,6 \pm 0,9$ & & $2,7 \pm 1,0$ & 8,31 \\
\hline Z & & & $3,78^{* * *}$ & & $-6,05^{* * *}$ & & $4,12^{* * *}$ & & $5,26^{* * *}$ & \\
\hline
\end{tabular}

$>$ signifikanter Rückgang der Vitalität laut Wilcoxon-Test 
$\mathrm{Zu}$ jedem Aufnahmezeitpunkt waren die Unterschiede zwischen den Vitalitätswerten der Ebereschen auf bewachsenen und unbewachsenen Standorten signifikant (s. Abb. 189). Die entsprechende Kreuztabelle weist zudem eine signifikante Korrelation der Sterblichkeitsrate mit dem Standort im vegetationsfreien oder besiedelten Bereich nach $\left(\mathrm{Chi}^{2} 13,55^{* * *}\right)$.

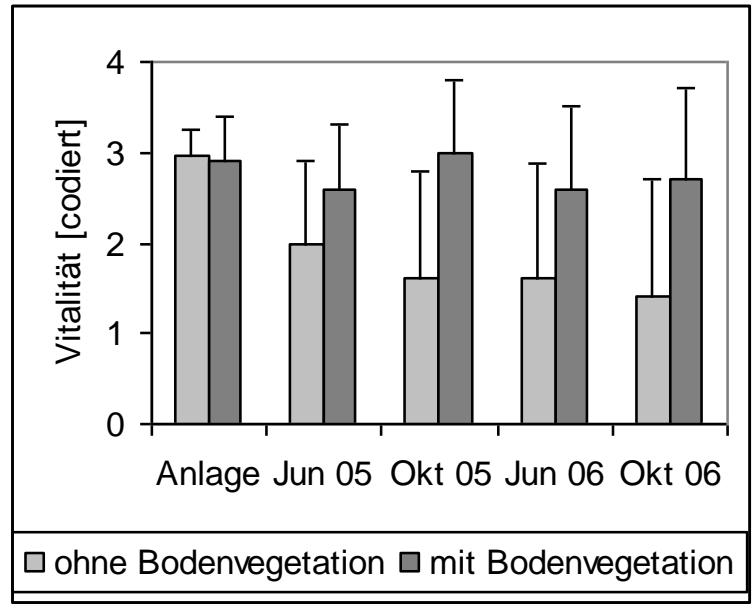

Abb. 189: Vitalität der Ebereschen [codiert: $4=$ vital bis $0=$ tot, s. S. 27] in Bereichen ohne (n=76) und mit $(n=44)$ Spontanvegetation im Versuchsverlauf; MW u. Std.abw.; zu jedem Aufnahmezeitpunkt signifikante Unterschiede nach U-Tests

\section{Ebereschen auf Versuchsfläche B}

Die ausschließliche Betrachtung der Ebereschen auf Versuchsfläche B ergab ebenfalls, dass die mittlere Vitalität in Bereichen mit Spontanvegetation $\mathrm{zu}$ fast jedem Aufnahmezeitpunkt (ausgenommen bei der Aufnahme im Juni 2006) signifikant höher lag als ohne Bewuchs (s. Abb. 190 links).

Tab. 103: Vitalität der Ebereschen [codiert: $4=$ vital bis $0=$ tot, s. S. 27] auf Fläche B in Bereichen ohne $(n=10)$ und mit $(n=30)$ Spontanvegetation im Versuchsverlauf; MW u. Std.abw.; je Aufnahmezeitpunkt Ergebnisse von U-Tests (Z) auf signifikante Unterschiede zwischen den Standorten; je Standort Ergebnisse von Friedmann-Tests $\left(\mathrm{Chi}^{2}\right)$ auf signifikante Unterschiede zwischen den Aufnahmezeitpunkten

\begin{tabular}{|l|l|l|l|l|l|l|l|l|l|l|}
\hline B & $\begin{array}{l}\text { April } \\
2005\end{array}$ & $\begin{array}{l}\text { Juni } \\
2005\end{array}$ & $\begin{array}{l}\text { Oktober } \\
2005\end{array}$ & $\begin{array}{l}\text { Juni } \\
2006\end{array}$ & $\begin{array}{l}\text { Oktober } \\
2006\end{array}$ & $\mathrm{Chi}^{2}$ \\
\hline o.BV & $2,8 \pm 0,4$ & $1,9 \pm 0,9$ & & $1,8 \pm 1,4$ & & $1,7 \pm 1,5$ & $1,2 \pm 1,4$ & 5,64 \\
\hline m.BV & $2,9 \pm 0,5$ & $2,5 \pm 0,7$ & & $2,8 \pm 0,9$ & & $2,4 \pm 1,1$ & & $2,5 \pm 1,1$ & 5,35 \\
\hline Z & & $-2,04^{*}$ & & $-2,63^{* *}$ & & $-1,21$ & & $-2,77^{* *}$ & \\
\hline
\end{tabular}

Die durchschnittliche Vitalität in bewachsenen Bereichen bewegte sich nach anfänglich 2,9 $\pm 0,5$ zwischen 2,4 $\pm 1,1$ und 2,8 $\pm 0,9$, in unbewachsenen dagegen nach anfänglich 2,8 $\pm 0,4$ zwischen $1,9 \pm 0,9$ im Juni 2005 und 1,2 $\pm 1,4$ im Oktober 2006 (s. Tab. 103). Auf beiden Standorten war die Veränderung der Vitalität im Versuchsverlauf nicht signifikant, was in Bereichen ohne Spontanvegetation auf die hohen Standardabweichungen zurückzuführen ist.

\section{Ebereschen auf Versuchsfläche D}

Auch auf Versuchsfläche D lag die mittlere Vitalität der Ebereschen in Bereichen mit Spontanvegetation zu jedem Aufnahmezeitpunkt signifikant höher als ohne Bewuchs (s. Abb. 190 rechts). 
Tab. 104: Vitalität der Ebereschen [codiert: $4=$ vital bis $0=$ tot, s. S. 27] auf Fläche D in Bereichen ohne $(\mathrm{n}=26)$ und mit $(\mathrm{n}=14)$ Spontanvegetation im Versuchsverlauf; MW u. Std.abw.; je Aufnahmezeitpunkt Ergebnisse von U-Tests (Z) auf signifikante Unterschiede zwischen den Standorten; je Standort Ergebnisse von Friedmann-Tests $\left(\mathrm{Chi}^{2}\right)$ auf signifikante Unterschiede zwischen den Aufnahmezeitpunkten

\begin{tabular}{|l|l|l|l|l|l|l|l|l|l|l|}
\hline D & $\begin{array}{l}\text { April } \\
2005\end{array}$ & & $\begin{array}{l}\text { Juni } \\
2005\end{array}$ & $\begin{array}{l}\text { Oktober } \\
2005\end{array}$ & $\begin{array}{l}\text { Juni } \\
2006\end{array}$ & $\begin{array}{l}\text { Oktober } \\
2006\end{array}$ & Chi $^{2}$ \\
\hline o.BV & $2,9 \pm 0,3$ & $>$ & $1,8 \pm 0,8$ & $2,0 \pm 1,3$ & & $1,8 \pm 1,3$ & $>$ & $1,7 \pm 1,3$ & $19,03^{* * *}$ \\
\hline m.BV & $2,9 \pm 0,3$ & & $2,6 \pm 0,6$ & & $3,3 \pm 0,5$ & & $3,0 \pm 0,4$ & & $3,0 \pm 0,6$ & 4,77 \\
\hline Z & & & $3,14^{* * *}$ & & $3,54^{* * *}$ & & $3,16^{* * *}$ & & $3,17^{* * *}$ & \\
\hline
\end{tabular}

$>$ signifikanter Rückgang der Vitalität laut Wilcoxon-Test

Die Werte betrugen in besiedelten Bereichen nach anfänglich 2,9 $\pm 0,3$ zunächst 2,6 $\pm 0,6$ und lagen dann zwischen 3,0 $\pm 0,4 / 0,5$ und 3,3 $\pm 0,5$. In unbesiedelten Bereichen bewegten sie sich nach anfänglich 2,9 $\pm 0,3$ zwischen 2,0 $\pm 1,3$ und 1,7 $\pm 1,3$. Nur dort war eine signifikante Vitalitätsabnahme im Versuchsverlauf (zu Beginn und zum Ende des Untersuchungszeitraums) zu verzeichnen (s. Tab. 104).
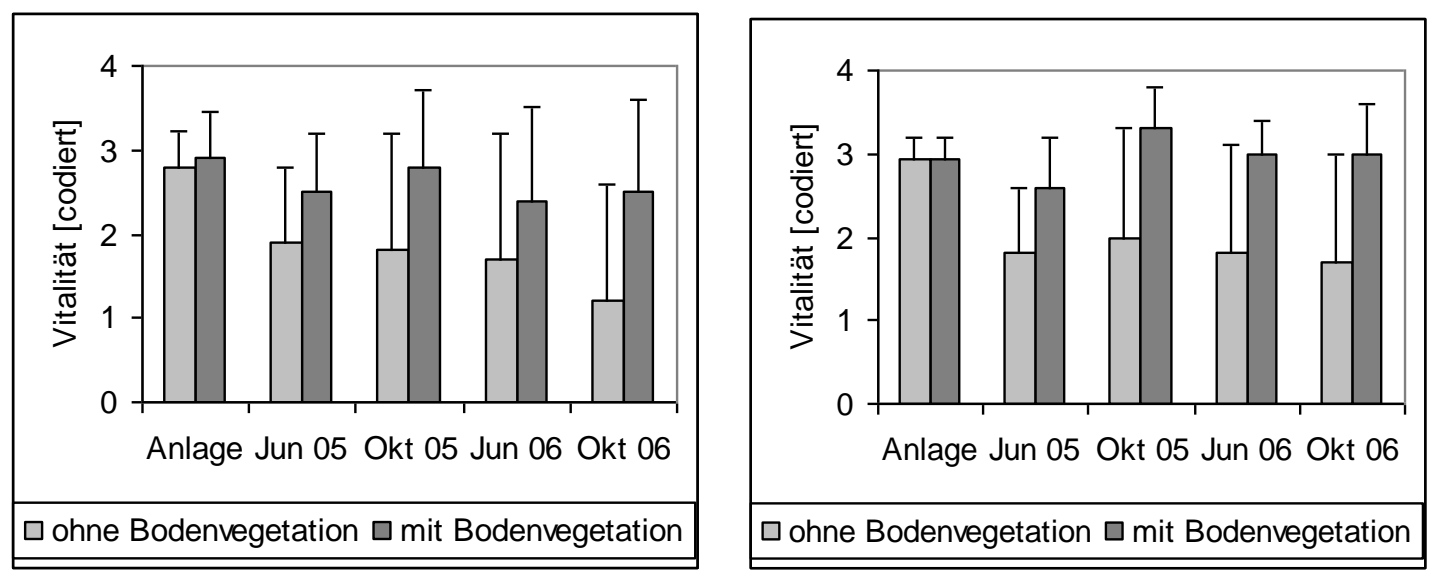

Abb. 190: Vitalität der Ebereschen [codiert: $4=$ vital bis $0=$ tot, s. S. 27] auf Fläche B (links; $n=10 / 30$ ) sowie Fläche D (rechts; $n=26 / 14$ ) in Bereichen ohne und mit Spontanvegetation im Versuchsverlauf; MW u. Std.abw.; außer auf Fläche B im Juni 2006 zu jedem Aufnahmezeitpunkt signifikante Unterschiede nach U-Tests

\subsubsection{Schwarz-Erle}

Der Pflanzenstandort in vegetationsfreien oder spontan besiedelten Bereichen (bzw. die zugrunde liegenden Bodenbedingungen) hatte sowohl insgesamt als auch auf den in Frage kommenden Versuchsflächen (B und D; A blieb vegetationsfrei) Einfluss auf die Vitalität der Erlen.

\section{Erlen insgesamt}

Die durchschnittliche Vitalität der Erlen sowohl in Bereichen mit als auch ohne späterer spontaner Bodenvegetation veränderte sich im Versuchsverlauf signifikant (s. Tab. 105). In beiden Fällen nahm sie zunächst von den recht hohen Ausgangswerten $(3,6 \pm 0,5$ bzw. 3,7 $\pm 0,5)$ signifikant auf $2,3 \pm 1,0$ bzw. 2,7 $\pm 0,7$ im Juni 2005 ab. 
Tab. 105: Vitalität der Erlen [codiert: $4=$ vital bis $0=$ tot, s. S. 27] in Bereichen ohne $(n=74)$ und mit $(\mathrm{n}=46)$ Spontanvegetation im Versuchsverlauf; MW u. Std.abw.; je Aufnahmezeitpunkt Ergebnisse von UTests (Z) auf signifikante Unterschiede zwischen den Standorten; je Standort Ergebnisse von FriedmannTests $\left(\mathrm{Chi}^{2}\right)$ auf signifikante Unterschiede zwischen den Aufnahmezeitpunkten

\begin{tabular}{|l|l|l|l|l|l|l|l|l|l|l|}
\hline & $\begin{array}{l}\text { April } \\
2005\end{array}$ & & $\begin{array}{l}\text { Juni } \\
2005\end{array}$ & & $\begin{array}{l}\text { Oktober } \\
2005\end{array}$ & $\begin{array}{l}\text { Juni } \\
2006\end{array}$ & $\begin{array}{l}\text { Oktober } \\
2006\end{array}$ & Chi $^{2}$ \\
\hline o.BV & $3,6 \pm 0,5$ & $>$ & $2,3 \pm 1,0$ & & $2,3 \pm 1,2$ & & $2,2 \pm 1,5$ & $>$ & $1,7 \pm 1,4$ & $78,38^{* * *}$ \\
\hline m.BV & $3,7 \pm 0,5$ & $>$ & $2,7 \pm 0,7$ & $<$ & $3,4 \pm 1,0$ & & $3,3 \pm 1,1$ & & $3,2 \pm 1,1$ & $34,37^{* * *}$ \\
\hline Z & & & $2,37^{* *}$ & & $-5,12^{* * *}$ & & $4,17^{* * *}$ & & $-5,48^{* * *}$ & \\
\hline
\end{tabular}

$>$ signifikanter Rückgang, < signifikanter Anstieg der Vitalität laut Wilcoxon-Test

Auf später bewachsenen Standorten erholten sich die Erlen schnell von dem „Pflanzschock“; ihre mittlere Vitalität stieg zum Oktober 2005 wieder signifikant auf 3,4 $\pm 1,0$ an und blieb im weiteren Versuchsverlauf recht konstant. Auf bis zuletzt unbesiedelten Standorten blieb die mittlere Vitalität der Erlen dagegen zunächst konstant bei knapp über „2“, um dann zur letzten Aufnahme im Oktober 2006 nochmals signifikant auf eher geringe 1,7 $\pm 1,4$ zu sinken.

$\mathrm{Zu}$ jedem Aufnahmezeitpunkt waren die Durchschnittsvitalitätswerte der Erlen auf bewachsenen Standorten signifikant höher als auf unbewachsenen (s. Abb. 191). Laut der entsprechenden Kreuztabelle besteht zudem eine signifikante Korrelation der Sterblichkeitsrate mit dem Standort im vegetationsfreien oder besiedelten Bereich ( $\left.\mathrm{Chi}^{2}{ }^{10,08 * *}\right)$.

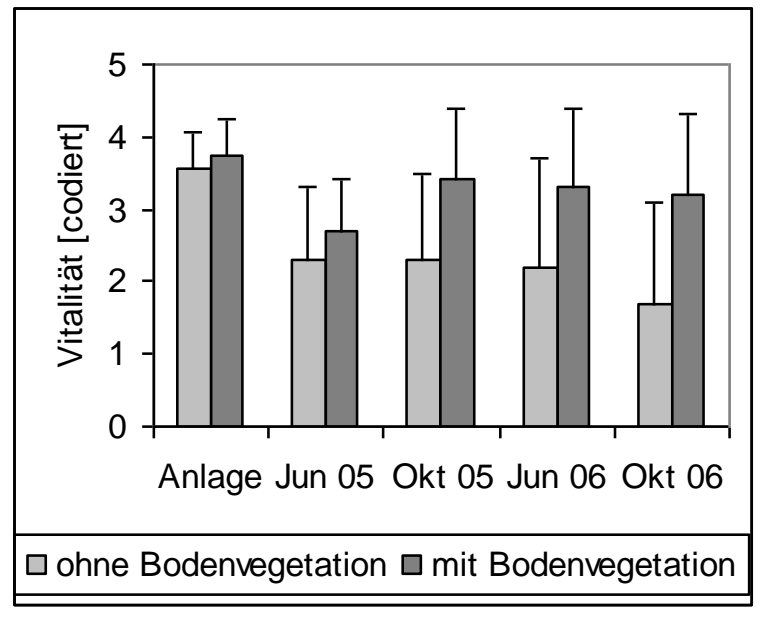

Abb. 191: Vitalität der Erlen [codiert: $4=$ vital bis $0=$ tot, s. S. 27] in Bereichen ohne $(n=74)$ und mit $(\mathrm{n}=46)$ Spontanvegetation im Versuchsverlauf; MW u. Std.abw.; zu jedem Aufnahmezeitpunkt signifikante Unterschiede nach U-Tests

\section{Erlen auf Versuchsfläche B}

Auf Fläche B bestanden deutliche Unterschiede zwischen den Vitalitätswerten der Erlen auf Standorten mit und ohne Spontanvegetation (s. Abb. 192 links). In unbesiedelten Bereichen nahm die mittlere Vitalität zu Versuchsbeginn signifikant von 3,9 \pm 0,4 auf 2,1 \pm 0,6 im Juni 2005 ab und sank noch einmal signifikant zum Ende des Untersuchungszeitraums auf nur noch 0,9 \pm 1,1 im Oktober 2006. 
Tab. 106: Vitalität der Erlen [codiert: $4=$ vital bis $0=$ tot, s. S. 27] auf Fläche B in Bereichen ohne ( $n=8)$ und mit ( $n=32)$ Spontanvegetation im Versuchsverlauf; MW u. Std.abw.; je Aufnahmezeitpunkt Ergebnisse von U-Tests (Z) auf signifikante Unterschiede zwischen den Flächen; je Fläche Ergebnisse von FriedmannTests $\left(\mathrm{Chi}^{2}\right)$ auf signifikante Unterschiede zwischen den Aufnahmezeitpunkten

\begin{tabular}{|l|l|l|l|l|l|l|l|l|l|l|}
\hline B & $\begin{array}{l}\text { April } \\
2005\end{array}$ & & $\begin{array}{l}\text { Juni } \\
2005\end{array}$ & & $\begin{array}{l}\text { Oktober } \\
2005\end{array}$ & $\begin{array}{l}\text { Juni } \\
2006\end{array}$ & $\begin{array}{l}\text { Oktober } \\
2006\end{array}$ & $\mathrm{Chi}^{2}$ \\
\hline o.BV & $3,9 \pm 0,4$ & $>$ & $2,1 \pm 0,6$ & & $2,1 \pm 1,1$ & & $1,6 \pm 1,3$ & $>$ & $0,9 \pm 1,1$ & $20,75^{* * *}$ \\
\hline m.BV & $3,7 \pm 0,5$ & $>$ & $2,9 \pm 0,6$ & $<$ & $3,5 \pm 0,9$ & & $3,4 \pm 1,0$ & $>$ & $3,2 \pm 1,1$ & $20,63^{* * *}$ \\
\hline Z & & & $-3,12^{* * *}$ & & $-5,25^{* * *}$ & & $-3,32^{* * *}$ & & $-3,69^{* * *}$ & \\
\hline
\end{tabular}

$>$ signifikanter Rückgang, < signifikanter Anstieg der Vitalität laut Wilcoxon-Test

Zwar nahm auch im mit Spontanvegetation besiedelten Bereich die durchschnittliche Vitalität der Erlen zunächst signifikant von 3,7 \pm 0,5 auf 2,9 \pm 0,6 im Juni 2005 ab, bereits während der ersten Vegetationszeit stieg sie jedoch wieder signifikant auf 3,5 \pm 0,9 im Oktober 2005 (s. Tab. 106). Die leichte, signifikante Abnahme zum Ende des Versuchs auf $3,2 \pm 1,1$ änderte nichts an der insgesamt sehr guten Vitalitätsentwicklung der Erlen in bewachsenen Bereichen auf Fläche B, im Gegensatz zu den eher mäßigen, zum Ende sehr geringen Vitalitätswerten in unbewachsenen Bereichen. Während des gesamten zweijährigen Untersuchungszeitraums war auf Fläche B die durchschnittliche Vitalität der Erlen in Bereichen mit Spontanvegetation signifikant besser als in unbewachsenen Bereichen.

\section{Erlen auf Versuchsfläche D}

Die Vitalitätsentwicklung der Erlen in bewachsenen und unbewachsenen Bereichen auf Fläche D war der auf Fläche B recht ähnlich. Auf unbewachsenen Standorten sank ihre mittlere Vitalität zu Beginn und zum Ende des Untersuchungszeitraums signifikant von zunächst 3,8 $\pm 0,4$ auf 1,8 $\pm 0,8$ im Juni 2005 bzw. 1,8 $\pm 1,5$ im Oktober 2006 (s. Tab. 107).

Tab. 107: Vitalität der Erlen [codiert: $4=$ vital bis $0=$ tot, s. S. 27] auf Fläche D in Bereichen ohne ( $\mathrm{n}=26)$ und mit ( $\mathrm{n}=14)$ Spontanvegetation im Versuchsverlauf; MW u. Std.abw.; je Aufnahmezeitpunkt Ergebnisse von U-Tests (Z) auf signifikante Unterschiede zwischen den Flächen; je Fläche Ergebnisse von FriedmannTests $\left(\mathrm{Chi}^{2}\right)$ auf signifikante Unterschiede zwischen den Aufnahmezeitpunkten

\begin{tabular}{|l|l|l|l|l|l|l|l|l|l|l|}
\hline D & $\begin{array}{l}\text { April } \\
2005\end{array}$ & & $\begin{array}{l}\text { Juni } \\
2005\end{array}$ & & $\begin{array}{l}\text { Oktober } \\
2005\end{array}$ & & $\begin{array}{l}\text { Juni } \\
2006\end{array}$ & $\begin{array}{l}\text { Oktober } \\
2006\end{array}$ & Chi $^{2}$ \\
\hline o.BV & $3,8 \pm 0,4$ & $>$ & $1,8 \pm 0,8$ & & $2,1 \pm 1,2$ & & $2,0 \pm 1,5$ & $>$ & $1,8 \pm 1,5$ & $36,76^{* * *}$ \\
\hline m.BV & $3,9 \pm 0,4$ & $>$ & $2,3 \pm 0,7$ & $<$ & $3,1 \pm 1,1$ & & $3,1 \pm 1,3$ & & $3,1 \pm 1,2$ & $16,29^{* *}$ \\
\hline Z & & & $1,79^{*}$ & & $2,56^{* *}$ & & $2,32^{*}$ & & $2,80^{* *}$ & \\
\hline
\end{tabular}

$>$ signifikanter Rückgang, < signifikanter Anstieg der Vitalität laut Wilcoxon-Test

Auf bewachsenen Standorten nahm die Vitalität zwar zunächst ebenfalls signifikant von 3,9 $\pm 0,4$ auf 2,3 \pm 0,7 im Juni 2005 ab, stieg aber schon im Verlauf der ersten Vegetationszeit wieder signifikant auf 3,1 \pm 1,1 im Oktober 2005 an. Ab Juni 2005 waren auch auf Fläche D die guten Vitalitätswerte der Erlen in mit Spontanvegetation besiedelten Bereichen signifikant höher als die mäßigen Werte in vegetationsfreien Bereichen (s. Abb. 192 rechts). 

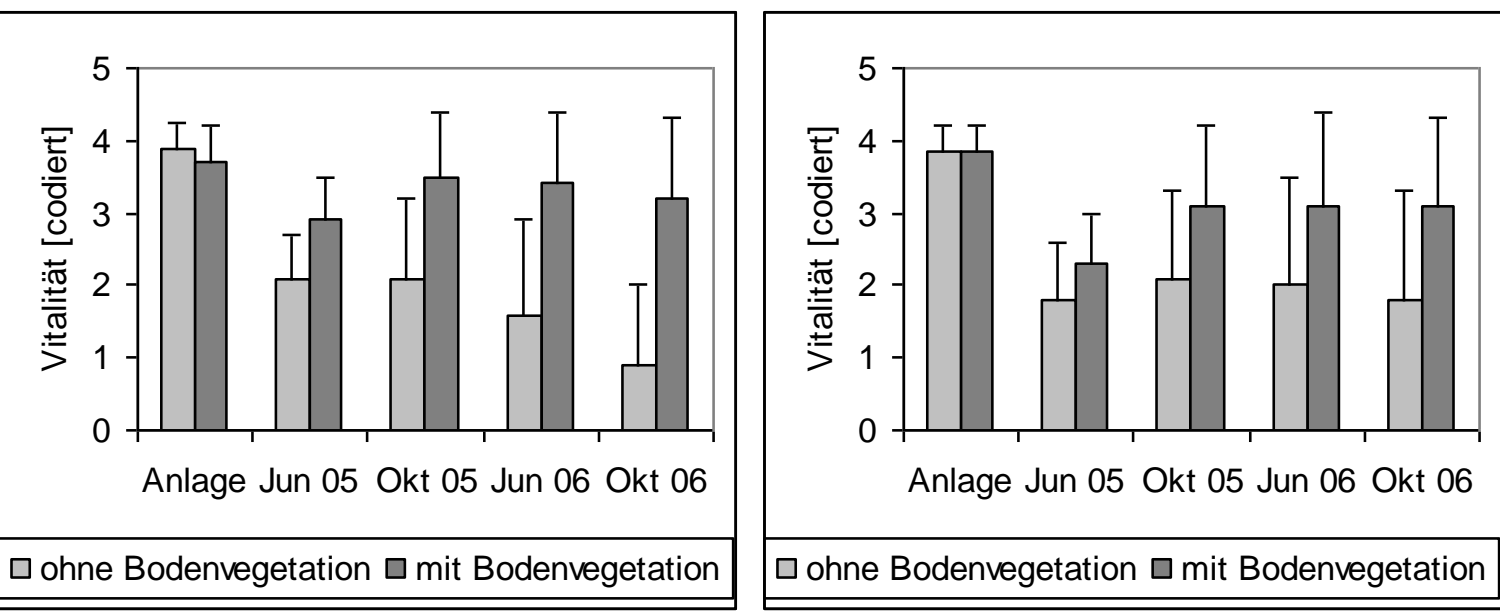

Abb. 192: Vitalität der Erlen [codiert: $4=$ vital bis $0=$ tot, s. S. 27] auf Fläche B (links; $n=8 / 32$ ) sowie Fläche D (rechts; $n=26 / 14$ ) in Bereichen ohne und mit Spontanvegetation im Versuchsverlauf; MW u. Std.abw.; zu jedem Aufnahmezeitpunkt signifikante Unterschiede nach U-Tests

\subsubsection{Douglasie}

Sowohl insgesamt als auch innerhalb beider in Frage kommender Versuchsflächen (B und D; A blieb vegetationsfrei) hatte der individuelle Pflanzenstandort in Bereichen mit oder ohne Entwicklung von Spontanvegetation nachweisbar Einfluss auf die Vitalitätsentwicklung der Douglasien (auf Fläche B zunächst auf etwas höherem Niveau und insgesamt deutlicher als auf Fläche D).

\section{Douglasien insgesamt}

Die durchschnittliche Vitalität aller Douglasien, die zufällig in Teilbereichen gepflanzt wurden, in denen sich später spontan Bodenvegetation entwickelte, nahm zu Versuchsbeginn zunächst signifikant von recht guten 3,1 $\pm 0,5$ auf mäßig gute 2,6 $\pm 0,9$ ab. Im weiteren Versuchsverlauf blieb der Vitalitätsmittelwert relativ konstant, mit einer leichten, signifikanten Abnahme auf mäßige 2,4 $\pm 1,2$ zum Ende des Versuchs (s. Tab. 108).

Tab. 108: Vitalität der Douglasien [codiert: $4=$ vital bis $0=$ tot, s. S. 27] in Bereichen ohne $(n=119)$ und mit ( $\mathrm{n}=73$ ) Spontanvegetation im Versuchsverlauf; MW u. Std.abw.; je Aufnahmezeitpunkt Ergebnisse von UTests (Z) auf signifikante Unterschiede zwischen den Standorten; je Standort Ergebnisse von FriedmannTests $\left(\mathrm{Chi}^{2}\right)$ auf signifikante Unterschiede zwischen den Aufnahmezeitpunkten

\begin{tabular}{|l|l|l|l|l|l|l|l|l|l|l|}
\hline & $\begin{array}{l}\text { April } \\
2005\end{array}$ & & $\begin{array}{l}\text { Juni } \\
2005\end{array}$ & & $\begin{array}{l}\text { Oktober } \\
2005\end{array}$ & & $\begin{array}{l}\text { Juni } \\
2006\end{array}$ & $\begin{array}{l}\text { Oktober } \\
2006\end{array}$ & Chi $^{2}$ \\
\hline o.BV & $3,2 \pm 0,4$ & $>$ & $1,8 \pm 1,0$ & & $1,8 \pm 1,2$ & $>$ & $1,2 \pm 1,2$ & $>$ & $1,1 \pm 1,2$ & $191,8^{* * *}$ \\
\hline m.BV & $3,1 \pm 0,5$ & $>$ & $2,6 \pm 0,9$ & & $2,6 \pm 1,0$ & & $2,6 \pm 1,3$ & $>$ & $2,4 \pm 1,2$ & $9,62^{*}$ \\
\hline Z & & & $4,86^{* * *}$ & & $4,94^{* * *}$ & & $-6,73^{* * *}$ & & $-6,38^{* * *}$ & \\
\hline
\end{tabular}

$>$ signifikanter Rückgang der Vitalität laut Wilcoxon-Test

Der mittlere Vitalitätswert der Douglasien mit Standorten in bis zum Abschluss der Versuche vegetationsfreien Teilbereichen sank dagegen gleich zu Beginn deutlich stärker von 3,2 $\pm 0,4$ auf 
$1,8 \pm 1,0$ im Juni 2005. Zum und im 2. Vegetationsjahr erfolgten weitere signifikante Abnahmen der Durchschnittsvitalität auf schließlich 1,1 $\pm 1,2$ im Oktober 2006.

Zu jedem Aufnahmezeitpunkt waren die Unterschiede zwischen den mittleren Vitalitätswerten der Douglasien auf bewachsenen und unbewachsenen Standorten signifikant (s. Abb. 193). Die Korrelation der Sterblichkeitsrate der Douglasien mit ihrem Standort im vegetationsfreien oder besiedelten Bereich ist laut entsprechender Kreuztabelle ebenfalls signifikant ( $\mathrm{Chi}^{2} 24,37^{* * *}$ ).

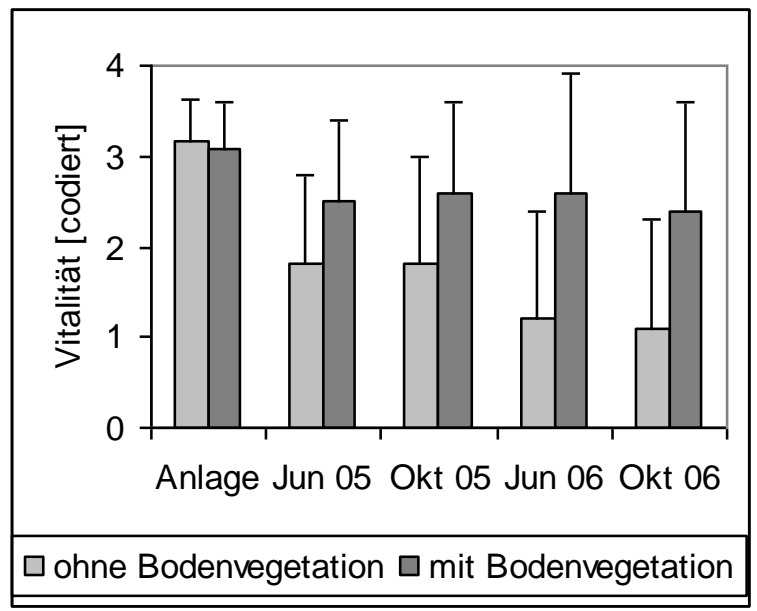

Abb. 193: Vitalität der Douglasien [codiert: 4 = vital bis $0=$ tot, s. S. 27] in Bereichen ohne (n=119) und mit $(n=73)$ Spontanvegetation im Versuchsverlauf; MW u. Std.abw.; zu jedem Aufnahmezeitpunkt signifikante Unterschiede nach U-Tests

\section{Douglasien auf Versuchsfläche B}

Auf Fläche B sank die durchschnittliche Vitalität der Douglasien in unbewachsenen Bereichen signifikant von anfänglich 2,9 $\pm 0,3$ auf Werte knapp über „2“ im ersten und nochmals auf Werte knapp über „1“ im 2. Untersuchungsjahr (s. Tab. 109).

Dagegen lagen die durchschnittlichen Vitalitätswerte der Douglasien in bewachsenen Bereichen auf Fläche B während des gesamten zweijährigen Untersuchungszeitraums bei Werten von knapp „3“. Nicht einmal zu Versuchsbeginn („Pflanzschock“) nahm die Vitalität hier signifikant $\mathrm{ab}$.

Tab. 109: Vitalität der Douglasien [codiert: $4=$ vital bis $0=$ tot, s. S. 27] auf Fläche B in Bereichen ohne $(n=22)$ und mit $(n=44)$ Spontanvegetation im Versuchsverlauf; MW u. Std.abw.; je Aufnahmezeitpunkt Ergebnisse von U-Tests (Z) auf signifikante Unterschiede zwischen den Flächen; je Fläche Ergebnisse von Friedmann-Tests $\left(\mathrm{Chi}^{2}\right)$ auf signifikante Unterschiede zwischen den Aufnahmezeitpunkten

\begin{tabular}{|l|l|l|l|l|l|l|l|l|l|l|}
\hline B & $\begin{array}{l}\text { April } \\
2005\end{array}$ & & $\begin{array}{l}\text { Juni } \\
2005\end{array}$ & $\begin{array}{l}\text { Oktober } \\
2005\end{array}$ & & $\begin{array}{l}\text { Juni } \\
2006\end{array}$ & $\begin{array}{l}\text { Oktober } \\
2006\end{array}$ & Chi $^{2}$ \\
\hline o.BV & $2,9 \pm 0,3$ & $>$ & $2,2 \pm 1,0$ & & $2,0 \pm 1,0$ & $>$ & $1,3 \pm 1,0$ & & $1,2 \pm 1,0$ & $37,18^{* * *}$ \\
\hline m.BV & $2,8 \pm 0,4$ & & $2,9 \pm 0,7$ & & $3,0 \pm 0,7$ & & $2,8 \pm 0,9$ & & $2,6 \pm 0,9$ & 4,59 \\
\hline Z & 0,60 & & $-3,05^{* *}$ & & $-3,92^{* * *}$ & & $-4,94^{* * *}$ & & $-4,62^{* * *}$ & \\
\hline
\end{tabular}

$>$ signifikanter Rückgang der Vitalität laut Wilcoxon-Test

\section{Douglasien auf Versuchsfläche D}

Auf Fläche D sank die mittlere Vitalität der Douglasien sowohl in Bereichen ohne als auch mit Spontanbewuchs zunächst signifikant von Werten deutlich über „3“ auf 1,6 $\pm 1,1$ bzw. 2,0 $\pm 1,0$ 
im Juni 2005. In besiedelten Bereichen blieben die Werte relativ konstant auf diesem sehr mäßigen Niveau von etwa „2“, in unbesiedelten Bereichen sanken sie zum und im 2 . Untersuchungsjahr auf geringe Werte knapp über „1“ (s. Tab. 110).

Tab. 110: Vitalität der Douglasien [codiert: $4=$ vital bis $0=$ tot, s. S. 27] auf Fläche D in Bereichen ohne $(\mathrm{n}=35)$ und mit $(\mathrm{n}=29)$ Spontanvegetation im Versuchsverlauf; MW u. Std.abw.; je Aufnahmezeitpunkt Ergebnisse von U-Tests (Z) auf signifikante Unterschiede zwischen den Flächen; je Fläche Ergebnisse von Friedmann-Tests $\left(\mathrm{Chi}^{2}\right)$ auf signifikante Unterschiede zwischen den Aufnahmezeitpunkten

\begin{tabular}{|l|l|l|l|l|l|l|l|l|l|l|}
\hline D & $\begin{array}{l}\text { April } \\
2005\end{array}$ & & $\begin{array}{l}\text { Juni } \\
2005\end{array}$ & & $\begin{array}{l}\text { Oktober } \\
2005\end{array}$ & & $\begin{array}{l}\text { Juni } \\
2006\end{array}$ & $\begin{array}{l}\text { Oktober } \\
2006\end{array}$ & Chi $^{2}$ \\
\hline o.BV & $3,3 \pm 0,5$ & $>$ & $1,6 \pm 1,1$ & & $1,5 \pm 1,2$ & $>$ & $1,2 \pm 1,4$ & $>$ & $1,1 \pm 1,3$ & $56,26^{* * *}$ \\
\hline m.BV & $3,4 \pm 0,5$ & $>$ & $2,0 \pm 1,0$ & & $2,1 \pm 1,3$ & & $2,2 \pm 1,6$ & $>$ & $2,1 \pm 1,6$ & $25,23^{* *}$ \\
\hline Z & 0,71 & & $-1,59$ & & $-1,68^{*}$ & & $-2,68^{* *}$ & & $-2,79^{* *}$ & \\
\hline
\end{tabular}

$>$ signifikanter Rückgang der Vitalität laut Wilcoxon-Test

Auf beiden Versuchsflächen (B, D) bestanden zu jedem Aufnahmezeitpunkt (außer im Juni 2005 auf Fläche D) signifikante Unterschiede zwischen den stets besseren mittleren Vitalitätswerten der Douglasien in Bereichen mit und ohne Spontanvegetation (s. Abb. 194).
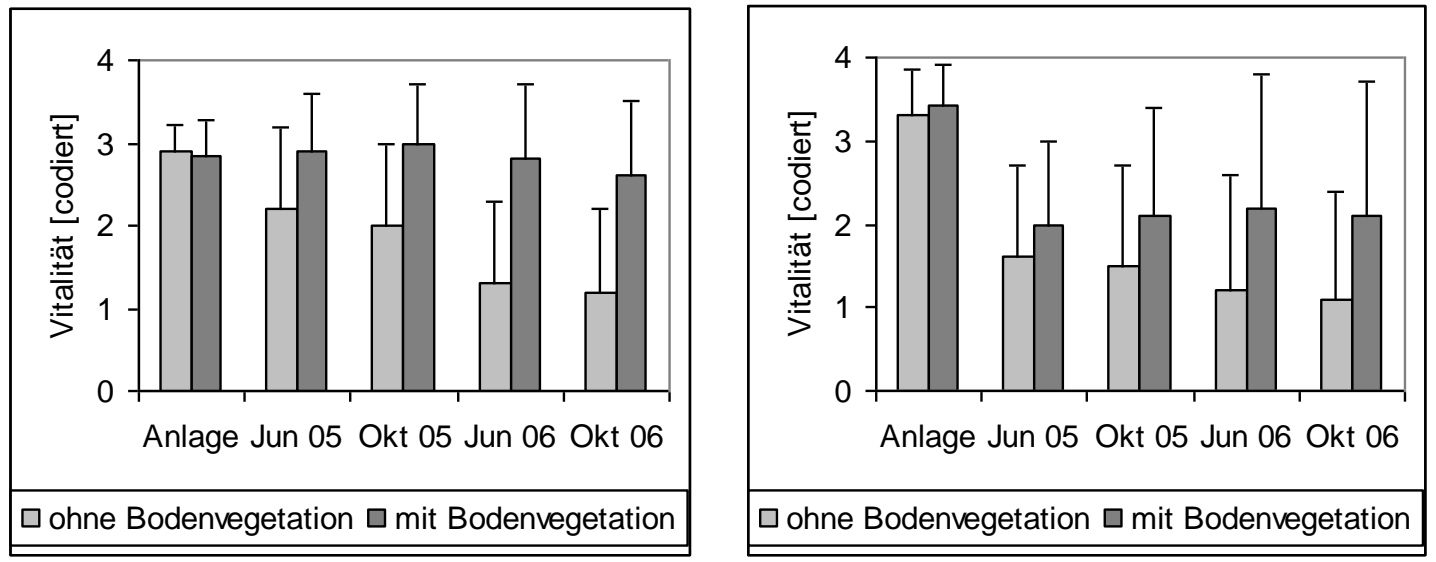

Abb. 194: Vitalität der Douglasien [codiert: $4=$ vital bis $0=$ tot, s. S. 27] auf Fläche B (links; n=20/44) sowie Fläche D (rechts; $n=35 / 29$ ) in Bereichen ohne und mit Spontanvegetation im Versuchsverlauf; MW u. Std.abw.; außer auf Fläche D im Juni 2005 zu jedem Aufnahmezeitpunkt signifikante Unterschiede nach U-Tests

\subsubsection{Wald-Kiefer}

Der Pflanzenstandort in vegetationsfreien oder spontan besiedelten Bereichen (bzw. die zugrunde liegenden Bodenbedingungen) hatte sowohl insgesamt als auch auf den in Frage kommenden Versuchsflächen (B und D; A blieb vegetationsfrei) Einfluss auf die Vitalität der Kiefern.

\section{Kiefern insgesamt}

Insgesamt bestanden zu jedem Aufnahmezeitpunkt signifikante Unterschiede zwischen den Durchschnittsvitalitätswerten der Kiefern auf bewachsenen und unbewachsenen Standorten. 
Die durchschnittliche Vitalität der Kiefern, die zufällig in den Bereichen gepflanzt wurden, in denen sich später spontan Bodenvegetation entwickelte, sank zu Versuchsbeginn signifikant von $3,0 \pm 0,5$ bei Anlage auf nur noch 1,6 $\pm 1,3$ im Juni 2005. Mit leichten, signifikanten Schwankungen im 2. Versuchsjahr blieb es auf diesen Standorten bei recht geringen Mittelwerten (s. Abb. 195). Der mittlere Vitalitätswert der Kiefern mit Standorten in bis zum Abschluss der Versuche vegetationsfreien Bereichen nahm anfänglich noch deutlicher und ebenfalls signifikant von 3,0 $\pm 0,6$ bei Anlage auf 0,5 $\pm 1,0$ im Juni 2005 ab, um bis Oktober 2005 weiter signifikant auf sehr niedrige $0,2 \pm 0,8$ zu sinken (s. Tab. 111).

Tab. 111: Vitalität der Kiefern [codiert: $4=$ vital bis $0=$ tot, s. S. 27] in Bereichen ohne $(n=76)$ und mit ( $\mathrm{n}=44$ ) Spontanvegetation im Versuchsverlauf; MW u. Std.abw.; je Aufnahmezeitpunkt Ergebnisse von UTests (Z) auf signifikante Unterschiede zwischen den Standorten; je Standort Ergebnisse von FriedmannTests $\left(\mathrm{Chi}^{2}\right)$ auf signifikante Unterschiede zwischen den Aufnahmezeitpunkten

\begin{tabular}{|l|l|l|l|l|l|l|l|l|l|l|}
\hline & $\begin{array}{l}\text { April } \\
2005\end{array}$ & & $\begin{array}{l}\text { Juni } \\
2005\end{array}$ & & $\begin{array}{l}\text { Oktober } \\
2005\end{array}$ & & $\begin{array}{l}\text { Juni } \\
2006\end{array}$ & $\begin{array}{l}\text { Oktober } \\
2006\end{array}$ & $\mathrm{Chi}^{2}$ \\
\hline o.BV & $3,0 \pm 0,5$ & $>$ & $0,5 \pm 1,0$ & $>$ & $0,2 \pm 0,7$ & & $0,2 \pm 0,7$ & & $0,2 \pm 0,8$ & $142,8^{* * *}$ \\
\hline m.BV & $3,0 \pm 0,6$ & $>$ & $1,6 \pm 1,3$ & & $1,3 \pm 1,6$ & $<$ & $1,5 \pm 1,8$ & $>$ & $1,3 \pm 1,7$ & $21,66^{* * *}$ \\
\hline Z & & & $4,59^{* * *}$ & & $4,90^{* * *}$ & & $4,98^{* * *}$ & & $4,82^{* * *}$ & \\
\hline
\end{tabular}

$>$ signifikanter Rückgang, < signifikanter Anstieg der Vitalität laut Wilcoxon-Test

Grund für die sehr niedrigen Vitalitätswerte war die sehr hohe Ausfallrate der Kiefern (57 \% auf bewachsenen, $93 \%$ auf unbewachsenen Standorten). Die entsprechende Kreuztabelle weist signifikante Korrelationen der Sterblichkeitsrate der Kiefern mit dem Standort im vegetationsfreien oder besiedelten Bereich nach ( $\mathrm{Chi}^{2}$ 23,33***).

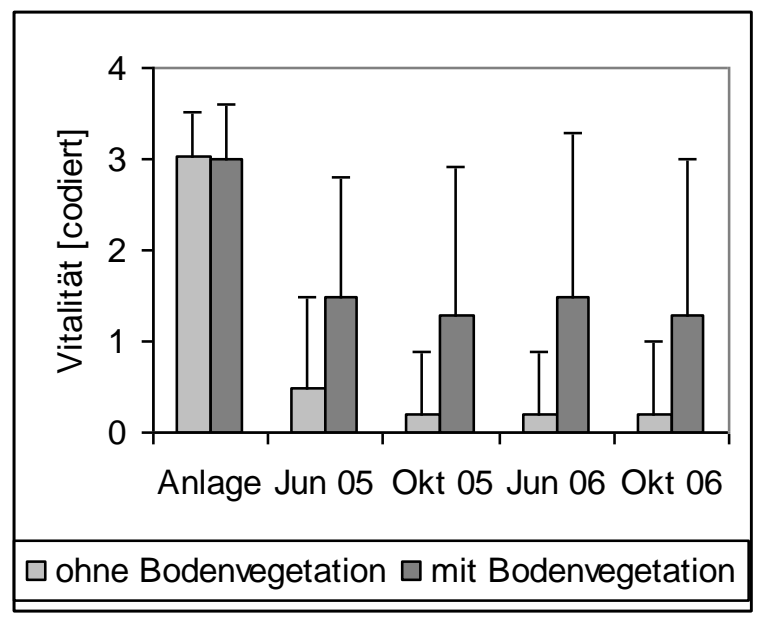

Abb. 195: Vitalität der Kiefern [codiert: $4=$ vital bis $0=$ tot, s. S. 27] in Bereichen ohne (n=76) und mit $(n=44)$ Spontanvegetation im Versuchsverlauf; MW u. Std.abw.; zu jedem Aufnahmezeitpunkt signifikante Unterschiede nach U-Tests

Zudem stand ein Großteil der Pflanzen mit Vitalitätsbewertungen von „2“, „3“ oder "4“ (Juni 2005: $67 \%$, Oktober 2005 u. Juni 2006: $79 \%$, Oktober 2006: $82 \%$ ) in den mit Spontanvegetation besiedelten Bereichen der Versuchsflächen.

Neben den vergleichsweise günstigeren bodenchemischen Bedingungen könnte in diesen Bereichen das Vorhandensein von Mykorrhiza-Partnern (im Gelände erkennbar anhand entsprechender Pilzfruchtkörper-Funde, s. S. 289) die Vitalität der obligat auf diese Symbiosen angewiesenen Kiefern positiv beeinflusst bzw. überhaupt erst das Überleben der Pflanzen gewährleistet haben. Tatsächlich befanden sich die Pflanzenstandorte der wenigen in 
vegetationsfreien Bereichen überlebenden Kiefern sämtlich in unmittelbarer Nähe zu bewachsenen Bereichen.

\section{Kiefern auf Versuchsfläche B}

Auf Fläche B sank die mittlere Vitalität der Kiefern in unbewachsenen Bereichen von 3,0 \pm 0 auf $1,0 \pm 1,4$, in bewachsenen Bereichen von 3,0 $\pm 0,7$ auf $1,7 \pm 1,2$ (s. Tab. 112). Zum 2. Versuchsjahr erfolgte in bewachsenen Bereichen ein leichter, signifikanter Anstieg auf $1,8 \pm 1,8$, gefolgt von einer ebenso leichten, signifikanten Abnahme auf 1,6 \pm 1,7 zum Ende der zweiten Vegetationszeit. Ab Oktober 2005 bestanden statistisch signifikante Unterschiede zwischen den mittleren Vitalitätswerten der Kiefern in Bereichen mit und ohne Spontanvegetation (s. Abb. 196 links).

Tab. 112: Vitalität der Kiefern [codiert: $4=$ vital bis $0=$ tot, s. S. 27] auf Fläche B in Bereichen ohne ( $n=7)$ und mit (n=33) Spontanvegetation im Versuchsverlauf; MW u. Std.abw.; je Aufnahmezeitpunkt Ergebnisse von U-Tests (Z) auf signifikante Unterschiede zwischen den Flächen; je Fläche Ergebnisse von FriedmannTests $\left(\mathrm{Chi}^{2}\right)$ auf signifikante Unterschiede zwischen den Aufnahmezeitpunkten

\begin{tabular}{|l|l|l|l|l|l|l|l|l|l|l|}
\hline B & $\begin{array}{l}\text { April } \\
2005\end{array}$ & & $\begin{array}{l}\text { Juni } \\
2005\end{array}$ & & $\begin{array}{l}\text { Oktober } \\
2005\end{array}$ & & $\begin{array}{l}\text { Juni } \\
2006\end{array}$ & $\begin{array}{l}\text { Oktober } \\
2006\end{array}$ & Chi $^{2}$ \\
\hline o.BV & $3,0 \pm 0$ & $>$ & $1,0 \pm 1,4$ & & $0,3 \pm 0,8$ & & $0,4 \pm 1,1$ & & $0,4 \pm 1,1$ & $11,74^{*}$ \\
\hline m.BV & $3,0 \pm 0,7$ & $>$ & $1,7 \pm 1,2$ & & $1,5 \pm 1,6$ & $<$ & $1,8 \pm 1,8$ & $>$ & $1,6 \pm 1,7$ & $12,97^{*}$ \\
\hline Z & 0,14 & & $-1,27$ & & $-1,92^{*}$ & & $-1,38^{*}$ & & $-1,72^{*}$ & \\
\hline
\end{tabular}

$>$ signifikanter Rückgang, < signifikanter Anstieg der Vitalität laut Wilcoxon-Test

Die insgesamt recht niedrigen Durchschnittswerte hingen wiederum vor allem mit der hohen Ausfallrate bei dieser Baumart zusammen (mit Bodenvegetation: $49 \%$, ohne Bodenvegetation: $86 \%)$.

\section{Kiefern auf Versuchsfläche D}

Auf Fläche D nahm die Durchschnittsvitalität (s. Tab. 113) von der Anlage bis Juni 2005 ebenfalls signifikant von $3,1 \pm 0,3$ auf $1,1 \pm 1,3$ in besiedelten und von $3,0 \pm 0,5$ auf $0,4 \pm 0,9$ in vegetationsfreien Bereichen ab (hier sank die Vitalität bis Oktober 2005 weiter signifikant auf nur noch $0,2 \pm 0,7)$.

Tab. 113: Vitalität der Kiefern [codiert: $4=$ vital bis $0=$ tot, s. S. 27] auf Fläche D in Bereichen ohne $(n=29)$ und mit $(\mathrm{n}=11)$ Spontanvegetation im Versuchsverlauf; MW u. Std.abw.; je Aufnahmezeitpunkt Ergebnisse von U-Tests (Z) auf signifikante Unterschiede zwischen den Flächen; je Fläche Ergebnisse von FriedmannTests $\left(\mathrm{Chi}^{2}\right)$ auf signifikante Unterschiede zwischen den Aufnahmezeitpunkten

\begin{tabular}{|l|l|l|l|l|l|l|l|l|l|l|}
\hline D & $\begin{array}{l}\text { April } \\
2005\end{array}$ & & $\begin{array}{l}\text { Juni } \\
2005\end{array}$ & & $\begin{array}{l}\text { Oktober } \\
2005\end{array}$ & & $\begin{array}{l}\text { Juni } \\
2006\end{array}$ & $\begin{array}{l}\text { Oktober } \\
2006\end{array}$ & Chi $^{2}$ \\
\hline o.BV & $3,0 \pm 0,5$ & $>$ & $0,4 \pm 0,9$ & $>$ & $0,2 \pm 0,7$ & & $0,2 \pm 0,8$ & $0,2 \pm 0,8$ & $56,31^{* * *}$ \\
\hline m.BV & $3,1 \pm 0,3$ & $>$ & $1,1 \pm 1,3$ & & $0,7 \pm 1,6$ & & $0,7 \pm 1,6$ & $0,6 \pm 1,4$ & $10,89^{*}$ \\
\hline Z & 0,52 & & $1,83^{*}$ & & 1,16 & & 1,16 & & 1,08 & \\
\hline
\end{tabular}

$>$ signifikanter Rückgang der Vitalität laut Wilcoxon-Test

Nur im Juni 2005, zwei Monate nach Versuchsanlage, bestanden signifikante Unterschiede zwischen den mittleren Vitalitätswerten der Kiefern in besiedelten und unbesiedelten Bereichen (s. Abb. 196 rechts). Insgesamt waren die Mittelwerte hier sehr gering. Die Ausfallrate der 
Kiefern auf Fläche D war so hoch (82 \% in besiedelten, $93 \%$ in unbesiedelten Bereichen), dass kaum ein Einfluss des individuellen Pflanzenstandortes ablesbar wurde.
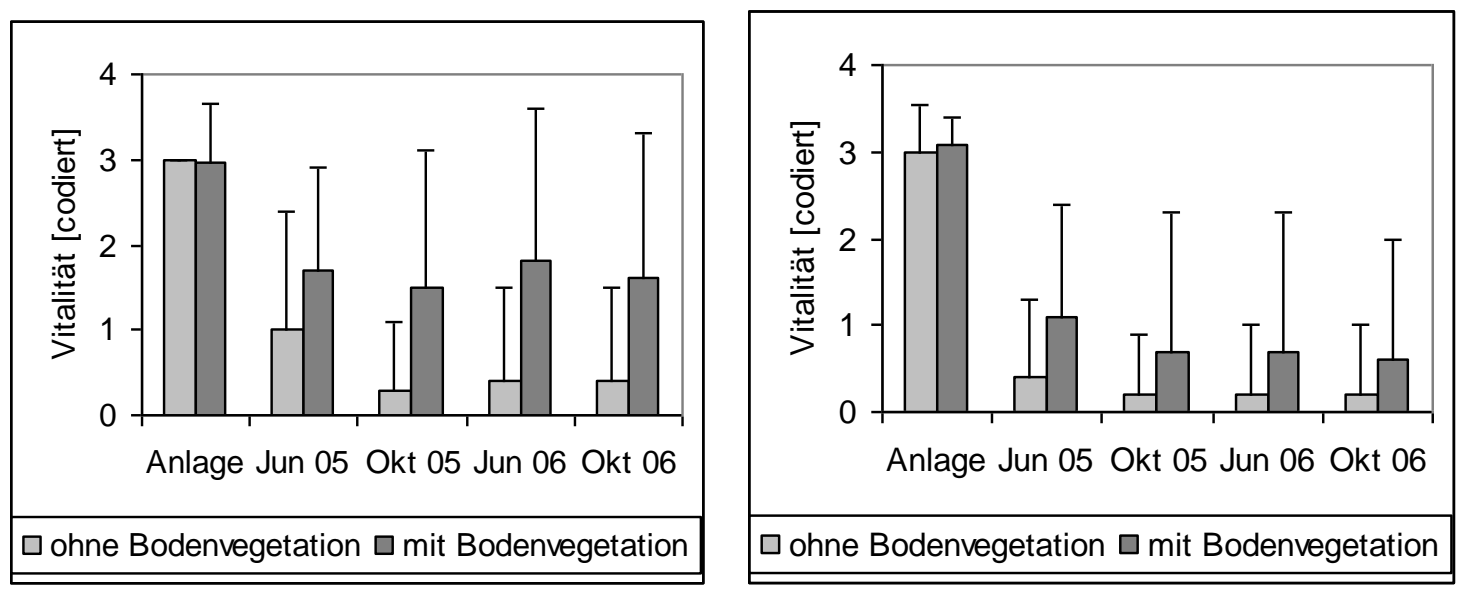

Abb. 196: Vitalität der Kiefern [codiert: $4=$ vital bis $0=$ tot, s. S. 27] auf Fläche B (links; $n=7 / 33$ ) sowie Fläche D (rechts; n=29/11) in Bereichen ohne und mit Spontanvegetation im Versuchsverlauf; MW u. Std.abw.; auf Fläche B ab Oktober 2005, auf Fläche D nur im Juni 2005 signifikante Unterschiede nach UTests

\subsubsection{Wachstumsentwicklung}

Im Folgenden wird die Wuchsentwicklung der Versuchsbäume anhand der Ergebnisse statistischer Analysen der Messungen verschiedene Wuchsparameter (s. S. 79) auf Einflüsse durch den Pflanzenstandort in im Versuchsverlauf mit Spontanvegetation bewachsenen (vergleichsweise günstigere Bedingungen) oder bis Versuchsende vegetationsfreien Bereichen (vergleichsweise ungünstigere Bedingungen) untersucht (zu den unterschiedlichen Standortbedingungen s. ab S. 44).

Da der Einflussfaktor „Pflanzenstandort auf einer der drei Versuchsflächen“ (s. ab S. 245) teilweise eine wichtige Rolle spielte, wurden die Wirkungen des „Standortes ohne/mit Spontanvegetation" auf die Wachstumsentwicklung der Versuchspflanzen auch unter Ausschluss dieses Faktors untersucht. Dies geschah, indem ausschließlich die Bäume mit Standorten auf einer bestimmten Versuchsfläche (zu den unterschiedlichen Standortbedingungen s. ab S. 44) betrachtet wurden.

Die bereits zu einem frühen Zeitpunkt überwiegend oberirdisch abgestorbenen Eichen konnten nicht in die Wachstumsanalysen einbezogen werden.

\subsubsection{Spitz-Ahorn}

Bei den Ahornen wurde sowohl insgesamt als auch bei ausschließlicher Betrachtung der Versuchspflanzen auf Fläche B ein Einfluss des Pflanzenstandortes in Bereichen ohne oder mit 
spontaner Bodenvegetation bzw. der zu Grunde liegenden standörtlichen Unterschiede auf ihre Wuchsentwicklung festgestellt.

Wachstumsparameter mit entsprechenden signifikanten Unterschieden (s. Tab. 114) sind:

- Durchmesser des Wurzelhalses

- Volumen des Haupttriebs (errechnet aus den Messwerten Wurzelhalsdurchmesser, Spitzendurchmesser und Länge des Haupttriebs) sowie die daraus errechnete

- Trockenmasse des Haupttriebs

Tab. 114: Wachstumsparameter der Ahorne insgesamt, auf Fläche B sowie bei Versuchsabschluss geerntete Stichprobe mit signifikant unterschiedlichen Ergebnissen je nach Standort in Bereichen ohne oder mit Spontanvegetation; MW u. Std.abw.; Ergebnisse von U-Tests

\begin{tabular}{|l|l|l|l|l|}
\hline \multirow{2}{*}{ Ahorne } & Wachstumsparameter & $\begin{array}{l}\text { Ohne } \\
\text { Boden- } \\
\text { bewuchs }\end{array}$ & $\begin{array}{l}\text { Mit } \\
\text { Boden- } \\
\text { bewuchs }\end{array}$ & $\begin{array}{l}\text { Ergebnis } \\
\text { U-Test } \\
\text { (Z) }\end{array}$ \\
\hline \multirow{2}{*}{$\begin{array}{l}\text { insgesamt } \\
\mathrm{n}=31 / 56\end{array}$} & Durchmesser Wurzelhals [mm] & $6,5 \pm 1,6$ & $6,0 \pm 1,7$ & $1,69^{*}$ \\
\cline { 2 - 5 } & Volumen Haupttrieb [cm $\left.{ }^{3}\right]$ & $6,1 \pm 4,2$ & $5,1 \pm 4,1$ & $1,71^{*}$ \\
\cline { 2 - 5 } & Trockenmasse Haupttrieb [g] & $7,4 \pm 5,1$ & $6,2 \pm 5,0$ & $1,71^{*}$ \\
\hline $\begin{array}{l}\text { mit Standort auf } \\
\text { Fläche B } \\
\mathrm{n}=13 / 38\end{array}$ & Durchmesser Wurzelhals [mm] & $6,6 \pm 1,0$ & $5,8 \pm 1,5$ & $1,83^{*}$ \\
\hline $\begin{array}{l}\text { geerntet bei } \\
\text { Versuchsabschluss } \\
\mathrm{n}=11 / 12\end{array}$ & $\begin{array}{l}\text { Trockenmasse Haupttrieb und } \\
\text { Wurzel [g] }\end{array}$ & $21,3 \pm 11,7$ & $13,5 \pm 7,2$ & $-1,91^{*}$ \\
\hline
\end{tabular}

\section{Ahorne insgesamt sowie auf Versuchsfläche B}

Sowohl insgesamt (s. Abb. 197 links) als auch bei alleiniger Betrachtung der auf Versuchsfläche B gepflanzten Ahorne (s. Abb. 197 rechts) waren die Wurzelhalsdurchmesser in vegetationsfreien Bereichen signifikant größer als in Bereichen mit Spontanvegetation. Sie betrugen auf vegetationsfreien Standorten 6,5 $\pm 1,6 \mathrm{~mm}$ bzw. 6,6 $\pm 1,0 \mathrm{~mm}$, auf bewachsenen Standorten $6,0 \pm 1,7 \mathrm{~mm}$ bzw. 5,8 $\pm 1,5 \mathrm{~mm}$.

Das Volumen der Haupttriebe (s. Abb. 198 links) lag in unbewachsenen Bereichen mit durchschnittlich 6,1 $\pm 4,2 \mathrm{~cm}^{3}$ signifikant über dem in bewachsenen Bereichen ermittelten Durchschnittswert von 5,1 $\pm 4,1 \mathrm{~cm}^{3}$. Bei annähernd gleichen Haupttriebslängen (ohne Bewuchs: $33,2 \pm 8,8 \mathrm{~cm}$; mit Bewuchs: $31,6 \pm 7,6 \mathrm{~cm}$ ) war dies auf die in vegetationsfreien Bereichen höheren Spitzen- und Wurzelhalsdurchmesser zurückzuführen. 


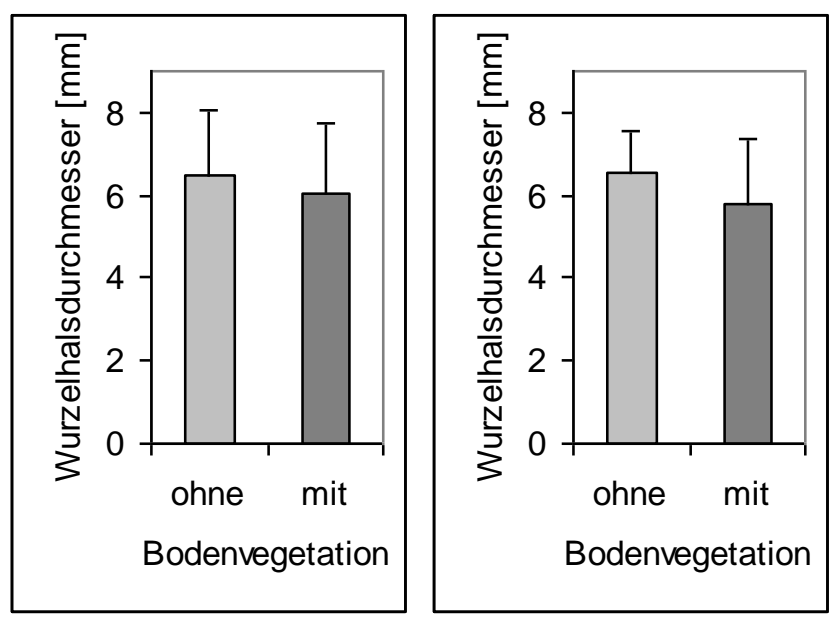

Abb. 197: Wurzelhalsdurchmesser [mm] der Ahorne insgesamt (links; $n=31 / 56$ ) sowie auf Fläche B (rechts; $n=13 / 38$ ) getrennt nach Standorten in Bereichen ohne und mit Spontanvegetation; MW $u$. Std.abw.; jeweils signifikante Unterschiede nach U-Tests

Die Trockenmasse der Haupttriebe (s. Abb. 198 rechts) war entsprechend bei den Ahornen in Bereichen ohne Spontanvegetation mit 7,4 $\pm 5,1 \mathrm{~g}$ signifikant höher als in Bereichen mit Spontanvegetation mit 6,2 $\pm 5,0 \mathrm{~g}$.
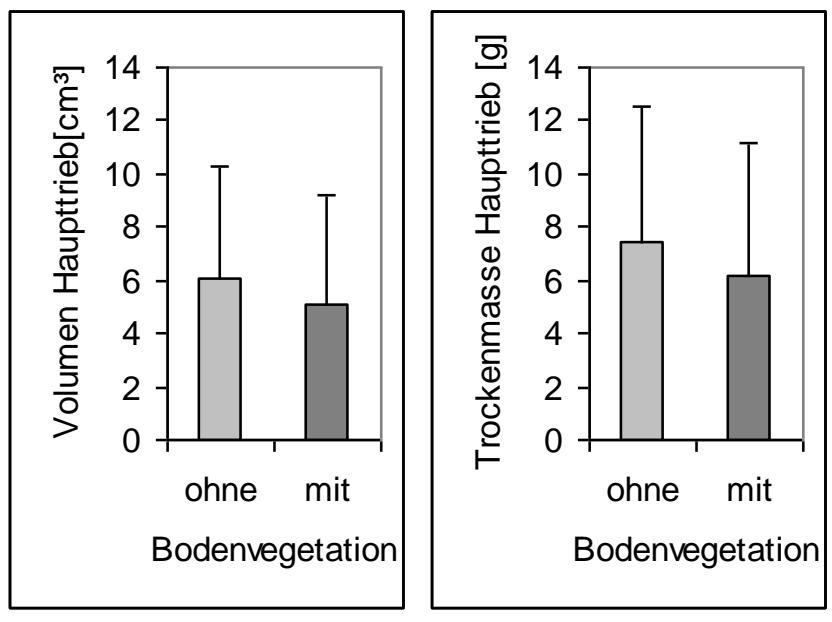

Abb. 198: Volumen $\left[\mathrm{cm}^{3}\right]$ (links) sowie Trockenmasse [g] (rechts) des Haupttriebs der Ahorne insgesamt getrennt nach Standorten in Bereichen ohne $(n=31)$ und mit $(n=56)$ Spontanvegetation; MW u. Std.abw.; jeweils signifikante Unterschiede nach U-Tests

Im Gegensatz zum bei den anderen eingesetzten Baumarten beobachteten Trend schien bei den Ahornen ein Standort in Bereichen ohne Spontanvegetation zu stärkerem Wurzelhalswachstum der Versuchsbäume zu führen als ein Standort in mit Spontanvegetation besiedelten Bereichen. Dies gilt sowohl insgesamt als auch beschränkt auf die Ahorne auf Versuchsfläche B. In allen Fällen waren die Unterschiede nicht groß, aber aufgrund der hohen Zahl an in die Analyse einbezogenen Wiederholungen dennoch signifikant.

\section{Ahorne auf Versuchsfläche D}

Das Wachstum der Ahorne auf Versuchsfläche D zeigte Parallelen zu den Ergebnissen für Versuchsfläche B. Zwischen Bereichen ohne und mit Bodenvegetation wurden jedoch keine signifikanten Unterschiede festgestellt. 


\section{Bei Versuchsabschluss geerntete Ahorne}

Bei Versuchsabschluss waren 33 der insgesamt 192 Ahorne geerntet, getrocknet und - in die Fraktionen Haupttrieb, Seitentriebe sowie Wurzel zerlegt - gewogen worden. Dies erlaubte u. a. die Untersuchung weiterer Wachstumsparameter hinsichtlich eines Einflusses des individuellen Pflanzenstandortes in bewachsenen und unbewachsenen Bereichen auf die Wuchsentwicklung. Dabei wurden signifikante Unterschiede der summierten Biomasse (Trockenmasse) von Haupttrieb und Wurzel zwischen den Ahornen mit Standorten in Bereichen mit und ohne Spontanvegetation festgestellt.

Bei den Ahornen mit Standorten in unbewachsenen Bereichen wurden mit 21,3 $\pm 11,7 \mathrm{~g}$ rund 60 $\%$ höhere Trockenmassen ermittelt als in bewachsenen Bereichen mit 13,5 \pm 7,2 g (s. Abb. 199).

Dieses Ergebnis bestätigt die bereits dargestellten Untersuchungsergebnisse und steht damit in deutlichem Gegensatz zu den Analyseergebnissen bei den anderen verwendeten Baumarten.

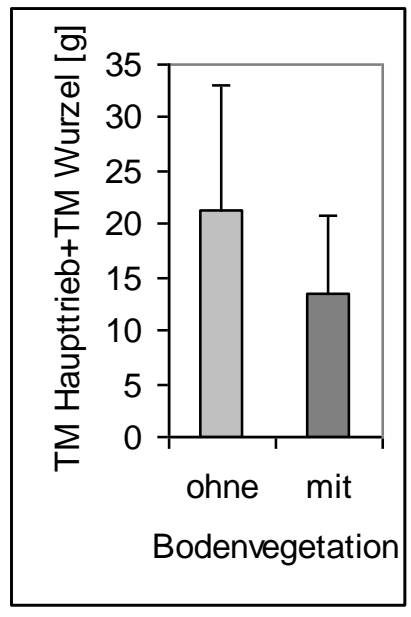

Abb. 199: Trockenmasse [g] von Haupttrieb und Wurzel der geernteten Ahorne getrennt nach Standorten in Bereichen ohne ( $\mathrm{n}=11)$ und mit $(\mathrm{n}=12)$ Spontanvegetation; MW u. Std.abw.; signifikante Unterschiede nach U-Test

\subsubsection{Eberesche}

Im Falle der Ebereschen wurde sowohl insgesamt als auch bei ausschließlicher Betrachtung der Versuchspflanzen auf Fläche D ein Einfluss des Pflanzenstandortes in Bereichen ohne oder mit spontaner Bodenvegetation bzw. der zugrunde liegenden standörtlichen Unterschiede auf ihre Wuchsentwicklung festgestellt (s. Tab. 115).

Wachstumsparameter mit signifikanten Unterschieden je nach Standort der Ebereschen in bewachsenen oder unbewachsenen Bereichen:

- Zuwachs 2005

- gesamte Länge der Seitentriebe sowie die daraus errechnete

- Trockenmasse der Seitentriebe

- Quotient aus Haupt- und Seitentrieblänge

- Quotient aus den errechneten Trockenmassen von Haupt- und Seitentrieben 
Tab. 115: Wachstumsparameter der Ebereschen insgesamt sowie auf Fläche D mit signifikant unterschiedlichen Ergebnissen je nach Standort in Bereichen ohne oder mit Spontanvegetation; MW u. Std.abw.; Ergebnisse von U-Tests [Z]

\begin{tabular}{|c|c|c|c|c|}
\hline Ebereschen & Wachstumsparameter & $\begin{array}{l}\text { Ohne } \\
\text { Boden- } \\
\text { bewuchs }\end{array}$ & $\begin{array}{l}\text { Mit } \\
\text { Boden- } \\
\text { bewuchs }\end{array}$ & $\begin{array}{l}\text { Ergebnis } \\
\text { U-Test } \\
\text { (Z) }\end{array}$ \\
\hline \multirow{5}{*}{ insgesamt } & Zuwachs Haupttrieb $2005[\mathrm{~cm}] \mathrm{n}=56 / 44$ & $4,1 \pm 4,0$ & $6,6 \pm 5,5$ & $-2,27^{* *}$ \\
\hline & Länge Seitentriebe $[\mathrm{cm}] \mathrm{n}=17 / 34$ & $75 \pm 72$ & $101 \pm 61$ & $-2,08^{*}$ \\
\hline & Trockenmasse Seitentriebe [g] n=17/34 & $4,6 \pm 4,4$ & $6,2 \pm 3,7$ & $-2,08^{*}$ \\
\hline & Haupt-/Seitentrieblänge $n=17 / 34$ & $2,2 \pm 2,2$ & $1,4 \pm 1,1$ & $2,06^{*}$ \\
\hline & $\begin{array}{l}\text { Trockenmasse Haupt-/Seitentriebe } \\
\mathrm{n}=17 / 34\end{array}$ & $7,4 \pm 6,3$ & $4,8 \pm 3,8$ & $2,46^{* *}$ \\
\hline \multirow{5}{*}{$\begin{array}{l}\text { mit Standort } \\
\text { auf Fläche D }\end{array}$} & Zuwachs Haupttrieb $2005[\mathrm{~cm}] \mathrm{n}=24 / 14$ & $3,3 \pm 3,0$ & $6,8 \pm 5,5$ & $1,96^{*}$ \\
\hline & Länge Seitentriebe $[\mathrm{cm}] \mathrm{n}=10 / 11$ & $87 \pm 90$ & $124 \pm 40$ & $-1,90 *$ \\
\hline & Trockenmasse Seitentriebe [g] n=10/11 & $5,3 \pm 5,5$ & $7,6 \pm 2,5$ & $-1,90^{*}$ \\
\hline & Haupt-/Seitentrieblänge $n=10 / 11$ & $2,6 \pm 2,9$ & $0,8 \pm 0,2$ & $-1,97^{*}$ \\
\hline & $\begin{array}{l}\text { Trockenmasse Haupt-/Seitentriebe } \\
n=10 / 11\end{array}$ & $8,8 \pm 8,0$ & $3,5 \pm 1,3$ & $-2,32^{*}$ \\
\hline
\end{tabular}

\section{Ebereschen insgesamt sowie auf Versuchsfläche D}

Der Zuwachs der Haupttriebe im 1. Untersuchungsjahr (2005) sowie die nach zwei Jahren gebildeten Längen und daraus errechneten Trockenmassen der Seitentriebe waren bei den Ebereschen (sowohl insgesamt als auch auf Versuchsfläche D beschränkt) in bewachsenen Bereichen signifikant höher als in unbewachsenen Bereichen (s. Abb. 200).

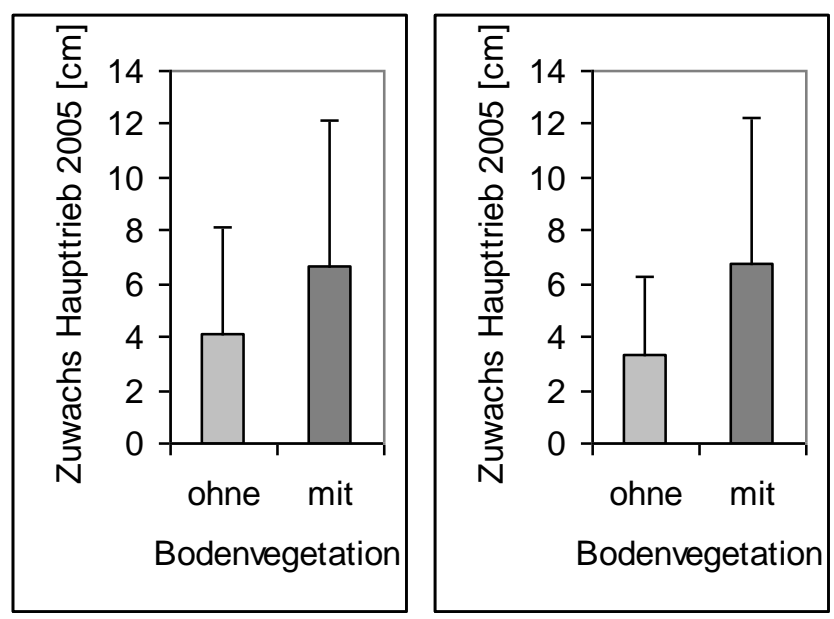

Abb. 200: Zuwachs [cm] des Haupttriebs im 1. Vegetationsjahr, Ebereschen insgesamt (links; n=56/44) sowie auf Fläche D (rechts; $n=24 / 14$ ) getrennt nach Standorten in Bereichen ohne und mit Spontanvegetation; MW u. Std.abw.; jeweils signifikante Unterschiede nach U-Tests

Auf Fläche D betrug der Zuwachs in Bereichen mit Bodenbewuchs $(6,8 \pm 5,5 \mathrm{~cm})$ mehr als das Doppelte (206 \%) des Wertes in unbewachsenen Bereichen $(3,3 \pm 3,0 \mathrm{~cm})$. Insgesamt lag er in Bereichen mit Spontanvegetation $(6,6 \pm 5,5 \mathrm{~cm}) 61 \%$ höher als in Bereichen ohne Spontanvegetation $(4,1 \pm 4,0)$. 


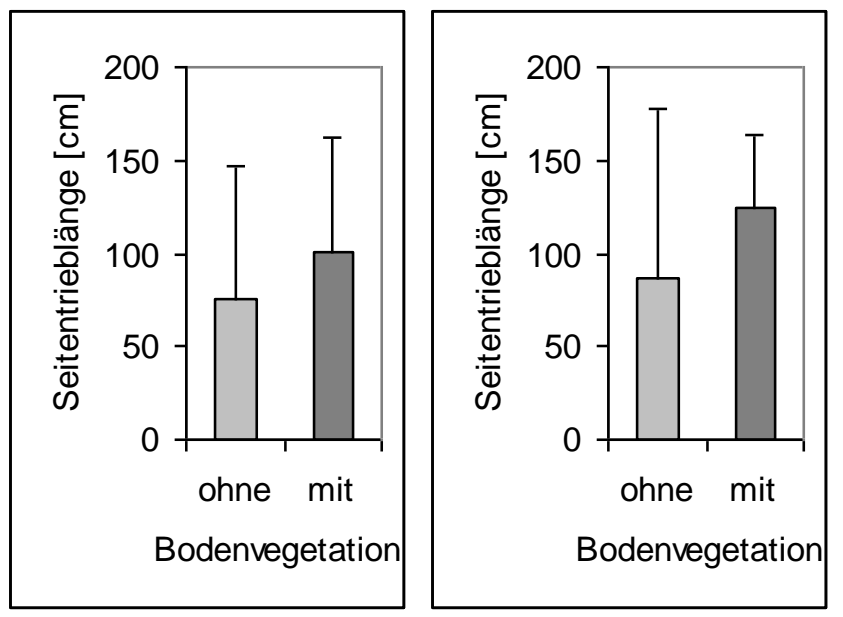

Abb. 201: Seitentrieblängen [cm] der Ebereschen insgesamt (links; n=17/34) sowie auf Fläche D (rechts; $\mathrm{n}=10 / 11$ ) getrennt nach Standorten in Bereichen ohne und mit Spontanvegetation; MW u. Std.abw.; jeweils signifikante Unterschiede nach U-Tests

Die mittlere Länge (s. Abb. 201) und Trockenmasse (s. Abb. 202) der Seitentriebe waren auf Fläche D auf bewachsenen Standorten (124 $\pm 40 \mathrm{~cm} ; 7,2 \pm 2,5 \mathrm{~g})$ um $43 \%$ höher als auf unbewachsenen Standorten $(87 \pm 90 \mathrm{~cm} ; 5,3 \pm 5,5 \mathrm{~g}$ ). Bei den Ebereschen insgesamt lag dieser Wert in Bereichen mit Bodenbewuchs $(101 \pm 61 \mathrm{~cm} ; 6,2 \pm 3,7 \mathrm{~g})$ etwa $35 \%$ höher als in unbesiedelten Bereichen (75 $\pm 72 \mathrm{~cm} ; 4,6 \pm 4,4 \mathrm{~g})$.
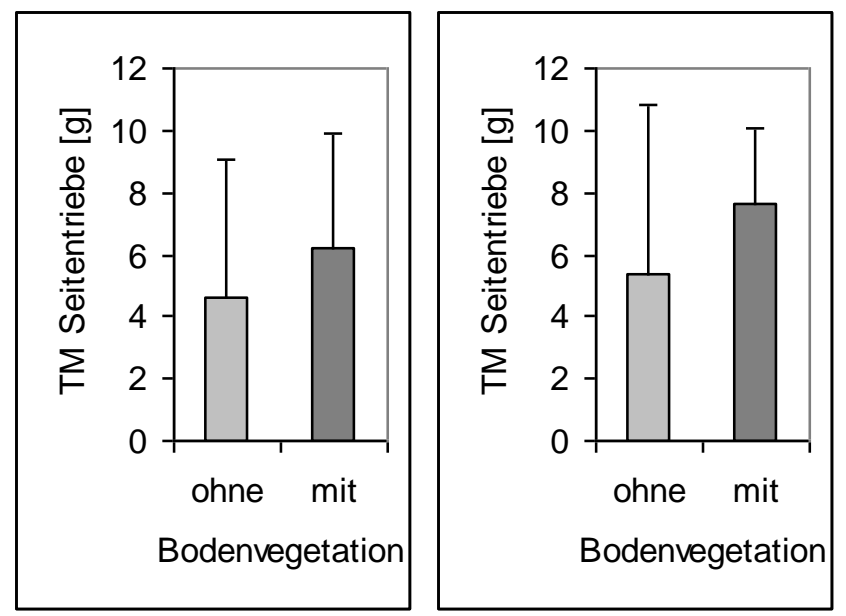

Abb. 202: Trockenmassen [g] der Seitentriebe der Ebereschen insgesamt (links; $n=17 / 34$ ) sowie auf Fläche D (rechts; n=10/11) getrennt nach Standorten in Bereichen ohne und mit Spontanvegetation; MW u. Std.abw.; jeweils signifikante Unterschiede nach U-Tests

Das Verhältnis aus Haupt- und Seitentrieblängen (s. Abb. 203) sowie das Verhältnis der Trockenmassen von Haupt- und Seitentrieben (s. Abb. 204) lagen auf Standorten in Bereichen mit Bodenvegetation signifikant niedriger als auf Standorten in unbewachsenen Bereichen.

Dies galt sowohl für die Ebereschen auf Fläche D (Haupt-/Seitentrieblänge: mit Bodenbewuchs: $0,8 \pm 0,2$; ohne Bodenbewuchs: 2,6 \pm 2,9; Trockenmasse Haupt-/Seitentriebe: mit Bodenbewuchs: $3,5 \pm 1,3$; ohne Bodenbewuchs: 8,8 \pm 8,0) als auch für die Gesamtheit aller untersuchten Ebereschen (Haupt-/Seitentrieblänge: mit Bodenbewuchs: 1,4 $\pm 1,1$; ohne Bodenbewuchs: 2,2 \pm 2,2; Trockenmasse Haupt-/Seitentriebe: mit Bodenbewuchs: 4,8 $\pm 3,8$; ohne Bodenbewuchs: 7,4 $\pm 6,3$ ). 
Dabei waren die mittleren Längen (88 - $95 \mathrm{~cm}$ ) und Trockenmassen (23 - $27 \mathrm{~g}$ ) der Haupttriebe trotz der Standortunterschiede vergleichbar. Der Grund für die so unterschiedlichen Verhältnisse lag in der im Mittel größeren Länge (s. Tab. 115) und rund $40 \%$ höheren Trockenmasse der Seitentriebe in besiedelten Bereichen.
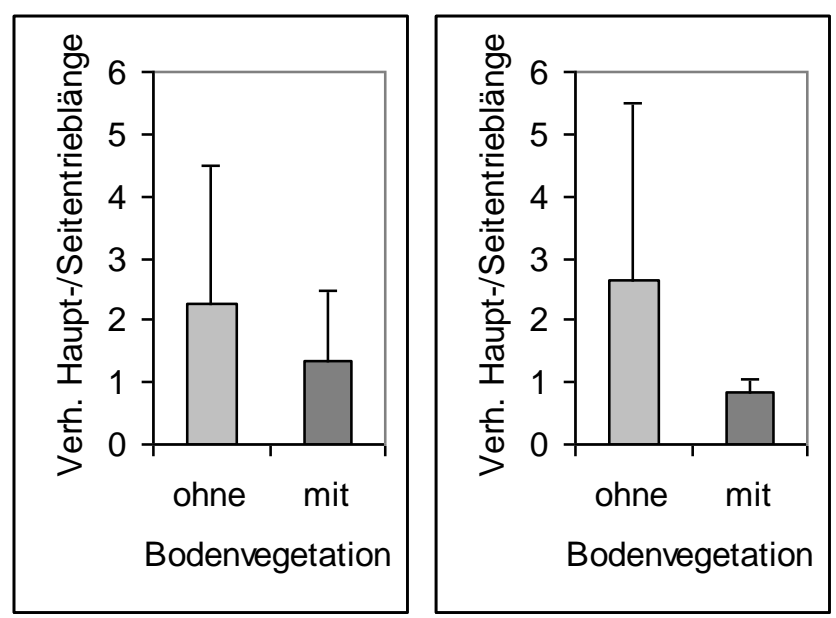

Abb. 203: Verhältnis der Haupt- und Seitentrieblängen der Ebereschen insgesamt (links; n=17/34) sowie auf Fläche D (rechts; n=10/11) getrennt nach Standorten in Bereichen ohne und mit Spontanvegetation; MW u. Std.abw.; jeweils signifikante Unterschiede nach U-Tests

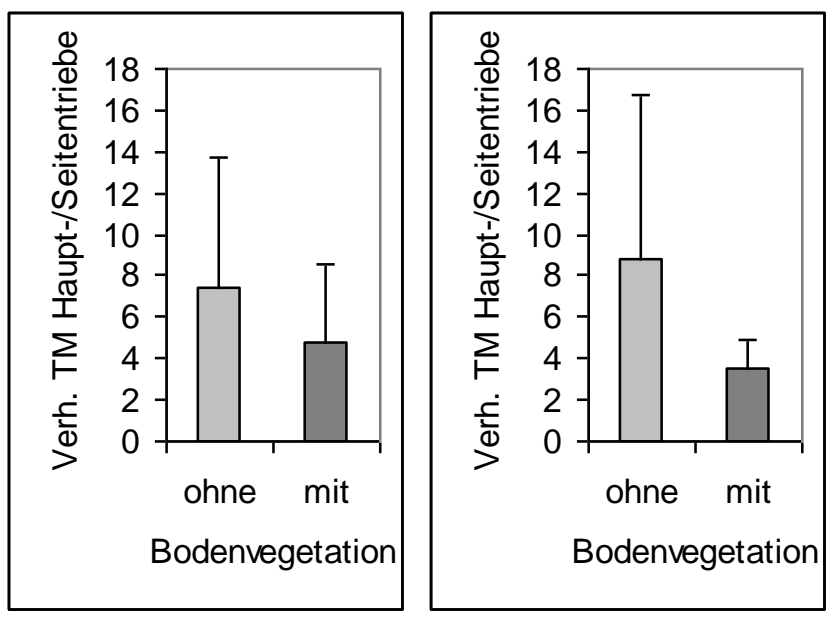

Abb. 204: Verhältnis der Trockenmassen der Haupt- und Seitentriebe der Ebereschen insgesamt (links; $\mathrm{n}=17 / 34$ ) sowie auf Fläche D (rechts; $\mathrm{n}=10 / 11$ ) getrennt nach Standorten in Bereichen ohne und mit Spontanvegetation; MW u. Std.abw.; jeweils signifikante Unterschiede nach U-Tests

\section{Ebereschen auf Versuchsfläche B}

Das Wachstum der Ebereschen auf Fläche B ähnelte insgesamt dem auf Fläche D, jedoch wurden auf Fläche B keine signifikanten Unterschiede je nach Standort in bewachsenen und unbewachsenen Bereichen festgestellt. 


\subsubsection{Schwarz-Erle}

Im Falle der Erlen wurde bei nahezu allen aufgenommenen Wachstumsparametern ein signifikanter Einfluss des Pflanzenstandortes in Bereichen ohne oder mit spontaner Bodenvegetation (bzw. der zugrunde liegenden standörtlichen Unterschiede) nachgewiesen (s. Tab. 116). Dies betraf sowohl die Erlen insgesamt als auch nur die Erlen auf den Versuchsflächen B bzw. D (auf der komplett vegetationsfreien Versuchsfläche A entfiel die Unterscheidung nach Pflanzenstandorten in besser und schlechter versorgten Bereichen).

Tab. 116: Wachstumsparameter der Erlen insgesamt sowie auf Fläche B bzw. Fläche D mit signifikant unterschiedlichen Ergebnissen je nach Standort in Bereichen ohne oder mit Spontanvegetation; MW u. Std.abw.; Ergebnisse von U-Tests [Z]

\begin{tabular}{|c|c|c|c|c|}
\hline Erlen & Wachstumsparameter & $\begin{array}{l}\text { Ohne } \\
\text { Boden- } \\
\text { bewuchs }\end{array}$ & $\begin{array}{l}\text { Mit } \\
\text { Boden- } \\
\text { bewuchs }\end{array}$ & $\begin{array}{l}\text { Ergebnis } \\
\text { U-Test } \\
\text { (Z) }\end{array}$ \\
\hline \multirow{10}{*}{$\begin{array}{l}\text { insge- } \\
\text { samt }\end{array}$} & Zuwachs Haupttrieb $2005[\mathrm{~cm}] \mathrm{n}=37 / 41$ & $8 \pm 6$ & $12 \pm 5$ & $-3,18^{* * *}$ \\
\hline & Zuwachs Haupttrieb $2006[\mathrm{~cm}] \mathrm{n}=37 / 41$ & $10 \pm 7$ & $22 \pm 12$ & $-4,43^{* * *}$ \\
\hline & Zuwachs Haupttrieb gesamt [cm] n=37/41 & $18 \pm 11$ & $33 \pm 16$ & $-4,39 * * *$ \\
\hline & Durchmesser Wurzelhals [mm] n=37/41 & $15 \pm 3$ & $18 \pm 4$ & $-3,70^{* * *}$ \\
\hline & Volumen Haupttrieb $\left[\mathrm{cm}^{3}\right] \mathrm{n}=37 / 41$ & $88 \pm 34$ & $138 \pm 67$ & $-3,74^{* * *}$ \\
\hline & Trockenmasse Haupttrieb [g] n=37/41 & $41 \pm 20$ & $64 \pm 31$ & $-3,74^{* * *}$ \\
\hline & Länge Seitentriebe $[\mathrm{cm}] \mathrm{n}=36 / 40$ & $287 \pm 138$ & $464 \pm 225$ & $-3,91^{* * *}$ \\
\hline & Trockenmasse Seitentriebe [g] n=36/40 & $19 \pm 9$ & $30 \pm 15$ & $-3,91^{* * *}$ \\
\hline & Haupt-/Seitentrieblänge $n=36 / 40$ & $0,5 \pm 0,2$ & $0,4 \pm 0,2$ & $-3,64^{* * *}$ \\
\hline & Oberirdische Trockenmasse $[\mathrm{g}] \mathrm{n}=36 / 40$ & $60 \pm 28$ & $94 \pm 45$ & $-3,63^{* * *}$ \\
\hline \multirow{6}{*}{$\begin{array}{l}\text { mit } \\
\text { Standort } \\
\text { auf } \\
\text { Fläche B }\end{array}$} & Zuwachs Haupttrieb 2005 [cm] n=8/32 & $6 \pm 4$ & $11 \pm 6$ & $-2,36^{* *}$ \\
\hline & Zuwachs Haupttrieb 2006 [cm] n=3/29 & $6 \pm 2$ & $22 \pm 12$ & $-2,36^{* *}$ \\
\hline & Zuwachs Haupttrieb gesamt [cm] n=3/29 & $14 \pm 4$ & $34 \pm 15$ & $-2,40^{* *}$ \\
\hline & Durchmesser Wurzelhals [mm] n=3/29 & $13 \pm 2$ & $18 \pm 3$ & $-2,43^{* *}$ \\
\hline & Volumen Haupttrieb $\left[\mathrm{cm}^{3}\right] \mathrm{n}=3 / 29$ & $65 \pm 15$ & $136 \pm 50$ & $-2,49 * *$ \\
\hline & Trockenmasse Haupttrieb [g] n=3/29 & $30 \pm 7$ & $63 \pm 23$ & $-2,49^{* *}$ \\
\hline \multirow{5}{*}{$\begin{array}{l}\text { mit } \\
\text { Standort } \\
\text { auf } \\
\text { Fläche D }\end{array}$} & Zuwachs Haupttrieb 2005 [cm] n=25/14 & $5 \pm 5$ & $9 \pm 6$ & $2,22^{*}$ \\
\hline & Zuwachs Haupttrieb 2006 [cm] n=14/12 & $9 \pm 9$ & $22 \pm 13$ & $-2,60^{* *}$ \\
\hline & Zuwachs Haupttrieb gesamt [cm] n=14/12 & $17 \pm 12$ & $33 \pm 17$ & $-2,29 *$ \\
\hline & Länge Seitentriebe [cm] n=14/12 & $281 \pm 136$ & $469 \pm 303$ & $-1,80^{*}$ \\
\hline & Trockenmasse Seitentriebe [g] n=14/12 & $18 \pm 9$ & $31 \pm 20$ & $-1,80^{*}$ \\
\hline
\end{tabular}




\section{Erlen insgesamt sowie auf den Versuchsflächen B und D}

Der Zuwachs der Haupttriebe der Erlen war in beiden Untersuchungsjahren (Anlagejahr 2005, 2006) ebenso wie der Gesamtzuwachs in bewachsenen Bereichen signifikant höher als in unbewachsenen Bereichen (s. Abb. 205, Abb. 206 u. Abb. 207). Dies galt sowohl für die Erlen insgesamt als auch bei einzelner Betrachtung der Erlen auf Versuchsfläche B bzw. D.
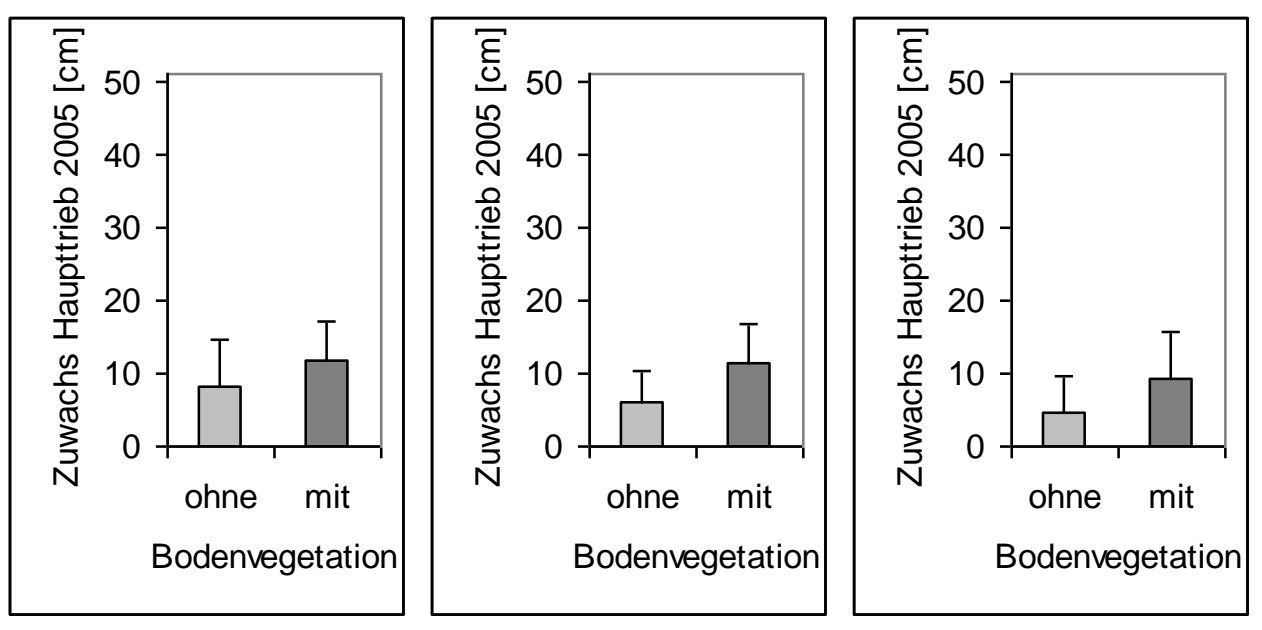

Abb. 205: Zuwachs [cm] des Haupttriebs im 1. Vegetationsjahr, Erlen insgesamt (links; n=37/41), auf Fläche B (Mitte; n=8/32) sowie auf Fläche D (rechts; n=25/14) getrennt nach Standorten in Bereichen ohne und mit Spontanvegetation; MW u. Std.abw.; jeweils signifikante Unterschiede nach U-Tests
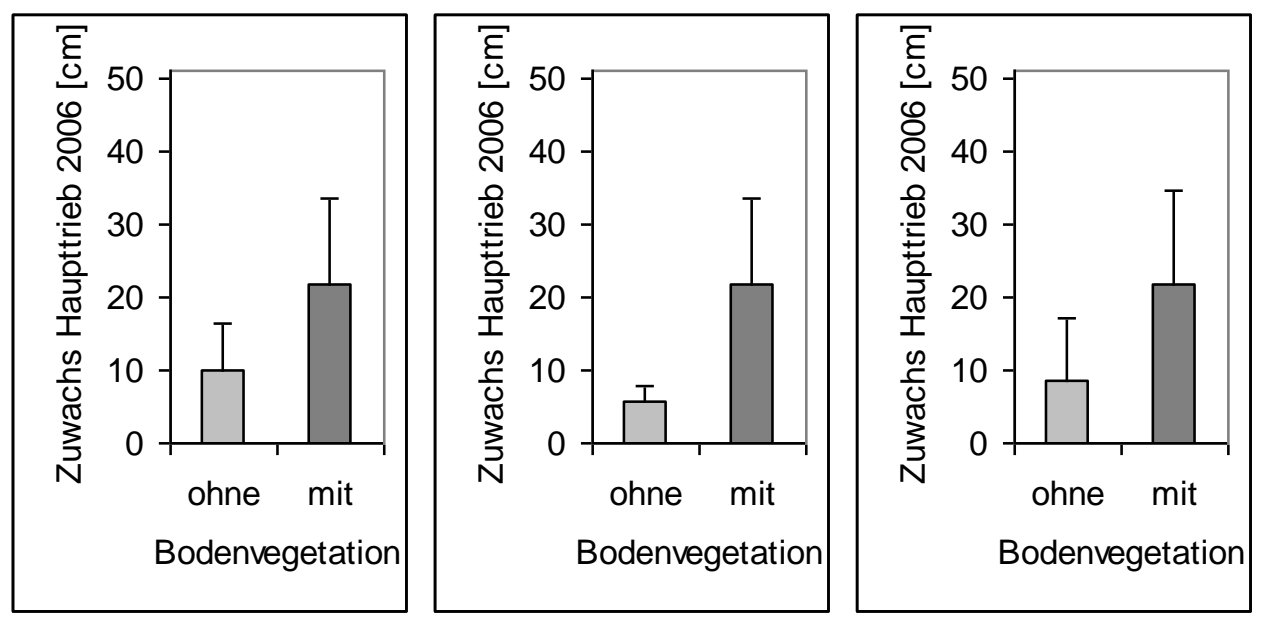

Abb. 206: Zuwachs [cm] des Haupttriebs im 2. Vegetationsjahr, Erlen insgesamt (links; n=37/41), auf Fläche B (Mitte; $n=3 / 29$ ) sowie auf Fläche D (rechts; $n=14 / 12$ ) getrennt nach Standorten in Bereichen ohne und mit Spontanvegetation; MW u. Std.abw.; jeweils signifikante Unterschiede nach U-Tests 

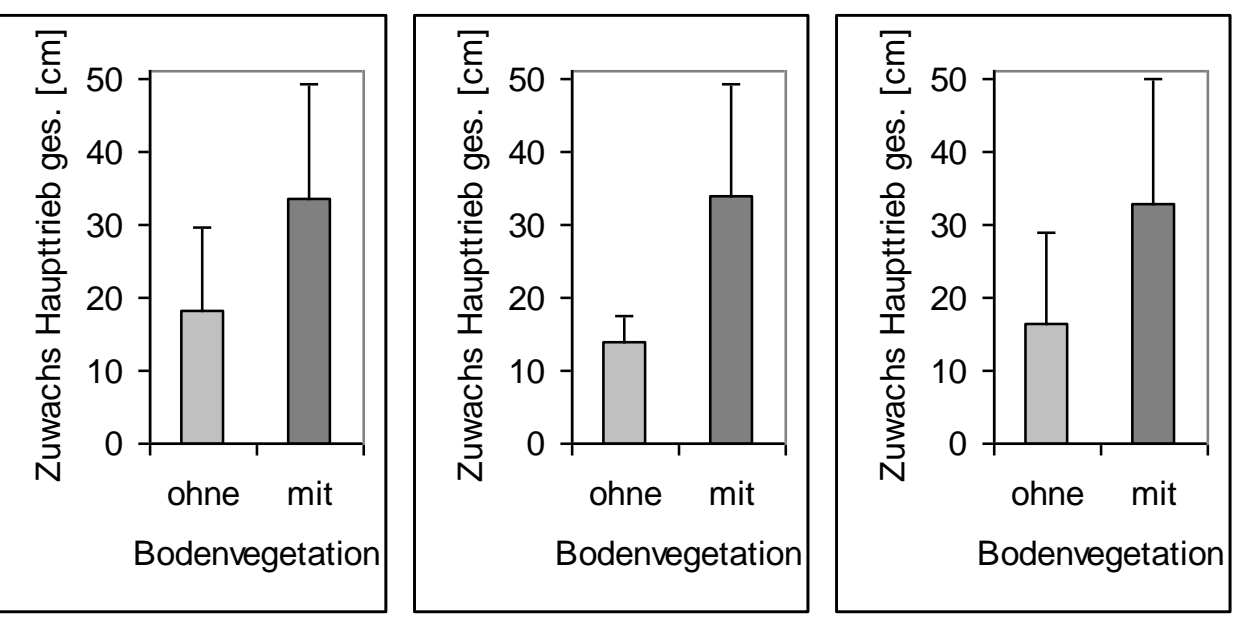

Abb. 207: Gesamtzuwachs [cm] des Haupttriebs, Erlen insgesamt (links; n=37/41), auf Fläche B (Mitte; n= 3/29) sowie auf Fläche D (rechts; $n=14 / 12$ ) getrennt nach Standorten in Bereichen ohne und mit Spontanvegetation; MW u. Std.abw.; jeweils signifikante Unterschiede nach U-Tests

Dieser Zuwachs-Unterschied je nach individuellem Pflanzenstandort war in 2006 noch deutlicher als in 2005: Nach Überwindung des Pflanzschocks (2005) betrug der Zuwachs der Erlen in Bereichen mit Spontanvegetation in 2006 mit Werten von knapp $22 \mathrm{~cm}$ mehr als das Doppelte des Zuwachses in unbewachsenen Bereichen. Dort wurden in beiden Jahren Zuwächse unter $10 \mathrm{~cm}$ ermittelt.
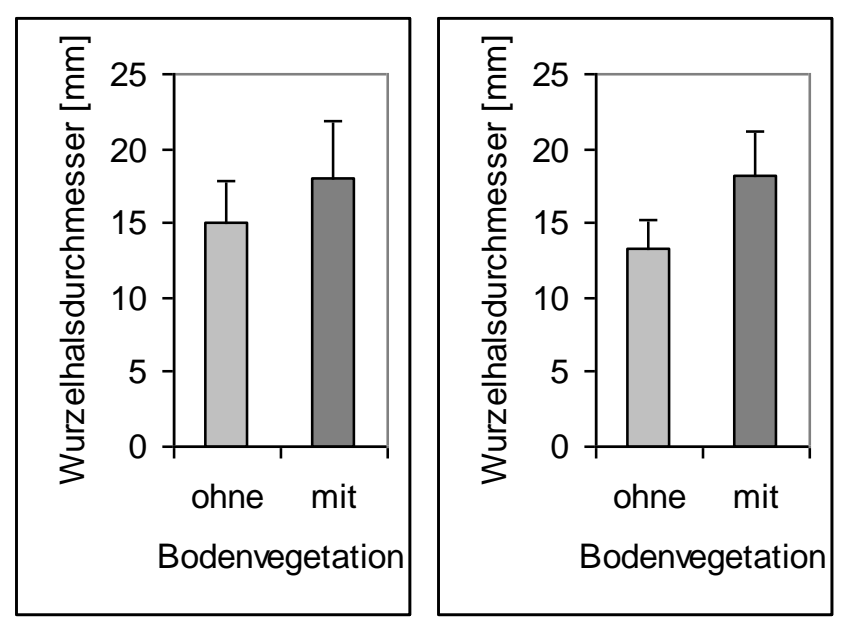

Abb. 208: Wurzelhalsdurchmesser [mm] der Erlen insgesamt (links; $n=37 / 41$ ) sowie auf Fläche B (rechts; $\mathrm{n}=3 / 29$ ) getrennt nach Standorten in Bereichen ohne und mit Spontanvegetation; MW u. Std.abw.; jeweils signifikante Unterschiede nach U-Tests

Sowohl insgesamt als auch bei Betrachtung nur der Erlen auf Fläche B waren die ermittelten Wurzelhalsdurchmesser (s. Abb. 208) in Bereichen mit spontaner Bodenvegetation mit ca. 18 mm (17,9 $\pm 3,9$ mm gesamt; 18,1 $\pm 2,9$ mm auf Fläche B) signifikant größer als in Bereichen ohne spontane Bodenbesiedelung mit 15,0 $\pm 2,8 \mathrm{~mm}$ (gesamt) bzw. 13,3 $\pm 2,0 \mathrm{~mm}$ (Fläche B). 


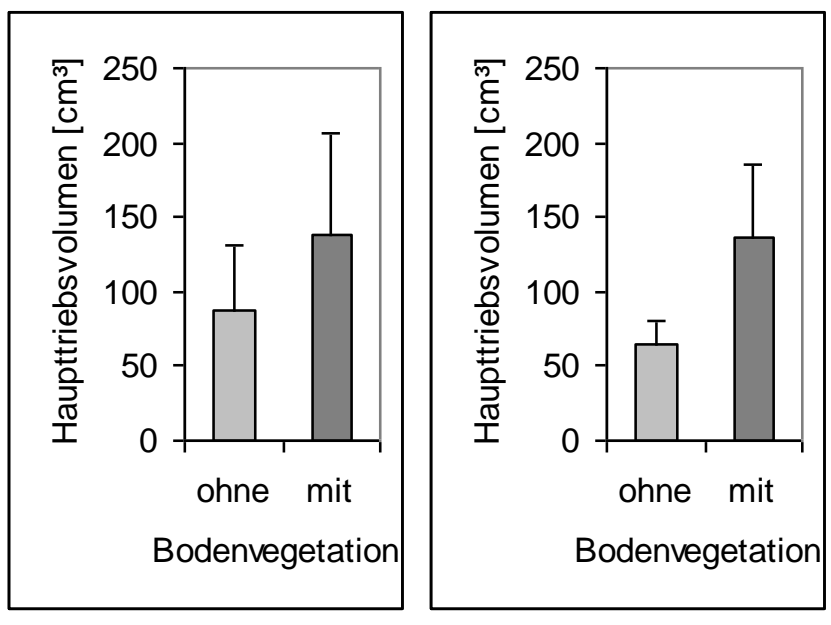

Abb. 209: Volumen $\left[\mathrm{cm}^{3}\right]$ des Haupttriebs der Erlen insgesamt (links; $\mathrm{n}=37 / 41$ ) sowie auf Fläche B (rechts; $n=3 / 29$ ) getrennt nach Standorten in Bereichen ohne und mit Spontanvegetation; MW u. Std.abw.; jeweils signifikante Unterschiede nach U-Tests

Das mit Hilfe der Messwerte Wurzelhalsdurchmesser, Spitzendurchmesser und Haupttriebslänge errechnete Volumen des Haupttriebs der Erlen unterschied sich sowohl insgesamt als auch beschränkt auf Versuchsfläche B signifikant nach dem individuellen Pflanzenstandort in besser (mit Bodenbewuchs) oder schlechter (ohne Bodenbewuchs) versorgten Bereichen (s. Abb. 209). Gleiches galt für die aus seinem Volumen errechnete Trockenmasse des Haupttriebs (s. Abb. 210). Bei Betrachtung der Erlen insgesamt steht einem mittleren Haupttriebsvolumen von $88 \pm 34 \mathrm{~cm}^{3}$ (einer mittleren Trockenmasse von $41 \pm 20 \mathrm{~g}$ ) in unbesiedelten Bereichen ein mit $138 \pm 67 \mathrm{~cm}^{3}$ (64 $\pm 31 \mathrm{~g}$ ) um $57 \%$ höherer Wert in besiedelten Bereichen entgegen. Bei den Erlen auf Fläche B tritt der Unterschied der Haupttriebsvolumina und -trockenmassen je nach Standort noch deutlicher hervor: Mit $136 \pm 50 \mathrm{~cm}^{3}$ (63 $\pm 23 \mathrm{~g}$ ) liegt der Wert in bewachsenen Bereichen rund doppelt so hoch wie in unbewachsenen Bereichen mit $65 \pm 15 \mathrm{~cm}^{3}$ (30 $\left.\pm 7 \mathrm{~g}\right)$.

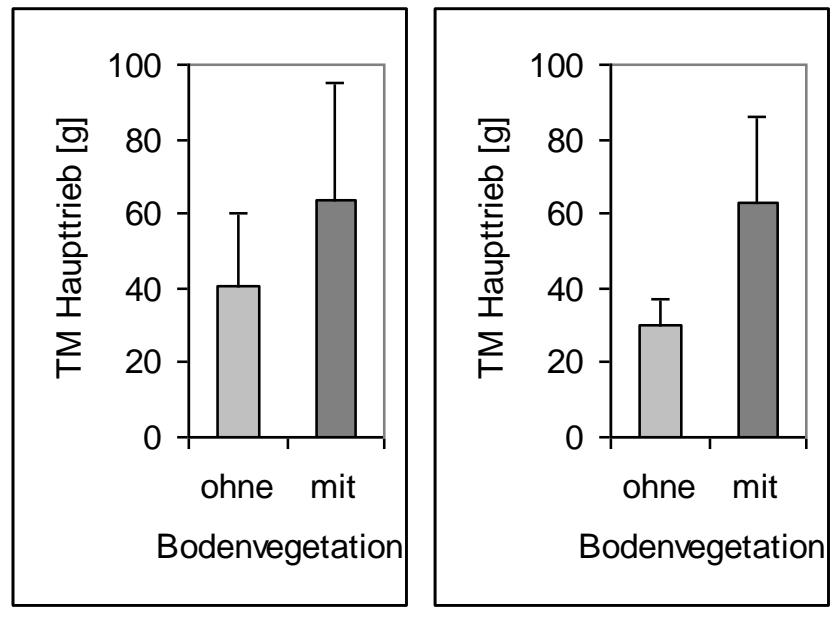

Abb. 210: Trockenmasse [g] des Haupttriebs der Erlen insgesamt (links; n=37/41) sowie auf Fläche B (rechts; $n=3 / 29$ ) getrennt nach Standorten in Bereichen ohne und mit Spontanvegetation; MW u. Std.abw.; jeweils signifikante Unterschiede nach U-Tests 
In Bereichen mit Spontanvegetation lagen die durchschnittlichen Längen (s. Abb. 211) und die daraus errechneten Trockenmassen der Seitentriebe der Erlen (s. Abb. 212) sowohl insgesamt als auch beschränkt auf Versuchsfläche D signifikant höher als in unbewachsenen Bereichen. Der Unterschied war wiederum recht deutlich: Auf Standorten mit Bodenbewuchs wurden Seitentrieblängen von $464 \pm 225 \mathrm{~cm}$ (gesamt) bzw. $469 \pm 303 \mathrm{~cm}$ (Fläche D) ermittelt; auf vegetationsfreien Standorten von $287 \pm 138 \mathrm{~cm}$ (gesamt) bzw. $281 \pm 136 \mathrm{~cm}$ (Fläche D). Die entsprechenden Trockenmassen betrugen bei Erlen in bewachsenen Bereichen etwa $30 \mathrm{~g}$ (gesamt: 30,3 \pm 14,6 g bzw. Fläche D: 30,6 \pm 19,7 g); in unbewachsenen Bereichen etwa 18-19 g (gesamt: 18,7 \pm 9,0 g bzw. Fläche D: 18,3 $\pm 8,9 \mathrm{~g}$ ).
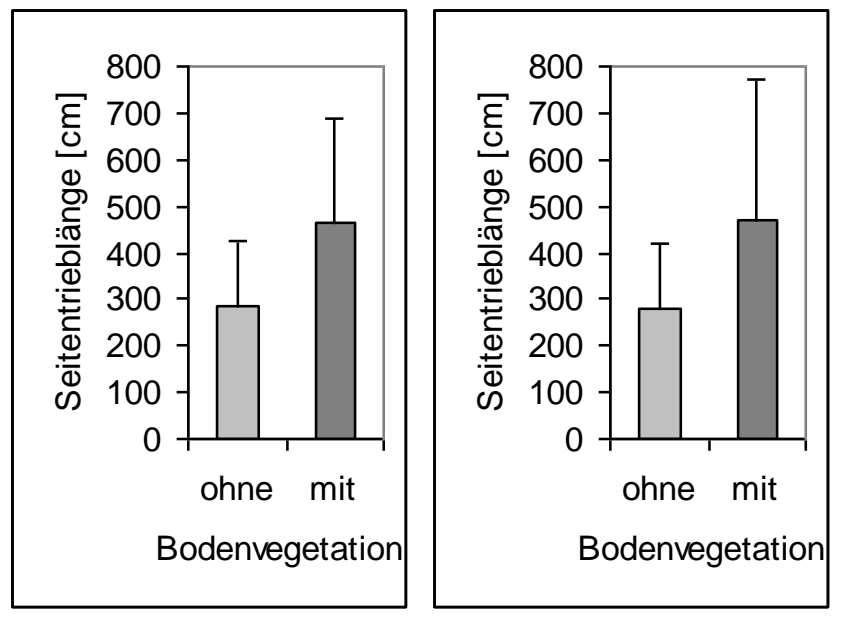

Abb. 211: Seitentrieblängen [cm] der Erlen insgesamt (links; $n=36 / 40$ ) sowie auf Fläche $D$ (rechts; $\mathrm{n}=12 / 14$ ) getrennt nach Standorten in Bereichen ohne und mit Spontanvegetation; MW u. Std.abw.; jeweils signifikante Unterschiede nach U-Tests
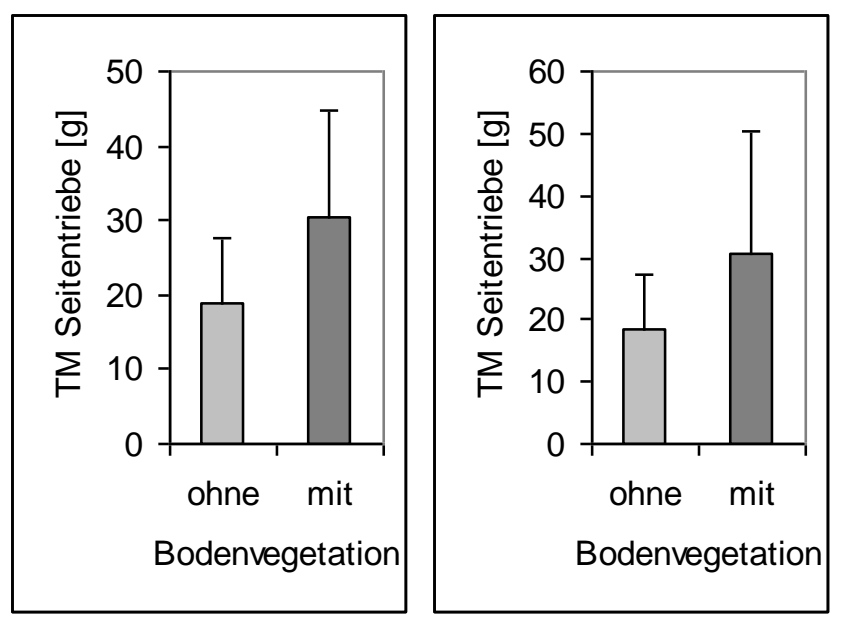

Abb. 212: Trockenmassen [g] der Seitentriebe der Erlen insgesamt (links; $\mathrm{n}=36 / 40$ ) sowie auf Fläche D (rechts; $\mathrm{n}=12 / 14$ ) getrennt nach Standorten in Bereichen ohne und mit Spontanvegetation; MW u. Std.abw.; jeweils signifikante Unterschiede nach U-Tests

Das Verhältnis aus Haupt- und Seitentrieblängen der Erlen war auf Standorten in Bereichen mit Bodenvegetation signifikant kleiner als auf Standorten in unbewachsenen Bereichen (s. Abb. 213 links), was auf die erheblich höhere Seitentrieblänge auf bewachsenen Standorten (s. Tab. 116) zurückzuführen ist. Dass dieser Unterschied (HT/ST-Länge mit Bodenbewuchs: 0,4 \pm 0,2; ohne Bodenbewuchs: $0,5 \pm 0,2$ ) zwar signifikant, aber nicht besonders groß ist, liegt an den bei 
Versuchsende infolge des unterschiedlichen Zuwachses (s. Tab. 116) in Bereichen mit Bodenvegetation ebenfalls größeren Haupttrieblängen der Erlen.

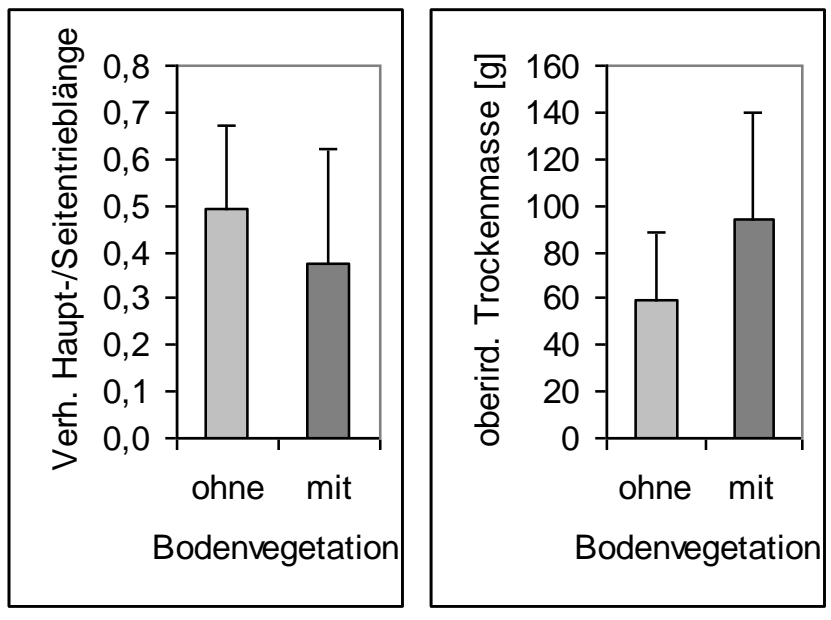

Abb. 213: Verhältnis der Haupt- und Seitentrieblängen (links) sowie oberirdische Trockenmasse [g] (rechts) der Erlen insgesamt $(\mathrm{n}=78 ; 37 / 41)$ getrennt nach Standorten in Bereichen ohne und mit Spontanvegetation; MW u. Std.abw.; jeweils signifikante Unterschiede nach U-Tests

Die Summe der Trockenmassen der Haupt- und Seitentriebe, zusammengefasst als oberirdische Biomasse (Trockenmasse) der Erlen bezeichnet, lag auf bewachsenen Standorten mit $94 \pm 45 \mathrm{~g}$ signifikant um über $50 \%$ höher als auf unbewachsenen mit $60 \pm 28 \mathrm{~g}$ (s. Abb. 213 rechts).

\subsubsection{Douglasie}

Im Falle der Douglasien wurde sowohl insgesamt als auch bei ausschließlicher Betrachtung der Versuchspflanzen auf Fläche B ein Einfluss des Pflanzenstandortes in Bereichen ohne oder mit spontaner Bodenvegetation (bzw. der zugrunde liegenden standörtlichen Unterschiede) auf den Zuwachs des Haupttriebs im Versuchsverlauf festgestellt (s. Tab. 117).

Tab. 117: Zuwachs [cm] des Haupttriebs der Douglasien insgesamt sowie auf Fläche B mit signifikant unterschiedlichen Ergebnissen je nach Standort in Bereichen ohne oder mit Spontanvegetation; MW u. Std.abw.; Ergebnisse von U-Tests [Z]

\begin{tabular}{|l|l|l|l|l|}
\hline \multirow{2}{*}{ Douglasien } & $\begin{array}{l}\text { Zuwachs des } \\
\text { Haupttriebs }[\mathrm{cm}]\end{array}$ & $\begin{array}{l}\text { Ohne } \\
\text { Bodenbewuchs }\end{array}$ & $\begin{array}{l}\text { Mit } \\
\text { Bodenbewuchs }\end{array}$ & $\begin{array}{l}\text { Ergebnis U- } \\
\text { Test (Z) }\end{array}$ \\
\hline \multirow{2}{*}{$\begin{array}{l}\text { insgesamt } \\
\mathrm{n}=55 / 62\end{array}$} & 2005 & $3,2 \pm 2,0$ & $5,6 \pm 3,4$ & $-3,67^{* * *}$ \\
\cline { 2 - 5 } & 2006 & $6,3 \pm 4,2$ & $10,4 \pm 8,5$ & $-2,50^{* *}$ \\
\cline { 2 - 5 } & gesamt & $9,6 \pm 4,9$ & $16,1 \pm 9,9$ & $-4,09^{* * *}$ \\
\hline $\begin{array}{l}\text { mit Standort auf } \\
\text { Fläche B } \\
\text { n=9/40 }\end{array}$ & 2005 & $3,7 \pm 2,2$ & $6,1 \pm 2,9$ & $-2,42^{* *}$ \\
\cline { 2 - 5 } & 2006 & $5,1 \pm 2,9$ & $9,6 \pm 6,2$ & $-2,02^{*}$ \\
\cline { 2 - 5 } & gesamt & $8,8 \pm 4,8$ & $15,7 \pm 7,4$ & $-2,60^{* *}$ \\
\hline
\end{tabular}




\section{Douglasien insgesamt}

Der Zuwachs des Haupttriebs der Douglasien in im Versuchsverlauf bewachsenen Bereichen lag sowohl im ersten (2005) als auch im zweiten (2006) Untersuchungsjahr sowie insgesamt signifikant 65 \% - 75 \% höher als in bis Versuchsabschluss unbewachsenen Bereichen (s. Abb. 214). Im Mittel betrug er in vegetationsfreien Bereichen $3,2 \pm 2,0 \mathrm{~cm}$ in 2005 und $6,3 \pm 4,2 \mathrm{~cm}$ in 2006 (9,6 4,9 cm insgesamt), in Bereichen mit Spontanvegetation 5,6 $\pm 3,4 \mathrm{~cm}$ in 2005 und $10,4 \pm 8,5 \mathrm{~cm}$ in $2006(16,1 \pm 9,9 \mathrm{~cm}$ insgesamt $)$.
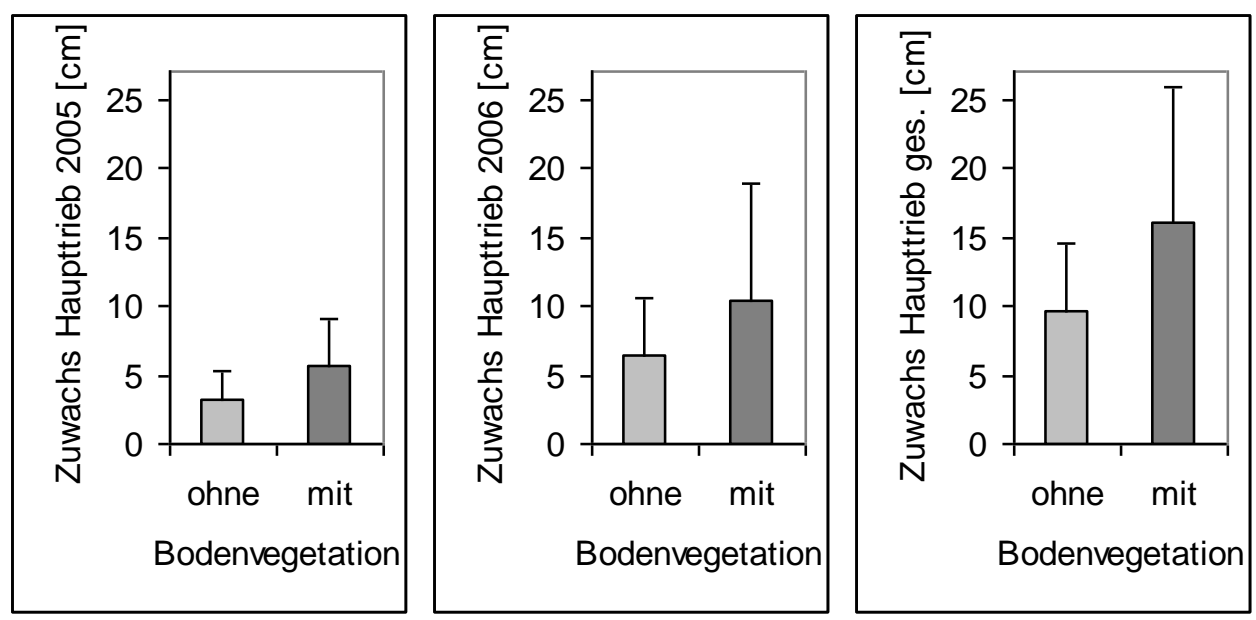

Abb. 214: Zuwachs [cm] des Haupttriebs der Douglasien im 1. (links) und 2. Vegetationsjahr (Mitte) sowie Gesamtzuwachs (rechts) getrennt nach Standorten in Bereichen ohne $(n=55)$ und mit $(n=62)$ Spontanvegetation; MW u. Std.abw.; jeweils signifikante Unterschiede nach U-Tests

\section{Douglasien auf Versuchsfläche B}

Betrachtet man nur die Douglasien auf Versuchsfläche B, so ergaben sich auch hier signifikante Zuwachsunterschiede der Haupttriebe je nach Pflanzenstandort in bewachsenen oder unbewachsenen Bereichen (s. Abb. 215). In Bereichen mit Bodenvegetation lag der mittlere Zuwachs in 2005 um $65 \%$, in 2006 um $88 \%$ sowie insgesamt um $78 \%$ über den Werten in unbesiedelten Bereichen. Dort betrug er 3,7 $\pm 2,2 \mathrm{~cm}$ in 2005 und 5,1 $\pm 2,9 \mathrm{~cm}$ in $2006(8,8 \pm 4,8$ $\mathrm{cm}$ insgesamt), in Bereichen mit Spontanvegetation 6,1 $\pm 2,9 \mathrm{~cm}$ in 2005 und 9,6 $\pm 6,2 \mathrm{~cm}$ in $2006(15,7 \pm 7,4 \mathrm{~cm}$ insgesamt $)$. 

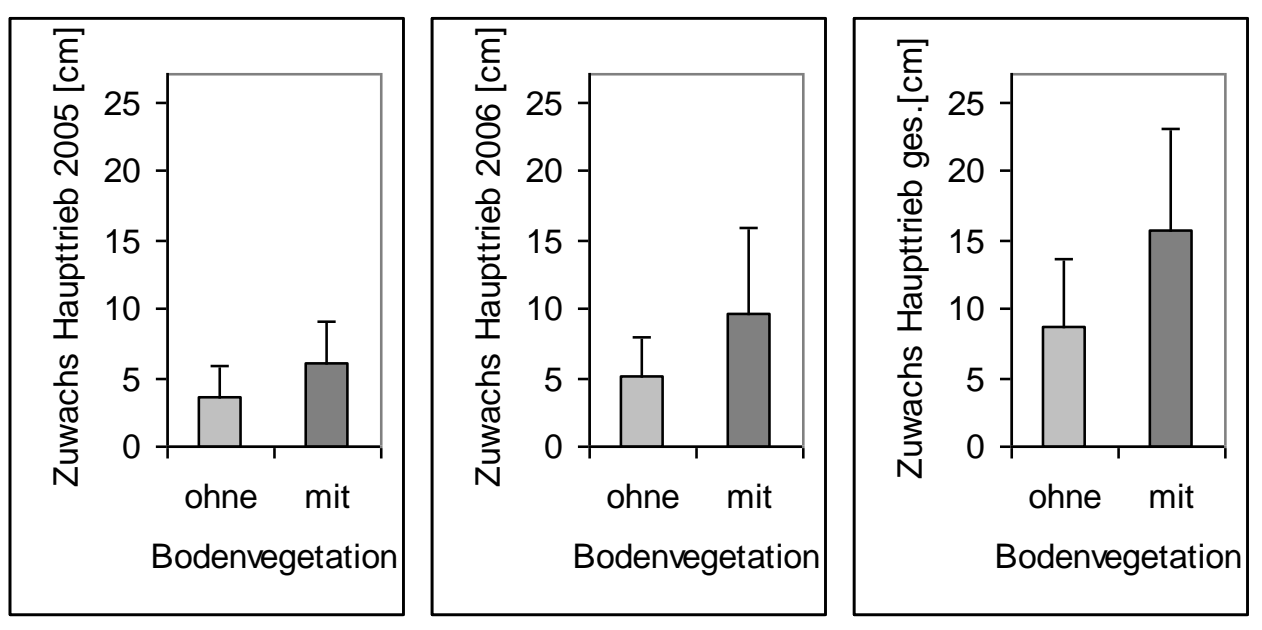

Abb. 215: Zuwachs [cm] des Haupttriebs der Douglasien auf Versuchsfläche B im 1. (links) und 2. Vegetationsjahr (Mitte) sowie Gesamtzuwachs (rechts) getrennt nach Standorten in Bereichen ohne ( $\mathrm{n}=9$ ) und mit ( $n=40)$ Spontanvegetation; MW u. Std.abw.; jeweils signifikante Unterschiede nach U-Tests

\section{Douglasien auf Versuchsfläche D}

Anders als auf Fläche B wurden bei den Douglasien auf Fläche D keine signifikanten Wachstumsunterschiede zwischen bewachsenen und unbewachsenen Standorten festgestellt.

\subsubsection{Wald-Kiefer}

Aufgrund der hohen Ausfallrate bei den Kiefern (57 \% auf bewachsenen, $93 \%$ auf unbewachsenen Standorten) standen für alle Wachstums-Untersuchungen, die über das 1. Versuchsjahr hinausgingen, von ursprünglich 120 lediglich noch 24 lebende, ungeschädigte Bäume zur Verfügung.

Sowohl insgesamt als auch bei ausschließlicher Betrachtung der Versuchspflanzen auf den in Frage kommenden Flächen B und D (A blieb vegetationsfrei) wurde ein signifikanter Einfluss der kleinräumigen standörtlichen Unterschiede (Bereiche ohne und mit Entwicklung von Spontanvegetation) auf den Zuwachs des Haupttriebs festgestellt (s. Tab. 118).

Tab. 118: Wachstumsparameter der Kiefern insgesamt sowie auf Fläche B bzw. Fläche D mit signifikant unterschiedlichen Ergebnissen je nach Standort in Bereichen ohne oder mit Spontanvegetation; MW u. Std.abw.; Ergebnisse von U-Tests [Z]

\begin{tabular}{|l|l|l|l|l|}
\hline \multirow{2}{*}{ Kiefern } & $\begin{array}{l}\text { Zuwachs des } \\
\text { Haupttriebs [cm] }\end{array}$ & $\begin{array}{l}\text { Ohne } \\
\text { Bodenbewuchs }\end{array}$ & $\begin{array}{l}\text { Mit } \\
\text { Bodenbewuchs }\end{array}$ & $\begin{array}{l}\text { Ergebnis U- } \\
\text { Test (Z) }\end{array}$ \\
\hline \multirow{3}{*}{ insgesamt (n=5/19) } & 2005 & $4,0 \pm 3,7$ & $9,3 \pm 4,3$ & $2,54^{* *}$ \\
\cline { 2 - 5 } & 2006 & $12,2 \pm 7,0$ & $19,9 \pm 9,6$ & $-1,67^{*}$ \\
\cline { 2 - 5 } & gesamt & $16,2 \pm 6,8$ & $29,2 \pm 11,7$ & $-2,28^{*}$ \\
\hline $\begin{array}{l}\text { mit Standort auf } \\
\text { Fläche B n=3/22 }\end{array}$ & 2005 & $2,0 \pm 3,5$ & $7,6 \pm 5,4$ & $-1,82^{*}$ \\
\hline $\begin{array}{l}\text { mit Standort auf } \\
\text { Fläche D n=6/6 }\end{array}$ & 2005 & 0 & $3,0 \pm 3,9$ & $-2,29^{*}$ \\
\hline
\end{tabular}




\section{Kiefern insgesamt}

Der durchschnittliche Zuwachs des Haupttriebs der Kiefern auf bewachsenen Standorten war sowohl im ersten (2005) als auch im zweiten (2006) Untersuchungsjahr sowie insgesamt signifikant höher als in bis Versuchsabschluss unbewachsenen Bereichen (s. Abb. 216). Im Anlagejahr (2005) betrug er in Bereichen mit Spontanvegetation 9,3 $\pm 4,3 \mathrm{~cm}$ und war damit deutlich mehr als doppelt so hoch wie in vegetationsfreien Bereichen $(4,0 \pm 3,7 \mathrm{~cm})$. Im Folgejahr (2006) wurde in bewachsenen Bereichen mit 19,9 $\pm 9,6 \mathrm{~cm} 63 \%$ mehr Zuwachs gemessen als in unbewachsenen Bereichen $(12,2 \pm 7,0 \mathrm{~cm})$. Insgesamt war der Zuwachs in Bereichen mit Bodenbewuchs mit 29,2 $\pm 11,7 \mathrm{~cm} 80 \%$ höher als in Bereichen ohne Bodenbewuchs $(16,2 \pm 6,8 \mathrm{~cm})$.
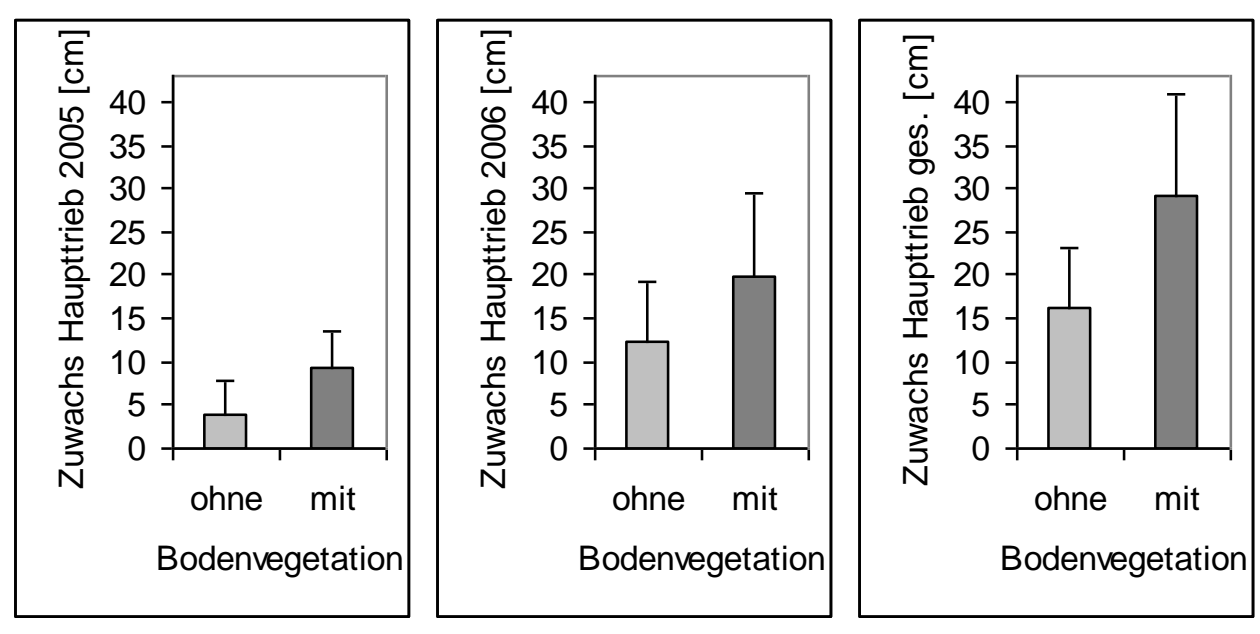

Abb. 216: Zuwachs [cm] des Haupttriebs der Kiefern im 1. (links) und 2. Vegetationsjahr (Mitte) sowie Gesamtzuwachs (rechts) getrennt nach Standorten in Bereichen ohne $(n=5)$ und mit $(n=19)$ Spontanvegetation; MW u. Std.abw.; jeweils signifikante Unterschiede nach U-Tests

\section{Kiefern auf den Versuchsflächen B und D}

Aufgrund der hohen Ausfallrate bei dieser Baumart im weiteren Versuchsverlauf konnten bei alleiniger Betrachtung der Kiefern auf den Versuchsflächen B (s. Abb. 217 links) bzw. D (s. Abb. 217 rechts) nur im 1. Untersuchungsjahr signifikante Zuwachsunterschiede je nach Standort in bewachsenen und unbewachsenen Bereichen ermittelt werden. Auf Fläche B war bei den Kiefern in unbesiedelten Bereichen wenig $(2,0 \pm 3,5 \mathrm{~cm})$, auf Fläche $D$ gar kein mittlerer Zuwachs der Haupttriebe zu verzeichnen. In besiedelten Bereichen betrug der Zuwachs auf Fläche B 7,6 $\pm 5,4 \mathrm{~cm}$, auf Fläche D recht geringe 3,0 $\pm 3,9 \mathrm{~cm}$. 


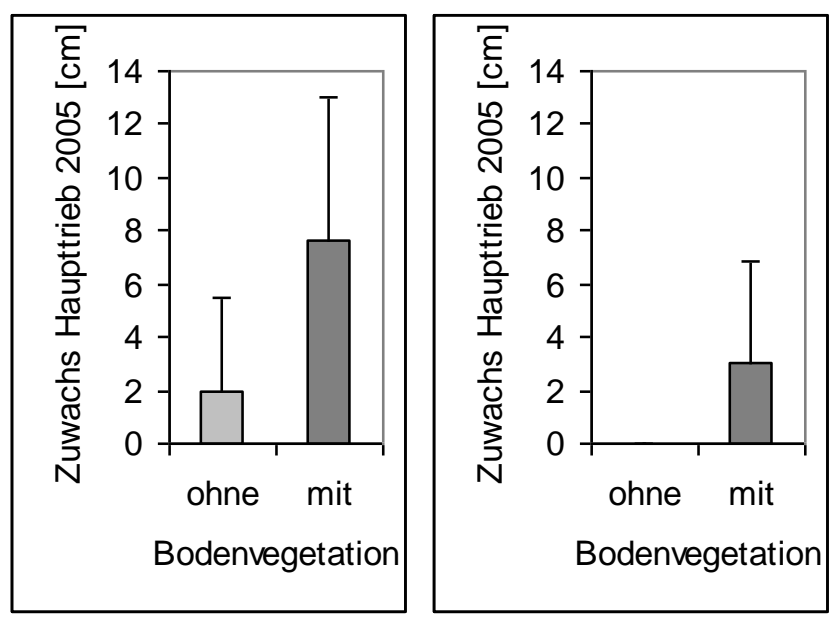

Abb. 217: Zuwachs [cm] des Haupttriebs im 1. Vegetationsjahr, Kiefern auf Fläche B (links; n=3/22) sowie auf Fläche D (rechts; $n=6 / 6$ ) getrennt nach Standorten in Bereichen ohne und mit Spontanvegetation; MW u. Std.abw.; jeweils signifikante Unterschiede nach U-Tests 


\section{$5 \quad$ Mykorrhizierung im Freiland- und Topf-Versuch}

Auf den Freiland-Versuchsflächen B und D wurden in Bereichen mit Spontanvegetation im Versuchsverlauf wiederholt Pilz-Fruchtkörper beobachtet, auf Fläche B zahlreicher als auf Fläche D. Ihre Bestimmung ergab, dass neben den in den Mykorrhiza-Varianten geimpften, fruchtkörper-bildenden Arten (Paxillus involutus und Scleroderma citrinum) noch weitere Pilzarten vertreten waren, darunter häufig Telephora terrestris und Laccaria laccata, beides ebenfalls Mykorrhiza-Bildner. Dies zeigt, dass in den Haldenböden teilweise durchaus Mykorrhiza-Pilze vorhanden sind oder dass diese von angrenzenden Flächen in die Haldenböden einwandern. Auf der vegetationsfreien Fläche A konnten außer wenigen Exemplaren der Art Paxillus involutus in Randbereichen keine weiteren Pilz-Fruchtkörper gefunden werden.

Um den Erfolg und den Grad der Mykorrhizierung innerhalb der beimpften Varianten V11-V16 (s. S. 20) zu ermitteln, waren nach Abschluss des Untersuchungszeitraums die Wurzeln von insgesamt 35 Douglasien und 13 Eichen im Labor auf Ekto-Mykorrhiza untersucht worden (s. S. 28). Ein solcher direkter Nachweis war für die Ahorn-Wurzeln nicht möglich, da es bislang keine befriedigende Methode zur Untersuchung der empfindlichen Ahorn-Wurzeln auf EndoMykorrhizierung gibt (Polle 2007).

Die Mykorrhizierungsraten lagen bei den Eichen zwischen „2,0“ (mittlerer Mykorrhizierungsgrad; s. S. 28) und „3,0“ (hoher Mykorrhizierungsgrad), bei den Douglasien zwischen „2,7“ und „3,0“. Zwischen den insgesamt sechs Mykorrhiza-Varianten (Impfung in Kombination mit Superabsorber, Stockosorb® und/oder Kalk-Gabe) gab es bei beiden Baumarten keine signifikanten Unterschiede hinsichtlich der Mykorrhizierungsrate. Ebenso wenig ließen sich signifikante Unterschiede zwischen den drei Versuchsflächen oder dem Pflanzenstandort in Teilbereichen mit und ohne Bodenvegetation feststellen.

Bei den Topf-Versuchen im Gewächshaus zeigten sich im Versuchsverlauf bei beiden Nadelbaumarten unabhängig von der Variante Pilzfruchtkörper, die sich sowohl auf den Bodenoberflächen der Töpfe als auch an der Topfaußenseite (an den unteren Topfperforationen) entwickelten. Ihre Bestimmung ergab, dass es sich nicht nur um die geimpfte Art Paxillus involutus handelte, sondern auch um Laccaria laccata und am häufigsten um Telephora terrestris. Fruchtkörper dieser Arten konnten auch auf den Freiland-Versuchsflächen gefunden werden (s.o.), so dass anzunehmen ist, dass die Pilze auch in dem für die TopfVersuche verwendeten Haldensubstrat bereits vorhanden waren. Ihre Verbreitung, vor allem von Telephora terrestris, auf nahezu alle Töpfe erfolgte vermutlich über das Gießwasser.

Auch in den Topf-Versuchen waren nach Abschluss des Untersuchungszeitraums die Wurzeln von insgesamt 10 Douglasien und 10 Kiefern, die mit Mykorrhiza-Pilzen gepflanzt worden waren (s. S. 33), im Labor auf Ekto-Mykorrhiza untersucht worden. Ihre Mykorrhizierungsraten lagen unabhängig von der Variante einheitlich bei knapp „3,0“ (hoher Mykorrhizierungsgrad). 


\section{$6 \quad$ Wurzelentwicklung im Topf-Versuch}

Bei allen Baumarten unterschieden sich die Wurzelballen der Kalk- und Kompost-Varianten, also derjenigen Varianten, in denen durch Zugabe von Bodenhilfsstoffen der pH-Wert des Bodensubstrats erhöht und entsprechend die Austauscherbelegung verändert wurde (s. ab S. 58), von den Wurzelballen der übrigen Varianten.

Die Wurzeln beider Nadelbaumarten waren in den Kalk- und Kompost-Varianten dunkler als in den übrigen Varianten und bei den Douglasien auch reicher verzweigt (hier v. a. mit KalkDüngung).

Bei den Ebereschen fielen in diesen Varianten (ebenfalls v. a. mit Kalk-Düngung) vergleichsweise viele, helle Feinwurzeln auf.

Dies deutet u.a. auf eine Aufhebung der (auch im Freiland nachgewiesenen) Aluminiumtoxizität durch die pH-Wert-Erhöhung hin (Aluminiumtoxizität schädigt Wurzeln und hemmt die Feinwurzelentwicklung; Ulrich 1980/81, Bergmann 1993, Scheffer \& Schachtschabel 2010). Zudem wirkte die verbesserte Nährstoffverfügbarkeit und geringere anderweitige Schadstoffbelastung in den Kalk- und Kompostvarianten sicher auch auf das Wurzelwachstum positiv.

Die Ahorne zeigten in diesen Varianten eine gleichmäßige Durchwurzelung, während bei allen übrigen Varianten das Wurzelwerk einen mehr oder weniger stark ausgeprägten „Blumentopf" (oder „Lampenschirm“) bildete, wie die Zeichnungen in Abb. 218 veranschaulichen. Die eigenartige Verformung der Ahorn-Wurzelballen hatte offenbar direkt oder indirekt mit der Bodenreaktion und einer versauerungsbedingten Schadstoffbelastung zu tun (z.B. wiederum durch Aluminiumtoxizität gehemmtes Wurzelwachstum). Grund für dieses „Ausweichen“ fast aller Wurzeln an die Topf-Innenwand könnte daher sein, dass das Bodensubstrat in dem Bereich durch herab laufendes Gießwasser (Auswaschung) weniger $\mathrm{Al}^{3+} \mathrm{u}$. ä. enthielt. 

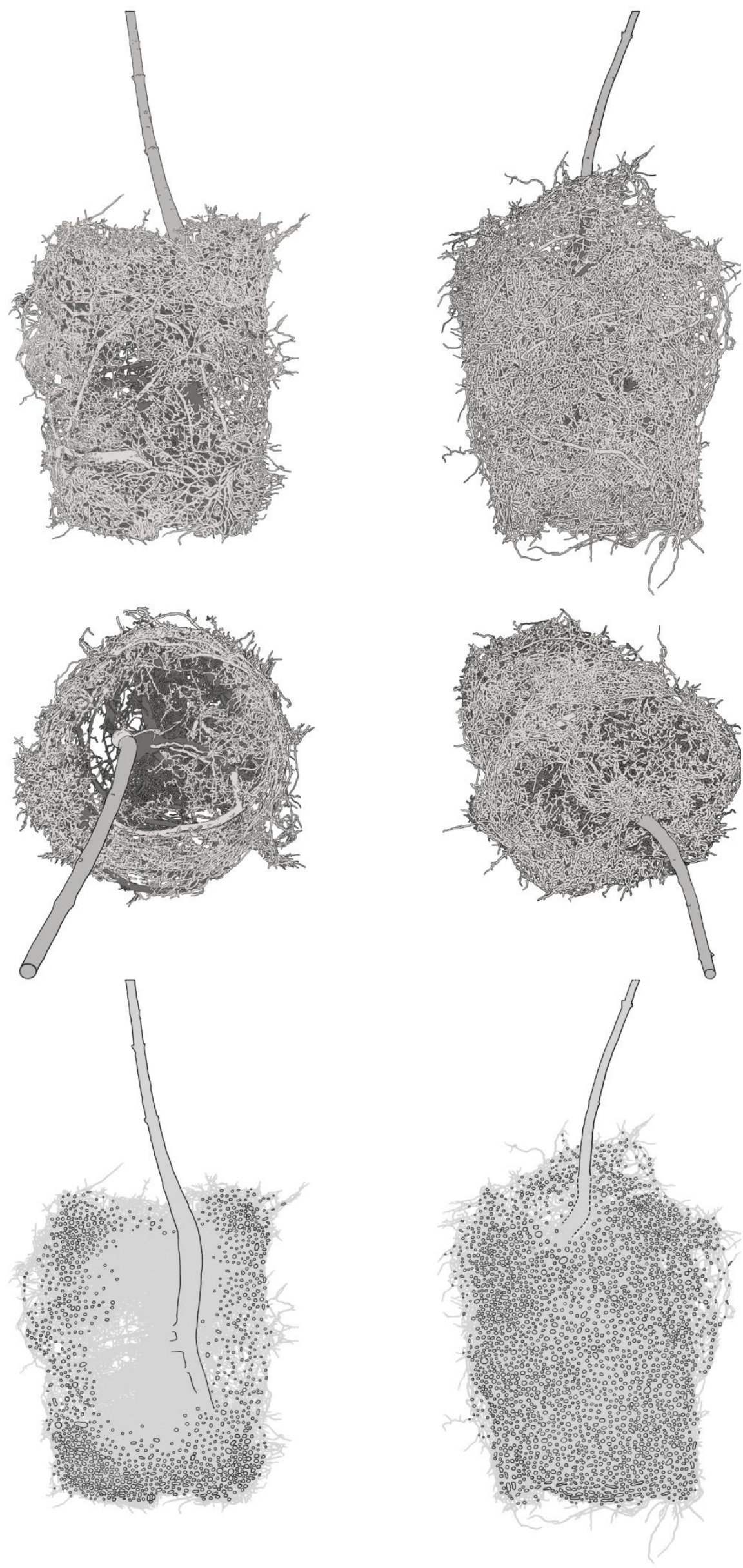

Abb. 218:

Wurzelwerke zweier Ahorne im TopfVersuch. Links Behandlungsvariante ohne, rechts Behandlungsvariante mit Kalk-Düngung (oben: Seitenansicht, Mitte: Draufsicht, unten: schematische Schnittzeichnung) 


\section{$7 \quad$ Zusammenfassung Pflanzen}

In den folgenden Kapiteln werden die Ergebnisse der Auswertungen von Blatt- bzw. Nadelanalysen, Vitalitätsschätzungen und Wachstumsmessungen zusammengefasst. Nach einer Kurzdarstellung der Standorteinflüsse werden für jede Baumart (unter Berücksichtigung dieser Einflüsse) die Situation der unbehandelten Kontrollen sowie ggf. der Einfluss von Behandlungsvarianten kurz wiedergegeben. Aus der Informationsfülle der vorangegangenen Ergebnis-Kapitel wurden dabei nur die Punkte herausgezogen, die zur Beurteilung der Eignung von Baumarten und Bodenhilfsstoffen auf den in Frage kommenden Standorten wesentlich sind.

Die ab Seite 58 beschriebenen und auf Seite 73 zusammengefassten Effekte der Kalk- und Kompost-Düngungen auf die chemischen Bodeneigenschaften (höherer pH-Wert, höhere Austauschkapazität, andere Austauscherbelegung, im Fall von Kompost höhere C-, N- und PGehalte) sowie der Perlit- und Kompost-Gaben auf die physikalischen Bodeneigenschaften (Herabsetzung der Bodenverdichtung, Erhöhung des Gesamtporenvolumens, dadurch weniger reduzierende Bedingungen) führten vielfach auch zu Veränderungen der Blatt- und Nadelspiegelwerte gegenüber den jeweils unbehandelten Kontrollen. Auch in den Assimilationsorganen der mit Mykorrhiza-Pilzen oder Wasserspeichersubstanzen gepflanzten Bäume wurden gegenüber den Nullvarianten teilweise erheblich veränderte Element-Gehalte gemessen. In den Zusammenfassungen finden sich der Übersichtlichkeit halber jeweils nur die Ergebnisse der Blatt- und Nadelanalysen wieder, die als Begründung von Vitalitäts- und Wachstumsunterschieden zwischen den Versuchsvarianten dienen können. Eine vollständige Zusammenstellung und Bewertung der Element-Gehalte in den einzelnen Varianten findet sich beginnend ab Seite 105.

\subsection{Einfluss des Standortes auf einer der drei Versuchsflächen}

Der aus 936 Bäumen bestehende Freiland-Versuch auf dem Gelände der Ronneburger Absetzerhalde (12 Wiederholungen je Baumart und Behandlungsvariante) wurde auf drei Versuchsflächen (A, B und D) verteilt angelegt (pro Versuchsfläche 4 Wiederholungen je Baumart und Behandlungsvariante). Die Interpretation der erhobenen Vitalitäts- und Wachstumsdaten hinsichtlich der Wirkungen der eingesetzten Bodenhilfsstoffe wurde auch durch die Tatsache erschwert, dass teilweise bereits der Pflanzenstandort auf einer dieser drei Versuchsflächen Einfluss auf Vitalität und Wachstum der Versuchspflanzen hatte.

So hing bei vier der sechs Baumarten die Sterblichkeitsrate signifikant mit dem Pflanzenstandort auf Versuchsfläche A, B oder D zusammen. Bei den Eichen und Ahornen war die Ausfallrate auf Fläche A deutlich höher als auf den Flächen B und D, bei den Nadelbäumen wiesen die Flächen A und D höhere Ausfallraten als Fläche B auf.

Die in Abb. 219 zusammengestellte, je nach Standort unterschiedliche Vitalität bei Versuchsabschluss veranschaulicht den Einfluss der Bodenbedingungen auf den drei Versuchsflächen auf die Pflanzenentwicklung aller 6 Baumarten. 


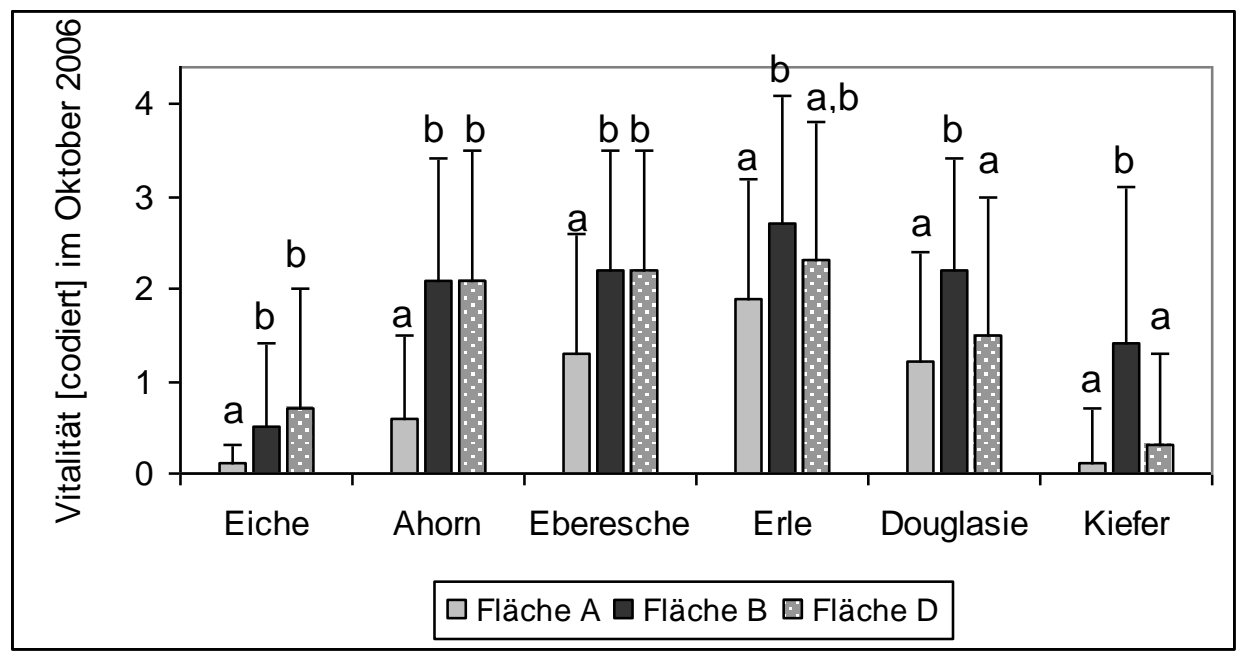

Abb. 219: Vitalität [codiert: $4=$ vital bis $0=$ tot, s. S. 27] der sechs Baumarten auf den drei Versuchsflächen (A, B, D) nach 2 Vegetationsjahren; MW u. Std.abw; Buchstaben kennzeichnen je Baumart homogene Gruppen nach U-Tests

\subsubsection{Versuchspflanzen insgesamt}

Insgesamt bot Fläche B allen sechs Baumarten auf je nach Baumart unterschiedlichem Niveau bessere Standortbedingungen als Fläche A (s. Abb. 219).

Die mittlere Vitalität der Nadelbäume und der Ahorne war auf Fläche A zu jedem Aufnahmezeitpunkt, die der übrigen Laubbäume ab Oktober 2005 signifikant geringer als auf Fläche B.

Bei den Ahornen und Kiefern spiegelte sich dieses Verhältnis auch im Zuwachs des 1. Versuchsjahres, bei den Erlen in nahezu allen erhobenen Wachstumsparametern und bei den Douglasien im Haupttriebs-Zuwachs sowie im Verhältnis aus ober- und unterirdischer Trockenmasse wieder (B: die höhere oberirdische Trockenmasse bei ähnlicher Wurzelmasse führte zu einem höheren und damit ungünstigerem Spross-Wurzel-Verhältnis).

Fläche D nahm bei den Erlen hinsichtlich der Vitalitäts- und Wachstumsentwicklung eine Mittelstellung ein (gegenüber Fläche A bestanden keine signifikanten Unterschiede, während die Werte gegenüber Fläche B zum Teil gleichwertig, zum Teil geringer waren).

Bei den übrigen Laubbaumarten wurden auf Fläche D ab Oktober 2005 vergleichbare Vitalitätswerte ermittelt wie auf Fläche B. Auch der Zuwachs der Ahorne im 1. Versuchsjahr sowie die Wachstumsentwicklung der Douglasien ab dem 2. Versuchsjahr waren auf Fläche D ähnlich wie auf Fläche B.

Hinsichtlich der Vitalitätswerte beider Nadelbaumarten sowie des Zuwachses der Kiefern im 1. Versuchsjahr waren dagegen die Ergebnisse auf Fläche D und auf Fläche A vergleichbar.

Die unterschiedliche Entwicklung der Versuchspflanzen auf den drei Versuchsflächen kann zumindest teilweise auch durch die unterschiedliche Verteilung besserer (mit Spontanvegetation besiedelter) und schlechterer (vegetationsfreier) Standorte erklärt werden. So blieb Fläche A komplett vegetationsfrei, während auf Fläche B schließlich 72 \%, auf Fläche D immerhin $43 \%$ der Versuchspflanzen Standorte hatten, die im Versuchsverlauf von Spontanvegetation besiedelt wurden. 
Um diesen Einfluss auszuschließen, wurden alle Versuchspflanzen auf unbewachsenen und alle Versuchspflanzen auf bewachsenen Standorten getrennt voneinander auf Unterschiede zwischen den Versuchsflächen untersucht.

\subsubsection{Versuchspflanzen in Bereichen ohne Spontanvegetation}

Bei Betrachtung ausschließlich der Versuchspflanzen mit Standorten in bis Versuchsende vegetationsfreien Bereichen (bei allen Baumarten vergleichsweise geringere Vitalitätswerte, s. ab S. 257) bestanden zumindest bei den Laubbäumen teilweise signifikante Vitalitätsunterschiede zwischen den drei Versuchsflächen.

Bei den Eichen gab es auf diesen ungünstigeren Standorten lediglich auf Fläche D überhaupt überlebende Exemplare. Die Vitalität der Ebereschen war zumindest bei einer Aufnahme (Oktober 2005) auf der vegetationsfreien Fläche A signifikant geringer als in unbewachsenen Bereichen auf Fläche B. Bei den Ahornen wurde ab Oktober 2005 auf Fläche A ein geringerer Durchschnittswert ermittelt als in diesen Bereichen auf Fläche B und D. Im völligen Gegensatz dazu lag zu Versuchsbeginn (Juni 2005) die Vitalität der Erlen auf Fläche A signifikant höher als in den vegetationsfreien Bereichen der Flächen B und D, was jedoch im weiteren Verlauf des Versuchs keinen Fortbestand hatte.

Bei beiden Nadelbaumarten bestanden auf den unbewachsenen, ungünstigeren Standorten keine Vitalitätsunterschiede je nach Versuchsfläche. Auch konnte bei keiner Baumart eine entsprechend unterschiedliche Wachstumsentwicklung ermittelt werden (aufgrund der schlechteren Standortbedingungen eher eingeschränktes Wachstum der Versuchspflanzen).

\subsubsection{Versuchspflanzen in Bereichen mit Spontanvegetation}

Bei Betrachtung ausschließlich der Bereiche, in denen sich im Versuchsverlauf Spontanvegetation etablierte (bei allen Baumarten vergleichsweise bessere Vitalitätswerte, s. ab S. 257), bestanden ebenfalls teilweise signifikante Unterschiede zwischen den beiden betreffenden Versuchsflächen B und D (Fläche A blieb vegetationsfrei) hinsichtlich der Vitalitätsund Wachstumsentwicklung der Versuchspflanzen.

Bei den Nadelbäumen sowie den Erlen war in bewachsenen Bereichen ein leichter Vorteil der Pflanzen auf Fläche B zu erkennen. Bei den Erlen und Kiefern beschränkte sich dies jedoch auf bessere Vitalitätswerte zu Beginn (Erle) bzw. zum Ende (Kiefer) des Untersuchungszeitraums. Bei den Douglasien wurden im gesamten 1. Versuchsjahr in bewachsenen Bereichen auf Fläche B bessere Vitalitätswerte ermittelt.

Dagegen wiesen die bei Versuchsende ermittelten Wurzelhalsdurchmesser der Douglasien ebenso wie der Zuwachs der Ahorne im 1. Versuchsjahr auf leicht bessere Wuchsbedingungen in bewachsenen Bereichen auf Fläche D hin. Auch bei den Ebereschen zeigten die Wurzelhalsdurchmesser sowie die mit den Seitentrieben zusammenhängenden Wachstumsparameter in diesen Bereichen auf Fläche D bessere Ergebnisse. Hier wurden zudem zu Beginn und zum Ende des Untersuchungszeitraums, bei den Eichen bei einer Aufnahme (Juni 2006) signifikant bessere Vitalitätswerte ermittelt. 


\subsubsection{Ernährung und Belastung der Bäume auf den drei Versuchsflächen}

Neben den aufgrund eines zeitweise defekten Wildzaunes auf Fläche A relativ hohen Wildschäden, die (vor allem bei den Ahornen) ebenfalls zur schlechten Vitalitäts- und Wachstumssituation der Versuchspflanzen auf Fläche A beitrugen, wurde eine teils unterschiedliche Versorgungs- und Belastungssituation der Bäume auf den drei Versuchsflächen festgestellt.

Die vergleichsweise schlechteste Entwicklung aller Baumarten auf Fläche A ist nicht einer mangelnden Nährstoffversorgung zuzuschreiben. Zum einen lag die effektive Austauschkapazität in den Böden der drei Versuchsflächen auf A und B im mittleren, auf D dagegen mit einem nicht einmal halb so hohen Wert im niedrigen bis mittleren Bewertungsbereich. Zum anderen wurden ausgenommen bei den Kiefern, die zumindest im 1. Untersuchungsjahr auf allen drei Flächen geringe Stickstoff- und Phosphor-Gehalte zeigten, bei keiner Baumart auf Fläche A Nährstoff-Defizite festgestellt (alle wichtigen Nährstoff-Gehalte lagen mindestens im ausreichenden, teilweise im über ausreichenden Bereich).

Auf Fläche B galt dies nur für die Eichen und Erlen, auf Fläche D nur für die Ahorne.

Dagegen wiesen die übrigen fünf Baumarten auf Fläche D vor allem (trotz ausreichender Phosphor-Gehalte im Boden) eine unzureichende Phosphor-Versorgung auf, was nach Bergmann (1993) auf Aluminium-Toxizität hindeutet. Bei den Ebereschen und Erlen auf dieser Fläche war zudem die Kalium-Versorgung nicht ausreichend.

Auch auf der bei allen Baumarten besten Fläche B wurden bei den Ahornen, Ebereschen und Nadelbäumen jeweils defizitäre Stickstoff- und (ausgenommen bei den Douglasien) PhosphorVersorgungen (entspricht Aluminium-Toxizität) festgestellt. Ersteres kann auf den insgesamt geringen Gehalt an Stickstoffverbindungen im Boden zurückgeführt werden. Die Ahorne und Ebereschen wiesen zudem knapp nicht ausreichende Kalium-Gehalte auf.

Auffällig waren bei allen Baumarten die hohen Magnesium-Gehalte in den Assimilationsorganen. Die Magnesium-Gehalte in den Böden der drei Versuchsflächen lagen auf A und B oberhalb, auf D (weniger als halb so hoher Gehalt) dagegen im Rahmen üblicher Gehalte. Umgekehrt war der Anteil an Magnesium-Ionen an der Austauscherbelegung auf Fläche D signifikant weit höher und lag über den in landwirtschaftlich genutzten Böden üblichen sowie den für die (Kultur-) Pflanzenernährung optimalen Gehalten. Entsprechend wurden bei allen Baumarten die jeweils höchsten Magnesium-Gehalte auf Fläche D gemessen.

Neben der Nährstoffversorgung war auch die Belastung der Versuchspflanzen mit verschiedenen Schwermetallen teilweise je nach Versuchsfläche unterschiedlich hoch, erklärte jedoch ebenfalls nicht die oben beschriebene unterschiedliche Vitalitäts- und Wachstumsentwicklung je nach Versuchsfläche.

So wurden bei allen Baumarten auf allen drei Flächen sehr hohe Kupfer-Gehalte in den Assimilationsorganen gemessen. Auf den Flächen A und B waren erhöhte bis stark belastende Kupfer-Bodengehalte festgestellt worden, wobei der Gehalt auf Fläche A signifikant höher war (toxische Wirkung möglich). Dennoch lagen die Blattgehalte der Ebereschen und Erlen auf allen drei Flächen etwa in der gleichen Größenordnung. Bei den Eichen und Ahornen war der KupferGehalt auf Fläche B, bei den Kiefern auf Fläche D etwas geringer als auf den übrigen beiden Flächen. Allenfalls in den Douglasien-Nadeln wurden wie erwartet auf Fläche A gegenüber B und D deutlich höhere Kupfer-Gehalte ermittelt. 
Trotz starker Cadmium-Belastung des Bodens konnten in den Blättern und Nadeln der Versuchspflanzen überwiegend keine Cadmium-Gehalte nachgewiesen werden. Lediglich bei den Douglasien wurde auf Fläche A ein leicht erhöhter, auf Fläche B dagegen ein sehr erhöhter Cadmium-Gehalt gemessen (höchster Bodengehalt auf Fläche B, dicht gefolgt von Fläche A, mit einigem Abstand gefolgt von Fläche D; Unterschiede zwischen den Flächen jedoch nicht signifikant). Auf Fläche B bestanden zudem bei den Ahornen und Erlen Cadmium-Gehalte, die über bzw. knapp bei dem Wert lagen, der nur von einem Viertel aller im Rahmen des Deutschen Waldbodenberichtes untersuchten Buchen (einzige dort untersuchte Laubbaumart) überschritten wurde (75er-Perzentil; BMELF 1997b).

Auf Fläche A konnten bei den Ahornen und Ebereschen, auf Fläche B bei den Eichen, Ebereschen und beiden Nadelbaumarten, auf Fläche D (mehr als doppelt so hoher Blei-Gehalt im Boden; oberer Normalbereich) nur bei den Kiefern keine nachweisbaren Blei-Gehalte in den Assimilationsorganen ermittelt werden. In den Laubbäumen auf den jeweils verbleibenden Flächen wurden vergleichsweise hohe Blei-Blattgehalte gemessen, die außer bei den Ebereschen höher als bei 90 \% der im Rahmen des Deutschen Waldbodenberichtes untersuchten Buchen (BMELF 1997b) lagen. Beide Nadelbaumarten wiesen auf Fläche A minimale, die Douglasien auf Fläche D normale Blei-Nadelgehalte auf.

Bei den Douglasien (Ausnahme: Fläche D) und den Erlen wurden Nickel-Gehalte gemessen, die oberhalb der Normalgehalte nach Smidt (1999) sowie innerhalb der kritischen Konzentrationen nach Alloway (1999) lagen. Die mit Abstand höchsten Nickel-Blattgehalte wiesen die Erlen auf den Flächen A und B auf.

Die in den Assimilationsorganen der Versuchspflanzen ermittelten Chrom-Gehalte lagen zumeist weit unterhalb der kritischen Konzentrationen nach Alloway (1999). Lediglich der in den Douglasien-Nadeln auf Fläche B gemessene, mit Abstand höchste Wert (sowie der Gehalt des Eichen-Laubs auf Fläche D, der knapp innerhalb dieser Spanne lag) fiel in diesen kritischen Bereich.

Bei der Analyse von Blatt- und Nadelspiegelwerten ist zu beachten, dass die Element-Gehalte zwischen zwei Aufnahmen teilweise stark schwanken können, wie auch der Vergleich der in beiden Untersuchungsjahren (2005 und 2006) auf Fläche D gemessenen Daten zeigte. So war etwa der Kobalt-Gehalt in 2006 bei allen Baumarten höher (meist noch unterhalb der Normalgehalte nach Smidt 1999). Gleiches galt für den Phosphor-Gehalt bei den Eichen, Erlen, Douglasien und Kiefern sowie den Chrom-Gehalt bei den Erlen und Douglasien. Bei den übrigen Element-Gehalten gab es baumartbedingt unterschiedliche Entwicklungen, wobei viele Gehalte im 2. Untersuchungsjahr im Schnitt geringer waren als im ersten.

In jedem Fall boten die nur im 1. Jahr auf allen drei Flächen durchgeführten Schadstoff-Analysen (gegenüber der Wiederholungsanalyse auf Fläche D im 2. Jahr wurden dabei weniger Elemente untersucht, s. S. 25) keine Erklärung für das bei allen Baumarten schlechtere Abschneiden auf Fläche A und das bessere Abschneiden auf Fläche B.

Dies lässt die Vermutung vergleichsweise höherer Belastungen mit Schwefel (höchster, wenngleich auch nicht signifikant unterschiedlicher Bodengehalt auf Fläche A) und/oder Mangan auf Fläche A zu (theoretisch ist auch die Belastung mit einem Element, das nicht Gegenstand der Analysen war, etwa einem gänzlich anderen Schwermetall, denkbar). 


\subsection{Einfluss des Standortes mit oder ohne Spontanvegetation}

Bei allen sechs Baumarten erhielt etwa ein Drittel der Versuchspflanzen zufällig einen Standort in den Bereichen der Flächen B und D, in denen sich im Versuchsverlauf spontan Bodenvegetation entwickelte. Diese Standorte sind vermutlich auf eine im Jahr 2000 erfolgte Kalkungsmaßnahme mit unregelmäßiger Verteilung des Düngekalks zurückzuführen. Sie zeichneten sich gegenüber den bis Versuchsabschluss vegetationsfrei gebliebenen Bereichen durch einen leicht höheren pH-Wert $(4,0$ im Vergleich zu 3,6) und eine in der Folge veränderte Austauscherbelegung mit höherer Basensättigung aus (s. ab S. 50). Bei den Pflanzen auf diesen Standorten ist deshalb von einer gegenüber den unbewachsenen Bereichen besseren Versorgung mit Calcium und Kalium sowie einer geringeren Belastung mit Eisen, Mangan und Aluminium auszugehen, was mit einer besseren Phosphor-Versorgung einhergehen dürfte (Aluminium- und Mangan-Toxizität hemmen die Phosphor-Aufnahme, s. ab S. 342). Zudem wurden in den bewachsenen Bereichen Mykorrhiza-Pilzfruchtkörper beobachtet, was zumindest dort das Vorhandensein potentieller Partner für diese für Bäume gerade auf schwierigen Standorten so vorteilhafte Symbiose nachweist.

Insgesamt hatte der Standort in Bereichen mit oder ohne Etablierung von Bodenvegetation bei allen sechs Baumarten deutlichen Einfluss auf die Vitalitäts- und Wachstumsentwicklung, wie auch die in Abb. 220 zusammengestellte, je nach Standort unterschiedliche Vitalität aller 6 Baumarten bei Versuchsabschluss verdeutlicht.

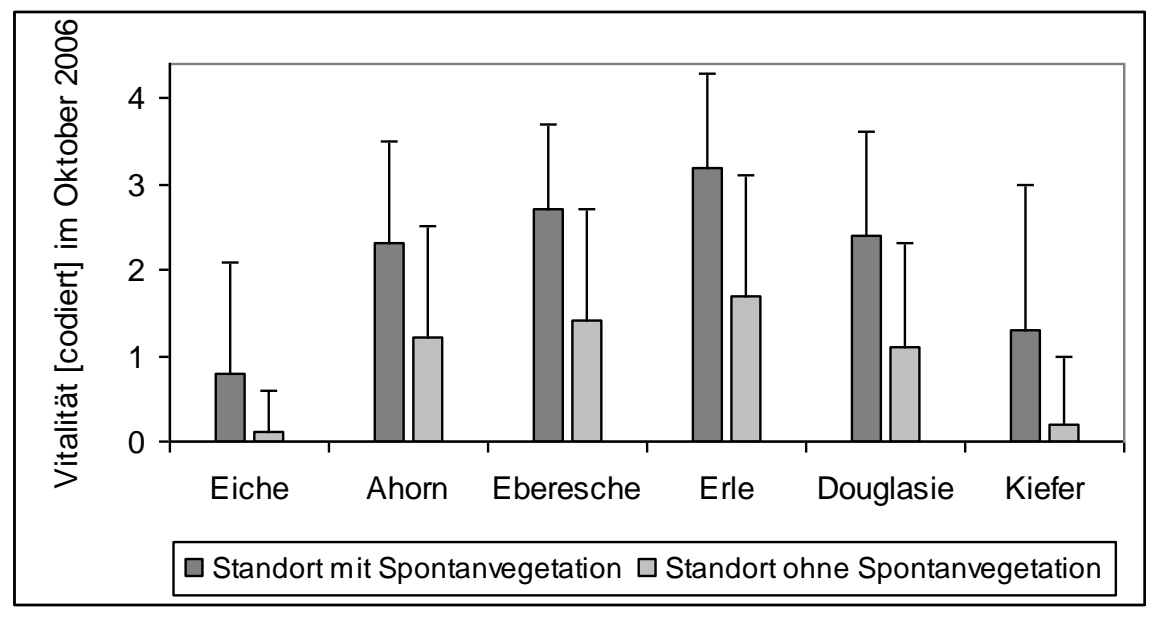

Abb. 220: Vitalität [codiert: $4=$ vital bis $0=$ tot, s. S. 27] der sechs Baumarten auf Standorten mit und ohne Spontanvegetation nach 2 Vegetationsjahren; MW u. Std.abw; jeweils signifikante Unterschiede nach UTests

\subsubsection{Standorteinfluss auf die Vitalität der Versuchspflanzen}

In bewachsenen Bereichen waren die Sterblichkeitsraten geringer und die durchschnittlichen Vitalitätswerte insgesamt zu jedem Aufnahmezeitpunkt signifikant besser (bei Eichen und Kiefern durch die hohen Ausfallraten auf geringem Niveau; s. Abb. 220).

So nahm bei allen sechs Baumarten die mittlere Vitalität auf unbewachsenen Standorten im Versuchsverlauf deutlich ab. In Bereichen mit Bodenbewuchs ging die Vitalität der Ahorne (bei Versuchsabschluss "2,3“ mit, „1,2“ ohne Spontanvegetation) und Douglasien (bei Versuchsabschluss „2,4“ mit, „1,1“ ohne Spontanvegetation) dagegen nur leicht zurück. Bei den 
durch hohe Ausfälle insgesamt sehr geringen Werten der Eichen (bei Versuchsabschluss „1,3“ mit, „0,2“ ohne Spontanvegetation) und Kiefern (bei Versuchsabschluss „0,8“ mit, „0,1“ ohne Spontanvegetation) waren in den bewachsenen Bereichen im Versuchsverlauf leichte Vitalitätsverbesserungen zu beobachten. Auf diesen Standorten nahm auch die Vitalität der insgesamt sehr guten Erlen nach dem Pflanzschock wieder zu (bei Versuchsabschluss „3,2“ mit, "1,7“ ohne Spontanvegetation). Bei den Ebereschen blieb die mittlere Vitalität in diesen besseren Bereichen im gesamten Versuchsverlauf durchgängig konstant (bei Versuchsabschluss „2,7“ mit, „1,4“ ohne Spontanvegetation).

\subsubsection{Standorteinfluss auf das Wachstum der Versuchspflanzen}

Bei vier der fünf untersuchten Baumarten (da die Eichen überwiegend oberirdisch abstarben, konnten sie nicht in die Untersuchungen zur Wachstumsentwicklung einbezogen werden) führte auch der Vergleich von Wachstumsparametern zu signifikant besseren Ergebnissen auf Standorten mit Bodenvegetation.

Insgesamt sowie in beiden Jahren einzeln lag der Zuwachs des Haupttriebs der Douglasien in den günstigeren Bereichen 65-88 \% über den Werten in den ungünstigeren Bereichen. Bei den 24 bei Versuchsabschluss noch lebenden Kiefern (davon lediglich 5 mit Standorten ohne Spontanvegetation) war der Gesamtzuwachs in den günstigeren Bereichen um 80 \% höher.

Bei den Ebereschen nahmen Seitentrieblängen und -trockenmassen auf bewachsenen Standorten 35-43 \% stärker zu. Der Haupttriebs-Zuwachs im 1. Jahr lag dort insgesamt 60 \% höher als, auf Fläche D sogar mehr als doppelt so hoch wie in unbewachsenen Bereichen.

Bei den Erlen bedeutete ein individueller Pflanzenstandort in den besser versorgten Bereichen je nach betrachteter Gruppe (Erlen insgesamt - Erlen auf Fläche B - Erlen auf Fläche D) höhere Haupttriebs-Zuwächse von 40-80 \% im 1. Jahr, 120-270 \% im 2. Jahr und 80-140\% gesamt, außerdem eine Erhöhung der Wurzelhalsdurchmesser um 20-40 \%, der Haupttriebs-Volumina und -Trockenmassen um 60-110 \%, der Länge und Trockenmassen der Seitentriebe um 60-70 \% und der gesamten oberirdischen Biomasse um $57 \%$.

Bei den Ahornen (durch die relativ hohe Ausfallrate sowie den starken Wildverbiss ohne Fläche A) war trotz höherer Vitalität auf bewachsenen Standorten interessanterweise ein umgekehrter Effekt der unterschiedlichen Standortbedingungen auf die Wachstumsentwicklung zu messen: Der Wurzelhalsdurchmesser und die (davon beeinflussten) Wachstumsparameter Volumen und Trockenmasse des Haupttriebs waren auf vegetationsfreien Standorten signifikant um etwa 10$20 \%$ höher als in Bereichen mit Bodenbewuchs. Bei den innerhalb der Mykorrhiza-Varianten geernteten Ahornen (s. S. 28) lag die Summe der Trockenmassen von Haupttrieb und Wurzel (= Gesamtbiomasse ohne die ohnehin kaum vorhandenen Seitentriebe) in unbewachsenen Bereichen um 60 \% über dem Wert auf bewachsenen Standorten.

Der Vergleich von Vitalitäts- und Wachstumsentwicklung der Baumarten je nach Standort mit oder ohne Spontanvegetation führte auch bei einzelner Betrachtung von Versuchsfläche B bzw. D überwiegend zu mit dem Gesamtbild übereinstimmenden Ergebnissen. Bei den Ahornen konnte auf Fläche B jedoch kein standortabhängiger Vitalitätsunterschied, auf Fläche D kein entsprechender Unterschied der Wachstumsentwicklung festgestellt werden. Gleiches galt für die Wachstumsentwicklung der Ebereschen auf Fläche B sowie der Douglasien auf Fläche D. 


\subsection{Rot-Eiche}

Im Freiland-Versuch wurden auf den drei Versuchsflächen A, B und D insgesamt 192 Eichen in 16 Versuchsvarianten gepflanzt (V1: Kontrolle, V3: Stockosorb®, V5: Superabsorber, V7: Perlit, V9: Kompost sowie V2, V4, V6, V8, V10 als Kombinationen mit Kalk-Düngung; V11-V16 als Kombinationen mit Mykorrhiza-Impfung; s. S. 20).

\section{Ausgangszustand}

Bei Versuchsbeginn wiesen die Eichen eine durchschnittliche Haupttrieblänge von $63 \mathrm{~cm}$ auf. Die mittlere Ausgangsvitalität war mit „2,3“ (codierter Vitalitätswert, s. S. 27) gegenüber den anderen Baumarten relativ gering (Ausnahme: Ahorn). Bald nach der Pflanzung war ein Großteil der Eichen oberirdisch abgestorben (schlechtes Pflanzenmaterial als eine Ursache).

\section{Wildschäden}

Gut ein Viertel der Eichen wurde im Versuchsverlauf durch Wild geschädigt.

\section{Ausfallrate}

Bei Versuchsende nach zwei Jahren waren $82 \%$ der Pflanzen ausgefallen, ein im Vergleich zu den anderen Baumarten (Ausnahme: Kiefer) relativ hoher Anteil. Die Ausfallrate war von Beginn an relativ hoch und stieg vom 1. zum 2. Untersuchungsjahr noch einmal deutlich an (von $35 \%$ und $46 \%$ in 2005 auf $75 \%$ und $82 \%$ in 2006).

\section{Vitalität insgesamt}

Durch die hohe Sterblichkeit und die geringe Zahl vitaler Pflanzen (Vitalitätswert von „3“ und "4") wiesen die Eichen insgesamt vergleichsweise sehr geringe Vitalitätswerte auf (Abnahme von anfänglich „2,3“ auf Werte unter „1“ im weiteren Versuchsverlauf). Die mittleren Vitalitätswerte der lebenden Eichen lagen jeweils im Juni und Oktober 2005 bzw. 2006 bei „1“; "1,4“; „1,8“ und „2,3“ und erholten sich damit von sehr geringen auf mäßige Werte.

\section{Wachstum insgesamt}

Zuwachsuntersuchungen konnten bei den Eichen generell nicht durchgeführt werden, da bei den wenigen überlebenden Pflanzen oftmals zumindest der Haupttrieb abstarb.

\section{Standorteinfluss insgesamt}

Bei Versuchsabschluss nach 2 Jahren lag die durchschnittliche Vitalität der Eichen auf Fläche A bei „0,1“, auf Fläche B bei „0,5“ und auf Fläche D bei „0,7“. In vegetationsfreien Bereichen (pH 3,6) betrug der Mittelwert "0,1“, in Bereichen, in denen Bodenbewuchs stattfand ( $\mathrm{pH} 4,0)$, „0,8“.

\subsubsection{Unbehandelte Kontrollen}

\section{Ernährung und Belastung der Kontrollen}

Unter unbeeinflussten Bedingungen (Kontrolle, Nullvariante V1) bestanden bei den Eichen auf Fläche D Defizite in der Versorgung mit wichtigen Nährstoffen (Stickstoff, Phosphor, Mangan) sowie eine vielfältige Belastungssituation (Schwefel, Eisen, Kupfer, Aluminium).

Der niedrige Stickstoff-Gehalt war auf die geringen Bodengehalte zurückzuführen, während der trotz ausreichender Bodengehalte geringe Phosphor-Blattgehalt laut Bergmann (1993) auf 
Aluminium-Toxizität hinwies. Der Mangan-Gehalt war im Vergleich mit den Kontrollen anderer Baumarten sowie mit den Behandlungsvarianten der Eichen auffallend gering.

Die Kalium-, Calcium-, Zink- und Natrium-Gehalte lagen dagegen im ausreichenden bzw. optimalen, teilweise auch überversorgten Bereich (Zn, Na).

Die Blattgehalte an Magnesium, Schwefel, Eisen, Kupfer und Aluminium waren unterschiedlich deutlich (teilweise extrem) überhöht.

Dabei spiegelte der Magnesium-Gehalt den sehr hohen Anteil der Magnesium-Ionen an der Austauscherbelegung im Boden wider. Der Kupfer-Gehalt lag bereits im kritischen Bereich nach Alloway (1999). Der Aluminium-Gehalt überschritt eine Überversorgung um das 36-fache, der Eisen-Gehalt eine Extremversorgung um das 8-fache. Die ebenfalls mehr als extreme SchwefelKonzentration spiegelte die hohen Schwefel-Bodengehalte wider und erreichte toxisches Niveau. Sie lag damit etwa bei dem Doppelten der im Rahmen des Deutschen Waldbodenberichtes in Buchenblättern gemessenen Maxima, während die exorbitant hohen Eisen- und AluminiumGehalte diese jeweiligen Maxima um ein Vielfaches übertrafen.

Der Chrom-Gehalt in den Blättern der Kontroll-Eichen lag knapp innerhalb des kritischen Bereichs nach Alloway (1999), während die Nickel- und Kobalt-Gehalte unauffällig waren (unter- bzw. innerhalb der Normalgehalte nach Smidt 1999). Die Blätter der unbehandelten Eichen enthielten zudem keine nachweisbaren Blei- oder Cadmium-Gehalte.

Von allen sechs Baumarten wiesen die unbehandelten Eichen die höchsten Eisen-, Aluminium-, Kobalt- und Chrom-Gehalte sowie die niedrigsten Mangan-Gehalte (mit weitem Abstand) und (gemeinsam mit den Douglasien) Nickel-Gehalte in ihren Assimilationsorganen auf.

\section{Vitalität der Kontrollen}

Die mittlere Vitalität der unbehandelten Eichen sank direkt nach der Versuchsanlage auf knapp über „0“, was mehr oder weniger einem Komplettausfall entspricht.

$\mathrm{Zu}$ keinem Zeitpunkt bestanden signifikante Vitalitätsunterschiede zwischen den 12 unbehandelten Kontrollpflanzen und den Gesamtmittelwerten aller 192 Eichen.

Gegenüber den Nullvarianten der anderen Baumarten (mit Ausnahme der Kiefern im Oktober 2005) war die Vitalität im gesamten Versuchsverlauf signifikant geringer (bei der letzten Aufnahme im Oktober 2006 bestanden keine signifikanten Vitalitätsunterschiede zwischen den Kontrollen der sechs Baumarten mehr).

\section{Wachstum der Kontrollen}

Zuwachsuntersuchungen konnten bei den Eichen generell nicht durchgeführt werden, da bei den wenigen überlebenden Pflanzen oftmals zumindest der Haupttrieb abstarb.

\section{Standorteinfluss auf die Kontrollen}

Auf den Flächen A und D befand sich die Nullvariante zufällig auf Standorten ohne Spontanvegetation, auf Fläche B in einem Bereich mit Spontanvegetation. Dieser individuelle Pflanzenstandort führte bei den Eichen jedoch nicht $\mathrm{zu}$ signifikanten Unterschieden der insgesamt geringen Vitalität. 


\subsubsection{Effekte der Behandlungsvarianten}

Bei sehr geringen Vitalitätswerten bestanden bei den Eichen insgesamt keine signifikanten Vitalitätsunterschiede zwischen den verschiedenen Bodenhilfsstoff-Varianten. Es konnte jedoch ein positiver Effekt der Beigabe von Mykorrhiza-Inokulum auf den Austrieb (in den entsprechenden Varianten trieben deutlich mehr Pflanzen überhaupt aus) sowie den Neuaustrieb nach Absterben des Haupttriebs beobachtet werden. Die Mykorrhizierungsraten lagen in allen Mykorrhiza-Varianten im Freiland-Versuch zwischen „2,0“ (mittlerer Mykorrhizierungsgrad, s. S. 28) und „3,0“ (hoher Mykorrhizierungsgrad).

Die Blätter der Eichen in den Mykorrhiza-Varianten wiesen gegenüber der unbehandelten Kontrolle geringere Kupfer-, Aluminium- und Eisen-Gehalte, teilweise auch geringere Schwefel-Gehalte sowie geringere Natrium- und Chrom-Gehalte auf. Die Kupfer-Gehalte waren in Kombination mit Kalk (V12), Stockosorb® (V13) oder beidem (V14) nur noch als ausreichend, die Eisen-Gehalte in V13 und V14 nur noch als überversorgt und der SchwefelGehalt in V14 nur noch als optimal zu bewerten. Auch die Aluminium-Gehalte waren in den beiden Kombinationen mit Stockosorb ${ }^{\circledR}$ am geringsten, lagen aber weiterhin oberhalb einer Überversorgung.

Zusätzlich zur geringeren Schadstoffbelastung wurden in den Mykorrhiza-Varianten überwiegend höhere (ausreichende) Stickstoff-Gehalte, teilweise auch höhere Phosphor-, Kalium- und Calcium-Gehalte sowie geringere Magnesium-Gehalte gemessen.

Dabei wurden mit Mykorrhiza-Impfung ohne weitere Bodenhilfsstoff-Behandlung (V11) die höchsten Stickstoff-, Phosphor- und Kalium-Gehalte sowie der geringste Magnesium-Gehalt ermittelt. V11 und die Kombination Mykorrhiza-Stockosorb ${ }^{\circledR}$ (V13) waren die einzigen Varianten, in denen das Eichen-Laub bei keinem Nährelement Defizite aufwies. Die hier optimale Phosphor-Versorgung deutet nach Bergmann (1993) darauf hin, dass keine Aluminium-Toxizität bestand.

Insgesamt konnte bei den Eichen mit Mykorrhiza-Impfung eine gegenüber der Nullvariante bessere Ernährungs- und Belastungssituation festgestellt werden, wobei dies in Kombination mit Superabsorber (V15 ohne, V16 mit zusätzlicher Kalk-Gabe) weniger deutlich war.

\subsection{Spitz-Ahorn}

Im Freiland-Versuch wurden auf den drei Versuchsflächen A, B und D insgesamt 192 Ahorne in 16 Versuchsvarianten gepflanzt (V1: Kontrolle, V3: Stockosorb®, V5: Superabsorber, V7: Perlit, V9: Kompost sowie V2, V4, V6, V8, V10 als Kombinationen mit Kalk-Düngung; V11-V16 als Kombinationen mit Mykorrhiza-Impfung; s. S. 20).

\section{Ausgangszustand}

Bei Versuchsbeginn wiesen die Ahorne eine durchschnittliche Haupttrieblänge von $26 \mathrm{~cm}$ (für das bestellte Sortiment von 60-100 cm deutlich zu klein) und einen gegenüber den anderen Baumarten (Ausnahme: Eiche) relativ geringen durchschnittlichen Vitalitätswert von „2,5“ auf. 


\section{Wildschäden}

Insgesamt waren im Versuchsverlauf $41 \%$ der Ahorne von Wildschäden betroffen (vor allem auf Fläche A), deutlich mehr als bei den anderen fünf Baumarten.

\section{Ausfallrate}

Bei Versuchsende nach zwei Jahren waren $35 \%$ der Pflanzen ausgefallen (+ $10 \%$ absterbend). Die Ausfallrate stieg vom 1. zum 2. Untersuchungsjahr deutlich an (von $2 \%$ und $8 \%$ in 2005 auf $30 \%$ und 35 \% in 2006; im Topf-Versuch im Gewächshaus mit 37 \% ähnliche Ausfallrate).

\section{Vitalität insgesamt}

Die Ahorne insgesamt wiesen im Versuchsverlauf vergleichsweise mäßig bis geringe Vitalitätswerte auf $(2,5 \pm 0,6>2,3 \pm 0,9>1,9 \pm 1,1>1,7 \pm 1,3>1,6 \pm 1,4)$. Die mittleren Vitalitätswerte der lebenden Ahorne lagen jeweils bei $2,4 \pm 0,9 ; 2,1 \pm 1,0 ; 2,5 \pm 0,8$ und 2,5 $\pm 0,9$.

\section{Wachstum insgesamt}

Der Gesamtzuwachs des Haupttriebs der überlebenden, nicht durch Wild geschädigten Ahorne nach 2 Jahren betrug im Mittel $6 \mathrm{~cm}$. Die Messergebnisse der weiteren aufgenommenen Wachstumsparameter sind der Übersichtlichkeit halber in Tab. 119 aufgeführt.

\section{Standorteinfluss insgesamt}

Bei Versuchsabschluss nach 2 Jahren lag die durchschnittliche Vitalität der Ahorne auf Fläche A bei „0,6“, auf den Flächen B und D jeweils bei „2,1“. In vegetationsfreien Bereichen (pH 3,6) betrug der Mittelwert „1,2“ und in Bereichen, in denen Bodenbewuchs stattfand (pH 4,0), lag er bei „2,3“. Im völligen Gegensatz zu den Ergebnissen der übrigen Baumarten zeigten die Ahorne auf den ungünstigeren Standorten $10 \%$ - 20 \% höhere Wurzelhalsdurchmesser, HaupttriebsVolumina und -trockenmassen sowie bei der innerhalb der Mykorrhiza-Varianten geernteten Stichprobe (s. S. 28) 60 \% höhere oberirdische Biomassen als in besser versorgten Bereichen.

\subsubsection{Unbehandelte Kontrollen}

\section{Ernährung und Belastung der Kontrollen}

Ohne Bodenhilfsstoffbehandlung (Kontrolle, Nullvariante V1) bestanden bei den Ahornen auf Fläche D Defizite in der Versorgung mit wichtigen Nährstoffen (Stickstoff, Phosphor, Kalium, Calcium) sowie eine vielfältige Belastungssituation (Schwefel, Eisen, Kupfer, Aluminium). Der trotz ausreichender Bodengehalte geringe Phosphor-Blattgehalt wies laut Bergmann (1993) auf Aluminium-Toxizität hin.

Die Blattgehalte an Magnesium, Schwefel, Eisen, Mangan, Kupfer, Aluminium und Natrium waren unterschiedlich deutlich (teilweise extrem) überhöht.

Sowohl der Magnesium-Gehalt als auch die Schwefel-Konzentration spiegelten die Bodenbedingungen (sehr hoher Anteil der Magnesium-Ionen an der Austauscherbelegung, hohe Schwefel-Gehalte) wider. Der Schwefel-Gehalte lag dabei mehr als doppelt so hoch wie der Grenzwert, ab dem laut van den Burg (1985, 1990) Toxizitätssymptome oder Wachstumsrückgang festgestellt wurden oder möglich sind, was das sehr geringe Wachstum der Ahorne erklären könnte. Ebenfalls exorbitant hoch waren sowohl der Aluminium-Gehalt, der eine Überversorgung um das 20-fache überschritt, als auch der Eisen-Gehalt, der 6-mal so hoch wie die Obergrenze ausreichender Normalgehalte lag. Der Kupfer-Gehalt lag im kritischen 
Bereich nach Alloway (1999). Der Natrium-Gehalt lag oberhalb von als extrem eingestuften Konzentrationen. Der Mangan-Gehalt überstieg die ausreichenden Normalgehalte deutlich, wobei diese Literaturwerte kritisch zu betrachten sind (s. ab S. 333). Die Magnesium-, Schwefel-, Eisen- und Aluminium-Gehalte lagen erheblich oberhalb der entsprechenden im Rahmen des Deutschen Waldbodenberichtes in Buchenblättern gemessenen Maximalwerte. Von allen sechs Baumarten wiesen die unbehandelten Ahorne den höchsten Schwefel-Gehalt (gemeinsam mit den Kiefern) sowie den höchsten Natrium-Gehalt in ihren Assimilationsorganen auf.

Die Zink-, Nickel-, Kobalt- und Chrom-Gehalte waren dagegen unauffällig. Die Blätter der unbehandelten Ahorne enthielten zudem keine nachweisbaren Blei- oder Cadmium-Gehalte.

\section{Vitalität der Kontrollen}

Die mittlere Vitalität der unbehandelten Ahorne ging erst zum 2. Vegetationsjahr (2006) deutlich von Werten um „2“ auf unter „1“ zurück (Gründe: Ausfall der in 2005 gerade noch lebenden Pflanzen, außerdem keine hohen Vitalitätsbewertungen mehr in 2006). Im 2. Versuchsjahr war die Vitalität der Nullvariante signifikant geringer als der Gesamtschnitt aller 192 Ahorne. Zu den Kontrollen der anderen Baumarten bestanden im gesamten Versuchsverlauf kaum signifikante Vitalitätsunterschiede. Ausnahmen waren die stets geringeren Werte der sehr schwachen unbehandelten Eichen sowie der bessere Wert der unbehandelten Erlen im Juni 2006. Bis Versuchsabschluss waren 58 \% der unbehandelten Ahorne abgestorben, wobei die Kontrolle auf Fläche A komplett ausfiel.

\section{Wachstum der Kontrollen}

Der Gesamtzuwachs des Haupttriebs der überlebenden, nicht durch Wild geschädigten KontrollAhorne nach 2 Jahren betrug im Mittel nur $2 \mathrm{~cm}$. Die Messergebnisse der aufgenommenen Wachstumsparameter sind der Übersichtlichkeit halber in Tab. 119 aufgeführt. Die verschiedenen Wachstumswerte der Kontrollen waren relativ gering. Im 2. Jahr (2006) war kein Zuwachs der Haupttriebe mehr zu verzeichnen. Entsprechend war auch der Gesamtzuwachs signifikant geringer als im Gesamtdurchschnitt aller Ahorne. Bei den übrigen Wachstumsparametern bestanden dagegen keine signifikanten Unterschiede zwischen der unbehandelten Kontrolle und dem Gesamtdurchschnitt (die Baumart wies insgesamt nur geringes Wachstum auf).

Tab. 119: Messergebnisse der verschiedenen Wachstumsparameter der unbehandelten Ahorne sowie aller Ahorne im Versuchsverlauf; MW u. Std.abw.; Fettdruck markiert signifikant geringere Werte als im Gesamtdurchschnitt (siehe auch Tab. A 14 und A 15)

\begin{tabular}{|l|l|l|}
\hline Wachstumsparameter & Kontrolle & gesamt \\
\hline Zuwachs Haupttrieb 2005 [cm] & $2 \pm 3$ & $2 \pm 3$ \\
\hline Zuwachs Haupttrieb 2005 red.* $[\mathrm{cm}]$ & $2 \pm 2$ & $2 \pm 3$ \\
\hline Zuwachs Haupttrieb 2006 [cm] & $\mathbf{0}$ & $4 \pm 5$ \\
\hline Zuwachs Haupttrieb gesamt [cm] & $\mathbf{2} \pm \mathbf{2}$ & $6 \pm 7$ \\
\hline Durchmesser Wurzelhals** [mm] & $5 \pm 1$ & $6 \pm 2$ \\
\hline Volumen Haupttrieb $^{* *}\left[\mathrm{~cm}^{3}\right]$ & $4 \pm 2$ & $6 \pm 4$ \\
\hline TM Haupttrieb errechnet $^{* *}[\mathrm{~g}]$ & $5 \pm 3$ & $7 \pm 5$ \\
\hline
\end{tabular}

* reduziert auf die Gruppe der auch noch in 2006 lebenden, nicht (durch Wild) geschädigten Ahorne

** bei Versuchsabschluss nach 2 Jahren (Oktober 2006) 


\section{Standorteinfluss auf die Kontrollen}

Auf den Flächen A und D befand sich die Nullvariante zufällig auf Standorten ohne Spontanvegetation, auf Fläche B in einem Bereich mit Spontanvegetation. Dieser individuelle Pflanzenstandort hatte Einfluss auf die Vitalitätsentwicklung der unbehandelten Ahorne, nicht jedoch auf die (insgesamt recht geringe) Wachstumsentwicklung.

Bei Versuchsabschluss betrug die mittlere Vitalität der Kontroll-Ahorne in vegetationsfreien Bereichen „0,5“ (Fläche A: Totalausfall der Kontrolle im Versuchsverlauf; Fläche D: „1“). In günstigeren Bereichen, in denen sich auch Spontanvegetation entwickeln konnte (Fläche B), war die Vitalität zum Ende der 2. Vegetationszeit mit „1” ebenfalls niedrig. Der geringe Zuwachs der Kontroll-Ahorne war vom individuellen Pflanzenstandort unabhängig.

\subsubsection{Effekte der Behandlungsvarianten}

Insgesamt sowie beschränkt auf Fläche D und auf Standorte ohne Entwicklung von Spontanvegetation bestanden bei den Ahornen in beiden Versuchsjahren signifikante Vitalitätsunterschiede zwischen verschiedenen Varianten.

Auf Fläche A (schlechteste Standortbedingungen) wurden nur relativ zu Versuchsbeginn signifikante Vitalitätsunterschiede festgestellt (im weiteren Versuchsverlauf variantenübergreifend nur noch sehr geringe Werte).

Auf Fläche B sowie auf Standorten mit Entwicklung von Bodenbewuchs (günstigere Bedingungen) kamen dagegen erst im 2. Vegetationsjahr Behandlungseffekte zum Tragen (zuvor variantenübergreifend vergleichsweise hohe Vitalitätswerte). Im Vergleich zu anderen Baumarten wurden bei den Ahornen auf Fläche B Effekte der Behandlungsvarianten weniger durch den Einfluss der hier besonders ausgeprägten kleinräumigen Standortheterogenität verzerrt.

Bei der Juni-Aufnahme des heißen, trockenen Sommers 2006 konnten auf allen Standorten (ausgenommen auf Fläche A) Behandlungseinflüsse auf die Vitalität der Ahorne festgestellt werden.

Bei Versuchsabschluss nach zwei Jahren im Oktober 2006 waren dagegen nur auf Fläche B (vergleichsweise beste Standortbedingungen) noch Effekte von Bodenhilfsstoffen nachweisbar.

Unabhängig vom Standort waren es im 1. Vegetationsjahr Mykorrhiza-Impfungen und KalkGaben, im 2. Jahr weitere Mykorrhiza- und Kalk-Varianten sowie Kompost-Gaben, die zu gegenüber der Kontrolle signifikant besseren Vitalitätsbewertungen führten.

Bodenhilfsstoffe zur Verbesserung der physikalischen Bodeneigenschaften: Perlit, Wasserspeichersubstanzen

Perlit (V7) oder Stockosorb® (V3) allein hatten keinen Effekt auf die Vitalitätsentwicklung der Ahorne. Die Pflanzung mit Superabsorber allein (V5) hatte entweder ebenfalls keine oder aber eine negative Wirkung. Nur in dieser Variante war der mittlere Vitalitätswert bereits wenige Wochen nach Versuchsbeginn signifikant abgesunken. Sowohl insgesamt als auch auf Standorten ohne Spontanvegetation sowie auf Fläche D war im 1. Untersuchungsjahr die 
Vitalität der Ahorne in dieser Variante signifikant geringer als in der unbehandelten Kontrolle. Im 2. Versuchsjahr galt dies auch für die Ahorne mit Standorten in bewachsenen Bereichen, während in unbewachsenen Bereichen sowie auf den Flächen A und D sämtliche mit Superabsorber gepflanzten Ahorne ausfielen.

Eine wie auch bei anderen Baumarten festgestellte, vergleichsweise hohe Schadstoff-Belastung der Ahorne in dieser Variante kann nur vermutet werden, da aufgrund der starken Ausfälle keine Probennahme zur chemischen Analyse der Blattgehalte möglich war.

Auf allen Standorten (ausgenommen Versuchsfläche B) war die Wirkung der Kalk-Gabe in Kombination mit Perlit (V8) vermindert. Auf Fläche B wurden dagegen mit dieser Kombination im 2. Vegetationsjahr im Vergleich zur Kontrolle signifikant höhere Vitalitätswerte (bei Versuchsabschluss V8: „2,8“, V1: „1“) sowie Wurzelhalsdurchmesser (V8: 6,6 mm, V1: 5 mm) ermittelt. Es ist nicht auszuschließen, dass hier auch die bei der Baumart Ahorn weniger ausgeprägten, aber dennoch vorhandenen Standorteinflüsse auf Fläche B eine Rolle spielten.

Auch Superabsorber konnte die Wirkung von Kalk nicht verstärken bzw. verzögerte oder verminderte sie, indem positve Effekte durch Kalk in Kombination mit Superabsorber (V6, V16) erst zu einem späteren Zeitpunkt oder gar nicht nachweisbar waren.

Eine Kombination mit Stockosorb® beeinflusste die Wirkung der Kalk-Gabe überwiegend nicht. Auf ungünstigeren, vegetationsfreien Standorten wurde durch diese Kombination jedoch ein positiver Effekt erreicht. Die Vitalität der Ahorne war hier im 2. Sommer mit „2,3“ signifikant höher als bei einzelner, jeweils wirkungsloser Anwendung von Kalk (V2: „1,3“) oder Stockosorb® (V3: „0,6“). Im Gegensatz dazu war auf günstigeren, bewachsenen Standorten die eigentlich positive Wirkung der Kalk-Gabe mit Stockosorb ${ }^{\circledR}$ nicht mehr nachweisbar.

Die mit Stockosorb® (V3), Superabsorber und Kalk (V6) sowie Perlit und Kalk (V8) gepflanzten Ahorne zeigten außerordentlich hohe Mangan-Blattgehalte, die zwischen 2600 und $3000 \mathrm{mg} / \mathrm{g}$ und damit etwa 4-mal so hoch wie in der unbehandelten Kontrolle lagen. Im Ahorn-Laub der Perlit-Kalk-Variante (V8) wurde zudem der deutlich höchste Schwefel-Gehalt gemessen, der mit 7,9 mg/g mehr als das Doppelte des Grenzwertes zu toxischen Gehalten betrug (van den Burg 1985, 1990).

Die Kombination von Mykorrhiza-Impfungen mit Wasserspeichersubstanzen führte je nach Standort zu sehr unterschiedlichen Ergebnissen. Stockosorb® (V13) bzw. Superabsorber (V15) konnten auf den Flächen A und B den Effekt der Zugabe von Mykorrhiza-Pilzen, der allein (V11) nicht signifikant war, verstärken. Im Gegensatz dazu verschlechterte auf Fläche D die Kombination mit Stockosorb® (V13) den dort sehr guten Effekt von Mykorrhiza-Pilzen allein (V11). In vegetationsfreien Bereichen war die positive Wirkung der Kombination aus Mykorrhiza und Kalk mit Superabsorber (V16) verzögert, in bewachsenen Bereichen (im Versuchsverlauf auch auf Fläche D) vermindert. Gleichzeitig hatte jedoch in bewachsenen Bereichen die Kombination aus Superabsorber und Mykorrhiza ohne Kalk-Gabe (V15) einen positiven Effekt auf Vitalität und Wurzelhalsdurchmesser der Ahorne.

Bodenhilfsstoffe zur Verbesserung der chemischen Bodeneigenschaften: Kalk Abgesehen von den kalkfreien Mykorrhiza-Varianten hatten ausschließlich pH-Wert-erhöhende Behandlungen, vor allem die Kalk-Gaben, positive Effekte auf die Entwicklung der Ahorne. So 
wurde in den Varianten mit Kalk-Gabe im Gegensatz zur Kontrolle im Versuchsverlauf kein signifikanter Vitalitätsrückgang festgestellt.

Die Kalk-Gaben spielten bei dieser Baumart sowohl auf den ungünstigeren, vegetationsfreien als auch auf den günstigeren, mit Spontanvegetation besiedelten Standorten eine Rolle. In ungünstigeren Bereichen war der positive Kalkungs-Effekt teils erst in Kombination mit Stockosorb® nachweisbar, in günstigeren Bereichen wurde er durch diese Kombination teils vermindert. Die Kombination mit Perlit verminderte, mit Superabsorber verminderte oder verzögerte teilweise die Wirkung der Kalk-Gabe.

Insgesamt, bei den Ahornen mit Standort in bewachsenen Bereichen sowie auf Fläche B - also vor allem unter vergleichsweise günstigeren Bodenbedingungen - wurden in den Kalk- und Kompost-Varianten signifikant höhere Wurzelhalsdurchmesser von rund $7 \mathrm{~mm}$ (Kontrollen: 5 $\mathrm{mm}$ ) festgestellt. Bei den übrigen aufgenommenen Wachstumsparametern bestanden keine signifikanten Unterschiede je nach Variante (generell relativ geringes Wachstum bei dieser Baumart).

Im Topf-Versuch konnte bei den mit Kalk gedüngten Ahornen eine gleichmäßige Durchwurzelung beobachtet werden, während die Wurzeln in allen übrigen Varianten an die Topfinnenwand auswichen und selbst eine Topfform bzw. einen umgedrehten „Lampenschirm“ (s. Abb. 218, S. 290f) bildeten.

Bodenhilfsstoffe zur Verbesserung der physikalischen und chemischen Bodeneigenschaften: Kompost

Insgesamt wurde in den Ahorn-Varianten mit Kompost-Gabe im Gegensatz zur Kontrolle im Versuchsverlauf kein signifikanter Vitalitätsrückgang festgestellt.

Die Kompost-Gaben allein blieben jedoch auf den ungünstigeren Standorten (vegetationsfreie Bereiche, Fläche A, in diesem Fall auch Fläche D) ohne Wirkung. In Bereichen ohne Bodenbewuchs wurde die Wirkung von Kalk durch Kompost im Versuchsverlauf verbessert, auf der ebenfalls vegetationsfreien Fläche A dagegen vermindert.

Unter vergleichsweise besseren Standortbedingungen (Bereiche mit Spontanvegetation, Fläche B) verbesserten Kompost-Gaben dagegen die Vitalität der Ahorne, die zum Versuchsabschluss am Ende der 2. Vegetationszeit auf Fläche B bei guten „3,3“ (V9, ohne zusätzliche Kalk-Gabe) bzw. „3,5“ (V10, mit zusätzlicher Kalk-Gabe) lag (Kontrolle dort zu dem Zeitpunkt: „1“). Die Wurzelhalsdurchmesser der Ahorne auf günstigeren Standorten bzw. auf Fläche B wurden bei einer kombinierten Behandlung aus Kompost und Kalk am deutlichsten gegenüber der Kontrolle erhöht.

Im Topf-Versuch konnte bei den mit Kompost gedüngten Ahornen ebenso wie mit Kalk-Gaben eine gleichmäßige Durchwurzelung beobachtet werden.

Die Blattanalysen zeigten sowohl bei den mit Kalk als auch bei den mit Kompost gedüngten Ahornen teilweise verglichen mit der Kontrolle höhere Nährstoff- und geringere SchadstoffGehalte, wobei die Bewertung der Schadstoff-Belastung sich jedoch nicht änderte (Ausnahme: nur noch ausreichender Kupfer-Gehalt mit Kompost-Düngung). Eindeutige Gemeinsamkeiten dieser Varianten bei einzelnen Elementen, die sie klar von den kalk- und kompostfreien 
Varianten unterschieden und die bessere Vitalitäts- und Wachstumsentwicklung anhand eines bestimmten Effektes erklärt hätten, waren nicht auszumachen.

Bodenhilfsstoff zur Verbesserung der biologischen Bodeneigenschaften: MykorrhizaInokulum

In sämtlichen (auch den kalkfreien) Mykorrhiza-Varianten wurde (im Gegensatz zur Kontrolle und den übrigen kalkfreien Varianten) im Versuchsverlauf kein signifikanter Vitalitätsrückgang festgestellt.

Auf allen Standorten konnten Mykorrhiza-Impfungen die Vitalität der Ahorne erhöhen, auf den günstigeren Standorten teilweise auch die Wurzelhalsdurchmesser $7 \mathrm{~mm}$ gegenüber $5 \mathrm{~mm}$ in der Kontrolle). Auf Fläche D, zum Ende des Versuchs auch auf Fläche B war dies ohne weitere Bodenhilfsstoffe, auf den übrigen Standorten erst in Kombination mit Wasserspeichersubstanzen und/oder Kalk der Fall. Dabei wurden auf vegetationsfreien, ungünstigeren Standorten insgesamt nur mit Kalk bessere Ergebnisse erzielt. Auf allen anderen Standorten, auch auf der ebenfalls vegetationsfreien, vergleichsweise schlechtesten Fläche A, konnten auch kalkfreie Mykorrhiza-Kombinationen die Vitalität verbessern. Dass mit den Varianten V13 und V15 selbst kalkfreie Behandlungskombinationen zu gegenüber der Kontrolle signifikant besseren Vitalitätswerten führten, ist angesichts der sehr stark versauerten Bodenverhältnisse (s. S. 44) bemerkenswert. Diese Ergebnisse belegen, dass trotz der niedrigen Bodenreaktion Mykorrhiza-Impfungen auch ohne pH-Wert-Anhebung die Wuchsbedingungen der Ahorne verbessern können.

Bei Versuchsabschluss lag auf Fläche B die Vitalität der Ahorne in den kalkfreien MykorrhizaVarianten zwischen „2,3“ und “2,8“, mit der Kombination aus Mykorrhiza, Stockosorb® und Kalk (V14) wurden „3,0“ erreicht, während die Kontrolle auf „1“ abgesunken war.

Die Blattanalyse der mit Mykorrhiza-Inokulum gepflanzten Ahorne wies überwiegend gegenüber der Nullvariante deutlich geringere Magnesium-, Schwefel-, Eisen-, Kupfer-, Aluminium-, Natrium- (gegenüber der Kontrolle waren die Natrium-Gehalte in sämtlichen Behandlungsvarianten erheblich geringer), Nickel-, Kobalt- und Chrom-Gehalte nach. Dabei wurden teilweise bei den Schwefel- und Kupfer-Gehalten nur noch ausreichende (S: V12, V13; $\mathrm{Cu}:$ V12-15) Gehalte gemessen. Die Aluminium-Gehalte waren dagegen nach wie vor als vielfach über ausreichend einzustufen. Die Ernährungssituation verbesserte sich etwas durch je nach Variante höhere, als ausreichend bewertete Stickstoff- (V11, V12), Phosphor- (V14-16; hier also keine Aluminium-Toxizität zu erwarten), Calcium- (V12-V14) und Kalium-Gehalte (V11; deutlich höchster Wert aller Varianten) bei gleichzeitig niedrigeren, nur noch ausreichenden Magnesium-Gehalten.

\subsection{Eberesche}

Im Freiland-Versuch wurden auf den drei Versuchsflächen A, B und D insgesamt 120 Ebereschen in zehn Versuchsvarianten gepflanzt (V1: Kontrolle, V3: Stockosorb®, V5: Superabsorber, V7: Perlit, V9: Kompost sowie V2, V4, V6, V8, V10 als Kombinationen mit Kalk-Düngung; s. S. 20). 


\section{Ausgangszustand}

Bei Versuchsbeginn wiesen die Ebereschen eine durchschnittliche Haupttrieblänge von $73 \mathrm{~cm}$ und einen mittleren Vitalitätswert von „3“ (relativ gut entwickelt mit geringen Einschränkungen, s. S. 27) auf.

\section{Wildschäden}

Ein Viertel der Ebereschen wurde im Versuchsverlauf durch Wild geschädigt.

\section{Ausfallrate}

Bei Versuchsende nach zwei Jahren waren $29 \%$ der Pflanzen ausgefallen (+ $5 \%$ absterbend), ein im Vergleich zu den anderen Baumarten (Ausnahme: Erle) relativ geringer Anteil. Die Ausfallrate stieg im Versuchsverlauf von 2,5 \% im Juni 2005 über $17 \%$ und $25 \%$ auf $29 \%$ im Oktober 2006 (im Topf-Versuch im Gewächshaus vermutlich aufgrund fehlender Wildschäden, regelmäßiger Bewässerung deutlich geringere Ausfallrate von nur 2,5 \%).

\section{Vitalität insgesamt}

Die Ebereschen insgesamt wiesen im Versuchsverlauf recht mäßige Vitalitätswerte von um „2" auf $(3,0 \pm 0,4>2,2 \pm 0,9 ; 2,1 \pm 1,3 ; 2,0 \pm 1,3>1,9 \pm 1,3)$. Die durchschnittliche Vitalität der lebenden Exemplare lag von Juni 2005 bis Oktober 2006 zwischen 2,2 und 2,6 (2,2 \pm 0,8; 2,5 \pm 0,$9 ; 2,6 \pm 0,6$ und $2,6 \pm 0,7$ ).

\section{Wachstum insgesamt}

Der Gesamtzuwachs des Haupttriebs der überlebenden, nicht durch Wild geschädigten Ebereschen nach 2 Jahren betrug im Mittel $17 \mathrm{~cm}$. Die Messergebnisse der weiteren aufgenommenen Wachstumsparameter sind der Übersichtlichkeit halber in Tab. 120 aufgeführt.

\section{Standorteinfluss insgesamt}

Bei Versuchsabschluss nach 2 Jahren lag die durchschnittliche Vitalität der Ebereschen auf Fläche A bei „1,3“ und auf Fläche B und D jeweils bei „2,2“. In vegetationsfreien Bereichen (pH 3,6) betrug der Mittelwert „1,4“ und in Bereichen, in denen Bodenbewuchs stattfand (pH 4,0), lag er bei „2,7“. Auf diesen günstigeren Standorten lag auch der Zuwachs zumindest im 1. Jahr höher (um $60 \%$ ). Auch die Entwicklung der Seitentriebe war hier besser als auf den ungünstigeren Standorten (insgesamt $35 \%$ mehr Länge und Trockenmasse).

\subsubsection{Unbehandelte Kontrollen}

\section{Ernährung und Belastung der Kontrollen}

Unter unbeeinflussten Bedingungen (Kontrolle, Nullvariante V1) bestanden bei den Ebereschen auf Fläche D Defizite in der Versorgung mit wichtigen Nährstoffen (Phosphor, Kalium) sowie eine vielfältige Belastungssituation (Schwefel, Mangan, Aluminium). Der trotz ausreichender Bodengehalte geringe Phosphor-Blattgehalt wies laut Bergmann (1993) auf AluminiumToxizität hin.

Die Blattgehalte an Magnesium, Schwefel, Mangan, Natrium und Aluminium waren unterschiedlich deutlich überhöht. Sowohl der Magnesium-Gehalt als auch die SchwefelKonzentration spiegelten die Bodenbedingungen (sehr hoher Anteil der Magnesium-Ionen an der Austauscherbelegung, hohe Schwefel-Gehalte) wider. Die mehr als extreme SchwefelKonzentration erreichte dabei toxisches Niveau. Die gemessenen Magnesium- und Schwefel- 
Gehalte waren höher als die im Rahmen des Deutschen Waldbodenberichtes in Buchenblättern gemessenen Maxima.

Im Gegensatz zu den Kontrollen anderer Baumarten wurden jedoch keine überhöhten Kupferoder Eisen-Gehalte festgestellt. Die Stickstoff-, Calcium-, Zink-, Nickel-, Kobalt- und ChromGehalte waren ebenfalls unauffällig (trotz geringer Stickstoff-Bodengehalte ausreichend, normal bzw. unkritisch). Die Blätter der unbehandelten Ebereschen enthielten zudem keine nachweisbaren Blei- oder Cadmium-Gehalte.

Von allen sechs Baumarten wiesen die unbehandelten Ebereschen die höchsten Calcium- und Mangan-Gehalte sowie die niedrigsten Eisen- (ebenso: Erle), Aluminium- (ebenso: Erle), Kupfer-, Kobalt- und Chrom-Gehalte in ihren Assimilationsorganen auf.

\section{Vitalität der Kontrollen}

Die mittlere Vitalität der unbehandelten Ebereschen sank vor allem durch Pflanzenausfälle im 1. Versuchsjahr ( $40 \%$ bis Juni 2005) von „3,1“ auf „1,5“ und blieb dann relativ konstant (50\% Ausfall der Kontroll-Ebereschen insgesamt, wobei die Kontrolle auf Fläche A komplett ausfiel).

Im 2. Untersuchungsjahr (Juni 2006) war die Vitalität der 12 Kontroll-Ebereschen gegenüber der Vitalität aller 120 Ebereschen insgesamt signifikant geringer (positive Effekte der Bodenhilfsstoffbehandlungen).

\section{Wachstum der Kontrollen}

Der Gesamtzuwachs des Haupttriebs der überlebenden, nicht durch Wild geschädigten KontrollEbereschen nach 2 Jahren betrug im Mittel $9 \mathrm{~cm}$. Die Messergebnisse der verschiedenen aufgenommenen Wachstumsparameter sind der Übersichtlichkeit halber in Tab. 120 aufgeführt.

Tab. 120: Messergebnisse der verschiedenen Wachstumsparameter der unbehandelten Ebereschen sowie aller Ebereschen im Versuchsverlauf; MW u. Std.abw.; Fettdurck markiert signifikant geringere Werte als im Gesamtdurchschnitt (siehe auch Tab. A 14 und A 15)

\begin{tabular}{|c|c|c|}
\hline Wachstumsparameter & Kontrolle & gesamt \\
\hline Zuwachs Haupttrieb 2005 [cm] & $4 \pm 4$ & $5 \pm 5$ \\
\hline Zuwachs Haupttrieb 2005 red.* [cm] & $6 \pm 4$ & $7 \pm 5$ \\
\hline Zuwachs Haupttrieb 2006 [cm] & $3 \pm 3$ & $10 \pm 8$ \\
\hline Zuwachs Haupttrieb gesamt [cm] & $9 \pm 5$ & $17 \pm 11$ \\
\hline Durchmesser Wurzelhals** [mm] & $8 \pm 2$ & $10 \pm 2$ \\
\hline Volumen Haupttrieb** $\left[\mathrm{cm}^{3}\right]$ & $17 \pm 8$ & $35 \pm 20$ \\
\hline TM Haupttrieb (errechnet) ${ }^{* *}[\mathrm{~g}]$ & $11 \pm 5$ & $22 \pm 13$ \\
\hline Länge Seitentriebe ${ }^{* *}[\mathrm{~cm}]$ & $59 \pm 65$ & $92 \pm 65$ \\
\hline TM Seitentriebe (errechnet) $^{* *}[\mathrm{~g}]$ & $4 \pm 4$ & $6 \pm 4$ \\
\hline HT-/ST-Länge ** & $3,5 \pm 4,1$ & $1,7 \pm 1,6$ \\
\hline TM oberirdisch (errechnet) $^{* *}[\mathrm{~g}]$ & $16 \pm 5$ & $29 \pm 17$ \\
\hline TMHT/TMST (errechnet)** [g] & $10 \pm 13$ & $6 \pm 5$ \\
\hline
\end{tabular}

* reduziert auf die Gruppe der auch noch in 2006 lebenden, nicht (durch Wild) geschädigten Ebereschen

** bei Versuchsabschluss nach 2 Jahren (Oktober 2006) 
Bei 6 der 13 erhobenen Parameter fielen die Messergebnisse in der Nullvariante signifikant geringer aus als im Gesamtdurchschnitt (positive Effekte der Bodenhilfsstoffbehandlungen). $\mathrm{Zu}$ den Nullvarianten der anderen Baumarten (mit Ausnahme der oberirdisch abgestorbenen Kontroll-Eichen) bestanden beim Zuwachs im 1. Jahr keine signifikanten Vitalitätsunterschiede. Im 2. Jahr war der Zuwachs der unbehandelten Erlen, Douglasien und Kiefern signifikant höher als der Zuwachs der Kontroll-Ebereschen.

\section{Standorteinfluss auf die Kontrollen}

Auf den Flächen A und D befand sich die Nullvariante zufällig auf Standorten ohne Spontanvegetation, auf Fläche B in einem Bereich mit Spontanvegetation. Dieser individuelle Pflanzenstandort hatte Einfluss auf die Vitalitäts- und Wachstumsentwicklung der unbehandelten Ebereschen.

Bei Versuchsabschluss lag die mittlere Vitalität der Kontroll-Ebereschen in vegetationsfreien Bereichen bei „0,5“ (Fläche A: Totalausfall; Fläche D: „1,0“), in Bereichen, in denen sich auch Spontanvegetation entwickeln konnte (Fläche B), bei „2,8“. Der Zuwachs des Haupttriebs im 1. Jahr war hier mit im Schnitt $7 \mathrm{~cm}$ auch deutlich höher als in den ungünstigeren Bereichen mit 2 $\mathrm{cm}$. Darüber hinaus bestanden keine signifikanten Unterschiede hinsichtlich der Wuchsentwicklung.

\subsubsection{Effekte der Behandlungsvarianten}

Bei den Ebereschen insgesamt konnten erst im 2. Versuchsjahr (also noch nicht im Pflanzjahr) signifikante Vitalitätsunterschiede zwischen einzelnen Behandlungsvarianten ausgemacht werden, die auch bei Versuchsabschluss noch bestanden. Ein Einfluss der Behandlung auf die Wuchsentwicklung wurde ebenfalls nur im 2. Jahr und nur auf einer Versuchsfläche (D) festgestellt, wo der Haupttriebs-Zuwachs je nach Variante signifikant unterschiedlich war.

Zu Beginn des ersten Sommers nach der Pflanzung (Aufnahme im Juni 2005) waren auf Fläche A (relativ ungünstige bodenchemische Bedingungen) die Vitalitätswerte der Ebereschen in allen Behandlungsvarianten signifikant besser als in der sehr schlechten unbehandelten Nullvariante, die dann bereits auf "0,5“ abgesunken war. Diese Unterschiede bestanden jedoch im weiteren Versuchsverlauf nicht fort.

Bodenhilfsstoffe zur Verbesserung der physikalischen Bodeneigenschaften: Perlit, Wasserspeichersubstanzen

Bei Betrachtung der Ebereschen insgesamt hatte die Zugabe von Perlit, Stockosorb® oder Superabsorber allein keine Wirkung auf ihre Entwicklung.

Wenige Wochen nach der Pflanzung (Aufnahme im Juni 2005) waren jedoch in Bereichen mit Spontanvegetation (vergleichsweise günstigere bodenchemische Bedingungen) die mittleren Vitalitätswerte mit Superabsorber (V5 ohne, V6 mit Kalk-Gabe: je "1,8“) sowie mit Perlit und Kalk (V8: „2,3“) signifikant schlechter als in der sehr guten Kontrolle („3,3“). Im weiteren Verlauf des Versuchs waren diese Unterschiede jedoch nicht mehr nachweisbar. 
Der für die Ebereschen insgesamt belegte positive Einfluss der Kalk-Gabe im 2. Versuchsjahr 2006 war in Kombination mit Superabsorber (V6) oder Perlit (V8) am Ende der Vegetationszeit (nach dem sehr trockenen Sommer 2006) nicht mehr nachweisbar. In Kombination mit Stockosorb® (V4) hatte die Kalk-Gabe aufgrund der bei dieser Variante hohen Standardabweichungen überhaupt keine signifikante Wirkung.

Die Blattanalysen zeigten in den Varianten V5 (Superabsorber), V6 (Superabsorber und Kalk) und V8 (Perlit und Kalk) auffallend hohe Schadstoff-Gehalte.

Beide Superabsorber-Varianten wiesen hohe Schwefel-Gehalte im toxischen Bereich auf, die noch deutlich höher als in der ohnehin belasteten Kontrolle lagen. In den Varianten V5 und V8 waren sowohl die Eisen- (in der Kontrolle ausreichend, normal) als auch die AluminiumGehalte (in der Kontrolle knapp höher als überversorgt) extrem erhöht. In den drei Varianten wurden zudem die höchsten Kupfer-Gehalte ermittelt (wiederum nur hier höher als in der unbehandelten Kontrolle).

Bodenhilfsstoffe zur Verbesserung der chemischen bzw. der physikalischen und chemischen Bodeneigenschaften: Kalk, Kompost

Kalk- und Kompost-Gaben hatten einen gegenüber der Nullvariante positiven Einfluss auf die Vitalitäts- und Wachstumsentwicklung der Ebereschen, der nur auf den bodenchemisch günstigeren Standorten, auf denen sich im Versuchsverlauf auch Spontanvegetation ansiedeln konnte, keine Rolle spielte.

In allen Behandlungsvarianten mit Kalk und/oder Kompost gab es (im Gegensatz zur Kontrolle und den kalk-/kompostfreien Varianten) während der gesamten zweijährigen Versuchsdauer keine signifikante Abnahme der mittleren Vitalität.

Im Juni 2006 war die mittlere Vitalität der mit Kompost oder Kalk gedüngten Bäume (allerdings nicht in Kombination mit Stockosorb®) signifikant besser $\left(, 2,3^{\prime \prime}-, 2,8^{\prime \prime}\right)$ als in der Kontrolle („1,3“). Im Oktober 2006 wiesen die Varianten, die lediglich Kalk und/oder Kompost enthielten (V2, V9 und V10) immer noch signifikant bessere („2,3“ - „2,6“) Werte als die Nullvariante („1,3“) auf, die Kombinationen mit Superabsorber oder Perlit (V6, V8) dagegen nicht mehr.

Mit einer Dünger-Kombination aus Kompost und Kalk (V10) war im 2. Jahr ein signifikant höherer durchschnittlicher Zuwachs des Haupttriebs zu verzeichnen als im 1. Jahr (in der Nullvarianten ging er dagegen signifikant von 6 auf $3 \mathrm{~cm}$ zurück). Auf Fläche D war in dieser Variante der Zuwachs im 2. Jahr mit $25 \mathrm{~cm} \mathrm{2-} \mathrm{bis} \mathrm{4-mal} \mathrm{so} \mathrm{hoch} \mathrm{wie} \mathrm{in} \mathrm{den} \mathrm{anderen}$ aufgenommenen Varianten mit Werten zwischen 6 und $13 \mathrm{~cm}$.

Im Topf-Versuch waren in sämtlichen Wiederholungen der Kalk- und Kompostvarianten im Vergleich zu den übrigen Varianten viele, helle Feinwurzeln zu beobachten.

Generell bestanden bei der Versorgung mit wichtigen Nährstoffen auch in sämtlichen Behandlungsvarianten noch Defizite. Der höchste (und einzige ausreichende) Phosphor-Gehalt wurde mit Kompost-Kalk-Düngung (V10) gemessen (einzige Variante mit positivem Effekt nicht nur auf die Vitalitäts-, sondern auch auf die Wachstumsentwicklung). Nach Bergmann (1993) ist der in den übrigen Varianten trotz ausreichender Bodengehalte bestehende Phosphormangel ein Zeichen für Aluminium-Toxizität. 
Auffälligste Gemeinsamkeit bei den Blattspiegelwerten der mit Kalk und/oder Kompost gepflanzten Varianten waren die geringeren Mangan-Gehalte, während die kalk- und kompostfreien Behandlungsvarianten (V3, V5, V7) ebenso wie die Nullvariante (mit Abstand höchster Gehalt aller Baumarten; Mangan-Toxizität wahrscheinlich) deutlich über optimale Mangan-Gehalte aufwiesen.

In den Kompost-Varianten (V9 ohne, V10 mit zusätzlicher Kalk-Gabe) fielen zudem geringere Magnesium-, Schwefel- und Natrium-Gehalte (in der Kontrolle jeweils überhöht) und vergleichsweise sehr geringe Nickel-Gehalte auf. Der Schwefel-Gehalt war in diesen Varianten nur noch als „ausreichend bzw. normal“ einzustufen (gegenüber „knapp toxisch bzw. über extrem" in der Kontrolle).

Gleiches galt für die Kombination aus Perlit und Kalk (V8), jedoch waren hier (im Gegensatz zu den Kompost-Varianten) die Eisen- und Aluminium-Gehalte extrem erhöht.

\subsection{Schwarz-Erle}

Im Freiland-Versuch wurden auf den drei Versuchsflächen A, B und D insgesamt 120 Erlen in zehn Versuchsvarianten gepflanzt (V1: Kontrolle, V3: Stockosorb®, V5: Superabsorber, V7: Perlit, V9: Kompost sowie V2, V4, V6, V8, V10 als Kombinationen mit Kalk-Düngung; s. S. 20).

\section{Ausgangszustand}

Bei Versuchsbeginn wiesen die Erlen eine durchschnittliche Haupttrieblänge von $101 \mathrm{~cm}$ (für das bestellte Sortiment von 60-100 cm bereits relativ groß) und einen sehr guten durchschnittlichen Vitalitätswert von „3,6“ (bester Ausgangswert aller Baumarten) auf.

\section{Wildschäden}

Mit nur $11 \%$ wurden vergleichsweise wenige Erlen im Versuchsverlauf durch Wild geschädigt.

\section{Ausfallrate}

Bei Versuchsende nach zwei Jahren waren $22 \%$ der Pflanzen ausgefallen $(+6 \%$ absterbend), was die geringste Sterblichkeitsrate aller Baumarten darstellt. Sie stieg im Versuchsverlauf von 2,5 \% im Juni 2005 über $10 \%$ und $17 \%$ auf $22 \%$ im Oktober 2006.

\section{Vitalität insgesamt}

Die Erlen insgesamt wiesen von allen eingesetzten Baumarten die besten mittleren Vitalitätswerte im Versuchsverlauf auf $(3,6 \pm 0,5>2,5 \pm 1,0<2,7 \pm 1,3 ; 2,6 \pm 1,4>2,3 \pm 1,5)$. Die mittlere Vitalität der lebenden Erlen lag jeweils bei 2,5 $\pm 0,9 ; 3,0 \pm 0,9 ; 3,2 \pm 0,9$ und 2,9 $\pm 0,9$. Damit waren die Vitalitätswerte der Erlen im gesamten Versuchsverlauf sowohl insgesamt als auch bezogen auf die jeweils lebenden Pflanzen mäßig bis gut.

\section{Wachstum insgesamt}

Der Gesamtzuwachs des Haupttriebs der überlebenden, nicht durch Wild geschädigten Erlen nach 2 Jahren betrug im Mittel $26 \mathrm{~cm}$. Die Messergebnisse der weiteren aufgenommenen Wachstumsparameter sind der Übersichtlichkeit halber in Tab. 121 aufgeführt. 


\section{Standorteinfluss insgesamt}

Bei Versuchsabschluss nach 2 Jahren lag die durchschnittliche Vitalität der Erlen auf Fläche A bei „1,9“, auf Fläche B bei „2,7“ und auf Fläche D bei „2,3“. In vegetationsfreien Bereichen (pH 3,6) betrug der Mittelwert „1,7“ und in Bereichen, in denen Bodenbewuchs stattfand ( $\mathrm{pH} 4,0$ ), lag er bei „3,2“. Auf diesen günstigeren Standorten lagen auch die Ergebnisse bei fast allen erhobenen Wachstumsparametern signifikant zwischen $20 \%$ (Wurzelhalsdurchmesser) und $120 \%$ (Zuwachs des Haupttriebs im 2. Jahr) höher.

\subsubsection{Unbehandelte Kontrollen}

\section{Ernährung und Belastung der Kontrollen}

Unter unbeeinflussten Bedingungen (Kontrolle, Nullvariante V1) bestanden bei den Erlen auf Fläche D im Gegensatz zu den anderen Baumarten abgesehen von einem knapp nicht ausreichenden Kalium-Gehalt keine Defizite in der Versorgung mit wichtigen Nährstoffen.Ihre Symbiose mit Luftstickstoff-fixierenden Actinomyceten macht die Erlen hinsichtlich ihrer von den Bodengehalten unabhängigen, stets ausreichenden Stickstoff-Versorgung zu einem Sonderfall.

Die Blattgehalte an Schwefel, Kupfer, Zink, Mangan, Nickel und Aluminium waren unterschiedlich stark überhöht. Die ausreichenden Phosphor-Gehalte waren nach Bergmann (1993) jedoch ein Hinweis darauf, dass keine Aluminium-Toxizität bestand. Die mehr als extreme Schwefel-Konzentration im Laub der unbehandelten Erlen spiegelte die hohen Schwefel-Bodengehalte wider und erreichte toxisches Niveau. Die gemessenen Schwefel-Gehalte lagen höher als die im Rahmen des Deutschen Waldbodenberichtes in Buchenblättern gemessenen Maxima. Die Kupfer- und Nickel-Gehalte waren deutlich höher als ausreichend/normal und lagen in jeweils kritischen Bereichen.

Im Gegensatz zu den Kontrollen anderer Baumarten wurden keine überhöhten Magnesium-, Eisen- oder Natrium-Gehalte festgestellt. Die Kobalt- und Chrom-Gehalte waren ebenfalls unauffällig (unter normal bzw. unkritisch). Die Blätter der unbehandelten Erlen enthielten zudem keine nachweisbaren Blei- oder Cadmium-Gehalte.

Von allen sechs Baumarten wiesen die unbehandelten Erlen die höchsten Stickstoff-, Phosphor-, Kalium-, Zink-, Kupfer- und (zusammen mit den unbehandelten Kiefern) Nickel-Gehalte sowie (gemeinsam mit den unbehandelten Ebereschen) die niedrigsten Eisen- und Aluminium-Gehalte in ihren Assimilationsorganen auf.

\section{Vitalität der Kontrollen}

Die anfänglich hohe Vitalität der unbehandelten Erlen sank durch einen Rückgang bei den sehr guten Vitalitätsbewertungen ("4“) bald nach der Pflanzung sowie den Ausfall eines Drittels der Kontrollen im 1. Versuchsjahr auf einen Mittelwert über „2“, um während der 2. Vegetationszeit auf knapp unter „2“ abzunehmen (42\% Ausfall der Kontroll-Erlen insgesamt).

Zwischen den 12 Kontroll-Erlen und der Gesamtheit aller 120 gepflanzten Erlen bestanden zu keinem Zeitpunkt signifikante Vitalitätsunterschiede. 
Zu den Nullvarianten der Ebereschen und Douglasien bestanden im gesamten Versuchsverlauf keine signifikanten Vitalitätsunterschiede. Im 1. Jahr war zudem die Vitalität der KontrollAhorne, im Juni des 2. Jahres die der Kontroll-Kiefern nicht signifikant unterschiedlich (beide zu den übrigen Aufnahmezeitpunkten signifikant geringer, ebenso Eichen $\mathrm{zu}$ allen Aufnahmezeitpunkten). Im Oktober 2006 bestanden keine signifikanten Vitalitätsunterschiede zwischen den Nullvarianten der sechs Baumarten mehr.

\section{Wachstum der Kontrollen}

Der Gesamtzuwachs des Haupttriebs der überlebenden, nicht durch Wild geschädigten KontrollErlen nach 2 Jahren betrug im Mittel $26 \mathrm{~cm}$. Die Messergebnisse der verschiedenen aufgenommenen Wachstumsparameter sind der Übersichtlichkeit halber in Tab. 121 aufgeführt. Signifikante Wachstumsunterschiede zwischen den 12 Kontroll-Erlen und der Gesamtheit aller 120 gepflanzten Erlen bestanden nicht. Von allen eingesetzten Baumarten erzielten die Erlen die (signifikant) höchsten Wachstumswerte, teilweise waren die Messergebnisse um ein Vielfaches höher.

Tab. 121: Messergebnisse der verschiedenen Wachstumsparameter der unbehandelten Erlen sowie aller Erlen im Versuchsverlauf; MW u. Std.abw (siehe auch Tab. A 14 und A 15)

\begin{tabular}{|c|c|c|}
\hline Wachstumsparameter & Kontrolle & gesamt \\
\hline Zuwachs Haupttrieb 2005 [cm] & $8 \pm 6$ & $8 \pm 6$ \\
\hline Zuwachs Haupttrieb 2005 red.* [cm] & $10 \pm 6$ & $10 \pm 6$ \\
\hline Zuwachs Haupttrieb 2006 [cm] & $16 \pm 13$ & $16 \pm 11$ \\
\hline Zuwachs Haupttrieb gesamt [cm] & $26 \pm 18$ & $26 \pm 16$ \\
\hline Durchmesser Wurzelhals** [mm] & $16 \pm 4$ & $16 \pm 4$ \\
\hline Volumen Haupttrieb** $\left[\mathrm{cm}^{3}\right]$ & $103 \pm 54$ & $114 \pm 62$ \\
\hline TM Haupttrieb errechnet ${ }^{* *}[\mathrm{~g}]$ & $47 \pm 25$ & $53 \pm 27$ \\
\hline Länge Seitentriebe** $[\mathrm{cm}]$ & $369 \pm 224$ & $380 \pm 207$ \\
\hline TM Seitentriebe errechnet** $[\mathrm{g}]$ & $24 \pm 15$ & $25 \pm 14$ \\
\hline HT-/ST-Länge ** & $0,4 \pm 0,2$ & $0,4 \pm 0,2$ \\
\hline TM oberirdisch errechnet** [g] & $71 \pm 39$ & $78 \pm 42$ \\
\hline TMHT/TMST errechnet** [g] & $2,0 \pm 0,3$ & $2,2 \pm 0,5$ \\
\hline
\end{tabular}

* reduziert auf die Gruppe der auch noch in 2006 lebenden, nicht (durch Wild) geschädigten Erlen

** bei Versuchsabschluss nach 2 Jahren (Oktober 2006)

\section{Standorteinfluss auf die Kontrollen}

Auf den Flächen A und D befand sich die Nullvariante zufällig auf Standorten ohne Spontanvegetation, auf Fläche B in einem Bereich mit Spontanvegetation. Dieser individuelle Pflanzenstandort hatte Einfluss auf die Wachstumsentwicklung der unbehandelten Erlen; signifikante Vitalitätsunterschiede wurden dagegen nicht nachgewiesen.

Bei Versuchsabschluss lag die mittlere Vitalität der Kontroll-Erlen in vegetationsfreien Bereichen bei „1,1“ (Fläche A: „1,3“, hier bei allen anderen Baumarten Totalausfall der Kontrolle; Fläche D: „1,0“). In günstigeren Bereichen, in denen sich auch Spontanvegetation entwickeln konnte (Fläche B), betrug die Vitalität „2,8“. Hier zeigten auch die meisten Wachstumsparameter um 120-175 \% höhere Werte (der Wurzelhalsdurchmesser lag hier ca. 50 \% höher als auf ungünstigeren Standorten). Zudem konnte eine positive Zuwachsentwicklung vom Anlagejahr (2005) zum 2. Jahr (2006) nachgewiesen werden (Verdoppelung des Jahreszuwachses von 13 
$\mathrm{cm}$ auf $27 \mathrm{~cm}$ in bewachsenen Bereichen, dagegen in beiden Jahren jeweils $8 \mathrm{~cm}$ Zuwachs in vegetationsfreien Bereichen).

\subsubsection{Effekte der Behandlungsvarianten}

Die Bodenhilfsstoffe hatten kaum signifikante Wirkung auf die Wuchsentwicklung der Erlen (weder insgesamt noch bei einzelner Betrachtung der verschiedenen Standorte).

Vitalitätsunterschiede je nach Behandlungsvariante bestanden bei den Erlen insgesamt und den Erlen mit vergleichsweise besseren Standorten (Fläche B und D sowie Bereiche, in denen sich auch Spontanvegetation entwickeln konnte) ebenfalls nicht (Vitalitätsunterschiede zwischen Varianten auf Fläche B waren eindeutig auf die dort besonders ausgeprägte kleinräumige Heterogenität der Bodenbedingungen zurückzuführen).

Bei einzelner Betrachtung der ungünstigeren Standorte (Versuchsfläche A sowie Bereiche ohne Spontanvegetation) konnten dagegen Effekte der Behandlungen auf die Vitalität der Erlen festgestellt werden, die auf Fläche A nur relativ zu Versuchsbeginn (Aufnahme im Juni 2005), auf unbewachsenen Standorten insgesamt ausschließlich im Frühsommer des 2. Untersuchungsjahres (Aufnahme im Juni 2006) bestanden.

Bodenhilfsstoffe zur Verbesserung der physikalischen Bodeneigenschaften: Perlit, Wasserspeichersubstanzen

Die Wasserspeichersubstanzen allein hatten keinen signifikanten Effekt auf die Entwicklung der Erlen.

Auch die Vitalität der mit Perlit gepflanzten Erlen (V7) unterschied sich zu keinem Zeitpunkt signifikant von der Kontrolle.

Jedoch nahm mit Perlit (wenn auch auf vergleichsweise niedrigem Niveau: Vitalität bei Versuchsabschluss „2,2“) im Gegensatz zur Kontrolle die Vitalität während der gesamten Versuchsdauer nicht signifikant ab. Gleichzeitig war der Zuwachs des Haupttriebs mit Perlit im 2. Jahr signifikant höher als im 1. Jahr.

Für die Kombination aus Stockosorb® und Kalk (V4) traf beides ebenso zu (Vitalität bei Versuchsabschluss „2,5“).

Die auf Fläche A (relativ ungünstige Bodenbedingungen) wenige Wochen nach der Pflanzung (Aufnahme im Juni 2005) gegenüber der Kontrolle signifikant bessere Vitalität der Erlen mit Kalk-Gaben bestand in Kombination mit Superabsorber (V6) oder Perlit (V8) nicht.

Wie die Analyse der Blattspiegelwerte zeigte, blieb das Defizit bei der Kalium-Versorgung auch beim überwiegenden Teil der Behandlungsvarianten bestehen. Lediglich bei Pflanzung mit Perlit (V7) wurde ein voll ausreichender Blattgehalt gemessen. Diese Variante war die einzige mit ausreichender Kalium- und Phosphor-Versorgung, was trotz einer der Kontrolle ähnlichen Belastungssituation (Ausnahme: keine überhöhten Nickel-Gehalte) der Grund für die ausbleibende Verschlechterung der Vitalitätswerte sowie die positive Wachstumsentwicklung im Versuchsverlauf sein könnte. 
In der Kombination aus Perlit und Kalk (V8) konnte ähnlich wie in den Kompost-Varianten ein Rückgang der in der Kontrolle überhöhten Magnesium-, Schwefel-, Aluminium- und NickelGehalte sowie ein Anstieg der Calcium-Gehalte festgestellt werden. Jedoch waren hier sowohl der Kalium- als auch der Phosphor-Gehalt nicht ausreichend. Der trotz ausreichender Bodengehalte sehr geringe, von allen Varianten mit Abstand niedrigste Phosphor-Gehalt ist nach Bergmann (1993) als Zeichen für Aluminium-Toxizität zu werten.

Nicht ausreichende Phosphor- und Kalium-Gehalte fanden sich darüber hinaus nur in den kalkfreien Wasserspeichersubstanz-Varianten (V3: Stockosorb®; V5: Superabsorber). Diese beiden Varianten wiesen zudem auffallend hohe Belastungen mit Schwefel, Eisen, Kupfer und Aluminium (Aluminium-Toxizität nach Bergmann (1993) durch die geringen Phosphor-Gehalte bestätigt) sowie höhere Chrom-Gehalte als die Kontrolle auf. In der Superabsorber-Variante (V5) wurde außerdem ein exorbitant hoher Kobalt-Gehalt gemessen, der um ein Vielfaches über den übrigen Varianten sowie über den Normalgehalten lag und als toxisch einzustufen ist.

\section{Bodenhilfsstoff zur Verbesserung der chemischen Bodeneigenschaften: Kalk}

Generell waren bei den Erlen unter ungünstigeren Standortbedingungen (auf der unbewachsenen Fläche A sowie auf vegetationsfreien Standorten) höhere Vitalitätswerte in den Varianten mit Kalk- oder/und Kompost-Düngung zu beobachten. Auf den übrigen Standorten (Fläche B oder D; Bereiche mit Spontanvegetationsentwicklung) spielten Kalk und Kompost dagegen keine Rolle.

Auf Fläche A war wenige Wochen nach der Pflanzung (Aufnahme im Juni 2005) die mittlere Vitalität der Erlen mit Kalk-Gaben (allerdings nicht in Kombination mit Superabsorber oder Perlit) mit „3,5“ bzw. „4“ signifikant höher als in der unbehandelten Kontrolle („2,5“).

Im weiteren Verlauf des Versuchs waren diese Unterschiede jedoch nicht mehr nachweisbar.

Auffälligste Gemeinsamkeit bei den Blattspiegelwerten der mit Kalk und/oder Kompost gepflanzten Varianten waren die zwar immer noch überhöhten, aber gegenüber den kalk- und kompostfreien Behandlungsvarianten (V3, V5, V7) und der Nullvariante deutlich geringeren Kupfer-Gehalte (sowie die geringeren Kobalt- und Chrom-Gehalte; teilweise auch die geringeren Mangan-Gehalte).

\section{Bodenhilfsstoff zur Verbesserung der physikalischen und chemischen} Bodeneigenschaften: Kompost

Bei den mit Kompost gepflanzten Erlen (V9 ohne, V10 mit zusätzlicher Kalk-Gabe; Vitalität bei Versuchsabschluss: „3,0“) nahm im Gegensatz zur Kontrolle die mittlere Vitalität während der zweijährigen Versuchsdauer nicht signifikant ab. In diesen Varianten war im 2. Jahr auch ein signifikant höherer durchschnittlicher Zuwachs des Haupttriebs zu verzeichnen als im 1. Jahr

Im Juni des 2. Vegetationsjahres (2006) war bei den Erlen mit Standorten in Bereichen ohne Entwicklung von Spontanvegetation (niedrigerer pH-Wert, ungünstigere Austauscherbelegung) ein positiver Einfluss der Kompost-Düngung (V9) auf die Vitalität signifikant. Hier bestand immer noch ein sehr guter Durchschnittswert von „3,5“, während die unbehandelte Kontrolle bei „1,8“ lag. Bei Versuchsabschluss im Oktober 2006 war dieser Effekt zumindest statistisch nicht mehr nachweisbar. 
In den Kompost-Varianten wurden, ebenso wie in den Kalk-Varianten, gegenüber der Kontrolle deutlich geringere Kupfer-Gehalte (sowie geringere Kobalt- und Chrom-Gehalte; teilweise auch geringere Mangan-Gehalte) festgestellt. Darüber hinaus fielen in den Kompost-Varianten geringere Magnesium-, Schwefel-, Aluminium- und Nickel-Gehalte auf (in der Kontrolle jeweils unterschiedlich stark überhöht, im Fall von Schwefel knapp toxischer Gehalt), die nur noch als „ausreichend bzw. normal“ einzustufen waren (Aluminium: überversorgt; Nickel: unter normal). Die überhöhten Magnesium-Gehalte gingen zugunsten der bereits ohne Behandlung ausreichenden Calcium-Gehalte zurück, die damit mehr als das 3-fache des Kontrollwertes betrugen, während die Kalium-Versorgung kaum profitierte.

\subsection{Douglasie}

Im Freiland-Versuch wurden auf den drei Versuchsflächen A, B und D insgesamt 192 Douglasien in 16 Versuchsvarianten gepflanzt (V1: Kontrolle, V3: Stockosorb®, V5: Superabsorber, V7: Perlit, V9: Kompost sowie V2, V4, V6, V8, V10 als Kombinationen mit Kalk-Düngung; V11-V16 als Kombinationen mit Mykorrhiza-Impfung; s. S. 20).

\section{Ausgangszustand}

Bei Versuchsbeginn wiesen die Douglasien eine durchschnittliche Haupttrieblänge von $27 \mathrm{~cm}$ und einen durchschnittlichen Vitalitätswert von „3“ (relativ gut entwickelt mit geringen Einschränkungen, s. S. 27) auf.

\section{Wildschäden}

Verglichen mit den anderen fünf Baumarten waren die Douglasien im Versuchsverlauf kaum von Wildschäden betroffen (insgesamt $5 \%$ geschädigte Bäume).

\section{Ausfallrate}

Bei Versuchsende nach zwei Jahren waren $34 \%$ der Pflanzen ausgefallen (+ $9 \%$ absterbend; Vitalitätswert „1“). Die Ausfallrate stieg vom 1. zum 2. Untersuchungsjahr deutlich an (von $10 \%$ und $17 \%$ in 2005 auf $30 \%$ und $34 \%$ in 2006; im Topf-Versuch im Gewächshaus mit $33 \%$ ähnliche Ausfallrate).

\section{Vitalität insgesamt}

Insgesamt wiesen die Douglasien im Versuchsverlauf vergleichsweise mäßige bis geringe Vitalitätswerte auf $(3,1 \pm 0,5>2,1 \pm 1,0 ; 2,1 \pm 1,2 ; 1,7 \pm 1,4>1,6 \pm 1,4)$. Die mittleren Vitalitätswerte der lebenden Douglasien lagen jeweils bei $2,4 \pm 0,8 ; 2,6 \pm 0,7 ; 2,5 \pm 0,9$ und 2,4 \pm 0,9 .

\section{Wachstum insgesamt}

Der Gesamtzuwachs des Haupttriebs der überlebenden, nicht durch Wild geschädigten Douglasien nach 2 Jahren betrug im Mittel $13 \mathrm{~cm}$. Die Messergebnisse der weiteren aufgenommenen Wachstumsparameter sind der Übersichtlichkeit halber in Tab. 122 aufgeführt.

\section{Standorteinfluss insgesamt}

Bei Versuchsabschluss nach 2 Jahren lag die durchschnittliche Vitalität der Douglasien auf Fläche A bei „1,2“, auf Fläche B bei „2,2“ und auf Fläche D bei „1,5“. In vegetationsfreien 
Bereichen (pH 3,6) betrug der Mittelwert "1,1“ und in Bereichen, in denen Bodenbewuchs stattfand (pH 4,0), lag er bei „2,4“. Auf diesen günstigeren Standorten lag auch der Zuwachs des Haupttriebs in beiden Jahren sowie gesamt signifikant um 65-80 \% höher.

\subsubsection{Unbehandelte Kontrollen}

\section{Ernährung und Belastung der Kontrollen}

Unter unbeeinflussten Bedingungen (Kontrolle, Nullvariante V1) bestanden bei den Douglasien auf Fläche D deutliche Defizite in der Versorgung mit den meisten wichtigen Nährstoffen (vor allem Phosphor, Calcium, Magnesium, aber auch Kalium, Zink) sowie eine vielfältige Belastungssituation (Schwefel, Eisen, Aluminium; je nach Quelle der Bewertungsstufen auch Kupfer). Die Bewertung der Stickstoff- und Mangan-Gehalte variiert je nach Quelle (s. Anhang 2) zwischen gering und ausreichend/optimal.

Der trotz ausreichender Bodengehalte auffallend geringe Phosphor-Nadelgehalt wies laut Bergmann (1993) auf Aluminium-Toxizität hin.

Die Blattgehalte an Schwefel, Eisen und Aluminium sowie - je nach Quelle der Bewertungsstufen (s. Anhang 2) - auch Kupfer waren unterschiedlich deutlich überhöht. Die sehr hohe Schwefel-Konzentration spiegelte die hohen Bodengehalte wider und überschritt die Schadstoffgrenzwerte. Der Aluminium-Gehalt lag fast doppelt so hoch wie die Obergrenze einer Extremversorgung und weit oberhalb der im Rahmen des Deutschen Waldbodenberichtes in Nadeln gemessenen Maximalwerte.

Die Nickel-, Kobalt- und Chrom-Gehalte sowie der Natrium-Gehalt waren unauffällig. Die Nadeln der unbehandelten Douglasien enthielten zudem keine nachweisbaren Blei- oder CadmiumGehalte.

Von allen sechs Baumarten wiesen die unbehandelten Douglasien die niedrigsten Phosphor-, Calcium-, Magnesium-, Zink-, Schwefel- und (gemeinsam mit den Eichen) Nickel-Gehalte in ihren Assimilationsorganen auf.

\section{Vitalität der Kontrollen}

Die mittlere Vitalität der unbehandelten Douglasien sank erst zum und im 2. Versuchsjahr von „3“ auf Werte deutlich unter „2“. In beiden Jahren fiel knapp ein Drittel der Kontroll-Douglasien aus (58 \% Ausfall insgesamt, wobei die Kontrolle auf Fläche A komplett ausfiel), im 2. Jahr ging zudem der Anteil sehr gut bewerteter Pflanzen deutlich zurück.

Zu keinem Aufnahmezeitpunkt wurden signifikante Vitalitätsunterschiede zwischen der Nullvariante und dem Gesamtschnitt aller Douglasien festgestellt.

$\mathrm{Zu}$ den Vitalitätswerten der unbehandelten Ahorne, Ebereschen und Erlen bestanden im Versuchsverlauf keine signifikanten Unterschiede. Im 1. Jahr war die mittlere Vitalität der unbehandelten Eichen und Kiefern, im 2. Jahr nur noch die der unbehandelten Eichen signifikant geringer. Zuletzt (Oktober 2006) bestanden keine signifikanten Vitalitätsunterschiede zwischen den Nullvarianten der sechs Baumarten mehr. 


\section{Wachstum der Kontrollen}

Der Gesamtzuwachs des Haupttriebs der überlebenden, nicht durch Wild geschädigten KontrollDouglasien nach 2 Jahren betrug im Mittel $19 \mathrm{~cm}$. Die Messergebnisse der verschiedenen aufgenommenen Wachstumsparameter sind der Übersichtlichkeit halber in Tab. 122 aufgeführt.

Der mittlere Zuwachs der Haupttriebe im 1. Jahr sowie der Gesamtzuwachs lagen in der unbehandelten Kontrolle signifikant höher als bei den Douglasien insgesamt, was auf die sehr gute Kontrolle auf Fläche B zurückzuführen ist.

Die Ergebnisse der Wachstumsmessungen unterschieden sich zwischen den beiden Nadelbaumarten (Douglasien und Kiefern) nicht signifikant.

Tab. 122: Messergebnisse der verschiedenen Wachstumsparameter der unbehandelten Douglasien sowie aller Douglasien im Versuchsverlauf; MW u. Std.abw.; unterstrichener Fettdruck markiert signifikant höhere Werte als im Gesamtdurchschnitt (siehe auch Tab. A 14 und A 15)

\begin{tabular}{|c|c|c|}
\hline Wachstumsparameter & Kontrolle & gesamt \\
\hline Zuwachs Haupttrieb 2005 [cm] & $6 \pm 4$ & $4 \pm 3$ \\
\hline Zuwachs Haupttrieb 2005 red.* [cm] & $9 \pm 3$ & $5 \pm 3$ \\
\hline Zuwachs Haupttrieb 2006 [cm] & $10 \pm 7$ & $9 \pm 7$ \\
\hline Zuwachs Haupttrieb gesamt [cm] & $\underline{19 \pm 7}$ & $13 \pm 9$ \\
\hline Durchmesser Wurzelhals $^{* *}[\mathrm{~mm}]$ & $7 \pm 1$ & $7 \pm 3$ \\
\hline Volumen Haupttrieb** $\left[\mathrm{cm}^{3}\right]$ & $7 \pm 3$ & $10 \pm 15$ \\
\hline TM Haupttrieb errechnet** [g] & $5 \pm 2$ & $7 \pm 10$ \\
\hline TM Wurzel errechnet** [g] & $9 \pm 1$ & $10 \pm 4$ \\
\hline TMHT+TMW errechnet** $[\mathrm{g}]$ & $14 \pm 3$ & $17 \pm 14$ \\
\hline TMHT/TMW errechnet** [g] & $0,5 \pm 0,2$ & $0,6 \pm 0,4$ \\
\hline
\end{tabular}

* reduziert auf die Gruppe der auch noch in 2006 lebenden, nicht (durch Wild) geschädigten Douglasien

** bei Versuchsabschluss nach 2 Jahren (Oktober 2006)

\section{Standorteinfluss auf die Kontrollen}

Der individuelle Pflanzenstandort hatte Einfluss auf die Vitalitäts- und Wachstumsentwicklung der unbehandelten Douglasien (auf den Flächen A und D befand sich die Nullvariante zufällig auf Standorten ohne Spontanvegetation, auf Fläche B in einem Bereich mit Spontanvegetation).

Bei Versuchsabschluss betrug die mittlere Vitalität der Kontroll-Douglasien in vegetationsfreien Bereichen „0,3“ (Fläche A: Totalausfall der Kontrolle im Versuchsverlauf; Fläche D: „0,5“). In günstigeren Bereichen, in denen sich auch Spontanvegetation entwickeln konnte (Fläche B), lag die Vitalität bei hohen „3,3“. Dort wurde im Anlagejahr (2005) ein Haupttriebs-Zuwachs von 10 $\mathrm{cm}$, auf den ungünstigeren Standorten von $3 \mathrm{~cm}$ (zwischen Fläche A: 0,7 cm und Fläche D: $6 \mathrm{~cm}$ bestanden ebenfalls signifikante Unterschiede) gemessen.

\subsubsection{Effekte der Behandlungsvarianten}

Zwischen den Behandlungsvarianten konnten bei Betrachtung aller Douglasien insgesamt keine signifikanten Unterschiede hinsichtlich ihrer Vitalität nachgewiesen werden, wohl aber hinsichtlich ihres Zuwachses. Nach günstigeren und ungünstigeren Standorten getrennt 
(günstigere Standorte: in Bereichen mit Spontanvegetation bzw. auf der in weiten Teilen bewachsenen Versuchsfläche B; ungünstigere Standorte: in Bereichen ohne Spontanvegetation bzw. auf der völlig vegetationsfreien Versuchsfläche A) wurden dagegen sowohl signifikante Vitalitäts- als auch Zuwachsunterschiede je nach Behandlungsvariante ermittelt.

Dabei waren die auf Fläche B festgestellten Unterschiede zwischen den Varianten eindeutig auf die dort besonders ausgeprägte kleinräumige Heterogenität der Bodenbedingungen zurückzuführen. Die Ergebnisse für Fläche B schlugen sich stark in den Ergebnissen für Standorte mit Spontanvegetation sowie auch in den Ergebnissen für die Douglasien insgesamt nieder.

Auf den günstigeren Standorten spielten die Bodenhilfsstoffe keine große Rolle für Vitalität und Wachstum der Douglasien (hier auch ohne Behandlung gute Ergebnisse). Auf den ungünstigeren Standorten wurden dagegen z.T. deutlich Behandlungseinflüsse festgestellt (hier v.a. bei der Kombination mehrerer Bodenhilfsstoffe Verbesserungen gegenüber der Kontrolle).

Die Unterschiede zwischen den Varianten (und damit die Behandlungseffekte) waren bei den Douglasien jedoch grundsätzlich nur im 1. Vegetationsjahr (2005) statistisch signifikant, bei Versuchsabschluss in 2006 waren sie nicht mehr nachweisbar.

Bodenhilfsstoffe zur Verbesserung der physikalischen Bodeneigenschaften: Perlit, Wasserspeichersubstanzen

Perlit, Stockosorb ${ }^{\circledR}$ oder Superabsorber hatten allein keinen Effekt auf die Entwicklung der Douglasien.

In Kombination mit Perlit bestand die auf den ungünstigeren Standorten (ohne Spontanvegetation) ansonsten positive Wirkung der Kalk-Gabe nicht. Auch Stockosorb® oder Superabsorber verminderten (beide) oder verzögerten (Superabsorber) teilweise den Effekt der Kalkung.

Dagegen konnten auf diesen vergleichsweise schlechteren, stärker versauerten Standorten sowohl Stockosorb ${ }^{\circledR}$ als auch Superabsorber teilweise die Mykorrhiza-Impfungen deutlich unterstützen. Kombinationen aus Mykorrhiza und Wasserspeichersubstanzen hatten hier als einzige Varianten ohne zusätzliche Kalk-Gaben einen positiven Einfluss.

Insgesamt (standortunabhängig) führte der Zusatz von Stockosorb® bei der MykorrhizaImpfung (V13 ohne, V14 mit Kalk) bei der Trockenmasse der Seitentriebe (4,9 bzw. 5,3 g) und dem Wurzelhalsdurchmesser (8,6 bzw. 8,3 mm) zu signifikant besseren Ergebnissen gegenüber der reinen Mykorrhiza-Variante (V11: 1,8 g; 6,1 mm). Die Kombinationen mit Superabsorber (V15 ohne, V16 mit Kalk) hatten dagegen keinen zusätzlichen Effekt auf das Wachstum der Douglasien.

In den Perlit-Varianten (V7 ohne, V8 mit zusätzlicher Kalk-Gabe) wurden AluminiumNadelgehalte gemessen, die etwa doppelt so hoch wie die Obergrenze extremer Gehalte für Kiefern (Hofmann \& Krauss 1988) und damit noch etwas höher als der ohnehin hohe Gehalt in der Kontrolle und deutlich höher als in den übrigen Behandlungsvarianten lagen. In diesen beiden Varianten sowie in der Stockosorb®-Kalk-Kombination wurden zudem sehr hohe, deutlich über ausreichende Kupfer-Gehalte ermittelt, die ebenfalls den Gehalt in der Nullvariante überstiegen. 
Bodenhilfsstoff zur Verbesserung der chemischen Bodeneigenschaften: Kalk Im Anlagejahr (2005) waren Vitalität und Wachstum der Douglasien auf ungünstigeren (stärker versauerten) Standorten mit Kalk-Gabe jeweils höher als ohne (jedoch nicht in Kombination mit Perlit, teilweise auch nicht mit Stockosorb® oder Superabsorber).

Auf Fläche A zeigten die Kalk-Varianten (ausgenommen die Kalk-Perlit-Kombination V8) signifikant um 1-2 Bewertungsstufen höhere Vitalitätswerte als die Kontrolle mit „1,3“ im Juni und „0,8“ im Oktober 2005. Gleiches galt für den Zuwachs im 1. Vegetationsjahr, der mit Kalk das 3- bis 8-fache des Kontrollwertes $(0,7 \mathrm{~cm})$ erreichte. In Kombination mit Superabsorber (V6, V15, V16) trat der positive Kalkungseffekt verzögert ein.

Der Zusatz von Kalk bei der Mykorrhiza-Impfung (V12) führte insgesamt (standortunabhängig) zu einer signifikant höheren Trockenmasse der Seitentriebe $(3,7$ g) gegenüber der reinen Mykorrhiza-Variante (V11: 1,8 g).

Im Topf-Versuch war bei den mit Kalk (bzw. Kompost) gedüngten Douglasien eine gegenüber den kompost- und kalkfreien Varianten dunklere Färbung und reichere Verzweigung der Wurzeln zu beobachten, was für einen Effekt der pH-Wert-anhebenden Bodenhilfsstoffe spricht.

Bodenhilfsstoff zur Verbesserung der physikalischen und chemischen Bodeneigenschaften: Kompost

Die Kompost-Düngung allein (ohne zusätzliche Kalk-Gabe) führte bei den Douglasien im Freiland-Versuch nicht zu messbaren Vitalitäts- oder Wachstumsunterschieden.

Jedoch konnte bei den mit Kompost gepflanzten Douglasien (V9 ohne, V10 mit zusätzlicher KalkGabe) im Versuchsverlauf im Gegensatz zur Kontrolle sowie anderen Behandlungsvarianten keine signifikante Abnahme der Vitalität festgestellt werden.

Im Topf-Versuch war ebenso wie bei den Kalk-Varianten mit Kompost eine dunklere Färbung und reichere Verzweigung der Douglasien-Wurzeln zu beobachten.

Bodenhilfsstoff zur Verbesserung der biologischen Bodeneigenschaften: MykorrhizaInokulum

Die Mykorrhizierungsraten der Douglasien lagen im Freiland-Versuch in allen MykorrhizaVarianten zwischen „2,7“ und „3,0“ (hoher Mykorrhizierungsgrad; (fast) alle Wurzelspitzen mykorrhiziert; s. S. 28), im Topf-Versuch einheitlich ebenfalls bei knapp „3“.

Im Gegensatz zur Kontrolle und den übrigen Behandlungsvarianten (ausgenommen Kompost) nahm die Vitalität der Douglasien mit Kombinationen aus Mykorrhiza-Impfung und Wasserspeichersubstanz-Beigabe (V13 - V16) im gesamten Versuchsverlauf nicht signifikant ab.

Auf Fläche A konnten von Wasserspeichersubstanzen unterstützte Mykorrhiza-Impfungen trotz der geringen Bodenreaktion auch ohne zusätzliche pH-Wert-Anhebung (durch Kalk-Gaben) die Wuchsbedingungen für die Douglasien verbessern. Dabei führte die Kombination mit Stockosorb® (V13) auf geringem Niveau zu einem höheren Zuwachs des Haupttriebs im Anlagejahr $(2,7 \mathrm{~cm}$ gegenüber 0,7 cm in der Kontrolle). In der Kombination mit Superabsorber (V15) wurde dagegen zum Ende der ersten Vegetationszeit ein höherer Vitalitätswert ermittelt ("2,3" gegenüber “0,8” in der Kontrolle). Die positiven Wirkungen dieser Kombinationen sind 
auch insofern interessant, als Mykorrhiza (V11), Stockosorb® (V3) oder Superabsorber (V5) jeweils allein keinen Effekt auf die Entwicklung der Douglasien hatten.

Auf unbewachsenen Standorten allgemein wurden zum Ende der ersten Vegetationszeit nur bei den Douglasien mit Behandlungskombinationen aus Mykorrhiza-Inokulum, Wasserspeichersubstanzen und Kalk (V14 mit Stockosorb ${ }^{\circledR}$, V16 mit Superabsorber) gegenüber der Nullvariante $\left(„ 1,8^{\prime}\right)$ signifikant höhere Vitalitätswerte $\left(, 2,5^{\prime}\right)$ ermittelt.

Die Nadelspiegelwerte der Douglasien zeigten bei den Behandlungsvarianten überwiegend höhere, in den Varianten mit Kalk-Gabe bzw. Mykorrhiza-Inokulum verschiedentlich bereits ausreichende Nährstoff-Gehalte. Im Vergleich auffallend hoch waren dabei der Phosphor-Gehalt in der Stockosorb®-Kalk-Variante V4 sowie die Calcium-, Magnesium- und Mangan-Gehalte in den Mykorrhiza-Varianten V14, V15 u. V16.

In allen Mykorrhiza-Varianten wurden ausreichende Calcium- und Magnesium-Gehalte gemessen, mit Ausnahme von V14 (Mykorrhiza-Stockosorb®-Kalk) auch ausreichende Phosphor-Gehalte. Die Kalium-Gehalte waren in der reinen Mykorrhiza-Variante (V11) und den Kombinationen mit Superabsorber ausreichend, die Stickstoff-Gehalte in den Kombinationen mit Stockosorb® (in der unbehandelten Kontrolle wiesen die Douglasien bei sämtlichen genannten Nährstoffen Defizite auf).

Die Eisen- und Aluminium-, teilweise auch die Kupfer-Gehalte (und damit die entsprechenden Belastungen) waren in den Kalk-, Kompost- und Mykorrhiza-Varianten (mit Ausnahme der Perlit-Kalk-Kombination V8, bzgl. Kupfer auch der Stockosorb®-Kalk-Kombination V4) zum Teil erheblich geringer als in der Nullvariante.

Innerhalb der Mykorrhiza-Varianten senkten die reine Mykorrhiza-Impfung (V11) und die Kombination mit Kalk (V12) die Kupfer-Gehalte am stärksten (V12 auch die Eisen- und Aluminium-Gehalte), gefolgt von den Stockosorb®-Kombinationen (V13, V14) und dann von den Superabsorber-Kombinationen (V15, V16)

Die bereits ohne Behandlung sehr hohen Schwefel-Gehalte waren in den Behandlungsvarianten noch unterschiedlich deutlich höher; die entsprechende Belastung der Pflanzen blieb also bestehen.

\subsection{Wald-Kiefer}

Im Freiland-Versuch wurden auf den drei Versuchsflächen A, B und D insgesamt 120 Kiefern in zehn Versuchsvarianten gepflanzt (V1: Kontrolle, V3: Stockosorb®, V5: Superabsorber, V7: Perlit, V9: Kompost sowie V2, V4, V6, V8, V10 als Kombinationen mit Kalk-Düngung; s. S. 20). 


\section{Ausgangszustand}

Bei Versuchsbeginn wiesen die Kiefern eine durchschnittliche Haupttrieblänge von $27 \mathrm{~cm}$ und einen mittleren Vitalitätswert von „3“ (relativ gut entwickelt mit geringen Einschränkungen, s. S. 27) auf.

\section{Wildschäden}

Etwa $22 \%$ der Kiefern wurden im Versuchsverlauf durch Wild geschädigt (Abknicken des Haupttriebs).

\section{Ausfallrate}

Bei Versuchsende nach zwei Jahren waren 80 \% der Pflanzen ausgefallen, ein im Vergleich zu den anderen Baumarten (Ausnahme: Eiche) relativ hoher Anteil. Die Ausfallrate war von Beginn an relativ hoch und stieg im 1. Untersuchungsjahr deutlich von $56 \%$ im Juni auf $80 \%$ im Oktober an. Im 2. Jahr kamen keine weiteren Ausfälle hinzu.

\section{Vitalität insgesamt}

Durch die hohe Sterblichkeit waren die durchschnittlichen Vitalitätswerte der Kiefern sehr gering (Abnahme von anfänglich 3,0 $\pm 0,5$ auf Werte unter „1“). Die mittlere Vitalität der lebenden Kiefern lag von Juni 2005 bis Oktober 2006 bei 2,1 \pm 0,9; 3,0 \pm 0,8; 3,3 \pm 0,7 und 3,0 \pm 1,0. Damit wiesen die wenigen lebenden Kiefern nach dem Pflanzschock wieder recht gute Vitalitätswerte auf.

\section{Wachstum insgesamt}

Der Gesamtzuwachs des Haupttriebs der überlebenden, nicht durch Wild geschädigten Kiefern (insgesamt nur 24 Wiederholungen) nach 2 Jahren betrug im Mittel $27 \mathrm{~cm}$. Die Messergebnisse der weiteren aufgenommenen Wachstumsparameter sind der Übersichtlichkeit halber in Tab. 123 aufgeführt.

\section{Standorteinfluss insgesamt}

Bei Versuchsabschluss nach 2 Jahren lag die durchschnittliche Vitalität der Kiefern auf Fläche A bei „0,1“, auf Fläche B bei „1,4“ und auf Fläche D bei „0,3“. In vegetationsfreien Bereichen (pH

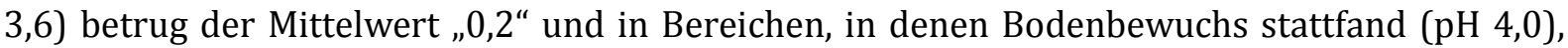
lag er bei „1,3“. Auf diesen günstigeren Standorten lag auch der Zuwachs des Haupttriebs in beiden Jahren sowie gesamt höher (um $130 \%$ in 2005, 60 \% in 2006 und 80 \% gesamt).

\subsubsection{Unbehandelte Kontrollen}

\section{Ernährung und Belastung der Kontrollen}

Unter unbeeinflussten Bedingungen (Kontrolle, Nullvariante V1) bestanden bei den Kiefern auf Fläche D Defizite in der Versorgung mit wichtigen Nährstoffen (Stickstoff, je nach Quelle der Bewertungsstufen auch Calcium) sowie eine vielfältige Belastungssituation (vor allem mit Schwefel, Kupfer, Nickel).

Die Nadelgehalte an Magnesium, Schwefel, Eisen, Kupfer, Aluminium und Nickel waren unterschiedlich deutlich überhöht. Die mehr als extremen Magnesium- und SchwefelKonzentrationen spiegelten die hohen Magnesium-Sättigungen und Schwefel-Bodengehalte wider und betrugen das 4,5-fache (Magnesium) bzw. das Doppelte (Schwefel) der im Rahmen des Deutschen Waldbodenberichtes in Kiefern-Nadeln ermittelten Maximalwerte. Der Schwefel- 
Nadelgehalt überschritt die Schadstoffgrenzwerte für Kiefern-Nadeln. Der hohe Eisen-Gehalt lag im Bereich einer Überversorgung, der sehr hohe Kupfer-Gehalt oberhalb einer Extremversorgung. Der Nickel-Gehalt war höher als normal (Smidt 1999) und nach Alloway (1999; sehr weite, allgemeine Wertespanne) kritisch.

Der ausreichende Phosphor-Nadelgehalt bedeutet nach Bergmann (1993), dass trotz des knapp über extremen, im Bereich der im Deutschen Waldbodenbericht ermittelten Maxima liegenden Aluminium-Gehaltes keine Aluminium-Toxizität bestand.

Im Gegensatz zu anderen Baumarten wurden keine überhöhten Mangan-, Zink- und NatriumGehalte gemessen. Die Phosphor-, Kalium-, Kobalt- und Chrom-Gehalte waren ebenfalls unauffällig und von den meisten Quellen als ausreichend, optimal, mittel bzw. unterhalb normaler oder weit unterhalb kritischer Konzentrationen eingestuft. Die Blätter der unbehandelten Kiefern enthielten zudem keine nachweisbaren Blei- oder Cadmium-Gehalte.

Von allen sechs Baumarten wiesen die unbehandelten Kiefern die höchsten Magnesium-, Schwefel- (ebenso: Ahorn) und Nickel-Gehalte (ebenso: Erle) in ihren Assimilationsorganen auf.

\section{Vitalität der Kontrollen}

Die mittlere Vitalität der unbehandelten Kiefern sank vor allem durch Pflanzenausfälle im 1. Versuchsjahr von „3“ auf Werte zwischen „1,5“ und unter „1“ und blieb dann relativ konstant (58 \% Ausfall der Kontroll-Kiefern insgesamt, wobei die Kontrolle auf Fläche A komplett ausfiel).

Im Juni 2005, wenige Wochen nach Versuchsanlage, war die Vitalität der unbehandelten Kiefern signifikant geringer als die aller Kiefern insgesamt. Im weiteren Versuchsverlauf bestanden aufgrund der insgesamt hohen Ausfälle keine diesbezüglichen signifikanten Vitalitätsunterschiede mehr.

$\mathrm{Zu}$ den Vitalitätswerten der unbehandelten Ebereschen und Ahorne bestanden im Versuchsverlauf keine signifikanten Unterschiede. Die mittlere Vitalität der unbehandelten Douglasien und Erlen war zumindest im 1. Untersuchungsjahr besser, die der Eichen in beiden Jahren schlechter. Zuletzt (Oktober 2006) bestanden keine signifikanten Vitalitätsunterschiede zwischen den Nullvarianten der sechs Baumarten mehr.

\section{Wachstum der Kontrollen}

Der Gesamtzuwachs des Haupttriebs der überlebenden, nicht durch Wild geschädigten KontrollKiefern nach 2 Jahren betrug im Mittel $15 \mathrm{~cm}$. Die Messergebnisse der verschiedenen aufgenommenen Wachstumsparameter sind der Übersichtlichkeit halber in Tab. 123 aufgeführt. Bei fast allen aufgenommenen Parametern (nur an lebenden Pflanzen messbar) waren die Kontrollwerte signifikant geringer als der Gesamtdurchschnitt.

Bezüglich der erhobenen Wachstumswerte bestanden keine signifikanten Unterschiede zwischen den beiden Nadelbaumarten (Douglasien und Kiefern). 
Tab. 123: Messergebnisse der verschiedenen Wachstumsparameter der unbehandelten Kiefern sowie aller Kiefern im Versuchsverlauf; MW u. Std.abw.; Fettdruck markiert signifikant geringere Werte als im Gesamtdurchschnitt (siehe auch Tab. A 14 und A 15)

\begin{tabular}{|c|c|c|}
\hline Wachstumsparameter & Kontrolle & gesamt \\
\hline Zuwachs Haupttrieb 2005 [cm] & $4 \pm 5$ & $5 \pm 5$ \\
\hline Zuwachs Haupttrieb 2005 red.* [cm] & $7 \pm 5$ & $8 \pm 5$ \\
\hline Zuwachs Haupttrieb 2006 [cm] & $8 \pm 2$ & $18 \pm 10$ \\
\hline Zuwachs Haupttrieb gesamt [cm] & $15 \pm 4$ & $27 \pm 12$ \\
\hline Durchmesser Wurzelhals** [mm] & $7 \pm 2$ & $11 \pm 4$ \\
\hline Volumen Haupttrieb** $\left[\mathrm{cm}^{3}\right]$ & $10 \pm 8$ & $31 \pm 28$ \\
\hline Trockenmasse Haupttrieb errechnet** [g] & $5 \pm 4$ & $16 \pm 14$ \\
\hline Länge Seitentriebe** [cm] & $63 \pm 37$ & $138 \pm 89$ \\
\hline TM Seitentriebe errechnet** [g] & $3 \pm 2$ & $7 \pm 5$ \\
\hline HT-/ST-Länge** & $1,0 \pm 0,7$ & $0,6 \pm 0,4$ \\
\hline TM oberirdisch errechnet** [g] & $9 \pm 5$ & $24 \pm 18$ \\
\hline TMHT/TMST errechnet** [g] & $1,9 \pm 1,1$ & $2,3 \pm 1,4$ \\
\hline TM Wurzel errechnet** [g] & $9 \pm 3$ & $14 \pm 5$ \\
\hline TMHT+TMW errechnet** [g] & $14 \pm 6$ & $30 \pm 20$ \\
\hline TMHT/TMW errechnet** [g] & $0,6 \pm 0,2$ & $1,0 \pm 0,5$ \\
\hline TM gesamt errechnet $^{* *}[\mathrm{~g}]$ & $18 \pm 8$ & $38 \pm 23$ \\
\hline TM oberird./TM unterird. en & $0,9 \pm 0,3$ & $1,5 \pm 0,6$ \\
\hline
\end{tabular}

* reduziert auf die Gruppe der auch noch in 2006 lebenden, nicht (durch Wild) geschädigten Kiefern

** bei Versuchsabschluss nach 2 Jahren (Oktober 2006)

\section{Standorteinfluss auf die Kontrollen}

Der individuelle Pflanzenstandort hatte Einfluss auf die Vitalitäts- und Wachstumsentwicklung der unbehandelten Kiefern (auf den Flächen A und D befand sich die Nullvariante zufällig auf Standorten ohne Spontanvegetation, auf Fläche B in einem Bereich mit Spontanvegetation).

Bei Versuchsabschluss lag die mittlere Vitalität der Kontroll-Kiefern in vegetationsfreien Bereichen bei „0,3“ (Fläche A: Totalausfall der Kontrolle; Fläche D: „0,5“). In günstigeren Bereichen, in denen sich auch Spontanvegetation entwickeln konnte (Fläche B), betrug die Vitalität „2,0“. Der Zuwachs des Haupttriebs im 1. Jahr ergab hier im Schnitt 9 cm, während die Kontroll-Kiefern in ungünstigeren Bereichen überhaupt kein Wachstum aufwiesen. Darüber hinaus bestanden keine signifikanten Unterschiede hinsichtlich der Wuchsentwicklung.

\subsubsection{Effekte der Behandlungsvarianten}

Nur relativ zu Versuchsbeginn bestanden bei den insgesamt durch hohe Ausfallraten sehr schwachen Kiefern signifikante Vitalitätsunterschiede zwischen verschiedenen Varianten. So war bereits wenige Wochen nach der Pflanzung (Aufnahme im Juni 2005) die Vitalität der Kiefern durch hohe Pflanzenausfälle in sämtlichen Behandlungsvarianten (Ausnahmen: Kompost-Varianten) mit Werten unter "1“ signifikant niedriger als in der Nullvariante, obwohl auch die Vitalität der unbehandelten Kiefern zu dem Zeitpunkt bereits auf „1,5“ abgenommen 
hatte. Grund dafür war neben der insgesamt hohen Sterblichkeit die standortbedingt relativ gute Kontrolle auf Fläche B („2,5“ im Juni 2005, „2,0“ bei Versuchsende im Oktober 2006).

Bodenhilfsstoffe zur Verbesserung der physikalischen Bodeneigenschaften: Perlit, Wasserspeichersubstanzen

Damit war auch die Vitalität der Kiefern in den Perlit-, Stockosorb®- und SuperabsorberVarianten (ohne und mit zusätzlicher Kalk-Gabe), die bald nach der Pflanzung bis auf wenige Exemplare komplett abstarben, nach kurzer Zeit signifikant niedriger als in der unbehandelten Kontrolle.

Die Wasserspeichersubstanz Superabsorber (V5) schien jedoch auf einige der erhobenen Wachstumsparameter einen signifikant positiven Einfluss zu haben. Mit Superabsorber wurden im Versuchsverlauf 50-90 \% mehr Haupttriebs-Zuwachs und $60 \%$ höhere HaupttriebsVolumina bzw. -Trockenmassen als in der unbehandelten Kontrolle ermittelt. Die Aussagekraft dieser Ergebnisse ist insofern eingeschränkt, als die Daten aufgrund der sehr hohen Ausfallrate bei den Kiefern nur an 3 Wiederholungen der Superabsorber-Variante und an 5 Nullvarianten erhoben werden konnten. Möglicherweise ähnliche Effekte mit Stockosorb® oder Perlit konnten nicht untersucht werden (weniger als 3 überlebende Wiederholungen).

\section{Bodenhilfsstoff zur Verbesserung der chemischen Bodeneigenschaften: Kalk}

Die Vitalität der Kiefern in sämtlichen Kalk-Varianten (ausgenommen in der Kombination mit Kompost), die bald nach der Versuchsanlage mehr oder weniger komplett ausfielen, war ebenfalls nach kurzer Zeit signifikant niedriger als in der unbehandelten Kontrolle.

Bodenhilfsstoff zur Verbesserung der physikalischen und chemischen Bodeneigenschaften: Kompost

Auch die Ausfallraten der mit Kompost gedüngten Kiefern (V9 ohne, V10 mit zusätzlicher KalkGabe) waren von Beginn an hoch, jedoch vergleichsweise geringer als in den übrigen Behandlungsvarianten. Es bestanden keine signifikanten Vitalitätsunterschiede zur unbehandelten Kontrolle (Vitalität wenige Wochen nach der Pflanzung: Kontrolle: „1,5“; Kompost-Variante: „1,8“; Kompost-Kalk-Variante: „1,4“; übrige Varianten: unter „1“).

Im Gegensatz zur Kontrolle (Vitalität bei Versuchsabschluss: „0,8“) erfolgte in den beiden Kompost-Varianten (Vitalität bei Versuchsabschluss: „1,3“ bzw. „1,4“) jedoch keine signifikante Abnahme der mittleren Vitalität während der zweijährigen Versuchsdauer.

Im 2. Vegetationsjahr lag der Zuwachs des Haupttriebs bei den mit Kompost gedüngten Kiefern mit $24 \mathrm{~cm}$ (V9) bzw. $25 \mathrm{~cm}$ (V10) zudem signifikant höher als im 1. Jahr mit $5 \mathrm{~cm}$ bzw. $10 \mathrm{~cm}$ (positive Wuchsentwicklung).

Die Kompost-Düngung hatte darüber hinaus auf einen großen Teil der erhobenen Wachstumsparameter einen signifikant positiven Einfluss. Sie führte zu gegenüber der Kontrolle 2- bis 3-mal so hohen Zuwächsen und 3- bis 5-mal so hohen Trockenmassen, wobei die oberirdische Trockenmasse stärker zunahm als die unterirdische.

Aufgrund der hohen Pflanzenausfälle lagen nur für die Kontrolle sowie die beiden KompostVarianten die Ergebnisse von Nadelanalysen vor. Demnach konnte die Kompost-Düngung die je 
nach Quelle der Bewertungsstufen defizitäre Calcium-Versorgung mehr als ausgleichen. Auch der Kalium-Gehalt stieg an, mit zusätzlicher Kalk-Düngung stärker als ohne auf einen bereits über optimalen Wert. Die Stickstoff-Gehalte blieben dagegen gering. Die in der Kontrolle überhöhten Eisen- und Aluminium-Gehalte sowie die bei dieser Baumart besonders auffällig hohen Schwefel- und Magnesium-Gehalte waren mit Kompost mehr oder weniger deutlich niedriger, nach den verwendeten Quellen jedoch überwiegend ebenso einzustufen wie in der Kontrolle. Eine Ausnahme bildete der Aluminium-Gehalt, der in der kalkfreien KompostVariante im Optimalbereich lag.

Die Kupfer-Belastung blieb bestehen und verstärkte sich durch die Düngung sogar noch. Hinzu kam ein starker Anstieg der Zink-Gehalte auf mehr als extreme Werte. Auch der bereits auffällige Nickel-Gehalt nahm deutlich zu (ebenso wie der weiterhin unauffällige Kobalt-Gehalt). Die Mangan-Gehalte stiegen erheblich an (vor allem in der kalkfreien Variante), waren jedoch noch nicht als bedenklich einzustufen.

Die durch Kompost-Düngung teilweise deutlich verbesserte Ernährungssituation und die geringere Belastung mit einigen Elementen schien die höhere Belastung mit anderen jedoch mehr als aufzuwiegen, wie die Vitalitäts- und Wachstumsanalysen zeigten.

Bei den Kiefern im Topf-Versuch war bei den mit Kompost bzw. Kalk gedüngten Pflanzen eine gegenüber den kompost- und kalkfreien Varianten deutlich dunklere Färbung der Wurzeln zu beobachten. Demnach hatten im Topf-Versuch beide pH-Wert-anhebenden Bodenhilfsstoffe einen Effekt. Im Freiland hatte jedoch nur die zur Verbesserung der chemischen und physikalischen Bodenbedingungen eingesetzte Kompost-Düngung tatsächlich messbare Auswirkungen auf die Vitalitäts- und Wachstumsentwicklung der Kiefern.

Im Freiland-Versuch auf den Ronneburger Tagebaufolgeflächen wurden bei der Baumart Kiefer keine Mykorrhiza-Varianten angelegt, im Topf-Versuch im Gewächshaus dagegen schon. In diesen Varianten wiesen die Kiefernwurzeln einheitlich Mykorrhizierungsraten von knapp „3“ auf (hoher Mykorrhizierungsgrad; (fast) alle Wurzelspitzen mykorrhiziert; s. S. 28). Starke Fruchtkörperbildung (mindestens zwei verschiedene Pilz-Arten) in und an sämtlichen mit Kiefern bestandenen Töpfen im Gewächshaus-Versuch wies darauf hin, dass bei allen Versuchspflanzen unabhängig von der Variante Symbiosen aufgebaut worden waren. Die Pilzsporen waren vermutlich teilweise im verwendeten Haldensubstrat vorhanden, teilweise wurden sie ausgehend von den Mykorrhiza-Varianten (Impfung mit Paxillus involutus, s. S. 31) über das Gießwasser verbreitet. Das Vorhandensein von Mykorrhiza-Partnern und die regelmäßige Bewässerung im Gewächshaus könnten Gründe dafür sein, dass die Ausfallrate der Kiefern im Topf-Versuch mit $10 \%$ deutlich geringer als im Freiland (80 \%) war. 


\section{Diskussion}

In den folgenden Kapiteln werden die Ergebnisse der im Rahmen der vorliegenden Dissertation durchgeführten Untersuchungen zur Strandortproblematik der Ronneburger Tagebaufolgeflächen, zur Wirkung der eingesetzten Bodenhilfsstoffe und zur Eignung der verwendeten Baumarten diskutiert. Darüber hinaus erschien neben einer kritischen Betrachtung der angewandten Methoden auch eine Auseinandersetzung mit in der Literatur teilweise widersprüchlichen Bewertungen und Grenzwerten von Element-Gehalten in Assimilationsorganen angebracht.

Da die Lausitzer Bergbaufolgelandschaft seit vielen Jahren im Mittelpunkt ungezählter Forschungsprojekte steht, beziehen sich die bei der Ergebnisdiskussion zum Vergleich genannten Beispiele oft auf diese Region (soweit nicht anders angegeben). Dem Vergleich der Versuchspflanzungen auf den Ronneburger Kippenstandorten mit den umfangreichen Erfahrungen aus der Lausitz sind jedoch auch Grenzen gesetzt, die zum einen in den standörtlichen Unterschieden, zum anderen meist im Alter der untersuchten Bäume bestehen. So handelt es sich bei den Lausitzer Rekultivierungsflächen meist um bereits meliorierte Braunkohlenkippenstandorte auf armen Sanden mit kohlehaltigen Substraten (z.B. Katzur et al. 1999b, Hüttl \& Weber 2001, Ertle et al. 2006). Zum anderen werden in den Lausitzer Arbeiten meist nicht die ersten Jahre nach der Pflanzung von Sämlingen, sondern bereits ältere Bestände untersucht. 


\section{Methodik}

\subsection{Versuchsdesign}

Für die vorliegende Arbeit wurden schwerpunktmäßig Freiland-Versuche im ehemaligen Tagebaugebiet Ronneburg angelegt, die durch Topf-Versuche im Gewächshaus in Göttingen ergänzt wurden. Das Substrat für die Topf-Versuche wurde auf der ehemaligen Absetzerhalde in Ronneburg in unmittelbarer Nähe $\mathrm{zu}$ den Freiland-Versuchsflächen gewonnen. Diese zweigliedrige Versuchsanordnung hat sich bewährt, vor allem, indem im Topf-Versuch die Wirkungen der eingesetzten Bodenhilfsstoffe auf die Bodeneigenschaften (in Relation zur unbehandelten Kontrolle) deutlich einfacher untersucht werden konnten als im Freiland. Grenzen der Übertragbarkeit von Untersuchungsergebnissen der Topf-Versuche auf FreilandBedingungen waren klar erkennbar und bezogen sich vor allem auf fehlende ElementNachlieferung und veränderte Infiltrationsbedingungen im Topf.

Im Zuge der statistischen Auswertung der im Freiland-Versuch gesammelten Daten zeigten sich einige Schwächen des Freiland-Versuchsdesigns, die oft zu sehr kleinen Stichproben oder sehr großen Streuungen der Werte führten. So waren für drei der sechs Baumarten zehn Versuchsvarianten, für die übrigen drei Arten sechzehn Versuchsvarianten mit jeweils zwölf Wiederholungen (verteilt auf drei Versuchsflächen) angelegt worden.

Die drei Versuchsflächen wiesen teilweise stark unterschiedliche Standortbedingungen auf. Auch die bei Versuchsanlage nicht vorhersehbaren Standortunterschiede innerhalb der Flächen - markiert durch Bereiche, in denen sich im Versuchsverlauf Spontanvegetation entwickeln konnte, und Bereiche, die bis Versuchsabschluss vegetationsfrei blieben - hatten teils großen Einfluss auf die Pflanzenentwicklung.

Die statistischen Analysen des Einflusses der verschiedenen Behandlungsvarianten auf die Pflanzenentwicklung wurden dadurch teils erheblich erschwert, indem oft entweder hohe Standardabweichungen (bei Betrachtung aller zwölf Wiederholungen, ungeachtet ihres Standortes) oder eine sehr geringe Zahl an Wiederholungen (bei Betrachtung der Versuchspflanzen getrennt nach Standorten) das Herausarbeiten signifikanter Unterschiede zwischen den Varianten unmöglich machten.

Hohe Ausfallraten (auf diesen Standorten zu erwarten) verschärften die Problematik der relativ geringen Anzahl an Wiederholungen noch.

Die recht hohe Zahl an Behandlungsvarianten (teils einzelne Bodenhilfsstoffe, teils Bodenhilfsstoff-Kombinationen) und Baumarten (vier Laub- und zwei Nadelbaumarten) führte $\mathrm{zu}$ großen Datenmengen und ging teilweise $\mathrm{zu}$ Lasten der Übersichtlichkeit der Untersuchungsergebnisse.

Bei der Auswahl der angelegten Versuchsvarianten hätte angesichts der Bedeutung von Mykorrhiza bei der Wiederbegrünung vergleichbarer Standorte im Versuchsdesign ein noch stärkeres Gewicht auf Mykorrhiza-Impfungen gelegt werden können. So hätten für jede verwendete Baumart, mindestens aber für die obligat auf Mykorrhiza angewiesenen (im vorliegenden Fall also auch für die Kiefern), Mykorrhiza-Varianten vorgesehen sein sollen. Angesichts der meist guten Reaktion der untersuchten Mykorrhiza-Varianten auf 
unterstützende Maßnahmen zur Erhöhung von pH-Wert (Kalk-Gabe) und Bodenfeuchte (Wasserspeichersubstanzen) wäre auch eine Kombination aus Mykorrhiza-Impfung und Kompost-Gabe interessant.

\subsection{Untersuchungsmethodik}

Zur Beurteilung der Pflanzenentwicklung unter den gegebenen und durch Bodenhilfsstoffe veränderten Standortbedingungen wurden neben Messungen verschiedener Wachstumsparameter auch gutachterliche Einschätzungen der Pflanzenvitalität vorgenommen. Sowohl der Boden als auch die Assimilationsorgane der Pflanzen wurden chemischen Analysen unterzogen. Laut Bergmann (1993) sind die drei Methoden visuelle Diagnose, Pflanzenanalyse und agrochemische Bodenanalyse stets als eine Einheit anzusehen.

Um trotz aller bei einer Schätzung der Pflanzenvitalität gegebenen Subjektivität möglichst miteinander vergleichbare Ergebnisse zu erhalten, wurden die Einschätzungen stets von derselben Person (Verfasserin) durchgeführt und in beiden Untersuchungsjahren zu den jeweils gleichen Zeitpunkten wiederholt. Zudem erfolgte die Einstufung anhand einer zuvor festgelegten fünfstufigen Bewertungsskala. Vergleichbare Vitalitätsstufen-Schlüssel für verschiedene Baumarten wurden beispielsweise von Roloff (2001) entwickelt (von $0=$ vital, ungeschädigt bis 3 = stark geschädigt, absterbend) und fanden in einer Vielzahl von Arbeiten Anwendung (z.B. Dmyterko 2006 und 1998, Buck-Sorlin \& Bell 2000). Laut Klug (2005) hat sich in der Praxis und vor allem bei Erstellung von Baumkatastern eine Unterteilung in fünf Vitalitätsstufen zwischen "gesund“ und „tot" bewährt.

In der vorliegenden Arbeit stimmten die Ergebnisse der Vitalitätsschätzungen in aller Regel mit den Ergebnissen der Wachstumsmessungen überein oder widersprachen ihnen zumindest nicht. Da die gegebenen, ungünstigen Standortbedingungen teilweise nur sehr geringes Wachstum ermöglichten, stellten die Vitalitätsbewertungen eine sinnvolle Ergänzung der Messergebnisse dar. Oft ergab sich erst aus der Kombination beider Methoden ein vollständiges Bild zur Beurteilung der Pflanzenentwicklung.

Auch Stähr et al. (2000) hielten bei der Untersuchung von Kippen-Erstaufforstungen die Einbeziehung okularer Vitalitätsparameter trotz der gegebenen Gefahr einer subjektiven Variation für sinnvoll.

Die durchgeführten chemischen Blatt- und Nadelanalysen zeigten vielfach Erklärungen für gute oder schlechte Vitalitäts- und Wachstumsentwicklungen auf, während die Bodenuntersuchungen Begründungen für hohe oder niedrige Element-Gehalte in den Assimilationsorganen lieferten (effektive Kationenaustauschkapazität, Austauscherbelegung, reduzierende Bedingungen durch Verdichtung etc.).

Aufgrund der sehr heterogenen Standortbedingungen schwankten die Ergebnisse der chemischen Analysen einzelner Bodenproben teilweise stark, was bei der Bildung von Mittelwerten zu hohen Standardabweichungen führte. Wenn möglich, ist eine Erhöhung der Stichprobenanzahl deshalb generell sinnvoll.

Die aus Zeit- und Kostengründen beabsichtigte Beschränkung des Probenumfangs und Analyseaufwands (im 1. Jahr wurden die Pflanzen aller drei Versuchsflächen, im 2. Jahr 
ausschließlich die Pflanzen auf Fläche D einer chemischen Analyse unterzogen, wobei das Spektrum der analysierten Elemente im 2. Jahr deutlich erweitert war) führte dazu, dass nur für Fläche D Informationen zur Versorgung bzw. Belastung der Pflanzen mit Schwefel, Eisen, Mangan, Aluminium und Natrium zur Verfügung standen.

Die Auswertung der vollständigen Bodenanalysen und der mit den genannten Lücken vorhandenen Pflanzendaten zeigte jedoch, dass die unterschiedliche Entwicklung der Bäume auf den drei Versuchsflächen höchstwahrscheinlich in ihrer unterschiedlich hohen Belastung mit Kupfer, Schwefel und Mangan begründet lag. Im Nachhinein wäre folglich ein auf allen drei Versuchsflächen entsprechend erweitertes Spektrum der in den Assimilationsorganen analysierten Elemente sinnvoll gewesen.

Angesichts des teils großen Standorteinflusses wären zudem für jede Baumart die Analyse von Blatt- und Nadelspiegelwerten getrennt nach individuellem Pflanzenstandort in Bereichen mit und ohne Entwicklung von Spontanvegetation wünschenswert gewesen. So konnten wiederum lediglich aus den für diese Bereiche vorliegenden Ergebnissen der Bodenanalysen Schlussfolgerungen auf die Ernährungs- und Belastungssituation der betreffenden Pflanzen gezogen werden.

Der Untersuchungszeitraum der vorliegenden Arbeit deckt mit zwei Jahren zwar die auf derartigen Standorten oft kritische Etablierungsphase von Bäumen ab. Dennoch wäre eine längere Begleitung bzw. eine mit zeitlichem Abstand durchgeführte WiederholungsUntersuchung der Versuche interessant, zumal die Vitalität der Versuchspflanzen teilweise zum Ende der zweiten Vegetationszeit noch einmal abgenommen hatte. So könnte überprüft werden, wie lange die bei einigen Bodenhilfsstoffen festgestellten positiven Wirkungen anhalten und wie sich die Bäume mit Nachlassen der Effekte weiter entwickeln.

Nach Böcker et al. (1998), Katzur et al. (1998) und Ertle et al. (2006) ist zudem das Wachstum von z.B. Kiefern und Rot-Eichen auf Kippenstandorten in den ersten Jahren nach der Pflanzung zunächst deutlich gebremst.

Laut Hüttl (2001) ist die „...Frage nach der Nachhaltigkeit der Entwicklung der Ökosysteme in den durch den Tagebau stark veränderten Landschaften [...] nach wie vor offen. ...".

Auch Knoche et al. (2002) weisen darauf hin, dass selbst bei erfolgreichen Wiederaufforstungen aufgrund der von ungestörten Standorten stark abweichenden bodenchemischen Bedingungen auch nach Jahrzehnten nicht klar ist, ob diese Waldökosysteme sich weiter stabil entwickeln oder die Rekultivierung doch langfristig scheitert.

Ein längerfristiges Monitoring von Rekultivierungsversuchen erscheint deshalb unabdingbar. 


\section{Bewertungen von Element-Gehalten in Assimilationsorganen in der Literatur}

Um Aussagen zur Versorgungs- und Belastungssituation der Versuchspflanzen treffen zu können, wurde die Höhe der in ihren Blättern und Nadeln gemessenen Element-Gehalte anhand von entsprechenden Einstufungen verschiedener Autoren (s. Anhang 2) bewertet. Teilweise bestanden zwischen den Quellen deutliche Unterschiede in der Einschätzung zu geringer, ausreichender, optimaler und zu hoher Element-Gehalte.

Im Rahmen der vorliegenden Arbeit war es nicht möglich, die Literaturwerte abschließend zu überprüfen und jeweils als „zutreffend“ bzw. „nicht zutreffend“ einzuordnen; zu komplex sind auf den in vielerlei Hinsicht ungünstigen Haldenstandorten die Schadursachen. So war in aller Regel nicht ein einzelner zu hoher oder zu geringer Element-Gehalt in den Assimilationsorganen der Grund für Vitalitäts- und Wachstumsdefizite, sondern das Zusammenspiel aus verschiedenen hohen Schadstoff-Belastungen, teils geringer Nährstoff-Versorgung und anderen Faktoren wie Wasser- und Sauerstoffmangel durch Bodenverdichtung, Fehlen passender Mykorrhiza-Partner und Verbissschäden.

Zudem erscheint nahe liegend, dass die Toleranz von Pflanzen gegenüber einem sehr hohen (belastenden) oder sehr niedrigen (mangelhaften) Element-Gehalt unter ohnehin problematischen Bedingungen (Synergie-Effekte) eine andere ist als auf einem ansonsten günstigen Standort mit optimaler Versorgung.

Die Probleme bei der Verwendung verschiedener Quellen zur Einschätzung von ElementGehalten in Blättern und Nadeln beginnen schon damit, das mache Bewertungsskalen sehr differenziert in 5 Stufen, manche in 3 Stufen unterteilt sind und manche nur einen (relativ weit gefassten) Bereich ausreichender Gehalte vorgeben (z. B. Bergmann 1993). Dazu variieren die Begrifflichkeiten; so ist parallel etwa von „ausreichenden“, „mittleren“ oder „normalen“, teils auch von „guten“ oder „optimalen“ Gehalten die Rede.

Teilweise wird beim Vergleich von Bewertungsbereichen verschiedener Autoren offensichtlich, dass in jüngeren Arbeiten die Einteilungen älterer Quellen übernommen (und ggf. angepasst) wurden. Bestehen Unterschiede, so handelt es sich häufig um unterschiedlich hohe Untergrenzen einer ausreichenden Versorgung. Wird ein Element-Gehalt in einem solchen (teilweise sehr weiten) Grenzbereich gemessen, ist aufgrund der unterschiedlichen Quellen eine Aussage zur ausreichenden oder unzureichenden Versorgung der Pflanze schwer möglich. Gleiches gilt beispielsweise für einen vergleichsweise hohen Schwermetall-Gehalt bei durch verschiedene Autoren unterschiedlich hoch angesetzten Belastungsgrenzen.

Diese gegeneinander leicht oder auch stärker verschobenen Unter- und Obergrenzen bei der Einstufung von Element-Gehalten waren beim Studium der verschiedenen Quellen erwartet worden, da die den Quellen jeweils zugrunde liegenden Daten von Faktoren wie Standortverhältnissen, Klimabedingungen und Methodik (Versuchsaufbau, Witterungsverhältnisse zum Zeitpunkt der Probennahme, Aufnahme und Interpretation von Pflanzenschäden etc.) abhängen.

In einigen Fällen fielen jedoch auch massive Widersprüche bei der Einstufung von ElementGehalten auf (z.B. Zink, Mangan). 


\subsection{Rot-Eiche}

Für die in der vorliegenden Untersuchung verwendete Baumart Rot-Eiche liegen in der Literatur kaum eigene Bewertungsskalen der Blattspiegelwerte vor, so dass auf solche Einstufungen für Stiel- und Trauben-Eichen zurückgegriffen wurde. Lediglich Heinsdorf (1999) nennt explizit Bewertungen der Stickstoff-Gehalte sowie die Obergrenze optimaler Phosphor-Gehalte in den Blättern von Rot-Eichen. Im Vergleich zu Stiel- und Trauben-Eichen ist der Nährstoff-Bedarf der Rot-Eichen demnach geringer.

Eine ausreichende Kalium-Versorgung ist bei Eichen nach Heinsdorf (1999) und dem österreichischen BFW (2005/7) ab Blattgehalten von gut $5 \mathrm{mg} / \mathrm{g}$ gegeben, während nach Bergmann (1993) erst ein doppelt so hoher Kalium-Blattgehalt von $10 \mathrm{mg} / \mathrm{g}$ eine ausreichende Versorgung gewährleistet. In diesem Bereich liegt wiederum nach Heinsdorf (1999) bereits die obere Grenze einer Überversorgung mit Kalium. Untersuchungen an Eichen auf Kippenstandorten bestätigten nach Stähr (2003) eher die von Heinsdorf festgelegten Versorgungsbereiche.

Die obere Grenze einer Extremversorgung mit Calcium liegt nach Heinsdorf (1999) demnach bei Blattgehalten von gut 15 mg/g, während das österreichische BFW (2005/7) erst ab diesem Wert eine optimale Calcium-Versorgung bei Eichen sieht.

Ein ähnlicher Widerspruch ergibt sich bei der Bewertung der Zink-Blattgehalte, die nach Heinsdorf bei mehr als $40 \mathrm{mg} / \mathrm{g}$ bereits die Obergrenze einer Extremversorgung überschreiten, nach dem BFW dagegen erst ab $50 \mathrm{mg} / \mathrm{g}$ auf eine optimale Versorgung hinweisen.

\subsection{Spitz-Ahorn}

Die vom österreichischen BFW (2005/7) als ausreichend aufgeführten Element-Gehalte in Ahorn-Blättern stimmen überwiegend mit den entsprechenden Einschätzungen in Bergmann (1993) überein. Die Literatur-Zusammenstellung in van den Burg $(1985,1990)$ weist naturgemäß größere Spannweiten auf. Widersprüche ergeben sich hinsichtlich der Grenzen zwischen mangelhaften und ausreichenden Phosphor-Gehalten, die bei van den Burg mit 1,3 $\mathrm{mg} / \mathrm{g}$ niedriger liegt als bei Bergmann/BFW mit 1,5 mg/g. Gleiches gilt für die entsprechende Grenze bei Kalium-Gehalten (7,8 mg/g bei van den Burg, $10 \mathrm{mg} / \mathrm{g}$ bei Bergmann/BFW). Die Untergrenzen ausreichender Calcium- und Zink-Gehalte liegen umgekehrt bei van den Burg (Ca: $5 \mathrm{mg} / \mathrm{g}$, Zn: $30 \mathrm{mg} / \mathrm{kg}$ ) mehr oder weniger doppelt so hoch wie bei Bergman /BFW (Ca: $3 \mathrm{mg} / \mathrm{g}$, $\mathrm{Zn}: 15 \mathrm{mg} / \mathrm{kg})$.

Für die Laubbaumarten Eberesche und Erle konnten keine artspezifischen Angaben gefunden werden. Die Bewertung der Mineralstoff-Gehalte in der Trockenmasse des Ebereschen- und Erlen-Laubs war daher nach den entsprechenden Einstufungen von Blattgehalten verschiedener Laubbaumarten (Ahorn, Birke, Buche, Eiche, Esche, Linde, Pappel) in Bergmann (1993) erfolgt.

\subsection{Douglasie}

Laut Bergmann (1993) sind bei Douglasien bereits Stickstoff-Nadelgehalte von $11 \mathrm{mg} / \mathrm{g}$ ausreichend, während in IFTNC (1987) und Heinsdorf (1999) erst Gehalte ab 14 bzw. 14,9 mg/g 
als ausreichende Versorgung gelten. Ein Vergleichswert für Fichten des österreichischen BFW (2005/7) setzt eine ähnliche Versorgungs-Untergrenze von $15 \mathrm{mg} / \mathrm{g}$.

Für andere Elemente als Stickstoff konnten allein bei Bergmann (1993) explizite Bewertungen von Element-Gehalten in Douglasien-Nadeln gefunden werden. Ein Vergleich dieser Einstufungen mit den Skalen für Fichten und Kiefern in anderen Quellen zeigte einige Unterschiede. So stimmt die Untergrenze ausreichender Zink-Nadelgehalte $(15 \mathrm{mg} / \mathrm{kg})$ bei Bergmann (1993) mit der Untergrenze geringer Gehalte im Deutschen Waldbodenbericht (BMELF 1997b) überein. Die Spanne ausreichender Kupfer-Nadelgehalte ist mit 2-10 mg/kg bei Bergmann sehr weit und enthält die Untergrenze sehr hoher Gehalte $(7 \mathrm{mg} / \mathrm{kg})$ laut Deutschem Waldbodenbericht, die von weniger als $2 \%$ der im Rahmen des Berichtes untersuchten Fichten überschritten wurde.

Die sowohl im Deutschen Waldbodenbericht als auch vom österreichischen BFW (2005/7) für Kiefern und Fichten gleichermaßen festgelegten Einstufungen von Eisen-Nadelgehalten wurden in der vorliegenden Arbeit zur Beurteilung sowohl der Kiefern als auch - mangels eigener Skalen für diese Baumart - der Douglasien verwendet. Unterschiedliche Wertebereiche der beiden Skalen überschneiden sich stark. So liegt die Spanne ausreichender bzw. optimaler EisenGehalte in BFW (2005/7) zwischen 30 und $180 \mathrm{mg} / \mathrm{kg}$, während in BMELF 1997b bereits Werte ab $100 \mathrm{mg} / \mathrm{kg}$ als hoch eingestuft werden.

\subsection{Wald-Kiefer}

Für die verbreitete Forstbaumart Kiefer liegen vergleichsweise viele Bewertungsskalen für Element-Gehalte in ihren Nadeln vor (Hofmann \& Krauss 1988, Bergmann 1993, BMELF 1997b, BFW 2005/7). Die unteren Grenzen der als ausreichend, optimal oder mittel bezeichneten Gehalte schwanken je nach Quelle für Stickstoff zwischen 14 und 16 mg/g, für Kalium zwischen 3,9 und $5 \mathrm{mg} / \mathrm{g}$, für Calcium zwischen 2,1 und 2,9 mg/g und für Magnesium zwischen 0,6 und 1 mg/g. Völlig aus dem Rahmen fallen die laut Hofmann \& Krauss (1988) bereits optimalen Phosphor-Nadelgehalte von 0,75 bis $1,19 \mathrm{mg} / \mathrm{g}$, die weit unter den in den anderen Quellen als ausreichend angegebenen Gehalten liegen (ab 1,3 bzw. 1,4 mg/g).

Das österreichische BFW (2005/7) legt als Schwefel-Schadstoffgrenzwert je nach Nadeljahrgang Nadelgehalte von $1,1 \mathrm{mg} / \mathrm{kg}, 1,4 \mathrm{mg} / \mathrm{kg}$ und $1,7 \mathrm{mg} / \mathrm{kg}$ fest. Hüttl (1991) geht dagegen von einer optimalen Schwefel-Versorgung bei Nadelgehalten zwischen 1,1 und $2 \mathrm{mg} / \mathrm{kg}$ aus und sieht erst Gehalte über $2 \mathrm{mg} / \mathrm{kg}$ als Zeichen anthropogener Belastung an. Generell fällt auf, dass die beiden älteren Quellen (Hofmann \& Krauss 1988, Hüttl 1991) deutlich höhere Schwefel-Nadelgehalte als gering, ausreichend, hoch etc. bewerten als die jüngeren (BMELF 1997b, BFW 2005/7).

Die Obergrenze mittlerer, optimaler bzw. ausreichender Eisen-Gehalte wird vom BMELF (1997b) bei $100 \mathrm{mg} / \mathrm{kg}$, von Hofmann \& Krauss (1988) und vom BFW (2005/7) bei etwa doppelt so hohen Werten (200 bzw. $180 \mathrm{mg} / \mathrm{kg}$ ) gesehen.

Die Obergrenze ausreichender Kupfer-Gehalte liegt bei Bergmann (1993) mit $10 \mathrm{mg} / \mathrm{kg}$ erheblich höher als in den übrigen Quellen (maximal $7 \mathrm{mg} / \mathrm{kg}$ ). 
Die deutlichsten Diskrepanzen zwischen den verschiedenen Quellen ergeben sich baumartübergreifend bei der Einstufung der Mangan-Gehalte. Ein Grund dafür könnte sein, dass Mangan-Toxizität auf sehr stark sauren Böden häufig mit Aluminium-Toxizität und einem Mangel an Nährelementen einhergeht, was eine genaue Bestimmung der Ursache von Schadsymptomen erschwert (Bergmann 1993, Scheffer \& Schachtschabel 2010).

Nach Heinsdorf (1996) sind Eichen mit Mangan-Blattgehalten von $200 \mathrm{mg} / \mathrm{kg}$ bis rund 400 $\mathrm{mg} / \mathrm{kg}$ mangelhaft versorgt, von rund $400 \mathrm{mg} / \mathrm{kg}$ bis rund $800 \mathrm{mg} / \mathrm{kg}$ unterversorgt und von rund $800 \mathrm{mg} / \mathrm{kg}$ bis $1550 \mathrm{mg} / \mathrm{kg}$ optimal versorgt. Stähr (2003) geht nach eigenen Analysen der Mangan-Blattgehalte von Eichenbeständen von einer ausreichenden Versorgung bei Werten ab $400 \mathrm{mg} / \mathrm{kg}$ aus und widerspricht Bergmann (1993), der in Gehalten von 35-100 mg/kg bereits eine gesicherte Ernährung sieht.

Für Ahorne liegen bei Bergmann (1993) die als ausreichend betrachteten Mangan-Blattgehalte mit 30-100 mg/kg sehr ähnlich (die Spanne von $30 \mathrm{bzw}$. 35-100 mg/kg wird auch für weitere Laubbäume angegeben). In den pflanzenanalytischen Beurteilungswerten des österreichischen Bundesforschungs- und Ausbildungszentrum für Wald, Naturgefahren und Landschaft (BFW) werden für Ahorne Mangan-Gehalte im Laub von 30-150 mg/kg als ausreichend und ab 150 $\mathrm{mg} / \mathrm{kg}$ als optimal eingestuft, während van den Burg $(1985,1990) 473 \mathrm{mg} / \mathrm{kg}$ als obere Grenze ausreichender Normalgehalte ausmacht.

In allen verwendeten Quellen liegen die Bewertungsbereiche für Mangan-Gehalte in den Assimilationsorganen von Nadelbäumen höher als von Laubbäumen. Für Kiefern und Fichten werden meist die gleichen Einstufungen herangezogen. Auch hier bestehen erhebliche Unterschiede zwischen verschiedenen Autoren.

Bergmann (1993) nennt mit ausreichenden Mangan-Nadelgehalten von 50-500 mg/kg wiederum die vergleichsweise niedrigsten Gehalte. Vom österreichischen BFW (2005/7) wird mit Mangan-Gehalten in Nadeln von 50-6000 mg/kg eine sehr weite Spanne als ausreichend bzw. optimal bewertet.

Die im Deutschen Waldbodenbericht (BMELF 1997b) verwendete Klassifikation von ManganGehalten in Nadeln stuft Konzentrationen unter 1000 mg/kg als gering ein. Nach Hüttl (1992) weisen im Falle einer normalen Manganversorgung Fichtennadeln des jüngsten Nadeljahrganges Mangan-Gehalte von 1000 bis 2000 mg/kg Trockenmasse auf.

Bei sehr stark versauerten Waldböden würden laut Scheffer \& Schachtschabel (2010) in Fichtennadeln bis über $5000 \mathrm{mg} / \mathrm{kg}$ gemessen. Fichten seien allerdings gegen Mangan-Toxizität sehr resistent.

Die für Pflanzen generell verallgemeinerten Angaben in Alloway (1999) sehen den Bereich kritischer Mangankonzentrationen, oberhalb dessen toxische Auswirkungen wahrscheinlich sind, bei 300-500 mg/kg. In Scheffer \& Schachtschabel (2010) sowie Bergmann (1993) werden bei Kulturpflanzen bzw. landwirtschaftlichen Nutzpflanzen Mangan-Gehalte von über 1000 $\mathrm{mg} / \mathrm{kg}$ als ein meist sicheres Zeichen für einen Überschuss und das Auftreten von Ertragsminderungen infolge Mangan-Toxizität angesehen. Abgesehen von der auch hier wieder augenfälligen Diskrepanz zwischen den Grenzwerten scheinen auch die hier vorgenommenen Verallgemeinerungen nicht sinnvoll, da die Reaktion auf hohe Mangan-Gehalte stark von der jeweiligen Pflanzenart abhängig sei, wie in Scheffer \& Schachtschabel (2010) selbst betont wird. 
Unter diesem Gesichtspunkt sind neben den bei Alloway (1999) für verschiedene Schwermetalle (Mangan, Zink, Kupfer, Nickel, Kobalt, Blei, Cadmium, Chrom) aufgeführten kritischen Konzentrationen in Pflanzen auch die bei Smidt (1999) ebenfalls für verschiedene Schwermetalle (Zink, Kupfer Nickel, Kobalt, Blei, Cadmium) angegebenen Normalgehalte in Pflanzen im Einzelfall zu hinterfragen.

Zumindest die Werte für Zink (normal nach Smidt 1999: 150-200 mg/kg, kritisch nach Alloway 1999: $100-400 \mathrm{mg} / \mathrm{kg}$ ), Kupfer (normal: $15-20 \mathrm{mg} / \mathrm{kg}$, kritisch: $20-100 \mathrm{mg} / \mathrm{kg}$ ), Blei (normal: 10-20 mg/kg, kritisch: $30-300 \mathrm{mg} / \mathrm{kg}$ ) und vor allem für Cadmium (normal: $5-10 \mathrm{mg} / \mathrm{kg}$, kritisch: $5-30 \mathrm{mg} / \mathrm{kg}$ ) erscheinen sehr hoch und sind sicher nicht für alle Baumarten anwendbar. So sind in sämtlichen sonst verwendeten Quellen die Einstufungen für verschiedene Baumarten teilweise deutlich niedriger.

Dabei liegen die oberen Grenzen ausreichender, mittlerer oder optimaler Kupfer-Gehalte je nach Baumart bei maximal 10 oder $12 \mathrm{mg} / \mathrm{kg}$ (meist noch deutlich darunter) und damit unter der bei Smidt als normal angegebenen Spanne $(15-20 \mathrm{mg} / \mathrm{kg})$. Gleiches gilt für ausreichende Zink-Gehalte, die durchweg im zweistelligen Bereich liegen, während Smidt normale ZinkGehalte in Assimilationsorganen mit 150-200 mg/kg angibt.

Für Kiefern-Nadeln werden in weiteren Quellen vielfach Blei-Normalgehalte von unter $5 \mathrm{mg} / \mathrm{kg}$ angegeben (vgl. Reigber \& Braun 1985). Für Fichtennadeln werden vom österreichischen BFW (2005/7) Blei-Gehalte von 3-5,9 mg/kg und Cadmium-Gehalte von 0,05-0,09 mg/kg als normal eingestuft (Blei-Gehalte ab $20 \mathrm{mg} / \mathrm{kg}$ und Cadmium-Gehalte ab 0,2 mg/kg gelten demnach als sehr erhöht). Als toxische Schwelle für Cadmium-Gehalte in Kiefern-Nadeln werden Werte um 3 mg/kg genannt (vgl. Burse \& Schramm 1996).

Im Deutschen Waldbodenbericht, in den durchaus auch mit Schwermetallen belastete Flächen einbezogen waren, liegen zudem die maximal im Laub von Buchen ermittelten Kupfer-Gehalte immer noch unter den Normalgehalten bei Smidt (1999), während die maximal gemessenen Blei-Gehalte im unteren Bereich dieser Normalgehalte einzuordnen wären. Die Zink- und Cadmium-Gehalte der im Rahmen des Deutschen Waldbodenberichtes untersuchten Fichten und Kiefern weisen ebenfalls Maxima auf, die teils erheblich unter den Normalgehalten bei Smidt liegen. 


\section{Standortproblematik}

Im Folgenden werden die standörtlichen Besonderheiten der bei Ronneburg untersuchten Tagebaufolgeflächen hinsichtlich Klima, Bodenphysik, Bodenchemie, kleinräumiger Standortheterogenität und Mykorrhiza diskutiert.

\subsection{Klimatische Standortbedingungen}

Die in aller Regel ungünstigen bodenphysikalischen Eigenschaften von Haldensubstraten (s.u.) können bereits für sich Überleben und Wachstum von Pflanzen negativ beeinflussen (Bussler et al. 1984). Die Kombination aus unzureichender Wasserverfügbarkeit und einem problematischen Mikroklima (Katzur et al. 1998, Walker 2002) durch stetigen Wind, starke Einstrahlung und entsprechend hohe Verdunstungsraten führt somit erst recht zu trockenen Bodenbedingungen (Schulz \& Wiegleb 2000). Extreme Witterungsbedingungen, wie etwa das in Ronneburg sehr trockene Frühjahr im Jahr der Anlage (2005) sowie der heiße und trockene Sommer 2006, besitzen bei den insgesamt schwierigen Standortbedingungen auf ehemaligen Tagebauflächen sowohl auslösenden als auch mitwirkenden Charakter (Hüttl 1991). Die für die vorliegende Arbeit durchgeführten Freiland-Versuche im ehemaligen Ronneburger Tagebaugebiet erstreckten sich über die beiden (im Vergleich zu langjährigen Mittelwerten für Temperatur und Niederschlag, s. ab S. 14) klimatisch außergewöhnlich ungünstigen Jahre 2005 (warmer, trockener April = Monat der Versuchsanlage) und 2006 („Super-Sommer"). Es kann davon ausgegangen werden, dass die teilweise sehr schlechte Vitalitätsentwicklung der Versuchspflanzen auch mit diesen klimatischen Gegebenheiten zusammenhing. Da jedoch nach Einschätzung des Potsdam-Institutes für Klimafolgenforschung gerade auch in dieser Region Deutschlands die Dürregefahr (geringere Wasserverfügbarkeit, ungünstige klimatische Wasserbilanz, Abnahme der Sommerniederschläge, erhöhte Verdunstung) zukünftig zunehmen wird (UBA 2005), konnten auf diese Weise Baumarten und Bodenhilfsstoffe bereits unter Extrembedingungen getestet werden.

\subsection{Physikalische Standortbedingungen}

Durch die technische Herstellung von Tagebaufolgeflächen (Verschüttung bzw. Absetzung des Haldenabraums, mechanische Belastung durch Befahren mit schwerem Gerät) weisen Kippenstandorte meist hohe Bodendichten auf (Bussler et al. 1984, Katzur \& Haubold-Rosar 1996, Hohensee 2005, Simmons et al. 2008, Scheffer \& Schachtschabel 2010). Im Ronneburger Haldensubstrat, das durch seinen relativ hohen Feinbodenanteil anfälliger für Verdichtung ist als etwa sandige Böden, wurden Bodendichten bis 1,8 g/ $\mathrm{cm}^{3}$ (im Mittel 1,5 g/ $\mathrm{cm}^{3}$ ) gemessen. Bei einem Vergleich von rekonstruierten Haldenböden und ungestörten Referenzflächen in Indiana wurden auf dem Haldenstandort die höheren Bodendichten festgestellt, die mit Werten zwischen 1,5 g/ $\mathrm{cm}^{3}$ und 1,8 g/ $\mathrm{cm}^{3}$ in einem ähnlichen Bereich lagen (Bussler et al. 1984). 
Die Bodenverdichtung hat negativen Einfluss auf Anteil und Durchgängigkeit der Poren im Boden (Hohensee 2005), was zu gestörten Luft- und Wasserregimen führt (Petrova 1995, Häge 1996).

Daneben tragen die oft hohen Skelettgehalte (im vorliegenden Fall bis zu 55 \%) und minimalen Anteile an organischer Substanz in den Haldenböden $\mathrm{zu}$ ihrer meist geringen Speicherkapazität für pflanzenverfügbares Wasser bei (Bussler et al. 1984, Walker et al. 2004, Hohensee 2005). Bussler et al. (1984) ermittelten auf einem Haldenstandort in Indiana verglichen mit einem ungestörten Standort geringere pflanzenverfügbare Wassergehalte von 16,5 Vol.- $\%$ in der obersten und 10,8 Vol.- $\%$ bis 11,7 Vol.- $\%$ in darunter liegenden Bodenschichten. Die im Rahmen der vorliegenden Untersuchungen gemessenen $\mathrm{nFK}$ waren mit 9,1 Vol.-\% in der obersten und 6,9\% in der darunter liegenden Schicht sogar noch deutlich niedriger.

Ein mindestens ebenso großes Problem der Wasserversorgung auf ehemaligen Tagebaustandorten ist die oft geringe Benetzbarkeit, Infiltrationsfähigkeit und Wasserleitfähigkeit der Böden, die die Aufnahme von Niederschlagswasser und die Auffüllung der oft ohnehin geringen Wasserspeicherkapazität erschwert. In der vorliegenden Untersuchung wurden keine entsprechenden Messungen vorgenommen, jedoch zeigten Beobachtungen in Topf-Versuchen mit Haldensubstrat eine extrem langsame Versickerung des zugegebenen Gießwassers. Im Freiland führen diese ungünstigen Substrateigenschaften schon bei geringen Niederschlägen zu verstärktem oberflächlichen Abfluss von Niederschlagswasser, was neben der ungenügenden Wasserversorgung von Pflanzen auch Schäden durch Wassererosion zur Folge hat (Katzur \& Haubold-Rosar 1996, Scheffer \& Schachtschabel 2010). Auf den Ronneburger Versuchsflächen entstanden so durch abfließendes Niederschlagswasser zahlreiche Rinnen sowie bis zu 1,5 m tiefe Gräben (Versuchsfläche A). In ebenen oder ganz leicht eingesenkten Bereichen konnte das Niederschlagswasser dagegen nicht abfließen und bildete wiederum schon bei geringen Niederschlägen aufgrund der sehr verlangsamten Versickerung dauerhaft überstauende Pfützen, was zum Absterben der betroffenen Versuchspflanzen führte. Eine ursprünglich geplante vierte Versuchsfläche „C“ musste aufgegeben werden, da sie oft zu großen Teilen unter Wasser stand.

Als eine Ursache für die herabgesetzte Benetzbarkeit von Haldensubstraten (Häge 1996), die periodisch nach Austrocknung auftritt und lange anhalten kann, vermuten Katzur \& HauboldRosar (1996) auch hydrophobe Reaktionen von Eisen- und Aluminium-Verbindungen in den schwefelhaltigen Tertiärsubstraten.

Der Grund für die geringe Infiltrationsfähigkeit und Wasserleitfähigkeit verdichteter Haldenböden (Bussler et al. 1984, Shrestha \& Lal 2008, Simmons et al. 2008) kann zum einen ein durch Verdichtung verminderter Grobporenanteil sein. Wichtiger als ihr Anteil ist jedoch die Länge und Durchgängigkeit der vertikalen Grobporen, die Niederschlagswasser in tiefere Bodenschichten leiten könnten (Zwölfer et al. 1994). Im vorliegenden Fall des Ronneburger Haldensubstrats ist die Luftkapazität und damit der Anteil weiter Grobporen, die für den Transport von Wasser entscheidend sind, mit 12,8 Vol.-\% bis 13,7 Vol.-\% sogar als hoch einzuschätzen (Bodenkundliche Kartieranleitung 2005; s. S. 41). Ursache für die dennoch beobachtete stark verlangsamte Versickerung von Wasser ist wahrscheinlich eine nicht mehr gegebene Durchgängigkeit (Kontinuität) der Grobporen (Zwölfer et al. 1994) durch Zerscherung im Verlauf der Bodenverdichtung (Thüringer Landesanstalt für Landwirtschaft 2001). 
Thüringer Landesanstalt für Landwirtschaft 2001:

„... die Grobporen (...) sind für den Makrotransport von Wasser und Gasen verantwortlich und bestimmen damit maßgeblich die Durchfeuchtungs- und Durchlüftungsverhältnisse im Boden. Sie sind (...) gegenüber mechanischer Bodenbelastung sehr empfindlich. (...) So wirkt die Druckbelastung eines nassen Bodens knetend. Dabei verändert sich das Porenvolumen nicht oder nur unwesentlich. Es werden aber die Grobporen zerschert. Dabei wird deren Durchlässigkeit unterbrochen. (...)

Die Wasserdurchlässigkeit ist ein Parameter, mit dem die Fähigkeit des Bodens für den Makrostofftransport beschrieben werden kann. Diese Transportleistung (...) hängt vom Anteil an Grobporen, deren effektiver Länge (Tortuosität) und Durchgängigkeit (Kontinuität) ab. Der Einfluss der Porenform wird deutlich, wenn ein Boden mit hohem Grobporenanteil entgegen der Erwartung eine niedrige Durchlässigkeit aufweist. Dann sind diese Poren stark verwickelt oder inselartig angeordnet. ..."

In Scheffer \& Schachtschabel (2010) wird auf das spezielle Problem von Rekultivierungen, die in Form von Schüttungen (früher auch als Spülversatzflächen) hergestellt wurden, hingewiesen. Demnach müsse bei Neuanlage ein Porensystem erzeugt werden, das die jeweils klimabedingt anfallende Wassermenge schnell genug im Bodenvolumen verteilt. Außerdem müsse festgelegt werden, wie viel Wasservorrat im durchwurzelbaren Bereich speicherbar sein muss, damit zu erwartende Trockenperioden nicht die Vegetation schädigen. Zur technischen Umsetzung der Erzeugung eines Porensystems oder einer bestimmten Wasserspeicherkapazität werden keine Angaben gemacht.

Laut der Thüringer Landesanstalt für Landwirtschaft (2001) sind zur Regeneration von Böden mit durch Bodenverdichtung zerscherten Grobporen biogene Regenerierungsprozesse nötig, die mit der Anlage vertikaler Röhren durch Wurmtätigkeit und Wurzelwachstum beginnen. Diese Röhren erhöhen das Grobporenvolumen nur unwesentlich, verbessern aber die Durchlässigkeit des Bodens beträchtlich.

Katzur \& Haubold-Rosar (1996) weisen darauf hin, dass auf verdichteten Haldenböden eine forstliche Nutzung günstiger sei als eine landwirtschaftliche. Der lockernde Effekt von Baumwurzeln und das Ausbleiben des regelmäßigen Befahrens mit in der Landwirtschaft üblichem schwerem Gerät führten zu geringeren Bodendichten und höherer Wasser- und Luftdurchlässigkeit.

\subsection{Chemische Standortbedingungen}

Bei der Charakterisierung von Haldensubstraten hinsichtlich essentieller Nährstoffe und anderer Elemente (ausreichende oder unzureichende Versorgung, Toxizität) bestehen laut Walker et al. (2004) erhebliche Unsicherheiten.

Auf den im Rahmen der vorliegenden Arbeit untersuchten ehemaligen Tagebauflächen bei Ronneburg sind hinsichtlich der bodenchemischen Bedingungen vor allem Pyrit-0xidation und Versauerung, Schwefelbelastung, Aluminium- und Mangantoxizität, Schwermetallbelastung (v.a. Kupfer, Eisen), eingeschränkte Nährstoffverfügbarkeit (v.a. Stickstoff, Phosphor, Kalium, z.T. Calcium) und hohe Magnesium-Gehalte von Bedeutung. 
Die chemischen Bodenbedingungen scheinen für die Pflanzenentwicklung auf diesen Standorten ausschlaggebend zu sein, da sowohl das Vorhandensein von Spontanvegetation als auch die Vitalität der Versuchspflanzen bei allen sechs Baumarten stark vom pH-Wert des Bodens und damit von den davon abhängigen Faktoren Aluminium- und Mangantoxizität, Schwermetalllöslichkeit und Nährstoffverfügbarkeit abhingen.

\subsubsection{Pyrit-Oxidation und Versauerung}

Die Vermischung der Bodenschichten bei der Wiederablagerung von Haldensubstrat begründet letztendlich die auf großer Fläche hoch problematischen bodenchemischen Eigenschaften von Tagebaufolgestandorten. Tertiär-Substrate aus teils großen Tiefen gelangen so an die Bodenoberfläche; die darin typischerweise enthaltenen Eisensulfite, vor allem Pyrit $\left(\mathrm{FeS}_{2}\right)$, werden dem Luftsauerstoff ausgesetzt und oxidieren. Bei ihrer Verwitterung entsteht Schwefelsäure $\left(\mathrm{H}_{2} \mathrm{SO}_{4}\right)$, die den Boden stark bis extrem versauert (Beispiele aus der Lausitz und aus Bayern ebenso wie aus Neu-Kaledonien von Jaffré et al. 1994, Rodenkirchen 1996, Katzur \& Haubold-Rosar 1996, Böcker et al. 1998, Schulz \& Wiegleb 2000, Hüttl 2001). In verschiedenen Arbeiten aus der Lausitz werden pH-Werte von um 3 und deutlich darunter, teilweise bis unter 2 genannt (Katzur 1997, Knoche et al. 2000, Hüttl 2001, Hohensee 2005).

Im Ronneburger Haldensubstrat wurden nicht ganz so niedrige pH-Werte zwischen 3,3 und 4,0 (KCl-Lösung) gemessen; die Bodenreaktion ist damit dennoch bereits als sehr stark sauer einzustufen.

Hüttl \& Weber (2001) beschreiben, dass in Lausitzer Haldenböden auch nach 10-jähriger Bodenentwicklung noch unverwittertes Pyrit (und damit ein hohes Potential zur weiteren Bodenversauerung) zu finden sei. Nach 20 Jahren sei das vorhandene Pyrit komplett verwittert, jedoch seien Kippböden auch noch nach 40 Jahren trotz stattfindender Bodenentwicklung durch den Prozess der Pyritoxidation geprägt (Hüttl 2001).

Die starke Versauerung (verursacht durch die Belüftung von Tertiärsubstraten) stellt das Grundproblem der ungünstigen bodenchemischen Bedingungen auf Haldenstandorten dar. So gehen mit sinkendem pH-Wert zunehmend Protonen, Aluminium sowie Schwermetalle in die Bodenlösung über, was zu Ernährungsstörungen durch Ionenkonkurrenz sowie Öko- und Phytotoxizität führt (Häge 1996, Hüttl 2001, Walker 2002).

Versuchspflanzungen auf unterschiedlich versauerten Kippenstandorten in Pennsylvania zeigten denn auch bei allen verwendeten Baumarten, auch den robustesten Pionieren, nur geringe Überlebens- und Wachstumsraten, wenn der pH-Wert des Bodens unter 3,5 lag (Davidson 1979).

Diese Beobachtung bestätigt sich in den für die vorliegende Arbeit durchgeführten Ronneburger Freiland-Versuchen. Hier war die Pflanzenvitalität aller sechs Baumarten in den Teilbereichen mit durchschnittlichem pH-Wert von 3,6 nachweisbar geringer (ohne Behandlung nach 2 Jahren sehr niedrige Vitalitätswerte; maximal 1,8 bei den Erlen) als in den Teilbereichen mit einem pHWert von im Schnitt 4,0 (ohne Behandlung nach 2 Jahren bei den Erlen, Ebereschen und Douglasien ganz gute Vitalitätswerte von 2,8 bzw. 3,3). In Teilbereichen mit Entwicklung von spontaner Bodenvegetation lagen die pH-Werte bei 4,0, während sich bei $\mathrm{pH} 3,6$ kein Bodenbewuchs einstellte. 


\subsubsection{Schwefelbelastung}

Aufgrund ihres hohen Gehaltes an Eisen-Sulfiden und deren Verwitterung (v.a. PyritVerwitterung) enthalten Tertiärsubstrate hohe Schwefel-Gehalte (Beispiele aus der Lausitz und aus Bayern: Rodenkirchen 1996, Böcker et al. 1998, Katzur \& Haubold-Rosar 1996, Hüttl 2001, Hüttl \& Weber 2001, Münzenberger et al. 2004), die mit den jeweiligen Ton- und Schluffgehalten des Bodens ansteigen (Böcker et al. 1999).

Eine weitere Quelle können Schwefel-Depositionen aus schwefelhaltigen Emissionen (anthropogene $\mathrm{SO}_{2}$-Emissionen) sein, die als $\mathrm{SO}_{2}$-Adsorption an Bodenpartikeln und Vegetation (Laub/Nadeln), aber auch als schwefelsäurehaltiger Niederschlag stattfinden (Scheffer \& Schachtschabel 2010).

Laut LAWuF Gotha (2002) dürfte die Verbindung aus anorganischem Schwefel selbst, der als $\mathrm{SO}_{4}$ in die Bodenlösung übergeht, und den niedrigen $\mathrm{pH}$-Werten der Haldenböden phytotoxisch wirken. Nach Scheffer \& Schachtschabel (2010) kann $\mathrm{SO}_{4}$ nur dann als Schadstoff wirken, wenn es als leichtlösliches Magnesiumsulfat in hoher Konzentration vorliegt (Salzböden). Liegt Schwefel dagegen in Sulfidform (z.B. Eisensulfid) vor, kann durch das Auftreten von Schwefelwasserstoff $\left(\mathrm{H}_{2} \mathrm{~S}\right.$; starkes Pflanzengift $)$ Pflanzenwachstum mehr oder weniger vollständig unterbunden werden.

Mit Konzentrationen zwischen 0,4 mg/g und 3,2 mg/g (im Mittel 1,4 mg/g) wies das Ronneburger Haldensubstrat sehr erhöhte Schwefel-Gehalte auf, die sich in über extremen, toxischen, jenseits von Schadstoffgrenzwerten liegenden Schwefel-Gehalten in den Assimilationsorganen der Versuchspflanzen aller sechs getesteten Baumarten niederschlugen (z.B. das sehr geringe Wachstum der besonders stark belasteten Ahorne könnte hierdurch erklärt werden). Baum (2004) stellte einen Einfluss des Schwefel-Gehaltes auf die Mykorrhiza in kontaminierten Böden fest. Das besonders schlechte Abschneiden aller Baumarten auf Versuchsfläche A könnte somit unter anderem auf den dort höchsten Schwefel-Bodengehalt von $2 \mathrm{mg} / \mathrm{g}$ zurückgeführt werden (direkt durch Pflanzenschädigung und indirekt durch Mykorrhiza-Einschränkung). Insgesamt kann die Schwefel-Belastung sicher als eines der Hauptprobleme am Ronneburger Standort gesehen werden.

\subsubsection{Aluminium- und Mangantoxizität}

Auf Haldenstandorten führt die bei Pyrit-Verwitterung entstehende Schwefelsäure $\left(\mathrm{H}_{2} \mathrm{SO}_{4}\right) \mathrm{zu}$ einer beschleunigten Bodenversauerung und hat so u.a. die Freisetzung von Protonen, $\mathrm{SO}_{4}^{-}, \mathrm{Fe}-$ und Al-Ionen zur Folge (Katzur 1997, Katzur et al. 1999b, Münzenberger et al. 2004, Hohensee 2005, Scheffer \& Schachtschabel 2010). Unter solchen Bedingungen kann die Wuchsleistung von Pflanzen durch Aluminium-Toxizität und die Protonen-Konzentration begrenzt sein (Ulrich 1980/81). Zwar weisen viele Waldstandorte keine höheren pH-Werte auf. Nach Hüttl (1991) sind viele Waldbäume, vor allem richtig ernährte und mykorrhizierte Bäume, tolerant gegenüber Aluminium-Toxizität. Laut Ulrich (1980/81) bestehen bei einer fortgeschrittenen Versauerung jedoch große Schwierigkeiten bei der Begründung eines neuen Bestandes.

Das Wurzelsystem von Bäumen wird durch Aluminium-Toxizität eingeschränkt, indem sich Wurzeln aus tieferen Bodenschichten zurückziehen und gleichzeitig weniger Feinwurzeln gebildet werden (Ulrich 1980/81), mit negativen Effekten sowohl auf die Ernährungssituation als auch auf die Wasserversorgung und Stabilität der Pflanze. 
Zudem führt ein $\mathrm{Al}^{3+-}$ Überschuß in der Bodenlösung zu direkten Wurzelschädigungen, was ebenfalls die Ionen- und Wasserverlagerung von der Wurzel in den Spross hemmt (Bergmann 1993, Scheffer \& Schachtschabel 2010).

Eine pflanzenschädigende Aluminiumkonzentration in der Bodenlösung wird deshalb nicht unbedingt durch überhöhte Aluminium-Gehalte in der Pflanze angezeigt, sondern vielmehr indirekt in Form von Nährstoffmangel. Vor allem die Phosphor-Aufnahme wird durch $\mathrm{Al}^{3+}$ Toxizität gehemmt, so dass niedrige Phosphor-Gehalte stets auf $\mathrm{Al}^{3+-U ̈ b e r s c h u s s ~ s c h l i e ß e n ~}$ lassen, falls kein Phosphor-Mangel im Boden vorliegt (Bergmann 1993).

Stähr et al. (1999) nennen als weitere Ursache für Phosphor-Mangel in Pflanzen eine PhosphorFestlegung in kohlehaltigen Kippenböden.

Da die Phosphor-Gehalte in den Ronneburger Kippenböden innerhalb der üblichen Spanne in ungedüngten Böden der gemäßigten Breiten liegen (Scheffer \& Schachtschabel 2010; s. S. 48) und das Substrat aufgrund seines geringen Kohlenstoff-Gehaltes als kohlefrei gelten kann (s. S. 47), ist der bei allen Baumarten, vor allem bei den Ahornen und Ebereschen feststellbare Phosphor-Mangel vermutlich auf Aluminium-Toxizität (und Mangan-Toxizität, s.u.) zurückzuführen. Darüber hinaus weisen alle Baumarten teils exorbitant hohe AluminiumGehalte in ihren Assimilationsorganen auf.

Hohe Aluminium-Konzentrationen können nicht nur auf die Wurzeln von Waldbäumen, sondern auch auf ihr Mykorrhizasystem toxisch wirken (Scheffer \& Schachtschabel 2010), was wiederum die Nährstoff- und Wasserversorgung der Bäume verschlechtert.

Insgesamt stellen auf $\mathrm{Al}^{3+-}$ Überschuss beruhende Schädigungen einen wesentlichen wachstumsbegrenzenden Faktor vieler saurer Böden dar. $\mathrm{Al}^{3+}$-Anreicherung wird damit als Hauptursache für die Schadwirkungen saurer Böden auf Pflanzen angesehen (Bergmann 1993).

Nach Scheffer \& Schachtschabel (2010) haben sowohl $\mathrm{Al}^{3+-}$ als auch $\mathrm{Mn}^{2+-}$ Ionen toxische Wirkungen auf Bäume. Aluminium- und Mangantoxizität sei auf sehr stark sauren Standorten (mit) eine wesentliche Ursache für Waldschäden.

Während Aluminium-Toxizität in anderen Arbeiten als Problematik von sehr stark versauerten Haldenstandorten angesprochen wird, kommt Mangan-Toxizität meist nicht vor. Beides ist jedoch auf sehr stark sauren Standorten häufig verbunden, was z.B. eine genaue Bestimmung der Ursache von beobachteten Schadsymptomen erschwert (Bergmann 1993, Scheffer \& Schachtschabel 2010).

Nach Bergmann (1993) ist Manganüberschuss in der Praxis weit häufiger verbreitet als angenommen. Es handelt sich um einen wesentlichen wachstumshemmenden Faktor auf sauren Böden. Unter reduzierenden Bedingungen bei pH-Werten $<5,5$ hat Mangan eine hohe Löslichkeit. Dabei werden große Mengen an Mangan von den Pflanzen aufgenommen und in die Assimilationsorgane eingelagert. Als Faktoren, die zu einer starken Freisetzung, Anreicherung und Aufnahme von Mangan bis hin zur Toxizität führen können, werden neben hohen austausch- und verfügbaren Bodengehalten relativ niedrige pH-Werte $(<5,5 / 6,0)$, ein hohes Reduktionsvermögen der Böden (staunasse/zeitweilig überflutete Böden), Bodenverdichtung und -verschlämmung sowie unzureichende Kalkversorgung bzw. länger unterlassene KalkDüngungsmaßnahmen genannt. Auch nach Scheffer \& Schachtschabel (2010) können bei hoher 
$\mathrm{Mn}^{2+}$-Konzentration in stark sauren, tonreichen Böden, besonders bei schlechter Dränung oder zeitweiliger Überflutung, toxische Wirkungen bei Pflanzen auftreten.

Aufgrund der ungünstigen bodenphysikalischen Eigenschaften des Haldensubstrats am Ronneburger Standort sind die genannten Faktoren dort zumindest in Teilbereichen gegeben. Zusammen mit der durch die Versauerung ohnehin hohen Löslichkeit von Mangan spiegelt sich dies in den teilweise exorbitant hohen Mangan-Gehalten der Assimilationsorgane der Versuchspflanzen wider (anders als Aluminium-Toxizität wird Mangan-Toxizität durch einen hohen Mangan-Gehalt in den Pflanzen angezeigt; Bergmann 1993, Scheffer \& Schachtschabel 2010), die zumindest bei den Laubbäumen teilweise phytotoxische Konzentrationen erreichen dürften.

Hohe Mn-Konzentrationen in der Bodenlösung beeinträchtigen offenbar nicht nur (gemeinsam mit hohen Fe- und Al-Konzentrationen) in Form von Ionenkonkurrenz um Austauscherplätze die Ernährungssituation von Pflanzen (Verdrängung von anderen Nährelement-Ionen). Block (1997) beobachtete bei Douglasien eine Behinderung der Phosphor- und Magnesiumaufnahme bei hohen Mangan-Gehalten im Boden, was an die verminderte Phosphoraufnahme bei hohen Al-Konzentrationen in der Bodenlösung erinnert.

Generell ist die Reaktion auf hohe Mangan-Gehalte stark von der jeweiligen Pflanzenart abhängig (Scheffer \& Schachtschabel 2010). Auch ergeben sich bei der Einstufung schädigender Gehalte in Assimilationsorganen große Unterschiede zwischen verschiedenen Autoren, wie ab Seite 333 dargelegt ist.

Auf den im Rahmen der vorliegenden Arbeit untersuchten Flächen bei Ronneburg könnte Aluminium- und Mangantoxizität ein Grund für die trotz ausreichender Phosphor-Gehalte und Basen-Sättigungen unzureichenden Nährstoffversorgungen der Versuchsbäume sein (allerdings gerade nicht bzgl. Magnesium).

\subsubsection{Schwermetallbelastung}

Tagebau-Kippsubstrate weisen oft hohe Schwermetall-Gehalte auf. So enthalten die Folgeflächen bayerischer Pyriterz-Tagebaue sehr hohe Konzentrationen an Eisen, Kupfer und Zink (Rodenkirchen 1996). Nach Nickelerz-Extraktion in Neu-Kaledonien wurden in den Rohböden hohe Nickel, Chrom- und Eisenmengen festgestellt (Cherrier 1990, Jaffré et al. 1994). Hüttl (2001) nennt für Lausitzer Untersuchungsflächen ebenfalls hohe Eisen-Gehalte. Vor allem die Schluff- und Tonfraktionen von Haldenböden im Südschwarzwald sind reich an Blei, Zink, Kupfer und Cadmium (Hurrle 1981).

Auf den Ronneburger Versuchsflächen wurden vor allem starke Kupfer-Belastungen gemessen. Staudenrausch et al. (2005) stellten in dieser Region im selben Zeitraum ebenso hohe Kupfer-Gehalte fest. Die im Rahmen der vorliegenden Arbeit durchgeführten Messungen erbrachten zudem sehr hohe Cadmium-Gehalte und erhöhte Chrom-Konzentrationen.

Die niedrigen $\mathrm{pH}-$ Werte der Haldensubstrate führen zu einer Mobilisierung von Schwermetallen, die phyto- bzw. ökotoxische Konzentrationen in der Bodenlösung erreichen können (Katzur 1997, Hüttl 2001, Hohensee 2005). Neben schädigenden Wirkungen bei verstärkter Pflanzenaufnahme besteht die Gefahr der Auswaschung von Schwermetallen und damit der 
Kontamination von Oberflächengewässern und Grundwasser (Wolff \& Riek 1995, Katzur 1997, Hohensee 2005).

Auf den Ronneburger Versuchsflächen ergab die Analyse der Assimilationsorgane bei fünf der sechs verwendeten Baumarten hohe Kupfer-Belastungen (Eiche, Ahorn, Erle, Douglasie und Kiefer). Bei Eichen und Ahornen wurden zudem belastende Eisen-Gehalte festgestellt, während Erlen und Kiefern belastende Nickel-Konzentrationen aufwiesen. Auf die teils exorbitant hohen Mangan-Gehalte wurde in diesem Kapitel bereits eingegangen.

Die im Rahmen der vorliegenden Untersuchungen in den Assimilationsorganen gemessenen Eisen-Gehalte erscheinen im Vergleich mit auf anderen Tagebaustandorten ermittelten Belastungen teilweise sehr hoch. So nennt Hurrle (1981) hohe Eisen-Konzentrationen in den Nadeln verschiedener Baumarten auf Bergbauhalden im Südschwarzwald von $261 \mathrm{mg} / \mathrm{kg}$. Die im Ronneburger Versuch gemessenen Werte lagen im Mittel noch etwas darüber bei $280 \mathrm{mg} / \mathrm{kg}$ (Kiefer) und $297 \mathrm{mg} / \mathrm{kg}$ (Douglasie), erreichten jedoch maximal $357 \mathrm{mg} / \mathrm{kg}$ bzw. $519 \mathrm{mg} / \mathrm{kg}$. Noch deutlicher ist die Diskrepanz zwischen einem als exorbitant hoch bezeichneten Einzelwert in Eichen-Blättern auf einem meliorierten Kippenstandort, der bei 310 mg/kg lag (Stähr 2003), und den auf den Ronneburger Flächen gemessenen Werten. Bei den Eichen wurden hier in Mischproben je Variante Eisen-Blattgehalte von 167 - 3291 (im Mittel 1163) mg/kg, bei den Ahornen von 253 - 1466 (im Mittel 819) mg/kg festgestellt. Bei den Erlen ergaben die Analysen 152 - 798 (im Mittel 308) mg/kg, bei den Ebereschen 100 - 403 (im Mittel 197) mg/kg, so dass auch bei dieser am wenigsten mit Eisen belasteten Baumart einzelne Varianten Werte oberhalb des von Stähr (2003) hervorgehobenen Einzelwertes zeigten.

Im Gegensatz zu anderen Untersuchungen auf Kippenstandorten (z. B. Hurrle 1981) wurden im Rahmen der vorliegenden Arbeit keine Belastungen der bei Ronneburg gepflanzten Bäume mit Blei, Cadmium oder Zink festgestellt.

Angesichts der sehr hohen gemessenen Cadmium-Bodengehalte verwundert die Tatsache, dass die Cadmium-Gehalte in den Assimilationsorganen der Versuchspflanzen überwiegend unter der Nachweisgrenze lagen. Dazu kommt, dass drei Jahre vor den Analysen im Rahmen dieser Arbeit auf denselben Flächen von der Thüringer Landesanstalt für Wald und Forstwirtschaft (LAWuF Gotha 2002) um ein Vielfaches geringere Cadmium-Gehalte ermittelt wurden (s. S. 46).

Vor diesem Hintergrund können Fehler beim Messen beider Messreihen (Freiland-Proben im Jahr 2005, Gewächshaus-Proben im Jahr 2006) oder aber beim Ein- bzw. Übertragen der Messdaten (Komma-Verschiebung) nicht gänzlich ausgeschlossen werden.

\subsubsection{Nährstoffverfügbarkeit}

Haldenstandorte werden häufig als nährstoffarm charakterisiert (Katzur 1997, Böcker et al. 1998, Knoche et al. 2000, Schulz \& Wiegleb 2000, Walker 2002). Grund dafür können einerseits geringe Makronährstoff-Gehalte der Substrate (Beispiele aus der Lausitz und Neu-Kaledonien: Cherrier 1990, Jaffré et al. 1994, Häge 1996, Hüttl \& Weber 2001, Hohensee 2005), andererseits eine vor allem durch Versauerung herabgesetzte Verfügbarkeit vorhandener Nährstoffe (Beispiele aus der Lausitz und der Ronneburger Region: Katzur \& Haubold-Rosar 1996, Kohls et al. 1999, Münzenberger et al. 2004, Hohensee 2005) sein. 
So senkt die bei der fortgesetzten Pyrit-Oxidation auf Tagebaufolgeflächen entstehende Schwefelsäure $\left(\mathrm{H}_{2} \mathrm{SO}_{4}\right)$ die pH-Werte des Substrats (Bodenversauerung), was zur verstärkten Lösung und Auswaschung von Schwermetallen und Nährstoffen führt (Scheffer \& Schachtschabel 2010). Mit zurück gehenden pH-Werten werden Aluminium, Mangan und Eisen zunehmend mobil. Der Anteil entsprechender Ionen sowie der Protonen an der Austauscherbelegung steigt, während gleichzeitig der Anteil an Ca-, Mg-, Ka- und Na-Ionen (Basen-Sättigung) sinkt. Damit verschlechtert sich die Ernährungssituation von Pflanzen (Scheffer \& Schachtschabel 2010, Bergmann 1993).

Laut Häge (1996) ist ein großer Teil der Haldenböden in der Lausitz aufgrund ihrer ungünstigen Bodeneigenschaften selbst nach aufwendigen Meliorationsmaßnahmen nur wenig fruchtbar.

Dagegen wird laut Böcker et al. (1998) die Nährstoffausstattung von Kippenböden vielfach unterschätzt. Zwar sei bei Kippenerstaufforstungen durch Nährstoffmangel (v.a. N, P) limitiertes Pflanzenwachstum in den ersten Jahren nichts Außergewöhnliches (z.B. Münzenberger et al. 2004), mit Bestandesentwicklung und Etablierung ökosystemarer Stoffkreisläufe verbessere sich die Ernährungssituation jedoch zunehmend (Stähr et al. 1999, Knoche et al. 2000, Katzur \& Böcker 2001). Aufgrund der oft hohen Grundausstattung frisch verkippter Substrate (Stähr et al. 1999) können „junge“ Haldenböden sogar ein höheres Nährstoffpotential aufweisen als ungestörte Standorte, die schon lange Zeit Verwitterungs- und Stoffverlagerungsprozessen unterliegen (Katzur 1997, Böcker et al. 1998, 1999). Bei einem Vergleich von Kippen- und ungestörten Flächen im Südwesten Indianas war die chemische Ausstattung des Kippsubstrats ebenfalls mindestens gleichwertig oder besser als die der Referenzböden (Bussler et al. 1984).

Auf den Ronneburger Versuchsflächen wurden aufgrund der bislang fehlenden HumusAkkumulation erwartungsgemäß geringe Stickstoff-Bodengehalte gemessen (Stähr et al. 1999), was bei allen Baumarten (mit Ausnahme der durch ihre Symbiose mit Luftstickstoff-fixierenden Bakterien vom Stickstoffangebot des Standortes unabhängigen Erle) zu unzureichenden Stickstoff-Gehalten in den Assimilationsorganen führte. Darüber hinaus war jedoch auch hier eine zumindest potentiell gute Nährstoff-Situation gegeben. So lagen die Phosphor-Gehalte des Bodens im Rahmen üblicher Werte (Scheffer \& Schachtschabel 2010), die Basen-Sättigung trotz hoher Löslichkeit von Aluminium, Mangan und Eisen im mittleren bis mäßig hohen, basenreichen Bereich (BMELF 1997b, AK Standortskartierung 2003).

Dennoch zeigten die Analysen der Assimilationsorgane unzureichende Versorgungen der Versuchspflanzen mit Phosphor und, Eichen und Kiefern ausgenommen, Kalium an. Bei den im Vergleich etwas anspruchsvolleren Ahornen und Douglasien wurden zudem teils zu geringe Calcium-Gehalte, bei den unbehandelten Douglasien sogar (trotz genereller Extremversorgung, auch bei allen Douglasien-Behandlungsvarianten) ein knapp nicht ausreichender MagnesiumGehalt ermittelt.

Als Grund für die Ernährungsstörungen bleibt eine Hemmung der Nährstoff-Aufnahme durch phytotoxische Gehalte von Aluminium, Mangan, Kupfer und Schwefel und eine auch dadurch verursachte Wurzelschädigung zu vermuten. Auch könnten z.B. die überhohen MagnesiumGehalte und -Sättigungen durch Nährstoffantagonismen/Ionenkonkurrenz etwa für die teils unzureichende Kalium-Ernährung der Versuchspflanzen mit verantwortlich sein. Zudem können sehr tiefe pH-Werte zu einer geringen Löslichkeit von Phosphaten führen. 


\subsubsection{Hohe Magnesium-Gehalte}

Das Ronneburger Haldensubstrat wies überraschend hohe Magnesium-Gehalte auf, die zu ebensolchen Magnesium-Sättigungen und überwiegend extrem hohen Blatt- und Nadelgehalten führten.

Der Bodengehalt lag mit im Schnitt 5,3 mg/g deutlich höher als etwa der von Hohensee (2005) im Mineralboden meliorierter Lausitzer Kippenstandorte gemessene Magnesium-Gehalt von 2,1 mg/g. Katzur et al. (1999b) maßen auf ebensolchen Standorten Mg-Sättigungen zwischen 1,8 \% und 12,5\%, was als ausreichend bis hoch eingestuft wird. Die Magnesium-Sättigungen im Ronneburger Haldensubstrat lagen dagegen bereits ohne Kalkung bei mindestens 8,0 \% (Fläche A), auf den fünf Jahre vor der Probennahme mit 2,7 t/ha Magnesiumkalk gedüngten Flächen B und D zwischen $19,4 \%$ und $33,7 \%$.

Sie übertreffen damit zum Teil sogar die nach Scheffer \& Schachtschabel (2010) in landwirtschaftlich genutzten Böden üblichen Werte von 5-25 \% (für die (Kultur-) Pflanzenversorgung werden hier Werte um $15 \%$ als optimal angesehen).

Auf Haldenstandorten (versauert, Mangan- und Aluminium-Toxizität) wird sonst oft eine mangelhafte Magnesium-Versorgung beschrieben (z.B. Hüttl 1991, Scheffer \& Schachtschabel 2010). Jedoch enthielten auch Rohböden nach Nickelerz-Tagebau in Neu-Kaledonien trotz Mangel bei den anderen Makronährstoffen hohe Magnesium-Gehalte (Cherrier 1990, Jaffré et al. 1994). Meliorierte Kippenstandorte in der Lausitz wiesen laut Münzenberger et al. (2004) ebenfalls unter anderem hohe Magnesium-Konzentrationen in der Bodenlösung auf.

In Stähr et al. (1999) führte eine teilweise vorliegende Extremversorgung von Kiefern, Eichen und Birken auf ebensolchen Standorten in der Lausitz nicht zu erkennbaren Schäden und/oder Wuchsdepressionen. Laut Fiedler (1988), Heinsdorf (1988) und Hofmann \& Heinsdorf (1990) können hohe Gehalte wichtiger Elemente wie Stickstoff und Schwefel in Assimilationsorganen (im Bereich einer Über- oder Extremversorgung) auf eine hohe technogene Belastung mit deutlicher Beeinträchtigung von Vitalität und Stabilität hinweisen, während über optimale Kalium- und Calcium-Gehalte kaum akute Ökosystemschäden zur Folge haben. Auch Bergmann (1993) führt an, dass hohe oder besser relativ hohe Konzentrationen an Makronährstoffen meist unproblematisch sind. Mit Ausnahme von N-Überschuss würden diese selten zu starken Schäden oder zum Absterben von Pflanzen führen. Jedoch könnte die überhohe MagnesiumKonzentration zu Lasten der Verfügbarkeit anderer Nährstoff-Kationen gehen, da z.B. die an den Austauschern sorbierte Kalium-Menge auch von Art und Konzentration der konkurrierenden Kationen (Aluminium, Calcium, Magnesium) abhängt (Scheffer \& Schachtschabel 2010). Die trotz der im Rahmen üblicher Werte liegender Kalium-Bodengehalte (Scheffer \& Schachtschabel 2010) auf den Ronneburger Versuchsflächen ermittelte teils unzureichende Kalium-Ernährung der Versuchsbäume könnte somit auch durch die sehr hohen Magnesium-Gehalte und Sättigungen erklärt werden.

Bei zukünftigen Bodenmeliorationsmaßnahmen auf den Ronneburger und vergleichbaren Standorten erscheint in jedem Fall die Verwendung magnesiumfreier Düngekalke angezeigt. 


\subsection{Kleinräumige Standortheterogenität}

Auf Tagebaufolgeflächen gilt eine hohe kleinräumige Standortheterogenität als charakteristisches Merkmal derart gestörter Landschaften (Wecker 2005). Sie ist das Ergebnis der Vermischung von Sedimentmassen aus unterschiedlichen, teils großen Tiefen bei Abbau, Transport, Lagerung und Wieder-Verfüllung sowie einer fortschreitenden Pyrit-Oxidation und Versauerung (z. B. Gerke 2006, Baumann et al. 2005, Hangen et al. 2005, Hüttl \& Weber 2001).

Auf kleinstem Raum können sich sowohl bodenphysikalische als auch bodenchemische Parameter erheblich ändern. Münzenberger et al. (2004) nennen schwankende pH-Werte und weisen darauf hin, dass die physikalischen und chemischen Bedingungen der oberen Bodenschicht auch noch nach einer Melioration sehr heterogen bleiben. Auch Böcker et al. (1998) stellten wechselnde Aziditäten in bereits grundmeliorierten Kippenböden fest. Nach Wecker (2005) trägt die Einarbeitung basischer Meliorationsmittel in den Oberboden sogar zusätzlich zur Heterogenität der Standortbedingungen bei.

Die hohe kleinräumige Substratheterogenität vor allem der chemischen Bodenbedingungen führt zu einer unausgewogenen Nährstoffverfügbarkeit (Münzenberger et al. 2004), zudem entwickeln sich Wurzelsysteme und Mykorrhiza anders als auf ungestörten Flächen (Hüttl \& Weber 2001, Münzenberger et al. 2004).

Die Besonderheit der Haldenstandorte stellt auch ihre wissenschaftliche Untersuchung vor Schwierigkeiten, indem durch die auf kleinstem Raum unterschiedlichen Standortbedingungen die Streuungen von Einzelmessungen erwartungsgemäß hoch sind (Hohensee 2005), was ihre statistische Analyse und die Herausarbeitung signifikanter Unterschiede und Zusammenhänge erschwert. Dazu besteht das Problem der Nicht-Erfassung von heterogenen Bodenverhältnissen bei der Bildung von Mischproben oder der Betrachtung von Mittelwerten (Wecker 2005).

Die drei untersuchten Ronneburger Versuchsflächen (A, B und D) unterschieden sich vor allem hinsichtlich ihrer chemischen Bodenbedingungen. Sie wiesen teilweise deutlich schwankende Nährelement- und Schwermetall-Gehalte sowie unterschiedlich hohe Austauschkapazitäten auf. Auch innerhalb der nur etwa $2.000 \mathrm{~m}^{2}$ großen Versuchsflächen bestanden kleinräumige Standortunterschiede. Auf den Flächen B und D wurde dies klar durch die in manchen Bereichen auflaufende Spontanvegetation indiziert, während direkt benachbarte Bereiche frei von Bodenbewuchs blieben. Der einzige nachweisbare, jedoch offensichtlich wesentliche Unterschied zwischen diesen Bereichen war der in der obersten Bodenschicht leicht, aber signifikant höhere pH-Wert in bewachsenen Bereichen. Dies war verbunden mit einer veränderten Löslichkeit von Elementen und damit einer für die Pflanzenernährung deutlich günstigeren Austauscherbelegung mit höheren Kalium- (von 0,6 \% auf 2,8 \%) und Calcium- (von $15 \%$ auf $44 \%$ ) Sättigungen, einer insgesamt höheren Basen-Sättigung (von $37 \%$ auf $67 \%$ ) sowie niedrigeren Eisen- (von 1,4 \% auf 0,14 \%), Mangan- (von 1,2 \% auf 0,8 \%) und Aluminium- (von $54 \%$ auf $28 \%$ ) Sättigungen.

Da sich die übrigen Bodenparameter nicht unterschieden, ist als Ursache in diesem Fall weniger unterschiedliches verkipptes Substrat, sondern eher eine unregelmäßige Verteilung des im Jahr 2000 (fünf Jahre vor Versuchsanlage) ausgebrachten Düngekalks zu vermuten. Dafür spricht auch, dass sich auf Fläche A, die von den Kalkungen ausgenommen war, keine Spontanvegetation entwickelte. 
Demnach wäre am Ronneburger Standort eventuell bereits eine leichte Anhebung des pHWertes in der obersten Bodenschicht - im vorliegenden Fall von 3,6 auf 4,0 (gemessen in $\mathrm{KCl}$ Lsg.) - ausreichend, um Pflanzenwachstum und damit eine natürliche Wiederbesiedelung der andernfalls vegetationsfreien Flächen zu ermöglichen.

Arbeiten über Tagebaufolgeflächen in der Lausitz, in Tschechien oder im US-amerikanischen Bundesstaat Washington schildern ebenfalls, dass auf zunächst rohen Kippenböden (Katzur et al. 1999a) Bereiche vegetationsfrei blieben, während sich in anderen Bereichen Spontanvegetation ansiedeln konnte (Heilmann 1990, Prach et al. 1999, Schulz \& Wiegleb 2000).

Wie auch auf den Ronneburger Versuchsflächen handelt es sich bei der spontan auflaufenden Bodenvegetation häufig um (Dominanz-) Bestände von Calamagrostis epigejos (Vosátka 1989, Prach et al. 1999, Katzur et al. 1999a, Schulz \& Wiegleb 2000, Landeck et al. 2001, Hodacova \& Prach 2003, Enkhtuya et al. 2005, Hohensee 2005). Laut Hodacova \& Prach (2003) fördern die technischen Remodellierungsmaßnahmen bei der Herstellung von Tagebaufolgeflächen die Ausbreitung dieses klonal wachsenden Grases durch die Verbreitung seiner Rhizome.

Während die flächenhafte Ausbreitung des konkurrenzstarken Grases vielfach als negativ angesehen wird, da sie eine Gehölzbesiedelung erschwert (Schulz \& Wiegleb 2000), konnten in verschiedenen Untersuchungen auf Haldenstandorten in der Lausitz und in Nord-Böhmen auch positive Aspekte festgestellt werden.

So begünstigte laut Boronczyk (2006) die Deckung von Calamagrostis epigejos das Höhenwachstum von Ahornen auf Haldenstandorten.

In einem weiteren Beispiel wiesen die Wurzeln von Acer pseudoplatanus auf Kippenflächen mit Gras-Unterwuchs (Calamagrostis spp., Agrostis tenuis) signifikant höhere Mykorrhizierungsraten auf als ohne, wobei dies sowohl für den ganzen Bestand als auch für individuelle Bäume galt. Im Substrat wurden entsprechend in den bewachsenen Bereichen mehr Mykorrhiza-Pilz-Sporen gefunden als in vegetationsfreien Bereichen (Vosátka 1989).

Bei Versuchen mit Acer pseudoplatanus, Alnus glutinosa und Salix purpurea-Sämlingen in Haldensubstrat wurde durch Bodenbewuchs mit Calamagrostis epigejos nicht nur die Mykorrhiza-Entwicklung beimpfter Sämlinge gefördert, sondern es fanden auch erfolgreiche Infektionen der Bäume mit der arbuskulären Mykorrhiza des Grases über Kontakt mit dessen extraradikalen Mycel statt (Enkhtuya et al. 2005). Direkter Wurzel-Kontakt zwischen BaumSämlingen und Gras beeinflusste dabei das Wachstum der Sämlinge negativ, die MykorrhizaEntwicklung (Kolonisierung der Wurzeln, Sporen-Anzahl, Länge des extraradikalen Mycels) dagegen positiv. Diese Ergebnisse könnten zur Erklärung des in der vorliegenden Arbeit festgestellten geringeren Dickenwachstums der Ahorne auf Standorten mit Bodenvegetation bei gleichzeitig besserer Vitalitätsbewertung dienen.

Angesichts der wichtigen Rolle der Mykorrhiza für das Pflanzenwachstum auf Haldenstandorten könnte das überwiegend nachweisbar bessere Abschneiden der Versuchspflanzen in mit Spontanvegetation (Calamagrostis epigejos, Moose) besiedelten Bereichen der Ronneburger Versuchsflächen somit nicht nur auf die bessere Nährstoffverfügbarkeit (günstigere Austauscherbelegung durch leicht höhere $\mathrm{pH}$-Werte) zurückzuführen sein.

Neben einer Unterstützung der VAM-Infektion durch das Gras könnten die leicht höheren pHWerte in diesen Bereichen auch das Vorhandensein von Ekto-Mykorrhiza-Pilzen erhöhen (bzw. 
überhaupt erst ermöglichen) und die quantitative und qualitative Entwicklung von EktoMykorrhizen fördern (nach Weissenhorn (2002) und Baum (2004) spielt der Boden-pH-Wert vor allem für Ekto-Mykorrhiza-Pilze eine wichtige Rolle). $\mathrm{Zu}$ dieser Überlegung passt der im Rahmen der vorliegenden Untersuchung festgestellte große Einfluss des individuellen Pflanzenstandortes auf die Vitalitäts- und Wachstumsentwicklung der Versuchsbäume, vor allem der obligat auf Ekto-Mykorrhiza angewiesenen Arten.

Ein weiterer Grund für die bessere Entwicklung sowohl der Versuchspflanzen als auch der Mykorrhiza (wiederum mit positivem Einfluss auf die Versuchspflanzen) in diesen Bereichen wäre im Zusammenhang mit den langen Trockenperioden in 2005 und 2006 (s. ab S. 14) ein höherer Verdunstungsschutz durch die Bodenvegetation (Kottke et al. 1993 weisen auf die Abhängigkeit der Mykorrhiza-Vitalität von der Bodenfeuchte hin).

\subsection{Mykorrhiza}

Die Rolle von Mykorrhiza-Pilzen bei der Etablierung von Bäumen auf TagebauRekultivierungsflächen und für die Entwicklung dieser Standorte insgesamt wird vor allem in jüngerer Zeit immer wieder betont (Hüttl 2001, Hüttl \& Weber 2001, Hüttl \& Gerwin 2003, Sänger 2003) und ist entsprechend Gegenstand von Forschungsarbeiten

Mykorrhiza-Pilze stellen laut Sänger (2003) einen wichtigen Faktor bei der Primärsukzession auf Bergbauhalden dar. So könnte die Mehrzahl der Gehölzarten, die zum großen Teil obligatorisch auf die Symbiose mit Pilzen angewiesen sind, ohne Mykorrhiza den Standort Halde nicht besiedeln. Baumarten, die fakultativ mit Mykorrhiza-Pilzen Symbiosen eingehen, zeigen höhere Ausfallraten, wenn diese im Boden fehlen (Grime et al. 1987).

Münzenberger et al. (2004) nennen die Baum-Pilz-Symbiose eine essentielle Strategie für die Etablierung von Wald-Ökosystemen auf Tagebaufolgeflächen als „neuen“ Standorten ("terra nova").

Die Bedeutung von Mykorrhiza gerade auf diesen Flächen hat mehrere Gründe.

So können die Pilzhyphen das erschlossene Bodenvolumen vergrößern und auch in Poren vordringen, die für Feinwurzeln bereits zu klein sind (Jongmans et al. 1997). Dadurch kann die Wasserversorgung erhöht werden, was auf diesen Standorten mit oft limitierender Bodenfeuchte ein substantieller Vorteil sein kann (Walker et al. 2004). Dass Münzenberger et al. (2004) auf gestörten Standorten auch während der trockenen Sommerperiode hohe Mykorrhiza-Vitalität und -Aktivität feststellten, unterstreicht die Bedeutung von Mykorrhiza vor allem auf jungen Rekultivierungsstandorten mit gerade erst beginnender Boden- und Ökosystementwicklung.

Ebenso kann durch Mykorrhizierung die Nährstoffversorgung, vor allem mit Stickstoff und Phosphor, verbessert werden (u.a. Schelter et al. 2000, Caravaca et al. 2003, Sammler 2004, Mäder et al. 2006) was Hüttl \& Weber (2001) als einen Schlüsselfaktor für das Überleben von Bäumen auf jungen Haldenböden bezeichnen. Nach Rieske (2001) profitieren die beteiligten Pflanzen unter nährstoffarmen Standortbedingungen am meisten von ihrer Mykorrhiza. Hohensee (2005) unterstreicht die Bedeutung von Mykorrhiza im Nährstoffkreislauf gestörter Standorte und damit für deren weitere (Boden-) Entwicklung. 
Desweiteren kann eine Mykorrhizierung die Schwermetalltoleranz von Pflanzen auf den meist mit hohen Schwermetall-Gehalten belasteten Kippsubstraten erhöhen, indem die SchwermetallAufnahme in die Pflanzen herabgesetzt wird (Sharples et al. 2000, Baum 2004, Marian et al. 2009). Darüber hinaus sind nach Hüttl (1991) richtig ernährte und mykorrhizierte Bäume auch toleranter gegenüber Aluminiumtoxizität.

Die Anzahl überlebender Ausbreitungseinheiten von Pflanzen und Pilzen in den Substraten von Tagebaufolgeflächen (in diesem Beispiel in der Niederlausitz) ist in der Regel gering, weil der einstige Oberboden - so noch vorhanden - lange Zeit unter unnatürlichen Bedingungen gelagert oder aber mit Unterboden vermischt worden ist (Hohensee 2005).

Haldenrohböden sind zunächst frei von Mykorrhiza-Pilzen, die meist langsam einwandern und bei über längere Zeit fehlenden Wirtspflanzen wieder zurückgehen (Miller 1987, Thompson 1987). In der Lausitz wurde innerhalb kurzer Zeit (eines Jahres) nach der Sanierung eine Besiedlung von Tagebaufolgeflächen mit Pflanzen, Tieren und Mikroorganismen, darunter auch Mykorrhiza-Pilzen und Stickstoff-fixierenden Bakterien, beobachtet (Kolk \& Bungart 2000, Hüttl \& Weber 2001).

Spontaner Bodenbewuchs konnte auch teilweise auf den im Rahmen der vorliegenden Arbeit angelegten Versuchsflächen bei Ronneburg festgestellt werden, jedoch nur in Bereichen, die einen leicht höheren pH-Wert aufwiesen - vermutlich eine Folge der fünf Jahre vor der Versuchsanlage durchgeführten Flächenkalkung (unregelmäßige Verteilung des Düngekalks). Dass in diese Bereiche auch Mykorrhiza-Pilze einwanderten, belegen Fruchtkörperfunde im Gelände. Da der pH-Wert eines Standortes vor allem für Ekto-Mykorrhiza-Pilze auch von Bedeutung ist (Weissenhorn 2002, Baum 2004), ist zu vermuten, dass in die saureren Bereichen der Versuchsflächen ( $\mathrm{pH} 3,6$, keine Bodenvegetation) zumindest weniger Pilze einwanderten.

Dies wiederum könnte - neben der besseren Nährstoffsituation durch die leicht höheren pHWerte - ein Grund dafür sein, warum sich die Versuchspflanzen, vor allem auch die obligat auf Mykorrhiza angewiesenen Nadelbäume und die ebenfalls Ekto-Mykorrhiza bildenden Erlen (Höster 1993), in den bewachsenen Bereichen so deutlich besser entwickelten als in den unbewachsenen.

Ebenso könnte der Faktor Mykorrhiza eine Rolle bei der unterschiedlichen Entwicklung der Versuchspflanzen auf den drei Versuchsflächen spielen. So wurden auf der im Versuchsverlauf zu einem überwiegenden Teil mit Spontanvegetation bewachsenen Fläche B die meisten Pilzfruchtkörper gefunden. Auf der vegetationsfreien Fläche A bildeten sich nur in einem bewachsenen Randbereich Pilzfruchtkörper (der geringe pH-Wert und hohe Schwefel-Gehalt auf dieser Fläche sind auch für Mykorrhiza ungünstig; Weissenhorn 2002, Baum 2004). Auch auf der schließlich knapp zur Hälfte mit Bodenvegetation bewachsenen Fläche D fanden sich Pilzfruchtkörper, jedoch nur in bestimmten Bereichen und nicht so zahlreich wie auf Fläche B.

Wenngleich Pilze auch ohne (oberirdische) Fruchtkörperbildung im Boden vorhanden sein können, deuten diese Beobachtungen möglicherweise auf eine höhere Präsenz potentieller Symbiosepartner auf Fläche B als auf Fläche A hin, was zu den Ergebnissen der Vitalitäts- und Wachstumsanalysen der Baumarten passen würde. Die vergleichsweise positive oder negative Entwicklung der verschiedenen Baumarten auf Fläche D könnte demnach auch mit dem Vorhandensein oder Fehlen der jeweils passenden Partner zusammenhängen. 
In bereits bestehenden Kippenforsten herrschen meist außerordentlich gute Mykorrhizierungsverhältnisse vor (Kolk 1998). Die Entwicklung der Humusschicht beginnt hier mit einer extrem hohen Menge an Bodenpilzen, die auf vergleichbaren, aber ungestörten Standorten generell viel geringer ist (Hüttl \& Weber 2001). So wiesen Kiefern auf rekultivierten Braunkohle-Kippen auch höhere Mykorrhizierungsraten auf als in ungestörten Böden (Münzenberger et al. 2000). Zudem wurde auf gestörten Standorten in der gesamten Vegetationszeit - auch in den trockenen Sommermonaten - eine außerordentlich hohe Vitalität der Mykorrhizen beobachtet (Münzenberger et al. 2004), während auf ungestörten Standorten zwischen Juli und September die Mykorrhiza-Vitalität deutlich zurückging (Münzenberger et al. 1995). Dies ist umso bemerkenswerter, als nach Kottke et al. (1993) die Mykorrhiza-Vitalität normalerweise auch von der Bodenfeuchte abhängt.

Angesichts des warmen, trockenen Frühjahrs 2005 (Jahr der Versuchsanlage) und des heißen, trockenen Sommers 2006 (s. ab S. 14) sowie der durch Bodenverdichtung ungünstigen Wasserversorgung auf den Ronneburger Tagebaufolgeflächen könnte eine derartige, hohe Mykorrhiza-Vitalität und -Aktivität einer der Gründe für die bei allen Versuchspflanzen höheren Überlebensraten in den bewachsenen Bereichen der Versuchsflächen sein (vermutlich mehr Mykorrhiza-Pilze in diesen Bereichen).

Die Frage nach der Auswirkung von problematischen Standortbedingungen auf Tagebaufolgeflächen wie etwa Schwermetall-Kontaminationen auf die Mykorrhiza wird in verschiedenen Untersuchungen unterschiedlich beantwortet.

So führt nach Kothe (2005) auf Waldstandorten eine Schwermetallbelastung des Bodens zur Verringerung der Mykorrhizierung und der Biodiversität der Mykorrhiza-Pilze. Nach Trüby (1994) war bei extrem hohen Schwermetall-Gehalten eine vergleichsweise niedrige Zahl an Pilzarten an der Mykorrhizierung von Waldbäumen beteiligt. Jedoch wiesen die Wurzeln aller untersuchten Bäume vitale Mykorrhizen auf, so dass keine nachhaltige Schädigung des Mykorrhizabesatzes durch toxische Schwermetalle erfolgte. Auch González-Chávez et al. (2009) stellten bei fast allen Pflanzen auf einer Halde mit hohen Cadmium-Gehalten vesikulärarbuskuläre Mykorrhizen fest. Nach Baum (2004) waren auf mit Schwermetall kontaminierten Böden weder die Diversität noch die Besiedlungsrate von Ekto-Mykorrhiza-Pilzen an den Feinwurzeln von Salix caprea reduziert.

Auf Rohbodenstandorten im ehemaligen Uranerz-Tagebaugebiet Ronneburg war nach Staudenrausch et al. (2005) sowohl die Artendiversität der Mykorrhiza-Pilze als auch die Mykorrhizierung der Pflanzen etwa halb so hoch wie auf Referenzstandorten. Das in die Kippenflächen neu eingewanderte Pilzartenspektrum umfasste dabei diejenigen Arten des auf den Referenzflächen heimischen Spektrums, die tolerant gegenüber Schwermetallbelastung, sauren Bodenbedingungen, limitierter Nährstoffverfügbarkeit und problematischem Mikroklima (Trockenheit, hohe Temperatur und Einstrahlung) sind. Speziell angepasste Arten, die nur auf den kontaminierten Böden vorkamen, wurden nicht gefunden.

Die hohe Mykorrhiza-Aktivität auf Kippen zeigt, dass die Mykorrhiza von den extremen Standortbedingungen auf Rekultivierungsstandorten wenig beeinträchtigt wird (Münzenberger et al. 2004).

Dies gilt auch für die im Rahmen der vorliegenden Arbeit untersuchten Tagebaufolgeflächen bei Ronneburg mit ihren teils sehr ungünstigen Standortbedingungen (Versauerung, Schwermetallund Schwefelbelastung, Trockenheit). Einerseits belegen dies die zumindest in den etwas 
weniger sauren ( $\mathrm{pH}$ 4,0), auch mit Moosen und Gräsern bewachsenen Bereichen teils massenhaften Fruchtkörperfunde der Arten Paxillus involutus, Telephora terrestris (auch auf Tagebaufolgeflächen in der Niederlausitz häufig, Hohensee 2005) und Laccaria laccata. Andererseits spricht auch der positive Einfluss der Mykorrhiza-Inokulation auf Pflanzenvitalität und Wachstum gegen eine Einschränkung der Mykorrhiza-Entwicklung und -Aktivität durch die Standortbedingungen. 


\section{Wirkung von Bodenhilfsstoffen}

Im folgenden Kapitel wird die Wirkung der im Rahmen dieser Arbeit getesteten Bodenhilfsstoffe Perlit, Wasserspeichersubstanzen, Kalk, Kompost und Mykorrhiza-Inokulum anhand von (so vorhanden) weiteren Beispielen ihrer Anwendung bei der Rekultivierung von Haldenböden diskutiert.

Es ist zu beachten, dass sich die Ergebnisse dieser Arbeit auf den Zeitraum der ersten zwei Jahre nach der Pflanzung von Bäumen konzentrieren und sich somit Aussagen über BodenhilfsstoffEffekte auch nur für diesen (für die Etablierung von Pflanzen bedeutenden) Zeitraum treffen lassen. Die Fragen nach der Dauer der Wirksamkeit der Behandlungen und der weiteren Entwicklung der Bäume, auch nach einem eventuellen Nachlassen der Wirkung, bleiben offen.

Auf diesen Punkt, wenn auch in einem anderen Maßstab, weisen Hüttl \& Weber (2001) ebenfalls hin. Demnach sind trotz der bereits jahrzehntelangen Rekultivierungsforschung und -erfahrung auf den Lausitzer Tagebaufolgeflächen aufgrund der extremen Standortbedingungen keine sicheren Voraussagen zu einer über diesen Zeitraum hinaus gehenden Entwicklung von Waldbeständen möglich.

Nach Wilden et al. (2001) überwiegt die Störung ehemaliger Tagebauflächen letztlich die Effekte von Bodenhilfsstoff-Behandlungen. So könne durch Mineraldünger, Kompost und Klärschlamm zwar eine Standortverbesserung erreicht werden, der Effekt dieser Maßnahmen auf die chemischen Bodenbedingungen sei im Vergleich zu der Auswirkung der Tagebautätigkeit jedoch gering.

Dennoch ist denkbar, dass mit einer Unterstützung zumindest der ersten, kritischen Anwuchsphase von Bäumen durch den Einsatz von Bodenhilfsstoffen auch ihre weitere Entwicklung positiv beeinflusst oder überhaupt erst ermöglicht werden kann.

\subsection{Zur Verbesserung der Bodenphysik: Perlit, Wasserspeichersubstanzen}

Perlit (expandiertes vulkanisches Material, s. S. 5) scheint bislang nur in einigen wenigen Versuchen zur Verbesserung der Bodenbedingungen auf Haldenstandorten eingesetzt worden zu sein.

So berichten Larson \& Patel (1992) von einem Gewächshaus-Versuch, in dem einjährige Liquidambar styraciflua-Sämlinge in Haldensubstrat nur geringes Wachstum zeigten, während die Mischung dieses Substrats mit Perlit oder Oberboden das Sämlings-Wachstum jeweils verbesserte.

Uresk \& Yamamoto (1986, 1994) testeten in Gewächshaus- und Freiland-Versuchen verschiedene trockenheits- und salztolerante Pflanzenarten mit einer Reihe von Bodenhilfsstoffen vor allem zur Verbesserung der Bodenstruktur, darunter auch Perlit. Im Gewächshaus wurde bei drei der acht verwendeten Arten ein positiver Effekt der PerlitBehandlung auf Überlebensrate und Wachstum (Biomasse) festgestellt (Uresk \& Yamamoto 1986). 
Bei dem darauf folgenden, auf Bentonit-Haldenböden in Wyoming durchgeführten Feldversuch mit einem auf sechs Arten reduzierten Spektrum fielen fünf Arten mehr oder weniger vollständig und eine Art (Atriplex canescens) etwa zur Hälfte aus. Dabei überlebten von den mit Perlit gepflanzten A. canescens $90 \%$, was die höchste Überlebensrate aller Behandlungsvarianten darstellte (Uresk \& Yamamoto 1994).

In einem Freiland-Versuch in den Niederlanden mit ungünstigen physikalischen (Bodenverdichtung) und chemischen (in diesem Fall Salzbelastung) Bodenbedingungen konnte der Einsatz von Perlit die Situation der Bäume nicht verbessern (Weissenhorn 2002).

In den vorliegenden Untersuchungen konnte die Anwendung von Perlit als Beimischung zum Ronneburger Haldensubstrat ebenfalls nicht überzeugen.

Zwar wurden im Topf-Versuch durch Perlit-Gaben die Bodendichte gesenkt und das Gesamtporenvolumen erhöht. Auch konnte eine Verbesserung der Infiltrations- und Wasserleitfähigkeit des Substrats beobachtet werden; seine Wasserspeicherkapazität sank jedoch.

Auf Vitalität und Wachstum der Bäume hatte die Perlit-Gabe überwiegend wenig Wirkung. Lediglich die gegenüber den problematischen (chemischen) Standortbedingungen robusteren Erlen zeigten eine vergleichsweise gute Entwicklung bei Behandlung des Bodens mit Perlit, indem (wie auch in anderen Varianten, s. ab S. 195) ihre Vitalität im Versuchsverlauf nicht signifikant abnahm und ihr Zuwachs sich im 2. Jahr signifikant steigerte.

Bei der Versuchsplanung erschien eine Kombination aus Perlit-Beimischung und Kalk-Gabe (Variante V8) geeignet, um sowohl den bodenphysikalischen als auch den bodenchemischen Standortproblemen zu begegnen. Bei allen Baumarten, bei denen diese Varianten untersucht werden konnte (bei den Eichen und Kiefern aufgrund der hohen Ausfälle nicht möglich), wurden jedoch positive Effekte der Kalk-Gaben in Kombination mit Perlit sogar gemindert.

Dabei fielen in den Assimilationsorganen der Freiland-Versuchspflanzen mit Perlit-Gabe (und hier eben vor allem in der Perlit-Kalk-Kombination V8) hohe, teilweise auch gegenüber der Kontrolle erhöhte Schadstoff-Gehalte auf (Ahorn: S, Mn; Eberesche: S, Fe, Al, Cu; Erle: mangelhafter, mit Abstand geringster P-Gehalt, was auf Al-Toxizität hindeutet; Douglasie: Al, $\mathrm{Cu}$ ). Begründungen dafür oder Beispiele ähnlicher Beobachtungen konnten nicht gefunden werden.

Insgesamt scheint gerade unter den schwierigen bodenchemischen Standortbedingungen auf den Ronneburger Haldenflächen Perlit nicht das Mittel der Wahl zu sein.

Die alleinige Zugabe von Wasserspeichersubstanzen (sowohl des petrochemischen Produktes Stockosorb ${ }^{\circledR}$ als auch des Stärke-basierten Superabsorbers aus Osnabrück) führte im TopfVersuch nicht zu einer Erhöhung der Wasserspeicherkapazität des Haldensubstrats. Eins der Hauptprobleme des dortigen Wasserhaushaltes, die durch Zerscherung der Grobporen sehr geringe Infiltrationsfähigkeit des Bodens, blieb bestehen. Durch eine in Laborversuchen beobachtete Verkrustungsneigung der Stärke-basierten Superabsorber (Kirscht, unveröffentlicht) ist zudem eine Verhärtung der Bodenoberflächen mit negativer Wirkung auf die ohnehin schon geringe Infiltrationsfähigkeit des Bodens denkbar.

Vitalität und Wachstum der im Freiland-Versuch getesteten Baumarten wurden (ohne gleichzeitige Verbesserung der ungünstigen bodenchemischen Bedingungen oder Mykorrhiza- 
Impfung) nicht positiv beeinflusst. Bei den Ahornen und Ebereschen war die Vitalität mit Superabsorber-Gabe sogar signifikant schlechter als in der unbehandelten Kontrolle. In den Wasserspeichersubstanz-Varianten (auch in Kombination mit Kalk) wurden teils sehr hohe, die Belastungen der Kontrollen noch übertreffende Schadstoff-Konzentrationen in den Assimilationsorganen der Versuchsbäume festgestellt (Ahorn: $\mathrm{Mn}$; Eberesche: $\mathrm{S}, \mathrm{Fe}, \mathrm{Al}, \mathrm{Cu}$; Erle: $\mathrm{S}, \mathrm{Fe}, \mathrm{Al}, \mathrm{Cu}, \mathrm{Cr}, \mathrm{Co}$; Douglasie: $\mathrm{Cu}$ ). Dies könnte zumindest teilweise auf eine Verschärfung von reduzierenden Bedingungen im Boden durch die aufgequollenen Wasserspeicher-Gele zurückzuführen sein (z.B. deutlich mehr Mangan-Freisetzung unter reduzierenden Bedingungen nach Bergmann 1993, Scheffer \& Schachtschabel 2010), ließ sich ursächlich jedoch nicht völlig erklären und konnte auch nicht mit ähnlichen Beobachtungen verglichen werden.

Referenzen für die Anwendung von Stärke-basierten Superabsorbern fehlen, da diese im Rahmen der vorliegenden Arbeit erstmals in Freiland-Versuchen eingesetzt wurden.

Andere Arbeiten zum Einsatz von petrochemischen Wasserspeichersubstanzen bei der Rekultivierung von Tagebaufolgeflächen zeigten unterschiedliche Ergebnisse.

Die Wismut $\mathrm{GmbH}$ selbst hat in Sachsen über das Forschungsinstitut für Bergbaufolgelandschaften e.V. den Einsatz von Hydrogelen ohne Erfolg getestet (Arenhövel 2001; genauere Informationen über diese Untersuchung liegen bislang nicht vor)

Beim Pflanzen einheimischer Gehölzarten auf einer ehemaligen Kohle-Tagebaufläche mit verdichtetem Boden in Illinois wurden die Wurzeln zunächst in eine Suspension aus hydrophilen Polymer und Wasser getaucht (Ashby 1997). Effekte auf die Entwicklung der Arten waren kaum nachweisbar.

Mit einem ähnlichen Verfahren (Tauchen der Wurzeln in Wasser-absorbierendes Gel) wurden auf zwei Tagebaufolgeflächen in West Virginia Sämlinge verschiedener Baumarten (darunter auch Quercus rubra und Pinus sylvestris) behandelt, was teilweise zu höheren Überlebensraten führte (Hicks 1992). Ausgenommen bei Robinia pseudoacacia wird der Vorteil durch diese Maßnahme allerdings als eher gering beschrieben.

Auf einer Haldenfläche eines Braunkohle-Tagebaus in Polen wurden verschiedene HydrogelApplikationsformen an Pinus sylvestris-Sämlingen getestet (Ptach et al. 2009). Deren Überlebensrate nach einem Vegetationsjahr unterschied sich nur teilweise von der Kontrolle (in einem Fall etwas höhere, in einem Fall etwas geringere Überlebensraten als ohne Behandlung), während der Zuwachs durch Hydrogel erhöht wurde.

Aufforstungsversuche ehemaliger ostdeutscher Tagebauhalden mit Quercus petraea ergaben dagegen größere Überlebenschancen und Wuchsleistungen der Pflanzen beim Einsatz von Hydrogelen (Katzur et al. 2002).

Auch die Überlebensrate von Abies chephalonica- und Pinus nigra-Sämlingen auf kalkreichen Halden eines Bauxit-Tagebaus in Griechenland lag umso höher, je höher die applizierte Hydrogel-Menge war (Brofas et al. 2004)

In einem Austrocknungsversuch im Gewächshaus mit Populus euphratica (salztolerant) in stark salzhaltigem Haldensubstrat wurde dessen Wasserhaltekapazität sowie die Überlebensdauer und Wurzelmasseproduktion der Pflanzen ebenfalls durch höhere Hydrogel-Applikationen erhöht (Hüttermann et al. 1997). 
Allgemein scheint der Erfolg oder Misserfolg der Verwendung von Wasserspeichersubstanzen von der Textur des $\mathrm{zu}$ behandelnden Substrates abzuhängen. So wurden unter Laborbedingungen in einer Reihe von unterschiedlichen Topf-Versuchen (mit oder ohne Pflanzen) beim Einsatz von Wasserspeichersubstanzen in feinbodenreichen Substraten überwiegend wenig positive (teilweise sogar negative), in sandigen Substraten dagegen meist sehr gute Ergebnisse erzielt (Kirscht, unveröffentlicht). Bei einem Versuch zur Entwicklung trockenheitsempfindlicher Zimmerpflanzen (Schwertfarn Nephrolepis exaltata) in mit Wasserspeichersubstanzen vermischtem Sand konnte die Variante mit dem im Ronneburger Freiland-Versuch so abgeschlagenen Stärke-basierten Superabsorber die ebenfalls guten Ergebnisse in der Variante mit petrochemischen Hydrogel sogar übertreffen.

Dies legt die Vermutung nahe, dass die unter anderen Umständen viel versprechenden Produkte (sowohl die herkömmlichen, auf Erdöl basierenden als auch die sehr begrüßenswerte Entwicklung von neuartigen, aus nachwachsenden Rohstoffen bestehenden Wasserspeichersubstanzen) für die in Ronneburg vorliegenden Standortbedingungen (schluffiger Lehm) nicht geeignet sind.

Bei Rekultivierungsversuchen auf einer Halde einer ostdeutschen Kalimine wurden verschiedene Bodenhilfsstoffe miteinander kombiniert. Flexible Pflanzcontainer mit einer Schicht aus Hydrogel sowie einer Mischung aus Haldensubstrat und getrocknetem bzw. kompostiertem Klärschlamm ermöglichten es Amorpha fruticosa, Elaeagnus angustifolia und Populus deltoides, unter den ungünstigen Standortbedingungen der Halde zu wachsen (Kahl et al. 2000).

In Versuchen zur Rückgewinnung von Halden eines Schiefer-Steinbruchs in Wales wurden mit Kompost gefüllte Pflanztaschen auf einer Schicht aus Hydrogel plaziert. Gegenüber der Variante ohne Hydrogel erhöhte sich die Wachstumsrate (Wurzelwachstum) der gepflanzten Bäume, nicht jedoch ihre Überlebensrate in trockenen Zeiten (Rowe et al. 2005). Die Autoren vermuten, dass Hydrogel die Nährstoffauswaschung aus dem Substrat reduzieren, aber auch einen negativen Effekt auf die Stickstoff-Verfügbarkeit haben könnte. Die wahrscheinlichere Erklärung für die wenig erfolgreiche Anwendung von Hydrogel ist ihrer Meinung nach, dass die Substanz nicht genügend verfügbares Wasser speichern konnte. Die Verfasser führen dies auf Schrumpfungen und Bewegungen des Hydrogels und/oder einen Rückgang der Wasserhaltekapazität durch Umweltfaktoren wie extreme Temperaturen oder Sonnenlicht zurück.

In den Versuchspflanzungen im ehemaligen Ronneburger Tagebaugebiet setzte die Kombination mit Wasserspeichersubstanzen die positive Wirkung von Kalk-Gaben auf Vitalität und Wachstum herab (Ahorn, Eberesche, Douglasie: bei beiden Wasserspeichersubstanzen; Erle: bei Superabsorber) oder verzögerte den Effekt zumindest (Ahorn, Douglasie: bei Superabsorber). Wie beschrieben, zeigten die Bäume in diesen Varianten teils auffallend hohe SchadstoffBelastungen. Bei den Ahornen konnte die Kombination mit Stockosorb® den Kalk-Effekt standortabhängig verstärken (schlechtere, vegetationsfreie Standorte) oder vermindern (günstigere, mit Spontanvegetation besiedelte Standorte).

Die in der vorliegenden Untersuchung sehr erfolgreichen Mykorrhiza-Impfungen führten in Kombination mit Wasserspeichersubstanzen bei den Douglasien zu besseren Ergebnissen hinsichtlich Pflanzenvitalität und -wachstum. Dagegen wurde der Mykorrhiza-Effekt bei den Ahornen wiederum standortabhängig durch Wasserspeichersubstanzen entweder verstärkt 
oder vermindert. Nach Kottke et al. (1993) ist die Bodenfeuchte von Bedeutung für EktoMykorrhiza-Pilze, was zumindest die gute Wirkung der Behandlungskombination bei den EktoMykhorriza-bildenden Douglasien erklären könnte (Ahorne bilden VA-Mykorrhiza aus).

Der Vergleich des an diesem Standort wirkungslosen (teilweise sogar negativ wirkenden) Einsatzes von Wasserspeichersubstanzen allein mit den teilweise sehr positiven Auswirkungen ihrer Kombinationen mit Mykorrhiza-Impfungen weist auf interessante Synergie-Effekte hin. Offenbar konnten die Pflanzen direkt überhaupt nicht, wohl aber indirekt über eine Unterstützung ihrer Mykorrhiza-Pilze von den Wasserspeichersubstanzen profitieren.

Bemerkenswert ist, dass diese Kombinationen auf den sehr stark sauren Ronneburger Standorten auch ohne gleichzeitige pH-Wert-Anhebung funktionierten.

\subsection{Zur Verbesserung der Bodenchemie: Kalk}

Kalkungen werden in Untersuchungen und aufgrund langjähriger praktischer Erfahrungen oft als Basis jeglicher Rekultivierungsbemühungen von den meist durch die Verwitterung von Eisenoxid (Pyrit, Markasit) sehr sauren Haldensubstraten gesehen (z. B. Bussler et al. 1984, Katzur 1997, Katzur et al. 1999a,b, Böcker et al. 1999). Da in schwefelhaltigen Kippenböden durch die fortgesetzte Pyrit-Oxidation die mit einer grundlegenden Kalkung angestrebte $\mathrm{pH}$ Wert-Erhöhung oft nicht für längere Zeit oder gar dauerhaft erhalten bleibt (Böcker et al. 1998, Katzur et al. 1999b) werden auch wiederholte Kalkungsmaßnahmen als zweckmäßig erachtet (z. B. auf neuen Waldstandorten mit pH-Werten unter 4 bis in $30 \mathrm{~cm}$ Bodentiefe, Katzur et al. 1999a).

Kalkungen werden seit Beginn planmäßiger Rekultivierungen ehemaliger Tagebauflächen im vergangenen Jahrhundert zur Anhebung der niedrigen $\mathrm{pH}$-Werte und damit zur Verbesserung der Nährelementverfügbarkeit und der Verringerung der Löslichkeit potentiell schädigender Schwermetalle wie Kupfer, Zink etc. eingesetzt (z. B. Häge 1996, Katzur \& Haubold-Rosar 1996, Rodenkirchen 1996). Bestehende Mangan- und Aluminium-Toxizität kann durch Anhebung des Boden-pH-Wertes beseitigt werden (Scheffer \& Schachtschabel 2010).

In der vorliegenden Untersuchung wurden die Boden-pH-Werte in der obersten Bodenschicht durch Kalk- (oder Kompost-) Gaben auf 5,6 (5,7) erhöht, was in dem nach Katzur et al. (1999a, b) und Rodenkirchen (1996) anzustrebenden Bereich liegt (zur Verringerung der $\mathrm{Cu}$ - und ZnLöslichkeit sollte der $\mathrm{pH}$-Wert $\left(\mathrm{H}_{2} \mathrm{O}\right)$ in der oberen Bodenschicht zwischen 5 und 6 liegen und in jedem Fall nicht unter 4 sinken). Die Kalk-Gabe verbesserte die Nährstoffverfügbarkeit und die Belastungssituation im Haldensubstrat. Aus Gründen der Praktikabilität und der Übersichtlichkeit wurden die Veränderungen im Einzelnen bereits an Ort und Stelle interpretiert, so dass hier auf Seite 58ff (Zusammenfassung S. 73) verwiesen wird.

Als Folge der durch die Kalk-Gabe günstigeren chemischen Bodenbedingungen verringerte sich im Freiland-Versuch teilweise die Schadstoff-Belastung der Versuchspflanzen (s. ab S. 105), während sich ihre Nährstoffversorgung teilweise verbesserte, wodurch Vitalität und Wachstum erhöht wurden. Bei den im Vergleich anspruchsvolleren Ahornen war der Kalk-Effekt auf allen Standorten ablesbar. Bei den Ebereschen, Erlen und Douglasien bestand der positive Einfluss in den bis Versuchsende vegetationsfreien Bereichen (geringerer $\mathrm{pH}$-Wert), spielte aber auf den 
etwas besseren, im Versuchsverlauf mit Spontanvegetation bewachsenen Teilflächen (leicht höherer pH-Wert) keine Rolle.

Günstigere Bodenverhältnisse und Pflanzenentwicklung durch Kalkungsmaßnahmen auf sauren Kippenstandorten sind in einer Vielzahl von Arbeiten dokumentiert, beispielsweise in Untersuchungen in der Lausitz von Katzur et al. (z. B. 1998, 1999 b).

Ohne Kalkungen blieben Tagebaufolgeflächen dagegen teilweise auch Jahrzehnte nach Nutzungsaufgabe vegetationsfrei (Katzur \& Haubold-Rosar 1996, Rodenkirchen 1996, Hüttl \& Weber 2001).

Die auf den Versuchsflächen der vorliegenden Untersuchung ausgemachten, bis Versuchsende unbewachsenen oder mit Spontanvegetation besiedelten Teilbereiche unterschieden sich ausschließlich durch ihren pH-Wert (in bewachsenen Bereichen leicht höher) sowie die davon bestimmte Austauscherbelegung (in bewachsenen Bereichen günstiger). Die Vermutung liegt nahe, dass der Grund für diese unterschiedliche Entwicklung eine unregelmäßige Verteilung des Düngekalks bei der im Jahr 2000 durchgeführten Flächenkalkung ist (Böcker et al. 1998 weisen auf stark wechselnde Aciditäten in grundmeliorierten Kippenböden, Katzur et al. 1999b auf die ungleichmäßige Verteilung meliorativer Düngekalke in Haldensubstraten hin). Zu dieser Interpretation passt, dass sich auf Versuchsfläche A, die nicht in die Kalkungsmaßnahme einbezogen war, überhaupt keine Spontanvegetation entwickelte. Entsprechend schien in diesem Fall eine Kalkung die Entwicklung von Spontanvegetation überhaupt zu ermöglichen. Auch die Entwicklung der im Rahmen der vorliegenden Untersuchung gepflanzten Bäume war in Bereichen mit Spontanvegetation ( $=$ mit leicht höherem pH-Wert) bei allen Baumarten vergleichsweise besser.

Bei Rekultivierungsmaßnahmen auf Tagebaufolgeflächen werden Kalkungen oft mit weiteren (NPK-) Düngungen kombiniert (Heinsdorf 1984, 1985; Bussler et al. 1984, Häge 1996; Katzur \& Haubold-Rosar 1996, Katzur et al. 1999b, Knoche et al. 2000). In der vorliegenden Arbeit wurden ebenfalls gute Ergebnisse mit der Kombination aus Kalk- und Kompost-Gabe erzielt.

Weitere erfolgreiche Kombinationen waren die Behandlungsvarianten mit MykorrhizaImpfungen und Kalk. Die Kalk-Gaben konnten sowohl bei Ahornen als auch bei Douglasien den Mykorrhiza-Effekt vor allem auf den saureren, unbewachsenen Standorten unterstützen und verstärken. Nach Weissenhorn (2002) und Baum (2004) ist der pH-Wert des Bodens für EktoMykorrhiza von Bedeutung.

Auf sauren (Halden-) Standorten besteht oft Magnesiummangel, so dass zur Bodenmelioration üblicherweise magnesiumhaltige Kalke eingesetzt werden, die deshalb auch in der vorliegenden Versuchsanordnung verwendet wurden. Da im Ronneburger Haldensubstrat jedoch überraschend hohe Magnesium-Gehalte und -Sättigungen und in den Assimilationsorganen der Versuchspflanzen extreme Magnesiumüberschüsse nachgewiesen wurden, ist auf diesem und vergleichbaren Standorten bei Kalkungsmaßnahmen das Ausweichen auf ein magnesiumfreien Düngekalk angezeigt. 


\subsection{Zur Verbesserung der Bodenphysik und -chemie: Kompost}

Wie die Ergebnisse der vorliegenden Untersuchung zeigen, führten Kompost-Gaben zu deutlich positiven Veränderungen der Bodenbedingungen.

So nahm die Trockenraumdichte des Substrates ab, sein Gesamtporenvolumen dagegen zu. Die Wasserspeicherkapazität wurde gegenüber der Kontrolle nicht erhöht, jedoch bestätigten Beobachtungen im Topf-Versuch eine bessere Infiltrationsfähigkeit durch die Beimischung von Kompost ins Haldensubstrat. Die Auswirkungen der Kompost-Gabe umfassten zudem die Anhebung des niedrigen pH-Wertes auf 5,7 und damit in einen Bereich des „ökologischen Optimums“ (Ulrich 1980/81) sowie die Erhöhung der effektiven Austauschkapazität, der Nährstoff-Gehalte im Boden und der Nährelement-Sättigungen (im Gegensatz zu der Kalk-Gabe konnte die Kompost-Gabe dabei auch die Kalium-Sättigung erhöhen), während gleichzeitig die Mobilität von Schadstoffen gesenkt wurde. An dieser Stelle soll wie bereits bei den Ausführungen zur Wirkung der Kalk-Gabe auf die entsprechenden Kapitel im Ergebnisteil verwiesen werden, in dem auch die zahlreichen Effekte der Kompost-Düngung auf die chemischen Bodenparameter direkt interpretiert wurden (s. ab S. 58, Zusammenfassung S. 73).

Auch andere Arbeiten berichten durchweg positiv über den Einsatz von Kompost-Düngungen bei Rekultivierungsmaßnahmen.

So dienten Kompost-Gaben auf Kohle-Tagebauflächen in Bulgarien einer schnellen Humusanreicherung und einer Aktivierung des Bodens (Häge et al. 1996).

Auf Haldenflächen eines ehemaligen Zinn-Tagebaus in China nahmen gepflanzte Gehölze mit Kompost-Düngung (ebenso wie in der hier vorliegenden Untersuchung) messbar weniger Schwermetalle auf und entwickelten sich besser (Song ShuQiao et al. 2004).

Laut einer aktuellen Arbeit von Cunha-Queda et al. (2010) werden Komposte bei Rekultivierungsmaßnahmen zunehmend eingesetzt, da sie die Bodenqualität verbessern und den Bedarf an anorganischen Düngern senken. Gegenstand dieser Untersuchung war, ob Kompost zur Sanierung zweier unterschiedlich versauerter und mit Schwermetallen ( $\mathrm{Cu}$ und $\mathrm{Zn}$ bzw. $\mathrm{Pb}$ ) belasteter Haldensubstrate aus einem mit Spurenelementen kontaminierten Tagebau in Portugal dienen kann. Pflanzenwachstum und diverse Bodenparameter wurden durch Kompost-Gaben positiv beeinflusst; die Sickerwässer waren nicht mehr ökotoxisch. Teilweise waren die Ergebnisse mit Kompost-Düngung besser als mit einer zum Vergleich vorgenommenen Kalk-Düngung.

Dies deckt sich mit den Ergebnissen der vorliegenden Dissertation. In den Analysen der Assimilationsorgane wurden bei den mit Kompost gedüngten Bäumen eine teils verbesserte Nährstoff-Versorgung und teils geringere Schadstoff-Gehalte festgestellt. Dabei übertrafen die Effekte der Kompost-Varianten, in denen bei der Pflanzung immerhin ein Drittel des zurück ins Pflanzloch gegebenen Haldensubstrats durch Kompost ersetzt wurde (s. S. 19f), z.T. ebenfalls die Wirkungen der Kalk-Gaben. So konnten z.T. die bei allen Baumarten belastenden SchwefelGehalte auf ausreichende Normalgehalte gesenkt werden (Eberesche, Erle). Auch die Schwermetall-Gehalte waren überwiegend geringer.

Sowohl Vitalität als auch Wachstum der Versuchspflanzen wurden, vor allem (bei den Ebereschen und Erlen ausschließlich) auf den ungünstigeren, stärker versauerten, nicht mit 
Spontanvegetation besiedelten Standorten durch Kompost-Gaben deutlich positiv beeinflusst. Bei den anspruchsloseren Baumarten Eberesche, Erle und Kiefer nahmen die KompostVarianten dabei jeweils die Spitzen-Positionen ein.

Teilweise ergaben sich auch positive Synergie-Effekte bei der Kombination der beiden Bodenchemismus-verbessernden Bodenhilfsstoffe Kalk und Kompost (z.B. Ebereschen: nur in dieser Variante V10 ausreichende P-Versorgung, keine Al-Toxizität).

Wie im nächsten Abschnitt mit Literatur-Beispielen belegt, erscheint auch eine Kombination aus Kompost-Düngung und Mykorrhiza-Impfung bei der Rekultivierung von Tagebaufolgeflächen viel versprechend.

\subsection{Zur Verbesserung der Bodenbiologie: Mykorrhiza-Inokulum}

Die wichtige Rolle von Mykorrhiza bei der Rekultivierung von Haldensubstraten (s. ab S. 350) ist in jüngerer Zeit zunehmend in den Fokus entsprechender Untersuchungen gerückt. Diese haben zumindest im Inland vor allem die Situation der Mykorrhiza auf Rekultivierungsflächen und ihren Effekt auf die dort gepflanzten Bäume zum Gegenstand. Erfahrungen mit dem aktiven Einsatz von Mykorrhiza-Pilzen bei Kippenbepflanzungen gibt es dagegen vor allem aus den nordamerikanischen Staaten, wo bereits seit den 1980er Jahren bei TagebauRekultivierungsmaßnahmen Mykorrhiza-Impfungen durchgeführt werden.

So beobachteten Beckjord \& McIntosh (1984) auf kanadischen Kohle-Tagebauflächen bei RotEichen-Sämlingen, die mit an schwierige Standortbedingungen angepassten Mykorrhiza-Pilzen inokuliert wurden, eine geringere Sterblichkeit und höheres Wachstum gegenüber uninokulierten Sämlingen.

Auch bei den Rot-Eichen auf den Ronneburger Freiland-Versuchsflächen konnten MykorrhizaImpfungen Überlebensrate und Neuaustrieb nach oberirdischem Absterben positiv beeinflussen.

Mykorrhiza-Impfungen von auf Eisenerz-Kippenstandorten im Staat New York gepflanzten Kiefern-Sämlingen (Pinus resinosa) führten ebenfalls zu besseren Überlebensraten. Messungen von Wuchsparametern in den ersten beiden Jahren zeigten hier jedoch lediglich in der ersten Vegetationszeit eine höhere Zunahme des Wurzelhalsdurchmessers im Vergleich zur Kontrolle (LoBuglio \& Wilcox 1988).

Nach Cordell et al. (2002) wurden in Ohio ab 1982 Mykorrhiza-Impfungen für großflächige Wiederbegrünungs-Maßnahmen aufgelassener Abbauflächen eingesetzt, was die Effektivität dieser Maßnahmen erhöhte und ihre Gesamtkosten stark reduzierte. Dabei wurden mit Mykorrhiza inokulierte Kiefern und Eichen ohne weitere Bodenmelioration in die sehr stark versauerten ( $\mathrm{pH}$ 2,9-3,4) Substrate gepflanzt. Die Überlebensraten der beimpften Bäume lagen mit $85 \%$ deutlich höher als die der Kontrollen mit 50 \%, was auf eine erhöhte Wasser- und Nährstoffaufnahme bei verringerter Aufnahme toxisch wirkender Elemente und somit insgesamt auf Stressreduktion zurückgeführt wurde. Auch auf das frühe Wachstum der Bäume wirkte sich die Mykorrhiza-Impfung günstig aus. Im Westen der USA wurden ähnliche Erfolge bei der Rekultivierung von hoch gelegenen, ariden Abbauflächen unter Verwendung von Bäumen, Sträuchern und Gräsern erzielt, die mit entsprechend ausgewählten Mykorrhiza-Pilzen inokuliert wurden (Cordell et al. 2002). 
In einem weiteren Beispiel wurden mit Mykorrhiza-Pilzen inokulierte Birken-Sämlinge in Haldensubstrat gepflanzt und über 30 Monate hinweg untersucht (Walker et al. 2004). Sie zeigten sowohl oberirdisch als auch unterirdisch gutes Wachstum, wobei das Wurzelwachstum stärker war als das der Triebe, was zu geringen Spross-Wurzel-Verhältnissen führte (nach Lavender (1984) bei problematischen Standortbedingungen von großer Bedeutung; nach Hendry \& Grime (1993) Zeichen für die Stresstoleranz einer Pflanze). Durch die bessere Wurzelentwicklung mit mehr Feinwurzeln wurde mehr Bodenraum erschlossen, was auf Tagebaufolgeflächen mit oft schwieriger Nährstoff- und Wasserversorgung von Vorteil ist.

Gegenüber den nicht inokulierten Kontrollen wurden bei inokulierten Sämlingen erhöhte Wasseraufnahmen während und im Anschluss an simulierte Austrocknungsphasen sowie höhere Blattgehalte kritischer Nährelemente (v.a. Stickstoff) und geringere Gehalte potentiell phytotoxischer Metalle (v.a. Mangan, Aluminium) nachgewiesen. Die Phosphor-, Calcium, Eisenund Zink-Gehalte wurden dagegen nicht beeinflusst.

Die im Rahmen der vorliegenden Arbeit durchgeführten Blatt- bzw. Nadelanalysen ergaben bei den mit Mykorrhiza-Inokulum (ohne weitere Bodenhilfsstoffe) gepflanzten Eichen höhere N-, Pund K-, bei den Ahornen höhere N- und K- sowie bei den Douglasien höhere P-, K-, Ca- und MgGehalte. Die Gehalte verschiedener potentiell phytotoxischer Metalle nahmen dagegen ab (Eichen: $\mathrm{Fe}, \mathrm{Cu}, \mathrm{Al}, \mathrm{Na}, \mathrm{Co}, \mathrm{Cr}$; Ahorne: $\mathrm{Na}, \mathrm{Ni}, \mathrm{Co}$; Douglasien: $\mathrm{Fe}, \mathrm{Cu}, \mathrm{Al}, \mathrm{Na}, \mathrm{Co}$ ) Bei den Eichen und Douglasien führte dies zu einem Rückgang der $\mathrm{Cu}$-Belastung sowie der Al-Toxizität; bei den Ahornen war dies (sowie eine Abnahme der Fe- und Cr-Gehalte) in Kombination von Mykorrhiza-Impfungen mit Kalk und/oder Wasserspeichersubstanzen der Fall (s. ab S. 105). Darüber hinaus konnten in den Mykorrhiza-Varianten zumindest bei den Laubbäumen (Eiche, Ahorn) auch deutlich geringere Schwefel-Gehalte festgestellt werden, die in Kombination mit weiteren Bodenhilfsstoffen von toxischen Belastungen auf ausreichende Normalgehalte sanken. Bei den Douglasien nahmen die Schwefel-Belastungen dagegen in allen Behandlungsvarianten zu und lagen sämtlich oberhalb von Schadstoff-Grenzwerten.

Walker et al. (2004) schließen aus ihren Untersuchungen, dass mit entsprechender Mykorrhiza geimpfte Birken unter den sehr ungünstigen Standortbedingungen ehemaliger Tagebauflächen ohne Einsatz von chemischen Düngemitteln gedeihen können.

Für die im Ronneburger Freiland-Versuch getesteten, gegenüber den Birken deutlich anspruchsvolleren Baumarten Ahorn und Douglasie gilt dies so nicht. Für eine anhaltend positive Wirkung der Mykorrhiza war hier zumindest eine Anhebung des $\mathrm{pH}$-Wertes (durch eine 5 Jahre vor Versuchsanlage erfolgte Flächenkalkung oder durch Kalk-Gaben bei der Pflanzung) erforderlich.

Cordell et al. (2002) berichten von einem wachsenden Interesse an der Anwendung von Mykorrhiza-Impfungen bei Tagebau-Rekultivierungsprogrammen in den USA sowie verschiedentlich im Ausland.

So finden sich inzwischen auch aus Tschechien und Deutschland Beispiele für entsprechende Untersuchungen:

Bei der Aufforstung von Kippen in Nord-Böhmen verbesserte eine künstliche Mykorrhizierung (VAM) das Wachstum von Laubbaum-Sämlingen (Sorbus aucuparia, Acer pseudoplatanus) (Vosátka 1990). 
In weiteren Experimenten mit Laubbaum-Sämlingen (Acer pseudoplatanus, Alnus glutinosa, Salix purpurea) in Haldensubstrat hatte eine Inokulation mit VA-Mykorrhiza-Pilzen ebenfalls einen positiven Effekt auf das Pflanzenwachstum (Enkhtuya et al. 2005). Bei den auf den Ronneburger Tagebaufolgeflächen gepflanzten Ahornen (Acer platanoides) erhöhte sich durch MykorrhizaImpfung die Pflanzenvitalität. Bei insgesamt sehr geringem Wachstum dieser Baumart konnte außer bei den Wurzelhalsdurchmessern (und hier auf sehr geringem Niveau) jedoch bei keinem Wachstumsparameter ein Einfluss der Mykorrhiza-Impfung festgestellt werden.

In sandigen Substraten mit Braunkohlefragmenten, wie sie etwa auf ehemaligen BraunkohleTagebauflächen in der Lausitz häufig vorkommen, zeigten mit Paxillus involutus (Batsch) Fr. inokulierte Kiefern-Sämlinge im Vergleich zur Kontrolle eine höhere Wurzeltrockenmasse, Anzahl an Wurzelspitzen und Wurzellänge (Baumann et al. 2005).

Nach Gebhardt et al. (2007) würde im Braunkohle-Abbaugebiet Lausitz eine Inokulation mit standortangepassten Mykorrhiza-Pilzen die Kolonisierung von Rot-Eichen-Wurzeln und damit Pflanzenwachstum und Überlebensrate in den ersten Jahren nach der Pflanzung erhöhen.

In einem Gewächshaus-Versuch mit Haldensubstrat von einem brasilianischen KassiteritTagebau hatte die gleichzeitige Anwendung von Mykorrhiza-Impfung und Kompost-Düngung einen deutlich positiven Effekt auf Höhe und Trockenmasse der Haupttriebe der Versuchspflanzen sowie ihren Gehalt an Stickstoff und Phosphor. Die Autoren bezeichnen die Kombination aus Düngung mit organischem Kompost und Mykorrhiza-Impfung als essentiell für das Pflanzenwachstum auf vergleichbaren Standorten und als Grundvoraussetzung für eine nachhaltige Aktivierung der biologischen Bodenaktivität (Mendes Filho et al. 2010).

In Spanien und der Schweiz sowie in den Niederlanden existieren Beispiele für die Anwendung von Mykorrhiza-Impfungen zwar nicht auf Tagebaufolgeflächen, jedoch unter ebenfalls schwierigen Standortbedingungen:

So erzielten auf degradierten semiariden Standorten in Spanien Mykorrhiza-Impfungen bei gleichzeitiger Kompost-Düngung ebenfalls gute Erfolge (Caravaca et al. 2003). Mit dieser Behandlungskombination wurden bei Olea europaea L. subsp. sylvestris die höchsten Zunahmen der Spross-Biomasse ermittelt. Die Ergebnisse übertrafen die bei einzelner Anwendung der Hilfsmaßnahmen erzielten und lagen 12-mal höher als in der unbehandelten Kontrolle.

In einem Freiland-Versuch in den Niederlanden konnten Mykorrhiza-Impfungen die Situation von Bäumen auf verdichteten, mit Salz belasteten Standorten (Straßenraum) verbessern (Weissenhorn 2002).

Bei einem Ansaatversuch auf erosionsgefährdeten Rohböden in alpinen Zonen (Hochlagen in einem schweizerischen Skigebiet) führte erst ein Bodenhilfsstoffprodukt, dass eine Kombination aus einem Inokulum verschiedener vesikulär-arbuskulärer Mykorrhiza-Pilze, Sporen des Bodenpilzes Penicillium sp., Alginaten, Polysacharid und einem organischen Nährstoffkonzentrat darstellte, zu guten Deckungsgraden (Schmid 2006a). Hier übernahm das ausgebrachte Mykorrhiza-Inokulum zudem die Rolle einer Pionier- oder Ammenkolonisation, die auch die Entwicklung von Mykorrhiza mit lokal bereits im Boden vorhandenen MykorrhizaPilzen förderte (Schmid 2006b).

In den ungünstigeren, stärker versauerten Bereichen der Ronneburger Versuchsflächen, in denen sich auch keine Spontanvegetation ansiedeln konnte, hatte bei den Ekto-Mykorrhiza- 
bildenden Douglasien eine Inokulation allein ebenfalls keinen Effekt. Die Bodenbedingungen waren hier für die von dem pH-Wert (Weissenhorn 2002, Baum 2004) und der Bodenfeuchte (Kottke et al. 1993) abhängigen Ekto-Mykorrhiza-Pilze offenbar zu schlecht. In Kombination mit Kalk-Gaben und/oder Wasserspeichersubstanzen konnten dagegen positive Mykorrhiza-Effekte nachgewiesen werden. Bei den VA-Mykorrhiza-bildenden Ahornen bestanden standortabhängig teils bereits ohne, teils ebenfalls nur mit Unterstützung durch weitere Bodenhilfsstoffe positive Auswirkungen der Mykorrhiza-Impfungen.

Bemerkenswert erscheint, dass auf den insgesamt sehr stark sauren Ronneburger Standorten überhaupt Behandlungsvarianten ohne Anhebung des pH-Wertes messbar erfolgreich waren, was bei den getesteten Mykorrhiza-Impfungen (teils allein, teils zumindest unterstützt durch Wasserspeichersubstanzen) jedoch der Fall war.

Ob auf den Ronneburger Versuchsflächen vor allem die im Rahmen der vorliegenden Arbeit nachgewiesene Verbesserung der Nährstoffversorgung und Hemmung der SchwermetallAufnahme (bei den Ahornen auch der Schwefel-Aufnahme), oder ob auch eine - hier nicht im Experiment überprüfte - verbesserte Wasserversorgung sowie Förderung der Infektion mit vorhandenen Pilzen für die bessere Entwicklung der mit Mykorrhiza-Inokulum gepflanzten Bäume sorgte, ist nicht erwiesen. Von einer positiven Beeinflussung aller drei Faktoren kann vermutlich ausgegangen werden.

\section{Eignung von Baumarten}

Nachfolgend werden die Untersuchungsergebnisse zu den sechs getesteten Baumarten RotEiche, Spitz-Ahorn. Eberesche, Schwarz-Erle, Douglasie und Wald-Kiefer im Vergleich mit entsprechenden Erfahrungen aus anderen Rekultivierungsprojekten (Untersuchung teils ebenfalls junger Sämlinge, teils älterer Bestände) diskutiert. Dabei wird teilweise auch genauer auf die Baumarten, ihre Eigenschaften und ihre Verwendung bei Rekultivierungsmaßnahmen eingegangen.

Die Untersuchung der Eignung einzelner Arten zur Tagebau-Rekultivierung zielt gerade auf diesen problematischen Standorten grundsätzlich auf eine Pflanzung in Baumartenmischungen ab. Reinbestände sind aus Gründen der Stabilität und der wenig günstigen Standortbeeinflussung nicht geeignet. So zeigen z.B. Pappel- und Birkenreinbestände auf ehemaligen Halden häufig bereits relativ früh Verlichtungs- und Absterbeerscheinungen (Selent 1993). Bei Rot-Eichen- oder Kiefern-Reinbeständen besteht Windwurfgefahr (Katzur et al. 1999b). Zudem sind Baumartenmischungen hinsichtlich Streuabbau, Humuszusammensetzung, Nährstoffkreislauf und Auswirkungen auf die Bodenentwicklung deutlich vorteilhafter (z.B. Heuson 1929, Dan'ko 1986, Häge 1996, Katzur \& Haubold-Rosar 1996, Böcker et al. 1998, 1999, Katzur et al. 1999a, Ertle et al. 2006).

Die im Rahmen der vorliegenden Arbeit getroffenen Aussagen fußen auf Untersuchungen von Bäumen in den ersten 2 Jahren nach der Pflanzung und damit auf dieser sehr wichtigen Anwuchsphase. Ihre weitere Entwicklung ist auf diesen problematischen Kippenstandorten nicht zu prognostizieren und nur durch Langzeitbeobachtungen zu verfolgen (Hüttl \& Weber 2001). 


\subsection{Rot-Eiche}

Die Ergebnisse der vorliegenden Arbeit erlauben keine abschließende Bewertung der Eignung der Baumart Rot-Eiche (Quercus rubra) für die Pflanzung auf den Ronneburger Tagebaufolgeflächen und vergleichbaren Standorten; zu groß war die Ausfallrate. Grund für die hohen Ausfälle der unbehandelten Eichen könnte neben dem schlechten Ausgangsmaterial zum einen auch ihre problematische Versorgungs- und Belastungssituation sein. Zum anderen (und damit zusammenhängend) spielt bei dieser obligat auf Ekto-Mykorrhiza angewiesenen Baumart auch das Vorhandensein von passenden Symbiosepartnern bei der Pflanzung eine große Rolle.

Es konnte eine so deutlich positive Reaktion auf die Mykorrhiza-Inokulation nachgewiesen werden, dass diese beim Einsatz von Rot-Eichen auf vergleichbaren Rekultivierungsflächen unbedingt empfohlen wird. Da ebenso wie die Rot-Eichen auch die einheimischen Eichenarten stark mykotroph sind (Sammler 2004), gilt diese dringende Empfehlung generell auch für andere Arten der obligat auf Mykorrhiza angewiesenen Gattung Quercus (Höster 1993).

Der positive Effekt von Mykorrhiza-Impfungen auf die Überlebensrate (und das Wachstum) von Rot-Eichen auf Tagebaufolgeflächen ist auch in entsprechenden Versuchen z. B. in der Lausitz (Gebhardt et al. 2007) und in Ohio (Cordell et al. 2002) dokumentiert. Die Pflanzung von RotEichen (und anderen Baumarten) mit Mykorrhiza-Impfungen zur Begrünung ehemaliger Tagebaugebiete wird in ihrer nordamerikanischen Heimat ohne weitere Bodenmelioration bereits seit Beginn der 1980er Jahre erfolgreich praktiziert (Cordell et al. 2002). Verschiedene Arbeiten heben hervor, dass eine Eignung der Rot-Eiche zur Rekultivierung von Bergbaukippen in Verbindung mit einer Ekto-Mykorrhizierung der Baumwurzeln gegeben ist (Molina \& Trappe 1982, Beckfjord \& Mcintosh 1984, Wöllecke et al. 2001).

Allgemein hat die Verwendung von Rot-Eichen bei Tagebau-Rekultivierungsmaßnahmen bereits eine lange Tradition. In der Lausitz wurde die Baumart vor allem zwischen 1960 und 1975 (Häge 1996, Katzur \& Haubold-Rosar 1996) häufig eingesetzt. Sie spielt bis heute bei der forstlichen Rekultivierung der Lausitzer Bergbaufolgelandschaft eine große Rolle (Preußner 1998, Sammler 2004) und ist auch Bestandteil des für zukünftige Rekultivierungsmaßnahmen im Lausitzer und Mitteldeutschen Revier vorgesehenen Baumartenspektrums (LMBV 2009).

Hintergrund sind verschiedene Eigenschaften der Rot-Eiche. So hat die Baumart eine sehr große Standortamplitude (Katzur et al. 1998) und kann auch auf armen, sandigen, mäßig trockenen, sauren bis neutralen Böden gut gedeihen, auf Kalkböden sowie auf verdichteten und staunassen Standorten (wie in Ronneburg teilweise gegeben) dagegen schlecht (Sander 1990, Sammler 2004). Aspekte des Waldbrandschutzes spielen beim Einsatz der Rot-Eiche ebenfalls eine Rolle (Mutscher 1963, Lorenz 1967, in: Stähr 2003). Die Baumart gilt als anspruchslos, dennoch sollte im Vorfeld ihrer Pflanzung auf Kippsubstraten eine nachhaltige Verbesserung der Aciditätsverhältnisse erfolgen (Stähr 2003). Von Vorteil ist auf diesen Standorten ihre Fähigkeit, auch sehr stark saure Bodenschichten ( $\mathrm{pH}<4,0)$ zu durchwurzeln (Mutscher 1963, Lorenz 1967, in: Stähr 2003).

Der Nährstoffbedarf von Rot-Eichen wird als geringer als der von Trauben-Eichen eingestuft (Heinsdorf 1996, 1999, Stähr 2003), wenngleich nach Böcker et al. (1999) die Standortansprüche von Trauben-Eichen häufig überbewertet wurden, was dazu führte, dass diese Baumart bislang zu Unrecht wenig auf Kippen eingesetzt wurde. Demnach hat TraubenEiche auf Haldenstandorten sogar geringere Startschwierigkeiten als die anspruchsloseren 
Arten Kiefer oder Birke. Bei einzelnen Elementen zeigt Trauben-Eiche dagegen auch nach Jahrzehnten noch deutliche Defizite (Katzur \& Böcker 2001).

Beide Eichen-Arten zeigen auf schwefelhaltigen Kippenböden in der Lausitz nach Bodenverbesserung mit Kalk oder Braunkohleasche sehr gute Ergebnisse (Katzur \& HauboldRosar 1996).

Ergebnisse wie diese sind besonders vor dem Hintergrund interessant, dass der Einsatz von RotEichen bei der Tagebau-Rekultivierung auch kritisch gesehen wird.

So zeigten Untersuchungen ehemaliger Tagebauflächen im Rheinland, dass eine Bepflanzung mit Trauben-Eichen die Bodenentwicklung und das Bodenleben deutlich positiver beeinflusst als eine Bepflanzung mit Rot-Eichen, was u. a. auf das schwer zersetzbare Laub und die höhere Festlegung von Nährstoffen im Holz zurückgeführt wurde (Nicolini \& Topp 2005) . Böcker et al. (1999) empfehlen deshalb, Rot-Eichen grundsätzlich nur in Mischung mit bodenverbessernden Baumarten einsetzen.

Darüber hinaus wird der Einsatz von Rot-Eichen aufgrund ihrer großen Konkurrenzstärke (Katzur et al. 1998, 1999b), ihres Ausbreitungspotentials, der Ausbreitungsgeschwindigkeit und ihres geringen Wertes für den Naturschutz kritisch gesehen. Als nicht-heimische, invasive Art wird die Rot-Eiche als potentielle Bedrohung für die heimische Vegetation eingestuft (Kowarik 1995, Hodacova \& Prach 2003).

\subsection{Spitz-Ahorn}

Ahorne werden bei Kippenerstaufforstungen vergleichsweise weniger häufig eingesetzt, wobei zudem Berg-Ahorn (Acer pseudoplatanus) öfter verwendet zu werden scheint als der im Rahmen der vorliegenden Arbeit getestete Spitz-Ahorn (A. platanoides).

Im für Rekultivierungsmaßnahmen im Lausitzer und Mitteldeutschen Revier vorgesehenen Baumartenspektrum (LMBV 2009) sind Ahorne nicht enthalten. Jedoch sind Spitz-Ahorne beispielsweise in Tschechien (Hodacova \& Prach 2003) und in geringen Anteilen auch in der Lausitz auf ehemaligen Braunkohle-Tagebaustandorten gepflanzt worden (Häge 1996).

Nach Katzur et al. (1999a) ist die Art je nach Standort eine der Nebenbaumarten in anzustrebenden Mischwäldern auf den Kippen und Halden der Lausitz und sollte dort zur Bodenpflege eingemischt werden.

Laut Benkwitz et al. (2002) sind die windverbreiteten Spitz-Ahorne auf Haldenstandorten teilweise Einwanderer späterer Sukzessionsstadien.

Dass die Verwendungsmöglichkeiten dieser Baumart bei Tagebau-Rekultivierungen stark standortabhängig sind, dokumentieren verschiedene Untersuchungsergebnisse.

So führten Versuche zur Bepflanzung von Tagebau-Kippen im Nordwesten Tschechiens zu einer Empfehlung von Spitz-Ahornen für diese Standorte (Kupka \& Dimitrovsky 2006). Die Baumart erzielte dort nach den ebenfalls verwendeten Erlen und Ebereschen den meisten Zuwachs. 
Dagegen waren bei Versuchen zur Rekultivierung von Haldensubstraten in Großbritannien Ahorn-Arten (Acer platanoides, A. pseudoplatanus) nur auf Standorten mit besserer Nährstoffversorgung erfolgreich und wurden nicht für die Bepflanzung von Rohböden bzw. Böden ohne enthaltene organische Substanz empfohlen (Binns \& Fourt 1981).

Auch in den Ronneburger Versuchen zeigten die Ahorne (auch im Vergleich zu den Ebereschen und Erlen) eine stark defizitäre Nährstoff-Versorgung bei gleichzeitig hoher SchadstoffBelastung. Die vergleichsweise ungünstigeren, frei von Spontanvegetation bleibenden Bereiche boten den Ahornen offenbar derart problematische Standortbedigungen, dass die Art hier auch mit Bodenhilfsstoff-Behandlungen nicht erfolgreich war. Selbst auf etwas günstigeren Standorten, auf denen sich im Versuchsverlauf Spontanvegetation ansiedeln konnte, ließ die Vitalität der unbehandelten Ahorne im 2. Vegetationsjahr stark nach (Ebereschen, Erle und Douglasien wiesen hier auch ohne Behandlung bis Versuchsende gute Vitalitäten auf). Zwar reagierte die Art gut auf Kalk- bzw. Kompost-Düngung sowie besonders auf MykorrhizaImpfungen. Trotz in diesen Varianten teils höheren Nährstoff- und geringeren SchadstoffBlattgehalten und höherer Vitalität konnte die Versorgungs- und Belastungssituation jedoch nicht so weit verbessert werden, dass (von einzelnen Exemplaren abgesehen) ein nennenswertes Wachstum erreicht worden wäre. Hier spielten vermutlich die sehr hohen, toxischen Schwefel-Gehalte eine Rolle.

Bei der Saat von Ahornen auf ostdeutschen Haldenstandorten wurde ebenfalls nur ein sehr geringes Höhenwachstum erreicht (Boronczyk 2006). Ebenda begünstigte die Deckung von Calamagrostis epigejos das Höhenwachstum von (gepflanzten) Ahornen.

Auf den Ronneburger Versuchsflächen zeigten die Ahorne nur geringes Wachstum. In (mit Calamagrostis epigejos, Moosen) bewachsenen Bereichen wies die Baumart zwar eine höhere Vitalität auf, die nach zwei Jahren ermittelten Wurzelhalsdurchmesser (und damit zusammenhängende Wachstumsparameter wie etwa das Haupttriebsvolumen) waren dort jedoch teils geringer als in vegetationsfreien Bereichen. Untersuchungen von Enkhtuya et al. (2005) könnten für diese Konstellation eine Begründung liefern: Bei Versuchen auf Kohlehaldensubstrat beeinflusste direkter Wurzel-Kontakt zwischen Ahorn-Sämlingen und Calamagrostis epigejos das Wachstum der Sämlinge negativ, die Mykorrhiza-Entwicklung (Kolonisierung der Wurzeln, Sporen-Anzahl, Länge des extraradikalen Mycels) dagegen positiv. Das Gras unterstützte die Mykorrhiza-Entwicklung inokulierter Sämlinge und infizierte Sämlinge mit eigener VA-Mykorrhiza.

In stark versauerten Bodenbereichen der Lausitzer Kippsubstrate war laut Hüttl \& Weber (2001) das Wurzelwachstum eingeschränkt, wenn auch nicht komplett unterbunden. Sänger (1993, 2003) beobachtete ebenfalls auf Ronneburger Haldenstandorten bei Bäumen eine Anpassung der Wurzelmorphologie an abiotische Standortfaktoren.

Die im Rahmen der vorliegenden Arbeit durchgeführten Topf-Versuche mit dem sehr stark sauren Ronneburger Haldensubstrat $(\mathrm{pH}$ in KCl-Lösung 3,6, Bewertung nach AK Standortskartierung 2003, Scheffer \& Schachtschabel 2010) zeigten in den ohne Kalk oder Kompost (und damit ohne pH-Wert-Anhebung) angelegten Varianten im Vergleich zu diesen ebenfalls Beeinträchtigungen des Wurzelwachstums. Während sich dies bei den Nadelbäumen und den Ebereschen in Form einer geringeren (Fein-) Wurzelmasse und veränderter Wurzelfärbung äußerte, konnte bei den Ahornen mit dem Ausweichen sämtlicher Wurzeln an die Topfinnenwand eine extreme Wuchsanomalie beobachtet werden. Da diese Verformungen in 
den Varianten mit Kalk und Kompost (Anhebung des pH-Wertes auf 5,6 bzw. 5,7) nicht bestanden, liegt ein Zusammenhang mit durch Versauerung ungünstigen chemischen Bodeneigenschaften auf der Hand. Eine wahrscheinliche Ursache ist eine unter sauren Bedingungen hohe Konzentration von $\mathrm{Al}^{3+}-$ Ionen in der Bodenlösung, da dies nachgewiesenermaßen (Ulrich 1980/81, Bergmann 1993, Scheffer \& Schachtschabel 2010) zu Wurzelschäden und vermindertem Wurzelwachstum führen kann (Aluminium-Toxizität). Die verglichen mit den anderen untersuchten Baumarten starke Reaktion der Ahornwurzeln könnte als Ausweichen in weniger ungünstige Bereiche gesehen werden: Direkt an der Topfinnenwand wurden durch daran herablaufendes Gießwasser vermutlich $\mathrm{Al}^{3+-}$ und andere, durch die sauren Bedingungen vermehrt in der Bodenlösung vorhandene Ionen (Protonen, Mn-, Fe-Ionen...) ausgewaschen. Diese vergleichsweise höhere Empfindlichkeit der Ahornwurzeln gegenüber Versauerung prädestiniert die Baumart nicht für die Pflanzung auf den Ronneburger und ähnlichen, durch fortschreitende Pyrit-Oxidation sehr stark sauren Haldenflächen.

Da ehemalige Tagebaugebiete aufgrund ihrer Größe und relativen Ungestörtheit oft hohe Wilddichten aufweisen, ist zudem die Attraktivität von Ahornen für Wild hier äußerst nachteilig. In Untersuchungen von Ashby (1997) wurden auf Tagebaufolgeflächen vor allem bei AhornArten Überleben und Wachstum durch Wildschäden reduziert. Auf den Ronneburger Versuchsflächen wurden die Ahorne von allen sechs getesteten Baumarten am stärksten durch Wild geschädigt. Auf Versuchsfläche A, die durch umgestürzte Zaunpfosten und Unterspülungen des Wildzaunes (Niederschlags-Erosionsrinnen) zeitweilig frei zugänglich war, wurden die Ahorne beinahe komplett verbissen.

Für die Pflanzung auf den Ronneburger und vergleichbaren Standorten scheint die Baumart insgesamt eher weniger geeignet zu sein.

Allgemein ist bei der Verwendung von Spitz-Ahornen zur Tagebau-Rekultivierung neben einer Verbesserung der bodenchemischen Bedingungen eine Mykorrhiza-Impfung (VAM) sehr empfehlenswert.

\subsection{Eberesche}

Ebereschen wurden und werden verschiedentlich bei Rekultivierungen ehemaliger Tagebauflächen in Mischung mit anderen Baumarten verwendet (Bradshaw et al. 1978, Hutchinson 1984, Richardson 1985, Vosatka 1990, Perkins \& Vann 1995, Kupka \& Dimitrovsky 2006). Insgesamt wird die Baumart jedoch im Vergleich mit anderen eher seltener gepflanzt und ist beispielsweise auch nicht Bestandteil des für Rekultivierungsmaßnahmen im Lausitzer und Mitteldeutschen Revier vorgesehenen Baumartenspektrums (LMBV 2009).

Dass die Eberesche mit den schwierigen Bedingungen vieler Tagebaufolgeflächen grundsätzlich zurechtkommt, beweisen zahlreiche Berichte ihrer spontanen Einwanderung in entsprechende Standorte (Beispiele aus Süd-Wales, dem Mitteldeutschen Revier und der Lausitz: Dawkins et al. 1985, Benkwitz et al. 2002, Hohensee 2005).

Dazu könnte die Baumart auch eine im Rahmen der vorliegenden Arbeit festgestellte, vergleichsweise höhere Schwermetalltoleranz befähigen. So fiel bei den durchgeführten Analysen der Assimilationsorgane auf, dass bei den Ebereschen (im Gegensatz zu anderen 
untersuchten Arten) trotz der ungünstigen Bodenverhältnisse keine Schwermetallbelastung mit Kupfer, Eisen oder Nickel bestand.

Eine Untersuchung der frühen Entwicklung verschiedener Baumarten in gepflügten bzw. mit Kohleasche gedüngten sauren Haldensubstraten erbrachte für die Eberesche in beiden Varianten keine guten Ergebnisse (Perkins \& Vann 1995).

In den ungünstigeren Bereichen (die Art zeigte einen deutlichen Einfluss der kleinräumig unterschiedlichen Standortbedingungen) der sehr stark versauerten Ronneburger Standorte war die Entwicklung der unbehandelten Ebereschen durch Aluminium- und Mangantoxizität ebenfalls schwach (geringe Vitalitäts- und Wachstumswerte sowie im Tpfversuch beobachtetes eingeschränktes Feinwurzelwachstum,). Die Art sprach hier jedoch sehr gut auf Kompost- und Kalk-Düngung an und zeigte in den entsprechenden Varianten eine verbesserte Feinwurzelentwicklung, zufrieden stellende Vitalitätswerte und ein deutlich höheres Wachstum. Durch die Kompost- oder Kalk-Gaben wurden erheblich reduzierte Mangan-Blattgehalte gemessen. Bei kombinierter Kompost-Kalk-Düngung bestand keine Aluminium-Toxizität. Kompost-Gaben senkten zudem den ohne Behandlung extrem hohen, im toxischen Bereich liegenden Schwefel-Gehalt auf ausreichende Normalgehalte.

Nach Pflanzversuchen in einem Tagebaugebiet im Nordwesten Tschechiens wurde die Eberesche, die in den ersten Jahren einen im Vergleich zu anderen Baumarten hohen Zuwachs zeigte, ausdrücklich für den Einsatz auf vergleichbaren Standorten empfohlen (Kupka \& Dimitrovsky 2006).

Auch auf den Ronneburger und ähnlichen Tagebaufolgeflächen können Ebereschen gepflanzt werden; dabei sollte auf den Flächen, auf denen sich bislang noch keine Spontanvegetation ansiedeln konnte (s. S. 37), die genannte Dünger-Kombination zum Einsatz kommen.

Angesichts der - durch die Ergebnisse der vorliegenden Arbeit unterstrichenen - großen Bedeutung von Mykorrhiza für das Pflanzenwachstum auf Tagebaufolgeflächen und der positiven Effekte entsprechender Impfmaßnahmen erscheint zudem auch beim Einsatz von Ebereschen auf diesen Standorten eine Mykorrhizierung sinnvoll. Laut Helfer (1997) bilden Ebereschen regelmäßig VA-Mykorrhiza aus. Die Impfung von Ebereschen-Sämlingen mit VAMykorrhiza führte auf Kippsubstraten in Nord-Böhmen zu verbessertem Wachstum (Vosatka 1990).

\subsection{Schwarz-Erle}

Erlen sind in der Lage, Symbiosen mit Luftstickstoff-bindenden Bakterien der Gattung Frankia (Actinomycetaceae) einzugehen, die auch als „Strahlenpilze“ bekannt sind. Dabei bilden sich an den Erlenwurzeln bis zu tennisballgroße verholzende Knollen, die so genannten Rhizothamnien. Nach Werner (1987) können Schwarz-Erlen durch eine solche Symbiose 50-200 kg $\mathrm{N}_{2}$ pro Hektar und Jahr fixieren. Somit ist die Baumart vom Stickstoffangebot ihres Standortes weitgehend unabhängig und entsprechend gut geeignet für die Erstbesiedelung stickstoffarmer Rohböden wie etwa verkipptes Haldensubstrat. Nach Kohls et al. (1999) wird die Erle oft auf nährstoffarmen Tagebau-Rekultivierungsflächen eingesetzt. 
Auf den Ronneburger Versuchsflächen wurden im Rahmen der vorliegenden Arbeit bei den Erlen (abgesehen von in einigen Varianten unzureichenden Kalium-Blattgehalten) kaum Nährstoffdefizite festgestellt, was im Gegensatz zu den übrigen getesteten Baumarten stand.

Durch ihr stickstoffreiches Laub trägt die Erle zur Bodenverbesserung auf Tagebaufolgeflächen bei (Keleberda 1981, Kulhavy \& Grunda 1991, Walker et al. 2005). Aufgrund dieser Wirkung werden Erlen beispielsweise in der Lausitz auf Kippenstandorten als Misch- oder Nebenbaumarten empfohlen (Böcker et al. 1999, Katzur et al. 1999a). Bei der Rekultivierung eines Manganerz-Tagebaus in der Ukraine führte die Einmischung von Erlen in eine Kiefernpflanzung zu verglichen mit Kiefern-Reinbeständen schnellerer Rekultivierung der Standorte und besserem Wachstum der Kiefern (Dan'ko 1986). Binns \& Fourt (1981) empfahlen nach Untersuchungen auf Rekultivierungsstandorten in Großbritannien, dass bei fehlendem Oberboden oder organischer Substanz Erlen 50 \% des gepflanzten Bestandes ausmachen sollten.

Weiterhin sind Erlen unempfindlich gegenüber Staunässe, einem Problem, das auf dem Standort Halde aufgrund des verdichteten Bodens häufig beobachtet werden kann. Nach Ammer et al. (1994) sind Erlen auch auf extrem verdichteten Tonabbauflächen zu bevorzugen.

Neben ihren Eigenschaften als Pionierbaum, Stickstoff sammelnde Hilfspflanze und „Wasserpumpe“ verfügt die Erle zudem über ein stabilisierendes Wurzelsystem, das zur Befestigung von Hängen, Böschungen und Ufern beiträgt (Kilian et al. 1994).

In der vorliegenden Untersuchung bestand ein weiterer - angesichts der hohen Wilddichten auf großflächig ungestörten ehemaligen Tagebauflächen sehr wichtiger - Vorteil in der vergleichsweise geringen Attraktivität dieser Baumart für Wild. So wurden an den Erlen auf den Ronneburger Versuchsflächen deutlich weniger Verbissschäden festgestellt als an anderen getesteten Baumarten.

Insgesamt scheinen Erlen gegenüber den rauen Standortbedingungen auf ehemaligen Tagebauflächen eine hohe Toleranz zu zeigen (z.B. auf Kippenstandorten in Indiana, Hensley \& Carpenter 1984).

Auf den Ronneburger Versuchsflächen erzielten die Erlen ebenfalls recht gute Vitalitäts- und Wachstumsergebnisse; in Bereichen, in denen sich bereits Spontanvegetation etablieren konnte, auch ohne jede Bodenhilfsstoff-Behandlung.

Von den sechs getesteten Baumarten schnitt die Erle am besten ab. Der Einfluss der verschiedenen Behandlungsvarianten war bei dieser Baumart am wenigsten deutlich. Auf Kohletagebau-Rekultivierungsstandorten in Großbritannien wurde die Entwicklung der Erle ebenfalls als relativ unabhängig von der Behandlung beschrieben, wenngleich manche Düngevarianten die Ergebnisse verbesserten (Steer \& Baker 1997). Auf sauren Tagebaustandorten in Pennsylvania zeigten Erlen teilweise eine gute Entwicklung. Jedoch waren auf sehr sauren Teilflächen mit pH-Werten unter 3,5 auch bei dieser Baumart Überlebensrate und Wachstum gering (Davidson 1979). Unter ebenfalls sehr sauren Standortbedingungen nach Tagebau in Indiana waren die Überlebensraten von Erlen bei Kalk-Düngung unabhängig von der Höhe der Kalk-Gabe gut, während sie ohne Kalkung weniger als $10 \%$ betrugen (Carpenter \& Hensley 1979).

Am Ronneburger Standort fiel insgesamt eine starke Reaktion der Baumart auf die kleinräumig unterschiedlichen Standortverhältnisse auf. Hier überlebten unbehandelte Erlen zwar selbst auf 
der ungünstigsten Versuchsfläche A (die Nullvarianten der übrigen Baumarten fielen hier komplett aus), bei etwas höheren pH-Werten im Bereich der Kontrolle auf Fläche B zeigten sie jedoch eine bessere Entwicklung mit deutlich höherem Wachstum.

Insgesamt ist die Erle, deren Einsatz bei der Rekultivierung von Tagebaufolgeflächen bereits eine lange Tradition hat (beispielsweise in der Lausitz, im Mitteldeutschen Revier, in Tschechien und Serbien: Häge 1996, Katzur \& Haubold-Rosar 1996, Smit \& Veselinovic 1997, Hodacova \& Prach 2003, LMBV 2009), auch für die Pflanzung am Ronneburger Standort zu empfehlen. Um eine gute Entwicklung auch auf den saureren Teilflächen zu ermöglichen, ist eine Initialdüngung mit Kompost (und Kalk) ratsam.

Auf Kohle-Kippsubstraten hatte die Impfung von Erlen-Sämlingen mit VA-Mykorrhiza positive Wirkung auf das Pflanzenwachstum (Enkhtuya et al. 2005). Wie alle übrigen (in der vorliegenden und anderen Arbeiten) untersuchten Baumarten kann also auch die vergleichsweise robuste Erle auf den hoch problematischen Haldenstandorten von einer Mykorrhiza-Impfung profitieren, weshalb diese Maßnahme ebenfalls empfohlen wird.

\subsection{Douglasie}

Douglasien werden in ihrer nordamerikanischen Heimat zur Rekultivierung von Tagebauflächen, beispielsweise nach Kohleabbau in Washington (Heilmann 1990), eingesetzt. Für die Bepflanzung von Tagebauflächen in Virginia, wo seit Jahrzehnten umfangreiche Erfahrungen mit heimischen Harthölzern gesammelt werden, wird die Douglasie ebenfalls als geeignet empfohlen (Tobert et al. 1989). Auch aus Serbien wird über die Wiederaufforstung von degradierten Böden nach Kohle-Tagebau unter anderem mit Douglasien berichtet (Smit \& Veselinovic 1997). Aufgrund ihrer Sensibilität gegenüber Frostschäden und unfruchtbaren Böden wurden Douglasien für die Aufforstung ehemaliger Ölschiefer-Tagebaue in Estland dagegen als ungeeignet eingestuft (Kaar 2002).

Beispiele für den Einsatz von Douglasien bei Tagebau-Rekultivierungsmaßnahmen in Deutschland konnten etwa im Lausitzer (z.B. Katzur et al. 1999c) und im rheinischen Braunkohlerevier (z.B. Jansen 1997) oder im Helmstedter Revier (z.B. Schröter 2003) sowie auf ehemaligen Bergbauhalden im Südschwarzwald (Hurrle 1981) gefunden werden.

Im für aktuelle Rekultivierungsmaßnahmen im Lausitzer und Mitteldeutschen Revier vorgesehenen Baumartenspektrum (LMBV 2009) ist die nicht heimische Douglasie jedoch nicht enthalten.

Die höhere Trockenheitstoleranz der Douglasie (Richter 1997) könnte auf den bezüglich der Wasserversorgung schwierigen Haldenstandorten und angesichts von sich ändernden klimatischen Bedingungen vorteilhaft sein. So war im Ronneburger Freiland-Versuch die Ausfallrate bei den Douglasien deutlich geringer als bei den Kiefern, deren schlechtes Abschneiden vermutlich zumindest teilweise mit dem sehr trockenen Frühjahr nach der Pflanzung im April 2005 zusammenhing.

In verschiedenen Untersuchungen wurden bei Douglasien Schäden und Ernährungsstörungen durch Manganüberschuss festgestellt (Beispiele aus Rheinland-Pfalz, dem Eifel-Moselraum sowie den belgischen Ardennen: Block 1997, Schöne 1997, Weissen 1997). Demnach ist die 
Baumart bei einem Überangebot an Mangan stärker gefährdet als Fichten oder einheimische Laubbaumarten, was gegen die Verwendung von Douglasien auf sehr stark sauren, verdichteten Standorten (beides fördert Mangan-Belastung, s. ab S. 342) spräche.

Zumindest eine höhere Mangan-Aufnahme der Douglasien unter gleichen Standortbedingungen kann nach den Ronneburger Freiland-Versuchen jedoch nicht bestätigt werden. Während die Assimilationsorgane der untersuchten Laubbäume (Eiche, Ahorn, Eberesche, Erle) maximale Mangan-Gehalte zwischen $3000 \mathrm{mg} / \mathrm{kg}$ und $3600 \mathrm{mg} / \mathrm{kg}$ (Kiefern: $2800 \mathrm{mg} / \mathrm{kg}$ ) aufwiesen, lagen die höchsten in den Douglasien-Nadeln ermittelten Gehalte bei gut $2000 \mathrm{mg} / \mathrm{kg}$. Diese Gehalte wurden lediglich in drei Varianten erreicht, während die Gehalte der anderen 13 Varianten deutlich niedriger waren. Bei diesen drei Varianten handelte es sich um MykorrhizaKombinationen, in denen Vitalität und Wachstum der Douglasien teilweise signifikant erhöht waren, so dass die Mangan-Gehalte (bei sehr unterschiedlicher Bewertung in der Literatur, s. ab S. 333) offensichtlich keine einschränkende Belastung darstellten.

In den völlig vegetationsfreien Bereichen der Ronneburger Versuchsflächen, die einen geringeren $\mathrm{pH}$-Wert und keinen Bodenbewuchs aufwiesen, zeigten die Douglasien eine deutlich schlechtere Entwicklung als in den Bereichen, in denen sich aufgrund der (hinsichtlich pH-Wert, Austauscherbelegung und damit Nährstoffverfügbarkeit) etwas günstigeren Bodenbedingungen auch Spontanvegetation ansiedeln konnte. Insgesamt spielte bei den Douglasien der Standort in einem dieser beiden Bereiche eine besonders große Rolle.

Dabei war neben einer potentiell besseren Versorgungs- und Belastungssituation vermutlich das in diesen Bereichen nachweisbare Vorhandensein von Mykorrhiza-Pilzen (und damit von u.a. für Nadelbäume so wichtigen Symbiosepartnern) entscheidend.

So wiesen die unbehandelten Douglasien auf Fläche B - hier wurden im Bereich der Nullvariante massenhaft Pilz-Fruchtkörper gefunden - im gesamten Versuchsverlauf eine sehr gute Vitalität auf. In den ungünstigeren, vergleichsweise stärker sauren Bereichen der Ronneburger Versuchsflächen waren die Bodenbedingungen für Ekto-Mykorrhiza-Pilze (laut Weissenhorn 2002 und Baum 2004 vom pH-Wert abhängig) vermutlich zu schlecht: Mykorrhiza-Impfungen allein (V11) hatten hier keinen Effekt auf die Douglasien, sondern zeigten erst in Kombinationen mit Kalk und/oder Wasserspeichersubstanzen Wirkung, die allerdings nicht über das erste jahr hinaus nachweisbar war.

Insgesamt sollte bei der Pflanzung von Douglasien auf Tagebaufolgeflächen vor allem darauf Wert gelegt werden, dass (ggf. durch Impfung) geeignete Mykorrhiza-Partner vorhanden sind und dass (ggf. durch Kalkung) die Bodenbedingungen für eine Einwanderung und vitale Entwicklung dieser Pilze ausreichend sind.

\subsection{Wald-Kiefer}

Die Kiefer ist die häufigste Baumart bei Rekultivierungen z.B. in der Lausitz und im Mitteldeutschen Revier (Häge 1996, Preußner 1998) und wird dort vor allem seit den 1970er Jahren verstärkt gepflanzt (Häge 1996, Katzur \& Haubold-Rosar 1996). Aufgrund der standörtlichen Verhältnisse in der Lausitz wird die Kiefer dort auch in Zukunft sehr große Bedeutung haben (Preußner 1998, Ertle et al. 2006). Sie ist fester Bestandteil des für 
Rekultivierungsmaßnahmen im Lausitzer Revier vorgesehenen Baumartenspektrums (LMBV 2009) und wird in Katzur et al. (1999a) als eine der Hauptbaumarten in anzustrebenden Mischwäldern auf den Kippen und Halden der Lausitz genannt.

Grund für den erfolgreichen Einsatz der Kiefer auf Braunkohle-Kippenflächen in der Lausitz (Katzur \& Haubold-Rosar 1996) oder etwa bei der Rekultivierung von ÖlschieferTagebauflächen in Estland (Kaar 2002) ist ihre große Standortamplitude (Böcker et al. 1999), die diese Baumart zu einem anspruchslosen Pionier auf Extremstandorten macht (Stähr 2003). So ist nach Heinsdorf \& Tölle (1991) die Kiefer (unter mitteleuropäischen Verhältnissen inkl. Kippenstandorten) stets ausreichend mit Calcium versorgt und kann auch bei geringem entsprechendem Nährstoffpotential des Bodens ihren Kalium-Bedarf decken (Stähr 2003). In der vorliegenden Untersuchung konnte dies im Wesentlichen bestätigt werden (bzgl. Calcium abhängig von der herangezogenen Quelle der Bewertungsstufen); dabei hoben sich vor allem die ausreichenden Kalium-Nadelgehalte von der diesbezüglich unzureichenden Versorgung der anderen Baumarten (außer Eiche) ab.

Auf Rohboden-Rekultivierungsstandorten (Standorte ohne Oberboden oder organische Substanz) werden Kiefern in Mischung mit bodenverbessernden Baumarten wie Erlen empfohlen (Beispiel aus Abbaugebieten in Großbritannien: Binns \& Fourt 1981), was sowohl das Wachstum der Kiefern verbessert als auch die Rekultivierungszeit verkürzt (z. B. in einem ehemaligen Manganerz-Tagebau in der Ukraine, Dan'ko 1986).

Bei Kippenerstaufforstungen ist aufgrund der ungünstigen Standortbedingungen auch bei Kiefern in den ersten Jahren ein gegenüber ungestörten Standorten stark vermindertes Wachstum festzustellen (Böcker et al. 1998, Katzur et al. 1998, Ertle et al. 2006).

Die Kiefern weisen dabei vor allem Stickstoff-Defizite auf, was mit den Ergebnissen der vorliegenden Untersuchung auf den Ronneburger Versuchsflächen übereinstimmt.

Durch Bodenentwicklung und Etablierung ökosystemarer Stoffkreisläufe können sich Ernährungssituation und Wachstum von Kiefern auf Kippsubstraten jedoch zunehmend verbessern und ein hohes Niveau erreichen (Böcker et al. 1998, Stähr et al. 1999, Knoche et al. 2000, Katzur \& Böcker 2001, Ertle et al. 2006).

Kiefern auf sauren Tagebaustandorten in Pennsylvania konnten sich teilweise gut entwickeln, jedoch waren bei pH-Werten unter 3,5 auch bei dieser Baumart Überlebensrate und Wachstum gering (Davidson 1979). Auf extrem sauren ehemaligen Pyriterz-Tagebauflächen in Bayern mit hohen Schwefel- und Schwermetall-Gehalten erwies sich die Kiefer dagegen als besonders gut angepasste Baumart mit hoher Schwermetall-Toleranz (Rodenkirchen 1996).

Die auch in der vorliegenden Untersuchung gegebene Schwermetallbelastung der Kiefern stellte ebenfalls keine entscheidende Einschränkung dar. Dies wurde anhand der Kompost-Varianten deutlich. Gegenüber der Kontrolle wurden hier neben teils angehobenen Nährstoff-Gehalten auch teilweise erheblich höhere Schwermetall-Gehalte gemessen, während die Schwefel-Gehalte zwar sanken, jedoch immer noch extrem hoch und oberhalb der Schadstoff-Grenzwerte blieben. Dennoch zeigten die mit Kompost-Gaben gepflanzten Kiefern eine bessere Vitalität und deutlich stärkeres Wachstum. Die Wurzel- bzw. unterirdische Biomasse (Verdoppelung gegenüber der Kontrolle) nahm dabei jedoch nicht so stark zu wie die Spross- bzw. oberirdische Biomasse (Verfünffachung gegenüber der Kontrolle). Nach Hendry \& Grime (1993) ist das Verhältnis dieser beiden Parameter ein Maß für die Biomassenallokation und damit dafür, wie viele 
Assimilate der Blätter in die Wurzel transportiert werden. Stresstolerante Pflanzen investierten im Verhältnis viel in die unterirdische Biomasse und wiesen so ein hohes Wurzel-SprossVerhältnis auf. Lavender (1984) nannte ebenfalls (hier umgedreht) ein geringes Spross-WurzelVerhältnis als bei problematischen Standortbedingungen von großer Bedeutung.

Das schlechte Abschneiden (mehr oder weniger Totalausfall) der Kiefern in den Kalk-Varianten lässt den Schluss $\mathrm{zu}$, dass die in den Kompost-Varianten günstigeren bodenchemischen Bedingungen nicht der alleinige Grund für die insgesamt bessere Entwicklung der Kiefern sein können. Vielmehr könnte auch eine durch Kompost-Einmischung verbesserte Benetzbarkeit, Infiltrationsfähigkeit und Wasserleitfähigkeit (s. ab S. 55) die Wasserversorgung der Kiefern positiv beeinflusst haben. Unter Umständen denkbar (jedoch nicht überprüft) wäre auch ein Vorhandensein von Mykorrhiza-Pilzsporen in dem zwar durch Hitze-Entwicklung beim Gärprozess „sterilisierten“, jedoch anschließend für längere Zeit unter freiem Himmel abgelagerten Kompost, so dass es in diesen Varianten vielleicht eher zu einer u.a. für alle Nadelbäume so wichtigen Baum-Pilz-Symbiose kommen konnte.

Angesichts des Gesamtbildes geringer Standortansprüche und hoher Toleranz der Kiefer gegenüber widrigen Bedingungen sowie ihrer unzähligen erfolgreichen Einsätze bei Tagebaurekultivierungen waren die hohen Ausfallraten dieser Baumart im 1. Jahr des Ronneburger Freiland-Versuchs so nicht erwartet worden. Die Begründung dafür könnte die Kombination aus zwei Faktoren liefern: Anhaltende Trockenheit in den Wochen nach der Pflanzung im sehr warmen, niederschlagsarmen Frühjahr 2005 (s. S. 14) sowie im individuellen Fall das Fehlen passender Mykorrhiza-Partner. Letzteres könnte bei den betroffenen Bäumen den raschen Aufbau einer für die Baumart Kiefer lebensnotwendigen Ekto-Mykorrhiza (Höster 1993, Kottke 2005), die auch die kritische Wasserversorgung verbessert hätte, unmöglich gemacht haben. Es erscheint denkbar, dass im Freiland-Versuch angesichts der Trockenperiode nach der Versuchsanlage nur die Kiefern überlebten, die rasch genug passende SymbiosePartner vorfanden. Für diese Erklärung spricht, dass die überlebenden Kiefern Standorte entweder innerhalb oder in unmittelbarer Nähe der Teilflächen hatten, auf denen im Versuchsverlauf Spontanvegetation und Pilzfruchtkörper nachgewiesen wurden (s. S. 37). Zudem war die Ausfallrate der Kiefern in Töpfen mit Haldensubstrat im Gewächshaus sehr gering $(10 \%$ gegenüber $80 \quad \%$ im Freiland-Versuch). Im Unterschied $\mathrm{zu}$ den Freilandbedingungen war hier eine regelmäßige Bewässerung gegeben, auch waren sämtliche Kiefern durch zufällig im verwendeten Substrat vorhandene sowie über das Gießwasser verbreitete Pilzsporen nachweislich mykorrhiziert.

Dass (in Kombination mit anderen ungünstigen Standorteigenschaften) sehr trockene Bedingungen problematisch für Kiefern sein können, belegen auch Untersuchungen auf sehr warmen, trockenen Kohletagebaufolgeflächen in Bulgarien, die zu der Forderung führten, den Einsatz der auf diesen Standorten bis dahin häufig verwendeten Kiefern zu begrenzen (Petrova 1995).

Die Einmischung von $30 \mathrm{~g}$ Kalk (in der vorliegenden Untersuchung wurden 50 g verwendet) direkt in das Pflanzloch-Substrat auf versauerten Tagebauflächen in der Sierra Nevada hatte aufgrund der Wechselwirkungen bei sehr trockenen Verhältnisse einen negativen Effekt auf Überleben und Wachstum zweijähriger Pinus jeffreyi Grev. \& Balf. (Walker 2002). Hier lässt sich eventuell eine Parallele zur vorliegenden Untersuchung ziehen, in der die Kiefer nach anhaltender Trockenheit im Anschluss an die Pflanzung auch in sämtlichen Kalk-Varianten (ausgenommen der Kombination mit Kompost) hohe Ausfallraten zeigte. 
Durch die insgesamt hohe Sterblichkeit der Kiefern bei den im Rahmen der vorliegenden Arbeit durchgeführten Versuchspflanzungen, über deren Gründe nur Vermutungen angestellt werden konnten, ist eine Beurteilung der Eignung dieser Art für die Pflanzung auf den Ronneburger Kippen-Rohböden nicht möglich. Belegt werden konnte dagegen eine positive Reaktion auf Kompost-Gaben. Mykorrhiza-Impfungen sollten auch bei dieser obligat auf Mykorrhiza angewiesenen Baumart erwogen werden. 


\section{Fazit \& Empfehlung}

Was sind die Hauptprobleme des Standortes Uranerz-Tagebaufolgeflächen Ronneburg? Welche der sechs untersuchten Baumarten Rot-Eiche, Spitz-Ahorn, Eberesche, Schwarz-Erle, Douglasie und Wald-Kiefer haben sich - zumindest nach zweijähriger Untersuchung - auf dem Haldenstandort als geeignet erwiesen? Welche der eingesetzten Bodenhilfsstoffe Perlit, Wasserspeichersubstanzen, Magnesiumkalk, Kompost und Mykorrhiza-Inokulum konnten in diesem Zeitraum Bodenbedingungen, Nährstoff-Versorgung, Schadstoff-Belastung, Vitalität und Wachstum der Versuchspflanzen positiv beeinflussen? Was sind die effektivsten, für die Praxis empfehlenswertesten Kombinationen?

Das Fazit der vorliegenden Arbeit beantwortet diese Fragen und bestätigt bzw. verwirft damit die zu Beginn des Projektes aufgestellten Arbeitshypothesen (s. S. 10).

\section{Standortproblematik}

Die schwierigen Standortbedingungen auf den Ronneburger Tagebaufolgeflächen bestehen zunächst vor allem in einem ungünstigen Bodenchemismus, der überwiegend auf PyritVerwitterung zurückzuführen ist.

Die potentielle Ernährungssituation ist abgesehen von geringen Stickstoff-Gehalten (auf Rohböden ohne Humus-Akkumulation zu erwarten) hinsichtlich Boden-Gehalten, effektiver Austauschkapazität, Austauscherbelegung und Basensättigung vergleichsweise günstig. Hohe Magnesium-Gehalte und -Sättigungen lassen jedoch Nährstoff-Antagonismen vermuten.

Problematisch sind vor allem hohe Schadstoff-Belastungen der Böden, vornehmlich mit Schwefel und Kupfer, die sich in teils extrem hohen Belastungen der Versuchspflanzen widerspiegeln. Die Assimilationsorgane wiesen zudem ebenfalls extrem hohe Eisen- und Aluminium-Gehalte, teilweise auch Mangan-Gehalte auf. Die fortgesetzte Pyrit-Verwitterung sorgt hier für eine Nachlieferung von Schwefel und Eisen sowie durch Schwefelsäure für eine zunehmende Versauerung des Bodens, was die Mobilität von Kupfer, Eisen, Aluminium und Mangan begünstigt.

Als ein Hauptproblem des untersuchten Standortes sind durch toxische Konzentrationen dieser Stoffe verursachte Wurzel- und Pflanzenschädigungen zu vermuten, die Nährstoff- und Wasserversorgung, Vitalität und Wachstum der Pflanzen beeinträchtigen.

$\mathrm{Zu}$ der bodenchemischen Standortproblematik kommt ein ungünstiger Wasserhaushalt, der auf die geringe Infiltrations- und Wasserleitfähigkeit des Bodens (verminderte Durchlässigkeit vorhandener Grobporen durch Verdichtung, Zerscherung) und seine geringe nutzbare Feldkapazität (verminderte Anzahl an Mittelporen und engen Grobporen durch Verdichtung) zurückzuführen ist. Neben Wasserstress entstehen dabei durch Verdichtung und zeitweise Überstauung Sauerstoffmangel und somit reduzierende Bedingungen, was wiederum die Mobilität von z.B. Mangan verstärken kann. 
Das problematische Mikroklima auf den nicht oder wenig bewachsenen Flächen war gerade in den beiden klimatisch so ungünstigen Untersuchungsjahren 2005 (warmes, trockenes Frühjahr im Anlagejahr) und 2006 (lang anhaltend heißer, trockener Sommer) ein weiterer Faktor.

Unter insgesamt derart ungünstigen Standortbedingugen spielen Symbiosen (Mykorrhiza) für Pflanzen eine wichtige Rolle. Auf den Ronneburger Flächen schien in Bereichen mit vergleichsweise geringeren $\mathrm{pH}$-Werten, in denen sich auch keine Spontanvegetation ansiedeln konnte, das Fehlen passender Mykorrhiza-Partner eine Erklärung für das schlechte Abschneiden der darauf angewiesenen Bäume sein zu können.

\section{Bodenhilfsstoffe}

Zur Verbesserung der physikalischen Bodeneigenschaften: Perlit, Wasserspeichersubstanzen

Insgesamt konnten die zur Verbesserung der physikalischen Bodenbedingungen eingesetzten Bodenhilfsstoffe auf den Ronneburger Tagebaufolgeflächen nicht überzeugen.

Perlit führte zwar zu einer Abnahme der Trockenraumdichte des Haldensubstrates, einem Anstieg seines Gesamtporenvolumens (stärker als mit Kompost) sowie einer verbesserten Infiltrations- und Wasserleitfähigkeit, jedoch auch zu einer Abnahme der Wasserspeicherkapazität im Topf-Versuch.

Bei alleiniger Perlit-Beimischung bestand überwiegend kaum ein Effekt auf die Entwicklung der Versuchspflanzen. In Kombination mit Kalk minderte Perlit teilweise den positiven KalkEinfluss. Die Assimilationsorgane der Versuchspflanzen wiesen mit Perlit sowie mit Wasserspeichersubstanzen teils hohe Schadstoff-Gehalte auf.

Wasserspeichersubstanzen hatten im Topf-Versuch keinen Effekt auf die physikalischen Bodeneigenschaften (mit Superabsorber wurde die Wasserspeicherkapazität etwas herabgesetzt). Lehmböden (wie auf den Ronneburger Halden vorherrschend) scheinen nicht das richtige Einsatzgebiet für Wasserspeichersubstanzen zu sein. Dies bestätigten auch begleitende Laborversuche, während mit beiden Wasserspeichersubstanzen in Sandböden überwiegend gute Ergebnisse erzielt wurden (Kirscht, unveröffentlicht).

Auf Vitalität und Wachstum der Versuchspflanzen blieb der Einsatz von Wasserspeichersubstanzen allein weitgehend wirkungslos. Die mit Superabsorber gepflanzten Bäume zeigten oft die geringsten Vitalitäts- und Wachstumswerte, in einigen Fällen signifikant geringere als die unbehandelten Kontrollpflanzen.

Jedoch konnte der zusätzliche Einsatz von Wasserspeichersubstanzen die positiven Effekte der Mykorrhiza-Impfungen z.T. unterstützen, während die der Kalkungen teilweise gemindert/verzögert, teilweise verstärkt wurden.

Bei vergleichbaren Rekultivierungsvorhaben könnten allenfalls Wasserspeichersubstanzen als Unterstützung von Mykorrhiza-Impfungen verwendet werden. Diese interessanten SynergieEffekte verdienen eine genauere Untersuchung. Da der Effekt stark standortabhängig war (auch negative Wirkung möglich), sollten vor der Anwendung im konkreten Fall zunächst entsprechende Tests erfolgen. 


\section{Zur Verbesserung der chemischen Bodeneigenschaften: Kalk}

Die Kalk-Gaben hoben den niedrigen pH-Wert des sehr stark sauren Haldensubstrats auf einen Wert im mäßig sauren Bereich („ökologisches Optimum“, Ulrich 1980/81). Damit einher ging eine Verbesserung des Nährstoffangebotes und eine deutlich höhere Elastizität des Bodens gegenüber Säurebelastung. Die Versuchspflanzen wiesen standortabhängig mit Kalk-Düngung eine geringere Schadstoff-Belastung, bessere Nährstoff-Versorgung, bessere Vitalität sowie stärkeres Wachstum auf. Teilweise hatten Kombinationen mit Stockosorb®, Kompost oder Mykorrhiza einen verstärkten Effekt.

Darüber hinaus wurde im Versuchsverlauf offensichtlich, dass eine bereits im Jahr 2000 in Teilen der Ronneburger Flächen durchgeführte Kalkungsmaßnahme die Besiedelung dieser dadurch etwas weniger sauren Bereiche mit Spontanvegetation zur Folge hatte, Pflanzenwachstum auf diesen andernfalls vegetationsfrei bleibenden Flächen also überhaupt erst ermöglichte.

Zur Verbesserung der physikalischen und chemischen Bodeneigenschaften: Kompost Die Kompost-Düngung hob den niedrigen pH-Wert des sehr stark sauren Haldensubstrats auf einen Wert im mäßig sauren Bereich („ökologisches Optimum“, Ulrich 1980/81). Damit einher ging eine deutlich größere Elastizität des Bodens gegenüber Säurebelastung. Die Kohlenstoffund Stickstoff-Gehalte des Bodens wurden erhöht; insgesamt wurde das Nährstoffangebot verbessert. Zudem nahm die Trockenraumdichte des Bodensubstrats ab, während das Gesamtporenvolumen anstieg. Die Infiltrations- und Wasserleitfähigkeit des Bodens verbesserte sich, die Wasserspeicherkapazität änderte sich dagegen nicht.

Die Versuchspflanzen wiesen standortabhängig mit Kompost-Düngung eine bessere Ernährungs- und Belastungssituation, bessere Vitalität sowie stärkeres Wachstum auf. Abgesehen von den Mykorrhiza-Varianten wurden jeweils die Spitzenwerte in den KompostVarianten ermittelt; die Ergebnisse waren teils noch besser als mit Kalk. Teilweise hatte eine Kombination aus Kompost- und Kalk-Düngung einen verstärkten Effekt. Vor allem die anspruchsloseren Baumarten Eberesche, Erle und Kiefer konnten von den Kompost-Düngungen profitieren.

\section{Zur Verbesserung der biologischen Bodeneigenschaften: Mykorrhiza-Inokulum}

Die Beimpfung von Bäumen mit Mykorrhiza-Pilzen bei der Pflanzung führte zu guten Mykorrhizierungsgraden. Insgesamt war ein deutlich positiver Effekt auf die Ernährungs- und Belastungssituation, Vitalität und Wachstum zu verzeichnen. Bei den betreffenden Baumarten wurden die Spitzenwerte stets mit Mykorrhiza-Impfung gemessen. Zusätzliche Gaben von KalkDünger und/oder Wasserspeichersubstanzen, auch von Stockosorb® oder Superabsorber allein, verbesserten teilweise den Effekt. Selbst ohne Bodenhilfsstoffe zur Verbesserung der Bodenreaktion konnten mit Mykorrhiza-Impfungen deutlich positive Wirkungen erzielt werden, was angesichts der niedrigen $\mathrm{pH}$-Werte bemerkenswert ist.

Der Einsatz von Mykorrhiza-Impfungen ist auf vergleichbaren Standorten unbedingt empfehlenswert, vor allem bei der Pflanzung von obligat auf Mykorrhiza angewiesenen, aber auch bei fakultativ Mykorrhiza-bildenden Baumarten. Das unmittelbare Vorhandensein von passenden Symbiosepartnern bei der Pflanzung stellt unter derart ungünstigen Bodenbedingungen einen erheblichen Startvorteil dar. 


\section{Baumarten}

\section{Rot-Eiche}

Die Eichen zeigten im Ronneburger Freiland-Versuch sehr hohe Ausfallraten, was mit der eher schlechten gelieferten Pflanzenqualität sowie einem Mangel an passenden Mykhorriza-Partnern zusammenhängen kann. Im Rahmen der vorliegenden Untersuchung kann deshalb keine abschließende Bewertung der Eignung dieser Baumart für die Ronneburger und andere Tagebaufolgeflächen mit ähnlichen Bedingungen erfolgen.

Es konnte jedoch ein positiver Einfluss des Mykorrhiza-Inokulums festgestellt werden. Die Überlebensrate der beimpften Eichen war deutlich höher; bei den bereits oberirdisch abgestorbenen Pflanzen erfolgte in diesen Varianten ein Neuaustrieb aus der Wurzel. Insgesamt scheinen bei der Pflanzung von Eichen auf vergleichbaren Standorten Mykorrhiza-Impfungen sehr vorteilhaft zu sein.

\section{Spitz-Ahorn}

Ahorne sind für die Teilflächen der ehemaligen Ronneburger Absetzerhalde, die bis Versuchsende frei von Spontanvegetation blieben (im Jahr 2000 nicht gekalkt; pH 3,6), nicht geeignet. Nachgewiesene Effekte der Behandlungsvarianten führten hier weder zu ausreichend guten Ergebnissen noch hielten sie bis zum Ende des zweijährigen Untersuchungszeitraums an.

Dagegen können Ahorne auf den Teilflächen, auf denen sich im Versuchsverlauf Spontanvegetation etablieren konnte (im Jahr 2000 gekalkt; pH 4,0), mit MykorrhizaImpfungen und/oder einer pH-Wert-Erhöhung mittels Kalk- und/oder Kompost-Düngung über 2 Versuchsjahre erfolgreich bestehen, ohne diese Bodenhilfsstoffe jedoch nicht.

Insgesamt sprechen eine Reihe von Faktoren eher gegen eine Verwendung der (gegenüber den anderen getesteten Baumarten anspruchsvolleren) Ahorne auf den Ronneburger Tagebaufolgeflächen sowie unter ähnlichen Standortbedingungen. Dazu gehören die im Vergleich schlechteste Ernährungs- und höchste Belastungssituation, das geringe Wachstum, die stark gestörte Wurzelentwicklung durch Versauerung, die wahrscheinliche Konkurrenz durch Bodenvegetation und die sehr starken Wildschäden.

\section{Eberesche}

Auf Teilflächen mit vergleichsweise ungünstigeren Standortbedingungen (im Jahr 2000 nicht gekalkt; pH 3,6), die dauerhaft vegetationsfrei blieben, konnte sich die Eberesche im Ronneburger Versuch nicht bewähren.

Auf demgegenüber günstigeren Standorten (im Jahr 2000 gekalkt; pH 4,0) ist die Baumart dagegen selbst ohne Bodenhilfsstoff-Behandlung verwendbar.

Insgesamt zeigten die Ebereschen einen positiven Effekt der pH-Wert-erhöhenden Bodenhilfsstoffe Kompost und Kalk. Die besten Ergebnisse wurden mit einer kombinierten Behandlung aus Kompost- und Kalk-Düngung erzielt. 
Schwarz-Erle

Von den sechs getesteten Baumarten ist die Schwarz-Erle deutlich am besten zur Pflanzung auf den Ronneburger und vergleichbaren Standorten geeignet.

Bereits ohne Bodenhilfsstoff-Behandlung zeigte das Laub dieser (durch Symbiosen mit Luftstickstoff-fixierenden Bakterien von der geringen standörtlichen Stickstoff-Versorgung unabhängigen) Baumart kaum Nährstoff-Defizite.

Auf der ehemaligen Ronneburger Absetzerhalde können Erlen auf den problematischeren Standorten (im Jahr 2000 nicht gekalkt; pH 3,6) in Verbindung mit Kompost-Düngung erfolgreich gepflanzt werden.

Auf den vergleichsweise weniger problematischen Teilflächen (im Jahr 2000 gekalkt; pH 4,0), auf denen sich auch Spontanvegetation etablieren konnte, ist die Verwendung dieser Baumart auch ohne Bodenhilfsstoff-Behandlungen möglich.

\section{Douglasie}

Die Douglasie ist für die ungünstigeren Bereiche der ehemaligen Ronneburger Absetzerhalde (im Jahr 2000 nicht gekalkt; pH 3,6), die auch frei von Spontanvegetation blieben, nicht geeignet. Zunächst viel versprechende Effekte von Kalk-Gaben und Mykorrhiza-Kombinationen bestanden nur im 1. Vegetationsjahr, im 2. Jahr ging auf diesen Standorten die Vitalität der Douglasien insgesamt deutlich zurück.

Auf den günstigeren Standorten (im Jahr 2000 gekalkt; pH 4,0) innerhalb der Ronneburger Tagebaufolgeflächen, die im Versuchsverlauf auch durch Spontanvegetation (und MykorrhizaPilze) besiedelt wurden, können Douglasien dagegen sogar ohne jede weitere Behandlung gepflanzt werden.

Verbesserte bodenchemische Bedingungen und das bei der Pflanzung unmittelbare Vorhandensein passender Symbiosepartner zur Mykorrhiza-Bildung sind somit für die Entwicklung der Douglasien auf vergleichbaren Tagebaufolgeflächen von großer Bedeutung.

\section{Wald-Kiefer}

Die Kiefern zeigten im Ronneburger Freiland-Versuch eine hohe, ursächlich nicht vollständig geklärte Sterblichkeit. Eine abschließende Bewertung der Eignung dieser Baumart auf den untersuchten Standorten ist dadurch nicht möglich. Denkbare Gründe für die hohen Ausfälle sind das Fehlen passender Mykorrhiza-Partner in Kombination mit starkem Trockenstress durch die anhaltende Trockenperiode zur Zeit der Pflanzung.

Kompost-Gaben hatten deutlich positive Effekte und führten zu einer guten Entwicklung der Kiefern. Beim Einsatz dieser Baumart auf vergleichbaren Standorten scheint zudem nach den Beobachtungen in den Freiland- und Gewächshaus-Versuchen eine Mykorrhiza-Impfung empfehlenswert. 


\section{Empfehlung für die Praxis}

Für die Rekultivierung der Ronneburger und vergleichbarer Tagebaufolgeflächen scheint eine Mischung aus Erlen, Ebereschen und Douglasien viel versprechend. Erlen sollten dabei den Hauptteil ausmachen, da diese Baumart im Freiland-Versuch am meisten überzeugte und ihre bodenverbessernden Eigenschaften gerade auf diesen problematischen Standorten vorteilhaft sind.

Weisen die für eine Bepflanzung vorgesehen Flächen mindestens einen pH-Wert (KCl-Lsg.) von 4,0 in den obersten $5 \mathrm{~cm}$ (bzw. 3,8 in den obersten $15 \mathrm{~cm}$ ) des Bodens auf, konnte sich bereits Bodenvegetation etablieren und sind nachweisbar bereits Mykorrhiza-Pilze eingewandert, können die drei Baumarten ohne weitere Bodenhilfsstoff-Behandlung verwendet werden.

Sind die pH-Werte geringer und die Flächen auch Jahre nach Stilllegung vegetationsfrei, sollte bereits deutlich im Vorfeld geplanter Pflanzungen zunächst eine Flächenkalkung mit möglichst gleichmäßiger Verteilung des Kalks durchgeführt werden. Nach den vorliegenden Untersuchungsergebnissen scheint diese Maßnahme für die Entwicklung von Spontanvegetation, die Einwanderung von Mykorrhiza-Pilzen und die Pflanzung des überwiegenden Teils der Baumarten notwendig zu sein. Bei wie auf den Ronneburger Flächen hohen Magnesium-Gehalten und -Sättigungen solte magnesiumfreier Düngekalk eingesetzt werden.

Da im Einzelfall nicht klar sein kann, wie schnell Mykorrhiza-Pilze die verbesserten Standorte wieder besiedeln, ist bei der Pflanzung zumindest bei den obligat darauf angewiesenen Douglasien eine Beimpfung sinnvoll. Aufgrund der Standortproblematik spielen Symbiosen für das Pflanzenwachstum auf Tagebaufolgeflächen eine derart große Rolle, dass bei Rekultivierungsmaßnahmen Beimpfungen generell nur von Vorteil sein können.

Zumindest bei den Ebereschen und Erlen sollte auf diesen Flächen bei der Pflanzung eine Kompost-Gabe ins Pflanzloch erfolgen, um einen guten Start zu ermöglichen.

Nach den Ergebnissen der vorliegenden Arbeit sollte mit diesem Konzept auf vergleichbaren Standorten die Etablierung von Bäumen und somit die Anlage von gepflanzten „Inseln“ gelingen. Wie sich die Bäume über die untersuchten 2 Jahre hinaus weiter entwickeln, ist zu beobachten. Gleiches gilt für den Erfolg der „Insel-Strategie“ (s. S. 5), die darauf abzielt, dass durch von diesen Inseln ausgehende Standortbeeinflussung Sukzession auch in benachbarten, unbehandelten Bereichen stattfindet. 


\section{VIII.Zusammenfassung}

Tagebaumaßnahmen führen durch Entfernung des Oberbodens, Vermischung von Bodenschichten bei der Wiederverfüllung von Restlöchern und Maschineneinsatz dazu, dass auf Tagebaufolgeflächen meist extrem schwierige Standortbedingungen für Pflanzenwachstum herrschen. Dazu zählen v.a. Bodenverdichtung und Bodenversauerung durch die Verwitterung von Eisensulfiden, was Ernährungsstörungen und Belastungen mit Schwermetallen und anderen Schadstoffen zur Folge hat. Die Bodenbedingungen sind auf kleinem Raum sehr heterogen. Das ungünstige Mikroklima der vegetationsfreien Flächen verstärkt die durch Bodenverdichtung schwierige Wasserversorgung. Mykorrhiza-Pilze fehlen oft zunächst.

Ziel dieser Arbeit war die Entwicklung eines möglichst wenig aufwendigen Konzeptes, um mit Hilfe geeigneter Baumarten und Bodenhilfsstoffe zumindest auf kleiner Fläche eine Begrünung von Kippen-Rohböden zu erreichen, um so Startpunkte einer Sukzession zu etablieren.

$\mathrm{Zu}$ diesem Zweck wurden verschiedene Baumarten (Quercus robur, Acer platanoides, Sorbus aucuparia, Alnus glutinosa, Pseudostuga menziesii und Pinus sylvestris) und Bodenhilfsstoffe zur Verbesserung der physikalischen (Perlit, Wasserspeichersubstanzen: sowohl herkömmliches, petrochemisches Hydrogel als auch neuartiger Superabsorber aus pflanzlicher Stärke), chemischen (Kalk), physikalischen und chemischen (Kompost) sowie biologischen (MykorrhizaImpfung) Bodeneigenschaften getestet. Die Bodenhilfsstoffe wurden einzeln und miteinander kombiniert eingesetzt. Auf auch Jahre nach der Ablagerung des Haldensubstrats noch vegetationsfreien Flächen im ehemaligen Ronneburger Uranerz-Abbaugebiet wurden Freilandversuche mit knapp 1.000 Bäumen angelegt; Topfversuche im Gewächshaus dienten der Begleitung und Vertiefung. Die physikalischen und chemischen Bodeneigenschaften der Versuchsflächen wurden analysiert, die Effekte der Bodenhilfsstoffe darauf im Topfversuch überprüft. Die Entwicklung der Versuchspflanzen wurde über zwei Jahre hinweg durch regelmäßige Vitalitätsschätzungen auf einer 5-stufigen Skala, Messungen verschiedener Wuchsparameter und Analysen der Elementgehalte in den Assimilationsorganen untersucht.

Die Böden wiesen eine sehr geringe Wasserspeicherkapazität und eine stark gestörte Infiltrations- und Wasserleitfähigkeit auf. Das Nährstoffpotential war mit Ausnahme sehr geringer Stickstoff-Gehalte gut. Eine sehr starke Versauerung sowie stark belastende Kupferund Schwefel-Gehalte waren die Haupt-Probleme. Auffällig waren hohe Magnesium-Gehalte und -Sättigungen. Die Versuchspflanzen waren entsprechend sehr stark mit Schwefel und Kupfer sowie mit Eisen, Aluminium und teilweise Mangan belastet und zeigten auffallend hohe Magnesium-Gehalte. Sie wiesen Ernährungsdefizite auf, die auf die geringe Stickstoffversorgung, Nährstoffantagonismen/Ionenkonkurrenz und Toxizität zurückgeführt werden können.

Im Verlauf des Versuchs entwickelte sich auf einigen Versuchsflächen in Teilbereichen Spontanvegetation (Moose, Calamagrostis epigejos). Bodenuntersuchungen ergaben leicht höhere pH-Werte und eine entsprechend günstigere Ernährungssituation in diesen Bereichen, vermutlich aufgrund einer unregelmäßigen Flächenkalkung einige Jahre vor Versuchsbeginn. Die Entwicklung der Versuchspflanzen wurde stark von den Standortunterschieden beeinflusst.

Kalk und Kompost hatten deutlich positive Effekte auf die chemischen Bodenbedingungen und die Pflanzenentwicklung. Mit Kompost war der Einfluss vor allem bei den anspruchsloseren 
Baumarten Eberesche, Schwarz-Erle und Wald-Kiefer oft größer. Daneben zeigten MykorrhizaImpfungen eine starke Wirkung, vor allem in Kombination mit Kalk und/oder Wasserspeichersubstanzen. Die positiven Wirkungssynergismen von Mykorrhiza-Impfungen und Wasserspeichersubstanzen auch ohne Kalk-Gaben waren angesichts der sehr stark sauren Standortverhältnisse bemerkenswert. Darüber hinaus hatten Wasserspeichersubstanzen wie auch Perlit keine, teilweise sogar negative Effekte durch Herabsetzung der Kalk-Wirkung in kombinierten Varianten. Zudem wiesen die mit Perlit oder Wasserspeichersubstanzen gepflanzten Bäume teils hohe Schadstoff-Belastungen auf. Die Bodeneigenschaften wurden nicht beeinflusst; die feinbodenreichen Lehmböden mit ihrer geringen Infiltrationsfähigkeit durch Zerscherung der Grobporen bei Verdichtung schienen für den Einsatz von Wasserspeichersubstanzen weniger geeignet zu sein.

Das Vorhandensein von Pilz-Partnern zur Mykorrhiza-Bildung ist auf diesen schwierigen Standorten offenbar von besonderer Bedeutung, da diese Symbiose die Wasserversorgung von Pflanzen verbessern kann, außerdem ihre Ernährung fördert und die Schadstoff-Aufnahme hemmt, wie im Rahmen der vorliegenden Arbeit bestätigt werden konnte. So konnten durch kombinierte Mykorrhiza-Impfungen teilweise selbst die extremen Schwefel-Gehalte auf ein normales Maß gesenkt werden, was mit Kalkung allein nicht der Fall war.

Die obligat Mykorrhiza bildenden Rot-Eichen und Wald-Kiefern, zwei eigentlich zur Tagebaurekultivierung sehr geeignete und viel verwendete Baumarten, zeigten insgesamt hohe Ausfallraten. Bei den Eichen spielte dabei die schlechte Qualität des Pflanzenmaterials, bei den Kiefern wahrscheinlich starke Trockenheit zum Zeitpunkt der Versuchsanlage im Frühjahr 2005 eine Rolle. Bei den ebenfalls obligat Mykorrhiza bildenden Douglasien war der Standort in günstigeren Bereichen, in denen sich auch Spontanvegetation entwickeln konnte und in die nachweislich Mykorrhiza-Pilze einwanderten, von großer Bedeutung. Wie die als einzige Baumart nicht mit Kupfer belastete Eberesche und die durch ihre Symbiose mit Stickstofffixierenden Bakterien sehr gut geeignete Erle, die von allen Baumarten die besten Ergebnisse zeigte, konnte sich auch die Douglasie auf diesen etwas besseren Standorten selbst ohne Bodenhilfsstoffe zufrieden stellend entwickeln. Angesichts des extremen Sommers 2006 kam vermutlich auch ihre Trockenheitstoleranz zum Tragen. Die Spitz-Ahorne zeigten hohe Schadstoff-Belastungen, kaum Wachstum und eine stark gestörte Wurzel-Ausformung. Die Baumart wurde zudem stark verbissen und erwies sich insgesamt als wenig geeignet.

Auf Grundlage der Ergebnisse der auf den Ronneburger Tagebaufolgeflächen durchgeführten Untersuchungen wird für die Rekultivierung dieser und vergleichbarer Standorte eine Mischung aus Erlen, Ebereschen und Douglasien empfohlen, wobei die Erle auch aufgrund ihrer Standort verbessernden Eigenschaften den größten Anteil einnehmen sollte. In stärker versauerten $\mathrm{pH}$ $\mathrm{KCl}<4$ ), frei von Bodenvegetation bleibenden Bereichen sollte einige Zeit im Vorfeld der Pflanzungen eine Kalkung mit aufgrund der Bodengehalte magnesiumfreiem Kalk erfolgen, um die Voraussetzungen für Bodenvegetation und Mykorrhiza-Pilze $\mathrm{zu}$ verbessern. Bei den Ebereschen und Erlen ist eine Kompost-Gabe ins Pflanzloch als Starthilfe sinnvoll. Zumindest bei den Douglasien sollten Mykorrhiza-Impfungen durchgeführt werden, die generell auf diesen Standorten empfehlenswert sind und somit auch für die Ebereschen und Erlen sehr vorteilhaft sein können.

Die Dauer der Wirkung der Bodenhilfsstoffe und die über die beobachtete Zeit hinaus gehende Entwicklung der Bäume sind unter den gegebenen, sehr schwierigen Standortbedingungen mit fortschreitender Pyrit-Verwitterung und damit Bodenversauerung offen. 


\section{Literaturverzeichnis}

Ad-hoc-AG Boden 2005: Bodenkundliche Kartieranleitung. Hrsg.: Bundesanstalt für Geowissenschaften und Rohstoffe in Zusammenarbeit mit den Staatlichen Geologischen Diensten. 5. Auflage. Hannover. 438 S.

Alloway, B.J. (Hrsg.), 1999: Schwermetalle in Böden: Analytik, Konzentrationen, Wechselwirkungen. Übersetzung von Reimer, T. \& Eis, R. Springer Verlag.

Ammer, C., Burschel, P. \& Brunner, A., 1994: Erste Ergebnisse einer Untersuchung über die Eignung verschiedener Baumarten zur Rekultivierung von Tonabbauflächen. Forstwissenschaftliches Centralblatt 1994, 113, 3/4: 175-193.

AK Standortskartierung (in der AG Forsteinrichtung), 2003: Forstliche Standortsaufnahme: Begriffe, Definitionen, Einteilungen, Kennzeichnungen, Erläuterungen. 6. Auflage, IHW-Verlag, Eching bei München.

Arenhövel, W., 2001: Schriftliche Mitteilung des Leiters der Abteilung 2 der Thüringer Landesanstalt für Wald und Forstwirtschaft vom 19.09.2001.

Arenhövel, W., 2002: Schriftliche Mitteilung des Leiters der Abteilung 2 der Thüringer Landesanstalt für Wald und Forstwirtschaft vom 15.07.2002.

Ashby, W.C., 1997: Soil ripping and herbicides enhance tree and shrub restoration on stripmines. Restoration Ecology 1997, 5, 2: 169-177.

Baum, C., 2004: Mykorrhizierung und saprotrophe Rhizosphärenmykoflora von Salix und Populus spp. auf landwirtschaftlichen Nutzflächen und auf Schwermetall kontaminierten Böden. Habilitationsschrift. Rostock.

Baumann, K., Schneider, B.U., Marschner, P. \& Hüttl, R.F., 2005: Root distribution and nutrient status of mycorrhizal and non-mycorrhizal Pinus sylvestris L. seedlings growing in a sandy substrate with lignite fragments. Plant and Soil 2005, 276, 1/2: 347-357.

Beckjord, P.R. \& Mcintosh, M.S. 1984: Growth and fungal persistence by Quercus rubra inoculated with ectomycorrhizal fungi and planted on a clear-cutting and strip mine. Can. J. Bot. 62: 1571-1574.

Bergmann, W. (Hrsg.), 1993: Ernährungsstörungen bei Kulturpflanzen: Entstehung, visuelle und analytische Diagnose. 3., erweiterte Auflage, Gustav Fischer Verlag, Jena.

Beese, F., 2007: Mündliche Mitteilungen des Leiters der Abteilung Ökopedologie der gemäßigten Zonen der Fakultät für Forstwissenschaften und Waldökologie der Georg-August-Universität Göttingen in 2007.

Benkwitz, S., Tischew, S. \& Lebender, A., 2002: "Arche Noah" für Pflanzen? Zur Bedeutung von Altwaldresten für die Wiederbesiedlungsprozesse im Tagebaugebiet Goitsche. Hercynia 2002, 35, 2: 181-214. 
BFW (Bundesforschungs- und Ausbildungszentrum für Wald, Naturgefahren und Landschaft Österreich), 2005/7: Pflanzenanalyse - Beurteilungswerte.

(http://bfw.ac.at/rz/bfwcms.web?dok=6226)

Binns, W.O. \& Fourt, D.F., 1981: Surface workings and trees. Occasional Paper, Forestry Commission, UK 1981, 10: 60-75.

Block, J., 1997: Schadsituation der Douglasie in Rheinland-Pfalz - Symptome und Ausmaß der Erkrankung, bisherige Untersuchungen. In: W. Maurer und U. Tabel (Hrsg): Stand der Ursachenforschung zu Douglasienschäden - derzeitige Empfehlungen für die Praxis. Mitteilungen aus der Forstlichen Versuchsanstalt Rheinland-Pfalz 1997, 41: 46-75.

BMELF, 1997a: Deutscher Waldbodenbericht 1996. Ergebnisse der bundesweiten Bodenzustandserhebung im Wald von 1987 - 1993 (BZE). Band 1. Stand 2007.

BMELF, 1997b: Deutscher Waldbodenbericht 1996. Ergebnisse der bundesweiten Bodenzustandserhebung im Wald von 1987 - 1993 (BZE). Band 2. Stand 2007.

BMELV (Hrsg.), 2006: Arbeitsanleitung für die zweite bundesweite Bodenzustandserhebung im Wald (BZE II). 2. Auflage.

BMVEL (Hrsg.), 2003: Wasserhaushalt von Waldökosystemen: Methodenleitfaden zur Bestimmung der Wasserhaushaltskomponenten auf Level-II-Flächen. Level II Ad hoc AG „Wasserhaushalt“ der Bund-Länder-Arbeitsgruppe Forstliches Umweltmonitoring.

Böcker, L., Stähr, F. \& Katzur, J., 1998: Waldwachstum auf Kippenstandorten des Lausitzer Braunkohlereviers. AFZ-Der Wald 1998, 13: 691-694.

Böcker, L., Katzur, J. \& Stähr, F., 1999: Bodenkennwerte und Waldwachstum der KippenErstaufforstungen. AFZ-Der Wald 1999, 25: 1336-1338.

Brofas, G., Varelides, C. \& Mantakas, G., 2004: Effect of a hydrogel on plant survival in mining spoils (4th year results). In: Bhattacharya, J., Deb, D., Jain, M.K. \& Bhattacherjee, A. (Hrsg.), 2004: Tamsem - Proceedings of the conference on technology and management for sustainable exploitation of minerals and natural resources. 5-7 February 2004, Kharagpur: 329-334.

Boronczyk, M., 2006: Saatversuche in der Bergbaufolgelanschaft. Diplomarbeit, Fachhochschule Anhalt, Abt. Bernburg.

Bradshaw, A.D., Humphries, R.N., Johnson, M.S. \& Roberts, R.D., 1978: The restoration of vegetation on derelict land produced by industrial activity. In: Holdgate, M.W. \& Woodman, M.J. (Hrsg.), 1978: The breakdown and restoration of ecosystems. Univ. Liverpool, UK: 249-278.

Buck-Sorlin, G.H. \& Bell, A.D., 2000: Crown architecture in Quercus petraea and Q. robur: The fate of buds and shoots in relation to age, position and environmental perturbation. Forestry (Oxford) 2000, 73, 4: 331-349.

Burse, K.D. \& Schramm, H.-J., 1996: Waldbodenzustandsbericht für Thüringen. Mitteilungen der Landesanstalt für Wald und Forstwirtschaft 1996, 10.

Bussler, B.H., Byrnes, W.R., Pope, P.E. \& Chaney, W.R., 1984: Properties of minesoil reclaimed for forest land use. Soil Science Society of America Journal 1984, 48, 1: 178-184. 
Caravaca, F., Figueroa, D., Azcon-Aguilar, C., Barea, J.M. \& Roldan, A., 2003: Medium-term effects of mycorrhizal inoculation and composted municipal waste addition on the establishment of two Mediterranean shrub species under semiarid field conditions. Agriculture, Ecosystems \& Environment 2003, 97, 1/3: 95-105.

Carpenter, P.L. \& Hensley, D.L., 1979: Utilizing N2-fixing woody plant species for distressed soils and the effect of lime on survival. Botanical Gazette 1979, 140, Supplement: S76-S81.

Cherrier, J. F., 1990: Revegetation of mined areas in New Caledonia. Bois et Forêts des Tropiques 1990, 225: 5-23.

Cordell, C.E., Mans, L.F. \& Marx, D.H., 2002: Mycorrhizal fungi and trees - a successful reforestation alternative for mineland reclamation. Western Forest and Conservation Nursery Association Conference, Kailua-Kona, Hawaii, USA, 22-25 August 2000. Proceedings - Rocky Mountain Research Station, USDA Forest Service 2002, RMRS-P-24: 206-212.

Cunha-Queda, C., Alvarenga, P., Nobre, A. \& Varennes, A. de, 2010: Effect of municipal solid waste compost on mine soils as evaluated by chemical, biological and biochemical properties of soil. Compost Science \& Utilization 2010, 18, 2: 89-96.

Dan'ko, V.N., 1986: Utilizing Alnus glutinosa for afforestation of spoil mounds in the steppe. Lesnoe Khozyaǐstvo 1986, 9: 52-53.

Davidson, W.H., 1979: Results of tree and shrub plantings on low pH strip-mine banks. USDA Forest Service Research Note NE 1979, 285.

Dawkins, H. C., Hockin, R. L. \& Power, J. D., 1985: First observations of ecological surveillance plots on afforested open-cast spoil in South Wales. C.F.I. Occasional Papers, Commonwealth Forestry Institute, University of Oxford 1985, 25 pp. ii +67 pp.

DEBRIV (Deutscher Braunkohlen-Industrie-Verein e.V.), 2000: Jahresbericht 1999. Senftenberg.

DIN 18916, 2002: Vegetationstechnik im Landschaftsbau. Pflanzen und Pflanzarbeiten. Beuth Verlag GmbH, Berlin.

Dmyterko, E., 1998: Methods for assessing damage in oak stands. Sylwan 1998, 142, 10: 29-38.

Dmyterko, E., 2006: Characteristics of the crown as the basis of the method for assessing damage to black alder stands [Alnus glutinosa (L.) Gaertn.]. Prace Instytut u Badawczego Leśnictwa Rozprawy i Monografie 5. Warszawa. $102 \mathrm{~S}$.

Dohrenbusch, A. \& Arenhövel, W., unveröffentlicht: Rekultivierung eines ehemaligen UranerzTagebaus in Ronneburg. Durchführung und vorläufige Ergebnisse der Vorversuche.

DWD (Deutscher Wetterdienst, Chen, X.), 1994: Phänologische Naturraumkarte. (http://www.deutscher-wetterdienst.de/de/FundE/Klima/KLIS/daten/nkdz/fachdatenbank/ datenkollektive/phaenologie/beob_netze/naturraumkarte.htm\#41)

Dytham, C., 2003: Choosing and using statistics. A biologist's guide. $2^{\text {nd }}$ edition. $248 \mathrm{~S}$.

Ehlers, W., 1996: Wasser in Boden und Pflanze: Dynamik des Wasserhaushalts als Grundlage von Pflanzenwachstum und Ertrag. Verlag Eugen Ulmer, Stuttgart. 272 S. 
Enkhtuya, B., Pöschl, M. \& Vosátka, M., 2005: Native grass facilitates mycorrhizal colonisation and $\mathrm{P}$ uptake of tree seedlings in two anthropogenic substrates. Water, Air, and Soil Pollution 2005, 166, 1/4: 217-236.

Ertle, C., Wenk, G., Böcker, L. \& Preußner, K., 2006: Ertrags- und Wachstumsprognosen von Kiefernbeständen auf Kippen. AFZ-Der Wald 2006, 19: 1057-1059.

Fettweis, U., Bens, O., Koch, A. \& Hüttl, R.F., 2002: Gestaltung von Bergbaufolgelandschaften des Niederlausitzer Braunkohlereviers für eine zukünftige Bodennutzung. Anreicherung und Charakterisierung der organischen Bodensubstanz auf Rekultivierungsflächen unter Pinus nigra und Pinus sylvestris. Schriftenreihe der Deutschen Geologischen Gesellschaft, 2002, 21: 120.

Fiedler, H.J., 1988: Die Wirkung qualitativ unterschiedlicher Immissionen auf Bodenfruchtbarkeit und Bestandesernährung. Soz. Forstwirtsch. 1988, 38: 331-333.

Forstliche Bundesversuchsanstalt, 1992: Österreichische Waldbodenzustandsinventur. Mitteilungen der Forstlichen Bundesversuchsanstalt 168.

Gebhardt, S., Neubert, K., Wöllecke, J., Münzenberger, B. \& Hüttl, R.F., 2007: Ectomycorrhiza communities of red oak (Quercus rubra L.) of different age in the Lusatian lignite mining district, East Germany. Mycorrhiza 2007, 17, 4: 279-290.

Gerke, H.H., Hangen, E., Schaaf, W. \& Hüttl, R.F., 2002: Untersuchungen zum Wasserhaushalt eines Schwarzkiefern-Ökosystems auf einer rekultivierten Kippe mit heterogenem Kippkohlesandboden. Verhandlungen der Gesellschaft für Ökologie 2002, 32, 234.

Gerke, H.H., 2006: Exploring preferential flow in forest-reclaimed lignitic mine soil. Advances in Geoecology 2006, 39: 380-387.

GFN \& IVÖR (i.A. des BfN): Landschaftssteckbriefe. Ergebnis des F+E-Vorhabens "Verbreitung und Gefährdung schutzwürdiger Landschaften in Deutschland"

(http://www.bfn.de/0311_landschaften.html)

González-Chávez, M.C., Carrillo-González, R. \& Gutiérrez-Castorena, M.C., 2009: Natural attenuation in a slag heap contaminated with cadmium: The role of plants and arbuscular mycorrhizal fungi. Journal of Hazardous Materials 2009, 161, 2/3: 1288-1298.

Grime, J.P., Mackey, J.M., Hillier, S.H. \& Read, D.J., 1987: Floristic diversity in a model system using experimental microcosms. Nature (London) 1987, 328: 420-422.

Gutachterausschuss Forstliche Analytik (Hrsg.), 2005: Handbuch forstliche Analytik. Eine Loseblatt-Sammlung der Analysemethoden im Forstbereich. Grundwerk 2005 mit Ergänzungen 1, 2 (2006) und 3 (2007).

Häge, K., 1996: Recultivation in the Lusatian Mining Region - targets and prospects. Water, Air \& Soil Pollution 1996, 91, 1/2: 43-57.

Häge, K., Drebenstedt, C. \& Angelov, E., 1996: Landscaping and ecology in the lignite mining area of Maritza-east, Bulgaria. Water, Air \& Soil Pollution 1996, 91, 1/2: 135-144. 
Hangen, E., Gerke, H.H., Schaaf, W. \& Hüttl, R.F., 2005: Assessment of preferential flow processes in a forest-reclaimed lignitic mine soil by multicell sampling of drainage water and three tracers. Journal of Hydrology (Amsterdam) 2005, 303, 1/4: 16-37.

Heilman, P.E., 1990: Growth of Douglas fir and red alder on coal spoils in western Washington. Soil Science Society of America Journal 1990, 54, 2: 522-527.

Heinsdorf, D., 1984: Wirkung von Mineraldüngung auf Ernährung und Wachstum von Winterlinden (Tilia cordata Mill.) auf Kippbodenformen der Niederlausitz. Beiträge für die Forstwirtschaft 1984, 18, 1: 28-36.

Heinsdorf, D., 1985: Ergebnisse von Mineraldüngungsversuchen zu Androscoggin-Pappeln auf Kippsanden ausgekohlter Braunkohlentagebaue im Bezirk Cottbus. Beiträge für die Forstwirtschaft 1985, 19, 1: 34-40.

Heinsdorf, D., 1988: Ergebnisse boden- und nadelanalytischer Untersuchungen in durch

Fremdstoffeinflüsse vitalitätsgeminderten Fichten- und Kiefernbeständen und Folgerungen für Düngemaßnahmen. Soz. Forstwirtsch. 1988, 38: 33-335.

Heinsdorf, D. \& Tölle, H., 1991: Bodennährstoffe und Ernährung der Kiefer im nordostdeutschen Tiefland. In: Berichte aus Forschung und Entwicklung, Eberswalde, 1991, 25: 20-35.

Heinsdorf, D., 1996: Boden- und ernährungskundliche Untersuchungen in geschädigten Eichenbeständen des nordostdeutschen Tieflandes. Mitt. an Biol. Bundesanst. f. Land- und Forstwirtsch., Berlin, 1996, 318: 79-98.

Heinsdorf, D., 1999: Zum Problem der Ernährung und Düngung der Kiefer unter den Bedingungen hoher Fremdstoffeinträge. Kolloquium aus Anlass des 100jährigen Geburtstags von Adolf Olberg in Göttingen.

Helfer, W., 1997: Pilze an Vogelbeere. In: Bayerische Landesanstalt für Wald und Forstwirtschaft, 1997: Beiträge zur Vogelbeere. Bericht zur Fachtagung über die Vogelbeere, Baum des Jahres 1997, in Hohenberg an der Eger am 19./20.9.1997.

Hendry, G. \& Grime, J., 1993: Methods in Comparative Plant Ecology: A laboratory manual. Chapman \& Hall, London, 252 S.

Hensley, D.L. \& Carpenter, P.L., 1984: Effect of lime additions to acid strip-mine spoil on survival, growth and nitrogen fixation (acetylene reduction) of several woody legume and actinomycetenodulated species. Plant and Soil 1984, 79, 3: 353-367.

Heuson, R., 1929: Praktische Kulturvorschläge für Kippen, Bruchfelder, Dünen und Odländereien. Verlag Neumann-Neudamm.

Hicks, R.R.Jr., 1992: Root dipping of seedlings with water-absorbent gel improves survival on surface mine sites in West Virginia. Tree Planters' Notes 1992, 43, 4: 159-162.

Hiekel, W., Fritzlar, F., Nöllert, A. \& Westhus, W., 2004: Die Naturräume Thüringens. Naturschutzreport 21, Jena. 
Hildmann, E., 1998: Technische und historische Aspekte der Wiedernutzbarmachung. In: Pflug, W. (Hrsg.): Braunkohletagebau und Rekultivierung. Landschaftsökologie - Folgenutzung Naturschutz. Springer Verlag, Berlin, Heidelberg, New York: 797-808.

Hodacova, D. \& Prach, K., 2003: Spoil heaps from brown coal mining: Technical reclamation versus spontaneous revegetation. Restoration Ecology 2003, 11, 3: 385-391.

Hofmann, G. \& Heinsdorf, D., 1990: Depositionsgeschehen und Waldbewirtschaftung. AFZ-Der Wald 1990, 40: 208-213.

Hofmann, G. \& Krauss, H.-H., 1988: Die Ausscheidung von Ernährungsstufen für die Baumarten Kiefer und Buche auf der Grundlage von Nadel- und Blattanalysen und Anwendungsmöglichkeiten in der Überwachung des ökologischen Waldzustands. Soz. Forstwirtsch. 1988, 38: 272-273.

Hohensee, C., 2005: Molekularbiologische Identifizierung und Beobachtungen zur Funktion von Mykorrhiza-Pilzen auf Rekultivierungsstandorten der Niederlausitzer Bergbaufolgelandschaft. Dissertation an der Brandenburgischen Technischen Universität Cottbus. 109 S.

Höster, H.R., 1993: Baumpflege und Baumschutz. Grundlagen, Diagnosen, Methoden. Stuttgart, Ulmer Verlag.

Hutchinson, M., 1984: Greening the valleys. GC \& HTJ 1984, 196, 4: 12-14.

Hurrle, H., 1981: Schwermetalle in Nadelbäumen auf alten Bergbauhalden im Südschwarzwald. AFZ-DER WALD 1981, 152, 12: 234-238

Hüttermann, A., Reise, K., Zommorodi, M. \& Wang, S., 1997: The use of hydrogels for afforestations of difficult stands: Water and salt stress. Afforestation in semi-arid regions. Findings and perspectives. Proceedings. International Symposium in the People's Republic of China, Datong/Jinshatan, June 1-6 1997: 167-174.

Hüttl, R.F., 1991: Die Nährelementversorgung geschädigter Wälder in Europa und Nordamerika. Freiburger Bodenkundl. Abh. 28. Freiburg im Breisgau 1991.

Hüttl, R.F., 1992: Die Blattanalyse als Diagnose- und Monitoringinstrument in Waldökosystemen. Freiburger Bodenkundl. Abh. 30: 31-59.

Hüttl, R.F., 2001: Rekultivierung im Braunkohletagebau - Fallbeispiel Niederlausitzer Bergbaufolgelandschaft. Akademie-Journal, Magazin der Union der deutschen Akademien 1: 712.

Hüttl, R.F. \& Weber, E., 2001: Forest ecosystem development in post-mining landscapes: A case study of the Lusatian lignite district. Naturwissenschaften 2001, 88, 8: 322-329.

Hüttl, R.F. \& Bens, O., 2003: Bodenverbrauch durch Braunkohletagebau. Entwicklungspotentiale von Bergbaufolgestandorten. Petermanns Geographische Mitteilungen 147, 3: 58-67.

Hüttl, R.F. \& Gerwin, W., 2003: Forest rehabilitation on post-mining landscapes - a German case study. Bringing back the forests: Policies and practices for degraded lands and forests. Proceedings of an international conference, Kuala Lumpur, Malaysia, 7-10 October 2002. RAP Publication 2003, 14: 85-96. 
IFTNC (Intermountain Forest Tree Nutrition Cooperative), 1987: 7th Annual Report, April 1987. College of Forestry, Wildlife and Range Sciences, University of Idaho, Moscow, Idaho, U.S.A. 39 S. Zit. in: Hüttl, R. F., 1991: Die Nährelementversorgung geschädigter Wälder in Europa und Nordamerika. Freiburger Bodenkundliche Abhandlungen 28.

Jaffré, T., Rigault, F. \& Sarrailh, J.M., 1994: Revegetation of old mining sites in New Caledonia. Bois et Forêts des Tropiques 1994, 242: 45-57.

Jansen, R., 1997: Ökologischer Ausgleich durch forstwirtschaftliche Rekultivierung. In: BUND Bund für Umwelt und Naturschutz Deutschland, Landesverband Nordrhein-Westfalen e.V. (Hrsg.): Braunkohle und Rekultivierung - Dokumentation der Tagung der Natur- und Umweltschutzakademie des Landes Nordrhein-Westfalen (NUA) am 8. März 1997 in Jülich.

Janssen, J. \& Laatz, W., 2005: Statistische Datenanalyse mit SPSS für Windows. 5., neu bearbeitete und erweiterte Auflage. Springer Verlag.

Jochimsen, M.E.A., 1996: Reclamation of colliery mine spoil founded on natural succession. Water, Air \& Soil Pollution 1996, 91 : 99-108.

Jongmans, A.G., Van Breemen, N., Lundström, U., Van Hees, P.A.W., Finlay, R.D., Srinivasan, M., Unestam, T., Giesler, R., Melkerud, P.A. \& Olsson, M., 1997: Rock-eating fungi. Nature 1997, 389: 682-683.

Kaar, E., 2002: Coniferous trees on exhausted oil shale opencast mines. Metsanduslikud Uurimused 2002, 36: 120-125.

Kabata-Pendias, A. \& Pendias, H., 1992: Trace Elements in Soils and Plants. 2. Auflage, CRC Press, Boca Raton/FL.

Kahl, L., Kluge, R. \& Thomas, S., 2000: Evaluation of an attempt to cultivate shrubs and trees on a heap of a potash mine. Landscape and Urban Planning 2000, 51. 2/4: 109-112.

Katzur, J., 1995: Flächenrecycling im Lausitzer Braunkohlerevier - Wiedernutzbarmachung extrem saurer schwefel- und kohlehaltiger Kippböden. In: Genske, D. \& Noll, H.-P.: Brachflächen und Flächenrecycling: 237-244.

Katzur, J., 1997: Bergbaufolgelandschaften in der Lausitz - Naturraumpotentiale und Naturressourcen im Braunkohlerevier. Naturschutz u. Landschaftsplanung 29, 4: 114-121.

Katzur, J. \& Haubold-Rosar, M., 1996: Ameloration and reforestation of sulphurous mine soils in Lusatia (Eastern Germany). Water, Air \& Soil Pollution 1996, 91: 17-32.

Katzur, J., Böcker, L., Stähr, F. \& Mertzig, C.-C., 1998: Zu den Auswirkungen der Meliorationstiefe auf das Waldwachstum der Kippen-Erstaufforstungen. Beitr. Fortswirtsch. u. Landsch.ökol. 1998, 32, 4: 170-178.

Katzur, J., Böcker, L. \& Stähr, F., 1999a: Humus- und Bodenentwicklung in KippenForstökosystemen. AFZ-Der Wald 1999, 25: 1339-1341.

Katzur, J., Böcker, L., Knoche, D. \& Mertzig, C.-C., 1999b: Untersuchungen zur Optimierung der Meliorationstiefe für die forstliche Rekultivierung schwefelsaurer Kippenböden. Beitr. Forstwirtsch. u. Landsch.ökol. 1999, 33, 4: 172-179. 
Katzur, J., Böcker, L., Stähr, F. \& Landeck, I., 1999c: Zustand, Entwicklung und Behandlung von Waldökosystemen auf Kippenstandorten des Lausitzer Braunkohlenrevieres als Beitrag zur Gestaltung ökologisch stabiler, multifunktional nutzbarer Bergbaufolgelandschaften. Abschlussber., Forschungsinst. f. Bergbaufolgelandsch., DBU Förderkennz. 06733, Finsterwalde,306 S.

Katzur, J. \& Böcker, L., 2001: Auswirkungen von Meliorationstiefe, Substrattyp und Baumart auf die Humus- und Bodenentwicklung sowie Blatt- und Nadelspiegelwerte von Jungbeständen schwefelsaurer Kippenböden. Beitr. Forstwirtsch. u. Landsch.ökol. 2001, 35, 2: 69-76.

Katzur, J., Böcker, L., Fischer, K., Liebner, F. \& Marski, R., 2002: Aufforstung von Halden unter Verwendung neuartiger Bodenverbesserungsmittel. AFZ-Der Wald 2002, 6: 287-290.

Keleberda, T.N., 1981: Promotion of forest growth on industrial waste lands. Vestnik Sel'skokhozyaistvennoi Nauki Moscow, USSR, 1981, 1: 139-143.

Kesel, R., Koehler, H. \& Heyser, W., 2005: Erfolge mit Mykorrhiza bei Renaturierungen und Aufforstungen degradierter Standorte. Vortrag im Rahmen der NNA-Fachtagung „Das Mykorrhiza-Netzwerk - Geheimnisvolle Pilze im Boden und ihre Bedeutung bei Renaturierungen und Aufforstungen“, 27.-28.9.2005, Schneverdingen.

Kilian, W., Mutsch, F. \& Kreisl, R., 1994: Die Düngung im Wald, II. Teil. Fachbeirat für Bodenfruchtbarkeit und Bodenschutz, Wien.

Klimaatlas, 1953: Klimaatlas für das Gebiet der deutschen Demokratischen Republik. Hrsg.: Meteorologischer und hydrologischer Dienst der DDR. Akademie Verlag, Berlin.

Kloke, A., 1989: Das „Drei-Bereiche-System“ für die Bewertung von Böden mit Schadstoffbelastung. VDLUFA-Schriftenreihe, Kongreßb. 1988, VDLUFA-Verlag, Darmstadt: 1117-1127.

Klug, P., 2005: Vitalität und Entwicklungsphasen von Bäumen. ProBaum 2005, 1: 1-4.

Knabe, W., 1957: Untersuchungen für die Voraussetzungen der Rekultivierung von Kippen im Braunkohlebergbau. Dissertation an der Humboldt-Universität Berlin.

Knoche, D., Embacher, A. \& Katzur, J., 2000: N-, P- und K-Umsatz von Eichenökosystemen auf Kippenstandorten. AFZ-Der Wald 2000, 21: 1147-1151.

Knoche, D., Embacher, A. \& Katzur, J., 2002: Water and element fluxes of red oak ecosystems during stand development on post-mining sites (Lusatian lignite district). Water, Air, and Soil Pollution 2002, 141, 1/4: 219-231.

Köhler, W., Schachtel, G. \& Voleske, P., 2002: Biostatistik. Eine Einführung für Biologen und Agrarwissenschaftler. 3. Auflage. Springer Verlag Berlin, Heidelberg, New York, Barcelona, Hong Kong, London, Mailand, Paris, Tokyo. 301 S.

Kohls, S.J., Baker, D.D., Kremer, D.A. \& Dawson, J.O., 1999: Water-retentive polymers increase nodulation of actinorhizal plants inoculated with Frankia. Plant and Soil 1999, 214: 105-115.

Kolk, A., 1998: Waldökosysteme auf Kippenstandorten. TP 4 und 5: Untersuchungen zur Mykorrhizierung von Waldbäumen und zur Bodenmikrobiologie auf forstlich rekultivierten 
Kippenstandorten des Lausitzer und des Mitteldeutschen Braunkohlereviers. Tagungsband 2. Statusseminar zur BMBF-Fördermaßnahme „Sanierung und ökologische Gestaltung der Landschaften des Braunkohlenbergbaus in den neuen Bundesländern“, Cottbus.

Kolk, A. \& Bungart, R., 2000: Bodenmikrobiologische Untersuchungen an forstlich rekultivierten Kippenflächen im Lausitzer Braunkohlenrevier. In: Broll, G., Dunger, W., Keplin, B. \& Topp, W. (Hrsg.), 2000: Rekultivierung in Bergbaufolgelandschaften. Bodenorganismen, bodenökologische Prozesse und Standortentwicklung. Springer Verlag Berlin, Heidelberg, New York: 187-205.

Koske, R.E. \& Gemma, N.J., 1989: A modified procedure for staining roots to detect VA mycorrhizas. Mycological research 1989, 92, 486-505.

Kothe, E., 2005: Dekontamination und Renaturierung von Uranbergbauflächen mit „Heil“Pflanzen und Mykorrhiza-Pilzen. Vortrag im Rahmen der NNA-Fachtagung „Das MykorrhizaNetzwerk - Geheimnisvolle Pilze im Boden und ihre Bedeutung bei Renaturierungen und Aufforstungen“, 27.-28.9.2005, Schneverdingen.

Kottke, I., Weber, R., Ritter, T. \& Oberwinkler, F., 1993: Activity of mycorrhizas and health status of trees on diverse forest stands in West Germany. In: Hüttl, R.F. \& Mueller-Dombois, D. (Hrsg.), 1993: Forest decline in the Atlantic and Pacific regions. Springer Verlag Berlin, Heidelberg, New York: 189-201.

Kottke, I., 2005: Mykorrhiza und Emissionshandel: Zum Widerspruch zwischen dem tropischen Bergregenwald und den Kiefernaufforstungen in Südecuador. Vortrag im Rahmen der NNAFachtagung „Das Mykorrhiza-Netzwerk - Geheimnisvolle Pilze im Boden und ihre Bedeutung bei Renaturierungen und Aufforstungen“, 27.-28.9.2005, Schneverdingen.

Kowarik, I., 1995: Time lags in biological invasions with regard to the success and failure of alien species. In: Pysek, P., Prach, K., Rejmanek, M. \& Wade, M. (Hrsg.), 1995: Plant invasions - general aspects and special problems. SPB Academic publishing, Amsterdam: 15-38.

Kulhavy, J. \& Grunda, B., 1991: Soil aspects of forest reclaiming of coal-mining wastes. Zemljište i Biljka 1991, 40. 1: 43-47.

Kupka, I. \& Dimitrovský, K., 2006: Silvicultural assessment of reforestation under specific spoil bank conditions. Journal of Forest Science 2006, 52, 9: 410-416.

Kutscheidt, J., 2006: Mündliche Mitteilungen in 2006/2007 / vom 20.6.2006.

Landeck, I., Katzur, J., Böcker, L. \& Stähr, F., 2001: Zeigerwert der Waldbodenvegetation in Kippen-Forstökosystemen. AFZ-Der Wald 2001, 12: 624-627.

Larson, M.M. \& Patel, S.H., 1992: Allelopathic influences of herbaceous species affect early growth of tree seedlings in minesoil. Land reclamation: Advances in research \& technology. Proceedings of the International Symposium 14-15 December 1992 Nashville, Tennessee: 337345.

Lavender, D.P., 1984: Plant physiology and nursery environment: interactions affecting seedling growth. In: Duryea, M.L. \& Landis, T.D. (Hrsg.), 1984: Forest nursery manual: production of bareroot seedlings. Martinus Nijhoff/Dr W. Junk, The Hague: 133-141. 
LAWuF Gotha (Landesanstalt für Wald und Forstwirtschaft Thüringen), 2002: Hydrogelversuch Haldenaufforstung Wismut - Bodenzustand. LAWuF Gotha, Ref. 1.2, Thüringen, unveröff., $20 \mathrm{~S}$.

Lechner, M.D., 2002: Superabsorber als Trockensauger. Nachwachsende Rohstoffe 2002, 19: 6667.

Le Quéré, A., Wright, D.P., Söderström, B., Tunlid, A. \& Johansson, T., 2005: Global Patterns of Gene Regulation Associated with the Development of Ectomycorrhiza Between Birch (Betula pendula Roth.) and Paxillus involutus (Batsch) Fr. MPMI 2005, 18, 7: 659-673.

LMBV (Lausitzer und Mitteldeutsche Bergbau-Verwaltungsgesellschaft mbH) (Hrsg.), 2009: Rekultivierung von Bergbaufolgelandschaften. Nachhaltige Bergbausanierung. 56 S.

LoBuglio, K.F. \& Wilcox, H.E., 1988: Growth and survival of ectomycorrhizal and ectendomycorrhizal seedlings of Pinus resinosa on iron tailings. Canadian Journal of Botany 1988, 66, 1: 55-60.

Lorenz, W. D., 1967: Untersuchungen über die Wiederurbarmachung von kulturfeindlichen Kippen nach dem Domsdorfer Verfahren. Dissertation, Humboldt-Univ., Berlin.

Lorenz, A., Tischew, S. \& Mahn, E.G., 2009: Analyse der Sukzessionsdynamik spontan entwickelter Wälder auf Kippenflächen der ehemaligen ostdeutschen Braunkohlentagebaue als Grundlage für Renaturierungskonzepte. Forstarchiv 2009, 80, 5: 151-162.

Lozán, José L. \& Kausch, H., 2007: Angewandte Statistik für Naturwissenschaftler. 4., korrigierte/überarbeitete und ergänzte Auflage. Wissenschaftliche Auswertungen, Hamburg. $303 \mathrm{~S}$.

Mäder, P., Fließbach, A., Dubois, D., Gunst, L., Jossi, W., Widmer, F., Oberson, A., Frossard, E., Oehl, F., Wiemken, A., Gattinger, A. \& Niggli, U., 2006: The DOK experiment (Switzerland). In: Raupp, J., Pekrun, C., Oltmanns, M. \& Köpke, U. (Hrsg.), 2006: Long Term Field Experiments in Organic Farming. ISOFAR Scientific Series No 1. Verlag Dr. Köster, Berlin.

Marian, M., Varga, C., Mihaly-Cozmuta, L., Peter, A., Mihaly-Cozmuta, A. \& Boltea, D., 2009: Evaluation of the Phytoremediation Potential of the Populus tremula in Tailing Ponds. Bulletin UASVM Agriculture 2009, 66, 2.

Meiwes, K.J., König, N., Khana, P.K., Prenzel, J. \& Ulrich, B., 1984: Chemische Untersuchungsverfahren für Mineralböden, Auflagehumus und Wurzeln zur Charakterisierung und Bewertung der Versauerung in Waldböden. Berichte d. Forschungszentrums Waldökosysteme/Waldsterben 1984, 7.142 S.

Mendes Filho, P.F., Vasconcellos, R.L. F., Paula, A.M. de \& Cardoso, E.J.B.N., 2010: Evaluating the potential of forest species under "microbial management" for the restoration of degraded mining areas. Water, Air, and Soil Pollution 2010, 208, 1/4: 79-89.

Mikola, P., 1969: Afforestation of treeless areas. Unasylva 1969, 92, 23 (1).

Miller, R.M., 1987: The ecology of vesicular-arbuscular fungal-species diversity at different scales. In: Safir, G. R. (Hrsg.): The Ecophysiology of VA Mycorrhizal Plants. Boca Raton (CRC Press). 
Molina, R. \& Trappe, J.M. 1982: Applied aspects of ectomykorrhizae. In: Subba Rao, R. (Hrsg.), Advances in Agricultural Microbiology. London: 305-334.

Münzenberger, B., Lehfeldt, J., Schmincke, B., Strubelt, F. \& Hüttl, R.F., 1995: Reaction of mycorrhizal and non-mycorrhizal Scots pine fine roots along a deposition gradient of air pollutants in eastern Germany. Water, Air, and Soil Pollution 1995, 85: 1191-1196.

Münzenberger, B., Golldack, J., Wöllecke, J. \& Hüttl, R.F., 2000: Mykorrhizierung der Kiefer auf Standorten mit natürlich gelagerten und stark veränderten Böden. AFZ-Der Wald 2000, 55, 21 : 1144-1146.

Münzenberger, B., Golldack, J., Ullrich, A., Schmincke, B. \& Hüttl, R.F., 2004: Abundance, diversity, and vitality of mycorrhizae of Scots pine (Pinus sylvestris L.) in lignite recultivation sites. Mycorrhiza 2004, 14: 193-202.

Mutscher, K., 1963: Die bisherigen Versuche zur Rekultivierung der Hochhalde Schwarzkollm und die daraus zu ziehenden Schlußfolgerungen für die künftige Kippenrekultivierung. Dipl.arb., Humboldt-Univ., Institut f. Landschaftspflege, Berlin.

Nicolini, F. \& Topp, W., 2005: Soil properties in plantations of sessile oak (Quercus petraea) and red oak (Quercus rubra) in reclaimed lignite open-cast mines of the Rhineland. Geoderma 2005, 129, 1/2: 65-72.

Perkins, P.V. \& Vann, A.R., 1995: The early performance of deciduous trees grown in acidic minespoil ameliorated with pulverized fuel ash. Land Degradation \& Rehabilitation 1995, 6, 1: 57-67.

Petrova, R., 1995: Temperature and water regimes of waste-tips from opencast mining of lignite coal. In: Tsanikov, G., Bojinov, H. \& Bogdanov, B., 1995: Proceedings of a jubilee symposium marking 125 years of the Bulgarian Academy of Sciences and 65 years of the Forest Research Institute, Sofia, Bulgaria, 22.-23. September 1994: 215-225.

Polle, A., 2007: Mündliche Mitteilung von Prof. Dr. Andrea Polle, Direktorin der Abteilung Forstbotanik der Fakultät für Forstwissenschaften und Waldökologie der Universität Göttingen vom 22.11.2007.

Prach, K., Pysek, P. \& Smilauer, P., 1999: Prediction of vegetation succession in human-disturbed habitats using an expert system. Restoration Ecology 1999, 7, 1: 15-23.

Preußner, K., 1998: Wälder und Forste auf Kippenstandorten. In: Pflug, W. (Hrsg.), 1998: Braunkohletagebau und Rekultivierung. Landschaftsökologie - Folgenutzung - Naturschutz. Springer Verlag, Berlin, Heidelberg, New York: 600-609.

Prüeß, A., 1992: Vorsorgewerte und Prüfwerte für mobile und mobilisierbare, potentiell ökotoxische Spurenelemente in Böden. Verlag U. E. Grauer, Wendlingen. 148 S.

Prüeß, A., 1994: Einstufung mobiler Spurenelemente in Böden. In: Rosenkranz, D., Einsele, G. \& Harress, H.M. (Hrsg.), 1994: Bodenschutz. Berlin.

Ptach, W., Boczon', A. \& Wróbel, M., 2009: The use of hydrogel in afforestation of postindustrial areas. Journal of Water and Land Development 2009, 13: 125-135. 
Rehfuess, K.E., 1990: Waldböden. Entwicklung, Eigenschaften und Nutzung. Pareys Studientexte Nr. 29. Paul Parey Verlag, Hamburg und Berlin. 294 S.

Reigber, E. \& Braun, G., 1985: Forstliche Bioindikatoruntersuchungen in Bayern - Methodik und erste Ergebnisse 1981/82. Forstliche Forschungsberichte, München, Nr. 68. 179 S.

Richardson, J.A., 1985: Creating a mixed woodland on a pit heap slope. Vasculum 1985, 70, 3: 1725 .

Richter, J., 1997: Ertragskundliche und forstschutztechnische Erfahrungen mit der Douglasie im östlichen Sauerland. Mitteilungen aus der Forstlichen Versuchsanstalt Rheinland-Pfalz 1997, 41.

Rieske, L.K., 2001: Influence of symbiotic fungal colonization on oak seedling growth and suitability for insect herbivory. Environmental Entomology 2001, 30, 5: 849-854.

Rodenkirchen, H., 1996: Versuch der Rekultivierung einer schwermetallreichen Bergbauhalde. AFZ-Der Wald 1996, 51, 18: 1005-1008.

Roloff, A., 2001: Baumkronen. Ulmer Verlag, Stuttgart

Rothmaler, W. (Begründer); Schubert, R. \& Vent, W. (Hrsg.), 1994: Exkursionsflora von Deutschland. Band 4. Gefäßpflanzen: Kritischer Band. 8. Auflage. Gustav Fischer Verlag Jena, Stuttgart. $811 \mathrm{~S}$.

Rowe, E.C., Williamson, J.C., Jones, D.L., Holliman, P. \& Healey, J.R., 2005: Initial tree establishment on blocky quarry waste ameliorated with hydrogel or slate processing fines. Journal of Environmental Quality 2005, 34, 3: 994-1003.

Sachs, L., 2002: Angewandte Statistik. Anwendung statistischer Methoden. 10. Auflage. Springer Verlag Berlin, Heidelberg, New York. 889 S.

Sammler, P., 2004: Die Rot-Eiche (Quercus rubra L., Fagaceae) als stark mykotrophe Gehölzart ein Vergleich der Makromyzetenflora unter Rot-Eichen und einheimischen Eichen in der Umgebung von Potsdam, Deutschland. Feddes Repertorium Weinheim 2004, 115, 1/2: 102-120.

Sander, I. L. 1990: Quercus rubra L. northern red oak: 727-733. In: Burns, R.M. \& Honkala, B.H. (Hrsg.), 1990: Silvics of North America, Agriculture Handbook 654, Vol. 2. Washington D.C.

Sänger, H., 1995: Flora and vegetation on dumps of uranium mining in the southern part of the former GDR. Acta Societatis Botanicorum Poloniae 1995, 64, 4: 409-418.

Sänger, H., 2003: Raum - Zeit - Dynamik von Flora und Vegetation auf Halden des Uranbergbaus. Ökologie und Umweltsicherung (Universität Kassel) 23.

Sänger, H., 2006: Flora und Vegetation im ehemaligen Uranbergbaurevier Ostthüringens. Weißdorn-Verlag Jena. $380 \mathrm{~S}$.

Scheffer, F. \& Schachtschabel, P., 2010: Lehrbuch der Bodenkunde. 16. Auflage, Spektrum akademischer Verlag, Heidelberg. 569 S.

Schlichting, E., Blume, H.-P. \& Stahr, K., 1995: Bodenkundliches Praktikum. Eine Einführung in pedologisches Arbeiten für Ökologen, insbesondere Land- und Forstwirte und für Geowissenschaftler. Blackwell, Berlin, Wien. 295 S. 
Schmid, T., 2006a: Ansaat von Rohböden in alpinen Zonen unter Verwendung von MykorrhizaPilzen. Projekt der geoVerde AG/Otto Hauenstein Samen AG. Handout im Rahmen der Arbeitstagung Mykorrhiza 2006 in Basel.

Schmid, T., 2006b: Native Spezialisten vs. ubiquitäre Generalisten - Pionierkolonien fördern die Sukzession. Projekt der geoVerde AG/Otto Hauenstein Samen AG. Handout im Rahmen der Arbeitstagung Mykorrhiza 2006 in Basel.

Schöne, D., 1997: Nährstoffmängel, Wuchsanomalien und Manganüberschuss bei Douglasie im Mosel-Eifelraum. In: Maurer, W. \& Tabel, U. (Hrsg): Stand der Ursachenforschung zu Douglasienschäden - derzeitige Empfehlungen für die Praxis. Mitteilungen aus der Forstlichen Versuchsanstalt Rheinland-Pfalz 1997, 41: 46-75.

Schroeder, D., 1992: Bodenkunde in Stichworten. 5., revidierte und erweiterte Auflage von W.E.H. Blum (Bearb.). Hirts Stichwörterbücher, Hirt in der Gebrüder-BorntraegerVerlagsbuchhandlung, Berlin, Stuttgart.

Schröter, F., 2003: Tagebau und Rekultivierung bei der Braunschweigischen Kohlen-Bergwerk AG (BKB). Exkursionsbericht des VDI AK Umwelttechnik, VDI-Bezirksverein Braunschweig.

Schulz, F. \& Wiegleb, G., 2000: Development options of natural habitats in a post-mining landscape. Land Degrad. Develop. 2000, 11: 99-110.

Schwerdtfeger, G., Roeschmann, G. \& Kuntze, H., 1994: Bodenkunde. 5. neubearbeitete und erweiterte Auflage. Verlag Eugen Ulmer, Stuttgart. 423 S.

Selent, H., 1993: Untersuchungen von verschiedenen Pappelbestockungen auf Kippenböden im Raum Bitterfeld und Vorschläge zu deren weiterer waldbaulicher Behandlung. Diplomarbeit an der TU Dresden.

Sharples, J.M., Meharg, A.A., Chambers, S.M. \& Cairney, J.W., 2000: Symbiotic solution to arsenic contamination. Nature 2000, 404: 951-952.

Shrestha, R.K. \& Lal, R., 2008: Land use impacts on physical properties of 28 years old reclaimed mine soils in Ohio. Plant and Soil 2008, 306, 1/2: 249-260.

Simmons, J.A., Currie, W.S., Eshleman, K.N., Kuers, K., Monteleone, S., Negley, T.L., Pohlad, B.R. \& Thomas, C.L., 2008: Forest to reclaimed mine land use change leads to altered ecosystem structure and function. Ecological Applications 2008, 18, 1: 104-118.

Smidt, S., 1999: Lexikon waldschädigende Luftverunreinigungen. Forstliche Bundesversuchsanstalt Wien (Hrsg.). Aktualisierte Fassung der FBVA-Berichte Nr. 1997, 199. Stand: 20.10.1999.

Smit, S. \& Veselinovic, N., 1997: Recultivation by afforestation of minespoil banks of opencast lignite mine "Kolubara". $147 \mathrm{~S}$.

Song ShuQiao, Zhou Xing, Wu Huan \& Zhou YongZhang, 2004: Application of municipal garbage compost on revegetation of dumping grounds of tin mine tailings. Rural Eco-Environment 2004, 20, 2: 59-61, 76. 
Staudenrausch, S., Kaldorf, M., Renker, C., Luis, P. \& Buscot, F., 2005: Diversity of the ectomycorrhiza community at a uranium mining heap. Biology and Fertility of Soils 2005, 41, 6: 439-446.

Stähr, F., Katzur, J. \& Böcker, L., 1999: Nadel- und Blattspiegelwerte der Hauptbaumarten auf Kippenstandorten. AFZ/DerWald 1999, 25: 1342-1343.

Stähr, F., Katzur, J. \& Böcker, L., 2000: Untersuchungen zur Nährstoffversorgung der Kiefernforsten auf Kippenstandorten des Lausitzer Braunkohlenreviers. AFZ/DerWald 1999, 25 : 1342-1343.

Stähr, F., 2003: Interaktionen zwischen Boden und Bestockung auf Kippenstandorten des Niederlausitzer Braunkohlereviers am Beispiel der Rekultivierungsbaumarten Gemeine Kiefer, Gemeine Birke und Trauben-Eiche - Wachstums-, ernährungs- und bodenkundliche Untersuchungen. Dissertation, Dresden.

Steer, P. \& Baker, R. M., 1997: Colliery spoil, sewage and biomass - potential for renewable energy from wastes. Aspects of Applied Biology 1997, 49: 300-305.

Thomasius, H. \& Häfker, U., 1998: Forstwirtschaftliche Rekultivierung. In: Pflug, W. (Hrsg.), 1998: Braunkohletagebau und Rekultivierung. Landschaftsökologie - Folgenutzung Naturschutz. Springer Verlag, Berlin, Heidelberg, New York: 797-808.

Thomasius, H., Wünsche, M., Selent, H. \& Bräunig, A., 1999: Wald- und Forstökosysteme auf Kippen des Braunkohlebergbaus in Sachsen - ihre Entstehung, Dynamik und Bewirtschaftung. Schriftenreihe der Sächsischen Landesanstalt für Forsten 1999, 17: 1-71.

Thompson, J.P., 1987: Decline of vesicular-arbuscular mycorrhizae in long fallow disorder of field crops and its expression in phosphorus deficiency of sunflower. Austr. J. of Agric. Res. (Melbourne) 1987, 38: 847-867.

Thüringer Landesanstalt für Landwirtschaft 2001: Merkblatt Bodenphysikalische Parameter zur Beurteilung der Bodenfruchtbarkeit und bodenphysikalische Untersuchungen.

Tischew, S., 1996: Analyse von Mechanismen der Gehölzsukzession auf Braunkohletagebaukippen. Verh. Ges. Ökol. 1996, 26: 407-416.

TMLNU (Thüringer Ministerium für Landwirtschaft, Naturschutz und Umwelt), 2005: Forstbericht 2005. $96 \mathrm{~S}$.

TMLNU (Thüringer Ministerium für Landwirtschaft, Naturschutz und Umwelt), 2006: Forstbericht 2006. 104 S.

Trüby, P., 1994: Zum Schwermetallhaushalt von Waldbäumen. Freiburger Bodenkundliche Abhandlungen 1994, 33. Freiburg im Breisgau. 286 S.

Tyler, G., 1992: Critical Concentrations of Heavy Metals in the Mor Horizon of Swedish Forests. SNV-Report 4078. Solna.

Ulrich, B., 1980/81: Stoffhaushalt von Wald-Ökosystemen II. Bioelement-Haushalt. Vorlesungsskripte, 3. Auflage Wintersemester 1980/81. Institut für Bodenkunde und Waldernährung der Universität Göttingen. 
UBA (Umweltbundesamt) (Hrsg.), 2005: Klimawandel in Deutschland. Vulnerabilität und Anpassungsstrategien klimasensitiver Systeme. Studie des Potsdam-Institutes für Klimafolgenforschung i. A. des Umweltbundesamtes. 202 S.

Uresk, D.W. \& Yamamoto, T., 1986: Growth of forbs, shrubs, and trees on bentonite mine spoil under greenhouse conditions. Journal of Range Management 1986, 39, 2: 113-117.

Uresk, D. W. \& Yamamoto, T., 1994: Field study of plant survival as affected by amendments to bentonite spoil. Great Basin Naturalist 1994, 54, 2: 156-161.

van den Burg, J., 1985: Foliar analysis for determination of tree nutrient status - a compilation of literature data. „De Dorschkamp“ Institute for Forestry and Urban Ecology, Rapport Nr. 414, Wageningen.

van den Burg, J., 1990: Foliar analysis for determination of tree nutrient status - a compilation of literature data, 2. Literature 1985-1989. „De Dorschkamp“ Institute for Forestry and Urban Ecology, Rapport Nr. 591, Wageningen.

Vosátka, M., 1989: VA mycorrhiza in stands of two hardwood species on sites disturbed by $\mathrm{SO}_{2}$ emissions and on strip-mine spoil banks in Northern Bohemia. In: Vančura, V. \& Kunc, F. (Hrsg.), 1989: Interrelationships between microorganisms and plants in soil. Proceedings of an International Symposium, Liblice, Czechoslovakia, Jun. 22-27, 1987: 149-156.

Vosátka, M., 1990: Investigation of VAM Sorbus aucuparia and Acer pseudoplatanus stands at air polluted localities and mine spoils in North Bohemia. Agriculture, Ecosystems \& Environment 1990, 29, 1-4: 443-450.

Walker, R.F., 2002: Responses of Jeffrey Pine on a surface mine site to fertilizer and lime. Restoration Ecology 2002, 10, 2: 204-212.

Walker, R.F., McLaughlin, S.B. \& West, D.C., 2004: Establishment of Sweet Birch on Surface Mine Spoil as influenced by Mycorrhizal Inoculation and Fertility. Restoration Ecology 2004, 12, 1: 819.

Walker, R.F., West, D.C. \& McLaughlin, S.B., 2005: Interactive influences of fertility and nodulation on growth, nutrition, and water relations of European alder in a mine soil. Journal of Sustainable Forestry 2005, 20, 2: 83-104.

Wecker, B., 2005: Kleinräumige Heterogenität kohlehaltiger Kippböden und ihre Auswirkungen auf den Stoffhaushalt. Dissertation an der Brandenburgischen Technischen Universität Cottbus. $95 \mathrm{~S}$.

Weissen, F., 1997: Schadensstand und Nährstoffversorgung der Douglasie in den belgischen Ardennen. In: Maurer, W. \& Tabel, U. (Hrsg.), 1997: Stand der Ursachenforschung zu Douglasienschäden - derzeitige Empfehlungen für die Praxis. Mitteilungen aus der Forstlichen Versuchsanstalt Rheinland-Pfalz 1997, 41: 46-75.

Weissenhorn, I., 2002: Mycorrhiza and salt tolerance of trees. EU project Mycorem QLK3-199900097. Scientific Report. Pius Floris Boomverzorging Nederland bv, Vught, NL.

Werner, D., 1987: Pflanzliche und mikrobielle Symbiosen. G. Thieme Verlag, Stuttgart. 
Wilden, R., Schaaf, W. \& Hüttl, R.F., 2001: Element budgets of two afforested mine sites after application of fertilizer and organic residues. Ecology of post-mining landscapes. International Symposium and SCOPE Workshop on Ecological Engineering and Ecosystem Restoration, Cottbus, Germany, 15.-19. March 1999. Ecological Engineering 2001, 17, 2/3: 253-273.

Wirth, C., Schulze, E.-D., Schwalbe, G., Tomczyk, S., Weber, G.-E. \& Weller, E., 2004: Dynamik der Kohlenstoffvorräte in den Wäldern Thüringens. Thür. Landesanstalt für Wald, Jagd und Fischerei in Zusammenarbeit mit dem Max-Planck-Institut für Biogeochemie, Gotha, Jena.

Wolff, B. \& Riek, W., 1995: Deutscher Beitrag zur europäischen Waldbodenzustandserhebung (Levvel I). Arbeitsbericht des Instituts für Forstökologie und Walderfassung 1995, 1. Bundesforschungsanstalt für Forst- und Holzwirtschaft Hamburg. 73 S.

Wöllecke J.J., Gebhardt, S., Münzenberger, B. \& Hüttl, R.F., 2001: SUBICON - Successional change and biodiversity conservation in a red oak chronosequence. - Succession of diversity and function of ectomycorrhizal types in red oak forest ecosystems. BIOLOG EUROPE. Project ID: 01LC0018 (SUBICON Subprojekt 1) 01. 03. 2001-29. 02. 2004.

Wünsche, M. \& Selent, H., 2000: Waldökosysteme und Waldbau auf Kippen und Halden im Mitteldeutschen Braunkohlerevier. Forstwiss. Beiträge Tharandt, Beiheft 1: 96-111.

Zimmermann, R.-D., 1990: Erste Ergebnisse des Klon-Fichten-Meßnetzes Baden-Württemberg. AFZ-DER WALD 1990, 45: 281-284.

Zwölfer, F., Geiss, M., Adam, P., Heinrichsmeier, K. \& Hermann, H., 1994: Erhaltung fruchtbaren und kulturfähigen Bodens bei Flächeninanspruchnahmen. Umweltministerium BadenWürttemberg (Hrsg.), Stuttgart. 


\section{Abbildungsverzeichnis}

Abb. 1: Temperatur (Monatsmittel); langjähriges Mittel 1961-1990 (DWD-Wetterstation Flughafen Gera-Leumitz) sowie 2005 (Wismut-Wetterstation Ronneburg Hochplateau Absetzerhalde; keine Werte für Jan-Feb) und 2006 (Wismut-Wetterstation Ronneburg Tagebau)

Abb. 2: Monatliche Niederschlagsmenge; langjähriges Mittel 1971-2000 (DWD-Wetterstation Flughafen Gera-Leumitz) sowie 2005 (Wismut-Wetterstation Ronneburg Hochplateau Absetzerhalde; keine Werte für Jan-Feb) und 2006 (Wismut-Wetterstation Ronneburg Tagebau)

Abb. 3: Versuchsdesign (schematische Darstellung) des Freiland-Versuchs, im April 2005 auf drei Versuchsflächen auf der ehem. Ronneburger Absetzerhalde realisiert; Varianten s. S. 20 ... 21 Abb. 4: Bereiche, in denen sich im Versuchsverlauf Spontanvegetation entwickelte (schraffiert) und bis Versuchsende vegetationsfreie Bereiche auf den Versuchsflächen B (links) und D (rechts); schematische Darstellung; Kreise = Standorte der Versuchspflanzen; Varianten s. S. 20

Abb. 5: Beziehung zwischen Wasserspannung [pF] und Wassergehalt [Vol.-\%] des Haldenbodens (links: Tiefenstufe 0-5 cm; rechts: Tiefenstufe 10-15 cm) (pF-Kurve); Kurve durch Mittelwerte der gemessenen Werte mit Standardabweichungen sowie Kurve durch Mittelwerte der mit Hilfe der van-Genuchten-Gleichung errechneten Werte (interpolierte $p F-K u r v e$ ) (links: alpha $=5,614$, $\mathrm{n}=1,066$, Theta_r $=0$, Theta_s $=0,4333$; rechts: alpha $=34,54, \mathrm{n}=1,049$, Theta_r $=0$, Theta_s $=$ 0,4142 )

Abb. 6: Nutzbare Feldkapazität (= Anteile enge Grobporen + Mittelporen im Boden) [Vol.-\%] des Haldenbodens in zwei Tiefenstufen; MW u. Std.abw.; jeweils signifikante Unterschiede zwischen den Tiefenstufen nach U-Tests $(n=$ je 6$)$

Abb. 7: Trockenraumdichten [g/ $\left.\mathrm{cm}^{3}\right]$ im Freiland-Versuch (F “0“; n=16) u. im Topf-Versuch in der Null- (T „0“; n=6), Kompost- (T Ko; n=4) u. Perlit-Variante (T Pe; n=6) nach 3 Jahren; Mediane, 25. u. 75. Perzentil (die Box repräsentiert 50 \% der Werte), Spannweite (5. und 95. Perzentil), Minimum und Maximum; Buchstaben kennzeichnen homogene Gruppen nach UTests

Abb. 8: Gesamtporenvolumina [Vol.-\%] im Freiland-Versuch (F “0“; n=16) u. im Topf-Versuch in der Null- ( $\mathrm{T}$ „0“; n=6), Kompost- (T Ko; $\mathrm{n}=4$ ) u. Perlit-Variante (T Pe; n=6) nach 3 Jahren; Mediane, 25. u. 75. Perzentil (die Box repräsentiert 50 \% der Werte), Spannweite (5. und 95. Perzentil), Minimum und Maximum; Buchstaben kennzeichnen homogene Gruppen nach UTests.

Abb. 9: Volumetrischer Wassergehalt [\%] im Freiland-Versuch (F "0“; n=16) u. im Topf-Versuch in der Null- ( $\mathrm{T}$ „0“; n=6), Kompost- (T Ko; $n=4$ ), Perlit- (T Pe; n=6), Stockosorb®- (T Sto; $n=4$ ) u. Superabsorber-Variante (T Sup; $\mathrm{n}=5$ ) nach 3 Jahren; Mediane, 25. u. 75. Perzentil (die Box repräsentiert $50 \%$ der Werte), Spannweite (5. und 95. Perzentil), Minimum und Maximum; Buchstaben kennzeichnen homogene Gruppen nach U-Tests

Abb. 10: Bodenreaktion (pH-Wert in KCl-Lsg.) im Freiland-Versuch (F “0“; n=12) u. im TopfVersuch in der Null- (T „0“; n=4), Kalk- (T „Ka“; n=12) u. Kompost-Variante (T „Ko“; n=6) nach 3 Jahren; Mediane, 25. u. 75. Perzentil (die Box repräsentiert 50 \% der Werte), Spannweite (5. und 95. Perzentil), Minimum und Maximum; Buchstaben kennzeichnen homogene Gruppen nach UTests. 
Abb. 11: Schwefel-Bodengehalt [mg/g] im Freiland-Versuch (F "0“; n=12) u. im Topf-Versuch in der Null- ( $\mathrm{T}$ „0“; $\mathrm{n}=4$ ), Kalk- ( $\mathrm{T}$ „Ka“; $\mathrm{n}=12$ ) u. Kompost-Variante (T Ko; $\mathrm{n=6}$ ) nach 3 Jahren; MW u. Std.abw.; Buchstaben kennzeichnen homogene Gruppen nach U-Tests

Abb. 12: Kohlenstoff- (links), Stickstoff-Bodengehalte [mg/g] (Mitte) u. C/N-Verhältnisse (rechts) im Freiland-Versuch (F “0“; n=12) u. im Topf-Versuch in der Null- (T „0“; n=4), Kalk- (T „Ka“; n=12) u. Kompost-Variante (T „Ko“; n=6) nach 3 Jahren; MW u. Std.abw.; Buchstaben kennzeichnen jeweils homogene Gruppen nach U-Tests

Abb. 13: Phosphor-Bodengehalte [mg/g] (links) u. C/P-Verhältnisse (rechts) im FreilandVersuch (F “0“; n=12) u. im Topf-Versuch in der Null- (T „0“; n=4), Kalk- (T „Ka“; n=12) u. Kompost-Variante (T „Ko“; n=6) nach 3 Jahren; MW u. Std.abw.; Buchstaben kennzeichnen jeweils homogene Gruppen nach U-Tests.

Abb. 14: Effektive Kationen- Austauschkapazität $\left(\mathrm{AK}_{\mathrm{e}}\right)[\mathrm{mmol}(+) / \mathrm{kg}]$ im Freiland-Versuch (F " 0 “; $\mathrm{n}=16)$ u. im Topf-Versuch in der Null- (T „0“; $\mathrm{n=6}$ ), Kalk- (T „Ka“; n=12) u. Kompost-Variante (T „Ko“; n=4); Mediane, 25. u. 75. Perzentil (die Box repräsentiert 50 \% der Werte), Spannweite (5. und 95. Perzentil), Minimum und Maximum; Buchstaben kennzeichnen homogene Gruppen nach U-Tests

Abb. 15 a-k: Austauscherbelegung, Basen-Sättigung (BS), Erdalkali-Sättigung (ES) sowie Summe der Protonen- $u$. Eisen-Sättigungen [\% der $\mathrm{AK}_{\mathrm{e}}$ ] im Freiland-Versuch ( $\mathrm{F}$ “0“; n=12) u. im TopfVersuch in der Null- ( $\mathrm{T}$ „0“; $\mathrm{n}=4$ ), Kalk- ( $\mathrm{T}$ „Ka“; n=12) u. Kompost-Variante (T „Ko“; n=6) nach 3 Jahren; MW u. Std.abw.; Buchstaben kennzeichnen jeweils homogene Gruppen nach U-Tests....66 Abb. 16: Makronährstoff-Gehalte (N, P, K, Ca, Mg, S) [mg/g] in den Assimilationsorganen der Nullvariante der sechs Baumarten im Freiland-Versuch (Fläche D) im 2. Untersuchungsjahr (Mischproben).

Abb. 17: Mikronährstoff-Gehalte (Fe, $\mathrm{Mn}, \mathrm{Zn}, \mathrm{Cu}$ ) [mg/kg Trockenmasse] in den Assimilationsorganen der Nullvariante der sechs Baumarten im Freiland-Versuch (Fläche D) im 2. Untersuchungsjahr (Mischproben).

Abb. 18: Gehalte potentiell nützlicher Elemente (Al, Na, Ni, Co) [mg/kg Trockenmasse] in den Assimilationsorganen der Nullvariante der sechs Baumarten im Freiland-Versuch (Fläche D) im

2. Untersuchungsjahr (Mischproben).

Abb. 19: Chrom-Gehalte [mg/kg Trockenmasse] in den Assimilationsorganen der Nullvariante der sechs Baumarten im Freiland-Versuch (Fläche D) im 2. Untersuchungsjahr (Mischproben) 94 Abb. 20: Vitalität der Kontrollen [codiert: $4=$ vital - 0 = tot; s. S. 27] im Versuchsverlauf; MW u. Std.abw.; Buchstaben kennzeichnen je Aufnahmezeitpunkt homogene Gruppen nach U-Tests (je Baumart $\mathrm{n}=12$ )

Abb. 21: Häufigkeit der an die Kontrollen vergebenen Vitalitätswerte [codiert: $4=$ vital - $0=$ tot; s. S. 27] im Versuchsverlauf (je $n=12$ )

Abb. 22: Vitalität der Kontrollen [codiert: $4=$ vital - 0 = tot; s. S. 27] im Versuchsverlauf, getrennt nach Standorten; MW u. Std.abw. (je $\mathrm{n}=12$ )

Abb. 23: Zuwachs des Haupttriebs der Kontrollen im Anlagejahr (2005) auf Standorten o./m. Spontanvegetation; MW u. Std.abw.; außer bei Ahorn jeweils signifikante Unterschiede nach UTests.

Abb. 24: Zuwachs des Haupttriebs der Kontroll-Douglasien im Anlagejahr (2005) getrennt nach Versuchsflächen (A: n=3; B: n=4; D: $n=3$ ); MW u. Std.abw.; Buchstaben kennzeichnen homogene Gruppen nach U-Tests.

Abb. 25: Zuwachs des Haupttriebs der Kontroll-Erlen in beiden Untersuchungsjahren auf Standorten ohne $(n=4)$ und mit $(n=3)$ Spontanvegetation; MW u. Std.abw.; jeweils signifikante Unterschiede nach U-Tests. 
Abb. 26 links: $\mathrm{N}_{\mathrm{t}}$-Gehalte [mg/g] im Laub der Eichen auf den Versuchsflächen B und D im 1. (2005) und auf Fläche D im 2. (2006) Vegetationsjahr (Mischproben); rechts: differenziert nach Varianten (s. S. 20) auf Fläche D im 2. Jahr (2006) (Mischproben) 106

Abb. 27 links: $\mathrm{P}_{\mathrm{t}}-$ Gehalte [mg/g] im Laub der Eichen auf den Versuchsflächen B und D im 1. (2005) und auf Fläche D im 2. (2006) Vegetationsjahr (Mischproben); rechts: differenziert nach Varianten (s. S. 20) auf Fläche D im 2. Jahr (2006) (Mischproben) 106 Abb. 28 links: $\mathrm{K}_{\mathrm{t}}$-Gehalte [mg/g] im Laub der Eichen auf den Versuchsflächen B und D im 1. (2005) und auf Fläche D im 2. (2006) Vegetationsjahr (Mischproben); rechts: differenziert nach Varianten (s. S. 20) auf Fläche D im 2. Jahr (2006) (Mischproben)

Abb. 29 links: Cat - Gehalte [mg/g] im Laub der Eichen auf den Versuchsflächen B und D im 1. (2005) und auf Fläche D im 2. (2006) Vegetationsjahr (Mischproben); rechts: differenziert nach Varianten (s. S. 20) auf Fläche D im 2. Jahr (2006) (Mischproben) 108 Abb. 30 links: $\mathrm{Mg}_{\mathrm{t}}$-Gehalte [mg/g] im Laub der Eichen auf den Versuchsflächen B und D im 1. (2005) und auf Fläche D im 2. (2006) Vegetationsjahr (Mischproben); rechts: differenziert nach Varianten (s. S. 20) auf Fläche D im 2. Jahr (2006) (Mischproben) 108 Abb. 31: St-Gehalte [mg/g] im Laub der Eichen-Varianten (s. S. 20) auf Versuchsfläche D im 2. (2006) Vegetationsjahr (Mischproben)

Abb. 32: $\mathrm{Fe}_{\mathrm{t}}$-Gehalte [mg/kg] im Laub der Eichen-Varianten (s. S. 20) auf Versuchsfläche D im 2. (2006) Vegetationsjahr (Mischproben)

Abb. 33: $\mathrm{Mn}_{\mathrm{t}}$-Gehalte [mg/kg] im Laub der Eichen-Varianten (s. S. 20) auf Versuchsfläche D im 2. (2006) Vegetationsjahr (Mischproben)

Abb. 34 links: $\mathrm{Zn}_{\mathrm{t}}$-Gehalte $[\mathrm{mg} / \mathrm{kg}]$ im Laub der Eichen auf den Versuchsflächen B und D im 1. (2005) und auf Fläche D im 2. (2006) Vegetationsjahr (Mischproben); rechts: differenziert nach Varianten (s. S. 20) auf Fläche D im 2. Jahr (2006) (Mischproben)

Abb. 35 links: $\mathrm{Cu}_{\mathrm{t}}-$ Gehalte $[\mathrm{mg} / \mathrm{kg}]$ im Laub der Eichen auf den Versuchsflächen B und D im 1. (2005) und auf Fläche D im 2. (2006) Vegetationsjahr (Mischproben); rechts: differenziert nach Varianten (s. S. 20) auf Fläche D im 2. Jahr (2006) (Mischproben).

Abb. 36: Alt-Gehalte [mg/kg] im Laub der Eichen-Varianten (s. S. 20) auf Versuchsfläche D im 2. (2006) Vegetationsjahr (Mischproben)

Abb. 37: Nat-Gehalte [mg/kg] im Laub der Eichen-Varianten (s. S. 20) auf Versuchsfläche D im 2. (2006) Vegetationsjahr (Mischproben)

Abb. 38 links: $\mathrm{Ni}_{\mathrm{t}}-$ Gehalte $[\mathrm{mg} / \mathrm{kg}]$ im Laub der Eichen auf den Versuchsflächen B und D im 1. (2005) und auf Fläche D im 2. (2006) Vegetationsjahr (Mischproben); rechts: differenziert nach Varianten (s. S. 20) auf Fläche D im 2. Jahr (2006) (Mischproben)

Abb. 39 links: $\mathrm{Co}_{\mathrm{t}}-$ Gehalte $[\mathrm{mg} / \mathrm{kg}]$ im Laub der Eichen auf den Versuchsflächen B und D im 1. (2005) und auf Fläche D im 2. (2006) Vegetationsjahr (Mischproben); rechts: differenziert nach Varianten (s. S. 20) auf Fläche D im 2. Jahr (2006) (Mischproben)

Abb. 40 links: $\mathrm{Cr}_{\mathrm{t}}-\mathrm{Gehalte}[\mathrm{mg} / \mathrm{kg}]$ im Laub der Eichen auf den Versuchsflächen B und D im 1. (2005) und auf Fläche D im 2. (2006) Vegetationsjahr (Mischproben); rechts: differenziert nach Varianten (s. S. 20) auf Fläche D im 2. Jahr (2006) (Mischproben)

Abb. 41 links: $\mathrm{N}_{\mathrm{t}}$-Gehalte [mg/g] im Laub der Ahorne auf den Versuchsflächen A, B und D im 1. (2005) und auf Fläche D im 2. (2006) Vegetationsjahr (Mischproben); rechts: differenziert nach Varianten (s. S. 20) auf Fläche D im 2. Jahr (2006) (Mischproben).. 116 Abb. 42 links: $\mathrm{P}_{\mathrm{t}}-$ Gehalte [mg/g] im Laub der Ahorne auf den Versuchsflächen A, B und D im 1. (2005) und auf Fläche D im 2. (2006) Vegetationsjahr (Mischproben); rechts: differenziert nach Varianten (s. S. 20) auf Fläche D im 2. Jahr (2006) (Mischproben)... 
Abb. 43 links: $\mathrm{K}_{\mathrm{t}}-$ Gehalte [mg/g] im Laub der Ahorne auf den Versuchsflächen A, B und D im 1. (2005) und auf Fläche D im 2. (2006) Vegetationsjahr (Mischproben); rechts: differenziert nach Varianten (s. S. 20) auf Fläche D im 2. Jahr (2006) (Mischproben) 118 Abb. 44 links: Cat-Gehalte [mg/g] im Laub der Ahorne auf den Versuchsflächen A, B und D im 1. (2005) und auf Fläche D im 2. (2006) Vegetationsjahr (Mischproben); rechts: differenziert nach Varianten (s. S. 20) auf Fläche D im 2. Jahr (2006) (Mischproben). 119 Abb. 45 links: Mgt-Gehalte [mg/g] im Laub der Ahorne auf den Versuchsflächen A, B und D im 1. (2005) und auf Fläche D im 2. (2006) Vegetationsjahr (Mischproben); rechts: differenziert nach Varianten (s. S. 20) auf Fläche D im 2. Jahr (2006) (Mischproben).. 120 Abb. 46: St-Gehalte [mg/g] im Laub der Ahorn-Varianten (s. S. 20) auf Versuchsfläche D im 2. (2006) Vegetationsjahr (Mischproben) 121 Abb. 47: $\mathrm{Fe}_{\mathrm{t}}-\mathrm{Gehalte}[\mathrm{mg} / \mathrm{kg}]$ im Laub der Ahorn-Varianten (s. S. 20) auf Versuchsfläche D im 2. (2006) Vegetationsjahr (Mischproben). 122 Abb. 48: $\mathrm{Mn}_{\mathrm{t}}-\mathrm{Gehalte}$ [mg/kg] im Laub der Ahorn-Varianten (s. S. 20) auf Versuchsfläche D im 2. (2006) Vegetationsjahr (Mischproben)

Abb. 49 links: $\mathrm{Zn}_{\mathrm{t}}-$ Gehalte [mg/kg] im Laub der Ahorne auf den Versuchsflächen A, B und D im 1. (2005) und auf Fläche D im 2. (2006) Vegetationsjahr (Mischproben); rechts: differenziert nach Varianten (s. S. 20) auf Fläche D im 2. Jahr (2006) (Mischproben)... 124 Abb. 50 links: $\mathrm{Cu}_{\mathrm{t}}-$ Gehalte $[\mathrm{mg} / \mathrm{kg}]$ im Laub der Ahorne auf den Versuchsflächen A, B und D im 1. (2005) und auf Fläche D im 2. (2006) Vegetationsjahr (Mischproben); rechts: differenziert nach Varianten (s. S. 20) auf Fläche D im 2. Jahr (2006) (Mischproben).. 125 Abb. 51: Al $\mathrm{Al}_{\mathrm{t}}-\mathrm{Gehalte}$ [mg/kg] im Laub der Ahorn-Varianten (s. S. 20) auf Versuchsfläche D im 2. (2006) Vegetationsjahr (Mischproben) 126 Abb. 52: Nat-Gehalte [mg/kg] im Laub der Ahorn-Varianten (s. S. 20) auf Versuchsfläche D im 2. (2006) Vegetationsjahr (Mischproben) 127 Abb. 53 links: $\mathrm{Ni}_{\mathrm{t}}$-Gehalte [mg/kg] im Laub der Ahorne auf den Versuchsflächen A, B und D im 1. (2005) und auf Fläche D im 2. (2006) Vegetationsjahr (Mischproben); rechts: differenziert nach Varianten (s. S. 20) auf Fläche D im 2. Jahr (2006) (Mischproben). 127 Abb. 54 links: $\mathrm{Cot}_{\mathrm{t}}-\mathrm{Gehalte}[\mathrm{mg} / \mathrm{kg}]$ im Laub der Ahorne auf den Versuchsflächen A, B und D im 1. (2005) und auf Fläche D im 2. (2006) Vegetationsjahr (Mischproben); rechts: differenziert nach Varianten (s. S. 20) auf Fläche D im 2. Jahr (2006) (Mischproben).. 128 Abb. 55: $\mathrm{Pb}_{\mathrm{t}}$-Gehalte $[\mathrm{mg} / \mathrm{kg}]$ im Laub der Ahorne auf den Versuchsflächen A, B und D im 1. (2005) und auf Fläche D im 2. (2006) Vegetationsjahr (Mischproben)... 129 Abb. 56 links: $\mathrm{Cr}_{\mathrm{t}}-$ Gehalte [mg/kg] im Laub der Ahorne auf den Versuchsflächen A, B und D im 1. (2005) und auf Fläche D im 2. (2006) Vegetationsjahr (Mischproben); rechts: differenziert nach Varianten (s. S. 20) auf Fläche D im 2. Jahr (2006) (Mischproben).. 130 Abb. 57 links: $\mathrm{N}_{\mathrm{t}}$-Gehalte [mg/g] im Laub der Ebereschen auf den Versuchsflächen A, B und D im 1. (2005) und auf Fläche D im 2. (2006) Vegetationsjahr (Mischproben); rechts: differenziert nach Varianten (s. S. 20) auf Fläche D im 2. Jahr (2006) (Mischproben). 131 Abb. 58 links: $\mathrm{P}_{\mathrm{t}}-$ Gehalte $[\mathrm{mg} / \mathrm{g}]$ im Laub der Ebereschen auf den Versuchsflächen A, B und D im 1. (2005) und auf Fläche D im 2. (2006) Vegetationsjahr (Mischproben); rechts: differenziert nach Varianten (s. S. 20) auf Fläche D im 2. Jahr (2006) (Mischproben). 131 Abb. 59 links: $\mathrm{K}_{\mathrm{t}}$-Gehalte [mg/g] im Laub der Ebereschen auf den Versuchsflächen A, B und D im 1. (2005) und auf Fläche D im 2. (2006) Vegetationsjahr (Mischproben); rechts: differenziert nach Varianten (s. S. 20) auf Fläche D im 2. Jahr (2006) (Mischproben). Abb. 60 links: Cat-Gehalte [mg/g] im Laub der Ebereschen auf den Versuchsflächen A, B und D im 1. (2005) und auf Fläche D im 2. (2006) Vegetationsjahr (Mischproben); rechts: differenziert nach Varianten (s. S. 20) auf Fläche D im 2. Jahr (2006) (Mischproben). 
Abb. 61 links: Mgt-Gehalte [mg/g] im Laub der Ebereschen auf den Versuchsflächen A, B und D im 1. (2005) und auf Fläche D im 2. (2006) Vegetationsjahr (Mischproben); rechts: differenziert nach Varianten (s. S. 20) auf Fläche D im 2. Jahr (2006) (Mischproben)

Abb. 62: St-Gehalte [mg/g] im Laub der Ebereschen-Varianten (s. S. 20) auf Versuchsfläche D im

2. (2006) Vegetationsjahr (Mischproben)...

Abb. 63: Fet-Gehalte [mg/kg] im Laub der Ebereschen-Varianten (s. S. 20) auf Versuchsfläche D

im 2. (2006) Vegetationsjahr (Mischproben)

Abb. 64: $\mathrm{Mn}_{\mathrm{t}}-$ Gehalte [mg/kg] im Laub der Ebereschen-Varianten (s. S. 20) auf Versuchsfläche D

im 2. (2006) Vegetationsjahr (Mischproben)

Abb. 65 links: $\mathrm{Zn}_{\mathrm{t}}$-Gehalte $[\mathrm{mg} / \mathrm{kg}]$ im Laub der Ebereschen auf den Versuchsflächen A, B und D im 1. (2005) und auf Fläche D im 2. (2006) Vegetationsjahr (Mischproben); rechts: differenziert nach Varianten (s. S. 20) auf Fläche D im 2. Jahr (2006) (Mischproben)

Abb. 66 links: $\mathrm{Cu}_{\mathrm{t}}-\mathrm{Gehalte}[\mathrm{mg} / \mathrm{kg}]$ im Laub der Ebereschen auf den Versuchsflächen A, B und D im 1. (2005) und auf Fläche D im 2. (2006) Vegetationsjahr (Mischproben); rechts: differenziert nach Varianten (s. S. 20) auf Fläche D im 2. Jahr (2006) (Mischproben) 136

Abb. 67: Al ${ }_{t}-$ Gehalte [mg/kg] im Laub der Ebereschen-Varianten (s. S. 20) auf Versuchsfläche D im 2. (2006) Vegetationsjahr (Mischproben)

Abb. 68: Nat-Gehalte [mg/kg] im Laub der Ebereschen-Varianten (s. S. 20) auf Versuchsfläche D

im 2. (2006) Vegetationsjahr (Mischproben)

Abb. 69 links: $\mathrm{Ni}_{\mathrm{t}}-$ Gehalte $[\mathrm{mg} / \mathrm{kg}]$ im Laub der Ebereschen auf den Versuchsflächen A, B und D im 1. (2005) und auf Fläche D im 2. (2006) Vegetationsjahr (Mischproben); rechts: differenziert nach Varianten (s. S. 20) auf Fläche D im 2. Jahr (2006) (Mischproben) 138 Abb. 70 links: $\mathrm{Co}_{\mathrm{t}}-$ Gehalte $[\mathrm{mg} / \mathrm{kg}]$ im Laub der Ebereschen auf den Versuchsflächen A, B und D im 1. (2005) und auf Fläche D im 2. (2006) Vegetationsjahr (Mischproben); rechts: differenziert nach Varianten (s. S. 20) auf Fläche D im 2. Jahr (2006) (Mischproben)

Abb. 71 links: $\mathrm{Cr}_{\mathrm{t}}-\mathrm{Gehalte}$ [mg/kg] im Laub der Ebereschen auf den Versuchsflächen A, B und D im 1. (2005) und auf Fläche D im 2. (2006) Vegetationsjahr (Mischproben); rechts: differenziert nach Varianten (s. S. 20) auf Fläche D im 2. Jahr (2006) (Mischproben) 140

Abb. 72 links: $\mathrm{N}_{\mathrm{t}}-$ Gehalte [mg/g] im Laub der Erlen auf den Versuchsflächen A, B und D im 1. (2005) und auf Fläche D im 2. (2006) Vegetationsjahr (Mischproben); rechts: differenziert nach Varianten (s. S. 20) auf Fläche D im 2. Jahr (2006) (Mischproben)...

Abb. 73 links: $\mathrm{P}_{\mathrm{t}}$-Gehalte [mg/g] im Laub der Erlen auf den Versuchsflächen A, B und D im 1. (2005) und auf Fläche D im 2. (2006) Vegetationsjahr (Mischproben); rechts: differenziert nach Varianten (s. S. 20) auf Fläche D im 2. Jahr (2006) (Mischproben)

Abb. 74 links: $\mathrm{K}_{\mathrm{t}}-$ Gehalte [mg/g] im Laub der Erlen auf den Versuchsflächen A, B und D im 1. (2005) und auf Fläche D im 2. (2006) Vegetationsjahr (Mischproben); rechts: differenziert nach Varianten (s. S. 20) auf Fläche D im 2. Jahr (2006) (Mischproben)

Abb. 75 links: Cat-Gehalte [mg/g] im Laub der Erlen auf den Versuchsflächen A, B und D im 1. (2005) und auf Fläche D im 2. (2006) Vegetationsjahr (Mischproben); rechts: differenziert nach Varianten (s. S. 20) auf Fläche D im 2. Jahr (2006) (Mischproben)

Abb. 76 links: $\mathrm{Mg}_{\mathrm{t}}$-Gehalte [mg/g] im Laub der Erlen auf den Versuchsflächen A, B und D im 1. (2005) und auf Fläche D im 2. (2006) Vegetationsjahr (Mischproben); rechts: differenziert nach Varianten (s. S. 20) auf Fläche D im 2. Jahr (2006) (Mischproben) 144 Abb. 77: St-Gehalte [mg/g] im Laub der Erlen-Varianten (s. S. 20) auf Versuchsfläche D im 2. (2006) Vegetationsjahr (Mischproben)

Abb. 78: $\mathrm{Fe}_{\mathrm{t}}$-Gehalte [mg/kg] im Laub der Erlen-Varianten (s. S. 20) auf Versuchsfläche D im 2. (2006) Vegetationsjahr (Mischproben) 
Abb. 79: $\mathrm{Mn}_{\mathrm{t}}-\mathrm{Gehalte}[\mathrm{mg} / \mathrm{kg}]$ im Laub der Erlen-Varianten (s. S. 20) auf Versuchsfläche D im 2. (2006) Vegetationsjahr (Mischproben).

Abb. 80 links: $\mathrm{Zn}_{\mathrm{t}}-$ Gehalte [mg/kg] im Laub der Erlen auf den Versuchsflächen A, B und D im 1. (2005) und auf Fläche D im 2. (2006) Vegetationsjahr (Mischproben); rechts: differenziert nach Varianten (s. S. 20) auf Fläche D im 2. Jahr (2006) (Mischproben)

Abb. 81 links: $\mathrm{Cu}_{\mathrm{t}}-\mathrm{Gehalte}[\mathrm{mg} / \mathrm{kg}]$ im Laub der Erlen auf den Versuchsflächen A, B und D im 1. (2005) und auf Fläche D im 2. (2006) Vegetationsjahr (Mischproben); rechts: differenziert nach Varianten (s. S. 20) auf Fläche D im 2. Jahr (2006) (Mischproben). 148 Abb. 82: Alt-Gehalte [mg/kg] im Laub der Erlen-Varianten (s. S. 20) auf Versuchsfläche D im 2. (2006) Vegetationsjahr (Mischproben). 149

Abb. 83: Nat-Gehalte [mg/kg] im Laub der Erlen-Varianten (s. S. 20) auf Versuchsfläche D im 2. (2006) Vegetationsjahr (Mischproben). 150 Abb. 84 links: $\mathrm{Ni}_{\mathrm{t}}-$ Gehalte $[\mathrm{mg} / \mathrm{kg}]$ im Laub der Erlen auf den Versuchsflächen A, B und D im 1. (2005) und auf Fläche D im 2. (2006) Vegetationsjahr (Mischproben); rechts: differenziert nach Varianten (s. S. 20) auf Fläche D im 2. Jahr (2006) (Mischproben). 150 Abb. 85 links: $\mathrm{Co}_{\mathrm{t}}-\mathrm{Gehalte}[\mathrm{mg} / \mathrm{kg}]$ im Laub der Erlen auf den Versuchsflächen A, B und D im 1. (2005) und auf Fläche D im 2. (2006) Vegetationsjahr (Mischproben); rechts: differenziert nach Varianten (s. S. 20) auf Fläche D im 2. Jahr (2006) (Mischproben)...

Abb. 86: $\mathrm{Pb}_{\mathrm{t}}$-Gehalte $[\mathrm{mg} / \mathrm{kg}]$ im Laub der Erlen auf den Versuchsflächen A, B und D im 1. (2005) und auf Fläche D im 2. (2006) Vegetationsjahr (Mischproben) ...

Abb. 87 links: $\mathrm{Cr}_{\mathrm{t}}$-Gehalte [mg/kg] im Laub der Erlen auf den Versuchsflächen A, B und D im 1. (2005) und auf Fläche D im 2. (2006) Vegetationsjahr (Mischproben); rechts: differenziert nach Varianten (s. S. 20) auf Fläche D im 2. Jahr (2006) (Mischproben)... Abb. 88 links: $\mathrm{N}_{\mathrm{t}}$-Gehalte [mg/g] in den Nadeln der Douglasien auf den Versuchsflächen A, B und D im 1. (2005) und auf Fläche D im 2. (2006) Vegetationsjahr (Mischproben); rechts: differenziert nach Varianten (s. S. 20) auf Fläche D im 2. Jahr (2006) (Mischproben). 154 Abb. 89 links: $\mathrm{P}_{\mathrm{t}}$-Gehalte [mg/g] in den Nadeln der Douglasien auf den Versuchsflächen A, B und D im 1. (2005) und auf Fläche D im 2. (2006) Vegetationsjahr (Mischproben); rechts: differenziert nach Varianten (s. S. 20) auf Fläche D im 2. Jahr (2006) (Mischproben)...................155 Abb. 90 links: $\mathrm{K}_{\mathrm{t}}-\mathrm{Gehalte}[\mathrm{mg} / \mathrm{g}]$ in den Nadeln der Douglasien auf den Versuchsflächen A, B und D im 1. (2005) und auf Fläche D im 2. (2006) Vegetationsjahr (Mischproben); rechts: differenziert nach Varianten (s. S. 20) auf Fläche D im 2. Jahr (2006) (Mischproben). 156 Abb. 91 links: Cat-Gehalte [mg/g] in den Nadeln der Douglasien auf den Versuchsflächen A, B und D im 1. (2005) und auf Fläche D im 2. (2006) Vegetationsjahr (Mischproben); rechts: differenziert nach Varianten (s. S. 20) auf Fläche D im 2. Jahr (2006) (Mischproben)... 157 Abb. 92 links: Mgt $_{\mathrm{t}}-\mathrm{Gehalte}[\mathrm{mg} / \mathrm{g}]$ in den Nadeln der Douglasien auf den Versuchsflächen A, B und D im 1. (2005) und auf Fläche D im 2. (2006) Vegetationsjahr (Mischproben); rechts: differenziert nach Varianten (s. S. 20) auf Fläche D im 2. Jahr (2006) (Mischproben). 158 Abb. 93: St-Gehalte [mg/g] in den Nadeln der Douglasien-Varianten (s. S. 20) auf Versuchsfläche D im 2. (2006) Vegetationsjahr (Mischproben)

Abb. 94: $\mathrm{Fe}_{\mathrm{t}}$-Gehalte [mg/kg] in den Nadeln der Douglasien-Varianten (s. S. 20) auf Versuchsfläche D im 2. (2006) Vegetationsjahr (Mischproben) 160 Abb. 95: $\mathrm{Mn}_{\mathrm{t}}$-Gehalte $[\mathrm{mg} / \mathrm{kg}]$ in den Nadeln der Douglasien-Varianten (s. S. 20) auf Versuchsfläche D im 2. (2006) Vegetationsjahr (Mischproben) 160 Abb. 96 links: $\mathrm{Zn}_{\mathrm{t}}-$ Gehalte $[\mathrm{mg} / \mathrm{kg}]$ in den Nadeln der Douglasien auf den Versuchsflächen A, B und D im 1. (2005) und auf Fläche D im 2. (2006) Vegetationsjahr (Mischproben); rechts: differenziert nach Varianten (s. S. 20) auf Fläche D im 2. Jahr (2006) (Mischproben). 
Abb. 97 links: $\mathrm{Cu}_{\mathrm{t}}-\mathrm{Gehalte}[\mathrm{mg} / \mathrm{kg}]$ in den Nadeln der Douglasien auf den Versuchsflächen A, B und D im 1. (2005) und auf Fläche D im 2. (2006) Vegetationsjahr (Mischproben); rechts: differenziert nach Varianten (s. S. 20) auf Fläche D im 2. Jahr (2006) (Mischproben)

Abb. 98: $\mathrm{Al}_{\mathrm{t}}$-Gehalte $[\mathrm{mg} / \mathrm{kg}]$ in den Nadeln der Douglasien-Varianten (s. S. 20) auf

Versuchsfläche D im 2. (2006) Vegetationsjahr (Mischproben).

Abb. 99: $\mathrm{Na}_{\mathrm{t}}-\mathrm{Gehalte}[\mathrm{mg} / \mathrm{kg}]$ in den Nadeln der Douglasien-Varianten (s. S. 20) auf

Versuchsfläche D im 2. (2006) Vegetationsjahr (Mischproben).

Abb. 100 links: $\mathrm{Ni}_{\mathrm{t}}-\mathrm{Gehalte}[\mathrm{mg} / \mathrm{kg}]$ in den Nadeln der Douglasien auf den Versuchsflächen A, B und D im 1. (2005) und auf Fläche D im 2. (2006) Vegetationsjahr (Mischproben); rechts: differenziert nach Varianten (s. S. 20) auf Fläche D im 2. Jahr (2006) (Mischproben) 165 Abb. 101 links: Cot-Gehalte [mg/kg] in den Nadeln der Douglasien auf den Versuchsflächen A, B und D im 1. (2005) und auf Fläche D im 2. (2006) Vegetationsjahr (Mischproben); rechts: differenziert nach Varianten (s. S. 20) auf Fläche D im 2. Jahr (2006) (Mischproben) ...................166 Abb. 102: $\mathrm{Pb}_{\mathrm{t}}-$ Gehalte $[\mathrm{mg} / \mathrm{kg}]$ in den Nadeln der Douglasien auf den Versuchsflächen A, B und D im 1. (2005) und auf Fläche D im 2. (2006) Vegetationsjahr (Mischproben)

Abb. 103: $\mathrm{Cd}_{\mathrm{t}}-$ Gehalte $[\mathrm{mg} / \mathrm{kg}]$ in den Nadeln der Douglasien auf den Versuchsflächen A, B und D im 1. (2005) und auf Fläche D im 2. (2006) Vegetationsjahr (Mischproben) 168 Abb. 104 links: $\mathrm{Cr}_{\mathrm{t}}$-Gehalte $[\mathrm{mg} / \mathrm{kg}]$ in den Nadeln der Douglasien auf den Versuchsflächen A, B und D im 1. (2005) und auf Fläche D im 2. (2006) Vegetationsjahr (Mischproben); rechts: differenziert nach Varianten (s. S. 20) auf Fläche D im 2. Jahr (2006) (Mischproben) 169 Abb. 105 links: $\mathrm{N}_{\mathrm{t}}$-Gehalte [mg/g] in den Nadeln der Kiefern auf den Versuchsflächen A, B und D im 1. (2005) und auf Fläche D im 2. (2006) Vegetationsjahr (Mischproben); rechts: differenziert nach Varianten (s. S. 20) auf Fläche D im 2. Jahr (2006) (Mischproben) 170 Abb. 106 links: $\mathrm{P}_{\mathrm{t}}$-Gehalte [mg/g] in den Nadeln der Kiefern auf den Versuchsflächen A, B und D im 1. (2005) und auf Fläche D im 2. (2006) Vegetationsjahr (Mischproben); rechts: differenziert nach Varianten (s. S. 20) auf Fläche D im 2. Jahr (2006) (Mischproben) 170 Abb. 107 links: $\mathrm{K}_{\mathrm{t}}-$ Gehalte $[\mathrm{mg} / \mathrm{g}]$ in den Nadeln der Kiefern auf den Versuchsflächen A, B und D im 1. (2005) und auf Fläche D im 2. (2006) Vegetationsjahr (Mischproben); rechts: differenziert nach Varianten (s. S. 20) auf Fläche D im 2. Jahr (2006) (Mischproben) 171 Abb. 108 links: Cat-Gehalte [mg/g] in den Nadeln der Kiefern auf den Versuchsflächen A, B und D im 1. (2005) und auf Fläche D im 2. (2006) Vegetationsjahr (Mischproben); rechts: differenziert nach Varianten (s. S. 20) auf Fläche D im 2. Jahr (2006) (Mischproben). 172 Abb. 109 links: $\mathrm{Mg}_{\mathrm{t}}-\mathrm{Gehalte}[\mathrm{mg} / \mathrm{g}]$ in den Nadeln der Kiefern auf den Versuchsflächen A, B und D im 1. (2005) und auf Fläche D im 2. (2006) Vegetationsjahr (Mischproben); rechts: differenziert nach Varianten (s. S. 20) auf Fläche D im 2. Jahr (2006) (Mischproben). 172 Abb. 110: $\mathrm{S}_{\mathrm{t}}$-Gehalte [mg/g] in den Nadeln der Kiefern-Varianten (s. S. 20) auf Versuchsfläche D im 2. (2006) Vegetationsjahr (Mischproben) 173 Abb. 111: $\mathrm{Fe}_{\mathrm{t}}-\mathrm{Gehalte}[\mathrm{mg} / \mathrm{kg}$ in den Nadeln der Kiefern-Varianten (s. S. 20) auf Versuchsfläche D im 2. (2006) Vegetationsjahr (Mischproben). 174 Abb. 112: $\mathrm{Mn}_{\mathrm{t}}$-Gehalte $[\mathrm{mg} / \mathrm{kg}]$ in den Nadeln der Kiefern-Varianten (s. S. 20) auf Versuchsfläche D im 2. (2006) Vegetationsjahr (Mischproben) 174 Abb. 113 links: $\mathrm{Zn}_{\mathrm{t}}-$ Gehalte $[\mathrm{mg} / \mathrm{kg}]$ in den Nadeln der Kiefern auf den Versuchsflächen A, B und D im 1. (2005) und auf Fläche D im 2. (2006) Vegetationsjahr (Mischproben); rechts: differenziert nach Varianten (s. S. 20) auf Fläche D im 2. Jahr (2006) (Mischproben) ... 175 Abb. 114 links: $\mathrm{Cu}_{\mathrm{t}}$-Gehalte [mg/kg] in den Nadeln der Kiefern auf den Versuchsflächen A, B und D im 1. (2005) und auf Fläche D im 2. (2006) Vegetationsjahr (Mischproben); rechts: differenziert nach Varianten (s. S. 20) auf Fläche D im 2. Jahr (2006) (Mischproben). 
Abb. 115: Alt-Gehalte [mg/kg] in den Nadeln der Kiefern-Varianten (s. S. 20) auf Versuchsfläche D im 2. (2006) Vegetationsjahr (Mischproben)

Abb. 116: Nat-Gehalte [mg/kg] in den Nadeln der Kiefern-Varianten (s. S. 20) auf Versuchsfläche D im 2. (2006) Vegetationsjahr (Mischproben)

Abb. 117 links: $\mathrm{Ni}_{\mathrm{t}}-\mathrm{Gehalte}[\mathrm{mg} / \mathrm{kg}]$ in den Nadeln der Kiefern auf den Versuchsflächen A, B und D im 1. (2005) und auf Fläche D im 2. (2006) Vegetationsjahr (Mischproben); rechts: differenziert nach Varianten (s. S. 20) auf Fläche D im 2. Jahr (2006) (Mischproben)

Abb. 118 links: $\mathrm{Co}_{\mathrm{t}}-$ Gehalte $[\mathrm{mg} / \mathrm{kg}]$ in den Nadeln der Kiefern auf den Versuchsflächen A, B und D im 1. (2005) und auf Fläche D im 2. (2006) Vegetationsjahr (Mischproben); rechts: differenziert nach Varianten (s. S. 20) auf Fläche D im 2. Jahr (2006) (Mischproben). 178 Abb. 119 links: $\mathrm{Cr}_{\mathrm{t}}-$ Gehalte $[\mathrm{mg} / \mathrm{kg}]$ in den Nadeln der Kiefern auf den Versuchsflächen A, B und D im 1. (2005) und auf Fläche D im 2. (2006) Vegetationsjahr (Mischproben); rechts: differenziert nach Varianten (s. S. 20) auf Fläche D im 2. Jahr (2006) (Mischproben). 179 Abb. 120: Vitalität [codiert: $4=$ vital bis $0=$ tot, s. S. 27] der Eichen im Versuchsverlauf; MW u. Std.abw. (n=192)

Abb. 121: Relative Häufigkeit der Vitalitätswerte [codiert: 4 = vital bis $0=$ tot, s. S. 27] der Eichen im Versuchsverlauf $(\mathrm{n}=192)$...

Abb. 122: Vitalität [codiert: $4=$ vital bis $0=$ tot, s. S. 27] der Ahorne im Versuchsverlauf; MW u. Std.abw. (n=192)

Abb. 123: Vitalität [codiert: 4 = vital bis $0=$ tot, s. S. 27] der Ahorn-Varianten (s. S. 20) im Juni 2005, Juni 2006 und Oktober 2006; MW u. Std.abw.; Buchstaben kennzeichnen je Aufnahmezeitpunkt homogene Gruppen nach U-Tests, Fettdruck markiert signifikanten Unterschied zur Nullvariante (V1) (je Variante $\mathrm{n}=12$ )...

Abb. 124: Vitalität [codiert: 4 = vital bis $0=$ tot, s. S. 27] der Ahorn-Varianten (s. S. 20) auf Versuchsfläche A im Juni 2005; MW u. Std.abw.; Buchstaben kennzeichnen homogene Gruppen nach U-Tests, Fettdruck markiert signifikanten Unterschied zur Nullvariante (V1) (je Variante $\mathrm{n}=4$ )

Abb. 125: Vitalität [codiert: $4=$ vital bis $0=$ tot, s. S. 27] der Ahorn-Varianten (s. S. 20) auf Versuchsfläche B im Juni 2005, Juni 2006 und Oktober 2006; MW u. Std.abw.; Buchstaben kennzeichnen je Aufnahmezeitpunkt homogene Gruppen nach U-Tests, Fettdruck markiert signifikanten Unterschied zur Nullvariante (V1) (je Variante $n=4$ ) .

Abb. 126: Vitalität [codiert: $4=$ vital bis $0=$ tot, s. S. 27] der Ahorn-Varianten (s. S. 20) auf Versuchsfläche D im Oktober 2005 und Juni 2006; MW u. Std.abw.; Buchstaben kennzeichnen je Aufnahmezeitpunkt homogene Gruppen nach U-Tests; Fettdruck markiert signifikanten Unterschied zur Nullvariante (V1) (je Variante $n=4$ )

Abb. 127: Vitalität [codiert: 4 = vital bis 0 = tot, s. S. 27] der Ahorn-Varianten (s. S. 20) in vegetationsfreien Bereichen im Juni 2005 und Juni 2006; MW u. Std.abw.; Buchstaben kennzeichnen je Aufnahmezeitpunkt homogene Gruppen nach U-Tests, Fettdruck markiert signifikanten Unterschied zur Nullvariante (V1) (n=118).

Abb. 128: Vitalität [codiert: 4 = vital bis 0 = tot, s. S. 27] der Ahorn-Varianten (s. S. 20) in bewachsenen Bereichen im Juni 2006; MW u. Std.abw.; Buchstaben kennzeichnen homogene Gruppen nach U-Tests, Fettdruck markiert signifikanten Unterschied zur Nullvariante (V1) $(\mathrm{n}=74)$.

Abb. 129: Vitalität [codiert: 4 = vital bis 0 = tot, s. S. 27] der Ebereschen im Versuchsverlauf; MW u. Std.abw. (n=120)

Abb. 130: Vitalität [codiert: $4=$ vital bis $0=$ tot, s. S. 27] der Ebereschen-Varianten (s. S. 20) im Juni und Oktober 2006; MW u. Std.abw.; Buchstaben kennzeichnen je Aufnahmezeitpunkt 
homogene Gruppen nach U-Tests, Fettdruck markiert signifikanten Unterschied zur Nullvariante (V1) (je Variante $\mathrm{n}=12$ )

Abb. 131: Vitalität [codiert: $4=$ vital bis $0=$ tot, s. S. 27] der Ebereschen-Varianten (s. S. 20) auf Versuchsfläche A ( $n=40)$ im Juni 2005; MW u. Std.abw.; Buchstaben kennzeichnen homogene Gruppen nach U-Tests, Fettdruck markiert signifikanten Unterschied zur Nullvariante (V1) (je Variante $\mathrm{n}=4$ ).

Abb. 132: Vitalität [codiert: $4=$ vital bis $0=$ tot, s. S. 27] der Ebereschen-Varianten (s. S. 20) in bewachsenen Bereichen im Juni 2005; MW u. Std.abw.; Buchstaben kennzeichnen homogene Gruppen nach U-Tests, Fettdruck markiert signifikanten Unterschied zur Nullvariante (V1) $(\mathrm{n}=44)$

Abb. 133: Vitalität [codiert: $4=$ vital bis $0=$ tot, s. S. 27] der Erlen im Versuchsverlauf; MW u. Std.abw. $(\mathrm{n}=120)$...

Abb. 134: Vitalität [codiert: 4 = vital bis $0=$ tot, s. S. 27] der Erlen-Varianten (s. S. 20) auf Versuchsfläche A ( $n=40)$ im Juni 2005; MW u. Std.abw.; Buchstaben kennzeichnen homogene Gruppen nach U-Tests, Fettdruck markiert signifikanten Unterschied zur Nullvariante (V1) (je Variante $\mathrm{n}=4$ ).

Abb. 135: Vitalität [codiert: 4 = vital bis $0=$ tot, s. S. 27] der Erlen-Varianten (s. S. 20) auf Versuchsfläche B (n=40) im Juni 2005; MW u. Std.abw.; Buchstaben kennzeichnen homogene Gruppen nach U-Tests, Fettdruck markiert signifikanten Unterschied zur Nullvariante (V1) (je Variante $\mathrm{n}=4$ ).

Abb. 136: Vitalität [codiert: 4 = vital bis $0=$ tot, s. S. 27] der Erlen-Varianten (s. S. 20) in vegetationsfreien Bereichen im Juni 2006; MW u. Std.abw.; Buchstaben kennzeichnen homogene Gruppen nach U-Tests, Fettdruck markiert signifikanten Unterschied zur Nullvariante (V1) $(\mathrm{n}=74)$

Abb. 137: Vitalität [codiert: $4=$ vital bis $0=$ tot, s. S. 27] der Douglasien im Versuchsverlauf; MW u. Std.abw. $(\mathrm{n}=192)$....

Abb. 138: Vitalität [codiert: $4=$ vital bis $0=$ tot, s. S. 27] der Douglasien-Varianten (s. S. 20) auf Versuchsfläche A im Juni und Oktober 2005; MW u. Std.abw.; Buchstaben kennzeichnen je Aufnahmezeitpunkt homogene Gruppen nach U-Tests, Fettdruck markiert signifikanten Unterschied zur Nullvariante (V1) (je Variante $n=4$ )...

Abb. 139: Vitalität [codiert: $4=$ vital bis $0=$ tot, s. S. 27] der Douglasien-Varianten (s. S. 20) auf Versuchsfläche B im Juni 2005, Oktober 2005 und Juni 2006; MW u. Std.abw.; Buchstaben kennzeichnen je Aufnahmezeitpunkt homogene Gruppen nach U-Tests, Fettdruck markiert signifikanten Unterschied zur Nullvariante (V1) (je Variante $n=4$ ).

Abb. 140: Vitalität [codiert: 4 = vital bis $0=$ tot, s. S. 27] der Douglasien-Varianten (s. S. 20) in vegetationsfreien Bereichen im Juni und Oktober 2005; MW u. Std.abw.; Buchstaben kennzeichnen je Aufnahmezeitpunkt homogene Gruppen nach U-Tests, Fettdruck markiert signifikanten Unterschied zur Nullvariante (V1) (n=119).

Abb. 141: Vitalität [codiert: $4=$ vital bis $0=$ tot, s. S. 27] der Douglasien-Varianten (s. S. 20) in bewachsenen Bereichen im Juni und Oktober 2005; MW u. Std.abw.; Buchstaben kennzeichnen je Aufnahmezeitpunkt homogene Gruppen nach U-Tests, Fettdruck markiert signifikanten Unterschied zur Nullvariante (V1) (n=73).

Abb. 142: Vitalität [codiert: $4=$ vital bis $0=$ tot, s. S. 27] der Kiefern im Versuchsverlauf; MW u.

Std.abw. $(\mathrm{n}=120)$.

Abb. 143: Relative Häufigkeit der Vitalitätswerte [codiert: $4=$ vital bis $0=$ tot, s. S. 27] der Kiefern im Versuchsverlauf ( $\mathrm{n}=120)$ 
Abb. 144: Vitalität [codiert: 4 = vital bis $0=$ tot, s. S. 27] der Kiefern-Varianten (s. S. 20) im Juni 2005; MW u. Std.abw.; Buchstaben kennzeichnen homogene Gruppen nach U-Tests; Fettdruck markiert signifikanten Unterschied zur Nullvariante (V1) (je Variante $\mathrm{n}=12$ ).

Abb. 145: Wurzelhalsdurchmesser [mm] der Ahorn-Varianten (s. S. 20) insgesamt; MW u. Std.abw.; Buchstaben kennzeichnen homogene Gruppen nach U-Tests; Fettdruck markiert signifikanten Unterschied zur Nullvariante (V1) (n=123).

Abb. 146: Wurzelhalsdurchmesser [mm] der Ahorn-Varianten (s. S. 20) auf Fläche B; MW u. Std.abw.; Buchstaben kennzeichnen homogene Gruppen nach U-Tests; Fettdruck markiert signifikanten Unterschied zur Nullvariante (V1) (n=44)

Abb. 147: Wurzelhalsdurchmesser [mm] der Ahorn-Varianten (s. S. 20) in Bereichen mit Spontanvegetation; MW u. Std.abw.; Buchstaben kennzeichnen homogene Gruppen nach UTests; Fettdruck markiert signifikanten Unterschied zur Nullvariante (V1) (n=56)

Abb. 148: Zuwachs [cm] des Haupttriebs von Ebereschen-Varianten (s. S. 20) im 2. Vegetationsjahr auf Fläche D; MW u. Std.abw.; Buchstaben kennzeichnen homogene Gruppen nach U-Tests $(\mathrm{n}=18) .$.

Abb. 149: Zuwachs [cm] des Haupttriebs der Douglasien-Varianten (s. S. 20) im 1.

Vegetationsjahr insgesamt; MW u. Std.abw.; Buchstaben kennzeichnen homogene Gruppen nach U-Tests, Fettdruck markiert signifikanten Unterschied zur Nullvariante (V1) (n=117) 218 Abb. 150: Zuwachs [cm] des Haupttriebs der Douglasien-Varianten (s. S. 20) im 1. Vegetationsjahr auf Fläche A; MW u. Std.abw.; Buchstaben kennzeichnen homogene Gruppen nach U-Tests, Fettdruck markiert signifikanten Unterschied zur Nullvariante (V1) (n=48) ....... 219 Abb. 151: Zuwachs [cm] des Haupttriebs der Douglasien-Varianten (s. S. 20) im 1. Vegetationsjahr auf Fläche B; MW u. Std.abw.; Buchstaben kennzeichnen homogene Gruppen nach U-Tests; Fettdruck markiert signifikanten Unterschied zur Nullvariante (V1) (n=60)...... 220 Abb. 152: Zuwachs [cm] des Haupttriebs der Douglasien-Varianten (s. S. 20) im 1. Vegetationsjahr in Bereichen ohne Spontanvegetation; MW u. Std.abw.; Buchstaben kennzeichnen homogene Gruppen nach U-Tests ( $n=96)$

Abb. 153: Zuwachs [cm] des Haupttriebs der Douglasien-Varianten (s. S. 20) im 1.

Vegetationsjahr in Bereichen mit Spontanvegetation; MW u. Std.abw.; Buchstaben kennzeichnen homogene Gruppen nach U-Tests; Fettdruck markiert signifikanten Unterschied zur Nullvariante (V1) $(\mathrm{n}=61)$.

Abb. 154: Trockenmasse der Seitentriebe [g] (links) und Wurzelhalsdurchmesser [mm] (rechts) der geernteten Douglasien-Varianten (s. S. 20); MW u. Std.abw.; Buchstaben kennzeichnen jeweils homogene Gruppen nach U-Tests; Fettdruck markiert signifikanten Unterschied zur reinen Mykorrhiza-Variante V11 $(\mathrm{n}=34)$.

Abb. 155: Zuwachs [cm] des Haupttriebs der Kiefern-Varianten (s. S. 20) im 2. Vegetationsjahr insgesamt (links), auf Versuchsfläche B (Mitte), in Bereichen mit Spontanvegetation (rechts); MW u. Std.abw.; Buchstaben kennzeichnen jeweils homogene Gruppen nach U-Tests ( $n=17) . .225$ Abb. 156: Gesamtzuwachs [cm] des Haupttriebs der Kiefern-Varianten (s. S. 20) insgesamt (links), auf Versuchsfläche B (Mitte), in Bereichen mit Spontanvegetation (rechts); MW u. Std.abw.; Buchstaben kennzeichnen jeweils homogene Gruppen nach U-Tests $(n=17)$................ 225 Abb. 157: Volumen [ $\mathrm{cm}^{3}$ ] (links) und Trockenmasse [g] (rechts) des Haupttriebs der KiefernVarianten (s. S. 20) insgesamt; MW u. Std.abw.; Buchstaben kennzeichnen jeweils homogene Gruppen nach U-Tests ( $\mathrm{n}=17)$.

Abb. 158: Oberirdische Trockenmasse [g] (links), Summe der Trockenmassen der Haupttriebe und Wurzeln (Mitte), Gesamt-Trockenmasse (rechts) der Kiefern-Varianten (s. S. 20) insgesamt; MW u. Std.abw.; Buchstaben kennzeichnen jeweils homogene Gruppen nach U-Tests (n=17).. 226 
Abb. 159: Verhältnis ober-/unterirdische Trockenmasse (links) sowie Verhältnis der Spross/Wurzel-Trockenmassen (rechts) der Kiefern-Varianten (s. S. 20) insgesamt; MW u. Std.abw.; Buchstaben kennzeichnen jeweils homogene Gruppen nach U-Tests $(\mathrm{n}=17)$.

Abb. 160: Vitalität der Eichen [codiert: $4=$ vital bis $0=$ tot, s. S. 27] auf den drei Versuchsflächen A, B und D im Versuchsverlauf; MW u. Std.abw.; Buchstaben kennzeichnen ggf. je Aufnahmezeitpunkt homogene Gruppen nach U-Tests (je Fläche $n=64$ ) ..

Abb. 161: Vitalität der Eichen [codiert: $4=$ vital bis $0=$ tot, s. S. 27] in bewachsenen Bereichen auf den Versuchsflächen B ( $n=43)$ und D ( $n=34)$ im Versuchsverlauf; MW u. Std.abw.; im Juni 2006 signifikante Unterschiede nach U-Tests

Abb. 162: Vitalität der Ahorne [codiert: $4=$ vital bis $0=$ tot, s. S. 27] auf den drei Versuchsflächen A, B und D im Versuchsverlauf; MW u. Std.abw.; Buchstaben kennzeichnen ggf. je Aufnahmezeitpunkt homogene Gruppen nach U-Tests (je Fläche n=64) .

Abb. 163: Vitalität der Ahorne [codiert: $4=$ vital bis $0=$ tot, s. S. 27] in vegetationsfreien Bereichen auf den drei Versuchsflächen A ( $n=64), B(n=21)$ und D ( $n=33)$ im Versuchsverlauf; MW u. Std.abw.; Buchstaben kennzeichnen ggf. je Aufnahmezeitpunkt homogene Gruppen nach U-Tests

Abb. 164: Vitalität der Ebereschen [codiert: $4=$ vital bis $0=$ tot, s. S. 27] auf den drei Versuchsflächen A, B und D im Versuchsverlauf; MW u. Std.abw.; Buchstaben kennzeichnen ggf. je Aufnahmezeitpunkt homogene Gruppen nach U-Tests (je Fläche $n=40$ ).

Abb. 165: Vitalität der Ebereschen [codiert: $4=$ vital bis $0=$ tot, s. S. 27] in vegetationsfreien Bereichen auf den drei Versuchsflächen A ( $n=40), B(n=10)$ und D $(n=26)$ im Versuchsverlauf; MW u. Std.abw.; Buchstaben kennzeichnen ggf. je Aufnahmezeitpunkt homogene Gruppen nach U-Tests

Abb. 166: Vitalität der Ebereschen [codiert: $4=$ vital bis $0=$ tot, s. S. 27] in bewachsenen

Bereichen auf den Versuchsflächen B $(n=30)$ und D ( $n=14)$ im Versuchsverlauf; MW u. Std.abw.; im Oktober 2005 und im Juni 2006 signifikante Unterschiede nach U-Tests

Abb. 167: Vitalität der Erlen [codiert: $4=$ vital bis $0=$ tot, s. S. 27] auf den drei Versuchsflächen A, B und D im Versuchsverlauf; MW u. Std.abw.; Buchstaben kennzeichnen ggf. je Aufnahmezeitpunkt homogene Gruppen nach U-Tests (je Fläche $n=40$ ) .

Abb. 168: Vitalität der Erlen [codiert: $4=$ vital bis $0=$ tot, s. S. 27] in vegetationsfreien Bereichen auf den drei Versuchsflächen A ( $n=40), B(n=8)$ und D ( $n=26)$ im Versuchsverlauf; MW u.

Std.abw.; Buchstaben kennzeichnen ggf. je Aufnahmezeitpunkt homogene Gruppen nach U-Tests

Abb. 169: Vitalität der Erlen [codiert: $4=$ vital bis $0=$ tot, s. S. 27] in bewachsenen Bereichen auf den Versuchsflächen B ( $n=32)$ und D ( $n=14)$ im Versuchsverlauf; MW u. Std.abw.; im Juni 2005 signifikante Unterschiede nach U-Tests

Abb. 170: Vitalität der Douglasien [codiert: $4=$ vital bis $0=$ tot, s. S. 27] auf den drei Versuchsflächen A, B und D im Versuchsverlauf; MW u. Std.abw.; Buchstaben kennzeichnen ggf. je Aufnahmezeitpunkt homogene Gruppen nach U-Tests (je Fläche n=64).

Abb. 171: Vitalität der Douglasien [codiert: $4=$ vital bis $0=$ tot, s. S. 27] in bewachsenen Bereichen auf den Versuchsflächen B $(n=44)$ und D ( $n=29)$ im Versuchsverlauf; MW u. Std.abw.; im Juni und Oktober 2005 signifikante Unterschiede nach U-Tests Abb. 172: Vitalität der Kiefern [codiert: $4=$ vital bis $0=$ tot, s. S. 27] auf den drei Versuchsflächen A, B und D im Versuchsverlauf; MW u. Std.abw.; Buchstaben kennzeichnen ggf. je Aufnahmezeitpunkt homogene Gruppen nach U-Tests (je Fläche $n=40$ )

Abb. 173: Vitalität der Kiefern [codiert: $4=$ vital bis $0=$ tot, s. S. 27] in bewachsenen Bereichen auf den Versuchsflächen B ( $n=33)$ und D $(n=11)$ im Versuchsverlauf; MW u. Std.abw.; im Oktober 2006 signifikante Unterschiede nach U-Tests 
Abb. 174: Zuwachs [cm] des Haupttriebs der Ahorne im 1. Vegetationsjahr insgesamt (links; n=125; A: 13, B: 58, D: 54), in Bereichen ohne (Mitte; n=57; A: 13, B: 18, D: 26) sowie mit (rechts; n=68; B: 40 D: 28) Spontanvegetation getrennt nach Versuchsflächen; MW u. Std.abw.;

Buchstaben kennzeichnen jeweils homogene Gruppen nach U-Tests. 246

Abb. 175: Wurzelhalsdurchmesser [mm] (n=38; B: 25, D: 13), Länge [cm] und Trockenmasse [g] der Seitentriebe, oberirdische Trockenmasse [g] und Verhältnis aus Haupt- und Seitentrieblängen (n=34; B: 23, D: 11) der Ebereschen in Bereichen mit Spontanvegetation getrennt nach Versuchsflächen; MW u. Std.abw.; jeweils signifikante Unterschiede nach U-Tests

Abb. 176: Zuwachs [cm] des Haupttriebs im 1. (links) und 2. Vegetationsjahr (Mitte) sowie Gesamtzuwachs (rechts) der Erlen getrennt nach Versuchsflächen (n=78; A: 20, B: 32, D: 26); MW u. Std.abw.; Buchstaben kennzeichnen jeweils homogene Gruppen nach U-Tests. Abb. 177: Wurzelhalsdurchmesser [mm] (links), Volumen [ $\left.\mathrm{cm}^{3}\right]$ (Mitte) und Trockenmasse [g] (rechts) des Haupttriebs der Erlen getrennt nach Versuchsflächen (n=78; A: 20, B: 32, D: 26); MW u. Std.abw.; Buchstaben kennzeichnen jeweils homogene Gruppen nach U-Tests.

Abb. 178: Länge [cm] (links) und Trockenmasse [g] (rechts) der Seitentriebe der Erlen getrennt nach Versuchsflächen (n=76; A: 20, B: 30, D: 26); MW u. Std.abw.; Buchstaben kennzeichnen jeweils homogene Gruppen nach U-Tests

Abb. 179: Oberirdische Trockenmasse [g] (links) und Verhältnis aus Haupt- und

Seitentrieblängen (rechts) der Erlen getrennt nach Versuchsflächen (n=76; A: 20, B: 30, D: 26);

MW u. Std.abw.; Buchstaben kennzeichnen jeweils homogene Gruppen nach U-Tests.

Abb. 180: Verhältnis der Trockenmassen der Haupt- und Seitentriebe der Erlen in

unbewachsenen Bereichen getrennt nach Versuchsflächen (n=34; A: 20, D: 14); MW u. Std.abw.; signifikante Unterschiede nach U-Test...

Abb. 181: Zuwachs [cm] des Haupttriebs der Douglasien im 1. (links) und 2. Vegetationsjahr (Mitte) sowie Gesamtzuwachs (rechts) getrennt nach Versuchsflächen (n=117; A: 30, B: 49, D:

38); MW u. Std.abw.; Buchstaben kennzeichnen jeweils homogene Gruppen nach U-Tests ....... 253 Abb. 182: Zuwachs [cm] des Haupttriebs im 1. Vegetationsjahr (links; n=68; B: 42, D: 26) und Wurzelhalsdurchmesser [mm] (Mitte) sowie Trockenmasse der Wurzel (rechts; n=64; B: 42, D: 22) der Douglasien in Bereichen mit Spontanvegetation getrennt nach Versuchsflächen; MW u. Std.abw.; jeweils signifikante Unterschiede nach U-Tests 253

Abb. 183: Verhältnis aus ober- und unterirdischer Trockenmasse der geernteten Douglasien getrennt nach Versuchsflächen (n=34; A: 12, B: 11, D: 11); MW u. Std.abw.; Buchstaben kennzeichnen homogene Gruppen nach U-Tests.

Abb. 184: Zuwachs [cm] des Haupttriebs im 1. Vegetationsjahr getrennt nach Versuchsflächen, Kiefern insgesamt (links; n=44; A: 7, B: 25, D: 12) sowie in Bereichen mit Spontanvegetation (Mitte; n=28; B: 22, D: 6); MW u. Std.abw.; Buchstaben kennzeichnen homogene Gruppen nach U-Tests; Verhältnis der Trockenmassen der Haupt- und Seitentriebe getrennt nach Versuchsflächen, Kiefern insgesamt (rechts; n=22; B: 18, D: 4); MW u. Std.abw.; signifikante Unterschiede nach U-Tests.

Abb. 185: Vitalität der Eichen [codiert: $4=$ vital bis $0=$ tot, s. S. 27] in Bereichen ohne ( $n=114)$ und mit ( $n=77$ ) Spontanvegetation im Versuchsverlauf; MW u. Std.abw.; zu jedem Aufnahmezeitpunkt signifikante Unterschiede nach U-Tests

Abb. 186: Vitalität der Eichen [codiert: $4=$ vital bis $0=$ tot, s. S. 27] auf Fläche B (links; $n=20 / 43$ ) sowie Fläche D (rechts; $n=30 / 34$ ) in Bereichen ohne und mit Spontanvegetation im Versuchsverlauf; MW u. Std.abw.; auf Fläche B zu jedem Aufnahmezeitpunkt, auf Fläche D im Oktober 2005 und Juni 2006 signifikante Unterschiede nach U-Tests.. 
Abb. 187: Vitalität der Ahorne [codiert: $4=$ vital bis $0=$ tot, s. S. 27] in Bereichen ohne $(n=118)$ und mit (n=74) Spontanvegetation im Versuchsverlauf; MW u. Std.abw.; zu jedem Aufnahmezeitpunkt signifikante Unterschiede nach U-Tests.

Abb. 188: Vitalität der Ahorne [codiert: $4=$ vital bis $0=$ tot, s. S. 27] auf Fläche D in Bereichen ohne $(n=33)$ und mit ( $n=31)$ Spontanvegetation im Versuchsverlauf; MW u. Std.abw.; außer im Oktober 2006 zu jedem Aufnahmezeitpunkt signifikante Unterschiede nach U-Tests

Abb. 189: Vitalität der Ebereschen [codiert: $4=$ vital bis $0=$ tot, s. S. 27] in Bereichen ohne $(n=76)$ und mit $(n=44)$ Spontanvegetation im Versuchsverlauf; MW u. Std.abw.; zu jedem Aufnahmezeitpunkt signifikante Unterschiede nach U-Tests

Abb. 190: Vitalität der Ebereschen [codiert: $4=$ vital bis $0=$ tot, s. S. 27] auf Fläche B (links; $n=10 / 30$ ) sowie Fläche D (rechts; $n=26 / 14$ ) in Bereichen ohne und mit Spontanvegetation im Versuchsverlauf; MW u. Std.abw.; außer auf Fläche B im Juni 2006 zu jedem Aufnahmezeitpunkt signifikante Unterschiede nach U-Tests.

Abb. 191: Vitalität der Erlen [codiert: $4=$ vital bis $0=$ tot, s. S. 27] in Bereichen ohne (n=74) und mit $(n=46)$ Spontanvegetation im Versuchsverlauf; MW u. Std.abw.; zu jedem

Aufnahmezeitpunkt signifikante Unterschiede nach U-Tests.

Abb. 192: Vitalität der Erlen [codiert: $4=$ vital bis $0=$ tot, s. S. 27] auf Fläche B (links; n=8/32) sowie Fläche D (rechts; n=26/14) in Bereichen ohne und mit Spontanvegetation im Versuchsverlauf; MW u. Std.abw.; zu jedem Aufnahmezeitpunkt signifikante Unterschiede nach U-Tests

Abb. 193: Vitalität der Douglasien [codiert: $4=$ vital bis $0=$ tot, s. S. 27] in Bereichen ohne $(n=119)$ und mit $(n=73)$ Spontanvegetation im Versuchsverlauf; MW u. Std.abw.; zu jedem Aufnahmezeitpunkt signifikante Unterschiede nach U-Tests...

Abb. 194: Vitalität der Douglasien [codiert: $4=$ vital bis $0=$ tot, s. S. 27] auf Fläche B (links; $\mathrm{n}=20 / 44$ ) sowie Fläche D (rechts; $\mathrm{n}=35 / 29$ ) in Bereichen ohne und mit Spontanvegetation im Versuchsverlauf; MW u. Std.abw.; außer auf Fläche D im Juni 2005 zu jedem Aufnahmezeitpunkt signifikante Unterschiede nach U-Tests.

Abb. 195: Vitalität der Kiefern [codiert: $4=$ vital bis $0=$ tot, s. S. 27] in Bereichen ohne $(n=76)$ und mit (n=44) Spontanvegetation im Versuchsverlauf; MW u. Std.abw.; zu jedem Aufnahmezeitpunkt signifikante Unterschiede nach U-Tests.

Abb. 196: Vitalität der Kiefern [codiert: 4 = vital bis 0 = tot, s. S. 27] auf Fläche B (links; n=7/33) sowie Fläche D (rechts; n=29/11) in Bereichen ohne und mit Spontanvegetation im Versuchsverlauf; MW u. Std.abw.; auf Fläche B ab Oktober 2005, auf Fläche D nur im Juni 2005 signifikante Unterschiede nach U-Tests.

Abb. 197: Wurzelhalsdurchmesser [mm] der Ahorne insgesamt (links; $n=31 / 56$ ) sowie auf Fläche B (rechts; $n=13 / 38$ ) getrennt nach Standorten in Bereichen ohne und mit Spontanvegetation; MW u. Std.abw.; jeweils signifikante Unterschiede nach U-Tests

Abb. 198: Volumen $\left[\mathrm{cm}^{3}\right.$ ] (links) sowie Trockenmasse [g] (rechts) des Haupttriebs der Ahorne insgesamt getrennt nach Standorten in Bereichen ohne $(n=31)$ und mit $(n=56)$

Spontanvegetation; MW u. Std.abw.; jeweils signifikante Unterschiede nach U-Tests

Abb. 199: Trockenmasse [g] von Haupttrieb und Wurzel der geernteten Ahorne getrennt nach Standorten in Bereichen ohne ( $\mathrm{n}=11)$ und mit $(\mathrm{n}=12)$ Spontanvegetation; MW u. Std.abw.; signifikante Unterschiede nach U-Test...

Abb. 200: Zuwachs [cm] des Haupttriebs im 1. Vegetationsjahr, Ebereschen insgesamt (links; $\mathrm{n}=56 / 44$ ) sowie auf Fläche D (rechts; $\mathrm{n}=24 / 14$ ) getrennt nach Standorten in Bereichen ohne und mit Spontanvegetation; MW u. Std.abw.; jeweils signifikante Unterschiede nach U-Tests ..276 
Abb. 201: Seitentrieblängen [cm] der Ebereschen insgesamt (links; n=17/34) sowie auf Fläche D (rechts; $n=10 / 11$ ) getrennt nach Standorten in Bereichen ohne und mit Spontanvegetation; MW u. Std.abw.; jeweils signifikante Unterschiede nach U-Tests .

Abb. 202: Trockenmassen [g] der Seitentriebe der Ebereschen insgesamt (links; $n=17 / 34$ ) sowie auf Fläche D (rechts; n=10/11) getrennt nach Standorten in Bereichen ohne und mit Spontanvegetation; MW u. Std.abw.; jeweils signifikante Unterschiede nach U-Tests. 277

Abb. 203: Verhältnis der Haupt- und Seitentrieblängen der Ebereschen insgesamt (links; $\mathrm{n}=17 / 34$ ) sowie auf Fläche D (rechts; $\mathrm{n}=10 / 11$ ) getrennt nach Standorten in Bereichen ohne und mit Spontanvegetation; MW u. Std.abw.; jeweils signifikante Unterschiede nach U-Tests.. 278 Abb. 204: Verhältnis der Trockenmassen der Haupt- und Seitentriebe der Ebereschen insgesamt (links; $n=17 / 34$ ) sowie auf Fläche D (rechts; n=10/11) getrennt nach Standorten in Bereichen ohne und mit Spontanvegetation; MW u. Std.abw.; jeweils signifikante Unterschiede nach UTests.

Abb. 205: Zuwachs [cm] des Haupttriebs im 1. Vegetationsjahr, Erlen insgesamt (links; n=37/41), auf Fläche B (Mitte; $n=8 / 32$ ) sowie auf Fläche D (rechts; n=25/14) getrennt nach Standorten in Bereichen ohne und mit Spontanvegetation; MW u. Std.abw.; jeweils signifikante Unterschiede nach U-Tests.

Abb. 206: Zuwachs [cm] des Haupttriebs im 2. Vegetationsjahr, Erlen insgesamt (links; $n=37 / 41$ ), auf Fläche B (Mitte; $n=3 / 29$ ) sowie auf Fläche D (rechts; $n=14 / 12$ ) getrennt nach Standorten in Bereichen ohne und mit Spontanvegetation; MW u. Std.abw.; jeweils signifikante Unterschiede nach U-Tests.

Abb. 207: Gesamtzuwachs [cm] des Haupttriebs, Erlen insgesamt (links; n=37/41), auf Fläche B (Mitte; n= 3/29) sowie auf Fläche D (rechts; n=14/12) getrennt nach Standorten in Bereichen ohne und mit Spontanvegetation; MW u. Std.abw.; jeweils signifikante Unterschiede nach UTests.

Abb. 208: Wurzelhalsdurchmesser [mm] der Erlen insgesamt (links; $n=37 / 41$ ) sowie auf Fläche B (rechts; $n=3 / 29$ ) getrennt nach Standorten in Bereichen ohne und mit Spontanvegetation; MW u. Std.abw.; jeweils signifikante Unterschiede nach U-Tests ..

Abb. 209: Volumen $\left[\mathrm{cm}^{3}\right]$ des Haupttriebs der Erlen insgesamt (links; $\mathrm{n}=37 / 41$ ) sowie auf Fläche B (rechts; $n=3 / 29$ ) getrennt nach Standorten in Bereichen ohne und mit Spontanvegetation; MW u. Std.abw.; jeweils signifikante Unterschiede nach U-Tests

Abb. 210: Trockenmasse [g] des Haupttriebs der Erlen insgesamt (links; $n=37 / 41$ ) sowie auf Fläche B (rechts; $n=3 / 29$ ) getrennt nach Standorten in Bereichen ohne und mit Spontanvegetation; MW u. Std.abw.; jeweils signifikante Unterschiede nach U-Tests. 282 Abb. 211: Seitentrieblängen [cm] der Erlen insgesamt (links; n=36/40) sowie auf Fläche D (rechts; $n=12 / 14$ ) getrennt nach Standorten in Bereichen ohne und mit Spontanvegetation; MW u. Std.abw.; jeweils signifikante Unterschiede nach U-Tests . 283

Abb. 212: Trockenmassen [g] der Seitentriebe der Erlen insgesamt (links; $n=36 / 40$ ) sowie auf Fläche D (rechts; $n=12 / 14$ ) getrennt nach Standorten in Bereichen ohne und mit Spontanvegetation; MW u. Std.abw.; jeweils signifikante Unterschiede nach U-Tests. 283 Abb. 213: Verhältnis der Haupt- und Seitentrieblängen (links) sowie oberirdische Trockenmasse [g] (rechts) der Erlen insgesamt (n=78; 37/41) getrennt nach Standorten in Bereichen ohne und mit Spontanvegetation; MW u. Std.abw.; jeweils signifikante Unterschiede nach U-Tests. 284 Abb. 214: Zuwachs [cm] des Haupttriebs der Douglasien im 1. (links) und 2. Vegetationsjahr (Mitte) sowie Gesamtzuwachs (rechts) getrennt nach Standorten in Bereichen ohne $(n=55)$ und mit ( $n=62)$ Spontanvegetation; MW u. Std.abw.; jeweils signifikante Unterschiede nach U-Tests 
Abb. 215: Zuwachs [cm] des Haupttriebs der Douglasien auf Versuchsfläche B im 1. (links) und 2. Vegetationsjahr (Mitte) sowie Gesamtzuwachs (rechts) getrennt nach Standorten in Bereichen ohne $(n=9)$ und mit $(n=40)$ Spontanvegetation; MW u. Std.abw.; jeweils signifikante

Unterschiede nach U-Tests 286

Abb. 216: Zuwachs [cm] des Haupttriebs der Kiefern im 1. (links) und 2. Vegetationsjahr (Mitte) sowie Gesamtzuwachs (rechts) getrennt nach Standorten in Bereichen ohne $(n=5)$ und mit ( $\mathrm{n}=19$ ) Spontanvegetation; MW u. Std.abw.; jeweils signifikante Unterschiede nach U-Tests....287 Abb. 217: Zuwachs [cm] des Haupttriebs im 1. Vegetationsjahr, Kiefern auf Fläche B (links; $\mathrm{n}=3 / 22$ ) sowie auf Fläche D (rechts; $n=6 / 6$ ) getrennt nach Standorten in Bereichen ohne und mit Spontanvegetation; MW u. Std.abw.; jeweils signifikante Unterschiede nach U-Tests 288 Abb. 218: Wurzelwerke zweier Ahorne im Topf-Versuch. Links Behandlungsvariante ohne, rechts Behandlungsvariante mit Kalk-Düngung (oben: Seitenansicht, Mitte: Draufsicht, unten: schematische Schnittzeichnung)

Abb. 219: Vitalität [codiert: $4=$ vital bis $0=$ tot, s. S. 27] der sechs Baumarten auf den drei Versuchsflächen (A, B, D) nach 2 Vegetationsjahren; MW u. Std.abw; Buchstaben kennzeichnen je Baumart homogene Gruppen nach U-Tests

Abb. 220: Vitalität [codiert: $4=$ vital bis $0=$ tot, s. S. 27] der sechs Baumarten auf Standorten mit und ohne Spontanvegetation nach 2 Vegetationsjahren; MW u. Std.abw; jeweils signifikante Unterschiede nach U-Tests 


\section{Im Anhang}

Abb. A 1: Relative Veränderung der Gehalte schädigend wirkender Elemente (Ab-/Zunahme der Schadstoffbelastung insgesamt) sowie der Nährstoff-Gehalte (Verbesserung/Verschlechterung der Ernährung) in den Behandlungsvarianten (s. S. 20) in Bezug auf die Kontrolle (V1) der Eichen. ...XVI

Abb. A 2: Relative $\mathrm{Fe}_{t^{-}}, \mathrm{Al}_{t^{-}}, \mathrm{Cu}_{\mathrm{t}^{-}}$-Gehalte [\%; 100\% entspricht dem jeweiligen Element-Gehalt in der unbehandelten Kontrolle $=$ Variante 1] im Ahorn-Laub (Mischproben) verschiedener Varianten (s. S. 20) auf Fläche D (fehlende Variante V5 zum Zeitpunkt der Probennahme im August 2006 ausgefallen) XVIII Abb. A 3: Relative Veränderung der Gehalte schädigend wirkender Elemente (Ab-/Zunahme der Schadstoffbelastung insgesamt) sowie der Nährstoff-Gehalte (Verbesserung/Verschlechterung der Ernährung) in den Behandlungsvarianten (s. S. 20) in Bezug auf die Kontrolle (V1) der Ahorne .. $\mathrm{XX}$ Abb. A 4: Relative Veränderung der Gehalte schädigend wirkender Elemente (Ab-/Zunahme der Schadstoffbelastung insgesamt) sowie der Nährstoff-Gehalte (Verbesserung/Verschlechterung der Ernährung) in den Behandlungsvarianten (s. S. 20) in Bezug auf die Kontrolle (V1) der Ebereschen XXIII Abb. A 5: Relative Veränderung der Gehalte schädigend wirkender Elemente (Ab-/Zunahme der Schadstoffbelastung insgesamt) sowie der Nährstoff-Gehalte (Verbesserung/Verschlechterung der Ernährung) in den Behandlungsvarianten (s. S. 20) in Bezug auf die Kontrolle (V1) der Erlen XXVI Abb. A 6: Relative Veränderung der Gehalte schädigend wirkender Elemente (Ab-/Zunahme der Schadstoffbelastung insgesamt) sowie der Nährstoff-Gehalte (Verbesserung/Verschlechterung der Ernährung) in den Behandlungsvarianten (s. S. 20) in Bezug auf die Kontrolle (V1) der Douglasien. XXIX Abb. A 7: Rot-Eichen (z.T. mit Herbstfärbung) auf den Ronneburger Freiland-Versuchsflächen mit Vitalitätsbewertungsstufe „2“ (links), „3“ (Mitte) und „4“ (rechts) (s. S. 27). XXXII Abb. A 8: Spitz-Ahorne (z.T. mit Herbstfärbung) auf den Ronneburger Freiland-Versuchsflächen mit Vitalitätsbewertungsstufe „2“ (links), „3“ (Mitte) und „4“ (rechts) (s. S. 27) XXXII Abb. A 9: Ebereschen (z.T. mit Herbstfärbung) auf den Ronneburger Freiland-Versuchsflächen mit Vitalitätsbewertungsstufe „2“ (links), „3“ (Mitte) und „4“ (rechts) (s. S. 27) XXXII Abb. A 10: Schwarz-Erlen auf den Ronneburger Freiland-Versuchsflächen mit Vitalitätsbewertungsstufe „2“ (links), „3“ (Mitte) und „4“ (rechts) (s. S. 27) XXXIII Abb. A 11: Douglasien auf den Ronneburger Freiland-Versuchsflächen mit Vitalitätsbewertungsstufe „2“ (links), „3“ (Mitte) und „4“ (rechts) (s. S. 27) XXXIII Abb. A 12: Wald-Kiefern auf den Ronneburger Freiland-Versuchsflächen mit Vitalitätsbewertungsstufe „2“ (links), „3“ (Mitte) und „4“ (rechts) (s. S. 27) XXXIII 


\section{Tabellenverzeichnis}

Tab. 1: Kennwerte zu Geologie, Böden und Wasserhaushalt im Naturraum Ronneburger Ackerund Bergbaugebiet (Hiekel et al. 2004).

Tab. 2: Klimacharakteristische Merkmale des Klimabereichs „Südostdeutsche Becken und Hügel“ (UBA 2005), des Klimabezirks „Thüringisch-Sächsisches Mittelgebirgsvorland“ (Hiekel et al. 2004) sowie langfristige Klimawerte der DWD-Messstation Flughafen Gera-Leumitz (19611990; Niederschlag: 1961-1990 u. 1971-2000)

Tab. 3: Durchschnittstemperatur $\left[{ }^{\circ} \mathrm{C}\right]$ und Niederschlagssumme $[\mathrm{mm}]$ im langjährigen Mittel (DWD-Wetterstation Gera-Leumitz) u. während des Versuchszeitraumes (Wismut-Wetterstation Ronneburg)

Tab. 4: Im Freiland-Versuch eingesetzte Baumarten, Herkünfte (o.A. = ohne Angabe), Sortimente (Alter / Form (ohne Ballen) / Haupttrieblängen [cm], in Klammern: tatsächlich gemessene Haupttrieblängen), Anzahlen; botanische/deutsche Artnamen: Rothmaler 1994 ............................ 18

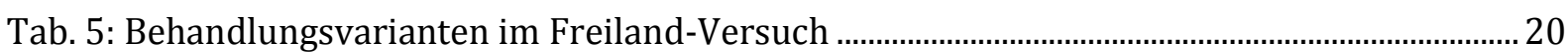

Tab. 6: Im Untersuchungsgebiet täglich erhobene meteorologische Parameter ................................. 22

Tab. 7: Einteilung der Porengrößenbereiche nach dem Äquivalentdurchmesser und der Wasserspannung [pF] als Grenzwert zur Entwässerung kreiskapillarer Poren (aus: Scheffer \& Schachtschabel 2010, verändert)

Tab. 8: Methoden der chemischen Analyse verschiedener Parameter in den Boden- und Pflanzenproben beider Aufnahmejahre (2005 und 2006) 26

Tab. 9: Im Gewächshaus-Versuch eingesetzte Baumarten, Herkünfte (o.A. = ohne Angabe), Sortimente (Alter / Form (ohne Ballen) / Haupttrieblängen [cm], in Klammern: tatsächlich gemessene Haupttrieblängen), Anzahlen; botanische/deutsche Artnamen: Rothmaler 1994...... 31 Tab. 10: Anteile [\%] der Fraktionen Ton, Fein- u. Mittelschluff (f+mU), Grobschluff (gU), Fein-, Mittel- u. Grobsand (fS, mS, gS) sowie Bodenartenuntergruppen im Freiland-Versuch, gesamt sowie getrennt nach Versuchsflächen und Bereichen o./m. Spontanvegetation; MW u. Std.abw.39 Tab. 11: Gesamtporenvolumina (GPV) und Porengrößenverteilung [Vol.-\%] im Haldenboden in zwei Tiefenstufen; MW u. Std.abw.; Ergebnisse von U-Tests (Z) auf signifikante Unterschiede $(\mathrm{n}=12)$

Tab. 12: Gesamtporenvolumina (GPV), Luftkapazität (LK = weite Grobporen), Feldkapazität (FK = GPV - LK), nutzbare Feldkapazität ( $\mathrm{nFK}$ = enge Grobporen + Mittelporen) sowie Totwasser (= FK - nFK = Feinporen] [Vol.-\%] im Haldenboden in zwei Tiefenstufen; MW u. Std.abw.; Ergebnisse von U-Tests $(\mathrm{Z})$ auf signifikante Unterschiede $(\mathrm{n}=12)$

Tab. 13: Kennwerte des Wasser- und Lufthaushaltes des Haldenbodens und Bewertung nach Bodenkundlicher Kartieranleitung (2005).

Tab. 14: Bodenreaktion (pH-Wert in KCl-Lsg.) in der oberen Schicht des Haldenbodens in zwei Tiefenstufen, gesamt sowie getrennt nach Bereichen o./m. Spontanvegetation; MW u. Std.abw.; Ergebnisse von $\mathrm{t}$-Tests ( $\mathrm{T})$ auf signifikante Unterschiede $(\mathrm{n}=12)$.

Tab. 15: Schwermetall-Gehalte [mg/kg] in der oberen Schicht des Haldenbodens, gesamt sowie getrennt nach Versuchsflächen; MW u. Std.abw.; Ergebnisse von H-Tests [H] auf signifikante Unterschiede; Buchstaben kennzeichnen je Zeile homogene Gruppen nach U-Tests $(n=12) \ldots . . . . .45$ Tab. 16: Kohlenstoff-, Stickstoff- und Phosphor-Gehalte [mg/g], C/N- und C/P-Verhältnisse in der oberen Schicht des Haldenbodens, gesamt sowie getrennt nach Versuchsflächen; MW u. Std.abw.; Ergebnisse von Varianzanalysen auf signifikante Unterschiede (F); Buchstaben kennzeichnen je Zeile homogene Gruppen nach Tukey-Tests $(n=12)$ 
Tab. 17: Nährelement-Gehalte in der oberen Schicht des Haldenbodens, gesamt sowie getrennt nach Versuchsflächen; MW u. Std.abw.; Ergebnisse von H-Tests [H] auf signifikante Unterschiede; Buchstaben kennzeichnen je Zeile homogene Gruppen nach U-Tests $(n=12)$

Tab. 18: Effektive Kationen-Austauschkapazität [mmol(+)/kg] in der oberen Schicht des Haldenbodens, gesamt sowie getrennt nach Versuchsflächen; MW u. Std.abw.; Ergebnis der Varianzanalyse auf signifikante Unterschiede (F); Buchstaben kennzeichnen homogene Gruppen nach Tukey-Test $(\mathrm{n}=12)$

Tab. 19: Austauscherbelegung, Basen-Sättigung (BS), Erdalkali-Sättigung (ES) sowie Summe der Protonen- u. Eisen-Sättigungen [\% der $\mathrm{AK}_{\mathrm{e}}$ ] in der oberen Schicht des Haldenbodens, gesamt sowie getrennt nach Bereichen o./m. Spontanvegetation; MW u. Std.abw.; Ergebnisse von UTests (Z) auf signifikante Unterschiede $(\mathrm{n}=12)$.

Tab. 20: Austauscherbelegung, Basen-Sättigung (BS), Erdalkali-Sättigung (ES) sowie Summe der Protonen- u. Eisen-Sättigungen [\% der $\mathrm{AK}_{\mathrm{e}}$ ] in der oberen Schicht des Haldenbodens, gesamt sowie getrennt nach Versuchsflächen; MW u. Std.abw.; Ergebnisse von H-Tests [H] auf signifikante Unterschiede; Buchstaben kennzeichnen je Zeile homogene Gruppen nach U-Tests $(\mathrm{n}=12)$

Tab. 21: Bewertung (= Elastizität gegenüber Säurebelastung) der relativen Austauscherbelegung bezogen auf die $\mathrm{AK}_{\mathrm{e}}$ im Haldenboden nach $\mathrm{AK}$ Standortskartierung (2003), gesamt sowie getrennt nach Bereichen o./m. Spontanvegetation; Fettdruck markiert signifikante Unterschiede $(\mathrm{n}=12)$

Tab. 22: Bewertung (= Elastizität gegenüber Säurebelastung) der relativen Austauscherbelegung bezogen auf die $\mathrm{AK}_{\mathrm{e}}$ im Haldenboden nach $\mathrm{AK}$ Standortskartierung (2003), gesamt sowie getrennt nach Versuchsflächen; Fettdruck markiert signifikante Unterschiede $(n=12)$...

Tab. 23: Kleinräumiger Standorteinfluss auf die bodenchemischen Eigenschaften des Ronneburger Haldensubstrats

Tab. 24: Trockenraumdichten (TRD) [g/ $\mathrm{cm}^{3}$ ], Gesamtporenvolumina (GPV) [Vol.-\%] u. volumetrischer Wassergehalt (Vol. WG) [\%] im Freiland-Versuch $u$. in verschiedenen Varianten im Topf-Versuch nach 3 Jahren; MW u. Std.abw.; Ergebnisse von H-Tests [H] auf signifikante Unterschiede; Buchstaben kennzeichnen je Spalte homogene Gruppen nach U-Tests.. . .55 Tab. 25: Bodenreaktion (pH-Wert in KCl-Lsg.) im Freiland-Versuch u. in verschiedenen Varianten im Topf-Versuch nach 3 Jahren; MW u. Std.abw.; Ergebnis des H-Tests auf signifikante Unterschiede; Buchstaben kennzeichnen homogene Gruppen nach U-Tests. .58

Tab. 26: Schwefel-Bodengehalt [mg/g] im Freiland-Versuch u. im Topf-Versuch in der Null-, Kalk- u. Kompost-Variante nach 3 Jahren; MW u. Std.abw.; Ergebnis des H-Tests auf signifikante Unterschiede; Buchstaben kennzeichnen homogene Gruppen nach U-Tests.

Tab. 27: Schwermetall-Bodengehalte [mg/kg] im Freiland-Versuch u. im Topf-Versuch in der Null-, Kalk- u. Kompost-Variante nach 3 Jahren; MW u. Std.abw.; Ergebnisse von H-Tests [H] auf signifikante Unterschiede; Buchstaben kennzeichnen je Zeile homogene Gruppen nach U-Tests; Fettdruck markiert signifikante Unterschiede gegenüber der Kontrolle im Topf-Versuch. .60 Tab. 28: Kohlenstoff-, Stickstoff-Bodengehalte [mg/g] u. C/N-Verhältnisse im Freiland-Versuch u. im Topf-Versuch in der Null-, Kalk- u. Kompost-Variante nach 3 Jahren; MW u. Std.abw.; Ergebnisse von H-Tests [H] auf signifikante Unterschiede; Buchstaben kennzeichnen je Spalte homogene Gruppen nach U-Tests; Fettdruck markiert signifikante Unterschiede gegenüber der Kontrolle im Topf-Versuch

Tab. 29: Phosphor-Bodengehalte [mg/g] u. C/P-Verhältnisse im Freiland-Versuch u. im TopfVersuch in der Null-, Kalk- u. Kompost-Variante nach 3 Jahren; MW u. Std.abw.; Ergebnisse von $\mathrm{H}$-Tests $[\mathrm{H}]$ auf signifikante Unterschiede; Buchstaben kennzeichnen je Spalte homogene 
Gruppen nach U-Tests; Fettdruck markiert signifikante Unterschiede gegenüber der Kontrolle im Topf-Versuch

Tab. 30: Nährelement-Bodengehalte [mg/g] im Freiland-Versuch u. im Topf-Versuch in der Null-, Kalk- u. Kompost-Variante nach 3 Jahren; MW u. Std.abw.; Ergebnisse von H-Tests [H] auf signifikante Unterschiede; Buchstaben kennzeichnen je Zeile homogene Gruppen nach U-Tests; Fettdruck markiert signifikante Unterschiede gegenüber der Kontrolle im Topf-Versuch 63

Tab. 31: Effektive Kationen-Austauschkapazität [mmol(+)/kg] im Freiland-Versuch u. im TopfVersuch in der Null-, Kalk- u. Kompost-Variante nach 3 Jahren; MW u. Std.abw.; Ergebnisse von $\mathrm{H}$-Tests $[\mathrm{H}]$ auf signifikante Unterschiede; Buchstaben kennzeichnen homogene Gruppen nach U-Tests; Bewertung nach AK Standortskartierung 2003 (Werte für B/C-Horizonte).

Tab. 32: Austauscherbelegung, Basen-Sättigung (BS), Erdalkali-Sättigung (ES) sowie Summe der Protonen- und Eisen-Sättigungen [\% der $\mathrm{AK}_{\mathrm{e}}$ ] im Freiland-Versuch u. im Topf-Versuch in der Null-, Kalk- u. Kompost-Variante nach 3 Jahren; MW u. Std.abw.; Ergebnisse von H-Tests [H] auf signifikante Unterschiede; Buchstaben kennzeichnen je Zeile homogene Gruppen nach U-Tests; Fettdruck markiert signifikante Unterschiede gegenüber der Kontrolle im Topf-Versuch.

Tab. 33: Bewertung (= Elastizität gegenüber Säurebelastung) der relativen Austauscherbelegung bezogen auf die $\mathrm{AK}_{\mathrm{e}}$ im Freiland-Versuch u. im Topf-Versuch in der Null-, Kalk- u. KompostVariante nach AK Standortskartierung (2003) und *BMELF 1997b; Fettdruck markiert signifikante Unterschiede gegenüber der Kontrolle im Topf-Versuch.

Tab. 34: Haupttrieblänge [cm] u. Vitalität [codiert: 4 = vital - 0 = tot; s. S. 27] der Bäume im Freiland-Versuch; MW u. Std.abw.; Ausgangszustand bei Versuchsanlage im April 2005 (n=936)

Tab. 35: Anzahl und Anteil [\%] der Versuchsbäume in Bereichen o./m. Spontanvegetation sowie Sterblichkeitsraten im Versuchsverlauf $(n=936)$.

Tab. 36: Standortabhängigkeit der Sterblichkeitsrate der Baumarten; Ergebnisse von Kreuztabellen ( $\mathrm{n}=936)$

Tab. 37: Vitalität der lebenden Bäume bei Versuchsabschluss [codiert: $4=$ vital - 0 = tot; s. S. 27]; insgesamt sowie getrennt nach Standorten in Bereichen $0 . / \mathrm{m}$. Spontanvegetation; MW u. Std.abw.; Ergebnisse der H- bzw. U-Tests auf signifikante Unterschiede (H bzw. Z); Buchstaben kennzeichnen je Spalte homogene Gruppen nach U-Tests.

Tab. 38: Anteil [\%] der durch Wild geschädigten Versuchsbäume.

Tab. 39: Beziehungen zwischen Länge des Haupttriebs (x) in cm und Trockenmasse des Haupttriebs (y) in g (Regressionsgleichungen und Bestimmtheitsmaße) für die beprobten Baumarten bei unbeeinflusster sowie durch den Nullpunkt gezwungener Trendlinie

Tab. 40: Beziehungen zwischen Volumen des Haupttriebs (y) in $\mathrm{cm}^{3}$ und Trockenmasse des Haupttriebs ( $\mathrm{x}$ ) in $\mathrm{g}$ (Regressionsgleichungen und Bestimmtheitsmaße) für die beprobten Baumarten bei unbeeinflusster sowie durch den Nullpunkt gezwungener Trendlinie

Tab. 41: Beziehungen zwischen Länge der Seitentriebe $(\mathrm{x})$ in $\mathrm{cm}^{3}$ und Trockenmasse der Seitentriebe (y) in g (Regressionsgleichungen und Bestimmtheitsmaße) für die beprobten Baumarten bei unbeeinflusster sowie durch den Nullpunkt gezwungener Trendlinie

Tab. 42: Beziehungen zwischen Durchmesser des Wurzelhalses ( $\mathrm{x}$ ) in $\mathrm{cm}^{3}$ und Trockenmasse der Wurzel (y) in g (Regressionsgleichungen und Bestimmtheitsmaße) für die beprobten Baumarten bei unbeeinflusster sowie durch den Nullpunkt gezwungener Trendlinie.

Tab. 43: Makronährstoff-Gehalte im Laub unbehandelter Eichen im Freiland-Versuch (Fläche D) im 2. Untersuchungsjahr (Mischproben), Einstufung durch verschiedene Autoren. Tab. 44: Makronährstoff-Gehalte im Laub unbehandelter Ahorne im Freiland-Versuch (Fläche D) im 2. Untersuchungsjahr (Mischproben), Einstufung durch verschiedene Autoren 
Tab. 45: Makronährstoff-Gehalte im Laub unbehandelter Ebereschen im Freiland-Versuch (Fläche D) im 2. Untersuchungsjahr (Mischproben), Einstufung durch verschiedene Autoren....84 Tab. 46: Makronährstoff-Gehalte im Laub unbehandelter Erlen im Freiland-Versuch (Fläche D) im 2. Untersuchungsjahr (Mischproben), Einstufung durch verschiedene Autoren .. .84 Tab. 47: Makronährstoff-Gehalte in den Nadeln unbehandelter Douglasien im Freiland-Versuch (Fläche D) im 2. Untersuchungsjahr (Mischproben), Einstufung durch verschiedene Autoren....85 Tab. 48: Makronährstoff-Gehalte in den Nadeln unbehandelter Kiefern im Freiland-Versuch (Fläche D) im 2. Untersuchungsjahr (Mischproben), Einstufung durch verschiedene Autoren....86 Tab. 49: Mikronährstoff-Gehalte im Laub unbehandelter Eichen im Freiland-Versuch (Fläche D) im 2. Untersuchungsjahr (Mischproben), Einstufung durch verschiedene Autoren . . .88 Tab. 50: Mikronährstoff-Gehalte im Laub unbehandelter Ahorne im Freiland-Versuch (Fläche D) im 2. Untersuchungsjahr (Mischproben), Einstufung durch verschiedene Autoren .. .88

Tab. 51: Mikronährstoff-Gehalte im Laub unbehandelter Ebereschen im Freiland-Versuch (Fläche D) im 2. Untersuchungsjahr (Mischproben), Einstufung durch verschiedene Autoren....89 Tab. 52: Mikronährstoff-Gehalte im Laub unbehandelter Erlen im Freiland-Versuch (Fläche D) im 2. Untersuchungsjahr (Mischproben), Einstufung durch verschiedene Autoren .. .89

Tab. 53: Mikronährstoff-Gehalte in den Nadeln unbehandelter Douglasien im Freiland-Versuch (Fläche D) im 2. Untersuchungsjahr (Mischproben), Einstufung durch verschiedene Autoren....90 Tab. 54: Mikronährstoff-Gehalte in den Nadeln unbehandelter Kiefern im Freiland-Versuch (Fläche D) im 2. Untersuchungsjahr (Mischproben), Einstufung durch verschiedene Autoren....91 Tab. 55: Gehalte potentiell nützlicher Elemente (Al, Ni, Na, Co) [mg/kg Trockenmasse] in den Assimilationsorganen der Nullvariante der sechs Baumarten im Freiland-Versuch (Fläche D) im

2. Untersuchungsjahr (Mischproben)

Tab. 56: Gehalte an Schwermetallen ohne Nährelementfunktion ( $\mathrm{Pb}, \mathrm{Cd}, \mathrm{Cr}$ ) [mg/kg

Trockenmasse] in den Assimilationsorganen der Nullvariante der sechs Baumarten im FreilandVersuch (Fläche D) im 2. Untersuchungsjahr (Mischproben)

Tab. 57: Vitalität der Kontrollen [codiert: 4 = vital - 0 = tot; s. S. 27] im Versuchsverlauf; MW u. Std.abw.; Ergebnisse von H-Tests (H) auf signifikante Unterschiede zwischen den Baumarten (Buchstaben kennzeichnen je Spalte homogene Gruppen nach U-Tests); Ergebnisse der Friedmann-Tests $\left(\mathrm{Chi}^{2}\right)$ auf signifikante Unterschiede zwischen den Aufnahmezeitpunkten; kursiver Fettdruck markiert signifikant geringere Mittelwerte als im Gesamtdurchschnitt der jeweiligen Baumart.

Tab. 58: Vitalität [codiert: $4=$ vital bis $0=$ tot, s. S. 27] der Eichen im Versuchsverlauf; MW u. Std.abw.; Ergebnis des Friedmann-Tests $\left(\mathrm{Chi}^{2}\right)$ auf signifikante Unterschiede zwischen den Aufnahmezeitpunkten ( $\mathrm{n}=192)$.

Tab. 59: Vitalität [codiert: 4 = vital bis $0=$ tot, s. S. 27] der Eichen-Varianten (s. S. 20) im Versuchsverlauf; MW u. Std.abw.; je Aufnahmezeitpunkt Ergebnisse von H-Tests (H) auf signifikante Unterschiede zwischen den Varianten; je Variante Ergebnisse von Friedmann-Tests $\left(\mathrm{Chi}^{2}\right.$ ) auf signifikante Unterschiede zwischen den Aufnahmezeitpunkten (je Variante $\mathrm{n}=12$ ). 182 Tab. 60: Vitalität [codiert: $4=$ vital bis $0=$ tot, s. S. 27] der Ahorne im Versuchsverlauf; MW u. Std.abw.; Ergebnis des Friedmann-Tests $\left(\mathrm{Chi}^{2}\right)$ auf signifikante Unterschiede zwischen den Aufnahmezeitpunkten ( $\mathrm{n}=192)$.

Tab. 61: Vitalität [codiert: $4=$ vital bis $0=$ tot, s. S. 27] der Ahorn-Varianten (s. S. 20) im Versuchsverlauf; MW u. Std.abw.; je Aufnahmezeitpunkt Ergebnisse von H-Tests (H) auf signifikante Unterschiede zwischen den Varianten; je Variante Ergebnisse von Friedmann-Tests $\left(\mathrm{Chi}^{2}\right)$ auf signifikante Unterschiede zwischen den Aufnahmezeitpunkten (je Variante $\mathrm{n}=12$ ). 184 
Tab. 62: Vitalität [codiert: $4=$ vital bis $0=$ tot, s. S. 27] der Ebereschen im Versuchsverlauf; MW u. Std.abw.; Ergebnis des Friedmann-Tests $\left(\mathrm{Chi}^{2}\right)$ auf signifikante Unterschiede zwischen den Aufnahmezeitpunkten ( $\mathrm{n}=120)$

Tab. 63: Vitalität [codiert: $4=$ vital bis $0=$ tot, s. S. 27] der Ebereschen-Varianten (s. S. 20) im Versuchsverlauf; MW u. Std.abw.; je Aufnahmezeitpunkt Ergebnisse von H-Tests (H) auf signifikante Unterschiede zwischen den Varianten; je Variante Ergebnisse von Friedmann-Tests $\left(\mathrm{Chi}^{2}\right)$ auf signifikante Unterschiede zwischen den Aufnahmezeitpunkten (je Variante $\mathrm{n}=12$ )..192 Tab. 64: Vitalität [codiert: 4 = vital bis $0=$ tot, s. S. 27] der Erlen im Versuchsverlauf; MW u. Std.abw.; Ergebnis des Friedmann-Tests ( $\mathrm{Chi}^{2}$ ) auf signifikante Unterschiede zwischen den Aufnahmezeitpunkten ( $\mathrm{n}=120)$

Tab. 65: Vitalität [codiert: $4=$ vital bis $0=$ tot, s. S. 27] der Erlen-Varianten (s. S. 20) im Versuchsverlauf; MW u. Std.abw.; je Aufnahmezeitpunkt Ergebnisse von H-Tests (H) auf signifikante Unterschiede zwischen den Varianten; je Variante Ergebnisse von Friedmann-Tests $\left(\mathrm{Chi}^{2}\right)$ auf signifikante Unterschiede zwischen den Aufnahmezeitpunkten (je Variante $\left.\mathrm{n}=12\right) . .196$ Tab. 66: Vitalität [codiert: 4 = vital bis $0=$ tot, s. S. 27] der Douglasien im Versuchsverlauf; MW u. Std.abw.; Ergebnis des Friedmann-Tests $\left(\mathrm{Chi}^{2}\right.$ ) auf signifikante Unterschiede zwischen den Aufnahmezeitpunkten ( $\mathrm{n}=192)$

Tab. 67: Vitalität [codiert: $4=$ vital bis $0=$ tot, s. S. 27] der Douglasien-Varianten (s. S. 20) im Versuchsverlauf; MW u. Std.abw.; je Aufnahmezeitpunkt Ergebnisse von H-Tests (H) auf signifikante Unterschiede zwischen den Varianten; je Variante Ergebnisse von Friedmann-Tests $\left(\mathrm{Chi}^{2}\right)$ auf signifikante Unterschiede zwischen den Aufnahmezeitpunkten (je Variante $\left.\mathrm{n}=12\right) . .202$ Tab. 68: Vitalität [codiert: $4=$ vital bis $0=$ tot, s. S. 27] der Kiefern im Versuchsverlauf; MW u. Std.abw.; Ergebnis des Friedmann-Tests $\left(\mathrm{Chi}^{2}\right.$ ) auf signifikante Unterschiede zwischen den Aufnahmezeitpunkten ( $\mathrm{n}=120)$.

Tab. 69: Vitalität [codiert: $4=$ vital bis $0=$ tot, s. S. 27] der Kiefern-Varianten (s. S. 20) im Versuchsverlauf; MW u. Std.abw.; je Aufnahmezeitpunkt Ergebnisse von H-Tests (H) auf signifikante Unterschiede zwischen den Varianten; je Variante Ergebnisse von Friedmann-Tests $\left(\mathrm{Chi}^{2}\right)$ auf signifikante Unterschiede zwischen den Aufnahmezeitpunkten (je Variante $\mathrm{n}=12$ )..208 Tab. 70: Wurzelhalsdurchmesser [mm] der Ahorn-Varianten (s. S. 20) insgesamt, auf Fläche B sowie in Bereichen mit Spontanvegetation; MW u. Std.abw.; Ergebnisse von H-Tests [H] auf signifikante Unterschiede; Buchstaben kennzeichnen je Spalte homogene Gruppen nach U-Tests

Tab. 71: Zuwachs [cm] des Haupttriebs (HT) der Ebereschen-Varianten (s. S. 20) im 2. Vegetationsjahr auf Fläche D; MW u. Std.abw.; Ergebnis des H-Tests auf signifikante Unterschiede; Buchstaben kennzeichnen homogene Gruppen nach U-Tests

Tab. 72: Zuwachs [cm] des Haupttriebs der Douglasien-Varianten (s. S. 20) im 1. Vegetationsjahr, insgesamt sowie nach Standorten getrennt; MW u. Std.abw.; Ergebnisse von H-Tests [H] auf signifikante Unterschiede; Buchstaben kennzeichnen je Spalte homogene Gruppen nach U-Tests

Tab. 73: Trockenmasse der Seitentriebe [g] und Wurzelhalsdurchmesser [mm] der geernteten Douglasien-Varianten (s. S. 20); MW u. Std.abw.; Ergebnisse von H-Tests [H] auf signifikante Unterschiede; Buchstaben kennzeichnen je Spalte homogene Gruppen nach U-Tests.

Tab. 74: Signifikant unterschiedliche Wachstumsparameter der Kiefern-Varianten (s. S. 20) insgesamt, auf Fläche B sowie in Bereichen mit Spontanvegetation; MW u. Std.abw.; Ergebnisse von $\mathrm{H}$-Tests $(\mathrm{H})$ auf signifikante Unterschiede; Buchstaben kennzeichnen je Zeile homogene Gruppen nach U-Tests.

Tab. 75: Vitalität der Eichen [codiert: $4=$ vital bis $0=$ tot, s. S. 27] auf den drei Versuchsflächen A, B und D im Versuchsverlauf; MW u. Std.abw.; je Aufnahmezeitpunkt Ergebnisse von H-Tests (H) 
auf signifikante Unterschiede zwischen den Flächen (Buchstaben kennzeichnen homogene Gruppen nach U-Tests); je Fläche Ergebnisse von Friedmann-Tests $\left(\mathrm{Chi}^{2}\right)$ auf signifikante Unterschiede zwischen den Aufnahmezeitpunkten (je Fläche $n=64$ ).

Tab. 76: Vitalität der Eichen [codiert: $4=$ vital bis $0=$ tot, s. S. 27] in vegetationsfreien Bereichen auf den drei Versuchsflächen A ( $n=64), B(n=20)$ und D $(n=30)$ im Versuchsverlauf; MW u. Std.abw.; je Aufnahmezeitpunkt Ergebnisse von H-Tests $(\mathrm{H})$ auf signifikante Unterschiede zwischen den Flächen; je Fläche Ergebnisse von Friedmann-Tests $\left(\mathrm{Chi}^{2}\right)$ auf signifikante Unterschiede zwischen den Aufnahmezeitpunkten

Tab. 77: Vitalität der Eichen [codiert: $4=$ vital bis $0=$ tot, s. S. 27] in bewachsenen Bereichen auf den Versuchsflächen B ( $n=43)$ und D ( $n=34)$ im Versuchsverlauf; MW u. Std.abw.; je Aufnahmezeitpunkt Ergebnisse von U-Tests (Z) auf signifikante Unterschiede zwischen den Flächen; je Fläche Ergebnisse von Friedmann-Tests $\left(\mathrm{Chi}^{2}\right)$ auf signifikante Unterschiede zwischen den Aufnahmezeitpunkten.

Tab. 78: Vitalität der Ahorne [codiert: $4=$ vital bis $0=$ tot, s. S. 27] auf den drei Versuchsflächen A, B und D im Versuchsverlauf; MW u. Std.abw.; je Aufnahmezeitpunkt Ergebnisse von H-Tests (H) auf signifikante Unterschiede zwischen den Flächen (Buchstaben kennzeichnen homogene Gruppen nach U-Tests); je Fläche Ergebnisse von Friedmann-Tests $\left(\mathrm{Chi}^{2}\right)$ auf signifikante Unterschiede zwischen den Aufnahmezeitpunkten (je Fläche $\mathrm{n}=64$ ). 231

Tab. 79: Vitalität der Ahorne [codiert: $4=$ vital bis $0=$ tot, s. S. 27] in vegetationsfreien Bereichen auf den drei Versuchsflächen A ( $n=64), B(n=21)$ und D ( $n=33)$ im Versuchsverlauf; MW u. Std.abw.; je Aufnahmezeitpunkt Ergebnisse von H-Tests $(\mathrm{H})$ auf signifikante Unterschiede zwischen den Flächen (Buchstaben kennzeichnen homogene Gruppen nach U-Tests); je Fläche Ergebnisse von Friedmann-Tests $\left(\mathrm{Chi}^{2}\right)$ auf signifikante Unterschiede zwischen den Aufnahmezeitpunkten.

Tab. 80: Vitalität der Ahorne [codiert: $4=$ vital bis $0=$ tot, s. S. 27] in bewachsenen Bereichen auf den Versuchsflächen B ( $n=33)$ und D ( $n=11)$ im Versuchsverlauf; MW u. Std.abw.; je Aufnahmezeitpunkt Ergebnisse von U-Tests (Z) auf signifikante Unterschiede zwischen den Flächen; je Fläche Ergebnisse von Friedmann-Tests $\left(\mathrm{Chi}^{2}\right)$ auf signifikante Unterschiede zwischen den Aufnahmezeitpunkten.

Tab. 81: Vitalität der Ebereschen [codiert: $4=$ vital bis $0=$ tot, s. S. 27] auf den drei Versuchsflächen A, B und D im Versuchsverlauf; MW u. Std.abw.; je Aufnahmezeitpunkt Ergebnisse von H-Tests (H) auf signifikante Unterschiede zwischen den Flächen (Buchstaben kennzeichnen homogene Gruppen nach U-Tests); je Fläche Ergebnisse von Friedmann-Tests $\left(\mathrm{Chi}^{2}\right)$ auf signifikante Unterschiede zwischen den Aufnahmezeitpunkten (je Fläche $\mathrm{n}=40$ ) ..... 234 Tab. 82: Vitalität der Ebereschen [codiert: $4=$ vital bis $0=$ tot, s. S. 27] in vegetationsfreien Bereichen auf den drei Versuchsflächen A ( $n=40), B(n=10)$ und D $(n=26)$ im Versuchsverlauf; MW u. Std.abw.; je Aufnahmezeitpunkt Ergebnisse von H-Tests (H) auf signifikante Unterschiede zwischen den Flächen; je Fläche Ergebnisse von Friedmann-Tests $\left(\mathrm{Chi}^{2}\right)$ auf signifikante Unterschiede zwischen den Aufnahmezeitpunkten

Tab. 83: Vitalität der Ebereschen [codiert: $4=$ vital bis $0=$ tot, s. S. 27] in bewachsenen Bereichen auf den Versuchsflächen B ( $n=30)$ und D $(n=14)$ im Versuchsverlauf; MW u. Std.abw.; je Aufnahmezeitpunkt Ergebnisse von U-Tests (Z) auf signifikante Unterschiede zwischen den Flächen; je Fläche Ergebnisse von Friedmann-Tests $\left(\mathrm{Chi}^{2}\right)$ auf signifikante Unterschiede zwischen den Aufnahmezeitpunkten.

Tab. 84: Vitalität der Erlen [codiert: $4=$ vital bis $0=$ tot, s. S. 27] auf den drei Versuchsflächen A, B und D im Versuchsverlauf; MW u. Std.abw.; je Aufnahmezeitpunkt Ergebnisse von H-Tests (H) auf signifikante Unterschiede zwischen den Flächen (Buchstaben kennzeichnen homogene 
Gruppen nach U-Tests); je Fläche Ergebnisse von Friedmann-Tests $\left(\mathrm{Chi}^{2}\right)$ auf signifikante Unterschiede zwischen den Aufnahmezeitpunkten (je Fläche $n=40$ ).

Tab. 85: Vitalität der Erlen [codiert: $4=$ vital bis $0=$ tot, s. S. 27] in vegetationsfreien Bereichen auf den drei Versuchsflächen A ( $n=40), B(n=8)$ und D ( $n=26)$ im Versuchsverlauf; MW u. Std.abw.; je Aufnahmezeitpunkt Ergebnisse von H-Tests (H) auf signifikante Unterschiede zwischen den Flächen; je Fläche Ergebnisse von Friedmann-Tests $\left(\mathrm{Chi}^{2}\right)$ auf signifikante Unterschiede zwischen den Aufnahmezeitpunkten

Tab. 86: Vitalität der Erlen [codiert: $4=$ vital bis $0=$ tot, s. S. 27] in bewachsenen Bereichen auf den Versuchsflächen B ( $n=32)$ und D ( $n=14)$ im Versuchsverlauf; MW u. Std.abw.; je Aufnahmezeitpunkt Ergebnisse von U-Tests (Z) auf signifikante Unterschiede zwischen den Flächen; je Fläche Ergebnisse von Friedmann-Tests $\left(\mathrm{Chi}^{2}\right)$ auf signifikante Unterschiede zwischen den Aufnahmezeitpunkten

Tab. 87: Vitalität der Douglasien [codiert: $4=$ vital bis $0=$ tot, s. S. 27] auf den drei Versuchsflächen A, B und D im Versuchsverlauf; MW u. Std.abw.; je Aufnahmezeitpunkt Ergebnisse von H-Tests $(\mathrm{H})$ auf signifikante Unterschiede zwischen den Flächen (Buchstaben kennzeichnen homogene Gruppen nach U-Tests); je Fläche Ergebnisse von Friedmann-Tests $\left(\mathrm{Chi}^{2}\right)$ auf signifikante Unterschiede zwischen den Aufnahmezeitpunkten (je Fläche $\left.\mathrm{n}=64\right) \ldots . . .240$ Tab. 88: Vitalität der Douglasien [codiert: $4=$ vital bis $0=$ tot, s. S. 27] in bewachsenen Bereichen auf den Versuchsflächen B ( $n=44)$ und D $(n=29)$ im Versuchsverlauf; MW u. Std.abw.; je Aufnahmezeitpunkt Ergebnisse von U-Tests (Z) auf signifikante Unterschiede zwischen den Flächen; je Fläche Ergebnisse von Friedmann-Tests $\left(\mathrm{Chi}^{2}\right)$ auf signifikante Unterschiede zwischen den Aufnahmezeitpunkten

Tab. 89: Vitalität der Kiefern [codiert: $4=$ vital bis $0=$ tot, s. S. 27] auf den drei Versuchsflächen A, B und D im Versuchsverlauf; MW u. Std.abw.; je Aufnahmezeitpunkt Ergebnisse von H-Tests (H) auf signifikante Unterschiede zwischen den Flächen (Buchstaben kennzeichnen homogene Gruppen nach U-Tests); je Fläche Ergebnisse von Friedmann-Tests $\left(\mathrm{Chi}^{2}\right)$ auf signifikante Unterschiede zwischen den Aufnahmezeitpunkten (je Fläche $\mathrm{n}=40$ )

Tab. 90: Vitalität der Kiefern [codiert: $4=$ vital bis $0=$ tot, s. S. 27] in bewachsenen Bereichen auf den Versuchsflächen B ( $n=33)$ und D ( $n=11)$ im Versuchsverlauf; MW u. Std.abw.; je Aufnahmezeitpunkt Ergebnisse von U-Tests (Z) auf signifikante Unterschiede zwischen den Flächen; je Fläche Ergebnisse von Friedmann-Tests $\left(\mathrm{Chi}^{2}\right)$ auf signifikante Unterschiede zwischen den Aufnahmezeitpunkten

Tab. 91: Zuwachs [cm] des Haupttriebs der Ahorne im 1. Vegetationsjahr insgesamt sowie mit Standorten in Bereichen ohne und mit Spontanvegetation getrennt nach Versuchsflächen; MW u. Std.abw.; Ergebnisse von H-Tests [H] auf signifikante Unterschiede; Buchstaben kennzeichnen je Zeile homogene Gruppen nach U-Tests.

Tab. 92: Wachstumsparameter der Ebereschen mit Standorten in Bereichen mit Spontanvegetation mit signifikant unterschiedlichen Ergebnissen je nach Versuchsfläche; MW u. Std.abw.; Ergebnisse von U-Tests

Tab. 93: Wachstumsparameter der Erlen insgesamt sowie in Bereichen ohne Spontanvegetation mit signifikant unterschiedlichen Ergebnissen je nach Versuchsfläche; MW u. Std.abw.; Ergebnisse von H- und U-Tests; Buchstaben kennzeichnen je Zeile homogene Gruppen nach UTests

Tab. 94: Wachstumsparameter der Douglasien insgesamt, in Bereichen mit Spontanvegetation sowie bei Versuchsabschluss geerntete Stichprobe mit signifikant unterschiedlichen Ergebnissen je nach Versuchsfläche; MW u. Std.abw.; Ergebnisse von H- und U-Tests; Buchstaben kennzeichnen je Zeile homogene Gruppen nach U-Tests 
Tab. 95: Wachstumsparameter der Kiefern insgesamt sowie in Bereichen mit Spontanvegetation mit signifikant unterschiedlichen Ergebnissen je nach Versuchsfläche; MW u. Std.abw.; Ergebnisse von H- und U-Tests; Buchstaben kennzeichnen je Zeile homogene Gruppen nach UTests. 255

Tab. 96: Vitalität der Eichen [codiert: $4=$ vital bis $0=$ tot, s. S. 27] in Bereichen ohne (n=114) und mit ( $n=77)$ Spontanvegetation im Versuchsverlauf; MW u. Std.abw.; je Aufnahmezeitpunkt Ergebnisse von U-Tests (Z) auf signifikante Unterschiede zwischen den Standorten; je Standort Ergebnisse von Friedmann-Tests $\left(\mathrm{Chi}^{2}\right)$ auf signifikante Unterschiede zwischen den Aufnahmezeitpunkten. 258

Tab. 97: Vitalität der Eichen [codiert: $4=$ vital bis $0=$ tot, s. S. 27] auf Fläche B in Bereichen ohne $(n=20)$ und mit $(n=43)$ Spontanvegetation im Versuchsverlauf; MW u. Std.abw.; je Aufnahmezeitpunkt Ergebnisse von U-Tests (Z) auf signifikante Unterschiede zwischen den Flächen; je Fläche Ergebnisse von Friedmann-Tests $\left(\mathrm{Chi}^{2}\right)$ auf signifikante Unterschiede zwischen den Aufnahmezeitpunkten.

Tab. 98: Vitalität der Eichen [codiert: $4=$ vital bis $0=$ tot, s. S. 27] auf Fläche D in Bereichen ohne $(n=30)$ und mit ( $n=34)$ Spontanvegetation im Versuchsverlauf; MW u. Std.abw.; je

Aufnahmezeitpunkt Ergebnisse von U-Tests (Z) auf signifikante Unterschiede zwischen den Flächen; je Fläche Ergebnisse von Friedmann-Tests $\left(\mathrm{Chi}^{2}\right)$ auf signifikante Unterschiede zwischen den Aufnahmezeitpunkten.

Tab. 99: Vitalität der Ahorne [codiert: $4=$ vital bis $0=$ tot, s. S. 27] in Bereichen ohne $(n=118)$ und mit ( $n=74)$ Spontanvegetation im Versuchsverlauf; MW u. Std.abw.; je Aufnahmezeitpunkt Ergebnisse von U-Tests (Z) auf signifikante Unterschiede zwischen den Standorten; je Standort Ergebnisse von Friedmann-Tests $\left(\mathrm{Chi}^{2}\right)$ auf signifikante Unterschiede zwischen den Aufnahmezeitpunkten.

Tab. 100: Vitalität der Ahorne [codiert: $4=$ vital bis $0=$ tot, s. S. 27] auf Fläche B in Bereichen ohne ( $\mathrm{n}=21)$ und mit $(\mathrm{n}=43)$ Spontanvegetation im Versuchsverlauf; MW u. Std.abw.; je Aufnahmezeitpunkt Ergebnisse von U-Tests (Z) auf signifikante Unterschiede zwischen den Flächen; je Fläche Ergebnisse von Friedmann-Tests $\left(\mathrm{Chi}^{2}\right)$ auf signifikante Unterschiede zwischen den Aufnahmezeitpunkten.

Tab. 101: Vitalität der Ahorne [codiert: $4=$ vital bis $0=$ tot, s. S. 27] auf Fläche D in Bereichen ohne $(n=33)$ und mit $(n=31)$ Spontanvegetation im Versuchsverlauf; MW u. Std.abw.; je Aufnahmezeitpunkt Ergebnisse von U-Tests (Z) auf signifikante Unterschiede zwischen den Flächen; je Fläche Ergebnisse von Friedmann-Tests $\left(\mathrm{Chi}^{2}\right)$ auf signifikante Unterschiede zwischen den Aufnahmezeitpunkten.

Tab. 102: Vitalität der Ebereschen [codiert: $4=$ vital bis $0=$ tot, s. S. 27] in Bereichen ohne $(n=76)$ und mit $(n=44)$ Spontanvegetation im Versuchsverlauf; MW u. Std.abw.; je Aufnahmezeitpunkt Ergebnisse von U-Tests (Z) auf signifikante Unterschiede zwischen den Standorten; je Standort Ergebnisse von Friedmann-Tests $\left(\mathrm{Chi}^{2}\right)$ auf signifikante Unterschiede zwischen den Aufnahmezeitpunkten.

Tab. 103: Vitalität der Ebereschen [codiert: $4=$ vital bis $0=$ tot, s. S. 27] auf Fläche B in Bereichen ohne $(n=10)$ und mit $(n=30)$ Spontanvegetation im Versuchsverlauf; MW u. Std.abw.; je Aufnahmezeitpunkt Ergebnisse von U-Tests (Z) auf signifikante Unterschiede zwischen den Standorten; je Standort Ergebnisse von Friedmann-Tests ( $\mathrm{Chi}^{2}$ ) auf signifikante Unterschiede zwischen den Aufnahmezeitpunkten.

Tab. 104: Vitalität der Ebereschen [codiert: $4=$ vital bis $0=$ tot, s. S. 27] auf Fläche D in Bereichen ohne $(n=26)$ und mit $(n=14)$ Spontanvegetation im Versuchsverlauf; MW u. Std.abw.; je Aufnahmezeitpunkt Ergebnisse von U-Tests (Z) auf signifikante Unterschiede zwischen den 
Standorten; je Standort Ergebnisse von Friedmann-Tests $\left(\mathrm{Chi}^{2}\right)$ auf signifikante Unterschiede zwischen den Aufnahmezeitpunkten

Tab. 105: Vitalität der Erlen [codiert: $4=$ vital bis $0=$ tot, s. S. 27] in Bereichen ohne (n=74) und mit ( $n=46)$ Spontanvegetation im Versuchsverlauf; MW u. Std.abw.; je Aufnahmezeitpunkt Ergebnisse von U-Tests (Z) auf signifikante Unterschiede zwischen den Standorten; je Standort Ergebnisse von Friedmann-Tests $\left(\mathrm{Chi}^{2}\right)$ auf signifikante Unterschiede zwischen den Aufnahmezeitpunkten

Tab. 106: Vitalität der Erlen [codiert: $4=$ vital bis $0=$ tot, s. S. 27] auf Fläche B in Bereichen ohne $(\mathrm{n}=8)$ und mit $(\mathrm{n}=32)$ Spontanvegetation im Versuchsverlauf; MW u. Std.abw.; je

Aufnahmezeitpunkt Ergebnisse von U-Tests (Z) auf signifikante Unterschiede zwischen den Flächen; je Fläche Ergebnisse von Friedmann-Tests $\left(\mathrm{Chi}^{2}\right)$ auf signifikante Unterschiede zwischen den Aufnahmezeitpunkten

Tab. 107: Vitalität der Erlen [codiert: $4=$ vital bis $0=$ tot, s. S. 27] auf Fläche D in Bereichen ohne $(n=26)$ und mit $(n=14)$ Spontanvegetation im Versuchsverlauf; MW u. Std.abw.; je

Aufnahmezeitpunkt Ergebnisse von U-Tests (Z) auf signifikante Unterschiede zwischen den Flächen; je Fläche Ergebnisse von Friedmann-Tests $\left(\mathrm{Chi}^{2}\right)$ auf signifikante Unterschiede zwischen den Aufnahmezeitpunkten

Tab. 108: Vitalität der Douglasien [codiert: $4=$ vital bis $0=$ tot, s. S. 27] in Bereichen ohne $(n=119)$ und mit ( $n=73)$ Spontanvegetation im Versuchsverlauf; MW u. Std.abw.; je Aufnahmezeitpunkt Ergebnisse von U-Tests (Z) auf signifikante Unterschiede zwischen den Standorten; je Standort Ergebnisse von Friedmann-Tests $\left(\mathrm{Chi}^{2}\right)$ auf signifikante Unterschiede zwischen den Aufnahmezeitpunkten

Tab. 109: Vitalität der Douglasien [codiert: $4=$ vital bis $0=$ tot, s. S. 27] auf Fläche B in Bereichen ohne ( $n=22)$ und mit $(n=44)$ Spontanvegetation im Versuchsverlauf; MW u. Std.abw.; je Aufnahmezeitpunkt Ergebnisse von U-Tests (Z) auf signifikante Unterschiede zwischen den Flächen; je Fläche Ergebnisse von Friedmann-Tests $\left(\mathrm{Chi}^{2}\right)$ auf signifikante Unterschiede zwischen den Aufnahmezeitpunkten.

Tab. 110: Vitalität der Douglasien [codiert: $4=$ vital bis $0=$ tot, s. S. 27] auf Fläche D in Bereichen ohne $(n=35)$ und mit ( $n=29)$ Spontanvegetation im Versuchsverlauf; MW u. Std.abw.; je Aufnahmezeitpunkt Ergebnisse von U-Tests (Z) auf signifikante Unterschiede zwischen den Flächen; je Fläche Ergebnisse von Friedmann-Tests $\left(\mathrm{Chi}^{2}\right)$ auf signifikante Unterschiede zwischen den Aufnahmezeitpunkten

Tab. 111: Vitalität der Kiefern [codiert: $4=$ vital bis $0=$ tot, s. S. 27] in Bereichen ohne $(n=76)$ und mit $(n=44)$ Spontanvegetation im Versuchsverlauf; MW u. Std.abw.; je Aufnahmezeitpunkt Ergebnisse von U-Tests (Z) auf signifikante Unterschiede zwischen den Standorten; je Standort Ergebnisse von Friedmann-Tests $\left(\mathrm{Chi}^{2}\right)$ auf signifikante Unterschiede zwischen den Aufnahmezeitpunkten

Tab. 112: Vitalität der Kiefern [codiert: $4=$ vital bis $0=$ tot, s. S. 27] auf Fläche B in Bereichen ohne ( $n=7)$ und mit (n=33) Spontanvegetation im Versuchsverlauf; MW u. Std.abw.; je Aufnahmezeitpunkt Ergebnisse von U-Tests (Z) auf signifikante Unterschiede zwischen den Flächen; je Fläche Ergebnisse von Friedmann-Tests $\left(\mathrm{Chi}^{2}\right)$ auf signifikante Unterschiede zwischen den Aufnahmezeitpunkten

Tab. 113: Vitalität der Kiefern [codiert: $4=$ vital bis $0=$ tot, s. S. 27] auf Fläche D in Bereichen ohne ( $n=29)$ und mit ( $n=11)$ Spontanvegetation im Versuchsverlauf; MW u. Std.abw.; je Aufnahmezeitpunkt Ergebnisse von U-Tests (Z) auf signifikante Unterschiede zwischen den Flächen; je Fläche Ergebnisse von Friedmann-Tests $\left(\mathrm{Chi}^{2}\right)$ auf signifikante Unterschiede zwischen den Aufnahmezeitpunkten. 
Tab. 114: Wachstumsparameter der Ahorne insgesamt, auf Fläche B sowie bei Versuchsabschluss geerntete Stichprobe mit signifikant unterschiedlichen Ergebnissen je nach Standort in Bereichen ohne oder mit Spontanvegetation; MW u. Std.abw.; Ergebnisse von UTests.

Tab. 115: Wachstumsparameter der Ebereschen insgesamt sowie auf Fläche D mit signifikant unterschiedlichen Ergebnissen je nach Standort in Bereichen ohne oder mit Spontanvegetation; MW u. Std.abw.; Ergebnisse von U-Tests [Z].

Tab. 116: Wachstumsparameter der Erlen insgesamt sowie auf Fläche B bzw. Fläche D mit signifikant unterschiedlichen Ergebnissen je nach Standort in Bereichen ohne oder mit Spontanvegetation; MW u. Std.abw.; Ergebnisse von U-Tests [Z]

Tab. 117: Zuwachs [cm] des Haupttriebs der Douglasien insgesamt sowie auf Fläche B mit signifikant unterschiedlichen Ergebnissen je nach Standort in Bereichen ohne oder mit Spontanvegetation; MW u. Std.abw.; Ergebnisse von U-Tests [Z]

Tab. 118: Wachstumsparameter der Kiefern insgesamt sowie auf Fläche B bzw. Fläche D mit signifikant unterschiedlichen Ergebnissen je nach Standort in Bereichen ohne oder mit Spontanvegetation; MW u. Std.abw.; Ergebnisse von U-Tests [Z]

Tab. 119: Messergebnisse der verschiedenen Wachstumsparameter der unbehandelten Ahorne sowie aller Ahorne im Versuchsverlauf; MW u. Std.abw.; Fettdruck markiert signifikant geringere Werte als im Gesamtdurchschnitt (siehe auch Tab. A 14 und A 15).

Tab. 120: Messergebnisse der verschiedenen Wachstumsparameter der unbehandelten Ebereschen sowie aller Ebereschen im Versuchsverlauf; MW u. Std.abw.; Fettdurck markiert signifikant geringere Werte als im Gesamtdurchschnitt (siehe auch Tab. A 14 und A 15)..... 309

Tab. 121: Messergebnisse der verschiedenen Wachstumsparameter der unbehandelten Erlen sowie aller Erlen im Versuchsverlauf; MW u. Std.abw (siehe auch Tab. A 14 und A 15)

Tab. 122: Messergebnisse der verschiedenen Wachstumsparameter der unbehandelten Douglasien sowie aller Douglasien im Versuchsverlauf; MW u. Std.abw.; unterstrichener Fettdruck markiert signifikant höhere Werte als im Gesamtdurchschnitt (siehe auch Tab. A 14 und A 15)

Tab. 123: Messergebnisse der verschiedenen Wachstumsparameter der unbehandelten Kiefern sowie aller Kiefern im Versuchsverlauf; MW u. Std.abw.; Fettdruck markiert signifikant geringere Werte als im Gesamtdurchschnitt (siehe auch Tab. A 14 und A 15). 


\section{Im Anhang}

Tab. A 1: Bewertung der Zink-, Kupfer-, Blei- und Cadmium-Gehalte im Boden bei der Österreichischen Waldbodenzustandsinventur (Forstliche Bundesversuchsanstalt 1992) ............. I Tab. A 2: Bewertung der Elementgehalte in Eichen-Blättern (Trauben- und Stiel-Eiche) nach Heinsdorf (1996)

Tab. A 3: Bewertung der Elementgehalte in Eichen-Blättern durch das Österreichische Bundesforschungs- und Ausbildungszentrum für Wald, Naturgefahren und Landschaft (BFW 2005/7) und ausreichende Mineralstoffgehalte in der Trockenmasse von Eichen-Blättern nach Bergmann (1993).

Tab. A 4: Bewertung der Stickstoffgehalte [mg/g] in Eichen-Blättern nach Heinsdorf (1999)......III Tab. A 5: Bewertung der Elementgehalte in Ahorn-Blättern nach Literaturzusammenstellung durch van den Burg $(1985,1990)$

Tab. A 6: Bewertung der Elementgehalte in Ahorn-Blättern durch das Österreichische Bundesforschungs- und Ausbildungszentrum für Wald, Naturgefahren und Landschaft (BFW 2005/7) und ausreichende Mineralstoffgehalte in der Trockenmasse von Ahorn-Blättern nach Bergmann (1993) .

Tab. A 7: Ausreichende Mineralstoffgehalte in der Trockenmasse von Blättern verschiedener Laubbaumarten (Ahorn, Birke, Buche, Eiche, Esche, Linde, Pappel) nach Bergmann 1993 IV Tab. A 8: Ausreichende Mineralstoffgehalte in der Trockenmasse von Douglasien-Nadeln nach Bergmann (1993).

Tab. A 9: Bewertung der Elementgehalte in Kiefern-Nadeln im Deutschen Waldbodenbericht Band 2 Teil 8 (BMELF 1997b) und Ernährungsstufen nach Hofmann \& Krauss 1988.

Tab. A 10: Bewertung der Elementgehalte in Kiefern-Nadeln durch das Österreichische Bundesforschungs- und Ausbildungszentrum für Wald, Naturgefahren und Landschaft (BFW 2005/7) und ausreichende Mineralstoffgehalte in der Trockenmasse von Kiefern-Nadeln nach Bergmann (1993)

Tab. A 11: Bewertung der Blei- und Cadmiumgehalte [mg/kg] in Fichtennadeln (BFW 2005/7) VI Tab. A 12: Anteile der nach der 2. Vegetationszeit lebenden / toten Versuchspflanzen aller sechs Baumarten unter verschiedenen Standortbedingungen.

Tab. A 13: Vitalität der Kontrollen [codiert: $4=$ vital bis $0=$ tot, s. S. 27] im Versuchsverlauf nach Standorten getrennt; MW u. Std.abw.; Ergebnisse von H-Tests [H] auf signifikante Unterschiede je nach Standort; Buchstaben kennzeichnen je Zeile homogene Gruppen nach U-Tests; signifikant geringere Mittelwerte, signifikant höhere Mittelwerte als im Gesamtdurchschnitt der jeweiligen Baumart (je Baumart $n=12$ ) VIII

Tab. A 14: Ergebnisse der Erhebungen verschiedener Wachstumsparameter an den Kontrollen; MW u. Std.abw.; Ergebnisse der H- bzw. U-Tests [H bzw. Z] auf signifikante Unterschiede zwischen den Baumarten; Buchstaben kennzeichnen je Zeile homogene Gruppen nach U-Tests; signifikant geringere Mittelwerte, signifikant höhere Mittelwerte als im Gesamtdurchschnitt der jeweiligen Baumart (s. Tab. A 15)...

Tab. A 15: Ergebnisse der Erhebungen verschiedener Wachstumsparameter (je Baumart Gesamtmittel aller beprobbaren Bäume); MW u. Std.abw.; Ergebnisse der H- bzw. U-Tests [H bzw. Z] auf signifikante Unterschiede zwischen den Baumarten; Buchstaben kennzeichnen je Zeile homogene Gruppen nach U-Tests.

Tab. A 16: Zuwachs [cm] des Haupttriebs im 1. und 2. Vegetationsjahr getrennt nach Baumarten und Varianten (s. S. 20); MW u. Std.abw.; Ergebnisse von Wilcoxon-Tests (Z) auf signifikante Unterschiede zwischen beiden Jahren; positive Entwicklung = signifikant höherer Zuwachs im 2. Jahr, negative Entwicklung = signifikant geringerer Zuwachs im 2. Jahr 
Tab. A 17: Blattspiegelwerte der Eichen (Mischproben) auf den Versuchsflächen B und D im 1. (2005) und auf Fläche D im 2. (2006) Vegetationsjahr. ..XIV

Tab. A 18: Makronährstoff-Gehalte [mg/g] im Eichen-Laub (Mischproben) verschiedener Varianten (s. S. 20) auf Fläche D (fehlende Varianten V2, V3, V5, V6, V8, V9 zum Zeitpunkt der Probennahme im August 2006 ausgefallen).

Tab. A 19: Gehalte an Mikronährstoffen ( $\mathrm{Fe}, \mathrm{Mn}, \mathrm{Zn}, \mathrm{Cu}$ ), nützlichen Elementen ( $\mathrm{Al}, \mathrm{Ni}, \mathrm{Na}, \mathrm{Co}$ ) und Schadstoffen $(\mathrm{Pb}, \mathrm{Cd}, \mathrm{Cr})[\mathrm{mg} / \mathrm{kg}]$ im Eichen-Laub (Mischproben) verschiedener Varianten (s. S. 20) auf Fläche D (fehlende Varianten V2, V3, V5, V6, V8, V9: zum Zeitpunkt der Probennahme im August 2006 ausgefallen). XV

Tab. A 20: Bewertung der Element-Gehalte im Eichen-Laub (Quellen: s. Anh. 2) der beprobten Versuchsvarianten (s. S. 20)

Tab. A 21: Relative Blattspiegelwerte [\%; V1 = 100 \%] der beprobten Eichen-Varianten (s. S. 20) auf Fläche D; Mischprobe je Variante; blau markiert mind. 25 \% höhere Werte als Kontrolle (V1), rot markiert mind. $25 \%$ niedrigere Werte als Kontrolle... XVI

Tab. A 22: Blattspiegelwerte der Ahorne (Mischproben) auf den drei Versuchsflächen im 1. (2005) und auf Fläche D im 2. (2006) Vegetationsjahr. XVII

Tab. A 23: Makronährstoff-Gehalte [mg/g] im Ahorn-Laub (Mischproben) verschiedener Varianten (s. S. 20) auf Fläche D (fehlende Variante V5 zum Zeitpunkt der Probennahme im August 2006 ausgefallen)

Tab. A 24: Gehalte an Mikronährstoffen ( $\mathrm{Fe}, \mathrm{Mn}, \mathrm{Zn}, \mathrm{Cu}$ ), nützlichen Elementen (Al, Ni, Na, Co) und Schadstoffen $(\mathrm{Pb}, \mathrm{Cd}, \mathrm{Cr})[\mathrm{mg} / \mathrm{kg}]$ im Ahorn-Laub (Mischproben) verschiedener Varianten (s. S. 20) auf Fläche D (fehlende Variante V5: zum Zeitpunkt der Probennahme im August 2006 bereits ausgefallen)

Tab. A 25: Bewertung der Element-Gehalte im Ahorn-Laub (Quellen: s. Anh. 2) der beprobten Versuchsvarianten (s. S. 20)

Tab. A 26: Relative Blattspiegelwerte [\%; V1 = 100 \%] der beprobten Ahorn-Varianten (s. S. 20) auf Fläche D; Mischprobe je Variante; blau markiert mind. 25 \% höhere Werte als Kontrolle (V1), rot markiert mind. 25 \% niedrigere Werte als Kontrolle .............................................................XX Tab. A 27: Blattspiegelwerte der Ebereschen (Mischproben) auf den drei Versuchsflächen im 1. (2005) und auf Fläche D im 2. (2006) Vegetationsjahr. ...XXI

Tab. A 28: Makronährstoff-Gehalte [mg/g] im Ebereschen-Laub (Mischproben) verschiedener Varianten (s. S. 20) auf Fläche D XXI Tab. A 29: Gehalte an Mikronährstoffen ( $\mathrm{Fe}, \mathrm{Mn}, \mathrm{Zn}, \mathrm{Cu}$ ), nützlichen Elementen ( $\mathrm{Al}, \mathrm{Na}, \mathrm{Ni}, \mathrm{Co}$ ) und Schadstoffen $(\mathrm{Pb}, \mathrm{Cd}, \mathrm{Cr})[\mathrm{mg} / \mathrm{kg}]$ im Ebereschen-Laub (Mischproben) verschiedener Varianten (s. S. 20) auf Fläche D . XXII Tab. A 30: Bewertung der Element-Gehalte im Ebereschen-Laub (Quellen: s. Anh. 2) der beprobten Versuchsvarianten (s. S. 20)................................................................................................ XXII Tab. A 31: Relative Blattspiegelwerte [\%; V1 = $100 \%$ ] der beprobten Ebereschen-Varianten (s. S. 20) auf Fläche D; Mischprobe je Variante; blau markiert mind. 25 \% höhere Werte als Kontrolle (V1), rot markiert mind. $25 \%$ niedrigere Werte als Kontrolle XXIII Tab. A 32: Blattspiegelwerte der Erlen (Mischproben) auf den drei Versuchsflächen im 1. (2005) und auf Fläche D im 2. (2006) Vegetationsjahr. XXIV Tab. A 33: Makronährstoff-Gehalte [mg/g] im Erlen-Laub (Mischproben) verschiedener Varianten (s. S. 20) auf Fläche D XXIV Tab. A 34: Gehalte an Mikronährstoffen ( $\mathrm{Fe}, \mathrm{Mn}, \mathrm{Zn}, \mathrm{Cu}$ ), nützlichen Elementen (Al, Ni, $\mathrm{Na}, \mathrm{Co}$ ) und Schadstoffen $(\mathrm{Pb}, \mathrm{Cd}, \mathrm{Cr})[\mathrm{mg} / \mathrm{kg}]$ im Erlen-Laub (Mischproben) verschiedener Varianten (s. S. 20) auf Fläche D. XXV 
Tab. A 35: Bewertung der Element-Gehalte im Erlen-Laub (Quellen: s. Anh. 2) der beprobten Versuchsvarianten (s. S. 20). $\mathrm{XXV}$

Tab. A 36: Relative Blattspiegelwerte [\%; V1 = 100 \%] der beprobten Erlen-Varianten (s. S. 20) auf Fläche D; Mischprobe je Variante; blau markiert mind. 25 \% höhere Werte als Kontrolle (V1), rot markiert mind. $25 \%$ niedrigere Werte als Kontrolle. Tab. A 37: Nadelspiegelwerte der Douglasien (Mischproben) auf den drei Versuchsflächen im 1. (2005) und auf Fläche D im 2. (2006) Vegetationsjahr XXVII

Tab. A 38: Makronährstoff-Gehalte [mg/g] in den Douglasien-Nadeln (Mischproben) verschiedener Varianten (s. S. 20) auf Fläche D (fehlende Variante V3 zum Zeitpunkt der Probennahme im August 2006 ausgefallen) XXVII Tab. A 39: Gehalte an Mikronährstoffen ( $\mathrm{Fe}, \mathrm{Mn}, \mathrm{Zn}, \mathrm{Cu}$ ), nützlichen Elementen ( $\mathrm{Al}, \mathrm{Ni}, \mathrm{Na}, \mathrm{Co}$ ) und Schadstoffen $(\mathrm{Pb}, \mathrm{Cd}, \mathrm{Cr})[\mathrm{mg} / \mathrm{kg}]$ in den Douglasien-Nadeln (Mischproben) verschiedener Varianten (s. S. 20) auf Fläche D (fehlende Variante V3 zum Zeitpunkt der Probennahme im August 2006 ausgefallen) XXVIII Tab. A 40: Bewertung der Element-Gehalte in den Douglasien-Nadeln (Quellen: s. Anh. 2) der beprobten Versuchsvarianten (s. S. 20) XXVIII Tab. A 41: Relative Nadelspiegelwerte [\%; V1 = 100 \%] der beprobten Douglasien-Varianten (s. S. 20) auf Fläche D; Mischprobe je Variante; blau markiert mind. 25 \% höhere Werte als Kontrolle (V1), rot markiert mind. $25 \%$ niedrigere Werte als Kontrolle. XXIX Tab. A 42: Nadelspiegelwerte der Kiefern (Mischproben) auf den drei Versuchsflächen im 1. (2005) und auf Fläche D im 2. (2006) Vegetationsjahr $\mathrm{XXX}$ Tab. A 43: Makronährstoff-Gehalte [mg/g] in den Kiefern-Nadeln (Mischproben) verschiedener Varianten (s. S. 20) auf Fläche D (fehlende Varianten V2-V8 zum Zeitpunkt der Probennahme im August 2006 ausgefallen) XXX

Tab. A 44: Gehalte an Mikronährstoffen ( $\mathrm{Fe}, \mathrm{Mn}, \mathrm{Zn}, \mathrm{Cu}$ ), nützlichen Elementen (Al, Ni, Na, Co) und Schadstoffen $(\mathrm{Pb}, \mathrm{Cd}, \mathrm{Cr})[\mathrm{mg} / \mathrm{kg}]$ in den Kiefern-Nadeln (Mischproben) verschiedener Varianten (fehlende Varianten V2-V8 zum Zeitpunkt der Probennahme im August 2006 ausgefallen) $\mathrm{XXX}$

Tab. A 45: Bewertung der Element-Gehalte in den Kiefernn-Nadeln (Quellen: s. Anh. 2) der beprobten Versuchsvarianten (s. S. 20) XXXI Tab. A 46: Relative Nadelspiegelwerte [\%; V1 = 100 \%] der beprobten Kiefern-Varianten (s. S. 20) auf Fläche D; Mischprobe je Variante; blau markiert mind. 25 \% höhere Werte als Kontrolle (V1), rot markiert mind. $25 \%$ niedrigere Werte als Kontrolle. .XXXI 


\section{Anhang}

\section{Quellen zur Bewertung der Schwermetallgehalte im Boden}

Zur Bewertung der mit Hilfe chemischer Analysemethoden (s. S. 25f) in den Böden der Versuchsflächen gemessenen Schwermetallgehalte wurden verschiedene Quellen herangezogen:

Bei der Österreichischen Waldbodenzustandsinventur erfolgt die Bewertung gemessener Zink-, Kupfer-, Blei- und Cadmium-Gehalte im Boden nach der in Tab. A 1 dargestellten Einteilung.

Tab. A 1: Bewertung der Zink-, Kupfer-, Blei- und Cadmium-Gehalte im Boden bei der Österreichischen Waldbodenzustandsinventur (Forstliche Bundesversuchsanstalt 1992)

\begin{tabular}{|l|l|l|l|l|l|l|}
\hline $\begin{array}{l}\text { Element } \\
{[\mathrm{mg} / \mathrm{kg}]}\end{array}$ & $\begin{array}{l}\text { Mangel } \\
\text { möglich }\end{array}$ & Normalbereich & $\begin{array}{l}\text { Oberer } \\
\text { Normalbereich }\end{array}$ & $\begin{array}{l}\text { Erhöhter } \\
\text { Gehalt }\end{array}$ & Belastung & Starke Belastung \\
\hline Zink & $<20$ & $21-50$ & $51-150$ & $151-300$ & & $>300$ \\
\hline Kupfer & $<7$ & $8-20$ & $21-50$ & $51-100$ & & $>100$ \\
\hline Blei & & $<20$ & $21-50$ & $51-100$ & $101-200$ & $>200$ \\
\hline Cadmium & & $<0,2$ & $0,21-0,5$ & $0,51-1,0$ & $1,01-3,0$ & $>3,0$ \\
\hline
\end{tabular}

In Alloway (1999) sind (mit Werten aus Kabata-Pendias \& Pendias 1992) folgende kritische Gesamtkonzentrationen von Schwermetallen in Böden zusammengestellt, womit der Bereich bezeichnet wird, oberhalb dessen toxische Wirkungen als möglich angesehen werden:

Zink: 70-400 mg/kg, Kupfer: 60-125 mg/kg, Blei: 100-400 mg/kg, Cadmium: 3-8 mg/kg, Chrom: 75-100 mg/kg, Nickel: 100 mg/kg, Kobalt: 25-50 mg/kg, Mangan: 1500-3000 mg/kg.

Die zum Teil recht großen angegebenen Spannweiten weisen darauf hin, dass es stets von den Eigenschaften des betreffenden Bodens abhängt, ab welchem Gehalt verschiedene Schwermetalle problematisch werden können. Insbesondere der pH-Wert eines Bodens, sein Tongehalt und sein Gehalt an organischer Substanz beeinflussen die Bindung bzw. Mobilität von Schwermetallen, indem etwa viele Schwermetalle erst bei niedrigeren $\mathrm{pH}$-Werten verstärkt in die Bodenlösung übergehen und somit mobil werden (Scheffer \& Schachtschabel 2010).

Kloke (1989) nennt in Abhängigkeit von den drei genannten Bodenfaktoren für verschiedene Schwermetalle tolerierbare Gesamtgehalte, oberhalb deren Pflanzenschädigungen auftreten können. Bei einem pH-Wert von 5, einem Tongehalt von 30\% und einem Gehalt an organischer Substanz von 1\% sind dies für Zink $90 \mathrm{mg} / \mathrm{kg}$, für Blei $300 \mathrm{mg} / \mathrm{kg}$ und für Cadmium 0,9 mg/kg. Da auf den Versuchsflächen der pH-Wert, der Tongehalt (19-26\%) und auch der Gehalt an organischer Substanz noch unter diesen Werten liegen, dürften dort die tolerierbaren Gesamtgehalte ebenfalls noch niedriger als diese Angaben sein.

Die so genannten „Vorsorgewerte“ (natürliche Gehalte einschließlich ubiquitärer anthropogener Kontamination) von Schwermetallen nach Prüeß $(1992,1994)$ liegen für Zink bei 85, für Kupfer bei 20 , für Blei bei 130 und für Cadmium bei $0,7 \mathrm{mg} / \mathrm{kg}$. 
Die Orientierungswerte für kritische Schwermetallkonzentrationen mit schädigenden Wirkungen auf Ökosystemkomponenten nach Tyler (1992) betragen fürZink 300, für Kupfer 20, für Blei 150 und für Cadmium 3,5 mg/kg.

Diese Einstufungen von Prüeß (1992, 1994) und Tyler (1992) beziehen sich auf Schwermetallgehalte in Humusauflagen. Da es sich bei den Oberböden auf den FreilandVersuchsflächen jedoch um Mineralböden ohne Humusauflagen handelt, werden diese Werte bei der Betrachtung der Analyseergebnisse nur vergleichend herangezogen.

\section{Quellen zur Bewertung der Elementgehalte in den Assimilationsorganen}

Die Bewertungen der mit Hilfe chemischer Analysemethoden (s. S. 25f) in den Assimilationsorganen gemessenen Elementgehalte fußen auf einer Reihe von Quellen:

\section{Eichen}

Bewertungen der Elementgehalte in Eichen-Blättern finden sich bei Heinsdorf (1996, s. Tab. A 2) sowie in den Beurteilungswerten zur Pflanzenanalyse des Österreichischen Bundesforschungsund Ausbildungszentrums für Wald, Naturgefahren und Landschaft (BFW 2005/7, s. Tab. A 3). Bei Bergmann (1993) sind für verschiedene Elemente ausreichende Mineralstoffgehalte in der Trockenmasse von Eichen-Blättern aufgeführt (s. Tab. A 3).

Tab. A 2: Bewertung der Elementgehalte in Eichen-Blättern (Trauben- und Stiel-Eiche) nach Heinsdorf (1996)

\begin{tabular}{|r|l|l|l|l|l|}
\hline & Mangel & $\begin{array}{l}\text { Unter- } \\
\text { versorgung }\end{array}$ & $\begin{array}{l}\text { Optimal- } \\
\text { versorgung }\end{array}$ & $\begin{array}{l}\text { Über- } \\
\text { versorgung }\end{array}$ & $\begin{array}{l}\text { Extrem- } \\
\text { versorgung }\end{array}$ \\
\hline $\mathrm{N}[\mathrm{mg} / \mathrm{g}]$ & $12,5-17,2$ & $17,2-21,9$ & $21,9-26,6$ & $26,6-31,3$ & $31,3-36,0$ \\
\hline $\mathrm{P}[\mathrm{mg} / \mathrm{g}]$ & & $1,0-1,4$ & $1,4-1,9(1,7)^{*}$ & $1,9-2,6$ & \\
\hline $\mathrm{K}[\mathrm{mg} / \mathrm{g}]$ & & $4,0-5,4$ & $5,4-7,5$ & $7,5-10,2$ & \\
\hline $\mathrm{Ca}[\mathrm{mg} / \mathrm{g}]$ & & $3,3-4,8$ & $4,8-7,1$ & $7,1-10,5$ & $10,5-15,6$ \\
\hline $\mathrm{Mg}[\mathrm{mg} / \mathrm{g}]$ & $0,6-0,9$ & $0,9-1,3$ & $1,3-2,1$ & $2,1-3,2$ & $3,2-5,0$ \\
\hline $\mathrm{S}[\mathrm{mg} / \mathrm{g}]$ & & $1,2-1,5$ & $1,5-1,9$ & $1,9-2,3$ & $2,3-2,8$ \\
\hline $\mathrm{Fn}[\mathrm{mg} / \mathrm{kg}]$ & $45-66$ & $66-96$ & $96-140$ & $140-205$ & $205-300$ \\
\hline $\mathrm{Al}[\mathrm{mg} / \mathrm{kg}]$ & $15-25$ & $396-782$ & $782-1547$ & & $71-119$ \\
\hline $\mathrm{Na}[\mathrm{mg} / \mathrm{kg}]$ & & $25-42$ & $42-71$ & $58-120,5$ & $120,5-125$ \\
\hline $\mathrm{Zn}[\mathrm{mg} / \mathrm{kg}]$ & & $13,5-28$ & $28-58$ & $21-29$ & $29-40$ \\
\hline
\end{tabular}

* Obergrenze der Optimalversorgung bei Rot-Eiche 
Tab. A 3: Bewertung der Elementgehalte in Eichen-Blättern durch das Österreichische Bundesforschungsund Ausbildungszentrum für Wald, Naturgefahren und Landschaft (BFW 2005/7) und ausreichende Mineralstoffgehalte in der Trockenmasse von Eichen-Blättern nach Bergmann (1993)

\begin{tabular}{|r|l|l|l|l|}
\hline & mangelhaft & ausreichend & optimal & ausreichend \\
\hline $\mathrm{N}[\mathrm{mg} / \mathrm{g}]$ & $<15$ & $15-25$ & $>25$ & $20-30$ \\
\hline $\mathrm{P}[\mathrm{mg} / \mathrm{g}]$ & $<1$ & $1-3$ & $>3$ & $1,5-3$ \\
\hline $\mathrm{K}[\mathrm{mg} / \mathrm{g}]$ & $<5$ & $5-13$ & $>13$ & $10-15$ \\
\hline $\mathrm{Ca}[\mathrm{mg} / \mathrm{g}]$ & $<4$ & $4-15$ & $>15$ & $3-15$ \\
\hline $\mathrm{Mg}[\mathrm{mg} / \mathrm{g}]$ & $<1$ & $1-2,5$ & $>2,5$ & $1,5-3$ \\
\hline $\mathrm{Mn}[\mathrm{mg} / \mathrm{kg}]$ & $<35$ & $35-150$ & $>150$ & $35-100$ \\
\hline $\mathrm{Zn}[\mathrm{mg} / \mathrm{kg}]$ & $<15$ & $15-50$ & $>50$ & $15-50$ \\
\hline $\mathrm{Cu}[\mathrm{mg} / \mathrm{kg}]$ & $<6$ & $6-12$ & $>12$ & $6-12$ \\
\hline
\end{tabular}

Heinsdorf (1999) nennt außerdem Wertebereiche für Stickstoffgehalte in Eichen-Blättern, wobei zwischen Rot-Eiche und Trauben-/Stiel-Eiche differenziert wird (s. Tab. A 4).

Tab. A 4: Bewertung der Stickstoffgehalte [mg/g] in Eichen-Blättern nach Heinsdorf (1999)

\begin{tabular}{|l|l|l|l|}
\hline & gering & mittel & hoch \\
\hline Rot-Eiche & $<17,7$ & $17,7-22,5$ & $>22,5$ \\
\hline Trauben-/Stiel-Eiche & $<20,7$ & $20,7-25,6$ & $>25,6$ \\
\hline
\end{tabular}

\section{Ahorn}

Van den Burg $(1985,1990)$ gibt nach einer Literaturzusammenstellung einen Überblick über die Bewertung von Elementgehalten in Ahorn-Blättern (s. Tab. A 5).

Tab. A 5: Bewertung der Elementgehalte in Ahorn-Blättern nach Literaturzusammenstellung durch van den Burg $(1985,1990)$

\begin{tabular}{|r|l|l|l|}
\hline & $\begin{array}{l}\text { Mangel- } \\
\text { symptome* }\end{array}$ & $\begin{array}{l}\text { Ausreichende } \\
\text { Normalgehalte** }\end{array}$ & $\begin{array}{l}\text { Toxizitätssymptome/ } \\
\text { Wachstumsrückgang*** }\end{array}$ \\
\hline $\mathrm{N}[\mathrm{mg} / \mathrm{g}]$ & $<17$ & $18-30$ & \\
\hline $\mathrm{P}[\mathrm{mg} / \mathrm{g}]$ & $<1,3$ & $1,3-5,4$ & \\
\hline $\mathrm{K}[\mathrm{mg} / \mathrm{g}]$ & $<7$ & $7,8-16$ & \\
\hline $\mathrm{Ca}[\mathrm{mg} / \mathrm{g}]$ & & $5-32,3$ & \\
\hline $\mathrm{Mg}[\mathrm{mg} / \mathrm{g}]$ & $<1,6$ & $1,9-4,6$ & \\
\hline $\mathrm{S}[\mathrm{mg} / \mathrm{g}]$ & & $1,5-2,9$ & $>3,3$ \\
\hline $\mathrm{Fe}[\mathrm{mg} / \mathrm{kg}]$ & & $63-212$ & \\
\hline $\mathrm{Mn}[\mathrm{mg} / \mathrm{kg}]$ & $<17$ & $11-473$ & \\
\hline $\mathrm{Zn}[\mathrm{mg} / \mathrm{kg}]$ & & $30-295$ & \\
\hline $\mathrm{Cu}[\mathrm{mg} / \mathrm{kg}]$ & & $2,4-12,8$ & \\
\hline
\end{tabular}

* Obere Grenze jener Werte, wo Mangelsymptome festgestellt wurden oder möglich sind

** Unteres Quartil der unteren Grenzen bis oberes Quartil der oberen Grenzen der Wertebereiche von ausreichenden Normalgehalten

*** Untere Grenze jener Werte, wo Toxizitätssymptome oder Wachstumsrückgang festgestellt wurden oder möglich sind 
Auch durch das österreichische BFW (2005/7) wird eine Einstufung der Elementkonzentrationen in Ahorn-Blättern vorgenommen (s. Tab. A 6). In Bergmann (1993) werden ausreichende Elementgehalte in Ahorn-Blättern genannt (s. Tab. A 6)

Tab. A 6: Bewertung der Elementgehalte in Ahorn-Blättern durch das Österreichische Bundesforschungsund Ausbildungszentrum für Wald, Naturgefahren und Landschaft (BFW 2005/7) und ausreichende Mineralstoffgehalte in der Trockenmasse von Ahorn-Blättern nach Bergmann (1993)

\begin{tabular}{|r|l|l|l|l|}
\hline & mangelhaft & ausreichend & optimal & ausreichend \\
\hline $\mathrm{N}[\mathrm{mg} / \mathrm{g}]$ & $<17$ & $17-22$ & $>22$ & $17-22$ \\
\hline $\mathrm{P}[\mathrm{mg} / \mathrm{g}]$ & $<1,5$ & $1,5-2,5$ & $>2,5$ & $1,5-2,5$ \\
\hline $\mathrm{K}[\mathrm{mg} / \mathrm{g}]$ & $<10$ & $10-15$ & $>15$ & $10-15$ \\
\hline $\mathrm{Ca}[\mathrm{mg} / \mathrm{g}]$ & $<3$ & $3-15$ & $>15$ & $3-15$ \\
\hline $\mathrm{Mg}[\mathrm{mg} / \mathrm{g}]$ & $<1,5$ & $1,5-3$ & $>3$ & $1,5-3$ \\
\hline $\mathrm{Mn}[\mathrm{mg} / \mathrm{kg}]$ & $<30$ & $30-150$ & $>150$ & $30-100$ \\
\hline $\mathrm{Zn}[\mathrm{mg} / \mathrm{kg}]$ & $<15$ & $15-50$ & $>50$ & $15-50$ \\
\hline $\mathrm{Cu}[\mathrm{mg} / \mathrm{kg}]$ & $<6$ & $6-12$ & $>12$ & $6-12$ \\
\hline
\end{tabular}

\section{Eberesche, Erle}

Für die Laubbaumarten Eberesche und Erle konnten keine artspezifischen Angaben gefunden werden, so dass zur Bewertung der Blattgehalte Angaben für verschiedene andere Laubbaumarten (Ahorn, Birke, Buche, Eiche, Esche, Linde, Pappel; s. Tab. A 7) vergleichsweise herangezogen wurden.

Tab. A 7: Ausreichende Mineralstoffgehalte in der Trockenmasse von Blättern verschiedener Laubbaumarten (Ahorn, Birke, Buche, Eiche, Esche, Linde, Pappel) nach Bergmann 1993

\begin{tabular}{|r|l|}
\hline & Laubbäume \\
\hline $\mathrm{N}[\mathrm{mg} / \mathrm{g}]$ & Von zw. 17 u. 25 bis zw. 22 u. 40 \\
\hline $\mathrm{P}[\mathrm{mg} / \mathrm{g}]$ & $1,5(1,8)-3(2,5)$ \\
\hline $\mathrm{K}[\mathrm{mg} / \mathrm{g}]$ & $10(12)-15(18)$ \\
\hline $\mathrm{Ca}[\mathrm{mg} / \mathrm{g}]$ & $3(2)-15(12)$ \\
\hline $\mathrm{Mg}[\mathrm{mg} / \mathrm{g}]$ & $1,5(2)-3(4)$ \\
\hline $\mathrm{Mn}[\mathrm{mg} / \mathrm{kg}]$ & $30(35)-100$ \\
\hline $\mathrm{Zn}[\mathrm{mg} / \mathrm{kg}]$ & $15-50$ \\
\hline $\mathrm{Cu}[\mathrm{mg} / \mathrm{kg}]$ & $6-12$ \\
\hline
\end{tabular}

\section{Douglasie}

In IFTNC (1987) werden Stickstoffgehalte in Douglasien-Nadeln unter $14 \mathrm{mg} / \mathrm{g}$ als unzureichend, zwischen $14 \mathrm{mg} / \mathrm{g}$ und $16 \mathrm{mg} / \mathrm{g}$ als ausreichend und ab $16 \mathrm{mg} / \mathrm{g}$ als gut eingestuft. Kaliumgehalte unter $6 \mathrm{mg} / \mathrm{g}$ liegen demnach im unzureichenden, zwischen $6 \mathrm{mg} / \mathrm{g}$ und $8 \mathrm{mg} / \mathrm{g}$ im ausreichenden und ab $8 \mathrm{mg} / \mathrm{g}$ im guten Wertebereich.

Bei Bergmann (1993) sind ausreichende Gehalte verschiedener Nährelemente in DouglasienNadeln zusammengestellt (s. Tab. A 8). 
Tab. A 8: Ausreichende Mineralstoffgehalte in der Trockenmasse von Douglasien-Nadeln nach Bergmann (1993)

\begin{tabular}{|l|l|}
\hline & Douglasie \\
\hline $\mathrm{N}[\mathrm{mg} / \mathrm{g}]$ & $11-17$ \\
\hline $\mathrm{P}[\mathrm{mg} / \mathrm{g}]$ & $1,2-3$ \\
\hline $\mathrm{K}[\mathrm{mg} / \mathrm{g}]$ & $6-11$ \\
\hline $\mathrm{Ca}[\mathrm{mg} / \mathrm{g}]$ & $2-6$ \\
\hline $\mathrm{Mg}[\mathrm{mg} / \mathrm{g}]$ & $1-2,5$ \\
\hline $\mathrm{Mn}[\mathrm{mg} / \mathrm{kg}]$ & $50-500$ \\
\hline $\mathrm{Zn}[\mathrm{mg} / \mathrm{kg}]$ & $15-80$ \\
\hline $\mathrm{Cu}[\mathrm{mg} / \mathrm{kg}]$ & $2-10$ \\
\hline
\end{tabular}

Heinsdorf (1999) bewertet Stickstoffgehalte in Douglasien-Nadeln von unter $14,9 \mathrm{mg} / \mathrm{g}$ als gering, Gehalte zwischen 14,9 mg/g und 19,3 mg/g als mittel und Gehalte über 19,3 mg/g als hoch.

\section{Kiefer}

Im Deutschen Waldbodenbericht Band 2 Teil 7-9 (BMELF 1997b) werden die Nadelspiegelwerte von Kiefern dargestellt und bewertet. (s. Tab. A 9)

Tab. A 9: Bewertung der Elementgehalte in Kiefern-Nadeln im Deutschen Waldbodenbericht Band 2 Teil 8 (BMELF 1997b) und Ernährungsstufen nach Hofmann \& Krauss 1988

\begin{tabular}{|c|c|c|c|c|c|}
\hline $\begin{array}{l}\text { BMELF 1997b } \\
\text { Hofmann \& Krauss } 1988\end{array}$ & $\begin{array}{l}\text { Sehr gering } \\
\text { Mangelvers. }\end{array}$ & $\begin{array}{l}\text { Gering } \\
\text { Untervers. }\end{array}$ & $\begin{array}{l}\text { Mittel } \\
\text { Optimalvers. }\end{array}$ & $\begin{array}{l}\text { Hoch } \\
\text { Übervers. }\end{array}$ & $\begin{array}{l}\text { Sehr hoch } \\
\text { Extremvers. }\end{array}$ \\
\hline $\mathrm{N}$ [mg/g] & $\begin{array}{l}<13 \\
9,3-12,1\end{array}$ & $\begin{array}{l}13-14 \\
12,1-15,8\end{array}$ & $\begin{array}{l}14-15 \\
15,8-20,6\end{array}$ & $\begin{array}{l}15-17 \\
20,6-26,8\end{array}$ & $\begin{array}{l}>17 \\
26,8-35,0\end{array}$ \\
\hline $\mathrm{P}[\mathrm{mg} / \mathrm{g}]$ & $\begin{array}{c}<1,2 \\
0,3-0,48\end{array}$ & $\begin{array}{l}1,2-1,4 \\
0,48-0,75\end{array}$ & $\begin{array}{l}1,4-1,8 \\
0,75-1,19\end{array}$ & $\begin{array}{l}1,8-2 \\
1,19-1,89\end{array}$ & $\begin{array}{l}>2 \\
1,89-3,0\end{array}$ \\
\hline $\mathrm{K}[\mathrm{mg} / \mathrm{g}]$ & $\begin{array}{r}<3,5 \\
2,4-3,0\end{array}$ & $\begin{array}{l}3,5-4 \\
3,0-3,9\end{array}$ & $\begin{array}{l}44-5 \\
3,9-4,9\end{array}$ & $\begin{array}{l}5-7 \\
4,9-6,0\end{array}$ & $\begin{array}{l}>7 \\
6,0-7,7\end{array}$ \\
\hline $\mathrm{Ca}[\mathrm{mg} / \mathrm{g}]$ & $\begin{array}{l}<2 \\
1,0-1,5\end{array}$ & $\begin{array}{l}2-2,6 \\
1,5-2,1\end{array}$ & $\begin{array}{l}2,6-3,3 \\
2,1-3,1\end{array}$ & $\begin{array}{l}3,3-4 \\
3,1-4,5\end{array}$ & $\begin{array}{l}>4 \\
4,5-6,5\end{array}$ \\
\hline $\mathrm{Mg}[\mathrm{mg} / \mathrm{g}]$ & $\begin{array}{r}<0,75 \\
0,25-0,4\end{array}$ & $\begin{array}{l}0,75-1 \\
0,4-0,6\end{array}$ & $\begin{array}{l}1-1,25 \\
0,6-0,9\end{array}$ & $\begin{array}{l}1,25-1,5 \\
0,9-1,5\end{array}$ & $\begin{array}{l}>1,5 \\
1,5-2,25\end{array}$ \\
\hline $\mathrm{S}[\mathrm{mg} / \mathrm{g}]$ & $\begin{array}{c}<0,05 \\
0,66-0,99\end{array}$ & $\begin{array}{l}0,05-1 \\
0,99-1,48\end{array}$ & $\begin{array}{l}1-1,2 \\
1,48-2,22\end{array}$ & $\begin{array}{l}1,2-1,4 \\
2,22-3,33\end{array}$ & $\begin{array}{c}>1,4 \\
3,33-5,0\end{array}$ \\
\hline $\mathrm{Fe}[\mathrm{mg} / \mathrm{kg}]$ & $\begin{array}{c}<20 \\
10-27\end{array}$ & $\begin{array}{l}20-50 \\
27-74\end{array}$ & $\begin{array}{l}50-100 \\
74-202\end{array}$ & $\begin{array}{l}100-500 \\
202-550\end{array}$ & $\begin{array}{c}>500 \\
550-1500\end{array}$ \\
\hline $\mathrm{Mn}[\mathrm{mg} / \mathrm{kg}]$ & $\begin{array}{c}<50 \\
80-152\end{array}$ & $\begin{array}{l}50-1000 \\
152-290\end{array}$ & $\begin{array}{l}1000-2000 \\
290-552\end{array}$ & $\begin{array}{l}2000-4000 \\
552-1051\end{array}$ & $\begin{array}{c}>4000 \\
1051-2000\end{array}$ \\
\hline $\mathrm{Zn}[\mathrm{mg} / \mathrm{kg}]$ & $\begin{array}{c}<15 \\
23-30\end{array}$ & $\begin{array}{l}15-30 \\
30-38\end{array}$ & $\begin{array}{l}30-50 \\
38-50\end{array}$ & $\begin{array}{l}50-70 \\
50-64\end{array}$ & $\begin{array}{l}>70 \\
64-83\end{array}$ \\
\hline $\mathrm{Cu}[\mathrm{mg} / \mathrm{kg}]$ & $\begin{array}{l}<2 \\
1,2-1,9\end{array}$ & $\begin{array}{l}2-3 \\
1,9-3,0\end{array}$ & $\begin{array}{l}3-5 \\
3,0-4,8\end{array}$ & $\begin{array}{l}5-7 \\
4,8-7,6\end{array}$ & $\begin{array}{l}>7 \\
7,6-12,0\end{array}$ \\
\hline $\mathrm{Al}[\mathrm{mg} / \mathrm{kg}]$ & $100-141$ & $141-198$ & $198-278$ & 278-391 & $391-550$ \\
\hline
\end{tabular}


Heinsdorf (1999) bewertet Stickstoffgehalte in Kiefern-Nadeln von unter 15,8 mg/g als gering, Gehalte zwischen 15,8 mg/g und 20,6 mg/g als mittel und Gehalte über 20,6 mg/g als hoch.

Durch das österreichische BFW (2005/7) wurde ebenfalls eine Einstufung der Elementgehalte von Kiefern-Nadeln aufgestellt (s. Tab. A 10). Bergmann (1993) nennt ausreichende Elementkonzentrationen in Kiefern-Nadeln (s. Tab. A 10).

Tab. A 10: Bewertung der Elementgehalte in Kiefern-Nadeln durch das Österreichische Bundesforschungs- und Ausbildungszentrum für Wald, Naturgefahren und Landschaft (BFW 2005/7) und ausreichende Mineralstoffgehalte in der Trockenmasse von Kiefern-Nadeln nach Bergmann (1993)

\begin{tabular}{|r|l|l|l|l|}
\hline & mangelhaft & $\begin{array}{l}\text { nicht } \\
\text { ausreichend }\end{array}$ & $\begin{array}{l}\text { ausreichend } \\
\text { bzw. optimal }\end{array}$ & ausreichend \\
\hline $\mathrm{N}[\mathrm{mg} / \mathrm{g}]$ & $<13$ & $13,1-16$ & $>16$ & $14-17$ \\
\hline $\mathrm{P}[\mathrm{mg} / \mathrm{g}]$ & $<1,2$ & $1,2-1,3$ & $>1,3$ & $1,4-3$ \\
\hline $\mathrm{K}[\mathrm{mg} / \mathrm{g}]$ & $<4,3$ & $4,3-5$ & $>5$ & $4-8$ \\
\hline $\mathrm{Ca}[\mathrm{mg} / \mathrm{g}]$ & $<0,6$ & $0,6-2,9$ & $>2,9$ & $2,5-6$ \\
\hline $\mathrm{Mg}[\mathrm{mg} / \mathrm{g}]$ & \multicolumn{5}{|l|}{$<0,6$} & $>0,6$ & $1-2$ \\
\hline $\mathrm{S}[\mathrm{mg} / \mathrm{g}]$ & Schadstoffgrenzwert: $1,1 / 1,4 / 1,7 \mathrm{mg} / \mathrm{kg} \mathrm{Ki} / \mathrm{Fi})$ \\
\hline $\mathrm{Fe}[\mathrm{mg} / \mathrm{kg}]$ & $<20$ & $20-29$ & $30-180$ & \\
\hline $\mathrm{Mn}[\mathrm{mg} / \mathrm{kg}]$ & $<20$ & $20-49$ & $50-6000$ & $50-500$ \\
\hline $\mathrm{Zn}[\mathrm{mg} / \mathrm{kg}]$ & $<15$ & $15-19$ & $20-70$ & $20-70$ \\
\hline $\mathrm{Cu}[\mathrm{mg} / \mathrm{kg}]$ & $<2$ & $2-3$ & $3-7$ & $4-10$ \\
\hline
\end{tabular}

\section{Schwermetalle}

In Smidt (1999) sind als Normalgehalte von Schwermetallen in Pflanzen folgende Werte aufgeführt: Zink: 150-200 mg/kg, Kupfer: 15-20 mg/kg, Nickel: 20-30 mg/kg, Kobalt: 10-20 $\mathrm{mg} / \mathrm{kg}$, Blei: $10-20 \mathrm{mg} / \mathrm{kg}$, Cadmium: $5-10 \mathrm{mg} / \mathrm{kg}$.

In Alloway (1999) werden mit Werten aus Kabata-Pendias \& Pendias (1992) Bereiche kritischer Konzentrationen verschiedener Schwermetalle in Pflanzen angegeben, oberhalb deren toxische Auswirkungen wahrscheinlich sind: Mangan: 300-500 mg/kg, Zink: 100-400 mg/kg, Kupfer: 20$100 \mathrm{mg} / \mathrm{kg}$, Nickel: 10-100 mg/kg, Kobalt: 15-50 mg/kg, Blei: 30-300 mg/kg, Cadmium: 5-30 $\mathrm{mg} / \mathrm{kg}$, Chrom: 5-30, mg/kg.

Für das Beispiel Fichtennadeln wird vom österreichischen BFW (2005/7) folgende Einstufung der Blei- und Cadmiumgehalte vorgenommen (s. Tab. A 11):

Tab. A 11: Bewertung der Blei- und Cadmiumgehalte [mg/kg] in Fichtennadeln (BFW 2005/7)

\begin{tabular}{|l|l|l|l|l|l|}
\hline & minimal & normal & leicht erhöht & mäßig erhöht & sehr erhöht \\
\hline $\mathrm{Pb}[\mathrm{mg} / \mathrm{kg}]$ & $<3$ & $3-5,9$ & $6-11,6$ & $12-20$ & $>20$ \\
\hline $\mathrm{Cd}[\mathrm{mg} / \mathrm{kg}]$ & $<0,05$ & $0,05-0,09$ & $0,1-0,14$ & $0,15-0,2$ & $>0,2$ \\
\hline
\end{tabular}




\section{3. Überlebensraten nach Standort, Vitalität der Kontrollen im Versuchsverlauf nach Standort, Wachstumswerte der Kontrollen und Gesamtmittel, Zuwachsentwicklung der Varianten im Versuchsverlauf}

Tab. A 12: Anteile der nach der 2. Vegetationszeit lebenden / toten Versuchspflanzen aller sechs Baumarten unter verschiedenen Standortbedingungen

\begin{tabular}{|l|l|l|l|l|l|l|}
\hline \multirow{2}{*}{ Standort } & \multicolumn{5}{|c|}{ Anteil bei Versuchsabschluss im Oktober 2006 lebend / tot [\%] } \\
\cline { 2 - 7 } & Eiche & Ahorn & Eberesche & Erle & Douglasie & Kiefer \\
\hline gesamt & $18 / 82$ & $65 / 35$ & $71 / 29$ & $78 / 22$ & $66 / 34$ & $20 / 80$ \\
\hline gesamt - ohne BV * & $8 / 92$ & $52 / 48$ & $59 / 41$ & $69 / 31$ & $18 / 82$ & $7 / 93$ \\
\hline gesamt - mit BV & $32 / 68$ & $85 / 15$ & $91 / 9$ & $93 / 7$ & $53 / 47$ & $43 / 57$ \\
\hline Fläche A & $5 / 95$ & $41 / 59$ & $57,5 / 42,5$ & $75 / 25$ & $53 / 47$ & $5 / 95$ \\
\hline Fläche B & $21 / 79$ & $80 / 20$ & $77,5 / 22,5$ & $85 / 15$ & $86 / 14$ & $45 / 55$ \\
\hline Fläche B - ohne BV & $0 / 100$ & $62 / 38$ & $50 / 50$ & $50 / 50$ & $65 / 35$ & $14 / 86$ \\
\hline Fläche B - mit BV & $30 / 70$ & $88 / 12$ & $87 / 13$ & $94 / 6$ & $95 / 5$ & $52 / 48$ \\
\hline Fläche D & $28 / 72$ & $73 / 27$ & $77,5 / 22,5$ & $75 / 25$ & $59 / 41$ & $10 / 90$ \\
\hline Fläche D - ohne BV & $20 / 80$ & $67 / 33$ & $65 / 35$ & $65 / 35$ & $46 / 54$ & $7 / 93$ \\
\hline Fläche D - mit BV & $35 / 65$ & $81 / 19$ & $100 / 0$ & $93 / 7$ & $76 / 24$ & $18 / 82$ \\
\hline
\end{tabular}

* Bodenvegetation 
Tab. A 13: Vitalität der Kontrollen [codiert: $4=$ vital bis $0=$ tot, s. S. 27] im Versuchsverlauf nach Standorten getrennt; MW u. Std.abw.; Ergebnisse von H-Tests [H] auf signifikante Unterschiede je nach Standort; Buchstaben kennzeichnen je Zeile homogene Gruppen nach U-Tests; signifikant geringere Mittelwerte, signifikant höhere Mittelwerte als im Gesamtdurchschnitt der jeweiligen Baumart (je Baumart $\mathrm{n}=12$ )

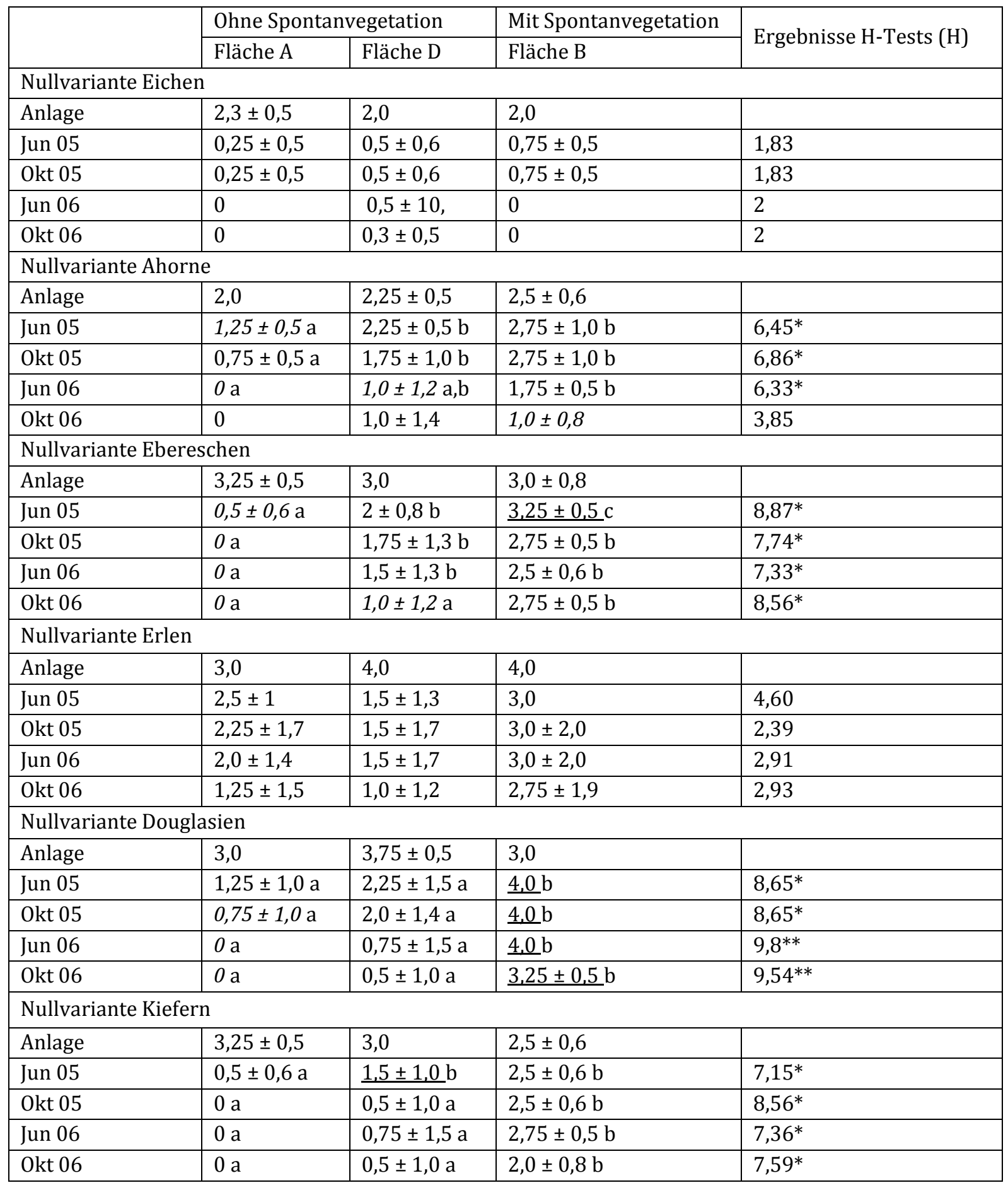


Tab. A 14: Ergebnisse der Erhebungen verschiedener Wachstumsparameter an den Kontrollen; MW u. Std.abw.; Ergebnisse der H- bzw. U-Tests [H bzw. Z] auf signifikante Unterschiede zwischen den Baumarten; Buchstaben kennzeichnen je Zeile homogene Gruppen nach U-Tests; signifikant geringere Mittelwerte, signifikant höhere Mittelwerte als im Gesamtdurchschnitt der jeweiligen Baumart (s. Tab. A 15)

\begin{tabular}{|c|c|c|c|c|c|c|}
\hline Wachstumsparameter & Ahorn & Eberesche & Erle & Douglasie & Kiefer & $\mathrm{H} / \mathrm{Z}$ \\
\hline $\begin{array}{l}\text { Zuwachs Haupttrieb } \\
2005[\mathrm{~cm}]\end{array}$ & $\begin{array}{l}2 \pm 3 \\
\mathrm{~N}=7\end{array}$ & $\begin{array}{l}4 \pm 4 \\
N=10\end{array}$ & $\begin{array}{l}8 \pm 6 \\
N=11\end{array}$ & $\frac{6 \pm 4}{N=10}$ & $\begin{array}{l}4 \pm 5 \\
N=8\end{array}$ & 6,58 \\
\hline $\begin{array}{l}\text { Zuwachs Haupttrieb } \\
2005 \text { red.* }[\mathrm{cm}]\end{array}$ & $\begin{array}{l}2 \pm 2 \\
\mathrm{~N}=4\end{array}$ & $\begin{array}{l}6 \pm 4 \\
N=5\end{array}$ & $\begin{array}{l}10 \pm 6 \\
N=7\end{array}$ & $\frac{9 \pm 3}{N=5}$ & $\begin{array}{l}7 \pm 5 \\
N=5\end{array}$ & 8,73 \\
\hline $\begin{array}{l}\text { Zuwachs Haupttrieb } \\
2006[\mathrm{~cm}]\end{array}$ & $\begin{array}{l}0 \\
\mathrm{~N}=4\end{array}$ & $\begin{array}{l}3 \pm 3 \\
N=5 \\
a\end{array}$ & $\begin{array}{l}16 \pm 13 \\
N=7 \\
b\end{array}$ & $\begin{array}{l}10 \pm 7 \\
N=5 \\
b\end{array}$ & $\begin{array}{l}8 \pm 2 \\
N=5 \\
b\end{array}$ & $\begin{array}{l}15,65^{* *} / \\
8,02^{*} \\
\text { (o.Ahorn) }\end{array}$ \\
\hline $\begin{array}{l}\text { Zuwachs Haupttrieb } \\
\text { gesamt }[\mathrm{cm}]\end{array}$ & $\begin{array}{l}2 \pm 2 \\
\mathrm{~N}=4\end{array}$ & $\begin{array}{l}9 \pm 5 \\
\mathrm{~N}=5\end{array}$ & $\begin{array}{l}26 \pm 18 \\
\mathrm{~N}=7\end{array}$ & $\frac{19 \pm 7}{N=5}$ & $\begin{array}{l}15 \pm 4 \\
\mathrm{~N}=5\end{array}$ & $\begin{array}{l}18,84 * * / \\
7,14 \\
\text { (o.Ahorn) }\end{array}$ \\
\hline $\begin{array}{l}\text { Durchmesser } \\
\text { Wurzelhals [mm] }\end{array}$ & $\begin{array}{l}5 \pm 1 \\
N=5 \\
a\end{array}$ & $\begin{array}{l}8 \pm 2 \\
N=6 \\
b\end{array}$ & $\begin{array}{l}16 \pm 4 \\
N=7 \\
c\end{array}$ & $\begin{array}{l}7 \pm 1 \\
N=5 \\
b\end{array}$ & $\begin{array}{l}7 \pm 2 \\
N=5 \\
a, b\end{array}$ & $19,57 * * *$ \\
\hline $\begin{array}{l}\text { Volumen } \\
\text { Haupttrieb }\left[\mathrm{cm}^{3}\right]\end{array}$ & $\begin{array}{l}4 \pm 2 \\
N=4 \\
a\end{array}$ & $\begin{array}{l}17 \pm 8 \\
\mathrm{~N}=5 \\
\mathrm{c}\end{array}$ & $\begin{array}{l}103 \pm 54 \\
N=7 \\
d\end{array}$ & $\begin{array}{l}7 \pm 3 \\
N=5 \\
b, c \\
\end{array}$ & $\begin{array}{l}10 \pm 8 \\
\mathrm{~N}=5 \\
\mathrm{a}, \mathrm{b}\end{array}$ & $20,06 * * *$ \\
\hline $\begin{array}{l}\text { TM Haupttrieb } \\
\text { errechnet** }[\mathrm{g}]\end{array}$ & $\begin{array}{l}5 \pm 3 \\
N=4 \\
a\end{array}$ & $\begin{array}{l}11 \pm 5 \\
\mathrm{~N}=5 \\
\mathrm{~b}\end{array}$ & $\begin{array}{l}47 \pm 25 \\
N=7 \\
c\end{array}$ & $\begin{array}{l}5 \pm 2 \\
N=5 \\
a\end{array}$ & $\begin{array}{l}5 \pm 4 \\
N=5 \\
a, b\end{array}$ & $17,68 * *$ \\
\hline $\begin{array}{l}\text { Länge } \\
\text { Seitentriebe }[\mathrm{cm}]\end{array}$ & - & $\begin{array}{l}59 \pm 65 \\
N=4 \\
a\end{array}$ & $\begin{array}{l}369 \pm 224 \\
N=7 \\
b\end{array}$ & - & $\begin{array}{l}63 \pm 37 \\
N=5 \\
a\end{array}$ & $11,18 * *$ \\
\hline $\begin{array}{l}\text { TM Seitentriebe } \\
\text { errechnet }^{* *}[\mathrm{~g}]\end{array}$ & - & $\begin{array}{l}4 \pm 4 \\
N=4 \\
a\end{array}$ & $\begin{array}{l}24 \pm 15 \\
N=7 \\
b\end{array}$ & - & $\begin{array}{l}3 \pm 2 \\
N=5 \\
a\end{array}$ & $11,14 * *$ \\
\hline HT-/ST-Länge & - & $\begin{array}{l}3,5 \pm 4,1 \\
N=4 \\
b\end{array}$ & $\begin{array}{l}0,4 \pm 0,2 \\
\mathrm{~N}=7 \\
\mathrm{a}\end{array}$ & - & $\begin{array}{l}1,0 \pm 0,7 \\
N=5 \\
b\end{array}$ & $6,44 *$ \\
\hline $\begin{array}{l}\text { TM oberirdisch } \\
\text { errechnet** }[\mathrm{g}]\end{array}$ & - & $\begin{array}{l}16 \pm 5 \\
\mathrm{~N}=4 \\
\mathrm{~b}\end{array}$ & $\begin{array}{l}71 \pm 39 \\
N=7 \\
c\end{array}$ & - & $\begin{array}{l}9 \pm 5 \\
N=5 \\
a\end{array}$ & $12,39 * *$ \\
\hline $\begin{array}{l}\text { TMHT/TMST } \\
\text { errechnet } * *[\mathrm{~g}]\end{array}$ & - & $\begin{array}{l}9,9 \pm 13,1 \\
\mathrm{~N}=4\end{array}$ & $\begin{array}{l}2,0 \pm 0,3 \\
\mathrm{~N}=7\end{array}$ & - & $\begin{array}{l}1,9 \pm 1,1 \\
\mathrm{~N}=5\end{array}$ & 2,63 \\
\hline $\begin{array}{l}\text { TM Wurzel } \\
\text { errechnet** [g] }\end{array}$ & - & - & - & $\begin{array}{l}9 \pm 1 \\
\mathrm{~N}=5\end{array}$ & $\begin{array}{l}9 \pm 3 \\
\mathrm{~N}=5\end{array}$ & $-0,95$ \\
\hline $\begin{array}{l}\text { TMHT+TMW } \\
\text { errechnet** }[\mathrm{g}]\end{array}$ & - & - & - & $\begin{array}{l}14 \pm 3 \\
\mathrm{~N}=5\end{array}$ & $\begin{array}{l}14 \pm 6 \\
\mathrm{~N}=5\end{array}$ & $-0,73$ \\
\hline $\begin{array}{l}\text { TMHT/TMW } \\
\text { errechnet** [g] }\end{array}$ & - & - & - & $\begin{array}{l}0,5 \pm 0,2 \\
\mathrm{~N}=5\end{array}$ & $\begin{array}{l}0,6 \pm 0,2 \\
\mathrm{~N}=5\end{array}$ & $-0,52$ \\
\hline $\begin{array}{l}\text { TM gesamt } \\
\text { errechnet** [g] }\end{array}$ & - & - & - & - & $\begin{array}{l}18 \pm 8 \\
\mathrm{~N}=5\end{array}$ & - \\
\hline $\begin{array}{l}\text { TM oberird./TM } \\
\text { unterird. errechnet** }[\mathrm{g}]\end{array}$ & - & - & - & - & $\begin{array}{l}0,9 \pm 0,3 \\
\mathrm{~N}=5\end{array}$ & - \\
\hline
\end{tabular}

- keine Daten aufgenommen bzw. Berechnung nicht möglich

* zwecks Vergleichbarkeit reduziert auf die auch noch in 2006 lebenden, nicht (durch Wild) geschädigten Bäume

** mit Hilfe von Formeln (Volumen) oder Regressionsgleichungen aus Messwerten errechnet 
Tab. A 15: Ergebnisse der Erhebungen verschiedener Wachstumsparameter (je Baumart Gesamtmittel aller beprobbaren Bäume); MW u. Std.abw.; Ergebnisse der H- bzw. U-Tests [H bzw. Z] auf signifikante Unterschiede zwischen den Baumarten; Buchstaben kennzeichnen je Zeile homogene Gruppen nach UTests

\begin{tabular}{|c|c|c|c|c|c|c|c|}
\hline Wuchsparameter & Ahorn & Eberesche & Erle & Douglasie & Kiefer & $\mathrm{H} / \mathrm{Z}$ & $\mathrm{n}$ \\
\hline $\begin{array}{l}\text { Höhe } \\
\text { bei } \\
\text { Pflanzung [cm] }\end{array}$ & $\begin{array}{l}26 \pm 6 \\
N=192 \\
a\end{array}$ & $\begin{array}{l}73 \pm 12 \\
\mathrm{~N}=120 \\
\mathrm{~b}\end{array}$ & $\begin{array}{l}101 \pm 9 \\
N=120 \\
c\end{array}$ & $\begin{array}{l}26 \pm 7 \\
N=192 \\
a\end{array}$ & $\begin{array}{l}27 \pm 8 \\
N=120 \\
a\end{array}$ & $505,90 * * *$ & 744 \\
\hline $\begin{array}{l}\text { Höhe } \\
\text { Oktober } \\
2005[\mathrm{~cm}]\end{array}$ & $\begin{array}{l}28 \pm 6 \\
N=125 \\
a\end{array}$ & $\begin{array}{l}78 \pm 13 \\
N=100 \\
c\end{array}$ & $\begin{array}{l}109 \pm 10 \\
N=115 \\
d\end{array}$ & $\begin{array}{l}29 \pm 7 \\
N=164 \\
a\end{array}$ & $\begin{array}{l}33 \pm 9 \\
N=44 \\
b\end{array}$ & $471,86 * * *$ & 548 \\
\hline $\begin{array}{l}\text { Höhe } \\
\text { Oktober } \\
2005 \mathrm{red} . *[\mathrm{~cm}]\end{array}$ & $\begin{array}{l}28 \pm 6 \\
N=87\end{array}$ & $\begin{array}{l}80 \pm 14 \\
N=60\end{array}$ & $\begin{array}{l}112 \pm 9 \\
N=78\end{array}$ & $\begin{array}{l}30 \pm 7 \\
N=117\end{array}$ & $\begin{array}{l}36 \pm 8 \\
\mathrm{~N}=24\end{array}$ & $277,66 * * *$ & 366 \\
\hline $\begin{array}{l}\text { Höhe } \\
\text { Oktober } \\
2006[\mathrm{~cm}]\end{array}$ & $\begin{array}{l}32 \pm 8 \\
\mathrm{~N}=87 \\
\mathrm{a}\end{array}$ & $\begin{array}{l}90 \pm 18 \\
N=60 \\
d\end{array}$ & $\begin{array}{l}128 \pm 17 \\
N=78 \\
e\end{array}$ & $\begin{array}{l}38 \pm 11 \\
\mathrm{~N}=117 \\
\mathrm{~b}\end{array}$ & $\begin{array}{l}55 \pm 13 \\
N=24 \\
c\end{array}$ & $287,18 * * *$ & 366 \\
\hline $\begin{array}{l}\text { Zuwachs } \\
\text { Haupttrieb } \\
2005[\mathrm{~cm}]\end{array}$ & $\begin{array}{l}1,9 \pm 2,5 \\
N=125 \\
a\end{array}$ & $\begin{array}{l}5,2 \pm 4,8 \\
N=100 \\
b\end{array}$ & $\begin{array}{l}8,0 \pm 6,2 \\
N=115 \\
c\end{array}$ & $\begin{array}{l}3,8 \pm 3,0 \\
N=164 \\
b\end{array}$ & $\begin{array}{l}4,7 \pm 5,2 \\
N=44 \\
b\end{array}$ & $91,94 * * *$ & 548 \\
\hline $\begin{array}{l}\text { Zuwachs } \\
\text { Haupttrieb } \\
2005 \text { red.* }[\mathrm{cm}]\end{array}$ & $\begin{array}{l}2,3 \pm 2,6 \\
N=87 \\
a\end{array}$ & $\begin{array}{l}6,8 \pm 4,8 \\
N=60 \\
c\end{array}$ & $\begin{array}{l}10,1 \pm 5,9 \\
N=78 \\
d\end{array}$ & $\begin{array}{l}4,5 \pm 3,1 \\
N=117 \\
b\end{array}$ & $\begin{array}{l}8,2 \pm 4,6 \\
\mathrm{~N}=24 \\
\mathrm{c}, \mathrm{d}\end{array}$ & $130,30 * * *$ & 366 \\
\hline $\begin{array}{l}\text { Zuwachs } \\
\text { Haupttrieb } \\
2006[\mathrm{~cm}]\end{array}$ & $\begin{array}{l}3,9 \pm 4,8 \\
N=87 \\
a\end{array}$ & $\begin{array}{l}10,4 \pm 8,1 \\
N=60 \\
b\end{array}$ & $\begin{array}{l}16,1 \pm 11,4 \\
N=78 \\
c\end{array}$ & $\begin{array}{l}8,5 \pm 7,1 \\
N=117 \\
b\end{array}$ & $\begin{array}{l}18,3 \pm 9,6 \\
\mathrm{~N}=24 \\
\mathrm{c}\end{array}$ & $106,32 * * *$ & 366 \\
\hline $\begin{array}{l}\text { Zuwachs } \\
\text { Haupttrieb } \\
\text { gesamt }[\mathrm{cm}]\end{array}$ & $\begin{array}{l}6,2 \pm 6,5 \\
N=87 \\
a\end{array}$ & $\begin{array}{l}17,1 \pm \\
10,6 \\
N=60 \\
c\end{array}$ & $\begin{array}{l}26,2 \pm 15,7 \\
N=78 \\
d\end{array}$ & $\begin{array}{l}13,0 \pm 8,5 \\
N=117 \\
b\end{array}$ & $\begin{array}{l}26,5 \pm \\
12,0 \\
N=24 \\
d\end{array}$ & $141,98 * * *$ & 366 \\
\hline $\begin{array}{l}\text { Durchmesser } \\
\text { Wurzelhals } \\
{[\mathrm{mm}]}\end{array}$ & $\begin{array}{l}6,1 \pm 1,5 \\
N=125 \\
a\end{array}$ & $\begin{array}{l}10,2 \pm 2,1 \\
\mathrm{~N}=85 \\
\mathrm{c}\end{array}$ & $\begin{array}{l}15,8 \pm 3,9 \\
N=92 \\
d\end{array}$ & $\begin{array}{l}7,4 \pm 2,8 \\
N=127 \\
b\end{array}$ & $\begin{array}{l}10,7 \pm 4,1 \\
N=24 \\
c\end{array}$ & $279,52 * * *$ & 453 \\
\hline $\begin{array}{l}\text { Durchmesser } \\
\text { Wurzelhals } \\
\text { red. [mm] }\end{array}$ & $\begin{array}{l}6,2 \pm 1,6 \\
N=87 \\
a\end{array}$ & $\begin{array}{l}10,4 \pm 2,2 \\
\mathrm{~N}=60 \\
\mathrm{c}\end{array}$ & $\begin{array}{l}16,5 \pm 3,7 \\
N=78 \\
d\end{array}$ & $\begin{array}{l}7,5 \pm 2,9 \\
N=117 \\
b\end{array}$ & $\begin{array}{l}10,7 \pm 4,1 \\
\mathrm{~N}=24 \\
\mathrm{c}\end{array}$ & $225,95 * * *$ & 366 \\
\hline $\begin{array}{l}\text { Länge } \\
\text { Seitentriebe } \\
{[\mathrm{cm}]}\end{array}$ & - & $\begin{array}{l}92 \pm 65 \\
N=51 \\
a\end{array}$ & $\begin{array}{l}380 \pm 207 \\
\mathrm{~N}=76 \\
\mathrm{c}\end{array}$ & - & $\begin{array}{l}138 \pm 89 \\
N=22 \\
b\end{array}$ & $88,43 * * *$ & 149 \\
\hline $\begin{array}{l}\text { Haupttrieb-/ } \\
\text { Seitentrieb- } \\
\text { Länge }\end{array}$ & - & $\begin{array}{l}1,7 \pm 1,6 \\
N=51 \\
b\end{array}$ & $\begin{array}{l}0,4 \pm 0,2 \\
N=76 \\
a\end{array}$ & - & $\begin{array}{l}0,6 \pm 0,4 \\
N=22 \\
a\end{array}$ & $72,04 * * *$ & 149 \\
\hline $\begin{array}{l}\text { Volumen } \\
\text { Haupttrieb } \\
{\left[\mathrm{cm}^{3}\right]}\end{array}$ & $\begin{array}{l}5,5 \pm 4,1 \\
N=87 \\
a\end{array}$ & $\begin{array}{l}34,8 \pm \\
20,1 \\
\mathrm{~N}=60 \\
\mathrm{c}\end{array}$ & $\begin{array}{l}114,4 \pm \\
62,1 \\
N=78 \\
d\end{array}$ & $\begin{array}{l}10,3 \pm \\
14,5 \\
N=117 \\
b\end{array}$ & $\begin{array}{l}31,2 \pm \\
27,5 \\
\mathrm{~N}=24 \\
\mathrm{c}\end{array}$ & $261,29 * * *$ & 366 \\
\hline $\begin{array}{l}\text { Trockenmasse } \\
\text { Haupttrieb } \\
\text { Ernte*** }[\mathrm{g}]\end{array}$ & $\begin{array}{l}7,1 \pm 4,4 \\
N=23 \\
b\end{array}$ & $\begin{array}{l}23,5 \pm \\
11,2 \\
N=5 \\
\mathrm{c}\end{array}$ & $\begin{array}{l}65,3 \pm 25,2 \\
N=6 \\
d\end{array}$ & $\begin{array}{l}5,6 \pm 3,8 \\
N=34 \\
a\end{array}$ & $\begin{array}{l}19,4 \pm \\
16,6 \\
N=6 \\
c\end{array}$ & $33,77 * * *$ & 74 \\
\hline $\begin{array}{l}\text { Trockenmasse } \\
\text { Haupttrieb } \\
\text { errechnet** }[\mathrm{g}]\end{array}$ & $\begin{array}{l}6,6 \pm 5,0 \\
N=87 \\
a\end{array}$ & $\begin{array}{l}22,3 \pm \\
12,9 \\
N=60 \\
d\end{array}$ & $\begin{array}{l}52,8 \pm 28,6 \\
N=78 \\
e\end{array}$ & $\begin{array}{l}7,2 \pm 10,2 \\
N=117 \\
b\end{array}$ & $\begin{array}{l}16,4 \pm \\
14,4 \\
N=24 \\
c\end{array}$ & $229,74 * * *$ & 366 \\
\hline $\begin{array}{l}\text { Trockenmasse } \\
\text { Seitentriebe } \\
\text { Ernte }[\mathrm{g}]\end{array}$ & $\begin{array}{l}0,4 \pm 0,6 \\
N=20 \\
a\end{array}$ & $\begin{array}{l}6,0 \pm 4,7 \\
N=5 \\
b\end{array}$ & $\begin{array}{l}25,2 \pm 18,2 \\
N=6 \\
c\end{array}$ & $\begin{array}{l}3,3 \pm 3,0 \\
N=34 \\
b\end{array}$ & $\begin{array}{l}7,3 \pm 8,0 \\
N=6 \\
b\end{array}$ & $44,17 * * *$ & 71 \\
\hline
\end{tabular}




\begin{tabular}{|c|c|c|c|c|c|c|c|}
\hline $\begin{array}{l}\text { Trockenmasse } \\
\text { Seitentriebe } \\
\text { errechnet }[\mathrm{g}]\end{array}$ & - & $\begin{array}{l}5,7 \pm 4,0 \\
\mathrm{~N}=51 \\
\mathrm{a}\end{array}$ & $\begin{array}{l}24,8 \pm 13,5 \\
N=76 \\
b\end{array}$ & - & $\begin{array}{l}7,4 \pm 4,7 \\
\mathrm{~N}=22 \\
\mathrm{a}\end{array}$ & $92,21 * * *$ & 149 \\
\hline $\begin{array}{l}\text { Trockenmasse } \\
\text { Wurzel } \\
\text { Ernte }[\mathrm{g}]\end{array}$ & $\begin{array}{l}9,5 \pm 6,6 \\
N=33 \\
a\end{array}$ & $\begin{array}{l}24,6 \pm \\
13,6 \\
N=6 \\
b\end{array}$ & $\begin{array}{l}81,7 \pm 30,2 \\
\mathrm{~N}=6 \\
\mathrm{c}\end{array}$ & $\begin{array}{l}9,0 \pm 5,5 \\
N=35 \\
a\end{array}$ & $\begin{array}{l}14,2 \pm \\
10,3 \\
\mathrm{~N}=6 \\
\mathrm{a}, \mathrm{b}\end{array}$ & $24,86^{* * * *}$ & 86 \\
\hline $\begin{array}{l}\text { Trockenmasse } \\
\text { Wurzel } \\
\text { Ernte red. [g] }\end{array}$ & $\begin{array}{l}10,2 \pm 6,7 \\
N=23 \\
a\end{array}$ & $\begin{array}{l}26,9 \pm \\
13,8 \\
N=5 \\
b\end{array}$ & $\begin{array}{l}81,7 \pm 30,2 \\
N=6 \\
c\end{array}$ & $\begin{array}{l}8,8 \pm 5,5 \\
N=34 \\
a\end{array}$ & $\begin{array}{l}14,2 \pm \\
10,3 \\
\mathrm{~N}=6 \\
\mathrm{a}, \mathrm{b}\end{array}$ & $24,09 * * *$ & 74 \\
\hline $\begin{array}{l}\text { Trockenmasse } \\
\text { Wurzel } \\
\text { errechnet [g] }\end{array}$ & - & - & - & $\begin{array}{l}9,8 \pm 3,7 \\
\mathrm{~N}=127\end{array}$ & $\begin{array}{l}13,9 \pm 5,3 \\
\mathrm{~N}=24\end{array}$ & $3,79 * * *$ & 151 \\
\hline $\begin{array}{l}\text { Trockenmasse } \\
\text { Wurzel } \\
\text { errechnet red. }[\mathrm{g}]\end{array}$ & - & - & - & $\begin{array}{l}9,9 \pm 3,8 \\
\mathrm{~N}=117\end{array}$ & $\begin{array}{l}13,9 \pm 5,3 \\
\mathrm{~N}=24\end{array}$ & $3,59 * * *$ & 141 \\
\hline $\begin{array}{l}\text { TMHT/TMST } \\
\text { Ernte }\end{array}$ & $\begin{array}{l}27,2 \pm \\
15,5 \\
N=20 \\
c\end{array}$ & $\begin{array}{l}6,7 \pm 5,4 \\
\mathrm{~N}=5 \\
\mathrm{~b}\end{array}$ & $\begin{array}{l}3,0 \pm 0,8 \\
\mathrm{~N}=6 \\
\mathrm{~b}\end{array}$ & $\begin{array}{l}2,1 \pm 0,9 \\
\mathrm{~N}=34 \\
\mathrm{a}\end{array}$ & $\begin{array}{l}3,9 \pm 1,5 \\
\mathrm{~N}=6 \\
\mathrm{~b}\end{array}$ & $50,30 * * *$ & 71 \\
\hline $\begin{array}{l}\text { TMHT/TMST } \\
\text { errechnet }\end{array}$ & - & $\begin{array}{l}5,6 \pm 4,9 \\
\mathrm{~N}=51 \\
\mathrm{~b}\end{array}$ & $\begin{array}{l}2,2 \pm 0,5 \\
\mathrm{~N}=76 \\
\mathrm{a}\end{array}$ & - & $\begin{array}{l}2,3 \pm 1,4 \\
\mathrm{~N}=22 \\
\mathrm{a}\end{array}$ & $67,07 * * *$ & 149 \\
\hline $\begin{array}{l}\text { Trockenmasse } \\
\text { oberirdisch } \\
\text { Ernte }[\mathrm{g}]\end{array}$ & $\begin{array}{l}8,0 \pm 4,9 \\
\mathrm{~N}=20 \\
\mathrm{a}\end{array}$ & $\begin{array}{l}29,5 \pm \\
15,6 \\
N=5 \\
b \\
\end{array}$ & $\begin{array}{l}90,5 \pm 41,9 \\
\mathrm{~N}=6 \\
\mathrm{c}\end{array}$ & $\begin{array}{l}8,8 \pm 6,5 \\
\mathrm{~N}=34 \\
\mathrm{a}\end{array}$ & $\begin{array}{l}26,7 \pm \\
24,0 \\
N=6 \\
b\end{array}$ & $29,63 * * *$ & 71 \\
\hline $\begin{array}{l}\text { Trockenmasse } \\
\text { oberirdisch } \\
\text { errechnet }[\mathrm{g}]\end{array}$ & - & $\begin{array}{l}28,8 \pm \\
16,7 \\
N=51 \\
b\end{array}$ & $\begin{array}{l}77,9 \pm 41,8 \\
N=76 \\
c\end{array}$ & - & $\begin{array}{l}23,9 \pm \\
18,1 \\
N=22 \\
a\end{array}$ & $78,69 * * *$ & 149 \\
\hline $\begin{array}{l}\text { Trockenmasse } \\
\text { Spross/Wurzel } \\
\text { Ernte }\end{array}$ & $\begin{array}{l}0,8 \pm 0,4 \\
\mathrm{~N}=23 \\
\mathrm{a}\end{array}$ & $\begin{array}{l}1,0 \pm 0,5 \\
\mathrm{~N}=5 \\
\mathrm{a}, \mathrm{b}\end{array}$ & $\begin{array}{l}0,8 \pm 0,1 \\
\mathrm{~N}=6 \\
\mathrm{a}\end{array}$ & $\begin{array}{l}0,7 \pm 0,3 \\
\mathrm{~N}=34 \\
\mathrm{a}\end{array}$ & $\begin{array}{l}1,4 \pm 0,4 \\
N=6 \\
b\end{array}$ & $14,00^{* *}$ & 74 \\
\hline $\begin{array}{l}\text { Trockenmasse } \\
\text { Spross/Wurzel } \\
\text { errechnet }\end{array}$ & - & - & - & $\begin{array}{l}0,6 \pm 0,4 \\
N=117\end{array}$ & $\begin{array}{l}1,0 \pm 0,5 \\
\mathrm{~N}=24\end{array}$ & $4,04 * * *$ & 141 \\
\hline $\begin{array}{l}\text { TMHT+TMW } \\
\text { Ernte }[\mathrm{g}]\end{array}$ & $\begin{array}{l}17,3 \pm \\
10,2 \\
N=23 \\
a, b\end{array}$ & $\begin{array}{l}50,4 \pm \\
23,7 \\
\mathrm{~N}=5 \\
\mathrm{c} \\
\end{array}$ & $\begin{array}{l}147,0 \pm \\
54,9 \\
N=6 \\
d\end{array}$ & $\begin{array}{l}14,3 \pm 8,8 \\
N=34 \\
a\end{array}$ & $\begin{array}{l}33,5 \pm \\
26,1 \\
N=6 \\
b, c\end{array}$ & $29,20 * * *$ & 74 \\
\hline $\begin{array}{l}\text { TMHT+TMW } \\
\text { errechnet }[\mathrm{g}]\end{array}$ & - & - & - & $\begin{array}{l}17,2 \pm \\
13,7 \\
\mathrm{~N}=117\end{array}$ & $\begin{array}{l}30,3 \pm \\
19,5 \\
\mathrm{~N}=24\end{array}$ & $3,85^{* * *}$ & 141 \\
\hline $\begin{array}{l}\text { TM oberird./ } \\
\text { TM unterird. } \\
\text { Ernte }\end{array}$ & $\begin{array}{l}0,8 \pm 0,4 \\
\mathrm{~N}=20 \\
\mathrm{a}\end{array}$ & $\begin{array}{l}1,2 \pm 0,5 \\
\mathrm{~N}=5 \\
\mathrm{~b}, \mathrm{c}\end{array}$ & $\begin{array}{l}1,1 \pm 0,2 \\
\mathrm{~N}=6 \\
\mathrm{~b}\end{array}$ & $\begin{array}{l}1,0 \pm 0,3 \\
\mathrm{~N}=34 \\
\mathrm{~b}\end{array}$ & $\begin{array}{l}1,8 \pm 0,5 \\
\mathrm{~N}=6 \\
\mathrm{c}\end{array}$ & $18,10^{* *}$ & 71 \\
\hline $\begin{array}{l}\text { TM oberird./ } \\
\text { TM unterird. } \\
\text { errechnet }\end{array}$ & - & - & - & - & $\begin{array}{l}1,5 \pm 0,6 \\
N=22\end{array}$ & - & 22 \\
\hline $\begin{array}{l}\text { Trockenmasse } \\
\text { gesamt } \\
\text { Ernte }[\mathrm{g}]\end{array}$ & $\begin{array}{l}19,2 \pm \\
10,4 \\
N=20 \\
a, b\end{array}$ & $\begin{array}{l}56,4 \pm \\
27,9 \\
N=5 \\
c\end{array}$ & $\begin{array}{l}172,2 \pm \\
71,8 \\
N=6 \\
d\end{array}$ & $\begin{array}{l}17,6 \pm \\
11,6 \\
N=34 \\
a\end{array}$ & $\begin{array}{l}40,9 \pm \\
33,8 \\
N=6 \\
b, c\end{array}$ & $27,03 * * *$ & 71 \\
\hline $\begin{array}{l}\text { Trockenmasse } \\
\text { gesamt } \\
\text { errechnet }[\mathrm{g}]\end{array}$ & - & - & - & - & $\begin{array}{l}37,7 \pm \\
23,2 \\
\mathrm{~N}=22 \\
\end{array}$ & - & 22 \\
\hline
\end{tabular}




\begin{tabular}{|c|c|c|c|c|c|c|c|}
\hline $\begin{array}{l}\text { Trockenmasse } \\
\text { Nadeln } \\
\text { Ernte }[\mathrm{g}]\end{array}$ & - & - & - & $\begin{array}{l}5,2 \pm 4,8 \\
\mathrm{~N}=34\end{array}$ & $\begin{array}{l}23,2 \pm 26 \\
\mathrm{~N}=6\end{array}$ & $1,97^{*}$ & 40 \\
\hline $\begin{array}{l}\text { Trockenmasse } \\
\text { oberird. m. Nadeln } \\
\text { Ernte }[\mathrm{g}]\end{array}$ & - & - & - & $\begin{array}{l}14,0 \pm \\
10,9 \\
\mathrm{~N}=34\end{array}$ & $\begin{array}{l}49,8 \pm \\
49,9 \\
\mathrm{~N}=6\end{array}$ & $2,16^{*}$ & 40 \\
\hline $\begin{array}{l}\text { TM oberird. } \\
\text { m.Nadeln } \\
\text { /TM Wurzel } \\
\text { Ernte }\end{array}$ & - & - & - & $\begin{array}{l}1,6 \pm 0,5 \\
\mathrm{~N}=34\end{array}$ & $\begin{array}{l}3,0 \pm 1,2 \\
\mathrm{~N}=6\end{array}$ & $3,03 * *$ & 40 \\
\hline $\begin{array}{l}\text { Trockenmasse } \\
\text { gesamt m. Nadeln } \\
\text { Ernte }[\mathrm{g}]\end{array}$ & - & - & - & $\begin{array}{l}22,8 \pm \\
16,0 \\
\mathrm{~N}=34 \\
\end{array}$ & $\begin{array}{l}64,0 \pm \\
59,7 \\
\mathrm{~N}=6 \\
\end{array}$ & $1,82 *$ & 40 \\
\hline
\end{tabular}

- keine Daten aufgenommen bzw. Berechnung nicht möglich

* zwecks Vergleichbarkeit reduziert auf die auch noch in 2006 lebenden, nicht (durch Wild) geschädigten Bäume

** mit Hilfe von Formeln (Volumen) oder Regressionsgleichungen aus Messwerten errechnet

*** an der bei Versuchsabschluss geernteten Stichprobe gemessene Werte 
Tab. A 16: Zuwachs [cm] des Haupttriebs im 1. und 2. Vegetationsjahr getrennt nach Baumarten und Varianten (s. S. 20); MW u. Std.abw.; Ergebnisse von Wilcoxon-Tests (Z) auf signifikante Unterschiede zwischen beiden Jahren; positive Entwicklung = signifikant höherer Zuwachs im 2. Jahr, negative Entwicklung = signifikant geringerer Zuwachs im 2. Jahr

\begin{tabular}{|c|c|c|c|c|c|c|}
\hline & & Ahorn (n) & Eberesche (n) & Erle (n) & Douglasie (n) & Kiefer (n) \\
\hline \multirow{3}{*}{ V1 } & Ergebnis Wilcoxon-Test (Z) & $-1,34$ & $-2,02^{*}$ & $-1,27$ & $-0,27$ & $-0,55$ \\
\hline & Zuwachs $2005[\mathrm{~cm}]$ & $2 \pm 2(4)$ & $6 \pm 4(5)$ & $10 \pm 6(7)$ & $9 \pm 3(5)$ & $7 \pm 5(5)$ \\
\hline & Zuwachs $2006[\mathrm{~cm}]$ & $0 \pm 0(4)$ & $3 \pm 2(5)$ & $16 \pm 13(7)$ & $10 \pm 7(5)$ & $8 \pm 2(5)$ \\
\hline \multirow{3}{*}{ V2 } & Ergebnis Wilcoxon-Test (Z) & $-1,00$ & $-0,40$ & $-0,07$ & $-0,17$ & - \\
\hline & Zuwachs $2005[\mathrm{~cm}]$ & $3 \pm 1(3)$ & $7 \pm 5(6)$ & $13 \pm 10(8)$ & $5 \pm 2(8)$ & - \\
\hline & Zuwachs 2006 [cm] & $2 \pm 2(3)$ & $10 \pm 8(6)$ & $12 \pm 7(8)$ & $7 \pm 8(8)$ & - \\
\hline \multirow{3}{*}{ V3 } & Ergebnis Wilcoxon-Test (Z) & $-0,91$ & $-0,45$ & $-1,36$ & $-0,73$ & - \\
\hline & Zuwachs $2005[\mathrm{~cm}]$ & $2 \pm 1(6)$ & $8 \pm 7(3)$ & $9 \pm 4(7)$ & $7 \pm 1(4)$ & - \\
\hline & Zuwachs 2006 [cm] & $1 \pm 1(6)$ & $7 \pm 6(3)$ & $15 \pm 13(7)$ & $13 \pm 13(4)$ & - \\
\hline \multirow{3}{*}{ V4 } & Ergebnis Wilcoxon-Test (Z) & $-0,52$ & $-1,08$ & $-1,94^{*}$ & $-1,52$ & - \\
\hline & Zuwachs $2005[\mathrm{~cm}]$ & $6 \pm 7(6)$ & $6 \pm 6(5)$ & $\underline{10 \pm 5(10)}$ & $3 \pm 2(8)$ & - \\
\hline & Zuwachs $2006[\mathrm{~cm}]$ & $6 \pm 6(6)$ & $14 \pm 13(5)$ & $\underline{15 \pm 12(10)}$ & $6 \pm 4(8)$ & - \\
\hline \multirow{3}{*}{ V5 } & Ergebnis Wilcoxon-Test (Z) & - & $-1,21$ & $-1,48$ & $-1,47$ & $-1,07$ \\
\hline & Zuwachs $2005[\mathrm{~cm}]$ & - & $4 \pm 4(5)$ & $7 \pm 2(5)$ & $3 \pm 2(7)$ & $10 \pm 3(3)$ \\
\hline & Zuwachs 2006 [cm] & - & $8 \pm 5(5)$ & $13 \pm 8(5)$ & $5 \pm 4(7)$ & $15 \pm 6(3)$ \\
\hline \multirow{3}{*}{ V6 } & Ergebnis Wilcoxon-Test (Z) & 0,00 & $-1,21$ & $-2,52^{* *}$ & $-1,12$ & - \\
\hline & Zuwachs 2005 [cm] & $2 \pm 1(3)$ & $4 \pm 2(6)$ & $\underline{7 \pm 5(9)}$ & $3 \pm 1(8)$ & - \\
\hline & Zuwachs 2006 [cm] & $2 \pm 3(3)$ & $8 \pm 8(6)$ & $\underline{14 \pm 9}(9)$ & $5 \pm 4(8)$ & - \\
\hline \multirow{3}{*}{ V7 } & Ergebnis Wilcoxon-Test (Z) & $-0,18$ & $-0,25$ & $-1,83^{*}$ & $-1,83^{*}$ & - \\
\hline & Zuwachs $2005[\mathrm{~cm}]$ & $2 \pm 1(4)$ & $7 \pm 4(7)$ & $\underline{14 \pm 2(5)}$ & $\underline{7 \pm 4}(5)$ & - \\
\hline & Zuwachs 2006 [cm] & $2 \pm 2(4)$ & $8 \pm 5(7)$ & $23 \pm 7(5)$ & $13 \pm 8(5)$ & - \\
\hline \multirow{3}{*}{ V8 } & Ergebnis Wilcoxon-Test (Z) & $-0,40$ & $-1,15$ & $-1,35$ & $-1,99 *$ & - \\
\hline & Zuwachs $2005[\mathrm{~cm}]$ & $2 \pm 2(6)$ & $6 \pm 5(7)$ & $13 \pm 5(7)$ & $\underline{3 \pm 1}(7)$ & - \\
\hline & Zuwachs $2006[\mathrm{~cm}]$ & $5 \pm 9(6)$ & $8 \pm 6(7)$ & $20 \pm 13(7)$ & $\underline{8 \pm 5}(7)$ & - \\
\hline \multirow{3}{*}{ V9 } & Ergebnis Wilcoxon-Test (Z) & $-2,20^{*}$ & $-1,44$ & $-1,90^{*}$ & $-1,89 *$ & $-1,83^{*}$ \\
\hline & Zuwachs $2005[\mathrm{~cm}]$ & $\underline{2 \pm 2(6)}$ & $8 \pm 7(8)$ & $\underline{11 \pm 5(10)}$ & $6 \pm 3(7)$ & $\underline{5 \pm 5(4)}$ \\
\hline & Zuwachs $2006[\mathrm{~cm}]$ & $\underline{7 \pm 5(6)}$ & $13 \pm 8(8)$ & $\underline{18 \pm 12(10)}$ & $\underline{11 \pm 7(7)}$ & $24 \pm 4(4)$ \\
\hline \multirow{3}{*}{ V10 } & Ergebnis Wilcoxon-Test (Z) & $-2,02^{*}$ & $-2,10^{*}$ & $-1,95^{*}$ & $-1,10$ & $-2,02^{*}$ \\
\hline & Zuwachs $2005[\mathrm{~cm}]$ & $\underline{2 \pm 2}(6)$ & $9 \pm 4(8)$ & $9 \pm 7(10)$ & $5 \pm 2(9)$ & $\underline{10 \pm 7}(5)$ \\
\hline & Zuwachs 2006 [cm] & $\underline{6 \pm 6}(6)$ & $\underline{19 \pm 9}(8)$ & $\underline{17 \pm 15}(10)$ & $8 \pm 5(9)$ & $\underline{25 \pm 11(5)}$ \\
\hline \multirow{3}{*}{ V11 } & Ergebnis Wilcoxon-Test (Z) & $-0,94$ & & & $-1,52$ & \\
\hline & Zuwachs $2005[\mathrm{~cm}]$ & $4 \pm 3(7)$ & & & $4 \pm 3(7)$ & \\
\hline & Zuwachs $2006[\mathrm{~cm}]$ & $5 \pm 6(7)$ & & & $6 \pm 3(7)$ & \\
\hline \multirow{3}{*}{ V12 } & Ergebnis Wilcoxon-Test (Z) & $-0,31$ & & & $-1,36$ & \\
\hline & Zuwachs $2005[\mathrm{~cm}]$ & $3 \pm 1(7)$ & & & $4 \pm 1(6)$ & \\
\hline & Zuwachs $2006[\mathrm{~cm}]$ & $3 \pm 3(7)$ & & & $6 \pm 3(6)$ & \\
\hline \multirow{3}{*}{ V13 } & Ergebnis Wilcoxon-Test (Z) & $-2,34^{* *}$ & & & $-2,67^{* *}$ & \\
\hline & Zuwachs $2005[\mathrm{~cm}]$ & $\underline{1 \pm 1(7)}$ & & & $\underline{6 \pm 6}(9)$ & \\
\hline & Zuwachs $2006[\mathrm{~cm}]$ & $\underline{3 \pm 1}(7)$ & & & $\underline{13 \pm 8(9)}$ & \\
\hline \multirow{3}{*}{ V14 } & Ergebnis Wilcoxon-Test (Z) & $-2,02^{*}$ & & & $-2,19 *$ & \\
\hline & Zuwachs $2005[\mathrm{~cm}]$ & $2 \pm 2(7)$ & & & $4 \pm 3(9)$ & \\
\hline & Zuwachs 2006 [cm] & $\underline{5 \pm 4}(7)$ & & & $9 \pm 5(9)$ & \\
\hline \multirow{3}{*}{ V15 } & Ergebnis Wilcoxon-Test (Z) & $-1,62$ & & & $-2,67^{* *}$ & \\
\hline & Zuwachs $2005[\mathrm{~cm}]$ & $2 \pm 1(7)$ & & & $\underline{3 \pm 3}(10)$ & \\
\hline & Zuwachs 2006 [cm] & $4 \pm 3(7)$ & & & $12 \pm 13(10)$ & \\
\hline \multirow{3}{*}{ V16 } & Ergebnis Wilcoxon-Test (Z) & $-1,28$ & & & $-1,75^{*}$ & \\
\hline & Zuwachs $2005[\mathrm{~cm}]$ & $3 \pm 2(6)$ & & & $\underline{3 \pm 2}(8)$ & \\
\hline & Zuwachs 2006 [cm] & $6 \pm 7(6)$ & & & $\underline{6 \pm 4}(8)$ & \\
\hline
\end{tabular}

- zu geringe Zahl (<3) überlebender, nicht (durch Wild) geschädigter Versuchspflanzen 


\section{Versorgung und Belastung der Rot-Eiche}

Tab. A 17: Blattspiegelwerte der Eichen (Mischproben) auf den Versuchsflächen B und D im 1. (2005) und auf Fläche D im 2. (2006) Vegetationsjahr

\begin{tabular}{|r|l|l|l|l|}
\hline \multirow{2}{*}{ Element } & \multicolumn{2}{|l|}{2005} & & 2006 \\
\cline { 2 - 3 } & $\mathrm{B}$ & $\mathrm{D}$ & & $\mathrm{D}$ \\
\hline $\mathrm{N}[\mathrm{mg} / \mathrm{g}]$ & 21,1 & 21,9 & $>$ & $19,6 \pm 3,1$ \\
\hline $\mathrm{P}[\mathrm{mg} / \mathrm{g}]$ & 1,8 & 0,9 & $<$ & $1,2 \pm 0,3$ \\
\hline $\mathrm{K}[\mathrm{mg} / \mathrm{g}]$ & 8,8 & 6,7 & $>$ & $5,2 \pm 1,8$ \\
\hline $\mathrm{Ca}[\mathrm{mg} / \mathrm{g}]$ & 8,2 & 10,9 & $>$ & $5,5 \pm 1,4$ \\
\hline $\mathrm{Mg}[\mathrm{mg} / \mathrm{g}]$ & 2,7 & 5,5 & $>$ & $4,4 \pm 1,3$ \\
\hline $\mathrm{S}[\mathrm{mg} / \mathrm{g}]$ & & & & $3,2 \pm 1,4$ \\
\hline $\mathrm{Fe}[\mathrm{mg} / \mathrm{kg}]$ & & & & $1163 \pm 980$ \\
\hline $\mathrm{Mn}[\mathrm{mg} / \mathrm{kg}]$ & & & & $1631 \pm 1068$ \\
\hline $\mathrm{Zn}[\mathrm{mg} / \mathrm{kg}]$ & 33,9 & 58,8 & $>$ & $28,0 \pm 4,8$ \\
\hline $\mathrm{Cu}[\mathrm{mg} / \mathrm{kg}]$ & 14,1 & 18,6 & $>$ & $15,5 \pm 5,9$ \\
\hline $\mathrm{Al}[\mathrm{mg} / \mathrm{kg}]$ & & & & $2058 \pm 1534$ \\
\hline $\mathrm{Na}[\mathrm{mg} / \mathrm{kg}]$ & & & & $51,1 \pm 23,2$ \\
\hline $\mathrm{Ni}[\mathrm{mg} / \mathrm{kg}]$ & 11,7 & 13,1 & $>$ & $11,8 \pm 4,1$ \\
\hline $\mathrm{Co}[\mathrm{mg} / \mathrm{kg}]$ & 2,1 & 1,9 & $<$ & $5,1 \pm 3,7$ \\
\hline $\mathrm{Pb}[\mathrm{mg} / \mathrm{kg}]$ & $\mathrm{u}$ & 3,9 & $>$ & $\mathrm{u}$ \\
\hline $\mathrm{Cd}[\mathrm{mg} / \mathrm{kg}]$ & $\mathrm{u}$ & $\mathrm{u}$ & $=$ & $\mathrm{u}$ \\
\hline $\mathrm{Cr}[\mathrm{mg} / \mathrm{kg}]$ & 1,4 & 5,2 & $>$ & $4,0 \pm 2,6$ \\
\hline
\end{tabular}

u Gehalt unterhalb der Nachweisgrenze

$>$ Zunahme, $<$ Abnahme, = unverändert

Tab. A 18: Makronährstoff-Gehalte [mg/g] im Eichen-Laub (Mischproben) verschiedener Varianten (s. S. 20) auf Fläche D (fehlende Varianten V2, V3, V5, V6, V8, V9 zum Zeitpunkt der Probennahme im August 2006 ausgefallen)

\begin{tabular}{|l|l|l|l|l|l|l|}
\hline & $\mathrm{N}$ & $\mathrm{P}$ & $\mathrm{K}$ & $\mathrm{Ca}$ & $\mathrm{Mg}$ & $\mathrm{S}$ \\
\hline V1 & 15,3 & 1,2 & 6,1 & 4,7 & 3,9 & 4,2 \\
\hline V4 & 19,9 & 1,2 & 7,0 & 3,5 & 3,9 & 2,4 \\
\hline V7 & 21,3 & 1,2 & 6,0 & 7,3 & 5,3 & 4,6 \\
\hline V10 & 19,1 & 1,1 & 4,3 & 5,8 & 3,4 & 1,5 \\
\hline V11 & 25,4 & 1,7 & 7,5 & 4,4 & 3,1 & 2,4 \\
\hline V12 & 21,3 & 1,1 & 7,0 & 6,9 & 4,4 & 3,3 \\
\hline V13 & 20,9 & 1,6 & 5,2 & 7,0 & 4,7 & 2,6 \\
\hline V14 & 19,0 & 1,3 & 3,8 & 6,4 & 3,4 & 1,4 \\
\hline V15 & 19,0 & 0,8 & 2,1 & 3,5 & 4,5 & 4,4 \\
\hline V16 & 14,7 & 1,0 & 3,1 & 5,7 & 7,6 & 5,6 \\
\hline
\end{tabular}


Tab. A 19: Gehalte an Mikronährstoffen (Fe, Mn, Zn, Cu), nützlichen Elementen (Al, Ni, Na, Co) und Schadstoffen (Pb, Cd, Cr) [mg/kg] im Eichen-Laub (Mischproben) verschiedener Varianten (s. S. 20) auf Fläche D (fehlende Varianten V2, V3, V5, V6, V8, V9: zum Zeitpunkt der Probennahme im August 2006 ausgefallen)

\begin{tabular}{|l|l|l|l|l|l|l|l|l|l|l|l|}
\hline & $\mathrm{Fe}$ & $\mathrm{Mn}$ & $\mathrm{Zn}$ & $\mathrm{Cu}$ & $\mathrm{Al}$ & $\mathrm{Na}$ & $\mathrm{Ni}$ & $\mathrm{Co}$ & $\mathrm{Pb}$ & $\mathrm{Cd}$ & $\mathrm{Cr}$ \\
\hline V1 & 2324 & 87 & 21,2 & 23,7 & 4263 & 85,3 & 6,1 & 13,8 & $\mathrm{u}$ & $\mathrm{u}$ & 6,9 \\
\hline V4 & 1416 & 2774 & 33,5 & 16,2 & 2811 & 38,6 & 13,0 & 3,9 & $\mathrm{u}$ & $\mathrm{u}$ & 5,7 \\
\hline V7 & 3291 & 3604 & 35,0 & 26,4 & 4850 & 79,0 & 8,9 & 5,4 & $\mathrm{u}$ & $\mathrm{u}$ & 8,5 \\
\hline V10 & 727 & 912 & 24,6 & 15,5 & 1237 & 30,1 & 8,7 & 2,7 & $\mathrm{u}$ & $\mathrm{u}$ & 3,0 \\
\hline V11 & 503 & 1078 & 33,0 & 17,5 & 1005 & 32,3 & 13,9 & 1,8 & $\mathrm{u}$ & $\mathrm{u}$ & 2,1 \\
\hline V12 & 1212 & 1678 & 23,4 & 10,1 & 2375 & 47,6 & 14,1 & 3,1 & $\mathrm{u}$ & $\mathrm{u}$ & 5,9 \\
\hline V13 & 195 & 2483 & 27,0 & 9,7 & 377 & 30,1 & 21,1 & 2,5 & $\mathrm{u}$ & $\mathrm{u}$ & 1,0 \\
\hline V14 & 167 & 1268 & 28,7 & 8,0 & 345 & 30,5 & 12,2 & 9,4 & $\mathrm{u}$ & $\mathrm{u}$ & 0,9 \\
\hline V15 & 923 & 638 & 23,8 & 14,6 & 1709 & 83,6 & 10,1 & 4,9 & $\mathrm{u}$ & $\mathrm{u}$ & 3,2 \\
\hline V16 & 868 & 1788 & 29,9 & 12,9 & 1609 & 53,5 & 10,2 & 3,7 & $\mathrm{u}$ & $\mathrm{u}$ & 3,0 \\
\hline
\end{tabular}

u Gehalt unterhalb der Nachweisgrenze

Tab. A 20: Bewertung der Element-Gehalte im Eichen-Laub (Quellen: s. Anh. 2) der beprobten Versuchsvarianten (s. S. 20)

\begin{tabular}{|c|c|c|c|c|c|c|c|c|c|c|}
\hline \multirow{2}{*}{ Element } & \multicolumn{10}{|c|}{ Bewertung der Element-Gehalte im Laub der Versuchsvarianten } \\
\hline & V1 & V4 & V7 & V10 & V11 & V12 & V13 & V14 & V15 & V16 \\
\hline \multicolumn{11}{|l|}{$\mathrm{N}$} \\
\hline \multicolumn{11}{|l|}{$P$} \\
\hline \multicolumn{11}{|l|}{$\mathrm{K}$} \\
\hline \multicolumn{11}{|l|}{$\mathrm{Ca}$} \\
\hline \multicolumn{11}{|l|}{$\mathrm{Mg}$} \\
\hline \multicolumn{11}{|l|}{$\mathrm{S}$} \\
\hline \multicolumn{11}{|l|}{$\mathrm{Fe}$} \\
\hline \multicolumn{11}{|l|}{$\mathrm{Mn}$} \\
\hline \multicolumn{11}{|l|}{$\mathrm{Zn}$} \\
\hline \multicolumn{11}{|l|}{$\mathrm{Cu}$} \\
\hline \multicolumn{11}{|l|}{$\mathrm{Al}$} \\
\hline \multicolumn{11}{|l|}{$\mathrm{Na}$} \\
\hline \multicolumn{11}{|l|}{$\mathrm{Ni}$} \\
\hline \multicolumn{11}{|l|}{ Co } \\
\hline $\mathrm{Cr}$ & & & & & & & & & & \\
\hline
\end{tabular}

\begin{tabular}{|c|c|c|c|c|}
\hline & & & & \\
\hline unter optimal, Mangel & $\begin{array}{c}\text { optimal, normal, } \\
\text { ausreichend, } \\
\text { unkritisch }\end{array}$ & überversorgt & $\begin{array}{c}\text { deutlich überversorgt, } \\
\text { kritisch }\end{array}$ & über extrem, toxisch \\
\hline
\end{tabular}


Tab. A 21: Relative Blattspiegelwerte [\%; V1 = $100 \%$ ] der beprobten Eichen-Varianten (s. S. 20) auf Fläche D; Mischprobe je Variante; blau markiert mind. $25 \%$ höhere Werte als Kontrolle (V1), rot markiert mind. $25 \%$ niedrigere Werte als Kontrolle

\begin{tabular}{|c|c|c|c|c|c|c|c|c|c|c|}
\hline \multirow{2}{*}{ Element } & \multicolumn{10}{|c|}{ relative Element-Gehalte im Laub der Versuchsvarianten [\%; V1 = $100 \%]$} \\
\hline & V1 & V4 & V7 & V10 & V11 & V12 & V13 & V14 & V15 & V16 \\
\hline $\mathrm{N}$ & 100 & 130 & 139 & 125 & 166 & 139 & 137 & 124 & 124 & 96 \\
\hline $\mathrm{P}$ & 100 & 100 & 100 & 92 & 142 & 92 & 133 & 108 & 67 & 83 \\
\hline $\mathrm{K}$ & 100 & 115 & 98 & 70 & 123 & 115 & 82 & 62 & 34 & 51 \\
\hline $\mathrm{Ca}$ & 100 & 74 & 155 & 123 & 94 & 147 & 149 & 136 & 74 & 121 \\
\hline $\mathrm{Mg}$ & 100 & 100 & 136 & 87 & 79 & $\overline{113}$ & $\overline{121}$ & 87 & 115 & 195 \\
\hline$S$ & 100 & 57 & 110 & 36 & 57 & 79 & 62 & 33 & 105 & 133 \\
\hline $\mathrm{Fe}$ & 100 & 61 & 142 & 31 & 22 & 52 & 8 & 7 & 40 & 37 \\
\hline $\mathrm{Mn}$ & 100 & 3188 & 4142 & 1048 & 1239 & 1928 & 2854 & 1457 & 733 & 2055 \\
\hline $\mathrm{Zn}$ & 100 & 158 & 165 & 116 & 156 & 110 & 127 & 135 & 112 & 141 \\
\hline $\mathrm{Cu}$ & 100 & 68 & 111 & 65 & 74 & 43 & 41 & 34 & 62 & 54 \\
\hline Al & 100 & 66 & 114 & 29 & 24 & 56 & 9 & 8 & 40 & 38 \\
\hline $\mathrm{Na}$ & 100 & 45 & 93 & 35 & 38 & 56 & 35 & 36 & 98 & 63 \\
\hline $\mathrm{Ni}$ & 100 & 213 & 146 & 143 & 228 & 231 & 346 & 200 & 166 & 167 \\
\hline Co & 100 & 28 & 39 & 20 & 13 & 22 & 18 & 68 & 36 & 27 \\
\hline $\mathrm{Cr}$ & 100 & 83 & 123 & 43 & 30 & 86 & 14 & 13 & 46 & 43 \\
\hline
\end{tabular}

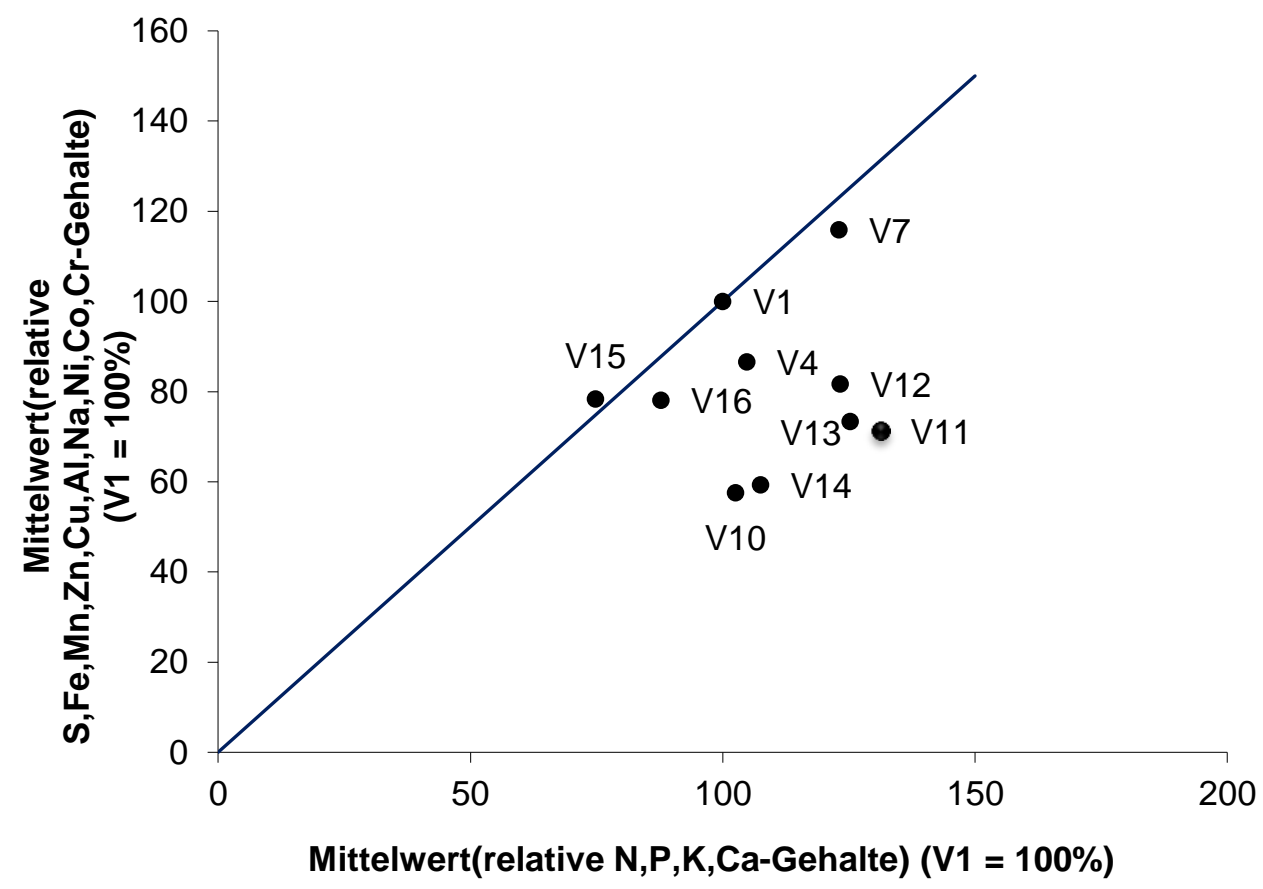

Abb. A 1: Relative Veränderung der Gehalte schädigend wirkender Elemente (Ab-/Zunahme der Schadstoffbelastung insgesamt) sowie der Nährstoff-Gehalte (Verbesserung/Verschlechterung der Ernährung) in den Behandlungsvarianten (s. S. 20) in Bezug auf die Kontrolle (V1) der Eichen

Anmerkung: Die Werte für Magnesium wurden ausgeklammert, da dieses Element aufgrund der überwiegend extrem hohen Gehalte durch Nährstoffantagonismen (z.B. auf die Kaliumversorgung) negativ wirkte. 


\section{Versorgung und Belastung des Spitz-Ahorns}

Tab. A 22: Blattspiegelwerte der Ahorne (Mischproben) auf den drei Versuchsflächen im 1. (2005) und auf Fläche D im 2. (2006) Vegetationsjahr

\begin{tabular}{|c|c|c|c|c|c|}
\hline \multirow{2}{*}{ Element } & \multicolumn{3}{|c|}{2005} & & \multirow{2}{*}{$\begin{array}{l}2006 \\
D\end{array}$} \\
\hline & $\mathrm{A}$ & B & $\mathrm{D}$ & & \\
\hline $\mathrm{N}$ [mg/g] & 22,7 & 13,3 & 19,3 & $>$ & $15,7 \pm 2,7$ \\
\hline $\mathrm{P}[\mathrm{mg} / \mathrm{g}]$ & 1,5 & 1,0 & 1,5 & $>$ & $1,1 \pm 0,3$ \\
\hline $\mathrm{K}[\mathrm{mg} / \mathrm{g}]$ & 13,6 & 7,8 & 11,6 & $>$ & $5,5 \pm 2,2$ \\
\hline $\mathrm{Ca}[\mathrm{mg} / \mathrm{g}]$ & 7,8 & 15,4 & 3,8 & $<$ & $5,0 \pm 2,3$ \\
\hline $\mathrm{Mg}[\mathrm{mg} / \mathrm{g}]$ & 2,3 & 4,3 & 5,2 & $>$ & $4,4 \pm 1,6$ \\
\hline $\mathrm{S}[\mathrm{mg} / \mathrm{g}]$ & & & & & $4,5 \pm 1,7$ \\
\hline $\mathrm{Fe}[\mathrm{mg} / \mathrm{kg}]$ & & & & & $819 \pm 400$ \\
\hline $\mathrm{Mn}[\mathrm{mg} / \mathrm{kg}]$ & & & & & $1464 \pm 863$ \\
\hline $\mathrm{Zn}[\mathrm{mg} / \mathrm{kg}]$ & 35,7 & 70,3 & 53,1 & $>$ & $33,8 \pm 8,6$ \\
\hline $\mathrm{Cu}[\mathrm{mg} / \mathrm{kg}]$ & 23,5 & 18,4 & 22,4 & $>$ & $14,5 \pm 5,5$ \\
\hline $\mathrm{Al}[\mathrm{mg} / \mathrm{kg}]$ & & & & & $1562 \pm 767$ \\
\hline $\mathrm{Na}[\mathrm{mg} / \mathrm{kg}]$ & & & & & $65,3 \pm 31,0$ \\
\hline $\mathrm{Ni}[\mathrm{mg} / \mathrm{kg}]$ & 16,5 & 23,5 & 14,4 & $>$ & $10,8 \pm 5,9$ \\
\hline Co $[\mathrm{mg} / \mathrm{kg}]$ & 7,1 & 2,5 & 3,1 & $<$ & $4,0 \pm 1,9$ \\
\hline $\mathrm{Pb}[\mathrm{mg} / \mathrm{kg}]$ & $\mathrm{u}$ & 3,7 & 4,7 & $>$ & $\mathrm{u}$ \\
\hline $\mathrm{Cd}[\mathrm{mg} / \mathrm{kg}]$ & $\mathrm{u}$ & 0,36 & $\mathrm{u}$ & $<$ & 0,0074 \\
\hline $\mathrm{Cr}[\mathrm{mg} / \mathrm{kg}]$ & 1,3 & 1,4 & 4,4 & $>$ & $3,0 \pm 1,4$ \\
\hline
\end{tabular}

u Gehalt unterhalb der Nachweisgrenze

$>$ Zunahme, < Abnahme, = unverändert

Tab. A 23: Makronährstoff-Gehalte [mg/g] im Ahorn-Laub (Mischproben) verschiedener Varianten (s. S. 20) auf Fläche D (fehlende Variante V5 zum Zeitpunkt der Probennahme im August 2006 ausgefallen)

\begin{tabular}{|l|l|l|l|l|l|l|}
\hline & $\mathrm{N}$ & $\mathrm{P}$ & $\mathrm{K}$ & $\mathrm{Ca}$ & $\mathrm{Mg}$ & $\mathrm{S}$ \\
\hline V1 & 14,2 & 0,7 & 7,2 & 2,6 & 6,6 & 7,9 \\
\hline V2 & 16,0 & 0,9 & 8,0 & 3,9 & 4,5 & 4,5 \\
\hline V3 & 18,5 & 0,8 & 5,6 & 7,5 & 3,5 & 3,1 \\
\hline V4 & 16,2 & 0,7 & 2,4 & 2,2 & 5,6 & 4,2 \\
\hline V6 & 13,8 & 0,9 & 3,0 & 5,8 & 5,9 & 4,7 \\
\hline V7 & 16,8 & 1,4 & 7,7 & 6,3 & 2,9 & 4,1 \\
\hline V8 & 17,8 & 1,4 & 5,9 & 7,5 & 7,9 & 7,9 \\
\hline V9 & 13,8 & 1,4 & 4,7 & 6,5 & 5,8 & 5,9 \\
\hline V10 & 16,7 & 1,0 & 3,3 & 6,5 & 4,7 & 3,6 \\
\hline V11 & 18,0 & 0,8 & 10,5 & 2,7 & 3,4 & 4,0 \\
\hline V12 & 20,1 & 1,0 & 7,1 & 5,8 & 3,4 & 2,7 \\
\hline V13 & 16,3 & 0,6 & 3,5 & 6,1 & 2,5 & 1,9 \\
\hline V14 & 12,8 & 1,5 & 3,9 & 8,1 & 3,6 & 3,0 \\
\hline V15 & 9,4 & 1,3 & 4,3 & 1,3 & 2,2 & 3,8 \\
\hline V16 & 14,4 & 1,4 & 5,9 & 2,0 & 3,3 & 5,7 \\
\hline
\end{tabular}


Tab. A 24: Gehalte an Mikronährstoffen (Fe, Mn, Zn, Cu), nützlichen Elementen (Al, Ni, Na, Co) und Schadstoffen (Pb, Cd, Cr) [mg/kg] im Ahorn-Laub (Mischproben) verschiedener Varianten (s. S. 20) auf Fläche D (fehlende Variante V5: zum Zeitpunkt der Probennahme im August 2006 bereits ausgefallen)

\begin{tabular}{|l|l|l|l|l|l|l|l|l|l|l|l|}
\hline & $\mathrm{Fe}$ & $\mathrm{Mn}$ & $\mathrm{Zn}$ & $\mathrm{Cu}$ & $\mathrm{Al}$ & $\mathrm{Na}$ & $\mathrm{Ni}$ & $\mathrm{Co}$ & $\mathrm{Pb}$ & $\mathrm{Cd}$ & $\mathrm{Cr}$ \\
\hline V1 & 1216 & 703 & 30,9 & 22,8 & 2380 & 152,7 & 16,5 & 8,0 & $\mathrm{u}$ & $\mathrm{u}$ & 3,8 \\
\hline V2 & 1170 & 1310 & 28,7 & 19,5 & 2102 & 66,7 & 10,8 & 3,9 & $\mathrm{u}$ & $\mathrm{u}$ & 4,4 \\
\hline V3 & 1095 & 2943 & 33,4 & 19,7 & 2030 & 75,8 & 7,4 & 3,8 & $\mathrm{u}$ & 0,11 & 3,4 \\
\hline V4 & 1104 & 512 & 42,3 & 13,9 & 2438 & 90,1 & 28,7 & 5,9 & $\mathrm{u}$ & $\mathrm{u}$ & 4,2 \\
\hline V6 & 1336 & 2616 & 35,8 & 20,7 & 2191 & 71,2 & 11,1 & 4,0 & $\mathrm{u}$ & $\mathrm{u}$ & 4,8 \\
\hline V7 & 745 & 1456 & 38,6 & 10,3 & 1447 & 38,3 & 8,6 & 3,8 & $\mathrm{u}$ & $\mathrm{u}$ & 3,5 \\
\hline V8 & 1004 & 2734 & 53,2 & 16,1 & 1962 & 63,5 & 10,0 & 3,5 & $\mathrm{u}$ & $\mathrm{u}$ & 3,1 \\
\hline V9 & 514 & 2710 & 33,0 & 9,0 & 929 & 29,5 & 5,9 & 2,5 & $\mathrm{u}$ & $\mathrm{u}$ & 1,8 \\
\hline V10 & 702 & 1316 & 38,1 & 15,6 & 1263 & 47,8 & 6,2 & 2,6 & $\mathrm{u}$ & $\mathrm{u}$ & 2,5 \\
\hline V11 & 1466 & 1294 & 32,8 & 22,8 & 2903 & 76,9 & 11,7 & 5,9 & $\mathrm{u}$ & $\mathrm{u}$ & 5,6 \\
\hline V12 & 385 & 979 & 27,8 & 7,7 & 716 & 42,4 & 5,4 & 1,7 & $\mathrm{u}$ & $\mathrm{u}$ & 1,5 \\
\hline V13 & 253 & 1232 & 22,6 & 8,0 & 444 & - & 8,1 & 1,4 & $\mathrm{u}$ & $\mathrm{u}$ & 1,0 \\
\hline V14 & 457 & 1086 & 43,8 & 7,7 & 923 & 31,9 & 8,2 & 1,7 & $\mathrm{u}$ & $\mathrm{u}$ & 1,5 \\
\hline V15 & 345 & 482 & 25,7 & 10,9 & 694 & 62,4 & 8,2 & 5,7 & $\mathrm{u}$ & $\mathrm{u}$ & 2,2 \\
\hline V16 & 501 & 579 & 20,4 & 13,0 & 1012 & 65,1 & 15,5 & 6,1 & $\mathrm{u}$ & $\mathrm{u}$ & 2,0 \\
\hline
\end{tabular}

u Gehalt unterhalb der Nachweisgrenze

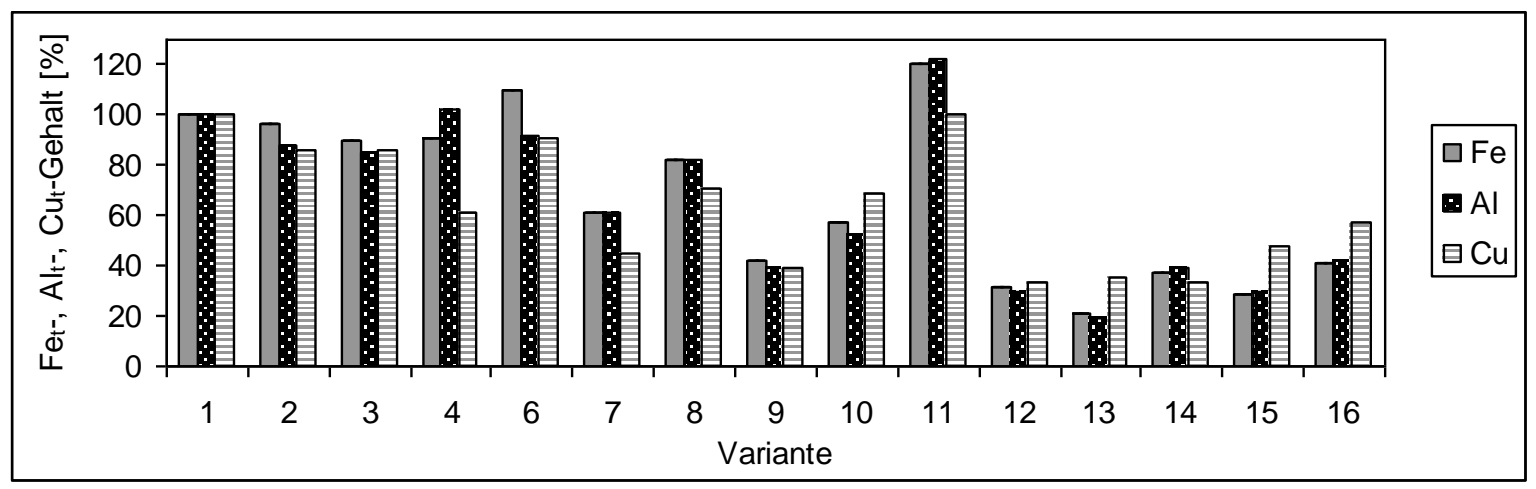

Abb. A 2: Relative $\mathrm{Fe}_{\mathrm{t}^{-}}, \mathrm{Al}_{\mathrm{t}^{-}}, \mathrm{Cu}_{\mathrm{t}}$-Gehalte [\%; 100\% entspricht dem jeweiligen Element-Gehalt in der unbehandelten Kontrolle = Variante 1] im Ahorn-Laub (Mischproben) verschiedener Varianten (s. S. 20) auf Fläche D (fehlende Variante V5 zum Zeitpunkt der Probennahme im August 2006 ausgefallen) 
Tab. A 25: Bewertung der Element-Gehalte im Ahorn-Laub (Quellen: s. Anh. 2) der beprobten Versuchsvarianten (s. S. 20)

\begin{tabular}{|c|c|c|c|c|c|c|c|c|c|c|c|c|c|c|c|}
\hline \multirow{2}{*}{ Element } & \multicolumn{15}{|c|}{ Bewertung der Element-Gehalte im Laub der Versuchsvarianten } \\
\hline & V1 & V2 & V3 & V4 & V6 & V7 & V8 & V9 & $\mathrm{V} 10$ & V11 & V12 & V13 & V14 & V15 & V16 \\
\hline $\mathrm{N}$ & & & & & & & & & & & & & & & \\
\hline$P$ & & & & & & & & & & & & & & & \\
\hline $\mathrm{K}$ & & & & & & & & & & & & & & & \\
\hline $\mathrm{Ca}$ & & & & & & & & & & & & & & & \\
\hline $\mathrm{Mg}$ & & & & & & & & & & & & & & & \\
\hline S & & & & & & & & & & & & & & & \\
\hline $\mathrm{Fe}$ & & & & & & & & & & & & & & & \\
\hline $\mathrm{Mn}$ & & & & & & & & & & & & & & & \\
\hline & & & & & & & & & & & & & & & \\
\hline $\mathrm{Zn}$ & & & & & & & & & & & & & & & \\
\hline $\mathrm{Cu}$ & & & & & & & & & & & & & & & \\
\hline $\mathrm{Al}$ & & & & & & & & & & & & & & & \\
\hline $\mathrm{Na}$ & & & & & & & & & & & & & & & \\
\hline $\mathrm{Ni}$ & & & & & & & & & & & & & & & \\
\hline Co & & & & & & & & & & & & & & & \\
\hline $\mathrm{Cr}$ & & & & & & & & & & & & & & & \\
\hline
\end{tabular}

\begin{tabular}{|c|c|c|c|c|}
\hline unter optimal, Mangel & $\begin{array}{c}\text { optimal, normal, } \\
\text { ausreichend, } \\
\text { unkritisch }\end{array}$ & überversorgt & $\begin{array}{c}\text { deutlich überversorgt, } \\
\text { kritisch }\end{array}$ & über extrem, toxisch \\
\hline
\end{tabular}


Tab. A 26: Relative Blattspiegelwerte [\%; V1 = 100 \%] der beprobten Ahorn-Varianten (s. S. 20) auf Fläche D; Mischprobe je Variante; blau markiert mind. $25 \%$ höhere Werte als Kontrolle (V1), rot markiert mind. $25 \%$ niedrigere Werte als Kontrolle

\begin{tabular}{|c|c|c|c|c|c|c|c|c|c|c|c|c|c|c|c|}
\hline \multirow{2}{*}{ Element } & \multicolumn{15}{|c|}{ relative Element-Gehalte im Laub der Versuchsvarianten [\%; V1 = $100 \%$ ] } \\
\hline & V1 & V2 & V3 & V4 & V6 & V7 & V8 & V9 & V10 & V11 & V12 & V13 & V14 & V15 & V16 \\
\hline $\mathrm{N}$ & 100 & 113 & 130 & 114 & 97 & 118 & 125 & 97 & 118 & 127 & 142 & 115 & 90 & 66 & 101 \\
\hline$P$ & 100 & 129 & 114 & 100 & 129 & 200 & 200 & 200 & 143 & 114 & 143 & 86 & 214 & 186 & 200 \\
\hline $\mathrm{K}$ & 100 & 111 & 78 & 33 & 42 & 107 & 82 & 65 & 46 & 146 & 99 & 49 & 54 & 60 & 82 \\
\hline $\mathrm{Ca}$ & 100 & 150 & 288 & 85 & 223 & 242 & 288 & 250 & 250 & 104 & 223 & 235 & 312 & 50 & 77 \\
\hline $\mathrm{Mg}$ & 100 & 68 & 53 & 85 & 89 & 44 & 120 & 88 & 71 & 52 & 52 & 38 & 55 & 33 & 50 \\
\hline$S$ & 100 & 57 & 39 & 53 & 53 & 59 & 100 & 75 & 46 & 51 & 34 & 24 & 34 & 48 & 72 \\
\hline $\mathrm{Fe}$ & 100 & 96 & 90 & 91 & 110 & 61 & 83 & 42 & 58 & 121 & 32 & 21 & 38 & 28 & 41 \\
\hline $\mathrm{Mn}$ & 100 & 186 & 418 & 73 & 372 & 207 & 389 & 385 & 187 & 184 & 139 & 175 & 154 & 69 & 82 \\
\hline $\mathrm{Zn}$ & 100 & 93 & 108 & 137 & 116 & 125 & 172 & 107 & 123 & 106 & 90 & 73 & 142 & 83 & 66 \\
\hline $\mathrm{Cu}$ & 100 & 86 & 86 & 61 & 91 & 45 & 71 & 39 & 68 & 100 & 34 & 35 & 34 & 48 & 57 \\
\hline $\mathrm{Al}$ & 100 & 88 & 85 & 102 & 92 & 61 & 82 & 39 & 53 & 122 & 30 & 19 & 39 & 29 & 43 \\
\hline $\mathrm{Na}$ & 100 & 44 & 50 & 59 & 47 & 25 & 42 & 19 & 31 & 50 & 28 & & 21 & 41 & 43 \\
\hline $\mathrm{Ni}$ & 100 & 65 & 45 & 174 & 67 & 52 & 61 & 36 & 38 & 71 & 33 & 49 & 50 & 50 & 94 \\
\hline Co & 100 & 49 & 48 & 74 & 50 & 48 & 44 & 31 & 33 & 74 & 21 & 18 & 21 & 71 & 76 \\
\hline $\mathrm{Cr}$ & 100 & 116 & 89 & 111 & 126 & 92 & 82 & 47 & 66 & 147 & 39 & 26 & 39 & 58 & 53 \\
\hline
\end{tabular}

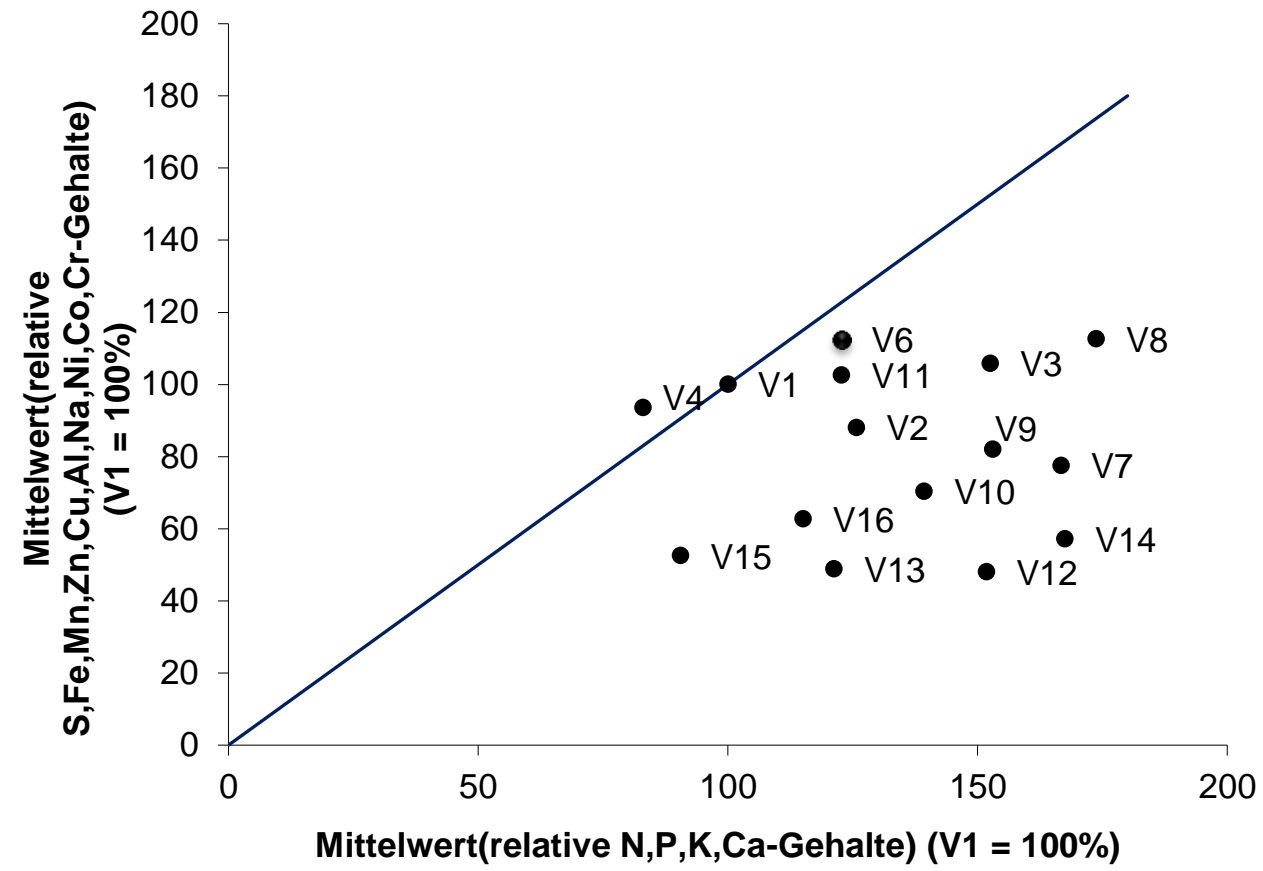

Abb. A 3: Relative Veränderung der Gehalte schädigend wirkender Elemente (Ab-/Zunahme der Schadstoffbelastung insgesamt) sowie der Nährstoff-Gehalte (Verbesserung/Verschlechterung der Ernährung) in den Behandlungsvarianten (s. S. 20) in Bezug auf die Kontrolle (V1) der Ahorne

Anmerkung: Die Werte für Magnesium wurden ausgeklammert, da dieses Element aufgrund der überwiegend extrem hohen Gehalte durch Nährstoffantagonismen (z.B. auf die Kaliumversorgung) negativ wirkte. 


\section{Versorgung und Belastung der Eberesche}

Tab. A 27: Blattspiegelwerte der Ebereschen (Mischproben) auf den drei Versuchsflächen im 1. (2005) und auf Fläche D im 2. (2006) Vegetationsjahr

\begin{tabular}{|c|c|c|c|c|c|}
\hline \multirow{2}{*}{ Element } & \multicolumn{3}{|c|}{2005} & & \multirow{2}{*}{$\begin{array}{l}2006 \\
D\end{array}$} \\
\hline & $\mathrm{A}$ & B & $\mathrm{D}$ & & \\
\hline $\mathrm{N}[\mathrm{mg} / \mathrm{g}]$ & 19,3 & 15,7 & 18,5 & $>$ & $14,7 \pm 2,9$ \\
\hline $\mathrm{P}[\mathrm{mg} / \mathrm{g}]$ & 1,6 & 1,3 & 1,1 & $>$ & $1,0 \pm 0,3$ \\
\hline $\mathrm{K}$ [mg/g] & 12,2 & 9,8 & 8,9 & $>$ & $5,7 \pm 2,8$ \\
\hline $\mathrm{Ca}[\mathrm{mg} / \mathrm{g}]$ & 18,0 & 18,9 & 13,1 & $>$ & $6,6 \pm 4,1$ \\
\hline $\mathrm{Mg}[\mathrm{mg} / \mathrm{g}]$ & 9,0 & 7,0 & 10,0 & $>$ & $5,9 \pm 3,3$ \\
\hline $\mathrm{S}[\mathrm{mg} / \mathrm{g}]$ & & & & & $3,7 \pm 2,0$ \\
\hline $\mathrm{Fe}[\mathrm{mg} / \mathrm{kg}]$ & & & & & $197 \pm 101$ \\
\hline $\mathrm{Mn}[\mathrm{mg} / \mathrm{kg}]$ & & & & & $1551 \pm 999$ \\
\hline $\mathrm{Zn}[\mathrm{mg} / \mathrm{kg}]$ & 45,8 & 31,9 & 46,7 & $>$ & $25,1 \pm 4,5$ \\
\hline $\mathrm{Cu}[\mathrm{mg} / \mathrm{kg}]$ & 17,2 & 16,0 & 18,0 & $>$ & $8,8 \pm 2,2$ \\
\hline $\mathrm{Al}[\mathrm{mg} / \mathrm{kg}]$ & & & & & $351 \pm 230$ \\
\hline $\mathrm{Na}[\mathrm{mg} / \mathrm{kg}]$ & & & & & $69,1 \pm 30,7$ \\
\hline $\mathrm{Ni}[\mathrm{mg} / \mathrm{kg}]$ & 24,1 & 29,9 & 20,2 & $>$ & $13,4 \pm 7,9$ \\
\hline Co $[\mathrm{mg} / \mathrm{kg}]$ & 3,6 & 2,4 & 2,7 & $<$ & $4,5 \pm 3,1$ \\
\hline $\mathrm{Pb}[\mathrm{mg} / \mathrm{kg}]$ & $\mathrm{u}$ & $\mathrm{u}$ & 2,7 & $>$ & $\mathrm{u}$ \\
\hline $\mathrm{Cd}[\mathrm{mg} / \mathrm{kg}]$ & $\mathrm{u}$ & $\mathrm{u}$ & $\mathrm{u}$ & $=$ & $\mathrm{u}$ \\
\hline $\mathrm{Cr}[\mathrm{mg} / \mathrm{kg}]$ & 1,0 & 0,7 & 1,3 & $>$ & $1,1 \pm 0,6$ \\
\hline
\end{tabular}

u Gehalt unterhalb der Nachweisgrenze

$>$ Zunahme, $<$ Abnahme, = unverändert

Tab. A 28: Makronährstoff-Gehalte [mg/g] im Ebereschen-Laub (Mischproben) verschiedener Varianten (s. S. 20) auf Fläche D

\begin{tabular}{|l|l|l|l|l|l|l|}
\hline & $\mathrm{N}$ & $\mathrm{P}$ & $\mathrm{K}$ & $\mathrm{Ca}$ & $\mathrm{Mg}$ & $\mathrm{S}$ \\
\hline V1 & 18,8 & 0,7 & 6,0 & 9,2 & 6,7 & 3,2 \\
\hline V2 & 15,5 & 0,7 & 3,2 & 6,8 & 7,9 & 2,9 \\
\hline V3 & 17,9 & 0,7 & 3,6 & 12,9 & 6,9 & 2,6 \\
\hline V4 & 12,2 & 0,9 & 4,7 & 6,8 & 8,2 & 3,5 \\
\hline V5 & 10,8 & 1,0 & 3,8 & 8,1 & 10,2 & 5,9 \\
\hline V6 & 10,2 & 1,3 & 10,9 & 8,2 & 7,2 & 6,0 \\
\hline V7 & 15,6 & 1,3 & 10,6 & 10,0 & 7,8 & 7,5 \\
\hline V8 & 15,2 & 0,6 & 3,5 & 0,9 & 1,6 & 2,1 \\
\hline V9 & 16,8 & 0,9 & 5,4 & 1,0 & 1,2 & 1,9 \\
\hline V10 & 14,3 & 1,4 & 5,0 & 1,5 & 1,0 & 1,9 \\
\hline
\end{tabular}


Tab. A 29: Gehalte an Mikronährstoffen ( $\mathrm{Fe}, \mathrm{Mn}, \mathrm{Zn}, \mathrm{Cu}$ ), nützlichen Elementen ( $\mathrm{Al}, \mathrm{Na}, \mathrm{Ni}, \mathrm{Co}$ ) und Schadstoffen $(\mathrm{Pb}, \mathrm{Cd}, \mathrm{Cr})[\mathrm{mg} / \mathrm{kg}]$ im Ebereschen-Laub (Mischproben) verschiedener Varianten (s. S. 20) auf Fläche D

\begin{tabular}{|l|l|l|l|l|l|l|l|l|l|l|l|}
\hline & Fe & Mn & $\mathrm{Zn}$ & $\mathrm{Cu}$ & $\mathrm{Al}$ & $\mathrm{Na}$ & $\mathrm{Ni}$ & $\mathrm{Co}$ & $\mathrm{Pb}$ & $\mathrm{Cd}$ & $\mathrm{Cr}$ \\
\hline V1 & 140 & 2714 & 22,7 & 7,3 & 175 & 75,1 & 14,1 & 4,2 & $\mathrm{u}$ & $\mathrm{u}$ & 0,7 \\
\hline V2 & 175 & 1686 & 19,8 & 6,9 & 236 & 108,7 & 28,6 & 2,3 & $\mathrm{u}$ & $\mathrm{u}$ & 0,6 \\
\hline V3 & 207 & 2931 & 34,6 & 7,1 & 283 & 94,0 & 12,9 & 2,9 & $\mathrm{u}$ & $\mathrm{u}$ & 1,1 \\
\hline V4 & 169 & 1136 & 23,9 & 8,3 & 225 & 88,8 & 16,3 & 2,9 & $\mathrm{u}$ & $\mathrm{u}$ & 0,8 \\
\hline V5 & 403 & 2013 & 24,7 & 11,9 & 717 & 101,6 & 10,4 & 2,2 & $\mathrm{u}$ & $\mathrm{u}$ & 1,8 \\
\hline V6 & 125 & 1759 & 26,3 & 10,7 & 173 & 61,5 & 21,2 & 3,0 & $\mathrm{u}$ & $\mathrm{u}$ & 0,9 \\
\hline V7 & 132 & 2345 & 30,7 & 7,4 & 174 & 72,2 & 13,8 & 2,8 & $\mathrm{u}$ & $\mathrm{u}$ & 1,1 \\
\hline V8 & 356 & 195 & 21,3 & 12,9 & 813 & 34,8 & 11,9 & 12,4 & $\mathrm{u}$ & $\mathrm{u}$ & 2,5 \\
\hline V9 & 100 & 346 & 22,1 & 8,1 & 321 & 24,4 & 1,9 & 5,1 & $\mathrm{u}$ & $\mathrm{u}$ & 0,9 \\
\hline V10 & 167 & 388 & 24,7 & 7,1 & 388 & 29,8 & 2,6 & 6,8 & $\mathrm{u}$ & $\mathrm{u}$ & 1,1 \\
\hline
\end{tabular}

u Gehalt unterhalb der Nachweisgrenze

Tab. A 30: Bewertung der Element-Gehalte im Ebereschen-Laub (Quellen: s. Anh. 2) der beprobten Versuchsvarianten (s. S. 20)

\begin{tabular}{|l|l|l|l|l|l|l|l|l|l|l|}
\hline \multirow{2}{*}{ Element } & \multicolumn{7}{|c|}{ Bewertung der Element-Gehalte im Laub der Versuchsvarianten } \\
\hline & V1 & V2 & V3 & V4 & V5 & V6 & V7 & V8 & V9 & V10 \\
\hline $\mathrm{N}$ & & & & & & & & & & \\
\hline $\mathrm{P}$ & & & & & & & & & & \\
\hline $\mathrm{K}$ & & & & & & & & & & \\
\hline $\mathrm{Ca}$ & & & & & & & & & & \\
\hline $\mathrm{Mg}$ & & & & & & & & & & \\
\hline $\mathrm{S}$ & & & & & & & & & & \\
\hline $\mathrm{Fe}$ & & & & & & & & & & \\
\hline $\mathrm{Mn}$ & & & & & & & & & & \\
\hline $\mathrm{Zn}$ & & & & & & & & & & \\
\hline $\mathrm{Cu}$ & & & & & & & & & & \\
\hline $\mathrm{Al}$ & & & & & & & & & & \\
\hline $\mathrm{Na}$ & & & & & & & & & \\
\hline $\mathrm{Ni}$ & & & & & & & & & \\
\hline $\mathrm{Co}$ & & & & & & & & & & \\
\hline $\mathrm{Cr}$ & & & & & & & & & \\
\hline
\end{tabular}

\begin{tabular}{|l|c|l|l|l|}
\hline unter optimal, Mangel & $\begin{array}{c}\text { optimal, normal, } \\
\text { ausreichend, } \\
\text { unkritisch }\end{array}$ & überversorgt & $\begin{array}{c}\text { deutlich überversorgt, } \\
\text { kritisch }\end{array}$ & über extrem, toxisch \\
\hline
\end{tabular}


Tab. A 31: Relative Blattspiegelwerte [\%; V1 = $100 \%$ ] der beprobten Ebereschen-Varianten (s. S. 20) auf Fläche D; Mischprobe je Variante; blau markiert mind. $25 \%$ höhere Werte als Kontrolle (V1), rot markiert mind. $25 \%$ niedrigere Werte als Kontrolle

\begin{tabular}{|c|c|c|c|c|c|c|c|c|c|c|}
\hline \multirow{2}{*}{ Element } & \multicolumn{10}{|c|}{$\begin{array}{l}\text { Relative Element-Gehalte im Laub der Versuchsvarianten } \\
{[\% ; \mathrm{V} 1=100 \%]}\end{array}$} \\
\hline & V1 & V2 & V3 & V4 & V5 & V6 & V7 & V8 & V9 & V10 \\
\hline $\mathrm{N}$ & 100 & 82 & 95 & 65 & 57 & 54 & 83 & 81 & 89 & 76 \\
\hline$P$ & 100 & 100 & 100 & 129 & 143 & 186 & 186 & 86 & 129 & 200 \\
\hline $\mathrm{K}$ & 100 & 53 & 60 & 78 & 63 & 182 & 177 & 58 & 90 & 83 \\
\hline $\mathrm{Ca}$ & 100 & 74 & 140 & 74 & 88 & 89 & 109 & 10 & 11 & 16 \\
\hline $\mathrm{Mg}$ & 100 & 118 & 103 & 122 & 152 & 107 & 116 & 24 & 18 & 15 \\
\hline$S$ & 100 & 91 & 81 & 109 & 184 & 188 & 234 & 66 & 59 & 59 \\
\hline $\mathrm{Fe}$ & 100 & 125 & 148 & 121 & 288 & 89 & 94 & 254 & 71 & 119 \\
\hline $\mathrm{Mn}$ & 100 & 62 & $\overline{108}$ & 42 & 74 & 65 & 86 & 7 & 13 & 14 \\
\hline $\mathrm{Zn}$ & 100 & 87 & 152 & 105 & 109 & 116 & 135 & 94 & 97 & 109 \\
\hline $\mathrm{Cu}$ & 100 & 95 & 97 & 114 & 163 & 147 & 101 & 177 & 111 & 97 \\
\hline $\mathrm{Al}$ & 100 & 135 & 162 & 129 & $\overline{410}$ & $\overline{99}$ & 99 & $\overline{465}$ & 183 & 222 \\
\hline $\mathrm{Na}$ & 100 & 145 & 125 & 118 & 135 & 82 & 96 & 46 & 32 & 40 \\
\hline $\mathrm{Ni}$ & 100 & 203 & 91 & 116 & 75 & 150 & 98 & 84 & 13 & 18 \\
\hline Co & 100 & 55 & 69 & 69 & 52 & 71 & 67 & 295 & 121 & 162 \\
\hline $\mathrm{Cr}$ & 100 & 86 & 157 & 114 & 257 & 129 & 157 & 357 & 129 & 157 \\
\hline
\end{tabular}

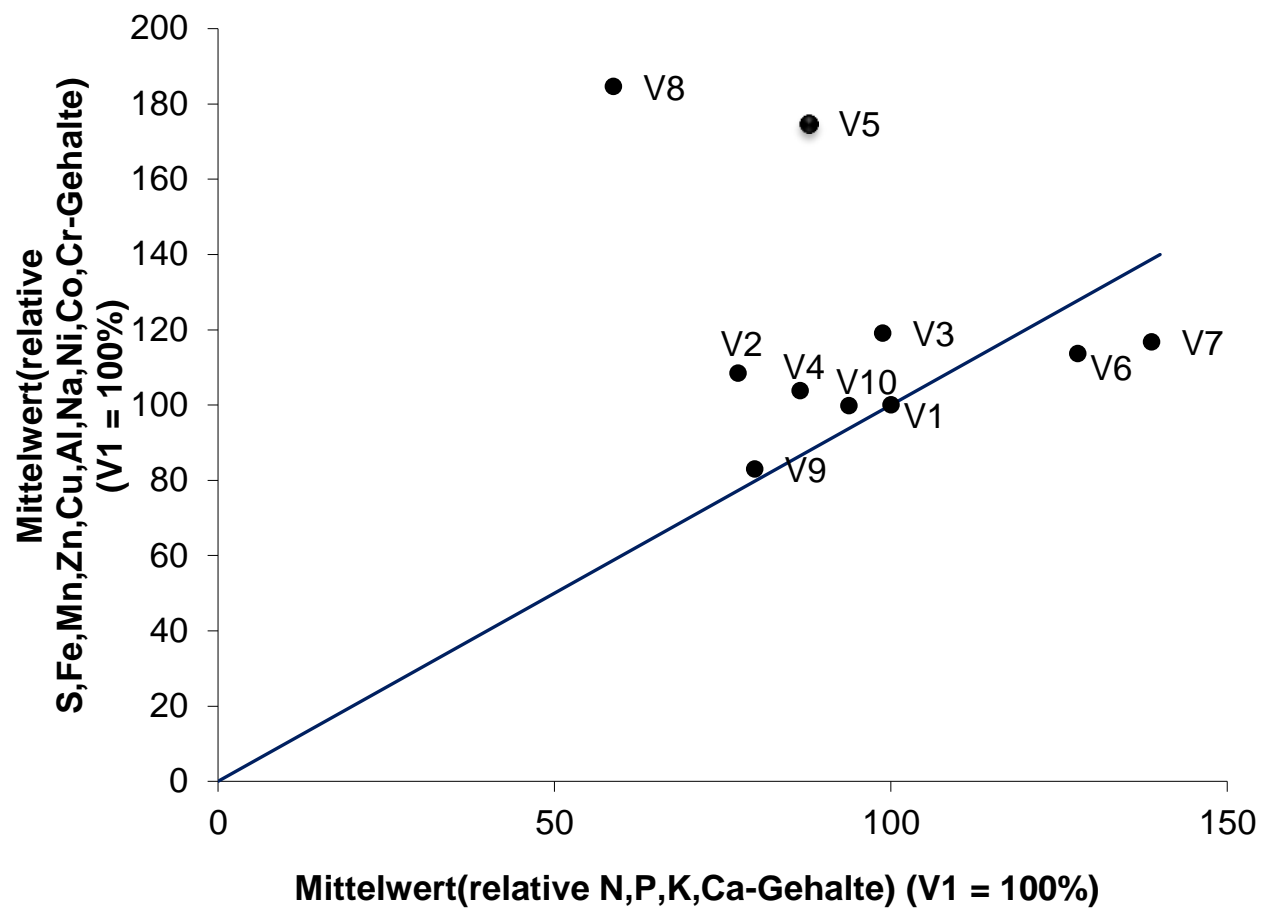

Abb. A 4: Relative Veränderung der Gehalte schädigend wirkender Elemente (Ab-/Zunahme der Schadstoffbelastung insgesamt) sowie der Nährstoff-Gehalte (Verbesserung/Verschlechterung der Ernährung) in den Behandlungsvarianten (s. S. 20) in Bezug auf die Kontrolle (V1) der Ebereschen

Anmerkung: Die Werte für Magnesium wurden ausgeklammert, da dieses Element aufgrund der überwiegend extrem hohen Gehalte durch Nährstoffantagonismen (z.B. auf die Kaliumversorgung) negativ wirkte. 


\section{Versorgung und Belastung der Schwarz-Erle}

Tab. A 32: Blattspiegelwerte der Erlen (Mischproben) auf den drei Versuchsflächen im 1. (2005) und auf Fläche D im 2. (2006) Vegetationsjahr

\begin{tabular}{|c|c|c|c|c|c|}
\hline \multirow{2}{*}{ Element } & \multicolumn{3}{|c|}{2005} & & \multirow{2}{*}{2006} \\
\hline & A & B & $\mathrm{D}$ & & \\
\hline $\mathrm{N}[\mathrm{mg} / \mathrm{g}]$ & 31,3 & 30,5 & 31,0 & $=$ & $30,8 \pm 3,1$ \\
\hline $\mathrm{P}[\mathrm{mg} / \mathrm{g}]$ & 1,5 & 1,9 & 1,3 & $<$ & $1,5 \pm 0,5$ \\
\hline $\mathrm{K}[\mathrm{mg} / \mathrm{g}]$ & 11,4 & 12,4 & 8,4 & $=$ & $8,2 \pm 2,3$ \\
\hline $\mathrm{Ca}[\mathrm{mg} / \mathrm{g}]$ & 11,6 & 15,7 & 11,1 & $>$ & $6,8 \pm 4,4$ \\
\hline $\mathrm{Mg}[\mathrm{mg} / \mathrm{g}]$ & 6,8 & 6,3 & 8,6 & $>$ & $5,0 \pm 1,8$ \\
\hline $\mathrm{S}[\mathrm{mg} / \mathrm{g}]$ & & & & & $3,6 \pm 1,4$ \\
\hline $\mathrm{Fe}[\mathrm{mg} / \mathrm{kg}]$ & & & & & $308 \pm 230$ \\
\hline $\mathrm{Mn}[\mathrm{mg} / \mathrm{kg}]$ & & & & & $1353 \pm 759$ \\
\hline $\mathrm{Zn}[\mathrm{mg} / \mathrm{kg}]$ & 90,0 & 94,1 & 100,2 & $=$ & $100,2 \pm 11,6$ \\
\hline $\mathrm{Cu}[\mathrm{mg} / \mathrm{kg}]$ & 27,6 & 26,4 & 25,0 & $>$ & $21,4 \pm 10,1$ \\
\hline $\mathrm{Al}[\mathrm{mg} / \mathrm{kg}]$ & & & & & $477 \pm 522$ \\
\hline $\mathrm{Na}[\mathrm{mg} / \mathrm{kg}]$ & & & & & $54,1 \pm 13,3$ \\
\hline $\mathrm{Ni}[\mathrm{mg} / \mathrm{kg}]$ & 56,0 & 55,4 & 39,6 & $>$ & $36,1 \pm 24,1$ \\
\hline Co $[\mathrm{mg} / \mathrm{kg}]$ & 3,9 & 4,5 & 2,7 & $<$ & $13,1 \pm 22,4$ \\
\hline $\mathrm{Pb}[\mathrm{mg} / \mathrm{kg}]$ & 3,2 & 4,4 & 4,6 & $>$ & $\mathrm{u}$ \\
\hline $\mathrm{Cd}[\mathrm{mg} / \mathrm{kg}]$ & $\mathrm{u}$ & 0,12 & $\mathrm{u}$ & $=$ & $\mathrm{u}$ \\
\hline $\mathrm{Cr}[\mathrm{mg} / \mathrm{kg}]$ & 0,9 & 1,2 & 1,8 & $<$ & $2,1 \pm 1,8$ \\
\hline
\end{tabular}

u Gehalt unterhalb der Nachweisgrenze

$>$ Zunahme, $<$ Abnahme, = unverändert

Tab. A 33: Makronährstoff-Gehalte [mg/g] im Erlen-Laub (Mischproben) verschiedener Varianten (s. S. 20) auf Fläche D

\begin{tabular}{|l|l|l|l|l|l|l|}
\hline & N & P & K & Ca & Mg & S \\
\hline V1 & 27,8 & 2,5 & 9,5 & 4,2 & 4,1 & 3,2 \\
\hline V2 & 28,2 & 1,5 & 5,4 & 3,6 & 7,0 & 4,7 \\
\hline V3 & 27,3 & 1,1 & 5,0 & 5,9 & 7,1 & 4,8 \\
\hline V4 & 37,5 & 1,6 & 6,1 & 3,1 & 7,1 & 3,4 \\
\hline V5 & 31,5 & 1,3 & 7,8 & 4,0 & 5,7 & 4,9 \\
\hline V6 & 30,1 & 1,7 & 8,9 & 3,8 & 5,0 & 3,7 \\
\hline V7 & 29,1 & 1,5 & 12,4 & 4,5 & 5,2 & 5,5 \\
\hline V8 & 32,2 & 0,7 & 7,4 & 12,9 & 3,0 & 1,3 \\
\hline V9 & 31,6 & 1,6 & 8,8 & 13,1 & 3,1 & 1,9 \\
\hline V10 & 32,9 & 1,4 & 10,6 & 13,4 & 2,4 & 2,4 \\
\hline
\end{tabular}


Tab. A 34: Gehalte an Mikronährstoffen (Fe, Mn, Zn, Cu), nützlichen Elementen (Al, Ni, Na, Co) und Schadstoffen (Pb, Cd, Cr) [mg/kg] im Erlen-Laub (Mischproben) verschiedener Varianten (s. S. 20) auf Fläche D

\begin{tabular}{|c|c|c|c|c|c|c|c|c|c|c|c|}
\hline & $\mathrm{Fe}$ & $\mathrm{Mn}$ & Zn & $\mathrm{Cu}$ & $\mathrm{Al}$ & $\mathrm{Na}$ & $\mathbf{N i}$ & Co & $\mathbf{P b}$ & Cd & $\mathrm{Cr}$ \\
\hline V1 & 171 & 1303 & 98,6 & 33,9 & 165 & 56,2 & 33,6 & 8,0 & $\mathrm{u}$ & $\mathrm{u}$ & 3,3 \\
\hline V2 & 251 & 728 & 93,4 & 17,4 & 374 & 56,3 & 84,9 & 4,1 & $\mathrm{u}$ & $\mathrm{u}$ & 1,4 \\
\hline V3 & 798 & 1103 & 86,4 & 29,4 & 1568 & 49,7 & 40,8 & 11,8 & $\mathrm{u}$ & $\mathrm{u}$ & 4,7 \\
\hline V4 & 318 & 577 & 105,3 & 23,1 & 554 & 41,4 & 64,4 & 3,4 & $\mathrm{u}$ & $\mathrm{u}$ & 1,4 \\
\hline V5 & 658 & 1714 & 107,8 & 35,0 & 1267 & 47,8 & 45,0 & 76,3 & $\mathrm{u}$ & $\mathrm{u}$ & 5,4 \\
\hline V6 & 173 & 839 & 88,5 & 21,3 & 226 & 41,4 & 30,8 & 3,1 & $\mathrm{u}$ & $\mathrm{u}$ & 1,3 \\
\hline V7 & 247 & 1397 & 113,9 & 27,0 & 337 & 37,6 & 26,1 & 9,7 & $\mathrm{u}$ & $\mathrm{u}$ & 2,2 \\
\hline V8 & 152 & 1609 & 98,5 & 10,1 & 93 & 61,5 & 10,2 & 4,7 & $\mathrm{u}$ & $\mathrm{u}$ & 0,3 \\
\hline V9 & 154 & 1024 & 89,0 & 8,3 & 99 & 73,2 & 10,0 & 5,0 & $\mathrm{u}$ & $\mathrm{u}$ & 0,4 \\
\hline V10 & 160 & 3240 & 120,9 & 9,0 & 83 & 76,5 & 15,0 & 5,4 & $\mathrm{u}$ & $\mathrm{u}$ & 0,4 \\
\hline
\end{tabular}

u Gehalt unterhalb der Nachweisgrenze

Tab. A 35: Bewertung der Element-Gehalte im Erlen-Laub (Quellen: s. Anh. 2) der beprobten Versuchsvarianten (s. S. 20)

\begin{tabular}{|c|c|c|c|c|c|c|c|c|c|c|}
\hline \multirow{2}{*}{ Element } & \multicolumn{10}{|c|}{ Bewertung der Element-Gehalte im Laub der Versuchsvarianten } \\
\hline & V1 & V2 & V3 & V4 & V5 & V6 & V7 & V8 & V9 & V10 \\
\hline $\mathrm{N}$ & \multicolumn{10}{|c|}{ ausreichend durch Symbiosen mit Luftstickstoff-fixierenden Bakterien (Actinomyceten) } \\
\hline \multicolumn{11}{|c|}{$x_{1}$} \\
\hline \multicolumn{11}{|l|}{$\mathrm{K}$} \\
\hline \multicolumn{11}{|l|}{$\mathrm{Ca}$} \\
\hline \multicolumn{11}{|l|}{$\mathrm{Mg}$} \\
\hline \multicolumn{11}{|l|}{$\mathrm{S}$} \\
\hline \multicolumn{11}{|l|}{$\mathrm{Fe}$} \\
\hline \multicolumn{11}{|l|}{$\mathrm{Mn}$} \\
\hline \multicolumn{11}{|l|}{$\mathrm{Zn}$} \\
\hline \multicolumn{11}{|l|}{$\mathrm{Cu}$} \\
\hline \multicolumn{11}{|l|}{$\mathrm{Al}$} \\
\hline \multicolumn{11}{|l|}{$\mathrm{Na}$} \\
\hline \multicolumn{11}{|l|}{$\mathrm{Ni}$} \\
\hline \multicolumn{11}{|l|}{ Co } \\
\hline $\mathrm{Cr}$ & & & & & & & & & & \\
\hline
\end{tabular}

\begin{tabular}{|l|l|l|l|l|}
\hline & & & & \\
\hline unter optimal, Mangel & $\begin{array}{c}\text { optimal, normal, } \\
\text { ausreichend, } \\
\text { unkritisch }\end{array}$ & überversorgt & $\begin{array}{c}\text { deutlich überversorgt, } \\
\text { kritisch }\end{array}$ & über extrem, toxisch \\
\hline
\end{tabular}


Tab. A 36: Relative Blattspiegelwerte [\%; V1 = 100 \%] der beprobten Erlen-Varianten (s. S. 20) auf Fläche D; Mischprobe je Variante; blau markiert mind. $25 \%$ höhere Werte als Kontrolle (V1), rot markiert mind. $25 \%$ niedrigere Werte als Kontrolle

\begin{tabular}{|c|c|c|c|c|c|c|c|c|c|c|}
\hline \multirow[t]{2}{*}{ Element } & \multicolumn{10}{|c|}{$\begin{array}{l}\text { relative Element-Gehalte im Laub der Versuchsvarianten } \\
\qquad[\% ; \mathrm{V} 1=100 \%]\end{array}$} \\
\hline & V1 & V2 & V3 & V4 & V5 & V6 & V7 & V8 & V9 & V10 \\
\hline $\mathrm{N}$ & 100 & 101 & 98 & 135 & 113 & 108 & 105 & 116 & 114 & 118 \\
\hline$P$ & 100 & 60 & 44 & 64 & 52 & 68 & 60 & 28 & 64 & 56 \\
\hline $\mathrm{K}$ & 100 & 57 & 53 & 64 & 82 & 94 & 131 & 78 & 93 & 112 \\
\hline $\mathrm{Ca}$ & 100 & 86 & 141 & 74 & 95 & 90 & 107 & 307 & 312 & 319 \\
\hline $\mathrm{Mg}$ & 100 & 171 & 173 & 173 & 139 & 122 & 127 & 71 & 76 & 59 \\
\hline $\mathrm{S}$ & 100 & 147 & $\overline{150}$ & $\overline{106}$ & $\overline{153}$ & 116 & $\overline{172}$ & 41 & 59 & 75 \\
\hline $\mathrm{Fe}$ & 100 & 147 & 467 & 186 & 385 & 101 & 144 & 89 & 90 & 94 \\
\hline $\mathrm{Mn}$ & 100 & 56 & 85 & 44 & 132 & 64 & 107 & 123 & 79 & 249 \\
\hline $\mathrm{Zn}$ & 100 & 95 & 88 & 107 & 109 & 90 & 116 & 100 & 90 & 123 \\
\hline $\mathrm{Cu}$ & 100 & 51 & 87 & 68 & 103 & 63 & 80 & 30 & 24 & 27 \\
\hline $\mathrm{Al}$ & 100 & 227 & 950 & 336 & 768 & 137 & 204 & 56 & 60 & 50 \\
\hline $\mathrm{Na}$ & 100 & 100 & 88 & 74 & 85 & 74 & 67 & 109 & 130 & 136 \\
\hline $\mathrm{Ni}$ & 100 & 253 & 121 & 192 & 134 & 92 & 78 & 30 & 30 & 45 \\
\hline Co & 100 & 51 & 148 & $\overline{43}$ & $\overline{954}$ & 39 & 121 & 59 & 63 & 68 \\
\hline $\mathrm{Cr}$ & 100 & 42 & 142 & 42 & 164 & 39 & 67 & 9 & 12 & 12 \\
\hline
\end{tabular}

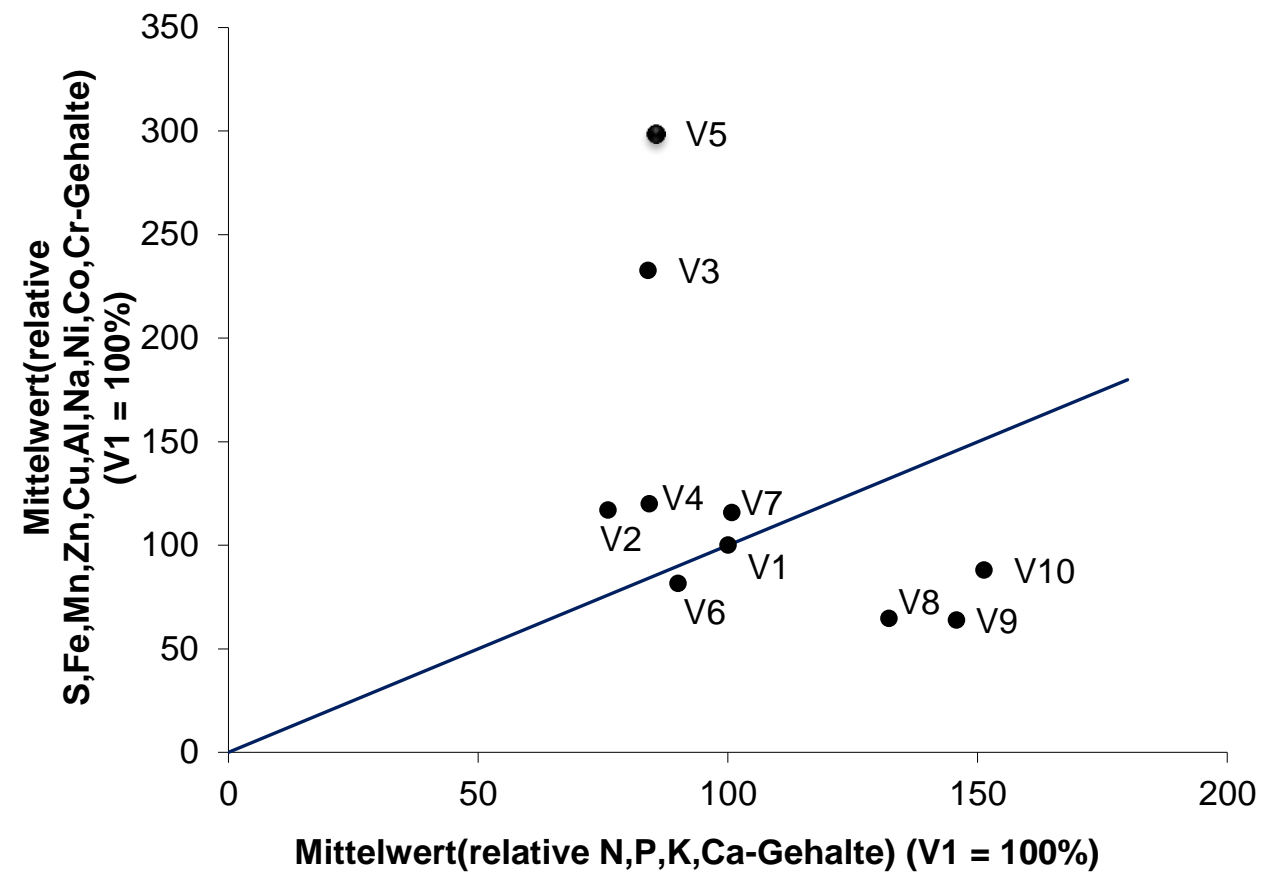

Abb. A 5: Relative Veränderung der Gehalte schädigend wirkender Elemente (Ab-/Zunahme der Schadstoffbelastung insgesamt) sowie der Nährstoff-Gehalte (Verbesserung/Verschlechterung der Ernährung) in den Behandlungsvarianten (s. S. 20) in Bezug auf die Kontrolle (V1) der Erlen

Anmerkung: Die Werte für Magnesium wurden ausgeklammert, da dieses Element aufgrund der überwiegend extrem hohen Gehalte durch Nährstoffantagonismen (z.B. auf die Kaliumversorgung) negativ wirkte. 


\section{Versorgung und Belastung der Douglasie}

Tab. A 37: Nadelspiegelwerte der Douglasien (Mischproben) auf den drei Versuchsflächen im 1. (2005) und auf Fläche D im 2. (2006) Vegetationsjahr

\begin{tabular}{|c|c|c|c|c|c|}
\hline \multirow{2}{*}{ Element } & \multicolumn{3}{|c|}{2005} & & \multirow{2}{*}{$\begin{array}{l}2006 \\
D\end{array}$} \\
\hline & A & B & D & & \\
\hline $\mathrm{N}$ [mg/g] & 16,9 & 12,4 & 17,5 & $>$ & $13,1 \pm 2,7$ \\
\hline $\mathrm{P}[\mathrm{mg} / \mathrm{g}]$ & 1,9 & 1,5 & 1,1 & $<$ & $1,4 \pm 0,7$ \\
\hline $\mathrm{K}[\mathrm{mg} / \mathrm{g}]$ & 12,4 & 12,1 & 8,9 & $>$ & $6,7 \pm 2,7$ \\
\hline $\mathrm{Ca}[\mathrm{mg} / \mathrm{g}]$ & 4,3 & 3,7 & 13,0 & $>$ & $2,5 \pm 1,7$ \\
\hline $\mathrm{Mg}[\mathrm{mg} / \mathrm{g}]$ & 4,5 & 4,0 & 9,4 & $>$ & $3,4 \pm 3,1$ \\
\hline $\mathrm{S}[\mathrm{mg} / \mathrm{g}]$ & & & & & $3,9 \pm 1,8$ \\
\hline $\mathrm{Fe}[\mathrm{mg} / \mathrm{kg}]$ & & & & & $297 \pm 134$ \\
\hline $\mathrm{Mn}[\mathrm{mg} / \mathrm{kg}]$ & & & & & $692 \pm 616$ \\
\hline $\mathrm{Zn}[\mathrm{mg} / \mathrm{kg}]$ & 51,1 & 60,8 & 59,3 & $>$ & $21,7 \pm 7,1$ \\
\hline $\mathrm{Cu}[\mathrm{mg} / \mathrm{kg}]$ & 47,3 & 29,0 & 18,6 & $>$ & $9,2 \pm 2,8$ \\
\hline $\mathrm{Al}[\mathrm{mg} / \mathrm{kg}]$ & & & & & $598 \pm 263$ \\
\hline $\mathrm{Na}[\mathrm{mg} / \mathrm{kg}]$ & & & & & $67,4 \pm 36,1$ \\
\hline $\mathrm{Ni}[\mathrm{mg} / \mathrm{kg}]$ & 33,9 & 36,5 & 21,1 & $>$ & $12,4 \pm 6,0$ \\
\hline Co $[\mathrm{mg} / \mathrm{kg}]$ & 6,3 & 6,3 & 2,2 & $<$ & $4,8 \pm 2,2$ \\
\hline $\mathrm{Pb}[\mathrm{mg} / \mathrm{kg}]$ & 2,4 & $\mathrm{u}$ & 3,9 & $>$ & $\mathrm{u}$ \\
\hline $\mathrm{Cd}[\mathrm{mg} / \mathrm{kg}]$ & 0,10 & 0,66 & $\mathrm{u}$ & $=$ & $\mathrm{u}$ \\
\hline $\mathrm{Cr}[\mathrm{mg} / \mathrm{kg}]$ & 3,9 & 13,2 & 1,4 & $<$ & $2,4 \pm 1,1$ \\
\hline
\end{tabular}

u Gehalt unterhalb der Nachweisgrenze

$>$ Zunahme, $<$ Abnahme, = unverändert

Tab. A 38: Makronährstoff-Gehalte [mg/g] in den Douglasien-Nadeln (Mischproben) verschiedener Varianten (s. S. 20) auf Fläche D (fehlende Variante V3 zum Zeitpunkt der Probennahme im August 2006 ausgefallen)

\begin{tabular}{|l|l|l|l|l|l|l|}
\hline & $\mathrm{N}$ & $\mathrm{P}$ & $\mathrm{K}$ & $\mathrm{Ca}$ & $\mathrm{Mg}$ & $\mathrm{S}$ \\
\hline V1 & 13,8 & 0,3 & 4,2 & 0,6 & 0,8 & 1,6 \\
\hline V2 & 17,3 & 1,2 & 3,1 & 1,7 & 1,9 & 2,1 \\
\hline V4 & 16,5 & 3,5 & 10,6 & 3,5 & 3,5 & 5,0 \\
\hline V5 & 10,5 & 0,7 & 4,5 & 1,5 & 2,0 & 3,0 \\
\hline V6 & 13,1 & 1,2 & 9,9 & 1,8 & 1,8 & 3,9 \\
\hline V7 & 13,2 & 1,5 & 9,0 & 1,6 & 2,6 & 5,3 \\
\hline V8 & 9,4 & 1,4 & 6,5 & 1,3 & 2,0 & 4,4 \\
\hline V9 & 10,8 & 1,0 & 4,5 & 1,2 & 1,7 & 2,6 \\
\hline V10 & 14,2 & 1,5 & 9,0 & 1,7 & 1,6 & 3,6 \\
\hline V11 & 12,6 & 1,7 & 7,7 & 2,2 & 1,8 & 3,8 \\
\hline V12 & 7,8 & 1,7 & 4,7 & 2,0 & 1,5 & 1,9 \\
\hline V13 & 15,5 & 1,6 & 4,4 & 2,2 & 2,2 & 3,2 \\
\hline V14 & 16,2 & 0,8 & 4,0 & 4,8 & 9,2 & 5,9 \\
\hline V15 & 14,3 & 1,4 & 6,6 & 6,4 & 9,9 & 4,2 \\
\hline V16 & 11,2 & 1,2 & 11,5 & 5,1 & 9,0 & 8,4 \\
\hline
\end{tabular}


Tab. A 39: Gehalte an Mikronährstoffen (Fe, Mn, Zn, Cu), nützlichen Elementen (Al, Ni, Na, Co) und Schadstoffen $(\mathrm{Pb}, \mathrm{Cd}, \mathrm{Cr})[\mathrm{mg} / \mathrm{kg}]$ in den Douglasien-Nadeln (Mischproben) verschiedener Varianten (s. S. 20) auf Fläche D (fehlende Variante V3 zum Zeitpunkt der Probennahme im August 2006 ausgefallen)

\begin{tabular}{|l|l|l|l|l|l|l|l|l|l|l|l|}
\hline & $\mathrm{Fe}$ & $\mathrm{Mn}$ & $\mathrm{Zn}$ & $\mathrm{Cu}$ & $\mathrm{Al}$ & $\mathrm{Na}$ & $\mathrm{Ni}$ & $\mathrm{Co}$ & $\mathrm{Pb}$ & $\mathrm{Cd}$ & $\mathrm{Cr}$ \\
\hline V1 & 473 & 180 & 10,8 & 10,1 & 963 & 58,8 & 3,9 & 7,3 & $\mathrm{u}$ & $\mathrm{u}$ & 3,1 \\
\hline V2 & 400 & 380 & 13,4 & 6,4 & 653 & 107,4 & 7,0 & 4,9 & $\mathrm{u}$ & $\mathrm{u}$ & 3,6 \\
\hline V4 & 214 & 405 & 29,5 & 13,3 & 549 & 70,4 & 16,6 & 10,4 & $\mathrm{u}$ & $\mathrm{u}$ & 3,6 \\
\hline V5 & 395 & 562 & 20,6 & 8,2 & 738 & 51,1 & 6,8 & 4,5 & $\mathrm{u}$ & $\mathrm{u}$ & 3,5 \\
\hline V6 & 116 & 410 & 17,7 & 7,9 & 274 & 30,6 & 9,2 & 2,9 & $\mathrm{u}$ & $\mathrm{u}$ & 1,1 \\
\hline V7 & 519 & 758 & 38,5 & 12,1 & 1087 & 67,4 & 8,2 & 5,2 & $\mathrm{u}$ & $\mathrm{u}$ & 2,7 \\
\hline V8 & 437 & 372 & 25,2 & 14,9 & 1013 & 68,7 & 23,4 & 5,4 & $\mathrm{u}$ & $\mathrm{u}$ & 3,4 \\
\hline V9 & 193 & 213 & 17,0 & 5,0 & 422 & 24,7 & 6,7 & 2,9 & $\mathrm{u}$ & $\mathrm{u}$ & 2,6 \\
\hline V10 & 199 & 448 & 17,9 & 8,4 & 435 & 27,4 & 8,4 & 3,4 & $\mathrm{u}$ & $\mathrm{u}$ & 1,3 \\
\hline V11 & 166 & 434 & 29,6 & 7,0 & 373 & 21,6 & 10,9 & 3,2 & $\mathrm{u}$ & $\mathrm{u}$ & 3,9 \\
\hline V12 & 73 & 306 & 18,9 & 6,9 & 189 & 39,0 & 21,5 & 2,6 & $\mathrm{u}$ & $\mathrm{u}$ & 1,4 \\
\hline V13 & 279 & 384 & 18,0 & 7,5 & 616 & 120,8 & 14,0 & 7,3 & $\mathrm{u}$ & $\mathrm{u}$ & 1,8 \\
\hline V14 & 327 & 1766 & 22,2 & 8,6 & 533 & 126,9 & 13,2 & 4,0 & $\mathrm{u}$ & $\mathrm{u}$ & 1,1 \\
\hline V15 & 317 & 1655 & 20,0 & 11,0 & 495 & 84,7 & 16,3 & 4,7 & $\mathrm{u}$ & $\mathrm{u}$ & 1,4 \\
\hline V16 & 347 & 2104 & 26,5 & 11,0 & 623 & 111,4 & 19,9 & 2,9 & $\mathrm{u}$ & $\mathrm{u}$ & 1,5 \\
\hline
\end{tabular}

u Gehalt unterhalb der Nachweisgrenze

Tab. A 40: Bewertung der Element-Gehalte in den Douglasien-Nadeln (Quellen: s. Anh. 2) der beprobten Versuchsvarianten (s. S. 20)

\begin{tabular}{|c|c|c|c|c|c|c|c|c|c|c|c|c|c|c|c|}
\hline \multirow{2}{*}{ Element } & \multicolumn{15}{|c|}{ Bewertung der Element-Gehalte im den Nadeln der verschiedenen Behandlungsvarianten } \\
\hline & V1 & V2 & V4 & V5 & V6 & V7 & V8 & V9 & V10 & V11 & V12 & V13 & V14 & V15 & V16 \\
\hline \multicolumn{16}{|l|}{$\mathrm{N}$} \\
\hline \multicolumn{16}{|l|}{$P$} \\
\hline \multicolumn{16}{|l|}{ K } \\
\hline \multicolumn{16}{|l|}{$\mathrm{Ca}$} \\
\hline \multicolumn{16}{|l|}{$\mathrm{Mg}$} \\
\hline \multicolumn{16}{|l|}{$S$} \\
\hline \multicolumn{16}{|l|}{$\mathrm{Fe}$} \\
\hline \multicolumn{16}{|l|}{$\mathrm{Mn}$} \\
\hline \multicolumn{16}{|l|}{$\mathrm{Zn}$} \\
\hline \multicolumn{16}{|l|}{$\mathrm{Cu}$} \\
\hline \multicolumn{16}{|l|}{$\mathrm{Al}$} \\
\hline \multicolumn{16}{|l|}{$\mathrm{Na}$} \\
\hline \multicolumn{16}{|l|}{$\mathrm{Ni}$} \\
\hline \multicolumn{16}{|l|}{ Co } \\
\hline $\mathrm{Cr}$ & & & & & & & & & & & & & & & \\
\hline
\end{tabular}

\begin{tabular}{|l|c|c|c|c|}
\hline & & & \\
\hline unter optimal, Mangel & $\begin{array}{c}\text { optimal, normal, } \\
\text { ausreichend, } \\
\text { unkritisch }\end{array}$ & überversorgt & $\begin{array}{c}\text { deutlich überversorgt, } \\
\text { kritisch }\end{array}$ & über extrem, toxisch \\
\hline
\end{tabular}


Tab. A 41: Relative Nadelspiegelwerte [\%; V1 = $100 \%$ ] der beprobten Douglasien-Varianten (s. S. 20) auf Fläche D; Mischprobe je Variante; blau markiert mind. $25 \%$ höhere Werte als Kontrolle (V1), rot markiert mind. $25 \%$ niedrigere Werte als Kontrolle

\begin{tabular}{|c|c|c|c|c|c|c|c|c|c|c|c|c|c|c|c|}
\hline \multirow[t]{2}{*}{ Element } & \multicolumn{15}{|c|}{$\begin{array}{l}\text { relative Element-Gehalte in den Nadeln der Versuchsvarianten } \\
\qquad[\% ; \mathrm{V} 1=100 \%]\end{array}$} \\
\hline & V1 & \begin{tabular}{|l|} 
V2 \\
\end{tabular} & V4 & V5 & V6 & V7 & V8 & V9 & V10 & V11 & V12 & V13 & V14 & V15 & V16 \\
\hline $\mathrm{N}$ & 100 & $\underline{125}$ & 120 & 76 & 95 & 96 & 68 & 78 & 103 & 91 & 57 & 112 & 117 & 104 & 81 \\
\hline$P$ & 100 & 400 & 1167 & 233 & 400 & 500 & 467 & 333 & 500 & 567 & 567 & 533 & 267 & 467 & 400 \\
\hline $\mathrm{K}$ & 100 & 74 & $\underline{252}$ & 107 & $\underline{236}$ & $\underline{214}$ & 155 & 107 & $\underline{214}$ & 183 & 112 & 105 & 95 & 157 & $\underline{284}$ \\
\hline $\mathrm{Ca}$ & 100 & 283 & 583 & 250 & 300 & 267 & 217 & 200 & $\underline{283}$ & 367 & 333 & 367 & 800 & 1067 & 850 \\
\hline $\mathrm{Mg}$ & 100 & $\underline{238}$ & $\underline{438}$ & 250 & $\underline{225}$ & $\underline{325}$ & $\underline{250}$ & $\underline{213}$ & $\underline{200}$ & $\underline{225}$ & 183 & $\underline{275}$ & 1150 & 1238 & $\underline{1125}$ \\
\hline$S$ & 100 & 131 & 313 & 188 & 244 & 331 & 275 & 163 & 225 & 238 & 119 & 200 & 369 & 263 & 525 \\
\hline $\mathrm{Fe}$ & 100 & 85 & 45 & 84 & 25 & 108 & 92 & 41 & 42 & 35 & 15 & 59 & 69 & 67 & 73 \\
\hline $\mathrm{Mn}$ & 100 & $\underline{211}$ & $\underline{225}$ & 312 & $\underline{228}$ & 421 & 207 & 118 & $\underline{249}$ & 241 & $\underline{170}$ & $\underline{213}$ & 981 & 919 & 1169 \\
\hline $\mathrm{Zn}$ & 100 & 124 & 273 & 191 & 164 & $\underline{356}$ & 233 & $\underline{157}$ & 166 & 274 & $\underline{175}$ & 167 & 206 & $\underline{185}$ & 245 \\
\hline $\mathrm{Cu}$ & 100 & 63 & $\underline{132}$ & 81 & 78 & 120 & $\underline{148}$ & 50 & 83 & 69 & 68 & 74 & 85 & 109 & 109 \\
\hline $\mathrm{Al}$ & 100 & 68 & 57 & 77 & 28 & 113 & 105 & 44 & 45 & 39 & 20 & 64 & 55 & 51 & 65 \\
\hline $\mathrm{Na}$ & 100 & 183 & 120 & 87 & 52 & 115 & 117 & 42 & 47 & 37 & 66 & $\underline{205}$ & $\underline{216}$ & 144 & $\underline{189}$ \\
\hline $\mathrm{Ni}$ & 100 & 179 & $\underline{426}$ & 174 & $\underline{236}$ & 210 & 600 & 172 & $\underline{215}$ & 279 & 551 & 359 & 338 & $\underline{418}$ & 510 \\
\hline Co & 100 & 67 & 142 & 62 & 40 & 71 & 74 & 40 & 47 & 44 & 36 & 100 & 55 & 64 & 40 \\
\hline $\mathrm{Cr}$ & 100 & 116 & 116 & 113 & 35 & 87 & 110 & 84 & 42 & 126 & 45 & 58 & 35 & 45 & 48 \\
\hline
\end{tabular}

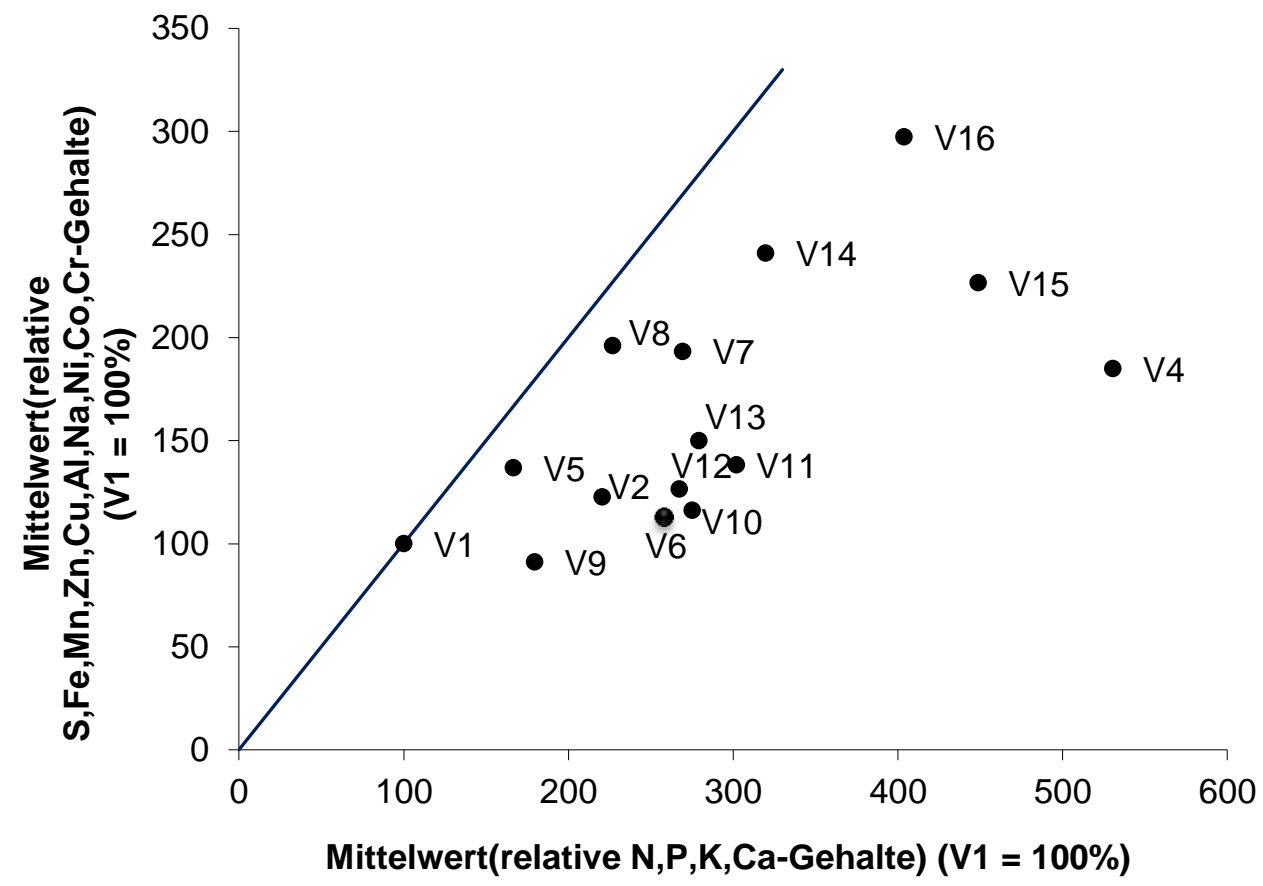

Abb. A 6: Relative Veränderung der Gehalte schädigend wirkender Elemente (Ab-/Zunahme der Schadstoffbelastung insgesamt) sowie der Nährstoff-Gehalte (Verbesserung/Verschlechterung der Ernährung) in den Behandlungsvarianten (s. S. 20) in Bezug auf die Kontrolle (V1) der Douglasien

Anmerkung: Die Werte für Magnesium wurden ausgeklammert, da dieses Element aufgrund der überwiegend extrem hohen Gehalte durch Nährstoffantagonismen (z.B. auf die Kaliumversorgung) negativ wirkte. 


\section{Versorgung und Belastung der Kiefer}

Tab. A 42: Nadelspiegelwerte der Kiefern (Mischproben) auf den drei Versuchsflächen im 1. (2005) und auf Fläche D im 2. (2006) Vegetationsjahr

\begin{tabular}{|c|c|c|c|c|c|}
\hline \multirow{2}{*}{ Element } & \multicolumn{3}{|l|}{2005} & & \multirow{2}{*}{$\begin{array}{l}2006 \\
D\end{array}$} \\
\hline & A & B & $\mathrm{D}$ & & \\
\hline $\mathrm{N}$ [mg/g] & 14,7 & 13,6 & 14,3 & $>$ & $13,0 \pm 2,3$ \\
\hline $\mathrm{P}[\mathrm{mg} / \mathrm{g}]$ & 1,2 & 1,2 & 0,75 & $<$ & $1,7 \pm 0,1$ \\
\hline $\mathrm{K}[\mathrm{mg} / \mathrm{g}]$ & 4,7 & 7,3 & 7,6 & $>$ & $6,5 \pm 1,9$ \\
\hline $\mathrm{Ca}[\mathrm{mg} / \mathrm{g}]$ & 3,3 & 4,2 & 5,0 & $>$ & $3,9 \pm 1,6$ \\
\hline $\mathrm{Mg}[\mathrm{mg} / \mathrm{g}]$ & 2,1 & 1,8 & 2,5 & $<$ & $7,8 \pm 1,3$ \\
\hline $\mathrm{S}[\mathrm{mg} / \mathrm{g}]$ & & & & & $5,3 \pm 2,0$ \\
\hline $\mathrm{Fe}[\mathrm{mg} / \mathrm{kg}]$ & & & & & $280 \pm 73,5$ \\
\hline Mn [mg/kg] & & & & & $1615 \pm 1161$ \\
\hline $\mathrm{Zn}[\mathrm{mg} / \mathrm{kg}]$ & 33,8 & 55,9 & 45,8 & $<$ & $94,9 \pm 50,0$ \\
\hline $\mathrm{Cu}[\mathrm{mg} / \mathrm{kg}]$ & 18,9 & 18,3 & 15,1 & $<$ & $21,0 \pm 5,3$ \\
\hline $\mathrm{Al}[\mathrm{mg} / \mathrm{kg}]$ & & & & & $430 \pm 160$ \\
\hline $\mathrm{Na}[\mathrm{mg} / \mathrm{kg}]$ & & & & & $68,2 \pm 14,0$ \\
\hline $\mathrm{Ni}[\mathrm{mg} / \mathrm{kg}]$ & 10,5 & 7,7 & 6,3 & $<$ & $54,6 \pm 14,7$ \\
\hline Co $[\mathrm{mg} / \mathrm{kg}]$ & 2,6 & 1,9 & 1,8 & $<$ & $9,7 \pm 4,1$ \\
\hline $\mathrm{Pb}[\mathrm{mg} / \mathrm{kg}]$ & 2,4 & $\mathrm{u}$ & $\mathrm{u}$ & $=$ & $\mathrm{u}$ \\
\hline $\mathrm{Cd}[\mathrm{mg} / \mathrm{kg}]$ & $\mathrm{u}$ & $\mathrm{u}$ & $\mathrm{u}$ & $=$ & $\mathrm{u}$ \\
\hline $\mathrm{Cr}[\mathrm{mg} / \mathrm{kg}]$ & 1,2 & 1,5 & 1,7 & $>$ & $1,2 \pm 0,4$ \\
\hline
\end{tabular}

u Gehalt unterhalb der Nachweisgrenze

$>$ Zunahme, $<$ Abnahme, = unverändert

Tab. A 43: Makronährstoff-Gehalte [mg/g] in den Kiefern-Nadeln (Mischproben) verschiedener Varianten (s. S. 20) auf Fläche D (fehlende Varianten V2-V8 zum Zeitpunkt der Probennahme im August 2006 ausgefallen)

\begin{tabular}{|l|l|l|l|l|l|l|}
\hline & $\mathrm{N}$ & $\mathrm{P}$ & $\mathrm{K}$ & $\mathrm{Ca}$ & $\mathrm{Mg}$ & $\mathrm{S}$ \\
\hline V1 & 12,7 & 1,7 & 4,6 & 2,3 & 9,3 & 7,6 \\
\hline V9 & 10,8 & 1,6 & 6,4 & 5,4 & 7,3 & 4,0 \\
\hline V10 & 15,4 & 1,8 & 8,4 & 4,0 & 6,8 & 4,4 \\
\hline
\end{tabular}

Tab. A 44: Gehalte an Mikronährstoffen ( $\mathrm{Fe}, \mathrm{Mn}, \mathrm{Zn}, \mathrm{Cu}$ ), nützlichen Elementen ( $\mathrm{Al}, \mathrm{Ni}, \mathrm{Na}, \mathrm{Co}$ ) und Schadstoffen $(\mathrm{Pb}, \mathrm{Cd}, \mathrm{Cr})[\mathrm{mg} / \mathrm{kg}]$ in den Kiefern-Nadeln (Mischproben) verschiedener Varianten (fehlende Varianten V2-V8 zum Zeitpunkt der Probennahme im August 2006 ausgefallen)

\begin{tabular}{|l|l|l|l|l|l|l|l|l|l|l|l|}
\hline & Fe & $\mathrm{Mn}$ & $\mathrm{Zn}$ & $\mathrm{Cu}$ & $\mathrm{Al}$ & $\mathrm{Na}$ & $\mathrm{Ni}$ & $\mathrm{Co}$ & $\mathrm{Pb}$ & $\mathrm{Cd}$ & $\mathrm{Cr}$ \\
\hline V1 & 357 & 516 & 37,3 & 16,4 & 574 & 82,9 & 39,5 & 5,4 & $\mathrm{u}$ & $\mathrm{u}$ & 1,3 \\
\hline V9 & 210 & 2829 & 121,3 & 26,8 & 258 & 54,9 & 55,3 & 10,3 & $\mathrm{u}$ & $\mathrm{u}$ & 0,7 \\
\hline V10 & 274 & 1500 & 126,0 & 19,8 & 457 & 66,8 & 68,9 & 13,4 & $\mathrm{u}$ & $\mathrm{u}$ & 1,6 \\
\hline
\end{tabular}

u Gehalt unterhalb der Nachweisgrenze 
Tab. A 45: Bewertung der Element-Gehalte in den Kiefernn-Nadeln (Quellen: s. Anh. 2) der beprobten Versuchsvarianten (s. S. 20)

\begin{tabular}{|c|c|c|c|}
\hline \multirow[t]{2}{*}{ Element } & \multicolumn{3}{|c|}{$\begin{array}{c}\text { Bewertung der Element-Gehalte in den Nadeln der verschiedenen } \\
\text { Behandlungsvarianten }\end{array}$} \\
\hline & V1 & V9 & V10 \\
\hline $\mathrm{N}$ & & & \\
\hline$P$ & & & \\
\hline $\mathrm{K}$ & & & \\
\hline $\mathrm{Ca}$ & & & \\
\hline $\mathrm{Mg}$ & & & \\
\hline$S$ & & & \\
\hline $\mathrm{Fe}$ & & & \\
\hline $\mathrm{Mn}$ & & & \\
\hline $\mathrm{Zn}$ & & & \\
\hline $\mathrm{Cu}$ & & & \\
\hline $\mathrm{Al}$ & & & \\
\hline $\mathrm{Na}$ & & & \\
\hline $\mathrm{Ni}$ & & & \\
\hline Co & & & \\
\hline $\mathrm{Cr}$ & & & \\
\hline
\end{tabular}

\begin{tabular}{|l|l|l|l|l|}
\hline & & & \\
\hline unter optimal, Mangel & $\begin{array}{c}\text { optimal, normal, } \\
\text { ausreichend, } \\
\text { unkritisch }\end{array}$ & überversorgt & $\begin{array}{c}\text { deutlich überversorgt, } \\
\text { kritisch }\end{array}$ & über extrem, toxisch \\
\hline
\end{tabular}

Tab. A 46: Relative Nadelspiegelwerte [\%; V1 = $100 \%$ ] der beprobten Kiefern-Varianten (s. S. 20) auf Fläche D; Mischprobe je Variante; blau markiert mind. $25 \%$ höhere Werte als Kontrolle (V1), rot markiert mind. 25 \% niedrigere Werte als Kontrolle

\begin{tabular}{|l|l|l|l|}
\hline \multirow{2}{*}{ Element } & \multicolumn{3}{|c|}{$\begin{array}{c}\text { relative Element-Gehalte in den Nadeln der } \\
\text { Versuchsvarianten [\%; V1 } 100 \%]\end{array}$} \\
\cline { 2 - 4 } & V1 & V9 & V10 \\
\hline $\mathrm{N}$ & 100 & 85 & 121 \\
\hline $\mathrm{P}$ & 100 & 94 & 106 \\
\hline $\mathrm{K}$ & 100 & $\underline{139}$ & $\underline{183}$ \\
\hline $\mathrm{Ca}$ & 100 & $\underline{235}$ & $\underline{174}$ \\
\hline $\mathrm{Mg}$ & 100 & 78 & 73 \\
\hline $\mathrm{S}$ & 100 & 53 & 58 \\
\hline $\mathrm{Fe}$ & 100 & 59 & 77 \\
\hline $\mathrm{Mn}$ & 100 & $\underline{548}$ & $\underline{291}$ \\
\hline $\mathrm{Zn}$ & 100 & $\underline{325}$ & $\underline{338}$ \\
\hline $\mathrm{Cu}$ & 100 & $\underline{163}$ & 121 \\
\hline $\mathrm{Al}$ & 100 & $\mathbf{4 5}$ & 80 \\
\hline $\mathrm{Na}$ & 100 & 66 & 81 \\
\hline $\mathrm{Ni}$ & 100 & $\underline{140}$ & $\underline{174}$ \\
\hline $\mathrm{Co}$ & 100 & $\underline{191}$ & $\underline{248}$ \\
\hline $\mathrm{Cr}$ & 100 & $\underline{54}$ & 123 \\
\hline
\end{tabular}




\section{Photos der Vitalitätsstufen „2“, „3“ und „4“}

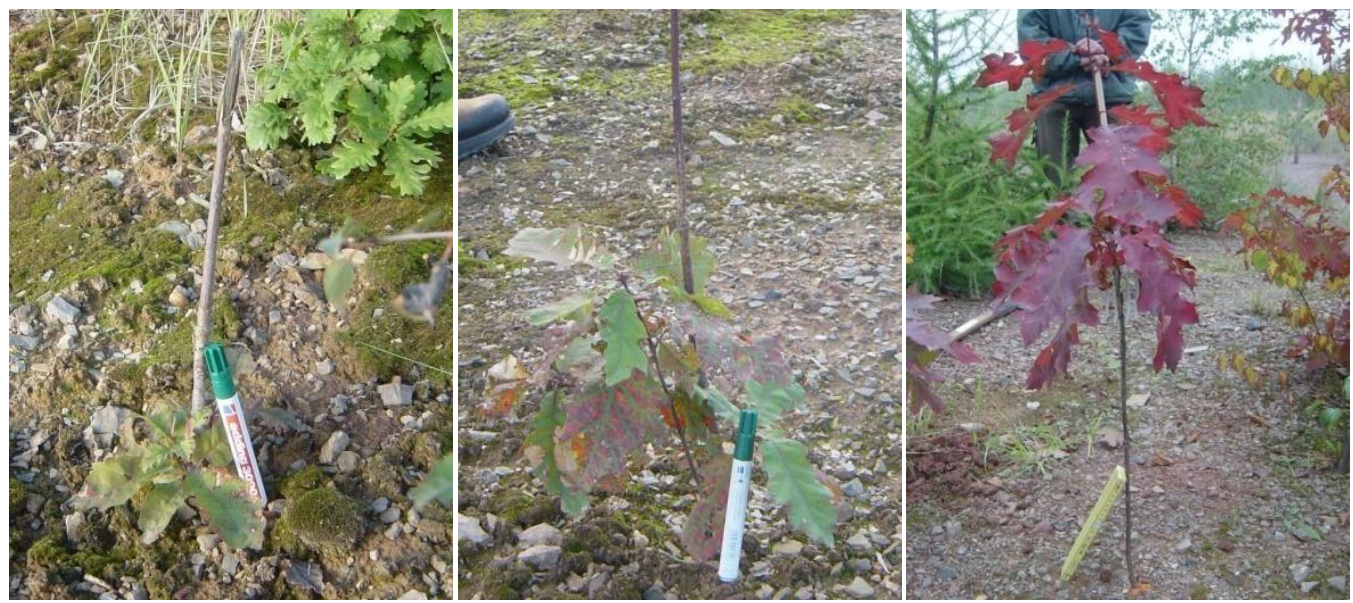

Abb. A 7: Rot-Eichen (z.T. mit Herbstfärbung) auf den Ronneburger Freiland-Versuchsflächen mit Vitalitätsbewertungsstufe „2“ (links), „3“ (Mitte) und „4“ (rechts) (s. S. 27)
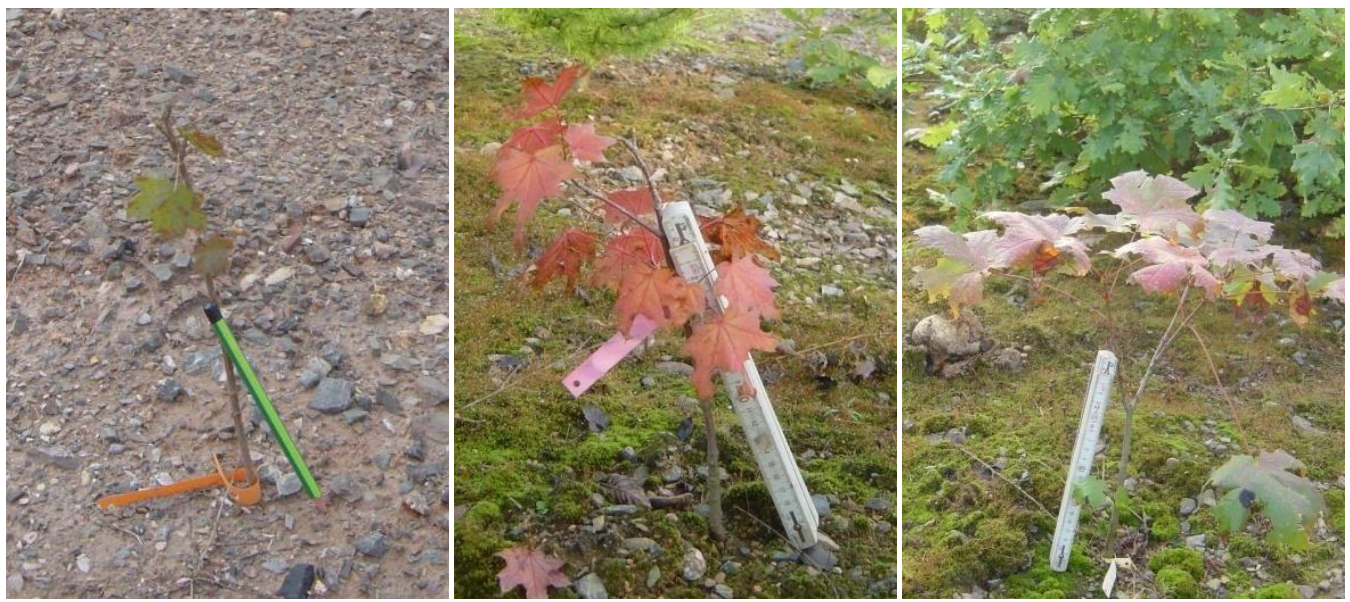

Abb. A 8: Spitz-Ahorne (z.T. mit Herbstfärbung) auf den Ronneburger Freiland-Versuchsflächen mit Vitalitätsbewertungsstufe „2“ (links), „3“ (Mitte) und „4“ (rechts) (s. S. 27)
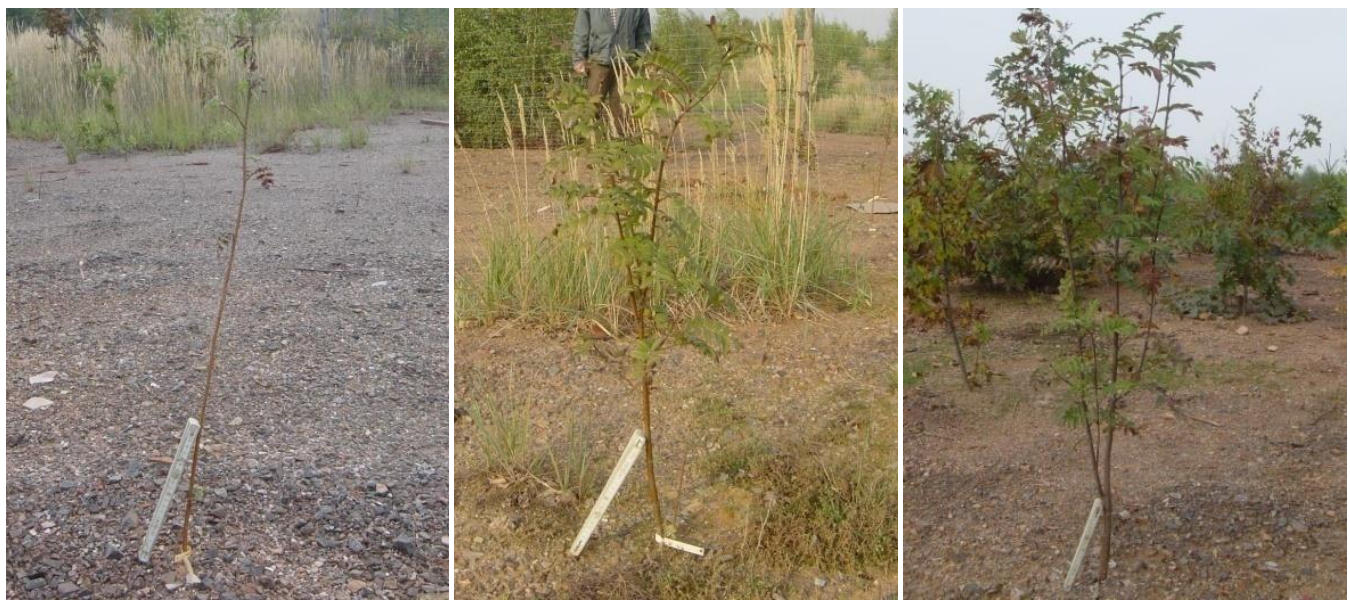

Abb. A 9: Ebereschen (z.T. mit Herbstfärbung) auf den Ronneburger Freiland-Versuchsflächen mit Vitalitätsbewertungsstufe „2“ (links), „3“ (Mitte) und „4“ (rechts) (s. S. 27) 


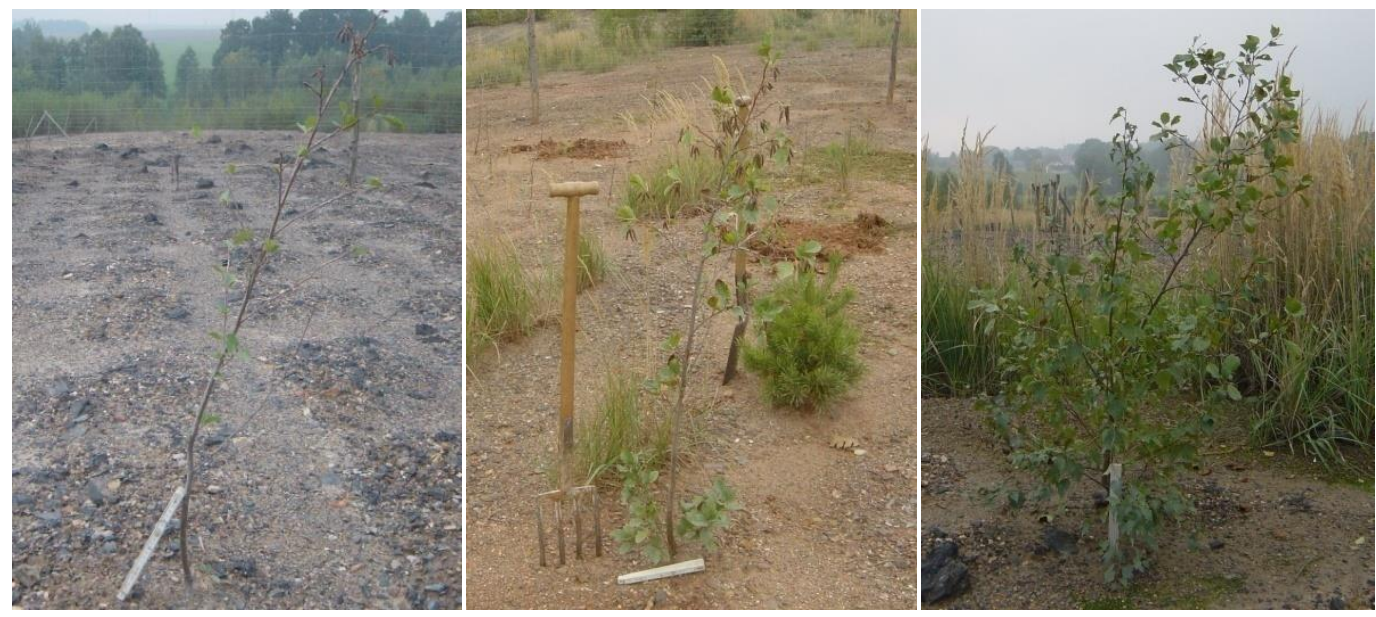

Abb. A 10: Schwarz-Erlen auf den Ronneburger Freiland-Versuchsflächen mit Vitalitätsbewertungsstufe „2“ (links), „3“ (Mitte) und „4“ (rechts) (s. S. 27)
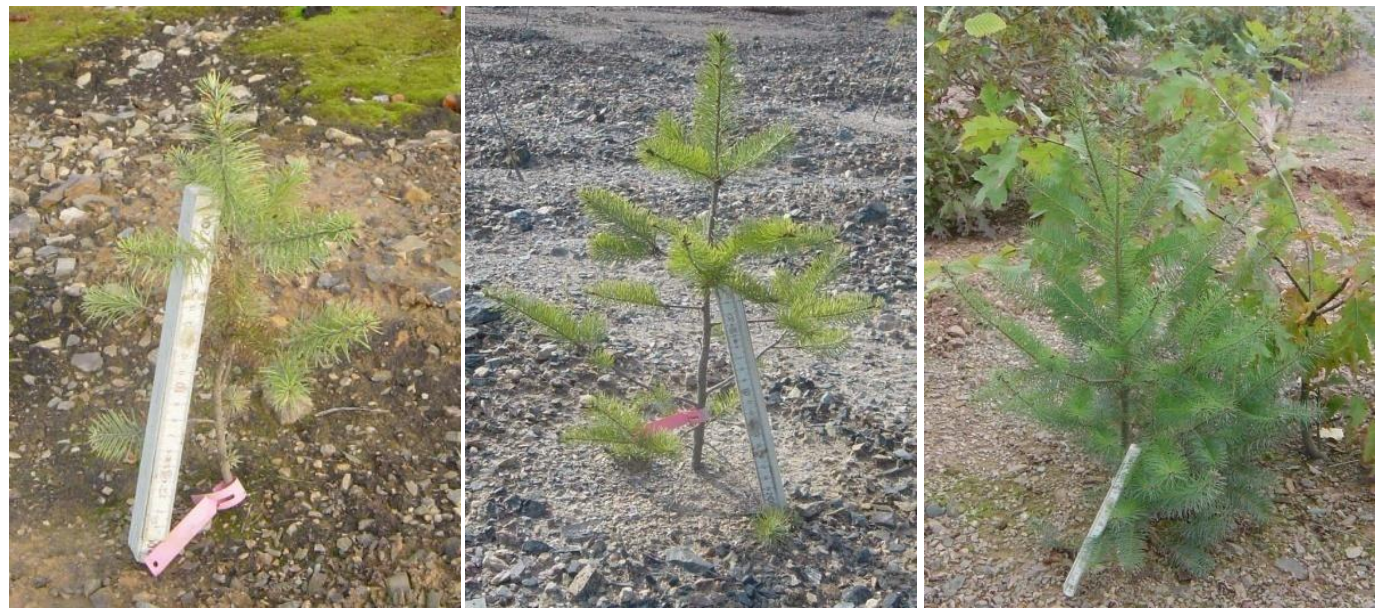

Abb. A 11: Douglasien auf den Ronneburger Freiland-Versuchsflächen mit Vitalitätsbewertungsstufe „2“ (links), „3“ (Mitte) und „4“ (rechts) (s. S. 27)
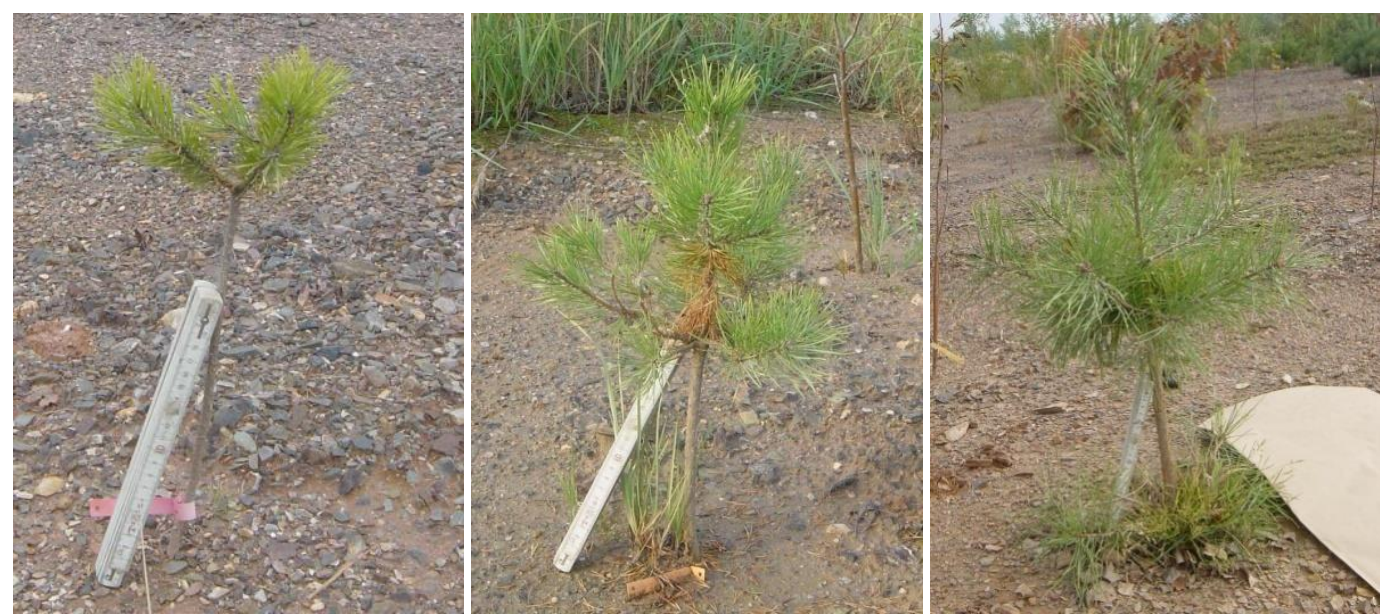

Abb. A 12: Wald-Kiefern auf den Ronneburger Freiland-Versuchsflächen mit

Vitalitätsbewertungsstufe „2“ (links), „3“ (Mitte) und „4“ (rechts) (s. S. 27) 